

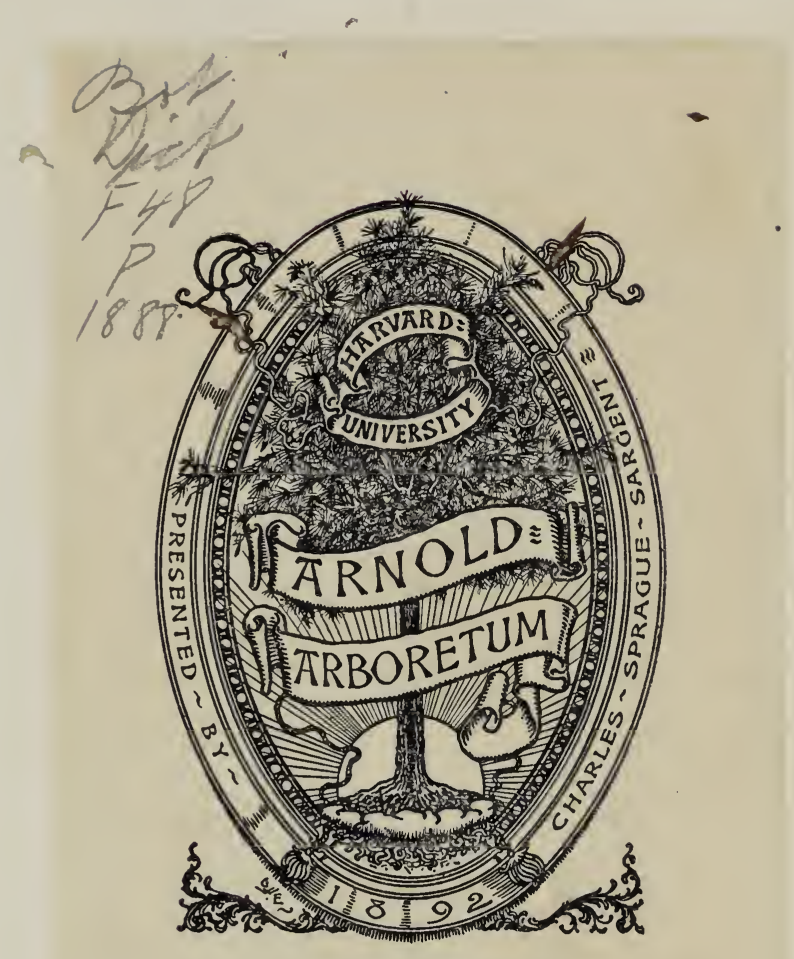



Digitized by the Internet Archive in 2017 with funding from BHL-SIL-FEDLINK 


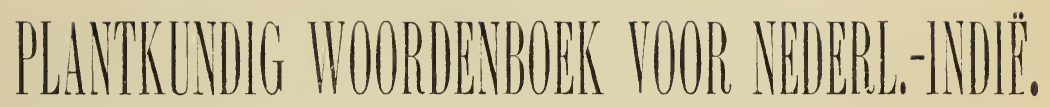




\section{吧 INDISCHE MERCUUR,}

Met medewerking van vele deskundigen.

$$
\text { Prijs } f \text { 12.- per jaar, }
$$

franco Nederland, Indië en Union Postale (bij vooruitbetaling).

(Zie verdere mededeelingen aan het einde van dit werk). 
$\#$

\section{PLANTKUNDIG}

\section{WOORDENBOEK}

vook

\section{NEDERLANDSCH-INDIE;}

MET KORTE AANWIJZINGEN VAN HET

GENEESKUNDIG- EN HUISHOUDELIJK GEBRUIK DER PLANTEN,

EN

VERMELDING DER VERSCHILLENDE

INLANDSCHE EN WETENSCHAPPELIJKE BENAMINGEN

DOOR

$$
\text { G. } J \cdot f \text { I L E } \mathrm{T} \text {, }
$$

Oud-Officier van Gezondheid van het N.-T. Leger.

Tweede vermeerderde en verbeterde druk.

AMsterdaA,

J. H. D E B USSY.

1888. 
Qet.1908
18787

19. I N Pen

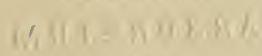

asmyer li 


\section{VERK L A R I N G}

DER VERKOR'TINGEN IN DIT WOORDENBOEK VOORIIANDEN.

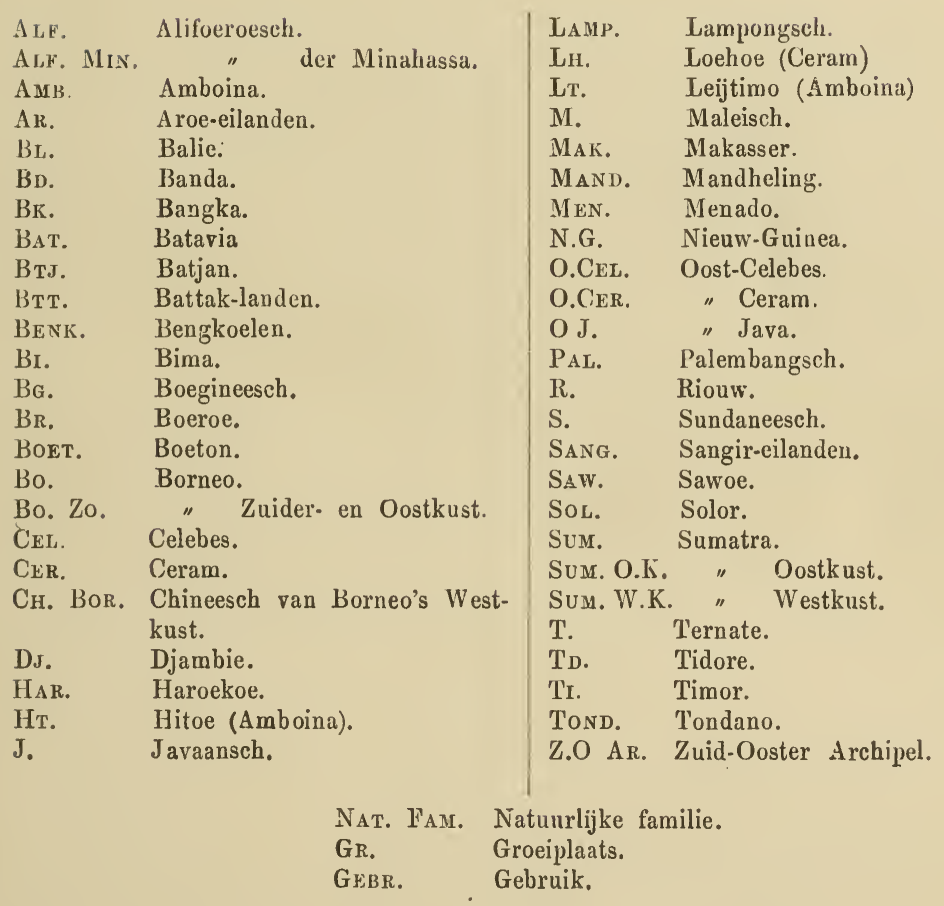





\section{VOORWOORD VAN DEN SCHRIJVER.}

Reeds eenige jaren geleden schreef ik een lijst der inlandsche plantenbenamingen dezer gewesten, die in het negentiende deel van het Natuurkundig Tijdschrift voor Nederlandsch-Indië geplaatst werd. Sedert dien tijd zijn wederom vele, ook nieuwe, namen bekend geworden, en wel vooral door het verschijnen der Flora van Indië, door professor $\mathrm{Miquel}$, en de nasporingen van Teysmann en Binnendijk, Kürz en anderen. Ook zelve spoorde ik, wanneer daartoe de gelegenheid zich aanbood, zooveel mogelijk in mijn omgeving plaatselijke benamingen der planten op; drukke dienstbezigheden verhinderden mij echter dikwijls zóóveel te doen, als ik wel gewenscht had. Ilk achtte het daarom noodzakelijk dezen mijnen vroegeren arbeid te herzien, en een uitvoeriger en verbeterd werk het publiek aan te bieden.

Tijdens de uitgave mịner vroegere lijst makte men reeds de opmerking, dat het wenschelijk zou geweest zijn, wanneer ik bij elke plant ook de groeiplaats en het gebr:ilk had opgegeven; ik zag toen tegen de moeielijkheid hiervan op, zoowel als tegen den omvarg, welke ik dacht dat deze lijst daardoor verkrijgen zoude. Bij deze omwerking heb ik getracht hieraan zooveel mogelijk te voldoen, en ook de nieuwste nomenclatuur gevolgd. Dit laatste was echter moeilijk, daar mij op deze afgelegen plaats niet dadelijk alle nieuwere bulpbronnen ten dienste stonden, zoodat ik, vooral voor de Cryptogamen, nog wel eens een ouden naam heb moeten behouden.

Omtrent de schrijfwijze der inlandsche namen, die veelal naar 
de uitspraak, volgens het gehoor, zijn opgeteekend, merk ik a:n, dat bij deze zooveel mogelijk de Hollandsche spelling is gevolgd.

Ten einde in geen herhalingen te vervallen, heb ik elken naam een doorloopend volgnommer gegeven, en telkens bij herhaling teruggewezen naar het eerste nommer, waaronùer de bedoelde plant in dit boek reeds voorkomt. Elk eiland toch van dezen Archipel heeft gewoonlijk zijne eigene, soms meer dan ééne taal, van daar dat dezelfde plant dikwerf onder meer en zeer verschillende namen voorkomt. -

En hiermede hoop ik wederom iets verricht te hebben om de studie der Botanie in deze gewesten gemalkelijker te maken; hoofdzakelijk echter om beter te kunnen geraken tot de kennis van het medische en technische nut der Indische planten. Zijn deze opgaven al zoo beknopt mogelijk, het zal aan anderen later gemakkelijk gemaakt zijn op dezen grondslag voort te bouwen.

Me n ado.

F I L E T.

\section{EEN WOORD TOT INLEIDING.}

Door H. W I T T E.

Het zal nu ongeveer een jaar geleden zijn, dat de heer Kolff mij het handschrift van dit werk toonde, met verzoek het te willen inzien, en, bijaldien hij tot de uitgave er van besloot, mij met de correctie der drukproeven te willen belasten, voor zoover dit namelijk die der wetenschappelijke namen betrof, daar dit natuurlijk door den Schrijver, die zich nog steeds in Indië bevindt, niet kon geschieden.

Te gereeder toonde ik mij, na een vluchtige doorzage van het manuscript, hiertoe bereid, daar mij gebleken was dat het werk, vooral wat 
de vermelding betreft van het gebruik, door de inlanders van vele planten gemaakt, zeer veel bevatte, wat mij nog geheel onbekend was, en er zeker geen beter middel bestaat om de bijzonderheden uit een boek als dit te leeren kennen, dan al de drukproeven een paar malen in haar geheel door te zien.

Ik heb mij in mijne verwachting in dit opzicht niet bedrogen gezien, maar van den heer Filet veel vernomen, wat mij levendige belangstelling inboezemde, en vaak heb ik het geduld en de volharding bewonderd voor de samenstelling van zulk een werk zoo dringend noodig.

Toch aarzelde ik een oogenblik aan het verzoek des Uitgevers te voldoen, om er een inleidend woord aan toe te voegen.

Het kwam mij voor, dat ik mij daardoor den schijn van aanmatiging op den hals zou halen, zoowel tegenover den Schrijver, als tegenover het Publiek, iets waarop ik nu juist niet bijzonder gesteld ben.

Aan den anderen kant echter moest ik wel toegeven, dat niemand - behalve de Schrijver - thans beter met den inhoud van dit werk bekend kan zijn, dan ik; terwijl mij volkomen vrijheid werd gelaten, dit «woord vooraf» geheel naar eigen goedvinden in te richten.

Welnu, hetzij dan zoo; en het eerste, wat ik er van te zeggen heb, is, dat dit werk mij een bij uitnemendheid praktisch boek gebleken is.

Ten opzichte van de herleiding der inlandsche namen van de beschreven, in den Indischen Archipel groeiende planten tot de wetenschappelijke, ontbrak tot hiertoe een dikwijls en vaak zoo dringend noodige vraagbaak; 't was dan een zoeken zonder eind in verschillende werken, veel tijdverlies on dit veelal nog te vergeefs.

Ware het alleen om deze reden, ik zou niet aarzelen te zeggen, dat de heer Filet een hoogst nuttig werk heeft verricht; een werk, warrdoor hij vooral aan de bezitters en gebruikers van Miquel's Flor van Ned.-Indii een grooten dienst heeft bewezen.

Maar niet alleen dezen, niet alleen den kruidkundigen zal het boek veel gemak opleveren, ieder, die in den plantengroei onzer Oost-Indische eilanden eenig belang stelt, wien het niet onverschillig is to weten in hoe velerlei opzichten vooral de inlanders, ook de Europeanen, zich de voortbrengselen der Indische vegetatie, 't zij ter voeding, 't zij als geneesmiddelen, 't zij eindelijk voor tal van technische of huishoudelijke doeleinden, ten nutte maken, zal dit Woordenboek gewis vaak ter hand nemen en het met vrucht raadplegen, ondanks de beknoptheid der mededeelingen, die de Schrijver zich tot beginsel schijnt te hebben gesteld.

Vooral eehter ambtenaren, officieren, plantagebezitters, in één woord, al die Nederlanders, die jaren - soms hun leven - lang zich bewegen te midden dier weelderige vegetatie, en er toch huns ondanks genoegzaam 
vreemdelingen in blijven; die vaak op hun reizen ronddwalen door en bewonderen wat ze niet, of slechts zeer oppervlakkig kennen, terwijl eenige meerdere kennis hun zooveel gemak, genot, ja vaak voordeel zou kunney opleveren, dezen inzonderheid moge dit boek ten zeerste aanbevolen worden.

Dat het volledig is, zou ik niet gaarne durven beweren; ja, ik geloof het zelfs niet, maar dit is ook van een eerste poging op breede schaal in dit opzicht niet te vergen of te verwachten; zeker echter is het, dat de Schrijver met nauwgezette zorg de voornaamste bronnen op dit gebied zich heeft ten nutte gemaakt, terwijl ten overvloede zijn eigen aanteekeningen, gedurende een reeks van jaren gemaakt, veel zullen hebben aangevuld.

Het spreekt van zelf, dat wij het werk in zijn geheel en dus onveranderd lieten, zooals de Schrijver zijn zorgvuldig bewerkte kopie den Uitgever toevertrouwde; wijzigingen of veranderingen stonden ons niet vrij, ook waar wij die misschien wenschelijk achtten. Omtrent de spelling der wetenschappelijke plantennamen bestaat over 't algemeen weinig verschil van gevoelen; anders echter is dit, waar het geldt de schrijfwijze der inlandsche namen, waaromtrent, gelijk mij vaak bleek, ieder, die eenige jaren in Indië verkeerd heeft, zoo wat zijn eigen meening heeft.

Zonder nu daarom als verdediger van den Schrijver in dit opzicht te willen optreden - waartoe zeker niemand minder competent is dan ik zal mij hier de opmerking toch wel veroorloofd zijn, dat purisme min. der in de bedoeling des Schrijvers kon liggen, waar hij zich hoofdzakelijk voorstelde een gemakkelijk hulpmiddel, een goed bruikbaar, en in vele opzichten een praktisch nuttig boek te leveren.

Van harte wensch ik dat de Schrijver voor zijn belanglooze opoffering van veel tijd en moeite, in de erkenning van dit laatste door hen die 't zich ten nutte kunnen maken - en die zijn velen - een aangename voldoening moge vinden.

$$
\text { Leiden, Juni '76. }
$$

H. WIT TE. 


\section{VOORW00RD VAN DE TWEEDE UITGAVE}

De voortdurerde aanviaag naar dit werk nadat de eerste uitgave was uitverkoclit, is de beste aaubereling van G. J. FILET'S "Plantkundig woordenboek van Ned. Indië.»

IVij hebben het genoegen hierbij een tweeden vermeerderden en verbeterden druk aan te bieden aan het betrekkelijk groote publiek, dat in den noesten en veeljarigen arbeid van den geleerden schrijver belang stelt.

De Heer Filet heeft deze nieuwe uitgave persoorlijk herzien. Het aanhangsel van de cerste uitgave is in dezen druk in den alphabetischen tekst overgebracht. Een aantal nicuwe namen zijn hovendien hijgevoegd, zoodat de volledigheid en de bruikbaarheid van dit woordentoek is vermeerderd.

1. II. DE BUSSY. Uitgever. 

1. Aäntingan $\mathrm{S} .=$ A eroe e $\mathrm{phalus}$ c apitatus Benth., Nat. fam. der Lab i a ta $x$. Gr. in bijna geheel Indië; éénjarig.

2. Abo-ado S. = Callie arpa cana I., Nat. fanı. der Verben aces. Gr. door bijna geheel Ned.-Indië; heester. GEBR. Men bezigt het kruid als verdeelend middel op wonden om zwelling te vocrkomen.

3. Aboe-daka M. = Ardisia rubiginosa Miq., Nat. fam. der Myrsineæ. Gr. Snmatra W.K.; heester.

4. Aboëa Амв. = Dioseorea bulb if era l., Nat. fam. der Di os e orex. Gr. in bijwa geheel Indië gekweekt. GEißr. l)e knollen dezer slingerplant zijn een gewild voedingsmiddel; rauw gegeten zijn zij girtig.

5. Aboebo. MaK. = Dioseorea Kleiniana Kth. en D. pentaphylla L., Nat. fam, der Dioseorea. Gr. en Gerr. als No. 4.

6. Adal-adal J. $=\mathrm{Cr}$ ot on Tigli um I., Nat. fam. der Euphorbiacea. Gr. in bijna geheel Ned.-Indië; kleine boom. Geвк. Het hout, de bladeren en zaden gebruikt men om vissehen te bedwelmen; de wortel wordt tegen waterzueht aaugewend, terwijl de zaden en olie $\{\mathrm{Ol}$. Crotouis) sterk drastiseh werken.

7. Adappo Alf. Min. = Termiualia Catappa I, Nat. fam. der Combretacex. Gr. bijna overal in Indië. Hooge boom. GEBr. Het hout is een sterk bouwhout; den bast en de bladeren gebruikt men tot looiing van leder, tot zwartverving van katoen en om inkt van te maken; de bast is als samentrekkend en harsrijk geneesmiddel bij spruw, enz. zeer gewild: de zaden zijn eetbaar en smaken bijna als amandelen.

8. Adas M. \& J. $=$ Focuieulum vulgare Grtu., Nrt. fam. der Umbellifere. Gr. hier ell daar gekweekt; overblijvend. GFBR. Tevert de fenkel.
9. Adas-adassan $J_{\text {. }}=\mathrm{G}$ o m phren a globosa L., Nat. fam. der A marantaeex Gr. als sierplant in bijna alle tuinen; éénjarig. Gebr. Men eet de bladeren als groente; zij werken openend, oplossend.

10. Adas-manies $M .=$ Pin pinella Auisum I., Nat. fam. der Umbellifer $x$. Gr. hiel en daar in tuinen; éénjarig, het is de gewone Anijs $=b$. Anethum graveolens L, Nat. fam. der Umbellifers. Gr. mede gekweekt in eenige tuinen; éénjarig; deze is de gewone Dille.

11. Adas-ollanda $\mathrm{J}$. $=$ Fo enie ulum vulgare Grtn. (Zie No. 8.)

12. Adas-tjina M. = Illicium an is atum L., Nat. fain. der M agn o lia e e. Gr. op Java in eenige tuinen; heester, welks zaden de bekende steranijs zijn.

13. Adjeran-cetan J. $=$ Bidens pilosa I., Nat. fam. der Composita; Gr. Jarr bij Malang en elders; éénjarig; is een lastig onkruid.

14. Affi-affi $\mathrm{Cr}_{\text {. }}=$ Avicennia offieinalis $I_{\text {., }}$ Nat. fam. der Verbenaс е г. Gr. door geheel Ned.-Indië; hooge boom. GeBr. Het hout bezigt men als bonw- en brandhout; de stam zweet een groene aromatisehe hars uit, die op Nieuw-Zceland gegeten wordt; ook kent men aan den wurtel een de geslaehtsdrift opwekkende kraeht toe; de onrijpe zaden wendt men als een verzaehtend eataplasma aan, terwijl de rijpe in tijden van nood gegeten worden.

15. Afil Ti. $=$ Hymenodietyon timoranum Span., Nat. fam. der $\mathbf{R}$ :1biaec Gr. Tinor en Sawoe; hooge boom. Gubr. Deze boom levert eell zeer hard en goed bouwhout eu een bitteren, samentrekkenden bast; vermoedelijk is deze laatste het op de Javaansehe bazarars verkoeht wordeude $\mathrm{kaj}$ o e $\mathrm{timor}$ dat als 
harsrijk, samentrekkend middel veel wordt gebruikt en door WAITZ uitvoerig beschreven is. In allen gevalle verdicnt deze boom een zeer nauwkeurig onderzoek, om zijn verwantschap net de $\mathrm{C}$ in eho n asoorten.

16. Affo T. $=$ Hernandia sonora I., Nat. fam. der Hernandiace Gr. Java $\in$ n de Molukken. GEis. Het jonge hout voor drijf houten aan vischnetton, het oudere voor stijlen en kleine masten; den wortcl bezigt men tegen het pijlgif. Alle deelen der plant werken stcrk purgeercnd: uit de zaden bereidt men een rette olie.

17. Aforo BG. $=\mathrm{Aboebo}$ (Zie No. 5.)

18. Aga-aga AlF. MIN. $=$ Ptcrocarpus indicus Willd, Nat. fam. der $\mathrm{P}$ a p ilio n a c e $æ$. Gr. in bijna geheel Indië; hooge boom. Grir. Dezc levert een zcer gezocht, fraai geaderd cn sterk bour - en meubclhout het lingoä-hout der Molukken of Sono-hout van Java. Het door insnijding verkrcgen sap, 't welk in den handel als Oosind. kinagom bekend is, gebruikt men tot het politoeren van nieubelen en geeft men inwendig bij chronische diarrhaea, spruw, enz. Den bast geeft men tegen dezelfde zickten en bezigt hem ook als touwwerk voor vischnetten. Het hout wordt soms als reukwerk gebrand.

19. Aga-mantjik Sum. W. $\mathrm{K}=\mathrm{X} \mathrm{y}$ $r$ is melanocephala Miq., Nat. fam. der X yrideæ. Gr. Java en Sumatra tot $6000^{\prime}$; éénjarig.

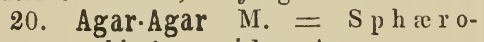
c oc cus lichenoides Ag., en

21. Agar-Agar koening $M .=S p h$ ærococeus lichenenoides Ag. var. te $\mathrm{n} u$ is, Nat. fam. der Floride $\mathrm{x}$; Gк. bijna overal in Indië. GEвr. Deze zeewieren bevatten veel geleiachtig slijm en zetmeel, zwellen in water tot gclei op, wordcu veel als verkoelende drank cn voor gebakken gebezigd en leveren mede de grondstof voor de eetbare vogelnestjes.

22. Ágila. $\mathbf{M}=a$. $\mathrm{Aquilaria}$ A gallocha Rxb., Nat. fam. der Aquil a ri n e x. Gr. Java, Sumatra, Borneo; hooge boom. GEBR. Hij levert het ware Aloëhout op, dat vroeger tot de tonische zenuwmiddelen gerekend werd $=b$. Exc o e c a ria A g a llo c ha I., Nat. fam. der Fuplorbi a c a ; GR. van Java tot N.-Guinca; hooge boom. GriBr. Deze lcvert aan den handel ook een soort van Aloëhout; hij bcrat een zeer scherp en giftig melksap, voor de oogen zeer schadelijk, dat zcer lastig bij het kappen is; uit den stam verkrijgt men een welriekcnde hars en olie; de schors wendt men als braak- en purgeermiddel aan.

23. Aha $\mathrm{HT}_{\mathrm{T}}=\mathrm{Gossypium}$ ind i c u m L a m., Naf. fam. der M a lv ac e x. GR. in gehcel Indië aangekwcekt; hcester. GEBR Deze levert een goede, doch grove boomwol; alle deelen der plant bezitten cen verzachtende slijm; de bladeren zullen braking opwckken.

24. Ahaän Амв. = $a$. Cu r culigo l a tifolia Drya nd., Nat. fam. der H y p oxidea. Gr. Java, Sumatra, de Molukken; overblijvend. GEı13. Men bezigt de bladeren tot inpakking: de zoete vruchten worden gegeten $=b$. E p i d e nd r u m t u b ros u m L o u r., Nat. fam. $\mathrm{der} O \mathrm{O} \mathrm{ch}_{\mathrm{i} \mathrm{d}} \mathfrak{\mathrm { c }} ; \mathrm{Gr}$. in gehcel Indië; Aard-Orchider.

\section{Ahaän abbal Amв. en}

26. Ahaän malona Aмк. = Calanthe veratrifolia $\underline{r}$. Br., Nat. fam. der Orchidex. Gr. in geheel Indië. Aard-Orchider.

27. Ahaijr Amb. = Unc a ri a lanos a $W$ a l 1,, Nat. fain. der $R$ u biac eæ. GR. Java, Sumatra, de Molukken. slingerplant. GEBR. De stam bevat een helder drinkwater; de jonge twijgen bezigt men tot het zwartverven, de oude voor vlechtwerk; deze plant bevat weinig gambir.

28. Ahamaijoe Амв. $=\alpha$. Eos s 5 pi u m in di c um Lam. (Zie No. 23.) = b. Eriodendrum an fractuos u m 1)C., Nat. fam. der Ster culi a c ca. $\mathrm{GR}_{\mathrm{R}}$. door geheel Indië; hooge boom. GEBR. Het lichte hout is geschikt voor insectenkistjes; de bladereu bezigt men bij wijze van zeep; de vruchten leveren ecu grove boomwol, als $\mathrm{k}$ a p o $\mathrm{k}$ bekend; een slijmig aftreksel der bladeren geeft men bij hoest, bij gonorrhæ, enz., uit dc zaden bereidt men een lampolic.

29. Aheij Axu. = $\mathrm{Ab}$ o e bo. (Zie No. 5)

30. Ahoe-ila Амв. = Vig u a $\mathrm{Ca}$ tjang Endl., Nat fam. der Papli. o n a c e r. Gr. in geheel Indië gekweekt. GEBR. De booucn zijn een zccr gezochte groentc. 
31. Ahuë-maun Аsis. $=P$ h a suol us rediatus L., Nat. fam. der Papili o n a e ex. Gr. in geheel Indië gekweekt; éénjarig. Gribr. De zaden zijn een zeer gezocht en gezond voedsel; men besprenkelt ze soms met water en laat ze twee à drie dagen uitschieten, waarna ze een aangename groente (katjang toemboe) en salade opleveren. De wortel bezit verdoovende eigensehappen.

32. Ahuelloe Cr. $=\mathrm{D}$ i o s p y r os Ebenum Retz., Nat fam. der $\bar{E}$ b en a e ex. Gr. Sumatra, de Molukken. Gribr. Deze boom levert een soort van zwart ebbenhout, dat voor huisbouw in meubelen kan dienen; de vruchten worden hier en daar gegeten.

33. Ahuo AмB. = Dioscorea bulbifera L. (Zie No. 4.)

34. Ahtes $\mathrm{M}$. $=\mathrm{Adas}$ M. (Zie No. 8.)

35. Aij-alija $А м в,=E$ u e a l y $\mathrm{p}$ t u s d e gl up ta Bl., Nat. fam. der M y rt a e c a. Gr. Celebes, Ceram; een zeer hooge boom, met harsrijken, aromatisehen bast. Hij wordt ook als ,aij-alla" opgegeven.

36. Aijassa $\mathrm{H}_{\Delta \mathrm{R} .}=\mathrm{Ev}$ od i a la t if o li a DC., Nat. fam. der D i o s m ex. Gr. de Molukken. Geirr. Deze boom levert een zeer vaste hars voor soldeersel.

37. Aijaur Амв. = Melanolepis? e al cosa Miq., Nat. fam. der Euphorb i a сег. Gr. de Molukken; kleine boom. GeBr. Het hout bezigt men veelal voor omheiuingen; hier en daar brandt men het als reukwerk; de gekneusde bladeren gebruikt men uitwendig bij huidziekten, tegen schurft.

38. Aijessi AmB. = Bassi a $10 \mathrm{ng}$ ifolia L., Nat. fam der Saputacer. Gr. in geheel Indië; hooge boom. GeBr. IIij levert een zeer hard en harsrijk bouwhout; het melksap, door persing uit de sehil der jonge takken en onrijpe vruch. ten verkregen, bezit een samentrekkende kraeht; de rijpe zaden leveren een zeer bruikbare vette olic; de vleezige bloemkroon wordt rauw en geroosterd gegeten; de bessen hobben een naar druiven zweemenden smaak.

39. Aijewan Hт. $=a$. Podocar pus bracteata Bl. en $b$. P. Kumphi 131. Nat. fam. der Podoearpex. Gr. $a$. Java, b. de Molukken. Gribr. Beide boomen leveren een lieht bouw- en meubelhout.

40. Aijhau-madelle IIт. $=\mathrm{Cana-}$ rium mieroearpum Wlld., Nat. fam. der A myridex. Gr. de Molukken; hooge boom. Grbl. Hij levert een lieht bouwhout, een zeer welriekende hars en uit de zaden, veel vette olie.

41. Aij-hin-toea $\mathrm{Cr}_{\mathrm{r}}=\mathrm{L}$ a e t a r i a e o e e in e a T. et B., Nat. Fam. der A p o е y $\mathrm{n}$ e $x$. Gr. Ceram; kleine boom.

42. Aijhoit Амв. $=$ Coix agres$\mathrm{t}$ i s $\mathrm{L}$ o u r. Nat. fam.der Gra m in ex. GR. Java en de Molukken; éénjarig. Gebr. De harde zwarte zaden gebruikt men voor bidsnoeren en guirlandes.

43. Aijhosso Амв. $=\mathrm{H}$ e r $\mathrm{n}$ a $\mathrm{n}$ d i a o vigera L., Nat. fam. der H e rn a nd i a e e æ. Gr. de Molukken; kleine boom. GEBr. Het lichte, sponsachtige hout is ongeschilt voor huisbouw; men snijdt er fraaie sehilden en beeldhouwwerk uit vour de stevens der prauwen.

44. Aijhuaa Нт. $=\mathrm{E}$ u p or b i a nereifolia L., Nat. fam. der E uphorbia e eæ $\mathrm{GR}_{\mathrm{R}}$, door geheel Indië; heester. GÉR. Deze eactusaardige struik bevat in al hare deelen overvloedig een scherp melksap, dat drastische eigenschappen bezit en als zoodanig, ook als hydragogum en vermifugum dikwijls is angewend; uitwendig bezigt men het bij furunculi en andere zwellingen; de wortel zal tegen slangenbeten heilzaam zijn.

45. Aijhuaa ette A. mette Asis. = Neuburgia museuliformis Miq., Nat. fam. der A p o е y и e Molukken, Nieur-Guinea; middelmatige boom.

46. Aijhuaa ketjil Asв. en fijhuaa mahina $A \mu \mathrm{B}=\mathrm{Kal}$ a nehoё $\mathrm{la} \mathrm{e}$ i$n$ i a t a DC., Nat fam. der Crassula. e e æ. Gr. in geheel Indië, overblijvend. GFBß. De bladeren gebruikt men uitwendig als verkoelend en wondheelend middel; het sap dezer bladeren wor!t soms tegen koorts gedronken.

47. Aijkaijn Lr. $=\mathrm{Sechle} \mathrm{i} \mathrm{che} \mathrm{r:a}$ tr ij u g a W ll d., Nat. fam. der S a p i ndacę. Gr. door geheel Ned.-Indië, hooge boom. GeBr. Het hout is vast, grof, wit en sterk, oud zijnde meer rosaehtig als Nani; zeer geschikt voor huisbouw, meubelen en gereedsehappen. De bast behoort tot de simmentrekkende geneesmiddelen; de jonge, zure bladeren eet men als groente bij viseh; de vruehten zijn zoetzuur en eetbaar; de vruchtschalen bezigt inen voor sicraad; uit de zaden verkrijgt men een vette olie, waarmede de bekende Makasser-olie gemaakt wordt. 
48. Aijkau boppo $A м B=\mathbf{J}$ am bos o bifaria Wght., Nat. fam. der Myrt a e e. Gr. Amboina; kleine boom. Gebre. Het hout soms voor huisbouw.

49. Aijkau kapoel Амв. $=(Z i e$ No. 54.)

50. Aijkau laun ela Амв. = Ja mbosa alba Rmph., var. sylvestris alba $R m p h .$, Nat. fan. der Myrtaee Gr. de Molukken, hooge boonl. Gebr. Men plant hem veel aan om de lekkere vruehten; deze verseheidenheid is waarschijnlijk de oorspronkelijke witte vorm der djamboe; liet hout bezigt men voor kromhouten en de sehors en bladeren uitwendig als adstringens op verzweringen.

51. Aijkau laun maun $А$ м. = $a$ Nelitris rubra Bl. en $b$ N. alba Bl., Nat. fam. der Myrtae a. Gr. de Molukken; groote heesters. GEBR. Het hout bezigt men voor stijlen, kleine gereedschappen en brandhout; de bladeren als samentrekkend middel bij spruw.

52. Aijlaloe $\triangle м в=A$ d e $n$ an thera Pavonina. L., Nat. fam. der M imos eæ Gr. in geheel Indië; hooge boom. GEвR. Het sterke, roode hont is zeer gesehikt voor bouwhout; in Bengalen bezigt men het ook als vertstof; de fraaie roode zaden gebruikt men voor halssnoeren en het wegen van goud; zij zijn evenals die der volgende plant algemeen bekend onder den naam van biedjie saga M.; van den schil ontdaan eet men ze gekookt, bij wijze van erwten.

53. Aijlaloen Нr. $=$ Abrus præeatorius L., Nat. fam. der Papilio$\mathrm{n}$ a cex. Gr. in geheel Indië; slingerplant. GEBk. Den wortcl gebruikt men in plaats van zoethoutwortel; de bladeren in aftreksel bij katarrhen, vooral der luehtwegen, uitwendig tegen kies- en tandpijn en als mondspoeling bij spruw; de fraaie zaden dienen voor halssnoeren in bidkransen; fijn gestampt bezig melı ze bij het soldeeren van gond; soms worden zij gegeten, doch rerwekken allieht kolijk; volgens $\mathrm{BL} \mathrm{iNCO}$ geeft men ze, op wijn afgetrokken, tegen epilepsie en hartziekten.

54. Aijlanoe Hosso Нт. = Hernadia ovigera I., (Zie No. 43.)

55. Aijlanoo-seloe HT. = A etinodaphne Rumphii Bl., Nat. fam. der L a ll rinex. Gr, de Molukken, middelmatige boom. GEBR. Het liehte hout bij huisbouw, vooral voor daksparren; de bladeren uitwendig op verwondingen door pijlen en vissehen veroorzaakt.
56. Aijlanoe-soenoe Амв. $=M$ appa moluee an a $\mathrm{S} p \mathrm{rg}$., Nat fam der E 1 ph o r b i a e ex. Gr. Sumatra, Celebes, de Molukken; middelmatige boom. GLbR. Hij levert een sterk, wit hout, ge schikt voor vaatwerk; de groote bladereu gebruikt men als servetten.

57. Aplanto Амв. $=A$ ilanthus molueeana DC., Nat. fam. der Simar u b a e ex. Gr. de Molukken; hooge boom . GeBr. Alle deelen zijn zeer bitter.

58. Aijlaroe $A м B .=A d e n a n t h e r a$ Pavonina L. (Zie No. 52.)

59. Ag̈laroe-pidjar Амв. $=\mathrm{A}$ brus prace t orius L. (Zie No. 53.)

60. Aijlaroe-pobon Ams. = Pongamia? corollaria Miq., Nat. fam. der Papilionaeer. Gr. de Molukken; hooge boonl. GEBR. De sehoone zaden zijn zeer gezoeht voor halssicraden; ook bezigt men ze bij het soldeeren van goud.

61. Aijlassalinoe Aмв. $=$ Dillenia speeiosa Thb., Nat fam. der Dilleniaceæ. Gr. in geheel Indie; hooge boom. Gkizr. Hij levert een hars, die de sehrijnwerkers gebruiken; den bast wendt men uitwendig tegen jicht aan; de bladeren bezigt men als loog tot wassehing van het hoofdhaar en zuivering van zilverwerk; het geeonfijte sap der jonge vrueht geeft men bij vele borstaandoeningen; de rijpe vruehten zijn eenigszins laxecrend, men eet ze als toespijs bij viseh en maakt er azijn van.

62. Aijlatoe Arв. = Hernandia sonora $\mathrm{I}$ (Zie No. 16.)

63. Aijlau-essl Амв. $=$ B as si a long ifolia $\mathrm{L}$ (Zie No. 38.)

64. Aijlau-njid AмB. $=$ Medinilla maeroearpa Bl., Nat fam. der Melas t o m a e é. Gr. de Molukken. Gebr. De bast van deze en andere soorten nitwendig bij gewriehtsziekten, op beten van visschen en slangen en op furuneuli

65. Aịjlau-sala $А м в .=C$ issus e inerea T,am., Nat. fam. der A in peli$\mathrm{d}$ e GR. in geheel Indië; slingerplant. GEBR. Met eet de zure bladeren soms als groente; uitwendig bezigt men ze als huidprikkelend middel en in aftreksel tegen koorts.

66. Aijlau-tołban $A \mathrm{MB}=\mathrm{V}$ it ex

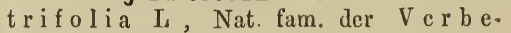
$\mathrm{n}$ a e e ce. Gr. in geheel Indië; heester. GEBR. In de huishouding bezigt men de bladeren dikwijls tot het weren van insecten, b. v. de klanders uit de rijst, als 
geneesmiddel zijn ze, inwendig toegediend, een goed aromatiseg, zweetdrijvend middel ; uitwendig gebruikt men ze als verdeelend en pijnstillend bij zwercu, kncuzingell, ook bij beri-beri, tegen scabies, enz.

67. Aijlaun-ahussen Амв $=a$. Vernouia cinerea Less., Nat. fam. der Compositæ. Gr. in geheel Indië; éénjarig. Gubr. Men geeft den wortel tegen hoest en buikloop; men eet het kruid als groente en bezigt het tegen het uitvallen van het haar; uitwendig gebruikt men het als weekmakende pap op gezwellen. = b. Vernonia leptophylla DC.; Nat. fam. en GR. als boven; overblijvend. Gebr. Men geeft dit kruid bij zwaren hoest aan kraamvrouwen.

69. Aijlaun-ahussen toani Амв. = a. Bidens Walliehii DC. en $b$ B. peduneularis Galld., Nat. fain. der Compositæ. Gr. in geheel Indië; éénjarig. Gerr. Men eet het jonge kruid als grocnte, geeft het tegen hoest ea op brandwonden; den wortel kauwt men bij tanipijn.

69. Aijlaun-hitoe Амв. = Coleus a mboinicus Lour., Nat. fam. der Labiatæ. GR. in geheel Indië; éénjarig. Gér. Men geeft de bladeren tegen koorts, asthma, stuipen en vallende ziekte.

70. Aijlaun-kapepoeli $\mathrm{Cr}$. $=\mathrm{Hy}$ drocotyle asiatiea L., Nat. fam. der Umbellifera. Gr. in geheel Indië; overblijvend. GFBR. Dit kruid wordt zeer veel gebruikt; men eet het als groente, kent het een oplossende, pisdrijvende en woudheclende kracht toe, en geeft het bij hoest, waterzueht, graveel en ander nierenlijden en diarrhaea. Op Mauritius zag men het met gevolg bij lepra toedienen. Volgens BuANco is het sap heilzaam bij verduistering der cornca.

7i. Aijlaun-mahaij AML $=a$. Psyllanthus Niruri L. en $b$. Ph, uriu aria Wld., Nat. fam. der Euphorbi с ег. Gr. in geheel Indië, ćénjarig. Gebr. Beide deze kruidjes bezitten wondhec!ende, pisdrijvende en afvoerende eigensshappen, worden daarom bij alle lijden van pisbuis, blaas en nicren veelvuldig gegeven en ook als vruchtafdrijvend middel misbruikt

72. Aijlaun-mamulin $\mathrm{Cr} .=\mathrm{R} u \mathrm{el}$ lia discolor Nees, Nat. fam. der Acanthaceac. Gr. de Molukken en Java; heestertje. GFBR. Ileeft een groote vermaardheid als duivelbezwerend middel.
73. Aijlaun manoek. AMA. $=a$. Cassia Sophora L. en b. C. Tora I, Nat. fam. der Papilion a e æ. Gr. in geheel Indië; éénjarig. G EBR. Men nuttigt beide kruiden als groente en legt ze op allerlei wonden en zweren vall kippen en andere vogels.

74. Aijlaun maroea Aив. = M ussacnde frondosa L., var. glabra, Nat. fam. der $\mathrm{Bub}$ iacex. Gr in geheel Indië; heester. GEBR. Men wendt het sap aan bij oogontstekingen en geeft de zaden tegen physeouic der milt na koortsen.

75. Aijlaun marva HT. = Dartus perlarius Lour. (?), Nat. fam. der Solanacex. GR. de Molukken; heester. GEBR. Men geeft den wortel als verkoelend, zacht laxeerend middel bij koortsen; de bladeren zijn een gewild middel tegen mazelen.

76. Aijlaun niwel Амв. = $a . \mathrm{No}_{0}$ thopanax coehleatum Miq., Nat. fam. der Araliaeeæ. Gr. door geheel Indië in tuinen en paggers; heester. GEBR. De stam levert cen op opopanax gelijkende gomhars; de op schoteltjes gelijkende bladeren gebruikt men als zoodanig, de jonge eet men als groente; op Ternate $\operatorname{legt}$ men ze, met olie bestreken, op zwerende borsten. Wortel en bladeren bezitten zweet- en pisdrijvende eigenschappen. $=6$. Nothopanax pinnatum M iq., Nat. fam. als hoven. Gr. de Molukken, veelal in paggers; heester. GEBR. Men cet de jonge bladeren als groente.

77. Aijlaun-nija Hт. $=R$ u e $11 \mathrm{i}$ a dis color Nees. (Zie No. 72.)

78. Aijlaun-oerita $\mathrm{AMB}$. $=\mathrm{Treve}$ sia molue e n a $\mathbf{M}$ i q., Nat. fam. der A ra 1 i a e e r. Gr. de Molıkken; heester. Gевв. De schor's is mogelijk gesehikt voor papierberciding; deze en de bladeren geeft men bij een onderbuiksziekte, ,Sakit gorita" geheeten; de bittere bessen worden door vogels gezoeht.

79. Aijlaun paija mata Амв. = a. Dentella repens Forst., Nat. fam. der $R u b i$ a e e. Gr. yeheel Indië; overblijvend. GEвR. De bladeren gebruikt men litwendig tegen seluurft en herpes en op nagelzweren. $=6$ B o n n a y veronica folia Sprg., Nat, fam. der Serophularineac. Gr. geheel Indië, overblijvend. GErR. $\mathrm{Al}_{3}$ voren

50. Aijlaun peu-peu iIT $=\mathrm{V}$ er. no $\mathrm{nica}$ cinerea $\mathrm{I}_{\text {ess., }}$ (Zie No.67 a.) 
81. Aijlaun rihute $А м в .=H у-$ droeotyle asiatiea L. (Zie No. 70.)

82 aijlaun sehoe $\mathrm{Aмв}$. $=\mathrm{V}$ erno 1 i a einerea Less (Zie No. 67a.)

83. Aijlaun seloer LT. en

8\%. Aijlaun seron $\mathrm{AT}$. = A e tin 0 d a ph ne Ru in phi i B l. (Zie No. 55.)

85. Aijlaun tahina $\mathrm{Aмв} .=a . \mathrm{Co}_{0}$ leus amboinicus Lour (Zie No. 69 .) $=$ b. Conyza balsamifera L., Nat. fam. der Compositæ. Gr. door geheel Indië; heester. GEBr. De eenigszins naar Salvia riekende, balsemachtige bladeren worden als groente gegeten, nitwendig veel in baden en stovingen aangewend, geven een goede mondspoeling bij salivatie en, iuwendig, in aftreksel gegeven, een goed diaphoreticum en expeetorans.

86. Aijlaun tahur Aмв. = P othomorphe subpeltata Miq, Nat. fun. der Pi per a e ex. Gr. in geheel Indië. Gebr. Men eet de jonge bladeren als groente, geeft ze tegen kneuzingen en bij waterzucht; de zaden worden als lekkeruij en orik tegen hoest gegeten.

87. Aijlaun üa massari LT. $=$ Vernonia einerea Less. (Zie No. $67 a$.

\section{Aijlaun-uijn Амв. en}

89. Aijlaun-wakkan $\Lambda$ мв. $=\mathrm{Cu}$ $r$ a ng a a m a r a Juss., Nat. fam. der S e ro phularinex. Gr. door geheel Indie; overblijvend. Gribr. Een aftreksel van dit zeer bitter kruid wordt gegeven tegen koorts en ingewandswormen.

90. Aijlilin $А м в .=G$ r a p to $\mathrm{ph}$ y ll u m hortense Nees Nat fam. der A c a n th a e e r. Gr. door geheel Indië, met vier verscheidenheden als sierplant en in omheiningen; heester. Gerr. Men gebruikt de bladeren tot reiniging van het hoofdliaar, uitwendig als verdeclend rijprnakend middel op furuneuli en andere zwellingen en bij sehurft, inwendig voor kraamvrouwen bij vermoeidheid.

91. Aijloaha Амв. en Aijloaha oetan Aмв. = R uelli a repanda I, Nat. fam der Acanthacere. Gr. Java en de Molukken; overblijvend. Gebr. Een gezoeht middel tegen betoovering en als zoodanig aangewend bij alle ziek'en, welke de inlander zieh niet kan verklaren, of waarbij hij geen uitkomst weet en die hij dus aan den duivel toeschrijft.

92. Aij lohoen oebi Амв. $=\mathrm{C}$ i ssus latifolia Vahl. Nat. fan. der A mpelidea. Gr. de Moluklen; sli- gerplant. Gebr. Het gekneusde kruid als rijpmakend, etterbevorderend middel bij zweren, furuneuli en andere zwellingen.

93 Aijlohoij Амв. = Nothopanax eoehleatum Miq. (Zie No. 76a.)

94. Aij lomamar dawon besaar Aмв. = Helieia molueeana R. Br. Nat. fam. der P rote a e e. Gr. A mboina; kleine boom.

95. Aijlou-aha Cr. $=\mathrm{P}$ er istro. phe tinetoria Nees., Nat. fam. der $\mathrm{A}$ e a $\mathrm{nt}$ h a e er. Gr. in geheel Indië; kleine heester. Gebr. De bladeren gebruikt men tot het roodverven van garen.

96. Aijlouha-poetie Амв. $=\mathrm{H} \mathrm{у-}$ po ës tes p urp urea B. Br., Nat. fam. der A e a n th a e ex, Gr. Java, Amboina ; overblijvend; sierplant.

97. Aijmahala| of Aijmalaha Амв. = $\Lambda \mathrm{l} \mathrm{bizzia}$ spee. indef., Nat. fam. der M i m o s e æe. Gr. de Molukken; hooge boomen. GeBr. Het hout soms voor stijlen, kisten en lijsten.

98. Aij-mahoe $A M \mathrm{~B}_{0}=\mathrm{L}$ ans i u d om estie um J a e k. Nat. fam. der M eli a e e $\propto$. Gr. door geheel Indië; hooge boom. GeBr. Het hout is zeer sterk; geschikt vour huisbouw en gereedsehappen; de vruchten, meer algemeen als lansa of lansap M. bekend, zijn zeer gezoeht en gezond; hare sehil brandt men als reukwerk, deze verbreidt eene benzoëgeur, de zaden zijn wormdrijvend, volgens sommigen. ook koortswerend.

99. Aijamhoe abba Амв. = Cookia punetata Retz., Nat. farn. der A u r a n ti a e e $⿱$ r. Gr. de Sunda-Arehipel en Molukken; boom. GEBR. Men wendt den bast en de bladeren nitwendig bij seabies aan; de bladeren worden hier en daar als aromatiseh maagmiddel aangewend en ook als koortswerend aangeprezen; proeven omtrent deze laatste eigensehap hebben eehter gefaald; de vruehtjes worden in China en elders gegeten, doeh moeten bedwelmend zijn.

100. Aij-makianinoe Амв. $=1$ il. lenia serrata Thb. -- Nat. fam. der Dill e n i a e e æ. Gr. Java, Celebes, Amboina; hooge boom. Gris. Het hout is hard, doeh spoedig wormstekig; de bast wordt tegen spruw en asthma aangewend; de vruehten worden gegeten.

I01. Aij-makka-loelan Нт. $=\mathrm{Pa-}$ vetta amboinie a Bl. Nat. fam. der $\mathrm{M}$ a lva e e $\mathrm{I}_{\mathrm{C}}$. Sumatra, de Molukken; heester. GEbr. De wortel uit- 
wendig als roodmakend en blaartrekkend middel.

102. Aij-makuninoe Амв. = I) ille ni a speeios a Th b., (Zie No.61).

103. Aij-maloe Амв. = Urostigma Rumphi $\mathrm{Miq}$, Nat. fam. der A r t o erpex. Gr. in geheel Indië; fraaie, hooge boom, die om zijn schoonheid dikwijls aangeplant wordt.

104. Aij-manoek Амв. $=\mathrm{El} \mathrm{l}$ o e a r u s s erratus L., Nat. fam. der Tili a e e æ. Gr. in geheel Indië; hooge boom. GEBR. Het hout is gesehikt voor huisbouw, doch in den grond niet duurzaam; de vruehten zijn eetbaar; de fraaie zaden zijn zeer gezocht voor halssnoeren en bidkrausen.

105. Aij-massanino2 AмB. = Dillenia serrata $\Gamma$ hb (Zie No. 100.)

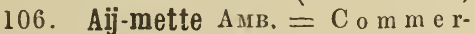
sonia e ehinata Forst., Nat. fam. der $B$ ü $t$ t $\mathrm{a}$ e ri a e e Indië, hooge boom. Gribr. Het hout voor huisbouw, vooral voor daksparren; de bast voor tonwwerk en lont.

10\%. Aij-metten of Aij-miten Br $=\mathrm{Maba}$ Ebenus Spr.: Nat. fant. der Ebenaceæ. Gr. de Moluklien; boom. GEBR. Ilet hout is het beste zwarte Indisehe ebbenhout.

208. Aijmiri of Amiri BR. $=\mathrm{H}$ e rn a ndia so nora L. (Zie No. 16.)

109. Aij-moesin Br. $=\mathrm{Quereus}$ moln e e a n a $\mathrm{Rm}$ ph., Nat. fam. der $\mathrm{Cu}$ o u lifer æ. Gr. Celebes en de Molukken; hooge boom. GeBr. Het hout is sterk, zeer gesehikt voor huis- en seheepsbouw; de vruchten worden geroost gegeten en gelijken veel op onze eikels, doeh hebben meer den smaak van kastanjes.

110. Aij-nahoe AvB. $=$ Melast o ma polyant hum Bl. Nat. fam. der $\mathrm{Melas}$ tom a e e $x$. GR. overal in Indië zeer gemeen; heester Gebr. Het sap der wortels geeft men bij zenuwtoevallen ex tegen ingewandswormen; de samentrekkende bladeren bij diarrhaea, dysenterie, gonorrhae, fluor albus, en z.; de rijpe vrichten zij:ı cetbaar.

111. Aij-nitoe $\mathrm{AMb}=\mathrm{Melan}$. le $p$ is (?) e al e os a M i q. (Zie No. 37.)

112. Aijoelan $А м B$. en.

113. Aijoelit $\mathrm{AmB} .=\mathrm{S}$ a ndoric u m ind i c um Cav., Nat. fan. der Ml eli a e ex. Gr. Java, de Molukken; hooge boom. Geisr. llet hout is genrig, zeer gesehikt voor bonwhout en kistjes; den aromatiseh-bitteren wortelbast geeft men bij maagpijn; de zure vruehten worden hier en daar gegeten en hare sehillen geconfijt.

114. Aijokkol ketjil Амв. $=$ Plumb a g o ro s e a L. . Nat. fam. der Plumb a g i n e r. Gr. in geheel Indië als sierplant in tninen; heestertjc. GeBr. De scherpe wortel kan als roodmakend en blaartrekkend middel gebruikt worden; hij is nareotiseh en wordt tot de alexi-pharmaea gerekend; een aftreksel der wortels geeft men aan zieke paarden, om ze vet en glanzend te maken.

115. Aijokkoli $\Lambda \mathrm{mB}$. en

116. Aijokkor $\mathrm{AMB}$. $=$ Croton Tigli u in 1. (Zie No. 6.)

117. Aijpakka $\triangle \mathrm{MB}=\mathrm{Cordia}$ M y x a L.; Nat. fam. der Co di a e e $G_{R}$. in geheel Indië; middelmatige boom. GŁBR. De wortel werkt laxeerend; den bast geeft men op Java bij koortsen; de gedroogde vruchten, vroeger in den handel als Sebestenae of Myxæ, zijn zfer slịmig en worden bij buikziekten en blaasaandoeningen toegediend; zij werken zacht afvoerend, bijna alı de Cassia.

118. Aijpakka-djawa $А м в=U$ rostigma Ruphi Miq. (Zie No. 103.)

119. Aijpassa Ani. $=a . \mathrm{Ma} \mathrm{ch} \mathrm{i-}$ ln s od oratissima $\mathrm{Ne}$ es. Nat. fam. der L a u rin ex. Gr. de Sunda-eilanden en Molukken; hooge boom. Gebr. II t hout is zeer gesehikt voor hu s- en seheepsbouw. - $b$. $\mathrm{H}$ a a si a me di a $\mathrm{Bl}$, Nat. fam. als boven. GR. de Molukken; hooge boom GEBR. Het hout is zeer geschikt voor huisbouw en roeispanen.

120. Aij-poetie Амв. $=a . \mathrm{M} \mathrm{el} \mathrm{a-}$ l e u e a $L$ e u e a d e ndron L., Nat. fam. der Myrta e a e. Gr. Celebes en de Molukken; hooge boom. Gebr. Het hout is een zecr goed timmerhout; den bast bezigt men tot het kalefaten van sehepen; de geurigc vruehten eet men als speecrij. $=b$. $\mathrm{P}$ i s o $\mathrm{n}$ i a a $\mathrm{lb}$ a $\mathrm{S}$ p a n., Nat. farn. der $\mathrm{Ny}$ e tag i n e a e. Gr. Java, Celebes en de Molukken, veelal angerlant; boom. GEBr. Van den Moluksehen Koolboom eet men de bladeren in plaats van kool en gebruikt ze reelal bij het toebereiden van viseh.

121. Aij-polat Амв. = I a p о $\mathrm{r}^{\circ}$ te a a mplissima Miq. en I., dee um a m a W ed d., Nat. fam der U r ticac cé. Gr Java en de Molukken; hees- 
ter's. Geir. Men gebruikt de bladeren als huidprikkel bij rheumatismus, verlamming, enz.

122. Aij-samara Aмк. = C a s u arina equisetifolia L. en C. nodifl or a $\mathbf{H}^{\prime}$ orst., Nat. fam. $\operatorname{der} \mathrm{C}$ a su arin e æ. Gr. bijna overal in Indië; hooge boomen. GEBR. Het harde, roode, eenigszins welriekende hout gebruikt men zelden voor huisbouw, meer voor stelen of seheden van wapens en voor houtskolen; den samentrek. kenden bast geeft men als tonieum, vooral bij bloedspuwing en als zenuwopwekkend middel; hij moet goed zijn bij partus en ook de menses bevorderen. De bladeren bezigt men bij feesten tot versiering; de hars is geschikt om mede te kalefaten.

123. Aij-sana $А$ мв. $=\mathrm{Sph}$ ær oce us lieh en oides Ag., var. ten uis. (Zie No. 20,)

124. Aij-tette laun maun Aмв.,

125. Aij-cette obte $\mathrm{Cr}_{\mathrm{r}}$. en

126. Aij-tette olite $\mathrm{Cr}$. $=\mathrm{C}$ o d i $œ$ u m molue e a u m D o u., Nat. fam. der E u phorbia e e Indië in alle tninen als sierplant, met vier verseheidenheden; heester. GLBR. De wortel en bast zijn zeer seherp; derı wortel geeft men soms als laxans en bij maagpijn; de jonge takken geeft men aan buffels om vet te worden; de bladeren bezigt men veel tot opsiering bij partijen; die der roode variëteit eet men als groente; uitwendig legt men ze op verharde gezwellen en bij lendepijn.

127. Aij-tette-tueban Амв. $=\mathrm{Vi}$ textrifolia L. (Zie No. 66.)

128. Aij-tiba Аuв. $=\mathrm{Ne}$ penthes phyll amphora Wlld., Nat. fam. der $\mathrm{Nepenthex.} \mathrm{Gr.} \mathrm{Java} \mathrm{de} \mathrm{Mo-}$ lukken; slingerplant. Geвr. Sommigen drinken het in de kannetjes bevattende water tegen hoest.

129. Aij-timon Амв. = Polyphragun o s ericeum l) esf., Nae. fam. der R u bi a e e æ. Gr. de Molukken; heester. GEBr. Het hout voor kleine balken en vischfuiken; den bast kauwt men in plaats van pinang.

130. Aij-toëa $\mathrm{C}_{R} .=\mathbb{E}$ i e e r as floridum R. \& Seh., Nat. fam. der $\mathbb{E}$ g i e e r e æ. Gr. Oost-Java en de Nolukken; kleine boom.

131. Aij-toeban Амв. = a. Vit ex trifolia L. (Zie No 66); en $b$. V it ex N e g u u d o L., Nat. fam. der Verbe na e é Gr. in geheel Indië; heester.
Gebr. Men kent aan den wortel pis- en wormdrijvende eigensehappen toe.

132. Aijjukka AMB. $=$ Arali a javanie a M iq., Nat. fam, der A rali a c e æ. Gr. Java en de Molukken, veel in omheiningen; heester.

133, Aijjukka Амв. = L e e a s a mbucina Wlld., Nat. fam. der A mpelideæ. Gr. in geheel Indië; heester. Gebr. Men plant dezen heester veel aan uit bijgeloof, ter verdrijving ran kwade geesten uit de velden en bij ziekten; de bladeren worden als groente gegeten, en men bezigt ze uitwendig als verkoelend middel bij oogziekten en koorts; het sal uit den stam druppelt men bij doofheid in de ooren: het geraspte hout legt mell bij wijze van pap op verlamde ledematen; het hout en de bladeren wendt men als bloedstelpend bij wonden aan.

134. Aij.wahaoe $\mathrm{Cr}_{\mathrm{r}}=\mathrm{A}$ e orus terrestris $R m p h$. Nat. fam. der Oronti a c e a e. GR. overal in Indië; moerasplant. GeBr. De wortel heeft de. zelfde eigenschappen en wordt aangewend als die onzer "radix ealami aromatici".

135. Aij-wara Амв. $=\mathrm{Flage} l \mathrm{la}$ ria indica L., Nat. fam. der Flage $\mid l$ a ri e a e. Gr, overal in Indië; slingerplant. GEBR. Deze plant bezit samentrekkende en wondheeleude eigenschappen; op Java eet men de bladeren bij wijze $\mathbf{v}$ an groente en reinigt men er het hoofdhaar mede; de stengels gebruikt men als bindtouw.

136. Aijwel Амв. = Dios e orea K leiniana Kth. en D. pentaphylla L. (Zie No. 5.)

137. Airi-koekoen S. $=$ M y r istiea c o r tic os a Hf. eu Th., Nat. fani. der Myristiceae. Gr. in den geheelen Arehipel GeBr. Het hout van dezen boom is een sterk bouwhout; de zaden bevatten een vette en alomatisehe olie.

138. Ais $B K .=V$ a e eini u m mala e c e n s e Wght., Nat. fam. der Va ec in i e a e. Gr. Banka; heester.

139. Ajam bakoekoe M. $=a$. R nbes a cuminatissimus $\mathrm{Hassk}$ en $b$. $\mathrm{R}$ u bes mot u e e a n s L. Nat. fam. der Ros a e a e. Gr. de Sunda- ell Moluksche eilanden; heesters. GEBr. Het sap dezer plant wendt men als prikkelend oogwater aan; men eet de bladeren als groente; zoo ook de vruehten, die zoet en saprijk zijn.

140. Ajapanna S. \& M. = E u pa- 
torium ayapanna Vent., Nat. fam. der Compositæ. Gr. de Sunda-eilanden. GEBR. Het kruid dezer overblijvende plant gebruikt men inwendig tegen hoofdpijn, ook op onzuivere zweren en slangenbeten; een aftreksel ervan geeft men als zweetdrijvend middel bij koortsen, waterzucht, enz.

141. Ajer R. = Aralia javanica Miq. (Zie No. 132.)

142. Ajer-ajer Sum. = Lansium a q uæum Jack, Nat. fam. der Meliaceae. Gr. Java, Sumatra; boom.

143. Ajong-ajong $\mathrm{S}$. $=$ Quamoclit coccinea Mnch., Nat. fam. der Convolvulaceæ GR. Java in tuimen; slingerplant.

144. Akanakan. Sus. = Artocarpus polyphema Pers., Nat. fam. der A r tocarpex. Gr. Java, Sumatra, enz. in tuinen; hooge boom. GEBR. Het hout is zeer geschikt voor huisbouw en meubelen; het vruchtvleesch wordt gaarne gegeten en ook de pitten worden gekookt of geroosterd genuttigd.

145. Akar ${ }^{1}$ ) ampaloe kampong Sum. = Tetracera scaberrima Miq., Nat. fam. der Dilleniacer. Gr. Sumatra; slingerplant.

146. Akar ampaloe riemboe Sum. = Tetracera rigida B l., Nat. fam. als voren. Gk. Sumatra; slingerplant. GEBr. Volgens $\mathrm{Hasskarl}$ wordt het sap van alle Tetracera-soorten tegen hoest gedronken, wendt men het jonge loof op slangenbetesı aan, leveren de ranken eeu goed touwwerk bij waterwerken en dienen de bladeren tot het polijsten van hout.

147. Akar-ampar BK. $=\mathrm{E} \mathrm{m} \mathrm{b} \mathrm{e} 1$ i a das y th y r a M i q. (4825).

148. Akar-api-api Вк. = Embelia oblongata Miq., Nat. fam. der M ylsineæ. Gr. Sumatra, Bangka; heester.

149. Akar-bandar $\mathrm{BK}_{\mathrm{K}}=\mathrm{S} \mathrm{milax}$ setosa Miq., Nat. fam. $\operatorname{der} \mathrm{S}$ milac e :. Gr. Bangka; overblijvend.

150. Akar-barak PAL. = C hailletia sumatrana Miq., Nat. fam. der Chailletiace æe. Gr. Sumatra's O.K.; klimplant.

151. Akar-beboeloes Bk. (Zie No. 1 ว)

152. Akar-behahau Sum. W. K. = Vitis(?) imperiales M i q. Nat. fam. der A pelide ac. Gr. Sumatra's W.K. slingerplant.

1) Akar beteekent wortel.
153. Akar-binassa M. $=\mathrm{Pl} \mathrm{u} \mathrm{m}$ b a g o ro se a L. (Zie No. 114.)

154. Akar-boeah Sus. W.K. = Briedelia stipularis Bl., Nat. fam. der $E$ u phorbi a c e . Gr. Java, Sumatra; heester. Gebr. Het sap der jonge takken wordt in de oogen gedruppeld tegen vlekken op het hoornvlies; de bladeren geeft men aan de kraamvrouwell en uitwendig tegen hoofdpijn; op de Philippijnen rookt men ze als tabak.

155. Akar-boelan $\mathrm{M} .=\mathrm{Z}$ an on i aind i c a L. (Zie No. 8720).

156. Akar-boeloes Вк. $=\mathrm{Anc}$ istrocladus penangianus Wall., Nat. fam. der Dipterocarpex. Gr. Bangka; boom.

157. Akar-darik-darik Sum. W.K. $=$ Cissus darik Miq., Nat. fam. der A mpelidex. Gr. Sumatra; slingerplant.

158. Akar gameh SuM. W.K. = Diss ochæta Diepenhorstti Miq., Nat. fam. der M e la s t o m a c ex. Gr. Sumatra; slingerplant.

159. Akar-iedjoe BK. = D e n d r otrophe varians Miq., Nat. fam. der $\mathrm{S}$ a n t a l a c e æ. Gr. Bangka; parasiet.

160. Akar-kait-kait Sum. W.K. = Cæsalpinia acanthobotrya Miq., Nat. fam. der Papilionace Gr. Sumatra; slingerplant.

161. Akar-kaloei Sum. $=\mathrm{Ph}$ anera f u lva Benth., Nat. fam. der P a pi-

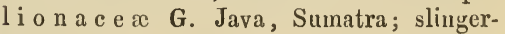
plant.

162. Akar-kaminjan M. = Di o scorea Diepenhorstiana Miq., Nat. fam. der Di os corex Gr. Sumatra; de bloemen dezer slingerplant rieken naar benzoë.

163. Akar-katong Bk. (Zie No. 156.)

164. Akar-kediloen $\mathrm{Bk}$. = M a s a ovat a A. DC., Nat. fam. der M y r sin e x. Gr. Bangka; heester.

115. Akar-kekait of kait-kait $\mathrm{M}$. $=a$. Uncaria ferruginea DC. (Zie No. 2392) en $=6$. Uncaria glab r at a DC, Nat. fam. der Rubiaceic. Gr. Java eu Sumatra; slingerplant.

166. Akar-kekowak Вк. = D i s s ochrta atrosticta Miq. (Zie No. 223.)

167. Akar-keporo Sum. = M o in ordisa denticulat a M i q., Nat. fam. der $C$ u $\mathrm{c}$ u r b i $t$ a e e $x$. Gr. Sumatra; slingerplant. 
168. Akar-ketangkiel $\mathrm{Bk} .=\mathrm{G} n \mathrm{e}-$ t u m n egle ctum Bl., Nat. fam. der G net a c e $æ$. Gr. Sumatra, Bornco, slingerplant.

169. Akar-ketjambang $\mathrm{M}_{\mathrm{.}}=\mathrm{I}$ e t t. s o mi a sumatran a Miq. Nat. fain. der Convolvulacex. G. Sumatra; slingerplant.

170. Akar-kiladja S. = Uvaria $\mathrm{d} u \mathrm{l}$ c is $\mathrm{D}$ u n (Zie No. 3649c.)

171. Akar-klibang $\mathrm{Bk}$. of

172. Akar-klipar $\mathrm{BK}$. $=\mathrm{Embe-}$ li a bracteos a Scheff., Nat. fam. der M y r's in ex. Gr. Bangka heester.

173. Akar-klimpar Bк. = E mbelia dasythyrsa Miq, (Zie No. 4825.)

174. Akar-koebang Sus. W.K.b. = Uvaria purpurea Bl., (Zie No. 573b.)

175. Akar-koekoetjingan $\mathrm{M}$. = Cibotium glaucescens Kalf., Nat. fam. der Polypodiacer. Cr. Java, Sumatra; Varen. GEBR. Het goudgele haar van den stronk wordt uitwendig veel als bloedstelpend middel gebruikt; een extract daarvan zal ook bij inwendige bloedingen, menstruaalvloed, enz. heilzaam zijn.

176. Akar-koenjit $\mathrm{BK}_{0}=\mathrm{C}$ os c i n iu m Blumeanum Miq. (Zie No. 180.)

177. Akar-koemit M. = L e tt somia to in e n tell a $\mathrm{Mliq}$., Nat. fam. en Br. als No. i69.

178. Akar-koening Str. O.K. = Strychnos palembanica $\mathbf{M}$ iq., Nat. fom. der L o g a n i a c e . Gr. Sumatrr: slingerrilant.

179. Akar-koening $\mathrm{M}_{\mathrm{s}}=\mathrm{D}$ a u c a s $\mathrm{C}$ a r o ta L., Nat. fam. der $\mathrm{U} \mathrm{m}$ bell j. $\mathrm{fe} r x$. Gr. hier en daar in tuinen wordt de peen als groente gekweekt.

180. Akar-koening SuM. W.K. = C o sc in i um Blume a n u 11 i ers, Nat. fam. der Me n is perma ce a. Gr. Snmatra; klimplant.

181. Akar-koessoe M. $=$ Poly podi u m quercifoli u m L., Nat. fam. der Poly podi a c e r. Gr. Java; overblijvend.

182. Akar-koetjing-koetjing M. = Toddalia aculeat a Pers. (Zie No. $456 b$.)

183. Akar-lada $\mathrm{M} .=\mathrm{Cubeb}$ a phyllos ticta Mi q., Nat. fam. der Pip er a c e æ. Gr. Sumatra; klimplant.

184. Akar-laha PAL. = Uvaria laha M i q., Nat. fam. der A n o n a c e. Gr. Sumatra; slingerplant.
185. Akar-lakoem M. $=\mathrm{C}$ is s u s c i$n$ e r e a $\mathrm{L}$ a m. (Zie No. 65.)

186. Akar-larah-batoe BK. = M e l odorum ba ncan um Scheff., Nat. fam. der A n o n a c ex. Gr. Billiton; slingerplant.

187. Akar-laroh Sum. $=$ Un on a disc o lor V a hl., Nat. fanl. der A n o n ac e æ. Gr. Java, Sumatra; slingerplant.

188. Akar-mangkedoen $\mathrm{BK} .=\mathrm{Fi}$ braurea tinctoria $L$ our., Nat. fam. der M e n is per m a c e . GR. Java, Sumatra, Bangka, Bornco; klimplant.

189. Akar-mangool PaL. = Milletia sericea W. \&A., var. a ur at a, Nat. fam. der P a pili o n a c e æ. Gr. Java, Sumatra, de Molukken; slingerplant. GEBR. Men klopt den bast en de stengels en werpt deze in het water om de visschen te bedwelmen; het gif schijnt voor den mensch niet schadelijk te zijn; een weinig van den bast of de bladeren geeft men aan kinderen om wormen te verdrijven.

190. Akar-marai Sum. W.K. = L e nc onotis anceps $J$ a ck, Nat. fam. der A p o с y n æ. Gr. Sumatra; heester.

191. Akar-mata-alie Sus. W.K. = Tinospora crispa $\mathrm{Ml}$ iers. (Zic No. 328.)

192. Akar-mendjoeloeng Bк. = (Zie No. 156.$)$

193. Akar-mensoewanie $\mathrm{BK} .=\mathrm{G}$ o $\mathrm{n-}$ a n i a b a nk an a T. \& B., Nat. fam. der $\mathrm{R} h$ a $\mathrm{m}$ e $æ$. Gr. Bangka; slingerplant.

194. Akar-mentaloet Bk. (Zie No. 164.)

195. Akar-mentjandiek $\mathrm{Bk}$. $=\mathrm{D}$ e $\mathrm{n-}$ drotrophe umbellata Miq. (Zie No. 1207.)

196. Akar-mesoenoor BK. $=\mathrm{De} n-$ drotrophe umbellata Miq., var. pauciflora $\mathrm{Miq}$.

197. Akar-misa Bo. $=U \mathrm{v}$ a ri a ov alifoli a Bl. (Zie No. 7706.)

198. Akar-nangkej PaL. $=\mathrm{C}$ o m b r etum trifolîatum Vent., Nat. fam. der $\mathrm{C}$ o m b reta ce æ. Gr. Java en Sumatra; slingerplant.

199. Akar-0eloe-oeloe Sus. W.K. = Cissus pubiflora Miq., Nat. fam. der A mpelideæ. Gr. Sumatra; slingerplant.

200. Akar-peloempang Вк. = G n ct u m fun i c l a re B l., Nat. fam. der G n c t a c e æ. Gr. in gcheel Indie; slingerplant. GERr. De bast is rijk aan vezelstof 
en zeer geschikt voor touwwerk; de zaden en jonge bladeren worden gegeten; het sap uit den stam bezigt men uitwendig bij zwellingen, inwendig tegen buiklijden.

201. Akar-penangil $\mathrm{BK}$. $=\mathrm{M}$ a $\mathrm{ru}$ $\mathrm{m}$ i a b a n c a $\mathrm{n}$ a $\mathrm{S}$ c h e f f., Nat. fam. der M e la s t o m a c e $æ$ Gr. Bangka; heester.

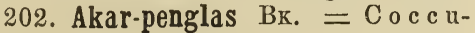
lus (Pericampylus) incan us Cole br. (Zie No. $489 a_{.}$)

203. Akar-pengIasan BK. $=\mathrm{C}$ a s s ytha filiform is L., Nat. fam. der L a u r i n e æ. Gr. Java, Bangka, de Molukken; overblijvend. GEBR. Deze plant is rijk aan plantensiijm; men gebruikt hare stengels afgetrokken tegen het uitvallen van het haar en inwendig bij buikaan. doeningen. Volgens HasskarL zal het sap ook wormdrijvend zijn; men gebruikt de geheele plant als labboer voor prauwen en de inlander hecht aan deze bladerlooze stengels een bijzonder bijgeloof.

204. Akar-pentjohan Sum. W.K. = Trichosanthes coriace a Bl. (Zie No. 644a.)

205. Akar-plawang $\mathrm{Br}_{0}=\mathrm{L}$ e $\mathrm{n} \mathrm{dr}$ otrophe ambellata Miq. (Zie No. 1207.)

206. Akar-poeloe M. $=\mathrm{Chiloc}$ a rp us Die pen hors ti i M q., Nat. fam. der A p o c y n a c e . Gr. Sumatra W.K.; slingerplant.

207. Akar-poeloeron M. $=\mathrm{Ar}$ is tolochia indica I., Nat. fam. der A ristolochic $x$. Gr. bijna in geheel Indië; slingerplant. GEBR. Deze plant is als volksmiddel en tegengift zeer geroemd, en zal in krachten bijna aan onze Rad. serpentariare gelijk zijn; de inlander geeft een aftreksel der bittere wortels bij koortssen, buikpijn, waterzueht, graveel en als stondendrijvend middel.

208. Akar-poeroct ajam SuM. W.K. $=$ Phanera phyrhaneura K o r th., Nat. fam. der Papill i o nac e æ. Gr. Sumatra; slingerplant; en $b$ $=\mathrm{Phanerastipularis} \mathrm{Korth.,}$ in alles als voren.

209. Akar-rarak $13 \mathrm{~K}$. = M itralla Ke n ti i M i r., Nat. fam. der A no nac e қ. Gr. Bangka.

710. Akar-rarak $13 к .=1^{\circ}$. U v a ${ }^{\circ}$ i a ova lifoli a Bl. (Zie No. 7706) $=20$. Pyramidanthe rufa Miq., Nat. fam. der $\Lambda$ n o n a c e ce. Gr. Bangka; heester.

211. Akar-rarak api Bк. = Melodorum bancanum Scheff., Nat. fam. der A n o n a c ex GR. Bangka; slingerplant.

212. Akar-rarak-laki BK. = U var i a h is ut a J a c k., v a r. ban c a n a, Nat. fam. der A n o n a c e æ. GR. Bangka; slingerplant.

213. Akar-rarak-poetih Вк. = 1". Uvaria hirsuta $\mathrm{J}$ a c k. (Zie voren.) $=2^{0}$. U $\nabla$ a r a L a re M q . (Zie No. 5276.)

214. Akar-rarap Bk. = $10 \mathrm{Uvaria}$ ovalifoli a Miq. (Zie No. 7706). = 20. Oxymitra ex is a M i ., Nat. fam. der A n o n ac eæ. Gr. Bangka; heester.

215. Akar-ratoes $\mathrm{PAL}_{\mathrm{L}}=\mathrm{C}$ is $\mathrm{s}$ is triternat a $M$ i q. Nat. fam. der A mpeli d e æ. Gr. Sumatra; slingerplant.

216. Akar-sambang Sur. W.K. = I pom a peltat a Chois., (Zie No. $303 a$.)

217. Akar-sari PAL. = Morin da rigi d a $M$ i q., Nat. fam. der $R$ u b e ac e r. Gr. Sumatra; heester.

213. Akar-sekarang Вк. (Zie No. 224.)

219. Akar-sekarang-batoe $\mathrm{BK}$. = Uvaria hirsuta Jack. (Zie No. 212.)

220. Akar-sekarang-boeboe Вк. = M elodorum bancan um Scheff. (Zie No. 211.)

221. Akar-sekarang-lang $\mathrm{BK}=\mathrm{O}$ х y$m$ it $r$ a excis a $M \mathrm{iq}$. (Zie No. 214b.)

222. Akar-sekar-boeboe $\mathrm{BK}_{\mathrm{.}}=\mathrm{Uva}$ ria macrophylla Rxb., Nat. fam. der A no na c e. Gr. Java, Bangka ; slingerplant.

223. Akar-sendoedoek Ak. = D is s oc h c t a a s r ostict a M i q., Nat.fam. der Melastom a e a. Gr. Bangka; slingerplant.

224. Akar-sengkarang $\mathrm{BK}_{\mathrm{.}}=1^{0}$. $\mathrm{U}$ n o$n$ a $d$ i s c o lo r A.Dc. (Zie No. 187.) $=2^{\circ}$. M elodor um ba ncan um Scheff. (Zie No. 211.) $=3^{0}$. P y r a in id a n the rufa Miq. (Zie No. 210.) = $4^{0}$. Uvaria ovalifolia Miq. (Zie No. 7706.) = $5^{0}$. U varia purpurea B l. (Zie No. 5736.)=60$. Uvaria bancana Scheff. Nat. fam. der Anonacex. Gr. Bangka; slingerplant.

225. Akar-sidingin-djambi M. = W s chy un thus volubilis Jack. Nat. fam. der C y r t a n d r a c e c. Gr. Sumatra's W.K.; klimplant.

226. Akar-sidjangkeh Sum. IV.K. = P' li a n e r a c a t a 1 p refo $l$ i a Mi ., Nat. fain. der Pap ilion a c e e. Gr. Sumatra; slingerplant. 
227. Akar-sidjangkeh Sum. W.K. = $\mathrm{Ph}$ a ne ra a c u $\mathrm{m}$ in a $\mathrm{t}$ is $\mathrm{s} \mathrm{m}$ a $M$ i q. GR. Sumatra; slingerplant.

228. Akar-taboeng-taboeng $\mathrm{II}$. = $\mathrm{Nepenthes} \mathrm{R}$ e in w a $\mathrm{r}$ tiana $\mathbf{M} \mathrm{iq}$. Nat. fain. der $\mathrm{N}$ e pen the r. Gr. Sumatra; slingerplant.

229. Akar-talie ambieng Sum. W.K. = Vitis Di e penhorstii M i q. Nat. fam. der A m pelide a. Gr. Sumatra; slingerplant.

230. Akar-talie-soemangeh Sur. W.K. $=$ G y u r a s umatrana Miq., Nat. fam. der Compositæ. Gr. Sumatra; slingerplant.

231. Akar-taloer. Sum. IV.K.. = S t ephan ia eapitat a S pr. (Cis s a mpelos Pareira L.) (Zie No. 447.)

232. Akar tamboesoe Sum. W.K. = Cissus pyrihodasys Miq. Nat. fam. der A m p eli d ex. Gr. Sumatra; slingerplant.

233. Akar-tandoek $\mathrm{M}=a$. C o n n arus Diepenhorstii en $=b$. C p y r hoearpus Miq., Nat. fam. der C o n n a ra e a. Gr. Sumatra; slingerplanten. $=c$. Fla courtia (?) e a m pto e e ras Miq., Nat. fam. der Bixac e æ. Gr. Sumatra's W.K.; boom.

234. Akar-tegarie of A. tengari $\mathrm{Bk}$. $=\mathrm{Di}$ a n l la b a n c a a $\mathrm{Ml}$ q., Nat. fam. der A s paragin e re. Gr. Bangka; overblijvend.

235. Akar-teklibang $\mathrm{Bк.} \mathrm{=} \mathrm{N} r \mathrm{y}-$ cibe eamptobotrya Miq., Nat. fam. der Ery e i b e æ. Gr. Bangka; slin. gerplant.

236. Akar-tidjan-kossik Sum. W.K. = Conyza riparia Bl., Nat. fum. der Com posita. Gr. Java, Sumatra, Bangka, Celebes; heester.

237. Akar-tikoes M. $=0$ phioxylon trifoliatum Grtn., Nat. fam. der A p o с y n æ. Gr. Java, de Molukken, veelal in tuinen; kleine heester. GEBR. De wortel wordt bij buiklijden, eholera en slangengif gegeven, zal mogelijk wormdrijvende eigenschappen bezitten en tegen lintworm dienstig zijn.

238. Akar-tjamakka S. $=a$. D i a. ne 11 a montan a B l., Nat. fan, der A s pa rag in e a. Gr. Java; overblijvend; GEBR. Men brandt zijn vleezigen wortel om zijn aangenamen geur als reukwerk en wendt hem uitwendig aan bij lendepijn. = b. Pardanthus chinensis Ker. Nat. fam. der I rider. Gr. Java, over- blijvend. GEBR. Aan den vleezigen wortel kent men openende en oplossende eigensehappen toe.

239. Akar-toepai Sum. W.K. = Z i z yphus subquinquenervia Mi q., Nat. fam. der $\mathrm{Rh}$ a m n e $x$. Sumatra; heester.

240. Akar-treba M. $=\mathrm{R}$ h i n a c a nthus communis $N$ ees, Nat. fam. der A c a $\mathrm{t}_{\mathrm{h}}$ a e ex. Gr. overal in Indië, vooral in de paggers; heester. GEBr. De bladeren en wortel zijn zeer dienstig bij vele huidziekten; vooral bij ringworm.

241. Akar-wangie $\mathrm{M}$. $=\mathrm{Andro-}$ p o g o l m urieatus R etz, Nat. fam. der G r a $\mathrm{m}$ i n e æ. GR. door gehcel Indië, vooral in tuinen; overblijvend. GEBr. Men legt de welriekende wortels om hunnen geur en tot wering van inseeten gaarne tussehen de kleederen, ook vleeht men er matjes van; men bereidt er een zweetdrijvenden drank van en stookt er een aromatisehe olie uit.

242. Akat $\mathrm{C}_{\mathrm{r}}=\mathrm{Brug}$ u iera g g m nor$r$ iz a $L$ a m., Nat. fam. der $\mathrm{R} \mathrm{h}$ i z ophorex. GR. vooral in de Molukken op moerassige gronden; middelmatige boom. Gerr. Men gebruikt den bast om garens rood te verven en Sagueer bitter te maken.

243. Akel MEN. = A renga s a e harifer a L a b., Nat. fam. der P a $1 \mathrm{~m}$ æ. Gr. in geheel Indië; hooge palmsoort. GeBr. Omtrent het nut der algemeen bekende Sagueer- of Gomotoepalm verwijs ik naar de bestaande handbocken.

244. Alabobo T. $=\mathrm{K}$ a la n c ho ё 1 a e i $n$ i a t a EC. (Zie No. 46.)

245. Aladie MaK. $=\mathrm{C}_{0} \mathrm{l}_{\mathrm{o}} \mathrm{c}$ a sia a $\mathrm{n}$ t i q o r u m Seht t., Nat. fam. der A roi d e æ. GR. in geheel Indië; overblijvend. Gris. Men ect de jonge bladeren, doch vooral de wortelknollen; zij moeten eehter gekookt of geroosterd worden, omdat ze anders te veel prikkelen.

246. Alaloen $\mathrm{BD}$. $=\mathrm{Ses}$ a m u m ind i e u rn DC., Nat. fam. der S e s a m e Gr. overal in Indië, gekweekt, éénjarig. GEBr. Men verbouwt deze plant om het zaad, dat men bij vele spijzen en gencesmiddelen gebruikt, en waaruit men een gezochte vette olie, Sesamolie, perst.

247. Alam-gadeh Sum. W.K. = R hiz o phora la tifolia M i q., Nat. fam. der Rhizophoreæ. Gr. Sumatra; boom.

248. Ala-manaij AмB. = M y r is $\mathrm{i}$ c a s y lvestris Hout t., Nat. fam. der M y ris ti e e a. Gr. de Molukken; hooge 
boom. GeBr. Het hout dient voor lieht timmerhout, de vruehten zijn alleen door vogels gezoeht.

24.9. Alangodeh Suar W.K. $=a$. B r u g u i r a $\mathrm{Rumphi}$ B l., (Zie No. 866b.) en $b$. B r u g u e r a ox y p y lla $M$ i q., Nat. fam. der $R$ h i z o p hor e æ. Gr. Sumatra en Bangka; boom.

250. Alar-poetih Sum. W.K. = C o oki a puetata Retz. (Zie No. 99.)

251. Alaun mahaij Amr. $=\mathrm{Oxal}$ is Re inward ti i $\mathrm{Z}$ u e e.; Nat. fam. der Ox a li d e ce. Gr. de Sunda- en Moluksehe Archipel; overblijvend. GEBr. Men prijst de knolletjes aan tegen graveel en den beet van seorpioenen; het bittere kruid wordt als tonieum en zaeht stimulans aangewend; verder bekleedt het een hoogen rang onc̉er de middelen tegen betoovering.

252. Alaun-pinan AмB. $=\mathrm{S}$ e i $\mathrm{n}$ dapsus(?) Rumphii Miq., Nat. fam. der A r o i d e æ. GR. de Molnkken; slingerplant. GeBr. Men gebruikt de stengels als bindtouw en de bladeren uitwendig bij pokken.

253. Aléa of Alija Mor, $=\mathrm{Z}$ ing $\mathrm{i}$ be $r$ offieinale L., Nat. fam. der $\mathrm{Z}$ i n g i b e r a c e æ. Gr. algemeen in Indië in tuinen, GEBR. de als specerij en genees. * middel bekende Gemberwortel wordt overal aangeplant.

254. Aléa-oetan Mor. $=\mathrm{Z}$ i n g i b e r $\mathrm{m}$ argin a $\mathrm{nm} \mathrm{R}$ oxb. (D y m e e w i ez i a $m$ a r in a t a $\mathrm{Horan}$ ), Nat. fam. der $\mathrm{Z}$ i n $\mathrm{g}$ i b a $\mathrm{x}$ a e r. Gr. Java de Molukken, overblijvend. GEBR. De wortel wordt zeer veel als bitter prikkelend geneesmiddel aangewend.

255. Aléa-paddi MoL. $=\mathrm{Z}$ ing $\mathrm{iber}$ gram ine um B l. (D y m z e w i ez i a graminea $\mathrm{H}$ oran), Nat fam. als boven. Gr. als boven. GEBr. Ook dezen wortelstok wendt men als prikkelend, opwekkend middel bijna bij alle uit- en inwendige geneesmiddelen aan.

256. Alei Sum. IV.K. = Parkia s u matran a M. i ., Nat. fam. der M imos ex. Gr. Sumatra; hooge boom.

257. Aleroen AuB. = Greenia macrophylla T. \& B., Nat. fam. der $R$ u b i a e e г. Gr. Amboina; heester.

259. Alhalla-ambon $\Lambda \mathrm{MB}$. $=I \mathrm{~m}$ p atiens 13 a ls a min a I. ; Nat. fam. der $\mathrm{B}$ a ls a m in e c. Gr. overal in tuinen; zaadplant. Grir. Het kruid dezer sierplant gebruikt men dikwijls op verwondingen en tot het roodverven der nagels.
260. Alie-ambing $\mathrm{J}_{0}=\mathrm{O}$ rehipeda grandifolia Miq., Nat. fam. der A p o e y n e $\propto$. Gr. Sumatra; boom.

261. Alla-antong $\mathrm{S}$. $=\mathrm{T}$ a b e r $\mathrm{n}$ æmontana javaniea Miq., Nat. fam. der A po e y n ex. Gl. Java en Balie; heester.

262. Allaar Амв. $=\alpha$. M om ordie a subangulat a B 1., Nat. fam. der Cue urbita c e r. Gr. Java, Amboina ; slingerplant. $=b . \mathrm{Triehos} \mathrm{nthes}$ trifoli a t a B I ; Nat. fam. en Gr. als boven: slingerplant. GEBR. De bladeren zijn als bittere groente gezoeht; de wortel sehuimt met water als zeep; aftreksel van het kruid drinkt men met sagoweer tegen vermocidheid en beri-beri.

263. Allang-allang $\mathrm{M}$. $=\mathrm{Im} \mathrm{pe}$ rat a a undinace a C y r ill. Nat. fam. der Gram in ex. Gr. in geheel Indië. Gєвв. dit lange, seherpe gras bezigt men veel tot het dekken van hnizen; de wortels geeft men in aftreksel tegen urethroblennorrhoea en hydrops.

264. Alligoeroea-bonga $\mathrm{T} .=\mathrm{T}$ aber namontan a coronaria R.Br., Nat. fam. der A p o e y $n$ e æ. Gr. als sierplant in vele tuinen; heester.

265. Allor-dawon $J .=A$ t riplex lit t o ralis L., Nat. fam. der $\mathrm{C}$ h e n op o d e æ. Gr. Java; éénjarig.

266. Aloer-aloer J. $=\mathrm{S}$ u æ d a i nd i e a $\mathrm{M}$ o q., Nat. fam. der $\mathrm{C}$ h e $n$ o p od e a. Gr. Java; overblijvend.

267. Alossul $А$ мв. $=$ C e d rela T o o n a $\mathrm{Rx}$ b., Nat. fam. der C edrel a e e æ. Gir. Java en de Molukken; honge boom. GEBr. Het hout is zeer gesehikt voor hnisraad en prauwen: de bast is als Cort. Cedrelae of Cort. China-China in den handel en wordt als toniseh-samentrekkend en koortswerend geneesmiddel veelvuldig aangewend.

268. Amakin-abbal Cr. = C o mmersonia e e inota Forst., (Zie No. 106.)

269. Amakir AMB. = Artoear. p us ine is a L., Nat. fam. der A rtoc a $r$ p e . Gr. in geheel Indië aangeplant; hooge boom. GeвR De broodboom wordt om zijne vruehten overal gezoeht en aangekweekt; de jonge vruehten eet men gekookt bij de rijst; de zaden eet men geroost of makt er meel van; het melksap is zeer gesehikt voor lijmstokjes tot vogelvangst.

270. Amale Aмв. = El a о a $\mathrm{r}$ in s I. (Zie No. 104.) 
271. Amassi Amr. \& Gr. $=\mathrm{Cu}$ b i-

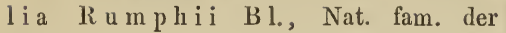
$\mathrm{S}$ a pi inda c $\mathrm{c}$. Gr. Celebes en dc Molukken; hooge boom. Gebr. Het hout bezigt men voor timmerhout; de versche zaden ect men als kastanjes.

272. Ambaloh BK. = D y s oxylumacutangulnm Miq., Nat. fam. der Mcli a cer. Gr. Bangka; hooge boom. GEBR. De inlanders gebruiken de vruchten van bijna alle soorten van dit geslacht, om harcn sterken knoflookgeur bij hunne spijzen.

273. Ambar-ambar BENK. $=\mathrm{R}$ a f flcsia Arnoldii RBr., Nat. fam. der R affles i a c e. Gr. Java, Sumatra; parasict.

274. Ambatsjan of Ambatjang M. = Ml angifera foetida Lour., Nat. fam. der A n a c a r d i a c e æ. Gr. door gehcel Indië; hooge boom. Geis. De vruchtcn zijn om haar wit, stinkend vlecsch zeer gezocht.

275. Ambe $J .=M$ angifcra ind i c a L. cu m variet.; Nat. fam. als voren; GR. door geheel Indië, aangeplant; hooge boom. Grbr. Ook dezen boom plant men om de aangename en zcer gczochte vruchten hoofdzakelijk aan; het hout dient soms voor bouwhout; den bitteren aromatischen bast van wortel en stam geeft men bij diarrhoea, leucorrhoea, enz.; de uit den stam verkregen hars gebruikt men als lijm; ook kent er men een antisyphilitische kracht aan toe; de bitterc zaden meent men dat wormdrijvend werken.

276. Ambi T. $=$ Artoc arpus inte gr if olia L., Nat. fam. der A r to๔ a r p e $æ$, Gr. overal angekwcekt; hooge boom. Gesr. Het hout is een fraai en stcrk bouw- en meubelhout; het melksap bezigt men voor lijmstokjes; de bladcren zijn geschikt voor het polijsten van hout; de vruchten en hare zaden zijn als lckkernij zeer gezocht, en worden, rijp en onrijp, rauw en gekookt gegeten.

277. Ambiet $\mathrm{S} .=a$. $\mathrm{Naucl}$ e a L a m. S p c c. plurima e; Nat. fam. der Rubi a ce æ. Gr. Java; boomer. GeBr. Volgens HasskarL is het hout van alle geschikt voor timmerhout en gereedschappen, en geeft men cen aftreksel van bladeren en vruchten tegen moeilijke urineloozing. $=b$. Elæocarpus serratus L. en E. angustifolius Bl. (Zic No. 104.) $=c$. Monoccras lancelatum Hassk., Nat. fam. der Tiliaccr. GR. Java; hooge boom. Gebr. Men bezigt het hout voor huisbouw en wendt de vrnchten als gencesmiddel aan.

278. Ambo-ambo LUM W.K. = Torilis a th riscus Gmel., Nat. fam. der U m b ellif e r æ. Gr. Sumatra; éénjarig.

279. Amboelan $=\mathrm{Mctroxylc}$ Rumphi i Mart., Nat. fam.der Pal$\mathrm{m} \rightsquigarrow$. Gr. Celebes en de Molukken; hooge palm. GeBr. in de Molukken wordt de Sagopalm vrij algemeen aangcplant, om daaruit door klopping het sagomeel te verkrijgen; men bezigt vcrder de bladstelen voor bouwing en de bladeren tot dekking van huizen.

280. Ambol J, = Gy $\mathrm{g} 0 \mathrm{pachys}$ tomentosa Bl., Nat. fam. der Rubiac eæ. Gr. Java en Celebes; slingerplant.

281. Ambong-ambong Sum. = Strobilanthes sumatrana Miq., Nat. fam. der A c a n th a c cæ. Gr. Sumatra; heester.

282. Amies-mata M. \& S. $=a$. Covellia Zollingeriana Miq., Nat. fam. der A r t o c a r p c æ. Gr. Java; heester. $=b . \mathrm{C}$ o v e $1 \mathrm{li}$ a $\mathrm{R}$ i bes $\mathbf{M}$ i q., Nat. fam. als boven. Gr. Java en de Molukken; hecster. Gesr. Van deze beide wendt men de bladeren uitwendig aan bij diarrhoei en kolijk. $=c$. $\mathrm{F} \mathrm{i} \mathrm{cus} \mathrm{h} \mathrm{u} \mathrm{m} \mathrm{i-}$ $\mathrm{l}$ is B o xb., Nat. fam. als boven; Gr. Java Sumatra; heester. $=d$. F'i cu s qu e r c if ol i a $R \times b$., Nat. fam. en $G r$. als boven; hooge boom. $=e$. Ficus heterophylla L. fil., Nat. fam. als boven. Gr. Java; boom. $=f$. $\mathrm{F}$ i c u s bigla nd ulos a Bl., Nat. fam. en Gr. als voren; slingerplant.

283. Amies-mata burrum S. $=\mathrm{F}$ icus purpurascens B l., Nat. fam. cn $G_{R}$. als voren; boom.

284. Amme Амв, of Ammo Амз. en

285. Ammelaun AMr. $=\mathrm{Ch}$ a vi c a B etle Miq., Nat. fam. der Piperac e æ. Gr. overal aangeplant; slingerplant. GEBR. Het gebruik der sirih- of betelbladeren als geliefkoosd kauwmiddel is overbekend; het door het kauwen verkregen vocht wordt bij zieken, enz, gaarnc uit bijgeloof angewend.

286. Ammelaun-abber $\mathrm{AMB},=\mathrm{C}$ h avica Mela miris Miq., Nat. fam. als voren. Gr. Java en de Molukken; slingerplant. GeBr. Ook de bladeren van deze soort gebruikt men tot het betelkauwen. 


\section{Ammelaun-abber mamare} АмB. en

288. Ammelaun-maäke Амв. $=\mathrm{Pi}$ per arborescens $R \times b$., Nat. fam. als voren, Gr. Java, de Molukken; slingerplant. GEBR. De Javanen leggen den roodmakenrlen wortel op jichtige zwellingen.

289. Ammelaun-nitoe $\mathrm{AmB}$. $=\mathrm{Ch}$ aviea majuseula Miq., Nat. fam. als boren. Gr. Java en de Molukken; slingerplant. GEBR. In de Molukken bezigt men het hout en de bladeren nitwendig tegen hoofdpijn en pijnen of verlammingen der ledematen.

290. Ammelaun-oene Ama. $=\mathrm{Cha-}$

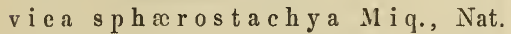
fam. en GR. als voren; klimplant. GEBR. Den wortel gebruikt nien bij tandpijn, tegen hoest en aamborstigheid; de bladeren kookt men gaarne bij paling.

291. Ammelaun-tallan laun maun Aмв. $=$ Piper aboreseens $\mathrm{R} \times \mathrm{b}$. (Zie No. 288.)

292. Ammelaun-tallan mahina ÀмB. $=$ Chaviea sarmentosa Miq., Nat. fam. als voren; Gr. Java, Sumatra, de Molukken; slingerplant. GeBr. De bladeren uitwendig bij koorts en buikpijnen.

293. Ammelaun-tallan mamoerie Амв. $=\mathrm{Chaviea} \mathrm{majuseula}$ M i q. (Zie No. 289.)

294. Ammelaun-tallan poetih Ame. $=$ (Zie No. 289.)

295. Ammo-ette-ette $\mathrm{AMK} .=\mathrm{C} \mathrm{h}$ avica $R$ oxburghi i M i q., Nat. fam. der $\mathrm{P}$ i perace $x$. Gr. Java en de Molukken; slingerplant. GEBR. De vruehtjes zijn de "Piper longum" der apotheken, welke door den inlander als speeerij en in vele geneeskrachtige mengsels gebruikt wordt.

296. Ampadoe-broeang M., R. = Brucea sumatrana $\mathrm{Rxb}$, Nat. fam. der Sima r u b a e a $\approx$. Gr. Java, Sumatra en de Molukken; heester. GEBR. Alle deelen dezer plant, van welke men in de Molukken een ruim gebruik maakt, zịn zeer bitter, en bevatten mogelijk eenig alealoide; den wortel geeft men ais laxeerend middel en bij koortsen; aan den bast kent meu een wormdrijvende kracht toe; de bladeren gebruikt men tegen pleuritis; de zaden echter worden het meest gegeten, zijn reeds een belangrijk handels-artikel en worden vooral tewen tussehenpoozende knorts en dysenteric aangeprezen.
297. Ampak. M. \& BL. $=\mathrm{E}$ v o d i a l a $\mathrm{t}$ if o $1 \mathrm{i}$ a DC. (Zie No. 36.)

298. Ampalan M., R. $=a$. M a $\mathrm{n}$ g i f e ra indio a I. (Zie No. 275) en = b. M. f o etid a L o ur. (Zie No. 274.)

299. Ampalah-battang Sum. WK. = Fieus politoria Lam., Nat. fam. der A rto e a p æ. Gr. Java, Sumatra; kleine boom. GEBR. De ruwe bladeren zijn zeer geschikt voor polijsten van houtwerken; het melksap neemt men in tegen diarrhoea en moeilijke urineloozing.

300. Ampalah-kari M. = I l li ge ra da s y phylla Miq., Nat. fam. der Illi g e r a c e æ. Gr. Sumatra; slingerplant. 301. Ampaleh-oelar Sum. W.K. = Fie us erinierva Miq., Nat. fam. der A r t o e a r p e $\propto$ Gr. Sumatra; heester.

302. Ampaloe M. = Dillenia e 1 o ng a t a M i q., Nat. fam. der Dillen i a e e . Gr. Sumatra's W.K.; boom.

303. Ampas.ampas MAK. $=a$. I. po$\mathrm{m} x$ a peltata Chois en $=b$. I e ymos a Bl. Nat. fam. der Convolvul a e e e. GR. bijna overal in Indië; slingerplanten. GEBR. Men eet de jonge bladeren soms als groente, gebruikt ze ook voor wassehen van het hoofdhaar en legt ze op zwerende borsten.

304. Ampelas S. \& M. $=\alpha$. F i e u s politorla Lam. (Zie No. 299); = b. Fie us rostra Lam. en $c$. Fie us u l m if o li a L a m. GR. Java; heesters. GEBR. Beider bladeren zijn ook geschikt tot het glad wrijven van hout.

305. Ampelas-amies mata $\mathrm{S}$. $=$ Fic us brevi e uspis Miq.; Gr. Java; heester.

306. Ampelas-aroij $\mathrm{S} .=\alpha$. $\mathrm{F}$ i e u s re e r va Mi q., Gr. Java en Sumatra; slingerplant. $=b . \mathrm{Pog}$ o notroph e javana Miq. (Ficusobtus a $\mathrm{H}$ ass k.) Gr. Java en Timor; slingerplant. $=c$. Urostigma triehse arpum Miq.; GR. Java en Timor; slingerplant.

307. Ampelas-badak S. $=a$. $\mathrm{F}$ i с $\mathrm{s}$ melinoearpa Bl. Gr. Java; boom. GEBR. De bladeren van dezen, ever als van Nos. 305 en 306, gebruikt met tot het polijsten vall houtwerken. $=b$. $\mathrm{C}_{0}$ vellia $\mathrm{Z}_{0} \mathrm{ll}$ ing erian a $\mathrm{M}$ i q. (Zie No. $282 a$. $=c$. Viburnumsambuein u m R w d t., Nat. fam. der C a p r if oli a e e a. Gr. de Sunda-cilanden; heester. 30s. Ampelas-battang Sum. W.K. = Fieus ampelas Burm., Gr. Java, Sumatra; kleine boom. Grisr. Ook 
de bladeren dezer soort bezigt men tot polijsten ran hout.

309. Ampelas-lumboet S. $=\mathrm{Ficus}$ politoria Lam. Zie No. 299)

310. Ampenieng $\mathrm{BK} .=1^{0}$. Que rcus Miqueliana $\mathrm{S}$ c lieff. $=2^{0}$. Q. c e r i cea $\mathrm{Sch}$ eff, en $=3^{0}$. Q. $\mathrm{tur}$ b in a ta Bl., Nat. fam. der C u p u li f c r Gr. Alle op Bangka; de derde ook op Java ; boomen, waarvan het harde hout als bouwhout gebezigd wordt.

311. Ampetoe-tona $\mathrm{M}=\mathrm{C}$ u r a n g a a ma r J uss. (Zie No. 89.)

312. Ampiri Bg. $=$ Alenrites triloba Frst. . Nat. fam. der Eu phorb i a c eæ. Gr. overal aangeplant; hooge boom. GeBr. De kamirienoten mengt men in vele spijzen als specerij; ook perst men uit deze een vette lampolie, die wel door sommigen gegeten wordt, doch tot de scherpe vergiften zal kunnen gerekend worden.

313. Amplas $\mathrm{S} \& \mathrm{M}$. $=\mathrm{Stre-}$ blus aspera Lour., Nat. fam. der A r t o c a r p e. Gr. algemeen in Indië; kleine boom.

314. Ampoelat-poelat $\mathrm{M} .=\mathrm{Ure}$ n a L a p a go S m., Nat. fam. der Malvaceæ. Gr. Java en Sumatra; heester.

315. Amulen $\mathrm{AMB}=a$. Wollastonia strigulos a DC. eu $b$. W. molucea DC., Nat. fam. der Compositæ. Gr. Java en de Molukken; beide overblijvend. GEBR. Het jonge loof eet men gaarne als groente; den wortel en de stengels geeft men als pisdrijvend geneesmiddel.

316. Anahan Амв, $=$ A rtoc a r p us poly phem a Pers. (Zie No. 144.)

317. Anapoel of anapoer Амв. = $\mathrm{H}$ o m a $\mathrm{ln}$ e in a $\mathrm{lb}$ a $\mathrm{H}$ s $\mathrm{kl}$., Nat. fam. der A roide o. Gr. Java en de Molukken; overblijvend. GEBr. Men bezigt der wortel bij de vischvangst.

318. Anapoer-aijer Амв. = A g l a on e m a oblongifolium K th., Nat. fam. der A roi de æ. Gr. de Molukken; overblijvend. GEBR. Men legt de bladeren op gezwellen en zuchtige deelen; zij werken roodmakend.

319. Anasser $\mathrm{A}$ MB. $=$ Pittos por r m R u m p h i P ü t., Nat. fam. der Pittosporea. Gr. de Molukken; kleine boom. Gebr. Het zeer zware hout bezigt men soms voor stijlen.

320. Anau M. \& R. $=$ Arenga s a c $\mathrm{ch}$ a rifera L a b. (Zie No. 243.)

321. Anau-koetari $\mathbf{M}$. = Areng a W esterhoutii Griff., Nat. fam. der Palm r. Gr. Malakka, Riouw (?); hooge Palm.

322. Andahan J. $=\mathrm{Alchemilla}$ villos a Jngh., Nat. fam. der $R$ os a: c e æ. Gr. Java 6- $8000^{\prime}$; kruid.

323. Andaloh Sum. W.K. $=a$. Mo. $\mathrm{rus}$ indic a $\mathrm{Rm} \mathrm{ph}$. (Zie No. 797a.) $=6$. Morus macroura Miq., Gr. Java en Sumatra; boom.

324. Andawalie $\mathrm{M}$. $=\mathrm{C}$ is s u s $\mathrm{p}$ pillosa Bl., Nat. fam. der A m peli d e æ. Gr. Java; slingerplant. GEBR. Men smeert den jongen kinderen het hoofd in met de fijn gewreven bladeren om den haargroei te bevorderen.

325. Andi-andi $J .=G$ r w i a o blong ifolia Bl., Nat. fam. der T il ia c e $е$. Gr. Java. GFbr. Den bast van dezen heester bezigt men als touw.

326. Andilan Sur. W.K. $=\mathrm{C}$ o mmersonia e chinata Frst., (Zie No. 106.)

327. Andilan-oertja Sum. W.K. = Grewia acuminat a Juss., Nat. fam. der Tilia c e. GR. Java en Sumatra; slingerplant.

258 Andiwalie $\mathrm{J}_{\mathrm{.}}=\mathrm{T}$ i nos por a crispa $M$ iers, Nat. fam. der $M$ e$\mathrm{n}$ is perma c e æ. GR. door gehcel Indië ; slingerplant. GEBR. Men geeft de bittere stengels bij tusschenpoozende koortsen; zij toonen zich soms zeer werkzaam, moeten echter met voorzichtigheid toegediend worden; zij verwekken licht braking en kunnen nimmer de kina vervangen.

329. Andjong-sirie Sux. W.K. = Esohynanthus atropurpurea v. Houtt., Nat. fam. der G e s n e riac е æ. Gr. Sumatra; kruid.

330. Andjorro $\mathrm{MAK}_{\mathrm{A}}=\mathrm{Coc}$ os n uc if er a L. ('Lie No. 393 en 3588.)

331. Andoedoe BL. = Caryota R u m phian a M r t., Nat. fam. der $\mathrm{P}$ a $\mathrm{lm}$ a $æ$. Gr. Balie, Celebes en de Molukken; zeer hooge Palm. GEBR. De bijzonder harde stam is geschikt voor huisbouw, vooral voor stijlen, sparren en latten.

332. Andoer-mangan $\mathbf{M}$. = C a s ua rin a sum atran a Jngh., Nat. fam. der C asuarineæ. Gr. Sumatra, Celebes; hooge boom. GEBr. Het hout bezigt nien voor bouwhout, brandhout en houtskolen.

333. Andong $=a$. Calodracon J a cquinii Planch. en b. C. ter- 
minalis Planeh., Nat. fain. der As paragineæ. Gr. Bijna overal in Indie, als sierplanten gekweekt, vooral in omheinil. gen. GEBR. De jonge bladeren wordeù gekookt bij de rijst gegcten; de wortels bij diarrhoea en dysenterie aangewend.

334. Adong-andong Sum. W.K. = Ptychosperma disticha Mi q., Nat. fam. der P a l m æ. GR. Sumatra; lage palmsoort

335. Andong-hiedjoe $\mathrm{M}$. $=\mathrm{C}$ a l odracon Jacquinii Planch., var. rubens $\mathrm{H}$ as s k. (Zie No. 333).

336. Andong-meirah $\mathrm{M}$. $=\mathrm{C}$ a lodracon Jacquilli Planch., var. astrosanguinea Hassk. (Zie No. 333).

337. Andong-watoe J. $=a$. C o r d yline R u p h i i H o ok., Nat. fam. der A s paraginea. Gr. Op Java en de Molukken, als sierplant; kleine heester. GEBR. Den wortel geeft men in afkooksel bij diarrhoea en gonorrhoea; de bladeren en schors wendt men uit-en inwendig bij beri-beri an. $=6$. Pavet a le u coxylon Miq., Nat. fam. der Rubiace GR. Midden-Java 3-4000'; heester.

338. Andormata M. = Freycinet i a s c ande ns G a $n$ d., Nat. fam. der P a n d a n e. Gr. Java, Timor, de Molukken; klimplant.

339. Andorwalli BL. = Anamirta Cocculus W. \& Arn., Nat. fam. dər M e $\mathrm{n}$ is per m a ceæ. Gr. Overal in Indië; ook aangcplant; slingerplant GEBR. Deze levert de bekende "Semina Cocculi Indici" of vischkorrels, welke tot het bedwelmen van visch en het sterker inaken van biersoorten vaak misbruikt worden; de stengels worden veel tcgen tusschenpoozcnde koortsen gegeven, zijn, met omzichtigheid toegedicnd, soms zeer heilzaam, doch zullen nooit de kina kunnen vervangen.

340. Angajin MaK. = Inocarpus c d u lis L, Nat. fam. der Hernandi a ce a. Gr. Java, Celebes, de Molukken; hooge boom. GEBr. Dezc boom wordt vecl om zijn fraaien vorm en geurige bloeincn aangeplant; de stcrk samentrekkendc bast wordt bij dyscnterie cn spruw zccr dikwijls toegcdiend; de vruchten of zaden zijn voor velc eilanders een vocdingsmiddel, en worden gekookt of geroost gegeten.

341. Anggroeng $\mathrm{S}$. of $=\mathrm{S}$ p o n i a velutilla l'lanch., Nat. fam. der C e l t i d e a, Gr. Java, Surnatra, Borneo.
Gkbr. De wortel, bast cn bladeren, die ecnigszins aromatisch zijn, zullen een specifiek middel tegen vallende ziekte zijn.

342. Angi-angin MaK. = Ay-S AMara. (Zie No. 122).

343. Angin $\mathrm{M}$. = Leucosyke al ba Z. \& M., Nat. fam. der U r t i a c e æ. $\mathrm{G}_{\mathrm{R}}$. In geheel Indië; heester.

344. Angin-Angin J. $=a$. L e u c os y k e a l b a Z. \& M. (Zic vorig No.). $=$ b. Al ch emilla villos a Jugh. (Zie No. 322) en $=c$. $\mathrm{R}$ a n u n u lus diff us u s D. C., Nat. fam. der R a n un. c u l a c e æ. GR. Java en Sumatra; overblijvend.

345. Angkaeing MaK. = I n o c a rp us edulis L. (Zie No. 340).

346. Angkeb-angkeb J. $=a$. Lightf o o t i a g a c il is M i q., Nat. fam. der C a m p a n u l a ce æ. Gr. Java tot $11000^{\prime}$; overblijrend $=b$. G e n t i a n a $q$ u a d r if a ri a. Bl., Nat. fam. der Gentiane Gr. Java 6-1000'; overblijvend.

347. Angoeri $\mathrm{M}$. $=\mathrm{Abutilon}$ hirtum I, a m., Nat. fam. der Malvac e $x$. Gr. In geheel Indie als sierplant; éénjarig. Geвr. Het kruid staat in verzachtendc eigenscharipen gelijk met onze Malva en Althæa.

34.8. Angor $\mathbf{M}=\mathrm{V}$ it is $\mathrm{vinifera}$ L., Nat. fam. der A m pelidex. Gr. J)e wijnstok wordt hier en daar om de lekkere vruchten aangekweekt.

349. Angor-oetan M. $=\mathrm{V}$ it is ind i c a L., Nat. fam. als boven. Gr. Java, Timor, de Molukken; slingerplant. GEBR. Het sap der stengels drinkt inen tegen koorts; de vruchten zijn eetbaar.

350. Angrek of Anggrek S, \& $\mathbf{M}$. $=a$. De algemeene benaming voor alle Orchidca. $=6$. Phrynium capitatum W lld., Nat. fam. der Cannaceæ. GR. Java; overblijvend. GEBR. De bladeren ge. bruikt men tot dekking van huizen en tot het inpakken van goederen. $=c . \mathrm{H} \mathrm{e} \mathrm{d} \mathrm{y-}$ chi um Roxburgh i B l., Nat. fam. der Z i n g i bera c e a. Gr Java; overblijvend; sierplant. $=d$. Rhcitrophyllum subverticillatu in Hassk., Nat. fam. der A p o с y n e r. Gr. Java; kleine heestcr. $=e . \mathrm{V} \mathrm{i} \mathrm{s} \mathrm{c} \mathrm{u} \mathrm{m} \mathrm{a} \mathrm{tic} \mathrm{ula} \mathrm{t} \mathrm{um}$ B r m., Nat. fam. der $\mathrm{L}$ or a $\mathrm{n}$ th a c e Gr. In geheel Indië; parasict.

351. Angrek-andjing M. $=\mathrm{E}$ pide nd r u c a n i n m B rm., Nat. fam. der O r c h i d ce. Gr. Java; parasict.

352. Angrek-bener $\mathrm{S} .=a$. $\mathrm{P} \mathrm{h} \mathrm{a}$. 
u s B l u m e i I in d l., Nat. fam. der Orc h id ex. Gr. Java; aardorchidee. $=b$. Cymbidium bicolor Lindl., Nat. fam. der Orchider. GR Java; parasiet.

353. Angrek-betoel $\mathrm{N} .=a . \mathrm{Als}$ vorig No. $=b$. C y m bidium cuspid a t u m Bl., Nat. fam. der Orchideæ. GR. Java; parasiet.

354. Angrek-bobotjangan $\mathrm{S} .=a$. Calanthe veratrifolia. R. Br., (Zie No. 26) en b. Z osterostylis a ra chnites bl. Nat, fam. der Orchid e æ. Gr. Java; aardorchidee.

3 วั. Angrek-dioek S. = $\mathrm{Erides}$ a c uminatissim um Lindl., Nat. fam. der Orchider. Gr. Java; parasiet.

356. Angrek-djamboe $\mathbf{M}=a$. Dendrobium purpureum $R \times b$. en $b$. D. bifarium Lindl., Nat. fam. der Orchideæ. Gr. De Molukken; parasieten.

357. Angrek-gehgehbengan $\mathrm{S} .=a$. $\mathrm{Nephelaphyllum} \mathrm{tenuiflorum}$ Bl. en $b$. Acanthophippium javanic u m B l., Nat. fam. der O r c h i d e Gr. Java; aardorchidee.

358. Angrek-grimis tana $\mathrm{S} .=\mathrm{Hy}$ steria reratrifolia $\mathrm{K} w d \mathrm{t}$. Nat. faul. der Orchideæ. Gr. Java; aardorchidee.

35\%. Angrek-kadakka S. = P t e r oceras radicans Hssk., Nat. fam. der Orchid $\mathrm{c} æ$. Gr. Java; parasiet.

360. Angrek-kassian M. = C $\mathrm{y}$ inbi dium ovatum Wlld, Nat. fam. der Orchidex. GR. Java; aardorchidee.

361 . Angrek-kassoemba M. = (Zie No. 909).

362. Angrek-katongging $\mathrm{M}$. $=\mathrm{Re}$ na $\mathrm{n}$ h era arachnites Lindl. Nat. fam. der $\mathrm{Orchide}$ æ. Gr. In geheel Indië; parasiet.

363. Angrek-ketjil M. = M i c r ostylis $R$ heedii Lindl., Nat. fan. der Or chi dex. Gr. Java; parasiet.

364. Angrek-ketjil-glap $\mathrm{N}_{\mathrm{I}}=\mathrm{V}$ a $\mathrm{ada}$ furva Lindl., Nat. fam. der O r ch id e æ. Gr. De Mlolukken; parasiet.

365. Angrek-kolan $\mathrm{Bk}$. $=\mathrm{Gr}$ a mmatophyllum scriptum Bl., Nat. fam. der Orchideæ. Gr. Bali en de Molukken; parasiet.

366. Angrek-kringsing $\mathrm{BL} .=(\mathrm{Zie}$ (Zie vorig nr.).

367. Angrek-kringsing-ketjil M. $=a$. Grammatophyll um s peciosum Bl. en $b$. $V$ anda lissochiloides Lindl., Nat. fam. der Orchi- deæ. Gr. Java, Bali en de Molukken; parasieteu.

36s. Angrek-lama $\mathrm{M}$. = C y m b idium cuspidatum Bl. (Zie No. $3536)$.

369. Angrek-lema M. = (Zie No. $353 b)$ en C y m bidi u m bi color Bl. (Zie No. 352).

370. Angrek-meirah M. $=a$. Renanthera moluccana Bl., Nat. fam. der Orchides. Gr. Amboina; parasiet. GEBR. Het jonge kruid wordt in het zont gelegd en gegeten. $=b . \mathrm{Limodorum}$ s p ath ulatum Wlld., Nat. fam. als Gr. Java; aardorchidee.

371. Angrek-0entjal S. $=a \cdot \mathrm{Cym}$. bidiu m al ifolium $S w$.. Nat. fam. als voren. Gr. Java; parasiet. $=b$. Saccolabium præmorsum Lindl, en $c$. S. g u t t a t um Li indl., Nat. fam. als voren. Gr. Jara; parasieten.

372. Angrek-oetan M. = Plocoglot $t$ is javanic a Bl., Nat fam. der $\mathrm{O}$ r ch i d e $x$. Gr. Java; aardchidee.

323. Angrek-plembang M. $=a$. D endrobium angulat u m Bl., $b$. Cleisostoma spathulathum Bl, en c. Cypripedium javanicum Rnwdt. Nat. fam. der Orchideæ. Gr. Java; de beide cerste parasieten, de laatste aard orchidee.

374. Angrek-poetih besaar M. = Phalæuopis a mabilis Bl., Nat. fam. als voren. Gr. Bijna overal in Indië; parasiet.

375. Angrek-poetih keljil M. = Cy mbidi um ovatum Wlld. (Zie No. 360).

376. Angrek-ringit boemio M. = $\mathrm{Hys}$ teria veratrifolia $\mathrm{R}$. Br. (Zie No. 35S).

377. Angrek-tana M. $=a, \mathrm{Ph}$ ajus callosus Lindl, Nat. fam. der O r c h i d e ce. Gr. Java, Amboina, aardorchidee. $=b$. Pla $t h a n$ thera Susan$\mathrm{n} æ \mathrm{~L}$ in d l. Gr. Java, Amboina; aardorchidee. $=c$. Epidendrum tubero. s u m L o u r. (Zie No. 24b).

378. Angrek-warna $M .=V$ anilla albida Bl., Nat. fam. der Orchideæ. GR. Java; parasiet.

379. Angriet $\mathrm{S} .=a$. Quercus $\mathrm{li}$ e a t a Bl., Nat. fam. der C u p u lifera. Gr. Java; hooge bonm. Gebr. Het hout kan zeer deugdzaam zijn. $=b$. Nauclea la nceolata Bl., Nat. fam. der R u bi a c e. Gr. Java, Sumatra; 
hooge boom. Gebr. Hij levert een goed bouwhout, dat niet door witte mieren wordt aangetast.

380. Angroeng $\mathrm{J} .=\mathrm{Gr}$ e wi a $\mathrm{c} 0$ u m n a r is S m., Nat. fam. der Tilia c e æ. Gr. Java; lage boom. Gebr. Men bezigt den bast als touw en voor vlechtwerk; de aromatisch bittere bast en de samentrekkende bladeren worden als geneeskrachtig aangeprezen.

381. Angsana S. \& $\mathrm{Ml}=\mathrm{Pt}$ e roc a r p u indicus Wlld, (Zie No. 18) en $b$. Pt. Zollingeri Miq. Gr. Java; hocge boom. Gebr. Als No. 18.

382. Ansang $\mathrm{S}$. $\doteq \mathrm{T}$ o u $\mathrm{rn}$ efortia Horsfieldii Miq., Nat. fam. der Asperifolix. Gr. Java, de Molukken; slingerplant.

383. Angsokka $\mathrm{S} .=\mathrm{P}$ a $\nabla$ e t t a indi c a L. \& a li x, Nat. fam. der Rub i a c e æ. Gr. Bijna overal in Indië; reel in tuinen als sierplanten; heester.

384. Anibong $\mathrm{MI}=\mathrm{C}$ a ry ot a u re ns l., Nat. fam. der P a lm æ. Gr. Riouw; hooge palm. GLBR. Het hout is geschikt voor stijlen; de vruchten worảen gegeten, doch zijn scherp.

385. Anipan-doerein AvB. $=$ A momum villosum Lour., Nat. fam. der Zingibaraceæ. Gr. Java en de Molukken; overblijvend. GEBR. Alleen de vruchten worden als lekkernij gegeten.

386. Anipan-wakkan Амв. = A lpini a gigante a Bl., Nat. fam. als voren; Gr. Celebes en de Molukken; ovcrblijvend.

$38 \%$ Anij Амв. = Pangium edule $\mathrm{R} w \mathrm{~d}$ t., Nat. fam. der Pangiaceæ. Gr. Bijna overal in Indië aangeplant; hooge boom. Gebr. Alle deelen van dezen boom bezitten visch- eu wormdoodende eigenschappen, evenals de Semina Cocculi; uit de zaden wordt soms een vettc olie geperst neer echter worden zij, op velerlei wijze tocbereid, gegeten en zijn zeer gezocht; zij moeten echter eerst in water geweckt of geroosterd worden, daar ze anders zcer bedwelmend werken en den dood kunnen veroorzaken.

388. Anij in lala $A з r B .=\mathrm{T} \mathrm{r}$ i $\mathrm{ch}$ osanthes trifoliat a B l., (Zic No. $262 b)$.

389. Anijs-kastella $\mathrm{T}$. $=\mathrm{N}$ ot hopa $n$ ax (?) a n is u m $\mathrm{Ml}$ i q., Nat, fam. der A raliaces. Gr. De Molukken; heester. GEBr. Het hout bezigt men soms voor stelen in gereedschappen; de zaden mengt men, in plaats van anijszaad, in vele genecsmiddelen. $=b . \mathrm{Z}$ a $\mathrm{nth}$ o $\times \mathrm{y}$ lu m zeylanicum D. C., Nat. fam. der D) i o s m e æ. Gr. De Molukken; heester. GEBr. Het hout bezigt men voor daksparren.

390. Anjal-binata Laurp. $=\mathrm{A} \mathrm{m}$ o 0 $\mathrm{r}$ a $\mathrm{T}$ e y smann i a $\mathrm{n}$ a $\mathrm{M}$ i q., Nat, fam. der $\mathrm{M}$ a lv a c e $æ$. Gr. Lampongs op Sumatra; boom.

391. Ankri J. = Phrynium densiflorum Bl., Nat. fam. der Cannac e æ. Gr. Java; overblijvend.

392. Annipa-wakkan Arr. = Alpinia malaccensis Rxb., Nat. fam. der Zingiberaceæ. GR, Java, Sumatra, de Molukken; overblijrend. GEBR. De geurige wortel wordt als speekselbevorderend middel gekanwd.

393. Anoer $R$. $=$ Cocos nucifer a L., Nat. fam. der Palmæ. Gr. Door geheel Indië, met vele verscheidenheden; hooge boom. Gribr. Het nut van den Kokos- of Klapperboom is te algemeen bekend, om er hier over uit te wijden; ik teeken alleen aan, dat van dezen nuttigen boom bijna alle deelen, zoo huishoudelijk als tot medische doeleinden, gebruikt worden.

394. Anroeda MaK. $=\mathrm{P}$ a r is t $\mathrm{r}^{0}$ phe tinctoria Nees. (Zie No. 95).

395. Anrore $\mathrm{M}_{\mathrm{AK}}$. $=$ Premna $\mathrm{C}_{0}$ rymbosa Rott., Nat. fam. der $V \mathrm{cr}$ be naceæ. Gr. Bijna overal aan de stranden; hooge hecster. Gebr. De stinkende bladeren worden door sommigen gegetcn; zij zijn echter bedwelmend.

396. Antannan $\mathrm{S}$. = Een algemeene naam roor alle $\mathrm{Hydrocutyle} \mathrm{soor-}$ ten.

397. Antannan-bener $\mathrm{S} .=\mathrm{H}$ y drocotyle asiatica L. (Zie No. 70).

398. Antannan-gedeh $\mathrm{S} .=a \cdot \mathrm{Hy}_{\mathrm{y}}$ drocotyle asiatica I. (Zie No. 70.) en $=b$. IIydrocotyle nitidula Rich; Gr. Java; overblijrend.

399. Antannan-leuwing $\mathrm{S} .=\mathrm{G}$ eophila ren iformis G. Don, Nat. fam. der R u bi ac cঞ. Gr. In geheel Indië; overblijvend.

400. Antannan-lumboet $\mathrm{S} .=\mathrm{Hydr} 0$ c o tyl c splenderus Bl., Nat. fam. der Umbellifere. Gr. Java; overblijvend. GeBr. MIen ect de bladeren bij de rijst als grocntc.

401. Antarsa Sum. $=$ Tetranthera citrata Nces, Nat. fam. der Laurinex, 
Gr. Java ell Sumatra; kleine, zecr geurige boom.

402. Antarta Sum. W. K. Polyadenia pepericarpa Miq., Nat. fam. der Lauriner. Gr. Sumatra; kleine boom. Gebr. Men eet de zaden in plaats van pepcr bij vele spijzen.

403. Antimon $R .=\mathrm{Cucumis}$ sativ us L., Nat, fam. der Cucurbit acer. Gr. Overal in tuinen gekweekt; slingerplant. GEBR. Het nut der gewone komkommers is elkeen bekend.

40\%. Antimon tikoes M. $=a$. Æeh. mandra Blumeana M. J. Roem., en b. As. indica R. Wgt., Nat. fam. der Cucurbitaceæ. Gr. $a$. Java en $b$. in de Molukken; slingerplanten. GEbr. De jonge vruchten kunnen als komkommers worden gegeten; het sap wendt men aan bij spruw cn zeere oogen van kleine kinderen.

405. Antjak of Antsjak J. \& BL., = Urostigma Rumphii Miq., (Zie No. 103).

406. Antjal S. = Scindapsus mont an K Kth., Nat. fam. der A roideæ. Gr. Java; slingerplant.

407. Antjal-beurriet $S .=$ Scindapsus sylvestris Kth., Nat. fam. als voren, Gr. Java; slingerplant.

408. Antjar $S_{*}=$ Antiaris toxicaria Iuesch., Nat. fam. der Artocarpeæ. Gr. Sumatra, Java, Borneo en Celebes; hooge boom. Gebr. Deze boom levert het beruchte Indische pijlvergift, waarover door Rumphius, BLUMe, VAN Hasselt en anderen uitvoerig is geschreven.

409. Antoenboes M. = Buch anania exyrhachis Miq., Nat. fam. der Anacardiacex. Gr. Sumatra's W. K.; hooge boom.

410. Antoerboeng Sum. = Amorphophallus gigas T. \& B., Nat. fam. A roideæ. Gr. Sumatra; overblijvend.

4.11. Antowalli BL., = Anamirta Cocculus W. \& Arn. (Zie No. 339.)

412. Apair Амв. = Astronia papetaria Bl., Nat. fam. der Melastomaceæ. Gr. De Molukken; heester. GLBr. Dc dikkere staminen bezigt men voor stijlen in huizen; den bast en de bladeren kookt men bij sago en ook bij visch, om aan dcze een aangenainen, zuren smaak te geven.

413. Apapa-karbou J. = Conyza indica Bl., Nat. fam. der Compositr. Gr. De Sunda-cilanden; heester, Grib.
De aromatische bladeren zijn in werking gelijk aan die van C. balsamifera. (Zie No. 85.)

414. Aperoe Alf. Min. = Evodia Minahassæ. T. \& B., Nat. fam. der Diosmeæ. Gr. Noord-Celebes; boom.

415. Apésoong Mand. = Flacourtia rukam Z. \& M., Nat. fanı. der Bixaceæ. Gr. Java, Sumatra, boom. Gebr. Men bezigt het hout om te bouwen; het is zwaar en sterk, doch klein van omvang; de naar rhabarber smakende bladeren wendt men als samentrekkend en maagvcrsterkend geueesmiddel aan; de vruchten worden veel gegeten.

416. Api-api S. \& M. = Avicennia officinalis L. (Zie No. 14) en $=\mathrm{A}$. alba Bl., GR. Bijna overal in Indië; kleine boom. Gebr. Het hout is alleen geschikt voor brandhout: de zaden worden gekookt en geroost, vooral op Celebes gegeten.

417. Api-api M. = Scyphiphora hydrophyllacea Grtn., Nat. fam. der Rubiaceæ. Gr. In gehecl Inflë; heester. 418. Api-api Вк. = Synoecia diversifolia Miq., Nat. fam. der Arto carpex. Gr. In geheel Indie; kleine boom.

419. Api-Api Mrn. = Celosia cristata L., Nat. fam. der Amarantac ear. Gr. Overal in Indië, als sierplant in tuinen; éénjarig. GEBR. Hct kruid is door velen als groente gezocht; de bloemen gebruikt men tegen diarrhoex en blennorrhoeæ.

420. Api-Api Sum. W. K. = Lumnitzera coccinea W. \& A., Nat. fam. der Combretaceæ. GR. De Sunda-eilanden; heester.

421. Api-Api-goening Sum. W. K. = Adinandra cyrtopoda Miq., Nat. fam. der Ternstroemiacer. Gr. Sumatra; heester.

422. Apiet J. $=$ Drymispermum Blumei Den., Nat. fam. der Thymelaceæ. Gr. Java; heester. Gebr. De inlanders bezigen den taaien bast als touw.

423. Apoe S. $=$ Polyosma integrifolia Bl., Nat. fam. der Escallonieæ. Gr. Java en Sumatra; heester.

424. Apokat M. = Persea gratissima Grtn., Nat. fam. der Laurineæ. Gr. Hier en daar gekweekt. Geibr. Deze boom wordt orn zijn lckkere vrnchtten, de bekende Advogado-peren, aangekweekt. 
425. Appa-appa besaar $\mathrm{J},=\mathrm{Phyl}-$ lodium pulchellum Dcn., Nat. fam. der Papilion a c ex. Gr. Door geheel Indië; heester. GEBR. De bladeren zijn aromatisch, volgens BLANco legt men zc als bederfwerend op cude zweren.

426. Appa-au of Appau Амв. = Colocasia (?) humilis Hassk., Nat. fam. der A roideæ. Gr. Java eu de Molukken; overblijvend. GEBR. De bladstelen worden gekookt, door menschen en diereı gegeten.

427. Appan-appan J. = Flemingia latifolia Bnth., Nat. fam. der Papilionacer. Gr. Java; heester.

428. Appija Амв. $=\Lambda \mathrm{cal}$ урh а bracteata Miq., Nat. fam. der E uphprbiacex. Gr. De Molukken; kleine boom. GEBR. Men bezigt het hout voor daksparren, en dient den samentrekkenden bast en bladeren tegen diarrhoese en leueorrhoeæ toe.

429. Ara-gatel PaL. $=$ Covellia a lbi pila Miq., Nat. fam. der A rtoc a r p e .. Gr. Sumatra; hooge boom.

430. Arang M. \& R. $=a$. Diospyros Ebenum Retz., (Zie No. 32); $=b$. M a b a Ebenus R.Br. (Zie No. 107), en c. Vitex pubescens Vahl, Nat. fam. der V e r b e n a e e . Gr. De Sunda-eilanden; hooge boom. GeBr. Het hout is zeer geschikt voor huisbouw; de schors en bladeren gebruikt inen tot het groenverven van kleederen, onder toevoeging van andere artikelen; aan den bast, de bladeren en den wortel kent men geneeskraehtige eigensehappen toe en mengt ze in onderseheidene mengsels tegen verkoudheid, hoofd- en lendepijn, rheumatismus, bij kraamvrouwen, enz.

431. Araroet M. \& J. $=\mathrm{M}$ aranta indiea L., Nat. farm. der Cannaeeæ. Gr. Overal in Indie gekweekt; overblijvend. GEBr. Deze plant levert het bekende arrowroot-meel op.

432. Arau $\mathrm{R} .=a$. C a su a rin a equisetifolia L., (Zic No. 122) en = b. Arenga saecharifera Lab. (Zie No. 243).

433. Areg-henghé $\mathrm{S}$. = Cardiosperinum Halieacabum L., Nat. fam. der $S$ a p ind a eеæ. Gr. In geheel Indië; ćénjarig. GEBR. Aan den slijmerigen wortel kent mell de openende, zweet- en pisdvijvende en steenbrekende eigensehappen toe; de bladeren en zadell worden als grocnte gegeten; de zaden, aan draden geregen, draagt men als sieraad om den hals.

434. Aren of Areng M. = Arenga saccharifera Lab. (Zie No. 243).

435. Areng. J. $=\mathrm{Mimosa} h$ amata Wlld. Nat. fam. der Mi mose $x$. Gr. Java; overblijvend.

436. Ares M. = Cyrtosiphonia sumatrana Miq., Nat. fam. der A po. су и ææ. Gr. Java, Sumatra, Timor; groote heester. Gebr. Het liehte hout bezigt men voor krisscheden, enz.

437. Areu $А м в .=P$ andanus mon. tanus Miq., Nat. fam. der Pandan eæ. Gr. Amboina; boomachtig. GeBr. De bladeren zijn zcer gezocht tot het vleehten van matten.

438. Arian $\mathrm{BG}_{\mathrm{G}}=\mathrm{C}$ issus repens I، am., Nat. fam. der Ampelideæ. Gr. Java en Celebes. Grir. De bladeren bezigt men tot het polijsten van houtwerken: ook eet men ze als groente, in plaats van zuring.

439. Arile Амв. $=\mathrm{V}$ ig u a $\mathrm{C}$ a tja ng Endl., (Zie No. 30).

440. Ariotton S. (Zie No. 504).

441. Ari ptychiuri Tr. = Typhonium c nspidatum Bl., Nat. fam. der Aroidex. Gr. Van Java tot Timor; overblijvend.

442. Aroi-kiladja $\mathrm{S}=\mathrm{U}$ v a ri a d ulc is D un. (Zie No. 3649c).

443. Aroi-pitjoeng-tjelling $\mathrm{S}$. $=$ $\mathrm{Fibraurea}$ tinet oria $\mathrm{L}$ o ur. (Zie voren).

444 Aroi-tarawoeloe S. = Cyelea peltata Hk. fs. \& Th. (Cisampelos Pareira L.). (Zie No. 447).

445. Aroij S. = Beteekent, evenals $\mathrm{O}$ j o t M. elke slingerplant.

446. Aroij-ampelas $\mathrm{S} .=\mathrm{Pog} 0$ notrophe phæopoda Miq., Nat. fam. der A r to e arpe e. Gr. Java; slingerplant.

447. Aroij-astrawoeloe $\mathrm{S}$. $=\mathrm{C}$ issampelos Pareira L., Nat. fam. der Men is permacer. Gr. Java; slingerplant. GEBR. De wortel was vroegcr als "Radix Pareira brava" oflicineel; bij bezit pisdrijvende en steenbrekende eigenschappen. De bladeren bevatten veel plintenslijin.

448. Aroij-babaliengbiengan $\mathrm{S}$. = Modecea cordifolia Bl., Nat. fam. der Passifloreac. Gr. Java; slingerplant GEßßR. Men bezigt de rauken dikwijls als touw, omdat zij lang onder water goed 
blijveu; het sap der stengels gebruikt men als wasehwater bij ontstoken der oogen.

449. Aroij-badoejoet S. = Triehosallthes villosa Bl, Nat. fam. der Cueurbitacex. Gr Java; slingerplant. GEвR. Het sap der plant geeft men bij lienterie te drinken.

450. Aroij-baget $\mathrm{S} .=a$. Toxoearpus mierophyllus Den. en $b$. T. Blumei Den., Nat. fam. der Aselepi. a dese. Gr. Java; slingerplanten.

451. Aroij-baliembieng $\mathrm{S}=a$. Combretum neurophyllum Miq.en b. C. latifolium Bl., Nat. fam. der Combretaeex Gr. Java; slingerplanten. GEBR. Volgens Hasskarl worden de jonge toppen der ranken gegeten, zijn deze zuuraehtig van smaak, en dienen de oudere stengels als touwwerk.

452. Aroij-balie landak $\mathrm{S} .=\mathrm{C}$ issus obovata Vahl (?) Nat. fam. der A m pelideæ. Gr. Java; slingerplant.

4.53. Aroij-baloempang S. $=\mathrm{I} p$ omæe peltata Chois. (Zie No. $303 a)$.

454. Aroij-bapa keboh $\mathrm{S}$. = Aristoloeli ia aeuminata $\mathbf{L}$ am. Nat. fam. der Aristoloehiea. Gr. Java; slingerplant

455. Aroh-beleh gehdigk S. of

456. Aroij-beloh getehpeh $\mathrm{S} .=a$. $\mathrm{Z}$ an thoxylum seandens Bl., Nat. der Zanthoxyleæ. Gr. Java; slinger. plant. GerR. Men gebruikt den bast als visehbedwelmend middel, vooral om palingen te vangen. $=b$. Tod d a li a a e ule a t a Pers., Nat. fam als voren. Gr. Java en Timor; slingerplant. GEBR. Alle deelen dezer plant zijn aromatisch, bitter en seherp; men voegt ze gaarne, als speeerij, bij vele spijzen, en dient ze als maagprikkelend en koortswerend middel toe.

357. Aroij-biliembie S. = Modeee a eordifolia Bl. (Zie No. 44.8).

458. Aroij-bobontengan $\mathrm{S}$. $==$ Bryonia seabrella L., Nat. fam. der Cue urbitacex. Gr. Overal in Indië; slingerplant. GEBR. Deze plant is om hare geurige bloemen gezoeht; de roode vruehtjes worden rauw bij de rijst gegeten.

459. Aroij-boddas $\mathrm{S}$. $=$ Mikania vol ubil is Wlld., Nat. fam. der Co in positæ. Gr. De Sunda-eilanden; slingerplant. Grir. Op Java bezigen de inlanders de gekneusde bladeren om op de wond te leggeu, door de besnijdenis der jongens verkregen, om hare genezing te bespoedigen.

460. Aroij-bodo landak $S_{0}=\mathrm{C}$ issus nodosa Bl., Nat. fam. der Ampeli de ז. Gr. Java, slingerplant. GEBr. De vruchten, gegeten wordende, veroorzaken liehtelijk ontsteking van mond- en keelholte en van de huid; zij worden als uitwendig geneesmiddel bij huidziekten aangewend.

461. Aroij-boeboeloet S. $=$ Gloe hidion lueidum Bl., Nat. fam. der Euphorbiacex. Gr. Java; kleine boom.

462. Aroij-boeboeloetang $\mathrm{S}$. = Spermacoee hispida L., Nat. fam. der Rubiacex. Gr. Java en Sumatra; overblijvend. GeBr. De stengels en bladeren als uitwendig geneesmiddel bij buikpijn.

463. Aroij-boeloe S. $=a$. I pomæe vitifulia $\mathrm{Sw} .=b$. Lepistemon flaveeens Bl. en $=c$. Argyreia eapitate Chois., Nat. fam. der Convolvulac eæ. Gr. Java; slingerplanten. GEBR. De vruehten van $\alpha$ zijn eetbaar.

464. Aroij-boeloo loetoeng $\mathrm{S}$. $=$ Speramaeoe hispida L.,. (Zie No. 462 ).

465. Aroij-boeloestroe S. = Luffa foetida Cav., Nat. fam. der Cueurbitaceæ. Gr. Java; éénjarig. Gebr. Van bijna alle Luffa-soorten worden de onrijpe vruehten als groente gegeten; rijp zijnde werken zij ontlastingberorderend.

466. Aroij-boengboeroetoe af Aroijgoengoeroetoe S. = Cissus L., Spee. div.

467. Aroij-bohol kehob of A-bohal kebak S. = Argireia speeiosa Sw., Nat. fam. der Convolvulae e æ. Gr. Java en elders in tuinen als sierplant.

468. Aroij-bungburummam assam $\mathrm{S} .=$ Cissus diseolor Bl., Nat. fam. der A m pelideæ. Gr. Java; slingerplant.

469. Ároij-bnrrio S. $=\mathrm{Hiptage}$ javaniea Bl., Nat. fam. der Malp ig h i a e e $x$. Gr. Java; slingerplant.

470. Aroij-dawon koentoet $\mathrm{S}$. = P $x d$ eria L Spee. div., Nat. fam. der Rubi a e æ.

471. Aroij-djantong S. = Triehos a $\mathrm{t}$ hes globos a Bl., Nat. fam. der $\mathrm{C}$ u e $\| \mathrm{r}$ b i t a e e $x$. Gr. Java; slingerplant. 
472. Aroij-djaroedjoe S. =- Dili$v$ a ria ili cifolia Juss., Nat. fam. der A cantháceæ. Gr. Algemeen in Indië; moerasplant. Gebr De aseh dezer plant levert eene goede loog; men prijst het kruid verder aan als heilzaam bij asthma en tot het verdrijuen der kwade geesîen bij zwangeren.

473. Aroij-doedoerenan S. = E 1 aa gnus latifolia L., en $b$. Elagnus regida Bl., Nat. fam. der Elæa gn eæ. Gr, Java; heesters. Gebr. De rijpe vruehten van beide worden gegeten.

474. Aroij-gadel of gatel $\mathrm{S}$. = Milletia serie ea W. \& A r n. (Zie No. 189).

475. Aroij-gadong $\mathrm{S}$. $=\mathrm{D}$ i oseorea hirsuta. Bl., Nat. fam. der Dioscoreæ. Gr. Java en de Molukken; slingerplant. Gebr. De wortels worden some gegeten; zij zijn eehtcr zeer scherp en vergiftig, en moeten eerst afgekookt en eenigen tijd onder den grond gelegd worden.

476. Aroij-gagaboesan $\mathrm{S} .=\mathrm{J} u \mathrm{~s}$. siæa Blumeana D. C., J. repens L., en J. suffrutieosa L., Nat. fam. der Oenotherex. Gr. Vrij algemeen in Indië; waterplanten. Gebr. Men kweekt ze aan als voedsel voor vissehen in vijvers.

477. Aroij-gambas S. = Momoldica subangulata Bl. (Zie No. 262a).

478. Aroij-gambir S. = Chiloearpus suaveolens Bl., Nat. fam. der A poeyneæ. Gr. Java en Sumatra; slingerplant. GEBR. Men bezigt het melksap voor vogellijm; het sap uit den stam geeft men bij dyserentie; dc jonge toppen der ranken en het peesaehtigc vleesch der pitten worden gegetell.

479. Aroij-gameh Sum. $=$ Dissochxta Diepenhorstii Miq., (Zie No. 158).

480. Aroij-garoet $\mathrm{S} .=a$. A eacia Intsia Wlld., b. A. pennata Wlld, $c$. A. concinna D. C. en $d$. Albizzia rubiginosa Miq., Nat. fam. der Mi. mos e x. Gr. Java en elders; slingerplanten.

481. Aroij-garoet gedeh $\mathrm{S} .=\mathrm{Mi}$ mosa asperata Wlld., Nat. fam. der M imosex. Gr. Java; slingerplant. GEBR. Het sap dezcr plant geeft men aan kraanvrouwen te drinken na de bcvalling.

482. Aroij-garoet pentjang $S$. = Entada pursetha l). C., Nat. fam. der
M i mos e r. Gr. Bijna overal in Indië ; slingerplant. Gebr. Volgens Rumphius zweet de oude stam een zeer heldere gom uit, wordt het sap uit den stam met Sagueer, tegen buikpijnen gedronken, en worden de zaden in de Molukken veelal geroosterd gegeten. Op Java wordt het sap gedronken, worden de bladeren als groente en de gerooste zaden door kraamvrouwen gegeten HoRSFIELD sehrijft aan deze braakverwekkende eigensehappen toe.

483. Aroij-gatel S. (Zie No. 474).

484. Aroij-gember $\mathrm{S}$. $=\mathrm{V}$ a he a gum mif era Lam., Nat. fam. der A p oс y n ex. Gr. Java; slingerplant. Geibr. het melksap bevet bevat veel eaoutchou.

485. Aroij-glata S. = a. Hippoeratea indica Wlld., $b$. H, glaga Krth., en $c$. Salaeia oblongifolia Bl., Nat. fam. der Hipporratea e æ. GR. Java; slingerplanten. GEBR. Het hout is voor brandhont zeer gezocht.

486. Aroij-goensing $\mathrm{s} .=\mathrm{Mucu-}$ mæ A d u s S pee. plu rimæ.

487. Aroij-goerahit $\mathrm{S} .=\mathrm{T}$ o d dalia micraeantha Miq., Nat. fam. der Zanthoxyleæ. Gr. Java; sliuger. plant.

488. Aroij-goeroet S. of A-gurreut S. = Zizyphus Horfieldii Miq., Nat. fam. der $R$ h a $m$ n e r. Gr. Java en Sumatra; slingerplant.

489. Aroij-goeroeng S. of A.-gurrung $\mathrm{S} .=a$. Pericampylus ineanus Miers, h. P. lagunosus Bl., $c$. Stephania hernandi folia Walp, Nat. fam. der Menispermaceæ. Gr. De Sunda-eilandəu; slingerplanten. GéBR, Het sap uit de stengels wendt men ter verkoeling op versche wonden aan; $d_{0}=$ Calonyetion speeiosum Chois, Nat. fain. der Convolval a e ex. Gr. Bijna overal in tuinen als sierplant; slingerplant.

490. Aroij-goeroeng boddas $\mathrm{S} .=$ $\mathrm{C}$ is a m p clos Pareira L. (Zie No. 447 ).

491. Aroij-goeroeng burrum $\mathrm{S} .=$ a. Stephania tomentos a S prg. en $b$. S. e or y m bos a Bl., Nat. fam. Gr. en GeBR. als No. 489 a. $-c$.

482. Aron-gontang $\mathrm{S} .=a$. Trichosanthes globosa Bl. (Zie No. 472) en $b$. Triehosanthes pubera B l. Gr. Java; slingerplant. Gér. Het sap der stengels laat men tegen doofheid in de ooren druppelen. 
493. Aroij-haäsman $\mathrm{s} .=\mathrm{Abrus}$ a cu tifolius Bl., Nat. fam. der Pa $\mathrm{P}$ li o n a c e $æ$. Gr. Java; slingerplant.

494. Aroij-hamproe bôgô $S .=B r y-$ onia perpusilla Bl., Nat. fam. der Cucurbitaccæ. Gr. Java; slingerplani. GEBr. Het sap geeft men als wormdoodend middel aan kinderen te drinken.

495. Aroij-harendong $\mathrm{S}$. $=\mathrm{M}$ a rumia muscosa Bl., Nat. fam. der Melastomaceæ. Gr. Java; slingerplant. GEBR. Het sap der plant geeft men tegen dysenterie te drinken; de eenigszins zoete vruchten worden gegeten.

496. Aroij-hariang $\mathrm{S}$. $=\mathrm{C}$ is s u s repen s $I_{\star}$ a m., (Zie No. 438).

497. Aroij-hariang burrum S. el

498. Aroij-hasseum $\mathrm{S}$. $=\mathrm{C}$ is s u s di s e ol or B l. (Zic No. 468).

499. Aroij-hoei tjoeöek S. = Dioscorea filiformis Bl. Nat. fam. der Dioscoreæ Gr. Java; slingerplant.

500. Aroij-hoei waleh S. $=\mathrm{K}$ a $r$ ivia $R$ heedi i M. J. Ro e m. Nat. fam. der Cu e u r bit a c e . Gr. Java; slingerplant.

501. Aroij-hoenjoer boeöet S. $=a$. Kadsura cauliflora Bl., b. K scaudens Bl. en c. Spærostemma axillare 131., Nat. fam. der Schizand race ce. Gr. Java; slingerplanten. Gebr. Men drinkt het sap dezer planten tegen kolijkpijnen en eet tot hetzelfde doel ook de bladeren en de wrange vruchten.

502. Aroij-jaha $\mathrm{S}$. $=\mathrm{Com} \mathrm{b} \mathrm{re}$ tu m punetatum Bl., Nat. fain. der Combretacex. Gr. Java en Borueo; slingerplant.

503. Aroij-jinjing koelit $\mathrm{S}$. = Nat. fam. der Rhamneæ. Gr. Timor, Java; slingerplant.

504. Aroij-jutton S. $=\mathrm{I} \mathrm{p}$ o m $æ$ a c y mos a B l. (Zie No. 303b).

505. Aroij-jutton béner $\mathrm{S}$. $=\mathrm{I}_{\mathrm{p}} \mathrm{0-}$ mica Turpethum R. Ar. Nat. fam. der Convolvulaceæ. Gr. Overal in Indië; slingerplant. Gebr. De "Radix turpethi" was vroeger officineel cn schijnt in werking de Jalappe nabij te komen.

506. Aroij-jutton boddas $\mathrm{S}$. $=$ Pharbitis hispida Chois, Nat. fam. der Convolvulaceæ. Gr. Op Java en elders in tuinen, als sierplant,

507. Aroij-jutton gedeh S. = I pomæe polyantha Miq., Nat. fam. als voren. GR. Java; slingerplant.

508. Aroij-jutton lumboet $\mathrm{S} .=\mathrm{C}$ on- volvulus parviflorus Vahl. Nat. fam. als voren. Gr. Algemeen in Indië; slingerplant; éénjarig. GEBR. Deze plant bezit purgecrende eigenschappen.

509. Aroij-kahawatang $\mathrm{S} .=\mathrm{S}$ a bia Menicosta Bl., Nat. fam. der S a bi ac e æ Gr. Java en Sumatra; slingerplant.

510. Aroij-kahitoetan badak $\mathrm{S}$. = P deria vetticillata Bl.

511. Aroij-kahitoetan gedeh $\mathrm{S}$. = P d e ria tome utoss Bl., en

512. Aroij-kahitoetan lumboet $\mathrm{S}$. $=\mathrm{P} x d$ eria tomentosa Bl, var. angustifolia Hassk., Nat. fam. der Rubiaceæ. Gr. Alle op Java; slingerplanten. Gebr. De bladeren van deze en andere $\mathrm{P} x d e$ ria-soorten verspreiden iu de zomerwarmte of fijngewreven een zeer onaangenamen reuk, waarnaar zij onder den naam van "dawon koentoet" algemeen bekeud zijn; de inlanders eten ze desniettegenstaande gaarne als groente, en nemen ze als windbrekend middel in. Volgens LinDLEY werkt de wortel braakwekkend en geeft men de bladeren ook tegen kourts en pisopstopping

513. Aroij-kait beussie $\mathrm{S} .=a$. Naucler L, spec. diversæ (Rubiaee $x) ;=b$. Pisonia villosa Poir., Nat. fam. der Nyctagineæ. Gr. Bïjla in geheel Indië; slingerplant.

514. Aroij-kajorangan $S .=L n f f a$ eordifolia Bl, Nat. fam. der Cueurbitaceæ. Gr. Java; slingerplant. Gebr. De vruchten en zaden worden met water fijngcwreven en op den buik gesmeerd tegen koorts, met opzetting der milt gepaard.

515. Aroij-kakapassan S. $=\mathrm{D}$ a l e c h a m pia bident a ta B l.; Nat. fam. der E u phor bi a e e . Gr. Java; slingerplant.

516. Aroij-kakatjiengan $\mathrm{S}_{\mathrm{O}}=\mathrm{M}$ orinda umbellata Bl., Nat. fam. der Rubi acex. Gr. Java, Sumatra, Bangka ; slingerplant.

517. Aroij-kakawatatan $\mathrm{S} .=\alpha$ I po. mæa filicaulis Bl., Nat. fam. der Convolvulaeeæ. Gr. Bijna overal in Indië; slingerplant. $b$. S e c amonc lanceolata Bl., $c$. S. line ata Bl.; $d$. Phyllanthera bifida B l., en $e$. Raphistemma Hooperianum Denc, alle behoorcnde tot de Nat. fam. der A sclepiadex. Gr. Op Java, Sumatra; slingerplanten.

518. Aroij-kakeedjoan $\mathrm{S} .=\mathrm{C}^{\prime} \mathrm{-}$ 
nocephaleus suaveolens Bl., Nat. fam, der Artoearpeæ Gr. Java, Sumatra; slingerplant. Gebr. Men bezigt de jonge stengsels als bindtouw, en ook tot het wasschen van het hoofdhaar; het sap wordt bij koortsen ingenomen.

519. Aroij-kalaijar S. $a .=$ Triehosanthes globosa Bl., (Zie No. 471) en $b$. Trichosanthes macrocarpa Bl., Nat. fam. der Cueurbitaceæ. Gr. Java; slingerplant. Gebr. Het sap van deze plant geeft men als wormdrijvend middel.

520. Aroij-kalaijar bêner $\mathrm{S} .=\alpha$. Bryonia seabrella L., (Zie No. $458) ;=b$. Zehneria exasperata $\mathrm{Miq}$. en $=c . \mathrm{Z}$. mucronata Miq. Nat. fam. der Cucurbitaceæ. Gr. Java; slingerplanten.

521. Aroij-kalaijar beurriet $\mathrm{S}$. $=$ a L $u$ ffa cordifolia Bl. (Zie No. 514); $=6$. Trichosanthes tricuspidata I. our., = $c$. Tr. laeiniosa Klein., en $=d$. Coecinia Wightiana M. J. $\mathrm{R}$ o e mer; alle behoorende tot de Nat. fam. der Cueurbitaceæ. Gr. Java en elders; slingerplanten. GeBR. Het sap van alle deze geeft men als wormdrijvend mid$d$ el; van $d$. eet men de bladeren en vruchten als groente.

522. Aroij-kalaijar burrum S. = Trichosanthes pubera Bl. (Zie No. 492b.)

523. Aroij-kalaijar gedeh $\mathrm{s} .=$ Trichosanthes pilosa Lour., Nat. fam. der Cuc urbitace ex. Gr. Java; slingerplant. GEBR. Het sap als wormdrijvend middel.

524. Aroij-kaliageh S. = Capparis T., Spee. scandentes, Nat. fam. der Capparide r. Gr. Java, slingerplanten. Gribr. Een koud aftreksel der stengels drinkt men tegen lendepijn.

525. Aroij-kamanden $\mathrm{S} .=a$. J asmin um crassifolium Bl.; = b. J. glabrum Wlld.; $=c$. J. glabriusculum Bl.; = d. J. subelongatum Bl.; = e.J. undulatnm Wlld., alle van de Nat. fam. der Jasmineæ. Gr. De Sunda-eilanden; slingerplanten. GEBR. De fijn gewreven bladeren worden ingewreven bij een gevoel van mierenkruipen in de handen, „Sakit kamanden" genaamd. $=f$. Elragnus ferruginea A. Rieh, Nat. fam. der Elæagnex. Gr. Java; heester. GEвR. De vruehten zijn eetbaar.

526. Aroij-kangkoeng $\mathrm{S}$. $=\mathrm{I} p \mathrm{o-}^{-}$ meæ reptans Poir., Nat. fam. der Convolvulaeeæ. Gr. Overal in Indië wild en gekweekt; moerasplant. GEBr. De jonge bladeren en stengels worden als een aangename groente, overal gezocht.

527. Aroij-karoewang $\mathrm{S}$. $=\mathrm{Ch}$ aviea majuscula Miq. (Zie No. 289.)

528. Aroij-karokkot $\mathrm{S}$. $=\mathrm{C}$ issus repens L a m. (Zie No. 433.)

529. Aroij-kasoengka $\mathrm{S}$. $=\mathrm{G} n \mathrm{e}-$ $\mathrm{t} u \mathrm{~m}$ funiculare L. (Zie No. 200.)

530. Aroij-kasoengka beurriet S.,

531. Aroij-kasoengka gedeh S. en

532. Aroij-kasoengka oentjal $\mathrm{S}$. = G n e tum ed u le Bl., Nat. fam. der Gnetaceæ Gr. Bijna overal in Indië; slingerplant. GeisR. De bast en de jonge ranken van deze planten zijn, evenals die van No. 200 , zeer rijk aan vezelstof, en er wordt een zeer geschikt en duurzaam touw van gemaakt; het sap geeft men aan kinderen tegen hevigen hoest en wormen; de zaden worden gekookt of geroost gegeten.

533. Aroij-katilang S. = Quamoclit vulgaris Chois., Nat. fam. der Convolvulaceæ. Gr. Algemeen in Indië tot sieraad in tuinen; slingerplant GEBR. De wortel zal als niesmiddel worden aangewend; de bladeren worden gebruikt op gezwellen als vcrdeelend geneesmiddel; het kruid en de zaden waren vroeger als laxantia officineel.

534. Aroij-katjambang S. of $\mathbf{A}$. kitjembang $S$. = Embelia gareiniæfolia Wall., Nat. fam. der Myrsineæ. GR. Java; slingerplant.

535. Aroij-katjambang gedeh $\mathrm{S}=$ Embelia javaniea Bl., Nat. fam. en Gr. Als voren; slingerplant. GEBr. Van deze beide gebruikt men den wortel bij de suikerbereiding uit het sap van den Aren; men drinkt het sap tegen hoest en buiklijden, en eet de jonge bladeren en vruchten als groente.

536. Aroij-katjapie $\mathrm{S} .=\mathrm{S}$ a b i a menieosta Bl. (Zie No. 509.)

537. Aroij-katoek S. $=\mathrm{Ty}$ lophora villosa Bl., Nat. fam. der A selepiadeæ. Gr. Java; slingerplant.

538. Aroij-katoek gajak S. $=$ A neilema secundiflorum Kth., Nat. fam. der Commelynaees. Gr Java en de Molukken; overblijvend. Gebr. Het kruid wordt als groente genuttigd.

ธ39. Ároij-katoek peutjang $\mathrm{S}$. = 
Aristoloehia iudiea L. (Zie No. 207) en $b$. A ristoloehia aeuminata Lam. (Zie No. 454.)

540. Aroij-kattam lumboet $\mathrm{S}$. = a. I pomar linifolia Bl. en $b$. I. littoral is Bl., Nat. fam. der Convolvul се ех GR. Java; slingerplanten.

541. Aroij-kawojang $\mathrm{S} .=a$. I pomæa vitifolia $\mathrm{S} w$. (Zie No. 463a.) b. I poma t uberosa L., Nat. fam. der Convolvulaeex. Gr. Op Java ingevoerd van Siduey; slingerplant. GEbr. De knollen worden gegeten, evenals die van Batatas adulis (Oebie); de wortels geeft men als purgeerend middel; $=c$. I poin a dasysperma Jaek., Nat. fam. als voreu. GR. Java, uit China overgebracht; slingerplant.

542. Aroij-kedjo S. $=\mathrm{C}$ is sus thyrsiflora Bl., Nat. fam. der Ampeli. deæ. Gr. Java; slingerplant.

543. Aroij-keekøedjoan $\mathrm{S} .=\mathrm{Co}_{0}$ noe ephalus suaveolens Bl. (Zie No. 518$.

544. Aroij-kehkep S. = Chaviea Blumei Miq., Nat. fam. der Piperaces. Gr. Java; slingerplant. Gerr. Het sap der stengels drinkt men bij hoest; de bladeren kauwt men als de sirihbladen.

545. Aroij-ketjil $\mathrm{S} .=a$. Convolv ul us parviflorus Vahl. (Zie No. 508$) ;=b$. I pom a o bs cura Jeq., Nat. fam. der Convolvulaceæ. Gr. Java, Timor; slingerplant.

546. Aroij-kiassahan $\mathrm{S}$. = Tetracera L. species permulta, Nat.fam. der Dill e n i a e e æ. Gr. Java en Sumatra; slingerplanten. Geib. De ranken bezigt men als grof touwwerk bij waterwerken; het sap der stengels drinkt men tegen hoest; de fijn gewreven jonge ranken en bladeren legt mell op wonden door slangenbeten veronrzaakt; de oude bladeren gebruikt men tot het polijsten van houtwerken.

547. Aroij-kiassahan lalakki S. $=$ Delima sarmentosa L., Nat. fam. Als voren. Gr. Overal in Indië; slingerplant. Grisi. De stengels voor grof bindwerk; het sap uitwendig bij oogzickte.

548. Aroij-kibara S. $=a \cdot \mathrm{Piper}$ arboreseens lixb. (Zie No. 2S8) en = b. Muldera baeeata Miq., Nat. fam. der Piperae æ. Gr. Java; slingerplant. GEBR. Men drinkt het sap tegen hoest en gebruikt de bladeren uitwendig bij keelpijn.

549. Aroij-kibarera $\mathrm{S} .=a$. Cissus javana D.C.; $=b$. C. compresa Bl. en andere; Nat. fam. der A mpelide s. Gr. Java; slingerplanten. Gebr. De bladeren van zeer vele $\mathrm{C}$ iss us-soorten eet men als groente in plaats van zuring; het sap der stengels drinkt men tegen hoest. De vruehten van eenige eet men als lekkernij.

550. Aroij-kibarera bener $\mathrm{S} .=\mathrm{C}$ issus mutabilis Bl., Nat. fam. en Gr. Als voren; slingerplant.

551. Aroij-kibarera boddas S. en

552. Aroij-kibarera boelet $\mathrm{S} .=\mathrm{C}$ i ssus nodosa Bl. (Zie No. 460.)

553. Aroij-kibarera gedeh $\mathrm{S}$. = a. Cissus seariosa Bl, en b. C. rhodoearpa Bl., Nat. fam. der A mpelideæ. Gr. Java; slingerplanten. Gebr. Als No. 549.

554. Aroij-kibarera lalakkina $\mathrm{S} .=$ $a$. Cissus nodosa BI. en $b$. Cissus diehotoma Bl., Nat fam. Gr. en Grar. Als voren.

555. Aroij-kibarera leutiek $\mathrm{S}$. = Cissus pergamacex Bl., Nat. fam. enz. Als voren.

556. Aroij-kibarera leutiek burrum S. = Cissus serrulata Rxb., Nat. fam. enz. Als voren.

557. Aroij-kibarera tjoetjoek S. $=\mathrm{C}$ issus papillosa Bl. (Zie No. 324.)

558. Aroij-kibattarah $\mathrm{S} .=a$. Wil. lughbeia javaniea Bl., Nat. fam. der A poeynex. Gr. Java; slingerplant. Gebr. Men gebruikt den bast tot het zwartverven van garens. $=b$. Ithnoearpus banta mensis Miq, Nat. fam. Gr. en GeBr. als $a .=c$. Polyozus latifolia Bl., Nat. fam. der Rubiaces. Gr. Java; slingerplant.

559. Aroij-kidjoeöe $\mathrm{S} .=\mathrm{P}$ ter $\mathrm{i}$ santhes eissoides Bl., Nat. fam. der A mpelidex Gr. Java en Sumatra; slingerplant.

560. Aroij-kikadantja $\mathrm{S} .=a . \mathrm{Me}$. lodinus laxiflorus Bl. en $b$. Melodinus orientalis Bl., Nat. fam. der Apoeynaces. Gr De Sunda-eilanden; slingerplanten. Gerr. Het melksap en de vruehten zijn zeer giftig; de bast levert een zeer korte, maar fijne vezelstof, welke als die der ananasbladeren kan gebruikt wordeu. 
561. Aroij-kikalindan $\mathrm{S} .=\mathrm{I}_{\mathrm{l}} \mathrm{o}-$ mæa obscura Jeq. (Zie No, 545b.)

562. Aroij-kikandel S. $=a$. D ischidia rhombifolli Bl., Nat. fam. der Asclepiadeæ. Gr. Java; slingerplant. $=b$. Hoya diversifolia Bl., Nat. fam. als voren. Gr. Java en de Molukken; slingerplant. GEBR. Het melksap smeert men, als verkoelend middel, op gestoken wonden, vooral op die door visschen.

563. Aroij-kikandel badok S. = Hoya macrophylla Bl., Nat. fam. $\mathrm{Als}$ boven. Gr. Java; slingerplant. GEBr. Het melksap prijst men aan als heilzaam op gestoken wonden door vergiftige visschen; de fijn gewreven bladeren gebruikt men uitwendig bij vermoeidheid en rheumatische pijnen, inwendig tegen gonorrhoea.

564. Aroij-kikandel lalakki S. $a .=$ No. 365. b. H o y c ori a e a B l, Nat. fam. en GR. Als voren; slingerplant.

565. Aroij-kikandel sabrang $\mathrm{S}_{\text {. }}=$ $a$. Hoy a coriacea R.Br. en $b$. Hoya la urifolia Desn., Nat. fam. Als voren. Gr. Op Java overgebracht van China en Timor; slingerplanten.

566. Aroij-kikangerangan $\mathrm{s}$. = $S$ alacia L. spec. diversæ, Nat. fam. der Hippocrateaceæ. Gr. Java; slingerplanten. GEBR. De fijn gewreven bladeren wendt men uitwendig bij hoofdpijn en schurft aan.

567. Aroij-kikawat $\mathrm{S}$. $=\mathrm{Sec}$ amone lanceolata Bl., Nat. fam. der Asclepiadeæ Gr. Java; slingerplant.

568. Aroij-kikooja $\mathrm{S}=\mathrm{Clema-}$ tis Leschenaultiana D.C. Nat. fam. der Ronunculaceæ. Gr. Java; slingerplant.

569. Aroij-kikoepoe S. $=$ M у 8 opyrum nervosum Bl, Nat. fam. der Olea ce æ. Gr. Java en Sumatra; slingerplant Gebr. Men drinkt het sap tegen buikziekten en lintworm.

570. Aroij-kikonneng.$=a$. An amirta Coeculus W. en Arn. (Zie No. 339.) = b. Tiliacora acuminata Mliers. Nat. fam. der $\mathrm{M}$ e $\mathrm{n}$ i s pe r ma. c eæ. Gr. De Sunda-eilanden; slingerplant. GEBR. Het sap bezigt men uit-en inwendig tegen loomheid in de ledematen en bij mocilijke urineloozing. $=c$. Erythro. palum seandens Bl., Nat. fam. der Erythropaleæ. Gr. Java; slingerplant. GeBr. De bast, in stukken gesneden en gestampt, wordt bij wijze van Sambal bij de rijst gegeten; met het fijn gewreven kruid wrijft men zich de beenen bij vermoeidheid in.

571. Aroij-kikontjang $\mathrm{S} .=\mathrm{Po}$ thos seandens L., Nat, fam. der A roideæ. Gr. Java en Sumatra; Gebr. De oudere stengels of ranken gebruikt men, gespleten, tot allerlei vlechtwerk; dc jongere tot het zwartverven van kleederen, en het sap uit- en inwendig bij lendepijnen.

572. Aroij-kikottok $\mathrm{S}$. $=\mathrm{Abrus}$ mclanospermus Hssk., Nat. fam. der Papilionacex. Gr. Java; slingerplant. GeBr. De ranken zijn een geschikt bindtouw bij waterwerken.

573. Aroij-kiladja $\mathrm{S} .=a \cdot \mathrm{Uva}-$ ria argentea Bl. Gr. Java; $=b$. U. purpurea Bl. Gr. Java en Sumatra; $=c$. U. c oncava T. \& B. Gr. Sumatra; $=d$. Melodorum latifolium Dun. Gr. Java en de Molukken; = $e$. Mitrephora multiflora Miq. Gr, Java; = $f$. M. humilis Bl, GR. Java; = g. M. micrantha Hssk. Gr. Java, en $=h$. Artabotrys hamatus R.Br. GR. Van Java tot Timor. Al deze slingerplanten behocren tot de Nat. fam. der A nonaceæ. GEBR. Men drinkt het sap tegen hoest en hoofdpijn; de stengels zijn een sterk touwwerk; de jonge bladeren gebruikt men uitwendig op wonden en bij schurft.

574. Aroij-kiladja besaar $\mathrm{S}$. = Unona dasymaschala Bl. Nat. fam. der A n on ac ex. Gr. Java, heestcr.

575. Aroij-kiladja lalakki S. = Artabotrys suaveolens B l., Nat. fam. Als voren. GR. Door geheel Indië; slingerplant. Gebr. De ranken dienen als touwwerk; de bladeren zijn door koebeesten zeer gezocht.

576. Aroij-kilampahan $\mathrm{S} .=\alpha$. Tylophora villosa Bl. (Zie No. 537); $=b$. Hoya maerophylla Bl. (Zie No. 563); $=c$. Hoya eoronaria $\mathrm{Bl}$., en $d$. Hoya clandestina Bl., Nat. fam. der A sclepiadex. Gr. Java en Sumatra; slingerplanten.

577. Aroij-kingkilaban $\mathrm{S}$. $=\mathrm{M}$ u ssaënda L. spec. diversæ, Nat. fam der Rubiacea. Gr. Java; slingerplanten. Gebr. De sappen bezigt men uit- en inwendig bij slepende oogontstekingen.

578. Aroij-kirapdat $\mathrm{S}=$ Combre- 
tum latfolium Bl. en C. neurophyllum Miq. (Zie No. $45 \mathrm{l} a$.)

579. Aroij-kisebeh $\mathrm{S}$. $=(Z$ ie het volgende woord.)

580. Aron-kisioech $\mathrm{S} .=a$. Cis. sus adnata Rxb.; =b. C. Blumeana Std., en $=c . \mathrm{C}$ repanda Vhl, Nat. fam. der Ampelideæ. Gr. Java; allen slingerplanten. GEBR. Het sap wordt tegen loest gedronken.

581. Aroij-kisioech bener S. $=\mathrm{C}$ issus thyrsiflora Bl. (Zie No. 542)

582. Aroij-kissioe S. (Zie No. 580.)

583. Aroij-kitjaäng $\mathrm{S} .=\mathrm{E} r \mathrm{yth} \mathrm{ro}$ stigm a diversifolium $\mathrm{Hassk}$; Nat. fam. der Amyrideæ. Gr. Java; slingerplant. GeBr. Nen eet de bladeren rauw met zout en met Sambal bij de rijst.

584. Aroij-kitjantoeng $\mathrm{S} .=\mathrm{M}$ elodor um spliærocarpum Bl., en M. Kentii H. fil. en T., Nat. fam. der Anona ceæ. Gr. Java; slingerplanten.

585. Aroij-kitjantjong S. $=\mathrm{H} \mathrm{a} \mathrm{bz} \mathrm{e-}$ lia a cuta Miq. Nat. fam. Als voren. Gr. Java; slingerplant.

586. Aroij-kitjarang $\mathrm{S} .=$ Connarus $\mathrm{H}$ asseltii Bl. en andere, Nat. fain. der Connara e e. Gr. Java; slingerplanten.

587. Aroij-kitjau S. = C is s u s hirtella Bl., Nat. fam, enz. (Zie No. 580.)

588. Aroij-kitjepot $S .=S a l a c i a$ maerophylla Bl. S. prinoides D, C, S. radula Dtr. en andere, Nat fam. der Hippoerateacer. Gr. Java en Sumatra; slingerende heesters. Glвk. Het hout is zeer gezocht om te branden; de jonge bladeren en vruehten worden rauw gegeten.

539. Aroij-kitjepot goenoeng S. = a. Salacia melittocarpa Bl. (Zie No. 588); $=b$. Stryehnos Colubrin a

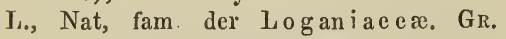
Op sommige der Sunda-eilanden; slingerplant. Geirr. Deze heester zal het slangenhout, Pao de Cobra opleveren, dat als heilzaam tegen den beet der Brilslang, Naga of Coba de Capella, geroemd wordt.

590. Aroij-kitjiendeh S. of

591. Aroij-kitjinti $\mathrm{S}$. $=$ Crudya orieutalis Hassk., Nat. fam. der Pap i li o n a c e . Gr. Java; slingerplant. GEBR. Het sap wordt gedronken tegen dysenterie.

592. Aroij-kitjoeboeloe S. = A roij boengboetoe S. (Zic No. 446.)
593. Aroij-kitjoebong $\mathrm{S}-\mathrm{Z}$ an oni a $m$ a croe ar p a B l, Nat. fam. der $\mathrm{Nh}$ and i rober. Gr. Java; slingerplant.

594. Aroij-kitjongtjorang $\mathrm{S} .=\mathrm{P}$ othos seaudens Bl. (Zie No. 571.)

595. Aroij kitongerret $\mathrm{S} .=1$ ) e $\mathrm{r}$ $r$ is uliginosa Benth., Nat. fam. der Papilionacex. Gr. In geheel Indië ; slingerplant. GeBR. Men bezigt den bast tot het bedwelmen van vissehen.

596. Ároij-koait beussi $\mathrm{S} .=a$. $P$ isonia villosa Poir. (Zie No. $513 b) ;=6 . \mathrm{Nauelea}$ L. diversie seandentes; Nat. fam. der Rubia e ex. GEBR. De jonge ranken bezigt men tot het zwartverven van kleedjes; de oudere stengels worden gespleten en voor vlechtwerk gebruikt.

597. Aröj-koejapoe S. $=a$. Argyreia mollis Chois., b. A. nitida Chois, $c$. A. tiliafolia W ght., Nat. fam der Convolvulaceæ. Gr. Java ell elders; slingerplanten. GrBr. Het sap en de fijngewreven bladeren wendt men in en om de oogen aan bij hoofdpijn en lichte ontstekingen.

598. Aroij-koekoehoelang $\mathrm{S} .=a$. Griffithia fragrans W. \& A., Nat. fam. der Rubiaceæ. Gr. Java; slingerplant; $=b$. Z izy phus javanens is Bl. en $=c$. Z. e eltidifolius D.C., Nat. fam. der $\mathrm{Rh}$ a m it e $\mathrm{G}_{\mathrm{R}}$. Java, Sumatra, Timor; slingerplanten.

599. Aroij-koekoehoelang gedeh S. =a. Zizyphus rufula Mi I. , Nat. fam Als voren. Gr. Java; slingerplant; $=b$. Zizy p us Horsfieldii Miq. (Zie No. 488.)

600. Aroij-koekoentoeng $\mathrm{S} .=\mathrm{I} p o-$ mæa vitifolia Sw. (Zie No. 463a.)

601. Aroij-koekoepoe S. (Zie A. kocpoe-koepoe S. No 605.)

602. Aroijkoekoek soompong = Zanonia maeroearpa Bl. (Zie No. 593).

603. Aroij-koeloek leukeut $\mathrm{S} .=a$. Salacia radula Dtr. (Zie No. 588.) $=b$. Chiloearpus denudatus B l., Nat. fam. der A p о с у n e æ. Gı. Java; slingerpant. Gesr. Men bezigt let melksap als vogellijm; het sap uit den stam driukt men bij verouderde dysellterie; de jonge ranken en het vleesch der pitten zijn zuurachtig en worden bij de rijst gegeten.

604. Aroij-koemper $\mathrm{S}=$ Parson. 
sia javanica B l., Nat. fam. der A poс у п е.. Gr. Java, slingerplant.

605. Aroij-koepoe-koepoe $\mathrm{S} . \neq a$. Phanera crymbosa Bnth., Nat. fam. der Papilio naceæ. Gr. Java; slingerplant. GEBr. De stengels leveren een zeer sterk touw; het sap geeft men in-en uitwendig bij buikpijnen en na zwangersehap. $=6$. P. Junghuhniana Bnth. en $=c$. P. scandens $R_{x}$ b., Nat. fam. enz. Als voren; $=$ P. purpurea Bnth., Nat. fam. en Gr. Als voren. GEBr. De stengels leveren een uitmuntend touwwerk; men drinkt het sap of kauwt de bladeren tegen hoest.

606. Aroij-koetjoeboeng $\mathrm{S} .=\mathrm{Ca}$ lonyction speciosum Chois. (Zie No. $489 d$ )

607. Aroij-kondang $\mathrm{S} .=a \mathrm{Pog} 0$ notrophe lavis Miq., = 6. P. piperifolia Miq. en P. rigida Miq., Nat. fam. der Artocarper. Gr. Java; slingerplanten. GEBr. $\mathrm{De}$ bast van $a$ dient in plaats van touw.

608. Aroij-konjal S. = Pogonotrophe lavis Miq. (Zic vorige No.) $=$ b. Fieus asperima T. $\&$ B. $=c$. F. filifomis Bl.; $=d$. F. obtusa Hassk.; $=e$. F. platycaula Miq.; $=f . \mathrm{F} \cdot \mathrm{S}$ panoghealla $\mathrm{Miq} . ;=g . \mathrm{F}$. strigosa Bl., $=h$. F. Teijsmanniana Miq. en $=i$. F. villosa Bl. Nat. fam. Als voren. Gr. Alle op Java; slingerplanten. GEBR. Vooral van $a$ eu $i$ gebruikt men den bast dikwijls als touw.

609. Aroij-konjal leutiek $\mathrm{S} .=\mathrm{Sy}-$ nocia falcata Miq., Nat. fam. der A rtoearpeæ. Gr. Java; slingerplant.

610. Aroij-korreg kottok S. = Bryonia seabrata Bl., Nat. fam. der Cucurbit acex. Gr. Java; slingerplant.

611. Aroij-korro rontong embeh S. en

\section{Aroij-korro ronteng kambing}

S. = Bryonia marginata Bl., Nat. fam. Gr. enz. Als voren.

613. Aroij-krawattan S. = Phyllantera bifida Bl. (Zie No. 5̌l7d.)

614. Aroij-lallan S. $=$ Gyn ura s a rmientos a D.C. Nat. fam. der Composita. Gr. Bijna overal in Indië; slingerplant. Grisr. Men ect de bladeren als groente, en doet ze ook in baden tegen rheumatismus en verlainmingen.

615. Aroij-landoek S. = a. Vitis trifolia L., en $=b$. Cissus landuk II assk., Nat. fam. der Ampelider.
Gr. Java; slingerplanten. Gквr. Van deze en volgende $\mathrm{C}$ is s u s-soorten-geeft men aan kinderen het sap te drinken, en wrijft zc den buik met de gekneusde bladeren in tegen ingewandswormen.

616. Aroij-landoek bener $\mathrm{S} .=\mathrm{C}$ is. sus cyanoearpa Miq. Gr. Jara.

617. Aroij-landoek gedeh $\mathrm{S}=\mathrm{Cis}$ sus geniculata Bl. Gr. Java.

618. Aroij-landoek leutiek S. $=\mathrm{C}$ is. sus cinerea 1 am. (Zie No. 65.)

619. Arojj-lokkot mata $\mathrm{S} .=a$. Artemisia indica Wlld. en $=6$. A. lavendulæfolia D.C., Nat. fam. der Compositæ. Gr. Java, Sumatra, cnz.; overblijvende planten. GEBR. Men bezigt vooral de eerste bij de Hindoes voor godsdienstige plechtigheden; op Java genecst men schurft met cen afkooksel der bla. deren.

620. Aroï-lomboë $\mathrm{S}=\mathrm{C}$ is s a inpelos Pareira L. (Zie No. 44\%.)

621. Aroij-lopang bongkoh $\mathrm{S}$. = Trichosanthes costata Bl., Nat. fam. der Convolvulaceæ. Gr. Java; slingerplant. Gebr. Als No. 471 en 519.

62. Aroij-luksa $\mathrm{S}$. $=\mathrm{P}$ i ptu $\mathrm{r}$ us repandus Wedd., Nat. fam. der Urticacer. Gr. Java en Amboina; slingerplant.

623. Aroij-malatti $\mathrm{S}$. $=\mathrm{J}$ a s $\mathrm{m}$ in u m L. Spee. plurima. (Zie No. $525 a-e$.)

624. Aroij-mandja of A-mandjel S. = Mediuilla radicans Bl., Nat. fam. der $\mathrm{M}$ e las to m a e r. Gr. Java; slingerplant.

625. Aroij-mangender of A.-mengender $\mathrm{S} .=a$. Combretum puuctatum Bl., (Zie No. 502); = 6 . $\mathrm{Hi}^{\text {p- }}$ poeratea indiea L. (Zic No. $485 a$. ) en $=c$. Salacia oblongifolia 131 . (Zie No. $485 c$ ). Onder dezen naam geeft Hasskarx aan, dat het sap der stengels bij koortsen wordt gedronken, en dat mer de gerooste jonge bladeren aan vrouwen te eten geeft, ter bevordering der kraamzuivering.

626. Aroij-mangoenang $\mathrm{S} .=\mathrm{Aga}$ nosma Blumei A. D.C. en Agauosma elegans G. Don., Nat. fain. der A poeynex. Gr Java; klimplanten.

627 Aroij-mata hiang S. = C ivsalpinia Nuga Ait., Nat. faun. der Papilion a cea. Gr. Java, Timor, de Molukken; slingerplant. Gerr. Eene afkooksel der wortels geeft men tegen graveel 
en steen; het sap uit deu stam wendt men uit- en inwendig aan bij oogziekten; daarvoor eet men ook de gerooste ourijpe vruchten, die bitter van smaak zijn; de fijn gewreven bladeren geeft men aan kraamvrouwen in, dadelijk na de bevalling ter versterking der baarmoeder.

628. Aroij-mata kantjil S. of

629. Aroij-mata peutjang $\mathrm{S}$. = Salaeia I. Spec. diversæ. Gebr. De ranken bezigt men voor bindwerk; de vruchten zijn goed om te eten.

630. Aroij-moending djaloe $\mathrm{S}$. = a. Combretum latifolium Bl, (Zie No. $451 b) ;=b$. Spatholobus litto. ralis Hassk., Nat. fam. der Papilio. naceæ. Gr. Java; slingerrilant. Gebr. Men drinkt het sap en wascht daarmede de voeten bij zwaarte en loomheid in de beenen; $=c$. Randia scandens D.C., Nat. fam. der Rubiaceæ. Gr. Java; slingerplant.

631. Aroij-mongol S. = (Zie No. 624.)

632. Aroij-mugmal $\mathrm{S} .=a . \mathrm{Ery}$ eibe paniculata $R \times b$., en $=b$. E. lavigata Wall., Nat. fam. der Erycibeæ. Gr. Java; slingerplanten.

633. Aroij-oëat bangkong $\mathrm{S}$. = Erythropalum scandens Bl. (Zie No. $570 c$.)

634. Aroij-oëat goeIong $\mathrm{S} .=\mathrm{C}$ alonyction triehospermum Chois, Nat. fam. der C o n volvul a e e æ. Gr. Java; slingerplant. GeBr. Bij zware vernoeidheid wrijft men zich met het gekneusde kruid de beenen of het geheele lichaam in.

635. Aroij-oebie djawa $\mathrm{S} .=\mathrm{B}$ a$\mathrm{t}$ a t a s ed a lis Chois, Nat. fam. der Convolvula ce æ. Gr. Door geheel Indië gekweekt; kruipende plant. GeBr. De zoete knollen worden algemeen als aardappelen genuttigd; de jonge uitspruit. sels ett men als aspergies en salade; de fijn gewreven bladeren wendt men aan op brandwonden en bij stijfheid der gewrichten.

636. Aroij-ojong $\mathrm{S} .=a$. $\mathrm{L}$ u f f a cordifolia Bl. (Zie No. 514) en $b$. Luffa pentandra Rxb., Nat. fam der Cucurbitaceæ. Gr. Java; slingerplanten. GEBR. Als No. 514.

637. Aroij-omas S. (Zie No. 636.)

638. Aroij-palembang S. (Zie A ngrek plembang S. \& M., No. 373.)

639. Aroij-papareh S. = Momordic a $\mathrm{Ch}$ arantia I., Nat. fam. der
Cueurbitacer. Gr. Bijua overal aangekweekt; slingerplant. Gквr. De bladeren, en vooral de bittere vruchten, worden, rijp en on rijp, als grcente, door zeer velen bij de rijst gegeten, en zijn zeer gezond; aan het sap der stengels kent men een bloedzuiverende, de zogafscheiding bevorderende en wormdrijvende kracht toe. De bladeren wendt men als wondzuiverend middel aan, en bezigt ze bij wijze van hop, ter bereiding van het zoogenaamde suikerbier; door de bladeren op sla-olie af te trekken, bereidt men een olie, die reel bij ontvellingen, brandwonden, enz. gebruikt wordt.

640 Aroij-papassang $\mathrm{S}$. $=\mathrm{Coc}$ e in ia grandis M. J. Roem. Nat. fam. der Cucurbitaceæ. Gr. Java en de Molukken; slingerplant. GEBr. Men eet de bladeren en ook de vruchten afgekookt bij de rijst.

64.1. Aroij-paria gingeh $\mathrm{S} .=\mathrm{Coc}-$ cinia grandis M. J. Roem. (Zie No. $640)$; $=$. Bryonia laciniosa L., Nat. fam. der Cucurbitacex. GR. Algemeen in Indie, slingerplant.

642. Aroij-patoek manoek $\mathrm{S} .=\alpha$. Tylophora villosa Bl. (Zic No. 537) en $=b$. Tylophora tenuis Bl, Nat. fam. der Alsclepiadeæ. Gr. Jara. = c. Thunbergia javanica Grtn. en andere soorten. Nat. fum. der Acantha. ceæ. Gr. Java en de Molukken, veel in tuinen tot sieraad; slingerplanten. = d. Modecca populifolia Zipp., Gr. Java en Tinor; $=e$. M. obtusa Bl., $=f$. M. palmata Lam.; = g. M. maerophylla Bl., =h. M. acuminata $\mathrm{Bl} .,=i . \mathrm{M}$. oblonga Hassk., $=k$. M. cardiocarpa Hassk., en $=l$. M. lo b a t a $J \mathrm{cq}$., allen behoorende tot de Nat. fam. der Passifloreæ. Gr. Java; slingerplanten. GEBR. De jonge ranken en bladeren van deze soorten worden, in stoom gekookt of geroost, bij de rijst gegeten; zoo ook het vleesch der pitten, nadat de vrucht gekookt en van de schil ontdaan is.

643. Aroij-patoek manoek lumboet S. = Modecea heterophylla Bl., Nat fam. Gr. en GeBr. Als voren.

644. Aroij-pitjoeng tjelleng S. = a. Triehosanthes coriacea Bl., = b. Tr. grandiflora Bl. en $=c$. Tr. he $x$ a sperma B l. Nat. fam. der $\mathrm{C}$ u e u r bit a e e $a$. Gr. Java; slingerplanten. Gebr. De sappen dienen als waschwater bij oogziekten. $=\mathrm{Hodgs}$ on i a 
heteroclita Hk. f. \& T., Nat. fam. der Cucurbitaeeæ GR. Java; slingerplant $=e$. Tiliacora a cuminata Miers (Zie No 570b) $=f$. Coceulus bantamensis Bl., Nat. fam. der Men i s permacer. Gr. Java; slingerplant. - g Phytocrene gigantea Wall. en h. Ph macrophylla Bl., Nat. fam. der Phytocrener Gr. West-Java; slingerplanten

645. Aroij-pitjoeng tjelleng bener $\mathrm{S} .=a$. Tiliacora acuminata Mrs. $($ Zie No. 5706$)=$ b. Anamirta flaves. cens Miq., Nat. fam. der Menispermacer. Gr Java en de Molukken. Gebr. Men bezigt de zaden tot het bedwelmen van visschen.

646. Aroij-plassario S. of A.-poelassarie $\mathrm{S} .=-a$ A ly $\mathrm{y}$ i a $\mathrm{stellata}$ R. \& S. Nat. fam. der A p o с y и e $x$ Gri. Algemeen in Indië; slingerplant. GEBR. De bast, ranken en bladeren zijn als reukmiddel, om tussehen de kleederen te leggren, zeer gezocht, en komen als aromatiseh-bitter geneesmiddel in de meeste geneeskrachtige mengsels voor. De bast bevat cen scherpe, aromatische hars, een vluchtige olie en een stinkende, bittere extractiefstof. $=b$. A ganosma B lumei A. D.C. en $c$. A. elegans G. Don. (Zie No. 626)

647. Aroij-puhjiet ajam $\mathrm{S} .=a$. Heligme javanica Bl., Nat. fam. der A pocynex. Gr. Java en Timor: slingerplant $=b$. Tylophora cuspid a ta Z i p p., Nat. fam. der A s c lepi a de x. Gr. Java, Timor, Bocton; slingerplant.c. Tyloph or a cissoides Bl., Nat fam. Als voren. Gr. Java; slingerplant. GLiBR. Men wendt de fijn gewreven bladeren nit-en inwendig bij diarrhoese aan.

648. Aroij-purries S. = Rour e opsis javanica Planeh., Nat. fam. der Co nu a ra eex. Gr. De Sunda-eilanden; slingerplant.

649. Aroij-reba bangon $\mathrm{S}$. = $\mathrm{Mi}$ mosa pudica Is, Nat. fam. der Mimosex. Gr. Overal in Indië; kruipende plant. G a BR De wortel werkt scherp prikkelend, brakingwekkend; de bladeren zullen giftig werken en vermoedelijk Cathartine bevatten; de inlanders doen de bladeren in het bad van een jong kind, om dit in slaap te doen vallen.

650. Aroij-saga leutiek S. $=$ A brus procatorius L. (Zic No. 53.)

641. Aroij-sahagi $S .=$ Gouania ferru'rginea Rwdt., Nat. fam. der Rhamner. Gr. Java; slingerplant. GEbr. De bast wordt inwendig tegen schurft aangewend.

652. Aroij-sanga langhit $\mathrm{S} .=a$. Cassytha filiformis $\mathbf{L}$. en $=b$. C. pubescens R.Br. Nat. fam., Gr. en GFbr. zie No. 203.

653. Aroij-sariboe of sariwoe S., en

654. Aroij-seboe of sewoe $\mathrm{S}$. $=\alpha$. $\mathrm{D}$ albergia $\mathrm{S}$ is s oo $\mathrm{R} \mathrm{x}$ b. en 6 . D. Pseudo-Sessoo Miq, Nat. fam. der Papiliouace Gr. Java, Sumatra en Borneo; slingerplanter. GEBR. Deze planten hebben haren grootsehen naam, sarib oe of seboe (duizend), hieraan te danken dat de inlanders haar voor alle ziekten gesehikt achten. De ranken worden afgetrokken en gebruikt tegen het uitvallen van het haar; ook schrijft men hun een wormdrijvende kraeht toe. De fijn gekneusde wortels en bladeren legt men op alle pijnlijke plaatsen. De bladeren, aan dieren te eten gegeven, doen bij deze, onzuivere wonden dadelijk een zuiver aanzien bekomen.

655. Aroij-seuseurehan $\mathrm{S} .=\mathrm{Mo}$. deeca Lam. Spee. diversea. (Zie No. $64.2 d-l)$

656. Aroij-sih $x$ jam S. en

657. Aroij-sikottok $\mathrm{S}$. $=\mathrm{Abrus} \mathrm{me}$ lanospermus Hassk. (Zie No. 572.) 658. Aroij-sijoek boddas $\mathrm{S}$. $=$ Cissus a dnat a Rxb. (Zie No. $590 \alpha$.)

659. Aroij-sijoek gedeh $\mathrm{S}$. = Cissus thyrsiflora Bl. (Zie No. 542.)

660. Aroij-sijoek hiedjoe $\mathrm{S} .=\mathrm{C}$ issus Blumeana Std. (Zie No. 580b.)

661. Aroij-sijoek lampoeng $\mathrm{S}=$ $V$ it is Symosa Bl., Nat. fam. der A $m$ p e lid e $x$. Gr. Java en de Molnkken; slingerplant.

662. Aroij-sijoek leutiek $S_{.}=\mathrm{C}$ is. sus repand a Vhl. (Zie No. 580c.)

663. Aroij-sirabeh S. of

664. Aroij-sirareb $S .=a$. Vit is indiea I. (Zie No. 349.) $=6$. Gou ania leptostachya D.C. en $=c$. G. retinaria I).C. Nat. fam. der Rhannex. GEBR. Den bast fijn gewreven legt men op scabieuse plaatsen.

665. Aroij-sisier $\mathrm{S} .=$ Tetrandra Zollingerian a M iq Nat. fam. der Asperifolice. Gr. Java; kleine heester.

666. Aroij-sivarah S. $=$ No. 663 en 664 .

66\%. Aroij-siwoeroengan S. $=$ Mus- 
saënda L. Spec. div. (Zie No. 577.)

668. Aroij-soesoean $\mathrm{S}$. $=$ Cissus papillosa Bl. (Zie No. 324) en = b. Vitis pubiflora Miq., Nat. fam. der $A \mathrm{mpelider.} \mathrm{Gr.} \mathrm{Java;} \mathrm{slinger-}$ plant.

669. Aroij-soesoe moendieng $\mathrm{S}$. = Elæagnus ferruginea R.Br. (Zie No. $525 f$ ) en $=6$. Parsonsia javanica 131. (Zie No. 604.)

670. Aroij-sowaghi $\mathrm{S}$. $=\mathrm{G}$ o u an i a L. Spec, d ivers æ. (Zie No. 65I en 664 )

671. Aroij-tali aijoenan $S$ Abrus melanospermus Hassk. (Zie fio. 572.)

672. Aroij-tali kintjier $\mathrm{S}=\mathrm{I}$ p o$m æ a$ obscura J acq. (Zie No. 545b.)

673. Aroij-tali landak $S .=a$. Cissus obovata Vhl. (Zie No. 452), en $b$. Modecca accuminata Bl (Zie No. 642h.)

674. Aroij-tangtang angin $\mathrm{S}$. = Plueknetia corniculata Prs. Nat. fam. der Euphorbiaceæ. Gr. Java en de Molukken; slingerplant GEBR. Het jonge kruid en de vrichten worden, in stoom gekookt, bij de rijst gegeten; de laatste hebben een zoetachtigen smak.

675. Aroij-tarawoeloe S. = Cissampelos Pareira I. (Zie No. 447.)

676. Aroij-tarroem $\mathrm{s}$. $=\mathrm{M}$ arsdenia parviflora Desn., en $=b$. MI. tinctoria R. Br., Nat. fam. der A scleli i deæ. Gr. Java, Sumatra, Borneo; slingerplantell. GEBR. De inlanders bereiden uit deze planten een kleurstof als indigo, welke zij tot het zwart verven hunner kleederen gebruiken.

677. Aroij-tatampaijam S. = I po$m$ ic a involucrata B I r m., Nat. fam. der Convolvulacer. Gr. Java; slingerplaut

678. Aroij-tatapaijan S. = Argyreia mollis Cho is. (Zie No. 597a.)

6'9. Aroij-tatapaijan gedeh S. = b. A rgyreia speciosa D. (Zie No. 467) en $=b$. A. 'T i li fol i a IV ght. (Zie No. 597c)

680. Aroij-tataroeman laut $\mathrm{S}_{\text {. }}=$ 1) albergia congesta Grah, Nat. fam. der Papilio n a c ex. Gr. Java; slingerplant.

681. Aroij-tawoeloe. T. (Zic No. 675.)

682. Aroij-tember kidang $\mathrm{S} .=\mathrm{En}$ tada Pursætha D.C. (Zie No. 482.)
683. Aroij-terong oetan S. $=\mathrm{He}$ ligme javanica Bl. (Zie No. 647a.)

684. Aroij-tiliel $\mathrm{S} .=\mathrm{Ph}$ a $\mathrm{n}$ e $\mathrm{ra}$ $\mathrm{del}$ ib is $\mathbf{M}$ iq., Nat. fam. der $\mathrm{P}$ apili o n a c e r. Gr. Java; slingerplant; GEBr. De tijne, dunne ranken bindt men zich om de lenden bij lendepijn, vooral na het paardrijden.

685. Aroij-tiwoek $\mathrm{S}$. = L u ffa $\mathrm{Pe}$ tola Ser., Nat. fam. der Cucurbitacer Gr. Bijna overal in Indië aangekweekt; slingerplant. GEBR. De rijpe vruchten zijn, gekookt, zeer gezocht bij de rijst; onrijp gegeten zullen zij ontlasting bevorderend werken $=\bar{b}$. Trichosanthes ovigera Bl., Nat. fam. Als voren; Gr. Java; slingerplant. GEBr. De vruchten worden gekookt en dan het vleesch der pitten, als een lekkere toespijs, bij de rijjst genuttigd.

686. Aroij-tjabeh $\mathrm{S} .=\mathrm{Ch}$ a vica dens a Miq., Nat. fam. der Pipcrac e æ. Gr. Java; slingerplant.

687. Aroij-tjaliengtjieng $\mathrm{S} .=\mathrm{Mo-}$ decca cordifoli a Bl., (Zie No. 448.)

688. Aroij-tjaloentjoen $\mathrm{S} .=\mathrm{Creo-}$ chiton pudibunda Bl., Nat. fam. der Melast om a ceæ. Gr. Java; slingerplant.

689. Aroij-tjam-tjoear S. en

690. Aroij-tjam-tjouw mienjak S. $=\mathrm{C}$ is a mpelos Pareira L. (Zie No, 447.)

691. Aroij-tjannar babi S. = Dioscorea Plum. en Smilax Tnf. Spec. diversæ. Geßr. De wortels van alle deze planten zijn een gezocht varkensvoeder.

692. Aroij-tjannar bokkor $\mathrm{S}$. $=$ Smilax Tnf. Species plurimæ. Gebr. Men gebruikt de bladcren uitwendig tegen hoest en asthma; ook bezigt men hen bij wijze van drinkglazen.

693, Aroij-tjapoe toehoer $\mathrm{S}=a$. Mikania volubilis Wlld. (Zic No. $459)$ en $=b$. Raphistemma Hooperianum Den., Nat. fam. der Asclepiad eæ. Gr. Java; slingerplant.

694. Aroij-tjaraijoeng $\mathrm{S} .=\mathrm{I}$ p omæa peltata Chois. (Zie No. 303a.)

695. Ároij-tjatjabëan $\mathrm{S} .=\mathrm{Q}$ u amoclit phocnicea Chois., Nat. fam. der Convolvulaccæ. Gr. Zeer algemeen als sierplant in tuincn; slingerplant.

696. Aroij-tjetjer S. A.-tjietjer S. = Roureopsis javanica Planch. (Zie No. 648.) 
697. Aroij-tjetjereh S. $=\mathrm{D}$ a 1 b e rgia tam a rindifolia $R \times b$. Nat. fam der P a pilion a c eæ. Gr. Java en Sumatra; slingcrplant.

695. Aroij-tjoekil andjieng $\mathrm{S}$. = D a lbergi a Sissoo R $\mathrm{xb}$. (Zie No. $654 a)$.

699. Aroij-toengkangkang $\mathrm{S} .=\alpha$. S t r ij c h n os c olubrina L. (Zie No. 104.) $=b$. Parsonsia javanica Bl., (Zie No. 604), =c. Chilo c arpus denudatus Bl. (Zie 603b). = d. Coelospermum scandens Bl. Nat. fam. der R u b i a c e æ. Gr. Java, Borneo en N. Guinea; slingerplant. $=e . \mathrm{G} \mathrm{y}$ nop a chys acumin a ta Bl., Nat.fam. als voren. Gr. Java en Sumatra; slingerplant. $=$ Cyrtoceras multifiorum Benn., Nat. fitm. der A s c lepi a dex. Java en Sumatra; slingerplant. $=g$. Cystidianthus campanulatus HI a s s k l., Nat. fam. als voren; Gr. Java ell Sumatra; slingerplant.

700. Aroij-tjoengkangkang beurriet leuwung $\mathrm{S}$. - V Vallar is laxiflo r a B l. (?), Nat. fam. der A p o c yn e $æ$. Gr. Java; slingerplant.

701. Aroij-tjoengkangkang lalakki S. = Chilocarpus suavolens B l. (Zie No. 478.)

702. Aroij-tjoentjoen S. $=\mathrm{Cl}$ e m a$\mathrm{t}$ is Leschenanltiana D.C. (Zie No. 498.)

703. Aroij-jtoektjoek goharit S. = Toddalia micracantha Miq. (Zie No. 487.)

704. Aroij-tjoetjoerian $\mathrm{S} .=\mathrm{Hi} \mathrm{p}$ p o c r a t e a indica L. (Zic No. 485 a.)

705. Aroij-tjullie mëong $\mathrm{S}$. $=\mathrm{Cu}$ beba mollis sima Miq. Nat. fam. der Pipera ceæ. Gr. Java; slingerplant.

706. Aroij-tjumpol kiekies S. = $\Lambda$ nodendrum coria ce um Miq., Nat. fam. der A p o с y e ic. Gr. Java; slingerplant. Gebr. De bladcren worden in stoom gekookt en met zout bij de rijst gegeten.

707. Aroüj-toekoel takkal S. = Croton denticultum Bl., Nat. fam. der En phor bi a c ex. Gr. Java en Timor; slingerplant.

708. Arobj-toekoel takkal mienjak S. $=\mathrm{C}$ o m b retu m W lli chi i D.C., Nat. fam. der Combret a c ex. Gr. Java ; slingerplant.

709. Aroij-walen S. = Phy 11 a n. hera bifida B 1. (Zie 517d.)
\%10. Aroij-wareng S. = C a n thiu m scandens Bl., Nat. fam. der $\mathrm{R}$ u b i a c e $x$. GR. Java; slingerplant. Gebr. De zure vruchten worden gegeten.

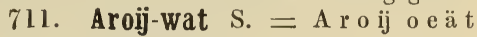
S. (Zie 633 en 634).

712. Aroij-wohwel oetan $\mathrm{S} .=$ Spermacoce hispida I. (Zie No. 452.)

713. Asang-asang Вк. $=1^{\circ}$. D i p t erocarpus Baudiikths, en $=2^{0}$. Dipt. appendiculatus $\mathrm{S}$ cheff., Nat. fam. der D i p ter o c a r pe æ. GR. Sumatra, Bangka; hooge, harsrijke boomen.

714. Aseh Mak. $=\mathrm{Orijza}$ sativa I. (Zie No. 6398.)

715. Aseh-poenoe Мак. $=\mathrm{O} \mathrm{rijz} \mathrm{a}$ glutino sa I o u r. (Zie No. 4282.)

716. Assa Har. $=\mathrm{Evodia}$ latifol i a D.C. (Zie no. 36.)

717. Assaihe-toenie Амв. $=\mathrm{Sm} \mathrm{i}$ lax zeylanica L., Nat. fam. der S milacineæ. Gr. Java en de Molukken; ovcrblijvend. GFBR. De wortel zal in werking aan Sarsaparille gelijk zijn; de inlanders geven de ranken en bladeren uit- en inwendig bij buikloop en windzucht; de jonge bladeren cet men als groente bij wijze van salade; ook de jonge knolachtige wortel wordt soms gegeten.

718. Assam M. $=$ Conyza nitida Zoll., Nat. fam. der Compositæ. Java 5-2000; kleinc heester.

719. Assam-anda LaMP. $=\mathrm{C}$ a $\mathrm{n}$ ari m fissistipulum Miq., Nat. fam. der A m y ide $x$. Gr. Sumatra; hooge boom.

720. Assam besembi Sux. W.K. = Oldenlandi a Teys mannian a $\mathrm{M}$ i q., Nat. fam. der $\mathrm{Rub}$ i a c e Gr. Sumatra; overblijvend.

721. Assam-doekoe IaMp. = Canari um rostrif e rum Mi q., Nat. fam. der A m y rid ex. Gr. Als boven; hooge boom.

722. Assam-dwaja M. of

723. Assam-kiranjie M. $=\mathrm{T}$ a $\mathrm{m}$ -

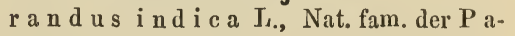
pilioncex. Gr. Door gehcel Indië aangeplant; schcone boom. Gebr. Het hout van den Tamarindeboom is grof en sterk, wordt niet door insceten aangetast en is zeer geschikt voor meubelen; het nut der viuchten en hare pulpa is overbekend.

724. Assam-koembang PaL. $=\mathbf{M}$ a gu if e r a $\mathrm{imilis} \mathrm{Bl.,} \mathrm{Nat.} \mathrm{fam.} \mathrm{der}$ A n a c a r d i c ex. Gr. Java en Sumatra; hooge boom. 
725. Assam-kranjie M. = I $\mathrm{i}$ a $1 \mathrm{i}-$ u $m$ ind um L., Nat. fam. der Pa pili o и a с е $x$. Gr. Java, Samatra, enz.; hooge boom. Grir. Het sterke hout bezigt men voor molens; de bladeren gebruikt men tot het schoonmaken van roestig ijzer; het vruchtmoes (Tamarind-plum) is alleraangenaamst zuur en wordt gaarne gennttigd.

726. Assam-manies $\mathrm{M}$. $=\mathrm{T}$ a $\mathrm{m}$ arind ns indica I. (Zie No. 723).

72\%. Assam-riang $\mathrm{M} .=\mathrm{Diplo}$ clinium areolatum Miq., Nat. fam. der B eg o n i a ce $\propto$. Gr. Java en Sumatra; overblijvend. $=b . \mathrm{P} \mathrm{l}$ a t y e e $\mathrm{n}$ trum robustum Miq (Zie No. 730.)

728. Assam-riang riang aboe Sux. W.K. $=$ Vitis hastata Miq. Nat. fam. der A mpelidex. Gr. Sumatra; slingerplant.

729. Assam-simpai M. = D i p loclinium Hasskarlian um Miq., Nat. fant. der B e g o n i a c e r. Gr. Sumatra ; overblijvend.

730. Assam-tamblloengan J. = Platycentrum robustum Miq., Nat. fam. als voren. GR. Java; overblijvend.

731. Assam-toesoer BK. $=\mathrm{H} \mathrm{i} \mathrm{b} \mathrm{i} \mathrm{s-}$ c us surattcnsis I., Nat. fam. der Malvaceæ. Gr. Bijna oreral in tninen; heester. GFir. De wortel wordt door sommige inlanders op Framboesix ( $\mathrm{P}$ a $t \in \mathrm{k} \mathrm{T}$., Boba M. of $\mathrm{Babintoe} \mathrm{M}$.) aangewend; de zure bladeren ect men als groente.

732. Assam-wollanda $\mathrm{M}$. $=\mathrm{H}$ ibiscns Sabdariffa L., Nat. fam. der M a l v a c e a. Gr. Bijna overal in Indiè. aangekweekt; zaadplant. GEBR. Zij wordt aangeplant om hare zure bladeren en sáprijke zaaddoozen, welke, bij wijze ran zuring, in rele spijzen en voor geleien gebruikt worden; aan den bitteren wortel sehrijft men cen oplossende werking toe.

733. Assam-zeijlon S. \& M. = G a rc in i a C a mbogia Desr., Nat. fam. der Clusia ce æ. GR. Op Java in tuinen, van Ceylon aangevoerd; boom. GFBr. De angenaam zure vruchten worden rauw en in zuur gelegd gegeten; de vruchtschil bevat een onaangenaam riekende, gele hars, die geen guttagom is en ook niet purgeerend werkt.

734. Assar Амв. $=\mathrm{S}$ е s u $\mathrm{v}$ i u m repe n s L., Nat. fam. der P or tu l a c e æ. Gr. Java en de Molıkken; éénjarig. Grebr. Deze plant bevat veel sodazouten; de bladeren worden als groente genuttigd.
735. Assa-wali $\mathrm{C}_{R_{0}}=\mathrm{P}$ ter o c a $\mathrm{r}$ pus flavus I, our., Nat. fam. der Papilionace Gr. De Molnkken; hooge boom. GFBr. Den bitteren bast houdt men voor een tegengif bij vischvergiftiging, en dient men als tonicum bij vele ziekten toe, vooral in- en nitwendig tegen beri-beri.

736. Assem MaMP $=$ A r rtera (?) ma crocarpa $\mathbf{1 1}$ i q., Nat. fam. der S a p ind a cex. Gr. Sumatra; boom.

737. Assior Sum. W.K. $=k x \mathrm{~m}$ p feria Galanga I., Nat. fam. der Zingiberacex. Gr. Door geheel Indie aangeplant; orerblijvend. GEsR. De wartel komt als specerij in vele spijzen; men mengt ze in verschillende mengsels tegen maagaandoeningen en voor kraamvrouwen; hij is nitwendig een goede hnidprikkel bij beenpijnen en inwendige ontstekingen. RUMPHIUs geeft nog aan, dat men er vruchtdrijvende kracht aan toekent, en het sap bij otorrhoea in de ooren wordt gedrnppeld.

728. Assiwoeng radja mantrio $S$. $=\mathrm{T} y \mathrm{pha}$ a gustifolia $\mathrm{I}_{\text {., }}$ Nat. fam. der Ty p h a c ex. Gr. Java, Timor; waterplant. Gerr. Men bezigt de bladeren tot het vlechten van hoeden; de onrijpe vruchtkolven dienen voor lont en met het zaadpluis vult men hoofdknssens.

739. Asso E. $=\mathrm{Hernandia} \mathrm{S}_{0-}$ nora L. (Zie No. 16).

740. Asso-kaloet Aлв. $=A \mathrm{chy}$ $r$ anthes bidentat a B l., Nat. fan. A m a r a $\mathrm{n}$ th a e e $x$. Gr. Java; overblijvend.

741. Asso-telina Амв. = Cy a thul a genicula ta Rxb., Nat. fam. als voren. Gr. Overal in Ned.-Indië; overblijvend. GEBR. Den fijngekneusden wortel dient men toe tegen koortsen en dysenterie, doch hoofdrakelijk tegen betoovering.

742. Asso-telina laun Амв. $=\mathrm{H}_{\mathrm{r}-}$ drocotyle asiatiea I. (Zie No. 70.)

743. Assum S. (Zie No. 718.)

744. Assum-aroij S. $=\mathrm{D}$ a $l$ b e r g i a $\mathrm{t} a \mathrm{~m}$ arindifolia $\mathrm{Bl}$. (Zie No. 697).

745. Atalai $\mathrm{Tr} .=\mathrm{Atal}$ a y a $\mathrm{sa}$ lic if ol i.n B l., Nat. fam. Uer S a p in$\mathrm{d}$ a c e a Gr. Timor; kleine boom.

746. Atang-atang PAL. $=\mathrm{E} l \cong 0-$ c a r p us ubmonoceras Miq., Nat. fam. der Tili a ceæ. Gr. Sumatra; boom.

747. Atie-aijer Sum. $=\mathrm{Nym}$ phæahirta Kiirz., Nat. fam. der Nymphæaceґ GR. Sumatra, Bangka; waterplant. 
748. Atie-atie BK. $=\mathrm{Coleus}$ a tropurpureus Bnth., Nat. fam. der L a b i a $t æ$. Gr. Java, Sumatra, de Molukken. GEBR. De bladcren zijn om hun aromatisehen geur zcer gezoeht, worden tot wering vau insecten tussehen de kleederen gelegd en komen in vele uit- en inwendige genecsmiddelen.

749. Atis T. \& Men. = A n o n a. s q u a mos a L., Nat. fam. der A n on ac e æ. Gr. Overal in Indië gekweekt; kleine boom. GeBr. De vruchten van dezen boom zijn om haar aangenaam, geurig, wit vleesch zeer gezocht; zij zijn zecr gezond, doch lastig om te eten, wegens de vele pitten; de bladeren gebruikt men tegen scabies.

750. Atjoeng $\mathrm{S} .=a . \mathrm{A} \mathrm{morph} \mathrm{o-}$ phallus ea mpanulatus Bl., Nat. fam. der A roide $æ$. GR. Door geheel Indië; overblijvend. Gerr. Met veel zorg krijgt men uit den knol dezer plant een zetmeel dat voor brood gesehikt is. $=b$. Conophallus bulbifer Sehtt. en $c$. C. giganteus Sehtt.; = $d$. Braehyspatha Muelleri Schtt. en $e$. B r. variabilis $\mathrm{Seht}$. alle van de Nat. fam. der A roideæ. GR. Java, Sumatra, enz.; overblijvende planten; alle deze plauten bezitten zeer stinkende blocmen; door den inlander $\mathrm{Ke} \mathrm{m} \mathrm{b}$ a $\mathrm{ng}$ of B o e n g a-b a n g k ej, lijkenbloem, genoemd; zij komen op drassige plaatsen veel voor.

751. Atjoeng-boddas $\mathrm{S} .=\mathrm{Bra}$ chyspatha variabilis Sehtt., var. immaculata Hassk. (Zie vorig nummer.)

752. Atoen-laut M. $=a$. Heritiera lit toralis Dryand., Nat. fam. der Sterculi a ce æ. Gr. Bijna overal in Indië; boom. GkbR. Het hout is vast en duurzaam, vooral geschikt voor scheepsbouw; den bitteren samentrekkenden bast dient men toe bij diarrhoea; de vruehten bezigt men als specerij bij sommige vischgereehten. $=b$. B rown $\mathrm{lon}$ i a a rgentat $\mathrm{ke}$. Nat. fam. der Tilia ce a. Gr. Boeroe; kleine boom.

753. Attehoe $\mathrm{Br}_{0}=\mathbf{J}$ a ger a spee ios a B l., Nat. fam. der S a p indac e æ. Gr. De Molukken; boom.

754. Attihoe-seloe Амв. = Pol у роdi um quercifolium L. (Zie No. 181.)

755. Attoenoe Sum. W.K. $=\mathrm{P}$ a ndanus labyrinthieus Kürz., Nat. fam. der Pandanes. Gr. Sumatra; boom.

756. Aule $\Lambda$ мв $=$ Bambusa verticillata Bl. (Lcleba Rumphiaua
K ü r z, va r.), Nat. fam. der G r a min e æ. GR. Bijna overal in Indië; hooge grassoort. Gebr. Deze bamboe wordt spoedig door inseeten aangetast, en is slechts gesehikt voor omhciningen; het water, dat zich binnen de stengelgeledingen verzamelt, wordt tegen buikaandoeningen gedronken.

757. Aupaloelan Аmв. $=\mathrm{P}$ a v c t a a m b o i n i a (Zie No. 101.)

758. Aupaloelan-mahina Амв. $=$ Cle rodendrum infortunatum L., Nat. fam. der V e r b e n a e e æ. Gr. Java en de Molukken, veelal in tuinien; heester. Gebr. De inlanders maken van de bladeren een veelvuldig gebruik; zij leggen ze nitwendig op wonden en abcessen en geven ze inwendig tegen koorts, vergrooting der milt, diarrhoea en bij slangenbeten.

759. Aupaloelan-poetih Амв. = Pothomorphes ubpeltata Miq. (Zie No. 86.)

760. Aussi-abbal $\mathrm{AmB}_{\text {. }}=\mathrm{C}$ u d ranus amboinensis $R m p h$. , Nat. fam. der Artoe arpe a. Gr. Java, Bima, de Molukken; heester. GEBr. Men gebruikt het hout om kleedingstukken geel of groen te vcrven; het melksap bezigt men als oogwater bij oogaandoeningen; een aftreksel der jonge takken geeft men tegen lendepijn en nierelijden; de bladeren worden rauw bij viseh gegeten

761. Aussi-pipis Амв. = Citrus L imonell us Hassk., Nat. fam. der A u r a n ti a c e $x$. Gr. Bijza overal in Indië aangeplant; boom. Gebr. De bladeren zijn om hunnen aangenamen geur zeer gezoeht in het wasehwater en bij eenige spijzen; de vrucht gebruikt men om te confijten en haar sap als eitroensap.

762. Aussi-woloe Амв. = Citrus $\mathrm{L}$ i m e t t a $R$ i s s o. Nat. fam. en Gr. a!s boven. GeBr. De vruchten zijn om het zure sap voor limonade en in sommigc spijzen zeer gezocht; dit sap is ook zcer gesehikt om goud schoon te wassehen; de vruchtschillen dienen tot confitur.

763. Awakkal S. $=$ Pteroe a pus flavus Lour. (Zie No. 735.)

764. Awar-awar S J. \& BL. = $a$. Fic us septiea $R \mathrm{mph}$., Nat. fam. der A r tocarpe a. Gr. Java, de Molukken; boom. GeBr. Het melksap is zeer giftig en bijtend, daarom gebruikt men dit en de bladeren uitwendig bij hardnekkige huidzickten, als bij herpes, pitiriasis, framboesix, enz. De inlandsehe bannelingen bezorgen zich hiermede ook dikwijls moed- 
willige ontvellingen om zieh daardoor aan den arbeid te onttrekken.

765. Awar-awar $=b$. Fieus al$l$ u $t$ a e e a B l., Nat. fam. als boven. Gr. Java; slingerplant. Geвr. Men druppelt het melksap in de ooren tegen doofheid.

766. Awi S. $=$ Bamboe M. $=\mathrm{B}$ a mbus a Sehreb. Spee. omnes.

767. Awi-apus $\mathrm{S} .=\mathrm{Ba} \mathrm{mbusa}$ Apus Sehlt. (Gigantochloa Apus K r z.), Nat. fam. der G r a m in e ז. Gr. Java; hooge grassoort. Gebr. Deze Bamboe gebruikt men als touwwerk, voor het vleehten van korven, tot het dekken vau huizen, voor besehotten en tot het vastbinden der dakbladen; de jouge uitspruitsels zijn, met vleeseh gekookt, een zeer gezoehte spijs.

768. Awi-atter S. B a mbusa vertieillata Bl. (Zie No. 756.)

769. Awi-bitoeng $\mathrm{S} .=\mathrm{B}$ a m bus a nigro-eiliata Büse. Nat. fam. der Gram ineæ. Gr. Java, Sumatra, de Molukken; zeer hooge grassoort. Gebr. De jonge spruiten van deze Bamboe zijn het meest gezoeht; zij dienen voor groente en worden in het zuur gelegd; het riet is bijzonder sterk, dient voor huisbouw, doch wordt spoedig door insecten aangetast.

770. Awi-el-el $\mathrm{S}$. $=\mathrm{B}$ a mbus a elegantissime Hassk. (Meloc anna elegantis sima Krz.). Nat. fam. der Gramine $x$. GR. Java; zeer hooge grassoort.

77]. Awi-gedeh S. = Gigantoehlo a maxima Kürz. Nat. fam. als voren. Gr. Java; zeer hooge grassoort. GEibr. Men eet de jonge uitspruitsels als groente, het riet dient voor huisbouw, beschotten en vloermatten; enkele geledingen gebruikt men als wateremmers en tot het opvangen van arengsap (Sagneer); het water, binnen de geledingen aanwezig, drinkt men als verkoelend geneesmiddel.

$$
\text { 772. Awi-gombong } \mathrm{S} \text {. }=\text { A.-ge- }
$$
deh $S$.

773. Awi-hauer-gading S. = S e hizostaehyn Durio Rupr., Nat. fam. der G r a mine $x$. Gr. Java, Sumatra; hooge grassoort. Gerr. Men eet de jonge spruiten; het riet dient tot beplanting van borstweringen en tot luisbouw.
774. Awi-hauer-geulies S. = B a mbusa fera Miq. (B. vulgaris W n d l., va r.), Nat. fam. der G r a m in e æ. GR. Vrij algemeen in Indië, zeer hooge grassoort. Gebr. De jouge spruiten zijn als groente zeer gezocht; het sterke riet gebruikt men als voetangels, draag. stokken en huisbouw.

775. Awi-hauer-konneng S. = (Zie No. 773.)

776. Awi-hauer-tjoetjoek S. = (Zie No. 773.)

777. Awi-hiedung $\mathrm{S} .=\mathrm{B}$ a mbusa n i g r a $L$ o d d (?), Nat. fam. der G r am in ex. Gr. Java; hooge grassoort. Gebr. De jonge uitspruitsels worden gegeten; het riet is minder geschikt voor huisbouw, omdat het spoedig door insecten verteerd wordt.

778. Awi-kriesiek $\mathrm{S} .=\mathrm{Seh}$ iz ostaehyum Blumei N. ab. Es., Nat. fam. der Graminex. Gr. Java en Sumatra; zeer hooge grassoort. GeвR. Ook van deze worden de jonge uitspruitsels gegeten; het riet gebruikt men voor stellages, ladders, wateremmers en vloermatten.

779. Awi-majang S. (Zie No. 778.)

780. Awi-tali S. $=\mathrm{B}$ a in bus a vertieillat a B l. (Zie No. 756.)

781. Awi-tamiang S. of

782. Awi-tamman $\mathrm{S}_{\text {. }}=\mathrm{B}$ a in busa vertieillata Bl. (Zie No. 756.)

783. Awi-tjangkorreh $\mathrm{S}$. $=\mathrm{Di}$ naehloa Tjaugkoreh Büse. Nat. fam. der Gra mine æ. Gr. Java; klimmende grassoort. Geвr. De rankeu zijn zeer sterk en geschikt voor bind- en vlechtwerk; het sap bezigt men als wasehwater bij ziekten der oogen, als anderszins; de jonge toppen worden gebraden en als wormdrijvend middel toegediend.

784. Awi-tjoetjoek S. = S e h iz 0staehyum Durio Rupr. (Zie No. 773.)

785. Awi-toetoel $\mathrm{S} .=\mathrm{B}$ a m b u s a fera Miq. variet. (Zie No, 774.)

786. Awi-ülül $\mathrm{S}$. $=\mathrm{B} \mathrm{a} \mathrm{m} \mathrm{b} \mathrm{u} \mathrm{a}$ elegantissima Hassk. (Zie No. 663.)

787. Awi-woeloeng $\mathrm{S}_{.}=\mathrm{Bambusa}$ nigra Lodd (?) (Zie No. 698.) 
785. Baai-ambon Pal. $=\mathrm{C}$ is $\mathrm{s} u \mathrm{~s}$ i n c a rn a t a T. \& B. Nat. fam. der $\mathbf{A}$ mp e li d e æ. Gr. Sumatra; slingerplant.

789. Baaijawie S. of Baijawie S.= A cer la urinum II ssk.; Nat. fam. der A c e r in c ce. Gr. Java; hooge boorn.

790. Ba-a-10 S. = Urostigma b engha len s c G a s p, Nat. fam. der A r t o c a r p e $x$. Gr. Ceylon. West-Java; hooge boom. GEBR. Hij levert ecn soort van gomlak en heeft eetbare vruchten.

791. Babadottan $\mathrm{S} .=$ II y p t i s suaveolens Poit., Nat. fam. der La b i a t:. Gr. Java en de Molukken; éénjarig: een sterk riekend onkruid.

792. Babadottan boddas $\mathrm{S} .=\mathrm{A} n \mathrm{i}$ so meles albiflora Miq., Nat. fam. als voren. Gr. Java; eenjarig; een sterk riekend onkruid.

793. Badadottan-burrum S. $=a$. A nis omeles malabarica R.Br., Nat. fam, der $L$ a b i a $\mathfrak{x}$. Gr. Java; een sterk riekend éénjarig kruid. $=b$. A g eratum conyzoides., caule rubro., Nat. fam. der C o m p o s it $x$. Gr. Bijna ovcral in Indië; éénjarig; zeer lastig onkruid. Gebr. Met de fijn gewreven wortels smeert men zich het lichaam in bij vermocidheid en gavatte koude; de gedroogde wortels trckt men af en drinkt men in plaats van thee; het jonge kruid wordt als groente gegeten.

794. Babadottan heedjoh $\mathrm{S}$. = A geratum conyzoides I., c a u le viri di. (Zie hicrvoren.)

795. Baban Pal. $=\mathrm{P}$ a ri n a r i u m suinatranum Benth., Nat. fam. der Chrysobalanca. Gr. Sumatra; boom.

796. Babaratti BK. = Lasianthus densifolius Miq., Nat. fam. der Rubiacex. Gr. Java en Bangka; heester.

797. Babasaran $\mathrm{S} .=a . \mathrm{M} \circ \mathrm{rus}$ indica L., Nat. fam. der A r t o carpe $x$. GR. Door gehcel Indië wild en gekweekt; kleine boom. GyBr. De Indische Moerbezie wordt om dc bladeren veel aangeplant voor de zijdecultuur; men kent aan de bladeren, dic men als groente eet, cen zogvermeerderende, stcenbrekende cn ontlasting bevorderende kracht toe, om deze laatstc eigenschap gebruikt de bc- volking ze in Indië zeer dikwijls; de flanwe vruchten worden gegeten. $=6$. Cephalotrophis javanica Bl., Nat. fam. als boven. Gr. Java en Timor; heester.

798. Babawangan $\mathrm{S} .=\alpha$. Eu ry. cles javanica M. J. Roemer, Nat. fam. der A mı r y ili d e æ. Gr. Java en Celebes, overblijvend Grik. De bol bezit purgcerende en brakingwekkcude

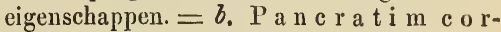
d a u m I. Nat, fam. der vorige. GR. Java; overblijvend. Gsis. Men wendt de bol uitwendig bij koortsen aan.

799. Babawangan-burrum $\mathrm{S}$. = Xyris calocephala Miq., Nat. fam. der X y ri d e $x$. Gr. Java; éénjarig.

800. Babawangan-gedeh S. $=\mathrm{E} \mathbf{r}$ o c a ulon sexangulare L., Nat. fam. der Erocanlon c a. Gr. Java; éénjarig.

801. Babawangan-leutiek S. = Erio c a ulon quinquangulare I. cn b. E. truncat um Hmlt., Nat. fam. en $\mathrm{Gr}$, als voren.

802. Babawangan-trisna $\mathrm{S}$. $=\mathrm{I} \rightsquigarrow$. manthus puniceus Jeq., Nat. fam. der A m a ryllide x. Gr. Overal in tuinen als sierplant; overblijvend.

803. Babie M.\&R. $=\mathrm{H}$ e n slovia paniculata Miq., Nat. fam. der H c n s lov i a c e. Gr. Java, Sumatra, enz.; hooge boom. GeBr. Het hout gebruikt men voor huisbouw; de jonge takjes eet men rauw bij dc rijst.

804. Babie-koeroes Sum. $=\mathrm{E}$ u r yc o m a longifolia J ck., Nat. fam. der S i m a r u b a c e a. Gr. Sumatra, Bangka; boom.

805. Babing J. = Sauropus rhamnoides Bl., Nat. fam. der Euphorb i a c ex. Gr. Java; groote heester. Gribr. Men cet de bladeren en vruchten afgekookt als groente; de bladeren bezigt men uitwendig ook bij hoofdyijn en furunculi. 806. Baboeta $\mathrm{Cr}_{\mathrm{r}}=\mathrm{E} \times \mathrm{c}$ o e c a r i A g allo cha I. (Zic No. 22b.)

80\%. Babon Bu. $=$ Premna $\mathbf{c}$ r y m b o s a Rottl. (Zic No. 395.)

808. Badar-badar Sum. W.K. $=a$. Eurya hirsutula Miq., Nat. fam. der Ternstroemiacex. Gr. Sumatra; 
heester. $=b$. M e li os ma poly ptera N iq., Nat. fam. der M eliosme æ. GR. Sumatra; heester.

809. Badjang-badjang $\mathrm{BL} .=\mathrm{Cb} \mathrm{ry-}$ sopogon a eiculatus Trin., Nat. fam. der $G r$ a mine x. Gr. Overal in Indië; is cen zeer lastig gras, omdat de zaadpluizen en aren zich altijd an de kleederen vasthechten.

810. Badjau-tjina $\mathrm{M}$. = R u elli a re p a n d a (Zie no. 91.)

811. Badjoe-Badjoe M. = Trie h o. lo b u s fulvus Bl., Nat. fam. der Conn a r a c ex. Gr. Sumatra; hooge boom.

812. Badjoele $\mathrm{T}$. $=\mathrm{M}$ e la leuc a L, e u a d e n d ron L. (Zie 120a.)

813. Bado Max. $=\mathrm{S}$ e hle i e hera trijug a Wlld. (Zie No. 47.)

S14. Bado-bado Sum. W.K. = Eurya hirsutula Miq. (Zie No. 808a.)

815. Badoejoet $\mathrm{S}$. $=\mathrm{Tricho}$. santhes villos a Bl. (Zie No. 449.)

816. Badoel S. $=a$. A morphophallus campanulatus Bl. Zie No. $750 a$.) cn $=b$. Conophallu s gigantcus $\mathrm{S}$ e hot t. (Zie 750c.)

817. Badoerie S. \& M. = Colotropis gigantea RBr., Nat. fam. der Asclepiader. Gr. Door geheel Ned. Indië; heester. GEBR. De wortel, rijk aan melksap, was vroeger als $R$ adix $M$ udar Officineel, hij werkt braakwekkend en anticachectisch, zal de Sarsaparille knnnen vervangen en heilzaam zijn bij syphilis en lepra; het laatste is mij nimmer gebleken. Rumphius prijst hem aan tegen stuipen der kinderen en WAITZ bezigde hem voor inspuiting tegen beginnende kanker der baarmoeder. De Javanen gebruiken het melksap op furunkels en tegen kiespijn door caries. De bladeren wenden zij aan op kloven in de voetzolen (sakit blah). Van den bast vlecht men touw. Met het zaadpluis vult men hoofdkussens. De bloemen gebruikt men voor bouquetten en als sicraad in het haar.

818. Badok-bankong $\mathrm{J} .=\mathrm{A} n \mathrm{i}$ s 0 meles ovata RBr., Nat. fam. der Libiatre. Gr. Bijna overal in Indië; is een zeer sterk riekend kruid.

819. Badori $\mathrm{S}$. $=\mathrm{B}$ o e hmeria s cabrella Gaud, Nat. fam. der U r t i c e . Gr. Java, Sumatra; heester.

820. Bagoe R. = Gnetum Gnem on L., Nat. fam. der Gnetaceæ. Gr. Bijna overal in Indië aangeplant; boom. GEBR. De jonge bladeren en vruehten zijn, als een aangename grocnte, overal zeer gezoeht; dc bast levert cen uitmuntende vezclstof, waarvan touw wordt geslagen, dat zeer duurzaam onder water is.

821. Bagoeh-pasir Sum. W.K. = Macroderis polyantha $\mathrm{Miq}$, Nat. fam. der Papilio n a cex. Gr. Sumatra; slingerplant.

822. Bah PaL. = Myristica eortieosa Hook. \& variet (Zie No. 137.)

823. Bahoes BL. of Baus BL. = Oryza sativa L. (semina denud a t a), Nat. fam. der G r a m i n c æ. Gk. l)e rijstplant wordt, met haar menigte verschcidenheden, overal verbouwd. GEBR. Zie later bij $\mathrm{P}$ a di e $\mathrm{M}$.

824. Bahoet Br. $=\mathrm{H}$ op e a selan i c a $R \times b$., Nat. fam. der $D$ ipter oc a $\mathbf{r}$ p е æ. Gr. De Molukken; hooge boom. Gebr. Het hout is zecr geschikt voor timmerhout, de hars gebruikt men voor fakkels en harpuis.

825. Bahoeta Sum. $=\mathrm{T}$ a e e a p a lm a t a Bl., Nat. fam. der T a c c a c e ce. GR. Java, Sumatra, enz.; overblijvend. GF.R. Men gebruikt den wortcl uitwendig cp verwondingen door slangenbeten ell den stengel op de hartkuil mij maagpijnen; het zetmeel wordt hier en daar gegeten.

826. Bai-rawa $M$. $=$ 过 i c e a s majus Grtn. (Zie No. 1556).

827. Bait-djaho LAMP. $=\mathrm{C}$ o mbretum sundaicum Miq., Nat. fam. der C o m b r e t a e e æ. Gr. Sumatra; slingerplant.

828. Baja Mak. $=a$. Mor ind a citrifolia L. Nat. fam. der Rubiac eæ. GR. Door geheel Indië; boom. Gebr. De wortels en vooral de bladeren gcbruikt men voor het rood verven van garens; zij bevatten een groene en ecn roode kleurstof; de jonge bladeren eet men gekookt als groente; ook bezigt men ze uit- en inwendig tot verschillende geneeskundige doeleinden, zooals bij koliek. pijnen, mocielijke urinelozing en vergrooting der milt; de vruehten eet men rijp en onrijp, doch gebruikt ze vooral tot rciniging van het hoofdhaar. $b$. M orinda b racte a ta $\mathrm{R} \times \mathrm{b}$., Nat fam. als voren. GR. Als boven; boom. GEBR. Huishoudelijk en geneeskrachtig hecft deze boom hetzelfdc nut; bovendicn bezigt men het hout nog vecl voor vogelkooien en gectt de vruehten aan kinderen als wormdrijvend middel.

829. Bajaman J. = Hymenodictyon Horsfieldii Miq., Nat fam. der 
R u bi a cex. Gr. Java; hooge boom. GERR. Deze boom bezit een zeer hard hont; de bittere en samentrekkende bast verdient, om zijn verwantschap met de kinasoorten, evenals die van No. 16, een nanwkenrig scheikundig onderzoek.

8:30. Bajang Мак. = In ts i a a mboinensis Thou ars, Nat. fam. der $\mathrm{P}$ a p ili o n a c e $x$. Gr. Java, Bornco, de Molıkken; hooge boom. GFBr. Het hout, ten onrechte ijzerhout genoemd, is een nitmuntend brandhout; het wordt ook wel voor bouwhont gebruikt, doch wordt licht door insecten angetast. $\mathrm{O}_{\mathrm{p}}$ Sumatra worden de zaden geroost gegeten.

8:1. Bajang-bajang Sum. W.K. = Fle urya cordata Ga nd, Nat. fam. der U r ti c a c e $x$. Gr. Java, Sumatra en elders; heester. GEBr. Zie later bij $\mathrm{K}$ e $\mathrm{m}$ a doe $\mathrm{M}$.

832. Bajang-bali J. $=\mathrm{M}$ o ch o sma polystachy um Benth., Nat. fam. der $I_{1}$ a b i a t $x$. GR. loor geheel Indië; een onaangenaam riekend éénjarig kruid. GeBr. Het jonge loof wordt ranw bij de rijst gegeten; de zaden laat men weken in suikerwater en drinkt dit als een verkoelenden drank.

833. Bajar-tohtoh PaL. $=\mathrm{Ur}$ a ri a o b cordat a Miq., Nat fam. der Papilior a ceæ. Gr. Sumatra; slingerplant.

834. Bajeh Sum. $=$ A re c a horrid a G riff., Nat. fam. der $\mathrm{P}$ a $1 \mathrm{~m} x$. Gr. Sumatra, Malakka.

835. Bajem BK. = Ardisiaerispa A. D.C., Nat. fam. der Myrs ine $x$. Gr. Java, Bangka; heester.

836. Bajem M. $=a . \mathrm{Enx} \times \mathrm{lus}$ c a udatus Moq.; $\quad$. Eux. polyga $\mathrm{m} n \mathrm{~s} \mathrm{Moq.;} c$. A maran tus tristi s $\mathrm{L} . ; d$. A m. ole race us L., alle van de Nat. fam. der A m a r a n t a c e $x$. Gr. Bijna overal in Indië; éénjarige planten. GEBR. Het kruid wordt als spinasie gegeteu.

837. Bajem-badoerie M. $=\mathrm{Am}$ arantus spiuosus L., Nat. fam., Gr. en Geir. als voren.

838. Bajem-besaar M. $=\mathrm{Cl}$ a d o staehys frutescens Don. Gr. De Molukken. Nat. fam. en GEBR, als voren. S39. Bajem-betoel $\mathrm{M} .=\mathrm{A}$ m a r a ntus retroflexus Bl. Gr. De Molnkken. Nat. fam. en Geisk. als No. 836.

840. Bajem-biloedoe BAtr. $=\mathrm{C} \mathrm{e-}$ losia eristata M i q. (Zic No. 4i3.) 841. Bajem-doeri .11. (Zie No. 83\%.)
842. Bajem-ejkor-koetjing M. = Celosia cristata Moq. (Zie No. 419.)

843. Bajem-loehoer Bu. $=$ (Zie No. 838.)

84.4. Bajem-meirah $\mathrm{M} .=\mathrm{A} \mathrm{m}$ arantns melancholicus Moq., Nat. fam. Gr. en Gerr. als No. 836.

84.5. Bajem-monjet $\mathbf{M} .=\alpha . A \mathrm{~m}$ arantus spinos us I. (Zie No. 837.) $=b$. Euxolus polystachys M iq. en $=r$. $s$ nx. viridis $M$ iq. Nat. fam. als vorell. Gr. Java; éénjarig. Gebr. als No. 836.

846. Bajem-oetan $M .=A$ m a r a ntus spinosus L. (Zie No. 837.)

847. Babem-pohon M. $=\mathrm{Cl}$ a d o st a chys frutescens i) on. (Zie No. 838.)

848. Bajem-sajor M. $=\mathrm{A}$ m a r a nt us olerace us L. (Zie No. $836 d$.)

849. Bajem-salassie $\mathrm{S}$. \& $\mathrm{M}$. = A marantus paniculatus L, Nat. fam. als voren. Gr. Door geheel Indië. GEBR. Het krnid is als groente zeer gezocht.

850. Bajem-toer J. $=\mathrm{Ch}$ e n o podium filic if oli u m $\mathrm{S}$ m.. Nat. fam. der $\mathrm{Ch}$ e n o p od e æ. Gr. Java; éénjarig.

851. Baijnan MaK. $=A$ ver $r$ ho a $\mathrm{C}$ a r a m bo I a J. $_{\text {, Nat. fam. der } \mathrm{O} \times \text { a- }}$ li d e æ. Gr. Door geheel Indië gekweekt; kleine boom. Grbr. De aangename, saprijkc vruehten zijn zeer gezocht; haar sap gebruikt men tot het polijsten van ijzer en tegen vlekken op de cornea.

852. Baijnan-saiijang MaK. = Cynometra cauliflora L. (Zie No. 5209.)

853. Baijnan-tiada Maк. $=\Lambda$ v e $\mathrm{r}$ rho a Bilimbi l., Nat. fam. en Gr. als voren. GEBR. De zeer seherpzure vinehten gebruikt men in vele spijzen of eet ze ingelegd; een marmelade dezer vruehten prijst men aan als zeer heilzaam bij sehenrbuik en galachtige ongesteldheid; het sap der vruchten gebrnikt men in de huishouding gewoonlijk om roest- en inktvlekken nit het linnengoed te verwijderen.

854. Baijn-djawa T. $-\mathrm{T}$ he s pesia macrophylla B l., Nat. fan. der Malvace a. Gr. Java en de Molukken; kleine boom. GeBr. Het hart van het hont is zeer gezocht voor geweerladen en fijne doosjes; de jonge bladeren eet men als groente; het hout geeft men tegen koorts, kolijk, enz. 
855. Baijngiri $\mathrm{Bt}$. = Urostigma nitidum Miq., Nat. fam. der Artoe a rpece. Gr. Java en Bali; een fraaie soort van Waringiuboom.

856. Bajoe $J .=\mathrm{Nipa}$ fruticans IV urmb., Nat. fam. der Paud a u ex. Gr. In geheel Indië wild en aaugeplant; kleine boom. Gerr. Men gebruikt de bladeren tot dekking van huizen en tot allerlei vleehtwerk; de vruehten worden rauw en geeonfijt gegeten; uit de bloemkolven tapt mell een slechte soort van palmwijn.

857. Bajoer S, J.\& M. $=a$. A e er la urinum Hassk. (Zie No. 789) $=b$. Pterosperm nm Blumeanum Krths. eu $=c$. Pt. snberifolium Lam., Nat. fam. der Büttueriaeer. Gr. Java; Sumatra, enz.; hooge boomein. GEBr. Beide deze boomen leveren ecu wit en sterk bouwhout, voor huisbouw zeer gesehikt, dat door inseeten niet wordt aangetast; $=d$. Engelhardtia serrata Bl., Nat. fam. der Juglandex. Gr. Java; hooge boom. GeBR, Men bezigt het hout voor huisbouw; het wordt echter spoedig door inseeten aangetast.

858. Bajoer-akar PaL. $=\mathrm{C}_{\text {a n- }}$ thiu glomerulatum Miq., Nat. fam. der Rnbiacex. Gr. Sumatra; boom.

S59. Bajondo $J .=E$ Ehinoehloa colon um Bïse, Nat. fam. der Gramineæ. Gr. Op Java, enz. in het veld en verbouwd. GEBR. Dit gras is een zeer gesehikt veevoeder.

860. Bakar Мak. = Artocarpus i ue is a L., var. b. lie vis. (Zie No. 269.)

S61. Bakattak S. $=$ Chaviea Blumei Miq. (Zie No. 544.)

862. Bakauw Вк. (Zie No. S66.)

S63. Bakauw-ketjil Bк, en

864. Bakauw-tingi $\mathrm{BK}$. $=\mathrm{C}$ e ri ops Caudoll eau a Arn., Nat. fain. der Khizophorex. Gr. Bangka; heester.

865. Bakkor M. $=\mathrm{Rhizophora}$ eonjugata L. . Nat. fam. der Rhizophorer. Gr. Algemeen aan de stranden; boom. Gerr. Men bezigt het hout voor daksparren en den bast tot het rood- en bruinverven van vischnetten, enz.

866. Bako of Bakoh S. \& J. =a. Rhizophora conjugata $\mathbf{l}$. (Zie vorig No.) $=b$. Bruguiera Rumphii Bl., Nat. fam., Gr. en Gebr. als voren. $=c$. Sonneratia a eida L. fil., Nat. fam. der Myrtaeex. Gr. Door geheel Indië; hooge boom. GEBR. Men gebruikt het hout in plaats van kurk, vooral voor de visehnetten, de bladeren en vruehteu worden, rauw en gekookt, bij viseh genuttigd. - Sonneratia alba Sm., Nat. fam. en Gr. als $c$. Gerr. Het hout wordt bij seheepsbonw gebezigd voor ribben en kromhonten; de bladeren en vruchten worden gegeten, eveuals die vau de vorige soort.

867. Bako S. = Nieotiana Tabae u un I., Nat. fam. der Solana cex. Gu. Bijna overal gekweekt; zaaiplant. GrBr. Het unt der 'T'abaksplant is te overbekend om het hier te omschrijven.

868. Bako-katjang $J .=R$ hizophora mueronata Lan., Nat. fam. der Rhizophorex. Gr. Overal in Indië aan de stranden; boom. GeBR. De stam levert goed braudhout; de vruehten kunnen gegeten worden.

869. Bakoeng S. \& $\mathrm{M} .=\alpha$. Crinum asiatieum L., Nat. fan. der A maryllideæ. Gr. Door geheel Indië; overblijvend. GEBR. De wortel is een zeer geschikt en aanbevelenswaardig braakmiddel ; de inlanders geven dien inwendig tegen piịlvergift, bij visch- en inseetenvergiftiging; uitwendig bij kloven eu abeessen der voetzolen (Sakit blah dan boebo el.) Als sierplant is zij in vele tuinen. $=b$. Crinum bankanum Kürz, Nat. fam. als boven. Gr. Bangka; overblijvend. $=c$. Paneratium zeylanicum L., Nat. fam. als voren. Gr. Java en de Molukken; overblijvend. Gér. De bol beschouwt men als zeer giftig; de inlander drnppelt haar sap in de coren tegen doofheid; ook deze komt als sierplant in vele tnintn voor.

870. Bakoeng-ajer M. $=a$. Chamaeladon angustifolium Sehott, Nat. fam. der Aroidex. Gr. Bangka; overblijvend. $=b$. Susum anthelminthieum Bl., Nat. fam. der Xerotidex Gr. Java, Sumatra, Bangka; waterplant. GEBR. Deze plant bezit wormdrijveude eigeusehappen.

871. Bakoh PaL. $=$ Canthium glomerulatnm Miq., Nat. fam. der Rubia e es. Gr. Sumatra; boom.

872. Bakoh Sum. W.K. $=$ Rhizophora conjugata L. (Zie No. 865.)

873. Bakok-detina Sum. W, K. $=\mathrm{R}$ h izophora latifolia Miq. (Zie No. 247.)

874. Balabi BD. = Premna corymbosa Rottl. (Zie No. 395.)

875. Balakama Mkx. $=0$ e i m u m 
sanctum L., Nat. fam. der I,abiatæ. Gr. Bijna overal in tuineu. Gerr. J)it kruid is, om den aangeramen geur, zeer gezocht; wordt als spcerij bij vele spijzen geroegd en als zweetdrijvend middel geroeind.

876. Balak-balak

877. Balak-balak-goenoeng Вк. = Quersus turbinata Bl. (Zie No. 310 s.)

878. Balakkatoa $\mathrm{S}$. = Z i n g i b e $r$ Cas il m u n a r R x b, Nat. fam. der Z i n g i b e ra e ae. Gr. Overal in Indië, wild en gekweekt: overblijvend. Grir. 1)e wortel dezer plant was vroeger als athereo-oleosum officineel; de inlanders bezigen dien als uit- en inwendig geneesmiddel, vooral bij kraamvrouwer. $=b$. Zi ngiber aquosum Bl., Nat. fam. als voren. Gr. Java; overblijvend.

879. Balam $M$. of Balem $M$. = Bassia Balem Miq, Nat. fam. der Sapotacex. Gr. Sumatra's O. Kinst; hooge boom. Geir. l)eze boom levert een mindere soort van gutta percha op.

850. Balam-boedjoe M. - Nothoenestis surnatrana Miq., -Nat. fam. ler Con narace. Gr. Sumatra's 0 . Kinst; boom.

881. Balam-boenga-tjinoh $\mathrm{M}$. = Bassia hypoleuea Miq., Nat. fam. der Sapotaeer. Gr. Sumatra W.Kust; hooge boom.

882. Balam-dadi $M .=$ Tabernamontana (?) ovalis Miq., Nat. fam. der A poeynea. Gr. Sumatra's IV. Kust; heester.

883. Balam-kalia-mangong Pa y na sumatrana Miq., Nat. fam. der Sa potaeer. Gr. Sumatra's O. Kust; boom.

854. Balem-palapa Sum. W. K. M. = Kibara eoreacea Endl., Nat. farn. der Monimiaecae. Gr. Java, Sumatra, Celebes; kooge boom. GẺr. De bladeren van dezen boom worden rauw tegen hoest gegeten.

855. Balam pelampar M. Sum. = M y ristie a l crigata Bl., Nat. fam. Jer My ristie ae. Gr. Java, Sumatra, A inboina; boom.

886. Balem-pelapah M., Sum. = Casearia gollocarpa Miq, Nat. fam. der Sa my dea. Gr. Sumatra; boon.

887. Balam-pelapalı $M$. = $\mathrm{kp} \mathrm{i-}$ eliaris maeroearpa Miq, Nat. fam. der Meliae ex. Gr. Suınatra's IV. Kust; boom.
888. Balam-pelapan Sum W. K. = M y ristiea subglobosa Miq., Nat. fam. der M y r isti e e a. Gr. Sumitra; boom.

889. Balam-pientieg-kajoe $\mathrm{Scm}$. Persea sum atran a ' $\mathrm{r}$. \& 13 , , Nat. fam. der I, a n rinea. Gr. Sumatra; boom.

890. Balam-tambaga Sum. = I s on a ndragutta Hassk., Nat. fam. der S a pot a e ex. Gr. Sumatra, Borneo; hooge boom. GEBR. Deze boom levert hooldzakelijk de Gutta-Pereha van den handel.

891. Balam-tandjoeng M. (Zie No. 893.)

892. Balam-tandoek Sum. = Ceratophorus Leerii Hassk., Nat. fam. als voren, Gr. Sumatra; hooge boon. GEBr. Onk deze boom levert Gutta Ferelia.

893. Balam-tjabeh $\mathrm{M}$. = C e r a t ophorus Leerii Hassk. (Zie No. 39?.)

894. Balam-tjina $\mathrm{M} .=\mathrm{S}$ i d e $\mathrm{ro-}$ xy lon a t te n nat $n \mathrm{~m}$ D.C., Nat fam. der S a potace a. Gr. Sumatra, Java, GEBr. Jeze boom levert een soort vall ijzerhout, zeer gesehikt voor huisbouw.

895. Balam-widoe Sun. W.K. = Carallia confinis B l., Nat. fam. der L e g n o t i e a. Gr. Java, Sumatra en Borneo; boom.

896. Balang-kian $\mathbf{M} .=\mathrm{G}$ lo b b apan ieoides Miq., Nat. fam. der Z i n g i b e r a e e $x$. Gr. Sumatra's Westknst; overblijvend.

897. Balang-kian-gedang $\mathbf{M}$. = G lo b a patens Mi q., Nat. fam. als voren. Gr. Sumatra's Westkust; overblijvend.

898. Balángeran Bo. Z.O. = $\mathrm{Ho}_{0}$ pea $\mathrm{B}$ a langeran $\mathrm{Kr}$ ths, Nat. fam. der Dipteroe arpea. Gr. Borneo; hooge boom. GEBr. Deze boom levert een zeer goed timmerhout en een hars, die in den handel $\mathrm{Njat}$ in g-m a h a mo n g genoemd wordt.

899. Balatoeng $M$ AK. $=$ Nephelin m lappaceum I. (Zie No. 6937)

900. Bale-hadap Вк. = Mussä̈nd a $r$ u fi ll ervis M iq., Nat. fam. der R n b i а e $x$. Gr. Sumatra, Bangka; slingerplant.

901. Baleh-angin $S .=$ Rottlera alba $R \times$ b., Nat. f́m. der Euplorbiae ex. Gr. Java, Sumatra; boom. Grв Het hout is gesehikt voor timmerhout 902. Baleh-balehang sum. = Siy. 
locory na dimorphophylla T. \& B., Nat. fam. der li ubi a e ex. Gk. Sumatra; boom.

903. Baletoetan M. = II o melane ma rubeseens Kunth, Nat. fam. der A roidex. Gr. Java en de Molukken; overblijrend. GEBr. Den stam, de stengels en bladeren gebruikt men in afkooksels uitwendig tegen vermoeidheid der lerdematen.

904. Baliego S. of Balieko S. $=a$. Benincasa cerifera Savi, Nat. fan. der $\mathrm{C}$ n e u r b it a c ex. Gr. Bijna overal in Ned. Indië; slingerplant. GEBR. De jonge vruchten worden gekookt als groente gegeten ook iu suiker geconfijt; het sap nit den stengel en de vruehten bezigt de inlander dikwijls op wonden als verkoelend middel. $=b$. C u c u $\mathrm{rb}$ it a villos a Bl., Nat. fam. als voren. Gr. Op Java gekweekt; slingerplant. GEßв. Men eet de vrueht als groente en geconfijt. = $c$. $\mathrm{Cu}$ e u r b it a pepo I, ; Nat. fam. als voren. Gr. Hier cn daar in tuinen; slingerplant. GEBR. De vrucht is de ook in Europa bckende Pompocn.

90う. Baliek-angien $\mathrm{B \kappa}$. $=\mathrm{Quer-}$ cus Benettii Miq. (Zie No. 1435).

906. Baliek-angien $\mathrm{S}_{.}=a$. Rott lera alba $R \times b$. (Zie No. 901.) $=$ b. Rottlera fcrrugluca Roxb., Nat. fam. der Euphorbiaeex. Gr. De Sundaarchipel; boom.

907. Baliek-angien-boddas S. = Rot tle ra Z ip peli i H as k., Nat. fam als voren. Gr. Java; kleine boom en

908. Baliek-angien-burrum $\mathrm{S}$. = Rottlera panienlata A. Juss, Nat. fam. en Gr. als voren. GEBr. Van het hout vervaardigt men buffelschcllen, windmolentjes en kano's, die goed blijven zoo lang zij te water zijn; den bast van beide gebruikt men tot het beschieten van hutten en rijsthokken.

909. Baliek-soempa S. $=\alpha$. Aralia javaniea Miq. en $b$. Ar. montana Bl., Nat. fan. der Araliaeex. Gr. Java; heesters GeBr. Het sap uit dc jonge takkcu van den laatstgenoemden heester wendt men aan als oogwater. = $c$. Wis a d ula zeylaniea Medik., Nat. fam. der M a lva ce e. Gr. Java; éénjarig.

910. Balintette $\mathrm{BI} .=\mathrm{I} \mathrm{pom} \times \mathrm{m}$ pelt a ta Chois. (Zie No. 303r).

.911. Balis-bukkol Mak. = Z iz y- phus J njuba I, am., Nat. fam, der If ha m in e a Gr. I)oor geheel Indië; boom. Gebr. De mortel en bast zijn bit. ter en worden, om de tonische eigenschappen, als geneesmiddel aangewend; de stam levert ecn sterk bonwhout; op de takken wordt soms gomlak gevonden; de flanwe vruehten worden door relen gegeten; zij warcn vroeger officinecl cul in gebruik bij borstaandocningen.

912. Balla-balla M. = Mou ochoria vaginalis Prsl., Nat. fam. der Pontederiacex. Gr. Java, Timor en de Molukken; waterplant. Gr.BR. I)en wortel, met suikcr gekookt, geeft men tegen lever- en maagaandoeningen; tot poeder gestampt en met suiker gemengd, prij-t men hem aan tegen asthma, ook kanit men hem bij tandpijnen; de jonge bladeren eet men als groente; een aftreksel van het kruid geeft meu tegen galkoortsen.

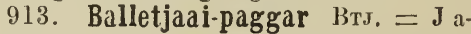
troph a $\mathrm{Cureas} L$, Nat. fam. der Euphorbiacex. Gr. Algemeen in Indië voor omheinirgen; hecster. Gebr. Deze plant is bijzonder rijk aan melksap, dic zeer zuirerend en wondheelend schijnt te zijn, cu daarom veel op wonden, vooral bij paarden aangewerd wordt; de Javanen maken er zich de tanden mede zwart. De bladeren bezigt men als roodmakend en als verdeelend middel op gezwellen. De zaden waren vroeger in de apotheken; zij werken stcrk drastiseh purgcerend en braakwekkend; zij bezitten een vette olie "Oleum infernale", die sterk purgeerend werkt; op Java wordt zij als lampolie cn ook tot het roodverven van garens getruikt. De zaden bevatten "acidum jatrophicum." I)c zaden en olic geeft men inwcudig bij waterzueht en uitwendig bij wormziekte.

914. Ballo $M_{\text {AK. }}=A$ re ng a s a ec h a rif cra $L_{a}$ a b. (Zie No. 243.)

915. Baloen-anjoek $\mathrm{S}$. = Polyalthia subeordata Bl., Nat. fam. der Anonacex. Gr. Java; boom. Gebr. Men gebruikt het hout voor huisbonw; de vruchten weudt men aan tegen colica spastica.

916. Baloen-injoek S. =a. Dy soxylum longifolium Bl., en b. Chisocheton patens Bl., beide van de Nat. fam. der Meliacex. Gr. Java; middelmatige boomen. GeBR. Het hout van bcide bezigt men als bonwhout.

917. Baloen-injoek-hiedung $\mathrm{S}$. = Chisoehcton divergens Bl. Nat. fam. als vorell. Gr. Java; boom. 
918. Baloengboeng $\mathrm{S} .=\mathrm{B}$ a $\mathrm{r}-$ riugtonia excelsa Bl., Nat. fam. der Mivitaceæ Gr. De Sunda-eilanden; boom. GELR. Het hout is een zeer goed bouwhout.

919. Baloeng-kajoe M. = G alea $\mathrm{r}$ a sessifis Z. \& M ; Nat. fanı. der Antidesmeæ. Gr. Java; heester.

920. Baloer MaL. $=J$ as minum $\mathrm{S} a \mathrm{mb}$ ac Ait., Nat. fam. der $J$ as in in eæ. Gr. Door geheel Indië aangekweekt on hare geurige bloemen; heestcr. GEBR. Deze bloemen zijn een algemeen gezocht schoouheidsmiddel; men gebruikt ze om den geur om het hoofdhaar, tusschen kleederen eil op de slaapplaatsen; men bereidt cr cen aromatiseh water en een vluchtige olie uit, die als Oleum rosarum gebruikt wordt; een aftreksel der bloemen wendt men als oogwater, bij lichte ongortstekingen van kinderen, aan.

921. Baloestroe M. $=a . \mathrm{Luffa}$ foetida Cav. (Zie No. 465) eu b. L u ffa petola Ser (Zie No. 685a).

922. Balong-balong $\mathrm{S}$. $=\mathrm{V}$ isc u m artieulat u m B urm. (Zie No. $350 e$ ).

923. Bama. Maк. \& T. $=$ Plumbago rosea L. (Zie No. 114.) $=b$. Enhalus Koenigii Rich, Nat. fem der Hydrocharideæ. Gr. Overal in de Indische Zee; waterplant. Gebr. Vau de bladvezels vervaardigt men vischnetten; de vruchten worden rauw, gekookt en gebraden gegeten.

924. Bambaloo BG. $=$ Ent a d a P u r sæth a D.C. (Zie No. 482).

925. Bambam BK. = Dipterocarpus lampongus Seheff., Nat fam. der Dipterocarpex. Gr. Sumatra, Bangka; hooge boom.

226. Bambang S. \& $\mathrm{M}$. = $\mathrm{Ma-}$ ra nta diehoto m a Wall, Nat. fam. der Caunacea. GR. Java en de Molukken; overblijvend. GEBr. Men bezigt de bladeren tot het inpakken vall groenten en kleinigheden; uit den stam klopt men vezeldraden, die voor allerlei vlecht- en bindwerk dienen; van de jonge spruiten vlecht men korven.

927. Bambang.boerong Sum. = М a$r$ a $n$ t a grandis $M$ iq., Nat. fant. als voren Gk. Sumatra's O.Kust, overblijvend.

928. Bamboe $11 .=A w \mathrm{i}$ S. (Zie No. 766 en volgende).

929. Bamboe-ampel BAT. $=\mathrm{B}$ a m. b ils a fera Miq (Zic No. 774).

930. Bamboe-andong $\mathrm{M}$. = $\mathrm{B}$ a $\mathrm{m}$ - busa vertieill ata Bl. (Zie No, 556$)^{\circ}$

931. Bamboe-andor $\mathrm{M}$. $=\mathrm{Den}-$ drocalamus strictus Nees, Nat. fam. der Gra min e æ. Gr. Java; hooge grassoort.

932. Bamboe-apoes $\mathrm{I}_{1}=\mathrm{B}$ a mbus a $\Lambda$ p us Sehlt. (Zie No. 767).

933. Bamboe atter $\mathrm{M}$. = B a mbusa vertieillata Bl. (Zie No. 756).

934. Bamboe-bitoeng M. $=a$. B a m b us a nigro-ciliata Büse. (Zie No. 769$)$. $=b$. Bambusa aspera $R \&$ S. Gigantochloa aspera $\mathrm{K}$ ürz), Nat. fam. der Gramineæ Gr. Java, Bali en de Molukken; zeer hooge rietsoort. GEBR. De jonge uitspruitsels worden als groente en ingelegd gegeten; het riet is zeer geschikt voor huisbouw; voor masten op kleine prauwen en voor watervaten.

935. Bamboe-boeloe akar M. = Melocanna gracilis Kürz, Nat. fam. der Gr a m in e æ. Gr. Java; hooge rietsoort.

936. Bamboe-boeloe koening. M. = Melocanna braehyelada Kürz, v a r. l u te a, Nat. fam. als voren. Gr. Java; hooge rietsoort.

937. Bamboe-boeloe hiedjoe M. = M eloeanua brachyelada Kürz, var. $v$ iridis. Nat. fam. en $G_{R}$. als voren. GEBR. No. 935 tot 937 worden gebruikt voor omheiningen.

938. Bamboe-djawa $\mathrm{M}$. = B a mb us a v u Igaris Wndl, Nat. fam der Gra m in e $x$. Gr. Java, de Molukken; zeer hooge rietsoort. Gebr. De jonge spruiten zijn gezocht als groente en om in het zuur te leggen; het riet is duurzaam, wanneer het niet aan regen is b!ootgesteld; men gebruikt het voor watervaten, tot het opvangen der Sagueer, voor zitbanken, omwandingen en deurstijlen. Aan een aftreksel van den bast kennen de inlanders eene bloedverdunnende kraeht toe, en geven dit bij knenzingen, aan kraamvronwen, euz.

939. Bamboe-duerle $\mathrm{M} .=\mathrm{Seh} \mathrm{i}$. zostaehyu Durio Rupr. (Zie No. 773$)$.

940. Bamboe-el-el M. $=\mathrm{B} \mathrm{a} \mathrm{m-}$ b us a elegan $\mathrm{t}$ is sema Il assk. (Zie No. 770).

941. Bamboe gading $\mathrm{M} .=$ (Zie No. 939).

942. Bamboe hauer geulies $S$. $=8$ a ub us a v llgaris Wend $l$. (Zie No. 939). 
943. Bamboe-hauer-konneng $\mathrm{S} .=$ B a mbusa vulgaris Weudl, vur. l u tea.

9:4. Bamboe-hauer-seh-hah S. = b a in b u s a vulgaris Wendl., var. t r e m u 1 a.

945. Bamboe-iraton J. $=a \cdot \mathrm{Schi}$ zostachium 1) urio Rupr. (Zie No. 773$)$. $=6$. Neloeanua tenuispic ulata k ürz, Nat fan. der Gram i n e a $x$ Gr. Jara; hooge grassoort.

946. Bamboe-itam M. = G ig a $11-$ tochloa Atter Kürz., Nat. fam. der Graminese. Gr. Jara; hooge rietsoort. GEBir. 1)e jonge spruiten worden gegeten; het riet gebruikt men bij huisbonw, doch wordt zeer spoedig door iuseeten verteerd.

947. Bamboe-kriesiek M. $=\mathrm{Schi}$ zostachyum Blumei N. ab Es. (Zie No. 778.)

948. Bamboe-lengka $M .=a$. (Zie No. $8(6) ;=b$. Ba m b u a nigruciliat a B üse. (Zie No. 769.)

949. Bamboe-majang $\mathrm{M}$. = (Zie No. 947).

950. Bamboe-oelar $\mathrm{M} .=\mathrm{M}$ eloc a $u n$ a serpentina $K \ddot{u} r z$. Nat. fam. der Graminex. Gr. Java; hooge rietsoort.

951. Bamboe-siriot-koeda $\mathrm{M}$. = M elocau ua Zollingerii K ürz. Nat. fam. der G r a m i n ex. Gr. Java; hooge rietsoort.

9ว2. Bambo8-talio $M .=B$ a $\mathrm{m}-$ b us a $A$ p us Sehll (Zie No. 767).

953. Bamboe-tamiang $\mathrm{M} .=\mathrm{Me}$ l o e a n n a B l u m e i K ürz., Nat. fam. Gr. en Grbr. (Zie No. 756 )

954. Bamboe-tjina M. = A ru $\mathrm{n}-$ dinaria glauceseens Beauv., Nat. fam, der Gramineæ Gr. Op Java en elders in tuincu, uit China en Japan overgebracht; fraaie en fijne rietsoort.

955. Bamboe-tjina-aloes $\mathrm{M}$. = I sehurochloa floribunda büse, Nat. fam. der Gram ineæ. Gr. Op Java in tuinen, uit Japan overgebraeht; fijue rietsoort.

956. Bamboe-toetoel $\mathrm{M}$. = $\mathrm{Ba} \mathrm{m-}$ bus a vulgaris Wendl., var. mac a $l$ a t a. (Zie No. 938.)

957. Bamboe-woelong S. \& $\mathrm{I}$. $=$ Gigaritochloa robusta K ii rz, Nat fam. der G r a m i n e e. Gr. Java, hooge rietsoort GEisr. Als No. 946.

958. Bamboelan-poejang $\mathrm{S}=\mathrm{Pa}$ - vetta subvelutina Miq., Nat. fam. der R ubiaecæ. Gr. Jara; heester.

959. Bana Bu. = S milax zeylan i e a I, (Zie No. 717.)

960. Bana Sus. W.K. = Tala a ma g i gantifolia Miq., Nat. fam. der II a g u ol i a e ex. Gr. Sumatra; hooge boom

961. Banar Sun. W.K. $=$ D i oseorea Zollingeriana $\mathrm{K} u \mathrm{nth}$, Nat. fam. der D i o s e oreæ: Gr. Sumatra, Java; slingerplant.

962. Bandiel $\mathrm{J},=\mathrm{Z} \mathrm{iz} \mathrm{yph} u \mathrm{~s}$ O enopolia Miq, Nat. fam. der R h a m n e a. Gr. Java; groote heester.

963. Bandira O.-I. = Urostigma R u mphi i M iq., (Zie No. 103.)

964. Bandjoh-poetih Sum. W.K. = Ewyekia tuberculata Bl., Nat. fam. der M e la st o m a e c a Gr. Suinatra, Borneo, de Molukken; boom.

965. Bangian J. = Gmelina villosa lixb, Nat. faun. der Verbenaceæ. Gı. Java, Sumatra, Cclebes; kleine boom. GeBr. Men wendt den wortel aan als tegengif bij vergiftigingen, en kent er ook een koortsdrijvende kracht aau toe.

966. Bangian-lalakki $\mathrm{Nl}$. = Se olopia rhinanthera Benn, Nat. fam. der B ix a c e $x$. Ga Jara; boom.

967. Bangka Sur. W.K. = Ploi arium (?) oblongifolium Miq., Nat. fam. der Camelliaeer. Gr. Sumatra; boom.

968. Bangka J. = H crin a n di a S o ll o r a L. (Zie No. 16.)

969. Bangkal R. = Nauclea parvifolia Rxb, Nat. fam. der Rubiacex. Gr. Java, de Molukken; hooge boom. GEBr. Het kastanjebruine hout is fijn van draad; doel niet bestand tegen vochtigheid; men draait er doosjes en andere lutishoudelijke kleinigheden van. De bast wordt, als bitter-tonisch middel, veelvuldig aangewend tegen tusschenpozende koortsen en hare gevolgziekten, bij diarrhote, spruw, enz.

970. Bangkiraij S. \& BK. = L ic uala p u mila $k$ nw., Nat. fam. der P a l mæ. Gr De Sunda eilauden; lage palın. Gebr. Van den stam ran dezeu palm maakt men wandelstokkeu.

971. Bangko J. \& BL. = R hi iz ophora mucronata Lam. (Zie No. 868).

972. Bangkoeang $\mathrm{M} .=a$. I pomœr mammosa Chois, Nat. fam. der Convolvulaeer. Gr. Bali, de Moluk- 
ker, gekweekt; slingerplant. GEвk. Men kweekt deze plant aan om de wortelknollen, welke veel worden gegeten en de zogafscheiding sterk zullen bevorderen; uit den bast der stengels vervaardigt men een fijn katoen, dat bijzonder koel is. = b. Paehyrrizus angulatus Rieh. Nat. fam. der Papilion a e $\alpha$. Gr. Oreral in Indië gekweekt; kleine heester. Grbr. Men eet de dikke wortelknol rauw en gekookt.

973. Bangkoeang-wollanda M. = I pomoa sidæfolia $\mathrm{Cho}$ is Nat. fam. der Convolvulacex. Gr. Java in tui. nen, uit Mexieo overgebraeht: slingerplant. GEBR. Zij wordt gekweekt wegens de eetbare knollen.

974. Bangkoedoe $\mathrm{M}=a$. $\mathrm{M}$ orinda umbellata L. (Zie No. 516) en $=b$. Morinda citrifolia I (Zie No. 828a.)

975. Bangkoedoe-badak $\mathrm{S}$. $=\mathbf{F}$ agraa volubilis Wall, Nat. fam der Logania e æ GR. Door geheel Indië; klimmende heester.

976. Bangkoedoe-dawon besaar N. $=$ Morinda eitrifolia L. (Zie No. $828 a)$.

977. Bangkoedoe-laki laki M. Mo. rinda bracteata $R \times$ b. (Zic No. $8286)$.

978. Bangkoedoe oetan $\mathrm{M}$. $=\mathrm{Fa}$ gra volubilis Wall. (Zie No 975.).

979. Bangkono I. $=\mathrm{P}$ a n d a n ophyllum palustre Hsskl. (Zie No. $2770 a$ )

980. Banglaai M. \& J. = Zingiber Cassumanar Rxb. (Zie No. $878 a$ ).

981. BangIaai lalakki M. = A lpinia malaecensis Rose. (Zie No. $392)$.

982. Bangô SANG. = Cocos nueifera L. ('Zie No. 393).

983. Bangoeng $\mathrm{J} .=a$. B arring tonia racemosa Bl. en b. B. acutangula Grtn., Nat. fam. der Myr. ta e ex, Gr. Java, enz, ; boomen. GEвR. Aan den wortel der eersten kent men een koortswerende kraeht toe.

984. Bangon-bangon $\mathbf{M}=$ Coleus amboinicus Lour. (Zie No. 69.)

985. Bangon-bangon-nabara AMr. = Celosia Cristata Miq. (Zie No. 419.)

986. Banitan PaL. $=a$. Guat. teria I'eysmannii Miq. Nat. fam. dex A non a ce $\propto$. Gr. Sumatra; boom. $=b$.
Mouoeeros(?) palembauir: um Miq., Nat. fam. der Tiliaceæ. GR. Sumatra; hooge boom.

987. Bonitan-poegoe PAL. $=U_{n}$ ona dasymaschala Bl. (Zie No. 574.)

988. Banit-itam $\mathrm{BK} .=\mathrm{C}_{\mathrm{y}}$ at $\mathrm{h}$ o. ealyx marginalis Seheff. Nat. fam. der A no n a e ex. Gr. Bangka; hoogc booin.

989. Bınkal S. en M. = Anthoeephalus indieus $\mathrm{Ri}$ h, Nat. fam. der Rubiaceæ. Gr. Java; hooge boom. 990. Bankal-laki-laki M. $=\alpha$. A nthoeephalus indieus Rieh. (Zie vorig No.) en $=b$. Nauclea parvifolia Rbx. (Zie No. 969.)

991. Bankal-parampoean M. = A nthoeephalus (?) Ca a m b a M iq., Nat fam. der Rubiaeex. Gr. Java in tuinen; hooge booll.

992. Bankil $\mathrm{M} .=\mathrm{R}$ hizophora c o n j u g a t a I. (Zie No. 865.)

993. Banneh MAx. $=\mathrm{Setaria}$ glauea Pd. B., Nat, fam der Graminea. Gr. Celebes Boeroe. Overblijvende plant. 994. Bantjet J. $=\mathrm{Turpin}$ ia s ph ac ro e a pa Hssk., Nat. fam. der Staphyleaeeæ. Gr. Java; hooge boom. GEBR. Het hout is zeer gesehikt voor gereedsehappen, maar niet voor huisbouw, omdat de witte mieren het spoedig antasten; de vruchten zijn cetbaar.

995. Bantji-leuheur $\mathrm{S} .=a$. Dee. ringia indiea Zoll. en b. 1). celosioides R.Br. Nat. fam. der A nuaran tacex. GR. Bijna overal in Indie; kleine heesters. GEBR. Beide worden aangeplant, omdat men de bladeren, in stoom gekoukt, als groente bij rijst nuttigt.

996. Bantjong PAL. $=\mathrm{P}$ a $\mathrm{r}$ in arium sumatranum Benth. (Zie No. 795.)

997. Banto-mienjak Sum en

¿98. Banto-oedang Sum. $=\mathrm{Pan} \mathrm{i}$ c um prostrat um L am. Nat. fam. der G r a m in e $x$. Gr. Java, Sumatra, Timor; gesehikt vecvoeder.

999. Bapasaij $\mathrm{C}_{R}=\mathrm{V}$ e nt i lagn ma deraspatana Grtn., Nat. fam. der R h a m e a. Gr. Java en de Molukken; slingerplant.

1000. Bapassongan $\mathrm{S}$. = S o n n eratia a id a L, (Zie No. $866 c$.)

1001. Bapa-tjeda MeN. = S e vola Ko en ig i V hl, Nat. fam. der A poeynex Gr. Bijna overal langs de 
stranden; hecster. GEßßr. Het hout gebruikt men alleen voor pennen of uagels; nit het weeke merg ran den stam snijdt men, voor fecsten, allerlei aardigheden, bloemen, vugels, enz., die zich gremakkelijk laten kleuren. Het sap der bessen drupjelt men in de oogen, bij verduisteringen van het hoornvlies. Alle declen der plant zijn zeer bitter, en worden daarom dikwijls tot rersterking toegediend, vooral bij berriberi; het sap uit den wortel zez̧t men dat hreilzaam is tegen dysenterie, en -een afkooksel van het hout geeft men tegen syphilis.

1002. Bapiang of Bepiang Laмp. = Uvaria astrostieta Miq, Nat. fam. der Anonacex; Gr. Sumatra; slingerplant. $=6$. Artabotrys sumatrau us miq., Nat. fam. als voreu. Gr. Sumatra; klimplant.

1003. Barakkattak $\mathrm{S} .=\mathrm{Ch}$ arica Melamiris Miq. (Zie No. 286.)

1004. Barang J. = Poly g o u u m Pus 1 mb u H a m., variet. Nat. fam. der Polyg o n ex. Gr. Java; overblijvend.

1005. Barang-barang $\mathrm{M}_{\mathrm{AK}}=\mathrm{P}$ ly podium quereifoli um L. (Zie No. 181.)

10:6. Barangan Sum. W. K. = a Castauea speetabilis Miq., en b. C. brevieuspis Nib., Nat. fam. der Cnpul liferx Gr. Sumatra; hooge boomen. GEBR. Vermoedelijk zijn de vruehten eetbaar.

1007. Barangan of Brangan Вк.= Castanopis costa ta Miq., Nat. faum. der Cin plifera. Gr. Bangka; looge boom.

100S. Barangan-babi BK.,

1009. Barangan-hadji $\mathrm{BK}$. en

1010. Barangan-padi $\mathrm{BK}$. = Cas. ta u o psis trisperna Scheff., Nat. fam. der Cu puliferæ. Gr. Bangka; hooge boom.

1011. Barangan padi PaL. = I i t hoc arpus javeusis B l., Nat. fam. der $\mathrm{C}$ u p u lifer $x$. Gr. Java, Sumatra; zeer hooge boom. GEBR. Het hout is grof, zeer moeilij's te splijten en wordt daaron zelden tot bouwhout gebezigd.

1012. Baratti Lıмp. $=\mathrm{S}$ horea leprosula $M$ iq., Nat. fam. der Dipterocarpex. Gr. Sumatra; hooge boom.

GEir. Het hout is geschikt voor bonwen.

1013. Baratti-baboe $\mathrm{L}_{\mathrm{A} \Perp \mathrm{P}}=\mathrm{Car}$ pophyllum ma eroearpum Miq. (Zie No. 1499).
1014. Bareh-Bareh Sux. = Alysearpus bupleurifolins D. C., var. flor. litteis, Nat. fam. der Papilio. n a e e. Gr. Java, Timor; éénjarig.

1015. Bareh bareh Sum. W.K. $=a$. A broma dentieulata Miq, Nat. fam. der Büttueriaceæ. Gr. Sumatra; beester. $=b$. Vernonia javanica DC., Nat. fam. der Compositx Gr. Java, Sumatra; hooge boom. Grir. Het hout bezigt men voor huisbouw, of sehoon het licht door witte mieren wordt aangetast.

1016. Baringin-rimbo Sum. W. K.= A u tidesmasalic ifolium Miq., Nat. fam. der A n tidesmeæ. Gr. Sumatra; boom.

1017. Baroboi of Boroboi J. = Gy no. troehes axillaris 3 l., Nat. fam. der Legnotideæ Gr. Java; enz.; kleine boom. Gebr. Het hout, dat zeer fraai eu sterk is, dient veel tot huisbouw en wordt niet door insecten aaugetast.

101S. Baroe M. (Waroe M.) = H ib iscus L. Spee. diversæ.

1019. Baroe T. $=\mathrm{C}$ a riot a $\mathrm{R} \mathrm{u} \mathrm{m}$ phian a M r t (Zie No. 331.)

1020. Baroe-gallam $\mathrm{M}_{\mathrm{aK}}$. $=\mathrm{Mela}$ le uc a Leucadendron L. (Zie No. $120 a$ )

5021. Baroe-laut $\mathrm{H}_{\mathrm{.}}=a$. Thespesia maerophylla Bl. (Zie No. 854). = b. Cordia subeordata L a m., Nat. fam. der $\mathrm{C}$ o r d i a e e $x$. Gr I ijna overal in den Indisehen Archipel; hooge boom. GeBr. Het hout is bruin en fraai zwart geaderd, bezit een angenameu muskusgeur en wordt veel gebruikt.

1022. Baroe-parteij $.1 .=T$ h c spesia maerophylla Bl. (Zie No. 854.)

1023. Baroe-tjina $\mathbf{M}=a$. A rte misia indica Willd. (Zie No, 619a) $=$ b. Artemisia vulgaris L., Nat. fam. der C o m p o sitæ Gr. Java, Sumatra, gekweekt; overblijvend. GéBr. De wortel wordt hier en daar tegen vallende ziekte geprezen; het kruid is lieht aromatiseh, samentrekkend en scherp.

1024. Baroenai $S .=G r a t a v a$ ma g 11 a 1) C, Nat. fam. der C a p p a r ide . Gr. Java; hooge boom. Gerr. De bast, met water fijn gestampt, wordt, als huidprikkelend en rookmakend middel, uitwendig anngewend tegen herige koortsen, krampen, enz

1025. Baroes Cr. = Cassia javan i c a $L$, Nat fam.der $C x s$ a $l p$ in i ex. Gr. Door geheel Ned.-Indië; hooge boom. 
Gebr. Uit het hart van den stam vervaardigt men sirih- en pinangdoozen.

1026. Baros J. $=a$. Fagræa volubilis Wall. (Zie No. 975). $=b$. M anglietia glauca Bl., Nat. fam. der M aguoliacex. Gr. Java; hooge boom. GEBR. Hij levert een goed bouw-en meubelhont, geschikt voor fijn werk.

1027. Baros-baros Sun. W.K. $=$ Abroma dentienlate Miq. (Zie No. $1015 a)$.

1128. Baso Амв. = D iplazi u m mala b a ri e um Spro., Nat. fam. der Poly podi a cex. Gr. Java, de Moluk. ken; overblijvend. GEBR. Meu kent aan deze varen dezelfde wormdrijrende eigenschappen toe, als aan de Polypodium Filix mas L. (Zie nog No. $7+80$ ).

1029. Basoeng PaL. $=A \mathrm{nis} \mathrm{op-}$ te ra pale in ba nie a Miq., Nat. fam. der Dipter o e a r pex. Gr. Sumatra; hooge boom.

1030. Bassang M. = Artocarpus (?) anisophylla Mliq., Nat. fam. der Artocarper. (Gr. Sumatra's O.Knst; boom.

1031. Basse BL. $=\mathrm{Ch}$ avica B etle Miq. (Zie No. 285.)

1032. Bassong Sum. W.K. $=\Lambda$ lstonia scholaris li.Br. (Zie No. 2350).

1033. Bata Cr. = Mangifera altissima Blaneo. Nat. fam. der A nac a $\mathrm{rdi}$ a e ex. Gr. De Molnkken; hooge boom. Gerr. De rijpe vruehten worden gegeten, doch vooral gebezigd tot het maken van azijn.

1034. Batakka Men. $=\mathrm{K} x \mathrm{~m} \mathrm{p}-$ f c r i a G a langa L. (Zie No. 737).

1035. Batang-ali M. = Leptasp i s ure e o lat a R.Br., Nat. fam. der Gramine re. Gr. Java en Sumatra; grassoort.

1036. Bâtang-talong PAL. $=\mathbf{M} \mathrm{y}-$ ristica eorticosa HK. \& Variet. (Zie No. 137).

1037. Batar Mak. of

1038. Batari $M .=S$ or g h $1 \mathrm{~m}$ s a e e h a tum P e r s. Nat. fam. der Gra me n i c ; Gr. Hier en daar aangekweekt; éénjarig. GEßR. De zaden worden in plaats van en als gierst gegeten.

1039. Batata-pantej $\mathrm{MeN}$. = I p oin $x$ a e s e a p r $\mathrm{S}$ w., Nat. fam. der C o $u$ v o I v u la e e æ. Gr. langs de stranden door den geheclen Archipel; slingerplant. GEBR. Aan de bladeren, welke veel soda bevatten, kent de inlander een sterke woudheclende kracht toe.
1040. Batatas M. Bat a ta s e dulis Chois. (Zie No. 635.)

1041. Bate M. \& Амв. = $a$. Ма ngifera foetida Lonr. (Zie No. 274). en $=\ell$. Albizzzia saponaria Bl., Nat fam. der M i mos ex. Gr. Celebes ell de Molukken; hooge boom. GkBr. De schors en bladeren worden, in plaats van zeep, tot wassehen gebruikt.

1042. Batel Br. $=$ N a $\mathrm{ng}$ if er a foetida l, o u r. (Zic No. 274.)

1043. Bati-bati BL. = L e n e a s linifolia Sprg., Zat. fam. der Labia$t x$. Gr. In geheel Indië; éénjarig. Gerr. De wortels dienen tot het roodverven der nagels; het kruid wordt als groente gegeten; men legt het ook op oude wonden, als wondzuiverend middel.

1014. Batik-batik Sum. W.K. = Embelia oblongata Miq. (Zie No 148.)

1045. Batjampia PaL. $=\mathrm{T}$ a rakto gen os Blumei Hassk., Nat. fam. der. Fl a e ourtiana ce. Gr. Java en Sumatra; hooge boom.

1046. Batjang M. $=a$. M a n g ifera foedita $L_{1}$ onr. (Zie No. 274) en $b$. Mangifera altissima Blanco. (Zie No. 1033.)

1047. Batoe $\mathrm{S} \& \mathrm{M}=a$. A morphophallus eampanulatus Bl. (Zie No. $750 a.)=b$. Conyzalacera Burm. Nat. fam. der Composit i x. Gr. Door geheel Indië; heester. Gerr. Alle deelen der plant worden als groente, bij wijze van spinazie, gegeten; de jonge toppen worden door kraamvrouwen als de sirih gekauwd.

1048. Batoe-lientjar S. \& M. = $\mathrm{Co}_{0-}$ n yze la e era $\mathrm{B} \mathrm{u} \mathrm{rm}$. (Zie vorig No.)

1049. Batoe-lientjar boddas $\mathrm{S}$. = Conyza laeera Burm; var. Commers on ii D.C.

1050. Batoe-lientjar berrum $\mathrm{S} .=$ Conyza la e era $B$ irm. var. Bnr$\mathrm{m}$ a $\mathrm{nn} \mathrm{i}$ D.C.

1051. Patoe-lientjar leutiek $\mathrm{s}$. = Co n y a laeera Burm, var. Blu$\mathrm{me} \mathrm{i} \mathrm{i)} \mathrm{C}$.

1052. Batoe-malakka M. = Mangifera foetida Lour. (Zie No. 274).

1053. Batoe seetan M. = II y men o. phallus dxmonum Nees. Nat. famder Gaster o m y e etes. Gr. Bijna overal iu Indië. GFrr. Men bezigt deze zwain tot het rijp maken van verharde gezwellen.

1054. Batsjam-batsjam Bг.= 
Diploclinium tuberosum Miq., Nat. fam. der Begoniaceæ. Gr. Java, Bali, de Molukken; overblijveud. GkвR. Men cet de zure bladeren als salade en kookt ze ook met visch.

1055. Battang-laboe Mak. el

1056. Battang-terrassa $\mathrm{I}_{\mathrm{AK}}$. = $\mathrm{B}$ a u n e h M a k.

1057. Battara-todjong-édja МАк. en

105\%. Battara-todjong-keboh MaK. $=\mathrm{S}$ orghu $\mathrm{m}$ S a ceharat u Pers. (Zie No. 1038 )

1059. Bateka M. = Citrullus ed ul is Spach, Nat. fam. der Cucurb i t a c e ic. Gr. Deze slingerplaut wordt overul aungekweekt. GEsR. De vruehten zijn om haar saprijk, fraai rood wruehtvleesch zeer gezocht; zij zijn zeer verkoelend, doch worden door personen met zwakke ingewanden moeilijk verdragen; de zaden waren vroeger officineel $\mathrm{cu}$ behoorden tot de vier verkoelende zaden.

1060. Baun N.G. (Zie No. 1081.)

1061. Bawa-appoer Амв en

1062. Bawa-foeroe $\mathrm{T}$. $=\mathrm{Fury}$ e les a m boi ne ns is $\mathrm{Herb}$. Nat. fan. der A m a ryllidere. Gr. Java en de Molukken; overblijvend. GEBR. De inlauders wenden deu wortel als braak- en purgeermiddel aan; van de tot poeder gestamptc wortels wordt tot een drachine genomen; de bladeren bezigt men als rijpmakend middel op gezwellen en abcessen.

1063. Bawang BK. = Aglaja glab r a $t$ a ' $\mathrm{T}$. \& B., Nat. fam. der Meliac e æ. Gr. Bangka; boom,

1064. Bawang S. \& $\mathbf{M}$. = Mangiferafoctida L o ur. (Zie No. 274).

1065. Bawang M. = Allium L. $\mathrm{S}$ pe eies divers $x$.

1066. Bawang-boddas $\mathrm{S}$. $=\mathrm{A} 1 \mathrm{l} \mathrm{i}$ u m s a tiv u m l., Nat. fam. der L i l ia e e $x$ Gr. De gewonc Ui wordt door geheel Indië verbouwd.

1067. Bawang-burrum $\mathrm{S} .=\mathrm{All} \mathrm{i}$ u $\mathrm{m}$ a s c a lon i e $\mathrm{m}$ L., Nat. fam. als boven. Gr. Ook de roode Chalot wordt op vele plaatsen verbouwd.

1068. Bawang-Kapal M. = Sisyrinchium latifolium Sw., Nat. fau. der Irideæ Gr. Op Java, uit Japan overgebracht; wordt als sierplant in vele tuinen gekweckt. GFBR. Op Java dient men de bladcr'n aan kraanviouwen toe; vernengd met die van Solan $1 \mathrm{~m}$ verbaseifolium L., Eclipta L., Pluchea balsamifera Less, Bambusa A pus $\mathrm{Schlt}$. en water.

1069. Bawang-kladi J. = Seirpus ju u coides $\mathrm{kx}$ b., Nat. fam. der C y p c ra e e a. GR. Java : overblijvend.

1070. Bawang-koetjeij M. = Allium nliginos um 1) on., Nat. fam. der Liliaeeæ Gr. Iu gehcel Indië in tuinen verbouwd, uit Japan overgebracht. GEBR. De bladeren zijn een zeer gezochte specerij in vele spijzen.

1071. Bawang-meirah M. = (Zie No. 1067).

1072. Bawang-oetan J. $=$ K $и \mathrm{r}$ eles a m boinensis $\mathrm{H}$ e rb. (Zie No. 1062).

1073. Bawang.poetih M. (Zie No. 1066).

1074. Bawang-poetih-oetan Aмв. $=$ Tacea paluata Bl. (Zie No. 825).

1075. Bawang-preij S. \& M. = Allium Porrum I., Nat. fam. der Lili a c cx. Gr. De Prei wordt op de meeste plaatsen aangekwcekt.

1076. Bawang-rakkj00 M. = A 1 . lium rakk'joo Sieb, Nat. fam. als voren. Gr. Buitenzorg, uit Japan overgebracht.

1077. Bawang-timor M. $\equiv a$. A llium ascalonicum L., val. (Zie No. 1067). = b. A lli um sin ic u $\mathrm{No}$. r o n h., Nat. fam. als voren. Gr. Buitenzorg, enz., uit China overgebracht.

1078. Bawang-tjina $M$. = Allium Cepa L., Nat. fam. der vorige. Gr. Wordt overal verbouwd. Gebr. Dezc is in de huishouding en in de geneesmiddelen zeer gezocht.

1079. Bawangan $\mathrm{S}$. $=\mathrm{L}$ ob eli a Horsfieldiana Miq., Nat. fam. der Lobeliaceæ. Gr. Java; overblijvend.

1080. Bawanger S. = Urostigma nervosum Miq., Nat fanı. der A r tocarper. Gr. Java; boom.

1081. Bawun N.G. $=$ Paijena baw un Seheff. Nat. fam. der Sapotace re. GR. Nieuw-Guinea. GEBR. Ife vruchten dezer plant zijn eetbaar en zeer gezocht.

1082. Bea-bea $\mathrm{S}$. $=\mathrm{S}$ a git a ri a hirundinacca Bl., Nat. fant. der A lisma e æ. Gr. De Sunda-cilanden; watcrplant. Gebr. De jonge bladereu en bladstelen zijn door velen als groente bij de rijst zeer gczocht.

1083. Bebakan LAMP. $=$ Microsepala acuminata Miq., Nat. fau der Euphorbiacese Gr. Sumatra; boom 
1084. Bebeak S. $=\mathrm{F}$ a g r $x$ a o b o. v a t a W a ll., Nat. fam. der L o g a n i ac e æ. Gr. Java, enz.: groote heester.

1085. Bebekoh LaMp. $=$ Dy sox y l u m lam pongu m Miq., Nat. fam. der Meliace $x$. Gr. Sumatra; hooge boom.

1086. Beberet $\mathrm{S}$. $=\mathrm{Du} \mathrm{ch}$ es nea c h rysantha Mi q., Nat. fam. der Rosaс с æ. Gr. Java; overblijvend. Gebr. De vruchtjes zijn eetbaar.

1087. Bebesahran S. $=\mathrm{M}$ or us ind i c a $\mathrm{Rm} \mathrm{ph}$. (Zie No. 797a.)

1083. Beboelootan S. = L im nophil a villos a Bl., Nat. fa m. der S crophularineæ. Gr. Java. Sumatra, waterplant.

1089. Bedaroh Sum. $=\mathrm{Neph}$ li u m e riopetal u m M iq., Nat. fam. der Sapindaceæ. Gr. Sumatra; boom.

1090. Bedas of

1091. Bedas $\mathrm{S} .=a$. Piper $\mathrm{n} \mathrm{i-}$ grum L., Nat. fam. der Piperacer. Gr. Deze slingerplant wordt bijna overal gekweekt aangetroffen. GEBR. Het nut der zwarte en witte peper is overbekend. $=b$. $\mathrm{Ch}$ avica macrostachya Miq, Nat. fam. als voren. GR. Java; slingerplant.

1092. Bedh R. =Carica Papaya L., Nat. fam. der Papay aceæ. GR. Door geheel Indië in tuinen; boomachtig. GEBR. De Papayaboom wordt overal, om zijn huishoudelijk en geneeskrachtig nut, aangeplant; de naar mierikswortel riekende wortel wordt bij aandoeningen van blaas en nieren toegediend; het sap uit den stam en de bladstelen geeft men inwendig tegen impetigo; de bladeren zijn zeer bitter en werken ontlastingbevorderend; zij worden als groente zeer gaarne gegeten en zijn roor paarden een uitmuntend geneesmiddel; de mannelijke bloemen eet men in azijn gelegd; de vruehten eet men onrijp als groente; zij smaken naar wortelen; rijp zijnde zijn zij, als nagerecht tamelijk gezocht; zij bezitten verkoelende zacht laxeerende eigenschappen; de zaden smaken als sterkers en zijn wormdoodend.

1093. Bedok-gih S. = Dichroeephala capitata Miq., Nat. fam. der C o m p o s itæ. Gr. Java; éénjarig.

1094. Bedok-gil S. $=\mathrm{Sph}$ Һ ranthus microcephalus Miq. Nat. fam. der Composit x. Gr. Java, Sumatra, Timor; éénjarig. GeBr. Volgens Branco bezigen de inlanders dit plantje tot cen genceskundig doel.
1095. Beedjo Вк. = B at atas ednlis Chois. (Zie No. 635.)

1096. Behdji J. = Cynoglossum javanicum Thb., Nat. fam. der A sperif ol iæ. Gr. Java, éénjarig.

1097. Bejoek M. $=$ Gnet u m acutatum Miq., Nat. fam. der Gnctac eæ. Gr. Sum. W. Kust; slingerplant.

1098. Beka-hitam LAMP. $=\mathrm{D} \mathrm{y-}$ soxylum lampongum Miq. (Zie No. 1085.)

1099. Belawa BG. = Gluta Benghas L., Nat. fam. der A n a cardiace $x$. GR. Door geheel Ned.-Indië; hooge boom. GEBr. Deze boom levert een fijn, fraai rood meubelhout, doch is moeilijk te kappen, om het bijzcnder scherpe melksap; ook levert hij een goede hars voor vernis.

1100. Belawan M. (Zie No. 1110.)

1101. Belehketehpek $\mathrm{S}$. $=\mathrm{E} \mathrm{ch}$ inocarpus Sigun Bl.. Nat. fam. der B i x a c e x. Gr. Java; boom. Gebr. De stam is zeer geschikt voor bouwhout; de zijdelingsche uitwassen van den stam bewerkt men tot wielen voor pedatties.

1102. Beliam-patjet PAL. = Alsodeia rug os a M i q., Nat. fam. der Vi ol arie $x$ Gr. Sumatra, boom.

1103. Belian Bo. of Blian Bo. = Eusideroxylon Zwageri T. \& B., Nat. fam. der L a u r i n e a. Gr. Bornen, Sumatra, Bangka; zeer hooge boom. GEBR. Deze boom levert het echte ijzerhout.

1104. Beliliek Вк. $=\mathrm{Bru}$ c e a s umatrana $R \times b$. (Zie No. 296.)

1105. Belijong M. $=\mathrm{Kibessia}$ a zurea D.C., Nat. fam. der Melas to$\mathrm{m}$ a $\mathrm{c}$ e $x$. Gr. Java en Sumatra; kleine boom. Gebr. Deze boom levert een zeer hard bouwhout, ten onrechte ijzerhout genoemd.

1106. Beloedroe J. $=\mathrm{L} \mathrm{uffa} \mathrm{Pe-}$ tol a $S$ e r. (Zie No. 685a.)

110\%. Beloengking Sum. W. K. = Trichosanthes Kadam Miq., Nat. fam. der Cucurbit a cex. Gr. Sumatra; slingerplant. GeBr. De inlanders bereiden uit de groote zaden een vette olie.

1108. Beloes. J. $=$ Trichosanthe s Ang uina L., Nat. fam. $\operatorname{der} \mathrm{Cu}$ c u r b i$\mathrm{t}$ a c e $æ$. Gr. Op Java in tuinen; slingerplant. GEBR. De vruchten worden rijp en onrijp als toespijze genuttigd; rijp zijnde wcrken zij purgeerend.

1109. Beloesoe. Вк. $=\mathrm{E} \mathrm{u} \mathrm{th} \mathrm{cm}$ is l e u c o c a r p a J a c k. (Zie No. 5862.)

1110. Boloewan M. = Te y sma n- 
II a altifrous Z. \& M. Nat. fam. der $P$ a $l \mathrm{~m}$ x. Gr. Sumatra.

1111. Belondottan J. = I y c o p e rsicum esculentum Mill.; Nat. fam. der S o l a n a c e x. Gr. Bïna overal aangeplant; éénjarig. GEBR. De Licfde's appelen worden in Indië bijna bij alle spijzen als specerij gebruikt, vooral echter bij visch; ook worden zij ingelegd gegeten; zij zullen uitwendig met goed resultaat bij antrax kunnen gebruikt worden. Op de Philippijnsche eilanden wendt men de bladeren voor eene vuil-groene kleurstof aan.

1112. Beloo-hitam $\Delta$ мв. $=\mathrm{M} \mathrm{a} \mathrm{b} \mathrm{a}$ $\mathrm{E} b$ e u s R. Br. (Zie No. 107.)

1113. Bemban $\mathrm{P}_{\mathrm{A}} \mathrm{L}=\mathrm{G}$ u a t t cria s u m atran a Mi q., Nat. fam. (ier A n on a c e æ. Gr. Snmatra: boom.

1114. Bemban-kihoh $\mathrm{P}_{\mathrm{AL}}=\mathrm{G}$ u a t. teria palembauica Miq., Nat. fam. als voren. Gr. Sumatra; boom.

1115. Bemben M., R. = M a n g if e r a l a u ri n a B l., var. B c m b e in B 1., Nat. fam. der A n a c a r d i a c ex. Gr. Bijna door gehcel Indië; boom. GEBr. Ook de vruchten dezer Mangasoort zijn door velen gezocht. (Zie verder No. 274.)

1116. Benakat PAL. $=\mathrm{C}$ o v elli a a l bi pila Miq., Nat. fam. der A r toc a r p e æ. Gr. Sumatra's O.Kust; hooge boom.

1117. Benang M., R. = Rostel1 u laria diffusa $N$ ees, Nat. fam. der A c a nth a c e $x$. Gr. Java en de Molukken; overblijvend. Gebr. De bladeren gebruikt men uitwendig bij kneuzingen.

1118. Benatan LaMp. $=\mathrm{Al} \mathrm{b} \mathrm{i} \mathrm{z} \mathrm{z} \mathrm{i} \mathrm{a}$ splendens Miq., Nat. fam. der Mimos e æ. Gr. Sumatra; hooge boom.

1119. Bendah $\mathrm{S} .=\mathrm{Art}$ o c arpus B l u m e i Tréc., Nat. fam. der A r toc a r p e æ. Gr. Java; hooge boom. Gebr. Men bezigt den bast als touwwerk en het melksap voor vogellijm.

1120. Bengang $\mathrm{S} .=\mathrm{N}$ e es i a al. t is s i m a Bl., Nat.fam. der Tili a c e $x$. Gr. Java; hooge boom. Gebr. Het fraaie, roode en sterke hout wordt tot haisbouw gebruikt en niet door insecten aangetast; de bladeren eu vruchten wendt men uiten inwendig bij fluor albus aan.

1121. Bengangan $\mathrm{J}_{.}=\mathrm{Poly}$ g on um $\mathrm{P}$ os u m b u H a m. (Zie No. 1004.)

1122. Bengberrettian $\mathrm{S} .=a . \mathrm{R}$ bus fraxinifolius Poir. en $b$. R u bus ros efolius Sm., Nat. fam. der Ros a c eæ. Gr. Java, Celebes, de
Molukken veelal in tuinen; kleine heesters. Gевr. Men drinkt een aftreksel der bladeren tegen dysenterie; de zuurzoete vruchten worden gegeten.

1123. Benger $\mathrm{S} .=a . \mathrm{Crat}_{\mathrm{t}} \mathrm{x} \mathrm{y}$ lon clandestill um Bl., Nat. fam. der H y peri ci n e æ. Gr. Java, Celebes; boom. GEBr. De stam levert een zeer geschikt hout voor huisbouw en prauwen, dat niet door insecten wordt vernield; de blade. ren kauwt men bij scorbutische aandoeningen van den mond. $=b$. L a g e r s tro $\mathrm{c}-$ mi a regina $R \times b$., Nat. fam. der L y t h r a r i e r. Gr. Java, enz.; hooge boom; cen sieraad in vele tuinen. GEBr. Hij bezit een fraai geaderd hout, geschikt voor hnisbouw, meubelen en vooral voor prauwen, dat niet door insecten wordt aangetast. = c. Lagerstroemia ovalifolia T. \& B., Nat. fam. dezelfde. Gr. Java; hooge boom. GEBr. Vermoedelijk als van $b$.

1124. Bengok M. = Otte li a jav a n i c a $\mathrm{M}$ i q., Nat. fam. der $\mathrm{H}$ y d roc h a r i d e $æ$. Gr. Java; waterplant. Gebr. Het kruid wordt door sommigen als grcente gegeten.

1125. Benkoe R. = Ceratorho. rus longe petiolatus T. \& B. Nat. fam. der S a p o t a ce e. GR. Riouw; hooge boom.

1126. Benöang PAL. $=0 \mathrm{ctom} \mathrm{c}$. les sum atrana Miq., Nat. fam. der $D$ a t i s c e $x$. Gr. Sumatra, de Molukken; hooge boom.

1127. Benoh $\mathrm{S} .=\mathrm{Pancratium}$ c ord a t u m L. (Zie No. 798b.)

1128. Berai $\mathrm{BK} .=\mathrm{Rhodamnia}$ spectabilis Bl., Nat. fam. der M yrt a c e æ. Gr. Java, Bangka; hooge boom.

1129. Berel Амв. = $\mathrm{Pand}$ an u s humilis $R m p h$. , Nat. fam. der $P$ a nd a n e æ. Gr. Java en de Molukken; boom. GEBr. Vau de bladeren vlecht men hoeden en matten, en gebruikt ze veel tot het inpakken van Java- of Arensuiker en als aas om visch mede te vangen; de jonge uiteinden der bladeren en de lloesem worden als groente gegeten.

1130. Berentang $\mathrm{BK} .=\mathrm{B} \mathrm{uch} \mathrm{a}$. nania racemiflora Miq., Nat. fam. der A n a c a r d i a c ex. Gr. Bangka; hooge boom.

1131. Beriwangoe $\mathrm{Br}_{0}=\mathrm{M}$ e troxylon elatum $M$ a r t. Nat. fam. der P a l m æ. Gr. Celebes, de Molukken; zeer hoogc boom. GEBr. Het zeer harde hout gebruikt men voor huisbouw; de jonge 
bladeren voor touw of garen; van het sponsachtige deel der bladstelen maakt men de deksels der blaaspijpen.

1132. Berneï Sum. = A n t i d e s m a salaccense Zoll., Nat. fam. der A n t idesmeæ. Gr. Java en Sumatra; heester.

1133. Bernei-padie Sum. O.K. = Antidesma leucopodum Miq., Nat. fam. der $A$ n tidesm ex. Gr. Sumatra; boom.

1 134. Bernei-talang PAL $=\mathrm{I}_{4}$ e i 0 c a r us arboreus Bl., Nat. fam. der Euphor bi a e a. Gr. Java, Sumatra; kleine boom. GEBR. Men bezigt den bast tot het roodverven van garens; met het sap van den bast en uit de jonge takken waseht men zich het lichaam, bij verschillend gewrichtslijden.

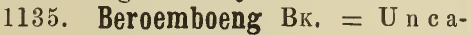
ria e urhynch a Mi q., Nat. fam. der R u bi a e æ. Gr. Bangka; slingerplant.

1136. Berohdjo S. = a. Euxolus polystachyus Willd. (Zie No. 8456). $=b$. A marantus paniculatus L. (Zie No. 849) en $=c$. Celosia argent e a L., Nat. fam. der A ma ran ta ce GR. Door geheel Indië in tuinen; éénjarig. GEBR. Het kruid wordt als groente gegeten en bezit oplossende eigensehappen.

113\%. Besieran $J_{0}=\mathrm{D}$ is porum m u l t if l o r u m Do $\mathrm{n}$, Nat. fam. der Melantha eеæ. Gr. Java; overblijvend.

1138. Bessa-magoemi T. = A r istoloehia indiea L. (Zie No. 207).

1]39. Betau MaK. $=$ Calo phyll u m in o p h y 11 l m L., Nat. fam. der C l u s i a e æ. Gr. Java, Celebes, de Molukken; hooge boom, GFiBR. De bast is rijk aan hars; men kent hem een pisdrijvende kracht toe, en geeft hem dikwijls tegen slijmvloeden; het hout is een zeer geschikt bouw- en meubelhout; de hars, die onder den nam van Ta e maha e vroeger officineel was, gebruikt men voor fakkels, en dient ze als purgeerend en braakwekkend middel toe; de in water gelegde bladeren bezigt men bij oogontstekingen; de vrouwen dragen de bloemen, om haar aangenamen geur, in het haar; uit de zaden perst men eene giftige, vette olie, die tegen sehurft en andere huidziekten wordt aangewend.

1140. Beteh-betie M., R. = Carie a P а р а у а I. (Zie No. 1092).

1141. Beteh-meirah MEN. $=\mathrm{Ho}_{\mathrm{O}}$ malonema rubeseens Kunth. ('Lie No. 903).
1142. Beteh-papaija M., R. en

1143. Beteh-rawang M., R. = C a$r$ i e a $P$ a p a a 1. (Zie No. 1092).

1144. Betie-betie BK. = Psychotria le u e c a r a M i ., Nat. fam.

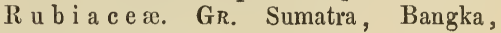
Borneo; heester.

1145. Bia S. $=$ A lo e a s i a in die a S e h o t t, Nat, fam. der A r o i d e . GR. $\mathrm{O}_{\mathrm{p}}$ alle eilanden in het wild en gekweekt; overblijvend. GEBR. De wortel is zeer seherp, en wordt bij de meeste inwendige ziekten als huidprikkelend middel gebezigd. HASSKarL geeft nog op dat het sap der bladstelen tegen hoest wordt gedronken.

1146. Bia-bia Br. = Monoehoria vagina I is Pres l. (Zie No. 912).

1147. Bia-hoet Br. = H o p e a s el a $\mathrm{ni}$ c a $\mathrm{R} \times \mathrm{b}$. (Zie No. 824).

l148. Biarang BK. $=\mathrm{G} \mathrm{ly} \mathrm{e} \mathrm{o} \mathrm{s} \mathrm{m}$ is pentaphylla Colebr., Nat. fam. der A u rantia e ææ. Gr. Java, Sumatra, Bangka, Timor; groote heester.

1149. Biarera T. $=\mathrm{O}$ r y a s a $\mathrm{t}$ v a $\mathrm{L}^{\cdot}$ (Zie No. 823), (de gekookte zaden).

1150. Bias M. $=$ A re a horrid a Griff. (Zie No. 834).

1151. Biawas MaK. $=a$. J a m b s a 1 b a $\mathrm{Rmph}$. ('Zie No. 50. .) $=$ b. J a mbos a celebica Bl., Nat. fam. der M y r ta e ж. Gr. Celebes; boom. Gebr. Het lichte hout wordt voor huisbouw gebczigd, de roode vruchten worden gegeten.

1152. Bibati LAMP. $=\mathrm{C}$ a $1 \mathrm{li}$ e a $\mathrm{ra}$ pentandra $R \circ x b$., Nat. fam. der $\mathrm{V}$ e r b c n a e ex. Gr. Đoor geheel Indië. GúBr. Men bezigt soms het hout van dezen boom voor huisbouw, het is eehter niet durrzaam.

1153. Bibiomaman $\mathrm{Cr}_{0}=\mathrm{N}$ oth opanax fruticosum Miq., Nat. fam. der A r a li a e e æ. Gr. Java, Celebes, de Molukken, veelal in tuinen en omheiningen als sierplant; heester. GEBR. Men eet de zumrachtige bladeren rauw en gekookt als groente; uitwendig bezigt men ze bij pokken, om de hevige jeukte tegen te gaan. Wortel en bladeren werken sterk diaretisch; de vrouwen gebruiken beide in aftreksel als stondendrijvend middel.

1154. Bibir-koeda M. = E læa gn us fer uginea A. Rieh. (Zie No. $525 f)$.

1155. Bibitoengan $\mathrm{J}$. $=\mathrm{Equ}$ is et u m d ebile $R$ upr., var. graeile, Nat. fam. der Fqu is etacere. Gr. Java; overblijvend. 
1156. Bidak-bangkong $\mathrm{J}$. $=\mathrm{V}$ e ru onia cinerea Lcss. (Zie No. 67a.)

1157. Bidara S. \& M. = Z i z y p h u s J u juba L am. (Zie No 911).

1158. Bidara-goenong $\mathrm{M}$. $=\mathrm{D}$ i o spyros heterophylla Wall., Nat. fam. der E b e n a c e æ. Gr. Java; boom.

1159. Bidara-ketjil M. of

1160. Bidara-leutiek S. = Z i z yph u s r ufula Miq. (Zie No. 599a).

1161. Bidara-laut $\mathrm{S} .=a . \mathrm{Z} \mathrm{i} \mathrm{z} \mathrm{y-}$ phus Horsficldii Miq. (Zie No. 488) en $=b$. Zizyph rufula Mi q. (Zie No. 599a).

1162. Bidara-pahit M. = S t r y c huo s c olubrina L. (Zie No. 5896).

1163. Bidara-patis $\mathrm{S}$. \& M. = Strychnos nux vomica L., Nat. fam. der Lo g a n i a c e æ. Gr. Oost-Java en de Molukken; boom. Gebr. Het nut vall den bast en de zaden (Kraanoogen) is in elke materies medica aangegeven.

1164. Bidara-poetih BK. = E n r yc oma longifolia Jack. (Zie No. 804).

1165. Bidata M. \& J. $=a$. S o nner a ti a a cida L.fs. (Zie No. 866c); en $=b$. Souneratia Pagatpat B l., Nat. fam. der M y rtaceæ. Gr. Java en de Molukken; boomen. Gebr. Het sterke hout is geschikt voor huis- en schcepsbouw : uit de zure vruchten maakt men azijn.

1166. Bidjan en Bidjin $R .=\mathrm{S}$ e $s$ am u m iud i c u m L. (Zie No. 246).

1167. Bidjietan M. $=\mathrm{L}$ a n si u m domesticum Ja ck $v$ ar. B. (Zie No. 98).

1168. Bido-bido $\mathrm{T}$. $=a . \mathrm{R} \mathrm{h} \mathrm{i} \mathrm{z} \mathrm{o-}$ phora conjugat a L. (Zie No. 865); en $=b$. Rhizophora mucronata L a m. (Zie No. 868).

1169. Bido-marau $\mathrm{T} .=\mathrm{Ch}$ a vic a Betle Miq. (Zie No. 285).

1170. Bido-masoffo T. = $\mathrm{Ch}$ avica siriboa Miq., Nat. fam. der Piperacex. Gr. Bijna overal aangeplant; slingerplant. Gebr. Deze plant, vooral de jongc vruchten, wordt bij, evenals en in plaats der betel (Zie No. 285) gebruikt; zij is echter iets scherper.

1171. Bido-ritsja T. $=\mathrm{Chavica}$ Koxburghi i M q. (Zie No. 295).

1172. Bidoer $\mathrm{S} .=\mathrm{Pandanus}$ latifolius Rmph., Nat. fam. der P a n d a n e r. Gr. Bijna door geheel Indië aangekweekt; heesterachtig. GEBR. De aangenaam riekende bladercn worden, fijn gesucden, op alle bazars verkocht en in het hoofdhaar gedragen; men kookt ze ook in de rijst om deze geurig te maken.

1173. Bidoerie $\mathrm{M}$. $=\mathrm{Cal}$ ot $\mathrm{ro}$ p is gigantea R.Br. (Zie No. 817).

1174. Bidôtô J. (Zie No. 1165).

1175. Bidôtô-oetan J. $=\mathrm{S}$ o n n e$r$ atia alb a $\mathrm{S}$ in. (Zie No. $866 d$ ).

1176. Biendala Sum. W.K. = Synœ c i a d i vers ifolia Miq. (Zie No. 418).

1177. Biendalan-katjang IAAP. Milletia sericea Miq. (Zie No. 189).

1178. Biengbien S. =a. Pty ch osperma latisect a Miq., Nat. fam. der P a l mæ. Gr. Java, Sumatra; hooge palm. GeBr. Volgens Hasskarl eet men de bladeren bij het bloedwateren, ontstaan dcor het overmatig gebruik der zaden van de Djengkol (Pithe col ob i u m big e m in u m M art); de vruchten worden fijngestamp $\hat{\imath}$ op schurft aangewend. $=b$. Ptychospcrma Kuhli i M i q., Nat. fam. als voren. Gr. Java; middelmatigc palm. $=c$. $\mathrm{Pt} \mathrm{y} \mathrm{ch}$ o s perma costata Miq., Nat. fam, als voren. GR. Java; middelmatige palm. $=\iota$. Ptychosperma noxa Miq., Nat. fanl. en $G_{R}$. Als boven.

1179. Biengkoeroe MaK. $=$ Mo$r$ inda bracteata $R$ \& B. (Zie No. 828b).

1180. Bienjaai BK. $=\mathbf{M}$ a $\mathrm{n}$ g i f $\mathrm{c} r$ a k e m a ng a Bl., Nat. fam. der A n ac a r d i a c e æ. Gr. Java, Bali, dc Molukken; hooge boom. GeBr. Deze Mangaboom bezit in al zijnc dcelen een zeer scherp sap, dat bij aanraking zeer spoedig een roosachtige ontsteking opwckt; de stinkende vruchten zijn door de inlanders zeer gezocht.

1181. Bientaroh $\mathrm{S} .=\mathrm{Ce}$ rbera O da 1 l a m Grtn., Nat. fam. der A p oc y n e æ. Gr. Bijna overal in den 0.-Ind. Archipel; hooge boom. Grisr. Deze boom bevat een zeer scherp en giftig melksap, dat Caoutchou oplevert; de bladeren en bast werken drastisch-purgeerend; de vrucht werkt narcotisch en wordt als zoodanig angewend; uit de zaden perst men op Java een vette lampolie, die in kleine giften purgeercnd, in groote echter narcotisch werkt.

1182. Bientaroh-leutiek S. = C e rbera lactaria Hmlt., Nat. fam. als voren. Gr. Bijna op alle cilanden; hooge boom. GeBr. Als No. 1181, ook 
prijst men het melksap aan als heilzaam op beten of steken van giftige vissehen.

1183. Bientatoing MaK. $=\mathrm{Caja}$ m us indie us S pr. (Zie No. 1210).

1184. Bientaus $\mathrm{S}$. $=\mathrm{Wright}$ i a p u bese e n s R.Br., Nat. fam. der A poc y n e æ. Gr. Java, Bali, Timor; boom. GEBR. Deze boom bevat een blauwe kleurstof.

1185. Bientienoe $\mathrm{S} .=\mathrm{V}$ is e $\mathrm{n}$ ia in di e a $\mathrm{H}$ o utt., Nat. fam. der Büttneria ex. Gr. Door geheel Indië; hooge boom. GEBR. Men plant dezen boom in tuinen veelal aan, om zijn spoedigen groei en goede schaduw; het hout is zeer week; de vezelachtige bast is zeer sterk en dient voor touw; men gebruikt den bast en het spint tegen paardendroes, door het den paarden in den neus te stoppen.

1186. Biet-boddas S. $=\mathrm{B}$ e t a v u lg a $r$ is $I$, var. a l b a, en

118\%. Biet-burrum $\mathrm{s}$. $=$ B eta v u lg a ris L., $_{\text {, }}$ a r. r u b r a. Nat. farn. der $\mathrm{C}$ h e n o p o d e $x$. Gr. Deze beide verscheidenheden der Biet worden hitr en daar aangeplant.

1188. Bifi-mafalla $\mathrm{T}$. $=\mathrm{H} \mathrm{e} \mathrm{r-}$ m a n d a $\mathrm{S}$ onor a L. (Zie No. 16.)

1189. Bihaun $\mathrm{BL}$. $=\mathrm{Di}$ os è ora a c ule at a I., Nat. fam. der Diose orea. Gr. Deze slingerplant komt overal in Indië voor, zoo wild als aangekweekt wegens de eetbare knollen, die, gekookt en geroost, een gewild voedsel zijn.

1190. Bijo Bu. $=$ M us a para $\mathrm{i}$ s i a e L., Nat. fam. der $M$ u s a e e Gr. De Pisang of Banaan groeit op alle eilanden met een menigte verscheidenheden, dic later onder het woord Pisang nader zullen besproken worden. GEBR. De stengel en bladeren zijn een gesehikt voeder voor het vee; den stam, die zich laat afsehilferen, gebruikt men tot het inpakken van tabak, groenten enz., en op de ziekenzalen voor het doen afvloeien van water bij irrigatie; de bladeren bezigt men voor het inpakken van goederen, in plaats van borden, voor oogsehermen; de zeer jonge nog niet ontwikkelde bladeren ziju zeer gesehikt voor boegies en spillen. Uit de bladstclen klopt men een fijn garen, en makt hicrvan manillatouw. Het vocht, door insnijding in den stengel bekomen, drinkt de Javaan tegen diarrhoea en dysenterie. 1)e jonge bloemen en bloemkolven (djantong pisang M. koesic M., Poesoe Alf. Min.) zijn een zecr gezochte groente. De vrucht wordt, rijp en onrijp, op allerlei wijze toebereid, als voedsel en lekkernij gegeten; onrijp, geroosterd of gebrand, geeft de inlander haar tegen diarrhoea.

1191. Bijo-loeton BL. $=\mathrm{Musa}$ $\mathrm{simi}$ a r m $\mathrm{Rmph}$., Nat. fam. als voren. Gr. Java, Bali, de Molukken; overblijvend. GEвR. Ook de vruehten van deze wilde Pisang worden bij gebrek gegeten, meer eehter zijn zij een geliefd voedsel van apen en meerkatten.

1192. Bikoro M. $=$ Morinda eitrif o li a I. (Zie No. 828a.)

1193. Bila Maк. en

1194. Bilak M. \& BL. $=$ Agle marmelos $R \times b$., Nat. fam. der A urantia e e. Gr. Java, Timor, enz.; boom. GEbr. Volgens eenigen geeft men een aftreksel van den wortel en den bast bij hypoehondrie, melancholie en hartbezwaren; volgens anderen tegen gestoorde spijsvertering en andere aandoeningen van het darmkanaal. De bladeren en bloemen gebruikt men tegen asthma en krampziekten. Op Java geeft men de bladeren aan paarden inwendig tegen wormen en uitwendig op wonden, door het drukken der zadels ontstaan. Vooral de vrueht wordt veel gebruikt; zij wordt met een huishoudelijk en geneeskundig oogmerk als lekkernij en als extract, siroop, eonserf, enz. bij diarrhoea en chronische dysenterie, genuttigd.

1195. Bili Sum. W.K. = P o t a m ogeton natans L., forma ind i e a $\mathrm{M}$ iq. Nat. fam. der $\mathrm{Naj}$ a d e $x$. Gr. Sumatra, waterplant.

1196. Biloeloe BL. = Areng a sa e harifera L ab. (fruetus). (Zie No. 243.)

1197. Bimbing S. \& J. = B i e $\mathrm{n}$ gb i e n S. (Zie No. 1178.)

1198. Binaloe-api Bк. $=1^{\circ}$. Dendrophthoë pentandra L., (Zie No. 12056 .) $=2^{\circ}$. Dendrophthö̈ iguea Seheff. en $=3^{\circ}$. Phœnieanthenum Bennettianum Miq., beide van de Nat. fam. der Loranthace a. Gr. Bangka: parasieten. $=4^{\circ}$. M a erosolen retusus J a ek. (Zic No. 3412.) $=5^{\circ}$. Elythrante albida Bl. (Zie No. 5922a.) $=6^{\circ}$. Vise u m a r ticulatum Brm. (Zie No. 350e.)

1199. Binaloe-tanah $\mathrm{BK}$. = D e $\mathrm{n}$ drotrophe buxifolia. Miq., Nat. fam. der $\mathrm{S}$ a $\mathrm{n}$ t a l a e c c. Gr. Bangka.

1200. Binang $M$. of Binong $M$. $=a$. B ll c ida $\mathrm{nit}$ ida $\mathrm{Hassk}$., Nat. 
fam. der C o mbretaceæ Gr. Java; heester, sierplant. $=b$. $\mathrm{T}$ etrameles n u d iflora $\mathrm{R} \mathrm{Br}$., Nat. fam. der D at is c ex. Gr. Java; hooge boom. $=c$. Pterocymbium javanicum RBr., Nat. fam. der Sterc uli a c e æ. Gr. Java; hooge boom.

1201. Binang-peutjang $\mathrm{S} .=a . \mathrm{Bu}$ c ida nitida $\mathrm{H}$ ass k. (Zie vorig No.) $=b$. Rottlera affinis $H$ assk., Nat. fam. der Euphorbi a c c æ. Gr. Java en Sumatra; heester. Grbr. Deze levert een roode kleurstof.

1202. Binang-poetjong $\mathrm{S}$. = Trewia nudiflora L., Nat. fam. der E u ph or bi a c ex, Gr. Java, boom.

1203. Binasie Sum. = Sid e roxyl u m a t.ten u at um Dc., Nat. fanı. der S a pota c e . GR. Java, Sumatra, Bangka; hooge boom. Gebr. Het hout staat in deugd bijna gelijk aan ijzerhout.

1204. Binasie-lari $M_{0}=\mathrm{Ch}$ i onanthus diver sifolia. Miq., Nat. fam. der Ole in ex. Gr. Sumatra's W. kust; boom.

1205. Bindaloe M. Sum. $=a$. Dendrotrophe plurinervia Miq., Nat. fam. der S a n t a l a c e æ. Gr. Sumatra; boom. $=b$. Dendropthö̈ pen$i$ andra L. en $=b$. D. costulata M i q., Nat. fam. der L or a n thace e. Gr. $a$. Sumatra, $b$, ook Java en Borneo; parasieten.

1206. Bindaloe-gadang M. Sum. = Dendropthoë dasystemon Miq., Nat. fam. der Loranthacex. Gr. Sumatra; parasiet.

1207. Bindaloe-gadjah Sum. Wk. = Dendrotrophe umbellata Miq., Nat. fam. der S a t a l a c e æ. Gr. Java en Sumatra; parasiet.

1208. Bindaloe-oeri Sum. Wk. = Phoenicanthem um longissimum Miq., Nat. fam. der Lor ant h a c e ז. Gr. Sumatra, parasiet.

1209. Bindaloe-rimbo Sum. Wk. = II edinilla Korthalsii Bl., Nat. fam. der M el as to m a c ex. Gr. Su. matra; parasietachtige heester.

1210 Bindatoin $\mathrm{MAK}_{\mathrm{A}}=\mathrm{Cajanus}$ indicus Spr., Nat. fam. der Papil i o n a c e $x$. Gr. Wordt door geheel Indie op akkers verbouwd; zaadplant. GEBr. De zaden ( $\mathrm{Katj}$ a n g G o c d e h) worden mecstal gcroost gegeten.

1211. Bindjei $\mathrm{R}$. = $\mathrm{M}$ a $\mathrm{ng}$ if e ra foetida Lo ur. (Zie No. 274.)
1212. Binei-oedang-taling $\mathrm{P}_{\mathrm{AL}}$. $=$ Ardisi a palembanic a Miq., Nat. fam. der II y rsine ac. Gr Sumatra; hcester.

1213. Bing-bing $\mathrm{S}$. $=\mathrm{P}$ in a $\mathrm{ng} \mathrm{a}$ B l. spe \%. di v.

1214. Bingkawan M. = Glcichcn i a Hermanni i R. Br., Nat. fam. der Gleicheniacex. Gr. hicr en daar in Indië; overblijvend. Gebr. In ZuidAzië, Japan en Nieuw-Zeeland wint men uit den wortel dezer varens een eenigszins bitter, soms aromatisch zetmeel, dat als voedscl wordt genuttigd. In Japan maakt men van de asch met aluin een poeder, dat bij spruw en ontrellingen der mond wordt aangewend.

1215. Bintan-besaar R. $=$ Cerbera Odalla m Grtn. (Zie No. 1181.)

1216. Bintan-ketjil R. = Cerbcra la ct a ri a $\mathrm{H} \mathrm{a} \mathrm{m}$. (Zie No. 1182.)

1217. Bintangor $\mathrm{BK} .=\mathrm{Calophyl}$ $1 \mathrm{ll} \mathrm{m}$ a moenum $W$ all., Nat. fam. der Clusi a ce .. Gr. Bangka; hooge boom.

1218. Bintangor-batoe $\mathrm{BK} .=\alpha$. Cal o phyllum lanigerum Miq., Nat. fam. Als voren. Gr. Bangka; boom. $=b$. Calophyllum Diepenhorstii M i q. Sumatra; boom.

1219. Bintangor-batong $\mathrm{B \kappa} .=\mathrm{C}$ alophyllu m bancanum Mi q. (Zie No. 1227.)

1220. Bintangor-biboelang $\mathrm{M}$. = C. alophyllum lanigerum Miq. (Zie No. 1222.)

1221. Bintangor-boenga $\mathrm{M}_{0}=\mathrm{C}$ alophyllum cymosum Miq.

1222. Bintangor-laboe $\mathrm{Bк} .=a$. Cal ophyllum la nigerum Miq., Nat. fum. Als voren. Gr. Bangka; hooge boom. $=b$. Calophyllum Teysmannii M i c. Gr. Sumatra; boom.

1223. Bintangor-laut $\mathrm{M}$. $=\mathrm{C}$ a lophyllum inophyllum L. (Zie No. 1139.)

1224. Bintangor-oetan $\mathrm{M}$. = Calophyllum spectabile Wlid, Nat. fam. der Clusiaceæ. Gr. Java, de Molukken, in tuinen en langs de wegen; hooge boom. GEBR. Het hout wordt gebruikt voor daksparren en masten van prauwen; een aftreksel van den wortel en de bladeren smeert men in bij rheumatische pijnen; de zure vruchten worden gegeten; zij ver. oorzaken echter lichtelijk buikpijn; uit het zaad bereidt men een vette lampolie, die 
ook uitwendig, bij huidziekten en rheumatismus ingewreven wordt.

1225. Bintangor-priet $\mathrm{BK}$. $=$ Caloph yllum plicipes Miq. Nat. fam. als boven. Gr. Bangka; boom.

1226. Bintangor-prit $\mathrm{BK}$. en

1227. Bintangor-soring $\mathrm{BK}=\mathrm{Ca}$ lo phyllum banean $1 \mathrm{~m}$ Miq. (Zie 1219.)

1228. Bintangor-tantoet $\mathrm{BK} .=\mathrm{Ca}$ lop hyllum bancan um Miq. Nat. fam als voren. Gr. Bangka; boom.

1229. Bintoengan $\mathrm{M}_{\text {. }}=\mathrm{B}$ i s $\mathrm{ch}$ off i a j a a u ic a Bl. (Zic No. 2352.)

1230. Bira T. $=$ Oryza sativa $\mathbf{L}$. (S e mina den udata). (Zie No. 823.)

1231. Bira M. =Alocasia indica S c hot t. (Zie No. 114.5.)

1232. Bira-aijer M. $=A$ gla onema oblongifolium Knth., (Zie No. 318.)

1233. Bira-boddas $\mathrm{S}=\mathrm{Aloc}$ asia variegat a C. Ko eh \& Bouché, Nat. fam. der A roi d e æ. Gr. Java enz. gekweekt; overblijvend; GEBR. De wortel wordt door sommigen, na afgekookt te zijı, gegeten; meer echter wordt hij als huidprikkelend en roodmakend middel tegen inwendige ziekten aangewend; met zout fijngewreven is de wortel een vermaard geneesmiddel tegen slangenbeten, bij kwaadaardige zweren en herpes.

1234. Bira-burrum S. $=\mathrm{Al}$ o c asia metalli a S ehott. var. Nat. fam. als de vorige. Gr. Java, Borneo, enz., overblijvend. Gebr. Als vorig No.

1235. Bira-kaladi M., R. $=\mathrm{C}_{0}$ locasia antiquorum Schot t. (Zie No. 245.)

1236. Bira-ketjil M., R., = Ty. phonium divaricatum Bl. Nat. fam. der A roider. Gr. Overal in Indië; overblijvend GıвR. De versche wortel is giftig, hij wordt echter, na afgekookt te zijn, gegeten.

1237. Bira-mata LAMP. = C a llæocarpus rhamnifolia Miq., Nat. fam. der C u p u l if e r $x$. Gr. Sumatra; hooge boom.

1238. Bira-meirah M., zic Birab u r u m S.

1239. Bira-negrie M., R. = A locasia macrorhiza Sehott, Nat. fam. der A r o i d e æ. Gr. Door geheel Indië; overblijvend; GFBR. De onderaardsche stengels, worden, na door wassehing en koking van hul seherp beginsel ontdaan te zijn, op sommige cilanden veel gegeten.
Volgens Hasskarl zou het sap uit de bladstelen bij hoest dienstig zijn. De fijngesneden wortels en bladeren gebruikt men uitwendig tegen gewrichtslijden.

1240. Birahi MaK. $=\mathrm{C}$ ovelli a racemifera Miq. Nat. fam. der A r toe a $\mathrm{rp}$ e . Gr. Sumatra, Celebes, de Molukken; hooge boom. Grbr. Het hout is slechts goed voor brandhout; dc jonge bladeren worden als groente gegeten, de vruchten zijn door sommigen gezocht.

1241. Biralla $\mathrm{M}_{\mathrm{AK}}$. $=\mathrm{Z}$ e a $\mathrm{M}$ a is L. (Zie No. 1878.)

1242. Birara J. $=\mathrm{Quamoclit}$ $v$ u lgaris $\mathrm{Ch}$ o is (Zie No. 533.)

1243. Birindjene $\mathrm{MAK}_{\mathrm{AK}}=\mathrm{Cl}$ e r od endrum in erme Grt n., Nat. fam. der Verbenaceæ. Gr. Door geheel Indië, veelal in tuinen; heester. Gebr. De wortels, bladeren en zaden geeft men in- en uitwendig tegen vischvergiftiging; de bladeren legt men ook als heelend op versehe wonden, en eet ze, jong zijnde, bij de rijst. Aan den wortel kent men purgeerende eigenschappen toe.

1244. Biring-biring Sum $=\mathrm{Pty}$ e hos perm a al b a T. \& B., Nat. fam. der P a l m x. Gr. Sumatra.

1245. Biring-ingoe Sum. $=\mathrm{B}$ egon ia lepida Bl. (Diploclinium le p i d u m M i q.), Nat. fam. der Begon i a c e $æ$. Gr. Sumatra; overblijvend.

1246. Biring-sangkalo Sum. = A ntidesma salace ens e Zoll. (Zie No. 1132).

1247. Biring-simolai Sum. $=A \mathrm{r}$ gostem ma Teysmannianum Miq., Nat. fam. der Rubiaceæ. Gr. Sumatra; overblijvend.

1248. Biring-tanah $\mathrm{M} .=\mathrm{C} \mathrm{a} \mathrm{m}$ pelia mollissima B l., Nat. fam. der Commelynaceæ. Gr. Java, Suma. tra; overblijvend.

1249. Biroe S. $=\mathrm{Can}$ ariopsis hispida Bl., Nat. fan. der Amyridex Gr. Java, Sumatra; hooge boom. GeBr. De inlanders gebruiken den fijn gestampten bast tegen abeessen onder de voetzolen.

1250. Biroeroeng $\mathrm{R}$. $=\mathrm{M}$ e lasto m a B u rm. speeies divers

125l. Biroeroeng-hitam R. = M elastoma polyanthum Bl. (Zie No. 110.)

1252. Biroeroeng-meirah $\mathrm{R}_{0}=\mathrm{Me}$ $\mathrm{l}$ a s $\mathrm{t}$ om a a s perum Bl., Nat. fam. der Melastomacex. Gr. Java, Sumatra, enz. heester. 
1253. Birong S. $=\mathrm{Hicus}$ toxic aria L., Nat. fam. der A r t o c a r p e æ. Gr. Java, de Molukken; boom. Gerr. Deze bevat een dik, geel, hevig bijtend melksap.

1254. Bisoel-boeroeng M. J. = A rarocarpus velutinus Scheff., Nat, fam. Anonacer. Gr. Java, heester

1255. Bisoroh S. $=a$. C ovelli a hispida Miq.. Nat. fam. der Artocarpeæ. Gr. Java en de Molukken; boom. GEBR. Men bezigt den bast voor touw; het sap geeft men tegen koorts, buikpijn en moeielijke urinelozing te drinken; de bladeren eet men als groente; evenzoo nuttigt men de bijna rijpe vruchten, nadat zij eerst afgekookt zijn. Het water, waarin de bladeren en vruchten gekookt zijn, geeft men veelal aan kraamvrouwen na hare bevalling te drinken. $=b$. Covellia canescens Kürz., Nat. fam. als boven. GR. Java; hooge heester.

1256. Bisoroh-hiedung S. $=$ Ficuss c a berrime B l., Nat. fam. der A rt o c a r p e . Gr. Java; heester. Gebr. Men geeft het sap tegen koorst, buiklijden en moeielijke urinelozing.

125\%. Bissie-bissie J. = P o n g ami a $\mathrm{gr}$ a nd if oli a Z. \& M. Nat. fam. der Papili o n a c e a . Gr. Java: slingerplant.

1258. Bissie-matan $\mathrm{Bv} .=\mathrm{H} \mathrm{y} \mathrm{d} \mathrm{r} \mathrm{o-}$ cotyle asiatica L. (Zie No. 70.)

1259. Bissoela MaK $=\mathrm{Licuala}$ B i ss ul a M iq., Nat. fam. der Palmæ. Gr. Celebes; lage palmsoort. Gerr. Uit de vezelen der bladeren weeft men een soort van kleedjes.

1260. Bitau MaK. $=\mathrm{Calophyl-}$ l u m in o phyllum L. (Zie No. 1139.)

1261. Bitoe-lientjar S. $=\mathrm{C}$ o n y z a l a ce r a B rm. (Zie No. 1047b.)

1262. Bitoele Men. = Dioscorea h irs nt a B l. (Zie No. 47 o.)

1263. Bladong BL. = Euphorbia nereifolia L. (Zie No. 44.)

1264. Biai-angien $\mathrm{BK} .=\mathrm{Quercus}$ baevi-petiolatus Scheff., Nat. fam. der Cupuliferæ. Gr. Bangka; hooge boom.

1265. Blankondang S. = C y clostemon macrophyllum Bl., Nat.

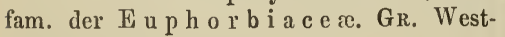
Java; boom.

1266. Blantoij $\mathrm{S} .=\mathrm{Arte} \mathrm{misia}$ ind i c a W $11 \mathrm{~d}$. (Zie No. 619a.)

1267. Blarong $J_{0}=\mathrm{M}$ a p pa de $\mathrm{n}$. tículata Bl., var. tomentosa Mor., Nat. fam. der Euphor bi ace . Gr. Java, de Molukken (?); boom. Gebr. Men gebruikt den bast voor het tanen der vischnetten.

1268. Bleketoepoek J. of Blakkatoepoe J. = Cla oxy ln m in d i c u m End), Nat. fam. der Eu phorbiac е г. Gr. Java, Timor. de Molukken; hooge heester. GEBR. Het hout gebruikt men veel als brandhout, doch het verspreidt een ondragelijken rook; het jonge loof eet men als groente; tegen asthma wrijft men den gekneusden bast, bladeren enz. op de borst in.

1269. Blendreng $\mathrm{S} .=\mathrm{H} \mathrm{y} \mathrm{me} \mathrm{n} \mathrm{o-}$ dictyon Horsfieldi M iq. (Zie No. 829.)

1270. Bliembieng 11. (ook Baliembing M., Bilimbo $T$. en Bilimbing M.) = A verrho a Cara mbola L. (Zie No. 85l.)

1271. Bliembieng-assem $\mathrm{M} .=\mathrm{A}$ verrhoa Carambola L. (Zie No. 851.)

1272. Bliembieng-bessie M. $=a$. A verrhoa Carambola L. en $b$. A. Bil i m b i L. (Zie No. 853.)

1273. Bliembieng-boelat M. on

1274. Bliembieng-boeloe $\mathrm{M}=\mathrm{A}$ ver$\mathrm{rho}$ a Bilimbi L. (Zie No. 853.)

1275. Bliembieng-kris $M$. en

1276. Bliembieng-manies $\mathrm{M}$. = A verrhoa Ca a mbola L.

1277. Bliembieng-oetan Амв. = El æ o c a r p us ed ulis T. \& B., Nat. fam. der Tiliacex. Gr. Amboina; boom.

1278. Bliembieng-pahit M. = D ap a n i a $r$ a c e mos a $K$ a r th, Nat. fam. der Oxalideæ. Gr. Sumatra, kleine boom.

1279. Bliembieng-rawah LAMP. = Leiopyis snmatrana Miq., Nat. fam. der Euphorbiaceic. Gr. Sumatra; boom.

1280 Bliembieng-tjina $\mathrm{M}$. = $\mathrm{C}$ ap u r a $\mathrm{Z}$ ollingerian a T. \& B., Nat. fam. der Sapindacer. Gr. Java; groote heester.

1281. Blinggit $J_{.}=\mathrm{S} \circ \mathrm{nchus}$ malajanus Miq., Nat. fam. der Compositæ. Gr. Java; éénjarig.

1282. Bloemboen-lalan J. = R hynchospora Wallichiana, Kth. Nat. fam. der Cy per a c e æ. Gr. Java, Sumatra; de Molukken; lage rietsoort.

1283. Bloemboeng-dalang $\mathrm{J}$. = Cassia marginata Roxb., Nat. fam. 
der Papilio n a e e r. Gr. Java; boom. Gebr. Deze komt als sierplant in vele tuinen voor; het met water fijngewreven zaad wordt, bij hardnekkige verstopping, op den buik ingewreven.

1284. Bloenbas M. en $J$. of

1285. Blontas M. \& J. $=\alpha . \mathrm{C} \mathrm{o}_{0}$ nyza indiea Bl. (Zie No. 413.) = b. Microglossa volubilis D.C. Nat. fain. der Com pos it æ. Gr. bijna overal in Indië; slingerplant. Geвr. Het krnid wordt als groente genuttigd en tegen koortsen toegediend.

1286. Boä J. \& BL. (Boeä of Woeä Alf. Min.) = Areea Catechu I., Nat. fam. der Pal ma. Gr. De Pinangpalm komt door geheel Indië in tninen voor. Gebr. Men gebrnikt de blad- en bloemscheden tot het inpakken van goederen. De noten zijn onmisbaar bij het betelkanwen, en aan het speeksel hierbij bekomen hecht de irlander een bijgeloovige waarde tegen de meeste ziekten. Oude rijpe noten zijn een goede looistof; volgens eenigen znllen zij cen sterk aphrodisiacum zijn. De Chineezen gebruiken een af kooksel der bolsters tegen dysenterie. De vrueht bevat catechu, doch in Ned.-Indië wordt deze dxarnit niet bereid.

1287. Boängit BL. $=a_{0}$ G $\mathrm{y} \mathrm{n}$ a $\mathbf{n}-$ dropsis pentphylla D.C. en $b$. Polan isia riscosa DC., beide van de Nat. fam. der C a pparidex. Gr. Bijua overal in tuinen; zaadplanten. GEBR. De bladeren ect men bij wijze van mostaardbladeren.

1288. Boär-massa J. = I po m $\propto$ a vitifolia Sw. (Zie No. $463 a$.)

1289. Bobalong $\mathrm{J}$. en $\mathrm{BL} .=\mathrm{Me}-$ la lenca $L$ e n e adendron L. (frue$t$ u s). (Zie No. 120a).

1290. Bobbi T. $=$ P a n g i n m edule $R$ wdt. (Zie No. 387).

1291. Bobo T. $=\mathrm{Nipa}$ fru $\mathrm{t}$ c ans Wrmb. (Zie No. 856).

1292. Bobolawa $\mathrm{T}$. $=\mathrm{C}$ a $\times$ y ophyll us aromaticus L., Nat. fam. der M y r a c e ie. Gr. De Kruidnagelboom wordt vooral in de Molukken aangekweekt, doch ook elders in tninen aangetroffen; het nut der bloemknoppen als specerij is overbekend.

1293. Bobossaren $\mathrm{S}$. $=\mathrm{M}$ or u s ind i c a $\mathrm{R} \mathrm{m} \mathrm{ph.} \mathrm{(Zic} \mathrm{No.} 797 \alpha$ ).

1294. Bodé J. $=a$. Chaviea majuseula Miq. (Zie No. 289) en 6. Chaviea Siriboa Miq. ('Lie No, 1181).
1295. Bodie M. = Caru m b i m populifolium Reinw., Nat. fam. der Enphorbi a ceie. Gr. Sumatra, Java, Bangka; kleine boom. Gквk. Den bast gebruikt men tot het zwartverven van katoenen stoffen; de bladeren mengt men gedroogd en fijngewreven, door het voeder van koebeesten, als worndrijvend middel.

1296. Bodjo-bodjol MaK. = A ndropogon $\mathrm{N}$ ardus L., is mogelijk A. muricatus Retz. (Zie No. 24l).

1297. Bodong-bodong $\mathrm{MAK}_{\mathrm{A}}=\mathrm{S} \mathrm{o}$ l a и и m esenlentum r. (Zie No. $2340)$.

1298. Boëai J. of Boeboëai S. = Plectocomia clongata Bl. Nat. fam. der P a l m x. Gr. Java; slingerplant, GrBR. Dit is eeu der langste en dikste rottan-soorten, van hare fijne sehil vlecht men hoeden, enz. Het sap wordt tegen koortseu gedronken; in een barnboe-koker ecn weinig met water gekookt, dient dit tot genezing van wonden of verbrandingen. Den van doorn bevrijden stam eet men op de Philippijnen, na dien geroost of gekookt tc hebben, bij wijze van salade. De vrucht is eetbaar.

1299. Воёаn Амв. = $\mathrm{L}_{\text {a }} \mathrm{ns}$ i $и \mathrm{~m}$ d o me sti c u m Ja ck. (Zie No. 98).

1300. Boëan Амв. of

1301. Boëan-abbal AMr. en

1302. Doean-taoeno Aмв. $=\mathrm{C}$ o oki a punctata Retz. (Zie No. 99).

1303. Boeboeken MaK. = Dillenia serrata Th $n$ b. (Zie No. 100).

1304. Boeboekoean S. $=a$. A dhat od a vasic a Nees., Nat. fam. der A can th a e ex. Gr. Java, heester. GEBr. Men kent aan de bittere aromatische bladeren, bloemen en zaden krampstillende eigenschappen toe. Vroeger waren de bladeren als "folia adhatodae" in de apotheken. $=6$. Peristrophe albiflora Hassk., Nat. fam. als voren. Gr. Java en 'Timor; kleine heester.

1305. Boeboelawan Aмв. $=\mathrm{Ca}_{\mathrm{a}}$ ryophyllus aromaticus L. (Zie No. 1292).

1306. Boeboeni $\mathrm{T} .=a \cdot \mathrm{Cassia}$ fist ula L., Nat. fam., der $\mathrm{C}$ x s a l p in i e a. Gr. Bijna op alle eilanden; boon. Gerr. Het gele, knoestige en moeilijk te splijten hont is zeer geschikt voor huisbouw en voor scheden van wapens; den bast keuwt men bij wijze van sirih. De bladeren en vruchten, fijngewreven, sineert de inlander op den buik van kinderen, 
om dezen ontlasting t3 bezorgen. Het vruchtmoes is als pulpa Cassic nog in onze apotheken. $=b$. Cassia megala n tha Desn., Nat. fam. als voren; Gr. Tínor; boom.

1307. Boeda $\mathrm{S} .=\mathrm{Artocarpus}$ el a stic a $\mathrm{R} w d t$., Nat. fam. der Arto. c a r p e x. Gr. Jara; hooge boom. Gebr. Het hont, dat door witte mieren spoedig wordt aangetast, dient slechts voor rijstblokken; van den bast maakt men een sterk, roodachtig touw; de bladeren bezigt men als onderlaag in rijst- of paddiehokken; het melksap dieut voor vogellijm en geeft men tegen dysenterie; de vrucht eet meu, evenals die der Nangka (A. i n t egrifolia L.), maar ze is niet zoo lekker.

1308. Boedie satoe Lamp. = S tilli ug i a pau iculata Miq., Nat. fam. der E u phorbi a c e r. Gr. Sumatra; hooge boom.

1309. Boedjangoet $\mathrm{S} .=\mathrm{M}$ e $\mathrm{n} \mathrm{th}$ a java nic a Bl., Nat. fam. der L ab i a $t$ æ. Gr. Java, Sumatra, enz.; overblijvend. GeBr. Het jonge kruid kau dienen in plaats van "herba menthæ piper"; de bladeren eet men als lekkernij bij de rijst.

1310. Boejoe-boejoe J. \& BL. = V ernon i a cinerea Less. (Zie No.67a).

1311. Boekit-selit M., Sum. = Chirita mollis Miq.. Nat, fam. der Cyrtandraccæ. Gr. Sumatra; heester.

1312. Boekoe-boekoe Sum. $=\mathrm{C}_{0-}$ velli a le picarpa Miq., Nat. fam. der A r to c a r p o æ. Gr. Java, Sumatra; heester. $=b$. Ficus serraria Miq., Nat. fam. Als roren. Gr. Sumatra, Menado; boom.

1313. Boekoo-boekoean MaD. = Wickstroemia Candolleaus Mrd. Nat. fam. der D a h n o ide æ. Gr. Java, Madura, heester.

1314. Boekoet KAMP. = Uristig. ma flavescens Miq., Nat. fam. als voren. Gr. Java, Sumatra; hooge boom.

1315. Boelang $R$. $=$ Coloc as ia a n tiquor u m S c hot t. (Zie No. 245.)

1316. Boelangan M. $=\mathrm{Gm}$ elin a villosa Rxb. (Zie No. 965.) $=b$. Dalbergia Zollingeriana Miq., Nat. fam. der Papilion a c e r. Gr. Java, Sumatra; heester. Grir. Het hout is als verfstof onder den naam van "Kajoe lakka" in den handel.

1317. Boeleijen Амв. = $\mathrm{Nipa}$ fructicans Warmb. (Zie No. 856).

13ls. Boelian Bk. = Eusideroxylon Z wageri T. \& B. (Zie No. 1103.;

1319. Boelie-boelie BG. $=X$ y loc a rpus Granatum $\mathrm{K}$ o e n., Nat. fam. der M eli a c e ז. Gr. Celebes, Timor, de Molukken; hooge boom. Gebr. Deze boom levert een geschikt meubelhout; den bast gebruikt men tot het bitter maken der Sagueer. Alle deelen van dezen boom, vooral de bast, het hout en de zadeu, zijn zeer bitter, en wordein bij verschillende aandoeningen der spijsverteerings organen als geneesmiddel toegediend.

1320. Boelillo Br. = M et rox $\mathbf{~ - ~}$ l u m filare Mlart., Nat. fam.der Palm ז. Gr. Boeroe, Ceram, enz.; hooge palm. GEBr. Uit de jonge bladeren klopt men garen tot het weven van kleedjes.

1321. Boeloe BL. = P a rin a ri u m multiflor um Miq., Nat. fam. der Chrysobalane $x$. Gr. De Sundaeilanden; boom. $=b$. Urostigma saxophilum Miq., Nat. fam. der Artocarp ex. GR. De Sunda-eilanden; heester.

1322. Boeloe J. = M e t rox y l u m Sagus Rttb., Nat. fam der Palmæ. GR. Wordt bijna oreral aangeplant gevondeu. Gebr. Deze palm levert een zeer goede soort ran Sago, die vooral uit Siak en Singapore uitgevoerd wordt; op Java eet men ze slechts bij gebrek aan rijst; de bladeren bezigt meu tot het dekken ran huizen.

1323. Boeloe M. MoL. $=\mathrm{B}$ a mb o e $\mathrm{MI}$.

1324. Boeloe S. = Urostig in a bi c or ne Miq., Nat. fam. der Artoc a r p e . Gr. Java, hooge boom. $=b$. Urostigma pilosum. Miq., Nat. fam. als voren. GR. Java; hooge boom, met eetbare vruchten. $=c$. U rostigma retusum Miq., Nat. fam. als voren. Gr. Sumatra; boom.

1325. Boeloe-badoerie M. = B a mbu sa teba Miq., Nat. fam. der Gramineæ. Gr. Java en de Molukken. GEBR. Dit zeer dikke riet, met korte geledingen, is slechts geschikt voor stijlen van huizen, het wordt niet door insecten aangetast.

1326. Boeloe-Boeloe R. = Tragia hirsuta Bl., Nat. fam. der E uph o r bi a c e re. Gr. Java, Sumatra; slingerplant.

1327. Boeloe-heuntjeu t-ninidoekoen 
S. = Cynoctonum Blumei Desn., Nat. fam. der A s cle p i a d e. Gr. Java, Sumatra; slingerplant.

1328. Boeloe-karissa MАK. en

1329. Boeloe-kas M. = B a in b u s a verticillata B l. (Zie No. 756).

1330. Boeloe-keij BD. $=\mathrm{Bambusa}$ fer a $\mathrm{Ml}$ i. (Zie No. 774).

13:31. Boeloe-mappa J. $=$ P ot h o s s c a ndens L. (Zie No. 57 1).

1332. Boeloe-mata-keboh S. = Eleo charis s u prolifera Std., Nat. fam. dar $\mathrm{C}$ y per a c ex. Gr. Java; rietsoort.

1333. Boeloe-mata-keboh-leutiek S. $=\mathrm{Ch}$ r to cy perus setaceus, Nat. fam. der C y p c r a c e æ. Gr. Java, Sumatra ; éénjarig. GEBR. Wit gras is een gezocht veevoeder

1334. Boeloe-ongko $\mathrm{J} .=$ A r toc arpus vene no s a $\mathrm{Z}$ o 11.. Nat. fam. der A rtoc arpea. Gr. Java; hooge boom, met een uiterst giftig melksap.

1335. Boeloe-potong M. \& J. = B a $\mathrm{mbusa}$ aspera K. \& S. (Zie No. $9343)$.

1336. Boeloe-samet M. (ook B. gantang M.) $=$ B a m bus excels a II i q., Nat. fam. der G r a m in e æ. Gr. Java en de Molukken; zeer hooge rietsoort. GEBR. Deze bamboe gebruikt men vooral voor vaatwerk, maten en voor vlerken van prauwen.

1337. Boeloe-seri BD. $=\mathrm{B}$ a m b il s a f e r a $\mathrm{M}$ q. (Zie No. 774).

1338. Boeloe-swangi $\mathrm{BD} .=\mathrm{B}$ a $\mathrm{m}$ b u s a a s pera R. \& S. (Zie No. 934b;).

1339. Boeloe-tangkoer $\mathrm{J}_{0}=\mathrm{U} \mathrm{r}_{\mathrm{n}}$ stigma pilos um Miq. (Zie No. $1324 b)$.

1340. Boeloe-toei MoL. = $\mathrm{Ba} \mathrm{m}$ bus a $l o n g i n o d$ is $M$ iq., Nat. fam. der Gra in in eæ. Gr. Java; de Molnkken. GEBR. Dit dunne riet, met zeer lange geledingen, bezigt men voor blaaspijpen, werpspiesen, fluiten en ombeiningen van tuinen.

1341. Boeloe-tombor BD. = B a mb us a fera Mi q. (Zie No. 774).

1342. Boeloe-wani M. \& $\boldsymbol{J}$. = B a m. bus a as p c a R. \& S. (Zie No. 934b).

134.3. Boeloe-wani-besaar M. = $\mathrm{Bambusa}$ excels a Miq. (Zie No. 133.36).

1344. Boeloen J. $=$ Metroxylon $\mathrm{S}$ a g 11 s $\mathrm{R} t \mathrm{tb}$. (Zie No. 1322).

1345. Boeloeng $S_{.}=a$. S o l a n u m
B l umei Nees, Nat. fam. der S o lan a c e . Gr. Java, Sumatra, Borneo, kleine heester. GEBr. De bladeren worden, rauw en in stoom gekookt, bij de rijst gegetcn; men eet ook de cenigszins zoete viuchten en houdt ze voor lekker. =- $b$. Solanum denticulat um Bl., Nat. fam. als boven. Gr. Java en Sumatra ; overblijvend.

1346. Boeloengan-roehol PAI. = I, e pidadenia $r u b r a$ B l., Nat. farn. der L a u r i n ex. Gr. Java, Sumatra; boom GEBR. Het hout is zeer hard en geschikt voor stelen van gercedschappen.

1347. Boeloestroe M. = $\mathrm{I}$ u ffa foet id a C a v. (Zie No. 465).

1348. Boelong J. \& B l. = S p h rococcus lichenoides var. te$n$ u is A g. ('Zic No. 20 en 21).

1349 Boembang LAMP. $=1$ ) i p torocarpus trinervis B 1. (Zie No. $6519 \alpha)$.

1:50. Boemboen Вк. = Ph x a $1 \mathrm{t}$ it u s nutalls H k. fs. \& Th. (Zie No. 1473!.

1351. Boemboeng-Belang $\mathrm{S} .=1 \mathrm{i}$ is. chidia cochlea e B l, Nat. fam. der Asclepiadex. Gr Sunda-Archipel ; parasiet.

1352. Boemit BL. $=$ Ficus $v$ arieg a t a B l., Nat. fam. der A r tocarpe $\mathrm{Gr}$. De Sunda-A rchipel; parasiet.

1353. Boemoes Lamp. $=$ Urostigma a n u lat u m M q., Nat. fam. der A r t o c a r p ex. Gr. Java, Sumatra; hooge boom.

1354. Boenda $\mathrm{S}=a$. Arto c a rpus Blumei Tréc. (Zie No. 1119). $=6$. A r tocarpus elastica $R$ wdt. (Zie No. 1307).

1355. Boeneh $\mathrm{MAK}_{\mathrm{A}}=\mathrm{A} \mathrm{nt}$ ides$\mathrm{ma}$ b unias S pr. (Zie No. 1425).

1356. Boenei Sum. W.K. = A n t idesma paniculatum B l., Nat. fam. der A ntidesmex. Gr. Java, Sumatra, Timor; boom. Gerr. De zllurachtig-zoete viuchten worden rauw gegeten.

1357. Boenga M. $=\mathrm{K}$ e $\mathrm{m}$ b a $\mathrm{n}$. $=$ flos, bloem.

1358, Boenga-baliktjaja $\mathrm{M}$. $=\mathrm{H} \mathrm{i-}$ biscus mutabilis $\Gamma_{1}$; ; Nat. fam. der M a lv a c e ж. Gr. Als sierplant door geheel Indië in tuinen; heester.

13.59. Boenga-biroe $\mathrm{M}$. = $(: 1 \mathrm{i}$ t $0-$ ri a tern a tea I., Nat. fam. der P'ap i 1 i o n a c ex. Gr. Algemeen in tuinen; slingerplant. GEBR. Aan den wortel kent 
men een braakwehkeude kracht toe; de bladereu en bloemen. legt men in water, tot dat dit blauw gckleurd is, en bezigt dit dan als oogwater bij lichte ontstekingeu; de bloemen wordeu gegeten, doch inzonderheid gebruikt om gebak fraai blauw te kleuren.

1360. Boenga-bissoe $\mathrm{M}_{\mathrm{AK}}=\mathrm{H} \mathrm{i}$. biscus rosa sinensis L., Nat. fun. der M a lv a cea. Gr. Overal in Indië als sierplant in tuinen, met een menigte verscheidenheden; heester. GEBR. De bladeren en bloemen zijn een verzachfend slijmig geneesmiddel, geschikt tegen borst- en blaasaandoeningen; de bloemen gebruikt men veel bij feesten, de roode tot het kleuren van gebak cn om schoenen fraai zwart te maken: de jonge bloemen of knoppen houdt men algerneen yoor vruchtafilrijvend.

1361. Boenga-bokki M. $=a$. G r a m$\mathrm{mat}$ a ply llum scriptum Bl. (Zie No. 365 ; en $b$. - G ram matoph y l1 " in s pe cio s um B l. (Zie No. $367 a_{\text {. }}$ )

1362. Boenga-djangan MAK. = $\mathrm{Fi}$ c us A l t im e raloo Rxb., Nat. fam. der $\Lambda$ rto c a r per. Gr. De Molukken ; boom. GEBr. De bladeren zijn als groente zeer gezocht; het melksap bezigt men op vergiftige wonden.

1363. Boenga-djawa MoL. $=\mathrm{Qu} \mathrm{a-}$ moclit vulgaris $\mathrm{Chois.}$ (Zie No. $533)$.

1364. Boenga-djeneh-mawara MAK. $=$ Plumieria a c utifolia Poir. (Zie No. 1367).

1365. Boenga-ejdja Mak. $=\mathrm{M}$ i c h elia ch am paca L. (Zie No. 4156).

1366. Boenga-gambier $\mathrm{M}$. = J a sm i u u gra ud iflorum L., Nat. fam. der J a s m in ex. Gr. Door geheel Indië als sierplant in tuinen; slingerplant.

1367. Boenga-goelong-tjoetjoe $M$. $=$ Plumiera acutifolia Poir., Nat. fain. der A p o c y n ex. Gr. Overal in Indië, vooral als sieraad op begraafplaatsen; boomachtig. GEBR. Men beschouwt den wortel in Bengalen als een doodelijk vergif. De Javaan bezigt den schors uitwendig bij scheuren en abcessen der voetzolen (sakit blah) en liet melksap tcgeu caries der tanden; de geurige bloemen legt hij tusschen de kleederen, vooral tot wering van insecten, soms worden deze ook geconfijt gegeten.

1368. Boenga-haramtsjada M. = Pentapetes ph nic a L., Nat. fam. der B ï t t n e r i a c ex. Gr. Overal als sierplant in tuinen; éénjarig.

3369. Boenga-japon M. = N e r i u m O le a nder I., Nat. fam. der A poс у и ех. GR. Als sierplant vrij algemeen in tuinen; heester; deze plant behoort tot de narcotische, scherpe vergiften.

1370. Boenga-kaki M. = Gramin atophylium seriptum Bl., (Zie No. 365).

1371. Boenga-kalente M. $=\mathrm{Cli}$ toria ternatea L. (Zie No. 1359.)

1372. Boenga-kambodja M. $=\mathrm{Plu}$ miera a cutifolia Poir. (Zie No. 1367).

1373. Boenga-kananga $\mathrm{M}$. = $\mathrm{C}$ ananga odorata HK. Fs. \& Tu.; Nat. fam. der A no naceæ. Gr. Door geheel Indië, om-de geurige bloemen, in tuiuen; hooge boom. GEBR. Het hout bezigt men tot huisbouw, doch het vergaat spoedig; den bast, met water fijngewreven, gebruiken de inlanders uitwendig tegen vergrooting dei milt. De bloemen draagt men in het haar, ook bereidt men uit deze een vluchtige olie, waarmede, bij guur weder en tegen koortsen, door velen dc huid wordt ingewreven. BLUME zag de zaadkorrels, fijngestooten met curcuma en gember, met goed gevolg uitwendig ge. bruiken tegen tusschenpoozeride koortsen.

1374. Boenga-kastela $\mathrm{T}$. $=\mathrm{Pe} \mathrm{n-}$ t a petes phanice a L. (Zie No. 1368).

1375. Boenga-knop M. = Go mphrena globosa L. (Zie No. 9).

1376. Boenga-koeboeran $\mathrm{M}=\mathrm{Plu}$ miera a utifolia Poir. (Zie No. $1367)$.

1377. Boenga-landak $\mathrm{M}$. \& $\mathrm{J}_{0}=$ Prionites Hystrix Miq. (Barleria Prionites I.), Nat. fam. der A c a $\mathrm{t} t \mathrm{~h}$ a c e æ. Gr. Door geheel Indië, meestal aangeplant in omheiningen; kleiue heester. GÉBR. Volgens RUмPнiUs geeft men het kruid uit-en inwendig tegen buikpijnen en pijnen in de zijden. Horsfielu zegt dat men aan dat kruid verzachtende en uitdrijvende krachten toekent. Volgens HASSKARL worden de bladeren, met kalk fijngewreven, tegen hoofdpijn ingesmeerd.

1378. Boenga-lawan M. $=\mathrm{Cary}$ o phy llus a rom a ticus L. (Zie Nu $1292)$.

1379. Boenga-mandoeroe MEN.

1380. Boenga-manila $\mathrm{M}$. $=\mathrm{Ta}$ berna niontan a coronaria RBr., (Zie No. 264). 
1381. Boenga-manoeroe BTJ en

1382. Boenga-manoor $\mathrm{M} .=\mathrm{J}_{\text {as }}$. minum Sambae L. (Zie No. 920.)

1383. Boenga-mantega $\mathrm{M} .=($ No. 1380.)

1384. Boengd-mata-hari'T. $=$ Pentapetes ph ni eea L. (Zie No. 1368.)

1385. Boenga-mati-hari $\mathrm{M}$. = $\mathrm{He}$ lianthus annuus L., Nat. fam der Compositæ. Gr. De Europeesche Zonnebloem wordt hier en daar in tuinen gekweekt. Gebr. Het zaad kan rauw eu gekookt worden gegeten en daaruit een zaehte, zoete olie bereid worden.

1386. Boenga-merak M. = Cæsalpinia puleherrima $S w$., Nat. fam. der Papilionaeeæ. Gr. Overal in tuinen en omheiningen als sierplant; heester. Gebir. Het dunne, zeer harde hout gebruikt men voor nagels in vaartuigen, omdat het zoo duurzaam is; het is in den handel als rood- of Chineeseh sapanhout, wegens de roode kleurstof; den wortel, die volgens sommigen giftig is, geeft men op Java aan kinderen tegen stuipen en vallende ziekte. LinDLEY kent daaraan tonisehe en aan de bladeren purgeerende eigensehappen toe. De bloemen zijn bij feesten zeer gezoeht; zij waren vroeger offieineel, zijn aromatiseh.bitter en worden tegen koortsen en chronische katarrhen toegediend.

1387. Boenga-nassi M. $=\mathrm{Cli}$ toria ternatea I. (Zie No. 1359.)

1388. Boenga-njingin $\mathrm{BL} .=\mathrm{T}$ abern montana e or on aria R. Br. (Zie No. 264.)

1389. Boenga-penjaton M. en J. = Clerodendrnm siphonanthus R. Br. Nat. fam. der V e r b e $и$ a e e Gr. Java, Celebes; heester; sierplant.

1390. Boenga-petang M. $=\mathrm{A} \mathrm{b} \mathrm{u}$ tilon hirtum G: I) on. (Zie No. 347.)

1391. Boenga-pitja-pingang M. =

Cle rodendrum infortunat um J. (Zie No. 758 )

1392. Boenga-poetri M. $=a$. Grammatophyllum seriptum Bl. (Zic No. 365.) en $b$. Grammatophyllum speciosum 13l. (Zie No. 367a.)

1393. Boenga-raja $\mathrm{M} .=\mathrm{Hibis-}$ eus rosa sinensis J. (Zie No. 1360.) 1394. Boenga-raja-poetie M. = B o e ng a poetri M.

1395. Boenga-siam M. = Per- gularia odoratissima L. Nat. fam. der A selepiadeæ. Gr. Deze slingerplant vindt men bijna overal in tuinen om hare geurige bloemen, die veelal in het haar gedragen of tussehen kleederen gelegd worden.

1396. Boenga-soessong $\mathrm{M} .=\mathrm{B}$. p o e tri M.

1397. Boenga-susanna M. = Platanthera SusannæBl. Zie No. 3776.)

1398. Boenga-tali $\mathrm{M} .=\mathrm{Q}$ u a mo elit vulgaris $\mathrm{Ch}$ ois (Zie No. 533.)

1399. Boenga-tandjong $\mathrm{M}=a$. Calophyllum inophyllum L. (Zie No. 1139) $=b$. Mimusops Elengi L., Nat. fam. der S a potaer. Gr. Dror geheel Ned. Indië in trinen en on de huizen, als sierplant en om de geurige bloempjes; boom. GeBr. Den wortel geeft men in af kooksel tegen spruw, als gorgeldrank; het grove hout is alleen gesehikt voor draaiwerk. De bittere, tonisehe bast wordt inwendig toegediend tegen koortsen, spruw, augina en tandpijn, uitwendig tegen slepende huidziekten. De geurige bloemen worden in het haar gedragen; uit deze stookt men een vluehtige olie en water, welk water men aan koortslijders toedient. De vruehtjes eet men als lekkernij on geeft ze ook in barensnuod. Uit het zaad perst men een door schilders zeer gezoehte vette olie, die ook aan barende vrouwen wordt ingegeven.

1400. Boenga-tenga-hari T. = $\mathrm{P}$ en t a petes $\mathrm{ph}$ h i e a L. (Zie No. 1368.)

1401. Boeaga-tiga-lapis $\mathrm{M}=\mathrm{C}$ alanthe veratrifoliak Br. (Zie No. 26.)

1402. Boenga-tsjana $\mathrm{M} .=\mathrm{C} x \mathrm{~s}-$ al pinia puleherrima L. (Zie No. 1386.)

1403. Boenga-tsjoepo M. = Pe $11-$ tapetes phouieea L. (Zie No. 1368.)

1404 Boenga-waktoe $\mathrm{M}$. = $\mathrm{H} \mathrm{i}-$ biscus mutabilis L. (Zie No. 1358.)

1405. Boenga-waktoe-ketjil M. = Mirabilis Jalappa J., Nat. fan. der $\mathrm{N}$ y e tag i n e ce. Gr. Overal in Indië in het wild en in tuinen; overblijvende plant. GEBR. De drastisch purgeerende wortel was vroeger offieineel, en werd lang voor de eehte Rad. Jalapper gehouden. Hij is minder sterk dan deze en wordt nog vooral tegen hydrops toegediend. Uit de 
ziden maken de Japanners een fraai wit blanketsel, dat ook aan onze indische vrouwell niet onbekend is.

1406. Boenga-waktoe-koening $M$. = Abutilonhirtum G. Don. (Zie No. 347.)

1407. Boenga-warie $M .=B$ o e ng a poetri M.

1408. Boenga-woengan $\mathrm{BL}=\mathbf{J}$ a sm i n u $\mathrm{m} \mathrm{S}$ a m b a c A it. (Zie No. 920.)

1409. Boenga-wollanda Амв. = Qu a moclit vulgaris Cho is (Zie No. 533.)

1410. Boengan $S_{0}=$ Neesia altissima B l. (Zie No. 1120.)

14.11. Boengang $\mathrm{S}$. $=\mathrm{M}$ e $\mathrm{mec}$ l o n n igrcsec n s H k. \& A., Nat. fam. der Melastomaceæ. Gr. De Sunda-eilanden; heester.

1412. Boengboelang $\mathrm{S}$. = Pre mna tomentosa Wlld., Nat. fam. der V e r b e n a c e $\propto$. Gr. Java; groote heester. GEBR. Het hout is zeer geschikt voor meubels.

1413. Boengboengdallang S. $=a$. Cassiajavaniea L. (Zie No. 1025.) en $b$. Cassia marginata $\mathrm{Rxb}$. (Zie No. 1730.)

1414. Boengboeroean S. $=\mathrm{C}$ iss us discolor Bl. (Zie No. 468.)

1415. Boengboeroetoe $\mathrm{S}$. $=\mathrm{C}$ issus arachnoidea Hassk., Nat. fam. der A m p e li d e æ. Gr. Java, Timor; slingerplant. Gebr. De zoete vruchten zijn door de inlanders zeer gezocht, en doen in smaak voor de gewone druiven weinig onder.

1416. Boenging-tegal $\mathrm{S} .=\mathrm{Co}_{0}$ vellia subopposita Miq., Nat fam. der Artoca rpex. Gr. Java; boom.

1417. Boengkeli PaL. $=\mathrm{N}$ a uc le a grandifolia Bl. (Zie No. 1870.)

1418. Boenglie $\mathrm{J} .=\mathrm{C}$ a lo s a $\mathrm{n}-$ thes indica Bl., Nat. fam. der Bigno nia cer. Gr. Bijna door geheel Indië; hooge boom. Gebr. Op Java en Sumatra bezigen oude inlanders den wortel tegen impotentia virilis. HASSKARL geeft op dat men bast en bladeren tegen maagaandoeningen toedient. De bladeren, bloemen en onrijpe vruchten worden gegeten.

1419. Boengo-Boengo $\mathrm{M}$. $=\mathrm{R} 0$ stellularia diffusa $\mathrm{N}$ ees. (Zie No. 1117.)

1420. Boengoer $\mathrm{S} .=a$. L a g e $\mathrm{r}$ st $r \propto m$ i a $r$ e $\mathrm{i} n æ R \times b$, en $b$. L a g. ovalifolia T. \& B. (Zie No. 1123c.)
1421. Boengoer $\mathrm{M} .=\mathrm{Grisle} \mathrm{a}$ tomentosa Roxb., Nat. fam. der L yth ra r i e æ. Gr. Java, Sumatra, Timor; heester. Gribr. Uit de bloemen bereidt men in Indië een gele kleurstof.

1422. Boengoer Sum. $=\mathrm{P}$ angium edule Rwdt. (Zie No. 387.)

1423. Boengohl PaL. $=$ Poly osm a mutabilis B l.. Nat. fam. der Escall on i eæ. Gr. Java, Sumatra; heester.

1424. Boenie-karambau J. en

1425. Boenie-karbau MAK. $=$ A nti desma Bunias Spr s., Nat. fam. der Antidesmex. Gr. Bijna overal in Indië aangeplant; hooge boom. GEBr. Je zuurachtige bladeren nuttigen de inlanders gaarne, zoo rauw als gekookt. Zij worden ook als zwectdrijpend middel gegeven tegen syphilitische aandoeningen en tegen uitputting; de vruchten worden rauw gegeten of bij visch gekookt.

1426. Boenjoen-boenjoen J. $=\mathrm{V}$ erno nia cincrea Less. (Zie No. 67a)

1427. Boenjouw $\mathrm{BK}$. $=\mathrm{Aglaja}$ tomentosa T. \& B. Nat. fam. der M eli aceæ. Gr. Bangka; heester.

1428. Boekaloenga BL. = I pom xa peltat a C hois. (Zie No. 303a.)

1429. Boenoe-kajoe PAL. = Bergsmia sumatrana Miq, Nat. fam. der Bixace r. Gr. Sumatra; boom.

1430. Boenoet $\mathrm{S}$. = Urostigma balicum Miq., Nat. fam. der A rtocarpex. Gr. Java en Bali; boom.

1431. Boenoet-kaladja S. = Urostigma religiosu m. Gasp. Nat. fam. als voren, Gr. Java; hooge boom. Gebr. Uit het melksap kan Caoutchou verkregen worden; den bast prijst men in afkooksel aan tegen diabetes; de vruchten zijn eetbaar.

1432. Boentak $\mathrm{S} .=\mathrm{Gu}$ et t a r da speciosa L., Nat. fam. der Rubiacer. Gr. Bijna overal wordt deze boom als sieraad in tuinen gevonden.

1433. Boentalie-ojot $\mathrm{S}=$ Tylophora c issoides B l. (Zie No. 647c.)

1434. Boentieng $\mathrm{BK} .=\mathrm{Quercus}$ sericea Scheff. Zie Ampenieng Вк.)

1435. Boentieng $\mathrm{BK}$. $=\mathrm{Quercus}$ Bennetti Miq. Nat. fam. der Cupuliferæ. Gr. Bangka; hooge boom.

14.36. Boentieries $S_{.}=$Ka la nch oё laciniata D.C. (Zie No. 46.)

1437. Boentieries-konneng $\mathrm{S}$. = $\mathrm{Kalanch}$ ö pinnata Prs. (Bryo- 
ophyllum calyeium Salisb.), Nat. fam. der Crossulacea. Gr. Door geheel Indië in tuinen; overblijvend. GEBR. De dikke bladeren worden uit- en inwendig als verkoelend middel aangeprezen; het sap ervan wordt tegen kourts ingenomen; inen legt ze ook in olic en wrijft deze in het haar tot bevordering van den hargroei. Men zegt dat de bladeren des morgens zuur, des middags smakelijk en 's avonds bitter ziju.

1438. Boentoengan Sum. W.K. = S a ur a y inflexide us Mi q., Nat. fam. der Ternst $\mathrm{r}^{\circ} \mathrm{m}$ i a e ex, GR. Suinatra; booin.

1439. Boentoet-andjing $\mathrm{M} .=\mathrm{G}$ y m. nothrix e le gans Büse, Nat. fam. der Graminea. Gr. Java; overblijvende grassoort.

1440. Boentoet-koetjing $\mathrm{M} .=\mathrm{A}$ e aly pha densiflora Bl. Nat., fam. der E u p h or bi a c ex. Gr. Door geheel Indië, meestal in tuinen; heester. GEBR. Rumpнius geeft op dat men den wortel en dc bladeren voor een speeifiek middel houdt tegen spruw der kinderen en tegen bloedspuwing; ook zou men de bladeren inwrijven tegen een soort van wilde melaatschheid, nom an poeti e M., het vitiligo of albinismus van den tegenwoordigen tijd.

1441. Boentoet-monjet $\mathrm{M} .=\mathrm{B}$. andjing $M$.

1442. Boentoet-oetjing $\mathrm{S} .=a$. Uraria picta Desv., Nat. fam. der Papilionace $x$. Gr. Bijna door geheel Indië; zaadplant. $=b$. Ur a r i a c r in i t a D e s v., Nat. fam. en Gr. als voreu; Gér. De inlanders wenden de fijngekneusde bladeren nitwendig tcger vergrooting van lever en milt aan.

1443. Boentoet-seroh S. $=a$. U r aria c rinita Des $v$., (Zie No, 1442b.) $=$ b. Pogostemon a ricularia H a s sk., Nat. fam. der Libia $t æ$. Gr. Door geheel Indië; een sterk-riekende, overblijvende plant. GF.BR. Volgens BLa vco is dit kruid vermaard als geneesmiddel tegen doof heid.

1444. Bantoet-sigoeng $\mathrm{S} .=\mathrm{Stro}$. bilanthes mosehifera Bl., Nat. fam. der A e a th a cex. Gr. Java ; kleine heester.

1445. Boentoet-tikoes S. \& M. = Heliophytum indicum D.C., Nat. fam. der Asperifolia. Gr. Overal in Ned.-Indië; éénjarig Gввr. Volgens Bla.vco bezigt men het sap op wratten, en dient men het zaad tegen derden- en vierdendaagsche kcortsen toe; eenigen wenden het sap, met keukenzout, tegen vlekken op het hoornvlies aan .

1446. Boera $\mathrm{M}$. $=\mathrm{F}$ is c us $\mathrm{T}$ a dj a m M iq., Nat. fam. der A r t o c a rp e a. Gr. Java; slingerplant.

1447. Boerahol $\mathrm{S}$. $=\mathrm{S}$ te le e h oc a r u s B u rahol lil., Nat. fam. der A nonacex. Gr. Java; boom. Gebr. De zoete vruchten worden rauw gegeten

1448. Boerang $\mathrm{BD}$. $=\mathrm{Covellia}$ $r$ a ce $\mathrm{m}$ if c ra $\mathrm{Niq}$. (Zic No. 1240).

1449. Boerieng LAMP. $=\mathrm{P}$ i n a $\mathrm{n}$ g a p a t u l a B l. (Zie Andong-Andong.)

1450. Boernai Sum. = Antidesma salac e n s e Zoll. (Zic No. 1132).

1451. Boero-malakko $\mathrm{T}$. $=\mathrm{C}$ is. s us repens L a m. (Zie No. 438).

1452. Boeroenaj $\mathrm{J}$. $=$ Crat $\mathrm{x}$ a m a g n a D.C. (Zie No, 1024).

1453. Boeroeng-randa $\mathrm{S} .=a . \mathrm{Ce}-$ ramanthus gracilis Hassk. , Nat. fam. der Euphorbia ceæ. GR. Java; kleine heester. GEBR, De hontskool gebruikt men om de tanden $\mathrm{zwart}$ te verven. $=b$. M e lanthesa rham no id e s B l., Nat. fam. als voren. Gr. Door geheel Indië; hecster.

1454. Boeroet S. = Artocarpus r i g i d u is l., Nat. fam. der A rtocarpex. Gr. Java en Sumatra; hooge boom. GEBR. Het roodachtige hout wordt gcbezigd voor huisbouw, meubels, wachtblokken, enz.; het melksap, met was gemengd, bezigt men tot het verven of batikken van sa. rougs en kleedjes. De znurachtig zoete vruchten zijn aangenaam om te eten.

1455. Roeron MAK. $=M$ a $\mathrm{Mnta}_{\mathrm{A}}$ dichotama Wall (Zie No. 926.)

1456. Boesso Амв. $=\mathrm{Z}$ i n g i b e $\mathrm{r}$ gramineurn Bl. (Zie No. 255.)

1457. Boessoe M. $=$ Pogostemon a uricularia Hassk (Zie No. 1443b).

1458. Boessoe-boessoe $\mathrm{MAK}_{\mathrm{A}}=a$. Ocimum sanctum L. (Zie No, 875.) $=$ b. Ocimum g'ratissimum L., Nat. fam. der $L a b$ i a tæ. Gr. Wordt, evenals O. sanctu m I., overal in tuinen gekwcekt en gebruikt.

1459. Boeta-boeta Bo, W. K. = Cerbera Odolla m H am. (Zie No. 1181.)

1460. Boetoo-kawanes $\mathrm{M}$. = $\mathrm{Sta-}$ chy a r phe ta in dica V a hl., Nat. fain. der Verbenacer. Gr. Overal in 
Indië, zoo wild als in tuinen; heester. Gєвr. $\mathrm{O}_{\mathrm{p}}$ Java drinkt men een af kooksel van den wortel tegen gonorrhoea, en geeft men een aftreksel der bladeren, gemengd met adas en poelassarie, tegen dysenterie.

1461. Boetoe-seetan M. $=\mathrm{H} \mathrm{y} \mathrm{m} \mathrm{e-}$ u ophallus dæmou um Nees. (Zie No. 1053).

\section{Boetoen S. of}

1463. Boeton-laut $M .=B$ a rrin rtonia speeiosa I.., Nat. fam. der M yrta e ex. Gr. Deze hooge boom groeit in Indië langs alle stranden. GEBr. Het sap, door iusnijding nit den stam bekomen, bezigt men als pisdrijvend iniddel. De bladeren gebruikt men bij wijze van borden. Uit de bloemen bereidt men in West-Indië een likeur „Fan de Créole,” genaamd. Het vruehtvleeseh wordt door somınigen gegeten. De fijngekneusde zaden bezigt men tot visehvangst; gebrand en gekauwd met pinang, banglaai en kruidnagelen geeft men ze tegen diarrhoea en kolijkpijnen. Uit het zaad perst men eer vette olie en een slijnig vocht, dat de Chineezen gebruiken om er hunne regeusehermen (pajongs) mede te bestrijken en waterdieht te maken.

1464. Boeton-gale MaK. of

1465. Boeton-gole MaK. = I rina glabra Bl., var. alb a Bl., Nat.fam. der Sapindacese. Gr. Bijna overal in Indië; hooge boom. Geвr. De bast dient tot het wassehen van het hoofdhaar en het dooden van ongedierte. Iet hout is zeer gesehikt voor huisbonw, voor het makeri van groote en vlakke borden (doelang) en roeispanen, het wordt echter spoedig door insecten aangetast. De zoete viuehten worden gegeten.

1466. Boewa-aroe M. = M y ristiea aruana Bl., Nat. fam. der Myristieex. Gr. De Molukken en NieuwGuinea; fraaie boom. Gerr. De vruehten eet men, om hare aangename zuurheid, gaarne bij visehspijzen; zij worden ook gekonfijt.

1467. Boewa-assoeseng M. = Neuburgia museuiliformis Miq., (Zie No. 45.)

1468. Boewa-ati-ati. Амв. $=\mathrm{Sa}$ na dera indiea Gærtn. (Zie No. 2452.)

1469. Boewa-batoe M. = Areng a saecharifera Lab. (Zie No. 243.)

1470. Boewa-boba Амв. $=\mathrm{Fy}$ nocaryam pyriforme Seheff., Nat. fam. der Ola ciner. Gr. Amboina; heester.

1471. Boewa-Boeton M. = Barringtonia speciosa L. (Zie No, 1463.)

1472. Boewadjarong $\mathrm{BD} .=1$ i osp yros Fben n k ktz (Zie No. 32.)

1473. Boewa-djoedjaroe $\mathrm{M}$. = Pha anthus nutans Hk. fs. \& Th., Nat. fam. der A non a c e æ. Gr. De Molukken; boom.

1474. Boewa-frangi Амв. = A n acard inm oeeidentale L., Nat. fam. der $A \mathrm{n}$ a $\mathrm{e}$ a r d i a e ex. Gr. Door geheel Indië in tuinen; boom. GEBR. De wortel werkt purgeerend; de samentrekkende bast wordt tegen spruw aangewend. Uit deu stam vloeit, bij insnijding, een gom, de Gomune d'aeajou van den handel, die voor boekenvernis zeer gezocht ls. De jonge bladeren worden als groente gegeten. De saprijke vruchtsteel, oneigenlijk de vrucht genoemd, is een zeer gezocht ooft, het sap gebruikt men voor limonade, terwijl er door gisting ook eeue soort van wiju, punch en azijn uit kan bereid worden. De zaden, die vroeger officineel waren, gelden nog als heilzaam tegen diarrhoea. Tussehen de schalen der noot en de zaden is een zeer scherp, blaartrekkend, giftig voeht anwezig, dat men als bijtmiddel op wratten, likdoorns en sproeten aanwendt. Dit sap, zoomede liet melksap des booms, bezigt men bij het besehilderen van lijnwaden. De zaadkernen zijn als lekkernij zeer gezocht, doch worden altijd goed afgewassen of geroosterd gegeten; volgens eenigen zullen zij de geslachtsdrift opwekken.

1475. Boewa-gore M. = G uil a n. d i n a Bo nd ue L., Nat. fam. der P a pilio n a e e. Gr. Vrij algemeen op alle eilanden; slingerplant. GEвr. De jonge bladeren worden, gekookt, tegen tussehenpoozende koortsen en ingewandswormen gegeven. De wortel en zaden sehijnen een bitter samentrekkend beginsel te bezitten, dat ten versterkende kraeht bezit, en nader verdiende onderzocht te worden. De zaden dienen aan kinderen en volwassenen als speeltuig, en worden vooral bij het tjonka-spel gebruikt; zij bezitten een brakingwekkend vermogen, worden tegen buikaandoeningen toegediend en schijnen ook het baren te kunnen vergemakkelijken.

1476. Boewa-hati M. T. $=\mathrm{S}$ o ul a in e a mara Lam., Nat. fam. der 
Simarnbaceæ. Gr. Java; de Molukken; heester. GEBR. Alle deelen dezer plant zijn zóó bitter dat reeds Rumpuius haar "rex amaroris" noemde; men schrijft daaraan dezelfde krachten als aan de Senega toe.

1477. Boewa-hatis M., T. $=$ An on a

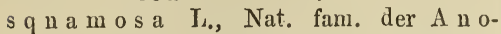
n a c e $x$. Gr. Vrij algemeen in tninen; boom. GEBR. De angenaam zoete vruchten zijn een gezocht ooft cn zeer gezond zoodat zij zelfs tegen ziekten der spijsverteringsorganen knnuen gegeven wordeu.

1478. Boewa-jakkies MEN. = A nac ardium occidentale L. (Zie No. 1474.)

1479. Boewa-kepaijong $\mathrm{B}_{\mathrm{K}}=\mathrm{S} \mathrm{c}$ aphin m W llich i i Walp., Nat. fam. der St erculiace æ. Gr. Sumatra, Bang$\mathrm{ka}$; hooge boom.

1480. Boewa-kira-kira Амв. = $\mathrm{X}$ y lo carpus obovat us Juss., Nat. fam. der Meliaceæ. Gr. Java, Bornco, de Molukken; hooge boom. GEBR. Als Xyl. Granatnm. (Zie No. 1319).

1481. Boewa-koan M. = Dracontomelon sylvestre Bl. Nat. fam. der An acardiace æ. Gr. Vrij algemecn in Indië verspreid; zeer hooge boom GEBR. Men wendt de bladeren an tegen spruw; de vruchten zijn als lekkernij zeer gewild; ze zijn echter aan jonge meisjes verboden.

1482. Boewa-kras M. $=\mathrm{Ale}$ urites trilob a Forst. (Zie No. 312.)

1493. Boewa-langhit $\mathrm{M}=\mathrm{S}$ a $\mathrm{p}$ ind u s R. arak I).C., Nat. fam. der S api ndaceæ. Gr. Vrij algemeen door Indië vcrspreid; hooge boom. GEBR. Het fraaie hout dient tot het maken van scheden voor wapens. In de Antillen telt men den bast en wortel onder de bitter-tonische gencesmiddelcn. De vrucht liceft bedwel. mende eigenschappen; men gebruikt ze vooral bij wijze van zeep tot wassching van het loofdhaar, waardoor tevens het ongedierte sterft.

1484. Boewa-1oeton $\mathrm{BI}_{\text {. }}=\mathrm{M}$ u s a simiaru in $\mathrm{kmph}$. (Zie No. 1191.)

1485. Boewa-malakka M. = a. E mblic a officinalis Grtn., Nat. fam. der Euphorbiaceæ. Gr. Op velc plaatsen in tuinen; boom. Gerr. Dell bast gebruikt men tot het zwartverven van kleedjes; de zure vruchten worden gegeten; zij zijn echter niet lekker. De ge- droogde steenvruchten waren vroeger als Myrobalani emblici in de apotheken; zij werden tegen diarrhoea, dysenterie en cholera gebruikt; thans zijn zij bniten gebruik. $=b$. Tetramerista glabra Miq, Nat. fam. der Ochnaceæ. Gr. Sumatra; boom. (?)

1486. Boewa-maloer M. = B rncea snmatrana Roxb. (Zie No. 296).

1487. Boewa-massie М. Амв. = Cubilia Rnmphii Bl. (Zie No. 271.)

1488. Boewa-nira $\mathrm{M} .=\mathrm{X}$ yloc a r p s Granat um Koen. (Zie No. 1319.)

1489. Boewa-nona of B. nonna M. = A nona reticulata L., Nat. fam. der A n o n a c e æ. Gr. Door geheel Indië in tninen. Gribr. Deze boonı wordt overal om de aangenaan zun rachtig zoete vinckten aangekweckt; dezc zijn zeer gezond en kunnen zelfs bij diarrhoea of dysenterie gegeten worden. De bast wordt door den inlander fijngewreven, en bij koortsen of vergrooting der milt op de miltstreek gelegd. De oladeren gebruilt men uitwendig als rijpmakend middel op abcessen, en geeft ze inwendig als wormdrijvend middel. Uit het zaad bereidt men een sterk samentrekkend cxtract, dat bij diarrhoea en dysenterie wordt toegediend.

1490. Boewa-oepas Аuв. = Sophora tomentosa L., Nat. fam. der Papilionacer. Gr. Java, Sumatra, de Molukken; groote heester. GEbr. De zaden waren vroeger als semina anticholerica in gebruik; zij zijn zeer bitter en purgeerend en worden daarom door den inlander tegen verschillende buikaandoeningen, vooral bij gestoorde galafscheiding cn cholera toegediend.

1491. Boewa-radja Tr. $=\mathrm{Heli} \mathrm{c-}$ t e res Is or a L., Nat. fam. der S te rc uli a c ex. Gr. Java, Timor, enz.; boomachtig. Geвr. De koningsvrucht van $\mathrm{Rn} \mathrm{mphins}$ wordt tegen hevige buikpijuen toegediend.

1492. Boewa-rau M. $=\mathrm{U}$ r a contomelon mangifernm Bl., Nat. fam. der Anacardiacer. Gr. Door gehecl Indië wild en in tuinen; zecr hooge boom. GEBR. Het witte, niet zeer harde hout gebruikt men voor schnitjes en kano's; de zure vruchten worden gegeten.

1493. Boewa-rau-oetan $\mathrm{M}$. = Dracontomelon sylvestre Bl. (7ic No. 14.81.)

1494. Boewa-rembang $\mathrm{M} .=a$. 
Sonneratia a cida $L$. fs. en $=b$. a l b a S m. (Zie No. 866 c. en d.)

1495. Boewa-saboen .í. = Sapind us Rarak DC. (Zic No. 1483.)

1496. Boewa-sawoh M. \& S. = Achras Sapota Linn. Nat. fam. der $S$ a p o t a c ex Gr. Hier en daar veel in tuinen; boom. GEBR. Op Java gebruikt men het hout voor fijne meubelen. De bast bevat een bitter melksap, en wordt als koortswerend middel aangeprezen; ook bereidt meu er een vette olie voor de huishouding uit. De aangenaam zoete vruchten (Sapodilla.pruimen of West-Indische mispels) ziju door velen zeer gczocht. De zaden zijn openend, pisdrijvend en heilzaam bij ziekten der urine-organen.

1497. Boewa-sawoh $\mathrm{S}$. $=\mathrm{M} \mathrm{imu}$ s o ps K a u ki L., Nat. fam. der S ap o t a c e r. Gr. Java, Borneo, Celebes; boom. Gerr. Het hout is een zeer geschikt en duurzaam bouwhout; de vruchten worden gegeten.

1498. Boewa-sima $M_{а K}=E l æ-$ o c a r p u s er rat us L. (Zie No. 104.)

1499. Boewa-tampajang BAт. = Carpophyllium macrocarpum Miq. Nat. fam. der S t i r c ul i a c e æ. Gr. Java. Bangka; ủe vrucht wordt gegeten, maar is flauw van smaak.

1500. Boewa-tampoei $\mathrm{AI}$. = H c dy. carpus malayanus Jack. Nat. fam. der S a pindace æ. Gr. Sumatra, Borneo; boom. GEBR. De vruchtcn worden gegeten.

1501. Boewa-tator $\mathrm{M} .=\mathrm{X}_{\mathrm{y}} \mathrm{lo-}$ c a r u s Gran tum Kocn. (Zie No. 1319).

1502. Boewa-tinta MEv. $=\mathrm{S}$ te $\mathrm{r}$ c uli a urceolat a Sm., Nat. fam. der Sterculi a c e Gr. Java. Timor, de Molukken; boom. Gebr. Het hout is licht, doch niet sterk, de bast wordt op Ternate als stondendrijrend reel aangewend; den schil der vruchten gebruikt men om kleedjes blauw te verven; de zaden zijn eetbaar als zij geroosterd zijn, zij veroorzaken echter lichtelijk hoofdpijn en duizeligheid.

1503. Boewa-tjoepa M. = Pierardia dulcis Jack. Nat. fam. der E uph or b i a c e $æ$. Gr. Sumatra; boom. GeBr. De aangenaam zuur-zoete vruchten zijn zcer gezocht.

1504. Bogem J. $=$ S o nneratia a c id a L.fs. (Zie No. $866 c$.)

1505. Bohk BL. = Dracontomelo n B l. S pec.
1506. Boisoea T. $=$ Ino carpus ed ul is L. (Zie No. 340.)

1507. Bojo-bilokka Mak, en

1508. Bojo-karappa $\mathrm{MAK}_{\mathrm{A}}=\mathrm{Cu}$ c u mis sativus L. (Zie No. 403).

1509. Bojo-laba $M_{A K} .=L a g e-$ naria idolatrica Ser. (Zie No. 4876.)

1510. Bojo-lompo Mak. en

1511. Bojo-pampoena MaK. = I agenaria hispida Ser. (Zie No. 5123.)

1512. Bokima-kotele T. $=\mathrm{Cli}$ itor i a tern a te a L. (Zie No. 1359.)

1513. Bokkaaij S. of Bokraij S. = Elat eri ospermum Tokbray BL., Nat. fam. der E u phor bi a ceæ. Gri. Java; hooge boom. GEBr. Het fraaie, witte, fijne en sterke hout wordt niet door witte mieren aangetast en is zeer geschikt voor bouwhout. De rijpe vruchten worden gegeten.

1514. Bollang $\mathrm{S} .=\mathrm{Colocasia}$ antiquorum Schott. (Zie No. 245.)

1515. Bollong J. \& $\mathrm{Bl}$. $=\mathrm{Mela}$ le u c a leucadendron L. (Zie No. 120a.)

1516. Bomberettian $\mathrm{S} .=a$. Rnbus fraxin ifolius Poir., en $b$. R. ro$\mathrm{s}$ æfoli us S m. (Zic No. 1122.)

1517. Bombo-terbang M. (Pombo terbang M.) = Pha la nopsis a mab i I i s Bl. (Zie No. 374.)

1518. Bomboelang $\mathrm{S}$. $=\mathrm{Premna}$ to mentos a Wlld. (Zie No. 1412.)

1519. Bombom S. \& M. $=\mathrm{Man}-$ gifera foctida Lour. var. Bombom B l. (Zie No. 274.)

1520. Bombori BD. $=\mathrm{I} \mathrm{pom} \mathrm{a}$ pes c aprie (Zie No. 1039.)

1521. Bona-ati $\mathrm{S} .=\mathrm{S}$ o u $\mathrm{I}$ a $\mathrm{mea}$ a m a r L a m. (Zie No. 1476.)

1522. Bondeh $\mathrm{M}_{\mathrm{AK}}=\mathrm{Bojo-laba}$ MAK.

1523. Bondor $\mathrm{S} .=\mathrm{B}$ en incas a cerifera Savi. (Zie No. 904a.)

1524. Bondot S. \& J. $=a$. L y c 0 . persicum esculentum Mill. (Zie No. 1111.) $=$ b. Cardiospermum Halic a c a b u m L. (Zie No. 433) en $=c$. Dichrocephala latifolia D,C., Nat. fam. der C ompositæ. Gr. De Sundaeilanden; zaadplant.

1525. Boneh Sur. Wr. = A n t idesma paniculatum B l. (Zic No. 1356.)

1526. Bonelau $\Lambda$ мв. $=\mathrm{Z}$ ing ib er marginat um Rxb. (Zie No. 254.)

1527. Bongok-alas J. $=\mathrm{C}$ as s i a fistula I. (Zie No. 1306a.) 
1528. Bongol-bas M. = Corypha u m bra culifera L., Nat. fam. der P a l mæ. Gr. Java, Celebes enz.; hooge palmboom. Gris. De boom is van zeer veel nut; de stam heeft een zeer vast hout en bevat reel sago; stukken van den stam worden uitgehold en met geitevel bespannen om te dienen als trommen (bedoek) bij de Mahomedaansche tempels; van het hout vervaardigt men ook verschillende gereedschappen. De bladeren dienen tot dekking ran huizen (atap), men vlecht er ook hoeden en doozen van. Van de jongere bladeren makt men koffiezakken en zeilen voor prauwen. Uit de bladstelen bereidt men een vrij sterk touw. De jonge top of de nog onontwikkelde bladeren (hoemoet) wordt als groente gegeten. Den samentrekkenden wortel dient men toe tegen dysenterie. De halfrijpe vruchten worden gegeten, van de rijpe maakt men rozenkransen.

1529. Bonteng $\mathrm{S}$. $=\mathrm{Cu} \mathrm{cumis}$ s a t i v u s L. (Zie No. 403.)

1530. Bonteng-pandjang $\mathrm{J}_{\mathrm{.}}=\mathrm{Cu}$ c u m is flexuosus L., Nat. fam. der $\mathrm{Cu}$ e u r b it a c e æ. GR. Op Java in tuinen ; slingerplant.

1531. Bonteng-soerie $\mathrm{S}$. = L a g en a ria vittat a $S$ er., Nat. fam. als voren. Gr. Op Java in tuinen aangekweekt; slingerplant. Geвr. De vruchten worden gegeten.

1532. Bontjo $\mathrm{S} .=\mathrm{T}$ e tranth e ra op positifolia Miq., Nat. fam. der L a u rineæ. Gr. Java en Sumatra; boom.

1533. Bontjo-soedoh $\mathrm{J} .=\mathrm{J}$ as. minum quinquenervium Bl., Nat. fam. der J a s m in e æ. Gr. Java; slingerplant.

1534. Bootsja T. $=$ Roxburghia javanica Kunth, Nat. fam. der R oxburghi a ce $x$. Gr. Java, Sumatra, de Molukken; slingerplant. GEBR. De wortels worden geconfijt gegeten.

1535. Doppo-tseda $\mathrm{T}$. $=\mathrm{B}$ a p at j e da M en. (No. 1001.)

1536. Bopröon J. en

1537. Bori T. = Anamirta Cocculus A. \& W. (Zie No, 339.)

1538. Borgka J. $=H$ e $r$ a n d i a So nor a L. (Zie No. 16.)

1539. Borie MeN. $=$ Ormocarpu m g l abram T. \& B., Nat. fam. der P apilionace $x$. Gr. Celebcs, Ccram; beester.

1540. Borie M. en
1541. Boroero T. $\mathrm{T}$ Croton Tigli u m L. (Zie No. 6.)

1542. Borra-boie $S$ (ook Burrebeüi S.) = Gynotroches axillaris B l. (Zie No. 101\%).

1543. Borra-boie-beurriet $\mathrm{S}$. = L a sianthus stipularis B l., Nat. fam. der $R$ u b i a e e æ. Gr. Java, Sumatra; Borneo; heester.

1544. Bossi S. $=\mathrm{W}$ en $\mathrm{dl}$ andia $l æ v i g$ a t a $M$ iq., Nat. fam. der R ub i a c e æ. Gr. Java; heester.

1545. Botolina $\mathrm{T}$. $=\mathrm{M}$ a b a $\mathrm{E} \mathrm{b}$ n u s R B r. (Zie No. 107).

1546. Bôtor J. = Ps ophocarpus tetrag o nolobus DC.; Nat. fam. der Papilionacex. Gr. Deze slingerplant wordt door geheel Indië in tuinen gevonden. Gebr. De bladeren, jonge takjes en onrijpe peulen worden in stoom gekookt en door velen als groente gegeten. Ook nuttigt men de zaden, nadat zij eerst in een ijzeren pan geroost zijn, totdat de schil is afgevallen.

1547. Bou-batati J. = Qu a moc lit v ulgaris Chois. (Zie No. 533.)

1548. Bragma $\mathrm{S}$. = Guatteria macroph vlla Bl. var. Bragma B l., Nat. fam. der A nonaceæ. Gr. Java; groote hecster. GeBr. De bladeren gebruikt men gaarne als wondheelend, etterverbeterend middel, vooral bij zweren aan de borsten van zogende vrouwen.

1549. Brambang $R$. = Allium Cepa L. \& aliæ. (Zie No. 1078.)

1 5̌50 Brambang Sux. WK. = Sonne r a ti a a cid a L. fs. (Zie No. 866c.)

1551. Brambang-oetan M. = Pancratium zeylanicum L. (Zie No. $869 c$.)

1552. Brang-pipit $\mathrm{Br}$. $=\mathrm{C}$ a s tanopsis trisperma Seheff. (Zie boven.)

1553. Brappa Bl. en

15ว4. Brappat M. $=a$. S o n n cratia alba Sm. en $b$. S. acida D.C. (Zie No. 866.)

1555. Brappat-gelang $\mathrm{M} .=\mathrm{Pem-}$ $p h$ is acidula $H^{\prime}$ orst., Nat. fam. der Lythrarica. Gr. Door geheel Ned. Indië; groote heester, GEBR. Het geurige hout is door de Clincezen zeer gezocht, die er kistjes van maken; de zure bladeren worden rauw bij de visch gegeten.

1556. Brappat-ketjil M. = $\mathrm{Ng}$ iceras majus Grtn., Nat. fam. der E g i c e r e a. Gr. Bijna nveral gezellig langs de zcestranden; hcester. GввR. Het 
hout is geschikt voor brandhout; de bloemen worden in het haar gedragen; de. bladeren eet men als groente.

1557. Brappat-poetih M. = Sonll cratia a cida D).(.. (Zie No. 866.)

1558. Brappat-loedong M. = Egiceras minus Grtn., Nat. fam. der Egicerex. Gr. In de Molukken gezellig aan de zeestranden; heester. GEBR. Het hout gebruikt men voor liandvatsels van krissen en kapnessen; den bast wendt men aan als vischvergif.

1559. Brawas PaL. = Tetranthera Braw as B l., Nat. fam. der L a u rineæ. Gr. Sumatra; boom.

1560. Bregedieng $\mathrm{BL} .=\mathrm{Gy} \mathrm{r}_{0}$ c a r us asiaticus Wlld, N'at. fam. der L a urineæ. Gr. Vsu Jara tot Timor; hooge boons.

1561. Brembets J. $=\mathrm{Rubus} \mathrm{m} \mathrm{o-}$ luccanus Rmph. (Zie No. 1396.)

1562. Brengbang $\mathrm{S}$. = Polyosma integrifolia Bl. (Zie No. 423.)

1563. Bretowalli J. = Anamirta Cocculus W. \& A. (Zie No. 339.)

1564. Bri-bri PAL. = Engelhartia palembanica Miq., Nat. fam. der Juglandeæ Gr. Sumatra; hooge boom.

1565. Bringin $\mathrm{R} .=\mathrm{Urostigma}$ b e $n \mathrm{j}$ a mine u m Miq., Nat. fam. der A r t o c a r e æ. Gr. Door geheel Indië. GEBR. Veelal pjant men dezen statigen, schaduwrijken boom, den kleinbladerigen Warengieboom, op pleinen, langs wegen, of op begraafplaatsen aan. Het sap, dat veel caoutchou bevat, staat bekend als een zacht oplossend geneesmiddel. De vruchten zijn eetbaar; zij worden echter rooral door vogels gezocht.

1566. Bringin-soensang Sum. WK. $=$ Synœcia diversifolia Miq. (Zie No. 418.)

1567. Brobasan J. $=$ Aneilena diversifolium Hassk., Nat. fam. der Commelyn aceæ. Gr. Java; overblijvend.

i568. Brodjo-wing $\mathrm{J}$. $=\mathrm{A} \mathrm{m}$ ar acarpus pubescens Bl., Nat. fam. der $\mathrm{Kubi}$ a cer. Gr. Java: hooge boom.

1569. Broetaka $\mathrm{BL}$. = S emecar. pus cassuvium Sprg., Nat. fam. der A n a c a diace re. Gr. De Molukken ; hooge boom. Grisr. Het hout dient tot brandhout; de bladeren gebruikt men om houtwerk zwart te maken, ook om te tatoueeren en tegen herpes; de vruchten worden gegeten.

1570. Brogo-wengi $\mathrm{J} .=\mathrm{M} \mathrm{ik} \mathrm{a-}$ nia volubilis Wlld., (Zie No. 459.)

1571. Bungburruman S. $=\mathrm{C}$ is- . sus discolor Bl. (Zie No. 468.)

1572. Bungo-bungo-parampoewan M. = Hypoëstes purpurea R.Br. No. 96.)

1573. Bunjieng $\mathrm{S} .=a . \mathrm{B}$ a la n ophora Forst Spec. omn., Nat. fam. der Balanophorea. Gr. Java; parasieten. GEBR. Deze planten bevatten alle veel plantenwas, waarvan de inlanders kaarsen maken. $=b, \mathrm{C}$ ovelli a hi spida Bl. (Zie No. 1255a) = c. C. lepicarpa Miq., (Zie No. 1312) $=d$. C. stict o c a r p a Miq., Nat. fam. der Artocarpere. Gr. Java; boom. $=e$. Ficus geminifolia Miq., var. ban t amensis, Nat. farn. der vorige. Gr. Java, Sumatra, Bangka; boom.

15้74. Bunjieng-bener S. en

1575. Bunjieng-happa $\mathrm{S}$. $=\mathrm{C}_{0}$ vellia subopposita Miq. (Zie No. 1416.)

1576. Bunjieng-burram $\mathrm{S}$. $=\mathrm{Fi}$ cus brevicuspis Miq. (Zie No. 305). 1577. Bunjieng-oraij $\mathrm{S} .=\mathrm{Covel}$ li a $r$ ufescens Kürz, Nat. fam. der A r t o c a r p e x. Gr. Java; heester.

1578. Bunjieng-tjaai S. = Covelli a le picarpa Miq. (Zie No. 1312.) $=6$. Covellia das ycaula Miq. Gr. Java, Batjan; heester. $=c$. Covellia did y m a M iq. Gr. Java, Sumatra; heester.

1579. Bunpröon BL. $=$ Anamirta c oc ulus W. \& A. (Zie No. 339)

1580. Buntjoi S. $=$ Pierardia r a c emos a Bl., var. Nat. fam. der Euphorbiaceæ. Gr. Java, Sumatra; boom. Gerr. Het fraaie, fijne, weeke, doch sterke hout is zeer geschikt voor huisbouw en fijne meubelen; de kleine vruchten hebben een zuur-zoetachtigen smaak, worden veel gegeten en zijn zeer gezond.

1581. Burrie S. $=$ Pteroc y m bi um javanicum H. \& B. (Zie No. 1200c.) 


\section{D.}

1582. Daban J. = Ardisia purpurea Rwdt., Nat. fam. der My rs ine $x$. Gr. Java: heester.

1583. Dabat-goena $J .=$ Vernonia leptophylla D.C. (Zie No. 676.)

1584. Dada-boerong $\mathbf{M}$. $=$ Ardisia Miqueliana Scheff., Nat. fam. der M yrsineaceæ. Gr. Bangka; heester.

1585. Dadah LaMr. $=a$. Artocarpus Dadah $\mathrm{Miq}$, en $=6$. A. tephrophylla Miq. Nat. fam. der Artocarper. Gr. Lampongs op Sumatra; boom.

1586. Dadap S. en M. = a. Erythrinæ L. Spec. diversæ, Nat. fam. der Papilionacex. Gebr. Alle dadapsoorten worden in plantsoenen als schaduwboomen aangeplant; zij groeien spoedig, geven een lichte schaduw, maar laten hunne bladeren veel valleı; men gebruikt ze ook als stutten voor slingerplanten, b.v. voor sirih, peper, enz; het weeke hout scheurt licht, men maakt er platen voor beschotten van. $=b$. Erythrina indica Lam., Nat, fam. en Gebr. Als voren. Gr. Geheel Indië.

1587. Dadap-bilindoeng S. of D.-blendoeng S. en D.-blindoeng $\mathrm{J}$. $=a$. Erythrina indica Iam. (Zie No. 15866 ). = b. Erythrina lithosperma Bl., Nat. fam. als voren. Gr. Java; boom. GEвR. De jonge bladeren, soms ook de zwarte zaden, worden rauw bij de rijst genuttigd. $=c$. Erythrina lobula ta Miq., Nat. fam. Gr. cn Gebr. Als bij $b$.

1588. Dadap-blem J. = Erythrina lobulata 11 iq. (Zie No. 1587c.)

1589. Dadap-bong J. = a. Erythrina spathacea D.C., Nat. fam. als boven. Gr. Op Java ingevoerd san St. Domingo; boom. GEBR. Ie sterk riekende bladeren worden fijngewreven en bij hoofdpijn van kleine kirideien op het voorhoofd gelegd.

1590. Dadap-doerie M. = Erythrina lithosperma B 1 . (Zie No. $1587 b$.

1591. Dadap-katteh S. = Micropteryx cristagalli Wlprs., Nat. fam. der Papilionacere. Gr. Uit Brazilië op Java gebracht; boomachtig.
1592. Dadap-malaijoe Sum. = Erythrina lithosperma Bl. (Zie No. $15876)$.

1593. Dadap-mienjak M. $=\mathrm{H}_{y}$. paphorus subumbrans Hassk., var. inermis Hassk. en

1594. Dadap-mienjak-tjoetjoek M. = Hypaphorus subumbrans Hassk., var. aculeatus Hassk. Nat. fam. der Papilionaceæ. Gr. Java; hooge boom. Gebr. Het sap uit de jonge takken van variëteiten wordt bij oogontstekingen als waschwater aangewend.

1595. Dadap-serep J. = Erythrin a fusca Lour., Nat. fam. als voren. Gr. Door geheel Ned.-Indië; boom. GEBR. De bladeren worden als groente gegeten.

1596. Dadap-sungüet $\mathrm{S}$. = Erythrina spathacea D.C. (Zie No. 1589.)

1597. Dadap-tüet S. en.

1598. Dadap-tis S. en

1599. Dadap-tjoejoek M. = Erythrina lithosperma Bl. (Zie No. 1587b.)

1600. Dadap-wangie M. = Erythrina spathacea D.C. (Zie No. 1589.) 1601. Dadauw Bк. = Isonandra Gutta Hk. (Zie No. 890 )

1602. Daghdagkseh BL. of

1603. Daghdogk $\mathrm{BL}_{\mathrm{L}}=\mathrm{P}$ isonia sylvestris T. \& B. Nat. fam. der Nyctaginex. Gr. Java en Bali; boom. Gebr. De bloemen, die den reuk van Heliotropen hcbben, dienden vroeger bij de kroning der keizers van Java.

1604. Dahingora T. \& MEN. = Codiæum moluccanum Desn. (Zie No. 126.)

1605. Daho S. = Dracontomelon mangiferum Bl. (Zie No. 1492.)

1606. Daleh Sum. W.K. $=a$. Memecylon subtrinervirm Miq. Nat. fam. der Melastomacer. Gr. Sumatra; heester. $=b$. Elæocarpus hypadenus Miq., Nat. fam. der Tiliaceæ. Gr. Sumatra; boom.

1607. Dahleh-badak Sum. W.K. = Ternstrœmia patens Chois., Nat fam. der Ternstrouniacex. Gr. Sumatra; heester.

1608. Dalimah $\mathrm{S}$. = Punica Granatum L., Nat, fam. der Granatcæ. 
Gr. Door geheel Indië gekweekt; groote heester. Gribr. De wortelschors is om haar wormdrijvend vermogen, vooral tegen lintworm, uit alle handboeken bekend; de om hare schoone kleur gezochte bloemen dienen in aftreksel als mondspoeling tegen scheurbuik en spruw; de zaden, en vooral de vruchtschillen, werken tonischadstringecrend en men gebruikt ze bij leacorrhoes, diarhoea en dysenterie; ook maakt men met sagueer-azijn een fraaie schrijfinkt; het vruchtmoes is als ooft door velen gezocht en wordt veelal met rooden wijn en suiker gegeter.

1609. Dalimah-hitam M. $=\mathrm{Pu}$ nica Granatum L., flora rubr. fr. n igra, Nat. fam., Gr. en Gebr. Als voren.

1610. Dalimah-katteh S. = Punica $\mathrm{n}$ an a L., Nat. fam, als voren. Gr. Java en elders gekweekt, uit Japan overgebracht. GeBr. Als voren.

1611. Dalimah-kennong S. of

1612. Dalimah-poetih M. = Punica Granatum L. var. albescens. (Zie No. 1613.)

1613. Dalimah-soesoen $\mathrm{M} .=\mathrm{Pu}$ nica Granatum L., var. fl. rubr. pleno (Zie No, 1608.)

1614. Daloe-daloe Sux. W.K. = Salix sumatrana Miq., Nat. fam. der Salicineæ. Gr. Sumatra; heester.

1615. Daloendoeng BL. $=$ Erythri$\mathrm{na}$ in dica Lam. (Zie No. 1587a.)

1616. Damar-serang $\mathrm{B \kappa}_{0}=$ Shorea sublacunosa $\mathbf{M l}$ iq., Nat. fam. der Dipterocarper. Gr. Bangka; hooge boom, die veel hars levert.

1617. Dammar M. en

1618. Dammar-batoe MI. = Dam. mara alba $R m p h$. Nat. fam. der Abietineæ. Gr. Door geheel Indië; hooge boom. GEBR. Deze boom levert de in den handel veel voorkomende dammarhars waarvan de inlanders flambouwen maken; het hout is zeer broos, en wordt, behalve voor klein draaierswerk, niet aangewend.

1619. Dammar-galla-galla M. = Canarium rostratum Zipp., Nat. fam. der Burseraceæ. Gr. De Molukken; hooge boom. GEBR. De hars van dezen boom gebruikt men tot het breeuwen van prauwen en voor fakkels.

1620. Dammar-hitam M. $=a$. Canarium lostratum Zipp. (Zie vorig No.) $=b$. Canarium longiflorum Zipp., Nat, fam., Gr. en Gebr. als voren.)
1621. Dammar-hitambaloe M. = Canarium serricuspe Miq., Nat. fam. der Burseracex. Gr. Sumatra; hooge boom. GEBR. Deze levert een bruikbare hars.

1622. Dammar-kloekoep Вк. = Vatica sublacunosa Miq., Nat. fam. der Dipterocarpeæ. Gr. Bangka; hooge boom.

1623. Dammar-malaijoe $\mathrm{M} .=\mathrm{Ho}$. pea selanica Rxb. (Zie No. 824).

1624. Dammar-mata-koetjing $M$. $=a$. Damara alba Rmph. (Zie No. 1618.) = b. Canarium dichotomum Miq., Nat. fam. der Burceraceæ. GR. Sumatra; hooge boom, welke eeu fraaie, doorschijuende hars oplevert. $=c$. $\mathrm{Ho}$ pea dryobalanoides Miq, Nat. fam. der Dipterocarpeæ. Gr. Sumatra; hooge boom. GeBr. Als $a$. en $b$.

1625. Dammar-mata-koetjing-me-

kon M. = Chrysophyllum suma. tranum Miq, Nat. fam. der Sapotac e $æ, G_{R}$, Sumatra's W.K.; boom.

1626. Dammar-mata-koetjing-poetih M. = Canariopsis hispidaBl. (Zie No. 1249.)

1627. Dammar-poetih M. = Dammara alba $\mathrm{Rmph}$. (Zie No. 1618). = b. Hopea dryobalanoides Miq: (Zie No. $1624 c$.)

1628. Dammar-selan $\mathrm{Cr}_{\mathrm{r}}=\mathrm{Ca}$ nariopsis glabra Bl., Nat. fam. der Burseracer. Gr. De Molukken, hooge boom, die eene geurige hars uitzweet.

1629. Dammar-silan M. of

1630. Dammar-sila M. = Hopea selanica Rxb. (Zie No. 824.)

1631. Dammar-toenie M. = Dammal'a alba Rumph. (Zie No. 1618.)

1632. Dammara M. = Vatica Rassak Bl., Nat. fam. der Dipterocarpeæ. Gr. Borneo; hooge boom. GrR. Deze boom levert een hars, Njato of $\mathrm{Nja}$ ting genoemd, die in groote hoeveelheid van Bandjermassing wordt uitgevoerd.

1633. Danau-madjang Sux. W.K. = Canarium odontophyllum Miq., Nat. fam. der A myrideæ. Gr. Sumatra; hooge boom.

1634. Dangan-dangan $\mathrm{M}$. = Carica Papaija L. (Zie No. 1092)

1835. Dangdang-gendies $\mathrm{S}$. = Beloperon? fulgida Hassk., Nat. fam. der Acanthaceæ. Gr. Java; heester (?).

1636. Dangdang-goela $\mathrm{S} .=\mathrm{Fe}-$ 
lanthera strigosa Miq. Nat. fam. der Amaranthacex Gr. Java; overblijvende plant.

1637. Dangdang-monjet $\mathrm{S} .=\mathrm{Myr}-$ t ace æ R.Br. spec. indef.

1638. Dangdur S. = Eriodendrum anfractuosum D.C. (Zie No. 28b.)

1639. Dangdur S, ook D. allas S. = Salmalia malabarica S. \& E., Nat. fam. der Sterculiaceæ. Gr. Bijna overal in Indië; zeer hooge boom. GEBR. De bast der wortels wordt gekweekt in water, en dit gedronken tegen een buikziekte, sakit kasambet of sakit kagendak genaamd. Volgens Endlicher is de honig nit de bloemen laxeerend en pisdrijvend. De vruchten leveren een slechte boomwol.

1640. Dangdur-allas $\mathrm{S} .=\mathrm{Cra-}$ tæva religiosa Forst., Nat. fam. der Capparideæ. Gr. Java, uit Malabar o vergebracht; zeer hooge boom. GEBR. Even als Cr. magna DC. (Zie No. 1024).

1641. Dangdur-gedeh $\mathrm{S}=\mathrm{S}$ terculia fœtida I.. Nat. fam. der Sterculiacex. Gr. Door geheel Indië; hooge boom. GEBR. Men bezigt den bast als zweeten pisdrijvend middel; het hout is licht te verwerken, doch niet duurzaam; uit de eetbare zaden perst men een vette olic, geschikt voor lampolie.

1642. Dangloe S. = Engelhardtia a ceriflora Bl. Nat. fam. der Juglandex. Gr. Java; hooge boom, levert vermoedelijk een goed bouwhout.

1643. Dangora M. $=\mathrm{Grapto-}$ phyllum hortense Nees. (Zie No. 90.)

1644. Dansidan M. = Cassytha fil iformis L. (Zie No. 203.)

1645. Daoena Alf. Mrn. $=a$, Chavica Betle Miq. (Zie No. 285) en = b. Chavica siriboa Miq. (Zie No. 1170.)

1646. Darambil Sum. WK. = A ralia dasyphylla Miq. (Zie No. 2275.)

1647. Darandas-manoek S. = Ficus Tadjam Miq. (Zie No. 1446.)

1648. Darangdang $\mathrm{S}$. = Ficus obscura Bl. Nat. fam. der Artocarpeæ. Gr. Java; heester.

1649. Darangdang aroij $\mathrm{S}$. = Ficus subulata Bl., Nat. fam. als voren. Gr. Java, Sumatra; slingerplant.

1650. Darangdang-beäs $\mathrm{S}$. $=\mathrm{F}$ icus scaberima Bl. (Zie No. 1256.)
1651. Darangdang-bener $\mathrm{S} .=\mathrm{Fi}$ cus obscura Bl. (Zie No. 1648.)

1652. Darangdang-kajoe $\mathrm{S} .=\mathrm{Fi}$. cus radicans $\mathrm{Rxb}$. Nat. fam. als boven. Gr. Java, Borneo, Celebes; groote heester.

1653. Darangdang-lessang S., ook

1654. Darangdang-litjin S. $=\mathrm{Fi}$ cus parietalis Bl., Nat. fam. als veren. Gr. Java; heester.

1655. Darangdang-mienjak $\mathrm{S}$. = Ficus urophylla Wall., Nat. fam. als voren. Gr. Java en Borneo; boom.

1656. Darẻhan-daréhan LAмp. = Di os pyros? cys top us M i q., Nat. fam. der E be и a c e . Gr. Sumatra; boom.

1657. Dareng-deng $\mathrm{S} .=a . \mathrm{Hyme-}$ nachne interrupta Büse, Nat. fam. der Gramineæ. Gr. Java, Sumatra; waterplant. GFer. De wortels gebruikt men voor lampenpitten. $=b$. H y m en a ch n e indica Büse. Nat. fam. Gr. en Gebr. als boven.

1658. Darestera MАK. = Ficus Altimeraloo Rxb. (Zie No. 1362.)

1659. Daringoe M. $\mathrm{M}$ corus terrestris $\mathrm{Rmph}$. (Zie No. 134.)

1600. Dataga T. $=$ Solanum ni. grum L., var. Kumphii. Nat. fam. der Salanaceæ. Gr. Bijna door geheel Indië; zaadplant. GEBr. De geheele plant wordt, afgekookt als groente, bij de rijst gegeten; de bladeren en vruchten worden ook ranw genuttigd. Deze plant zal zeer veel solanine bevatten, en heilzaam zijn op verharde en kankerachtige zweren.

1661. Dau-bande-daue $\mathrm{Bu}$. = Dracontomelon mangiferum Bl. (Zie No. 1492.)

1662. Dau-dau T. = Bruguiera cylindrica Bl., Nat. fam. der $\mathrm{Bh}$ izophoreæ. Gr. De Molukken; boom. GEBr. Het hout gebruikt men voor daksparren.

1663. Dau-lassi T. = Urtica ovalifolia Bl., (?) Nat. fam. der Urtica ceæ. Gr. Java, de Molukken; heester. GEBR. De bladeren worden veelvuldig als huidprikkel tegen inwendig lijden aangewend.

1664. Dauro-apapa J. = Desmodium polycarpum D.C. Nat. fam. der Papilion a ceæ. Gr. Bali; heester.

1665. Daussa Br. = Gendarussa vulgaris Nees, Nat. fam. der Acanthaceæ. Gr. Door geheel Indië, veelal 
in tuinen eu omheiuingen; heestcr. GEBR. Mleu geeft een afkooksel der wortels tegen koortsen cn cholera; cev aftreksel der aromatische bladeren is een geschikt zweetdrijvend middel bij katarrhale aandoeningen; uitwendig gebruikt men de bladeren tegen hoofdpijn, koorts, op furunkels en, geroost, op rheumatische gewrichtszwellingen.

1666. Daussa Амв. $=$ Crinum asiaticum L. (Zie No. 869a.)

1667. Dawon of Daauwn MI. $=$ Een blad.

1668. Dawon-api $=a$. Tragia voIubilis L. en $=b$. Tr. scandens L., Nat. fam. der Euphorbiaceæ.

1669. Dawon-apoe M. = Pistia Stratiotes L, Nat. fanl. der Aroidex. Gr. Vrij algemeen in Indië; waterplant. Gebr. Men kweekt dezc veel iu vischvijvers en stilstaande wateren, tot voedsel en schaduw roor de visschen; het sap zal zeer scherp zijn.

1670. Dawon-assam M. $=a$. Garcinia Cambogia L. (Zie No. 733). 6. Diploclinium tuberosum Miq. (Zic No. 1054.)

1671. Dawon-assam-ketjil M. = Oxalis corniculata L. Nat. fam. der Oxalidex. Gr. Java; overblijvend, kruipend.

1672. Dawon-baba M. = Sol anum nigrum L. Rumphii. (Zie No. $1660)$.

1673. Dawon-baggéa M. $=a$. P andanus Bagea Miq., Nat. fam. der Pandace æ. Gr. Dc Molukken; kleinc boom. GeBr. De bladeren bezigt men tot het ontwikkelen van deeg bij het bakken van een soort van brood of gebak, baggéa genaamd, gemaakt van sago, kanarie en cenig zout of suiker; men vlecht er ook matten ran. $=6$. Pandaus dubius Spreng.s, Nat. fam. dezelfde. Gr. Am. boina, kleine boom. GEBR. De jonge bladeren worden rauw gegeten; de draden der wortels bezigt men tot vlechtwerk.

1674. Dawon-bali-landak. M. (?) $=$ Cissus obovata Vhl. (Zie No. 452.)

1675. Dawon-baroe-laut M. = Croton aromaticum Wlld., Nat. fam. der Euphorbiacea. Gr. De Molukken; boom. GEBR. Het hout is zeer geschikt voor: schrijnwerkers. en draaierswerk.

1676. Dawon-batoe M. $=a$. Iri- na glabra Bl., var. solida. (Zie No., 1465.) $=$ b. Irina tomentosa BI. Nat. fam. der Sapindacer. Gr. Java, Sumatra, Timor; hooge boom. GeBR. Als No. 1465.

167\%. Dawon-benang $\mathrm{M} .=\mathrm{Pe}-$ ristrophe tinctoria Nees. (Zie No. 95.)

1678. Dawon-besaar M. = Mo. rinda citrifolia L: (Zie No. $828 a$.)

1679. Dawon-bisol M. = a. Vernonia cinerea Less. (Zie No. 67a.) $=$ b. Cissus repens Lam. (Zie No. 438) en $=c$. Ipomøa cymosa Bl. (Zie No. 303b.)

1680. Dawon-bisôl-an J. = G ra ptophyllum hortense Nees. (Zie No. 90.)

1681. Dawon-blibinam M. = Drymispermum Blumei Desn. (Zic No. 422.)

1682. Dawon-boba M. = a. Collyris major Vlil., Nat. fam. der Asclepiader. Gr. Java eu de Molukken; boomparasiet. GEBR. Een aftreksel dezer bladeren geeft men inwendig tegen framboesice en gonorrhoea. $=b$. Physalis indica Lam., Nat. fam. der Solonaс еæ. Gr. De Molukken; zaadplant. Gebr. Men eet het kruid als groente, geeft het tegen blaas- en nicrenlijdein, voornamelijk echter tegen pokken en framboesix.

1683. Dawon-boeaija M. $=a$. Dendrolobiam umbellatum W. en Arn. en $=b$. Icndrolobium cephalotes Bth., beide van de Nat. fam. der $\mathrm{Pa}_{\mathrm{a}}$ pilionacex. Gn. Door geheel Indië; heester. Gebr. Men eet de jonge bladeren bij visch, en geeft ze aan kraamvrouwen na de baring.

1684. Dawon-boekoe-boekoe M. = Mazus lævifolius Bl., Nat. fam. der Scrophularinex. Gr. Java, Timor; overblijvend.

1685. Dawon-boelan M. = Anamirta flavescens Miq. (Zie No. $645 b$.

1686. Dawon-boelan Men. = Pisonia alba Span. (Zie No. 120b.)

1687. Dawon-boelan-baboeloe M. = Cocculus glaucus D. C., Nat. fam. der Menispermacex. Gr. Amboina; slingerplant. GEвR. De bladeren gebruikt men om het hoofd mede te wasschen tegen het uitvallen van het haar, en geeft ze inwendig tegen koortsen en vergrooting der milt. 
1688. Dawon-boerong $\mathrm{M}_{\mathrm{N}}=\mathrm{Rh} \mathrm{i}$ ni a c a $\mathrm{th}$ us com mu is Nees. (Zie No. 240).

1689. Dawon-bongkoes M. = Curculigo latifolia Dryand. (Zie No. 24a).

1690. Dawon-daloewang S. = P s ychotria rhinocerotis Rnwdt. Nat. fam. der $R$ u b i a c ęe. Gr. Java, Sumatra; heester.

1691. Dawon-dammar-angoes M. $=a$. B i de n's ped u n cularis Gaud. en $=b$. B idens $W$ allichii D.C. (Zie No. 68).

1692. Dawon-djarong $\mathrm{M} .=\mathrm{B} \mathrm{i}$ dens Wallichii D.C. (Zie No. 68).

1693. Dawon-doelang $M .=M$ a $\mathrm{p}$ p a moluccana Sprg. (Zie No, วั6).

1694. Dawon-ejkor-bceaija M. = Teijsm an nia altifrons Zy M. (Zie No. 1110).

1695. Dawon-fransman M. $=a$. Eu patorium Ayapanna Vent. (Zie No. 140 ) en $=b$. Gendarussa vulgaris Nees. (Zic No. 1665).

1696. Daw on-gaba-gaba M. = Iriu a gl a b r a Bl., var. a l ba. 'Zie No. 1465 ).

1697. Dawon-galinggum $\mathrm{M}$. = Bixa Orellana L., Nat. fam. der Bixaceæ. Gr. Door geheel Indië angeplast, uit Amerika overgebracht; heester. GEBR. Deze wordt gewaonlijk in omheiningen aangetroffen; hare wortel zal een versterkende werking uitoefenen op de digestie-organen. Deı vezeligen bast gebruikt men als touw. Aan de aromatisch-bittere zaden kent men maggersterkende, samentrekkende en koortswerende eigenschappen toe. Het vruchtmoes is koortswerend, en zal een tegengif zijn tegen Maniocca-vergiftiging (de moederplant der W. Indische arrowroot); ook geeft men het tegen bicmorrhagieæ, diarrhoeæ en lithiassis. Uit de zaden bereidt men twee kleurstoffen, het orleansgeel en het orleansrood, die veel gebruikt worden tot het verven van laken, door schilders, tot het kleuren van boter, kaas, chocolade en zalven; deze stof zal afvoerende, bloedstelpende eigenschappen bezitten.

1698. Dawon-gatel M. $=a$. U rtica ovalifolia Bl. (Zie No. 1663). = h. La portea microstigma Gaud., Nat. fam. der Urticaceæ. GR. Java; kleine boom. Gebr. Men bezigt de bladeren als hu:dprikkel. $=c$. L a p orte a stimulans 11 i q., Nat. fam. als boven. Gr. Java; heester. GEBR. Als huidprikkel.

1699. Dawon-gatel-aijer $\mathrm{M}$. = Mucuna prurita Hk., Nat. fam. der Papilionacer. Gr. Bijna overal in Indië, zaadplant. GEBR. De wortel is, in aftreksel gegeven, een pisdrijvend middel en wordt tegen waterzucht toegediend; in af kooksel met honig zal hij tegen cholera dienstig ziju. Ook de peulen zullen pisdrijvend werken. De haren op de peulen zijn een sterk huidprikkel; 2 ij veroorzaken huidjeukte, pijn, roodheid en zelfs uitslag; zij zullen een mechanisch vergif zijn, doch worden desniettemin door den inlander, met honig of siroop vermengd, toegediend aan kinderen, tegen spoelwormen, welk door deze werktuigelijke prikkels zullen uitgedreven worden. Chamberlaine heeft deze werking microscopisch nagegaan. Op Java bezigt men de bladeren om er de handgrepen van wapens mede zwart te poctsen.

1700. Dawon-gatel-besaar M. = I a p orte a dec umana Wedd. (Zie No. 121).

1701. Dawon-gatel-matti M. = Fle ury a intcrrupta G a ud., Nat. fam. der Urticacer. Gr. Door geheel Indië; over blijvend. Gıbr. Te Ternate eet men het jouge kruid als groente; men bezigt het ook als weekmakend middel op abcessen.

1702. Dawon-getah-gambier M. = Unc a ri a a cida $R \times b$., Nat. fam. der $\mathrm{R} u \mathrm{~b}$ i a cex. Gr. Bijna overal in Indië, slingerplant. GEBR. Men gebruikt de bladeren hier en daar bij het betelkauwen.

1703. Dawon-getah-gambir-boeloeboeloe $M .=$ Uncaria lanosa Wall, (Zie No. 27).

1704. Dawon-gindi M. $=a . \mathrm{Ne}-$ penthes phyllamphora Wlld. (Zie No. 128). $=6$. Nepenthes melamphora $\mathrm{Rnwd}$ t. en $c$. N. macrostachya B l. Nat. fam. der $\mathrm{Nep}$ e $\mathrm{t}$ heæ. Gr. Java, Sumatra, Borneo; slingerplanten. GEBR. Het water, lat in de bekers blijft staan, wordt tegen hoest gedronken.

1705. Dawon-goendik $\mathrm{R}$. $=\mathrm{Ne}-$ penthes destillatoria $L_{\text {(?). }}$

1706. Dawon-gorita; $\mathrm{M}=$ Trcvesia moluccana Miq. (Zie No. 78).

1707. Dawon-gossok M. $=\mathrm{F}$ ic us politoria I a m. (Zie No. 299). 
1708. Daw01-grisek $\mathrm{Bo} .=\mathrm{No-}$ thopanax cochleat um Miq. (Zie No. $76 a$ ).

1709. Dawou-grissik M. $=\mathrm{No}$. thopa a $x$ ? pinnatum Miq. (Zie No. $76 b$ ).

1710. Dawon-hati-hati I. = $\mathrm{C}_{0}$ lens amboinicus Lour. (Zie No. 69).

1711. Dawon-heiran M. $=$ Leucas linifolia Sprg (Zie No. 1043).

1712. Dawon-hellebardies J. = Codiæum inoluccanum Decsn. (Zie No. 126).

17L3. Dawon-hidop M. $=0 \times a$ lis Reinwardtii Zucc. (Zie No. 25ั1).

1714. Dawon-hoje $\mathrm{M} .=a \cdot \mathrm{Co}_{0}$ le as tuberosus Bath., Nat. fam. der Labiatœ. Gr. Java en de Molukken in tuinen; orerblijvende plant. GrbR. De ronde, knollige wortels worden, afgekookt, irt plats van aardappelen gegeten en zijn zeer gezocht. $=b . \mathrm{Pachyrhizus}$ a.gulatus Bich. (Zie ヘ́. 972b).

1715. Dawon-ila-ila $\mathrm{J} .=\mathrm{R}$ uel. $\mathrm{li}$ a discolor $\mathrm{Nees}$. (Zie No. 72).

1716. Dawou-inggat $M=A c h y-$ ranthes aspera Lam., Nat. fam. der Amaranthaceæ GR. Java; overblijrend.

1717. Dawon-kajoe M. = Exo. carpus phyllanthoides Endl., Nat. fam. der $\mathrm{S}$ a nt a la ce e Gr. Ceram; boom.

1718. Dawon-kaki-koeda M. = II ydrocot Jle asiatica $L$, (Zie No. 70 ).

1719. Dawon-kali-dabat J. = Zizyphus Enoplia II q. (Zie No. 962 ).

1720. Dawon-kallak S. = Un ona d a s y a schal a Bl., Nat. fam. der A n o n a c e . Gr. IVest Java; heester.

1:21. Dawon-kambat Bo. = J a mbo s a peregrin a Bl., Nat. fam. der II y r t a c e æ. Gr. Borneo; boom.

1722. Dawon-kambing $\mathbf{M}$. $=a$. Premna corymbosa Rottl. (Zie No. $39 \check{s}) .=b$. P remna f ctida $\mathrm{R} w \mathrm{~d}$., Nat. fam. der Verben a ceæ. Gr. Java, Borneo, de Molukken; heester. Gebr. In de huishouding bezigt men het hoat voor stelen van gereedschappen, en men eet de bla. deren als groente bij visch. Volgens W wordt het hont van dezen heestev, vermoedelijk als kajoe-taai of stinkhout in den handel, gegeren tegen kolyken, hy- sterie en hypoctiondrie, en zel dit zeer werkzaam zijn.

1723. Dawon-kamoening II. = Murraya sumatrana Koxb, Nat. fam. der Aurantiacer. Gr. Door geheel Ned. Indië; heester. Gebr. Deze wordt veelal in tuinen gevonden om hare geurige bloemen; het hout is voor kris sen, stoelen eu draaiwerk zeer gezocht; den $b$ ist en de bladeren geeft men tegen asthma

1724. Dawon-kandal M. \& BL. = C ordi a My a L. (Zie No. 117).

1725. Dawon-kankoeng $\mathrm{M} .=\mathrm{IP} 0$ mœa reptans Poir. (Zie No. 526).

1726. Dawon-kapialoen $\mathrm{M}$. $=\mathrm{C}$ is. sus cinerea Lam. (Zie No. 65).

1727. Dawon-kapoer $\mathrm{M} .=\mathrm{II}$ lanolepis (?) calcosa Miq. (Zie No. 37).

1725. Dawon-kapoer-laut M. = Croton aromatic um Wlld. (Zie No. 1675).

1729. Dawon-kappal J. $=\mathrm{H}$ ova macrophyll a Bl. (Zie No. 563).

1730. Dawon-kardamon $\mathrm{MI}=\mathrm{L} \mathrm{im-}$ nophila punctata Bl., Nat. fam. der Scrophularineæ Gr. D: Sunda-eilanden; waterplant.

1731. Dawon-kassise $\mathrm{M}$. $=\mathrm{Co}$. locasia (?) humilis $\mathrm{H}$ assk. (Zie No. 426$)$.

1732. Dawon-katam-katam M. = $J$ a sminum dist ichum Bl., Nat. fam. der Jasminer. GR. Sumatra; slin. gerplant.

1733. Dawon-katsjo M. = Unc aria a cida $R \times b$. (Zie No. 1702.)

1734. Dawon-kattam M. = Ipomœa Pes-capræ Sw. (Zie No. 1039)

1735. Dawon-kemadoe M. = Dawon-gatel M1. (Zie No. 1698).

1736. Dawon-kendal M. $=\mathrm{C}$ ord ia su aveolens Bl., Nat. fam. der Cordia o c e . Gr. Java, Sumatra, enz.; boom. GFBR. Het witte, grove en weeke hout is niet duurzaam, en wordt spoedig door witte mieren aangetast; de bladeren gebruikt men uitwendig voor kraamvronwen, en geeft een aftreksel er van aan koortslijders te drinken. Den bast kauwt men bij de sirih, bij gebrek aan Gambir (Catechu).

1737. Dawon-ketjil M. =a. Phyllanthus Nuriri $L$. en $=b$. Phll. urinaria Wlld. (Zie No. 71b). = c. Anthocephalus indicus Rich. 
(Zie No. 989). $=d$. Melaleuca Cajuputi Rxb., Nat. fam. der Myrtac eæ. Gr. De Molukken; hooge boom. GEBR. Men gebruilkt het hout als timmerhout; de bladeren, zoomede de vruchten, zijn rijk aan aromatische olie, de Oleum Cajup uti, welke daaruit gestookt wordt, en vonral van Boeroe in den handel komt; de vruchten zijn een door de inlanders zeer gewilde specerij.

1738. Dawon-kekoeran M. \& S. $=a$. Hydrocotyle asiatica L. (Zie No. 70 ). $=b$. Curanga a mar Juss. (Zie No. 88 en 89). = $c$. Scutellaria ind ica $L$. en $=d$. Scut. cyrtopoda Miq., Nat. fam. der L abiatæ. Gr. Jara, uit China of Japan orergebracht; overblijvende planten.

1739. Dawon-koentcet S. \& M. = a. Pæderia tomentosa Bl. (Zie No. 511 en 512). $=6$. Pæderia fœtida L., Nat. føm. der $R$ ubiace $æ$. Gr. Door geheel Ned.-Indië; slingerplant. GEBR. (Zie het bij No. 508 aangegevene).

1740. Dawon-koepang J. \& M. C assia a lata L., Nat. fam. der Cæsalpinieæ. Gr. Overal in Ned.-Indië; heester. GEBR. De wortel, bast en vooral de stinkend en bitter smakende bladeren worden met zout, azijn of citroensap fijngewrever, en zoodanig uitwendig aangewend bij verschillende slepende huidziekten, doch vooral bij herpes circinnatus (ringworm), waartegen zij bijzonder zijn a an te raden. De bladeren worden ook inwendig in aftreksel gegeven, als laxans bij wijze van Senna, en wel van een half tot 1 ons op 8 ons water. De vruchten worden, rijp en onrijp, als groente gegeten.

1741. Dawon-koerang M. $=\mathrm{Cu}$ ranga a mara Jiss. (Zie No. 88 en 89 ).

1742. Dawor-kotrap M. = Cass ia alata I. (Zie No. 1740).

1743. Dawon-koijn $\mathrm{M}_{\text {. }}=\mathrm{Notho-}^{-}$ pan ax co ch leat um Miq. (Zie No. $76 a)$.

1744. Dawon-kopo-kopo M. $=a$. Cardiosperm um Halicacabum L. (Zie No. 433). = b. Physalis indica I. (Zie No. 168\%b). = c. Solanum nigrum Jck., var. Rumphii. (Zie No. 1660).

1745. Dawon-korra-korra Mos. = u. Phajus callosus Lindl. (Zie No. $377 a) .=b$. Curculigo latifolia Dryand. ('Zie No. 24a).
1746. Dawon-lajang-lajang M. = Polypodium quercitolium I. (Zie No. 181).

1747. Dawon-lakki M. = Lawso-

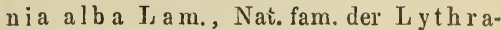
$\mathrm{ri} \varkappa$. GR. Overal in Indië in tuinen; hee:tcr. GEBR. Deze heester wordt vrij algemeen aangeplant, orn het reelvuldig gebruik cंer bladeren en den geur de $\mathrm{r}$ bloemen. De wortel zal de ech te radix alcannæ vera zijn; het hout, tot houtskool gebrand, gebruikt men bij spruw. De bladeren gebruikt men tot het roodverven van nagels, harcn en vcoral van marokijnleder; ook de bladeren en bloemen kauwt men bij spruw. De geurige blocmen legt men tusschen de kleederen en stookt er ook een vluchtige olie nit.

1748. Dawon-lakki-lakki M. $=\alpha$. Irina glabra Bl., var. solida Bl. (Zie No. 1465). = b. Irilla tomen. tos a Bl. (Zie No. $1676 d$ ).

1749. Dawon-lakoem M. $=$ Cissus cinerea $\mathrm{Kam}$. (Zie No. 65).

1750. Dawon-lida-lida M. = Plıanera (?) lingua Miq., Nat. fam. der Papilion aceæ. Gr. De Molukken slingerplant. GEBR. Men eet de bladeren als groente; de wortel dient, gekookt en in stukken gesneden, als bijvoegsel in baden bij verschillende ziekten; de gescheurde takken zweeten gom uit.

1751. Dawon-litti J. = Neptunia javanica Miq., Nat. fam. der Mimos e $x$. Gr. Java; kruid.

1752. Dawon-loba-moeloet M. = Phanera lingua Miq. (Zie No. 1750).

1753. Dawon-loeda M. = Spilanthes Pseudoacmella L., Nat. fam. der Compositæ. Gr. Java, Borneo, dc Molukken; kruid. GkBR. Op Java wendt men de bladcren uitwendig an bij stijfheid; pijn]ijke gewrichtsaandoeningen, enz. In de Molukken laten de Mahomedanen hunne kinderen de bloemhoofdjes kanwen, om daardoor een sterken speekselvloed op te wekken, en hun zoodoende moeilijke woorden beter te doen uitspreken.

1754. Dawon-loeloean-karbo J. = Panicum palmafolium Koen, Nat. fam. der Gramineæ. Gr. Java, Sumatra; overblijvend. GEBR. Op Java eet men de jonge uitspruitsels bij dc rijst, en gecft men ze ook aan kraamvrouwen na de bevalling. 
1755. Dawon-manen-manen MoL = $\mathrm{S}$ a uropus rhamnoides Bl. (Zie No. 805).

1756. Dawon.mangkok M. = $\mathrm{No-}$ thopaux cochleatum Miq. (Zie No. $76 a)$.

1757. Dawon-maniran-karbo J. = Callicarpa cana l. (Zie No. 2).

1758. Dawon-mata-pannas M. = $a$. A c h y a n tes bidentat a Bl., var. elongata Bl. (Zie No. 740). en = b. Cyathula oniculata Lour. (Zie No. 7411 ).

1759. Dawon-meirah M. = Irina glabra Bl., var. rubra Bl. (Zie No. 1465).

1760. Dawon-moeka-manies $\mathrm{M}$. = Vernonia leptophylla D.C. (Zie No. 67b).

1761. Dawon-moeka-sakit M. Vernonia cinerea Dess, (Zie No. $67 a)$.

1762. Dawon-moreto $\mathrm{T}$. $=\mathrm{Adha}$ toda moretiana Miq. Nat. fam. der Acanthaceæ. Gr De Molukken. Gebr. Dit kruid bezigt men bij ontstoken oogen, ook bij hoest, die na pokken en mazelen overblijft.

1763. Dawon-ngassi $\mathrm{T}_{\mathrm{I}}$ = $\mathrm{C}$ ordyline timorensis Planch., Nat. fam. der A sparagin eæ. Gr. Timor; heester.

1764. Dawon-ojot-tjintjan $\mathrm{B}_{\mathrm{AT}}$. = Cocculus ovalifoli us D.C., Nat. fam. der Menis permaceæ. GR. Java; hlimplant.

1765. Dawon-ottot M. = Plantago major L., Nat. fam. der Plantagineæ. Gr. De Sunda-eilanden; overblijvende plant. GeBr. Men legt de bladeren op versche wonden en zweren, en wendde ze vroeger tegen tusscherpoozende koortsen aan.

1766. Dawon-pakoe J \& M. = Polypodiacere diversa. Gebr. Men eet de bladeren, gekookt bij wijze van groente of als salade.

1767. Dawon-panoe M. = Jussira angustifolia Lam., Nat. fam. der Onagrariex. Gr. De Molukken; overblijvende plant. GeBr. Men wendt het gekneusde zaad uitwendig tegen witte huidverkleuring, panoe-poetih, aan.

1768. Dawon papeda $\mathrm{M}_{\text {. }}=$ Nothopanax cochleatum Miq. (Zie No. $76 \mathrm{rac}$.

1769. Dawon-papeda-padjang M.=
Nothopanax pinnatum Miq. (Zie No. $76 b)$.

1770. Dawon-papeda-papoea M. = Nothopanax fruticosum Miq. (Zie No. 1153).

1771. Dawon-parampoewan M. = Irina glabra Bl. (Zie No. 1465).

1772. Dawon-patjie-patjie M. = Le ucas linifolia Sprg. (Zie No. 1043).

1773. Dawon-patma J. $=\mathrm{Plum}$ bago rosea L. (Zie No. 114).

1774. Dawon-pegagan BAT. $=\mathrm{Hy}$ drocotyle asiatica L. (Zie No. $70)$.

1775. Dawon-petola M. = M a c odes petola Ii ndl., Nat. fam. der Orchideæ. Gr. Java, Amboina; kruipend gewas.

1776. Dawon-pittis $\mathrm{M} .=a . \mathrm{Hoya}$ macrophyll a B l. (Zie No. 563). = b. Hoya $\mathrm{Rumphi}$ i Bl., Nat. fam. der A s c lepiadeæ. Gr. Door geheel Indië; slingerplant. GeBr. De biaderen gebruikt men uitwendig als wondheelend middel, en geeft ze inwendig tegen gonorrhoea.

177\%. Dawon-pittis-ketjil M. = $a$. 1) ischidia Gaudichaudii Dcsn. en $=b$. Dischidia Kafflesiana Wall. Nat. fam. der A sclepiadeæ. Gr. Java, de Molukken; boomparasieten.

1778. Dawon-pittis-pittis M. = Di oscorea nummularia I am, Nat. fam. der Di us core x. GR. Java, de Molukken; slingerplant. GeBr. De wortels zijn door de wilde varkens zeer gezocht.

1779. Dawon-poeding M. = Graptophyllum hortense Nees. (Zie No. 90).

1780. Dawon-poepoor BD. $=$ Coleus atropurpureus Bnth. (Zie No. 748 ).

1781. Dawon-poetat M. = a. Barringtonia racemosa $\mathrm{Bl}$. en $=b$. B. acutangula Bl. (Zie No. 9836).

1782. Dawon-poetih $A$ мв. = Irina gl abra Bl. var. alba Bl. (Zie No. 1465 ).

1783. Dawon-poetih-ketjil M. = Metrosideros saligna Sm., Nat. fam. der Myrtace ; boom.

1784. Dawon-poetri M. $=a$. Mussaëuda frondosa L. (Zie No. 74). = b. Graptophyllum hortense Nees. (Zie No. 90). 
1785. Dawon-poka $\mathrm{S}=\mathrm{Sol}$ an u m Poka D u n., Nat. fam. der 3 o. l a n e a. Gr. Java; heester.

1786. Dawon-prada $\mathrm{M}$. = Graptophyllam hortense Nees. (Zie No. 90 ).

1787. Dawon-praon Sum. $=\mathrm{Te}$ tranthera Brawas Bl. (Zie No. 1559).

1788. Dawon-prasman $\mathrm{M}=\mathrm{D}$ awo u fransman M. (Zie No 1695).

1789. Dawon-ramboet M. =a. Ipomoa peltata Chois. (Zie No. 303a). $=b$. Ophioglossum pendulum L., Nat. fam. der Ophiogloss eæ. Gr. Java; overblijvende plant.

1790. Dawon-riengiet $\mathrm{M}_{0}=\mathrm{Hoy}$ a lac unosa Bl., Nat. fam. der A sc l e pi a d $x$. Gr. Java, Sumatra, enz. parasiet.

1791. Dáwon-roessa M. $=$ Alternanthera sessilis RBr., Nat. fam. der $A m a r^{\circ}$ a $t h$ a e e æ. Gr. Java; éénjarig.

1792. Dawon-rótti M. = Lepidium sativil L., Nat. fam. der Cruciferæ. Gr. Op Java en elders gekweekt; deze is de gewone Tuinkers.

1793. Dawon-sabrang M. $=\mathrm{D}$ awon hode M (Zie No. 1714).

1794. Dawon-sakko M. = S e mec arpus Cassuvi um Sprg (Zie No. $1569)$.

1795. Dawon-salari-bcelan M. = Ficus A ltimeraloo Rxb. (Zie No. 1362).

1796. Dawon-saláwar M. = Lawson i a a b a Lam. (Zie No. 1747).

1797. Dawon-saleh M. = Oph i oglossum ovatum Bl., Nat. fam. der Ophioglossex. Gr Java overblijvende plant. GeBr. Het jonge kruid wordt als groente gegeten.

1798. Dawon-salier $\mathrm{S}$. $=$ A cronychi a laurifolia Bl., Nat. fam. der Z a n thoxyle æ. Gr. Java; boom.

1799. Dawon-sambang $\mathrm{M}$. = A. brus melanospermus Hassk. (Zie No. 572).

1800. Dawon-sariboe BENK. $=\Lambda \mathrm{d}$ nandra dumos a J a sk., Nat. fam. der Ternstr $\propto$ mi a c e. Gr. Java, Sumatra; boomaektig.

1801. Dawon-sarong-boerong M. $=$ Rhinacanthus e ommun $\mathrm{N}$ e es. (Zie No. 240).

1802. Dawon-sasappo of D. sesapoe M. = Sida a cuta L. Nat. fam. der M a l $\nabla$ a e e c. Gr. Overa! in Indië, éénjarig. GEBR. Men gebruikt de wortels tegen tandpijn en buiklijden, en legt men het kruid als rijpmakend op abeessen.

1803. Dawon-sedjoek $\mathrm{M}$. $=\mathrm{Ka}$ lanchoë laciniata D.C. (Zie No, 46).

1804. Dawon-setan M. $=a$. D awo u-gat el M. (Zie No. 1698 en volg. $=b$. L e u a s lin ifolia Sprg. (Zie No. 1043).

1805. Dawon-sentak M. = Hydrocotyle asiatica L. (Zie No. 70).

1806. Dawon-sentak S. $=\mathrm{Hydro}$. cotyle sundaiea Bl., Nat, fam. der Um. bellifer $x$. GR. Java; kruipende plant.

1807. Dawon-setjang $\mathrm{M}$. $=\mathrm{C}_{\Re}$. s a $l p$ in i a $S$ a p p a u L. Nat. fam. der $\mathrm{C} æ \mathrm{~s} a l p$ in i e . Gr. In geheel Indië, veelal in omheiningen; slingerplant. GEBr. Het hout is als roode verfstof onder den naam van sappanhout in den handel; het is zeer hard en word t vooral gebruikt voor nagels in prauwen, lijstwerk en stoelen. Men geeft het in afkooksel inwendig als bloedstelpend middel, en, koud afgetrokken, voor oogwater bij katarrhale oogont. stekingen van kinderen.

1808. Dawon-setoegeh-angin $M$. $=$ Marsdenia parviflora Decsn. (Zie No. 676a).

1809. Dawon-sipat M. $=a$. Sida a e ta L. (Zie No. 1802). $=b$. Eelipta alba Hassk. var. e recta, Nat. fam. der Compositæ. Gr. Overal in Indië; éénjarig. Gebr. Men wendt het kruid als verkoelend middel aan, en geeft het sap tegen hoest $\mathrm{cn}$ tot bevordering $\nabla$ an den haargroei. $=c$. Caladracon termi$\mathrm{n}$ alis Planch. (Zie No. 333b).

1810. Dawon-sjoerare J. $=\mathrm{Ruel}$ lia discolor Nees. (Zie No. 72).

1811. Dawon-soebat M. = Deudrobium coneinnum Miq., Nat. fam. der $\mathrm{Orchide}$ e. Gr. Java. Amboina; parasiet.

181\%. Dawon-soeggi M. = Cordyline Rumphi i Hk. (Zie No. 337a).

18l3. Dawon-soeranteh Suм. Wк. $=$ Shorea subpeltata Miq., Nat. fam. der Dinterocarpe $x$. Gr. Sumatra; hooge boom.

1814. Dawon-soerroe J. $=\mathrm{Eu}$ phorbia antiquorum L, Nat. fam. der Euphorbiaceæ GR. Java; heester. GeBr. Deze plant bevat veel Euphorbium, cen zeer scherpe, licht brandbare hars. In 
Indië gebruikt nen deze met olie vermengd, uitwendig tegen rheumatismus en, inwendig tegen constinatio alvi; de Arabieren maken er, met meel, hunne sterk drastische pillen van. Op Java gebruikt men de gombars uitwendig, vermengd met temoe lawak (Rad Curcumæ Zerumbet), tegen scabies.

1815. Dawon-Sompitan $\mathrm{Ml}$. = Nepenthes Boschiana Krths, Nat. fam. der N epenther. Gr. Sumatra, Borneo; slingerplant.

1816. Dawon-sompittang $\mathrm{M}$. = Crinum asiaticum $\mathrm{L}$. (Zie No. 869a).

1817. Dawon-sopatie $\mathrm{J}=\mathrm{W}_{0} \mathrm{l}$ lastonia biflora D.C., Nat. fam. der C o m p o s it æ. Gr. Java; heester.

1818. Dawon-tadjoengan MAD. = Chionanthus laxiflorus Bl., Nat. fam. der Oleine re. Gr. Java en Sumatra; heester.

1819. Dawon-tali M. = Cassyta filiformis L. (Zie No. 203).

1820. Dawon-tallan BD. $=\mathrm{P}$ is 0 II i a a b a S pan. (Zie No. 1206).

1821. Dawon-tamman $\mathrm{J}=\mathrm{Co}_{0}$. di um molnccanum Desn. (Zie No. 126).

1822. Dawon-tang-tang J. = $\mathrm{P}$ olyg onum chinense I. var., Nat. fam. der Polygoneæ. Gr. Java en Sumatra; overblijvende plant.

1823. Dawon-tepalawan Sum. W.K $=$ Nothopanax cochleatum Miq. (Zie No. 76 ).

1824. Dawon-tarita BD. = Eclipt a a lba Hassk (Zie No. 1809b).

1825. Dawon-teman M. = Grapto. phyllum horterse Ns. (Zie No. 90).

1826. Dawon-tidoran M. en

1827. Dawon-tidor-tidor M. = II inosa pundica L. (Zie No. 649).

1828. Dawon-tikar $\mathrm{M}$. = P a ndanus ceramicus $R m p l$.. Nat. fam. der P and aneæ. Gr. De Molukken; boomachtig. GEBk. De vruchten gebruikt men bij wijze ran boter, en kookt ze, na in schijven tc zijn gesneden, bij de rijst.

1829. Dawon-tinta M. = Eclipta a l b a H as sk. (Zie No. 18096).

1830. Dawon-sinta $\mathrm{BD} .=\mathrm{Eu}$ phorbia thymifolia Wlld., Nat. fam. der $\mathrm{E} u \mathrm{ph}$ or bi a $\bullet$ e æ. Gr. Bijna overal in dezen Archipel; zaadplant. Grbr. Een aftreksel van dit kruid geeft men aan kleine kinderen tegen diarrhoea en tegen wormen; fijngewreven met adas, plassarie en water dient men het aan volwassenem toe, tegen diarrhoea en tegen dysenterie. Het melksap wendt men aan op rlekken van het hooruvlies. De fijngewreven plant legt men veelal op wonden en gezwellen.

1831. Dạwon-tjepper $\mathrm{S}$. $=\mathrm{Cu}$ beba mollissima Mliq. (Zie No. 705).

1832. Dawon-tjietjiap $\mathrm{S} .=1 \mathrm{e} \mathrm{u}-$ cas linifolia Sprg. (Zie No. 10+3).

1833. Dâwon-tjinta $\mathrm{M} .=a$. Phyllanthus Nuriri L. en $b . \mathrm{Ph}_{\text {uri- }}$ naria Wlld. (Zie No. 716).

1834. Dawon-toädjin Sum. Wк. = M us a ë nd a frondosa L.var. (Zie No. 74).

1835. Dawon-toelak J. $=\mathrm{G}$ r a ptophyllum hortense Nees. (Zie No. 90).

1836. Dawon-toenboe-dawon BK. $=\mathrm{Kalancl}$ o ë pinnata Pers. (Zie No. 143\%).

1837. Dawon-tôkol-manoesia M. $=$ Oxalis Reinwardtli Zucc (Zie No. 25l).

1838. Dawon-tsjoe-tsjoe-ramboet M. $=\mathrm{Hibiscus}$ surattensis L. (Zie No. 731).

1839. Dawon-ulang-ulang $\mathbf{~ 1 1}$. = Ficus Altimeralo $R \times b$. (Zie No. 1362).

1840. Dawon-wedoessan J. = Lant a n a mixta L., Nat. fam. der Acanth a c e $x$. Gr. Op Jara als sierplant in tuineu; heester

1841. Dedelangan S. = Bonnaya veronicæfolia Sprg. (Zie No. 796).

1842. Dêdesh $\mathrm{M}_{\text {. }}=\mathrm{S}$ a $\mathrm{ra} \mathrm{c}$ a in. dica L. (Jonesia asoca $R \times b$ ). Nat. fam. der Papilionaceæ. Gr. Op Java, Sumatra enz in vele tuinen wegens de geurige bloemen; kleine boom.

1843. Dedie Alf. Min. $=\mathrm{C}$ a n a. rium Rmph. Species diversæ.

1844. Degie T. $=\mathrm{Abelmosthus}$ M a nihot Med., Nat. fam. der M a l. vaceæ. Gr. In de Molukken in tuinen; heester.

1845. Delawang Sum. WK. = Solenostigma angustifolium Miq., Nat. fam. der C el ti d e $x$. Gr. Sumatra; boom.

1846. Delimah M., zie Dalimah S (No. 1608 en volgende).

1847. Delimah-laut $\mathrm{M} .=\mathrm{Xylo-}$ carpus granatum Koen. (ZieNo.1319). 


$$
\text { De. - Di. - Dj. }
$$

1848. Deloengoet M. = Stillin. gia paniculata .ll iq. (Zie No. 1308).

1849. Delongdong-betool BL. = Erythrina indica Lam. (Zie No. $1586 b)$.

1850. Delongdong-dadap $\mathrm{BL}$. = Erythrina respertilia Bnth., Nat. fam. der Papilion aces. Gr. Bali; boom.

185l. Demong J. = Graptophyl1 u m hortense Ns. (Zie No. 90).

1852. Denpoe-lellet J. $=a$. Gloehidion varium Miq., Nat. fam. der Euphorbi aceæ. Gr. Java; boom. $=b$. Orophea enneandra Bl., Nat. fam. der Anonacere. Gr. Java; heester.

1853. Dengen МАK. $=$ Dillenia serrata Thnb. (Zie No. 100).

1854. Denro MaK. $=\mathrm{P}$ and a n u s humilis Rmph. (Zie No. 1129).

1855. Deringoe $\mathbf{M}$. = Acorus terrestris Rmph. (Zie No. 134).

1856. Deringoe-laut $\mathrm{M} .=\mathrm{E} \mathrm{n} \mathrm{ha}$ lus Koenigii Rich. (Zie No. 923b).

1857. Dial-padiэ Вк. $=\mathrm{J}$ a mbosa tenuicuspis Miq. Nat. fam. der Myrtaceæ. Gr. Java en Bangka; boom.

1855. Dilem S. \& M. = a. Pogos. temom menthoides Bl. = 6 . Pogcomosus Miq. $=c$. $\mathrm{Pog}$. cristatus Hassk. $=d$. Pog. fraternus Miq. $=e$. Pog. gracilis Hassk, en $=f$. $\mathrm{Pog}$. tomentosus Hassk., alle van dc Nat. fam. der Labi a tæ. Gr. Java; overblijvende planten. GÉr. De geurige bladeren legt men veelal tussehen de kleederen tot wering vau insecten, en mengt ze ook in sommige nit- en inwendige geneesmiddelen.

1859. Dilem J. $=$ Coleus atropurpureus Bnth. (Zic No. 748).

1860. Diloewak J. = Grewia $M$ icrocos L, Nat. fam. der Tiliacea. Gr. Java; heester. GEur. De aromatisch bittere bast en de samentrckkende bladeren worden als geneesmiddel aangeprezen.

1861. Diloewang S. = Broussouetia papyrifera Vent., Nat. fam. der Artocarpeæ. Gr. Op Java in tuincn; hooge boom. GEBR. Den bast kan men als bindtouw gebruiken, doch men bczigt dien mecr tot het vervaardigen van ruwe klecdingstukken en papier; de zoete en sappige vruchten zijn cetbaar.

1862. Dinga-dinga T. = Poly podium quercifolium Wlld. (Zie No.
181). Gebr. Volgens Hasskarl wordt de wortel half gaar gebraden en het daaruit loopende sap tegen doofheid in de ooren gedruppeld.

1863. Dingding-andaun-padjing $J$. $=R$ a ellia repanda L. (Zie No. 91).

1864. Dingding-arie $\mathrm{J}$. cn

1865. Dingding-haij J. \& Bน. = Ruellia discolor Nees. (Zie No. 72).

1866. Dinggarongan S. $=\mathrm{A} \mathrm{ch} \mathrm{y}$. ranthes eancscens R.Br., Nat. fam. der Amaranthaceæ. Gr. Java, enz.; overblijvende plant.

1867. Dingin-dingia MAND. $=\mathrm{Ka}$ lanchoë pinnata Pers. (Zie No. 1437).

1868. Disau-sajo T. $=\mathrm{C}$ o $\mathrm{mm}$ e rsonia echinata Forst. (Zie No. 108).

1869. Djaät $\mathrm{S}$. = Psophocarpus tetragonolobus D.C. (Zie No. 1546). Van deze plant onderscheidt de Sundanees negen varieteiten, als $\alpha$. Djaät blauw, b. Dj. boddas, $c$. Dj. hiedung, $d . D j$. konneng, $e$. Dj. monjet, $f$. Dj. putoi blauw, g. Dj. putoi boddas gedeh, h. Dj. putoi boddas leutik, $i$. Dj. putoi hiedung en $k$. Dj. putoi konneng.

1870. Djabon J. = Nauclea grandifolia D.C., Nat. fam. der Rubi aceæ. Gr. Java; hooge boom. Gebr. Het roode en vaste hout bezigt men als timmerhout, doch het wordt spoedig door wittc mieren aangetast.

1871. Djabong Mak. $=\mathrm{S}$ in ap is a l b a I. (Zie No. 76ว̆6).

1872. Djadam $J_{0}=A l$ o $̈$ v ul gar is D.C., Nat. fam. der L il i a c e a. Gr. Op Java en elders in tuinen; overblijvende plant. Gebr. Deze levert de bekcnde Gummi Aloës. Op Java makt meı met het sap der bladeren een verkoelenden drank, tjin-tjouw genaamd, en ook, nadat de bladeren met kalkwater zijn uitgetrokken, een soort van gebak. Tegen hoofdpijn. legt men dc gekneusdc bladeren als verkoelend middel op het voorhoofd, en gebruikt ze tot wassching van het hoofdhaar, daar zij den haargroei zullen bevorderen. Een aftreksel der bladeren dicnt men als ontlastingbcrorderend middel toe.

1873. Djadjahëan $\mathrm{J} .=\mathrm{H}$ ed $\mathrm{y}$. chium angustifolium Wall., Nat. fam. der Z ing i ber a c c ז. Gr. Java; overblijvende plant. 
1874. Djadjambotan $\mathrm{S} .=\mathrm{d} \nabla 0-$ nymus javanicus Bl., Nat. fam der Celastrineæ. Gr. Java en Timor; kleine boom.

1875. Djadjawaij S. of Djadjawie M. $=a$. Urostigma Rumphii Miq. (Zie No. 103) $=6$. Urostigma benja. mineum Miq. (Zie No. 1565) en $=$ c. Urostigma hom a to c arpum Miq., Nat. fam. der $\Lambda$ rtocarpeæ. Gr. Java, Timor, enz.; hooge boom.

1876. Djago-moetrie $\mathrm{J} .=$ S orghum saccharatum Pers. (Zie No. 1038).

1877. Djagul-kedang $\mathrm{J} .=\mathrm{I}$ odes ovalis Bl., Nat. fam. de: Menisperma ceæ. Gr. Java; heester. (?)

1S78. Djagong S. \& M. =Z e a Mays L., Nat. fam. der $\mathrm{G}$ r a m ineæ. Gr. Overal in Indië als cultuurplant in tuinen; zaadplant. G⿺Br. Het voedend en geneeskrachtig vermogen der Turksche tarwe zal wcl aan een ieder bekend zijn; op Java verbouwt men el vier verscheidenheden van en wel: $a$. djagong-gedeh (var. pallida), b. dj. hawarah (var. hawarah), $c$.dj. tjo epak-gedeh (var. minor) en dj. tjoepak-leutiek (var. $m$ in im a).

1879. Djagong-tjeutriek $\mathrm{S}$. = Sorghum vulgare Pers; Nat. fam. der Gram in e $æ$. Gr. Op Java veelal om de rijstrelden aangeplant; zaadplant. GEB?. Het rijpe zaad wordt bij wijze van gierst gegeten.

1880. Djaha-gading $\mathrm{S} .=\mathrm{Cya}-$ nodaphne cuneata Bl., Nat. fam. der L a u r in eæ. Gr. Java, boom.

1881. Djahas J. $=$ Echinochloa Crus-galli P. d. B., Nat. fam. der G r a m in e æ.' Gr. Java, Timor; grassoort.

1882. Djaijantie $\mathrm{S} .=\mathrm{S}$ es b a n i a xgyptiaca Pers., Nat. fam. der Papili o naceæ. Gr. Op Java en Timor in tuinen; heester. GEbr. Deze plant behoorde vroeger onder de samentrekkende geneesmiddeleu.

1883. Djaijantie.ketjil M. = Ses. b a n i a paludos a J a c q., Nat. fam. als boven. Gr. Java; slingerplant.

1884. Djaheh S. \& M. = Z in g iber officinale L. (Zie No. 253).

1885. Djahej-tikoes BK. = G lobb a u liginosa Miq., Nat. fam. der Zingiberaceæ. Gr. Sumatra, Bangka; ${ }_{0}$ verblijvende plant.
1886. Djai-soe Cr. Bo. $=\mathrm{Cocos}$ n u c ifera L. (Zic No. 393).

1887. Djajem Bк. $=$ Clerodendrum inerme Grtn. (Zie No. 1243).

1888. Djalamampang $\mathrm{M} .=\mathrm{S}$ cin da $\mathrm{p}$ sus pertusus Schott. (Zie No. 5492).

1889. Djalam-garo $\mathrm{r}$. $=\mathrm{H}$ ib iscus surattensis l. (Zie No. 731).

1890. Djalatrang $S .=$ A rom adendron elegans Bl., Nat. fam. der Magnoliacex. Gr. Java; hooge boom. GEBR. Het hout is zeer sterk, zeer geschikt voor bouw- en meubelhout; de schors is. een aromatisch bitter geneesmiddel. $=b$. Michelia montana Bl., Nat. fam. der Magnoliaceæ. GR. Java en Sumatra ; hooge boom. Gebr. Deze boom levert een vrij goed bouw- en meubelhout; de aromatisch bittere bast gelijkt in werking eenigszins op de Cascarille, maar is minder bitter.

1891. Djalen J. $=\mathrm{Evon} \mathrm{y} \mathrm{mus}$ javanicus Bl. Zie No. 1874).

1892. Djali J. $=$ Eleusine Coracana Grtn., Nat. fam. der Gramineæ. Gr. Java. Gebr. Dit gras is een zeer goed voedsel voor paarden en buffe!s; het rijpe zaad wordt bij wijze van brij gegeten.

1893. Djalie J. eu

1894. Djalie-batoe J. = Coix Lac ryma L., Nat. fam. der Gra m in e Gr. Bijna overal in Indië, zaadplant. GEBR. $\mathrm{Na}$ eerst van de harde schil ontdaan te zijn, kan het rijpc zaad, bij gebrek, als voedingsmiddel benuttigd worden; op de Philippijnen maakt men er een meel van voor zwakke, pas van ziekte herstellende personen. Op Java vervaardigt men van de harde, blauwe zaden bidsnoeren en guirlandes voor feesten. Aan het steeuachtig omhulsel kent men een versterkende en pisdrijvende krocht toe; ook werd dit vroeger tcgen tering cn waterzucht toegediend.

1895. Djalie-betoel J. $=\mathrm{C}$ o ix a grestis $\mathrm{L}$ o u r. (Zis No. 42).

1896. Djalie-padie Sum. $=\mathrm{C}_{0} \mathrm{ix}$ K o e n i g i i S p r g., Nat. fam. als voren. Gr. Sumatra; zaadplant.

1897. Djallo-djallo $\mathrm{T} .=\mathrm{Scsu}$ vium repens Wlld. (Zie No. 734).

1898. Djamakka $\mathrm{S}$. = Akar tjamakka S. (Zie No. 238).

1899. Djamakka (tjamakka)-konneng $\mathrm{S} .=\mathrm{D}$ i anella javanica Bl. Nat, fam. der As para g i n e $æ$ Gir. Java; overblijvende plant. 
1900. Djambang $\mathrm{S} .=\mathrm{C}$ o el o s p e $\mathrm{r}$. mum scandens Bl. (Zie No. 699d).

1901. Djambeh S. = Areca Ca. te chu L (Zie No. 1286.)

1902. Djambeh-bener $\mathrm{S} .=\mathrm{Areca}$ a $\mathrm{lb}$ a $\mathrm{km} \mathrm{mh}$. Nat. fam. der $\mathrm{P}$ a $\mathrm{lm}$. Gr. Oost-Java en de Molukken; boom. Gebr. Als No. 1286.

1903. Djambeh-loeng-loeng $\mathrm{S}$. = A reca a lba R m ph., var. oblonga H k. GEBR. Als No. 1286.

1904 Djambeh-rendeh S. = A re c a triandra $R \times b$. Nat. fam. der Pa lin æ. Gr. Samatra, Java, Amboina. Gebr. als No. 1286,

1905. Djambeh-soesoe S. A r e c a a l b a $R \mathrm{mph}$. (Zie No. 1902.)

1906. Djamblang $\mathrm{M}_{\mathrm{S}}=\mathrm{S}$ y z $\mathrm{yg} \mathrm{i}-$ um jambolanum Rxb, Nat. fam. der II y r tac . GR. Door geheel Ned. Indië, veelal iu tuinen; middelmatige boom. Gebr. Het hout is een goed en sterk bouwhout; den bast gebruikt men tot het tanen varı vischuetten, deze is, in af kooksel tegen diarrhœa gegeven, so ms heilzaam. De bladeren worden raur gegeten en op sommige eilander als tabak gerookt. De vruchten zijn zeer gewild; zij worden rauw of in het zout ingelegd gegeten.

1907. Djamboe $\mathrm{S},=a . J$ a m b o $\mathrm{s}$ $\mathrm{Rmph}$. species plurimæ. $=$ b. Vangueria latifolia Miq. Nat. fam. der R u b i a c e se. Gr. Java; heester.

1908. Djamboe-ajer M. $=a$. J a m. bos a a lba kmph.; (Zie No. 50.) $=b$. J ambosa aquæa $\mathrm{Kmph}$; Nat. farn. der II y rtacer. GR. Door geheel Ned.Indië aangeplant; boom. GEBR. De aangenanie, zure en saprijke vruohten worden rauw en gestoofd gegeten; de bast zal, in aftreksel aangewend, heilzaam zijn tegen spruw der kinderen. $=c$. $\mathrm{J}$ a mbos a formosa Wght. Nat. fam. als boven. Gr. Java en Borneo; hooge boom. Gebr. De bladeren en vruchten wordel gegeten.

1909. Djamboe-ajar-mawar M. = $\mathrm{J}$ a mbosa v ulgaris Dc., Nat. fam. als voren. Gr. Op alle eilanden in tuinen; hooge boom. GEsR. De angenaam riekende en goed smakende vruchten zijn een gezocht ooft, dat rauw en gekonfijt wordt gegeten. De samentrekkende bast en de scherpe aromatische zaden worden tegen diarrhœa en dysenterie toegediend. De in suiker ingelegde blocmen geeft men als verkoelend en bedarend geneesmiddel. De zaden zijn werkzaam bevonden tegen katarrhale koortsen.

19l0. Djamboe-alfoeroe $\mathrm{M} .=\mathrm{S} y$ zygi um caryophyllifolium Dc., Nat. fam. Als voren. Gr. Java, Ceram; hooge boom. Gebr. De vruchten zijn eetbaar, doch niet zeer gezocht.

1911. Djamboe-aroeng $\mathrm{S} .=\mathrm{Psi}$ dium Guajava L., Nat. fam. der M yrt a ceæ. Gr. Door geheel Ned. Indië, zoo in het wild als aangeplant; boom. GEBR. Het weeke, doch sterke hout verwerkt men tot rijststampers, scheden van wapens, enz. De aromatische en samentrekkende bladeren waren vroeger officineel, en zijn tegen diarrhœa en slepende dysenterie zeer aan te bevelen. De vruchten zijn, rauw en gestoofd, zeel gewild eu zeer gezond.

1912. Djamboe-aroij $S .=S$ a geretia parviflor a D o n., Nat. fam. der $R$ h a $m$ e $æ$. Gr. Java; slingerplant.

1913. Djamboe-aijer $\mathrm{M}$. = J a mbosa vulgaris Dc., var. palembanic a D c. G.r. Jaza en Sumatra; de vruch. ten van dezen boom hebben een wrangen, minder aangenamen smaak.

1914. Djamboe-aijer Tond, = J a mbosa aquæa Rmph. var, angustifolia. Gr. Celebes: de zure vruchten dezer soort zijn zeer gezocht en worden, rauw en gepekeld, gegeten.

1915. Djamboe-aijer-ketjil M. = $J$ ambosa aqu xa Rmph. (Zie No. 1914).

1916. Djamboe-aijer-oetan M. = $\mathrm{J}$ a $\mathrm{m}$ bos a lin e a $\mathrm{r}$ is K tbs., Nat. fam. der M y rta c e æ. Gr. De Molukken ell kleine Sunda-cilanden; kleine boom.

1917. Djamboe-aj̈er-poetih M. = J ambosa aquæa R m p.; var. lim. bata (Zie 1914)

1918. Djambor-aijer-tjoribon M.= $\mathrm{Jambosa}$ alba $\mathrm{Rmph}$. (Zie No. 50.)

1919. Djamboe-bidji-bidji M. = Psidium Guajara I. (Zie No. 1911.)

1920. Djamboe-bliembieng M. = Euge nia uniflora L., Nat. fam. der M y r t a e e $x$. Gr. Op Java in tuinen, uit Brazilië; heester.

1921. Djamhot-boeroeng $\mathrm{N}$. $=\mathrm{J}$ amb os a densifl ora D c. Nat. fam. der M y r t a c e a. Gr. Java, Sumatra; boom. GERr. Men bezigt het hout tot huisbonw; 
het is grof en roodachtig, en wordt spoedig door witte mieren aangetast; den bast gebruikt men om er garens en touwwerk mede zwart te verven; de vruchten zijn cetbaar.

1922. Djamboe-bôl S. \& M. = J a mbos a domest ic a $R \mathrm{mph}$., Nat. fam. als voren. Gr. Door bijna geheel Indië in tuinen; hooge boom. Grar. De saprijke, aangenaam verfrisschende vruch. ten zijn zeer gezocht en gezond; zij worden rauw, gestoofd en gekonfijt gegeten. Men vindt van deze soort een menigte verscheidenheden

1923. Djamboe-bôl-besaar M. = $\mathrm{J}$ a m bos a domestica $\mathrm{Rmph}$. var. c a l a p paria $\mathrm{Bl}$. (Zie vorig No.)

1924. Djamboe-bôl-meirah M. = J a mbosa do in estica Rmph., var. rosea Bl.

1925. Djamboe-bôl-poetih M. = $J$ a m b os a domestica Rmph, var. minor B l.

1926. Djamboe-dajan $\mathrm{BD} .=\mathrm{J}$ a mbos a domestica $R \mathrm{mph}$. (Zie No. 1922.)

1927. Djamboediepa S. \& M. = J a mbosadomestica Rmph., var. p ur purea Bl.

1928. Djamboe-diepa Suм. Wк. = $J a m b o s$ a den $\mathrm{s}$ iflora D c. (Zie No. 1921.)

1929. Djamboediepo Sum. Wк. = Diospyros Diepenhorstii Miq. Nat. fam der E b e n a ce æ. Gr. Suma. tra; hooge boom.

1930. Djamboe-djene. Mak. = J a ınbos a quæa Rump. (Zie No. 1914.)

1931. Djamboe.goelampok S. = $\mathrm{J}$ a $\mathrm{mb}$ os a alba $\mathrm{R} \mathrm{mph.,}$ a a r. mi. crocarpa $\mathrm{H}$ assk. en obtus sissima Miq. (Zie No. 50.)

1932. Djamboe-goelo BK. = A nacardium occidentale L. (Zie No. 1474.)

1933. Djamboe-iroeng M. (Zie vorig No.)

1934. Djamboe-itam $\mathrm{H} .=\mathrm{J}$ a $\mathrm{m}$ : bosa domestica Rmph., var. nigra B l. (Zie No. 1922)

1935, Djamboe-kadjoe M. (Zie No. 1932.)

1936. Djamboe-kalang PAL. $=\mathrm{J}$ a mbos a subsessilis Miq., Nat. fam. der M y r t a c e æ. Gr. Sumatra; boom.

1937. Djamboe-koening $\mathrm{BL}_{0}=\mathrm{P}$ si- dium Guajava L. var. pyriferum R a d i. (Zie No. 1911.)

1938. Djamboe-kling M. = M y rt ns communis L., Nat. fam. der $\mathbf{M}$ y $r$ $\mathrm{t}$ a c e æ. Gr. Hier en daar in tuinen, uit Zuid-Europa overgebracht; heester. GEBr. De gewone Mirt wordt als aromatisch-tonisch geneesmiddel en als cosmeticum nu en dan aangewend.

1939. Djamboe.kloetoek S. \& M. $=a$. Psidium Guajava $\mathrm{L}_{\text {. }}$. (Zie No. 1911.) = b. Psidium pumilum Vhl., Nat. fam. Als voren. Gr. Bijna door geheel Indië; kleine boom. GEBR. Als No. 1806 ; ook worden, vooral door de Chíneezen in het daselijksch leven de bladeren als thee, zoomede veelvuldig tot vervalsching der thee gebruikt.

1940. Djamboe-klonkong MAK. = J a m bosa domestica Rmph., var. c a l a p paria Bl. (Zie No. 1922.)

1941. Djamboe-lumboet $\mathrm{S} .=\mathrm{Ps}$ dium pumilum Vhl. (Zie No. 19396.)

1942. Djamboe-malabar $\mathrm{M}_{0}=\mathrm{J}$ a mbosa formosa Wght. (Zie No. $1908 c$.)

1943. Djamboe mangeh $\mathrm{M}_{\mathrm{AK}}$. $=$ Jambosa rhytidobarpa Zoll, Nat. fam. der Myrtacex. Gr. Celebes; boom.

1944. Djamboe-masson J. en

1945. Djamboe-mendeh M, ook

1946. Djamboe-monjet $\mathbf{M}$. = A n ac a rdium occidentale I. (Zie No. 1474)

1947. Djamboe-meirah $\mathrm{M} .=\mathrm{J}$ a $\mathrm{m}$. bosa domestica $R \mathrm{mph}$. var. purpurea Bl (Zie No. 1922.)

1948. Djamboe-0etan M. $=a$. P s idi um Guajava L. (Zie No. 1911) en $=$ . J a nibosa domestica Rmph. var. nigra Bl. (Zie No. 1922.)

1949. Djamboo-oetan-poetih M. Jambosa alba Rmph, (Zie No. 50.)

1950. Djamboe 0ewer BL. $=\mathrm{J}$ a mbosa aquxa Rin $\mathrm{ph}$. (Zie No. 1915.)

1951. Djamboe-portugaal MaK. = Psidium Guajava L. var. pyriferum Raddi (Zie No. 1911.)

1952. - Djamboe-sakelat M. = S yzygium caryophyllifolium Dc. (Zie No. 1910.)

1953. Djamboe-semarang-meirah M. (burrum S.) = J a mbosa alba Rmph. var. fructo rubro. (Zie No. 50 .) 
1954. Djamboe-semarang-poetih M. (boddas $\mathrm{S}$.) $=\mathrm{Jambosa}$ a l ba $\mathrm{R} m \mathrm{ph}$. var.fructo alba (Zie No. ธ0.)

1955. Djamboe-soör Mak. = A nacardium oc cidentale L. (Zie No. 1474.)

1956. Djamboe-tjina $\mathrm{M}_{0}=\mathrm{Ps}_{\mathrm{i}}$ dium pumilum Vhl. (Zie No. 19396.)

1957. Djamboe-wollanda M. (Zie No. 1958.$)$

1958. Djamboe-wollanda V. = Persea gratissima Grtn. (Zie No. 424.)

1959. Djamoer-bankong J. $=\mathrm{P}$ achyma tuber rcgium Fr.. Nat. fam. de: Gasteromycetes. Gr. Java en de Molukken. GrBR. Deze rwamsoort wordt aangeprezen tegen diarrhœa, keelpijn en koortsen.

1960. Djamoer-tombong M. = L ycoperdon Trnf. Species. Nat. fam. der Gasternmycetes. Gr. Java en elders; zwammen.

1961. Djampang S. (ook Djambang S.) $=$ sleusine indica Grtn., Nat. fam. der Graminex. Gr. Door geheel Indië. Gebr. Dit gras is een zeer geschikt voeder voor paarden en buffels.

1962. Djampang-kahi $\mathrm{S}$. $=\mathrm{Hy}$ poës tes rosea Dcsn., Nat. fam. der A canthacex. Gr. Java, Timor; overblijvende plant.

1963. Djampang-koeda $\mathrm{S} .=\alpha$. Eleusine indica Grtn. (Zic No. 1961) en $=b$. Echinochloa Crus-galli P. de B. (Zie No. 1881.)

1964. Djampang-manggong S. El e usines coracana Grtn. (Zie No. 1892.)

1965. Djandjer-tako S. = Allophyllus sundanus Miq. (Schmidelia), Nat. fam. der Sa pindaceæ. Gr. Bijna overal in Indië; heester. Gebr. Het hout gebruikt men voor daksparren; de bladeren bij het blauwverven van kleederen; de vruchten zijn eetbaar.

1966. Djanggòlan S. = Mesona palustris Bl., Nat. farm. der I,abiatæ. GR. Java, Bornco, Celebes; overblijvende plant.

1967. Djang-kang J. = Sterculia foetid a L. (Zie No. 1641.)

1968. Djangkar-meirah M. = Snada indica Miq. (Zie No. 266.)

1960. Djangkoeng. $\mathrm{S} .=\mathrm{P}$ oly. gonum orientale L. Nat. fam. der Polygoneæ. Gr. De Sunda-eilanden, veelal in tuiner, wegens de roode blocmen; overblijvende plant. GEBR. Aan het ziltige, samentrekkende kruid kent men wondhcelende en steenbrekerde eigen schappen toe.

1970. Djanglot J. $=$ Gelonium glomerulatum Bl., Nat. fam. der E u p h or b i a c e cæ. GR. Java; heester. GEBR. Het hout van dezen altijd bloeienden heester gebruikt men voor stelen en lansen.

1971. Djangoean-rambit $\mathrm{S} .=\mathrm{P}_{0}$ gostemon auricularia Hassk. (Zie No. 1443b.)

1972. Djankorang $\mathrm{S} .=\mathrm{P}$ a ratropia longifolia D.C. Nat. fam. der A ra. li a ceæ. Gr. Java; heester. GEbr. Het sap werkt wormdrijyend.

1973. Djankorang-gompong $\mathrm{S}$. = Arthrophyllum Blumeanum Z \& M.; Nat. fam. der Araliaceæ. Gr. Java en Sumatra; boomachtig.

1974. Djapoengan S. = Sicg esbeckia orientalis L. Nat. fam. der Compositæ. Gr. Bijna door geheel Indië. zaadplant.

1975. Djarak S. \& M. = Ricinus c o m mun is L., Nat. fam. der Ėuph orbiaceæ. Gr. Op Java en elder's in tuinen gekweckt; zaadplant. Gebr. Het melksap druppelt men in de ooren tegen hoofdyijn en verkoudheid; de bladeren, met aluin fijngewreven, legt men dikwijls op chronische becuzweren, met melk gekookt zullen zij een goed weekmakend cataplasma vorinen. De zaden dient men als ontlastingbevorderend en wormdrijvend toe; hiertoe bereidt men de bekende ricinus-, castor- of wonder-olie, welke de inlanders soms als purgeermiddel geren, meest echter als lampolie bezigen; met kapok en kalk inuig vermengd, gebruikt men ze veel tot het kalefaten van vaartuigen.

1976. Djarak-kalappa M. en

1977. Djarak-kalappa-mienjak M. $=a$. Ricinus rugosus M.ill., Nat. fam. als voren. $G_{k}$. Op Java in tuinen; zaadplant. GEBR. Deze rordt, evenals de vorige. tot bereiding van olie aangekweekt. $=b$. Ricin us ruber $R \mathrm{mph}$. Nat. fam. als boven. Gr. op Java en de Molukken in tuinen. GEBR. Dc zaden dicnen tot oliebereiding; dc Chineczen houden deze plant in zeer hooge waardc, 
daar zij de bladeren en zaden tot velerlei in- en uitwendige geneesmiddelen gebruiken.

1978. Djarak-kaliki S. $=a . \mathrm{Ri}$ cinus ruber Rmph. (Zie hiervoren.) $=b$. Ricinus spectabilis Bl., Nat. fam. als boven. GR. Op Java in bergstreken; boomachtig. GEBR. Als No. 1975.

1979. Djarak-kaliki-burrum S. = Ricinus inermis Mill., Nat. fam. dezelfde. GR. Op Java in tuinen; zaadplant. GEBr. De zaden bezigt men tot het maken van olie.

1980. Djarak-kapri M. en

1981. Djarak-kosta $S .=J$ a t r 0$\mathrm{pha} \mathrm{Curcas}$ L. (Zie No. 913.)

1382. Djarak-malakka M. en

3983. Djarak-meirah M. $=\mathrm{R}$ cinus ruber Rmph. (Zie No. 1977b.)

1984. Djarak-poetih M. = RiciIl ns spectabilis Bl. (Zie No. 19786.)

1985. Djarak-selassar S. = Ricinus communis L. (Zie No. 1870.)

1986. Djarak-selassie-lalaLki M: $=$ Ricinus spectabilis Bl. (Zie No. 1978b.)

1987. Djarak-tjiná $\mathrm{MI}=\mathrm{J}$ a tr $\mathrm{o}$ pha multifida I., Nat. fam. der Euphorbi a ceæ. Gr. Door geheel Indië in tuinen; heester Gerr. Van deze sieraadplant wordt de dikke knolwortel, ra eerst op asch geroosterd te zijn, gegeten; de zaden wendt men aan even als die van Curcas purg\&ns Mdk. (Zie No. $820)$; men bereidt er eene olie uit, oleum pinhoen genaamd, die in werking gelijk aan oleum infernale is.

1988. Djaram J. $=\mathrm{D}$ es modium triflorum D.C.; Nat. fam. der Papili on a ceæ. Gr. Java, Sumatra, Timor, kruipende plant

1989. Djaram M. = Pavetta indica I. (Zie No. 383.)

1990. Djaran J. = Odina gum. mifera Bl., Nat. fam. der An acardiaсеæ. Gr. Op Java en elders langs de wegen; hooge boom. Gerr. Deze boom is zeer rijk an een gomsoort, die tot technisch gebruik zal kunnen dienstig zijn; het lichte hout splijt men, waarna het tot invatting van vlechtwerk dient; de bladeren en jonge uitspruitsels worden bij de rijst gegetcn.

1991. Djarieng J. \& M. = Pithecolobium lobatum. Bnth., Nat. fam. der Mimoser. Gr. Sumatra, Java, Borneo; zeer hooge boom. $=6$. Pithe- colobium angulatum Benth., Nat. fam. als $a$. Gr. Java en Sumatra; kleine boom.

1992. Djarieng-antoe $\mathrm{M}=a . \mathrm{P} \mathrm{i}$ thecolobium bigeminum Mart. (Zie No. 2038a.) = b. Pithccolobium acutangulum Miq. Gr. Palembang; boom.

1993. Djarieng-toepai l IMMP. $_{\mathrm{A}}=\mathrm{P}$ ithecolobium oppositum Miq. Gr. Sumatra; boom.

1994. Djaringgan $\mathrm{M}=\mathrm{A}$ c or u s terrestris $\mathrm{Rmph}$. (Zie No. 134.)

1995. Djaring-djaring-padang Sum. $W_{K}=$ Aganope floribunda Miq. Nat. fam. der Papilionaceæ. Gr. Sumatra; kleine boum.

1996. Djaroem Sum. W.K. $=\mathrm{S}$ araco (Jonesia) macroptera Miq. Nat. fam. der Papilionacex. Gr. Sumatra; kleine boom.

1997, Djaroem-djaroem M. = $a$. Pavetta incarnata Bl., Nat. fam. der $\mathrm{R} u$ b i a c e $æ$. Gr. Op Java en elders als sierplant in vele tuinen; heester. GEBR. Sornmigen eten de bloemen als sambal bij rijst. $=b$. Pavetta bandhuca $\mathrm{Rxb}$., Nat. fam. enz. als bij $a$.

1998. Djaroem-djarcem $\mathrm{PAI}_{L_{i}}=$ Gomphia sumatrana Jack. (Zie No. 7848.)

1999. Djarong S. J. \& M. $=a$. Plumbago Truf. Species diversæ; $=b$. Lepidagathis Wlld. Spccies plurimæ; $=c$. Eranthemum L. Species diversa; $=d$. Achyran. thes bidentata Bl. (Zie No. 740.) = $e$. Nomaphila corymbosa Nees. Nat. fam. der Acanthaceæ. Gr. Java; kl cine heester; $=f$. Dicliptera Burmanni Nees, Nat. fam. als boven. Gr. Java, Timor; zaadplant; $=9$. Bonn a y g rand iflor a Sprg., Nat fam. der S crophularinex. Gr. Door geheel Ned.-Indië overblijvende plant.

2000. Djarong-awehweh $\mathrm{S}$. = E bermayera Nees. Specime plurimx.

2001. Djarong-blaauw $\mathrm{S} .=\mathrm{B}$ a rleria cristata I. Nat. fam. der A canthace $æ$. Gr. Op Java en elders, vooral in heiningen, kleine heester. GEBR. Een af knoksel der wortels wordt tegen lendenpijn gedronken.

2002. Djarong-boddas $\mathrm{S} .=\mathrm{B}$ a $\mathrm{r}$ leria dichotoma $R \times b$., Nat fam. en GR. als roren.

2003. Djarong-boebeekoeän S. = Eranthemum viscidun Bl. Nat. 
fam. der A canth a c e $æ$. GR. Java; heester GEBR. Het sap der bladeren en uitspruitsels wordt tegen oogontstekingen in de oogen gedruppeld. $=b . \mathrm{H} \mathrm{y} \mathrm{g} \mathrm{r}$ o phil a o b o v a ta Ns., Nat. fam. $\Lambda$ ls boven. GR. Java; waterplant.

2004. Djarong-boeboekoeän-lumboet $S .=H y g r o p h i l a$ assurgens DB., Nat. fam. der Acanthacex. $G_{R}$. Java; waterplant.

2005. Djarong-boenga-landep M. = Prionitis hystrix Miq., (Zie No. 1377.)

2006. Djarong-boentoet-koetj ing M. = Crossandra infandibnliformis Bl., Nat. fam. der A canthac e æ. GR. Door geheel Indie als sierplant in vele tuinen.

2007. Djarong-djarong $\mathrm{M} .=\mathrm{P}$ vet t a a m boini ca Bl. (Zie No. 101.) 2008. Djarong-gedeh $\mathrm{S}$. = S t $\mathbf{r}_{0-}$ bilanthes glandulosa Bl., Nat. fam. der Acanthaceæ. GR. Java; heester.

2009. Diarung-konneng S. = Strobilanthes involncrata Bl. Nat. fam. als voren. Gr. Java; heester.

2010. Djarong-lalakki S. \& M. $=\alpha$. Stachytarpheta indica Vhl. (Zie No. 1460.) $=6$. Achyrantes aspera Lam. (Zie No. 1716) $=c . \mathrm{Ox}$ alis Reinwardtii Z ucc. (Zie No. 251.)

2011. Djarong-woengoe $\mathrm{S}$. = B a rleria cristata L. (Zie No. 2001.)

2012. Djatang S. = Spilanthes A cmella l., Nat. fam. der Composit $x$. Gr. De Sunda-eilanden; zaadplant. GeBr. Men vermoedt dat de wortel een purgecrende kracht bezit. Het krnid en de bloemen zijn dienstig bij waterzucht en pisopstopping; nitwendig legt men het gekneusde kruid op versche, verouderde en vergiftigde wonden. De bloemen dezer plant wekken, gekauwd wordende, een sterken speckselvlocd op, waarom de Maleische schoolmeesters deze den kinderen laten kauwen, om moeilijke woorden gemakkelijker te kunnen uitspreken om deze laatste eigenschap noemt men deze plant de A-B-C-plant.

2013. Djattie S. \& M. = Tectona gr a nd is L.f., Nat. fam. der V erbenac ææ. GR. Bijna overal aangeplant; hooge boom. GEBr. Het Teakhout is een der beste, hardste en duurzaamstc houtsoorten, bijzonder geschikt voor huis- en schcepsbouw. Inwendig toegedicnd, zal dit hout een robereerende en maagop- wekkende werking nitoefenen, eu heilzaam zijn tegen cholera. De gom of hars bezigt men tegen keelaandoeningen. Dc bladeren gebruikt men om andere houtsoorten fraai rood te kleuren, alvorens ze te politoeren, en ook om aan lijnwaden een vaste roode kleur te geven; met suiker ingelegd dient men ze toe tegen spruw. De bloemen bezitten een pisdrijvend vermogen.

2014. Djattie-aroij S. = Premna $p$ a r a s i i c a B l., Nat. fam. der V erb e $\mathrm{n}$ a c e $x$. Gr. Java; slingerplant.

2015. Djattie-wollanda S. \& M. Guazuma tomentosa H. B. \& K., Nat. fam. der Büttncriace æ. Gr. Op Java eil elders langs de wegen, nit Zuid-Amerika overgebracht; hooge boom. GEBR. Het hout wordt veel gebruikt voor planken in prardenstallen; de bast wordt in ZuidAmerika met gevolg aangewend bij herpes en lepra; de bladeren zijn een gezocht voedsel voor geiten.

2016. Djawer (of Djewer)-burrom S. = Coleus scutellarioides Bent. var. a urea. Nat. fam. der Labiatæ. Gr. Op Java en elders als sierplant in tuinen; overblijvend.

2017. Djawer-gedeh $\mathrm{S}$. $=$ Coleus macrophyllus Bnth., Nat. fam. als voren. Gr. Java; overblijvend.

2018. Djawer-goenong $\mathrm{S} .=\mathrm{Co}_{0}$ leus galeates Bnth., Nat. fam. als voren; Gr. Java en de Molukken; overblijvende plant.

2019. Djawer-konneng $\mathrm{S} .=\mathrm{Co-}$ le us bicolor Bnth., Nat. fam. der Labiatæ. Gr. Java in tuinen als sierplant, vooral om den aangenamen geur der bladeren, overblijvend; GEBR. De bladeren worden dikwijls als uitwendig geneesmiddel aangewend.

2020. Djawer-kottok S. = Coleus scutellarioides $B$ nth., met hare verscheidenheden: in $\mathrm{g}$ i a $\mathrm{t} u \mathrm{~s}, \mathrm{l}$ a $\mathrm{c}$ i n ia tus, Blnmei, celebisus, aureus, maculatus en atrosanguineus. Nat. fam. als voren. Gr. Op Java en elders als sierplanten in tuincn; overblijvend; GEBR. men geeft den wortel tegen diarrhoea, het kruid zegt men pis- en wormdrijvend tc zijn. $=b$. Moschosma polystachyn Bnth., (Zie No. 832.) = c. Sonerila tennifolia 13l., Nat. fam. der Melastomaccæ; Gr. Java en Sumatra; overblijvende plant.

20\%1. Djawer-kottuk-Lesaar s 
\&N. =Coleus macrophyllus Buth. (Zie No. 19l\%.)

2022. Djawer-kottok-goenong S

(Zie No. 2018.)

2023. Djawer-kottok-konneng S.

(Zie No. 2019.)

2024. Djawer-kottok-meirah S. \& M. $=$ Colens sentellarioides Benth. var. aureus. (Zie No, 2016.)

2025. Djawie-djawie M. = Urostigma Rumphii Miq., (Zie No. 103.)

2026. Djawoera $\mathrm{S}$. $=\mathrm{G}$ a rcinia cornea L., Nat. fam. der Clusiaceæ; Gr. Java, Celebes, de Molukken, boom; Gerr. Het duurzame hout is zeer geschikt voor balkjes en stijlen; den wortel gebrnikt men om cr Sagueer mede te makeu. = $b$. Garcinia dioica Bl., = c. G.lateriflora $\mathrm{Bl}$. en $=d$. G. longifolia Bl. Nat. fam. als boven. Gr. Java, hooge boomen; Geвa. Deze alle hebben vruchten, wier zaden met een dun, ruwachtig vleesch omgeven zijn, dat door velen gaarne gegeten wordt. De basten en vruchtschillen van alle Gareinia-soorten zijn zeer samentrekkend, bijzonder geschikt voor het looien van leder en het zwartverven, en kunnen tegen diarrhoea dienstig zijn.

2027. Djeänkong $\mathrm{S}$. = Polygonu mo rientale L. (Zie No. 1969.)

2028. Djebis-0etan M. $=\mathrm{V}$ itis ind i c a I. (Zie No. 349.)

2029. Djegeng $\mathrm{M}$. $=\mathrm{S}$ orgh u $\mathrm{m}$ v ul g a r e Pers, (Zie No. 1879.)

2030. Djekken $J .=S o u c h u s$ asper Vill., Nat. fam. der Compositæ; Gr. Op Java, uit Europa overgebracht; zaadplant. Gebr. De jonge, bittere bladeren der Ganzedistel kunnen als groente gegeten wordell.

2031. Djela-djela T. $=0 \mathrm{rtho-}$ pogon Burmanni R. Br. Nat, fam. der Gramineæ; Gr. Bijua door geheel Indië overblijvende plant; GıBr. Het zaad dezer grassoort is een geschikt voeder voor jonge eenden en kippen.

2032. Djelatong-karbou $\mathrm{II} .=\mathrm{Ur}$ tica (?) ovalifolia B l. (Zie No. 1663.)

2033. Djelie-menjan $\mathrm{S}$. = Scindapsus sylvestris Knth. (Zie No.407.)

2034. Djeloetong $\mathrm{BK} .=$ Alston i a e $\mathrm{x}$ i m i a Nliq., Nat. fam. der A poc y n e x; Gr. Bangka; boom.

2035. Djembieriet $\mathrm{S}$. $=\mathrm{T}$ a bernæ montana sphærocarpa Bl., Nat. fam, der A p o c yne ac; Gr. Op Java in vele tuinen als sierplant; heester; deze bevat veel en zeer giftig melksap.

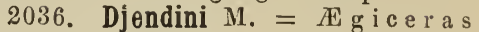
floridum R. \& S. (Zic No, 130.)

2037. Djendjer-takko S. = Allophyllus sundanus Miq. (Zie No. 1965.)

2038. Djenkol J. M. \& S. $=\alpha$. Pithecolobium bigeminum Mrt. Nat. fam. der Mimoseæ. Gr. Java; Sumatra enz.; hooge boom. GEBr. De stam levert cen slecht timmerhout; de jonge bladeren eet men als groente; de stinkende zaden eten de inlanders gaarne als toespijs bij de rijst; zij verwekken lichtelijk huiduitslag, en deelen aan de urine een ondragelijk sterken reuk mede; misbruikt wordende wekken zij dikwijls haematurie op. De geknensde schillen der peulen dienen tot wassching van het hoofdhaar. $=b$. Pithecolobium lobatum Bnth. (Zie No. 1991.) $=c$. Albizzia lucida B n t h. Nat. fam. Jer M i mo ce æ. Gr. Java, enz.; boom. Gebr. Ook de zaden van deze soort worden om hunne knoflookachtigen geur veelal bij de rijst gegeten.

2039. Djengkot $\mathrm{M} .=\mathrm{B}$ a s si a sericea Bl. Nat. fam. der Sapotacer. Gr. Java; een hooge boom, die waarschijnlijk een goed timmerhout levert.

2040. Djenkot (of Djenggot) S. = M imusops acuminata Bl. Nat. fam. der Sa potacex. GR. Java, Sumatra; boom. GEBR. Het hont is ongeschikt voor brandhout, doch zeer geschikt voor houtskolen; het melksap gebruikt men voor kleine fakkeIs.

2041. Djepoen $J .=A c a c i a \mathrm{~F}^{\mathrm{r}}$ nesiana Wlld. Nat. fam. der Mimoc e æ. Gr. Bijna overal in Indie, als sierplant in tuinen gezocht; heester. GEBR. De plant zweet veel gom uit. De wortel, bast en bladeren worden door de inlanders als braakmiddel gebruikt. De geurige, gele bloemen zijn zeer gezocht als cosmeticum en in likeuren; zij worden ook toegedicnd bij gestoorảe digestie, zenuwachtig maaglijden, enz. De jonge peulen bevatten een groote hoevcelheid eener kleverige lijmachtige stof, welke bij oogaandoenin. gen in het oog wordt gedruppeld, en dikwijls als lijm aangewend wordt. Het pulpa der vrucht beweert men zeer heilzaam te zijn tegen wonden in de ooghoeken.

2042. Djepon J. = Corchorus ol itorius L. Nat. faın. der Titiace se. Gr. 
Java, Sumatra. Timor; zaadplant. GEBr. Dit kruid eet men gaarne als groente; het werkt eenigszins ontlastingbevorderend; de zaden werken purgeerend.

2043. Djera Sum. W.K. = Eurya hirsutula Miq. (Zie No. 808a.)

2044. Djerawak Bк. = Leucopogon malayanus Jack. (Zie No. 8552.)

2045. Djeremeh-aoejoe B.K. = S alomonia cantoniensis Lour. Nat. fam. der Polygaleæ. GR. Sumatra, Banka, overblijvend.

2046. Djerenne $\mathrm{MAK}_{\mathrm{AK}}=\mathrm{D} \approx \mathrm{mo-}$ norhops J)raco Mart. Nat. fam. der Palmæ. Gr. Sumatra, Borneo; slingerpelm. GEBR. Deze Palm levert voortreffelijke wandelstokken. De vruchtschillen en vruchten leveren de beste soort van drakenbloed.

2047. Djeroedjoe M. \& J. $=a$. Dilivaria ilicifolia Juss. (Zie No. 472.) $=6$. Dilivaria ebracteata Juss. Nat. fam. der Acanthaceæ. Gr. Java, de Molukken; moerasplant. GEBR. De wortels wendt men uitwendig aan op rergiftigdc wonden cn bij beri-beri, inwendig tegen buikpijn. Het kruid is zeer gezocht door het rundree. $=c$. Dilivaria scandens Nces. Nat. fam. Gr. en GEBr. als de vorige.

2048. Djeroek (Djerook) S. J. \& M. $=$ Citrus L. Spec. omnes.

2049. Djeroek-amies $\mathrm{S}$. = Citirus Aurantium L. var. limettiformis, Nat. fam. der Aurantiacex. GR. Deze boom wordt bijna in alle tuinen gevonden; hij levert de zocte sinaasappels op.

2050. Djeroek-assam M. = $\mathrm{C}$ itrus medica L, Nat. fam, als boven. $\mathrm{GR}_{\mathrm{R}}$. Hier en daar in tuinen overgeplant; hij levert de gewone citroen, welker gebruik alom bekend is.

2051. Djeroek-assam-besaar $\mathrm{M}$. = Citrus graudis Hassk. var. spharocarpa en

2052. Djeroek-assam-pandjang $M$. $=$ Citrus grandis Hassk., var. o blonga. Nat. fam. als boren. Gr. Java; boomen. GEBR. Het zure sap der vruchten gebruikt men bij spijzcn en voor limonade; ook makt men er ijzerwerken mede schoon.

2053. Djeroek-badoerio $=$ Citrus ru a c rac a t h a 11 assk. (Zie No. 2070.)

2054. Djeroek-bali S. \& M. =
Citrus decumana L., varietates. Nat. fam. als voren. Gr. Op Java en elders in tuinen. GEBR. Deze boomen worden om de sappige vruchten aangeplant; zij zijn een kleinere soort der pompclmoes, om het aangename viuchtvleesch zcer gezocht, terwijl de vruchtschillen wel eens geconfijt worden.

2055. Djeroek-balik S. = Citrus o bversa $\mathrm{H}$ assk. Nat. fam. dezelfde. Gr. Java; boom, waarvan de vruchten soms gegetcn worden.

2056. Djeroek-banten $\mathrm{S}$. $=\mathrm{Ci}$ trus Aurantium L., microcarpa. GR. Op Java en elders in tuinen, levert een kleiue, zeer gezochte verscheidenheid van Sinaas-appelen.

2057. Djeroek-daliman $\mathbf{M} .=\mathrm{C}$ trus decumana L, $\nabla$ ariet.; deze levert, vooral rondom Batavia, de lekkerste soort van pompelnoes.

2058. Djeroek-djamblang $\mathrm{M}$. = Citrus decumana I., var. (Zie No. 2054.)

2059. Djeroek-djepoen $\mathrm{S} .=\mathrm{Ci}$ trus Aurantium l. Hiervan ziju drie gezochte, zoetc, saprijke soorten, de Ijepoen-bcsaar of macrocarpa, djepoenketjil of microcarpa en djepoen-sedang of limettifornis.

2060. Djeroek-gedogan M. = C itrus decumana L. var.

2061. Djeroek-gendie $\mathrm{M}$. $=\mathrm{Ci}$. trus pyriformis Hassk., var. Nat. fam. als boven. Gr. Java in het wild en in de tuinen. GFBR. De vruchten hebbeu een dikke schil cn een citroen-kleurig aangcnaam vleesch.

2062. Djeroek-hiedung $\mathrm{S}$. = $\mathrm{Ci}$. trus nobilis Lour. var. melanoc a r a Gr. Op Java cn clders in tuinen. De donkcrkleurige vruchten hebben ten aangenaam zoet sap en zijn zeer gezocht.

2063. Djeroek-honjeh-gedeh $\mathrm{S}$. = Citrus crassa Hassk., Nat. fam, als voren. GR. Java; van dezen boom treft men twce variëteitcn aan. Gußr. Je dikke schil der viuchten gebrnikt men ora te konfijten en het zure sap voor limonade.

2064. Djeroek-kapas $M$. = Citrus Limouelles Hassk. (Zie No. 761.)

2065. Djeroek-karbo M. = Citrus medica I. Gr. (Zie No. 2050.)

2066. Djeroek-lakki J. = Citrus nobilis Lour. (Zie No. 2062.)

2067. Djeronk-limoh $\mathrm{S}$. = Citrus 
trus Linıonelles Hassk., var. amblycarpa Hassk. (Zie No. 76l)

2068. Djeroek-limoh-gedeh $\mathrm{S}$. $=$ Citrus amara Il assk. Gr. Op Java en elders in tuinen; de goudgele, kleine, ronde vruchten bezitten een dunne schil en een groenachtig geel, bitterzmur vleesch; het san worde door sommigen gebruikt als dat van No. 761 .

2069. Djeroek-manalagie J. $=\mathrm{C} \mathrm{i}$ trus decumana L. (Zie No. 2057.)

2070. Djeroek-manies $\mathrm{M}$. = $\mathrm{Ci}$ trus macracantha $\mathrm{H}$ as sk., Nat. fam. als voren. $G_{B}$. $O_{p}$ Java en elders in tuinen. GEвк. De geelkleurige, ronde vruchten, met een matig dikke schil, behooren tot de aangenaainste zoete citroensoorten en zijn zeer gezocht.

2071. Djeroek-matjan $\mathrm{M}$. = $\mathrm{Ci}$ trus decumana L. (Zie No. 2057.)

2072. Djeroek-niepies S. \& M. = Citrus Limonellus Hassk. var. oxy carpa Has sk. Het gebruik der limmetjes is als No. 761 .

2073. Djernek-ojot $\mathrm{S}$, en

2074. Djeroek-pandan $\mathrm{M}$. $=\mathrm{C} \mathrm{i}$ trus decumana L. (Zie No. 2057.)

2075. Djeroek-pandjang $\mathrm{M}$. $=\mathrm{Ci}$ trus pyriformis Hassk. (Zie No. 2061).

20 6 . Djeroek-papaija $\mathrm{M} .=\mathrm{Ci}$ trus Papaya Hassk. Nat. fam. als voren. Gr. Java; boom. Gebr. Men gebruikt hiervan hoofdzakelijk de dikke vruchtschillen voor gebak en confituren.

2077. Djeroek-poerroet S. \& M. = Citrus Papepa Hassk., Nat. fam. als voren. Gr. De Sunda- en de Moiuksche eilanden; boom. GEBR. De biaderen hebben een aangenamen geur; men legt ze in waschwater, en gebruikt ze als specerij bij het braden van vleesch; de viuchtschillen worden met suiker ingelegd; het zure sap gebruikt men bij spijzen; vooral in de Molukken voor sagobrij ; nog gebruikt men dit sap bij de bereiding van verfstof uit de Kassoemba ( $\mathrm{Car}$ thamus ${ }^{\circ}$ tinctorius L.), door er bloemen mede uit te trekken, en ook uitwendig tegen fram. boesiac.

2078. Djeroek-post S. en M. $=\mathrm{Ci}$ trus amara Hassk. (Zie No. 2068.)

2079. Djeroek-ragie $\mathrm{J}$. $=$ Citrus A urantium I. var. microcarpa. (Zie No. 2059.)

2080. Djeroek-tandjong-poera S. = Citrus orata Hassk., Nat. fam. der Aurantiacex. Gr. Java; bəom. GEBR. De dikke, vleezige schil legt men in suiker als confituur, het zure sap dient als lemoensap.

2081. Djeroek-tangan $\mathrm{M}$. $=\mathrm{C} \mathrm{i-}$ trus sarcodactylis Sbld. Nat, fanı. als voren. Gr. Op Java, uit China overgebracht, en in tuinen veelal in potten gekweekt; kleine boom. GEBR. De zonderling gevormule vruchten, die veel op een gesloten vuist of klauw gelijken, worden, even als die der vorige soort angewend; de Chineezen plaatsen ze gewoonlijk als offerande vóór hmne huisgoden.

2082. Djeroek-tiepies M. $=\mathrm{Dj}$. niepies. (No. 20\%2.)

2083. Djeroek-tjoetjoek $\mathrm{S}$. $=\mathrm{C} \mathrm{i-}$ trus macracanth a Hassk. (Zie No. 2070.)

2084. Djeroek-tjoplok S. $=\mathrm{C} \mathrm{i-}$ trus nobilis l, our. var. chrysoc a r pa. (Zie No 2062.)

2085. Djeroekie $\mathrm{S}$. $=\mathrm{Chariessa}$ (Pleuropetalum Bl.) suaveolens Miq., Nat. fam. der I c a cineæ. Gr. Java; kleine boom.

2086. Djerrieng $\mathrm{S}=$ Pithecolobium umbellatum Bnth., Nat. fam. der Mimoseæ. Gr. Bijna in geheel Indie; hooge boom. GEBR. Het hout is fraai, wit met een rood hart, en sterk; het laat zich zeer moeilijk splijten en wordt daarom weinig gebruikt.

2087. Djeudjeroekan S. = Limonia spinosa Sprg., Nat. fam. der A urantiacea. Gr. Java, Noesa-Kembangan; heester.

2088. Djeudjeur-takkoh S. $=a$. Galearia sessil is Z. \& M. (Zie No. 919.) $=b$ Ryparia crsia Bl., Nat. fam. der Euphorbiacex. Gr. Java ; kleine boom.

2089. Djewor J. $=$ Commelyua paludosa B l., Nat. fam. der Commelynaceæ. Gr. Jara; overblijvende plant. GEBr. Men eet het jonge kruid gaarne gekookt als groente bij de rijst.

2090. Djidakaön $M .=C$ e los i a a r g e $\mathrm{t}$ e a $\mathrm{I}_{\text {. }}$ (Zie No. 1136c.)

2091. Djierak $\mathrm{S}$. $=\mathrm{Symplocos}$ fasciculata Zoll., Nat. fam. der Styrace $⿱$ c. Gr. Java, Bangka; heester. Gæвr. Men bezigt den bast tot het roodverven van garen en kleedjes.

2092. Djiging $\mathrm{S}$. = Indigofera hirsuta L., Nat. fam. der Papilionac ex. Gr. Bijna door geheel Indië; een 
onkruid, dat sleehts zeer weinig Indigo bevat.

2093. Djijanti S. (Zie No. 1882.)

2094. Djikoer $\mathrm{S}=\mathrm{T}$ a ce a palm a t a B l. (Zie No, 825.)

2095. Djingi S. \& M. $=\mathrm{L} n \mathrm{ff} \mathrm{a}$ acutangula Roxb., Nat. fam. der Cu. e u r bita e eæ. Gr. Bijna door geheel Indië in tuinen; zaadplant; GEBR. De vruehten worden vrij algemeen, afgekookt, als groente gegeten.

2096. Djing-tiang $\mathrm{PAL}_{\mathrm{AL}}=\mathrm{M}$ a p $\mathrm{pa}$ costulata Miq. Nat. fam. der Enphorbi с сеæ. Gr. Snmatra'a O.-kust; boom. 2097. Djinka M. $=\mathrm{Hi} \mathrm{bise} \mathrm{u} \mathrm{s}$ ros a-s in ens is I. (Zie No. 1360.)

2098. Djintan-oetan $\mathrm{M}_{\text {. }}=\mathrm{Ch} \mathrm{ry-}$ so pogon a iculatus Trin. (Zie No. 809.)

2099. Djinten M. $=\mathrm{Carum} \mathrm{Car}$ vi L., Nat. fam. der U $\mathrm{m}$ b e 11 i f.e ræ. Gr. Hier en daar in tuinen; zaadplant. GEBR. Het zaad is de gewone karwei of kummel uit den handel.

2100. Djinten-dawon $\mathbf{M} .=a$. $\mathrm{C}_{0}$ le as se utellarioides Benth., (Zie No. 2016.) $=$ b. Cole us e arnos us H a s s k, Nat. fam. der $L$ a b i a $t æ x$. Gr. Java, overblijvende plant.

2101. Djinten-hitam M. $=\mathrm{Nigella}$ s a tiva I., Nat. fam. der $R$ a n u n c ul a c e æ. GR. Hier en daar in tuinen; het zaad dezer plant is de zwarte karwei of zwarte kummel van den handel.

2102. Djinten-poetih $\mathrm{M}$. $=\mathrm{Cu} \mathrm{m}$ n u m C y mi n u $L$., Nat. fam, der $\mathrm{U} \mathrm{m}$ b e $1 \mathrm{l}$ i f e $\mathrm{r} x$. Gr. Hier en daar in tuinen, om hei komijnzaad, aangeplant. De drie aromatisehe zaden van No. 1992, 1994, 1995 vindt men in alle inlandsehe apotheken en op de bazars te koop; zij komen in de meeste samengestelde inwendige geneesmiddelen voor, inzonderheid tegen de onderbuiksziekten.

2103. Djirah Sum. = Eury a ph y llantoides Bl., Nat. fam. der T e r nstroem i a e $x$. Gr. Java en Sumatra 2-5000'; heester.

2104. Djoeät of Djoeët M \& J. = a. S y z y g u m J a m b o lan u m D e., (Zie No. 1906.) = $b$ Syzygium pscudo-jambolanu m M i q., Nat. fam. del Myrtaceæ. Gr. Java; hooge boom, dic in hoedanigheid waarsehijnlijk met de vorige overeenkomt.

2105. Djoedjar0e $\mathrm{T}$. $=$ C y cas cire in al is I., Nat. fam, der Cyea dea.
Gr. Wordt door geheel In dië in tuinen gevouden; boomachtig. GrвR. Uit den stam kan door kloppen Sago verkregen worden; de jonge, nog nict ontwikkelde bladeren leveren eene aangenome, zeer gezochte groente, de $\mathrm{Saj}$ or $\mathrm{radj}$ a, waarom deze boom voornamelijk wordt aangeplant. De vruehten worden gekonfijt gegeten; rauw genuttigd, veroorzaken zij verstopping; een afkooksel der jongere vruehten zal braakwekkend werken.

2106. Djoedjoeloek J. $=$ H y m ena ehne interrupta Büse (Zie No. 1657.)

2107. Djoegoel J. $=$ Elsholtzia e lat a Z. \& M. Nat. fam. der L abi at $₫$ GR. Java, 3-9000'; kleine heester.

2108. Djoekoe-pring LAMP. $=$ A postasia Wallich i R. Br., Nat. fam. der Apostasieæ. Gr. Java, Sumatra, Nieuw-Guinea ; overblijvende plant.

2109. Djoekoet S. beteekent kruid of onkruid.

2110. Djoekoet S. $=$ Dentella repens Forst, (Zie No. 79a.

2111. Djoek0et-akker-djamman S. $=$ Hyptis suaveolens Poit. (Zie No 791.)

2112. Djoekoet-baauw S. = A g eratum e onyzoides I., (Zie No. 794.)

2113. Djoekoet-babawangan S. = Se irpus juneoides Roxb. (Zie No. 1069.)

2114. Djoekoet-bapa-keboh S. = Striga euphrasioides Buth., Nat. fam. der Serophularine $x$. Gr. Java; zaadplant.

2115. Djookoet-biedrie S. = Moll ugo strieta I. Nat. fam. der Port u l a e e. Gr. Java, Timor. Deze éénjarige plant is door paarden en buffels zeer gezocht.

2116. Djoekoet-biengbieng-kassir S. (ook Dj. piengpieng-kassir) = Paspal u m L. S peeies plurimæ. Deze grassoorten zijn door paarlen en buffels zeer gezocht; ook kunnen de jonge spruiten $b_{i j}$ de rijst genuttigd worden $=b$. Seta $r^{\circ}$ a Te ijsmanni Miq., Nat. fam. der Graminex. Gr. Java; overblijrende plant.

2117. Djoekoet-boeboe-oet $\mathrm{S}$. = Fimbristylis efoliata Steud., Nat. fam. der Cyperaeex; Gr. Java cu Sumatra; overblijvende plant; deze rietsoort wordt door buffels, soms ook door paardeu gaarne gegeten. 
2118. Djoekoet-boeloe-mata $\mathrm{S} .=$ Fimbristylis Vhl. permultæ $=b$. Cyperus L. permultæ, alle even als de vorige gezocht.

2119. Djoekoet-boeloe-mata-keujoep-boddas $\mathrm{S}$. = Vandellia nervosa B ut h., Nat. fam. der Scrophula rineæ. GR. Java; zaadplant.

2120. Djoekoet-boeloo-mata-kebo S. = Chrtocyperus setaceus Nees., Nat. fam. als voren. GR. Java, Sumatra; zaadplant. $=b$. Lobelia L., Sp. d iversæ; overblijvende planten.

2121. Djoekoet-boeloe-mata-lumboot S. = Cyperus pennatus Lam., Nat. fam. der Cyperaceæ. Gr. Java en Timor (Zie No. 2117.)

2122. Djoekoet-boengboeng-delan leutiek S. $=a . \mathrm{K}$ ylling i a brevifolia Rttb. en $b$. K. pumilio Std., Nat. fam. der Cyperaceæ. Gr. Java en elders; overblijvende grassoorten.

2123. Djoekoet-boentoet-seroh S. $=A d h a t o d a$ Betonica Nees., Nat. fam. der Acanthaceæ. GR. Java; heester. 2124. Djoekoet-bohrang S. = M imosa pudica L. (Zie No. 649.)

2125. Djoekoet-djadjagoän $\mathrm{S}$. = Paspalum sumatrense Roth., Nat. fam. der Gramineæ. Gr. Java; Sumatra; overblijvende grassoort, als No. 2010.

2126. Djookoet-djaran S. (ook Dj. tjarang) = Anthisthiria ciliata $\mathrm{L}$, Nat. fam. der Gramineæ. Gr. Door geheel Indië. GEBR. Deze grassoort is een zeer geschikt voeder voor het ree; de in. landers eten ook de jonge uitspruitsels als groente. $=b$. Polygonum barbatum L. et variet., Nat. fam, der Polyg o neæ. GR. Java; overblijvende plant. GEBR. Men werpt het fijugekneusde kruid in het water om visschen te bedwelmen en te vangen.

2127. Djoekoet-djoedjooloek S. = Panicum auritum Prsl., Nat. fam. der Gramineæ. Gr. Java; overblijvend gras.

2128. Djoekoet-dongdoman $\mathrm{S}$. = Chrysopogon aciculatus Retz, (Zie No. 809.)

2129. Djoekoet-djorong S. = A chyranthes bidentata Bl., (Zie No. 740 .)

2130. Djoekoet-gehwor S. $=a$. Commelyna Dill., Specie's permultæ. $=b$. Campelia Rich., Species di. verseac. $=c$. Aneilema monadel- phum Kth. en $=d$. A. nudiflorum R. Br. $=e$. Tradescantia capitata Bl. Alle deze overblijvende planten beho oren tot de Nat. fam. der C o mmelynaс еæ. Gr. Op Java en elders. Gebr. De stengels en bladeren dezer planten worden, in stoom gekookt, bij de rijst gegeten.

2131. Djoekoet-hanjaroh S. $=\mathrm{Pa-}$ n i cu m milia re La m., Nat. fam. der Gramineæ. Gr. Java en Sumatra; overblijvend.

2132. Djoekoet-hoedjoh S. = Zoysia pungens Wlld., Nat. fam. als boven. Gr. Java; overblijvend.

2133. Djoekoet-kakawatan $\mathrm{S}_{\mathrm{e}}=a$. Panicum rigens $\mathrm{S} w$., Nat. fam. als voren. GR. Java; dit overblijvend gras is een geschikt veevoeder. $=b$. Cynodon Dactylon Pers. var. glabrata, in alles als bij $a_{0}=c$. Is chæmum ciliare Retz., zie het bij $a$. vermelde. $=d$. Andropogon pertusum Wlld., mede als bij $a$. opgegeven.

2134. Djoekoet-kamaloeän $\mathrm{S} .=\mathrm{Mi}$ mosa pudica L. (Zie No. 649.)

2135. Djoekoet-kapolloh S. $=$ D e ntella repens Forst (Zie No. 79a.)

2136. Djoekcot-kasimboekan S. = Drymaria diandra Bl., Nat. fam. der Caryophyllaceæ. Gr. Java; overblijvende plant. GEBR. De jonge toppen en bladeren worden rauw gegeten tegen opgezetheid van den buik.

2137. Djoekoet-kawassa S. $=$ Ardisia pumila Bl., Nat. fam. der Myrsineæ. Gr. Java; kleine heester. = b. Kalachoë laciniata Dc. en $=c$. K. pinnata Pers. (Zie No. 1436 en 1437.)

2138. Djoekoet-kikisian $\mathrm{S} .=a$. Ophiurus perforatus Trin., Nat. fam. der Gramineæ. Gr. Java; overblijvend $=b$. Rottboellia exaltata L. fs., Nat. fam. enz. als $a$.

2139. Djoekoot-lampoejangan $\mathrm{S}$. = Panicum tenue $R \times b$., Nat. fam. der Gramine æ. Gr. Java; overblijvend.

2140. Djoekoet-lari-lari $\mathrm{S}=\mathrm{Spi}$ nifex squarrosus L., Nat. fam. als voren. GR. De Sunda-eilanden; dit overjarige vlottende gras bedekt soms geheele kusistreken.

2141. Djoekoet-letta-ajam S. $=\mathrm{P}$ ouzolzia indica G a ud., Nat. fam. der Urtic a ceæ. Gr. Door geheel Indië; overblijvende plant. GEbR. Men legt dit kruid als weekmakend mid- 
del op bloedzweren en andere gezwellen.

2142. Djoekoet-lida-ajam S. \& M. (ook Dj. kaliwara S.) $=$ Spermacoce s ca berrim a. Bl.Nat.fam. der R ub i a ceæ. GR. Java en Sumatra; overblijvende plant. Gebr. De geheele plant wordt fijngewreven en op den buik van kinderen gesmeerd, die aan opgezetten buik en aan klierziekte lijden.

2143. Djoekoet-likisoenan $\mathrm{S} .=\mathrm{C}_{y}$ perus piptolepis $S$ teud., Nat. fam. der Cyperaceæ. Gr. Java; éénjarig.

2144. Djoekoet-lilisoenan gedeh S. $=\mathrm{M}$ ariscus umbellatus Vahl., Nat. fam. als voren. GR. Java; overblijvend.

2145. Djoekoet-loeloe S. = I n digofera hirsuta L. (Zie No. 2092.)

2146. Djoekoet-lokkot-mata S. = a. Artemisia indica Wlld. en $b$. A. lavendulæfolia Dc. (Zie No. 619b.)

2147. Djoekoet-maas $\mathrm{S} .=a . \mathrm{Ru}$ ellia repanda L. (Zie No. 9l.) $=b$. Peristrophe (?) salicifolia Miq., Nat. fam. der A canthaceæ. Gr. Java, Timor; heester. GŁBR. Men beweert dat deze plant vroeger het eenige voedsel der buffels was, en geeft het daarom thans nog aan vermagerde, ziekelijke beesten om weder vet te worden.

2148. Djoekoet-malela $\mathrm{S}$. = S p orobolos elongatus R.Br. Nat. fam. der $G r$ a m i n e æ. Gr. Java; overblijvend. $=b$. Polygala densiflora Bl. en $=c$. Pol. glomerata Lour., Nat. fam. der Polygaleæ. Gr. Java; overblijvende planten.

2149. Djoekoet-mamarakan S. = Echinochloa stagnina Beauv., Nat. fam. der Gramin e æ. Gr. Java; overblijvend.

2150. Djoekoet-mandel S. $=\mathrm{Ade}$. riostemma fastigiatum D c., Nat fam. der Compositæ. Gr. Java en Sumatra; éénjarig.

2151. Djoekoet-mandel-boddas $\mathrm{S}$. $=$ Adenostemma ovatum Miq., Nat. fam, als voren. Gr. Java; overblijvend.

2152. Djoekoet-manjerakan S. = a. Heteropogon polys tachy us B üse. Nat. fam. der Gramineæ. Gr. $\mathrm{Java}$; overblijvend. $=b$. Rot tboellia muricat a Retz., Nat. fam. dezelfde. Gr. Java, Sumatra, de Molukken; overblijvend. $=c$. Panicum frumeutaceum Rxb.
Nat. fam, zie boven. Gr. Java; overblijvend.

2153. Djoekoet-mata-boeng-boengdelan $\mathrm{S}$. = Kyllingia $\nabla$ agin ata L a m., Nat. furn. der C y p e r a c e GR. Java; overblijvend.

2154. Djoekoet-mata-keboh S. = Striga euphrasioides Benth. (Zie No. 2114.)

2155. Djoekoet-mata-keujup $\mathrm{S} .=$ a. V andellia crustacea Benth. en $b$. V. obtus a Miq. Nat fam. der S cr ophularineæ. Gr. De Sunda-eilanden; éénjarige planten. Gebr. Men bezigt het gekneusde kruid uitwendig bij herpes en als etterbevorderend middel op zwerende vlakten. $=c$. Bonn a y a $\mathrm{brahiata}$ Lk. $\&$ O., $=d$. B. reptans Sprg. en $=$ $e$. Mazus lævifolius Bl., Nat. fam. als boven. Gr. Van Java tot Timor; overblijvende planten. $=f$. I, o b el i a c æ spitosa Bl. en $=g$. L Cliffortiana Wlld., Nat. fam. der Lo beliaceæ. Gr. Java; overblijvende planten. $=h$. E u ph or. bi a reniform is Bl,, Nat. fam. der Euphorbiaceæ. Gr. Java; éénjarig.

2156. Djoekoet-mata-keojup-bod das $\mathrm{S}$. = Vandellia nervosa B e $t$ h. (Zie No. 2119.)

2157. Djoekoet-maijang $S .=C y-$ perus Ixia L., Nat. fam. der Cyperaceæ. Gr. Java, Celebes; overblijvend. GEBR. De inlanders gebruiken een aftreksel der bladeren tegen buikpijnen en tot opwekking van den stondenvloed.

2158. Djoekoet-maijang-leutiek S. = Cyperus Eragrostis Vahl., Nat. fam. als boven. GR. Java; overblijvend.

2159. Djoekoet-meurriet S. en.

2160. Djoekoet-moeria $\mathrm{S}$. $=\mathrm{D}$ ichrocephala latifolia. D.C. (Zie No. $1524 c$.)

2161. Djoekoet-njariengiet $\mathrm{S}_{.}=\mathrm{M}$ ic roc arpæa muscosa R.Br., Nat. fam. der S c rophula rineæ. Gr. De Sunda-eilanden; waterplant.

2162. Djoekoet-njehnjerehän $\mathrm{S}$. = $\mathrm{Microc}$ arpe mu s o s a RBr. (Zie voren); $=b$. Eragrost is e u chroa S t e u d., Nat. fam. der Gramineæ. Gr. Java, overblijvend.

2163. Djoekoet-njehreh S. = R hy nchospora Wallichiana Kth. (Zie No. 1282.)

2164. Djoekoet-oerieng-arieng S, $=a$. Lantana stricta L., Nat. fam. 
der V e rbeнасеæ. Gr. Op Java en elders in tuinen als sierplant; kleine heester. = b. Ptilotus corymbosus Bl., Nat. fam. der A m arantaceæ. Gr. Door bijna geheel Indië ; éénjarig. GEBR. Men gebruikt het kruid inwendig tegen slependen buikloop en schurft.

2165. Djoekoet-palias S. $=$ Pogonatherum crinitum Trin., Nat. fam. der Gramineæ. Gr. Java, Timor; overblijvend:

2166. Djoekoet-papawanang-gedeh S. = Isolepis uninodis Delil. Nat. fam. der Cyperaceæ. Gr. De Sundaeilanden; éénjarig.

2167. Djoekoet-pentoel S. $=\mathrm{Fim}$ bristylis regida Kth., Nat. famı. der C у p e r a c e æ. Gr. Java, Sumatra; overblijrend.

2168. Djoekoet-peperehpehtan S. = a. Oldenlandia brachypoda D.C. en $b$. Old. Heynii R.Br. Nat. fam. $\operatorname{der} R$ u bi a c e æ. Gr. De geheele SundaArchipel; overblijvende planten. Gebr. Het jonge kruid wordt rauw bij de rijst gegeten; ook is het door paarden en buffels zeer gezocht.

2169. Djoekoet-prasman $\mathrm{S} .=\mathrm{E} u-$ patorium Ayapanna Tent (Zie No. 140.)

2170. Djoekoet-prossot $\mathrm{S} .=\mathrm{P}_{0}$ la nisia viscosa R.Br. (Zie No. 1287b.)

2171. Djoəkoet-ramoh-gêges S. = Dj. Blengbieng-kassir $=$ (Zie No. 2116.)

2172. Djoekoet-rampoekassan S. = $\mathrm{Xerochloa} l a t i f o l i a \mathrm{H}_{\mathrm{a}} \mathrm{sk}$. Nat. fam. der Gramineæ. Gr. Java; een grassoort, die door paarảen en buffels zeer gezocht is.

2173. Djoekoet-rungiet $\mathrm{S} .=a$. Fimbristylis miliaceæ. Vahl., Nat. fam. der Cyperaceæ. Gr. Java, Sumatra, de Molukken; waterplant. $=b .0 \mathrm{l}$ denlandia paniculata L., Nat. fam. der $\mathrm{Rubiac}$ eæ. Gr. Door geheel Indië overblijvend.

2174. Djoekoet-saroenie $\mathrm{S} .=\mathrm{A}$ ca. ly $\mathrm{pha}$ hispida Burm., Nat. fam. der Euphorbiaceæ. Gr. Java; éénjarig. GEBR. Vele Acalypha-soorten worden als oplossend, ontlastingbevorderend, zweeten pisdrijvend aangeprezen.

2175. Djoekoet-seketi $\mathrm{S} .=\mathrm{N}$ a sturtium indicum D.C., Nat. fam. der Cruciferæ. Gr. Java; éénjarig. Geвr.
Met het fijngekneusde kruid wrijft men het lichaam tegen hitte bij koortsen. Dit kruid wordt ook met azijn bij wijze van salade gegeten.

2176. Djoekoet-seriawan $\mathrm{S} .=\mathrm{Fi}$ cus serpyllifolia Bl., Nat. fam. der Artocarpeæ. Gr. Java, kruipende plant.

2177. Djoekoet-sesehrehan $\mathrm{S} .=$ Andropogon I warancusa Roxb., Nat. fam. der Gramineæ. Gr. Op Java in tuinen; orerblijvend. GEвR. De bittere aromatische wortel wordt in Indië, even als die der Kalmus, gebruikt; ook zijn ċarmede in Europa proeven tegen Cholera genomen.

2178. Djoekoet-setan S. \& M. $=a$. Le ucas linifolia Sprg. (Zie No. 1043); = b. Polanisia viscosa D.C. (Zie No. 1287b.)

2179. Djoekoet-siraroe S. $=$ Ophioglossum petiolatum Hk., Nat. fam. der Ophioglosse æ. Gr. Java; orerblijvend.

2180. Djoekoet-sisier $\mathrm{S} .=\mathrm{O} p \mathrm{~h} \mathrm{i}$ orrhiza neglecta B l. Nat. fam.der Rubiaceæ. Gr. Java; overblijvend.

2181. Djoekoet-soemboe S. $=\mathrm{P}$ anicum a uritum Prsl. (Zie No. 2127.)

2182. Djoekoet-sorosattie $\mathrm{S}$. $=$ Dj.setan (Zie No. 2178.)

2183. Djoekoet-tapak-boeloe S. = Digitaria sanguinalis Scop. Nat. fam. der Gram ineæ. Gr. Java en Timor; overblijvend.

2184. Djoekoet-tapak-djalak $\mathrm{S}$. = a. Digit a ria digitat a Büse, Nat. fam. als voren. Gr. Java; overblijvend. = b. Cynodon Dactylon Pers. (Zie No. 2133b.)

2185. Djoekoet-tapak.gedeh S. $=a$. Digitaria pruriens Büse en $b$. Dig. ropalot rich a B üs e, Nat. fam. als voren. Gr. Java en Sumatra; overblijvende planten.

2186. Djoekoet-tatembaga $\mathrm{S} .=a$. Digitaria ciliaris Wlld. en $b$. Ischæmum muticum L., Nat. fam. als voren. Gr. Java, Sumatra, de Molukken, overblijrend.

2187. Djoekoet-tatembaga-lentiek S. $=a$. Pan ic u m brizoides J a c q. $=$ b. Eragrostis plamosa Lk. en $=c$. Didact y lon ramosum $\mathrm{m}$. et M., Nat. fam. der G r a m i n eæ. Gr. voor $a$. en $c$. Java, voor $b$. Java, Sumatra $\in \mathrm{n}$ de Molukken; overblijvend. 
2188. Djoekoet-tjaliengtjieng $\mathrm{S}$. = Oxalis L. S pecies diversæ.

2189. Djoekoet-tjarenjeh S. $=\mathrm{Me}$ l a $\mathrm{nth}$ es a a nee ps Miq., Nat. fam. der Euphorbiaceæ. Gr. Java, Celebes; heester.

2190. Djoekoet-tjengtjeng $\mathrm{S}$. $=$ Striga euphrasioides Bnth (Zie No. 2114.)

2191. Djoekoet-tjeutriek $\mathrm{S}$. = Sorgh um vulgare Pers. (Zie No. 1879.)

2192. Djoekoet-toemboe-eussie S. $=$ $\mathrm{Phyllanthus} \mathrm{Niruri} \mathrm{L.,} \mathrm{(Zie} \mathrm{No.}$ 71 a.)

2193. D joekoet-totongoän $\mathrm{S}$. $=\mathrm{Pa}$ nicum trigonum Retz., Nat. fam. der Gramineæ. Gr. Java; overblijvend.

2194. Djoekoot-tridi $\mathrm{S} .=a$. Mollugo stricta L, (Zie No. 2115.) $=b$. Lindenbergia urticæfolia Lehm., Nat. fam. dar Scrophularineæ. Gr. Java; overblijvend.

2195. Djoekoet-walet $\mathrm{S}$. $=\mathrm{Lou}$ rea vespertiliones Desv., Nat. fam. der Papilionaceæ; Gr. OP Java veelal in tuinen; zaadplant.

2196. Djoekoet-wargiet $\mathrm{S}$. $=\mathrm{Ru}$ elli a bicolor B l., Nat. fam. der Acanthaceæ. Gebr. Men gebruikt dit kruid uitwendig, door het fijngckneusd zich op het hoofd en lichaam in te wrijven bij koortsen.

2197. Djoekoet-wawalinian S. = Scirpus L., Species diversæ.

2198. Djoekoet-wawalinian-talie S. $=a$. Scirpus æmulans Steud. en $b$. Sc. mucronatus L., Nat. fan. der Cyperace æ. Gr. Java, Timor; overblijvend.

2199. Djoekoet-wawateran S. = Pan i cum prostratum Lam. Nat. fam. der Gramineæ. Gr. Java; overblijvend.

2200. Djoeko-toewa $I .=$ (Zie No. 2217.)

2201. Djoe-mali T. $=$ M ussaënda frondosa L. var. glabra (Zie No. 74.) 2202. Djoendjing-boekit $\mathrm{PAL}_{\mathrm{L}}$ = Actinodaphne pubescens Bl., Nat. fam. der L a u rines. Gr. Sumatra; boom. 2203. Djoengitan $\mathrm{I} .=\mathrm{I}$ od es ovalís Bl., Nat. farn. der Olacinex. GR. Java; slingerplant.

2204. Djoengoeng $\mathrm{S} .=\mathrm{H}$ eritiera littoralis Dryaud. (Zic No. $752 a$.)
2205. Djoerang of Djoerong $\mathrm{S}$. = Oreocnide sylvatica $\mathrm{Ml}$ iq., Nat. fam. der Urticaceæ. Gr. Java: heester.

2206. Djoere S. $=$ Clerodendrum Siph on anthus R.Br. (Zie No. 1389.) 2207. Djoerei S. $=a$. Cleroden$\mathrm{drum}$ infortun atum L., (Zie No. 758.) $=b$. A delia nereifolia Whgt., Nat. fam. der Euphorbiaceæ. Gr. Jaıa, Sumatra; heester. Grbr. Men bezigt het sap tot het zwartverven der tanden en tot versterking van het tandvleesch $=c$. Spathiostemon Bl., Species divers æ.

2208. Djoerei-boddas $\mathrm{S} .=\mathrm{Nerium}$ odorum Sol., flore albo cn

2209. Djoerei-burrum $\mathrm{S} .=\mathrm{N}$ erium o dorum Sol., flore rubro, Nat. fam. der A pocyneæ. Gr. Deze heesters vindt men door geheel Indië in tuinen als sierplanten aangekweckt; zij behooren tot de narcotisch-scherpe vergiften.

2210, Djoo-tse Cr. Bo. Citrus decumana L., (Zie No. 2054.).

2211. Djoewar of Djoeär Sum. WK. $=\mathrm{C}$ assia florida Vahl. Nat. der Papili o n ac e r. Gr. Sumatra, boom. GEBR. Deze levert eenc soort ijzerhout, dat bij den huisbouw zecr geschikt is voor stijlen.

2212. Djoho J. = Terminalia l a u rino ides T. en B. Nat. fam. Comb r e t a ce æ. Gr. Java; hooge boom.

2213. Djohoe BL. = Citrus limonellus Hassk. (Zie No. 761.).

2214. Djohoe-karbo Aмв. $=a . \mathrm{Ci}$. trus P a peda Niq. (Zie No. 2077.) $=b$. Citrus bergamia Risso. Nat. fam. der A urantiace æ. Gr. Algemecn in Indië, boom; Gebr. Mcn bezigt de vruchten hoofdzakelijk tot het schoonmaken van ijzer, het wasschen van het hoofdhaar en van klecderen.

2215. Djojomoetri I. = S orghum saccharatum Pers. (Zie No. 1038.)

2216. Djokka-sawoor I. $=\mathrm{P}$ im. pinella javana Dc., Nat. fam. der Umbelliferx. Gr. Java op 2-7000'; ovcrblijvende plant.

2217. Djokka-toewa $\mathrm{I}$. = A rte$\mathrm{m}$ is i a V u l g a ris. L. (Zie No. 1023b.)

2218. Djolo-madjiko 'T. $=\mathrm{D}$ od on x a a ngustifolia Blanco. Nat. fam. der $\mathrm{S}$ a $p$ i nd a c e ce. Gr. Bijna overal in Nedcrlandsch-Indië, heester. Gebr. Men zal het hout bij kolijk toedienen. 
2219. Djongeh S. \& $\mathbf{1}$. = a. Gynura sarmentosa Dc., (Zie No. 614.) $=\bar{b}$. Gynura aurantiaea Dc., Nat. fam. der Compositie. Gr. Java en de Molukken; slingerplant. $=c$. Gynura bieolor Dc. Nat. fam. dezelfde. Gr. De Molukken; overblijvend.

2220. Djongeh-boddas $\mathrm{S} .=\mathrm{Emi}$ li a s a gittata D.C., Nat. fam. der Compositæ. Gr. Algemeen in Indië; éénjarig.

2221. Djongeh-burrum $\mathrm{S} .=\mathrm{Emi}$ lia sonchifolia D.C. Nat. fam. als voren. GR. Algemeen in Indië; éénjarig. Gebr. Het jonge kruid wordt bij wijze van salade gegeten; men geeft het sap als bloedzuiverend middel te drinken, vooral tegen framboesiæ.

2222. Djontir J. =- Pelios anthes javanica Hassk., Nat. fam. der Ophio pog o neæ. GR. Java; overblijvend.

2223. Djung-djieng $\mathrm{S} .=\mathrm{Albizzia}$ stipulata Bth. cum varietatibus, Nat. fam. der M i mose a. Gr. Java; zeer hooge boom. Gebr. Deze boom zweet een gomsoort uit, veel gelijkende op Arabisehe gom; het hout is lieht en fraai, zeer gesehikt voor timmerhout, en wordt niet door witte mieren aangetast; den bast gebruikt men tot het bedwelmen van visschen.

2224. Djuntier $\mathrm{S} .=a . \mathrm{G} \mathrm{lob} \mathrm{b} \mathrm{a}$ marantina L., Nat. fam. der Zirgiberaeeæ. Gr. De Molukken; overblijvend. $=6$. Globba maeulata Bl., Nat. fam. als voren. Gr. Java; overblijvend. Gebr. Men eet de jonge bladeren gekookt bij de rijst.

2225. Djuntier-badak $\mathrm{S} .=\mathrm{Hel}-$ le ni a bra et e at a Bl., Nat. fam. als voren; Gr. Java; overblijiend.

2226. Djuntier-burrum $S$. en

2227. Djuntier-leutiek R. = Globb a mae ulata Bl., (Zie No. 2224b.)

2228. Dliesem $\mathrm{J}$. $=$ Blackwelli a tomentosa Vent., Nat. fam. der Ho. $\mathrm{m}$ alineæ. Gr. Java; hooge boom.

2229. Dodeko CeL. = Mangifera fœtida Lour. (Zie No. 274.)

2230. Doedie Alf. Min. $=\mathrm{No-}^{-}$ thopanax frutieosum Miq. (Zie No. 1] 53.)

2231. Doedoeitan $\mathrm{S} .=a$. A crostichum nummularifolium Bl., Nat. fam. der Poly podiace é. Gr. Op Java en elders; overjarige boomparasieten. GEBR. Het sap der dikke blaadjes drinkt men tegen hoest; een aftreksel der bladeren, gemengd meì adas-poelassarie en den wortel der Papaya, geeft men tegen buikpijnen. $=b$. Notoehlæna piloselloides Kaulf. en $=c$. Niphobolus earnosus Bl., Nat. fam. en GR. als voren. $=d$. Dischidia nummularia R.Br. Nat. fam. der A sele piadeæ. Gr. Java en de Molukken; klimplant.

2232. Doedoek S. $=a$. Pemphis acidula Forst. (Zie No. 1555.) $=b$. Lumnitzera raeemosa Willd., Nat. fam. der Co mbre tace æ. Gr. Java, NieuwGuinea; heester.

2233. Doedoerenan S. ook geschreven Doedoelam $\mathrm{M}_{.}=a . \mathrm{Pl}$ atea exe elsa Bl. en $=b$. Platea latifolia Bl., Nat. fam. der Ieaeineæ GR. Java; hooge boomen. $=c$. Sarcostigma Horsfieldii B unt., Nat. fam. als voren. Gr. Patjitan (Java); slingerende heester.

2234. Doedoewave J. $=\mathrm{H}$ orsfieldi \& a culeata D.C., Nat. fam. der Um. bell iferæ. Gr. Java; heester.

2235. Doehon S. = Ptychosperma noxa Miq. (Zie No. 1178d.)

2236. Doehon J.=Syzygium Zippelianum Miq., Nat. fam. der Myrta ce æ. Gr. Java; boom.

2237. Doek Bl. 三A reng a saecharifera Lab. (Zie No. 243.)

2238. Doek-doek J. \& BL. $=a$. Otanthera moluceana Bl., Nat. fam. der Melas to maeeæ. Gr. Java, Bali, de Molukken; heester. GeBR. Den samentrekkenden wortel zeeft men inwendig als een middel tegen abortus; de vruchten worden gaarne gegeten. $=b$. Melastoma polyanthum Bl. (Zie No. 110.) $=e$. Scyphiphora hydrophyllaeea Grtn. (Zie No. 417.)

2239. Doekoe S. \& M. = Lansium domestieum Jack. (Zie No. 98.)

2240. Doekoe-anggong Sum. W.K. = Dysoxylum macrocarpum Bl., Nat fam. der Melia e æ. Gr. Java en Sumatra; hooge boom. Gebr. Het hout gebruikt men voor huisbouw en gereedschappen; het is niet sterk en wordt ligt door inseeten aangetast; de bladeren en zaden eet men in plaats van uien.

2241. Doekoeng-anakh Sum. W.K. = Phyllanthus oxyphyllus Miq., Nat. fam. der E uphorbia e e. Gr. Sumatra; kruid.

2242. Doelang $\mathrm{M} .=a \cdot \mathrm{C}$ assia 
javanica L. (Zie No. 1025) $=b$. \& c ævola Koenigii Vahl. (Zie No. 1001.)

2243. Doelang-doelang Sus. W.K. $=$ Glochidioudasyanthum Kürz. Nat. fam. der $\mathbb{E}$ uphorbiaceæ. Gr.Sumatra; hoom.

2244. Doelang-doelang-betina M. $=\mathrm{S}$ ophoratomentosa L. (Zie No. 14.0.)

2245. Doelang-sentak $\mathrm{S}$. $=\mathrm{S}$ anicula montana $\mathrm{R} w d t$., Nat. fam. der Umbellif e.r æ. Gr. Java en Sumatra; overblijvende plant.

2246. Doempijas Alf. Min. = A verrho a Carambola L. (Zie No. 851.)

2247. DGempijas-toeama Alf. MiN. $=\mathrm{AverrhoaBilimbi} \mathrm{L.} \mathrm{(Zie} \mathrm{No.}$ 853.)

224.8. Doengoeng S. \& M. of

2249. Doengoer $\mathrm{M} .=$ Heritiera littoralis D ryand. (Zie No. 752.) 2250. Doe-0et $\mathrm{S}$. of Doäat $\mathrm{S}$ : $=$ Sy z ygi u m J a mb ol a n u m D.C. (Zie No. 1906.)

2251. Doerian MoL. of

2252. Doeren $\mathrm{M} .=\mathrm{Durio} \mathrm{zibe}$ thinus L. Nat. fam. der Sterculiaceæ. $G_{R}$. Algemeen door geheel Indië; zeer hooge boom. GEBR. Het hout bezigt men voor planken, doch wordt spoedig verteerd. Het weeke, witgele, sterkriekende vleesch der vruchten is als ooft zeer gezocht, en sterk voedend, doch moeilijk te verteren; op Sumatra makt het soms het hoofdvoedsel der bevolking uit; het veroorzaakt dikwerf huiduitslag, cn zoude op de geslachtsspheer opwekkend werken. De zaden worden geroosterd gegeten. De schil der vruchten, tot kool gebrand, dicnt voor tonder; de Chineezen gebruiken de asch van dit zaad bij de bereiding der Kasoemba-verf. Uitwendig gebruikt de Javaan dezen schil bij een huiduitslag, Koekoe-rawit genaamd, en wrijft er zich bij hardnekkige constipatio alvi den buik mede in.

2253. Doerian-doerian $\mathrm{P}_{\mathrm{AL}}$. $=\mathrm{P}_{\mathrm{a}}$ rinarium polyneurum Miq. Nat. fam. der Chry s o bal la ne æ. Gr. Sumatra; boom.

2254. Doeriban J. $=\mathrm{Hibuscus}$ rosa-sinensis (Zie No. 1360.)

2255. Doerie-entong J. O puntia polyantha Haw., Nat. fam. der C a c t c s. Gr. Op Java en elders in tuinell; heestcr. GEBr. Dezc stekclige No- palstruik wordt voor de Cochenille cultu ur aangekweekt.

2256. Doerie-kaliageh $\mathrm{S}$. $=\mathrm{M}$ acl u ra java n i c M iq., Nat. fam. der Art o carper. Gr. Java, Bima en de Molukken; groote heester. GuBR. Deze heester wordt als verfstof hier en daar aangekweekt; het harde, geelachtige hout gebruikt men voor gael- en groenverven. Het sap gebruikt men als oogwater. Een aftreksel der jonge takken geeft men tegen nierlijden.

2257. Doerie-karbo M. $=\mathrm{Art}$ botrys suaveolens Bl. (Zie No. 575.)

2258. Doerie-radak J. $=\mathrm{Gm} \mathrm{e}$ lin a si atica L., Nat. fam. der Verb e n a c e æ. Gr. Java, Borneo, Celebes; groote heester. GEBR. De slijmige bladeren geeft men bij urethro-blennorrhoeæ; het sap van de bladeren en vruchten druppelt men in de ooren tegen oorpijn. HoRsfield brengt den wortel tot de tonische middelen, en geeft aan, dat de Javanen deze plant als een giftplant beschouwen.

2259. Doeroekoenam J. $=\mathrm{R}$ anu nc u lus diffus us D.C. (Zie No. 344c.)

2260. Doesoeroe-badak LAMP. $=$ Melastoma sanguin e m Don., Nat. fam. der Melastomaceæ. Gr. De Sunda-eilanden; heester.

2261. Duetra M. $=\mathrm{D}$ a tu ra L. Species diversæ.

2262. Doewé BL. $=\mathrm{Syzyg} \mathrm{iu} \mathrm{m}$ J a m b o la n u D.C. (Zie No. 1906.)

2263. Doh J. = Sterculia nobili s Sm., Nat. fam. der Sterculi ace a. Gr. Java, Sumatra, enz.; groote hecster. GEBr. Men gebruikt het lichte hout voor huisbouw, het wordt echter spoedig aangetast. De zaden worden gegeten.

2264. Dohbosan $\mathrm{J} .=\mathrm{D}$ e s $\mathrm{mo-}$ di um retroflexum D.C., Nat. fam. der Papilionacex. Gr. Java; heester.

2265. Dohlok S. = Trichospermum javanicum Bl., Nat. fam. der Bixacex. Gr. Java; boom. Gebr. Van den vezeligen bast vcrvaardigt men een grof touw.

2266. Duka T. of

2267. Dokkoe T. $=a$. A rec a gland if ormis Houtt., Nat. fam. der $\mathrm{P}$ a $1 \mathrm{~m}$ x. Gr. De Molukken; hooge boom. GEBr. Men benuttigt het hout, om de bijzonderc hardheid, als timmcrhout. De kleine vruchten worden, om haren bitteren smaak en hardhcid, niet gebruikt, en allecn 
het omhulsel door vogels gegeten. $=b$. Ptychosperma $\mathrm{R}$ u $\mathrm{m}$ hi i B l., Nat. fam. dezelfde. Gr. Bali, Celebes en dc Molukken; hooge boom. GEBR. Het hout is week en niet duurzaam; het wordt slechts voor stijlen onder de huizen gcbruikt. De bittere pitten worden alleen ingeval van schaarschte in plaats van Arecanoten gekauwd.

2268. Domar Амв. of

2269. Domor Амв. of Domoel Амв. = Bambusa fera Miq. (Zie No. 774.)

2270. Donda-medang $\mathrm{J} .=\mathrm{C} \times 0$. tallaria verucosa L.; Nat. fam. der Papilionaceæ. Gr. Java en Sumatiæ; zaadplant.

2271. Dondo MAK. $=a$. $\mathrm{T} \mathrm{a} \mathrm{c} \mathrm{a}$ palm at a Bl. (Zie No. 825.) = b. Tacsa Rumphii J. C. Schauer, Nat. fam. en GeBr. als No. 825. Gr. Amboina.

2272. Dongdeh J. = Cassia floribunda Cav., Nat. fam. der Papilion a ceæ. Gr. Java; heester.

2273. Dongdong Sum. W.K. = Covellia hispida Miq. (Zie No. 1255a.)

2274. Dongi-dongi MaK. $=\mathrm{S} p \mathrm{p} æ$. rococcus lichenoides Ag. var. tenuis Ag. (Zie No. 20 en 21.)

2275. Dorambil Sum. W.K. = Arali a dasyphylla Miq., Nat. fam. der Araliaceæ. Gr. Java en Sumatra ; heester.

2276. Dotaga T. $a$. C a rd i s permum Halicacabum L. (Zie No.
433.) $=$ b. Physalis indica Lam. (Zie No. 1682b.)

2277. Dotto-doekkoe Амв. = V е n. tilago maderaspatana Grtn. (Zie No. 999.)

2278. Dowora T. = Intsia a nbornensis Thrs. (Zie No. 830.)

2279. Drangdang S. (cok Darangdang S.) $=\mathrm{Ficus}$ rostrata $\mathrm{Lam}$. (Zie No. 3046.)

2280. Drangdang-angin $\mathrm{S} .=\mathrm{Cal}$ pandria quincosaura Krths. Nat. fam. der Meliaceæ. Gr. Java; boom.

2281. Drangdang-aroij $\mathrm{S} .=\mathrm{Vil}$ laresia scandens Hassk., Nat. fam. der $\mathrm{Olac}$ iner. Gr. Java; slingerplant. 2282. Drangdang-kajoe $\mathrm{S}$. = F i. cus cerasiformis Parment., Nat. fam. der Arto c arpeæ. Gr. Java; heester.

2283. Dregel J. $=$ W or m i e $\mathrm{x}$. ce ls a J a ck., Nat. fam, der Dillen i a c e. Gr. Java en Sumatra; hooge boom.

2284. Drowak S. $=a$. Grew ia Blumei Hassk., Nat. farn. der Tiliac e a. Gr. Java en Sumatra; heester. Gebr. Het taaie bout is geschikt voor stelen van gereedschappen en vlechtwerk. $=b$. Grewia oppositifolia Ham., Nat. fam. enz. als voren; boom. $=c . \mathrm{Columbia}$ javanica Bl., Nat. fam. als boven. GR. Java; hooge boom. GeBr. De bast is zeer geschikt voor touw en laat zich gemak. kelijk met de hand draaien.
2285. Eboel M. $=$ O rania macroclada Mart., Nat fam. der Palmæ. Gr. Malakka.

2286. Eggel $\mathrm{S} .=\mathrm{X}$ erospermum Noronhianum Bl.. Nat. fam. der Sapindaceæ. Gr. Java; hooge boom. GEBR. Het hout is taai en sterk, geschikt voor molens, buffelkarren, ploegen en rijststampers, minder voor brandhout; de vruchten worden gegeten.

2287. Eijk Ar. $=$ Cinnamomum Culil aw an Nees. Nat, fam. der Is aurinex. Gr. Java, Sumatra, Celebes en de Molukken; hooge boom. Gebr. De bast was vroeger als Cortex Culilawan in onze apotheken, en behoorde tot dc samentrekkende ætherische middelen. Er wordt een vluchtige olie nit gestookt, dic tegen vele uitwendige aandoeningen zeer gewild is. Beide zijn nog in den inlandschen handel. 2288. Eylan-tassi Амв. = G a rcin ia coch inchinensis Chois., Nat. fam. der Clusiacex. Gr. Amboina; boom.

2289. Eijtale Амв. $=\mathrm{Cedrela}$ T o o n a $\mathrm{R}$ oxb., (Zie No. 267.).

2290. Ejkor-andjing $\mathrm{M} .=a$. H $\mathrm{e}$. liophytum indicum D.C. (Zie No. 
1445.) = b. Uraria lagopoides D.C. var. sumatrana. Nat. fam. der Papili on a c e. Gr. Sumatra, Java, enz ; overblijvend.

2291. Ejkor-koetjing $\mathrm{M}_{0}=a$. A calypin a densiflora Bl. (Zie No. 1440.) $=$ b. Acalypha Caturus Bl., Nat. fam. der Euphorbiacer. Gr. De Molukken; heester. Geßr. Den bast zal men tegen flnor albus en de bladeren tegen spruw aanwenden.

2292. Ejkor-koetjing-oetan M. = A e a lyph a Catn $\mathrm{rus}$ Bl. (Zie vorig No.)

2293. Ejkor-meöng $\mathrm{S} .=$ Desmodi $\mathrm{nm}$ polycarpum 1).(. (Zie No. 1664.)

2294. Ekana Амв. $=a$. $\mathrm{M}$ a р ра moíuccana Sprg. (Zie No. 56.) $=b$. Mappa Tanaria Sprg.. Nac. fam. der Euphorbiacer. Gr. Bijua overal in Indie; boom. GEBr. Het roode hout en den bast bczigt men tot het tanen van vischnctten: den bast dient men toe tegen diarrhoea en dvsenteric; de grootc bladeren gebruikt innn bij wijze van tafelborden.

2295. Elan Aмв. = $\alpha$. T) ioscorea b ul bifera T. (Zie No. 4.) $=6$. Melaleuea leueadendron $I_{\text {. }}$ (Zie No. 120a.)

2296. Ella S. of

2297. Elok M. R. $=a$. II cllenia braeteata 13l. (Zic No. 210i.) $=h$. Elettaria minuta Bl., Nat. fain. der Zingibcracce. Gr. Java; overblijvende plant. $=c . \mathrm{A} \mathrm{momum} \mathrm{ciliatum}$ Bl., Nat. fam. \& Gr. als $b=d$. A m cmum gracili l3l., Nat. fam. en Gr. als $b$. Grir. Het binnenste der stengcls wendt men als huidprikkel aan bij hoofd. pijn en oogaandoeningen; de rijpe zaden worden gegeterl.

2298. Emmes S. $=$ Luffa acutangula Roxb. (Zic No. 2095.)

2299. Enda-mali PAt. = $\mathrm{J}_{\text {, e e }}$ fuligiinosa Miq., Nat. fam. der J,e eacece. Gr. Surnatra, heester.

2300. Ender I. = A nethnm graveolens I. (Zie No. 106.)

2301. Endok-endok I. = Griın ilca divergens Miq., Nat. fam. der Rubiace

2302. Eng-sjong Си. $\mathrm{Bo}=\mathrm{O}$ ci$\mathrm{m} 1 \mathrm{~m}$ Basilic $1 \mathrm{~m}$ I. (Zic No. 4945.)

2303. Entjeng-entjeng $\mathrm{J} .=\mathrm{K}$ iescra minor Miq., Nat. fam. der Pa. piliouncerc. Gr. Java; heester.
2304. Entjeng-entjengan $\mathrm{J} .=\mathrm{G} \mathbf{y}$ nandropsis pentaphylla D.C. (Zie No. 1287a.)

2305. Entoe MrN. = Indigofera tinctoria L., Nat. fam. der Parilion a cеæ. Gr. Java, Sumatra en elders verbor:wd; zaadplant. GEBr. Deze plant dient tot bereiding der in den handel voorkomende en algemeen bekende kleurstof, de Indigo, welke nu en dan wel eens tegen hevig zenuwlijden, vallende ziekte, hysterie en dergelijke, met meer of minder goed gevolg, is aangewend. De inlanders op Java geven den wortel tegen koorts en bezigen de bladeren uitwendig als oplossend middel, bij verharde gezwellen. Nog zou een aftreksel der wortels wormdoodend werken, en worden de jonge takjes aangeprezen tegen spruw.

\section{Epaij Amb. en}

2307. Epaij-salaij Amb. = Astronia papetaria Bl., (Zie No. 412.)

2308. Epreoe Амв. = Elacocarpus moluccanus Scheff., Nat. fam. der Tiliacex. Gr. Amboina; boom.

2309. Eprioe Amb. = Elæoеагрus I., Speeies diversæ.

2310. Erang I. $=$ A reca $\mathrm{Nibung}$ M a rt., Nat. fam. der Palma. Gr. Vrij algemeen in Indie; hooge boom. GkBR. De stam levert uitmuntend en duurzaam paalwerk, vooral bij het bouwen van huizen op moerassige gronden; uitgehold wordende, zijn zij goedc buizen voor waterleidingen; de jonge bladknop is een lekkere palmkool, die men gekookt bij dc rijst eet; de jonge bladeren leveren cen goede dakbedekking.

2311. Erek Z0. Arch = Areca Cateehu 1., (Zie No. 1286.)

2312. Essoijr $\mathbf{A m b}=a \cdot \operatorname{Pod} 0 \cdot$ c arpus bracteata Bl. en b. P. Rnmphii Bl., (Zie No, 39.)

2313. Etjeëng S. v. M. = a. Mollochoria vaginalis Prsl. (Zic No. 912.) $=$ b. Monochoria pauciflora Knth, Gr. Java, waterplant. Geir. Je jonge bladeren cet men als groente. $=c$. Sagit taria hirundinaeea Bl. (Zic No. 1082.) $=d$. Sagittaria Blumci Kuth., Nat. fam. als $e$. Gr. Java, waterplant. Grвr. (Zie No. 1082.) = f. Hydrilla najadifolia 7 . et M., Nat. fam. der Hydrocharidese. Gr. I)c Sunda eilanden; waterplant.

231. Etjeëng-besaar $M=S a g$ ittaria hirulinacea. Bl. (Zic No. 1082.) 
2315. Etjeëng-gedeh S. = Monochoria hastæfolia Prsl. Nat. fam. der Pontederiaceæ. Gr. Java, Sumatra, enz, waterplant. Gebr. Ook de bladercn dezer soort eet men als groente.

2316. Etjeëng-hai-hai $\mathrm{S}$. = Ottclia javanica Miq. (Zie No. 1124)

2317. Etjeëng-lalakki S. $=a$ Sagittaria Blumei Knth. (Zic No. $2313 d.)=b$. Hydrocharis asiatica Miq., Nat. fam. der Hydrocharideæ. Gr. Java; waterplant.

2318. Etjeëng-lumboet $\mathrm{S}$ = Monochoria? linearis Miq, Nat. fam. der Pontederiacer. Gr. Java; waterplant, van welke ook de bladeren als grocnte gegeten worden.

2319. Ette-ambe $\mathrm{I} .=\mathrm{M}$ angifera indica L. (Zie No, 275.)

2320. Euri $S .=I m p c r a t a$ arun- dinacea Cyrill. (Zie No. 263.) 2321. Euri-gedeh $\mathrm{S} .=\mathrm{Sacch}$ ar u m s pontane um L., Nat, fam der Graminer. Gr. Door geheel Indic; hoog gras. Gezr. Dit hooge gras, de geliefde verblijfplaats van wild gedierte, gebruikt men soms tot het dekken van huizen; de jonge spruiten kunnen gegeten worden, terwijl het sap soms als oogwater wordt aangewend.

2322. Eurri BL. $=$ Pterocymbinm javanicum R.Br. (Zie No. 1200c.)

2323. Ewassa $\mathrm{Amb} .=a$. Tetranthera monopetala Rxb., Nat. fam. der Laurineæ. Gr. Java, Sumatra, cnz. hooge boom, $=b$. Tetranthera Rumphii Bl., Nat. fam. als voren. Gr. De Molukken; hooge boom. Glibr. Dezc boom levert een gocd bouwhout, dat ook geschikt is voor fijn werk, als doozen.
2324. Fala of Bana $B_{R},=$ Cordia subcordata Lam. (Zie No. 1021b.)

2325. Fana $\mathrm{T} .=\alpha$. M us a mindanensis Rinph., Nat. fam. der Mus a c eæ. Gr. Celebes, Sangir. Gilolo in tuinen; overblijvend. Grur. De stam levert de fraaie rezelstof, in den handel "koffo" genaamd, die vooral op de Philippijnen wordt verwerkt, een zeer lange vezel lcvert cn zeer geschikt is roor toawwerk en fijne kleedjes. $=b$. Musa amboinenscs Rmph., Nat. fam. dezelfde. Gr. De Molnkken in het wild; overblijvend. GEBR, De vezels dezer soort gebruikt men voor vischlijnen; het sap uit den stam geeft men te drinken bij kinderpokken; de vruchten zijn alleen door de boschkatten gezocht.

2326. Fan-njin-tsoi CH. Bo. = Sanropus rhamnoides Bl. (Zie No. 805.

2327. Fan-njin-won $\mathrm{CH}_{\text {. }} \mathrm{BN}_{\mathrm{N}}=\mathrm{Fa}$ græa auriculata Jack., Nat. fam. der Loganiaceæ. Gr. De Sunda-eilanden; heester, welkc om de welrickendc witte bloemen als sierplant gezocht is.

2328. Fan-sjoe-tin Cr. Bo. $=\mathrm{Ba}$ tatas edulis Chois. (Zie No. 635.)

2329 Fau-fau Mor. $=A \mathrm{lb} \mathrm{izz}_{3}$ saponaria bl. (Zie No. 1041b.) 2330. Fetoel $\mathrm{Br} .=$ Sandoricum indicum Cav. (Zie No. 113.)

2331. Fette-fette $\mathrm{T}$. $=\mathrm{Cr}$ in u m asiaticum I. ('Zie No. 869 a.)

2332. Fie-giong-seu Cн. Bо. = Foenicul u m vulgare Grtu. (Zie No. 8.)

2333. Fidakka T., of

2334. Fitakoe T., en

2335. Fitauer $\mathrm{BD} .=\mathrm{C}$ a l o p h y llum inophy!lum L. (Zie No 11:9.)

2336. Fissa-foeroe $\mathrm{T}$. $\mathrm{F}$ i $\mathrm{c} n \mathrm{~s}$ variegata Bl. (Zie No. 1352.)

2337. Flekke-natoor $\mathrm{Bn} .=\mathrm{Coc}$ cinia grandis M. J. Roemer. (Zic No. 64.0.)

2338. Foela-sapatoe Bat. en

2339. Foeng-fa CH. Bo. $=\mathrm{Hibis}$ cus rosa sinensis L. (Zie No. 1360.)

2340. Fokki-fokki T. \& MeN. = Salonum Melongena L, Nat. fam. der Salanex. Gr. Door geheel Indië in tuinen; zaadplaut. GeBr. I)c vruchten zijn cen gezochte groente; zij worden ranw, gekookt en gcbakken, ook door Europcanen bij de rịist gegeten.

234. L. Folle-aaros Jo $=J$ a s m i- 
num undulatum W1ld. (Zie No. $525 e$.)

2342. Folle-Kotta $\mathrm{J}=\Lambda \ddot{\mathrm{e}} \mathrm{rva}$ lanata Juss., Nat. fam. der A nuarant a cer. Gr. Java cn elders in tuinen; o verblijvend.

2343. Folle-malaga $J .=V$ in e a rosea 1., Nat. fam. der 4 poeynex. Gr. Door geheel Indië; als sierplant in tuinen; overblijvende plant met roode en witte bloemen.
2344. Eortago $\mathrm{T} .=a$. Eleusine indi c a Grtn., (Zie No. 1961.)= ర.1) a ctyloctænium agyptiacum Wlld., Nat. fam. der Gramineæ. Gr. Algemeen in Indië. Eénjarig. GeBr. Dit gras is een zeer gezocht vecvoeder; cen aftreksel der wortels geeft men bij buikloop.

2345. Fougul Bat. = Stereulia fotida L. (Zie No. 1641.)

2346. Fuo $\mathrm{T} .=\mathrm{Phascolus} \mathrm{ra}$ diatus L. (Zie No. 31.)
2347. Gaba-gaba Mor. $=$ Metroxylon Rumphii Bl. \& alix. (Zie No. $279,1131,1320 \mathrm{enz}$ ).

2348. Gabi-gabi T. $=$ A ctinodaphne Rumphii Bl. (Zie No. 55.)

2349. Gaboe BK. = Celosia argentea L. (Zie No $1136 c$.)

2350. Gaboes $\mathrm{M}$. $=\mathrm{Alsi}$ in ia scholaris R.Br., Nat. fum. der Apo. су nе æ. Gr. Java, Sumatra, de Molukken; boom. Gebr. Het hout is om zijuc weekheid en veerkracht zeer geschikt voor kurkeu en insektcnkistjes; men gebruikt het ook op de scholen voor kleine planken om letters in te griffelen. De bittere bast komt in geneeskracht met den Gentiaan. wortel overeen ; velen kenren er cen koortswerend vermogen aan toc. Hit melksap bezigt men op verwaarloosde, vuile wonden van paarden, koeieis enz.

2351. Gada-Gada Sum. Ok. = Nepenthes phyllamphora Wlld. (Zie No. 128 )

2352. Gadag S. \& R. = B i s choffia javanica Bl, Nat. fam. der Enp horbiacer. Gr. Java en Sumatra; hooge boom. GFBr. Het sterke, zeer fiju geaderdc en donkerkleurige hout is zeer geschikt voor huisbouw, en wordt nict door insekten aangetast. 1)e vruchten zijn zeer zuur en daarom niet ectbaar.

235̌3. Gadelän $J=1$ ) crris pubipetala Miq., Nat. fam, der Papilion a cex. Gr. Java; slingerplant.

2354. Gadis-batih Sur. Wk. =S terculia cuncifolia Miq., Nat. fam. der Sterenliacex Gr. Sumatra; boom.

2355. Gadoe $\mathrm{Ml}=$ Chavica sarmentos a Miq. (Zie No. 292.) 2356. Gadok S. \& M. = Bisch offia javanica Bl. (Zie No, 2352.)

2357. Gadong M. $=$ Dioseorea hirsuta Bl. (Zie No. 475.)

2358. Gadong-laweh $\mathrm{S} .=\mathrm{D} \mathrm{ry}$ mispermum Blumei Desn. (Zie No. 422.)

2359. Gadong-loemoet S. \& J M uldera ba ecata Miq. (Zic No. 54.86.)

2360. Gagaboesan S. (vocdsel voor de visschen, vooral voor gaboes) $=a$. Jussiæa L., Spec. diversæ. (Zic No. 476 en 1767.) $=b$. Servol a Koenig i i Vahl. (Zie No. 1001.) $=c$. Pent apetes phoenicea L. (Zie No. 1368.) $=d$. Erioraphe Punicea Miq., Nat. fan. der Büttneriacex Gr. Java; zadplant. $=e$. Bcloanthera oppositifolia Hassk., Nat. fam. der Portulaceæ. Gr. Java; éénjarig $=f$. $\mathbb{E} \mathrm{s} \mathrm{chyn}$ om en $\mathrm{c}$ indica L., Nat. fam. der Papilionac eæ. Gr. Java en Sumatra; éćnjarig. = g. Sesbania cochinchinensis D.C. Nat. fam. als voren. Gr. Java, laali, de Molukken; zaadplant. GEiBr. Op Java worden de bladeren gegeter. Volgens RUMPrius wordt cen aftreksel der bladeren tegen koorts gedronken, en zou de wortel heilzaam zijn tegen vergrooting der milt. $=h$. Ncptunia oleracea I,our., Nat. fam. der M i m os e . Gr. Java; watcrplant.

2361. Gaga-meirah $\mathrm{S} .=\mathrm{Rhodo}$. dendrou javanicum Rodt., Nat. fam. der Ericaceæ. Gr. Java, Sumatra; hcestcr. 
2302. Gagan-gagan-kebouw S. = D) esuodium barbatum Bnth., Nat. fam. der Papilionaceæ. Gr. Java; overblijvende plant.

2363. Gagang.goenoeng $\mathrm{J} .=\mathrm{V}$ io$\mathrm{l}$ a a la t a B g d k., Nat. fam. der Vi ol a c e æ. Gr. Java 6-8000'; overblijvend.

2364. Gagaway $\mathrm{S} .=$ Urostigma benjamine um Miq. (Zie No. 1565.)

2365. Gaharoe M. (Zie Garoe M.)

2366. Gailoeng-djangoeng $\mathrm{S}$. = Viendlaudia glabrata Dc., Nat. fam. der Rubiacere. Gr. Java; hecster.

2367. Gajam S \& M. (ook Gajang 11. en Gajim BD.) $=$ I no carpus edulis L. (Zic No. 340.)

2368. Gajati T. $=$ Aschynomene indica L. ('Zie No. $2360 f$.)

2369. Galatrang $\mathrm{S}$. = Michelia montana Bl. (Zie No. 18906)

2370 Galiassa T. $=A l_{p}$ in ia Galanga Sw., Nat. fam. der Z Zingiber a c eæ. Gr. Door geheel Indië gekweekt; overblijvend. GerR. De wortel, in Indië meer bekend als I,aus J. of Laukwas M., de Radix Galanga onzer apotheken, is een geliefde specerij in verschillende gereehten, die bij de rijsttafel behooren. Als geneesmiddel, inwendig toegediend, werkt hij maagsterkend en krampstiliend. Uitwendig, met aziju fijngewreven, bezigt men hem als roodmakerd en blaartrekkend middel. Met water fijngekneusd, wrijft de inlander zich hiermede gaarne de vermoeide ledematen in.

2371. Galieboeng S. = Cyrtandra rostrata Bl., Nat. fam. der Gesneriace $\boldsymbol{x}, G_{R}$. Java; heester. GEBR. Het jonge loof wordt door sommigen als groente gegeten.

2372. Galiboeng-boeloe S. $=a$. Gomphostemma macrophyllum Miq., en $=b$. G. petiolare Miq., Nat. fam. der Lubiatx. Gr. $a$. Op Java en Celebes; en $b$. Java; heesters.

2373. Galie-galie Sum. $=\mathrm{L}$ a sia Zollingeri Schtt., Nat. fam. der Aroideæ. Gr. Sumatra; slingerplant

2374. Galiengum S. = Bix a Orellana L. (Zie No. 1697.)

2375. Galingang Mand. = Cassia alata L. (Zie No. 1740.)

2376. Galing.galing $\mathrm{J} .=\mathrm{V}$ itex trifolia L. fs. (Zie No. 66.)

2377. Galli-galli $S_{0}$ \& $\mathrm{M}_{0}=a . \mathrm{Di}$. livaria ilicifolia Jss. (Zie No. 472.) $=b$. Dilivaria ebracteata Jss. (Zie No. 2047b.) $=c$. Dilivaria sealldens Nees. (Zie No. 2047c) $=d$. Dilivaria robusta Nees. Nat. fam. der Acanthacere Gr. Java; waterplant.

2378. Galoba Aмв. (Zie later bij Globba 11.)

2379. Galoegoe M. = Broussonetia papyrifera Vent. (Zie No. 1861.)

2380. Galoema M. = Rubia cordifolia L., Nat. fam. der Rubiaceæ. Gr. Java, Sumatra, Riouw; overblijvend. GEвR. De wortels en stengels bezigt men, even als de meekrap, tot het roodverven van katoenen goederen; zij houden echter beter kleur dan deze en de kleur is helderder op wollen- dan op katoenen stoffen.

2381. Galoempiet $\mathrm{S} .=a$. Cyclo. stemon cuspidatum Bl., Nat. fam. der Euphorbiaceæ. Gr. Java; boom. $=b$. Embryogonia arborea 'T \& Bk. Nat. fam. der Combretaceæ. Gr Java; hooge boom.

2382. Gamah Serawak. = Tacca Rumphii Schauer. (Zie No. 22716.)

2383. Gamasi MaK $=$ A r tos a r. pus ineisa L. (Zic No. 269.)

2384. Gamat Bц., J. \& M. = Cocc ulus glaueus D.C. (Zic No. 1687.)

2385. Gambas S. \& M. = a. Coccinia grandis M.J. Roemer. (Zie No. 640.)=b$. Coceinia Wightiana M. J. Roener. (Zie No. $521 d$.) $=c$. Cardiopteris lobata Wall., Nat. fam. der Olacinex Gr. Java; slingerplant. GEBR. De inlanders eten de bladeren bij wijze van groente.

2386. Gambas-kawong S. (Zie vorig No. bij c.)

2387. Gambe 0. Cel. $=$ Boehmeria nivea Gaud., Nat. fam der Urticaceæ. Gr. Vrij algemeen door geheel Indië verbouwd; kleite heester. Gris. Door weeking verkrijgt men uit den vezeligen bast het algemeen bckende Ramehvlas, ook Gohni genaamd, dat zeer geschikt is voor sterk touwwerk, vischlijnen en netten. Op Celebes gebruikt men het melksap als kleefstof voor het pijlgift. De wortels, in water geweekt, worden tegen bloedbraking toegediend.

2388. Gambier $\mathrm{M} .=\mathrm{Unc}$ a ria Gambir Roxb., Nat. fam. der Rubiac ææ. Gr. Bijna door geheel Indië verbouwd, vooral echter op Sumatra en in geregelde plantaadjes; slingerplant. GEBR. Weze hee- 
ster wordt aangeplant om de Gambir of Getah-Gambir, welke door koking uit de bladeren verkregen wordt, voor den inlander cen onmisbaar artikel bij het Betelkauwen is, in geneeskraeht gelijk staat met de Cateehu en naar Europa als looistof wordt uitgevoerd Bij gebrek aan Gambir kauwt men ook de bladeren.

2389. Gambier J. en

2390. Gambier-laut M. $=\mathrm{Cl}$ e $\times 0$. dendrum in erme Grtn (Zie No. 1243.)

2391. Gambier-tjaai $\mathrm{S} .=\mathrm{J}$ a s $\mathrm{m}$ in u m T o urnf. Spee. plurim a.

2392. Gambier-toepai $M_{0}=U$ n e a$r$ i a f e r u gin e a 1).C., Nat. fam. der $R$ u b i a c e . Gr. De Sunda-eilanden; slingerplant. GEBR. Deze plant bevat in hare bladeren ook veel Getah-Gambir of Catechu de bast is als toniseh-adstringeerend middel in de Indisehe apotheken, en wordt veelal na tussehenpsozende koortsen en bij slepende diarrhoeæ toegediend.

2393. Gambieran J. = U rostig a o b t u s if o li u m M i q., Nat. fam. der A r t o e a pex. Gr. Java; hooge boom. 2394. Gambir-gambir $\mathrm{M}$. $=\mathrm{Ch}$ isocheton diversif oli um Miq., Nat. fam. der M eli a e e. Gr. Sumatra's WVestkust; boom.

2395. Gamei-gamei Sur. W.k. = $B$ a e k a frutesee ns L., Nat. fam. der M eli a e e $æ$. Gr. Sumatra; heester. Gebr. De geurige bladeren en bloemen worden jaarlijks in groote hoeveelheden van Sumatra naar Java overgevoerd. In de Batalanden wendt men ze als diuretieuin en abortivum aan.

2396. Gamki $\mathbf{M}_{\mathbf{A K}}=\mathrm{B}$ o e $\mathrm{h}$ m eri a $n$ ive a G a ud. (Zic No. 2387.)

2397. Gammat $\mathbf{M}$. $=\mathrm{H}$ i b is e us $r$ a d i t u s Cav., Nat. fain der M a lv a e е æ. Gr. Op Java euz., als sierplant in tuinen; heester.

2398. Gammat-oetan M. $=a$. $\mathrm{Hi}$ biseus surattensis $I_{4}$. (Zie No. 731 .) $=6$. Chyloealyx perfoliat u s $\mathrm{H}$ a s s k., Nat. fam. der $\mathrm{P}$ o $1 \mathrm{yg}$ on e GFBR. De jonge spitsen der ranken en de bladeren worden als een zure gioente bij de rijst gegeten.

2399. Gammat-wolanda M. = H ibiseus $\mathrm{Sab}$ a a $\mathrm{r}$ if a I. (Zie No. 732.)

2400. Gamomong Sum. Ок. $=1$ ) i os. pyos Ebenum Cet\%. (Zie No.32.)

2.t0l. Gamongan $\mathrm{BL}_{\mathrm{L}}=\mathrm{Z}$ ing i- be $r$ a nu a i a $\mathrm{s}$ B l., Nat. fam. der $\mathrm{Z}$ ing i b e r a e e. Gr. Java en de Mo. lukken; overblijvend. GEBR. Den wortel mengt men in vele uit- en inwendige geneesmiddelen; de jonge nog niet outrolde bladeren zijn een lekkere groente.

2402. Gandapoera M J.\& BL. = Abelnosehus mosehatus Mönch., Nat. fam. der Malvaee a. Gr. Op Java, Sumatra en elders in tuinen; heester. GEBR. De bladeren bezigt men tot wassehing van het hoofdhaar. De zaden, onder den naam van Bisamkorrels in den handel, legt men om hun aangeuamen geur, trisschen de kleederen, gebruikt ze met bedakh bij vele huidaandoeningen, en bereidt er parfumeriën van; de Arabieren mengen ze in hunne koffie; als geneesmiddel toegediend, zullen zij versterkend maagprikkelend en pisdrijvend werken. In West-Indië houdt men ze voor een kraehtig middel tegen den beet van giftige slangen.

2403. Gandarassa $\mathrm{S} .=\mathrm{G}$ u a $1 \mathrm{th} \mathrm{e}$ ria punetata B l., Nat. fam. der Erieacex. GR. Java en Sumatra 5-7000'; heester.

2404. Gandaria M. \& J. = Bou ea Gandaria Bl., Nal. fam. der Anaeardi a e æ. Gr. Op Java en elders in tuinen; hooge boom. GEBR. Het fraaie en sterke hout gebruikt men voor huisbouw en allerlei gereedsehappen; de jonge bladeren eet men bij de rijst; de vruehten ziju zeer gezocht onrijp legt men ze in het zout; en rijp zijnde leveren zij een aangenaam ooft.

2405. Gandaroessa M. \& J. = G e nd a r us a v l garis $\mathrm{N}$ e es. (Zie No. 1685.)

2406. Gandaroessa-besaar MI. = Zanthoxylon zèlanieum D.C. (Zie No. 3896.)

24.07. Gandaroessa-koening $\mathrm{BD}$. = Codi um moln e e n u m Desn., (Zie No 1.26.)

2408. Gandaroessa-oetan M. =G en iostoma lasiostemon Bl., var. molue ea $\mathrm{n} \mathrm{um}$, Nat. fam. der L o g a $n$ i a e e ac. Gr. Minahassa (Celebes); heester.

\subsection{Gandasoelio M. (Gandasohlie)} $=a$. II edyehium e oro nari u Ko en., Nat. fam. der Z i n g i b e a e e. Gr. Hoor geheel Indië in tuinen; overblijvend. GEBr. Deze en andere H e d ye hi u n-soorten worden gaarne in tuinen gekweekt, om de zaehtriekende bloemen, welke de inlandsche vrouwen in het haar 
dragen. $=b$. Hedyehi $\|$ ul $\mathrm{li} u \mathrm{~g} \| \mathrm{la}$ t $1 \mathrm{~m}$ H a s s. Gr. Java en Sumatra. = c. $11 \mathrm{edychium} R \circ \mathrm{xburgh}$ i $13 \mathrm{l}$. (Zie No. 350 c.)

2410. Gandasoelie-0etan M. = H edyehium sumatran um Jaek, Nat. fam. als voren. GR. Sumatra; overblijvend.

2411. Gandja M. = Canna bis u ativa L., Nat. fam, der Cannabine re. Gr. Java en elder's in tuinen; zaadplant. GEBr. De Hennip tiert in Indië minder welig dan in Europa, en is daarom ook minder gezocht; have teehnisehe en medisehe (verdoovendc) eigensehapjen zijn over bekend.

2412. Gandja-rameh-tjina $\mathbf{M}$. = Corchorus capsularis L., Nat. fain. der Tilia e e. Gr. Java en de Molukken; zaadplant. GEBR. Deze plant, waarvas de bladieren als groente kunnen wordeı gegeten, wordt hoofdzakelijk om het bckende Juta-vlas aangrekweekt; de eultuur is echter nog niet uitgebreid.

2413. Gandjeng $\mathrm{MAK}$. = Chaviea s i r i b a M i q. (Zie No. 1170.)

2414. Gandoem $\mathrm{J}_{0}=\mathrm{Triti}$ e $\mathrm{m}$ v $u l g$ a r e L., Nat. fain. der G r a m in e r. Gr. De gewone tarwe wordt op Java. hier en daar aangeplant en verbruikt.

2415. Gandoh J. en

2416. Gandoi of Gondoi MaK. = Entada pursietha D C. (Zie No.482.)

2417. Gandok M. $=\mathrm{Argos}$ tem ma meerocephalum Miq., Nat. fam. der Rubi a e æ. Gr. Sumatra; overblijvend.

2418. Gandoola-boddas S. of G.-poetik M. = B a se 11 a a 1 b a L., Nat. fam. der Che no po de x. Gr. Java, de Molukken; éćnjarig

2419. Gandoola-burrum S. of G.meizah $\mathrm{M} .=a$. B a sell a r u bra $\mathrm{L}$. en $=b$. B asella e ordifolia $\mathrm{L}$ am., Nat. fam. en Gr. als voren. GeBr. Deze drie slingerplanten (2298 tot 2300 ) worden veel aangeplaut, omdat de bladeren als groente worden gegeten; volgens RUMPHIUS werken zij zacht ontlastingbevorderend. De Javanen dienen ze inwendig toe bij buikloop en nitwendig bij rheumatische aandoeningeu. De saprijke bessen gebruikt men tot roodkleuring van gebak en kon. fituren; in Japau kleurt men er ook aardewerk en katoenen stoffen mede.

2420. Gandroeng $\mathrm{S}_{*}=\mathrm{S}$ or $\mathrm{g} \mathrm{h} \mathrm{u}$ v u l g a r e Pers. (Zie No. 18\%9.)

2421. Ganggang $\mathrm{S} . \& \mathrm{M} .=a$. H y drilla najadivolia Z. \& M. (Zic
No. $\left.2313 f^{\circ}\right)=6$. B ly $\mathrm{x}$ a $R \circ \mathrm{x}$ b u $\mathrm{rg}$ hi i Rich, Nat. famt. der H y dro e h ari d e se. Gr. Java en Sumatra; waterplant. $=c$. Limnophilla pinuatifida Bl., Nat. fam. der S e r o p h u la ri ne a. Gr. Java waterplant. $=d$. Euhy $\mathrm{dra}$ pal u dos a D.C., Nat. fam. der Com. positæ. $\mathrm{G}_{\mathrm{R}}$ Java; waterplant. $=e$. J ussiæa repens L. (Zie No. 476.)

2422. Ganggang-besaar $\mathrm{M}$. = $\mathrm{O}$ tte li a javan i a Miq. (Zie No. 1124.)

2423. Ganggang.lumboet $\mathrm{S}$. $=\mathrm{M}$ ieroearpa museosa R.Br. (Zie No. 2161.$)$

2424. Gangangan $\mathrm{BL} .=\mathrm{G}$ y $\mathrm{r}^{-}$ e a pus asiatieus Wlld. (Zie No 1560 )

2425. Gangh $\mathrm{J} .=\mathrm{V}$ it is in die a L. (Zie No. 349 )

2426. Ganglot $\mathrm{S}$. $=\mathrm{Gel}$ o $\mathrm{n} \mathrm{i} \mathrm{um}$ glomerulatum Endl. (Zie No, 1970.)

2427. Gangoe $M=I$ p o m $\propto$ a reptans Poir. (Zie No. 526.)

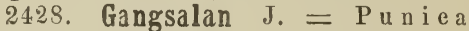
g r a n a t u m 1.. (Zie No. 1608.)

24.29. Ganiter M. of J. of

2430. Ganitrie S. J. \& M. $=a$. El $l$ o e a r us serratus $I_{\text {. }}$. en $b$. El co e a r p s angustifolius Bl. (Zie No. 104.)

2431. Ganja M. $=$ Corehorus e a ps u laris J. (Zie No. 2412.)

2432. Ganja-0etan M. -. C o r c hor us o litorius L. (Zie No. 2042)

2433. Ganjoeng-tjai L. $=\mathrm{H}$ y drilla najadivolia Z. \& M. (Zie No. $2313 f$.)

2434. Ganrot J. $=$ P oly g o $\mathrm{n} \mathrm{um}$ perforatum M e is n., Nat. fam. der Polyg on e г. Gr. De Sunda-archipel, overblijvend.

24:35 Garang-bauw $\mathrm{S}$. = Conyza la e e a B r m. (Zie No. 1047b)

2436. Garang-goenong $\mathrm{J}=\mathrm{A}$ r alia mo ntana Bl. (Zie No 9096.)

2437. Garintoel J. = Gnet u m g n e m o n I. (Zie No. 820.)

2438. Garo-kominian $\mathbf{M} .=\alpha, \mathrm{Aqui-}$ laria agalloeh a L. (Zie No. 22a) en $=$ b. Aquilaria seeundaria D.C., Nat. fam. der $\mathrm{Thy}$ mel $\mathrm{l}$ a c e $x$ Gr. De Molukken; boom.

2439. Garo-mata-boeta T. $=\mathrm{Ex}$ e o e a.ri a agallocha L (Zic No.22b.)

244.0. Garoe M. $=a$. A quila ri a a g a llo eha L. (Zie No. 22a.) $=b$. U rostigma elasti e um Miq., Nat. 
fam, der Artocarper. Gr. Java, Surnatra, enz.; hooge boom. GEBR. Deze boom levert, een der beste soorten van Caoutchouc of Gomclastiek.

2441. Garoe-enteroe Bк. = Aquilaria? baucana Miq., Nat. fam. der Thymelaceæ. Gr. Banka; hooge boom.

2442. Garoe-mienjak M. = Urostignu a procerum Miq, Nat. fam. als volen. Gr. Java en Sumatra; hooge boom. GEBR. Den bast bezigt men voor beschotteu in hutten in plaats vall bamboes. Het roodc hout brandt men als reukwerk tot berooking val kleederen en bij sterfgevallen. De roode vruchten, fijugestampt, gebruikt men om visschen te bedwelmen, ook perst men cr: eene lampolie nit (HASSKARL)

2443. Garoe-tjoempeka M. = Excoecaria agallocha L. (Zic No. 22b.)

2444. Garoengang Scm. $=\mathrm{N}$ a u c lea oxyphylla Miq., Nat. fam. der Rubiaceæ; hooge boom. Gr. Sumatra, Z. en O.-Knst.

2445. Garoentang Sum. $=\mathrm{Par}$ anephelium xestophylla Miq., Nat. fam. der Sapindace æ. Gr. Sumatra, Z. e'l O.-Kust; hooge boom.

2446. Garoet $\mathrm{BK} .=\mathrm{Rubus}$ a lcexfolius Poir, Nat. fam. der R os ace Gr. Java, Sumatra, enz. ; heester met eetbare viuchten.

2447. Garoet-badak S, = Lantana mixt a L. (Zie No 1840.)

244:9. Garoet-peutjang $\mathrm{S}$. $=\mathrm{Bra-}$ chypterum scandens W. \& A., Nat. fam. der Papilionacea. GR. De Sundaarchipel; slingelplant.

2449. Garong-garong $J_{0}=0$ din $a$ gummifera B1. (Zie No, 1990)

2450. Gatel M. en

2451. Gatep M. $=$ Inocarpus c dulis L. fs. (Zie No. 340.)

2452. Gatep-pahit $\mathrm{M}$. $=\mathrm{S}$ a $\mathrm{m}$ adera indica Grtn., Nat. fam. (ler Simarubacex. Gr. Java, enz. in tuinen; boom. Gebr. Alle declen van dezeu boom bevatten een zuiver bitter, voornamelijk de bast en bladeren, daarom zijn zij zeer heil\%aam als tonicum cu bij verminderde galafscheiding; men heeft den bast met goed gevolg bij cholera en tusschenpoozcnulc koortsen toegediend; ook de wortel en de bladeren worden tegen koortsen gegeven. De bast bevat ecne roode kleurstof, en geeft met dic van $M \circ \mathrm{r}$ in d a umbcllata I. het dnurzame rood der Oost-Indische zijden zakdocken.
24.53. Gatep-pahit M. $=\mathrm{S}$ a ma de ra brevipetala scheff., Nat. fam. der $\mathrm{S}$ i m a r u b e æ. Gr. Amboina, Java; boom.

2454. Geah-anda Lamp. = $\mathrm{Meme-}$ cylou luteolum Mig., Nat. fam. der M c mecyleæ. Gr. Sumatra; heester.

2455. Gebang S. \& M. en

2456. Gebang-paleng $\mathrm{S}$. = C o r ypha umbraculifera L. (Zie No. 1528.)

2457. Gebumbo J. (Zie No. 2462.)

24.58. Gedang S. \& J. $=a$. Mus a paradisiaca I. (Zie No. 1190) en = b. Carica Papaya I. (Zie No. 1092.) 2459. Gedang-ari $S_{0}=\mathrm{Al}$ disi a lævigata Bl., Nat. fam. der Myrsine æ. Gr. Java; boom.

2460. Gedang-gantoel S. en

2461. Gedang-kastella BAT. $=\mathrm{Ca}$ ric a Papaya I. (Zie No. 1092.)

2462. Gedebang $\mathrm{S}$. $=$ Pothomolphe subpeltata Miq. (Zie No. 86.)

2463. Gedebeh LAMP. $=M$ a $\mathrm{ng}$ ifera gedebch Miq., Nat fam. der A nacardia cer. Gr. Lampongs (Snmatra); hooge boom.

2464. Gedong-djengal $\mathrm{J} .=\mathrm{U} \times \mathrm{o}-$ stigma Hasseltii Miq., Nat. fam. der Artocarpeæ. Gr. Sumatra, Java tot Timor; boom.

24.65. Gedong-itari $\mathrm{J}_{\mathrm{g}}=\mathrm{Ar} \mathrm{disia}$ lævigata Bl. (Zic No. 2459.)

2466. Gedong-0elar of oêlô J. = Dactylotecnium ægyptiacum IVlld. (Zie No. 23446.)

2467. Gedong-djenkal J. (Zie No. 2464.)

2468. Geger-bintin $\mathrm{S} .=\mathrm{C}$ a st $\mathrm{a}$ nea javanica Bl., var. montano, Nat. fam. der Cupuliferc. Gr. Java; zeer hooge boom, GEBR. Het hout is zcer gecchikt voor bonwhont; de vruchten worden gekookt of geroosterd gegeten.

2469. Geger-takko S. = Glycos$m$ is cyanocarpa Sprg., Nat. fam. der A urantiacer. Gr. Java; hecster.

2470. Gehger-bengan $\mathrm{S}$. = $\mathrm{P}$ a r-

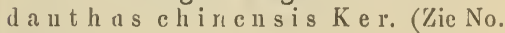
2386.)

2471. Gehwor (Zie No. 2089.)

24.72. Geja-an $J .=H$ I eliophyt $₫ \mathrm{~m}$ indicum 1).C. (Zic No. 1445.)

2473. Gelala-aijer $\mathrm{N}=\mathrm{Fryth} \times \mathrm{i}-$ na fusca Lour. ('Zie No. 1595.)

24.74. Gelala-hitam M. = krythrina fusca Lour. (Zie No. 1595.) 
2475. Gelala-lakki M. = Erythrilla picta L., Nat. fam. der Papilionaceæ. Gr. Celebes en de Molnkken; boom. GeBr. Deze boom plant men vooral in heiningen; men eet de bladeren bij de rijst, en prijst ze als bevorderend tot zogafscheiding aan; nitwendig legt men ze ook op oude zweren.

2476. Gelala-laut $\mathrm{M} .=($ Zie No. 247.1.)

2477. Gelala-poetih M. $=($ Zie No. 2475.)

2478. Gelam of Glam M. $=a$. M elaleuca Cajupiti Rxb. (Zie No. 1737 d. $=$ b. M elaleuca minor Smith., Nat. fam. der Myrtacer. Gr. Bijna overal in dezen Archipel; boom. GEBr. Men gebruikt het hout voor ribben en daksparren, den bast voor fakkels en voor het breeuwen vau prauwen.

2479. Gelang (Gellang) S. \& J. = $a$. Portulac a olerace a L. c u m viriet., Nat. fam. der Portulacex. Gr. Op Java en elders in het wild en gekweekt: zaadplant. GEBR. Het ziltige, znurachtige kruid eet men bij wijze van groente, het is verkoelend, oplossend en hcilzaam bij scorbut; men gebruikt het ook bij azijnmakerijen. De zaden behəorden vroeger tot de semina quatuor frigida minora en werden als stondendrijvend middel toegediend. $=b$. Sesuvium rcpens Wlld. (Zie No. 734 $)=c$. Trianthema sedifolia Vis., Nat. fam. als $a$. Gr. Java; éénjarig.

2480. Gelang-aijer $\mathrm{M}$. $=\mathrm{Olden}$ landia nndiflora $R \times b$., Nat. fam. der $\mathrm{R}$ n bi a cex. GR. Java; overjarig.

2481. Gelang-laut $\mathrm{I}_{2}=\mathrm{S}$ esuriu $\mathrm{m}$ repens Wlld. (Zie No. 734.)

2482. Gelan-passir M. $=a . \mathrm{P}$ ortulaca quadrifida L., Nat. fam. der Portul accæ. Gr. Java, Timor, enz.; zaadplant. $=b$. Pyxipoma polyan. dru in Fnzl., Nat fam. als voren. Gr. Java en de Molukken; zaadplant. Beide kunnen als groente worden genuttigd.

2483. Gelatrang S. (Zie No. 1890.)

2484. Gelipang-rimbo Suм. Wк. = Covellia Ribes Miq. (Zie No. 282b.)

2485. Geloepak J. $=$ Morinda polyneura Miq., Nat. fam. der Rn. b i c e e. Gr. Java; slingerplant.

2486. Gembang M. = Coryplı un braculifera L (Zie No. 1528.)

2487. Gembas J. $=\mathrm{Luffa}$ cordifolia Bl. (Zie No. 5̌l4.)
2489. Gembos J. $=\mathrm{S}$ ouchus as. per Vill. (Zie No. 2030.)

2489. Gendoeroe J. $=\mathrm{C}$ ary ot a furfuracea Bl., Nat fam. der Palin Gr. Bijna overal in Indië; honge Palm. GEBr. Deze boom levert goede sago ell sagueer; de vruchten zullen een scherp vocht bevatten.

2490. Geniestrie J. = Acronodia puuctata Bl., Nat. fam. der Tiliac eæ. Gr. Java: boom.

2491. Genkot $\mathrm{S}$. $=\mathrm{Mimusops}$ a c uminat a Bl. (Zic No. 2040.)

2492. Gentoengan J. $=\mathrm{Zehneria}$ deltoidea Miq., Nat. fam. der Cucurbitacer. Gr. Java; slingerplant.

2493. Gentong $\mathrm{J}_{\text {. }}=\mathrm{Ch}$ avica in ajuscula Miq. ('Lie No. 289.)

24.94. Gentongan J. $=$ Bisch offia javanica Bl. (Zie No. 2352.)

2495. Gering-geringan M. \& $\mathrm{BL}_{\mathrm{L}}$ = Crotalaria retusa I., Nat. fam. der Papilionaceæ. Gr. Jara, Sumatra, enz.; éénjarig.

2496. Geroeboet PaL. $=$ Conophal. lus giganteus Schott (Zie No. 750c.)

2497. Gerong J. $=$ Pothomorphe subpeltata Miq. (Zie No. 86.)

2498. Geroro-mafalla $\mathrm{T}$. $=$ Melastoma polyanthum Bl. (Zie No. 110)

2499. Gertok-pantok S. = S talagmites dulcis Camb, Nat. fam. der Clusiacex. Gr. Java in het wild en gckweekt; ook elders in tninen; boom. GFBr. Men cet de ourijpe, zure vruchteri gekookt met groenten; rijp zijn ze zuurachtig zoet en levcren een aangenaam ooft.

2500. Gestô J. = Conorephalus suaveolens Bl., femina. (Zie No. 51S.)

2501. Getah-gitan-gedang $\mathbf{M}$. = Willughbeia firma Bl., Nat. fam. der A p осупсæ. Gr. Java, Sumatra; slingerplant.

2502. Getah-gitan-gedong $\mathbf{M}$. = Melodiuns oricntalis Bl. (Zie No. $560 b$.)

2503. Getah-gitan-ketjil M. = Lenconotis eugenixfoli a D.C., Nat. fam. der A p осуие æ. Gr. Sumatra; kleinc heester.

2504. Getah-kadjei M. $=\alpha$. Urostigma glabellum Miq., Nat. fam. der A r tocar peæ. Gr. Java en Sumatra; hooge boom. Gebr. Deze boom bevat veel eaoutchouk; zijn jonge bladeren worden raıw en gekookt bij de rijst gegeten. = 
b. Urostigma Karet M., Nat. fam. als voren. GR. Java, Sumatra en elders; hooge boom. GeBr. Deze boom levert vooral de bekende caoutchouk of elastieke gom; het melksap wordt ook gebruikt voor fakkels en, versch zijnde, voor vogellijmı.

250ว. Getah-laboeai Sum. WK. = A lstonia costulata Miq., Nat. fam. der A pocynex. Gr. Sumatra; bonm.

2506. Getah-lahoe $\mathrm{M} .=\mathrm{Ficus}$ u mbellat a Vhl., Nat. fam, als voren; Gr. Palembang (Sumatra Z. O.); hooge boom. Gebr. Deze boom levert een in den handel voorkomenden was-stof.

2507. Getah-nganti of njantji M. = Chilocarpus? costatus Miq., Nat. fam. der A pocyneæ. Gr. Sumatra; slingerplant. GıBR. De hars van deze plant komt, even als die van No. 2501 in den inlandschen handel voor.

2508. Getah-sepoloh LaMP. $=\mathrm{Can}$ arium rugosum Miq., Nat. fam. der Amyridex. Gr. Sumatra en Borneo; hooge boom.

2509. Getel J. $=$ Derris multiflora Bnth., Nat. fam. der Papilion a ее. Gr. Java; slingerplant.

2510. Giba T. $=\mathrm{Z}$ anthoxy $\mathrm{lum}$ zeylanieum D.C. (Zie No. 389b.)

2511. Gigi-gadja M. = $\mathrm{Ag}$ i ceras majus Grtn. (Zie No. 1556.)

2512. Gigiel S. = Dichroa ey ani$t$ is Miq., Nat. fam. C̀er $S$ ax if $r$ ag ae e . Gr. Java en Sumatra; heester. Gebr. De bladeren worden boven het vuur gehouden en bij buikpijn warm op den buik gelegả.

25̃13. Gigirang J. = Aralia javanica Miq. (Z:c No. 909a.)

25̃l3bis. Gilapong Sum. Wк. = Fie us Gilapong Miq., Nat. fam. der Artoc a r pex. Gr. Sumatra; boom.

2514. Gilig J. $=$ Hunteria sundana Miq., Nat. fain. der A pocynex. Gr. Java; heester. GEBr. Horsfield prijst deze plant als tonisch en koortsdrijvend geneesmiddel aan; zij sehijnt dezelfde eigenschappen en geneeskracht te bezitten als de Ophioxylou serpentinum L. of Poeleh-pandak S. (Zie later.)

25 15. Ginalloä M. = G inalloa A rnottiana Korth., Nat. fam. der Loranthacex. Gr. Borneo; parasiet.

2516. Gindapoera-0etan J. = I pomaa vitifolia Sw. (Zie No. 4636.)

2517. Gindi-monjet M. en

2518. Gindi-seetan $M .=$ Nepen- thes phyllamphora Wlld. (Zie No. 127.)

2519. Gingiang $\mathrm{S} .=\alpha$. L e e a sambueina Wlld. (Zie No. 128.) $=b$. I, ee a hirsuta Bi., $=c$. Leea hilta Horn. en $=d$. Leea javanica Bl., alleu heesters van de Nat. fam. der I, e e acеæ. Gr. Java en elders. Gebr. De fijngewreven bladeren van bijna alle $I_{1}$ ee asoorten legt men op verouderde, vuile zweren, welke daardoor spoedig een zuiver aanzien bekomen.

2520. Gingiang-burrum S. = Leea rubra Bl., Nat. fam. en Gr. Als voren; heester. GEBR. De bladeren gebruikt men als hiervoren opgegeven; de vruehten geeft men tegen dysenterie en framboesiæ.

2521. Gingiang-lumboet $\mathrm{S} .=a$. Lcea humilis Hassk., Nat. fam. als voren. Gr. Java; heester. GuBr. Als No. $2519 d$. $=b$. Leea javanica Bl. (Zie No. $2519 d$.)

2522. Ginjeh S. \& J. = $a$. Cannabis nativa I. (Zie No. 2411.) $=b$. Theve tia neriifolia Juss., Nat. fam. fam. der A poey nеæ. Gr. Java, Sumatra, de Molukken in tuinen; heester. GEBR. Het melksap is zeer giftig en braakrerwekkend; de bittere bast werkt purgeerend en koortswerend; hij verdient een nauwkeurig onderzoek. Het hont, dat zeer onaangenaam riekt, gebruikt men tot het bedwelmen van visschen. De bladeren worden door sommige Bengalezen als tabak gerookt.

2523. Giong.meöng $\mathrm{CH}$. Во $=\mathrm{A}$ ndropogon Schoenanthus L., Nat. fam. der Gramineæ. Gr. Door geheel Indië aangeplant; ovcrblijvend GeBR. Het jonge gras gebruikt men veel als specerij in de Indisehe huishouding bij het bereiden van sausen, kerry's, groenten voor de rijsttafel, enz.; men mengt het ook in de Sagueer, en geeft het aan vrouwen, die pas bevallen zijn; men roemt het ten hoogste en wendt het aan als zweet-, pis- en koortsdrijvend en als maagsterkend middel. Uit het citrocngras of Sehreh $S$. stookt men ecn vluchtige olie, dic nitwendig bij allerlei aandoeningen wordt aangewend.

2524. Girak S. $=$ Symplocos fase i culata $\angle 011$. (Zie No. 2091.)

2524bis. Girang J. = Is e a $\mathrm{r}^{\mathrm{n}} \mathrm{kr}$ b B 1. (Zic No 2520).

2525. Giring-landak M. = Crotala ria retusa I. (Zic No. 2495.)

2526. Gitan $\mathrm{M} .=a$. $\mathrm{W}$ ill $\mathrm{ugh}-$ 
beia? apiculata Miq., Nat fam. der A pосу пеæ. Gr. Sumatra; slingerplant. $=b$. Mlelodinus orientalis Bl. (Zie No. 5606.) Het melksap van beide is in den inlandschen handel als getah pertja.

2527. Gitan-keijil $\mathbf{M}=$ Leuconotis cuspidata Bl., Nat fam. der A pocyn e . Gr. Sumatra; heester. GEBr. Het melksap levert een mindere soort ran getahpertja.

2528. Glaga M. \& S. = a. Saccha. rum spontaneum L. (Zie No. 2323.) $=b$. Phragmitas Roxburghii Nees, Nat. fam. der Gramineæ. GR. Java, Sumatra, enz.; overblịvend. GEBR. De jonge spitsen of spruiten dezer rietsoort worden gekookt bij de rijst gegeten.

2529. Glaga-proemboeng $\mathrm{J} .=\mathrm{Eula}$ lia japonica Trin, Nat. fam. der Gramineæ. Gr. Jara, Snmatra, enz.; overblijvend GEBR. Men bezigt dit gras soms om er atappen ombeen te naaien, ook wel om er rijst in te koken, ten einde deze geuriger te maken.

2530. Glam $\mathrm{M}_{\text {. }}=$ Melaleaca minor Sw. (Zie No. 2478b.)

2531. Glam.betie M. = Gordonia excelsa Bl., Nat fam. der Ternstrœmiaceæ. Gr. Java; hooge boom. GeBr. Den bast gebruikt men tot het tanen van vischnetten; het fijne, roode eu zware hout is zeer geschikt voor bouwhout, fijne meubels, rijststampers, enz.

2532. Gledok-pantoh $\mathrm{S} .=\mathrm{Paret} \pm \mathrm{a}$ odorata Bl., Nat. fam. der Rubiaceæ. Gr. Java, Sumatra, Borneo; heester.

2533. Glengang $\mathrm{M}$. $=\mathrm{C}$ assia alata L. (Zie No. 1740)

2534. Globba (Gãloba) Амв. $=a$. Alpinia gigantea Bl. (Zie No. 386.) = . Donacodes incarnata T. \& B., Nat. fam. der Zingiberaceæ. Gr. Amboina; overblijvend.

2535. Globba-boppo-loeloe ' $\mathrm{T} .=\mathrm{A}$ momum villosum Lour. (Zie No. 385.)

2536. Globba-doerian Амв. $=$ Donacodes rosca T. \& B., Nat. fam. als voren. Gr. Amboina; overblijvend.

2537. Globba-doerian-besaar Aмв. $=$ A momum villosum Lour.

2538. Globba.oetan-besaar Амв = Alpinia gigantea Bl. (Zie No. 386 )

2539. Globba-papoea-meirah Амв. = Amomum villosum Lour.

2540. Glodok-pantoh S. = Stalagmites dulcis Camb. (Zie No. 2499.)
2541. Gloegeh J. = Bixa Orellana L. (Zie No. 1697.)

2542. Gloegô M. = Broussonetia papyrifera Vent. (Zie No. 1861.)

2543. Gloegoer $B K$. = Garcinia Klabang Miq., Nat. fam der Clusiaceæ. GR. Bangka; boom.

2544. Gloengang Bк. = Caryophyllus fastigiatus Bl., Nat. fam. der Myrtaceæ. Gr. Java, Sumatra, Bangka; hooge boom.

2545. Glompan-tita DJ.= Sterculia urceolata Sm. (Zie No. 1502.)

2546. Gnemon $T$. en

2547. Gnemon-oetan II, J. = Gnetum gnemon L. (Zie No. 820.)

2548. Gnemon-tali M. = Gnetum edule Bl. en = Gnetum funiculare Bl. (Zie No. 200.)

2549. Gobbo T. $=$ Commelyna benghalensis I, Nat. fam.der Commel Inaceæ. Gr. Vrij algemeen in Indië; overblijvend. GFBr. Het jonge kruid eet men gekookt als groente bij de rijst.

2550. Gobi.gobi T. = Actinodaphe Rumphii Bl. (Zie No. 55.)

25วl. Godam of Godom BL. = Eleusine Coracana Grin. (Zie No. 1892)

25ว2. Godong J. $=$ Ranuuculus diffusus D.C. (Zie No. $344 c$.)

2553. Godong.djengk?l S. = Uros tigma Hasseltii Miq. (Zie No. 2464.

25.4. Godong-djoerang $\mathrm{J} .=\mathrm{Po}_{0}$ thos scandens L. (Zie No. 571.)

2555. Godong.laweh $\mathrm{S}$. $=$ Drymispermum Blumei Desn. (Zie No. 422.)

2556. Godong-lema J. $=$ Munroni a jaranica Bnnt., Nat. fam. der Meliacer Gr. Java; heester.

2557. Godong-nodjo J. = Strobilanthes crispa Bl., Nat. fam. der A cauthacer. Gr. Java; orerblijvende plant.

2558. Godong.poeloe J. = Macro. s olen tetragonus Bl., Nat. fam. der Loranthaceæ. Gr. Jara; parasiet.

2559. Godong-saroenie J. $=\mathrm{W}_{0} \mathrm{l}$ lastonia strigulosa DC. (Zie No315 a.)

2560. Godong.sengani $\mathrm{J} .=\mathrm{J}$ a $\mathrm{m}$ bosa rubricaulis Miq., Nat. fam. der Myrtaceæ. Gr. Java, Sumatra, Bangka; boom.

2561. Godong-sikel S. = I asianthus sylrestris Bl., Nat. fam. der Rubiaceæ. Gr. Java; heester. Gebr. Eren als van andere $L$ a sianthus-soorten, 
gebruikt men vermoedelijk ook van deze de bladeren tegen opgezetheid van den buik door winden.

2562. Godong widodarie $\mathrm{J} .=\mathrm{Agri}$ monia javanica Jugh., Nat. fam. der Rosaceæ GR. Java; heester.

2563. Goe T. $=$ Dendrolobium umbcllatum W. \& A. (Zie No. 1683a.)

2564. Goedeh S. $=$ Cajan us indic us Spr. (Zie No. 1210.)

2565. Goedeh J. = Parkia african a R Br., Nat. fam. der Minoseæ. Gr. Java, Sumatra, en elders in tuinen; hooge boom. GEBR. De jonge bladeren, doch rooral de onrijpe zaden zijn als toespijs bij de rijst zeer gezocht; zij wo:den rauw, gekookt en geroosterd gegeten, en bezitten, niettegenstaande den sterken knoflookreuk, een aangenamen smaak. Vooral in Afrika zijn de zaden zeer gezocht; men maakt er datar koekjes van, die bij elke spijs worden genuttigd; zij zullen meent men, de inpotentia virilis opheffen.

2566. Goedosari S $=$ Heterostemm a a cuminatum Dcsn., Nat fam. der Asclepiadeæ. Gr. Java; slingerplant.

2567. Goegong $\mathrm{BL} .=a \cdot R \mathrm{n} \mathrm{bus}$ acuminatissimus Hassk, en $=b$. R. moluccanus L. (Zie No. 139.)

2568. Goelinging-batawi Suм. Wк. = Cassia glauca L., Nat. fam. der Papilionace é. Gr. Java, Sumatra, Borneo en elders; boomachtige heester. GEßBR. Het hout verwerkt men voor scheden van krissen, enz.; de bladeren eet men als groente.

2569. Goelong-djangoeng $\mathrm{S}$. = Wendlandia glabrata DC. (Zie No. 2366 )

2570. Goelong-tjoetjoe M. = Plumieria a cut ifolia Poir. (Zie No. 1367.)

2571. Goema.goema J. $=0$ dina g $11 \mathrm{~mm}$ ifera Bl. (Zie No. 1990.)

2572. Goemaroe-koessoo 'T' \& MeN. $=$ Andropogon Schoenanthus L. (Zie No. 2523.)

2573. Goemere-laut $\mathbf{M} .=\mathrm{Premna}$ integrifolia I., Nat. fam. der Verbenaccr. Gr. Vrij algemeen in Indië; boom. GFBr. Het fraaie en sterke hout kan voor huisraad gebruikt worden. De bast en wortels zullen om de luchtige olie, tot de tonisch-opwekkende geneesmiddelen kunnen gebracht worden

2574. Goemi-ginati $\Lambda \mathrm{M}$. $=\mathrm{Coc}$ culus glaucus I).C. (Zie No. 1687.)
2575. Goemi-rotto-rotto $\mathrm{T}_{0}=\mathrm{Cis}$ sus repens Lam. (Zie No. 438.)

2576. Goemira $T$. en

2577. Goemira-laut $\mathrm{T}$. $=$ Premna foetida Rwdt. (Zie No. 1722b.)

2578. Goempoer J. $=\mathrm{T}$ etranthera alnoides Miq., Nat. fam. der Laurine æ. Gr. Java; hooge boom.

2579. Goenaga $\mathrm{T} .=$ Areca paniculat a Scheff, Nat fam. der Palmæ. Gr. Molukken; boom.

2580. Goenariah S. $=$ B on ea Gandaria Bl. (Zie No. 2404.)

2581. Goenda $S .=S p h e n o c l e a$ zeylanica Grtn., Nat. fam. der Campanulace æ. Gr. Java, Timor, cnz.; éénjarig. GEBR. De jonge bladeren, in stoom gekookt, worden bij de rijst gegeten; zij zijn aangenaam van smaak.

2582. Goenda-leutiek $\mathrm{S} .=\alpha$. $\mathrm{Her}$. pestis Monnieria H. B. \& K, Nat. fam. der Scrophularineæ. Gr. Java, Timor; overblijvend. $=b . \mathrm{V}$ and ellia sphærocarpa Bnth., Nat. fam. als voren. GR. Java; ćénjarig

2583. Goendo S. = Salix Horsfieldiana Miq., Nat. fam. der Salicineæ. Gr. Java en Sumatra; heester. GEBR. Hiervan wordt schellak en lakday verzameld, die in den handel komt.

2584. Goengoeroetoe $\mathrm{S} .=\mathrm{V}$ it is indica L. (Zie No. 349.) $=$ b. Cissus arachnoidea Hassk. (Zie IJo. 1415.)

2585. Goensieng S. \& J. $=a \cdot \mathrm{Ca}-$ navallia virosa W. \& A., Nat. fam. der Papili o n a c eæ. Gr. Java, Sumatra, Timor; éénjarig, kruipend. GEBR. De bladeren, bloemen en onrijpe peulen worden in stoom gekookt en bij de rijst gegeten; ook de rijpe zaden eet men gekookt bij de rijst. $=b$. Mucuna mon os perma D.C., Nat. fam. als voren. $G_{R}$ Hier en daai in Indië; slingerplant. Gebr. Het sap van deze en der volgende plant geeft men tegen wormen te drinken: een theekopje vol houdt men roor voldoende om daarvan verlost te worden.

2586. Goensieng.gedeh S. = Muc un a gigante a D.C., Nat. fam. als voren Gr. Bijna door geheel Indië; slingerplant

2587. Goentalian S. $=$ Boehmeria c li m e dio ides M i q., Nat. fam. der Urtic a c c r. Gr Java en Sumatra, hocster. Gebr. De bast, van de buitenschil bevrijd, wordt gedroogd en daarna tot touw verwerkt. 
2588. Goentoel M. = Trichosanthes tricuspidata Bl. (Zic No.521b.)

2589. Goepo-gatel $\mathrm{J}$. $=\mathrm{Hydroco-}$ tyle nepalensis Hk., Nat. fam. der Umbellifer $x$ GR. Java; overblijvend.

2590. Gcera-batoe T. $=a$. Nothopanax cochleatum Miq. (Zie No.76) $=b$. Nothopanax fruticosum Miq. (Zie No. 1153.)

2591. Goera-wilang S. $=\mathrm{Ziz}$ y phus Horsfieldii Miq. (Zie No. 488.)

2592. Goeroeng $\mathrm{S}=$ Peric a mpylus laquinonus Miq. (Zie No. 4896 .)

2593. Goetjingan $J_{.}=\mathrm{Trium}$. fetta caca Bl. Nat. fam. der Malvec eæ. Gr. Java; hcestertje.

2594. Goffo-haijran T. $=$ I,encas linifolia spr. (Zie No. 1043.)

2595. Goffo-haijran-miskien $\mathrm{T}$ : = $a$. Phyllanthus Niruri $\mathbf{L}$. cn $=b$. Ph. urinaria Wlld. (Zie No. 71b.)

2596. Gofforoe T. $=$ U rostigma nitid u in Miq. (Zie No. 855 )

2597. Gohi M.\&T. $=$ Ficus Wassa Roxb, Nat. fam. der Artocarpex. Gr. Cclebes, Ternate; heester. Gebr. Nen bezigt den bast voor touw; de jonge bladeren en de vruchten worden gekookt gegeten.

2598. Gohni Suм. Wк. $=$ Bo eh meria nive a Gaud. (Zie No. 2387.)

2599. Gohoengong BL. = Goegong Bl. 2600. Gomassi Maк. en

2601. Gomo T. \& MeN. = A rtocarpus incisa L. cum variet. lævis Miq. (Zie No. 269.)

2602. Gomo-landoek S. = Prionitis Hystrix Miq. (Zie No. 1377).

2603. Gomoetoe $M_{.}=$Arenga saccharifera Lab. (Zie No. 24.3.)

2604. Gomoho-papoea T. $=\mathrm{Lygo}$. dium microphyllum R. Br., Nat. fam. der Schizæacese Gr. De Molukken; slingerplant. GEBR. Men bezigt het loof evenals of in plaats ran dat der A diantum Capillus L.

2605. Gomote. T. $=$ Caryophyl. lus aromaticus L. (Zie No. 1292).

2606. Gompong S. \& J. = Hors. fieldia aculeata D.C. (Zie No. 2234.)

2607. Gompohr S. $=$ Mangifera macrocarpa Bl., Nat. fam. der A n acardiace . Gr. Java; hooge boom. GEBR. Men eet de zuur-bittcre vruchten, die echter dikwijls duizeligheid veroorzaken.
2605. Gondal S. \& $\mathbf{M} .=\alpha$. Ficus nodos a 'T. \& Bk., Nat. fam. der Artocarpeæ. Gr. De Molukken; boom. = b. Covellia racemifera Miq. (Zie No. 1240.)

2609. Gondang-kassé J. = Ä̈rva sangu inolenta Bl, Nat. fam. der A m ar an ta ce æ. GR. Java, de Molukken; overblijvend. Glebr. Dit kruid, dat oplossende eigenschappen bezit, mengt men in verschillende inlandsche mengsels, die uiten inwendig bij gonorrhoea en hæmaturia gegeven worden.

2610. Gondapoero J. $=a . \mathrm{Gaul}$ theria punctata Bl. (Zie No. 2403.) $=b$. A belmoschus ficulneus W. \& A., Nat. fam. der Malvaccæ. Gr. Java, Timor; heester.

2611. Gondo J. $=\mathrm{G}$ u il a n d in a B on d u c L. (Zie No. 1475.)

2612. Gongaij $\mathrm{BD} .=\mathrm{Acaci}$ a Hooperian a Z ipp., Nat. fam. der $\mathrm{Ni}$ m o s e æ. Gr. De Molukken; deze heester wordt veel in omheiningen aangeplant.

2613. Gongseng S. \& J. (Zie 2585.) 2614. Gora T'. $=\mathrm{Z}$ ing i ber officin ale L. (Zie No. 253 )

2615. Gora Men \& $\mathrm{T}=\mathrm{J}$ ambosa domestica $\mathrm{Rmph}$. (Zie No. 1922.) 2616. Gora-jadi T. $=\mathrm{J}$ a m bos a a qu x a $\mathrm{Rmph}$. (Zie No. 1914)

2617. Gora-jakkies MeN. = A n ac a r d um oc cidental e L. (Zie No. 1474 .)

2618. Goraka BTJ., T. \& Men. = Z ingiber officinale L. (Zie No. 253.)

2619. Gorang-ireng $\mathrm{J}$. $=\mathrm{H}$ or s. fieldi a a culeata D.C. (Zie No. 2234.)

2620. Goratsji $\mathrm{T}$. $=\mathrm{Curcum} \mathrm{a}$ lo ng a L., Nat. fam. der Zing ibe$r$ a c e $x$. Gr. Overal in Ned.-Indië in tuinell; overblijvend Grir. De curcumawortel wordt door den iulander veel gebruikt; bij feesten verft men zich als ideaal van schoonheid daarmede het geheele lichaam geel; wegens den prikkelenden smaak mengt men hem in bijna alle saucen en kerry's; als geneesmiddel dient men hem toe bij geelzucht, bij verstoppingen en tegen blaas- en nierstecnen; uitwendig bezigt men hem tegen velerlci zwellingen en abcessen en bij rheumatische aalloeningen.

2621. Goro T. en

2622. Goro-goro ' $\mathrm{T}$ '. $=\mathrm{Cer}$ bera lact a ria $\mathrm{H}$ a m. (Zic No. 1182) 
2623. Goroemi-dodo $\mathrm{T}$. $=\mathrm{Ru}$ elli a d iscolor Nees. (Zie No. 72.)

2624. Gossongi $\mathrm{T} .=\mathrm{Enhalus}$ K o en ig i R i ch. (Zie No. 923b.)

2625. Gossouw-roeri BтJ $=\mathrm{Eupa}$ torium A yapanna Vent. (Zie No. 140.)

2626. Gossouw-madoengi BтJ. $=$

Phyllanthus Niruri L. (Zie No. 71.) 2627. Gou $\mathrm{T}$. $=\mathrm{D}$ end rolobium u mbellatum W. \& A. (Zie No. 1683.)

2628. Govasa Амв. (Zie 4966.)

2629. Gowok M. $=\mathrm{J}$ a mbosa ea ulifl o ra D.C., Nat. fam. der M yrtacex. Gr. Java; boom. GeBr. Het hout is fraai rood, sterk, - grof en zwaar, en geschikt voor bouwhout; de zuurachtigzoete vruchten worden gegeten.

2630. Goijongong $J_{0}=A \mathrm{mphido-}$ nax bifaria N. ab Es., Nat. fam. der Graminere Gr. Java; overblijvend.

2631. Gozora T. = Mvristica fragrans Houtt., Nat. fam. der Myri sticeæ. Gr. De Molukken, Java, Sumatra, enz. in tuinen; boom. Gebr. Het gebruik der muskaatnoot en foelie is overbekend; ook de inlanders bezigen beide in vele spijzen en geneesmiddelen.

2632. Gram J. = Dolichos uniflorus Lam, Nat. fam. der Papilionaceæ. Gr. Op Java gekweekt; zaad- plant. Gebr. Het zaad is een gesehikt, doch zwaar voeder voor paarden.

2633. Gressek BL. = Ficus Altimeraloo Roxb. (Zie No. 1362.)

2634. Grien BK. en

2635. Grien-jandam $\mathrm{Bk} .=\mathrm{Ardi}$. sia Teysmanniana Seheff., Nat. fam. der Myrsineaceæ. Gr. Bangka; heester.

2636. Grigitang $\mathrm{M} .=\mathrm{Premna}$ integrifolia L. (Zie No. 2573.)

2637. Grinting-iawa $J .=P$ ernettia repens Zoll., Nat. fam. der Erie a ce æ. Gr. Java; heester.

2638. Groenboeng Sum. $W_{K} .=N$ auclea oxyphylla Miq. (Zie No. 2444.) 2639. Grung $\mathrm{J}$. $=\mathrm{Rubus}$ Horsfieldii Miq., Nat. fam. der Rosaceæ. Gr. Java; heester.

2640. Gliajava M. $=P$ sidium G u aj a v a L. (Zie No. 1911.)

2641. Guajava-ketjil M. en

2642. Guajava-laki-laki M. = Ps idium pumilum Vhl. (Zic No. 1939b.) 2643. Gumpohl $\mathrm{S} .=\mathrm{N}$ a u cle a grandifolia D.C. (Zie No. 1870.)

2644. Gondrei $\mathrm{J} .=\mathrm{Briedelia}$ la ne eolat a K ̈̈rz., Nat. fam. der E u p h or b i a c e. Gr. Java; boom.

2645. Gurrung S. $=$ Pericampylu ${ }_{\mathrm{s}}$ laquinosus Miq (Zie No. 489b.)
2646. Haät $\mathrm{BL}_{\tau}$ en

2647. Haät-adam BL. $=$ Ficus W a s a $R \times b$. (Zie No. 2597.)

2648. Habeam Bk. = Bassia longif olia L. (Zie No. 38.)

2649. Haëas $\mathrm{S} .=\mathrm{Jam}$ bosa virens Miq., Nat. fam. der Myrtacex. Gr. Java; boom. Gebr. De vruchten van dezen boom worden gegeten.

2650. Haffue $T$. en

2651. Haffoe-haffoe-soela T. $=\mathrm{Ca}$ nariopsis decumana Bl., Nat. fam. der $\Lambda$ myridex. Gr De Molukken; zeer 2ware boom. GeBr. Men bezigt de hars voor fakkels en tot harpuis; de zaden zullen bedwelmende eigenschappen bezitten.

2652. Hahaij-moeli Aмв. $=\mathrm{C}$ a ssia javan i a L. ('Zic No. 1025.)
26ว3. Hahanjiran S. = Erythrostigma diversifolia Hassk. (Zie No. 583.)

2654. Hahaöewan S. = a. Polyadenia grandifolia Miq., Nat. fam. der Laurineæ. Gr. Java; hooge boom. $=b$. Elæocarpus serratus L. (Zic No. 104.) $=c$. El locarpus glaber $\mathrm{Bl}$. $=d$. El. longifolins Bl. en $=$ e. El. floribuudus Bl., allen van de Nat. fam. der Tiliace æ. Gr. Java; hooge boomen. GkBr. Men bezigt hat hout voor huisbouw; de rruchten worden gegeten.

2655. Hahaöewan-peutjang $\mathrm{S}$. = Elæoearpus floribundus Bl. Zie vorig No.

2656. Hahappaän S. $=a$. P'hy l- 
lodium pulchellum 1)sv. (Zie No 425.) $=b$. Phyllodiumelegans Dsv., Nat. fam. Gr. en Gebr. als $\alpha .=c$. Flemingia strobilifera K.Br., Nat. fam. der Papilionaceæ. GR. Door geheel Ned -Indië; heester. Gebr. Men wrijft de bladeren met adas en dawon pœlassarie te zamen tot een pap, geeft deze aan kinderen in tegen wormen, en wrijft het overblijvende op den buik. $=d$. Crotal a ria sericea Ktz., Nat fam. als voren. Gr. Ovcral in Indië; éénjarige sierplant.

2657. Hahoëol Амв. $=\mathrm{Covelli}$ racemifera Miq. (Zie No. 1240.)

2658. Hahceroe Амв, en

2659. Hahoeroe-riri-oelan Амв. = Cyathea arborea Wlld., Nat. fam. der Cy ath e ace æ. Gr. Ned. Indië; boom. varen.

2660. Hahoeroe-ijar Амв. = $\mathrm{Po-}$ lypodium quercifolium I. (Zie Nos. 181 ell 1862.)

2661. Hahomboe M. = Milingtonia hortensis $L$ fs., Nat, fam. der Big n o n i a e æ. Gr. Java, Sumatra, Timor; boom.

2662. Hahumalosseij MAN. = $\mathrm{C}$ anariopsis hirsuta B l., Nat. fam. der A m yrideæ. Gr. De Molukken; hooge boom. GeBr. Deze boom levert een op kopal gelijkende hars en een welriekende olie.

2663. Hajam BD. = I n o c a r p s e du lis L. (Zie No. 340.)

2664. Haijlale Амв. $=\alpha$. I pomœa peltata Chois. (Zie No. 303a.) = b. I pom a ma mmosa Chois. (Zie No. 972a.)

2665. Haijoele of Haijoero Амв. = Dioscorea hirsuta B l. (Zie No. 475.)

2666. Hakka-leïlu $A м \boldsymbol{B} .=a$. A chy$r$ anthes bidentata Bl. (Zie No. $740)$ en $=b$. Cyathula genicul a t a Lo ur. (Zie No. 741.)

2667. Hakoer $\mathrm{C}_{\mathrm{R}}=\mathrm{Metroxyl}$ on fila r e Mat. (Zie No. 1320.)

2668. Hala Aмв. = Oryza sativa L. (Zie No. 823.)

2669. Halaul of Halaur Aмв. $=a$. Tetranthera monopetala Roxb. (Zie No. 2323) en $=b$. G labraria t e r s a L., Nat. fam. der $\mathrm{L}$ a u $r$ in e Gr. Geheel Indië; boom. GEBR. Het hout is geschikt voor huisbottw, doch wordt meer gebezigd voor prauwen, wegens de lichtheid en duurzaamheid in zeewater.
2670. Halaur-ketjil Амв. $=a$. G labraria tersa $L$. (Zie vorig No.) = b. Petranthera Forsteni i Bl, Nat. fam. der L a u ri n e æ. Gr. De Molukken; boom. GEBR Het hout is gezocht voor huisbouw en prauwen.

2671. Haleke(Hareke)-da won-besaar Амв. \& Cr. $=R$ ottlera hispida Kurz, Nat fam. der Euphorbiacex. Gr. De Molukken; boom.

2672. Haleke-dawon-ketjil Амв. = Mecostylis acalyphoides Kurz, Nat. fam. der Euphorbiaceæ. Gr. De Molukken; boom.

2673. Halekij-lau-muri Амв. =Cla oxy lum ind i c u m Endl. (Zie No. 1268.)

2674. Halekij-laun-0eloe Amb. = Croton aromaticum Wlld. (Zie No. 1675.)

2675. Halekij-laut $\Lambda$ мв. $=\mathrm{Cla-}$ oxylum indicum Endl. (Zie No. 1268.)

2676. Halekij-meirah Амв. = A calypha bracteata Miq. (Zie No. 428.)

2677. Halekij-poetih $\mathrm{Am}_{\mathrm{B}}=\mathrm{Cl}$ a. oxylu m indicum End l. (Zie No. 1268.)

2678. Halerij Mor. = Halekij Амв.

2679. Haliem Iıam. $=\mathrm{Aquila-}$ ria malaccensis L a m., Nat. fam. der Thy melaceæ. Gr. Sumatra, Bangka, de Molukken; boom. Gebr. Deze boom levert een Aloëhout, Bois d'Aigle of Garo de Malacea genoemd, dat vroeger ook tot de tonisch-opwekkende geneesmid. delen werd gebracht, en nog als welrierend middel wordt gebrand en zeer gezocht is. Op Sumatra gebruikt men het even als dat van A q. A g a $110 \mathrm{ch} \mathrm{a} \mathrm{L}$.

2680. Halija Амв. $=\mathrm{Z}$ i n g i b c of $\mathrm{fic}$ in al e L. (Zie 253.)

2681. Hamberang $S=F i c u s$ n i ve a Bl., Nat. fam. der A r to c a rpeæ. Gr. Java; heester. Gebr. Den bast gebruikt men voor bindtouw; de jonge bladeren kunneu, bij gebrek, roor paardenvoeder dienen.

2682. Hamberang-babak $\mathrm{S} .=a$. Fic us fulva $R n w d t$, Nat. fam, als voren. Gr. Java, Sumatra, Bangka; boom $=b$. Ficus hirta Vhl. Gr. Java; heester.

2683. Hamberang-boddas $\mathrm{S}$. = Ficus elegans Hassk., Nat. fam. als voren. Gr. Java, Sumatra; boom. Gebr. 
Het melksap dient nien toe bij hrmaturie; de paarden houden zeer veel van deze bladeren, en verkiezen ze boven gras; zij werken buikzuiverend.

2684. Hamberang-boenjoer $\mathrm{S} .=a$. Fic us t r a chy c o m a M i ., Nat. fam. als voren. GR. Java; slingerplant. $=b$. $\mathrm{F}$ i c us a l b a $\mathrm{R}$ w d t. Gr. Java en Bangka; heester.

2685. Hambeerang-burrum $\mathrm{s} .=$ Ficus fulva $R$ wdt. var. rubrin c r vi a (Zie No. 2682a.)

2686. Hamberang-ketjil M. $=\mathrm{P}_{0}$ go notrophe flavidula Miq., Nat. fam. als voren. GR. Java; slingerplant.

2687. Hamberang-meirah M. =

F i c s f u l va R w dt. (Zie No. 2682a.) 2688. Hamberang-mienjak S. \& M. $=$ Ficus elegans Hassk. (Zie No. 2683.)

2689. Hamberang-sughang $\mathrm{S}$. = Ficus elegans $\mathrm{H}$ ass k.

2690. Hambiroeng $\mathrm{S} .=a$. Vernonia javanica D C. (Zie No. 1015b.) $=b$. Vernonia Blumeana D.C., Nat. fam., Gr. en Gebr. als $a$.

269l. Hamerang $S .=$ Firmiana c o lo r a t a RBr., Nat. fam. der Sterc u li a c e æ. Gr. Java, Sumatra, Borneo, enz.; boom. GEBR. Het hout bezigt men tot huisbouw; het is echter niet sterk en wordt licht door insekten aangetast.

2692. Hami Br. = Pangium e dule $R$ nwdt. (Zie No. 387.)

2693. Hampadoe-kajoe M. = Diospyros pyrrhocarpa Miq., Nat. fam der Ebenace r. Gr. Sumatra's W.knst; boom.

2694. Hampelas S. (Zie No. 304.)

2695. Hamperoe $\mathrm{S}$. = Bryonopsis leucocarpa Miq., Nat fam. der Cucurbit a ceæ. Gr. Java; éénjarig.

2696. Hamperoe-badak $\mathrm{S}$. $=a$. Tabern montana sphærocarpa Bl. (Zie No. 2055.) $=b$. Orchipeda f ctida Bl., Nat. fam. der A poc yn e æ. Gr. Java; hooge boom. GéBr. Het melksap van dezen boom bezigt men soms bij huidziekten; het hout heeft geen waarde. $=c$. L a sianthus tomentos u s Bl., Nat. fam. der R u bi a ce GR. Java en Sumatra; heester.

2697. Hamperoe - badak - leuwung S. $=$ Chasalia robusta Miq. Nat. fam. der Rubiacex. Gr. Java en Sumatra; boom. Gebr. Men wendt de fijngewreven bladeren aan op wonden van paardè, dic door het drukken der zadels zijn ontstaan.

2698. Hamperoe-bôgô S. = C e$\mathrm{ph}$ a ëlis stipula ce a Bl., Nat. fam. der Rubiaceæ. Gr. Java en Sumatra; kleine heester. GEBR De fijngewreven bladeren worden uitwendig aangewend bij eene huidziekte, sakit balas S. genaamd.

2699. Handaroessa S. = Gandaroessa S. \& M. (Zie No. 2405 en vollg.)

2700. Handeöng $\mathrm{S} .=a$. Abutilon sundaicum Bl, Nat. fam. der M alvaces. Gr. Java; éénjarig. $=b$. A b utiloi atropurpureum Bl., Nat. fam. dezelfde. Gr. Java; éénjarig. GEBr. Deze plant bevat veel slijm, is verzachtend inwikkelend en kan als zoodanig onze Malva en Althra goed vervangen. $=c$. Co m m e rsonia echinata Forst. (Zie No. 106.)

2701. Handiwoeng $\mathrm{S}$. $=\mathrm{Areca}$ Nibung Mart. (Zie No. 2310.)

2702. Handja-sôno S. of Handjehsomek $\mathrm{S}=$ Cocculus glaucescens Bl., Nat. fam. der M en ispermacere. GR. Java; sliugerplant.

2703. Handjeulieh $\mathrm{S} .=\mathrm{Coix} \mathrm{La-}$ cryma L. (Zie No. 1894.)

2704. Handullum $\mathrm{S}_{0}=$ Graptophyllum hortense Nees. (Zie No. 90) inet de drie variëteiten: boddas, burrum en heedjoh s. of album, rubrum en viride $\mathrm{H}$ assk.

2705. Hanggassan-boddas $\mathrm{S} .=\mathrm{A}$ momum maximum Rxb., Nat. fam. der Zingiberaceæ. Gr. Java; overblijvend. GEBR. Volgens Lindley zijn de zaden vau deze de vroegere grana paradisiaca. Op Java wendt men den wortel aan als kraamzuiverend middel; de bladeren en vruchten worden gegeten.

2706. Hanggassan-burrum $\mathrm{S}$. = A momum maximum R.xb., var. rubescens. (Zie rorig No.)

2707. Hanggassan-gedeh S. = A momum dealbatum Rxb., Nat. fam. als voren. Gr. Java; overblijvend. GEBr. De jonge bladeren eet men gekookt bij de rijst, ook nuttigt men de zaden, welke aangenaam zoet zijn.

2708. Hanggassan-lumboet $\mathrm{s}$. = Elettaria Cardamom um White., Nat. fam. als voren. GR. Java; overblijvend. GEßr. Men kauwt de aromatische zaden, om deu adem een aangenamen geur mede tc deelen.

2709. Hangi T. $=$ Alstonia scliolaris $\mathrm{R} . \mathrm{Br}$. Zie No. 2350.) 
2710. Hanile oӧa Амв. = Sterculia urceolata Sm. (Zie No. 1502.) 2i11. Hanjah $S_{.}=$Nauclea grandifolia D.C. (Zie No. 1870.)

2712. Hanjarak $S .=$ Strobilanthes glandulosa Bl. (Zie No. 2008.) 2713. Hanjawar S. = a. Ptychosperma Kühlii Miq. (Zie No. ]178b.) $=b$. Areca pumila Mart., Nat. fam. der Palmæ. Gr. Java en Sumatra; lage Palm. Gebr. De jonge, nog niet ontwikkelde bladeren eet men rauw en gekookt bij de rijst.

2714. Hanjehreh S. = Coix Iacryma L. (Zie No. 1894.)

2 115 . Hanjehreh-leutiek $\varepsilon=$ Coix Lacryma L., var. minor Hassk.

2716. Hanjoewang $S .=$ Calodracon $\mathrm{J}$ acquinii $\mathrm{Planch}$, var. rubens Hassk. (Zie No. 333a.)

2717. Hanjoewang-burrum $\mathrm{S}=\mathrm{C} a-$ lodracon Jacquinii Planch. var. atrosanguineum Hassk. (Zie No. 333a.)

2718. Hanjoewang-kassintoe $\mathrm{S}$. = a. Cordyline flexuosa Miq. en $b$. Cordyline Sieboldii Planch., Nat. fam. der A sparagineæ. Gr. Java; heesters. GEBr. Yan deze en volgende Hanjoewang- of Cordy line-soorten eet men dc jonge bladeren geroost of gekookt bij de rijst, vooral tegen slechten eetlust, indigestie of brakingen; zij smaken zoetachtig. Van de stammell maakt men wandelstokken, aan welke men een vcrsterkende kracht toeschrijft.

2719. Hanjoewang-kassintoeblang S. = Cordyline Sieboldii Planch (Zic vorig No.)

2720. Hanjoewang-kassintoe-toelies $\mathrm{S} .=a$. Cordyline flexuosa Miq. (Zie No. 2718) en $=b$. Cordyline m aculata Planch. Gr. Java en Suma. tra; heester. GEizR. als No. 2718.

2721. Hanjoewang-merak S. = Cordyline Rumphii Hassk. (Zie No. $337 a$.)

2722. Hanöa Амв. $=$ Mappa Tauaria Sprg. (Zie No. 2294b.)

2723. Hantap S. $=a$. Tetrameles rufinervis Miq., Nat. fam. der Datisceæ. Gr. Java; boom. $=b$. Sterculia urceolata Sm. (Zie No. 1502.) $=c$. Sterculia subpeltata $\mathrm{Bl}$. en = d. Sterculia rubiginosa Vent., Nat. fam. der Sterculiacer. Gr. Java en Suınatra; heesters. GEBr. Het hout der mceste Sterculia-soorten bezigt men voor haisbouw ; het is echter niet sterk, en wordt spoedig door witte mieren aangetast. De pitten worden gegeten, doch bij voorkeur geroosterd, daar zij anders duizeling veroorzaken.

2724. Hantap-badak $\mathrm{s}$. = S t e rculi a javanica R.Br. GR. Java; booni. GeBr. als No. $2723 c$ en $d$.

2725. Hantap-batoe $\mathrm{S}$. = Sterculia Blumei G. Don. Gr. Java, Sumatra en Borneo; hooge boom. $=b$. Stereulia lævis Wall Gr. Java; groote heester.

2726. Hantap-beäs $S .=S$ te r cuita grandiflora Vent. Gr. Java; boom.

2727. Hantap-burrum $\mathrm{S}$. $=\mathrm{S}$ terculia javanica R. Br. (Zie $\mathrm{N}_{0}$ 2724.)

2\%28. Hantap-hoelang S. $=a$. Sterculia urceolata Sm. (Zie No. 1502.) $=$ b. Sterculia Subpeltata Bl. (Zie No. $2723 c.)=c$. Sterculia javanica R.B r. (Zie No. 2724.) $=d$. Firmiana colorata R Br. (Zie No. 2691).

2729. Hantap-kajoe-loemoet J. cn

2730. Hantap-passang $\mathrm{S}$. = Sterculia nobilis Sm. Gr. Java, Sumatra; boomachtige heester. GEBR. (Zie No. 2723c.)

2731. Hantap-ratoe S. = Sterculia Blumei G. Don. (Zie No. 2725a.)

2732. Han-soi Cн. Bо. = A maranthus oleraceus L. (Zie No. $836 d$ ) 2733. Haöëan S. (Zie hahaoewan S. Nos. $2654 / 5)$.

2734. Hapoöng S. = Dodon ca a ngustifolia Blanco. (Zie No. 2218.)

2735. Haraghag $\mathrm{S} .=\mathrm{P}$ a $\mathrm{ud}$ a $\mathrm{n}$ u $\mathrm{s}$ moschat us $R m p h$. , Nat. fam. der Pan dan ex. Gr. Java, de Mo'ukken; boomachtix, Gebr. Men bezigt de welrickende bladeren voor vlechtw crk, doch roornamelijk tot inpakken van arensuiker.

2736. Harawaij $\mathrm{S} .=a$. Procr is lat ifolia Bl., Nat. fam. der U. $t$ ic a c e æ. Gr. Java; heester. $=b$. B o e hmeri a javanic a H as sk., Nat. fam. dezelfde. Gr. Java; heester.

2737. Harawaij-awehweh $\mathrm{S}$. = Boehmeria palmata Hassk., Nat fam. als voren. Gr. Java; heester.

2738. Harawaij-lalakki S. = B o ehmeria nivea Ga ud. (Zie No. 2387.) 2739. Harendong $\mathrm{S} .=\alpha$. A r disia purpurea $\mathrm{Rnwdt}$. (Zie No. 1582.) $=b$. A rdis i a s e cios a Bl., Nat. fam. der M y rsineæ. Gr. Java; groote heester. $=c . R$ ho dom y rtu s to mentos a I).C., Nat. fam. der M yr- 
ta c eæ. Gr. Op alle Sunda-eilanden; groote heester. GEBR. Veelal als sierplant in tuinen; de bessen zijn eetbaar en vooral door kinderen gezocht. $=d$. M e la sto $\mathrm{m} \mathrm{a} \mathrm{B} \mathrm{rm}$. de meeste soorten. $=e$. Medinilla verrucosa Bl., Nat. fam. der Melas to m a c æ. Gr. Java; heester.

2740. Harendong-aroij $\mathrm{S} .=a$. Marumia muscosa Bl., (Zie No. 495.) $=$ b. Creochiton bibrace a $\mathrm{t}$ a B l., Nat. fam. der $\mathbf{M}$ e las t o$\mathrm{ma} \mathrm{c} \mathrm{ex.} \mathrm{Gr.} \mathrm{Java;} \mathrm{slingerplant.}=c$. Pogonanthera pulverulenta B l., Nat. fam. als $b$. Gr. Java; slingerplant.

2741. Harendong-aroij-boddas $S_{.}=$ Dis soch at a gasilis Bl., Nat. fam. als voren. Gr. Java, Sumatra, Borneo; slingerplant.

2742. Harendong-badak $\mathrm{S} .=a$. Il e lastom a sanguineum Bl., (Zie No. 2260.) $=$. . Marumia muscosa Bl. (Zie No. 495.)

2743. Harendong-boeloe $\mathrm{S} .=\mathrm{Ma}$ r u mia m u s cos a B l. (Zie No. 495.)

2744. Harendong-dioek $\mathrm{S} .=a$. Pogonanthera pulverulenta B 1. (Zie No. 27406.) = b. Medinilla cras sifolia B l., Nat. fam. der M elas t o m a c eæ. Gr. Java; heester.

2745. Harendong-goerong $\mathrm{S} .=a$. M. edinilla e ximia B l., Nat. fam. als boven. Gr. Java, Sumatra; heester. $=\bar{b}$. M elastom a polyanthum B 1. (Zie No. 110 ) $=c$. M e las to m a lanuginosum Bl. $=d$. M el. setigerum Bl., en $=e$. M el. sylvat i c u m B l. Gr. Java; heesters.

2746. Harendong-mengandoe $\mathrm{S}$. = a. Ml ed inilla hy pericifolia Bl., Nat. fam. der $\mathrm{Ml}$ e $\mathrm{l}$ a s t o m a c e . Gr. Java; parasiet. $=b$. $\mathrm{Es} \mathrm{ch} \mathrm{y} \mathrm{a} \mathrm{n} \mathrm{th} \mathrm{u} \mathrm{s}$ lo $\mathrm{n} g$ if $10 \mathrm{r}$ a D. C., Nat. fam. der Gesn e ri a c e æ. Gn. Java; overblijvend. = c. Proseephalium javanicum K orth., Nat. fam. der $\mathrm{Rub}$ i a c e GR. Java; parasiet.

2747. Harendong-sabrang $\mathrm{S}$. = Rhodomyrtus tomentosa D. C. (Zie No. $2739 c$.)

274. Harendong-tangkoerak S. = $\mathrm{Pach}$ y c entria co n s tricta B l., Nat. fam. der M elastom a cea. Gr. Java de Molukken; heester.

2749. Harendong-tapok S. $=$ M edinilla javanensis Bl., Nat. fam. als voren. GR. Java; heester. GkBr. De bessen zijn zoet en worden gegeten.

2750. Harenoh $\mathrm{S}$. $=\mathrm{Grew}$ i a $0 \mathrm{p}$ positifoli a Ham. (Zie No. 2284b.)

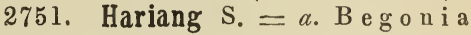
L., $\mathrm{S}$ pecies diversæ. $=b$. C i ss u s quadrang u laris 1., Nat. fam. der A m pelid e æ. Gr. Door geheel Ned-Indië; slingerplant. GkBr. De inlarders gebruiken een af kooksel der stengels, met tamarinde, uitwendig tegen rheumatismus; volgens $\mathrm{B} \mathrm{l}$ a n c o wendt men deze plant ook tegen slangenbeten aan.

2752. Hariang-aroij $\mathrm{S} .=\mathrm{C}$ issus repens Lam. (Zie No. 438.)

2753. Hariang-boeloe $\mathrm{S}$. = Platycentrum robustum Miq. (Zie No. 730.)

2754. Hariang-burrum $\mathrm{S}$. $=\mathrm{M}$ i tscherlichia coriacea Bl., Nat. fam. der B e g o n i a c e æ. Gr. Java, overblijvend.

2755. Hariang-dioek S. $=a$. $\mathrm{D}$ iploclini um longifoli um Miq. en $=6$. Dip. re pand u $\mathrm{ml}$., Nat. fam. der B e g o n i c eæ. Gr. Java; overblijvende planten.

2756. Hariang-doendoek S. $=\mathrm{Di}$ ploclini um longifoli u m Miq. (Zie voren.)

2757. Hariang-jentjang $\mathrm{s} .=\mathrm{Be}-$ gonia lepida Bl. (Zie No. 1245.)

2758 Hariang-limna $\mathrm{S} .=\mathrm{D}$ i p 10 c lin in $\mathrm{m} \mathrm{nb}$ eros um M iq. (Zie No. 1054.)

2759. Hariang-ojot $\mathrm{S}$. $=\mathrm{C}$ is s u s d i s color B l (Zie No. 468.)

2760, Hariang-peutjang $\mathrm{S} .=\mathrm{D} \mathrm{i}-$ ploclini um tu berosum Mi q. (Zie No. 1054.)

2761. Harikoekoen. S. $=\alpha$. $\mathrm{Pte}$ rosperm u suberifolium Willd. (Zie No. 857c.) $=$ b. Schoutenia o v a t a K th., Nat. fam. der Tili a c e $x$. Gr. Java; hooge boom, die een hard hout levert, dat voor timmerhout gesshikt is. = c. Cyclostemon mucronatum Bl., Nat. fam. der Euphorbiaccæ. Gr. Java; hooge boom; het hout is geschikt voor huisbouw.

2762. Haringin (Harienghien) $\mathrm{S} .=$ a. Cassia montana Heyne, Nat. fam. der Papilionacea. Gr. Java; groote heester. $=6$. Cassia timorensis D.C. Gr. Java, Sumatra, Timor; heestcr. = c. Cassia tomentosa L.fs. Gr. Java; heester. $=d$. Cassia suffruticosa 
Koen. Gr. Java; éénjarig. Gebr. Het hout dezer heesters is zeer taai, doch van geringen omvang en wordt daarom veel voor stelen van gereedschappen gebruikt.

2763. Hari-pingkoe S. $=$ Epich aris sericea Bl., Nat. fam. der Meliaceæ. Gr. Java; hooge boom. Gebr. Het hout levert een grof, sterk timmerhout.

2764. Haroe Амв. $=\mathrm{H} \mathrm{ibiscus}$ tiliaceus L. (Paritiam tiliaceum St. Hil.), Nat. fam. der Malvaceæ. GR. Door geheel Indië; matig hooge boom. GEBr. Een af kooksel der wortels geeft men als verkoelend middel tegen koortsen. Den vezeligen bast verwerkt men tot touwwerk. Het hout is licht, doch sterk, zeer geschikt voor huisborw, stijlen, buffelkarren, wielen, molens, zadels, enz.; $\mathrm{B} \mathrm{I}$ a n $\mathrm{c} 0$ kent er een braakwekkend vermogen aan toe. Alle deelen der plant, vooral de bladeren en bloemknoppen, bezitten een overvloedig zacht slijm, hetwelk dat onzer Malva gevoegelijk kan vervangen. Het sap der bladeren bezigt men als oogwater voor kinderen; een af kooksel daarvan geeft men veel tegen urathroblenorrhoex. Op de Philippijnen trekt men de bloemen op azijn af, en gebruikt deze uitwendig tegen oorpijnen.

2765. Haroe-laijn Амв. $=\mathrm{Thes}-$ pesia macrophylla Bl. (Zie No. 854.)

2766. Harrassas (ook Harras) $\mathrm{S} .=$ Vitex pubescens Vhl. (Zie No. $430 c$.)

2767 Harrassas-gedeh S. $=\mathrm{P}$ a n d anus cari cosus Rmph., Nat. iam. der P'andaneæ. Gr. Java en de Molukken; heester. Gebr. Men vervaardigt van de bladeren een grof soort van matten.

2768. Harrassas-lalakki S. $=a . \mathrm{H} \mathrm{y-}$ polythrum myrianthum Miq., Nat. fam. der Cyperaceæ. Gr. Java; overjarig. Gebr. Van deze rietsoort vervaardigt men een grof soort van matten en hoeden. b. Hypolytrum latifolium L. b. Rich. Nat. fam. GeBk. Als voren. Gr. Sumatra.

2769. Harrassas-leutiek S. $=a$. Pandanus humilis $R m p h$. (Zie No. 1129.) $=$ b. Pandanus Zippelianus Kurz. Gr. Java; hooge boom.

2770. Harrassas-tjaai S. $=$ a. P a ndanophyllum paiustre Hassk. en $=b$. Scirpodendron pandani. forme Zipp., Nat. fam. der Cyperaсеæ. Gr. Java; overjarige planten. GEbr. Als voren.

2771. Harreu-eus $S .=R u b u s ~ L$.
2772. Harreu-eus-badak $\mathrm{S} .=\mathrm{Ru}$ bus al cexfolius Poir. (Zie No. 2446) en Rubus moluccanus L. (Zie No. 139.)

2773. Harreu-eus-leutiek s. = Neillia thyrsiflora Don., Nat. fam. der Neilliaceæ. Gr. Java; heester.

2774. Harrea-eus-minjak S. \& J. $=a$. Rubus elongatus $\mathrm{Sm}$. en $=$ b. Rubus glomeratus Bl., Nat. fam. der Rosaceæ; heesters. Gebr. Het sap der jonge loten bezigt men als oogwater bij jonge kinderen, meenende daardoor het scherper zien te bevorderen; de vruchten worden gegeten.

2775. Harruga $\mathrm{S} .=a$. Bidens W allichii D. C. (Zie No. 68a.) $=b$. Bidens leucantha Wlld.; Nat. fam. der Compositæ. Gr. Java: éénjarig; een in tuinen zeer gevreesd onkruid.

2776. Hasseum S. (Zie Assam M.), de Tamarinde.

2777. Hataul-lau-muri Амв. = Calophyllum spectabile Wlld. (Zie No. 1224.)

2778. Hataul of Hatuala Aмв. = Calophyllum in ophyllum L. (Zie No. 1139.)

2779. Hate-bessi $\mathrm{T} .=a . \mathrm{Black}$ wellia fœtida Wall, Nat. fam. der Homalinex. Gr. Celebes en de Molukken; hooge boom. Gebr. Deze boom levert een deugdzaam timmerhout, geschikt voor balken, stijlen en kromhouten in vaartuigen. $=b . \mathrm{Nania} \mathrm{ver} \mathrm{a}$ M i q., Nat. fam. der M y rta c e æ. Gr. Celebes en de Molukken; hooge boom. GeBr. Deze boom levert een zeer zwaar, vast en hard hout, dat door insecten bijna niet wordt aangetast, en zeer geschikt is voor bouwhout, palen van zeehoofden, roeren voor schepen, enz.; het levert goede houtskolen. Den samentrekkenden bast geeft men tegen diarrhoea, dysenterie en witten vlued. 2780. Hate-boelan $\mathrm{T} .=\mathrm{P}$ is on i a a l b a S p a n. (Zie No. 120b.)

2781. Hate-doffal-madoro $T$. en

2782. Hate-fika-fika-ngadoe T. = Melanolepis? calcosa Miq. (Zie No. 37.)

2783. Hate-java $\mathrm{T}$. $=$ Urostigin a $\mathrm{R} \mathrm{umphii} M$ iq. (Zie No. 103.)

2784. Hate-kelang $\mathrm{T}$. $=\mathrm{Mela}$ le uca $I$ e u c a dendron L. (Zie No. $120 a$.)

2785. Hate-padeda $\mathrm{T}$. $=$ Ar ali is javanica Miq. (Zie No. 909a.) 
2786. Hate-sasoae $\mathrm{T} .=\mathrm{B}$ a s s i a long if oli a L a m. (Zie No. 38.)

2787. Hategou $\mathrm{T} .=\mathrm{Dendrolo-}$ bium ambellatum W. \& A. (Zie No. $1683 a$.)

2788. Hatoe-ehu Амв., en

2789. Hatoe-hanal Aмв., en

2790. Hatoe-kallan Амв. = Dip loclinium tuberosnm Miq. (Zie No. 1054.)

2791. Hatta-bëas $\mathrm{S} .=\mathbf{L y g}$ od iu m m icrophyll a m R.Br. (Zie No. 2604.)

2792. Hatta-gedeh $\mathrm{S} .=\mathrm{Lygo-}$ di um circinatum $S$ w., Nat. fam. der'S c h i zæa c æ. Gr. Java en de Molukken; slingerplant. GEBR. Men gebruikt het loof even als het Venushaar (A d ianthum capillus L.) Op Java eet men het als gr oente, bezigt het uitwendig bij verschillende wonden en kneuzingen en drinkt een aftreksel tegen moeilijke urinelozing. De stengels leveren een sterk touw.

2793. Hatta-lentiek S. = L y g odi a m m i c roph y llu m R. B r. (Zie No. 2604.)

2794. Hattau-ui Амв. = Calophyllum inophyllum L. (Zie No. 1139.)

2795. Hau-ettoet $A$ м. $=\mathrm{P} \approx \mathrm{d} \mathrm{e}-$ $\mathrm{r}$ ia foetida L. (Zie No. 1739b.)

2796. Haüer $\mathrm{S} .=a$. Bambusaceæ divers $x .=b$. Vitex L ou reirii H. \& A., Nat. fam. der Verben a c e Gr. Java; hooge boom.

2797. Haul-amoeret AMe. $=$ A ctinodaphne Rumphii Bl. (Zie No. 55.)

2798. Haun $\mathrm{Br} .=\mathrm{Metr}$ exyl on el at u m Mart. (Zie No. J131.)

2799. Haun-laijmoeloen Амв. en

2800. Haun-panteij Амв. $=P_{\text {a }}$ dan a s d u b i us Sprg. (Zie No. 1673b.)

2801. Haun-tä̈n Амв. $=\mathrm{P}$ a n d anus ceramicus $R \mathrm{mph}$. (Zie No. 1828 )

2802. Haun-wassi Амв. $=P$ a ndan us Bagea M iq. (Zie No. 1673a.) 2803. Hawalinjan S. \& J. = T y$\mathrm{pha}$ angustifolia L. (Zie No. 738$.

2804. Hёa-kawa Амв. $=\mathrm{C}$ a lamus equestris Wlld, Nat. fam. der P a lmæ. Gr. De Molukken; slingerplant. Gribr. De stengels gebruikt men om te binden en voor zweepen; van de bladeren kookt men een soort van sago Kawa genaamd.

2S05. Hea-moeli $\mathrm{Am}$. $=\mathrm{C}$ a s s i a j a $\nabla$ a n i a L. (Zie No. 1025.)

2806. Heas $\mathrm{S} .=\mathrm{J}$ a m b o $\mathrm{s} æ \mathrm{Rmph}$. $\mathrm{S} p$ eci es diver $\mathrm{s}$.

2807. Heët $А м в .=C o m m e l y n a$ benghalensis I. (Zie No. 2549.)

2808. Heli of Heri Амв. $=a$. D io s corea a lata L., Nat. fam. der Di o s c orineæ. Gr. Java, de Molukken; slingerplant. GевR. De wortelknollen, waarvan vele verscheidenheden voorkomen, zijn eetbaar en een zeer gezocht voedingsmiddel. $=b$. Dioscorea $\nabla$ ulga$\mathrm{r}$ is Miq. GR. De Molukken; slingerplant. GEBR. De wortelknollen zijn als dagelijksch voedsel zeer gezocht en gezoud, vooral wanneer ze gekookt of geroost genuttigd worden.

2809. Helleloh-dawon S. = A mo$\mathrm{mum}$ villosum I,our. (Zie No. 385.)

2810. Hena T. $=\mathrm{A} \mathrm{r} \mathrm{e} \mathrm{c} \mathrm{a} \mathrm{C} \mathrm{a} \mathrm{t} \mathrm{e} \mathrm{c} \mathrm{h} \mathrm{u}$ L. (Zie No. 1286.)

2811 Hena-hena $\mathrm{T} .=\mathrm{C}$ a l y $\mathrm{ptr}$ calyx spicatus Bl, Nat. fam. der P a l mæ. Gr. Java, Bangka, de Molukken; hooge Paln. GEBR. Het tamelijk vaste hout bezigt men voor huisbouw; de vruchten worden soms gekauwd, in plaats van pinang. of arecanoten.

2812. Henna $M .=L$ aws o nia a 1 b a L a m. (Zie No. 1747.).

2813. Hentjah $\mathrm{S} .=a$. $\mathrm{R}$ otle e a a cumin a ta Jss., Nat. fam. der Euph orb i a c e $x$. Gr. Java; heester. $=b$. MI ela nolepis multiglandulosa Rchb. \& $\mathrm{Z}$ oll., Nat. fam. dezelfde. Gr. Java : boom.

2814. Heri Амв. (Zie Heli Амв.)

2815. Heri-assapin AмB. en

2816. Heri-makilaoen Aмв. en

2817. Heri-malona Aмв., benevens.

2818. Heri-manoe Амв. = Dioscorea alata L. (Zie No. 2808 a.)

2819 Hermang $\mathrm{S}$. = Cratoxylon Hornschuchii Bl., Nat. fam. der Hypericiner. Gr. Java, boom. Grbr. Het hout levert zeer goede houtskolen; deze plant is zeer samentrekkend en bezit pisdrijvende eigenschappen.

2820. Heuer-djamoedjoe $\mathrm{S} .=\mathrm{P}_{0-}$ d ocarpus cupressin a RBr., Nat. fam. der Pod oc ardex. Gr. Java en Sumatra; hooge boom. GEBR. Het hout is een zeer goed meubelhout 
2821. Hila AмB. = Alocasia ma. crorrhiza Schott. (Zie No. 1239.)

2822. Hinam $\mathrm{Cr}_{\mathrm{r}}=\mathrm{M}$ a p a Tanaria Sprg. (Zie No. 22946.)

2823. Hinei BR. $=$ Hopea sel anic a Roxb. (Zie No. 824.)

2824. Hinoenang M. $=\mathrm{Cordia}$ subdentata Miq., Nat fam. derCordi a ceæ. Gr. Sumatra's Westkust; boom.

2825 Hiroeng $\mathrm{S} .=\mathrm{A} \mathrm{g}$ a $\mathrm{th}$ is a nthes javanica Bl., Nat. fam. der Combreta c eæ. Gr. Java; hooge boom. Gebr. Het stcrke hout dient voor huisbouw en planken; de zure vruchten worden gegeten, doch zijn niet lekker.

2826. Hissa Амв. $=$ Andropogon Schoenanthus L. (Zie No. 2523.)

2827. Hitjoe J. $=$ Kerria ja ponica D. C, Nat. fam. der Rosaceæ. Gr. Java, in tuinen, uit Japan overgebracht; sierplant; kleine heester.

2828. Hitta-oessi-laijn Амв. $=\mathrm{Z}$ i z yphus Horsfieldii Miq. (Zie No. 488.) 2829. Hoea $S .=B a t a t a s$ edulis Chois. (Zie No. 635.)

2830. Hoëa (ook Hoä) Aмe, = A rec a Catechu L. (Zie No. 1286.)

2831. Hoeä-alang Амв. en

2832. Hoeä-ewan Амв. $=\mathrm{C}$ al y ptrocalyx spicatus B l. (Zie No. 2811.)

2833. Hoeä-keker Амв. = A re c a $\mathrm{gland}$ if orm is Houtt. (Zie No. 2267.)

2834. Hoeä-nivel AмB. =a. Caly ptrocalyx spicatus Bl. (Zie No. 2811.) $=b$. Ptychosperma? Calapparia Miq., Nat. fam. der Palmæ Gr. Celebes en de Molukken; hooge Palm. Gebr. Men gebruikt de vruchten, echter meer voor een niet bekend geneeskundig, dan wel voor een huishoudelijk doel.

2835. Hoeäs $\mathrm{S}$. $=\mathrm{Jambos}$ a $\mathrm{v}$ rens Miq. (Zie No. 2649.)

2836. Hoeboel-katjoe S. $=\mathrm{Vac}$ cinium varingiæfolium. Miq., Nat. fam. der Vaccincæ. Gr. Java; hester.

2837. Hoeda $\mathrm{T}$. $=$ Metroxylon Rumphii Mart. (Zie No. 279.)

2338. Hoëh S. (ook Hoe S., eigenlijk Hoih S.) is de algemeene benaming voor Rottan-soorten.

2839. Hoëh-baloekboek S. = Dæmonorops oblongus Mart., Nat. fam. der Palm $æ$. Gr. Java; slingerplant. GEBr. Deze levert eene bindrotting, die nict sterk is; de jonge spitsen worden, in asch gebraden, gegeten.

2840. Hoëh-boeboeai S. of H. boe-

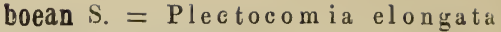
Bl. (Zie No. 1298.)

2841. Hoëh-boeboet S. $=\mathrm{C}$ a l a. mus Reinwardtii Bl, Nat. fam. der Palmæ. Gr. Java; slingerplant.

2842. Hoë-bogo S. of H-boggoh S. = Calamus adspersus Bl., Nat. fam. dezelfde. Gr. Java, Borneo; slingerplant.

2843. Hoëh-gelang $\mathrm{S}$. $=\mathrm{I})$ æ $\mathrm{m} \mathrm{o-}$ norops crinitus Bl., Nat. fam. als voren. GR. Borneo, Java, slingerplant. GEBr. Volgens $H$ e n r i c i levert deze plant de beste soort van Borneosche-rotting op.

2844. Hoëh-goerong S. en

2845. Hoëh-gorot S. = a. C a lamush eteroideus Bl., en $=b$. C. p a 11 e n s B l, Nat. fam. als voreil. Gr. Java; slingerplanten. Gebr. Deze beide planten leveren eene goede bindrotting.

284.6. Hoëh-kassoer S. (ook H-kessoer of H-kissoer S.) cn

2847. Hoëh-kidang $3 .=\mathrm{C}$ a la$\mathrm{m}$ u s or natus Bl, Nat. fam.der Pal$m æ$. Gr. 'ava en Sumatra; slingerplant. GEBr. Deze plant levert een zeer dikke rottansoort, die veelal over rivieren gespannen wordt, om er schuiten aan over te halen; als bindrotting gcbruikt, is zij niet sterk genoeg; de wortel, in water geweekt en geklopt, wordt dikwijls door kraamvrouwen, als pijnstillend middel, gedronken; de zure vruchten worden gegeter en zijn aangenaam verkoelend.

2848. Hoëh-korrot S. $=a \cdot \mathrm{Ca}$ $\mathrm{l}$ a mus heteroideus Bl. en $=b$. C. pallens Bl. (Zie No. 2845b.) =c. Ca lamus viminal is $R$ nwd t. Nat. fam. als boven. GR. Celebes; slingerplant. Gebr. Zij levert eene goede rottansoort, die als rotan-djawa reel in den handel komt.

2849. Hoëh-leilan S. en

2850. Hoëh-lielien S. = a. Calanus heteroid e us Bl. (Zie No. 2845a.) $=$ b. Calamus melanoloma Mart., Nat. fam. als voren. GR, Java; slingerplant. Gebr. Deze plant levert een goede soort van rottan, geschikt voor vlecht-en ook voor bindwerk.

2851. Hoëh-leles S. (ook H-leuleus S. en H-lullus S.) $=$ Calamus asperimus Bl, Nat. fam. der Palmæ. Gr. Java; slingerplant. GeBr. Deze plant levert eene zeer sterke, volgens sommigen de sterkste, rottansoort, zeer taai en buigzaam, uitmuntend geschikt voor vlecht- en bindwerk. 
2S52. Hoëh-marow BK. = B romhe a dia Finlaysonian a Lndl., Nat. fam. der Orchideæ. Gr. Bangka. Sumatra; overjarig.

2853. Hoëh-moeka S. $=a . \mathrm{Cala}$ mus heteroideusBl. var spisus $M$ i q. (Zie No. 2845a.) $=b . \mathrm{C}$ a $\mathrm{lam} \mathrm{u} \mathrm{s}$ c il i a $r$ is Bl., Nat, fam. der P a l mæ Gr. Java, Sumatra en Borneo; slingerplant GEBR. Zij levert een goede bindrotting.

2854. Hoëh-omas $\mathrm{S} .=a \cdot \mathrm{Cala}$ mus equestris Wlld. (Zie No. 2804.) $=b$. Calamus $\mathrm{javens}$ is B l. GR. Java en Sumatra, deze slingerplant levert een goede bindrotting. = c. Ca lamus spectabilis B l. Gr. Java; slingerplant GeBr. Deze plant levert een zeer gezochte, dunne, lange en zeer buigzame rottingsoort.

2855. Hoëh-paësan of paisan $\mathrm{S} .=$ Ceratolobus gla ue seens Bl. Nat. fam. der $\mathrm{P}$ a $1 \mathrm{~m} æ$. Gr. Java; slingerplant. G $\Xi \mathrm{BR}$. Deze dient in plaats van touw bij huisbouw.

2856. Hoëh-pahit S. $=\mathrm{Cal}$ a m u s c il i a ris Bl. (Zie No. 2853b.)

2857. Hoëh-pella $\mathrm{S} .=a$. Ceratolobus rudentum Lour., Nat. fam. der P a lmæ. Gr. Java; slingerplant. Gebr. Volgens $\mathrm{H}$ a s s k a rl levert deze soort geen sterk touwwerk; de jonge spitsen worden rauw of gekookt gegeten; zij zijn echter eenigzins wrang. $=b$. D)monorops accedens Bl., Nat., fam. als voren. Gr. Java en Sumatra; slingerplant. GEBR. De stengels leveren een zeer bruikbare soort van rotting, de jonge spitsen worden rauw of gekookt gegeten; de vruchten zweeten een geringe hoeveelheid drakenbloed uit, 't welk de inlanders bezigen om er kleine voorwerpen mede rood te verven.

2858. Hoëh-perlan S. of H. perlas $\mathrm{S} .=\mathrm{C}$ al a m u $\mathrm{gla}$ a cescens Bl., Nat. fam. dezelfde. Gr. Borneo in vochtige wouden; slingerplant. GEBr. Deze rotting is geschikt voor zweepen en voor bindwerk onder water.

2859. Hoëh-sampang $\mathrm{S} .=a \cdot \mathrm{C}$ ala mus rhomboideus Bl., Nat. fam. als voren. Gr. Java, Sumatra en Borneo; slingerplant. Geir. Deze plant levert voortreffelijke en taaie bindrotting, zeer geschikt voor vlechtwerk en zwaar touw. $=b$. Korthalsi a robusta B l., Nat. fam. als voren. Gr. Als boven.
GEBR. De stengels dezer slingerplant zijn geschikt voor bindtouw.

2860. Hoëh-seel S. of

2861. Hoëh-sellang $\mathrm{S} .=a . \mathrm{D} x-$ monorops a c cedens Bl., (Zie No. 28576 .) $=b$. Dæmonorops melan o c hæt e s B l., Nat. fam. als voren. Gr. Java; slingerplant. Gebr. Deze plant levert een dun, zeer lang en sterk touwwerk; de jonge toppen eet men bij de rijst; de oude bladeren gebruikt men tot het dekken van huizen. $=c$. Dæmonorops $r u b$ e $\mathrm{M}$ art. Gr. Java; slin. gerplant, GEBR. Waarschijnlijk gelijk aan dat der $\mathrm{C}$ a l a mus or a tus Bl. (Zie No. 2847.)

2862. Hoëh-segeh $\mathrm{S}$. = Calamus h e teroideus Bl., var. refract us. (Zie No. 2845a.)

2863. Hoëh-setie S. of H.-soettie $\mathrm{S} .=a$. 1) monorops r u ber B l. (Zie No. 2861c.) $=b$. C a l a m u $\mathrm{s}$ orn a t u s B l. (Zie No. 2847.

2864. Hoëh-tertas S. of

2865. Hoë-trattas S. en

2866. Hoë-tretas $\mathrm{S} .=\alpha$. C a lam u s heteroideus B l., var. proc e rus. (Zie No. 2845a.) $=b$. Dæmonoropsoblongus Mart. (Zie No, 2839.) $=c$. Dæmonorops platyac a $\mathrm{t}$ h u $\mathrm{s}$ Mart., Nat. fam. der Pal$\mathrm{m}$ æ. Gr. Java en elders; slingerplant.

2867. Hoëh-tjatjing S. $=a$. C a$1 \mathrm{a} \mathrm{mu} \mathrm{s}$ ciliaris B l. (Zie No. 2853b.) $=b$. Cala m s heteroideus Bl. v a r. (Zie No. 2845a.)

2868. Hoëh-walat $\mathrm{S}$. $=\mathrm{C}$ alamus cæsius Bl., Nat. fam. der Palmæ. Gr. Java, Sumatra, Borneo; slingerplant. GEBR. Deze dunne, lange, fijne en glanzende rotting is zeer geschikt voor bindwerk en tot het vervaardigen van fijne vloermatten.

2869. Hoei S. of Huwi S., een algemeene benaming voor aardappelen, aardknollen of yamswortels

2870. Hoei-apas S. = Dioscorea bulbifera L (Zie No. 4.)

287i. Hoei-badak S. $=$ Dioscorea spiculata Bl,, Nat. fam. der Dioscoriner. Gr. Java en de Mlolukken; slingerplant. Geír. Men eet de knollen gekookt, zij hebben een zeer aangenamen smaak.

2872. Hoei-dangdur $\mathrm{S} .=\mathrm{J}$ a $\mathrm{n}$ iph a M a nihot H. B. \& K., Nat. fam. der Euph o rbi aceæ. Gr. Door geheel Ned.Indië in tuinen; heester. GEBR. Deze plant 
is als kultuurplant zeer bekend, wegens de bereiding der Cassave of Maniokka. Op Java eet men de jonge bladeren als groente, houdt men de gekookte of gebraden wortels voor een aangename spijs, en geeft men de fijngesneden bladeren, gemengd met wat vruchten der Arenpalm en zemelen, aan paarden als wormdrijvend middel.

2873. Hoei-gadong S. $=D$ ioscorea hirsuta Bl. (Zie No. 475.)

2874. Hoei-kawojang S. $=\mathrm{D}$ i o scorea aculeata L. (Zie No. 1189.)

2875. Hoei-lielien S. $=$ Di oscor e a a lata L. (Zie 2808a.)

2876. Hoei-oepas $\mathrm{S}_{0}=$ Dioscorea bulbifera I. (Zie No. 4.)

2877. Hoei.poetoeng $\mathrm{S} .=\mathrm{Di}$ ios. co rea alata L. (Zie No. 2908a)

2878. Hoei-sawoet $\mathrm{S} .=a$. 1) i o scorea pentaphylla L. (Zie No. 5.) $=$ b. Dioscorea mollissima Bl. Gr. Noesa-kambangan; slingerplant. GEBR. Ook deze plant levert eetbare knollen.

2879. Hoei-sawoet-djahej $S=D$ i o scorea triphylla L., Nat. fam. der J i o s c orineæ. GR. Java; slingerplant. GEBR. Deze groote knol is zeer giftig; hij wordt echter eetbaar na langen tijd in water geweekt en gekookt te zijn.

2880. Hoei-tjekker S. (Zie vorig No.)

2881. Hoei-tjoeroek $\mathrm{S}_{.}=a$. D i o scorea filiform is Bl. (Zie No. 499.)

$=b$. Dioscorea pubera Bl. Gr. Jara en de Molukken;'slingerplant.

2882. Hoei-toedoeng S. $=a$. Dioscorea pubera Bl. (Zie No. 2881 $b$ ) = b. Hipocratea indica Wlld. (Zie No. $485 a$.)

2883. Hooi-trobong S. = Dioscorea aculeata $L$. (Zie No. 1189.)

2884. Hoelit-tanga Sum. $\mathrm{W}_{\mathrm{K}}$. $=$ Ceriops lucida Miq., Nat. fam. der Rhizophoreæ. Gr. Sumatra Bangka; heester.

2885. Hoelong of Hoerong Амв. = Lept ospermum a mboinense Bl; Nat. fam. der Myrtaceæ. Gr. De Molukken: bonm. GEer. Deze boom vindt men dikwijls als sieraad in tuinen; men bezigt het hout voor daksparren en voor stelen van verschillende gereedschappen.

2886. Hoenjoor-boeöet $\mathrm{S} .=\mathrm{K}$ ad. sura scandens L. (Zie No. 5016.)

2887. Hoenie $S .=$ Antidesma Bunias Sprg. (Zie No. 1425.)

2888. Hoenie-passier S. $=$ Anti- desma montanum Bl., Nat. fam. der Antidesmeæ. Gr. Java ell de Philippijnen; groote heester.

2889. Hoentje S. (Zie No. 2970.)

2890. Hoerek Bv. = Evia acida Bl., Nat. fam. der Anacardiacex Gr. Door den yeheelen Archipel in het wild en in tuinen; hooge boom. GeBr. Het hout van dezen boom is hard en wordt als bouwhout benuitigả. De zoetzure vruchten zijn aangenaam om te eten en verkoelend; zij zullen bij dysenterie heilzaam zijn, doch bevatten een giftige pit. Op de Zuidzee-eilanden bezigt men ze tegen galachtige aandoeningen en obstruktiën; men kent er aldaar eene antiseptische en ontlastingbevorderende kracht aan toe.

2891. Hoerip-tjaai S. = Strobilanthes crispa Bl.. (Zie No. 2557.)

2892. Hoeroe $S$. is een algemeene naam voor planten of boomen, voornanelijk uit de famililie der Laurineæ, die meest allen een goed bouwhout leveren.

5893. Hoeroe S. = a. Lepidadenia Wightiaana Nees, variet, Nat. fam. der La urineæ. GR. Java; boom. Deze boom levert een goed timmerhout; de zoete bessen worden gegeten; uit de zaden verkrijgt men een plantaardige was, tangkallak genaamd, waarvan men kaarsen makt. = b. Daphnidium cæsi um $\mathrm{N}$ e e s. Nat. fam. als $a$. Gr. Java en Sumatra; boom.

2894. Hoeroe-batoo S. $=a . \mathrm{Sch}$ im a W allich i i $\mathrm{Ch}$ o is., Nat. fam. der C a melli a c e $æ$ Gr. De Lampongs; hooge boom. Gerr. Deze boom levert een sterk bouwhout. $=6$. Actin od aphne javanica Miq. $=c$. Phøbe? cuspidata Bl. $=d$. Polyadenia poly antha Nees en $=e$. Tetranthera chrysopleura Bl., allen van de Nat. fam. der Laurineæ. GR, Jara; boomen, welke een goed bouwhout leveren. $=f$. Tetranthera monopetal a $\mathrm{R}$ oxb. (Zie No. 2323a.) en $=g$. G labraria T'ersa L., var. la urifolia. (Zie No. 2669b)

2895. Hoeroe-bessie $\mathrm{S} .=\mathrm{Cryp}$ to c a ry a ferrea Bl., Nat. fam. der L a u rineæ. Gr. Java; hooge boom. GeBr. Deze boom levert een zeer hard en deugdzaam bouwhout.

2896. Hoeroe-bourriet $\mathrm{S} .=\mathrm{Te}$ tranthera am ar a N e es. Nat. fam. als voren. GR. De Sunda-eilanden en. 
Nieuw-Guinea; boom. GEвr. Deze boom levert een licht, doch sterk bouwhout.

289\%. Hoeroe-dapoeng S.) $=a$. f l a b raria Tersa I, (Zie No.26696.) $=b$. Tetranthera monopetala Roxb. (Zie No. 2323a.) $=c$. M a ch il us odoratissima $\mathrm{N}$ e es. (Zie No. $\left.119 a_{0}\right)=d$. Lepidadenia hirta $\mathrm{B}$ 1. en $=e$. L. robusta B l., Nat. fam. der $L$ a u rineæ. Gr. Java; boomen, $=i$. Monoceras obtusum Hassk., Nat. fam. der Tilia ce æ. Gr. Java; boom. Geвr. Het lichte, fijne en sterke hout is zeer geschikt voor huisbouw en prauwen; het wordt niet door insekten aangetast.

2898. Hoeroe-dengek $\mathrm{S}$. $=\mathrm{T} \mathrm{e}$ tr anthera Dengek Miq., Nat. fan. der L a u r in e . GR. Java; boom.

2899. Hoeroe-gadieng $\mathrm{S}$. $=a . \mathrm{Gla}$ b a ria Tersa I. (Zie No. 2669b.) $=b$. Tetranthera, monopetale Roxb. (Zie No. 2323a.) =c. Phøbe spathulata Miq, Nat. fam. der Laur. i 1 e æ. Gr. Java; hooge boom. $=d$. $\mathrm{Polyadenia} g \mathrm{~mm}$ iflora $\mathrm{Nees}$. en $=e$. Pol. macrophylla Miq., Nat. fam. als voren. GR. Java; hooge boomen, die een sterk bouwhout opleveren. = f. Cylicodaphne Noronhiana B l. N. L. dezelfde. GR. Java, hooge boom. $=g$. Actinodaphne procera Nees, Nat. fam. dezelfde. Gr. Java, Sumatra, Celebes, Amboina; hooge boom. $=h$. Mastixia Junghuhniana Miq., Nat. fam. der Cornaceæ. Gr. Java; hooge boom.

2900. Hoeroe-hedjoh S. $=a$. Cryptocarya ferrea Bl. (Zie No. 2895.) $=b$. Tetranthera lucida Hassk. Nat. fam. der Laurineæ. Gr. Java en l3angka; hooge boom.

2901. Hoeroe-hieries $=a$. Tetranthera amal'a Nees. (Zie No. 2896.) $=$ b. Machilus odoratissima Nees. (Zie No. 119a.) = c. Polyadenia po. ly anth a $\mathrm{Ne} \in \mathrm{s}$. (Zie No. 2894d.) $\approx d$. Cryptocarya? reticulata Bl., Nat. der I, a urineæ. GR. Borneo; boom. $=e$. A c tinoda $p h$ ne areolata Bl., Nat. fam. dezelfde. Gr. Java; hooge boom.

2902. Hoeroe-kapas S. $=$ Platea latifolia Bl. (Zie No. 2233b.)

2903 Hoeroe-kapok S. = Actinodaphne macrophylla Nees, Nat. fam. der Laurineæ. Gr. Java; hooge boom.
2904. Hoeroe-kibedon S. = L e p idadenia diversifolia Bl., Nat. fam. als voren. Gr. Java; boom. GeBr. Volgens Hasskarl wordt op Java een aftreksel van het hout als thee gedronken; dit komt veel overeen met een afkooksel van kaneel.

2905. Hoeroe-kidang S. $=\alpha . \mathrm{Cry} \mathrm{p}$ tocarya ferrea Bl. (Zie No. 2895.) $=$ b. Endiandra rubescens Mi $q$, Nat. fam. als voren. Gr. Java en Sumatra; hooge boom, die een hard en roodachtig bouwhout levert.

2906. Hoeroe-kìdang-lalakki S. = Lepidaden i ferruginea B l., Nat. fam. der La urineæ. GR, Java kleine boom.

2907. Hoeroe-kimeöng $\mathrm{S}$. = A ctinod a phne glomerat a Nees, Nat. fam. als voren. Gr. Java en Sumatra; 2908. Hoeroo-kisehreh $\mathrm{S}$. $=\mathrm{L}$ e p id a den i a d i versifolia Bl. (Z i e No. 2904.)

2909. Hoeroe-koeneng $\mathrm{S} .=a . \mathrm{Po}_{0}$ lyadenia polyantha $\mathrm{N}$ e es. Zie No. $2894 d$.) $=$ b. Cryptocary a a c utiflor a Bl, Nat. fam. der L a urineæ. GR. Java; boom. $=c$. $\mathrm{T} \mathrm{e}$ tranthera resinosa Nees., Nat. fam. als voren. Gr. Java en Sumatra, hooge boom. GEBR. Deze boom levert een wit, grof en sterk bouwhout, dat niet door witte mieren wordt aangetast.

2910. Hoer oe-komploen S. $=\mathrm{Le}$ pidadenia robusta Bl. (Zie No. 2897e)

2911. Hoeroe-kroet $\mathrm{S}$. = Actinodaphne glomerata Nees. (Zie No. 2907.)

2912. Hoeroe-lemoh S. $=a$. Tetranthera citrata Nees. (Zie No. 401.) $=$ b.. Polyadenia subumbelliflora Nees. Nat. fam. der Lauri. neæ. Gr. Java en Sumatra; kleine boom

2913. Hoeroe-leuheur S. (ook H. luh-ur S.) $=a$. Phœbe declinata Nees en $=b$. Ph. parviflora Bl. beide van de Nat. fam. der Laurinex. Gr. Java; hooge boomen. $=c$. Carydaphne densyflora Bl., Nat. fam. als voren. Gr. Java; boom.

2914. Hoeroe-lielien S. = Mastixia pentandra Bl., Nat. fam. der Cornaceæ. Gr. Java; hooge boom.

2915. Hoeroe-lohor $\mathrm{s}$. $=$ Urophyllum corymbosum Krths., Nat. fam. der Rubiacex. GR. Java en Sumatra; heester.

2916. Hoeroe-madang $\mathrm{S}=a$. $\mathrm{Ma-}$ 
chilus odoratissima Nees. (Zie 119a.) $=b$. Polyadenia macrophylla Miq. $\mathrm{Z}$ ie No. 2899e.) = c. Cryptocarya tomentosa Bl, Nat. fam. der Laurineæ. Gr. Java en Borneo; hooge boom. $=d$. Beilschmidtia Madang Bl., Nat. fam. als voren. GR. Java; slanke boom. = e. Glabraria vestita Miq., Nat. fam. dezelfde. Gr. Java; boom. = $f$. Tetranthera elliptica Nees, Nat. fan. dezelfde. Gr. Java; boom.

2917. Hoeroe-madang-lalakkina S. $=a$. Tetranthera elliptica Nees. (Zie voren.) $=b$. Cryptocarya? reticulata Bl. (Zie No. 2901d.)

2918. Hoeroe-madoeng S.' $=a$. Cryptocarya tomentosa Bl. (Zie No. $2916 c$.) $=$ b. Daphnidium cæsium Nees. (Zie No. 2893b.)

29 19. Hoeroe-mandalaksa $\mathrm{S}_{.}=\mathrm{Pla}$ tea cxcelsa Bl. (Zie No. 2233a.)

2920. Hoeroe-mang = Lepidadenia? tephrophylla Mia., Nat fam. der La urineæ GR. Java; boom.

2921. Hoeroe-manga $\mathrm{S} .=a$. $\mathrm{P}_{0}$ lyadenia lucida Nees; Nat. fam.als voren. Gr. Java en Sumatra; boom. $=b$. Tetranthera angulata Nees, Nat. fam dezelfde. Gr. Java; hooge boom.

2922. Hoeroe-mangarawang $\mathrm{S}$. = Tetranthera macrocarpa Nees, Nat. fam. der Laurineæ. Gr. Java; he ester.

2923. Hoeroe-manoek S. $=a$. A cer la urinum Hassk. (Zie No. 789.) $=b$. Cryptocarya ferrea Bl. (Zie No. 2895 .) $=c$. Machilus odoratissima Nees. (Zie No. 119a.) $=d$. Phœbe declinata Nees. (Zie No. 2913a.) $=e$. Phœbe parviflora Nees. (Zie No. 2913b.) $=f$. Phœbe pubescens Nees, Nat. fam. der Laurineæ. Gr. Java; boom. =g. $\mathrm{Ph} \rightsquigarrow \mathrm{be}$ ? incerta Bl. Gr. Java; zeer hooge boom. $=h$. Daphniphyllam glaucescens Bl., Nat. fam. der Euphorbiaceæ. Gr. Java; boom.

2924. Hoeroe-manprang $\mathrm{S}$. = Endiandra rubescens Miq. (Zie No. 2905b.)

2925. Hoeroe-meirah $\mathrm{S} .=$ Cinnamomum iners $R w d t$. Nat. fam. der L a u rinex. GR. Ilava; hooge boom. GEBR. De bast en bladeren worden, met water afgetrokken, als thee gedronken; den bast van zijn buitenschil bevrijd en gedroogd, bezigt men als specerij bij eenige spijzen; van de zaden kunnen kaarsen gemaakt worden.

2926. Hoeroe-menek $\mathrm{S}$. $=\mathrm{Endi}$ a ndra rubescens Miq. (Zie No. 2905b.)

2927. Hoeroe-mentek S. $=a . \mathrm{Cry}$ tocary a ferrea Bl., (Zie No.2895.) $=b$. Cyanodaphne cuneata Bl. (Zie No. 1880.) $=$ c. Endiandra rubescens Miq. (Zie No. 2905b.) $=d$. Polyaden ia $\mathrm{subumbell}$ iflora Nees. (Zie No. 2912b.) $=e$. Parthenoxylon Pseudosasafras Bl., Nat. fam. der L a u r in eæ. Gr. Java en Sumatra; zware boom. Gebr. Het hout van dezen boom, op Sumatra Lasso genaamd, zal in plaats van Lign u m $\mathrm{S}$ a s s a fras kunnen gebruikt worden.

2928 Hoeroe-merang $\mathrm{S} .=\alpha$. Cryptocarya ferrea Bl. (Zie No. 2895.) = b. Tetranthera angulata Nees. (Zie No. 2921b.) $=c$. $\mathrm{Ph} \ltimes \mathrm{be}$ lamponga Miq., Nat. fam. der L a urineæ. Gr. S umatra; hooge boom.

2929. Hoeroe-mienjak $\mathrm{S} .=a$. Tetranthera resinosa Nees. (Zie No. $2909 c$.) en $=b$. Tetranthera angulata Nees. (Zie No. 2921b.)

2930. Hoeroe-mogol S. = Tetranthera Mogol Bl., Nat. fam. der Laurineæ. Gr. Java; boom.

2931. Hoeroe-mugmal S. $=\alpha$. L epidadenia ferruginea Bl. (Zie No. $2906)=b$. Lepidadenia Noronhiana B l., Nat. fam. der L a u ri a ce e. Gr. Java, Sumatra, enz.; hooge boom. $=c$. L e p idaden i a r u bra Bl., Nat. fam. als voren. Gr. Java; hooge boom. Gebr. Het harde hout is bijzonder geschikt voor stelen van huis- en tuingereedschappen. $=$ d. Gla braria Ters a L. (Zie No. 2669b.) $=e$. Glabraria restita. Miq. (Zie No. 2916e.) $=f$. Endiandra rubescens Miq. (Zie No. 2905b.) = g. Actinodaphe glabla Bl., Nat. fam. als boven. Gr. Java; boom.

2932. Hoeroe-ngoengnoek S. $=a$. Cryptocaria costata Bl., Nat. fam. der I aurineæ. Gr. Java; boom. Gebr. Het lichte, vezelige hout van dezen hoo. gen boom gebruikt men voor kisten, enz. $=$ b. Glabraria? nitens Miq, Nat. fam. dezelfde. Gr. Java; boom. $=c$. Elæocarpus stipularis B1., Nat.fam. der Tili a cex. Gr. Java; boom.

2933. Hoeroe-oelaoe S. $=$ Cyan odaphne cuneata Bl., (Zis No. 1880.) 
2934. Hoeroe-0endjoek S. $==a$. Cryptocarva costata Bl. (Zie No. $2932 a$ ), en $=6$. Cyanodaph ne cuneata Bl. (Zie No. 1880.)

293ว. Hoeroe-oendjoek-laoe $\mathrm{S}$. = Cyanodaphne cuneata Bl. (Zie No. 1880)

2936. Hoeroe-pajong S. $=a$. A ct inodap.hne procera Nees. (Zie No. $2899 g)=$ b. A ctinodaphne ylomerata Nees. (Zic No. 2907.) $=c$. Actiuodaphne quercina $\mathrm{N}$ e e s, Nat. fam. der $\mathrm{L}$ a u $\mathrm{r}$ i neæ, Gr. Java; boom.

293\%. Hoera-pajong-aloes S. en

2935. Hoeroe-pajong-bener S. = Actinodaphnc sphrerocarpa Nees, Nat. fam. Als voren. GR, Java; hooge boom;

2939. Hoeroe-pajong-boddas S. = Litsæa latifolia Bl, Nat. fam. dezelfde. Gr. Bijna overal in Ned. Indië; van dezen boom bestaan vijf variëteiten.

2940. Hoeroe-pajong-gedeh S. = A c tirodaphne procera Nees. (Zie No. 2899g.)

2941. Hoeroe-pajong-leutiek S. = A ctinodaphne glomerata Nees. (Zie No. 2907).

2942. Hoeroe-pantjar S. $=u$. T etranthera angulata Nees. (Zie No. 2921b.) $=b$. T et $r$ a u thera Pantj a ra. Bl., Nat. fam. der Laurineæ. Gr. Java; boom. $=c$. L i t s a $\mathrm{j}$ a $\mathrm{v}$ an i c a Bl., Nat. fam. dezelfde. Gr. Java; hooge boom.

2943. Hoeroe-passan S. = Tetranthera monopetala Roxb. (Zie No. $2323 a$.)

2944. Hoeroe-passeng S. = Leiocarpus arboreus Bl. (Zie No. 1134.)

2945. Hoeroe-passoeng $\mathrm{S}$. $=\mathrm{Te}$ tranthera monopetala Roxb., var. $\mathrm{m}$ in ox $\mathrm{N}$ e es. (Zie No. 2323a.)

2946. Hoeroe-paoel S. $=\mathrm{C}$ a r vodaphne densiflora Bl. (Zie No. 2913c.)

2947. Hoeroe-peutjang S. $=$ Acer la tr in u rn H assk. (Zie No. 789.)

2948. Hooroe-sariawan S. = Beil-

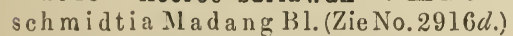
2949. Hoeroe-sehreh S. en

2950. Hoeroe-setan S. $=\mathrm{Le} \mathrm{pi-}$ dadenia diversifolia B l. (Zie No. 2904).

295l. Hoeroe-tangkallak S. $=u$. Lepidadeni a ferruginea B l. (Zie
No. 2906.) $=$ b. Myristica la ur i n a Bl., Nat. fam. der Myristiceæ. Gr. Java en Sumatra; hooge boom. GEBR. Het hout is zeer geschikt voor bouwhout; de vruchten zijn eetbaar.

2952. Hoeroe-tedak S. Cryptoc ary a costata Bl. (Zie No. 2932a.) 2953. Hoeroe-tjangkring $\mathrm{S} .=\mathrm{Te}$ tranthera Pantjara B l. (Zie No. 2942b.)

2954. Hoeroe-tjariang $\mathrm{S}_{0}=\mathrm{En}-$ diandra ru bescens Miq. (Zie No. 2905b.)

2955. Hoeroe-toelang $\mathrm{S} .=\mathrm{Act \textrm {i }}$. nodaphne procera Nees. (Zie No. 2899g.)

2956. Hoeroe-waleh $\mathrm{S}$. $=\mathrm{P}$ oly adenia polyantha Nees. (Zie No. 2894d.)

2957. Hoerong Амв. $=\mathrm{P}$ о а а mbo in ensis L., Nat. fam. der Gram i n e . Gr. A mboina; grassoort.

2958. Hoessoer Амв. = G a rinia c эrnea I. (Zie No. 2026a.)

2959, Hoetaulo Aмв. = Calo phyllum inophyllum L. (Zie No. 1139.)

2960. Hoettoem $А м \mathrm{~B}_{0}=\mathrm{B}$ arringtonia speciosa L. (Zie No. 1463.)

2961. Hoettoem-darat A $\Perp в$. en

2962. Hoettoem-leimoeri Амв. =a. Barringtonia a c ut angula Grtn. en $=b$. B. r a cemosa Bl. (Zie No. 983.) $=c$. B arr ing ton ia rubra Bl., Nat. fam. der Mrytacex. Gr. Le Molukken; bnom. Gebr. Men wendt den bast nitwendig aan bij schurft, bezigt de takken voor tuinstaken en eet de jonge bladeren als groente of salade,

2963. Hoewit-kelôpô J. en

2964. Hoewit-ketjambil J. en

296ว. Hoewit-krambil $\mathrm{J}_{0}=\mathrm{C}_{0}$ cos nu c if era I. (Zie No. 393.)

2966. Hohotoe-aman Aмв. $=a$.

Ele u s ine ind ica Ga ertı. (Zic No. 1961.)=$ b. Dactyloctenium rgyptiacum W1ld. (Zie No. 2:344b.)

2967. Hoi-lo-tjoeng Сн. Bo. = Casuarina equisetifolia Frst. (Zie No. 122.)

2968. Holan-fan-sjoe Cir. Bo. = a. Maranta indica J. (Zie No. 431.) $=$ b. Solanum tuberosum I., Nat. fam. der Solanacex. Gr. De aardappel wordt op Java, Sumatra, Celebes, Timor en elders verbouwd.

2969. Holo-holo A dia ovigera $\mathbf{L}$. (Zie No. 43.) 
2970. Honjeh S. = Caryodaphne densiflora Bl. (Zie No. 2913c).

297l. Honjeh-bener $\mathrm{S} .=\mathrm{Elet}$ t aria speciosa Bl., Nat. fam. der $\mathrm{Z}$ ing i b c racex. Gr. Java; overblijvende plant met vijf verschcidenheden. GEBr. De blader'n worden gekookt, en zijn aldus een aangenaam zure groente bij de rijst.

2972 Hunjeh-boeöet $\mathrm{s}$. $=$ Elettaria anthodioides T. \& B.; Nat. fam. als voren. Gr. Java; overblijvende plant.

2973. Honjeh-burrum S. = Elettaria pallida Bl., Nat. fam. dczelfue, Gr. Java; overblijvende plant. GeBr. De bladeren worden gegeten en zijn een zure groente; ook eet men de zaden, die zeer zoet en aangenaam van smaak zijn.

2974. Honjeh-lakka $\mathrm{S}_{\text {. }}=a$. Elet taria speciosa Bl., variet bract. incarn. fruct. rosac. (Zie No. 2971) $=$ b. Elettaria pallidaBl. (Zie No. 2973.)

2975. Honjeh-leuwung $\mathrm{S} .=$ Elettaria hæmisphærica Bl., Nat. fam. als voren. Gk. Java; overblijvend Gebr. Als No. 2973.

2976. Honjeh-merak S. = Elettaria rubra Miq, Nat. fam. dezelfde. Gr. Jara; overblijvend.

297\%. Honjeh-warak S. = Elettaria solaris Bl., Nat. fam. dezelfde. Gr. Java; overblijvend. GeBr. Als No. 2973.

2978. Honjeh-warak-burrum S. = Elettaria hismisphrerica Bl. (Zie No. 2975.)

2979. Horas-tadi SUM. WK. $=$ Ficus gibbosa Bl. cum variet, Nat. fam. der A r to c a r p ex. Gr. Java en Sumatra; boom.

2980. Hottong-bengala Альв. =-
Eleusine coracana Grtis. (Zic No. 1892.)

2981. Hua Aмв (Zic Hoea Aлгв.)

298:. Hua-soil Амв. ook

2983. Hua-tette Asiв, en

2994. Hua-tette-ewan А вв = Ptychospcrma saxatilis Bl., Nat. fam. der P a l mæ. Gr. Amboina; hooge Palm. GFbr. D? noten worden somıs gebruikt in plaats van die der gewone $\mathrm{Pi}$ nang (A reca Catechu $I_{1}$ ); de gebrande palmiet eet men teg sn zware hoest.

2985. Humelen Axв. $=\mathrm{Antho-}$ ce phalus Cadamba Miq. (Zie No. 991.)

2996. Humelen-malona Aмв. = A uthocephalus indicus lic ich. (Zie No. 959.)

2987. Huntjiet $\mathrm{S} .=a$. Adenocre. pis javanica Bl. ell $=b$. Cheilosa montana Bl., beide van de Nat. fam. der Enphorbiaceæ Gr. Java; klcine boomen. Gebr. De bast vall dezc beide boomen gebruikt men tot het roodverwen van garens, ook bij wijze van zecp, tot reiniging des lichaams.

2988. Hutte-ahüae Алв. $=\mathrm{E}$ uphorbia hirta D. C. (?), Nat. fam. der E u ph orbia c e ce. Gr. A mboina (?); heester. GEßs. Deze heester zal een goed geneesmiddel bij syphilis zijn.

2989. Hutta-gindam Азв. = Fi mbristylis polytrichoides Nees. Nat. fam. der C y p e r a $\mathrm{c} e \mathfrak{x}$. Gr. Vrij algemeen in Indië; overblijvend. GŁBR. Dit gras is een geschikt voedcr voor het vee. 2990. Hutta-laussa Амв. $=\mathrm{B} \mathrm{i}$ dens Wallich i D. C. (Zie No. 68a.) 2991. Hutta-oeroetta Amв. = Uren a $\mathrm{L}$ a p p a g o $\mathrm{S} \mathrm{m}$. (Zie No, 314.)

2992, Hutta-wonin Aмв. = G le ichenia $\mathrm{H}$ erma nnï R.Br. (Zie No. 1214.)
2993. Iboe-tjengkeh II. = Ca ryophyllus a romaticus J. (Zie No. 1292.) 2994. Iboel $\mathrm{BB} .=\mathrm{Caly} p \mathrm{troca}$ yx spicatus Bl. (Zie No. 2811.)

2995. Iboel M. \& Br. $=\mathrm{Pholi}$ d o c a r p u s I h u r B l., Nat. fam. der $\mathrm{P}$ a $\mathrm{lm}$ ic. Gr. Sumatra, Timor en de Molukken; hooge boom. Grßr. Het harde hout is zeer geschikt roor lansen en panlatten.

2996. Idat BK. = Cratoxylon microphyll u m $M$ i q., Nat. fam. der H y per i c i nex. Gr. Bangka; heester. 2997. Ide-ide-malakko T. $=\mathrm{Abl} \mu \mathrm{s}$ precatorius L. (Zie No. ว̌3.)

2999. Ido-mahoe $\mathrm{T}$. $=\mathrm{Saccha}$ - 
I u m edele Hassk., Nat. fam. der Gramineæ. Gr. Java en de Molukken; overjarig rict. GEBR. De jonge, nog niet geopende bloempluimen levcren een gezochte groente, ook voor de Europesche tafel; zij worcien gestoofd en gebakkcn gegeten; de smaak komt die der blocmkool zeer nabij; men kent er een pisdrij. vende werking an toe.

2999. Igo $=$ T. Cocos u ucifcra L. (Zie No. 393.)

3000. lgo-igo T. $=a$. Phy 11 a nthus Nuriri L. en 6. Ph. uriuaria IV I ld. (Zie No. 716.) = c. Oxal is Reiuwardtii Zucc. (Zie No. 25l.)

3001. Ihoer Амв. $=$ Pholidocar1) u s 1 h u r B 1. (Zie No. 2995.)

3002. Ilam Амв. $=$ Melaleuca leucodendron L (Zie No. 120 a.)

3003. Ilat S. \& J. $=a$. Cyperus L. Spec. permultæ. $=6$. Gahnia javanica Z. \& M., Nat. fam. der Cy per a c еæ. Gr. Java; overblijvend gras. = c. Rhynchospora aurea Vhl. Nat. fam. als $\delta$ GR. Ned.-Indië; overjarig gras. $=d$ Xerotes arenaria R.Br., Nat. fam. der X e roti d e æ. GR. Java; overjarig. $=e$. Hy polytrum latifolium L. C. Rich. (Zie No. 27686).

3004. Ilat-boeloe-mata $\mathrm{S} .=\mathrm{Cype}$ rus L. S pecies no n n l l ce.

3005. Ilat-gedeh $\mathrm{S} .=a . \times \mathrm{x} \times 0$. tes $l$ o $\mathrm{ng}$ if olia R.Br., Nat. fam. der Xerotideæ. Gr. Java; overjarig $=b$. Scleria lithospcrma Wlld., Nat. fam. der Cy perace e. GR Java en Je Mo. lukken; overjarig gras. $=c$. Cla d i u m M a $r$ is c u s R.Br., Nat fam. Als voren. Gr. Java; overjarig.

3006. Ilat-goenoeng $\mathrm{S} .=\mathrm{Fi} \mathrm{mbr}$ st y lis compla u a a $I_{1} k$, Nat. fam.

Als voren. Gk. Java; overjarig.

3007. Ilat-leutiek S. $=a$. Scleria lithosperma Willd. minor. (Zic No. 300 ๖. $=$ b. Scleria pubescens Std., Nat. fam. Als voren. Gr. Java; overjarig. 3008. Ilat-mienjak $\mathrm{S} .=\mathrm{S} \mathrm{cl} \mathrm{c} \mathrm{x}$ i a

$\mathrm{l}$ ic v is R $\mathrm{tz}$. GR. Java; overjarig.

3009. Ilat-tjaai S. = E rian $\mathrm{thus}$

$R$ i c h S pec. java n.

3010. Ila-a-un Axis. $=\mathrm{F}$ i c us po-

lit o ria J, a m. (Zic No. $304 a$ )

3011. Ilor J. $=$ Celcsia cristata

$11 \mathrm{i}$. (Zie No. 419.)

3012. Ilus $\mathrm{S} .=a . \mathrm{Amorphophal-}$ lus campan ula tus 331. (Zie No. 750 .)

$=$ b. Brehyspatha variabilis
Scliott. $=c$. Conophallus giganteus Schott. (Zie No. 750c.) = d. A ris ma filiformc B l, Nat. fam. der A roideæ. Gr. Java; overblijvend.

3013. Ilus-lemah S. $=a$. Typhonium cuspidatum. Bl. (Zie No. 4tl.) $=$ b. Typhonium divaricatum Bl. (Zie No. 1236,)

3014. Ilus-leutiek $\mathrm{S} .=\mathrm{Tac}$ c a palmata B l. (Zie No. 825.)

3015. Ilus-tanah $\mathrm{S}$. = IIus-lemah $\mathrm{S}$.

3016. Ima $\mathrm{T} .=a$. $\mathrm{Dios}$ orea a la t a L. (Zie No. 2808a.) = b. 1) i o s. c o r a v ulgaris Mi q. (Zie No. 2808b.) 3017. Ima-kastella ' $\mathrm{T}$. $=$ B atatas edulis Chois. (Zie No. 635.)

3018. Ima-sierum S. (ook Ima-sireum S.) $=a$. Hydnophytum moutanum Bl. Gi. Java ell Sumatra; $=b$. H y d n o phy tum formicarnm J a ck. GR. Java, Sumatra en de Molukken; = c. $\mathrm{M} \mathrm{y} \mathrm{r} \mathrm{me} \mathrm{cod} \mathrm{i} \mathrm{a} \mathrm{c} \mathrm{chinat} \mathrm{a} \mathrm{G} \mathrm{a} \mathrm{u} \mathrm{d.}$ Gr. Java en de Molukken.

Deze drie heesterachtige parasieten bchooren tot de Nat. fam. der $R$ u biace Gebr. Volgens $\mathrm{H}$ as s k a r l suijdt men den knolachtige stam in stukken, stampt dier met water fijn, en wrijft men tegen hoof ipijn zich daarmede het voorhoofd in.

3019. Imbo J. = A z a dirachta indica A Juss., Nat. fam. der $\mathbf{M}$ eli a c e $x$. Gr. Java en andere Sundaeilanden; boom. GeBr. De bast van dezcn boom is bitter tonisch, en wordt veel tegen tusschenpoozendc koortsen gcbezigd; uit de zaden wordt een vettc olie (O le um Margosæ) verkregen, welke men tegen hoofdpijn na zonuesteek aauwendt.

3020. Ina of Inam Auв. = Coloc as i a a tiquorum schott. (Zie No. 24วั.)

3021. Inaméan $\mathrm{AMB}=\mathrm{Mang}$ if era la $x$ if 1 or a $D$ e s r., Nat. fam. der $A$ n ac a $r d$ i n c e re, Gr. De Molukken: boom.

3022. Inan AuB. $=\mathrm{B}$ o e h m e r i a n ive a $\mathrm{G}$ a u d. (Lie No. 2387 )

3023. Indiapara $\mathrm{J}_{0}=\mathrm{O} \times$ al is $\mathrm{R}$ e in wardtii Zucc (Zie No, 2כ̌l.)

3024. Inei NAND. $=\mathrm{L}$ a w s o $\mathrm{nia}$ a 1 b a $\mathrm{L}$ a $\mathrm{m}$. (Zie No. 1747)

3025. Inei-ajer Sux. $\mathrm{WK}_{\mathrm{K}}=\mathrm{I} \mathrm{m}$ pat ie n a l b o.flava Miq., Nat. fam. der $\mathrm{B}$ als aminer. Gr. Sumatra; éćnjarig.

3026. Inei-ajer-koening Sum. Wk. $=a$. I m patiens 1 i e pen hoxtii $\mathrm{dl} \mathrm{iq}$. en $=$ b. I m p. pyrhotricha 
M iq., Nat. fam. Als voren. Gr. Sumatra; overjarige planten.

3027. Inei-ajer-poetih Sum. Wк. = Impatiens Teysuanni Miq., Nat. fam. Als voren. Gr. Sumatra; éénjarig.

3028. Ingas $\mathrm{J} .=\mathrm{Gluta} \mathrm{Ben}$ $\mathrm{gh}$ a s I. (Zie No. 1099.)

3029. Ingas-boerong $\mathrm{M} .=\mathrm{Bu}$ ch a n a nia a rborescens B l., Nat. fam. der $A$ n a c a rd i a c e æ. Gr. De Sunda-archipel; hooge boom. Gribr. Deze boom levert een fijn, rood en zwaur meubelhout, dat echter, wegens de hardheid, moeilijk tc splijten en, wegens het scherpe mclksap, moeilijk te verwerken is.

3030. Ingoe J. \& $\mathbf{M} .=a$. $\mathrm{R} u \mathrm{ta}$ gra ve ol en s L., Nat. fam. der Dios$\mathrm{m}$ e $æ$. Gr. Op Java en elders in tuinen; kleine heester. GEßr. Het gebruik der i Vijnruit, vooral bij stuipen van kinderen, is overbekend. $=b$. Ferula a s a f $\propto$ tida L. (gummi resina), Nat. fam. der Umbelliferc. Geble. Alleen de gomhars is op Java eu elders op de bazars te koop; zij wordt als specerij veelvuldig gebruikt, en is vooral zeer gezocht als geneesmiddel tegen den droes van paarden.

3031. Ingoe-ingoe $\mathbf{M} .=\mathrm{S}$ a uraya ferox Korth. S al. Spec, Nat. fam. der Ternstroemiaceæ. Gr. Sumatra en Borneo; heester.

3032. Ingoe-ingoe-riembo M. = Sauray a oxyphylla Miq., Nat. fam. Als voren. Gr. Sumatra; heester.

3033. Ingoe-maas II. = Pachy rrhizus angulat us Rich. (Zie No. 972b.)

3034. Ingouw Sus. $=\mathrm{S}$ a $\mathrm{u}$ r a y a pendula B l., Nat. fam. der T'ernst r o e mi a ce æ. Gr. Java en Sumatra; heester.

3035. Injarra $\mathrm{M}_{\mathrm{AK}}$. $=\mathrm{Premna}_{\mathrm{r}}$ corymbosa Rottl. (Zie No. 395.)

3036. Inne-ajer Амв. = Impatiens $\mathrm{Bals}$ a min a L. (Zie No. 259.)

3037. Inrore NaK. (Zie No. 3035.)

3038. Intsji $\mathrm{BI}_{0}=\mathrm{Evia}$ acida $\mathrm{Bl}$. (Zie No. 2890.)

3039. Intarran $J$ ell.

3040. Intarran-sesse $\mathrm{J} .=\mathrm{A} z \mathrm{a} \mathrm{d}$ rachta indica A. Juss. (Zic No, 3019. ) 304. I. Ipé S. \& J. $=$ Ficus brevipes Miq., Nat. fam. der Artocarpea. Gr. Java; boom.

3042. Ipi BG. $=$ Intsia amboinensis Thrs. (Zic No. 830.)

3043. Ipies.koeliet S. $=a$. M c me- cylon umbell at n m B l., Nat. fum. der Memecyler. Gr. Java; heester. GEBr. Den bast gebruikt men tot het roodverwen vall katoenen stoffen $=b$. Jambosa acuminatissima Hassk, Nat. fam. der M y l t a c e a. Gr. Java; hooge boon. Gebr. Den schor's bezigt mell tot het zwartverwen vain garens; den stam gebruikt men voor bouwhout, dat echter licht door witte mieren wordt aangetast; de vruchten ziju eetbaar, doch zuur en wrang. $=c$. $\mathrm{J}$ ambosa lineata $\mathrm{D}$. C, Nat. fam. Als voren. Gr. Java, Sumatra en Borneo; hooge boom. Gebr. Het vaste hout is zeer goed en duurzaan voor huisbouw, de vruchten worden gegeten, doch zijn zuur.

3044. Ipo M. $=a$. Antiaris toxicaria liesch. (Zie No. 408.) = b. Antiaris innoxia Bl., Nat. fam. der Artocarper. Gr. Celebes en de Molukken. Gebr. Als No. 408, doch zwakker. $=c$. $\Lambda$ ntiaris rufa Miq., Nat. fam. Als voren. Gr. Sumatra; hooge boom, welke vermocdelijk ooik giftige cigenschappen bezit.

3045. Ipo-binkarong ${ }^{\prime \prime}$. = Antia$r$ is $r$ ufa Miq. (Zie vorig No.)

3046. Isse Amb, $=\mathrm{D}$ a m mar $\mathrm{r}^{\circ}$ a $l$ b a $\mathrm{Rmph}$. (Zie No 1618.)

3047. Isse-poeter $А м в$, of

3048. Isse-poetih Ans. = U rostigm a Tjiela Miq., Nat. fam. der Artocarpece. Gi. Java en de Molukken; boom.

3049. Isse-seloe Aмв $=\mathrm{Can}$ a r i $и \mathrm{~m}$ rostratum Zipp. (Zie No. 1619.)

3050. Isser Aur. = Intsi a mboinensis Thrs. (Zie No. 830 )

3051. Issipoëan Aмв. $=a \cdot \mathrm{Achy}$ ranthes bidentata Bl. (Zie No. 740.) = b. Cyathula geniculata I,our. (Zie No. 741.)

3052. Itilat Амв. = Ficus politoria Lam. (Zie No. 299.)

3053. Itie-lemaun IAmP. $=$ Phrynium villosulum Miq., Nat. fam. der Cannace x. Gr. Sumatra; overjarig.

3054. Itit-biroe $\mathrm{S} .=\mathrm{Genios}$ toma montanum Z. \& M., Nat. fam. der Loganiacer. Gr. Java; heester.

3055. Ittil M. = Urostigma $\mathrm{n}$. tidum Miq. (Zie No. 855.)

3056. Iwak of Ywak BL. $=\mathrm{Co}_{0}$. leus amboinicus Lour. (Zie No. 69.) 3057. Iwoel S. $=$ Calyptrocalix spicat us Bl. (Zie $\bar{N}_{0,} 2811$.) 
3058. Jabbal Mor. $=$ Cerbera a c t a ri a H a m. (Zie No. 1182.)

3059. Jä̈ $\mathrm{Cr}_{\text {. }}=$ Dioscorea K le i n i a a $\mathrm{K}$ unth. (Zie No. 5.)

3060. Jagan-bajem $\mathrm{I}$. $=$ A maran. tus tristis L. (Zie 836c.) en $=b$. Euxolus polygamus Miq. (Zie No. 8366.)

3061. Jahaka Br. = A renga saccharifera T,ab. (Zie No. 243.)

306\%. Jajamboan $\mathrm{S}$. = Evoll ymus javanicus Bl. (Zie No. 1874.) 3063. Jalong LAMP. = Syzygiu m subtile Miq, Nat. fam. der Myrtace ae. Gr. Sumatra Z. O ; boom.

3064. Jambinoer Bтт. $=a$. Dacrydium elatum IVall. en $=6$. Dacrydium Junghuhnii MI q., Nat. fam. der Podocarpece. Sumatra, Borneo. enz.; altijd groene, hooge boomen.

306 J. Jamblang (ook Jambolang) S. I. \& M. $=a$. Syzygium jambolanum Rxb. (Zie No. 1906.) = b. Calophyl$1 \mathrm{um}$ inophyll $\mathrm{nm} \mathrm{L.} \mathrm{(Zie} \mathrm{No.} \mathrm{1139;}$ $=c$. Methonica superba Lam., Nat. fam. der Liliaccæ. GR. Java en elders; ovcrblijvend. GEBR. Men kent aan den knolwortel een narcotische werking toe.

3066. Jamblang-sabrang $\mathrm{s}$. = Imbricaria coriacea. A. Dc., Nat fam. der Sapotacre. Gr. Java, uit Madagaskar ingevoerd; hooge boom. GEBR. De zoete rruchten worden rauw gegeten.

3067. Jamboa M. = Citrus decumana L. (Zie No. 2054)

3068. Jambon S. $=a$. Coelospermum scandens Bl. (Zie No. 699d.) = b. Jambosa densiflora D. C. (Zie No. 1921.)

3069. Jamper-ender S. = Areca triandra Rxb. (Zie No. 1.904.)

3070. Janale Cr. $=\mathrm{C}_{\text {a n a } \mathrm{rium}}$ sylvestre Grtn, Nat. fam. der Burseracer. Gr. Dc Molukken, Sumatra; hooge boonl. Gerr. Het hout is zeer geschikt voor masten en stijlen; de zwarte hars gebruikt men roor fakkels.

307l. Janiri. $\mathrm{Cr}_{\mathrm{r}}=\mathrm{C}$ a n a $\mathrm{rium}$ mi c rocarpum IV 11 d. (Zie No. 40.)

3072. Jar (ook Jal) $\mathrm{A} м \mathrm{~s} .=a$. Canarium commune L., Nat. fam. der Burseracer. Gr. Door geheel Indië, veelal in trinen; hooge boom. GEsk. Uit den stam vloeit ecu hars, die men voor fakkels en ook tot het kalefaten van valtuigen bezigt. Het hout is grof eu sterk, doch minder geschikt voor huisbouw, orndat het spoedig door witte mieren wordt aangetast; men gebruikt het voor schenkbladen, roeispanen, enz. De zaden worden rijp en onrijp gegeten; zij komen in smaak de amandelen zeer nabij: en worden veel in gebak gebezigd; op Amboina en Banda bereidt men er een zeer gezocht hard brood van, baggêa genaamd, door ze met sago en suiker of zout te vermengen. $\mathrm{Zij}_{\mathrm{ij}}$ bevatten rijktlijk een zocte, vette olie, die tot het bereiden van spijzen gcbruikt wordt. In geneeskrachtige eigenschappen naderen deze zadell mede de amandelen. $=b$. Canarium M e henbethene Grtn., Nat. fam. dezelfde. Gr. De Molukken, zeldzaam op Java; hooge boom. GEBr. Nagenoeg als van $a$; de zaden zijn grooter, worden als ooft meer gezocht, doch bevatten minder olie.

3073. Jar-amin (Jal-amin) Ащв. = Canariopsis decumana Bl. (Zie No. 2651.)

30\%4. Jar-halat (Jal-halat) Амв. = Canarium zephyrinum Rmph., Nat. fanı. der B u r s r a c e., Gr. De Molukken; hooge boom. GeBr. De hars gelijkt on die der Dammar en wordt ook als zoodanig gebruikt; het hout is zcer geschikt voor masten; de zaden worden gegeten.

3075. Jar-mette (Jal-mette) Амв. $=\mathrm{Canarim}$ ros trat $\mathrm{rm} \mathrm{Z}$ i p p. (Zie No. 1609.)

3076. Jara-mahoe Амв. = Aleurites triloba Frst. (Zie No. 312.)

3077. Jariengoe $\mathrm{S} .=$ Acorus terretris $\mathrm{Rmph}$. (Zie No. 135.)

3078. Jasesel Амв. = Canarium microcarpum Wlld. (Zie No. 40.)

3079. Jasgil $\mathrm{Cr} .=\mathrm{Drimys}$ permuin revolutum T. \& B., Nat. fam. $\operatorname{der} A q u$ i la r i n e æ. Gr. Ceram en $N$. Guinea; heester.

3080. Jasia J. $=$ L e i o c a r pus f u u i c os u s $13 \mathrm{l}$.

3081. Jawer (Djawer) S. $=\mathrm{Cel}_{\text {- }}$ sia cristata Miq. (Zie No. 419.) be- 
nevens hare rariëteiten Jawer-ajam, J.gedeh en J.-kottok S.

3082. Jelamprong J. = Ficus oligosperma Miq., Nat. fam. der Artocar per. Gr. Java; boom.

30s3. Jena-jena Cr. $=\mathrm{Paudanus}$ Bagea Miq. (Zie No. 1673a)

3084. Jenka Mak. $=\mathrm{D}$ i o s c or e a a c u le a ta I. (Zie No. 1189.)

30š̃. Jonralloh $\mathrm{M}_{\mathrm{AK}}=\mathrm{C}$ a $\mathrm{rth}$ amus tinctorius L. (Zie No. 3897.) 3086. Jenroe Mak. = A renga saceharifera Lab. (Zie No. 243.)

3087. Jen-tjoe Сн. Bo. = II i r ab il s jalapa L. (Zie No. 140ə̃.)

3088. Jeradjo J. $=$ Clerodend r $u$ inerme Grtn. (Zie No. 1243.)

3089. Jetan Lavp. $=a$. I $\mathrm{chno}$ carpus bantamensis Miq. (Zie No. 5586$)=b$. I c hnoc a r p u s frute scens R Br. Gr. Java, enz; klimplant.

3090. Jets (Jebs) T. = Croton T i gli u m L. (Zic No. 6.)

3091. Jidjoeboe BL. $=\mathrm{Un}$ c a ri a a c id a Rxb (Zie No. 1702.)

3092. Jieriniengoh $\mathrm{M} \cdot=\mathrm{Ac}$ or u s ter restris $R \mathrm{mph}$. (Zie No. 134.)

3093. Joe-kam CH. Bo. = Cicca n od ifl o r a L a m., Nat. fam. der Eu up h o r b i a c e x. Gr. Java, Sumatra, Borneo, de Molukken; boom. Gebr. De wortel, aan welke men braakwekkende en purgeerende eigcnschappen tockent, bezit onder den bast een zeer giftig melksap, dat, aan de punt van pijltjes gesmeerd, bij hoenders onmiddellijk den dood veroorzaakt De inlander's bezigen een aftreksel ervan uitwendig tegen psoriasis plan- tar is (sakit-boeboelan J. \& M.) cn ge ven dat inwendig bij asthma, door een klein stukje met mostaardzaad en water fijn te wrijven. Als zweetdrijvend middel tegen syphilitische aandoeningen dieıt men een aftreksel der bladcren tce. De saprijke, zuurzoete vruchten worden rauw, gekookt, ingelegd en geconfijt gegeten. De zaden werken purgeerend.

3094. Joenglang $\mathrm{J}_{\mathrm{S}}=$ Methonica supe rba Lam. (Zie No $3065 a$.)

3095. Jokoe-temoenh $\mathbf{J}(?)=\mathrm{C}$ ovellia subopposita Miq. (Zie No. 1416.)

3096. Jombirrit $\mathrm{S} .=\mathrm{T}$ a be rn $x-$

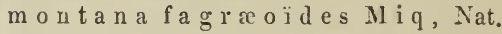
fam. der A p oс y a c ex. Gr. Java; heester.

3097. Jombo J. $=\mathrm{Xylocarpus}$ Granatum Koen. (Zie No. 1319.)

3098. Jottang S. = Plectranthus p u u c ta t u s l' iH ér i t., Nat. fam. der L a b i at e Gr Java; overblijrend (?).

3099. Jottang-gedeh $\mathrm{S} .=a . \mathrm{Oph}$ orrhiza sanguinea Bl., Nat. fam. der Rubiaccæ. Gr. Java; overblijvend. $=b$. Spilanthes oleracca Jeq, Nat. fam. der Compositæ. Gr. Java; zaadplant. GLBR. De bladeren, welke een sterke speekselvlocd opwekken, ncemt men in den mond tegen taud- of kiespijn.

3100. Jottang-goenoeng S. = Wollastonia montana D. C., Nat. fam. der Compositr. Gr. Java; kleine heester.

3101. Jottang-lumboet $\mathrm{S}$. = Spilanthes Pseudo-acmella L. (Zie No. 1753.)

3102. Juro MAk. = Arenga saecharifera Lab. (Zfe No. 243.)
3103. Ia of kaä Aur. = Gleiche. sia Hermanni i R.Br. (Zie No. 1214.)

3104. Kaào BL. = Dioscorea pentaphylla L. (Zie No. 5.)

3105. Kaba S. = Ficus tricolor Miq., Nat. fam. der Artocarpeæ. Gr. $\mathrm{J}$ a va; heester.

3]06. Kaba T. = Alocasia ma. crorhiza Schott. (Zie No. 1239.)

3107. Kabanbara $\mathrm{S} .=\mathrm{C}$ asearia velutina Bl., Nat. fam. der Samydeæ. Gr. Java en Sumatra; boom.
3108. Kabang S. \&

3109. Kabang-hitam M. = Clerodendrum lævifolium Bl., Nat. fam. der Verbenaceæ. Gr. Java; heester.

3110. Kabel BK. = Quercus Bennettii 11 iq. (Zie No. 1435.)

3111. Kabel BK. = Quercus brevipetiolatus $\mathrm{S} c h$ eff. (Zie voren.)

3112. Kabi-kabi T. = Graptophyllum hortensc Nees. (Zie No. 90.)

3113. Kabi-mangoe T. = Kalanchoë laciniata D. C. (Zie No. 46.) 
3114. Kaboe-kaboe M. = O ta n. thera Moluccana Bl. (Zie No. 2238a.)

3115. Kaboe-kaboe Bk. = Pithecolobium clypearia' Buth, Nat, fam. der M i m o ser. Gr Java, Sumatra, Borneo, de Molukken; hooge boom. GEBr. Uit den stam vervaardigt men grootc kano's, die licht, doch niet zcer duurzaam zijn, ondat het hout te vcel water opzuigt, en dus moeilijk droog wordt; men maakt uit het hout ook schilden of salowakko's. 1)c schors bezigt men tot het tanen van vischnetten.

3116. Kaboeko Br. = M etroxy$10 \mathrm{n}$ filare Mart. (Zie No. 1320.)

311\%. Kaboeng $\mathrm{R}$. = B orassus f l a bell ifor in is L, Nat. fam. der $\mathrm{Pa} l \mathrm{~m} x$. Gr. Bijna overal in dezen Ar. chipel; hooge boom. GkBr. Het harde, zwartgevlekte hout van den Lontar-Palm gcbruikt men voor kistjes cn traliewerk. De top (hoemoet) wordt rauw en gekookt bij de rijst gegeten. Beoosteu Java klopt men uit den stam dikwijls Sago, die hij rijkelijk berat. De gedroogde bladeren dienden vroeger, en doen dit ook thans nog, voor papier, waarop de inlander zijne legenden grift. $\mathrm{O}_{\mathrm{p}}$ Java plant men dezen boorn meer aan voor dc bereiding van suiker, die zoeter is dan die van den Arengpalm (No. 434), en verkregen wordt uit den aangenamen palmwijn, door insnijding vloeiende uit dc vrourvelijke bloemkolven. Volgens $R n \mathrm{mphi}$ us dient de Sagneer der mannelijke bloernkolven alleen als gèneesrniddel, en is heilzaam bij phthisis, dysenterie, enz. De vruchten zijn estbaar cn worden rauw of gekonfijt genuttigd.

3i18. Kaboer-kaboer J. = Polygonum orientale L. (Zie No. 1969.)

3119. Kaboer-kaboer-moeda .J. = Polygonum barbatnm $\mathrm{I}_{\text {. }}$ (Zie No. 21266.)

3120. Kaboewa T. $=$ Dioscorea bulbifera L. (Zie No. 4.)

3121. Kabou of kabau M. = Al. bizzia? acradena Miq., Nat. fan. der Mimosece. Fr. Sum. Wk.; boom.

3122. Kadaka-soesoerroe M. J. = Grammatophyllum speciosum Bl. (Zie No. 36 $\tilde{\tau} a$ )

3123. Kadaka-tjoeän $\mathrm{S}=a$. Smithia javanica Bnth. $\mathrm{en}=b$. Smithia sensitiva Ait., Nat. fam. der Papilionacere. Gr. Java cen Sumatra; overjarige planten; GEßr. Ic geheele plant wordt gekookt en gegeten, als ze kond geworden is, tegen moeilijke urineloozing en graveel.

3124. Kadam-kadam Sum. Wr. = a. Trichosanthes Kadam Miq. (Zie No. 1107.) $=$ b. Abutilou indicum G. Don., Nat farn. der Malvaces, Gr. Java en de Molukken; éénjarig. Gerb. Deze plant bezit verzachtendc en inwikkelende eigenschappen, even als de $\mathrm{M}$ a l v a en A l th ica.

3125. Kadatoëan $J_{.}=\mathrm{D}$ endrolobi u m u mbellat u m W. E. (Zie No. 1683 (.$)$

3126. Kadelan J. $=$ Atylos $a$ sca rabao i des Bnth., Nat. fam. der Papili o n a c e a. Gr. Java, Timor, de Molukken; zaadplant.

3127. Kadeleh of kadaleh S. M. \&

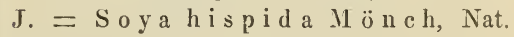
fam. der Papilion a e æ. Gr. Op Java en elders in tuinell, uit Japan overgebracht; zaadplant. Gebr. De zaden dienell tot bereiding der Soya of Kétjap.

3128. Kadipo-papoea M. $=\mathrm{C}$ o d $\mathrm{i}$ x u m molnce a n u D on. (Zie No. 126.)

3129. Kadjang S. Aut. J. = C o e1 a chne infirma $B$ ii se Nat. fam. der Gramine $x$ Gr. Java ; overjarig.

3130. Kadjang-kelang $\mathrm{S}$. = Clematis smilacifolia Wall., Nat. fam der Ranu nc ul a c e. Gr. Java; slingerplant.

3131. Kadjang of kadjoeng $\mathrm{S}$. = Uvaria purpurea Bl. (Zie No. 5736.)

3132. Kadjar S. \& J. $=$ Remusatia vivipara $\mathrm{S}$ chot t, Nat. fam. der A r o i d e ce. Gr. Java ; overjarig.

3133. Kadjar-kadjar S. \& J. $=a$. A locasia macrorhiza Schott. (Zie No. 1239.) = b. A loc as ia pube ra Schott., Nat. fam. der A ro id e $x$. Gr. Java; overjarig.

3134. Kadjou M. = A 1 a cardi um occidertale L. (Zie No. 1474.)

3134bis. Kadjou-djawa Mak., en

3135. Kadjou.kajoe MAK. = Agati g r a ndiflora De s r., Nat. fam. der Papilionacer. Gr. Door geheel Ned.Indië; boom. GEBR. De bittere bast der T o e ri zal, in kleine giften toegediend, hcilzaam zijn tegen dysenterie en spruw, in groote giften werkt hij braakwekkend; men rervaardigt uit dezen bast touw voor vischnetten; gedroogd en fijugestampt bezigt men hem tot blarketsel en als nitrendig 
geneesmiddel tegen sehurft. De bladeren eet men als groente, en gebruikt ze als zeep; zij bezitten een pijnstillend vermogen, eu dienen tot verlerlei geneeskundig gebruik. De bloemen eu jonge peulen leveren een gelief koosde groente. De gom, door insnijding uit den stam verkregen, bezigt men bij het inbinden van boeken.

3136. Kadjou-oetan M. = a. Anacardium occidentale L. (Zie No. 1474 ) en $b$. Semeearpus Cassuvi u m S prg. (Zie No. 1569.)

3137. Kado-kado $\mathrm{M} .=\mathrm{Ch}_{\mathrm{h}}$ viea sphærostaehya Miq. (Zie No. 290.)

3138. Kadoe $\mathrm{S}$. $=\mathrm{D}$ u rio $\mathrm{zibe}$ thinus L. (Zie No 2252.)

3139. Kadoekdoek J. \& BL. $=a$. Melas tom a poly anthum Bl. (Zie No. 110.) $=b$. Othanthera molu c c a n a Bl. (Zie No. 2238.)

3140. Kadoja $S_{0}=$ C a n a riopsis hispida B l. (Zie No. 1249.)

3141. Kadok MAK. =Oryza sativa I. (Semina coeta). (Zie No. 823.)

3142. Kadomaas $\mathrm{S}$. $=\mathrm{C}$ o d i $æ \mathrm{u} \mathrm{m}$ mol u e e a n u D D sn. (Zie No. 126.)

3143. Kadongdong S. \& M. $=a$. Evia aeida Bl. (Zie No. 2890.) $=b$. Evia a mara Comm., Nat. fam. der Spondiaeex. Gr. Java en de Molukken; hooge boom. GEBR. Men verkrijgt uit den stam een bittere gomhars ( $\mathrm{A} \mathrm{m} \mathbf{i}$ a ge. naamd); de vruehten worden gegeten. = c. Od in a $\mathrm{g}$ um mifera Bl (Zie No. 1990.) $=$ d. Rhus pubige r Bl., Nat. fam. der An a e a r d i c e æ. Gr. Op Java aangeplant; boom. $=e$. N othopanax obtusum Miq., Nat. fam. der Araliaee Gr. Java en Sumatra, veelal in omheiuingen; heester. Gebr. De jonge, zuuraehtige bladeren worden rauw als groente gegeten.

3144. Kadongdong-aroij $\mathrm{S} .=\mathrm{Rh}$ us nodosa Bl, Nat, fam. der Anacardi. a e e æ. Gr. Java en Sumatra; slingerpiant.

3145. Kadongdong-assam S. \& M. $=\mathrm{Evi}$ a a cida B l. (Zie No. 2890.)

3146. Kadongdong-goenoeng $\mathrm{M}$. = a. Evia a cida Bl. $=b$. Rhus retusa Zoll., Nat. fam. der A n a e a rd i a c e . Gr. Java; hooge boom.

3147. Kadongdong-laut M. $=a$. $\mathrm{Nothopanax}$ frutieos um $\mathrm{Miq}$. (Zie No. 1153) en $=b$. Nothopanax obtusum Miq. (Zie No. 314.3e.)

3148. Kadongdong-malakka M. = Evia a eid a Comm. (Zie No. 3143a.)
$3 \mathrm{~L} \pm^{\prime}$. Kidongdong-tjina $\mathrm{M}=\mathrm{N}_{\mathrm{O}}$ thopanar fruticosum. Miq. (Zie No. 1153.)

3150. Kadongdong-tjoekjoek s. = Evia borbon i e a La m.. Nat. fam, der S pondiacea. Gr. Java in tuinen, vall Borrlbon overgebraeht; hooge boom. GEBR. De wortel, bast en knoppen worden, om hunne samentrekkende eigenscliappen. als geneesmiddel aangewend; de zuuraehtige vruehten worlen gegeten en tegen galaehtige aandoeningen aangewend.

3]5]. Kafoewo T. $=$ Di o sc or ea b u lb i f e a L. (Zie No. 4.)

3152. Kahamaisso $\mathrm{T} .=\mathrm{A}$ garieus tuber regium Tr. (Zie No. 1959.) en $\mathrm{Pachyma}$ tuber regi in $\mathrm{Tr}$. (Zie No. 1959 )

3153. Kahil $\mathrm{Cr}_{\text {. }}=\mathrm{Br}$ u gu i e a Rumphi i Bl. (Zie No. S66b.)

3154 . Kahitoetan S. = I a s i a n. thus purpureus Bl, Nat fam. der $\mathrm{R} \mathrm{u}$ b i a e e $œ$. Gr. Java; heester. Gebr. De onaangenaam riekende bladeren vau alle Lasianthus- en Saprosmasoorten worden als geneesmiddel toegediend tegen gastrisehe opgezetheid vau den buik. troinmelz:cht, wormziekte der kindesen en ook aan kraamvrouwen, pas na de bevalling,g egeven $=b$. S a pros ma a r bore u m B l. Gr. Java, Sumatra, Borneo en Nieuw-Guinea; $=c$. S a prosma d i spar Ha ssk. Gr. Java. = d. S a. prosm a fruticosum. Bl. Gr. Java; alle heesters van de Nat. fain. der $k$ ub i a c e $x$. Gebr. Zie $a$; het hout van $b$ in den handel kitaai S. of kajoe-taai M. genoemd. en op rele bazars te koop, $z a l$, volgens Waitz, bij zenuwaandoeningen zeer werkzaain yijn.

3155. Kahit-ritan J. = Eurya glab ra B l., Nat. fam. der Ternstroemia eеæ. Gr. Java; groote heester. Gebr. Het fijne hout is niet sterk eu dus ondeugdzaam; het wordt spoedig door witte mieren aangetast en alleen voor de stijlen. van hutjes in de rijstvelden gebruikt.

3156. Kahoeroeman $\mathrm{BK} .=\mathrm{Spa}$. thodea $L$ ob bi i T. \& B.. Nat. fam. der Bign on i a e ex. Gr. Sumatra en Bangka; boom.

3157. Kaibobo Cr. $=\mathrm{C}$ as sia $\mathrm{mi-}$ mosoides l.., var. angus tissima, Nat. fam der Papilionace æ. Gr. W.-Java, Celebes en de Molukken; heester. Gerr. Volgens $\mathrm{Ru} \mathrm{m} \mathrm{ph}$ i u s wordt het kruid dikwijls in minnebrieven gesloten. 
3158. Kaim-goeloer Ar. = M y risti c a a r u a a B l. (Zie No. 1466.)

31 9. Kaïma Mes. $=\mathrm{J}$ a m bos a c or n ifoli a Bl., Nat. fam. der My r-

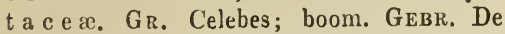
fraai roode, zure vruchten zijn zeer gezocht en worden rauw en ingezouten genuttigd.

3160. Rait-kait $\mathrm{M}_{0}=\mathrm{Un}$ c a ria pedicellata $R \times b$., Nat. fam. der R o b i a c ex. Gr. Java, Sumatra, Borneo en de Molukken; slingerplant, Ge BR. Deze struik bevat Catechu of Gutta gambir.

3161. Kait.kait-toepai M. = U n. c aria ferr uginea D. C. (Zie No. 2392.)

3162. Kajan S. $=$ Quercus map. a ce a Kths., Nat. fam. der Cup ulif e r æ. GR. Java, Sumatra, Borneo; hooge boom.

3163. Kajar-kajar S. = A l o c a sia macrorhiza Schott. (Zie No. 1239.)

3164. Kaij-kaijl Амв. $=$ Uncari a a cida $R \times b$. (Zie No. 1702.)

315. Kaij.ketoelan S. = Le pi 0 nurus sylvestris Bl., Nat. fam. der Ol a c in ex. Gr. Java; heester.

3166. Kai-moni M. $=\mathbf{M ~ u r r a ~ y ~ a ~}$ Sum a trana $R \times b$. (Zie No. 1723.)

3167. Kaij-rekewang Mes. = Covellia stictocarpa Miq. (Zie No. 1 วัษ $3 d$.)

3168. Kaij-woelan MeN. = Mu ssaenda frondosa L. (Zie No. 74.)

3169. Kaij-wori MeN. $=\mathrm{O}$ r moc a $\mathrm{r}$ u m g la brum T. \& B. (Zie No. 1539.)

3170. Kajoe M. Beteckent hout en is, even als $\mathbf{K} \mathbf{i} \mathrm{S}$, een zeer gebruikelijk ? voorzetsel bij vclc plautcunamen.

3171. Kajoe-aboe M. = Melios. m a la nce olat a Bl., var. charta. c e a, Nat. fam. der M e li o s m e x. Gr. Sumatra; heester. GEBR. Het hout der M e li o s m a-soorten is grof, rood en zeer week, wordt spoedig door insekten verteerd en alleen voor huisraad geberigd.

3172. Kajoe-ajer-laki-laki $\mathrm{M} .=\mathrm{A} \mathrm{ra}$ li a java n i a B l. (?). (Zic No. 909a.)

3173. Bajoe-ajer-parampoean M.= Leea sambucin a Wlld. (Zie No. 133.)

3174. Kajoe-ambaloe Вк. = D is o $x$ y lum a c utang ulum Miq. (Zie No. 272.)

3175. Kajoe-ambo M. Sus. = Podocarpus cupressina R B r. (Zic No. 2920.)
3176. Kajoe-anau LaMP. = A n a u a s u matran a Miq. Nat. fam.der Tilia c e æ. Gr. Sumatra; boom.

3177. Kajoe-angring $\mathrm{S}_{0}=\mathrm{D}$ a $\mathrm{m}$ $\mathrm{m}$ a r a lba. $\mathrm{Rmph}$. (Zie No. 1618.)

3178. Kajoe-angrin M. $=a$. Cas uarina equisetifolia Frst. en $=$ b. Casuarina nodiflora Frst. (Zie No. 122)

3179. Kajoe-angring $\mathrm{J}_{0}=\mathrm{P}$ a ras ponia parviflora Miq., Nat. fam. der Celt i dex. Gr. Oost-Java; boom.

3180. Kajoe-angrit $\mathrm{J}_{0}=\mathrm{J}_{\mathrm{a} \mathrm{m} \text { b o s a }}$ r h y chophylla Mi q, Nat. fam. der M y r t a c e æ. Gr. Java; boom.

3181. Kajoe-anjang MAD. $=$ Salix Z ollingeri a a Miq, Nat. fam. der

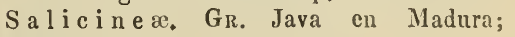
boom.

3182. Kajoe-ápi-api M. = a. A gic e ras majus Gr.t.n. (Zie No. 15ว6.) $=6$. Avicennia alba Bl. (Zie No. $416 b$.) $=c$. Avicennia officinali s L. (Zie No, 14.)

3183. Kajoe-apoen S. $=\mathrm{P}$ is t i $\mathrm{s}$ Stratiotes I. (Zie No. 1669.)

3184. Kajoe-ara-maas Bк. = $\mathrm{C}$ di x um moluceanum Desn. (Zic No. 126.)

3185. Kajoe-ara-pienda $\mathrm{BK}_{0}=\mathrm{Ph}$ hnicanthemum pentapetalum Miq., Nat. fam. der Lorant h a c e GR. Bangka ; parasiet.

3186. Kajoe-ara-tampa M. = U rostigma flavescens Miq. (Zic No. 1314 )

3187. Kajoe-arak I. $=\alpha$. Vitex $\mathrm{pubescens}$ Vhl. (Zie No. 4.30c.) = b. Vitex le ucoxylon L. fs. Nat. fam. der V c r be n a e æ. Gr. Java; dikkc boom.

3188. Kajoe-arang M. $=a$. M a b a Ebenus RBr. E $b$. Diospyos ol e if oli a Wa 11. Nat. fam. der Ebcn a c e a. Gr. Java; middelmatige boom. (Zie No. 107.)

3189. Kajoe-arang Mes. = Crat o x y l u m c el c b i c u B 1., Nat. fam. der H y p c ri ci n eæ. Gr. Celebes; boon. GEBR. Het hout is zecr hard, wordt niet door paalworm aangevreten, is geschikt voor inhouten en masten van prauwen cu lcvert zeer deugdzame houtskool.

3190. Kajoe-arang $\mathrm{BK}$. $=\mathrm{Sizy}$ g i u m brachybot rium Miq., Nat. fam. der M y rtace c. Gr. Sumatra, Bangka; hooge boom. 
3191. Kajoe-arang-0etan $\mathbf{~ 1 1}=1$ ) io spy r o s Eben um litz. (Zie No. 32.)

3192. Kajoe-assam $\mathbf{~} 1 .=\mathrm{T}$ a $\mathrm{ma-}$ rindus indica I, (Zie No 723)

3!93. Kajoe-assam-besaar $\mathrm{I} .=$ $\mathrm{G}$ a r c in i a C a mbog i a D esr. (Zie No. 733.)

3194. Kajoe-auwaran $\mathrm{BD} .=\mathrm{Plum}$ b a g o rosea L. (Zie No. 114.)

3195. Kajoe baai Laxp. = Gu a tteria Parveana $\mathbf{M i q}$, Nat. fam. der A n o n a c c ie. Gr. Sumatra, Java; boom.

3196. Kajoe-babasaran MI. = M or us ind i c a L. (Zie No. $797 a$.)

3197. Kajoe-babi S. $=$ Henslovia paniculata Miq. (Zie No. 803.)

3198. Kajoe-badar Sum. Wк. en

3199. Kajoe-badjok M. = B o b e a sericantha Miq., Nat fam. der Rub i a c e $\ltimes G_{r}$. Sumatra, Baugka; heestcr. 3200. Kajoe-bakkat J. \& M. = Cassia javanic a I. (Zie No. 1025.) 3201. Kajoe-bako M. = X ylocarpus Granatum Kocn." (Zie No. 1319.)

3202. Kajoe-balangeran $\mathrm{M}, \mathrm{Bo} . \mathrm{ZK}$. $=\mathrm{II}$ o pea balangeran Krths. (Zie No 898.)

3203 . Kajoe-banin J. = $\approx \mathrm{gice}$ ras majus Grtn. (Zie No. 1556.)

3204. Kajoe-banin $\mathrm{PA}_{\mathrm{A}}=\mathrm{T}$ al a . ma gigantifolia Miq. (Zie No. 960.)

3205. Kajoe-bappa $\mathrm{T}$. $=$ H оре а sela ni c a $\mathrm{k} \times$ b. (Zie No. 824.)

3206. Kajoe-barana M. = Rhodolcia Teysmanni Miq., Nat. fam. der 1) io smeæ. Gr. Sumatra; heester.

3207. Kajoe-barbak PaL, = Rottlera flavigutta Miq, Nat. fam. der E u phorbi aceæ. Gr. Sumatra Ok.; heester.

3208. Kajoe-barito $M .=$ Tetranthera varians Bl., Nat. fam. der I, a u rineæ Gr. Borne', Cclebes, Sumatra; boom.

3209. Kajoe-baroedan (eigenlijk Kajoe-paroedan) $\mathrm{M}$. = $\mathrm{Fli} \| \mathrm{d}$ e rsia a mbo in en s is Poir., Nat. fam. der C edrole a Gr. Amboina en Ceram; hooge boom. GEBR. Het hout bezigt nien voor stijlcn en timmerhout; de ho itige doorn. rijke vruchten gebruikt dc inlander in plaats van rasp.

3210. Kajoe-batoe lamp. = Hom ali u m grandiflor um Benth., Nat. fain. der $\mathrm{H}$ om a li n e $æ$. Gr. Sumatra; hooge boom

3.11. Kajoe-bawang M. en
3212. Kajoe-bawang poetih $M .=1: y-$ soxylnm alliaceum Bl. Nat. fam. der Meliaccae. Gr. Java en de Molukken; hooge boont. GEBR. Men gcbruikt het hout voor bouwhout ell gercedschappen; het is niet sterk en wordt spoedig door insekten aangetast. 1)c blad.ren en zadcu kunnen, bij wijzc van uien, als ioespijs gegeten worden.

3213. Kajoe-bedak Sus. Wк. = Eurya hirsutula IIiq (Zic No. 809) 3214. Kajoe-bedara SuM. $=\mathrm{M} \mathrm{y-}$ ristica corticosa Hk. fs. \& 'T. (Zie No. 137.)

3215. Kajoe-beghas PAI. = $\mathrm{V}$ ang n e r i a (C)ant is ium) palembanica M i q, Nat. fam der R u bi a ceæ. Gr. Sumatra en Bangka; heester.

3216. Kajoe-be zhas $P_{A L}$ (Zie vorig No.)

3217. Kajoe-bêlo $\mathbf{M}=a$. Schleic hera trijuga Wlld. (Zie No. 47.) $=b$. Timonius $R$ umphi Bl. (eu B o be a Sp.?), Nat fam. der ll n b i aс с $æ$ Gr De Molukken; boom. Grir. Het hout der lange en rechte takken gebruikt men voor zeroo's en voor daksparren; het is dunrzaam in het zcewater; de schors kan men in plaats van Pinang bij de siri kauwen; de wortcls kauwt men tegen koortsige aandoeningen.

3218. Kajoe-bemban PaL. $=G$ uatteria Bem ban M iq, Nat. fam. der A non a c cæ Gr Sumatra Ok, ; boom. 3219. Kajoe-bener $\mathrm{M}$. = H a r t. ighsea angustifolia Miq.. Nat. fam. der II eli a cex. Gr. Sumatra Wk.; hooge boom.

$322 \mathrm{C}$. Kajoe-bêranakh M. = Cas t anea? scssilifoli a Bl., Nat. fam. der C u p u li fe ræ. Gr. Java; hooge boom.

3221. Kajoe-bernam $\mathrm{M}=\mathrm{C}$ o r d y li 1 e oxy phylla $.1 \mathrm{iq}$., Nat. fam. der As p a ragi iner. Gr. Jumatra Wk.; heester.

3222. Kajoe-besaar $\mathrm{M}=\mathrm{M}$ o $\mathrm{r} \mathrm{s}$

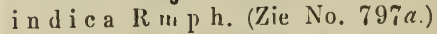

3223. Kajoe-bessie M. $=a$. Eusideroxylor Zwageri T. \& B. (Zie No. 1103.) $=b$ Intsia amboincnsis Thrs. (Zie No. 830.) $=c$ Nania vera Miq. (Zic No. 2779h.) =d. Bl ackwellia $f \propto t$ ida W all. (Zie No. 2779r.) $=e . \mathrm{Schleicheratrijuga} \mathrm{WlJd.}$ (Zie No. 47.) =f. Dodonæa Wait$\mathrm{z}$ i a n a B l., Nat. fam. der S a pindac e 2 . Oost-Java; bnom.

3224. Kajoe-bessie-bener $\mathrm{M} .=\mathrm{N}$ ania vera 11 iq (7ie No. 2779b.) 
3225. Kajoe-bidara PAL. $=$ Myristica palembanica $M$ iq, Nat. fam. der M y risticeæ Gr Sumatra Ok.; boom. 3226. Kajoe-bidara-laut M. of 3227. Kajoe-bidara-pahit $\mathrm{M}$. = Stryehnos murieat a Kostel. Nat. fam. der Loganiaces. Gr. Java. Timor er de Molnkken; boom. Gebr. Deze boom levert een wit, hard, niet zeer dik hout, dat a's geneesmiddel op alle bazars te koop en zeer gezocht is, en ten curechte voor Lignum $Q$ uassiæ wordt gehouden; het wordt a!s tonie um zeer dikwijls toegediend bij diarrhoea, dysenterie, spruw, koortsen en algemeene lichaamszwakte als gevolg daarvan, en blijkt vaak heilzaam.

3228. Kajoe-bilies MaD. = S e epas in a parvifolia R. \& Z. Nat. fam. der Euphorbiace $x$ Gr. Madura; heester.

3229. Kajoe-bintang MeN. = Muss a ënda frondos a L. (Zie No. 74.)

3230. Kajoe-bobata $\mathrm{T} .=\mathrm{An} \mathrm{a-}$ mirta flavescens li iq. (Zie No. $645 b)$.

323I. Kajoe-boddas S. en

3232. Kajoe-boddi MaK. = Urostig in a R umphii Miq. (Zie No. 103.) 3233. Kajoe-boelan $\mathrm{T}$. $=\mathrm{P}$ is onia alba Span. (Zie No. 320b.)

3234. Kajoe-boelan $В$. $=\mathrm{Qu}$ isqualis indiea I., Nat. fam. der Com. bretaceæ Gr. Vrij algemeen in Indië. GrizR. De bladeren worden somtijds als grvente, somtijds als wormdrijvend middel gegeten. Zeer algemeen is het gebruik der zaden als wormdrijvend middel; men geeft ze aan kinderen en volwassenen, zoo rijp als onrijp, of bij wijze van amandelen, waarnaar zij smaken, te eten, of men stampt ze fijn en dient ze met eenig aromatisch middel vermengd toe. Bij kinderen moet men echter zeer voorzichtig er mede zijn, daar zij lichtelijk braking, hik, duizeligheid, enz. veroorzaken.

3235. Kajoe-boelang $\mathrm{M} .=\mathrm{E} \mathbf{v}$. nymus javanie

3236. $\mathrm{Ka}$ e-boeloe BK. = M yrsine aven is A. Dc. (Zie No. 4235.)

3237. Kajoe-boeloe J. $=a$. Uros. $\mathrm{t} i \mathrm{~g}$ in a al tissimum Miq., Nat. fam. der Artoc a r p a. Gr. Java; boom. = b. Glochidion littorale Bl.var. banesnum. Nat. fam. der kuphor. b i a с ес. Gr. Java, Sımatra, Baıgka ; heester.
3238. Kajoe-boeloeng $\mathrm{S} .=\mathrm{C}$ searia subcuneata .11 iq., Nat. fa'n. der $\mathrm{S}$ a $\mathrm{m}$ y d e æ. Gr. Java; boom.

3239. Kajoe-boeta M. = $\mathrm{E}_{\mathbf{x} \text { e }}$ c a ria A gallo eh a L. (Zie No. 22b)

3240. Kajoe-boeton $\mathrm{M}$. = $\mathrm{B}$ a rringtonia speeiosa L. (Zie No. 1463 )

3241. Kajoe-boloh $\mathrm{BK}_{\mathrm{K}}=\mathrm{A} q \mathrm{quil}$ aria? b a neana Miq. (Zie No. 2441.)

3242. Kajoe-boolo Вк. = G о п y stylus baneanus Kurz., Nat. fa!n der Thy in el a a e æ. Gr Bangka; boom, mogelijk dezelfde als het vorig No.

3243. Kajoe-bras Lamp. = Trigoniastrum hy oleucum Miq. Nat. fain. der Trigonia e æ. Gr. Sumatra; heester.

3244. Kajoe-briang M. Sum. = $J$ a s m in um insigne Bl., Nat. fam. der J a smineæ. Gr. Sumatra Wk.; klinplant.

3245. Kajoe-dadieh Sum. $=$ U rostigma globosum Miq., Nat fam. der A r t o c a r p e . Gr. Java en Sumatra; klimplant.

3246. Kajoe-daha PAL. $=\mathrm{Uro-}$ phyllum umbellulatum Miq., Nat. fam. der Rubiaceæ. Gr. Sumatra Ok.; boom.

3247. Kajoe-dawar M. = Costus speeiosus L., Nat. fam. der Zingiberacex. Gr. Door geheel Indië in het wild en in tuinen; overjarig. GEBR. Volgens Endlieher is de wortel als bitter tonisch middel in gebruik. $\mathrm{R} u \mathrm{~m}$ $\mathrm{ph}$ i us roeint deze plant als verkoelend en zweetdrijvend, en zegt dat de bladereu als groente worden gegeten, en aangewend bij outstoken oogen en ter bevordering van den haargroei Volgens inlandsehe opgaven, worden de zaden als lekkernij gegeten; bezigt men het fijngekneusde kruid uit. wendig op slaugenbeten, dient men het sap der stengels tegen dysenterie toe, en gebruiken kraamvrouwen den wortel als kraamzuiverend middel.

3248. Kajoe-dehian PAL. $=\mathrm{Ag}$ la ja exi uni a Miq., Nat. fan. der M eli a c e ז. GR. Sumatra. Ok.; boom. 3249. Kajoe-demang (of kajoedemam?) BK. = a C a r y phyllus fastigiatus B l. (Zie No. 2544.) = b. Nelitris pallescens $\mathbf{M i q . ,}$ Nat. fam. der M y r t a c e $æ$ GR Bangka; heester.

3250. Kajoe-djakoel LAMP. $=\mathrm{Hal}^{\circ}$ 
tighsea costulata Mig., Nat. fam. der $\mathrm{II}$ e li a c e $x$; hooge boom. Gr. Sumatra.

3251. Kajoe-djamboe PaL. $=\mathrm{J}$ amb os a p ni c ti c u la ta Mi q, Nat. fam. der II yrtace x. Gr. Sumatra Ok.; hooge boom.

3252. Kajoe-djaran $\mathrm{S} .=a .0 \mathrm{di}-$ u a g u m m if e r a B l. (Zie No. 1990.) $=b$. Spathodea Diepenhorstii Miq., Nat. fam. der Bignonia ce æ. Gu. Sumatra; boom. $=c$. S p at hod e a $\mathrm{R}$ h e e d i i $W$ all. Gr. Java, Timor, Amboina; boom. GeBr. Van het hout van dezen boom verraardigt men dozen, sandalen en speelgoed.

3253. Kajoe-djati PaL. $=\mathrm{Mi}$. crose pala a cuminat a Miq. (Zie No. 1083.)

3254. Kajoe-djepoen. M. $=\mathrm{P}$ a rkinsonia a cule ata $I_{\text {. }}$, Nat. fam. der P a pilion a c e $x$. GR. Jara, Borneo, als sierplant in tuinen; hecster.

3255. Kajoe-djoengeh SuM. Wk. = Pyrenaria villosula Miq., Nat. fam. der C a melli a c e æ. Gr. Sumatra; boom.

3256. Kajoe-doelang BL. $=\mathrm{C}$ a ssi a fistula L. (Zie No. $1306 a$.)

3257. Kajoe-dôs. Laup. = En d iandra cuneata Miq.. Nat fam. der L a u r i n e .. Gr. Sumatra; boom.

3258. Kajoe-entra-mangâs M. = Ml emecylon edule Rxb. (Zie No. $4390 c$ )

3259. Kajoe-gaboes $\mathrm{N} .=\mathrm{Al}$. stonia scholaris R.Br. (Zie No. 2350.)

3260. Kajoe-gaboes-leutiek S. $=$ Blaberopus sericeus A. D.C., Nat. fam. der A p o c y n e æ. Gr. Java en Timor; heester.

3261. Kajoe-gading $\mathrm{BK}$. $=\mathrm{C}$ a $\mathrm{n}$ ti u $\mathrm{m}$ a le mbani cum T. \& B. (Zie No. 3215.$)$

3262. Kajoe-gadis $\mathrm{MI}=a$. U rostigma T jiela M i q. (Zie No. 3048.) $=b$. Pathenoxylon porrectum Bl. Nat. fam. der I, a u r in e æ. Gr. Java en Sumatra; hooge boom. Gerr. Men bezigt het grove, roode en sterke hout voor huisbouw; het wordt niet doorinsecten aangetast.

3263. Kajoe-gadong $\mathrm{S} .=$ P r e mna tomentosa Wlld. (Zie No. 1412.)

3264. Kajoe-galedoepa MoI. = Derris Forsteniana Bl., Nat. fam. der Papilionace ce. Gr. De Molukken, Celebes, Borneo; klimmende heester. Gebr. De uit den stam verkregen zwarte balsem dient tot samenstelling der Doepa, een reukwerk, even als wierook zeer gezocht. De steugels gebruikt men voor bindwerk en tot vischvergiftiging.

3265. Kajoe-ganemoe Mks. = Gnetum latifulium Bl., Nat. fam. der G n e tâ c e æ. Gr. Celebes. Java, slingerplant. Grbr. Waarschijnlijk even als No. 200.

3266. Kajoe-gara $\mathrm{P}_{\mathrm{AL}}$. $=\mathrm{C}$ a r y ophyllus fastigiatus Bl. (Zie No. 2544.)

3267. Kajoe-garoe M. $=a$. A q u ilaria A gallocha Roxb. (Zie No. $22 a.)=6$. A lo ëxylon Agallochum Lour., Nat. fam. der Papilionacex. Gr. Bormeo; boom. Geir. Deze boom levert het in den handel gezochte en beroemdc Aloë-hout; de stam levert een kostbarc hars op. $=c$. Urostigm a elasticum Miq. (Zie No. 24406.)

d. Gonystylus Miquelianus T.\& B., Nat. fam. der A quilarineæ. Gr. Java; hooge boom.

3268. Kajoe-garoe-engkares Bo. $=$ A quilaria Agallocha Rxb. (Zie No. 22a.)

3269. Kajoe-gedong Sux. Wk. = S y mplocos lachnobotrya Miq., Nat. fam. der S t y r a c æ. GR. Suma. tra; heester.

3270. Kajoe-gedong-arês $\mathrm{S}$. = Z eh neria deltoidea Miq. (Zie Nio. 2492.)

3271. Kajoe-gelam M. = M e laleuca leucadendron L. (Zie No. $120 a$.)

3272. Kajoe-gitta J. = Excœca$\mathrm{r}$ i a $\mathrm{A}$ g a ll o ch a L. (Zie No. 22b.)

3273. Kajoe-goela Sum. $=\mathrm{H} \mathrm{y} \mathrm{d}$ nocarpus $l æ v$ is Miq. Nat. fam der B i x a c e $æ$. Gr. Sumatra; boom.

3274. Kajoe-goele LaMP. = Bergs. mia? a cuminat a Miq., Nat. fam. der Bi $\mathbf{s}$ a c e $æ$. Gr. Lampongs; boom.

3275 . Kajoe-goendoeng $\mathrm{M} .=\mathrm{S}$ a uraya singalensis Korth. Nat. fam. der T ernstroemia ceæ. Gr. Sumatia ; heester.

3276. Kajoe-goenjoh Sum. = A glai a angustifolia T. \& B., Nat. fam. der M eli a ceæ. Gr. Sumatra; boom.

3277. Kajoe-goerda M. = Gua- 
z u m a tom entos a H., B. en K. (Zie No. 2015.)

3278. Kajce-gorita. M. = Trevesia moluccana $M \mathrm{iq.,}$ (Zie No. 78.)

3279. Kajoe-gretje M. = Cerbe$r$ a lact a ria $\mathrm{Ham}$. (Zie No. 1182).

3280. Kajoe-hoän BD. = Phaseolus radiat us L. (Zic No. 31.)

3281. Kajoe-hoän PaL. = Urophyllum coriacenm Miq., Nat. fam. der R ubiaceæ. Gr. Sumatra; boom.

3282. Kajoe-hoenjoh M. $=\mathrm{Har}$ tighsea angustifolia Miq. (Zie No. 3219.)

3283. Kajof-ida PAL. $=$ Eurya virens Bl., Nat. fam. der Ternstromiaceæ, Gr. Sumatra; boom.

3284. Kajoe.ikan-manassin $\mathrm{BD}$. = a. Ocimum sanctu in I. (Zie No. 875.) $=$ b. Ocimum gratissimum L. (Zie No. 14586.)

3285. Kajoe-itam (hitam) M. = Diospyros Ebcnum Rtz. (Zie No. 32.)

3286. Kajoe-japan J. = Cæsal. pinia pulcherima Sw. (Zie No. 1386.)

3287. Kajoe-kaleh Sum Wk. =Syzygium subnodosum Miq.; Nat. fam. der Myrtacex. Gr. Sumatra; boom.

3288. Kajoe-kaleh PAL. = Caryophyllus fastigiatus Bl. (Zie No. 2544 .)

3289. Kajoe-kaleh $\mathrm{M}_{\text {. }}=\mathrm{Harpul}$ li a cupanio ides $\mathrm{R} x \mathrm{~b}$., Nat. fam. der Sa p ind a ce r. Gr. Vrij algemeen in Indië; boom. GEBr. Alle deelen van dezen boom, doch vooral de zaden, worden voor zeer giftig gehouden.

3290. Ka joe-kaleh-aloes-dawon PAI, $=$ Syzygi um minutiflorum Miq., Nat. fam. der Myrtaceæ Gr. Sumatra; boom.

3291 . Kajoe-kaleh-djamboe-ajer Sum. Wk. = Jambosa? anostomosens II i I., Nat. fam. als voren. Gr. Sumatra; boom.

3292. Kajoe-kaleh-njang-djanten Stm. Wk. = Polygala sumatrana Miq., Nat. fam. der Polygalea. Gr. Sumatra; ovcrblijvend.

3293. Kajoe-kaleh-simienjak M. = Lonicera sumatrana Miq., Nat. fam. der Caprifoliacex. Gr. Sumatra; heester.

3294. Kajoe-kambing $M_{\mathrm{EN}}=\mathrm{Rhus}$ rufa T. \& B., Nat. fam. der A nacardiacex. Gr. Noord-Celebes; hooge boom.
GEBR. Het hout is zeer geschikt voor huisbouw; het geeft duurzame stijlen en planken. J)e jonge bladeren bezigt men tot het roodverwen van vloermatjes en andere zaken.

3295. Kajoe-kameleäng LAмP. $=$ Calyptroon sumatranum Miq., Nat. fam. der A porosea. Gr. Sumatra; boom. 3296. Kajoe-kantekka J. = Avicennia officinalis L. (Zie No. 14.)

3297. Kajoe-kantjil M. = $\mathrm{Halc}$. $\mathrm{r}$ agis disticha Jack, Nat. fam. der $\mathrm{Hal}$ a a geæ. Gr. Sumatra; hecster.

3298. Kajoe-kapal M. = Excoecaria Agallocha L. (Zie No. 22b.)

3299. Kajoe-kapas M. = Chæn olobium decemjugum Miq., Nat.fam. der Papilionaceæ. Gr. Sumatra Ok; heester.

3300. Kajoe-kapoer M. = Canarinm euptar on Miq., Nat. fam. der A m yridea. Gr. Sumatra; hooge boom. Geв r. dezc boom is zeer rijk aan hars en levert in den handel de Lagam-olie, waarmede onvoldoende proeven als antigonorrhoidum zijn genomen.

3301. Kajoe-kapoer MeN $=\mathrm{Cla}$. oxylon indicum Endl. (Zie No. 1268.)

3302. Kajoe-karvori M. =- Intsia a mboinensis Thrs. (Zie No. 830.)

3303. Kajoe-kawan I. $=$ Hopea selanica Rxb. (Zie No. 824)

3304. Kajoe-keboel LAмP. = Eury coma longifolia Jack. (Zie No. 804.)

330ว. Kajoe-keboeloh IAnP. $=\mathrm{La}^{-}$ sianthes oculus-cati $R$ wdt. Nat. fam. der Rubiacea. Gr. Java, Sumatra, Borneo; kleinc heester. GEBR. Het sap wordt als verkoelende drank tegen koortsen gegeven.

3306. Kajoe-kedjoh PAL. 二 Terminalia a denopoda Miq., Nat. fam. der Combretacer. Gr. Sumatra; hooge boom.

3307. Kajoe-kekepoel Lamy. en

3308. Kajoe-kepoel LAMP. $=a \mathrm{Pa-}$ rinarium sumatranum Benth. (Zie No. 795) en $=6$. Parinarum polyneurum Miq. (Zie No.2253)

3309. Kajoe-kelingoh LAMP. $=\mathrm{An}$ tidesma microcarpum Miq., Nat. fam. de Antidesmex. GR. Sumatra; boom.

3310. Kajoe-kemando LAMi. $=A \mathrm{l}$ tocarpus Kemando Miq., Nat. fam. der A rtocarpex. Gr. Sumatra; boom.

3311. Kajoe-keminjan M. - a 
Stryax Benzuiu Dryand. en = b. Stryax subdenticulata Miq., Nat. fam. der Stryracex. Gr a. Java, Sumatra en elders, $b$. Sumatra; beide hooge boomen. GEBR. Ilet hout is een slecht bouwhout, dat spoedig wordt aangevreten. De hars is in den handel zeer gezocht als reukmiddel en ter berooking. Het medisch nut der Benzoë en van het Benzoëzuur is nit de handboeken bekeud.

3312. Kajoe-kendoen $\mathrm{S} \& \mathrm{~J}$. = Barringtonia Reinwardtii Miq., Nat. farn. der M yrtaceæ. GR. Java; boom.

3313. Kajoe-ketjil Sum. Wk. = Glochidion varians Miq., Nat. fam. der E u phorbiaceæ Gr. Sumatra; heester.

3314. Kajot-damar BK. en

3315. Kaj00-ketoh BK. = Shorea sublacunosa Miq., var. angustifolia. (Zie damar-serang Вк.)

3316. Kajoe-kilam $\mathrm{M}=a . \Delta \mathrm{e}-$ la leuca leucadendrum I. (Zie No. $120 a.)=b$. Melalcuca Cajuputi $\mathrm{Rxb}$. (Zie No. 1737 d.) $=c$. Melale uca minor Sm. (Zie No. 2478b.)

3317. Kajoe-klapok $\mathrm{L}_{\Lambda M P}$. $=$ Tala uma gigantifolia Miq. (Zie No. 960.)

3318. Kajoe-koeda M. = a. Kajoe-djaran S. $=b$. Excœcaria Agallocha I. (Zie No. 22b.) $=c$. S arco. cephalas subditus Miq.; Nat. fam. der Rubiaceo. Gr. Java, Sumatra en Borneo; hooge boom.

3319. Kajoe-koekoen M. $=$ Heritiera littoralis Dryand. (ZieNo.752a.)

3320. Kajoe-koembang-molak S. = Lasianthus Lucidus Bl., Nat. : fam. der Rubiacese. Gr. Java: heester.

3321. Kajoe- oemit M. = Premna flavida Miq., Nat. fam. der Verbenaceæ. Gr. Sumatra Wk.; heester.

3322. Kajoe-koempang LAMP. = Syn œcia diversifolia Miq. (Zie No. 418.)

3323. Kajoe-koening M. $=a$. Anthocephalus? Cadamba Miq. (Zie No. 391.) $=b$. Nauclea parvifolia $\mathrm{R} \times \mathrm{b}$. (Zie No, 969.)

3324. Kajoe-koepang M. $=\mathrm{Chæ}$ nolobium decemjugum Miq. (Zie No. 3299.)

3325. Kajoe-koetana M. = Pittosporum Rumphii Pütterl. (Zie No 319.)

3326. Kajoe-kompit $\mathrm{PAL}_{\mathrm{L}}=\mathrm{Nau}-$ clea a ralioides $1 /$ iq. Nat. fam. der Rubi accæ. Gr. Sumatra; boom.

3327. Kajoe-korang $\mathrm{M}$. = Ar alia javanica Miq. (Zie No. 909a.)

3328. Kajoe-kratong BK. = Helicia obovata Bunt., Nat. fam. der Proteacer. Gr. Java en Bangka; heester.

$33: 9$. Kajoe-lada II. = Parthenoxylon porrectum Bl. (Zic No. 32626 )

3330. Kajoe-lakka I AMP. = Dalbergia Zollingeriana Miq. (Zie No. $1316 b$ )

3331. Kajoe-Jakka T. = Lawsonia alba Isa in. (Zie Na. 1747.)

3332. Kajoe-lalakki .I. cn

3333 Kajoe-lalang $\mathbf{J}=$ Calosantlres indica Bl. (Zie No. 14ls.)

3334. Kajoe-lale BD. $=$ A brus præcatorius L. (Zie No. 53.)

3335. Kajoe-lamassa LaMP. $=\mathrm{C}_{0}$ vellia a urata Miq, Nat. fam. der Artoca $r_{1}$ eæ. Gr. Sumatra, Bangka; boom.

3336. Kajoe-lampang PAL. $=$ Pseudotrewia cu neifolia Miq., Nat. fan. der Euphorbiacex. Gr Sumatra OK.; boom.

3337. Kajoe-lampar $\mathrm{PA}_{\mathbf{i}}=\mathrm{Ara-}$ lidium dentatum Miq, Nat. fam. der Araliaceæ. Gr. Sumatra; heester.

3338. Kajoe-landak M. = Prion itis bystrix Miq. (Zie No. 1377.)

3339. Kajoe-landin Sum WK. = Pilea pyrrhotricha Miq., Nat. fam. der Urticaceæ. Gr. Sumatra; heester.

3340. Kajoe-landoh Sum. O.K. = Talauma gigantifolia Miq. (Zie No. 960.)

3341. Kajoe-langhit M. = Ailanthus moluccana D.C. (Zie No 57.)

3342. Kajoe-lapi LaMP. = Memecylon lampongum Miq., Nat. fam. der Melastomacex. Gr. Lampongs; heester.

3343. Kajoe-lassi Амв. $=\mathrm{N}$ a uclea fagifolia T. \& B.; Nat. fam. der Rubiacer. Gr. Amboina, hooge boom.

3344. Kajoe-lassi M. $=$ Echinus trisulcus Lour. (Volgens Miquel is deze vermoedelijk te rangschikken onder het geslacht $\mathrm{C} \propto \mathrm{lodep}$ as Hassk.), Nat. fam. der Euphorbiaceæ, Gr. De Molukken; hooge boom. Gebr. Het hout van dezen boom is geschikt voor schtepsbouw, minder tot het bouwen van huizen, 
omdat het zoo licht scheurt; lict is echter uitmuntend voor fraaie meubels, als stoelen, kastelı, cnz.

3345. Kajoe-lawa PAL. = Guat. teria sumatrana $M$ iq. (Zic No. 1113.)

3346. Kajoe-lebe $\mathrm{M}$. $=$ Bassia longifolia J,am, (Kie No. 38.)

3347. Kajoe-lepi l,AMP. $=\mathrm{Van}$ gueria (ciathium) lalembanica il iq. (Zie No. 3215 )

3348. Kajoe-limau PAL = Gly. cosmis chlorosperma Miq., Nat. fam. der Aurantiacer. Gr. Java en Sumatra; boom.

3349. Kajoe-limoetan M. = Styrax Benzoiu I) ryaud (Zie No. 3311 a.)

3350 . Kajoe-lingöa M. = Pterocarpus indicus Wild. (Zie No. 18.)

3:35 L. Kajoe-lobang. Вк. = Unearia euryncha $\mathrm{Miq.}$ (Zie No 1135.)

3352. Kajoe-loebang Вк. = Vitex Negundo I. (Zie No. 1316.)

3353 . Kajoe-loeha $\mathrm{PAL}_{\mathrm{L}}=\mathrm{Cinna-}$ momuin sulphuratum Nees, Nat. fam. der I, a u riıc Ge. Java, Suınatra, Borueo; hooge boom GkBR Waarschijnlijk als dat bij No. 2287 aangegeven.

3354. Kajoe-loelofp Pas. = Cupania pleuropteris Miq., Nat. fam der Sapindacere. Gr. Sumatra en Borneo; boom.

3355. Kajoe-loeloes PAL. $=\mathrm{Cra}$ toxylon Ianceolatum Miq. Nat. fam. der Hypericiuca. Gr. Sumatra; boom.

3356 . Kajoe-loemoet PAs. = A lsodeia echiı ocarpa Korth., Nat. fam. der V i olarinex. Gr. Sumatra; boom.

33557. Kajoe-loeö S. = Myristica sublanceolata $\mathrm{M}$ iq, Nat. fan. der Myristicacere Gr. Java; boom.

3:)58. Kajoe-maas $\mathbf{M}=$ Codiæu molnccan un Rmph. (Zie No.126)

3359. Kajoe-maas MeN. = Nau-

clea parvifolia $R x$ b. (Zic No. 969.) 3360. Kajoe-madjannang $\mathrm{MAK}_{\mathrm{K}}=$ Erythrina indica I, am. (Zie No $1586 b$.)

3361. Kajoe-mahaloe LAMP. $=$ Tetranthera amara Necs (Zic No 2896.) 3362. Kajoe-maloe PAs. $=\mathrm{Tc}$ tranthera eapitulata Miq., Nat. fam. der I, a u ri ncæ. Gr. Sumatra; boorn. 3363 Kajoe-malouw PAL. $=\mathrm{Si}$. deroxylon? oxycdrum Miq.. Nat fam. der Sapotaccic. Gr. Sumatra OK.; hooge boom.

3364. Kajoe-manan of Kajoe-ma- nau I,AMP. = Parinarium multiflorum Miq. (Zie No. 132la)

3365. Kajoe-mang Вк. = P achystemon baneanum Miq.; Nat. fam. der Euphorbiaceæ. Gr., Bangka; boom.

3366. Kajoe-mangkeboel $\mathrm{BK}$. $=a$. Podocarpus amara Bl, Nat. fain. der Podocarpeæ. Gr. Java en Bangka; boom $=b$. Podocarpus latifolia W a ll., Nat fam. als voren. GR. Java en Bangka; huoge boom GeBr. lezc boom levert eell fraai, doch week cu niet sterk hout, dat voor huisbonw en huisraad gebruikt wordt.

3367 Kajoe-manies $=a$. Cin-

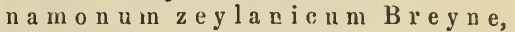
Nat. fam. Jer I, a u ri n e a Gr. Op Java, Sumatra en elders gekweekt; boom. G EBR. Deze boom levert cen der beste kaneelsoorten, waarvan bet huishoudelijk cn geneeskundig gebruik algemeen bekend is. $=b$. Cinna mom n $\mathrm{m} \mathrm{K}$ iamis $\mathrm{Nees}$. Nat. fam. als voren. Gr. Java en Sumatra; hooge boom. GEBR. Deze boom lcvert een soort van Massooibast op. Dezc bast is op alle Javaansehe bazars als gencesmiddel te koop; hij komt in aromatische en adstringeerende eigenschappen met de Sintok orereen; nalerc in werking de Cascarilla en Simaruba, en wordt vooral bij diarrhoca ell krampen in den onderbuik toegediend.

3368. Kajoe-manies-djawa $\mathrm{M}$. = $\mathrm{C}$ in numo in um iners $\mathrm{R} w \mathrm{dt}$. (Zie No 2925.)

3369. Kajoe manies-sabrang M. = Cinnamomum Kiamis Nees. (Zie No. $3367 b$.

3370. Kajoe-manies-tjina $\mathrm{M} .=\mathrm{Ci}$ n a mom um arom atieu m N ces, Nat. fam. als voren. Gr. Op Java in tuinen; boom. Grir. Deze boom levert de bekende Chineesche kaneel. $=b$. Glycyrrhiza glabra I. (Radix), Nat. fam. der Papilion acex Gr. Op Java gekweekt; overblijvcnde plant. GEBR. De bekende zoethoutwortel is op alle bazars te koop. 3371. Kajoe-mata-ajam Bк. = M ysine sumatra na Miq., Nat. fam. der M y rsinea c e $x$. Fr. Bangka; hecster. 3372. Kajoe-mata-boeta M. = Exc $\propto$ caria Agallocha I. (Zie No. 22b.) 3373. Kajoe-mata-ikan Bo. ZK. = Ardisia serrata Pcrs., var. scmiser at a Scheff., Nat fam. der M yr. sincace a. Gr. Bangka, Borneo; hecster. 3374. Kajoe.meirah M. = $a$. Pte- 
rocarpus indicus Wlld. (Zie No. 19). $=b$. Gmelina asiatica L. (Zie No. 225.8.)

3375. Kajoe-meirah-dawon-tjengkeh Mol. = Jambosa moluccana Miq., Nat. fam. der Myrtacer. Gr. De Molukken; boom.

3376. Kajoe-menoerang $. \mathrm{I}=\mathrm{Cy}$ licodaphne obtusifolia Nees, Nat. fam. der Laurineæ. Gr. Java; hooge boom. Geur. Een aftreksel van het hout drinkt men bij wijze vau kajoe manies.

3377. Kajoe.merak $\mathrm{B} L$. $=a . \mathrm{Ca}$ suarina equisetifolia Forst. en = b. C. nodiflora Forst. (Zie No. 122.) 3378. Kajoe-moni M. = Murraya sumatrana $R \times b$ (Zie No. 1723.)

3379. Kajoe-morea $\mathrm{M} .=$ Albizzia Dur. Spec. molucc.

3350. Kajoe.moron $\mathrm{M}_{\mathrm{0}}=\mathrm{Commer}$. sonia echinata Forst. (Zie No. 106).

3381. Kajoz-morsego M. = Helicia serrata R.Br., Nat. fam. der Protea. ceæ. Men kauwt den wortel tegen tand. pijn. De vruchten zijn zeer gezocht door vleermuizen (morsego Амв. \& BD.)

3382. Kajoe-nassi $\mathbf{M}=\mathbf{=}$ Dartus perlarius Lour. (?). (Zie No. 75).

3383. Kajoe-nassi T. = Strychnos muricata Kostel. (Zie No. 3227.)

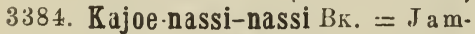
bosa buxifolia Miq. Nat. fam. der MI yrtacex. Gr. Bangka; boom.

3385. Kajoe-ngingeh $\mathbf{M}=$ Diospyros Teysmanni Miq. Nat. fam. der Ebenacer. Gr. Lampongs; boom.

3386. Kajoe-njinje M. = Anaxagorea sumatrana Miq. Nat. fam. der A nonaceæ. Gr. Lampongs; boom.

3387. Kajoe-no M. = Caryota No Becc. Nat. fam. der Palmac.Gr. Borneo; hooge palm. GEBR. De vezels worden voor touwwerk gabezigd.

3388. Kajoe-obi M. = Fagræa la tifolia Miq. Nat. fam. der Logani ace $æ$ Gr. Sumatra; heester.

3389. Kajoe-0edjan J. $=\mathbf{R}$ u bus Horsfieldii Miq. (Zie No. 2639.)

3390. Kajoe-oedjan PaL. = Rott lera rhynchophylla Miq., Nat. fam. der Euphorbiace æ. Gr. Sumatra, Java boom

3391. Kajoe-oedjauw Laje. = Mil. letia atropurpurea Buth.; Nat.fam. der Papilionacex. Gr. Sumatra; boom.

3392. Kajoe-oelar M. = S trecl. nos muricata Kostel. (Zic No. 3227.)
3393. Kajoe-0elet J. $=$ Helicteres Isora L. (Zie No. 14.91.)

3394. Kajos-deloe Lamp. $=$ Gi rouniera nervosa Planch, Nat.fam. der Celtideæ. Gr. Sumatra en Borneo; boom.

3395. Kajoe-0emoer-pandjang M. = Glaphyria nitida Jack., Nat. fam. der Ilyrtacea. Gr. Sumatra; heester. GEBR. In Bengkoelen drinkt men een aftreksel der biaderen in plaats van thee.

3396. Kajoe-oepas $\mathbf{M}$. = Antia$r$ is inn oxia Bl. (Zie No. 3044b.)

3397. Kajoe-oerip J. = Euphorbia Tirucalli L.; Nat. fam. der Euphorbiaceæ. Gr Op Java en elders, veelal in tuinen; heester. GEBr. Deze plant bevat overvloedig een scherp melksap, waaraan vele inlanders de kracht toekenren, om gebroken beeneinden weder te doen samen kleveu; zij gebruiken het dan ook uitwendig tegen fracturæ; verder op scabies, herpes en andere chronische huiduitslagen. De wortel en het jonge loof werken ontlastingbevorderend.

3398. Kajoe-oeroem LAMP. $=\mathrm{C}_{\mathrm{u}}$. pania erythrorachis Miq. Nat.fam. der Sapindaceæ. Gr. Sumatra boom.

3399. Kajoe-palakka $\mathrm{C}_{\mathrm{r}}=\mathrm{O} \mathrm{c}$. tomeles sumatrana $\| 1$ iq. var: mol u c cana. (Zie No. 1126.)

3400. Kajoe-pandan M. = Canarium subrepandnm Miq. Nat. fam. der A my ridęe. Gr. Sumatra WK., hooge boom.

3401. Kajoe-pangka $\mathrm{P}_{\mathrm{AL}}=\mathrm{PO}_{0}$ liosma integrifola Bl. (Zie No. 423.)

3402. Kajoe-paninz-paning-rassa Sus. W. K. = Quercusoxyryncha Miq. Nat. fam. der Cupuliferæ. Gr. Sumatra; hooge boom.

3403. Kajoe-panties LaMP. $=a . \mathrm{Pa}$ rinarium sumatranum Buth. (Zie No. 795.) = b. Gelonium obtusum Miq. Nat. fam. der Euphorbiacea. Gr. Sumatra; boom. = c. Sur egada lanceolata Baill. Nat. fam. als roren. Gr. Sumatra; heester.

3404. Kajoe-pantjil I. $=$ Sideroxylum ferrugineum Hk. \& A. Nat. fam. der Sapotace æ. Gr. Java; hooge boom.

330ว. Kajoe-pantjei LaMp. = A glaja lepidota Miq. Nat. fam. der Me-

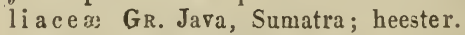

3406. Kajoe-papoea MoI. $=\mathrm{I}_{\mathrm{ep}} \mathrm{e}$ 
tospermum amboinense Bl. (Zie No. 2885.)

3407. Kajoe-para LAмP. = Gale aria sumatrana $\mathbf{M i q . ~ N a t . ~ f a m . ~ d e r ~}$ Antidesmeæ. Gr. Sumatra; heester.

3408. Kajoe-passa Sum. WK. = Mierosepala acuminata Miq. (Zie No. 1083.)

3409. Kajoe-passir Bat. 二 $\alpha$. Scyphiphora hydrophyllacea Grtn. (Zie No. 417) en $=b$. Lumnitzera racemosa Wlld (Zie No. 2232b.)

3410. Kajoe-passir M. = Catha montana Hassk. Nat. fam. der Celastrines. Gr. Jara, heester.

3411. Kajoe-patehak I. 二 $\mathrm{Hyme-}$ næa verrucosa L. Nat. fam. der Papilionaceæ. Gr. Java; hooge boom. Gebr. Deze boom levert een soort van kopalhars op.

$3411 a$. Kajoe-paija Sur. $=$ Sarcocephalus dasyphylla Miq. Nat. fam. der Rubiaceæ. Gr. Sumatra; hooge bcom.

3412. Kajoe.pienda $\mathrm{BK} .=\mathrm{Macro-}$ solen retusus Jack. Nat. fam. der L or an tha ceæ. Gr. Bangka; parasiet.

3413. Kajoe-noempang BK. en

3414. Kajoe-piendah BK. $=\mathrm{D}$ endropthae pentandraL (Zie No.1205.)

3415. Kajoe-poeak Bк. = Ardisia chrysophylloides Miq. (Zie No. 6003.)

3416. Kajoe-poegot Laxp. = Unona virgata Bl. Nat. fam. der A nonace Gr. Java en Sumatra; boom.

3417. Kajoe-poekon M. = Egiceras floridum R. \& S. (Zie No. 130.)

3418. Kajoe-poelah LAuP. $=\mathrm{Gar}$ denia resinifera Korth. Nat. fam. der $R u b$ i aceæ. Gr. Sumatra, Borneo; boom.

3419. Kajoe-poeieh Sux. = Cratæva magna D.C. (Zie No. 1024)

3420. Kajoe-poeleh Вк. = Eury. com a long if olia Jack. (Zie No. 804.)

3421. Kajoe-poeloet BK. 二 Chrysophyllum bancanum Kurz. Nat. fam. der Sapotacex. Gr. Bangka ; hooge boom.

3422. Kajoe-pôerieng $\mathrm{I} .=\mathrm{Codi}$ xum moluccanum Dcsn. (Zie No. 126).

3423. Kajoe-poetih M. $=a \mathrm{Mela}$ leuca leucadendron L. (Zie No. 120 a.) $=b$ Melaleuca Cajuputi Rxb. (Zie No $1737 d$ ) $=c$ Leptosper- mum amboinense Rwdt. (Zie No. 2885.) $=d$ Myrtus communis $L$. (Zie No. 1938.) = $c$ Canarium eupteron Miq. (Zie No. 3300), en $=f$ Eucalyptus alba Rwdt. Nat. fam. der Myrtaceæ. GR. De Molukken en Timor; hooge boom. GEBR. Deze boom bezit vermoedelijk veel hars en atherische olie.

3424. Kajoe-poetih-dawon-ketjil MI. $=$ Melaleuca minor Smith. (Zie No. 24786.)

3425. Kajoe-poetih-ketjil M. $=\mathrm{Me}$ laleuca Cajuputi Rxb. (Zie No. 1737 d.) $=6$. Leptospermum a mboi$n$ en s e $R w d t$. (Zie No. 2885.)

3426. Kajoe-poettar M. = Helicteres Isora L. (Zie No. 1491.)

3427. Kajoe-pojoh Lamp. = Troostwijkia singularis $M$ iq. Nat. fam. der Connaracex. Gr. Sumatra; boom.

3428. Kajoe-pokoen $\mathrm{J} .=\mathrm{Heri-}$ tiera littoralis Dryand. (Zie No. 752. )

3429. Kajoe-polis IaAM. = en

3430. Kajoe-poris $\mathrm{L}_{\mathrm{A} M \mathrm{P}}=a$. $\mathrm{Ho}_{\mathrm{o}}$ maliam sumatranum Miq. en $=b$. Homalium obovale Miq., Nat fam. der Homalinex. Gr. Sumatra; hooge boomen.

3431. Kajoe-popöan M. = Scolopia rhinanthera Benn. (Zie No. 966.)

3432. Kajoe-purries S. \& M. = Discostigma rostratum Hsskl., Nat. fam. der Clusiaceæ Gr Java; hooge boom. GeBr. De bast wordt gebruikt tot het roodverwen van garens.

3433. Kajoe-radja M. $=a \mathrm{Her-}$ nandia sonora L. Zie No. 16.) $=6$ Cassia fistula L. (Zie No. 1306a.) $=c$. Capellenia moluccana T. \& B., Nat. fam. der Euphor biace . Gr. De Molukken; boom

3434. Kajoe-ramo PAx. = Henslovia paniculata. Miq. (Zie No. 803.)

3435. Kajoe-ranoh LAMP. = Adinandra glabra Miq., Nat. fam. der Ternstrœmia ce a. GR. Suınatra; heester.

3436. Bajoe-rapat $\mathrm{J} .=\mathrm{Cleghor-}$ nia cymosa R. \& IV., Nat. fam. der E a phorbi a cer. Gr. Java; slingerplant.

3437. Kajoe-rârâ MEs = Mussaënda froudosi I. (Zie No. 74.)

3438. Kajoe-rassa MI. = Vatica? venulosa Bl., Nat. fam. der Dipterocarpeæ. Gr. Borneo; boom.

3439. Kajoo-rawang LAMP. = Leiopyxis sumatrana Miq. (Zie No. 1279.) 
3440. Kajoe-reboeng Sux. = Meliosma nitida Bl., Nat fam. der Meliosmer Gr. Jara en Sunatra; boom.

344.1. Kajoe-reta PAL. = Brachipterum microphyllnm Miq., Nat. fam. der Papilionac eæ. Gr. Sumatra; hooge boom.

3442. Kajoe-rimbo M. $=$ Dendrophthoë costulata Miq. (Zie No. 1205b.)

3444. Kajoe-roja Alf. Mis. = Casuarina equisetifolia Eort. (Zie No. 122)

3445. Kajoe-rono J. $=a$. Sonchus malayanus Miq. (Zie No. 1281.) $=b$. So nchus oreophilus Miq. Nat. fam. der Compositæ. Gr. Java; éénjarig.

3446. Kajoe-sabo Sus. W. K. = Fageræa sumatrana Miq., Nat. fant. der Loganiacer. Gr. Sumatra; boom.

3447. Kajoe-sala $\mathrm{Bk}$. $=$ Eurya nitida Kths. (Zie No. 8893.)

3448. Kajoe.sala PaL $=$ Furya virens Bl. (Zie No. 3283.)

3449. Kajoe-salangan LAMP. = Cinnamomu lampongum Miq. Nat. fam. der Laurineæ. Gr. Sumatra; boom.

3450. Kajoe-salowakko-meirah M. = Pithecolobium clypearia Bnth. (Zie No. 3115.)

345l. Kajoe-salowakko-poetih M. = A denanthera faleata I. Nat. fam. der Mimoseæ. Gr. De Molukken; hooge boom. Gebr. Het hout bezigt men voor kleine prauwen en schilden.

3452. Kajoe-sambarou PaL. $=$ Alsodeia grandis Miq. Nat. fam. der Violaceæ. Gr. Sumatra; boom.

3453. Kajoe-sanga $\mathrm{M} .=\mathrm{Gl} \mathrm{ut} \mathrm{a}$ Benghas L. (Zie No. 1099.)

3454. Kajoe-sappan M. = Cæesalpinia Sappan L. (Zie No. 1807.)

3455. Kajoe-sarasa Níoc. = Euc alyptus obliqua Hérit (?). Nat. fam. der Myrtaceæ. Gr. Timor en de Molukken: boom.

3456. Kajoe-sawan M. = Helicteres Is ora L. (Zie No. 1491.)

3457. Kajoe-sawo M. =a. Achras Sapota Iiinn. (Zie No. 1496.) $=6$ Mimusops Elengi L. (Zie No. 13996.) $=c$ Mimusops Kauki L. (Zie No. $1497)$.

34ว̌8. Kajoe-sea Alf. Mrv. = Morinda bracteata $\mathrm{R} \times$ b. (Zie No. 8286.)

3459. Kajoe-selah Lamp. = Phoebe lampong a Miq. (Zie No. 2928c.)
3460. Kajoe-selipei LaMP $=$ Antidesma microcarpum Miq. (Zie No. 3309.)

3461. Kajoe semoet $M .=$ Hernandia sonora L. (Zie No. 16.) $=b \mathrm{Nau}$. clea purpurascens Korth. Nat. fam. der Rubiaceæ. GR. Java en Sumatra; kleine boom.

3462. Kajoe-semoet Hor. $=\mathrm{Ca}^{\mathrm{a}}$ pellenia moluccana T. \& B. (Zie No. 3433c.)

3463. Kajoe-sepat $\mathrm{P}_{\mathrm{AL}}=\mathrm{Gom}$ phia sumatrana Jack. (Zie No. 7848.)

3464. Kajoe-seraboe $\mathrm{PAL}_{\mathrm{A}}=\mathrm{Ca}_{\mathrm{a}}$ rallia confinis Bl. (Zie No. 895.)

3465. Kajoe-siloek BK. = Gironniera nervos a Planch. (Zie No. 3394.)

3466. Kajoe-simboe I. $=$ Vernonia javanica Dc. (Zie No. 1015b)

3467. Kajoe-singal PAL. $=V$ iṣcum orientale L. Nat fam. der Visc a c er. Gr. Java, Sumatra, Borneo, Timor; parasiet.

3468. Kajoe-singol. $\mathrm{P}_{\mathrm{AL}}$. $=\mathrm{Sy}-$ noecia diversifolia Miq. (Zie No. 478.)

3469. Kajoe-sioh Liмp. = a. Also. deia echinocarpa Korth. (Zie No. $3356)=b$. Alsodeia dasypyхis Miq. Nat. fam. der Violaceæ. GR. Sumatra; boom.

3470. Kajoe-sirie Moc. $=\mathrm{Phane-}$ $\mathrm{ra}$ cordifolia Miq. Nat. fam. der Papilionaceæ. Gr. De Molukken; slingerplant.

$34 \pi 1$. Rajoe-soelamoe $\mathrm{M} .=$ Soulamea amara Lam. (Zie No. 1476.)

3472. Kajoe-soemang $M .=S p a-$ lanthus confertum Jack. Nat. fam. der Combretaceæ. Gr. Sumatra; heester.

3473. Kajoe-soesoe M. = $a \cdot \mathrm{Bru}$ guiera Rumphii Bl. (Zie No. 866b.) $=b$. Bruguiera parviflora W \& A., Nat. fam. der Rhizophoreæ. Gr. Vrij algemeen langs de stranden; boom. GEBR. De schors wordt veel gebruikt tot zwarten bruinverwen van garens en touwwerk. $=c$. Cerbera lactaria Ham. (Zie No. 1182.)

3474. Kajoe-sôkô J. = Saraca Zollingeriana Miq.: Nat. fam. der Papili onacer. GR. Java, veelal in tuinen; boom, met schoone, vuurroode bloemen.

3475. Kajoe-soloakko M. (?). = Oxal is Reinwardtii Zucc. (Zie No. 251.)

3476. Kajoe-sônô M, \& J. = Pte- 
rocarpus indicus 1 W 11 d. (Zie No. 18.) 3477. Bajoe-sonti BD. $=$ Botrymorus Paniculatus Miq., Nat. fam. der Artocarpex. GR. De Molukken; kleine boom. GEBR. Men gebruikt de schors der wortels tegen spruw en op herpesaardige uitslagen; de bladeren en den bast legt men op brandwonden.

3478. Kajoo-soreh M. = Quercus moluccana $\mathrm{Rmph}$. (Zie No. 109.)

3479. Kjaoe-stingl M. $=\mathrm{Pemph}$ is acidula Forst. (Zie No. 1555.)

3480. Kajos swangi BD. = Acorus ter estris Rinph. (Zie No. 135.)

3481. Kajoe-swangi $\mathrm{Cr}$. = Eu c aly ptus deglupta B l. (Zie No. 35)

3482. Kajoe-taai M. $=a$. Saprosm a a rboreum B l. (Zie No. 3154.b) = b. Viburnum sam bucinum Rwdt. (Zie No. 307 c.)

3483. Kajoe-tabak BK. = A quilaria malaccens is $I_{1}$ am. (Zie No. 2679.)

3484. Kajoe-tadja PAL. $=$ M y ristica leucoxyla Miq., Nat. fam. der II yristicaceæ. Gr. Sumatra Ok.; boom.

3485. Kajoe-tain S. $=\mathrm{G}$ e n iost 0 . ma montanum Z. \& M. (Zie No. 3054).

3486. Kajoe-tamia Sum. = $\mathrm{s} \mathrm{yz} \mathrm{y-}$ gi um javan i c u M M i q., Sumatra en Bangka; boom.

3487. Kajoe-tampang $\mathrm{M}$. = $\mathrm{A}$. tiaris? palem ba n i ca Miq., Nat. fam. der A r t o c a p e . Gr. Sumatra Ok.; boom.

3489. Kajoe-tana Lamp. = Trew ia nud iflora I. (Zie No. 1202.)

2489. Kajoe-tanang $\mathrm{MAK}_{\mathrm{K}}=\mathrm{F} \mathrm{i}$. cus varieg a t a B l. (Zie No. 1352.)

3490. Kajoe-tandue Sum. $\mathrm{W}_{\kappa} .=$ Symplocos iteophylla dliq., Nat. fam. der S t y r a c e æ. Gr. Sumatra, Bangka; heester.

3491. Kajoe-tandok MI. = Celtis c i n $n$ a $m$ om a $L$ ind l., Nat. fam. der C e l t i de ז. Gr. Java, Sumatra; hooge booin.

3492. Kajoe-tangan J. = Euphorb i a T ir u c a lli L. (Zie No. 3397.)

3493. Kajoe-tangar $\mathrm{T}$. $=\mathrm{Para}$. ropia rigida D.C., Nat. fam. der A rali a c ex. Gr. Java; groote heester. GEBR. Het hout is geschikt voor huisbouw. 3494. Kajoe-tango Sim. $\mathrm{W}_{\mathrm{K}}$. = Ceriops Incida Miq., (lie No. 2884.)
3495. Kajoe-tani MaK of

3496. Kajoe-teni MaK $=\mathrm{C}$ in $\mathrm{na}$ monum zeylanicum Br. (Zie No. 3367.)

3497. Kajoe-tapis Sum. WK. $=\mathrm{G}_{0}$. $\mathrm{niothalamus} \mathrm{Tap}$ is Miq., Nat. fam. der A non a e e. Gr. Sumatra; heester.

3498. Kajoe-tarie PAL. $=$ Polyos. m a fragrans Bnnt., Nat. fam. der Es c allo niæ Gr. Sumatra; heester.

3499. Kajoe-tawa $J .=S$ c i n d a psus? R u m p hi M i q., Nat. fam. der A r a 1 i a c e $æ$. Gr. Java en de Molukken; slingerplant. Geвr. Men bezigt de stengels bij wijze van bindtouw.

3500. Kajoe-temboe-sirem $\mathrm{S}$. = $J$ a $\mathrm{m}$ bos a a rom atica $M$ i q., Nat. fam. der Myrtaceæ. Gr. Java; boom. GEBR. Het hout is geschikt voor bouwhout.

3501. Kajoe-tengal J. $=\mathrm{He} \mathrm{m} \mathrm{i-}$ c y c li a r h a d o d i s c us $\mathrm{H}$ a s k., Nat. fam. der E u p orbia c e. Gi. Java; heester.

3502. Kajoe-tepang J. = C y li c odapheobtusifolia $\mathrm{N}$ ees (Zie No. 3376$.

3503. Kajoe-tihang $\mathrm{J}_{0}=\mathrm{Guat}$ teria gla uca Miq., Nat. fam. der A no n a c e $œ$. Gr. Java; boom. Gebr. Het grove, witte hout is sterk en geschikt voor bouwhout, doch niet bestand tegen vochtigheid.

3504. Kajoe-tikoes M. $=\mathrm{Al} \mathrm{biz-}$ z i a D r. S pecies tres indefin i $\mathrm{t}$ x. (Zie No. 97.)

3505. Kajoetiman LAMP. $=\mathrm{A}$ cron y c hia a pic ula t a Mi q., Nat. fam. der D i osm eæ. GR. Lampongs; boom.

3506. Kajoe-timo $\mathrm{PAL}_{\mathrm{A}}=\mathrm{V}$ e $\mathrm{r} \mathrm{n} n-$ n i a ja $\mathbf{a}$ n i a D.C. (Zie No. 10156, ) 3507. Kaoe-timon Амв. = Polyphragmou sericeum Desf. (Zie No. 129.)

3508. Kajoe-tina M. $=\mathrm{B}$ a s s i a e 10 ngat a M i q., Nat. fam. der S apot a c e $x$. Gr. Sumatra O.kust, hooge boom.

3509. Kajoe-tingie $\mathrm{M} .=\mathrm{Br}$ guiera parviflora IV. \& A. (Zic No. $3473 b$.)

35i0. Kajoe-tinjang $\mathrm{S} .=\mathrm{G} u$ a $\mathrm{t}-$ te ri a gla u c a M i q.. (Zie No. 35̌03.) 3511. Kajoe-tinta Mr. = Sterc u li a u r c o l at a S m. (Zie No. 1502 ) 3512. Kajóe-titi of K.titie Aur. - 
Vitex moluccana B l., Nat. fam. der V e r b e n a c e æ. Gr. De Mlolukken; boon. GEBR. Van het hout rervaardigt men kleine prauwen; de schors legt men op oude beenzweren, als samentrekkend middel.

35ı14. Kajôe-tjakrah J. = P a ra. tropia Junghuhniana Miq., Nat. fam. der A rali a c e æ. Gr. Java; boom. Gebr. Bouwhout.

3515. Kajoe-tjamara Y. = C a s uarina nodiflora Forst \& al. S p. (Zie No. ]22.)

3516. Kajoe-tjidako Mos. = A ntiaris innoxia Bl. (Zie No. 3044.)

3ə̌1\%. Kajoe-tjina $\mathrm{Ml}=\mathrm{Cudra-}$ nus amboinensis $R \mathrm{mph}$. (Zie No. 760.)

3ร̌l8. Kajoe-tjina-oetan M.= S milax zeylanica L. (Zie No. 717.)

3519. Kajoe-tjindana $\mathrm{M} .=\mathrm{S}$ a $\mathrm{n}$. $t$ a l u m a l b u m L. Nat. fam. der S a nt a l a c e æ. Gr. Op bijna alle Sunda-eilanden, wild en gekweekt; boom. GEBR. Deze boom levert het Sandelhout ran den handel, dat als reukwerk en als geneesmiddel door den inlander zeer gezocht is, en ook reel naar Europa wordt uitgevoerd. Het is thans buiten medisch gebruik, doch schijnt tot de samentrekkende middelen te behocren. Se oude boornen leveren het gele, de jongere het witte Sandelhout op.

3520. Kajoe-toeiang Lasp. = Tetragy a a cuminata II iq., Nat. fam. der E u ph o r bi a c e . Gr. Sumatra; boom.

3521. Kajoe-toessam Btt $=\mathrm{Pi}$ nus II erkusii Jungh \& de Vr.. Nat. fam. der A b i et in e æ. Gr. Sumatra; boom.

3522. Kajoe-tohlong-tohlongan MaD. $=$ Coffea madurensis T. \& B., Nat. fam. der $\mathrm{R}$ u b i a c e s. Gr. Madura; boom.

3ə23. Kajoe-tola J. = S ambucus c an adensis Thb., Nat. fam. der Caprifoliaceæ. Gr. Op Java gekweekt; overjarig.

3524. Kajoe-tombor $\mathrm{BD} .=\mathrm{Ficu} \mathrm{s}$ $\mathrm{se} \mathrm{p}$ ti c a $\mathrm{Rm} \mathrm{ph}$. (Zie No. 764a.)

3525 . Kajoe-totara $\mathrm{Ml}$. = Commersonia echinat a Forst. (Zie No. 106.)

3526. Kajoe-tuah Mev. = Sa uro. pus rhamnoides Bl. (Zie No. S0 ̌.)

3527. Kajoe-ulassi $\mathrm{M} .=\mathrm{E} \operatorname{ch}$ in us trisulcus Lo ur. (Zie No. 3344)
3528. Kajoe-wada Sum. WK. $=\mathrm{En}_{\mathrm{n}}$ diandra sumatrana Miq., Nat. fam. der La u rineæ. Gr. Sumatra; boom. GERR. Deze boom levert een goed bouwhout.

3529. Kajoe-wêroe J. = Lits se a densifolia Mi g., Nat. fam. als voren; Gr. Java; boom. Gebr. Ook dezen boom bezigt men voor huisbouw.

3530. Kajoe-wiejan Sum. $=\mathrm{Cu}$ dranus obovatus Tréc., Nat. fam. der Artoc arpe æ. Gr. Java en Sumatra; heester.

353 i. Kajoe-woena-woena $\mathrm{BD} .=$ $\mathrm{Hibiscus}$ rosa sinensis L. (Zie No. 1360.)

3532. Kajoe-wollanda M. = Quercus moluccana Rmph. (Zie No. 109.)

3533. Kaka-doeän S. 二 $\alpha$. D endrolobium cephalotes Benth. (Zie No. 1683b.) $=$ b. Nanopetalum m yria nth u m Has sk. Nat. fam. der Euphorbi a cer. Gr. Java en Bali. boom.

3ร34. Kakae-mea Амв. = Schleichera trijuga Wlld. (Zie No. 47.)

3 535. Kakahil (ook kakahir en kakabir) $\mathrm{Aurs}=a$ Uncaria lanosa Wall. (Zie No. 27.) $=b$ Uncaria acida Rxb. (Zie No. 1702.) $=c$ Uncaria Gambir Kxb. (Zie No. 2388.)

3536. Kakailo Амв. = Uncaria lanosa Wall. (Zie No. 27.)

3537. Kakajar I. = Polypodium laciniatum L. Nat. fam. der Polypodiace æ. Gr. Java; overjarig.

3538. Kakajar-laki-laki I. - A crostichum lanceolatum L. Nat. fam. als voren; Gr. Java; overjarig.

3539. Kakalapäan $s=0 \times$ a lis Reinwardtii $\mathrm{Z}$ ucc. (Zie No. 251.)

3540. Kakantjiengan S. $=$ II o$r$ ind a sarinentos a B l. Nat. fam. der R u bi a c e $æ$. Gr. Java; klimplant. $=b$ M orinda umbellata L. (Zie No. 516.)

3541. Kakapassan S. $=a \mathrm{Daphne}$ pendala Smith. Nat. fam. der Daphnoideæ. Gr. Java; boom. $=b$ Drymispermum Blumei Desn. (Zie No. 422) $=c$ D rym is permum l a u r ifolium Desn. Nat. fam. der Thymelace $x$. Gr. Timor; heester. GEBR. Nlen bezigt den bast voor bindtouw. $=d$ Flemingia strobilifera $\overline{\mathrm{R}} \mathrm{Br}$. (Zie No. 2656c) $=e \mathrm{Hibiscus}$ mutabilis L. (Zie No. 1358.) 
3542. Kakapassan-konneng $\mathrm{S}$. = Hibiscus Lampas Cav. Nat. fam. der Malvacer. Gr. Java in tuinen als sierplant; heester.

3543. Kakapassan-salandjar S. = Hibiscus venustus Bl. Nat. fam. als voren. GR. Java, dikwijls als sierplant in tuinen; heester. GEBR. Deze bezit verzachtende en weekmakende eigenscharpen, en wordt daarom veel toegediend bij koortsen, diarrhoeæ, genorrhoea, enz.

3544. Kakara M. = Ia abla b vulgaris Savi. Nat. fam. der Papilion a ce ce. Gr. Op Java en elders gekweekt; zaadplant. Grbr. Men eet de jonge peulen en rijpe zaden als groente. $=b$. Dolichos lignosus L., Nat. famı. dezelfde.Gr. Op Java en elder's verbouwd; zaad- en klimplant. GEBr. Ook hiervan nuttigt men de jonge peulen en rijpe zaden.

3545. Kakara-djoeleh M. = Dolichos unguiculatus L. (?), Nat. fam. als voren. Gr. Java, Sumatra, de Molukken in tuinen; zaad- en klimplant. GEBR. Men eet de peulen en rijpe zaden; versch zijnde, moeten zij met voorzichtigheid gegeten worden, daar zij licht duizeligheid opwekken; gedroogd zijn zij onschadelijk.

3546. Kakara-gatel M. = M ucun a prurita Hk. (Zie No. 1693.)

35 47. Kakara-lawit M. $=\mathrm{Lablab}$ microcarpus D.C., Nat. fam. als voren. GR. Java en de Molukken; zaadplant. Gebr. De bloemen, jonge peulen en rijpe zaden worden als groente genuttigd.

3548. Kakara-loengsir J. \& Bl. = Lablab perennans D.C. Nat. fam. als voren. Gr. Java, Bali, de Molukken; zaadplant. GEBR. De jonge peulen en rijpe zaden leveren een zeer gezochte groente.

3549. Kakará-parrang M. = C a navalli a gladiata D.C. Nat. fam. als voren. Gr. Java, Timor en de Molukken; zaadplant. GFBR. De bladeren en bloemen worden in stoom gekookt en bij de rijst gegeten, evenzoo de onrijpe peulen, die eerst dwars in tweeën worden gesneden, en de rijpe zaden.

3550. Kakara-poetih M. = Lablab perennans D.C. (Zie No. 3548.)

355l. Kakarja M \& Амв. = Elæoc arpus edulis T. \& B. (Zic No. 1277.)

3552. Kakatjangan S. = a. Crotallaria L. Spec. plurimæ. $=b$. Pcristrophe albiflora Hassk (Zie No. 1304b.) Zc. Neurocarplis ca- janifolius Presl., Nat. fam. der Papilion aceæ. Gr. Op Java uit Brazilië overgebracht; overblijvend. GEBR. Het kruid is door buffels en geiten zeer gezocht.

3553. Kakatjangan-aroij $\mathrm{S}$. $=\mathrm{Shu}$ teria vestita W. \& A., Nat. fam. als voren. Gr. Java; slingerplant.

3554. Kakatjangan-pollong $\mathrm{S}$. $=$ a. Crotallaria verrucosa L. (Zie No. 2270.) = b. Crotallaria striata D.C. Nat. fam. der Papilonaceæ. Gr. Java en Borneo; éénjarig.

3555. Kakatoeän-djaran $\mathrm{S}$. $=\mathrm{Hy}$ drocotyle splendens Bl. (Zie No. 400 )

3556. Kakau M. = Theobroma Cacao L. Nat. fam. der Büttneriaсег. Gr. Op Java, Timor, de Nlolukken, in tuinen als cultuurplant; boom. GEBR. Het genees- en huishoudkundig gebruik der chocolarle, cacaoboter, enz. is overbekend. De onrijpe vruchten leveren eene goede Bandoline voor het toilet der dames.

3557. Kakawatan S. 三a. Cynod on Dactylon Pers (Zie No. 21336.) $=b$. Cynodon setigerus Rich. Nat. fam. der Gramineæ. Gr. Java en elders; overblijvend. GEвR. Levert een geschikt veevoeder.

3558. Kakel BK. = Ficus renitens Miq. var: oblongifolia. Nat. fam. der A rtocarpex. Gr. Java en Bangka; hooge boom.

3559. Kakeli Mis. $=$ Columbia celebica Bl. Nat. fam. der Tiliaceæ Gr. Celebes; boom.

3560. Kakeli-in-taloen Mis. $=\mathrm{C}_{0}$. lumbia serratifolia D.C. Nat. fam. als voren. Gr. Celebes; heester.

3561 . Kakera-kikera M. $=a$ M elia a rguta D.C. $=b$ II elia Azedarach L. = c. Melia sambucina Bl. eu = d. Melia tomentosa Rxb., Nat. fam. der Meliaceæ. Gr. Op Java en elders, veela! in tuinen als sierplanten; $b$. hooge boom, de andere groote heesters. GEBR. Het hout van dezen boom is geschikt voor huisbouw en meubels; de bast van alle is bitter en weinig samentrekkend; hij wordt als tonisch middel aangeprezen bij koortsen, diarrboex en cholera en zal ook wormdrijvend werken; hij verdient een nauwkeurig, nader chemisch onderzoek. De zaden leveren een vette olie, zeer geschikt voor lampolie en voor schilders; men bezigt de zaden soms voor rozcnkrallsen.

3562. Kakerang Lגup. $=\mathbf{M}$ a p a 
trichocarpa Reich. fs. \& $\mathrm{Z}$ oll. Nat. fan. der Euphorbiacex, Gr. Sumatra; boom.

3563 . Kakil Cr. = B ruguiera gy mnorrhiza Lam. (Zie No. 242)

3564 Kakkas $J_{0}=\mathrm{Hi}_{\mathrm{p}}$ tage $\mathrm{mada}$ blota Grtn. Nat. Fam. der ML alpighiaceæ. Gr. Java; slingerplant.

356 5. Kakoeti-koeti Bokт. $=$ Vitis in dic a L. (Zie No. 349.)

3566. Kala-antong J. $=\mathrm{Tab}$ ernæmontana sphrerocarpa Bl. (Zie No. 2035 )

3567. Kala-kataminjan Sus. Wк. II ucuna gigantea D.C. (Zie No. 2586.)

3568. Kalabassa M. \& S. = La genaria vulgaris Ser., Nat. fam. der Cucurbitaceæ. Gr. Vrij algemeen in Indië; slingerplant. Gebr. De kalabasvrucht is bitter en oneetbaar, uitgehold en gedroogd dient $z i j$ voor gendies of waterkruiken.

3з69. Kalabbe Bozt. (Zie rorig No.)

3570 . Kalagansa M. \& J. $=a$. Gynancuropsis pentaphylla D.C. (Zie No. $128 \tau a)=b$. Polanisia viscosa D.C. (Zie No. 12876.)

3571. Kalago MI. = Ottelia a lismoides Rich., Nat. fam. der Hydrocharidex. Gr. Java en Sumatra; waterplant.

3572. Kalaijar J. \& S. = Trichosanthes tricuspidata Lour (Zie No. 5216 .)

3573. Kalaijar-badak $\mathrm{S}=\mathrm{Tricho-}$ santhes grandiflora Bl., (Zie No. 644b.)

3574. Kalak S. = Polyosma in tegrifolia Bl. (Zie No. 423) $=b$. Uvaria rufa Bl. Nat. fam. der Anonacer. GR. Java en Sumatra; slingerplant. $=c$. Saccopetalum Horsfieldii Bnnt, Nat. fam. als $b$. GR. Java; heester.

3575. Kalakambing $J_{0}=S_{\text {a r cobo- }}$ bus dichotomus R.Br., Nat. fam. der Aselepiadeæ. Gr. Java; slingerplaut. GEBR. Deze plant bezigt men tot vergiftiging of bedwelming van wilde varkens en tijgers.

3588. Kalapa M. \& $\mathrm{S},=$ Cocos nu cifera I. (Zie No. 393.)

Van deze zijn bekend de volgende variëteiten, als:

3589. Kalapa-babi M. . . = Cocos nucifera l. var pumila.

3590 . "-bali M. . . = " " "

$$
=b . " \quad " \quad \text { " macrocarpa. }
$$$$
=c \text {." " " cistiformis. }
$$

GEBR. Van de dikke vruehtschaal vervaardigt men bekers. 3591. "-besar M. . = Cocos nucifera L. var macrocarpa. 
3592. Kalapa-bohoe S. . . = a. Cocos nucifera L. varpachyphlus.

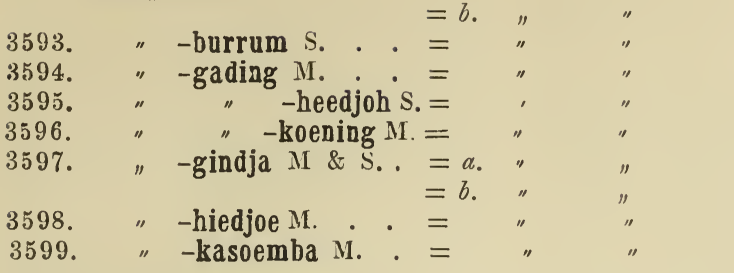

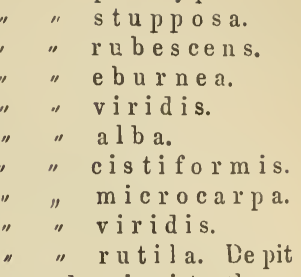
van deze is niet eetbaar.

3600. Kalapa-ketapang M. . = Cocos n u cifera L. var c is tiformis.

3601 .

3602 .

3603.

3604 .

3605 .

3606 .

3607 .

3608 .

3609 .

3610 .

3611 .

3612 .

3613.

$36\lfloor 4$.

3615 .

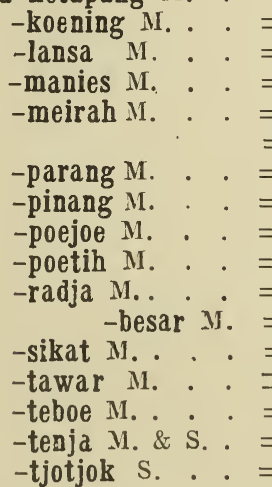

$=$ Cocos nucifera L. var cistif
$=$ " " $"$ alba.

$$
=\quad "
$$$$
="
$$$$
=a . " \text {. }
$$$$
=b \text {. " }
$$$$
=
$$$$
=
$$$$
=
$$$$
=
$$$$
=
$$$$
=
$$$$
\text { 三 }
$$$$
=
$$$$
=
$$
M. Kalapa-boeboer M., K.-dadir M., K.-kanarie M., K.-poean M. en K.-soesoe M., welke mogelijk alle dezelfde zijn, doch op verschillende andere eilanden anders gencemd worden; zij hebben alle een weeke of geleiachtige pit, een aangenamen, amandelachtigen smaak en leveren geen olie.

3616. Kalapa-djingie M. = Lodo icea sechellarum labill., Nat fam. der Palmæ. Gr. Op Java in sommige tuinen; boom. GeBri. De vruchten van dezen schoonen palm worden op zee veelal drijvende gevonden; de stroom voert ze van de Sechellen herwaarts. Aan de harde vruchtschalen hechtte men eertijds groote waarde, daar men ze een giftwerende kracht toeschreef.

361\%. Kalapa-kambing $\mathrm{M} .=\mathrm{Pla}$ colobium sumatranum Miq., Nat. fam. der Papilionacex. Gr. Sumatra W.kust. ?

3618. Kalapa-Iawut $\mathrm{M},=a$. B a rring tonia speciosa L, (Zie No. 1463.) $=b$. Lodoicea Sechellarum Labill. (Zie No. 3616.)

3619. Kalapa-loepa $J_{.}=$Ba r ringtonia specios a L. (Zie No. 1463.)

3620. Kalapa-oetan M. = M etroxylon elatum Mart. (Zie No. 1131.

3621. Kalapa-tjindana M. = Santalum album L. (Zie No. 3519.)
3622. Kalapa-tjoen $\mathrm{S} .=a \cdot \mathrm{My}-$ ristica globularia B l., Nat. fam.der Myristicacex. Gr. Molukken, Java, Amboina; boom. = Myristica irya G $æ r$ tn., Nat. fam. dezelfde. Gr. Java ; hooge boom.

3623. Kalapa-tjoen-bener S. = Myrystica glabra Bl., Nat fam. als voren. Gr. Java en Sumatra; boom. Gebr. Het hout is fraai en geel, doch ongeschikt voor bouwhout; de vruchten zijn eetbaar doch wrang.

3624. Kalapa-tjoen-beedjoh S. $=a$. Pyrenaria lanceolata T. \& $B_{0}=b$. Pyr. oidocarpa Krth. en $=c$. Pyr. scrrata Bl. Nat. fam. der Ternstrœ. miacer. Gr. Java; boomen.

3625. Kalapa-wanga Ces. $=$ Metroxylon elatum Mart.(Zie No. 1131.)

3626. Kalawara $\mathrm{S}$. $=\mathrm{Rh}$ inacan. thus communis Nees. (Zie No. 240.) 3627. Kalawassan J. \& Bl. = Leea sambucina Wlld. (Zie No. 133.)

3628. Kaledoepa BD. = Capsicum Tnft. Spec. divers $x$. 
3629: Kaleh-boenga-toedjong Sum. WK. = Memecylon minutiflorum Miq., Nat. fam. der Melastomacex. Gr. Sumatra; heester.

3630. Kaleij of Kakaleij 3 K. = Jambosa perforata $\mathrm{Miq}$, Nat. fam. der Myrtacer. Gr. Bangka; boom.

363i. Kalemangong IAarp. = Isonandra? lamponga Miq, Nat. fam. der Sapotaceœ. Gr. Sumatra; hooge boom.

3632. Kalemban $\mathrm{M}_{\mathrm{AK}}=\mathrm{Ch}$ avica sarmentosa Miq. (Zie No. 292.)

3633. Kalembemba BD. \& M. =

Entada pursætha D.C. (Zie No. 482.)

3634. Raleroengan J. of

3635. Kaleronkon J. = $\notin$ giceras floridum R. \& S. (Zie No. 130.)

3636. Kalet-akkar-mamboe Sux. $\mathrm{W}_{\mathrm{K}}$ = Ryparia cæsia Bl. (Zie No. 2085b.)

3637. Talet-minjak Sux. WK. = Solenostigma angustifolium Miq. (Zie No. 1845.)

3638. Kali Tr. $=$ Borassus fla. bellif ormis L. (Zie No. 3117.)

3639. Kaliageh $\mathrm{S}_{0}=\mathrm{Triphasia}$ sarmentosa Bl. Nat. fam. der A urantiaceæ. Gr. Java, veelal in tuinen; heester. GeBr. J) kleine roode vruchten worden gekonfijt gegeten.

3640. Kaliageh-goenong S. $=\mathrm{Cap}$ p.aris flexuosa Bl, Nat. fam. der Capparideæ. Gr. Java; heester.

3641. Kaliageh.lawut S. $=\mathrm{Catha}$ montana Hassk. (Zie No, 3410.)

3642. Kaliangauw $\mathrm{BK}$. $=$ Moline. ria longiflora Kurz. Nat. fam. der Hy poxider. Gr. Bangka; overblijvend.

3643. Kalidoeng $\mathrm{S} .=\alpha \cdot$ Cappa. l'is flexuosa Bl. (Zie No. 3640.) = b Gomphostemma javanicum Bnth. Nat. fam. der Labiat æ. Gr. Java; heester.

3644. Kalie-loemoet I. \& I. = Hydrocotyle Zollingeri Molkbr. Nat. fam. der Umbelliferæ. Gr. Java en Sumatra; overblijvend. GeBR. De bladeren worden als groente gegeten.

364.̌. Kalientang $\mathbf{M a K}$. = Moringa pterygosperma Grtn. (Zie No. 4.125.)

3646. Kaliki M. $=a$ Ricinus communis L. (Zie No. 1975). = b. Ricinus ruber Rmph. (Zie No. 1977b.) $=c$. Carica Papay a L. (Zie No. 1092.)

3647. Kaliki.oetan M. $=a \mathrm{Cro-}$ ton argyratum Bl. Nat. fam. der
Euphorbiaceæ. Gr. Java en Sumatra; groote heester. GEBR. Het grove, witte en sterke hout ran dezen heester is zeer geschikt voor huisbouw. $=b$ Rottlera rufidula Mi q. Nat. fam, als voren, Gr. Sumatra; heester.

3648. Kalimborrot (kalimorrot) I. = Castanea jaranica Bl. (Zie No. 2468.)

3649. Kallak S. \& I. = a Artabotrys intermedia Hassk. Nat. farn. der Anonaceæ. Gr. Java; klimmende heester. Gebr. Men vindt dezen heester veelal als sierplant bij de woningen, om de welriekende bloemen, die tusschen de kleederen gclegd worden. $=b$ Uvaria rufa Bl. (Zie No. 3574b.) $=c$ Uvaria dulc is Dun. Nat fam. als voren. Gr. Java; klimplant. $=d$ A porosa frutescens Bl. Nat. fam. der A porosex. Gr. Noesa-kambangan; heester.

3650. Kallas $\mathrm{I}$. $=\mathrm{C}$ on ocephal us suaveolens Bl. mas. (Zie No. 518.) 3651 . Kalleli Bu. $=$ Aleurites triloba Frst. (Zie No. 312.)

3652. Kallokane Ахв. $=\mathrm{Sph}$ æroc occus lichenoides Ag. var. tenuis. (Zie No. 20 en 21.)

3653. Kalodjo M. = U rostigma Rumphii Miq. (Zie No. 103.)

3654 . Ka!oekoe MaK. $=\mathrm{Cocos} n u$ cifera I. (Zie No. 393.)

3655. Kaloempang M. = a Sierculia fœtida L (Zie No. 1641.) = $b$ Sterculia hypostict a Miq. Nat. fam. der Sterculiacex. Gr. Sumatra; boom. $=c$ Aralidium dentatum Miq. (Zie No. 3337.)

36ว6. Kaloempang-babi M. = Sterculia chrysodasys Miq. Nat. fam. der S terculiaceæ. Gr. Sumatra; boom.

3657. Kaloempang-baras Sum. = Sterculia spectabilis II iq Nat. fam. zie voren. GR. Sumatra; hooge boom.

3658. Kaloempang.batienoh Suм.

$W_{k} .=$ St erculia crassinervia Miq.

Nat. fam. als roren. Gr. Sumatra; boom.

365\%. Kaloempang-boerong M,

3660 .

3661 .

3662 .

- ketjil M.,
- oetan M.,
-tsjendab

MAK. alle = Sterculia urceolata Sm. (Zie No. 1502.)

3663. Kaloewie S. \& M. = Arto. carpus incisa L. fs. (Zie No. 269.)

3664. Kalok-tjekko I. $=a$ Nepenthes melamphora $R w d t$. (Zie No. 
1704b.) $=3$. Nepenthes graeilis Kortl. Nat. fam. der Nepenthaee Gr. Jara, Sumatra, Borneo; slingerplant. GeBr. als bij No. 128 en 1704.

3665. Kalompong Mak. = Stereulia fotidia L. (Zie No. 164l)

3666. Kalondong-aroij $\mathrm{S}$. = Rhus nodosa Bl. (Źie No. 3144.)

3667. Kalonkan $\mathrm{Bi}_{0}=\mathrm{Ps}$ o $\mathrm{pho \text {ea }}$ pus tetragonolobus De. (Zie No. 1546.)

3668. Kalowaij M. AмB. =a A et inodaphne Rumphii 81. (Zie No. 55.) $=b$ Aetinodaphne moluecana Bl. Nat. fam. der I,aurineæ Gr. de Molukken; boom. Gkвr. als bij No. $55 .=c$ Enehidiumvertieillatum Jaek. (?). Nat. fum. der Euphorbiaecæ Gr. Su. matra; heester.

3669. Kaltiade MoL $=$ Cassia Tora L. var. 'T agera Vog (Zie No. 73 .

3670. Kam BI. = Flacourtia Jangomas Gmel. Nat. fam. der Bixacex. Gr. Java, Bali; boom. Grßr. De aangenaam zure vruchten worden rauw en gekonfijt gegeten.

3671. Kama (uok kamal) Aмв. = Dam in ara a lba $\mathrm{Rmph}$. (Zic No 1618). 3672. Kamálilan Arв. $=\mathrm{Hopea}$ selauica $R_{x} b$. (Zie No. 824)

3673. Kama-mette Амв. = Canarium rostratum Zipp. (Ziẹ No 1619.) 3674 Kamadjara-betoel $\mathrm{I}$ = Alpin ia malaseensis Rose. (Zie No. 392.) 3675 . Kamadoe I., zie Dawongatel 11 . 3676. Kamadoeän S. $=a \mathrm{Visc}$ a e $æ$ \& Lorallthace spec. diverse $=b$ Dendrophtloë lepidota Bl. Nat. fam. cier Lor a n th a e e æ. Gr. Java, Borneo en de Molukken; parasict.

3677. Kamakoän Aмв. $=a$ Ca nariopsis glabra Bl. (Zie No. 1628.) $=b$. Canariopsis liirsuta Bl. (Zie No. 2662.)

3678. Kamal $\mathrm{I} .=\mathrm{T}$ amarindus indica I. (Zie No. 7@3)

3679. Kamalandiengan J. M. \& S. $=a$. Leuciena glauea Bntl., Nat. farm der Mimoseic. Gr. Jara, uit WestIndië overgebracht; boom GEBR. Het harde hout bezigt men voor stelen van gereedschappen en schedeu van wapens; de jonge bladeren en ourijpe vruehten worden rauw bij de rijst gegeten; de riipe zadeu eet men geroosterd. $=b$. Albizzia montana Bilth., Nat. fam. als voren. Gr. Java en Sumatra; boom GEBr. De sehors van dezen boom bezigt men hier en daar tot het dekken van huizen. $=$ c. S ali. e ornia braehiata $R \times b$., Nat, fam. der Chenopodeæ Gr. Java en Bima; waterplant.

3680 . Kamalenga M. $=$ Benineasa eerifera Savi. (Zie No. 904a.)

3681. Kaman-silan Anв. = Canariopsis glabra 131. (Zie No. 1628.)

3682. Kamanden-0etan S. \& M. =

Daphne pendula Sm. (Zie No. 354.1 a.) 3683. Kamandre MaK. $=$ Croton

Tiglium L. (Zie No. 6.)

3684. Kamanga M. \& S. = Man. gifera Kemanga Bl. (Zie No. 1180.) 3685. Kamar AмB.

3686. Kamara koessoe T. $=$ A n dropogon S.chœnanthus L (Zie No. 2523.)

3687. Kamaras $\mathrm{S} .=$ Sareostigma II orsfield i i R. Br. (Zie No. 2233c.)

3688. Kamat $t_{\text {Mr }}=$ = Derris Forsteniana B]. (Zie No. 3264.)

3689. Kamatroe Sum. $=$ SehimaWalliehii Chois (Zie No. 2894a.)

3690. Kambehrong J. $=a$. A stronia spectabilis Bl Nat. fam. der Melast om aceæ. Gr. Java; hooge boom. Geis Het grove, roode en sterke hout wordt voor huisbonw gebezigd. $=b$. Astronia macrophylla Bl., Nat. fam. dezelfde. Gr. Java, Sumatra, Borneo ell de rolukken; boomachtig. Gribr. Vermoedelijk als $a$.

3691. Kambo-mantjik Sum. $W_{K}$, $=$ Seirpus juneoides Rxb. (Zie No. 1069.)

3692. Kamelan $\mathrm{AMr} .=a$. M ela. leuca leueadendron L. (Zie No. $120 a.)=b$. Nothopanax? Anisum Miq (Zie No. $389 a$.) $=$ c. Z a nthoxylon armatum DC, Nat. fam. der Zanthoxylex. Gr. Molukken; heester. 3693. Kamelan dawon-ketjil M. = I. eptospermu in amboinense kwdt. (Zie No. 2885.)

3694. Kamelaun Auв. $=$ Chaviea Betle Miq. (Zie No. 285.)

3695. Kami $A M B=\mathrm{Ca}$ uriopsis decumana Bl, (Zie No. 265l)

3696. Kamibela вD. = Urostigma Rumphii Miq. (Zie No. 103.)

3697. Kamilene Mor. = Wolla. stonia molueeaua D.C. (Zie No. $315 b)$

36.8. Ramirie M. $=$ Aleurites triloba Forst. (Zie No. 312.) 
3699. Kammang Nak. = Cordia Myxa L. (Zie No. 117)

3700. Kamoe-maätte $\mathrm{Aмв}=\mathrm{P}$ per arborescens R $\mathbf{x b}$. (Zie No. 288.)

3701. Kamoeboet $A м_{0}=$ Derris Forsteniana 131. (Zie No. 3264.)

3702. Kamoekoes S. \& M. $=\mathrm{Cu}$. beba officiunlis Miq., Nat. fam. der Piperacese Gr. Op Java, Sumatra, enz. in tninen; klimplant. GEBR. Het huishoudelijk en genteskundig gebruik der b a ccæ $\mathrm{cubeb}$ of staartpeper is te algemeen bekend, om het nog te omschrijien.

3703. Kamoel AмB. $=$ ('h a vic a Betle Miq. (Zie No. 285.)

3704. Kamoeloe-hahceä Амв. = Anamirta (jocculus W. \& A. (Zie No. 339.)

370弓 Kamoening J. 11. \& $\mathrm{S}=a$. Murraya I. Spec. diversæ $=6$. Murraya sumatrana Rxb (Zie No. 17\%3.;

3706. Kamoening.balou LaMP. = Visiania phyllothyrsa II iq., Nat. fam. der Ole in e æ. Gr. Sumatra; booin.

3707. Kamoening-doesson M. en

370s. Kamoening-japan M. = M u rraya exotica L. Nat. fam der A ura in tiacex. Gr. Rijna overal in Indië in tuinen; kleine boom. Gris. Het fijne, geele en sterke hout van deze sierplant is bijzonder gezccht voor handvatsels en scheden van wapens, wandelstokken, stoelen, enz De bladeren komen voor in vele mengstls, die bij wijze van poeder ingenomen worden tegen vermoeidheid, buikpijn, ellz.

3709. Kamoening-0etan M. $=a$. II uraya sumatrana Rxb. (Zie No. 17:3.) $=$ b. Visiania robusta D.C., var., Nat. fam. der Oleineæ. Gr. Sumatril, Javil, Madura; boom.

3710 Kamoening-tjina M. = A gla ja odorata Lour. Nat. farr. der Me. liacer. Gr. Vrij algemeen als sierplant in tuinen; heester. Gebr. De kleine, welriekende bloemen zijn zeer gezocht, èn om ze in het haar te dragen, èn om ze tusschen de kleedercn te leggen.

371!. Kampak J. = Hern andi a so nor a L (Zie No. 16.)

3\%12. Kampang.garang $\mathrm{J} .=a$. Drymisperm nm Blumei Desn. (Zie No. 422 ) = b. 1) rymispermum lanrifolium Desn. (Zie No. $354 \mid e$.)
3713. Kampanga-oetan PAL. $=\mathrm{Gu}$. atteria Parveana Miq., (Zie No. 3195.)

3714. Kampies J. $=\mathrm{Hernandia}$ soriora L. (Zie No. 16.)

3715. Kam.se $\mathrm{CH}_{\text {. }}$ Bo. = Citrus Aurantium L. (Zie No, 2049.)

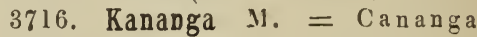
odorata Hk. fs. (Zie no, 1373.)

3717. Kananga $S_{0}=$ Lasianthis rigidus Miq, Nat. fam. der Rubiac e æ. Gr. Java $4000^{\prime}$; heester.

3718. Kananga-aroij $\mathrm{S} .=\mathrm{Artabo}$. trys interincdia Bl. (Zie No, $3649 a^{\circ}$ )

3719. Kananga-oetan M. = a. A r. tabotrys suaveolens Bl. (Zie No. 575.)=b$. Phæanthus nutans Hk. fs. \& Th. (Zie No. ]473.) =c M elodorum latifolium Dun. (Zie No. 573d.)

3720. Kananga-pantej Bo. = M e zzettia u mbellata Becc. Nat. fam. der A noulace Gr. Borneo; boom.

3721. Kananga-prit $J_{.}=\mathrm{C}_{\text {an }}$ anga od orata H. fs. (Zie No. 1373.)

3722. Kananga-reges $\mathrm{S}_{0}=a$ Lasiauthus tomentosus Bl. (Zie No. $2696 c)=$ b. Lasiauthus densifolins Miq., (Zie No. 796.) $=c$ Lasianthus rhinocerotis Bl., Nat. fam. der $k$ ubiace $x$. Gr. Java; kleine heester.

3723. Kananga-wangie $\mathrm{M}_{\mathrm{O}}=\mathrm{C} \mathrm{il}$ nanga odorata H. fs. en Th. (Zie No i 373.$)$

3724. Kanara M. = Dolichos lignos us L. (Zie No. 3544b)

3725. Kanara-lawut $.1 .=\mathrm{L}_{\mathrm{ab}} \mathrm{ab}$ microrarpus Wc. (Z ie No. 3547.)

3726. Kasara-poetih M. = Lablab perennans 1) e. (Zie No 3548.)

3727. Kanarie U. \& S. $=a . \mathrm{Ca}^{-}$ narium com nun e L. (Zie No. 3072 (t) $=$ b. C a narinm microcar p $1 \mathrm{~m}$ $\bar{W} l 1$ d. (Zie No 40$)=c$. Engelhardtia scriata Bl (Zin No. E57d.)

3728. Kanarie-ambon $\mathrm{Nl}$. = Canarium Mehenbethene Grtn. (Zie No. 3072a.)

3729. Kanarie-babie $\mathrm{M} .=\mathrm{C}$ a nariopsis decum an a BI. (Zie No. 2645.)

3730. Banarie-baggêa $M .=$ Canarium Mlehenbethene Grnt. (Zie No. 3072b.)

3731. Kanarie-barat $\mathbf{~} 1 .=\mathrm{Canz}$ rium zephyrinum Bmph. (Zie No 3074.)

3732. Kanarie-besaar $\mathbf{~} \mathrm{I}=a \cdot \mathrm{C} a$ 
narium mchenbethene Grtn. (Zie No. 3072b.) $=b$. ('anariopsis decuma ll a Bl. (Zie No 2651.)

3733. Kanarie-hitam M. = Canarium rostraium Zipp. (Zie No. 1619.)

3734. Kanarie-ketjil M. $=\mathrm{C}$ a n ar i u in z e phy rin u $\mathrm{Rmph}$. (Zie No 3074.)

3755. Kanarie-0etan M. $=a . \mathrm{C}$ anarium z e phy in um $\mathrm{R}$ in ph. = b C a narim sylvestre Grtn. (Zie No. 3070.)

3736. Kanarie-pandjang $\mathrm{M} .=\mathrm{Ca}$. narium commune L. (Zie No. 3072.)

3737. Kanarie-pendekh $\mathrm{M}$. $=\mathrm{Ca}$. nari um zephylinum $R \mathrm{mph}$. (Zie No. 3074 )

3738. Kanarie-wolanda $\mathbf{M}=\mathrm{A} \mathrm{m}$ y g. dalus communis I., Nat. fam. der A m y g dale æ. Gr. De amandelboom wordt op Java, om ziju aangename vruchten, in sommige tuinen gevonden; het gebruik is overbekend.

3739. Kanarie-xula M. = C a n ariopsis decumana Bl. (Zie No. 2651.)

3740. Kanawan M., Амв. = Cordia subcordata L a m (Zie No. $1021 b$.

3741. Kandajakkan $\mathrm{s}=\mathrm{P}$ il i o s$\mathrm{t}$ igm a a c i $\mathrm{m}$ m $\mathrm{B} n \mathrm{th}$., Nat. fam. $\mathrm{Pap}$ il i o n c e æ. Gr. Java en Timor; boom.

3742. Kandaka-nassi M. $=a$. R hi\% ophora in ucronata Lam. (Zie No. 868 .) $=$ b. Brugu i c a c a ryophylloides $\mathrm{Bl}$, Nat. fam. der lihizophorex. Gr. Overal in den Archipel langs de stranden; boom, slechts geschikt vonr braudhout.

3 443. Kandal M. \& J. = $a$. Cordi a $M$ y a L. (Zic No 117.) $=b$. Cordia bantamensis Bl., Nat. Ian. der Cordiacere. Gr. West-Java; hooge boo:n. = c. Quercus? a poros a Z. \& Ni., Nat. farn. der Cupuliferæ. Gr. Java; boom.

3744. Tandalen $\mathrm{J}=\mathrm{Freyci}$ i ct i a s a ndens G a d. (Zie No. 338.)

3745. Kandar J. \& S. = Paratropia elleptic a $\mathbf{M i q}$, Nat. fam. der A rali a cee. Gr Java, boom.

3746. Kandar-loetoeng $\mathrm{S} .=a$. T araktogenos Blum ei Hassk. (Zie No. 1045.) $=b$. Dodecastemon 'T'eijsma u i zoll., Nat. fam. der Eu. phorbiace a. Gr. Java en Timor; boom.
3747. Kandel J. $=$ Procris frut e s c e ns B l., Nat. fam. der U r t i c ac e æ Gr. Java; hecster.

3748. Kandelang $\mathbf{J}_{.}=$Urostigma c r a s ir a m e u m M iq., Nat fam. der A r t o c a r pe æ. Gr. Java; boom.

3749, Kandeli Moc. $=\mathrm{Ph}$ a s e. lus radiatus L. (Zic No. 31.)

3750. Kandies $\mathrm{BK}_{\mathrm{K}}=\mathrm{R} \mathrm{Rh \textrm {h } \text { os. }}$ tigm a parvifoli um Miq., Nat. fam. der Clus ia ceæ. Gr. Bangka; hoom.

375l. Kandies Sum. $=a$. G a r c i$\mathrm{n}$ i a m e r guense Wght. en $=b$. G. parvifolia Miq., Nat. fam. der C l u s i a c e æ. GR. Sumatra; boomen.

3752. Kandis $M_{0}=\mathrm{Act}$ illodaphne heterophylla Bl., Nat. fam. der la uri n æ. GR. Sumatra; hooge booin.

3753. Kandis $\mathrm{BK}$. = G a r c in i b ancan a $\mathbf{M}$ iq, Nat. fam. der C l usi a c e r. Gr. Bangka; boom.

3754. Kandis-kling $\mathrm{BK}$. $=\mathrm{Garci}$ ni a (Rhinostigm a) parvifolia M i q. (Zie No. 37516.)

3755. Kandoeng (of Kendoeng) $M$. $=a$. Sym plocos repandula Miq., en $=b$. S. la chnobotrya Miq., Nat. fam. der Stry a e æ. GR. Suma. iV.kust ; heesters.

3756. Kandoeng $\mathrm{S} .=a \mathrm{Helicia}$ s e r a t a R.B r. (Zie No. 3381.) $=b$. Helicia ja $\mathrm{i}$ a n i a B n t t., Nat. fam. der Proteac eæ. Gr. Java en Bangka; boomachtig.

3757. Kadoeng-gedeh S. (Zie vorig No. onder b.)

3758. Kandoeng-peutjang $\mathrm{S} .=a$. B r u c e s u in a t ran a $R x$ b. (Zie No 296.) $=b$. H elici a robus:a Wall., Nat. fam. der Prote a e æ. Gr. Java; hooge boom.

3759. Kandoeng-rimbo Sum. $=\mathrm{Ar}$ disia Korthisiana Scheff., Nat fam. der $M$ yrsine acex. Gr. Sumatra; beester.

3760. Kandoeroe $\mathrm{J} .=\mathrm{C}$ a r y o t a p r o p inqua Bl., Nat. fan. der Pal$\mathrm{m}$ æ. Gr. Java; hooge Palm.

3761. Kandong-batoe $\mathrm{M}$. $=\mathrm{N}_{\mathrm{o}}$ thopanax fruticosum Miq (Zie No. 1153.$)$

3762. Kandori M. \& S. = A de 11 anthera $\mathrm{Pav}$ a $\mathrm{i}$ a $\mathrm{L}$. (Zie No. 52.)

3763. Kankong $\mathrm{M}$. $=\mathrm{I}$ p o $\mathrm{m} \propto \mathrm{a}$ reptans Poir. (Zic No. 526.)

3764. Kangkong-oetan M. = Co m- 
melina benghalensis I. (Zie No 2549 )

376 . Kanigara II., R. = N s m. pha a stellata W ld d., Nat fam der N y m p h æ c e ie. Gr. Java, Riour, enz; waterplant.

3766. Karjaloet M. $=\mathrm{R}$ ox b lirghia javaniea Kunth. (Zie No. i534)

3767. Kanjar-kawang $\mathrm{J} .=\mathrm{C}$ a rdiopteris lobata W all. (Zie No. $2385 c$.)

3768. Kanjehreh S. = B riedelia la ve e olat a Krz. (Zie No. 2644.)

\section{Kanjehreh-badak-aroij S. =} Briedelia tomentosa Bl., Nat. fam. der E uphorbia e e. Gr. Java; klimmende heester. GEBR. Men bezigt de rauken als touw en $d \in n$ bast tot het zwart verwen van garevs. Het sap wordt tegen kolijkpijnen gedronken, ell aau kraamvrouwen na de bevalling gegeven als buikzuivcread midilel; meu drinkt het slechts eenmaal.

3770. Kanjehreh-boddas S. (Zie rorig No.)

3771. Kanjehreh-boddas-aroij S. = Briedelia stipularis Bl. (Zie No. 154.)

3772. Kanjehreh-lumboet (Zie rorig No.)

3773. Kanjoeng J. = Uvaria purpurea Bl. (Zie 573.)

3774. Kankong J. $=a$. C a s s y t a filiformis L. (Zie No. $20^{\circ}$ ) $=b$. $A$ u ise i a medium Chois. Nat. fam. der Convolvula e æ. Gr. Java en andere Sunda-eilanden; éénjarig.

3775. Kannakoer $\mathrm{AD}$. $=\mathrm{C}$ haviea siriboa Mi q. (Zie No. 1170.)

3776. Kanne M $\mathrm{K}$. = Erythrina f u s a Lour. (Zie No. 1595.)

3777. Kano-kano M. \& T. $=\mathrm{Gra}$. millex (A rundinacex) divers

3778. Kanoeno $\mathrm{T} .=\mathrm{C}$ ord i a subpubescens Desn.; Nat fam. der C o r d i a e ex. Gr. Timor; boom.

3779. Kanoer MaK- = Erythrina fusea L o ur. (Zie No. 1595.)

3780. Kanre-oelar MaK. $=a$. Coce in i a grandis N. J. Roem. (Zie No. 640.) = b. Momordiea sub a ngulata B l. (Zie No. 262a.)

3781. Kaö Br. = D ioscorea Klein ian a Kunth. (Zie No. 5.)

3782. Kaöe MaK. = Eriodendrum a nfraetuos um D.C. Zie No. 28b.)
3783. Kapa J. = Fieus trico1 o r 11 iq. (Zie No. 310ว.)

3784. Kapa O. Ces. = Cossypium vitifoli u in I, a m., Nat. fam. der M a l v a c e æ. Gr. Hier en daar gekweekt; heester. Griz. De bladeren worden als groentc gegeten; de wol der pitten levert een langen en zeer sterken draad.

3785. Kapa T. $=$ Gossypium indieum Lam. (Zic No. 23).

3786. Kapai R. = Ophioderma pendulum Endl., Nat. fam. der Ophioglossex. Gr. Sumatra, Riouw, enz.; overblijvend.

3787. Kapaja Mex. = Cariea Papaya. (Zie No. 1092.)

3788. Kapal S. = Excœearia A gallo eha I. (Zie No. 22b.)

3789. Kapalan J. $=\mathrm{Cle}$ mat is. Luesehenaultiana DC. (Zie No. 568.)

3790. Kapas M. \& J. $=a$. Gos. sypium indieum Lam. (Zie No. 23.) $=6$. Gossypium arboreu in L. Nat. fam. der M a lvaee a. Gr. Bijna overal in Indië. GlzR. Deze heester lerert een korte, sleehte boomwol.

3791. Kapas-anggries J. $=\mathrm{G}$ os s ypiun vi tifolium laam. (Zic No. 3684.).

3792. Kapas-antoe M. = Pavonia zeylanica Cav., Nat. fam. der Malva eеx. Gr. Java; heester.

3793. Kapas-bali J. $=$ G os s ypi um indieum $L$ a m., var. a rboreseens. (Zie No. 23).

3794. Kapas-bengala M. \& S. Gossypium vitifolium Lam., var. mac ul if lorum Hassk. (Zie No. 3784.).

3795. Kapas-besaar M. = a Gossypium vitifolium Lam. (Zio No. 3784.)=b$. Fossypium arboreum L. (Zie N. 3790b).

3796. Kapas-Letoel M. = Gossypium micranthum Cav., Nat. fun, der Mlva cex. Gr. Op Java in tninen; heester. Grir. De boomwol van dezen heester is de fijnste van alle katoensoorten, cn levert een sterken draad.

3797. Kapas-burrom S. = Gossypium purpuraseens Poir.; Nat. fam. als voren. Gr. (Op Java, gekwcekt; heester. GEBr. 1)eze plant levert ecu witte, lang. dradige, zcer gezochte boommol.

3798. Kapas-djawa J. $=$ Gossypium ind icum I. (Zie No. 23.)

3799. Kapas-gedeh S. = Gossypium vitifolium Lam., var. (Zic No. 3784.) 
3800. Kapas-hiedung $S .=$ Gossy. pium religiosum $I$, Nat. fam. der Malvace $x$. GR Op Java en elders gekweekt; heester. Geвr. Deze heester levert de in China zoo zeer gezochte gele Nangking-boomwol, welker kleur door het wasschen fraaier wordt.

3801. Kapas-hoema S. = Gossypium indicum Lam. (Zie No 23).

3802. Kapas-konneng S. $=\mathrm{H}$ ibisc us Lampas Cav. (Zie No. .)

3803. Kapas-lumbost $\mathrm{S}$. = Gossypium indicum I am. (Zie No, 23).

3804. Kapas-meirah M. 三 a. Gos. sypium indicum Iam. (Zie No. 23). $=b$. Gossyium purpurasens Poit. (Zie No. 3797).

3805. Bapas-morie II. \& S. = Gossypium micranthum Cav. (Zie No. 3796.

3806. Kapas-0etan 1. = Hibis. cus Lampas Cav. (Zle No. 3412).

3807. Kapas plembang $J .=$ Gossypium herbaceum L., Nat. fam der Malvacex. Gr. Uit China naar Java en Palembamg overgebracht en aldaar aangekweekt; heester. GeBr. Ieze heester levert een zeer bruikbare boomwol.

380s. Kapas-poeloe-laut J. = Gossypium barbadense L.. Nat. fam. als voren. GR. Op Java van Barbados ingevoerd, en aldaar angekweekt; heesier. GEBr. l)eze heester levert het zoogenaamde Sea-island cottnn.

3809. Kapas-randoe J. $=$ Gossypium micranthum Cav. (Zie No 3796)

3810. Kapas-rawang Sum. WK. = Prynos cymosa Hassk. Nat. fam. der Ilicineæ. Gr. Java en Sumatra; hooge boom.

3811. Kapastahon M. $=a$. Gossypium micranthum Cav. (Zie No. 3796.)=$ b. Gossypium purpurascens Poir. (Zie No 3797.)=c. Gossypium vitifolium Lam (Zie No. 3\%84.)

3812. Kupas-tjiendeh S. = A sclepias curassavica I., Nat. fam. der A sclepiaderc. Gr. Thans door Indië bijna verwilderd, uit $Z$ uid-Amerika overgebracht; overblijvend. GEBR. Deze plant wordt, om hare fraaie, goudgele bloemen veel in tuinen aangeplant. De wortel wordt in West-Indië als braking- en ontlasting. bevorderend middel (de wilde I pecacu$a n h$ a) toegediend, en gezegd zeer werkzaam te zijı bij druiper en witten vloed. Het melksap kent men ecn wormdrijvende kracht toe. De vruchten leveren een fijn glinsterende boomwol, minder geschikt tot vervaardiging van katoen, doch wel gebruikelijk bij de fabrikatie van vilten hoerlen.

3813. Kadas-wolanda $J .=$ Gos. sypium religiosum I. (Zie No. 3800.) 3814. Kappassans $\mathbf{~} .=$ A sclepias curassavica L (Zie No. 3812.)

3815. Kapawarita АмB. = Canan. ga odorata Hk. fs. (Zic No. 1373.)

3816. Kapeh-kapeh Suм. Wк. = S alix Horsfieldian a M i q. (Zie No.2583.)

3817. Kapeping-badak $\mathrm{S} .=\mathrm{Kie}$ sera sericea $R$ uwdt. Nat. fam. der Papilionacex. Gu. Java en Sumatra; boomachtig.

3818. Kapeij-gorita Амв. = Lygodium circinatum Sw. (Zie No. 2792). 3819. Kapeij-papoea $\mathrm{Aмв.} \mathrm{=} \mathrm{L} \mathrm{y} \mathrm{-}$ godium microphyllum R Br. (Zie No. 2604.)

3820. Kapi-oenan Str. Wк. = Chrysophyllum sumatranum Miq. (Zie No. 1625).

3821. Kapian-kapian Sus. Wк. = Fuirena pentagona Wght. Nat. fam. der Cyperacca. Gr. Java en Sumatra; overbliivend. Gebr. Van de stengels van dit ricigras maakt men eene grove soort van matten.

3822. Kapiendieng Suy. = $\mathrm{Te}$. tranthera mappacea B l. Nat. fam. der L a urineæ. Gr. Java en Sumatra; hooge boom.

3823. Kapinango S. $=a$ Dysoxylon laxiflorum Bl. Nat. fam. der Meliaceæ. Gr Java; boom. Gebr Het fraaie, fijngeaderde en welriekende hout van dezen boom wordt voor fijne meubclen en kleine stukken gebezigd. Om een fijne huid te bekomen, wrijft men zich met den fijngestampten bast bij het baden het lichaam in. $=6$ Epicharis? altis. sima Bl. Nat. fam. dezelfde. Gr. Java; hooge boom. GeBr. Het sterke, fiju geaderde hout van dezen boom is zeer geschikt voor huisbouw, voor wielen van karren, enz. Het wordt niet door witte mieren aangetast; de schors verspreidt een onaangenamen reuk, even als die ran excrementen.

3824. Kapini Sur. Wк. = a. Artocarpus elongata Miq. Nat. fam. der Artocarpex. Gr. Sumatra, boom. $=b$. Sloetia Sideroxylon T. \& B. Nat. fam. dezelfde. Gr. Sumatra en Riouw boom. 
3825. Kapintan I. $=\mathrm{Knoxia}$ mollis $\mathrm{R}$ Br. Nat fam. der Rubia. c е æ Gr. Jara; éénjarig

3826. Kapiriet-lumboet $\mathrm{S} .=a$. Boehmeria nirea Gaud. (Zie No. 2387.) $=6$ Pourolzia ovalis Miq., Nat. fanı. der Urticacex. Gr. Java en Sumatra; heester.

3827. Kapo-kapo Sum. Wк. = Glochidion littorale Bl. Zie No. $323 \%$.)

3828. Eapo-kapo Bl. = P is it a Stratiotes L. (Zie No. 1669.)

3829. Kapoeän I. = Ficus leucoptera Miq. Nat. fam. der Artoc a r p æ. Gr. Java; heester.

3830. Kapoelaga I. \& . I. = A momum $\mathrm{C}$ a r d a $m$ o m u $m$ L. Nat. fam. der Zingiberaceæ. Gr. Bijna door geheel Indië gekweekt; orerblijvend. GEBR. Deze plant levert de bekende $\mathrm{S}$ e $\mathrm{m}$ i ma $\mathrm{c}$ a $\mathrm{r}$. d a momi rot nuda. De gedroogde en fijngestampte wortel wordt door vrouwen ingenomen bij een gevoel van koude; een af kooksel der geheele plant wordt gedronken tegen moeheid en slapheid der lejematen.

3831 . Kapoendang-akar Sux. WK. = Goniothalamus Tapis Miq. (Zie No. $3 \pm 97$. )

3832. Kapoendoeng S. \& $\mathrm{I} .=a$ P i e r a d i a r a c e mos a Bl. (Zie No. 1丂80.) $=6$ Ardisia debus.mon. t is Miq Nat. fam. der Myrsine x. GR. Java; boom.

383:3. Kapoe-adja MEs. en

3834 . Kapoer-antjak S. $=\mathrm{Calo}$. phyllum inophyllum L. (Zie No. 1139)

3835. Kapoer-haroe II. = a Ca mphora sumatra na Miq. Nat. fam. der L a u rin ex. GR. Sumatra; hooge boom. Gebr. Leze boom levert de Sumatra-kanfer of kamfer van Baros. $=b$ Camphora officinarum C Baub. Nat. fam. der. L a u rine $æ$. Gr. Hier en daar in tuinen; hoowe boom. GkBR. Uit dezen boom verkrijgt men de bekende Jaransche kamfer. Uit de zaden wordt een vetsoort geperst, die, in plants van was, roor kaarsen wordt gebeziyd.

3si6. Kapoer-baros M. \& S. = A mom um Cardamom um L. (Zie No. 3830 .

3837. Kâpoer-gading $\mathrm{I} .=\mathrm{I}) \mathrm{aph}$ nidiam dæsium Niees. (Zie No. 28936.)

3538. Kapoesilan-ketjil $\mathrm{I} .=\mathrm{G}$ y m- ne un a lact ife rum R. B r. Nat. fam. der A scle piadex. Gr. Jara; slin. gerplant.

3839. Kapoh I. \& M. = Eriodendron a nfractuosum Dc. (Zie No. 28.)

384u. Kapok Alf. Mrs. = Hoei S. $=$ Oebie $M$.

$384 i$. Kapok-0etan $\mathbf{M}$. = S a l malia malabarica Sch. \& Endl. (Zie No. 1639.)

3842. Kappa-torroh $\mathrm{S} .=\mathrm{J} u \mathrm{~s}$ s i a repens L. (Zie No. 4i6.)

3843. Kappal I. \& $\mathrm{S}$. $=a$ Excœcaria $\mathrm{A}$ galloch a L. (Zie N.22b) $=b$ Cyrtoceras multiflorum Benn. (Zie No. 699f.) $=c$. Hoy a polsstachra Bl. Nat. fam. der A s c l e pi a d e r. Gr. Java en Snmatra; slingerplant $=d \mathrm{~S}$ y m p h y ic arpus chrysanthus Hassk. Nat. fam. als voren Gr. Java; slingerplant

3844. Kappan S. = Mristica l æviga ta Bl. (Zie No. 855 .)

$38: 5$. Kappal S. $=$ S a r c o c e phalas cordatus Miq. Nat. fam. der $\mathrm{R} u$ b i a c e $x$. Gr. Java; kleine boom.

3946. Kappoel Am. = Nelitris a l b a Bl. (Zie No. 5 16.$)=6$. Neli. tris rubra Bl. (Zie No. óla) $=c$ Fabrica? bracteata Rxb. Nat. fam. der II y rtace e. Gr. Ainboina; heester. GeBr. Als No. ว̆l.

3847. Kappol $\mathrm{S}$. $=A \mathrm{momum}$ C a rd a mo m u m L. Zie No. 3830.)

$38+8$. Kappol-leutiek $\mathrm{S} .=$ Filet. taria tomentosa 11 iq. Nat. fam. der Zi ng iberace a. Gr. Jara; orerblijrend.

3849. Kappol-sabrang S. = Elet$\mathrm{t}$ aria $\mathrm{C}$ arda $\mathrm{mom}$ u $\mathrm{m}$ Wit e. (Zie No. 2708.)

3850. Kara-kara-baina МıK en 3851. Kara-karai $\mathbf{M}_{\Delta \mathrm{K}}$. $=\mathbf{I}$ ab l a b cul trat us D.C. (Zie No. 3991.) 3552. Karaboe Sur. $W_{\mathrm{K}}=\mathrm{Con}$ narus semidecandrus. Jack. Nat. fam. der C o n n a r a c eæ. Gr. Sunutra; slingerplant.

3853. Xaram-karam Sum. Wк. = Glycosmis subopjosita Miq. Nat. fam. der A urantiaceæ. Gr. Sumatra; heester.

3854. Karamandijn $M_{\mathrm{AK}}=a$. Melastoma polyanthum Bl. (Zie No. 110.) $=b$. Otanthera moluccan a Bl. (No. 2238a.) 
3855. Karambau-dinar $\mathrm{BD}$. = Euphorbia nereifolia L. (Zie No. 44.) 3856 Karambil Sum. $W_{k}=$ Aralia dasyphylla $\mathbf{~}$ iq. (Zie No. 2275.) 38.57 Karamboä BD. = Gossypi$u m$ indicum Lam. (Zie No. 23.)

3858. Karamoenting $\mathbf{M}=a$, Melastoma polyanthum BI. (ZieNo. 110) $=$ b. Rhodomyrtus tomentosa D.S. (Zie No. 2739c.)

3859 . Karamoenting-rimbonjangdjanten $\mathbf{M}$. = Khodendrnm multi. culor Miq., Nat. fam. der krieacex. GR. Sumatra WK.; heester.

3860. Karandang $\mathrm{S}$ \& $\mathrm{M}$. = $\mathrm{Ca}_{\mathrm{a}}-$ rissa Carandas L., Nat. fam der A poсупељ. Gr. Java, Sumatra, Timor; heester, veelal in omheiningen aaugeplant. GeBr. De viuchten worden rauw en in het zuur ingelegd gegaten.

3861. Karanëang $J_{\text {. }}=$ Nothopanax? anisum Miq. (Zie No. 389a.)

3862. Karang-karang $\mathrm{M} .=a . \mathrm{Po-}_{0}$ lypodium quereifolium L. (Zie No. 181.) = b. Arytera Karang Miq,, Nat. fam. der Sap ind a e a. Gr. Sumatra; boom.

3863. Karang-karang-rimbo M. = A rytera Montana B 1. Nat. fam. als voren. GR Sumatra 2-3000' ; heester.

3864. Kararaweah S. = NI u una prurita Hk. (Zie No 1699.)

3865 . Karassa-dangdang $\mathrm{S} .=\mathrm{V}$ allaris pergulana Brm, Nat. fam. der A pосупег. Gr. Door geheel Indie; slingerplant, z'er gezocht om hare geurige blcernen

3\&66. Karbanga $\mathrm{T} .=\mathrm{Cnr} \mathrm{cuma}$ Z erumbet Rxb., Nat. fam. der Zingibil racec. GR. Overal in dezen Archipel; overblijvend. Gквк. Deze plant levert de bekende Radix Zedoariæ rotunda et longa.

3867. Karéo $\mathrm{S}$. = Alocasia macrorhiza Schott. (Zie No. 1239.)

3868. Karet S. \& $\mathrm{M} .=a$. Uros. tigma elasticum Niq. (Zie No. 2440b.) $=b$. Urostigma Karet $\| \mathrm{iq}$. (Zie No. 25046 )

3859. Karet-andjieng M. = Chrysophyllum rhodoneurum Hassk, Nat. fain. der Sapotaceæ. Gr. Java; hooge boom, die waarschijnlijk ook getah pertja levert.

38 0 . Karet-moendieng $\mathrm{S} .=\mathrm{Ca}-$ cosmanthus maerophyllus Hassk., Nat. fam. als voren. Gk. Java; hooge boom, welke getah pertja oplevert. 3871. Karet-pantjal S. = Sideroxylon attenuatum A. 1) C. (Zie No1203.

3872. Karet-tapok $\mathrm{S}$. $=\mathrm{Uros}_{\mathrm{rig}}$ ma Karet Miq. (Zic No. 2504b.)

3873. Kareta $\mathrm{M}_{\mathrm{AK}} .=\mathrm{Ps}$ ophoearpus tetragonolobus D.C. (Zie No. $1546)$.

3874. Bariskis MeN. $=\mathrm{He}$ lig ne minahassa T' \& B., Nat. fam. der Apoeyneæ GR Celebes Noordkust; slingerplant.

3875. Karoe-hoeman $B K=\mathrm{Spa}$. thodea Lobbii T. \& B (Zie No. 3156).

3876. Karoek of Karot $\mathrm{S} .=\mathrm{Cha}$. viea sarmentosa Miq. (Zie No. 292). 3877. Koeroek-manoek S. $=\mathrm{Cha}-$ viea $\mathrm{Mel}$ amiris Miq. (Zie No 286

3878. Karoendoeng $\mathrm{S}=a$. Solan um flaveseens Dun, Nat. fam. der Solanaceæ. Gr. Java; éénjarig. Gebr. De vruehten worden afgekookt bij de rijst gegeten. $=b$. Solanum ferox L., Nat. fan. als voren. GR. Java, Borneo, enz. soins gekweekt. GEBR. Ook hiervan eet men de vruchten afgekookt als groente bij de rijst. $=c$. Solanum trongum Po ir. Nat. fam. dezelfde. Gr. Door geheel Indië; éénjarig. GEBR Dit is in de tuinen een lastig onkruid, waarvan de vruehten zelden worden genuttigd; aan den wortel kent men een sterke vruehtdrijvende kracht toe.

3879. Karoendoeng-badak S.

3880. Karoendoeng-goenong $\mathrm{S}$. en

3881. Karoendoeng-sapi S. $=$ Sol an um ferox L. (Zie No. 38786.)

3882. Karoenroen $\mathrm{M}_{\mathrm{AK}}=a$. Dracontomelon mangiferum Bl. (Zie No. 1492.) = b. Evia aeida Bl. (Zie No. 2.890.)

\section{Karondong $\mathrm{S} .=$ Karoen-} doeng $S$.

3884 . Karpoo T. $=$ Tournefortia argentea L., Nat. fan. der Asperifolix. GR. Bijna overal in Indië; hees. ter. Grib. Men eet de ziltige bladeren gaarne als groentc bij de rịjst en zegt dat de wortel heilzaam zal zijn tegen galaehtige kolijk.

3885. Karughang $\mathrm{S}=$ Piper muricatum Bl. Nat. fam. der Pipec raeeæ. Gr. Java; slingerplant.

3886. Karumbie S. (Kareumbie S.) $=$ Carumbium populifolium kwd t. (Zie No 1295) 
3887. Karumbie-sabrang $\mathrm{S} .=$ S tillingia sebifera Wild. Nat. fam. der $\overline{\mathrm{c} u p h o r b i a c e x . ~ G r . ~ O p ~}$ Java nit Japan ingevoerd; hooge boom. GEBR. De zaden bevatten een vaste vetstuf, die veelal voor kaarsen wordt gebe. zigd; ook wordt er een zachte, zoete olie uit verkregen.

3888. Kasedel J. = Cord i M y x a L. (Zic No. 117 )

3889. Kasimboekan S. \& J. $=a$. Eelipta erecta Hassk. (Zie No. 1809b.) $=6$. P $x \mathrm{deria} \propto \mathrm{f}$ ida I. (Zie No. 17396).

3890. Kasingsat $\mathrm{S} .=\mathrm{C}$ assia o e e identalis L., Nat. fan der $\mathrm{P}$ ap il i o n a e ex. Gr. Java, Sumatra en elders; éénjarig. GEBR. De bladeren en onrijpe peulen eet men gekookt bij de rijst.

3891. Kasoergka S. \& J. = Gne$\mathrm{tum} \mathrm{latifolium} \mathrm{Bl.} \mathrm{(Zie} \mathrm{No.} \mathrm{3265.)}$

3892. Kasoengka-aroij $\mathrm{s} .=a$. Guetnm latifolium Bl. (Zie No. 3265.)=6$. Gnetum funiculare B 1. (Zie No. 200.)

3993. Kasoenka-beurriet $\mathrm{S} .=a$. Gnetum funieulare Bl. (Zie No. 200.) en $=b$. Gnetum edule Bl. (Zie No. 532.)

3894. Kasse-selan Br.. $=a \mathrm{Cr}$. n u m as iatie u m I. (Zie No. 869a.) $=b$ Paneratium zeglanieum L. (Zie No. $869 c$.)

3895. Kassi-berânakh M. = Bhodolei a Teysmanni Miq. (Zie No. 3206.)

3896. Kassoemba S. = $\mathrm{B} \mathrm{ix} \mathrm{a}$ Orella na L. (Zie No. 1697.)

3897. Kassoemba M. = Cartlia. mus tinetorius L. Nat. fam. der C o m positæ. Gr. Door geheel Indië; éénjarig. Gebr. Deze plant levert de bekende kleurstof, Saffloer genaand, welke in den indisehen handel zeer gewild is en wordt daarvoor aangeplant.

3898. Kassoemba-djawa M. (Zic vorig No.)

3899. Kassoemba-kling MI. = Bixa Orellana I. (Zie No. 1697.)

3900. Kassoh S. $=a$ S a e eh arum spontane um L. ('Zie No. 2321.) $=b$ Anthistiria eiliata L. (Zie No. 2 i26a.)

3901. Kassongket $\mathrm{S} .=\mathrm{Ph} \mathrm{r}$ gmites filiformis $S t d$. Nat fam. der $G r$ a in in ex. Gr. Java; rietachtig yras.
3902. Kastella BI. $=$ Bat a tas e dulis Chois. (Zic No. 635.)

3903. Kastoerie M. $=a \mathrm{Abel}$ mosehus mosehatus $M$ ö n ch (Zie No 2402) $=b$. Hibiscus surat. tensis L. (Zie No. 73l.) $=c \quad \mathrm{X}$ a nthophyllum adenopod u in Miq. Nat. fam. der Polyg a lex. Gr. Sumatra; boom.

3904. Katang $\mathrm{S} .=\mathrm{Grew}$ i a to. me ntos a Jus s. Nat. fain der Tiliae e $x$. Gr. Java en T'imor; hooge boom. GeBr. Het hout van dezen boom bezigt men voor hutjes in de rịstvelden; het is wit, week, grofvezelig en lieht en wordt spoedig door insecten aangetast.

3905 . Katapang M. \& S. = T e rminalia (catapl) a $I_{4}$, (Zie No. 7.) $=b$ Terminalia ehebula Wlld. Nat. fam. der Co m breta e ex. Gr. Java; hooge boom. Grisr. Deze boom levert een goed timmerhout. Op de bladeren ontwikkelt zich, door den steek van een insect, een soort van galloot, van dezelfde hoedanigheid als ce gewone; deze noten worden thans als looimiddel van Java veel uitgevoerd, en onder den naam van lljokjouten in den handel gebracht. 1)e vruclit wordt als purgeermiddel anngewend.

3006. Katapang-boddas $\mathrm{S}=\mathrm{T}$ e $\mathrm{r}$ mi na li a C a t a ply a. var.e hl o r oc a r p a H as sk. (Zie No. T.)

3907. Katapang-boeloe CEL. = T e rminalia mollis Z oll. Nat fam der Col breta e e Gr. Java ell Celebes; hooge boom.

3908. Katapang-burrum $\mathrm{S}=\mathrm{Ter}$ min a lis Catap pa I. var. rhodoc a r p a lla ssk. (Zie No. 7.)

3909. Katapang-gedeh $\mathrm{S} .=\mathrm{T}$ e $\mathrm{r}$ minalia Catap pa L. va $\mathrm{m}$ a e roe a r pa 11 assk. (Zie No. 7.)

3910. Katapang.goenoeng $\mathrm{S}=$ M o noceras obtusum Hassk. (Zie No. $2897 i$.)

3911. Katapang-oetan Aмв. = Terminalia sylvestris $R \mathrm{mph}$. Nat. fam. der Com breta e e $æ$. Gr. De Molukken; hooge boom.

3912. Katapang-pantej Амв. = Terminalia moluecana $L$ am. Nat. fam. als voren. Gr. de Molukken; hooge boom. GeBr. als bij No. $i$.

3913. Katapang-talang PAI. = Terminalia? adeuopoda Miq. (Zie No. 3306.) $=b$ Terminalia 
s u matrana $\mathbf{M}$ iq. Nat. fam. als de vorige. Gr. Sumatra; hooge boom.

3914. Kateja I. \& M. = Bruguiera p arviflora W. \& $\mathrm{d}$. (de schors). (Zie No. 34736.$)$

3915. Kateppeng Bı. I. \& S. $=a$ Cassia alata L. (Zie No. 1740) $=6$ Cassia Sophora L. en $=c$ Cassia Tora l. (Zie No. 73.)

3916. Kateppeng-badak S. $=a \mathrm{Cas}$ sia alata I. (zie No. 1740) = $b$ Cassia glauca Lam. (Zie No. 2568.) $=c$ Cassia indecora H. B. \& K. Nat. fam. der Papilion aceæ. Gr. Java in tuiren; heester.

3917. Kateppeng-keboh I. = C assia alata L. (Zie No. 1740.)

3918. Kateppeng-lumboet $\mathrm{S}$. = Cassia obtusifola L. cum. variet. Nat. fam. der Papilion aceæ. GR. Java; éénjarig. GEBR. Men wrijft kinderen, die niet slapen kunnen, met de fijngekneusde bladeren het lichaam in.

3919. Katês-gamblo I. = Carica P apaya L. femina. (Zie No. 1092.)

3920. Katês-gantoel $I_{0}=$ Carica Papay L. Mas. (Zie No. 1092)

3921 . Katigarrong $\mathrm{S} .=\mathrm{Crat} \mathrm{va}$ Tapia Bl. Nat. fam. der Caparideæ. GR. Java; boom.

3922. Katigret $I$. $=$ Mirabilis $\mathrm{J}$ a la p a L. (Zie No. 1405.)

3923. Katilan BAT. $=\mathrm{Amomum}$ maximum Rxb. (Zie No. 2705)

3924. Katilan $S .=Q u a m o c l i t$ vulgaris Chois. (Zie No. 533.)

3925. Katilang $\mathrm{I} .=\mathrm{Brucea} \mathrm{su}$. matrana $R x b$. (Zie No 226 )

3926. Katileng $=I$. Taraktoge nos

Bl nme i Hassk. (Zie No. 1045.)

3927. Katimôhôh S. \& I. = Kleinhovia hospita L. Nat. fam. der Büt tneriacer. Gr. Door geheel Ned. Indië; hooge boom. GEBR. Het sterke, fraai wit en zwart gevlekte hout van dezen boom is zeer gezocht voor scheden van krissen en audere wapens; fraai gevlekte stukken worden zeer duur betaald. De houtskool wordt gebruikt bij de buskruitbereiding. Den bast verwerkt men tot touw. De bladeren bezigt men tot reiniging van het hoofuhaar en ook bij ziekelijke zwelling der ballen. Het sap druppelt men in de oogen tegen beginnende blindheid. Volgens Blanco eet men de bladeren en jonge loten als groente, en zijn zij een voortreffelijk middel tegen Scabies, wanneer men de lijders met een afkooksel ervan wascht.

3928. Katingang $J_{.}=\mathrm{O} x a l$ is

Reinwardti i Zuc c. (Zie No. 25l).

3929. Katisan J. = Cynoglos. sum robustum Hassk., Nat. fam. der Asperifoliæ. GR. Java; overjarig. 3930 Katja $\mathbf{M}=$ Uncaria Gambir Rxb. (Ziie No. 238.5.)

3931. Katja-piering MI. (Zie onder kembang-katja-piering M.)

3932. Katja-piering-oetan J. = Taberna montana cor onaria R. Br. (Zie No. 264.)

3933. Katjang-mâ Сн. Bo. = Gomphostemma petiolare $M$ i q. (Zie No. 23726.)

3934. Katjang M. = Elke peulvrucht, 3935. Katjang-bagohloh J. = Vigna s in ens is $\mathrm{S}$ a vi. Nat. fam. der Papilion aะeæ. Gr. Hier en daar in tuinen verbouwd; zaadplant. GEBR. l'e jonge peulen en rijpe zaden worden gegeten.

3936. Katjang-bali M. = Cajanus indicus Spr. (Zie No. 1210.)

3937. Katjang-boedjit-bajam M. = Vigna sinensis $\mathrm{Savi}$, var. elongata Hassk. (Zie No. 3935.)

3938. Katjang-boelet $\mathrm{J}$. $=\mathrm{Phase}$ olus nanus I., Nat. fam. der Papilionaceæ. Gr. Hier en daar in tuinen; zaadplant. GEBR. De jonge peulen en rijpe zaden worden als groente genuttigd.

3939. Katjang-boeloe S. $=a$. Phaseolus radiatus L. (Zie No. 31.) $=b$. Soya hispida Mönch. (Zie No. 3127). 3940. Batjang-boeloe-aroij $\mathrm{S}$. = Rhynchosia viscosa D. C., Nat. fam. der Papilionacea. Gr. Java; slingerplant.

3941. Katjang-bogor $\mathrm{S} .=\mathrm{V}$ oandzeia subterranea Thrs., Nat. fam. als voren. Gr. Op Java en elders gekweekt; zaadplant. GEBR. De zaden zijn zeer gezoclit en wurden rauw, gekookt of geroosterd gegeten; men bereidt er ook gebak van; zij zijn zoet en olieachtig van smaak; door persing verkrijgt men er een groote hoeveelheid zachte, vette olie uit, welke hoofdzakelijk als lampolie wordt gebruikt. 3942. Katjang-boh Mak.

3943. Katjang-boontjes-boddas S. $=$ Phaseolus nanus L. (Zie No. 3938.) 3944. Katjang-boontjes-boddas-ge. deh S, ook

3945. Katjang-boontjes-hiedung S. en 
3946. Katjang-boontjes-leutiek S. = Phaseolus vulgaris L. (drie variëteiten), Nat. fam. der Papilionaceæ. fR Up Jara gekweekt; raadplant. GEBR. De jonge peulen en rijpe zaden worden gegeten.

3947. Katjang-dadap $\mathrm{S}$. = Vigna sill ensis Savi. (Zie No. 3935.)

3948. Katjang-djaleher-boeriek S $=a$ Phaseclus radiatus L. var. (Zie No. 3l) $=b$. Phaseolus nanus L. var. (Zie No. 3938.)

3949. Katjang-djariedjie of K-djarigi $\mathrm{S}$. = Lablab vulgaris Savi. (Zie No. $3544 a$.)

3950. Katjang-djepoen S. = Soya hispida Münch. (Zie No. 3127); benevens de variëteiten djepoen.boddas, $d j$. burrum, dj-hiedjoe en dj.-hieduag $S$. of leucosperma, rhodosperma, chlorosperma en melanosperma van Hasskarl.

$395 \mathrm{l}$. Katjang-djingkok $\mathrm{S} .=\mathrm{D}$ esmodium ren iforme D. C., Nat. fam. der Papilionaceæ. Gr. Java; overblijvend.

3952. Katjang-djohgoh S. = P h aseolus radiatus L. (Zie No. 31.)

3953. Katjang-gar J. = Dolichos Junghühuianus Bnth., Nat. fam. der Papilionaceæ. Gr. Java 3-500C; slingerplant.

3954. Katjang-gatel M. $=\mathrm{M}$ и una prurita Hk. (Zie No. 1699.)

3955. Kadja-gendja $\mathbf{M}$, = Phaseolus lunatus L., var. longe pedunculatus Rxb., Nat. fam. der Papilionaceæ. Gr. Java, Timor, enz.; zaadplant. GEBR Men eet de jonge peulen en rijpe zaden als groente.

3956. Katjang-girgadjie $\mathrm{M} .=\mathrm{Vi} g-$ na sinensis Savi, var. rubiginosa Hassk. (Zie No. 3935.)

3957. Katjang gluja $\mathrm{S} .=\mathrm{Ph}$ a se 0 lus lunatus L. cum variet. (Zie No. 3955$.

3958. Katjang-goedeh S. $=\alpha$. Cajanus indicus Sprg. (Zie No. 1210.) $=b$. Atylosia scarabæoides Bnth. (Zie No. 3126.)

3959. Katjang-goedeh-aroij S. = Atylosia albicas Bnth., Nat. fam, der Papili on aceæ. Gr. Java, overblijvend.

3960. Kaijang-goenong M. = Desmodium ganget icum D C, Nat. fam. als voren. $\mathrm{G}_{\mathfrak{}}$ Bijna overal in Indië; heester. GEBR. De bladeren van deze en andere Desmodium soorten wrijft men met kalk fijn, en legt ze op wonden, door slangeubeten veroorzaakt. Met die van $\mathrm{Gend}$ arussa vulgaris Nees; vermengd en fijngewreven, smeert men er zicl mede in tegen lendepijn.

3961. Katjang.goreng M. = Arachis hypogæa L., Nat. fam. dezelfde. GR. Door geheel Indië gekweelit; zaadplant. Gebr. Geheel als bij No. 3943 is opgegeven.

3962. Katjang-heedjoh S. of $K$. hiedjoe $M .=$ Phaseolus radiatus L. (Zie No 31.)

3963 Katjang-heedjoh-aroij $\mathrm{S} .=a$. Phaseolus Hernandesii Savi en $b$. Phas. Xuarezii Zucc., Nat. farn. der Papilion aceæ. Gr. Op Java in tuinen; zaadplanten. Gebr. Men eet de jonge pel. len en rijpe zaden.

3964. Katjang-hérang $\mathrm{S} .=\mathrm{Pha}$ seolus radiatus L. (Zie No. 3l).

3965. Katjang-hieries $\mathrm{S} .=\mathrm{C}$ ajanus ind icus Sprg. (Zie No. 1210.)

3966. Katjang-japan $\mathrm{M}=\mathrm{Ara-}$ chis hypogæa L. (Zie No. 3961.)

3967. Katjang-jat of djaät S. \& M. = Psophocarpus tetragonolobus D. C. (Zie No. 1546.)

3968. Katjang-kadeleh M. = Soуa hispida Mönch. (Zie No, 3127).

3u69. Katjang-kajoe M. = Cajanus indicus Sprg. (Zie No. 12l0).

3970. Katjang-kakara M. \& S. = a. Lablab micrucarpus D. C. (Zie No. 3547 ) en $=6$. Lablab vulgaris Savi (Zie No. 3544a).

3971. Katjang-kateppes S. \& M.= $\mathrm{L}$ abla b v ulgaris Savi. (Zie No. $3544 a$.)

3972. Katjang-katjang SuM. WK. = Canarallia rirosa W. \& A. (Zie No. 2585a).

3973. Katjang-keboh $\mathrm{S} .=\mathrm{Ph}$ aseolus trinervius Heyne, Nat. fam. der Papilio naceæ. Gr. Java; éénjarig.

3974. Katjang-kembang-kara $M$. = Katjang-kakara M. \& s,

3975 . Katjang $\cdot$ ketjil $M .=P h$ aseolus radiat us I. (Zie No. 31).

3976. Katjang-lâwut $\mathrm{M}$. = So. phora littoralis Schrad., Nat. fam. der Pa pilion a cex. Gr. Jara en Bangka, heester.

3977. Katjang-manilla $\mathrm{M} .=\mathrm{V}_{0}-$ andzeia subterranea Thrs. (Zie No. $3941)$.

3978. Katjang-mâs M. = Phaseo- 
lus lunatus L. \& var. (Zie No. 3955.) 3979. Katjang-meirah M. 二 Vigna Catjang Éndl. (Zie No. 30). 3980. Katjang-mienjak M. = A rachis hypogra L. (Zie No. 3961 .) 3981. Katjang-monjet $\mathbf{M}=a$. Neustanthus javanicus Bnth., Nat. fam. der Papilionaceœ. GR. Java; overblijvend. $=b$. Phaseolus Caracalla L., Nat fam. dezelfde. GR. Java; slingerplant. GeBR. De vruchten worden rijp en onrijp genuttigd. $=c$. Phase olus Hern andesii. (Zie No. 3963a.) $=d$. P h a s eolus trilobus A it., Nat. fam. als voren. Gr. Java: éénjarig. $=e$. Phaseolus Xnarezii Z ucc. (Zie No. 3936b.) = f. Dolichos scabriusculus $\mathrm{Hassk}$., Nat. fam. als voren. GR. Java; slingerplant. $=g . \mathrm{Pachyrrizus} \mathrm{mollis}$ Hassk., Nat. fam. als boven. Gr. Java; éénjarig,

3982. Katjang-njong $S .=P$ has e 0 lus atropu pureus D.C.. Nat fam.als voren. GR. Op Java in tuincn, uit Mexico ingevoerd; klimop. GEBR. Men eet de peulen en rijpe zaden als groente.

3983. Katjang-oetjie S. $=a$. Phase olus chrysanthus Savi. Nat. fam. dezelfde. Gr. Java; éénjarig. $=b . \mathrm{Pha-}$ seolus hispidulus Hassk. Gr. Java; klimplaut.

3984. Katjang-0etjie-leuwung $\mathrm{S} .=$ a. Phaseolus chrysanthus Savi. (Zie vorig No.) $=b$. Dolichos scabriusculus Hassk. (Zie No. 398if.) 3985. Katjang-pandjang $\mathrm{N} .=$ Vigna sinensis Savi. (Zie No. 3935.) 3986. Katjang-peda $\mathrm{s} .=\mathrm{Lablab}$ vulgaris Savi. (Zie No. 3544a.)

3987. Katjang-pendekh $\mathrm{M}$. $=\mathrm{Pha}$ seolus radiatus L. (Zie No. 31.)

3988. Katjang-pentjeringeh Sum. W.K. $=$ Rubus alcerfolius Poir. (Zie No. 2446)

3959. Katjang-poetih $\mathbf{M}=$ Vigna Catjang Endl. (Zie No. 30.) 3990 Katjang-porehek $\mathrm{S} .=a$. Phaseolus radiatus L. (Zie No. 31.) $=$ b. Phasenlus nanus L. (Zie No. 3938.)

3991. Katjang-prang J. 二 $\mathrm{Lablab}$ cultratus D.C., Nat. fam. der Papilion acere. Gr. Op Java en clders in tuinen; zaadplant. GEBr. Men eet de onrijpe en rijpe peulen als groente.

3992. Katjang-roaij of rowaij $\mathrm{s} .=$ Phaseolus lunatus L. (Zie No.3955.)
3993. Katjang-sápoe M. = Vigna sinensis Savi. (Zie No. 3935.)

3994. Katjang-sapoh S. $=\mathrm{Pha}$ seolus radiatus L. (Zie No. 31.)

3995. Katjang-soeöek S. of

3996. Katjang-soeöer S. en

3997. Katjang-tana M. 二 Arachis h уро gxa I. (Zie No 3961.)

3998. Katjang-tandoe J. = Cassia

Tora L. (Zie No. 73.)

3999. Katjang-tjina $\mathrm{M} .=a$. A rachis hypogæa L. (Zie No. 3961. $=b$. Phaseolus lunatus L. (Zie No. 3955.) $=c$, Vigna siuensis Savi. (Zie No. 3935.)

4000. Katjang-tjorang M. $=\mathrm{Pte}-$ roloma triquetrum B uth. Nat. fam. der Papilionaceæ. GR. Java, Borneo, de Molukken; heester.

4001. Katjang-toeroes $\mathrm{S} .=\mathrm{Vigna}$ sinensis Savi. (Zie No. 3935.)

4002. Batjem-tjem BL. = Evia a cida B l. (Zie No. 2890.)

4003. Katji-baranak M. = a. R hodoleia Teysmanni Miq. (Zie No. 2306.) $=$ b. Ixionanthus cuneata Miq., Nat. fam. der Ixio nantheæ. Gr. Sumatra O.kust; hooge boom.

4004. Batjo-katjo BK. = Pavetta pulcherrima T. \& B., Nat. fam. der $\mathrm{R} \mathrm{ub}$ i a c e $æ$. GR. Sumatrá en Bangka; heester.

4005. Katjoenda $M_{\mathrm{AK}}=\mathbf{M}$ ara $\mathrm{nta}$ ind ica I. (Zie No. 431.)

4006. Katjong-bèroek $\mathrm{M}$. $=\mathrm{Ne}$ penthes macrostachya Bl. (Zie No. ] $704 c$.)

4007. Katjou M. $=$ Uncaria Gambir $\mathrm{Kx}$ b. (Zie No. 2388.)

4008. Katoek S. $=a$. Melanthesa virgata Bl. Nat. fam. der Euphorbi acere. Gr. Java; heester. $=b$. Sauropus albicaus Bl. = c. Sauropus ind icus Wight. en $=d$. Sauropus macranthus H assk. Nat. fam. als voren. Gr. Java; hcesters. GEBR. Men eet le bladeren en vruchten ráuw en afgekookt bij de rijst. $=e$. Sauropus rhamroides Bl. (Zie No. 805.)

4009. Katoek-lawut $\mathrm{S} .=\mathrm{Vitex}$

$\mathrm{N}$ egundo L. (Zie No. 1.316)

4010. Katoeka kelang $\mathrm{S}$. $=\mathrm{Brie}$ delia stipnlaris Bl. (Zie No. 154).

4011. Katoelampa Br. = E l xocarpus oblongus Sm. Nat. fam. der Tiliaceæ. Gr. Bali en de Molukken; boom. Geвr. Het hout van dezen boom is vast, 
duurzaam en geschikt roor huisbouw. De vruchten worden gegeten.

4012. Katoelampa-badak $\mathrm{S}=a$. Elæocarpus macrophrllus Bl.. Nat. fam. als roren. Gr. Java en de Molukken; hooge boom. $=6$. Elæocarpus resinosus Bl. Gr. Jara; boou. FEBR. ran deze beide als bij $401 \mathrm{l}$ is opzegeren.

4013. Satoelampa-lawat $\mathrm{S} .=\mathrm{Vi}$ tex Negundo L. (Zie No. 13I6.)

4014. Katoelang J. $=$ Campelia glabrata Kunth.. Nat. fam. der Commely n a e æ. GR. Java; overblijrend kruid.

401ว. Eatoemba S. = Glochidion littorale Bl. (Zie No. 3237b.)

4016. Katoemba.lemang S. = Phyll anthus Nuriri I. (Zie No. Tla.)

4017. Katoembang S. en

4018. Katoembang-lemah S (Zie No. 4016)

4019 Katoembar I. \& M. $=\mathrm{C}_{0-}$ riandrum satirum L. Nat. fam. der Umbellifera. GR. Trij algencen in tuinen; zaadplaut. GeBr. Het bekende Corianderzaad wordt veelvuldig als specerij en als geneesmiddel aangewend.

4020. Batoempang $\mathrm{S} .=a$. Calicarpa lanata Vahl. Nat. fam. der Terben aсеæ. Gr. Jara. Surnatra, de Molukken; heester. GEBR. Mlen legt de fijngewreven bladeren op wonden, die sterk gezwalleu ziju, en wrijft ze ook in op lichaamsdeelen, die reeds lan z ziekelijk zịn. $=$ b. Callicarpa Iongifolia Lam. Nat. fam. dezelfde. GR. bijna overal in Indië; heester. GEBR. als $a$.

4021. Bateepang-badak S. $=a$. Callicarpa cana L. (Zie No. 2.) $=b$. Callicarpa lanata Tahl. (Zie No. 4020 a.)

4022. Katoempang-burrum $\mathrm{s}$. $=$ a Aërra lanata Juss. (Zie No. 2342.) = $b$ Aërra sanguinolenta Bl. (Zie No. 2609.)

1023. Katoempang-lanang S. = Rungia pectinata Nees. Nat fam. der Acanthaceæ. Gr. Jara; kruipende plant, en

Katoempang-tana M. = Hed yotis prostrata Korth Nat. fam. der Rubiaceæ. Gr. Java, Borneo, de Molukken; orerblijicend.

4024. Katoendeng $\mathrm{M}$. $=$ Vitex cofassus $R$ wdt. Nat. fam. der Verbenaceæ Gr. Celebes en de Molukken; hooge boom. GEBR Het hout ran dezen boom is bijzonder geschikt roor huis- en scheepsbouw.

4025. Batoepat-baroek M. 三 $\mathrm{Ne}$. penthes eustachra Miq. Nat. fam. der Nepentheæ. GR. Sumatra; slingerplant.

4026. Katoeri Sur. Wh. 二 Garcinia oxyëdra Miq. Nat. fam. der Clusiace æ. Gr. Sumatra; boom.

4027. Katoetoengkoel S. en

4028. Katoetoengkoel-goenong S. ook 4029. Katoetoetoen S. = Polrgala venenosa Juss. Nat. fam. dar Poly. galeæ. GR. Jara en Sumatra; heester. GEBR. Men eet de bladeren en jonge loten gehookt bij de rijst.

4030. Katônô I. = Alrsicarpus bupleurifolius Dc. (Zie No. 1014.) 4031. Katos I. \& S. 二 a Mimusops Kauki L. (Zie No. 1497.) $=6$ Protium javanicum Burm. Nat. fum. der Burseracea. GR. Java en de Mo. lukkeu. GEBR. Het harde hout ran dezen boom wordt meestal voor gereedschappen gebruikt; de jonge bladeren worden gegeten. 4032. Katsjem-sjem BL. 二a. Fria a cida Bl. (Zie No.2890). 二 b. Evia a ma ra Comm. (Zie No. 31436.)

4033. Katsji Mak 二 Diploclinium tuberosum Miq. (Zie No. 105ュ.)

403 4. Katsjong-broe M. = Nepenthes phyllamphora WIId. Zie No. ]2S.)

403 J. Battammon $\mathrm{IAK}$. 二 J a m. bosa a l ba $R m p h$. (Zie No. jo.)

4036. Kantari $\amalg=$ Curculigo latifolia 1)rrand. (Zie No. 24a.)

4037. Katta.mala BL. 二 Klein. horia hospita L. (Zie No. 3927.)

4038 Katti-katti M. en

4039. Katti-katti-besaar M. = Gui. landina Bonduc L. (Zie No. 1475.)

4040. Katti-katti-gora T. $=N$ o thopanax? anisum Jiq. (Zie No. $389 a_{.}$)

4041 Katti-katti.gora T. 二 $\mathrm{Z}$ anthosrlum armatum 1)c. (Zie No. $3692 c$.)

4042. Katti-katti-ketjil M. 二 $a$ Cæsalpinia Nuga Ait. (Zie No.627.) = $b \mathrm{Acacia} H o o p e r i a n a \mathrm{Zipp}$. (Zie No. 2612.)

4043. Katti-katti-pantej M. = Cæsalpinı Nuga Ait. (Zie No. 627.)

4044. Katta-koeti BAT. 二 Antidesma Bunias Sprg. (Zie No. 1425.) 
4045. Katti-laijoe I. = Erioglos. sum edule Bl. (Zie No, 3580.)

4046. Kaiti-mahar I. $=\mathrm{K}$ le inhovia hospita L. (Zie No. 3927).

4047. Kattimban $\mathrm{MAK}_{\mathrm{K}}=\mathrm{Al}$ pinia gigantea Bl. (Zie No. 386.)

4048. Kau Амв. = Pithecolobium clypearia Benth. (Zie No. 3115.)

4049. Kau-dallam $\mathrm{M}$. = Cordia 11 yxa L. (Zie No. 117 )

4050. Kawah M. 二 Coffea arabica L. Nat fam. der Rubiaceæ Gr. bijna overal in Indië als kultuurplant in tuinen; kleine boom. Gerr. Het hout levert fraaie wandelstokken; de bladeren worden, geroosterd en met water afgetrokken, in plaats der zaden gedronken. De zaden leveren de algemeen bekende soffie, over welker huishoudelijk en geneeskrachtig nut ik niet behoef uit te wijden.

40s̆l. Kawak Alf. Mıx. = Nauclea parvifolia Rxb. (Zie No. 969.)

40๖2. Kawakkal Aџв. = Pterocarpus flavus Lour. (Zie No 735 .)

4053. Kawan M. E Sideroxylon nitidum Bl. Nat. fam. der Sa potaceæ. Gr. Java; hooge buom. Gebr. Het zeer harde en vaste hout is een bijzonder goed bouwhont, ell wordt tot de soorten ran ijzerhout gerekend

40ว4. Kauwas Mak. 二K leinhoria hospita I. (Zie No. 3927.)

4055. Kawat $\mathrm{P}_{A L}=a$ Urostigma procerum Niq. (Zie No 2442.) $=b$ Urostigma sumatranuin Miq. Nat. fam. der Artocarpee. Gr. Sumatra; boom.

4056. Kawauw S = Milletia se. ricea W. \& A. (Zie No. 189.)

40ว7. Kawauw.ketjil M. = Derris bantamensis Hassk. Nat. fam. der Papilion a cex. GR. Java; slingerplant. 4058. Kawideh ALF. Mix. = 11 angifera indica l. var. Dodel Bl. (Zie No. 275.)

4059. Kawies $\mathrm{I}$. $=\mathrm{F} \in \mathrm{ronia}$ elephantu in Corr. Nat. fam. der Auran. ti a ceæ. Gr. Java en de Molukken; boom. GEBR. Het hout is slechts geschikt voor brandhout; de aangename zuurzoete vruch. ten worden rijp en onrijp door velen gezocht.

4060. Kawini S. \& M. = a. M a ngifera fotida Lour. rar. Kawini (Zie No. 374.) $=\lambda l$ angifera Kemanga Bl. (Zie No. 1180.)
4061. Kawista S. (Zie No. 4059.), en Kawista-batoe M. of kawistawatoe J. = Feronia lucida Scheffer, Nat. fam. der A u rantiaceæ. Gr. Java; boom.

4062. Kawoeng $\mathrm{S}$. = Arenga saccharifera Lab. (Zie No. 243.)

4063. Kawôh (kawok) S. \& M. = $\mathrm{S}$ a c c h a u $\mathrm{m}$ sponta n e $\mathrm{m} \mathrm{I}$. (Zie No. 2321.)

4064 . Kawohroh S. $=a \mathrm{~A}$ be lmoschus moschatus $\| \ddot{n c h}$. $(Z$ ie No. 2402. $)=$ b. A belmos chus ficulneus W. \& A. (Zie No. 2610b.) = c. Abelmochusesculentus W. \& A., Nat. fam. der $M$ a lv a c e æ. GR $O_{p}$ Java reel in tuinen, ingevoerd; zaadplant. GEBr. De wortel wordt gegeten; het slijmige vruchtomhulsel wordt in rele spijzen gemengd, is niet onaangenaam van smaak en voedzaam. $=d$. $\mathrm{H} \mathrm{i} \mathrm{b} \mathrm{is} \mathrm{c} \mathrm{u} \mathrm{s} \mathrm{viti-}$ f o li u s L., Nat. fam. als voren Gr. Op Java in tuinen; éénjarig. GEBR. Deze plant staat in geneeskracht gelijk aan onze A lth $\mathrm{h}$ a.

4065. Kawohroh-gedeh S. = A b e l mochus Vricseanus Hassk., Nat. fam. dezelfde. Gr. Java; heester.

4066. Kawojang S. = a. Cr y toc a ry a diversifolia Bl., Nat. fam. der L a u rine $x$. Gr. Java en Sumatra; boom. $=b$. Petalandra micran$\mathrm{th}$ a $\mathrm{H}$ a s sk., Nat. fam. der D ip t e r 0 c a r p e. Gr. Java; hooge boom. $=c$. Briedelia gla uca Bl., Nat. fam. der Euphor bi a c e . Gi. Java, boom. $=d$. Pyg u m parviflor um T. \& B., Nat. fam. der A m y gdale $æ . \mathrm{Gr}$.

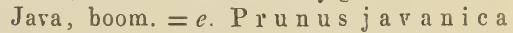
M i q., Nat. fam. als ruren. Gr. Java; boom.

4067. Kawo-kawo Mak. $=\mathrm{Er}$ iodendrum a n fractuos um D.C. (Zie No. 28b.)

4068. Kebag J $=\mathrm{F}$ i cus trico1 o r 11 iq. (Zie No, 3105.)

4069. Kebang M. = Coryli a u mbraculifera L. (Zie No. 1528) 4070. Kebarouw Lamp. $=\mathrm{P}$ a ra. tropia brachybotrya Mi q., Nat. fam. der Arali a c e bij Kemok-goendi S.

4071. Kebul $\mathrm{B \kappa} .=a$. Quercus Bennettii Iliq. (Zie No. 1435.) = b. Quercus Horsfieldii M iq.; Nat. fam. der Cu pulifere. Gr. Sumatra en Bangka; hooge boom. 
4072. Kebun J. = Barringto. u i a speciosa I. (Zie No. 1463.)

4073. Kedawoong J. $=$ Parkia in termedia $\mathrm{H}$ a ssk., Nat. fam. der II i o s eæ. Gr. Java; hooge boom, GEBr. In alles nagenoeg gelijk aan dat der Goedeh J. (No. 2561), de zaden zijn echter bitterder.

4074. Bedelee J. $=$ Grumilea divergens Mi iq. (Zie No. 2301.)

407 . Kedemoet $\mathrm{BK}$. $=\mathrm{Hopea?}$ fagifolia II iq., Nat. fam. der Dip terocarper. Gr. Bangka; hooge boom.

4076. Kedjih $J_{.}=\mathrm{E}$ berm a yera subpaniculta Hassk., Nat. fam. der A c a n thace e. Gr. Java; overblij. rend. GEBR. De jonge bladeren worden als groente gegetea.

$40 \pi$. Kedjimas $\mathrm{BL} .=\mathrm{D} u \mathrm{a} b$ a $\mathrm{n} \mathrm{g}$ a molucc a n a B l., Nat. fam. der L ythrarieæ. Gr. Java, Bali, de Molnkken; hooge boom.

4078. Bedoe BD. $=$ Colocasia an tiquorum Schott. (Zie No. 245.) 4079. Kedoe $\mathrm{S}_{.}=\mathrm{Polyos} \mathrm{ma} \mathrm{mu}$ $\mathrm{tabilis}$ is l. (Zie No. 1423.)

4080. Kedoel S. $=$ Bidens le uc antha Wlld, Zie No. 2775b.)

4081. Kedojâ (kadojo) J. = a. Eup. te ron nodosam II iq., Nat. fam. der Aralia c e æ. Gr. Java en de M 0 lukken; boom. GEBR. De uit dezen boom rloeiende zwartachtige hars riekt naar kamfer. Het hout is zeer geschikt voor planken ell vaartuigen. Omdat het naar Lavendel en Rosmarijn riekt, behoort het in de Molukken tot de berookingsmiddelen. $=$ b. Hartighsea mollis. sima Jus s., Nat. fam. der M elia. c e æ. Gk. Jara; hooge boom. Gebr. Het hout is niet sterk en wordt lichtelijk door insekten aangevreten; men bezigt het soms voor gereedschappen.

4082. Kedrepoel Lavp. $=\mathrm{Ficus}$ la m ponga $\|$ iq., Nat, fam. der A r. t o c a r p e r. Gr Sumatra; heester.

4083. Kee Mex. = Arenga sacc harifera Lab. (succus.) (Zie No. 243.)

4084. Keedjoh-beär S. $=A$ d e nos. t e m ma orat a m Miq. (Zie No. 21 sl.) 4085. Kear S. = Ia asianthus sylvestris Bl. No. 256l.)

4086. Kehboh MaK. = Phaseolas

I, n n a tus I. (Zie 3955.)

405\%. Kehkeb $\mathrm{S} .=a$. II u l d era b a c c at a $\| 1$ iq. (Zie No. $5+8 b$.) $=b$. Chavic a miniat a $M$ iq., $v$ a r., Nat. fam. der P i pera ce æ. GR. Jara; klimplant.

4088. Kehpas II. \& S. $=$ P ardanthus chinensis Ker. (Zie No. 238b.)

4089. Keiba J. $=$ Goss y p i m a rbore um L, (Zie No. $3791 \dot{b}$.)

4090. Kekedjoan S. eu

4091. Kekegoan-aroij S.二 Co nocephalus suareolens Bl. (Zie jls.)

4092. Kekel Амв. = Pandanus humilis Rmph. (Zie No. 1129)

4093. Kekel-ela Алв. $=\mathrm{P}$ andanus spurins Rmph., Nat. fam. der $P$ a ц d a и e æ. Gr. Java, Bali en de Molnk. ken; boomachtig. Gebr. De jonge bladeren worden soms als gruente gegeten, doch zij veroorzaken een gevoel ran scherpte in de keel; de oude bladeren gebruikt men tot het viechten ran matten.

4094. Kekel-maän Амв. $=\mathrm{P}_{\text {a n- }}$ danus hnmilis Rmph. (Zie No. 1129.)

4095. Kekela LaMP. = Pierardia dulcis Jack. (Zie No. 1503 )

4096. Kekembang-lawut Sux. = Ambroma fastuosa R Br., Nat. fam. der B üttneriaceæ. Gr. Sumatra, 'Timor en de Molukken; heester.

4097. Keker Амв $=a \mathrm{Pandanus}$ humilis $R \mathrm{mph}$. (Zie No. 1129.) = b. Pandanus spurius Rmph. (Zie No. 4039.) - c. Ptychosperma puni ce a Miq. Nat. fam. der Palma. Gr. De Molukken, huoge Palm. Gebr. Het hout wordt gebruikt roor paulatten. 4098. Keker-ela Амв. $=$ Panda. nus spurıus Rmph. (Zie No. 4093.)

4099. Keker-ewan Азв. $=a$. Pandanus ceramicus Rmph; (Zie No. 1828.) $=$ b. Pandants montanus II iq. (Zie No. $43 \pi$.)

4100. Keker-lejinoeton Анв. $=P_{a n}$ dan us humilis Rmph. (Zie No. 1129.)

4101. Keker-moni А nus latifolius Rmph. (Zie No. 1172.) 4102. Keker-wassi duв. $=a . P$ a danus ceramicus Rmph. (Zie No. 1828.) = . Pandanus sylvestris $R m p h$. Nat. fam. der Pandaneæ Gr. Amboina, boomachtig. Gerr. De bladeren dezer soort zijn bijzonder gezocht voor het vlechten van matten.

4103. Kèkewang ALF. Mix. = Fi- 
cus glomerata Thnb. (Ficus IV ass a $\mathrm{T}$ hnb.). (Zie No. 2597.)

4104. Kekil S. = Dichroa cyan it is Miq. (Zie No, 2อ̆12.)

4105. Kekoejoëan S. 二 Torenia asiatica L, Nat. fam. der Scrophula reneæ. GR Java; overblijvend. GEBR. Dit kruid wordt in Malabar als geneesmiddel sangewend.

4'06. Kekoeloh-talang LAsP. = Dodonæa? lamponga Miq, Nat. fam.

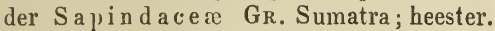

4107 Kekontolan S. \& M. $=a$. Helicteres lsora I. (Zie No. 1491.) $=6$. Oudemansia hirsuta Miq. \& a liæ; heesters, behcorende tot de Nat. fam. der Sterculiaceœ. Gr. Java.

4108. Kekopas Lamp. $=\mathrm{Nephe-}$ li u m eriopetalu m M iq. (Zie No. 1089.)

4109. Kekwasoh $\mathrm{B}_{\mathrm{K}}=$ Quercus bancana $\mathrm{S}$ ihe ff, Nat. fam. der $\mathrm{Cu}$ puliferæ. Gr. Bangka; boom.

4ll0. Kelalaij $\mathrm{BK}_{\mathrm{K}}=\mathrm{J}$ a m bosa perforata Miq. (7ie No. 3630.)

4111. Kelambar R. = Coros nucifera L. (Zic No. 293.)

4112. Kelan BD. $=$ Mela leuca

Leucadendron L. (Zie No. 120a.)

4113. Kelangissan $\mathrm{BL}$. $=$ Maranta dichotoma liild. (Zie No. 926.)

4114. Xelangsouw Bo. $=\mathrm{Drijoba-}$ lanops Camphora Colebr. (Zie No. 7903.)

4115. Kelat-Rimbo Sux. $W_{\kappa} .=$ Parinarinm asperulum 11 iq. Nat. fam. der Chrysobalanew. Gr. Jumatra hooge boom.

4116. Keledez R. = Batatas edulis Chois. (Zie No. 635.)

4117. Keleh-baheh $\mathrm{S}$. = Uncaria lanosa Wall. (Zie No. 27.)

4118. Kelemoer Mix. = Dillenia ochreata T. \& B. Nat. fam. der Dilleniacer. Gr. Celebcs, heester.

4119. Keleuëur S. = Diploclin iu rn tuberosum Miq. (Zie No. 10ว4.)

4120. Keliamba Вк. en

4121. Keliangauw $\mathrm{BK}$. = Molineria longiflora Kirz. (Zie No. 3642) 3642.)

4122. Keli-assapin Амв. = $\mathrm{D}$ ioscorca alata I. (Zie No. 2809a.)

4123. Kelimpok $\mathrm{Bk}$. $=$ Rottler a macrostachya Iiq. Nat. fam. der Euphorbiacce. Gr. Bangka, heester. 4124. Kelingkeng $\mathrm{R} .=\mathrm{Nephe}$ - li um li-tschi Camb. Nat. fam. der $\mathrm{Sa}$ pindace $æ \mathrm{GR}_{\mathrm{R}}$. Op Java en elders in tuinen, uit China overgebracht, booin. GEBR. Het hout is geschikt voor huisbouw. De vruchten, die een aangenamen zuur-zoetachtigen smaak hebben, zijn zeer gezond en door de Chineezen bijzonder gezocht; zij zullen heilzaam zijn bij gestoorde galafscheiding en ontstekingachtige aandoening; sommigen kennen er een stondendrijvende kracht aan toe; zij worden veelal gedroogd uit China aangevoerd onder den naam van Lengkeng of $\mathrm{Li}$ - t s c hi.

4125. Kellor M. \& I. = a Moring a pterygosperma Grtn. cn $=b$ Mo ring a poly gon a D c. Nat. fam. der M or ing e $æ$. GR. Vrij algemeen in dezen Archipcl; kleine boomen. Gıвr. Deze boomen groeien snel en worden door stekken spoedig vermenigvuldigd: men plant ze veel in peper-en sirih-tıinen. De schors, vooral die van den wortel, en de bladeren bevatten een scherp beginsel, in reuk en smaak aan dat ran dell Mierikswortel gelijk. De jonge wortel kan als dezc laatste als specerij bij sausen, visch of vleesch, en ook als huidprikkelend geveesmiddel gebezigd worden. Fijngewreveı, met water of azijn op eenig lichaamsdeel gelegd, werkt hij roodmakend en blaartrekkend. De bast en bloemen worden ook als $\mathrm{rub}$ ef $\mathrm{a}$ cientia aangewend. Volgens $R u m p h i u s$ gaat hec kauwen van een stukje wortel het bord tegen, doch veroorzaakt deze in groote giften strang urie en a bort us De bladeren en jonge peulen leveren eenc zeer gezochte, goedsmakende groente. Horsfield prijst deze bladeren aan als d i r e t i c u m; terwijl Ru m ph i u s zegt dat zij, met kalk fijngewreven, heilzaam zijn tegen herpes De onrijpe zaden worden op Java gegeten. I) rijpe zaden, in den handel bekend als $B$ e h e $n$-noten, Nux Behen, Glansunguntaria, enz. werden vroeger als braak-en purgeermiddel aangewend; zij bevatten een vette, zachte, reuk- en smaaklooze olie, de $\mathrm{B}$ ch c n-olie, die uit Bengalen cn WestIndië vecl naar Europa wordt gebracht, purgcerende eigenschappen bezit, doch hoofüzakelijk door horlogiemakers en tot het bereiden van fijne zalven rebruikt wordt, omdat zij niet droogt en niet ransig wordt. $L$ i $n$ n $æ$ u s leidt van deze hoom het $\mathrm{Lignn} n \mathrm{me} \mathrm{hriticum}$ af, dat hcilzaam tcgen niersteenen zou 
zijn, doch volgens anderen is dit van een anderen boom afkomstig.

4126. Kellor S. = Cæsalpinia N a g A it. (Zie No. 627.)

4127. Kellor-goenong $\mathrm{M}$. $=a \mathrm{Pi}$ thecolobium clypearia Bnth. (Zie No. 3115.$)=b \mathrm{Thalictram}$ gl y phoc arpum W. \& A. Nat. fam. der R a n n cula c e æ. GR. Java, overblijvend.

4128. Kellor-lawut Anв. = Albizzia littoralis T. \& B., Nat. fam. der Mimose æ. Gr. Amboina; boom.

4129. Kellor-oetan M- = Pithecolobium clypearia Bnth. (Zie No. 3115.$)$

4130. Kelo T. (Zie No. 4125.)

4131. Kéloro MaK. = Moring a pterygosperma Grnt. (Zie No. 4125 a.)

4132. Kemadoe J. \& M. = F l e u. ry a cordata Ga nd. (Zie Ño. 831.) $=$ b. Fleurya rstuans $G$ a ud., Nat. fam, del Urt i c ac e æ. Gr. Java en elders, veelal in tuinen; overblijvend. GEBR. De bladeren dezer heesters worden veelvuldig als huidprikkel aangewend bij inwendige pijnen, rheumatismus, verlammingen, slapeloosheid van hysterische vrouwen, enz., en werken soms als een heilzame afleiding. Hun prikkelende werking zal ontstaan door de klieren uitgezweet wordende bicarbonas ammoniæ. Den fijngeklopten bast bezigt men op Java als middel om visschen te bedwelmen. Het sap, door insnijding uit den stam bekomeu, druppelt men bij ontstekingen in de oogen.

4133. Kemalah-sira-- oetih IAMP. $=$ Prinos cymosa Hassk. (Zie No. 3810.)

4134. Kemanden-lakki-lakki Sur. $=$ B uchnera acuta J) csn., Nat. fam. der S c rophula ri n e æ. Gr. Sumatra, Madura; éénjarig.

4l35. Kemang II. \& S. = a. M a ng i f e r a f æ t i d a L o u r. (Zie No. 274.) $=$ b. 11 angifera K e manga Bl. (Zie No. 1180.)

4136. Kemang-bada $\mathrm{S}$. = M a n$\mathrm{g}$ if ir a $\mathrm{K}$ e m a n ga. Bl.

4137. Kemantan $M_{\text {A D }}=\mathrm{Conyza}$ l a c t u c $æ$ folia W a ll., Nat. fam. der C om pos it æ. Gr. Java, Madura, Celebes ; zaadplant.

4138. Kemantjieng-aroij $S .=A$ p ody tes javanica $\mathrm{H}_{\mathrm{a}} \mathrm{s}$ s k., Nat. fam. der $\mathrm{O} \perp$ a c i n e $æ$. Gr. Java, slingerplant.
4139. Kembang I. = Bloem.

4140. Rembang-ajer-mawar M. = Rosa T'nft. Species diversea en Kembang-ajer-mawar-wollanda M. = Rosa centifolia L., Nat. farn. der $\mathrm{R}$ os a c e r. Gr. Overal in tuinen; heester, Gebr. Het huishoudelijk en geneeskrachtig gebruik der gewone Roos wijkt in niets ran dat in Europa af.

4141. Kembang-ajer-mawar-pers M. $=$ Rosa dama s cena Mill., Nat. fam. als roren. Gr. Hier en daar in trinen; heester. GŁBR. Ook omtrent deze geldt wat bij de vorige soort is opgegeren.

4142. Kembang-bangkeh $\mathrm{M}$ \& $\mathrm{S}$. $=$ Bracleys patha variabilis $\mathrm{S}$ c li ot t. (Zie No. $750 \mathrm{c}$.)

4143. Kembang-bangkeh-boddas S. $=$ Brachysatha variabilis Schott., var. i $\mathrm{mmaculata} \mathrm{Hassk}$. (Zie No. $750 a$ )

4144. Kembang-boegang $\mathrm{S} .=a$. Clerodendrum calamitos u m L, Nat. fam. der $V$ erben a c e e Gr. Java en Sumatra, heester, sierplant in

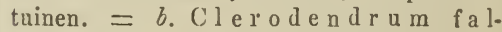
lax Lindl, Nat. fam. dezelfde. Gr. Jara; heester, sierplant. $=c$. C l e r odendrum infortunatum L. (Zie No. 758.) $=d$. (ile rod e n d r u m pan i cula t u m L. Nat. fam. als voren. Gr. Java, Sumatra, de Molukken; heester, sierplant. $=e$. C le rod e ndrum S iphonanthus R. Br. (Zie No. 1389.) $=f$. Clerodendrum villosum Bl., Nat. fam. dezelfde. GR. Java en Sumatra; heester, sierplant. GEBR. De fijngestampte bladeren legt men den kinderen op het hoofd tegen hevigen hoest.

4145 . Kembang-boekoe-boekoe I. $=\mathrm{Limnophil} \mathrm{a} \mathrm{punctata} \mathrm{Bl.} \mathrm{(Zie}$ No. 1730.)

4146. Kembang-dêhdesh I. $_{\text {. }}=\mathrm{S}$ a$\mathrm{rac}$ a in dica L. (Zie No. 1842.)

4147. Kembang-djangot M. en

4148. Kembang-dwang $\mathrm{J}$. $=\mathrm{C} x$ salpinia pulcherrima L. (Zie No. 1386.)

4149. Kembang.foetoe-bawa J. = $\mathrm{Hibiscus} m$ utabilis L. (Zie No. 1358.)

4150. Kembang-gedang $\mathrm{J} .=a$. $\mathrm{Canna}$ c occin a $\mathrm{A}$ it en $=b$. Canna flavescens L k. Nat. fam. der $\mathrm{C}$ a $\mathrm{n}$ n a c e æ. Gr. Java en elders, veelal in tuinen; overblijvende planten. GEBR. Men plant deze om hare roode en gele 
bloemen als sierplanten in tuinen. De zaden bezigt men tot het verraardigen van bidsnoeren ( $\mathrm{tasbih}$ ), ook soms in plaats van hagel op de vogeljacht. Ze schijnen zoomin tot huishoudelijk als geneeskrachtig doel op deze eilanden gebezigd te worden.

4151. Kembang-genni! J. = Plumb ago rosea L., (Zie No. 114.)

4752. Kembang-genni $\mathrm{S} .=\mathrm{Cler} 0-$ dendrum Horsfieldii Miq., Nat. fam. der Verben a e æ. Gr. Java, heester.

4153. Kembarg-goeling-tsjoe-tsjoe Аив. $=$ Plumeria acutifolia Poir. (Z ie No. 1367.)

4l 1 4. Kembang-kaij-rano $\mathrm{BD}$. = Cananga odorata Hk. fs. \& Th. (Zie No. 1373.)

4l 55. Kembang-kajoe-manies $J_{0}=$ Illicium anisatum DC. (Zie No. 12.) 4156. Kembang-kantil $\mathrm{J}_{\text {. }}=\mathrm{Mi}$ chelia champaca L., Nat. fam. der M agnoliaceæ. Gr. Bijna overal in dezen Archipel; hooge boom. GEBR. Het hout is zeer gezocht en geschikt voor huisbouw, meubels, wapens, enz. De wortel, bast en het hout zijn zeer rijk aan hars, bitter en aromatisch, en worden als zoodanig aangewend als prikkelend midáel der ingewanden en om den bloedsomloop te bevorderen in het poortaderlijk- en baarmoederlijk stelsel.

Den wortelbast geeft men in poederrorm met water als stondendrijvend en vruchtafdrijvend middel. Den bast geeft men ook tot bevordering der kraamzuivering. Een aftreksel der nog niet geopende knoppen met klapperwater drinkt nien tegen gonorrhoea. De bladeren geeft men uit- en in. wendig tegen rheumatismus en jicht, ook in gorgeldrank bij angina en slechtriekenden adem. De geurige bloemen zijn bijzonder uezocht; men draagt ze in het hoofdhaar en legt ze tusschen de kleederen; in $\mathrm{Ma}$ labar stookt men er een aromatisch water van, dat tegen flauwten wordt aangewend. De zaden, die een scherpe stof bevatten, wrijft men met gember en galangawortel fijv, en smeert dit op den buik van kinderen, die aan tusschempozende koortsen lijden, of door windzucht geplaagd worden.

4157. Kembang-kantjing $I_{0}=\mathrm{G}$ omphrena globosa L. (Zie No. 9.)

4158. Kembang-katja-piering M. \& $\mathrm{s} .=a$. Gardenia grandiflora Lour. Nat. fam. der $R$ ubiace $\mathfrak{x}$. Gr. Op Java en elders als sierplant in tuinen; heester. Gerr. De zaaddoozen van dezen heester leveren de in den handel voorkomeude geele verfstof, W ongski genaamd, die de Chineezen èn als kleurstof èn als geneesmiddel tegen koorts aanwenden. $=b . \mathrm{Garde}$ nia florida L. Nat. fanl, als voren. Gr. bijna overal als sierplant iu tuinen, heester. Gebr. Deze heester is zeer gezocht om hare geurige bloemen. Volgens sommigen zijn de bessen eetbaar, doch werken ze ontlastingbevorderend en wormdrijvend. De Chineezen bezigen het sap der bessen tot het roodverwen van papier, waarmede de theekisten beplakt worden; de kleurstof is zeer rast en benadeelt de thee niet. In Japan wordt uit dit sap een gele kleurstof bereid, zeer geschikt tot het kleuren ran aardewerk. De Chineezen tellen dit sap onder hunne rerkoelende en verzachtende geneesmiddelen.

4159. Kembang $\cdot$ kepeeting $\mathrm{I} .=\mathrm{Rh} 0$ dodendrum javanicum Ben 11. (Zie No. 2361.)

4160. Kembang klappal M. = Tabernæ montana Comingiana A. De. Nat. fam. der A po с y n ex. Gr. De Lampongs; heester.

4161. Kembang-koening $\mathrm{M} .=a$ Cassia Sophora I (Zie No. 73a) $=3$. Cassia occidental is I (Zie No.3890.)

4162. Kembang.koweh-gedeh S. = Canavallia virosa W. \& A. (Zie No. $2585 a$.)

4163. Kemkarg.koweh-leutiek S. = $\mathrm{C}$ a $\mathrm{n}$ a vallia gladiat a Dc. (Zie No. 3549$.

4164. Kembang-mantega M. s.S. a.Tabernæmontan a coronaria R. Br. (Zic No. 264.) b. Taberna montana pauciflora Bl., Nat. fam. der Apocynex. Gr. Java; klcine heester.

4.165. Kembang-mata-hari M. = Il lianthus annuus L. (Zie No. 1385.) 4166. Kembang-nagassarie M. \& S. = Acacia Farnesiana Wlld. (Zie No. 2041.)

4167. Kembang-norotja J. \& $\mathrm{BI}_{\text {, en }}$ 4168. Kembang-pageh-soreh M. =

Mirabilis Jalappa L. (Zie No. 1405.)

4169. Kembang-patrakombala $S$ en

4170. Kembang-patramangala $\mathrm{S}$. = Cæsalpinia puleherima Sw. (7ie No 1386.)

4171. Kembang-poekoel-ampat $\mathrm{M}$. $=$ Mirabilis Jal a ppa I. (Zie No. 1405)

4172. Kembang-pori $M_{A K}=$ Pothomorphe subpeltat a Miq. (Zie No. 86.) 
4173. Kembang-rientjiek-rien tjiek II. $\in \mathrm{n}$

4174. Kembang-ringgit-ringgit $M$. = Hoya lacunosa Bl (Zie No. 1790.)

417\%. Kembang-santen-boddis S. en

4176. Kembang santen-djaroeng S. = Pavetta incarnata Bl. (Zie No. $1997 a$.)

4177. Kembang-santen-meirah M. = Pavetta coccinea L, Nat. fam. der $R$ ubiaceæ. Gr. Op Java en elders als sierplant in tuinen; heester. GEBR. De wortel van deze plant bezit prikkelende en blaartrekkende eigenschappen en wekt den speekselvloed op. $=b$. Pavetta indica L. (Zie No. 383.) $=c \cdot \mathrm{P}$ a vett a stricta B l.; Nat. fam. als voren. Gr. Bijna overal in Indië als sierplant in tuinen; heester.

4175. Kembang-santen-poetih M. (Zie No. 4175.)

4179. Kembang-sapatoe $\mathrm{II}=\mathrm{Hi}$ biscus rosa sinensis L. (Zie No. 1360.)

4180. Kembang-sapatoe-blaauw M. $=$ Hibiscus syriacus L., Nat. fam. der Malvacex. Gr. Door geheel Indië als sierplant in tuinen; heester.

4181. Kembang-sapatoe-gedeh S. = Hibiscus ficulnoides Lindl., Nat. fam. als voren, Gr. Java; heester.

4152. Kembang-sari-tjina M. = Vin r. a ro sea L. (Zie No. 2343)

4153. Kembang-saroenie M. = Pyrethrum indicum Cass.; Nat. fam. der Composita. Gr. Java en elders als sierplant in tuinen; overblijvend. GEBR. Ėen aftreksel der bloemen geeft men als oogwater bij pijnlijke oogaandoeningen en ook als zweetdrijvend middel.

4184. Kembang-sewoe J. = G n aphalium saxatila Bl. Nat. fam. als voren. Gr. Oost-Java; overblijvend.

4185. Kembang-siesier. $\mathrm{S}$. = $\mathrm{T} \mathrm{e}$ tranda Z ollingeri Miq. (Zie No. 66弓.) of

4186. Kembang-siesiet-peussing S.

4187. Kembang-sirih M. = Eginetia Centronia Miq., Nat. fam. der Orobanche r. Gr. Java; overblijvend.

4188. Kembang-sisit-bessie S. C ollyris major Vahl. (Zie No. 1682a.)

4189. Kembang-sedap-malam J.en 4190. Kembang-soendal-malam M. = Polyanthes tuberosa L., Nat. fam. der Amaryllidex. Gr. Door geheel Indië als sierplant in tuinen; over- blijvend. Gєвr. De witte, sterk-riekende bloemer zijn door de schoone sexe zeer gezocht, en worden in het haar gedragen. Lindley meldt van deze plant, dat zij bij zoele avonden, na donder, phosphoresceerend is; ik merkte dit nimmer op. $\mathrm{Blanco}$ doet de geur der bloemen zoo sterk uitkomen, dat hij zegt, dat daardoor hysterische vronwen als dood ter neder vallen.

4191. Kembang-soreh J. \& 11. = a. Abutilon hirtum G, l) on. (Zie No. 347.)=6$. Mirabilis dichotoma L., Nat. fam. der Nyctagineæ. Gr. Hier en daar als sierplant in tuiuen; overblijrend. GEBR. De wortel bezit drastische eigenschappen.

4192. Kembang-soreh-ketjil II. = Abutilon indicum G. Don. (Zie No. 3124b.)

4193. Kembang-tala ng $S$. (K.-telang) = Clitoreaternatea I. (Zie No. 1359.)

4194. Kembang-tambaga $\mathrm{II} .=\mathrm{V}$ inca rosea L. (Zie No. 2343.)

4 | 9 ó. Kembang-tambagaän-ajer M. = Jussirea repens L. (Zie No. 4i6.) 4196. Kembang-tandjoong $\mathrm{M}$. = Ml i m us ops Elengi L. (Zie No. 13996.)

4197. Kembang-toela Lam?. = II us. saënda rufinervis Miq. (Zie No. 900.)

4198. Kembang-toendjoeng Bc. $\mathrm{N}$ y mphæa Lotus L. Nat. fam. der Nymphæa ceæ. Gr. Java en Bali; waterplant. Grbr. De Lotusbloem is zeer gezocht, en wordt uit een godsdienstig oogpunt veel aangekweekt.

4199. Kembang-toendjoeng $\mathrm{I}$. $=\mathrm{T}$ ala uma mutabil is Br. Nat. fam. der Magnoli acex. Gr. Java, Sumatra enz., heester. Gerr. Het hout van dezen heester bezigt men voor spinuewielen; de geurige bloemen zijn gezocht.

4200. Kambang-toendjoeng-nila-watie BL. = Limnanthemum indicnm Griseb., Nat. fam. der Gentianex. Gr. Vrij algemeen verspreid, waterplant. Gebr. De Chineezen eten de wortels gekookt en geroosterd en de stengels bij wiijze van artisjokken.

4201. Kembang-tongkeng MI. = P e rgularia odoratissima L. (Zie No. 1395.)

4202. Kembang-wa ribang $\mathrm{Br}_{\mathrm{s}}$. = Hibiscus rosa sinensis L. (Zie No. 1360.) 
4203. Kembes Mis. $=$ Jambosa a quxa Rmph. var. angustifolia B l. (Zie No. 19306.)

4204. Kembilie BK. $=$ Coleus tuberosus Bnth. (Zis No. 1714a)

4205. Kembodja $R .=$ Plumeria acutifolia Poir. (Zic No. 1367.)

4206. Kemeding Laup. $=\mathrm{Can}$ thium horridum Bl. Nat. fam. der $\mathrm{R}$ ubiace æ. Gr Java en Sumatra; heester. GEBR. De zure, eenigszins wrange vruchten worden afgekookt en bij de rijst gegeten.

4207. Kemeroekoep Bl. = Gyrocarpus asiaticus Wlld. (Zie No. 1560.)

4208. Kemingo $\mathrm{I}$. $=\mathrm{Cinnam} \mathrm{om} \mathrm{um}$ zeylani cum Breyn. (Zie No. 3367a.)

4209. Kemiren $\mathrm{I}$. $=\mathrm{Hern}$ andia sonora L. (Zie No. 16.)

4210. Kemisindir = Callæocarpus sumatrana Miq. Nat. fam. der Cupuliferæ. Gr. Sumatra; hooge boom.

4211. Kemisindir-baboei PaL. = Callæocarpus rhamnifolia Miq. Nat. fam. als voren. Gr. Sumatra; hooge boom.

4212. Kemmal I. = Tamarindus indica L. (Zie No. 723.)

4213. Kemoenting-akar $\mathrm{BK} .=1^{\circ}$. Dissochrta atrosticta Miq. (Zie No. 223.) en $=2^{\circ}$. Dissochæta bancana Miq., Nat. fam. der Melastomacex. Gr. Bangka : slingerplant.

4214. Kemoetjoer BK. = Syzygium jaranicum Miq. (Zie No. 3486.)

4215. Kemoetoen BK. = Tridesmis formoso Krths. Nat. fam. der $\mathrm{Hy}$ ) с ri cine $æ$. Gr. Vrij algemeen in Indië, boom.

4216. Kemoonong $\mathrm{I}$. = Pterocy mbium javanicum R. Br. (Zie No. $1200 \mathrm{c}$.)

4217. Kenaij Aмв. = Bobea Wal. lichiana Krths. (Polyphragmon sericeum Desf.). (Zie No. 129)

4218. Kenal Aus. = Kle inhovia hospita L. (Zie No. 3927.)

4219 . Kenassal Aus. $=a \mathrm{Barring}-$ touia racemosa B 1 . en $=b$. Barr. acutangula Grtn. (Zie No. 983b.)

4220. Kenau BD. en

4221. Kenawan Ays. $=$ Cordia subcordata Lam. (Zie No. 1021b)

4222. Kendajaän I. Piliostigma acidum Buth. (Zie No. 371.)

4223. Kendal $\mathrm{S}_{.}=a$. Cordia ban. t amensis Bl. (Zie No. 3743b.) $=b$.
Elæocarpus floribundus Bl. (Zie No. $2654 b$.)

4224. Kendal-aroij S. $=a$. Cordia latifolia Rxb. Nat. fam. Jer Cordiaceæ. Gr. Java; heester. $=b$. Derris uliginosa Bnth. (Zie No. 595.)

4225. Kendal-prit $\mathrm{S} .=\mathrm{C}$ ordia su aveolens Bl. (Zie No. 1736.)

4226. Kendal-rambat $\mathrm{S}$. = $\mathrm{Premna}$ trichostoma Miq. Nat. fam. der Verb e n a ceæ. Gr. Java, heester.

4227. Kendaloe $\mathrm{Bk}$. $=\mathrm{V}$ a ccin ium bancanum Kürz. Nat. fam. der $V$ accinea. Gr. Bangka; heester.

4228. Kendarah $\mathrm{S}_{\text {. }}=\mathrm{B}$ ou e a $\mathrm{G}$ a 11 . daria Bl. (Zie No. 2404.)

4229. Kendiroe $\mathrm{I}$. $\mathrm{C}$ ary ot a urens I. (Zie No. 384)

4230. Kendit-monjet $\mathrm{S}$. = Tiliac or a a cuminat a $\mathrm{M}$ i e rs. (Zie No. 570b.)

4231. Kendoe-amboet S. en

4232. Kendoe-kebe $\mathrm{S},=$ Cordia c a l o c o m a Mi q. Nat. fam. der Cordia cex. Gr. Java; boom.

4233. Kendoeng I. = Helicia javanica Benn. (Zie No. 3756b.)

4234. Kendoeng $\mathrm{BK} .=\mathrm{Symplocos}$ ferruginea Rxb. Nat. fam. der Symploc eæ. Gr. Java en Bangka; boon.

4235. Kendoeng-koebak BK. $=\mathrm{M} \mathrm{yr}$ sine aveuls A. Dc. Nat fam. der Myrsinex. Gr. Java, Sumatra en Bang. ka; boom.

4236. Kendong $I$. = Broussouetia papyrifera Vent. (Zie No. 1861.)

4237. Kendor I. = Aërva sanguinolenta Bl. (Zie No. 2609.)

4238. Kenehoene $\mathrm{Cr}_{\mathrm{r}}=\mathrm{Urostigma}$ nitidum Miq. (Zie No. 855 )

4239. Kengkeng $\mathrm{I}$. = Lasiolepis Bennettii Planch. Nat. fam. der Simarubaces. Gr. Java; heester.

4240. Keninga $\mathrm{I}$. $=\mathrm{C}$ in $n$ a $\mathrm{mom} \mathrm{um}$ zeylanicum Breyn. (Zie No. 3367 a.) 4241. Kenoedoh $\mathrm{B}_{\mathrm{K}}$. $=\mathrm{Rhodo-}$ myrtus tomentosa Dc. (Zie No). 2739c.)

4242. Kenoetang $\mathrm{BK}$. $=\mathrm{Mlel}$ as toma polyanthum Bl. (Zie No. 110.)

4243. Kenoetiang-akar Bk. =

D is sochrta astrosticta $M l i$ q. (Zie No. 223.)

4244. Kentang M. (Zie later bij Oebie MI), beteekent elke wortelknol, welke als de aardapjel kan gegeten worden.

4245. Kentang djawa $\mathrm{M} .=\mathrm{Co}$. 
leus tuberosus Bnth. (Zie No. 1714 .

4246. Kentang.hollanda M. $=\mathrm{S}$ o. lan um tuberosum L. (Zie No. 29696)

4.247. Kentang-saba M. (Zie No. 4.24ว.)

4218. Kentong-awar J. of Kentongsamaar $J_{0}=\mathrm{N}$ e penthes mela mphora $\mathrm{R}$ w d t. (Zie No. 1704b.)

4219. Kера Амв. $=a$. Eugen i c e r a soides $R \times b .=6$. E. $m$ i crobotrya Miq., en $=c$. E. pa in a te $n$ s is Mi q., Nat. fam. der My r t a c e $x$. GR. Bormeo en de Molukken; boomen.

4250. Kepajong $\mathrm{Bk} .=\mathrm{Carp}$. p hyllum macrocarpum $\mathrm{Miq}$. (Zie No. 1499.)

4251. Kepasseh IAMP. $=\mathrm{Parki} \mathrm{a}$ ma crocarpa Mi q., Nat. fam. der M i moser. Gr. Sumatra; hooge boom.

4252. Kepet-kepet-an J. = P a rdanthus chinensis Ker. (Zie No. 2386.)

42 ว3. Kepini of kepinis $\mathrm{R}=\mathrm{Nan}$ i a verra Mi q. (Zie No. 27796.)

4254. Kepipieng Вк. $=\mathrm{C}$ as s i a 1 a t a I. (Zie No. 1740.)

4255. Kepitoe $\mathrm{S}$. Fagraa lit. toralis Bl., Nat. fam. der Loganiaceæ. GR. In Indië vrij algemeen verspreid; heester.

4256. Kepodo S. = Codonopsis ja $\mathrm{r}$ anica Miq, Nat. fam. der Campan 11 la cer. GR. Java; overblijvend.

425\%. Kepoe-0etan T. = G у и u a a u r a tiaca Dc. (Zie No. 22196.)

4255. Kepoeë-doeren SAwoE. $=\mathrm{Bo-}$ rassus flabelliformis L. (Zie No. 3117.)

4259. Kepoeё-ngiejoe Sawoe. $=\mathrm{C}_{0-}$ cos nucifera L. (Zie No. 393.)

4260. Kepoh S. = Sterculia fo. lid a I. (Zie No. 1641.)

4261. Keppa $J_{\text {. }}=$ Ficustricolor Miq. (Zie No. 3105.$)$

4262. Keppel J. $=$ Cynomctra ramiflor a L., Nat. fam. der P apiliou a cece. Gr. Vrij algemeen in tuinen; boom. GrBR. De aangenaam zuurzoetachtig smakende vruchten worden rauw en gestoofd gegeten.

4263. Keppo-jangkang $J_{\text {. }}=$ sterculia fœtida L. (Zie No. 1641.)

4264. Kepul $J .=$ Stelechocarpus Burahol Bl. (Zie No. 1447.)

4265. Kerakuhr Mav. = Sauro. p us albicans Bl., var. 6.(Zie No. 40086. ) 4266. Kerassar $\mathrm{S} .=\mathrm{Spermaco-}$ ce hispida L. (Zie No. 462.)

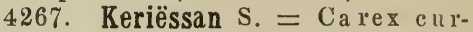
virostris Knth., Nat. fam. der Cyperaceæ. Gr. Java cn Sumatra; rietsoort. 4268. Kering-keringan M. = Crotalaria retusa L. (Zie No. 2495.) 4269. Kerjangoe $\mathrm{M} .=\mathrm{Acorus}$ terrestris $\mathrm{Rm} \mathrm{ph}$. (Zie No. 135.)

4270. Keroeboet Sum. WK. = $a$. A morphophallus gigas T. \& B. (ZieNo. 4i0.) $=$ b. Amorphophallus planus T. \& B. Nat. fam. der Aroider. GR. Sumatra; overblijvend.

4271. Kertau S. = Artocarpus Kertau Z \& M., Nat. fam. der Artocarpex. Gr. Op Java in sommige tuinen; hooge boom. GEbr. De vruchten worden, even als die der Nangka, gegeten.

4272. Kertjiertieng $\mathrm{BK}$. = M e m ecylon Vosmærianum Scheff., Nat. fam der Melastomacex. Gr. Bangka; heester.

4273. Kesekking $\mathrm{S} .=\mathrm{Grumilea}$ aurantiaca Miq., Nat fam. der Ku. bi aceæ. Gr. Java, Sumatra, Borneo: heester.

4274. Kesse of kese.$=$ Dodo. næa Burmanniana D.C., Nat. fam. der Sa pindacer. Gr. Java; boom.

4275. Ketakong-babie Bк. 二 Nepenthes Reinwardtiana Miq. (Zie No. 228)

4276. Ketakong-betoel Bк. = $\mathrm{Ne}$ penthes ampullacea Jack., Nat. fam. der Nepenthacea. Gr. Sumatra eщ Bangka; slingerplant.

4277. Ketakong-kidjang. $\mathrm{B} \kappa$. = a. Ncpenthes Reinwardtiana Miq. (Zic No. 228.) = b. Nepenthes Kortha lsiana Miq., Nat. fam. Gr. Als No. 1276.)

4278. Ketakong-mendjangan $\mathrm{BK}_{\text {. }}=$ Nepenthes $R$ afflesiana Jack., Nat. fam. en Gr. als No. 4276 .

4279. Ketakong-monjet $\mathrm{BK}_{\text {. }}=\mathrm{Ne}$ penthes gracilis Korth., var. (Zie No. 36646.$)$

4280. Ketakong-plandoh $\mathrm{B} \kappa .=\mathrm{Ne}$ penthes Teysuanniana Miq. Nat. fam. als voren. Gr. Bangka; slingerplant.

4281. Ketal S. = Dasyloma javanicum Miq. Nat, fam, der Umbelliferæ. Gr. Java; overblijvend. GEBr. De geheele plant wordt rauw bij de rijst gegeten. 
4282. Ketan M. \& $\mathrm{S}=\mathrm{Oryza}$ glutinosa Lour. Nat. fan. der Gramineæ. Gr. Overal in Indië met een rnenigte verscheidenheden; graansoort. GEBR. Deze aan kleefstof rijke rijstsoort is zeer gezocht, en wordt vooral voor gebak aangewend.

4283. Ketangkiel $\mathrm{BK}$. = Gnetum Gnemon L. (Zie No. 820)

4284. Ketapag I. $=$ Desmodium capitatum Dc. Nat. fam. der Papili o n a ceæ. Gr. Java, Sumatra, Borneo; overblijvend. GEвr. De bladeren van deze en andare Desmodium-soorten worden gekneusd en met kalk vermengd, op wonden van slangenbeten gelegd; ook worden zij fijngewreven met die van No. 1663, en bij lendenpijn in de lendenen ingesmeerd. 4285. Ketebonan I. $=$ Polyg on um chinense I. (Zie No. 1822.)

4286. Ketella-djindraal I,

4287. Ketella-kajoe I.

4288. Ketella-pohon I, en

4289. Ketalla-randoe $\mathrm{I}$. $=\mathrm{J}$ a nipha Mlanihot H. B. \& K. (Zie No. (872.)

4290. Ketembam of Ketembom Вк. = Calliocarpus rhamnifolia Miq. (Zie No. 4211.)

4291. Tetepong I. (Zie No. 4285.) 4292. Ketiauw Bk. = Sideroxylon glabrescens Miq. Nat. fam. der S a potace $æ$. Gr. Bangka; boon.

4293. Ketilan IJAMP. = Cyath 0calyx Sumatrana Scheff., Nat, fam. der Anonacer. Gr. Sumatra; boom.

4294. Ketimo I. $=\mathrm{K}$ leinhovia hospita L. (Zie No. 3927.)

4295. Ketimon $\mathrm{M} .=a$. $\mathrm{Cucumis}$ savitus L. (Zie No. 403) en $=b$. Cucumis Melo L. Nat. fam. der Cucur. bitaceæ. Gr. Op Java en elders in tuinen; klimplant. GEBr. Het huishoudelijk gebruik van den meloen is genoegzaam bekend.

4296. Ketip Mes. $=\mathrm{Pardanthus}$ chinensis Ker. (Zie No. 238b.)

4297. Ketjee J. = Mimusops

Flengi L. (Zie No. 1399b.)

4298. Ketjeklok J. = Quisqualis indica L. (Zie No. 3234)

4299. Ketjembang BAT. $=\mathrm{Embe-}$

Jia javanica A. Dc. (Zie No. 535.)

4300. Ketjïng.plandoe $\mathrm{BK}_{0}=\mathrm{En}_{\mathrm{n}}$ themis minor Jack. (Zie No. 6991.) 4301. Ketoedang J. = Viburnum sundaicum Miq.; Nat. fam. der Ca. prifoliaceie. Gr. Java, Sumatra; Borneo; heester. Gebr. Men bezigt de bladeren nitwendig tegen hoofdpijn en duizeligheid.

4302. Ketoembaram J. = Lysimachia Mönch Spec., Nat. fam. der Primulacer. Gr. Java; overblijrend.

4303. Ketoemboran $J .=$ Galium innocuum $\|$ iq, Nat. fam. der $R$ nb i a ceæ. Gr. Java; overblijvend.

4304. Ketohprak J. = Cyrtandræ diversæ.

4305. Ketongkat $\mathrm{Bk} .=\mathrm{P}$ a n d anus humilis Rmph. (Zie No. 1129.)

4306 Ketrik Bk. = Pithecolobium Clypearia Benth. (Zie No. 3115.)

4307. Kewetah-rintok $\mathrm{CEL}_{\mathrm{L}}=\mathrm{Bra}$ chys japonica Wight. Nat. fam. der H y p e r i c i n e æ. Gr. Java, Sumatra en Celebes; kruid.

4308. Ki-aboeben $\mathrm{S} .=\mathrm{V}$ i b u rn u $\mathrm{m}$ s und a i c um Miq. (Zie No. 4301.)

4309. Ki-adjak $\mathrm{S} .=b$. A rdisia fuliginos a B l, Nat. fam. der 11 y 1 s in e æ. Gr. Java; heester. Gebr. Het roode plantensap, rermengd inet klapiperolie, bezigt men uitwendig tegen schurft. $=b$. A r disia semidentata Miq., Nat. fam. als voren. Gr. Java; heester.

4310. Kiamban M. $=\mathrm{P}$ istia Stratioides L. (Zie No. 1669)

4311. Ki-amis S. (Zie Kajoe-manies M.)

4312. Ki-ampa M. $=\mathrm{Z}$ a n thoxyI o n M a r a m b ong M., Nat. fam. der D i o s m e æ. Gr. Sumatra's W.K.; heester,

4313. Ki-angier (of ki-anjer) $\mathrm{S}$. = a. Ot ophora a lat a Bl., Nat. fam. der S a pi nd a c ex. Gr. Jara; boom. $=$ b. Otophora a mon a Bl., Nat. fam. dezelfde. Gr. Java; heester. GEBR. De bast wordt, afgeschrapt en met water gemengd, gebruikt als gorgeldrank tegen heeschheid. De zure, wrange vruchten worden door sommigen gegeten. $=c$. Otophora spectabilis Bl., Nat. fam. als voren. Gr. Java en Borneo boom. 4314. Ki-angin $\mathrm{S} .=\mathrm{Mr}$ istica l a u r i n a B l. (Zie No. 295ib.)

4315. Ki-antjak $\mathrm{S} .=$ Urostigma $R$ u m phi Miq. (Zie No. 103.)

4316. Ki-apa $\mathrm{S} .=\mathrm{P}$ is tia $\mathrm{Str}$ tiotes I. (Zie No. 1669 )

4317. Ki-apiet $\mathrm{S}$. $=$ Petunga variabilis $H$ as sk., Nat. fam. der R n b i a c e ז. Gr. Jara, Sumatra, Borneo; 
boom. GEвR, Dc jonge, eenigszins wrange bladeren worden rauw bij de rijst gegeten.

4318. $\mathrm{Ki}$-apoe $\mathrm{S} .=a$. $\mathrm{Vibur}$ u u m c or i a c e u B B ., N a t. fam. der C a prifoli a c er. Gr. Java en Sumatra; boom. $=b$. Viburnum sun. d a icum Miq. (Zie No. 4301.) $=c$. Polyosma in tegrifolia B l. (Zie No. 423.)

4319. Bi-apoe-gedeh $\mathrm{S} .=\mathrm{V}$ i b u r. num s a m b u cin um $\mathrm{R}$ iv d $t$. (Zie No. $307 c$.)

4320. Ki-apoe-lumboet $\mathrm{S}$. $=\mathrm{V}$ ib ur u m sundaic um Miq. (Zie No. 4301.)

4321. Kiara $\mathrm{S} .=a$. Ficus creu u l at a $\mathrm{H}$ as sk. : Nat. fam. der A r t oc a $\mathbf{r}$ p e :e. Gr. Java; heester. $=$ b. Fi c us scleroptera Miq., Nat. fam. als voren. GR. Java; hooge boom. 三c. $\mathrm{Co}$. vellia scabra Kürz. Nat. fam. dezelfde. GR. Java; heester. $=d$. Urostigma xylophyllum Miq. Nat. fam. dezelfue. Gr. Java en Borneo; hooge booin.

4322. Kiara-anakh $\mathrm{S} .=\mathrm{Qu}$ u $\mathrm{r}$ cus fagiformis Jungli., Nat. fam. der Cupuliferæ. Gr. Java; zeer hooge boom.

4323. Kiara-attoel S. = Urostigma chrysotrix Mig. Nat. fam. der Artocarpeæ. Gr. Java; hooge boom. = 6. Urostigma cnueuron Iliq, Nat. fam. Als voren. GR. Java; boom. = $c$ Urostigma Hasselti Mi q. (Zie No, 2464.) $=d$. Urostign a m y sorense Miq. Nat. fam. als voren. GR. Java; boom. = c. Urostigma pilos $1 \mathrm{~m} \mathrm{Miq.} \mathrm{(Zie} \mathrm{No.} \mathrm{1324b.)}$

4324. Kiara-bëas S. $=a . \mathrm{Fi} \mathrm{c} \mathrm{us}$ i b bosa B 1. (Zie No. 2979.) $=b$. Ficus rostrata Lam. (Zie No. 3046.) c. Urostigma gla bell u m $M$ i q. (Zie No. 25U4a.) $=d$. Urostigma s u n d a i c u m $\mathbf{M l}$ i q., Nat. fam, als voren, Gr. Java; boom. =e. Urostigma vi r g a t u m M i $q$ Nat. fam. dezelide. Gr. Java en de Molukken; kleine boom.

4325. Kiara-boenjoer $\mathrm{S}$. $=a$. Urostigma Binnendijki i Mi q., Nat. fau. der A r t o c a r p e æ. Gr. Java; hooge boorn. $=b$. Urostigma s u d a i n m MI q (Zie No. 4324d.)

4326. Kiara-boenoet $\mathrm{S}$. 二 Uros. tigma glabellum M $\mathrm{l}$ q. (Zie No. $2504 a$.)

4327. Kiara-boewa $\mathrm{S} .=\mathrm{U}$ ros. tigma pruniforme Miq., Nat. fam. als voren. Gr. Java; hooge boom.

4328. Kiara-djiengkang $\mathrm{S},=a$. Urostigm a $1 \mathrm{t}$ is $\mathrm{im}$ um Miq. (Zie No. 3237 a.) $=6$. Urostigma flavescens $\mathrm{Miq}$. (Zie No. 1314.) $=c$. Urostigma nitidum Miq. (Zie No. 855.)

4329. Kiara-djindjang $\mathrm{S}$. = Uros. t ig ma s u n a i c u m M i q. (Zie No. $4324 d$.)

4330. Kiara-drangdang $\mathrm{S} .=\mathrm{F}$ c u s o b s c ura B l. (Zie No. 1648.)

4331. Kiara-gattul S. (Zie 4323.)

4332. Kiara.gedeh $\mathrm{S}$. $=\mathrm{Uros}$. tigma microcarpum Miq. Nat. fam. der Artocar peæ. Gr. Java en elder's; deze zeer hoogc boom is een groote soort Waringiboom.

4333. Kiara-gingang $\mathrm{S}$. $=$ Uros. t ig m a $\mathrm{Tj}$ i e l a M i q. (Zie No. 3048.)

4334. Kiara-goenoeng $\mathrm{S}_{\text {. }}=\mathrm{Uros}$ tigm a consociatum Miq. Nat. fam. als voren. Gr. Java, Soembawa; zeer groote boom.

4335. Kiara-jajava $\mathrm{S} .=\mathrm{Uros}-$ tigma benjam in um Miq. (Zie No. 1565.)

4336. Kiara-karet S. 二 $a$. U rostig ma elastic u m M i q. (Zie No. 24406 .) $=b$. Urostigma Karet Miq. (Zie No. 2504b.) 三 p rocer u m Miq. (Zie No. 2442.)

4337. Kiara-koang $\mathrm{S}$. = Vros t ig ma su perbum Mi q. Nat. fam. als voren. Gr. Java; hooge boom.

4338. Kiara-konneng $\mathrm{S} .=a$. U r ostigm a flavescen s Mi q. (Zie No. 1314.).) $=b$. Urostig mavalidum Niq. Nat. farn. als voren. Gr. Java; boom. GFBr. Deze boom levert een sterk bouwhout, dat veelal voor deuren gebruikt, maar door de witte mieren aangetast wordt.

4339. Biara-konneng-aroij $\mathrm{s} .=$ Urostigma flavescens Mi q. (Zie No. 13]4.)

4340. Biara-koppeng S. = $a . \mathrm{Fi}$ cus renitens Miq. (Zie No. 3558.) $=b$. Urostigma $\mathrm{HasseltiiMiq.}$ (Zie No. 2464.)

4341. Kiara-lëles $\mathrm{S}_{\text {. }}=\mathrm{U}$ ros ti gma saxophilu in Miq. (Zie No. 13216.)

4342. Riara-lumboet $\mathrm{S} \cdot=\mathrm{S}$ y $\mathrm{n} \propto-$ cia diversifolia Miq. (Zie No. 418.) 
4343. Kiara-mangarawang $\mathrm{s}$. = Urostigma virgat um Miq. Zie No. $4324 e$ )

4344. Kiara.mienjak $\mathrm{S} .=\mathrm{U}$ r 0 stigm a pse u d o-r u brum Miq. Nat. fam. der A r t oc a r p e æ. GR. Java; heester.

4345. Kiara-pajong S. $=a . \mathrm{Uro}$ st igma clusioides Miq. Nat. fam. als voren. GR. Java; hooge boom. $=b$. Urostigmagiganteum Mi q. Gr. Java; hooge boom. $=c$. U ro stigma obversum Miq. GR. Java; hooge boom $=d$. Urost ig m a procerum Miq. (Zie No. 2442.) $=e$. Trostigma p se udo-rubrum Miq. (Zie No. 4344.) $=f$. Urostig in a Wightian u m Miq. Gr. Java; hooge boom.

4346. Kiara-pajong-gedeh S. = Urostigma consociatum Miq. (Zie No. 4334.)

4347. Kiara-pareti $\mathrm{S}$. $=$ A r tocarpus tylophylla Miq. Nat. fam. als voren. Gr. Java. Men beweert dat deze boom niet giftig is.

4348. Kiara-peër S. = Urostigma rigidum Miq. Nat. fam. dezelfde. GR. Java; boom.

4349. Kiara-perreng $\mathrm{S} .=a$. Urostigma pyrifolium Miq. en $=b$. Ur. rubescens Miq. Nat. fam. dezelfde. Gr. Java; boomen.

4350. Kiara-poerroet $\mathrm{S}$. $=$ Uro. stigma callophyllum Miq. Nat. fam. als voren. Gr. Java. boom.

43з́1. Kiara-rambaî̉ (ook Kiararambak) $\mathrm{S} .=a$. Urostigma bicorne Miq. (Zie No. 1324a.) $=b$. Urostig un glaberrimum Miq. Nat. fam. der Artocarpeæ. Gr. Java; heester. = c. Urostigma involucratum Miq. Gr. Java; bcom. $=d$. Urostig. ma nitidum Miq. (Zie No. 855.)

4352. Kiara-tapok S. 二 $a$. U r ostigma excelsum Miq. Gr. Java; boom. $=6$. Urostigma involucratum Miq. (Zie vorig No.)

4.353. Kiara-tjohtjok $S .=U$ rostigma pilosum Miq. variet. (Zie No. 13216 .)

4354. Kiara-walen $\mathrm{S} .=\mathrm{Fic}$ u s gibbosa Bl. (Zie No. 2979.)

4355. Ki-aroij S. = Grewia tomentosa Juss. (Zie No. 3904.)

4356. Ki-assahan $\mathrm{S}$. 二 $a$. $\mathrm{F}$ i c u s cuspidata B l. Nat. fam. der $\Lambda$ rt 0 - c a r p ex. Gr. Vrij algemeen in Indië; boom. $=b$. Tetracera Assá D c. Nat. fam. der Dille n i a c e ז. Gr. Je Sunda-Archipel; slingerplant. GFrk. (Zie bij No. 546.)

4357. Ki-assahan-kajoe S. \& M. = Sponia annulata T. \& B. Nat. fam. der Celtide e. Gr. Java; boom. 4358. Ki-assahan-lalakki S. $=1$ ) eli m a s a rme nt os a I. (Zie No. 547.) 4359. Ki-attoel S. = Kiara-attoel s. 4360. Ki-au Sum. WK. $=\mathrm{C}$ h re nolobium septem jug um Miq. Nat. fam. der Papilio n a c e ce. Gr. Sumatra; heester.

4361. Ki-bab S. $=$ Ficus tricolor Mig. (Zie No. 3105.)

4362. Ki-babi $\mathrm{S}$. $=\mathrm{Henslovia}$ pani culata Miq. (Zie No. 803.)

4353. Ki-badak $\mathrm{S} .=\alpha$. Solanum ferox L. (Zie No. 3878b) $=b . \mathrm{F}$ a$\mathrm{g} r$ æa frag rans $\mathrm{R} \times \mathrm{b}$. Nat. fain. der L o g a n i ce e. Gr. Java en de Mo. lukken. Deze 30 voet hooge boom wordt, om den aangenamen geur der bloemen, veelvuldig in tuinen aangeplant. $=c$. Syzygi um laxif lor u m D. Nat. fam. der M y rt a c e æ. Gr. Java; boom. 4364. Ki-badoe $\mathrm{S}$. $=\mathrm{M}$ e m e c $y$ lon umbellatum B l. (Zie No. 3043b.) 4365. Ki-bajawak $\mathrm{S}$. $=a . \mathrm{Ev}$ odia Roxburghiana Hk. Nat. fám, der Di osmeæ. Gr, Java; hooge boom. = b. Philagonia sambucina $\mathrm{Bl}$. Nat. fam. der Simarubacea. Gr. Jara; hooge boom.

4366. Ki-banen S. $=\mathrm{Henslovia}$ paniculata Miq. (Zie No. 803.)

4367. Ki-bangbara $\mathrm{S} .=a$. A n t idesma heterophyllum Bl. Nat. farn. der Antidesmex. Gr. Java; heester. GF.BR. Men bezigt het plantensap tot het zwartkleuren der tanden en ook tegen tandpijn. De wrange vruchten worden door sommigen gegeter. $=b$. Paretta sylvatica Bl. Nat. fam. der Rubiacere GR. Java; heester. $=c$. Clerodendrum calamitosum J. (Zie No. 4l144a.) $=d$. Clerodendrum disparifolium Bl., Nat. fam. der Verbe nacer. Gr. Java, Sumatra, Borneo; heester $=e$. Clerodendrum eriosiphon Schaner., Nat. fam. als roren. Gr. Java en Borneo; heester. $=f . \mathrm{Cle}$ rodendrum læv ifolium Bl. (Zie No. 3109.)

4368. Kibang.kikoer IAMP. 二 I'o- 
gonotrophe sumatrana Miq., Nat. farn. der Artocarpex. Gr. Sumatra; slingerplant

4369. Mi-bantjet $\mathrm{S}_{\mathrm{S}}=a$. Turpinia sphærocarpa Hassk. (Zie No. 994.) $=$ b. Zanthoxylon montanum Bl., Nat. fam. der Diosmeæ. Gr. Java; boom. 4370. Xi-bara $\mathrm{S} .=a$. Kibar a coriacea Endl. (Zie No. 884f.) $=b$. Zuccarinia macrophylla Bl., Nat. fam. der Rubiaceæ. GR. Java; boom.

4371. Ki-bara-lalakki S. = Embelia javanica A. D. C. (Zie No. 535.) 4372. Ki-barachma S. $=a$. Di ospyros Ebenum Retz. (Zie No. 32.) $=b$. Picrasma javanica Bl., Nat. fam. der Sima r u b a ce æ. Gr. Java; boom, die uituemend bittere bestanddeelen bevat.

4373. Ki-barera $\mathrm{S} .=a$. Cissus nodosa Bl. (Zie No. 460) $=$ b. Gyvostemma pedata Bl. en $=c$. Gynostemma simplicifolia Bl., Nat. fam. der Erythropal a. Gr.Java; slingerplanten.

4374. Ki-barera-lalakki S. = Cis. sus in od osa Bl. (Zie No. 460.)

4375. Zi-barera lalakkina $\mathrm{S}$. $=$ Cissus dichotoma Bl. (Zie No. $554 \bar{b}$.)

4376. Ki-baroeangan $\mathrm{S}$. = $\mathrm{Am}$. racarpus pubescens Bl. (Zie No. 1568 , )

4377. Ki-batalli S. - Kixia a rborea Bl., Nat. fam. der A pocyneæ GR. Jara; kleine boom. GEBR. Het melksap van dezen boom wordt, met honig gemengd, als wormdrijvend middel toegediend.

4378. Ki-batáa $\mathrm{S} .=a$. Ichnocarpus bantamensis $\bar{B} \mathrm{l}$. (Zie No. $558 b.)=b$. Polyozus acuminata Bl., Nat. fam. der R ubiace æ. Gr. Java; heester. $=c$. Polyozu s latifolia Bl. (Zie No. $558 c$ ) $=d$. Willughbeia javanica Bl. (Zie No. ว̌58a.)

4379. Ki-batjeta $\mathrm{S} .=\mathrm{T}$ etr a c er a L. Species diversæ.

4380. Ri-batjeta-boddas S. $=\mathrm{C}$ ookia punctata Retz. (Zie No. 99.)

4381. Ki-batjeta-dawon S. = M u rray a fœt idissima T. \& B. Nat. fam. der A urautiace $x$. Gr. Java; heester.

4382. Zi-bawang $\mathrm{S} .=a \cdot \mathrm{H}$ a rtighsea excclsa A. Juss \& $=b$. H. Forsteri A. Juss. Nat. fam. der Meli a cer. Gr. Java; hooge boomen. GeBr. Het hout bezigt men soms voor gereedschappen; het is niet sterk en wordt licht aangevreten. $=c . \mathrm{H}$ a r tig h s ca moll is sima A. Juss. (Zie No. 4081b.) 4383. Kibawang-boddas S. of Kibawang-poetih M. = Dysoxylon alli a c e u m Bl. (Zie No. 3212.)

4384. Ki-bedas $\mathrm{S} .=\mathrm{T}$ etran $\mathrm{t}$ e$r$ a intermed i a $\mathrm{B} 1$.; Nat. fam. der L a u riner. Gr. Java; boom.

4385. Ki-belang $\mathrm{S}$. $=\mathrm{Qu \text {ercus }}$ p se ud o-moluc ca Bl, Nat. fam der Cu pulifer æ. Gr. Java; hooge boom. 4386. Ki-bêrit $\mathrm{S}$. = M e n o ceras. o b t u s u m Hassk. (Zie No. 2897/.) 4387. Ki-bêrrem $\mathrm{S}$. $=\mathrm{C}$ is su s pergamace a B l. (Zie No. 555.)

4388. Ki-berriet $\mathrm{S}$. of ki-beurriet S. = Chionanthus montana B l., Nat. fam. der Ol e in e æ. Gr. Java, Timor?; boom.

4389. Ki-besar $\mathrm{S}$. $=\mathrm{M}$ or u s ind i c a $\mathrm{R} \mathrm{m} \mathrm{ph.} \mathrm{(Zie} \mathrm{No.} \mathrm{797a.)}$

4390. Ki-bessie S. of ki-beussie S. $=a . \quad \mathrm{N}$ ania $\mathbf{v}$ era $\mathrm{Miq}$. (Zie No. $2779 b$.) $=b$. K i bes si a a u re aD.C. (Zie No. 1105.$)=c$. M e m e $\mathrm{ylon}$ e d u l e Roxb., Nat. fam. der M y rtac e æ. Gr. Java; heester; eetbare bessen opleverende. $=d$. M e me cy lo n ol ig o n e u r m Bl., Nat. fam. als voren. Gr. Java en Borneo; boom. Gebr. Het hout van dezen boom is van geringen omvang, doch zwaar, hard, sterk, rood, grof geaderd en moeilijk te splijten; men bezigt het vooral voor rijststampers.

4391. Ki-bewok $\mathrm{S} .=a$. G ly cos$\mathrm{m}$ is cy anoc ar pa Spreng. (Zie No. 2469 .) $=$ b. Milnea Blumei T. \& B., Nat. fam. der Meli a c e. Gr. Ja$\mathrm{va}$; heester. $=c$. Allophyllus fulvi in ervis Bl., Nat. fam. der Sa p ind a c e æ. Gr. Java; heester. Gebr. (als No. 1965.) $=d$. A $110 \mathrm{phyllus} \mathrm{sun-}$ danus Miq. (Zic No. 1965.) $=c$. Adelia javanio a Miq., Nat. fam. der Euph orbi a c e x. Gr. Java; heester. $=$ f. A paristhmium javense Endl, Nat. fam. als voren. Gr. Java; heester.

4292. Ki-bewok-peutjang $\mathrm{S}$. = A glaja odoratissima Bl. (Milne a T. \& B.). (Zie No. 43916.)

4393. Ki-bima $\mathrm{S} .=a . \mathrm{P} \mathrm{od} \mathrm{oc} \mathrm{a} \mathrm{r}$. pus latifolia Wall. (Zie No. 3366b.) $=b$. Leucoxylon buxifolium B l., Nat. fam. der $\mathrm{E} b$ e n a c e Java en Sumatra; hooge boom. Grir. Het fraai geaderde hout, ook Bendihont ge- 
naamd, gebruikt men soms voor huisbouw ; het wordt echter spoedig door insecten aangetast.

4394. Ki-bima-awehweh $\mathrm{S} .=\alpha$. Dammara alba $\mathrm{R}$ m pl.. (Zie No. 1618.) = Podocarpus latifolia Wall. (Zie No. 33666.)

4395. Ki-boddas $\mathrm{S} .=\mathrm{Bl}$ a c kwe lli a tomentos a Vent. (Zie No. 2228.) $4395 \alpha$. Ki-boeaija S. = Aralia ferox Miq., Nat. fam. der A ral i a cer. Gr. Java; boom.

4396. Bi-boeaija $\mathrm{S} .=\alpha$. Aralia montana B 1. (Zie No. 909b.) $=b$. I. e a sambucin a Willd. (Zie No. 133.) $=c$. L e e a scule a t a B l. Nat. fam. der L e e a c ex. GR. Java; heester. $=d$. Euchresta Horsfieldi B u n t. Nat. fam. der P a pilio n a ce Gr. Java; heester. GEBR. Alle deelen van dezen heester zijn zeer bitter, en daarom bekleedt hij een aanzienlijke plaats onder de inlandsche geneesmiddelen; de zaden, zoo in- als uitwendig toegediend, houdt men roor een tegengift bij elke vergiftiging, en een voorbehoedmiddel tegen vele ziekten.

4397. Ki-boegan $\mathrm{S}$. $=\mathrm{M} \mathrm{y} \mathrm{r} \mathrm{is-}$ tica hyposticta Miq., Nat fam. der My r istic e æ. Gr. Java; boom.

4398. Ei-boeloe $\mathrm{S} .=a$. G o m phostem a macrophyll um Miq. (Zie No. 2372.) = Gironnieracost a t a $\mathrm{M}$ i q. Nat. fam. der C e l t i deæ. GR. Java; boom. $=c$. H e d y o $t$ is $v$ enos a $K$ orth. Nat. fam. der $R u b i a-$ c e $x . \mathrm{GR}_{\mathrm{R}}$ Java; heester. $=d$. L a s ianthus oculus cati Rmph. (Zie No. 3305.) $=$ e. Mephitidia s a ng u in e a $H$ as s k. Nat. fam. der $R$ ub i a c e æ. Gr. Java; heester.

Volgens $\mathrm{H}$ a s s k a r l behooren de hees. tertjes, onder den naam van $\mathrm{Ki}$-boeloe bekend, tot de inlandsche geneesmiddelen, en wordt dezer sap gedronken als verkoe. lende drank bij hitte des lichaams en bij koortsen.

4399. Ki-boenga $\mathrm{S} . \doteq 1 \mathrm{~m} \mathrm{brica-}$ ria coriac e a. D c. (Zie No. 3066.) 4400. Ki-boenting S. = Mastixia tris hotom a B l. Nat. fam. der Coru a c e æ. Gr. Java; boom.

4401. Ki-boentoer $\mathrm{S} .=a$. L e ukos y k a lba Z. \& M. (Zie No. 343.) $=$ b. Le ukosy ke javanic a Z. \& M. Nat. fam, der Urticace $x$. GR. Java; heester.
4402. Kiboero $\mathrm{s} .=$ Ardisia poly neura Miq. Nat. fam. der Myrsineæ Gr. Java; heester.

4403. Ki-boma $\mathrm{S} .=$ Helicia javanica Bnnt. (Zie No. 37566.)

4404. Ki-bonteng $\mathrm{S} .=a$ Ulostigma altissim um Miq. (Zie No. $3237 c.)=b$. Myristica corticosa $\mathrm{H}$. fs. \& $\mathrm{Th}$. (Zie No. 13\%.) $=c$. Trevesia sundaica Miq. Nat. fam. der Araliaceæ. Gr. Java; kleine boom. GEBR, als No. 78 .

4405. Ki-buntalie $\mathrm{S},=\mathrm{K}$ i $\mathrm{x}$ i arbora Bl. (Zie No. 4377 .)

4406. Ki-buntur $\mathrm{S} .=a$. I e ukosyke javanica Z. \& M. (Zie No. 44016.) $=$ b. Morocarpus dichotomus Bl. Nat. fam. der Urti c a c e æ. GR. Java; heester. 二 $c$. Pipturus p ropinqu us Wedd. Nat. fam. dezelfde. GR. Java, Tïmor; heester.

4407. Kichkil $\mathrm{S} .=\mathrm{Adamia} \mathrm{cy-}$ a ne a W 11 . Nat. fam. der $S$ a $x$ ifrag a c e $x$. Gr. Java; heester. Gebr. De bladeren worden fijn gewreven, boven het vuur gehouden, en warm op den buik gelegd tegen buikpijnen.

4408. Kidag S. 二 I, o plost ylis javanica Miq. Nat. fam. der Poly. g a l e æ. Gr. Java; slingerplant.

4409. Ki-dammar $\mathrm{S}$. $=\mathrm{P}$ arin ari u m m a c rophy $11 \mathrm{u}$ in T.\& B. Nat. fam. der Chry s o a l a n e æ. Gr. Bau. tam; boom.

4410. Ki-djahej S. = Crot on argyratum Bl. (Zie No. 3647a.)

4411. Ki-djaleh $\mathrm{S}$. $=\mathrm{N}$ ory s a javanica Bl, Nat. fam. der $\mathrm{H}_{\text {y }} \mathrm{po}$. ric ineæ. Gr. Java; heester.

4412. Ki-djambang-badak. S. = Memecylon excels um Bl. Nat. fam. ảer M emecy le æ. Gı. Java; boom. GEBR. Het hout van dezen boom is een goed timmerhout.

4413. Ki-djambeh $\mathrm{S} .=a \mathrm{Meme-}$ cylon costatum Miq. Nat. fam, als voren. GR. De Sunda-eilauden; hooge boom. GeBr. Het hout van dezen boom is een goed en deugdzaam timmerhout. $=6 \mathrm{Memecylon} \mathrm{excelsum} \mathrm{Bl}$. (Zie No. 4412.) $=c$ Memecylon l a urifoliu m $\mathrm{N}$ a u d. Nat. fam. dezelfde. Gr. Java; boom. GEBr. Het hout van dezen boom is een goed en deugdzaam timmerhout; de zuurachtige vruchten worden als lekkelnij gegeten. $=d$ Memecylon oligoneurum Bl. 
(Zie No. $4390 d.)=e \mathrm{~J} \mathrm{a} \mathrm{m} \mathrm{bos} \mathrm{a} \mathrm{co-}$ s y m o sa $11 \mathrm{iq}$. Nat fam. der $\mathbf{M y r}$ t a c e ce. Gr. Java; boom.

4414. Ki-djambeh-awehweh $\mathrm{S}$. = $\mathrm{Ml}$ e m e c yl on ex celsum B l. (Zie No. 4412.)

4415. Bi-djangéan S. = Glabraria mollis Miq. Nat. fam. der L a urinex. Gr. Java; buom.

4416. Ki-djangoeän $\mathrm{S} .=\mathrm{W}$ e n dlandia glabatra De. (Zie No. 2366.)

4417. Zi-djanjoän S. - V a ngueria dicocea Miq. Nat. fam. der $\mathrm{Rubi}$ a c e. Gr. Java en Sumatra; heester.

44.18. Ki-djangtong $\mathrm{S}$. $=\mathrm{O} \times \mathrm{y}-$ unitra cuneiformis Bl. Nat. fam. der A n o n a c e ce. Gr. Java; heester.

4419. Ki-djatilie-aroij S. $=$ Prem. n a parasitic a Bl. (Zie No. 2014.)

4420. Ki-djeroek $\mathrm{S} .=a \mathrm{Te}-$ tranthera c itrata Nees. (Zie No. 401.$)=6 \mathrm{Limoniaspinoza}$ spreng. (Zie No. 2087.) $=c$ Gly. cosmis cyanocarpa spreng. (Zie No. 24.69.)

4421. Ki-djingkan-koelit $\mathrm{S}$. = $\mathrm{J}$ a m bos a acuminatis sima $\mathrm{H}$ as sk. (Zie No. $3043 b$ )

4422. Ki-djoelang $\mathrm{S} .=\mathrm{Pahudia}$ javanica Miq. Nat. fam. der Papil i o n a c eæ. Gr. Java en Sumatra, hoo. ge boom.

4423. Ki-djôso I. $=\mathrm{S}$ a lix Z ollingeria na. i q. (Zie No. 3181.)

4424. Kiempol S. $=\mathrm{Col}$ o c a s i a antiquorum Schott. (Zie No. 245.)

4425. Kientelan S. $=\mathrm{Polyg} 0-$ u $\mathrm{um} \mathrm{b}$ a r b a tu m I. (Zie No. 2126b.) 4426. Kiesiek Sum. $\mathrm{W}_{\mathrm{K}}=\mathrm{P}$ a $\mathrm{n}$. c u m palm folium Ko en. (Zie No. 1754$.

44:27. Ki-gaboes S. zie kajoe gaboes $\mathrm{MI}$.

4428. Ki-gandik $\mathrm{S} .=\mathrm{H}$ ens $10-$ $v$ ia $p$ an i culat a $\mathrm{M}$ i q. (Zie No. 803.)

4429. Bi-gangarongang $\mathrm{S} \cdot=\mathrm{Cap}$ paris flexuos a B l. (Zie No. 3640.)

4430. Ki-gangaung of ki-gangoäng $\mathrm{S} .=a$ Stylocoryna laxiflora B l. en $=b \mathrm{styl}$. tomentos a Bl. Nat. fam. der R u b i a c e æ. Gr. Java, Bornes; boomen.

4431. Ki-ganjöon S. $=\mathrm{Gl} \mathrm{a} \mathrm{b} \mathrm{r} \mathrm{a.}$ ria mollis Miq. (Zie No. 4415.)
4432. Ii-gorai S. $=\mathrm{Sp}$ o n i a velutina Planch. (Zie No. 341.)

4433. Ki-gurrung $\mathrm{S}$. $=\mathrm{J}$ a $\mathrm{m}$ b o s a t e tra go n a B l. Nat. farn. der M y rt a c e æ. Gr. Java; heester.

4434. Ki-ha T. $=\mathrm{Alo}$ c a s i a macrorhiza Schott. (Zie No. 1239.)

4435. Ki-hadjeroe $\mathrm{S}$. $=M$ e $\mathrm{m} \mathrm{e}$ cylon umbellatum Bl. (Zie No. 30436 .)

4436. Ki-hadji $\mathrm{S} .=a \mathrm{D}$ y soxylon macrocarpum bl. (Zie No. 2240.) $=b \mathrm{Mappiamontana} \mathrm{Miq.}$ Nat. fam. der I c a c i n e æ. GR. Java en Sumatra; iniddelmatige boom. $=c$. $\mathrm{Py}$ ge um latifolium Miq. Nat. fam. der Amygdalex. Gr. Java; boom.

4437. Ki-hanjer $S .=$ Erythrostigma diversifoli um Hassk. (Zie No. 583.)

4438. Ki-hanjoerang $\mathrm{S}$. $=a \mathrm{~V}$ angueria dicocca Miq. (Zie No. 44]7.) $=$ Wendlandia glabrata Dc. (Zie No. 2366.)

4439. Ki-haoet S. $=$ Glochidion obscurum Bl. Nat. fam. der Euphorb i a ceæ. Gr. Java; boom.

4440. Ki-hapas S. = Goniothalamus macrophyllus Bl. Nat. fain. der A nonacer. Gr. Java; heester.

444l. Ki-hapiet S. zie ki-apiet S. 4442. $\mathrm{Ki}$-harendong $\mathrm{S} .=a \mathrm{Ki}-$ bessia azurea Dc. (Zie No.1105.) = $b$ Astronia macrophylla en $=c$ A. spectabilis Bl. (Zie No. 3690.)

4443. Ki-haroeman $\mathrm{S} .=a \mathrm{Albiz}$ zia montana Benth. (Zie No. 36796.) $=b$ Pithecolobium montanum Benth. Nat. fam. der Mimosex. Gr. Java; boom. Geer. Het hout van dezen. boom is tijn, taai en sterk, doch van geringen omvang; het wordt voor stelen van gereedschappen, enz. gebruikt.

4444. Ki-harôepat $\mathrm{S} .=\mathrm{Maba}$ Ebenus R. Br. (Zie No. 107.)

4445. Ki-harpan of ki-harrepang S. = Canariopsis altissima Bl. Nat. fam. der Amyrideæ. Gr. Java ; hooge boom. GEBR. Het witte, grove en sterke hout dient voor huisbouw en is zeer duurzaam.

4446. Ki-hauer zie ki-hanjer $\mathrm{S}$.

4447. Ki-heuer $\mathrm{S}$. $=$ Quercus. s undaica Bl. Nat. fam. der Cupuliferæ. Gr. Java; boom, die een grof bouwhout levert.

4448. Ki-Riang S. = Albizzia 
lebekkoides Benth. Nat. fam. der Mimoseæ. Gr. Java, Timor; hooge boom. GEBR. Het hout van dezen boom is sterk, goed roor meubelhout en gelijkt veel op dat der Rhunghas. De bast wordt met trassi tot sa in bal bereid, en rooral gegeten door vrouwen, die aan buikpijn lijden of die pas gebaard hebben; ook bezigt men dezen bast tot het bedwelmen van visschen. De jonge bladeren worden als groente gegeten. $=b \mathrm{Albizzia} \mathrm{micran-}$ tha Boiv. Nat. fam. dezelfde. Gr. Java; hooge boom. $=c$ Albizzia procera Benth. Nat fam. als voren. GR. Java; hooge boom. GEBr. Deze boom zweet veel gom uit, die op Arabische gom gelijkt. Vermoedelijk bezigt men ook zijn bast als zeep, tot verdrijving van ongedierte, en geeft men het sap aan kraamvrouwen te drinken, tot bespoediging der uitdrijving van den moederknek. Het hout is zeer geschikt voor stijlen.

4449. Ki-hieriesan $\mathrm{S}$. = B udd lei a a siatica Lour. Nat. fam. der Loga-. n i a ceæ. Gr. De Sunda-eilanden; heester. GEBr. De bladeren van dezen heester legt men bij koortsen op den buik, na ze eerst boven het vuir verwarmd te hebben.

4450. Ki-hiloet $\mathrm{S}$. $=a \mathrm{An}$ is o meles malabarica R. Br. (Zie No. 792.) $=b$ Anisomeles ovata R. Br. (Zie No. 818.)

4451. Ki-hioer $S .=Q u e r c u s$ s $n$. daica B]. (Zie No. 4447.)

4452. Ki-hoedjang $\mathrm{S}$. 三 $a \mathrm{Hopea}$ selanica Roxb, (Zie No. 8\%4) = $b$ Engelhardtia aceriflora Bl. (Zie No. 1642.) $=c$ Engelhardtia $r^{\circ}$ igid a Bl. Nat. fam. der Juglan de æ. Gr. Java; hooge boom. $=d$. Engelhardtia spic at a Bl. Nat. fam. als voren. Gr. Java; hooge boom. GeBr. Het hout is van grooten omvang, nog al licht en zeer bruikbaar voor kano's, planken, wielen van karren; enz.

\section{Ki-hoegang S. Zie ki-hoe- djang $S$.}

4454. Ki-hoëh $\mathrm{S} .=a \cdot \mathrm{Evia} \mathrm{acida}$ Com m. (Zie No. 2890.) $=b$. Xerospermum Noronhianum Bl. (Zie No. 2286.) $=c$. Cupania diplopetala Hassk. Nat. fam. der Sa pindace a. GR. Java; middelmatige boom. $=d$. Cupan i a f u scescens Miq. Nat. fam. dezelfde. GR. Java; boom, waarvan het hout gebezigd wordt voor stijlen. $=e$. Arytera littoralis B. Nat. fam. dezelfde. Gr.
Java; boom. Gebr. Van het harde hout vervaardigt men verschillende werktuigen. $=f$. Sorindeia madagascariensis Thrs. Nat. fam. der Anacardiacer. Gr. Op Java in tuinen ingevoerd; boompje.

4455. Ki-hoë0et $\mathrm{S} .=a$. Antides ma paniculatum B1. (Zie No 1356.) $=b$. Callicarpa pentandra Roxb. (Zie No. 1152.) $=c$. Glochidion lutesceus Bl., Nat. fam. der Euphorbi а се æ. Gr. Java; heester. $=d$. G lochidion obscurum Bl. (Zie No. 4439.)

4456. Ki-hoera $\mathrm{S}$. $=$ Wallichia porphyrocarpa Mart., Nat. fam. der Palmæ. Gr. Java; lage palmsoort. Gebr. Men bezigt het harde, zware hout voor spinnewielen; de top (hoemoet) wordt als groente bij de rijst gegeten, en als geneesmiddel aangewend tegen dysurie door misbruik van $\mathrm{Dj}$ engkol veroorzaakt. De bladscheeden gebruikt men in plaats van valiezen om goederen tegen regen te bewaren. Deze kleine Palm wordt uit bijgeloof veelal langs de waterleidingen der rijstvelden aangeplant, oin de padie tegen ziekte te behouden.

4457. Ki-hoeroe Z. 三 $\alpha$. Endiandra rubescens Miq. (Zie No. 2905b.) $=b$. Parthenoxylon Psendosas. s afras B 1. (Zie No. 2927c)

4458. Ki-hoerong S. = Blumeana Korth., Nat. fam. der Tern-

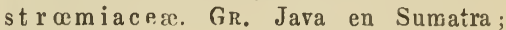
heester. $=b$. Eurya glabra Bl. (Zie No. 3155.)

4459. Ki-honeh $\mathrm{S}$. $=$ Ki-hoëh $\mathrm{S}$.

4460. Ki-honjeh $\mathrm{S}$. $=a$. Pitto. sporum densiflorum Pütterl. Nat. fam. der Pittosporeæ. Gr. Java en Sumatra; boom. GeBR. De fijn gestampte bladeren en vruchten werpt men in het water om de visschen te bedwelmen. $=60 \mathrm{Oea}$. lancea Lam., Nat. fam. der Oleacex. Gr. Op Java in tuinen van Mauritius overgebracht; boom.

4461. Ki-hor S. = Enàiandra rnbescens Miq. (Zie No. 290万弓.)

4462. Ki-jalitrie $\mathrm{S}$. $=$ Wrigthia pubescens R. Br. (Zie No. 1184.)

4463. Ki-jambeh $\mathrm{S}$. $=$ Cry ptocary a ferrea Bl. (Zie N.o. 2895.)

4464. Bi-jangkoran $\mathrm{S} .=\alpha$. A r throphyllum Blumeanum Z. \& M. (Zie No. 1973.) = b. Arthrophy $11 n \mathrm{~m}$ diversifolium Bl., Nat. fam. der A rali a cсæ. Gr. Java; boomachtig. $=c$. Tre. 
vesia sundaica Miq. (Zie No. 4404 c.) 4465. $\mathrm{Ki}$-japoe $\mathrm{S}_{0}=\mathrm{P}$ istia Stra. tiotes L. (Zie No. 1669.)

4466. Ki-joejoela S. 二 $a$. A moora aphanamixis R. \& Sch., Nat. fam. der Jeliaceæ. Gr. Java; hooge boom. $=b$. Heynea quinquejuga Roxb., Nat. fam. als voren. Gr. Jara ell de Molukken; boom.

4467. Ki-kadal $\mathrm{s} .=a$. Eurya clandestina Bl, Nat. fam. der Ternstrœmiace $x$. Gr. Java; boom. $=b$. B ̈̈ttneria angulata Hassk., Nat. fam. der Büttnariace x. Gr. Java; slingerplant.

4468. Kikadal-boddas $\mathrm{S}$. = B üt tneria flaccida Span., Nat. fam. der Büttneriaceæ. Gr. Java, Timor; slingerplant.

4469. Ki-kamanden $\mathrm{S}$. $=\mathrm{M} \mathrm{y} \times 0$. pyrum nervosum Bl. (Zie No. 569.)

4470. Ri-kanhoöng $\mathrm{S}$. = Stylo. coryna laxiflora Bl. (Zie No. 4430a.)

4471. Ki-kapas $S .=G u a t t e r i a$ macrophylla Bl. (Zie No. 1548.)

4472. Ki-katjambang $\mathrm{S}$. $=\mathrm{L}$ o $\mathrm{n}$ icera oxylepis Miq., Nat. fam. der C a p r if o li a c e æ. Gn. Java; slingerplant.

4473. Ki-katjang $\mathrm{S} .=a$. Evonym us javanicus Bl. (Zie No. 1874.) $=$ b. Strombosia javanica Bl., Nat. fam. der G la c i n ex. Gr. Java, Borneo, enz.; boom. GEbr. Deze groote en zware boom levert een zeer sterk en duurzaam bouwhout, dat niet door witte mieren wordt aangetast, en onder den grond lang goed blijft.

4474. Ki-katjapie $\mathrm{S} .=a$. E læocar pus tom c n to s u Bl., Nat. fam. der T i li a c eæ. Gr. Java; boom. GeBr. Als bij No. 2654. $=6$. S a n d or i c u m g l a b e rim um Hassk. en $=c$. S. n e r v o u m B l.. Nat. fam. der Mi e li ac e æ. Gr. Java; boomen GeBr. Deze boomcn leveren een sterk en fraai hout, dat zeer geschikt is voor huisraad. De vruchten zijn zuur en worden gegeten, doch niet met zooveel graagte als die der $\mathrm{S}$. in $\mathrm{d}$ i c u $\mathrm{m} \mathrm{Cav}$.

447 o. Ki-katoempang S. $=a$. S a mbucus javanica $R$ wd t., Nat. fam. der Caprifolia c e ce. Gr. Java; hees. ter. $=b$. V i burn a m sambucinum $R$ w d t. (Zie No. 307c.)

4476. Ki-kehlus S. en

4477. Ki-keleer S. $=\mathrm{Carg}$ i 1 i a maritima $H$ as sk., Nat. fam. der
E b e n a c e r. Gr. Java, Timor, Amboina; heester. GEBR. Het hout levert goede houtskolen.

4478. Ki-kekoepoe S. = $\mathrm{B} \mathrm{a} \mathrm{u} \mathrm{hi-}$ n i a irsuta $R$ w d t., Nat. fam. der P a pilion a c e. GR. Java; heester.

4479. Ki-kepper S. $=$ Monoceras obtusum Hassk. (Zie No. 2897f.)

4480. Ki-ketjangkir $\mathrm{S}$. $=\mathrm{A} \mathrm{b} \mathrm{ro-}$ m a a u usta B l., Nat. fam. der B ü ttn e r r i a c e e. Gr. Java; heester.

4481. Ki-keujup $\mathrm{S} .=a$. Strom. bosi a ja an i c a Bl. (Zie No. 44736.) $=b$. S a uraya crenulat a DC. en $=$ c. Saura a Haskarliana $\mathrm{M}$ i q., Nat. fam. der $\mathrm{T}$ e $\mathrm{r} n \mathrm{~s} t \mathrm{r} \propto \mathrm{m}$ i ac e æ. Gr. Java; heesters.

4482. Ki-keujup-goenoeng $\mathrm{S} .=\mathrm{P}$ olyosma velutina Bl., Nat. fam. der Es c a 11 on i e. Gr. Java en Sumatra; heester.

4483, Ki-kiginang $\mathrm{S}$. $=\mathrm{C}$ o $\mathrm{m} \mathrm{m} \mathrm{e}$ lina suffruticosa Bl., Nat. fam. der C o m m e li n e æ. Gr. Java, Sumatra; orerblijvend.

4484. Ki-kibissan $\mathrm{S} .=\mathrm{O}$ p h i u r u s c orymbosus Grtn., Nat. fam. der Gr a mi n e . Gr. Java; overblijvend. = b. Rottboellia exaltata L. fs, et. a l. s pec. (Zie No. 2138b.)

4485. Kikil I. $=$ A rdisia $v$ illos a Roxb. Nat. fam. der M y r in e æ. Gr. Java; heester.

4486. K:-kiieär S. $=\mathrm{C}$ a rg i li a maritim a Has sk. (Zie No. 4477.)

4487. Ki-klor $\mathrm{S} .=\mathrm{Diospyros}$ E b e n m R etz. (Zie No. 32.)

4488. Ki-koejah $=a$. Strophan. thus dichotomus Bl. Nat. fam. der A pocyner. Gr. Java; slingerplant. 二 b. Goniochitou arborescens Bl. Nat, fam. der M eliace æ. Gr. Java; boom. 4489. Ki-koejoeän $\mathrm{S}$. = V andellia crustacea Benth. (Zie No. 2155.) 4490. Ki-koekoeran S. $=a$. $\mathrm{Ca}$. rallia symmetria Bl. Nat. fam. der Legnotideæ. Gr. Java; boom. Gebr. Het hout van dezen boom is sterk, geschikt voor bouwhout en wordt niet door witte mieren aangetast. De bladeren bezigt men uitwendig tegen hoofdpijn en duizeligheid. $=b$. Heliciaserata $R$. Br. (Zie No. 3381.) = c. Polyosma ilic ifolia Bl. Nat. fam. der Esc a 11 on i e. Gr. Java; boom. $=d$. $\mathrm{V}$ iburnum sundaicum Mi q. (Zie No. 4301.) 
4491. Ki-koel of ki-toel s. = Co. vellia stictocarpa Miq. (Zie No. $1573 d$.)

4492. Ki-koempaai $\mathrm{S} .=a$. G ou iochiton arborescens Bl. (Zie No. 4488b.) $=$ b. L ycopodium L. Species diversæ $=c$. Ophioderma pendulum Endl. (Zic No. 3786.)

4493. Ki-koempaai-lumboet $\mathrm{S}$. = l, y c o pod i u m P h legmaria L. cum variet. diversis. Nat. fam. der I,ycopodiacer. Gr. Java; overblijvend. GEBR. De Indianen schrijven aan de ziltige, naar hooi riekende wortels een sterke antigastische en stondendrijvende kracht toe, en geven die ook bij longziekten en waterzucht. $\mathrm{Hij}_{\mathrm{ij}}$ speelt eene hoofdrol in hunne liefdedranken. Sommigen meenen dat het kruid een kleurstof bevat, of liever dat het tot schilderen kan gebruikt worden.

4494. Ki-koenggoeng $\mathrm{S}$. $=\mathrm{S} \mathrm{o} \mathrm{la-}$ n u m B l u me i N e e s. (Zie No. 1345a.)

4495. Ki-koeöet S. = Mastixia? cuneata Bl. Nat. fam. der Cornacex. Gr. Java; hooge boom.

4496. Ki-koepa $\mathrm{S} \cdot=$ Memecylon appendiculatum Bl. Nat. fam. der II elas tomaceæ. Gr. Java en Borneo; boom.

4497. Ki-koepoe-koepoe S. = $a$. Bauhinia tomentosal. Nat. fam. der Papili on ace $æ$. Gr. Java, Sumatra enz.; heester. GEBR. Het fijne, sterke, vaste en witte hout van dezen heester bezigt men voor handvatsels en scheeden van wapens. De zure bladeren gebruikt men op de Philippijnsche eilanden bij verschillende spijzen in plaats van azijn. Volgens $L$ ind. ley worden de knoppen en bloemen bij dysenterie gegeven. In Britsch-Indië bereidt men uit de zaden een vette olie, Downy mountain ebony oil genaamd. $=b$. Pteris anthes cissoidea Bl. (Zie No, 559.)

4498. Ki.koeraí $\mathrm{S} .=\mathrm{Sponia}$ virgata Plancl. Nat. fam. der C elt ide e. Gr. Vrij algemeen in Indië; boom.

4499. Ki-kondal S. $=\mathrm{D}$ is c hid i a $s$ a gitta t a D c s n. Nat. fam. der A s c le p i a d e æ. Gr. Java; slingerplant.

4500. Ki-konneng $\mathrm{S}$. = Coc cul us? l u cidus T. \& B. N̄at. fam. der Me n is perma ce æ. Gr. West-Java; slingerplant.

4501. Ki-konneng-kajoe S. $=a$.
Polyadenia grandifolia Miq. (Zie No. 2654a.) $=$ b. Raphidostigma $\mathrm{Z}$ ollingeri $\mathrm{Hassk}$. Nat. fam. der Ebenaceæ. Gr. Java; boom.

4502. Ki-koppi $\mathrm{S} .=a . \mathrm{C}_{\text {of f e a }}$ densiflora Bl. en $=b$. Coffea s und a u a Miq. Nat. fam. der R ubia c e æ. Gr. Java 2-4000'; kleine boomen. $=c$. Canthium glabrum Bl. Nat. fam. als voren. GR. Jara, Sumatra en Borneo; heester. $=d$. $\mathrm{Hypoba-}$ thrum frutescens Bl. Nat. fam. dezelfde. Gr. Java; heester.

4503. Ki-koppi-bener S. en

4504. Ki-koppian S. = Styloco. ryna fragrans Bl. Nat. fam. der R u b i a c ex. Gr. Java en Sumatra; lage boom.

4505. Ki-korres $\mathrm{S} .=a . \mathrm{Chasa-}$ lia robusta Miq. (Zie No. 2697.) = b. Chasalia expansa Miq. Nat. fam. der Rubiaceæ. Gr. Java en Sumatra; heester. GEBR. Den bast en de bladeren bezigt men uitwendig tegen slepende huidziekten, schurft enz; ook als bij No. 2698 is opgegeven. $=c$. Chasalia montana Miq. Nat. fam. dezelfde. Gr. Java; kleine boom. Gebr. als $b$. 三 $d$. Grumilea viridiflora Miq. et. al. s pec. Nat. fam. dezelfde. Gr. Java, Borneo; heester's.

4506. Ki-korres-woengoe S. $=a$. Chasalia robusta Miq. (Zie No. 2697.) $=$ b. Chasalia lurida Miq. Nat. fam. als voren. Gr. De Sunda-eilanden en Amboin a heester. GÉbr. (Zie No. $4505 b$.) $=c$. Psychotria gendarussæfolia Bl. Nat. fam. dezelfde. GR. Java; heester.

4507. Ki-koweh S. = Diospyros Kaki L. fs. Nat. fam. der Eben a ce Gr. Op Java en Celebes, overgebracht uit Japan; boom.

4508. Bi-laden Z. Bo. 二 Antho. cephalus morindæfolius Korth. Nat. fam. der Rubiacer. Gr. Java, Sumatra en Borneo; boom.

4๖09. Ki-ladja S. 二 $a$. Connarus

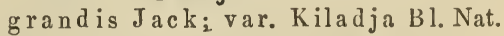
fam. der Connaracex. Gr. Java, Sumatra. enz. klimplant. $=b$. Mitrephora macrantha Hassk. (Zie No. 573g.) $=c$. Mitrephora multiflora Miq. (Zie No. 573e.) $=d$. Mitrephora polypyrena Bl. Nat. der Anonacer. GR. Java; boom. =e. Pseuduvaria reticulata Miq. Nat. farn. als voren. 
Gr. Java; heester. $=f$. Unona dasymaschala Pl. (Zie No. 574.) $=g$. Uvaria argenta $\mathrm{Bl}$ '(Zie No. 573a.) 4510. Ki-ladja Tr. E Uvari a timoriensis Bl., Nat. fam. als roren. Gr. Timor; heester. GeBr. De vrucht van dezen heester, welke op Timor lal a wordt genoemd, wordt gegeten.

4511. Ki-ladja-leutiek S. 二 Guatteria littoralis Bl. Nat. fam. dezelfde. Gr. West-Java; heester.

4512. Ki-ladjeroe $\mathrm{S}$. $\mathrm{Meme-}$ cylon umbellatum Bl.(ZieNo. 3043b.)

4513. Ki-lagidaij $\mathrm{S}$. $=\mathrm{V}$ a c c ini u m coriaceum Miq., Nat. fam. der $\mathrm{V}$ a c cin ex. Gr. Java; heester.

45 14. Ki-lagidaij-boeloe $\mathrm{S} .=1) \mathrm{i}$ plycosia pilosa Bl. Nat. fam. der Ericace æ. GR Java; heester.

4515. Ki-lahi Bo. = Echinus trisulcus Lonr. (Zie No. 3344.)

45 1.6. Ki.laketan $\mathrm{S}$. $=a$. Vib u rnum sambucinum Rwdt. (Zie No. $307 c$.) $=$ b. Aglaja Sulingi Bl. Nat. fam. der Meliacere. Gr. Java; boom.

4517. Ki-lakkatan S. = Grumilea viridiflora Miq. (Zie No. $4505 d$.) $=b$ Chrysophyll u m lanc e olat um A D c., Nat. fam. der Sap o t a c e æ. Gr. Java, Borneo, NieuwGuinea; hooge boom.

4วั18. Ki-lakki $\mathrm{S}$. $=a$. G rewia oblongifolia Bl. (Zie No. 325.) = b. Grewia $l æ v i g a t a V a h l$, Nat. fam. der Tili a c e æ. Gr. Java; kleine heester. GEBR. Den gedroogden bast bezig $t$ men als touw.

4519. Ki-lakki-aroij $\mathrm{S}_{.}=\mathrm{Gr}$ ewi a o d o r a t a B l., Nat. fam. als voren. Gr. Java; heester. GEBr. Als voren.

4520. Ki-lalaijoe S. $=a$. L e pisanthes montan a Bl., Nat. fam. der S a pind a c e r. Gr. Java; hooge boom. GEBr. Het hout is een zeer duurzaam timmerhout. $=b$. E ri o g los s u m ed a le Bl. (Zie N 0.3580 .)

4521. Ki-lalaijoe-hiedung S. $=\mathrm{E}$ rio glossum edule Bl. (Zie No. 3580.)

4522. Ki-lalompong $\mathrm{S}$. 二 $\mathrm{H}$ a r puli a rupestris Bl., Nat. fam. der S a pindace Gr. Java en NieuwGuinea; hooge boom.

4523 Kilam Aмв.二 $a$. Melaleuca leucadendron L. (Zie No. 120a) = b. Melaleuca Cajuputi Roxb. (Zie No. 1737 d.)

4524. Bi-lambôetang $=a$. Allo. phyllus fulvinervis Bl. (Zie No $4381 c.)=b$. Allophyllus sundanus Miq. (Zie No. 4381d.)

4525. Ki-lampajang S. = Allophyllus sundanus Miq. (Zie No. 4381 d.)

4526. Ki-lampanie $\mathrm{S} .=a$. A rdisia Sw. Species diversæ. Gebr. De bladeren van de meeste der volgende heesters, onder den naam van ki-lampanie voorkomende, worden uitwendig bij natuurlijke pokken aangewend; zij worden, volgens $\mathrm{H}$ asskarl, daartoe vermengd met het sap van verschillende $B$ oehmeriasoorten, van Alyxia stellata en met aluin. $=b$. Ardisia purpurea $R$ wdt. (Zie No. 1582.) $=c$. Ardisia nutans A. D. C., Nat. fam. der Myrsineæ. Gr. Java; kleine heester.

4527. Ki-lampanie-badak S. = A rdisia macrophylla Bl., Nat. fam. als voren. Gr. Java; heester.

4528. Ki-lampanie-gedeh $\mathrm{S} .=a$. Ardisia complanata Wall., Nat. fam. dezelfde. Gr. Java en Sumatra; kleine heester. 二 $b$. Ardisia humilis Vahl, Nat. fam. als voren. Gr. Java, Sumatra, enz.; heester. $=c$. Ardisia marginata B l. Gr. Java; heester. $=d$. Ardisia speciosa Bl. (Zie No. 2739b.)

4529. Ki-lampanie-heedjoh S. $=\mathrm{Ar}$ disia l urida Bl., Nat. fam. als vorell. GR. Java; groote heester.

4530. Ki-lampanie-lawut S. = Climacandra oborata Bl., Nat. fam. der Myrsineæ. Gr. Java; heester.

4531. Ki-lampanie-lumboet $\mathrm{S} .=\alpha$. Ardisia Blumei A.J.C.; en $=b$. Ardisia glabrata Bl., Nat fam. als voren. Gr. Java; kleine heesters. $=c$. Ardisia lurida Bl. (Zie vorig No.) $=d$. A rdisia pumila Bl. (Zie No. 2137.)

4532. Ki-langhit $\mathrm{S} .=\alpha$. E pich a ris sericea Bl. (Zie No. 2763.) $=b$. Eupteron nodosum Miq. (Zie No. 4081a.) $=c$. Arthrophyllum diversifolium Bl. (Zie No 4464b.) $=d$. Paratropia longifolia DC. (Zie No. 1972a.)

4533. Ki-langler $=a$. Peron ema canescens Jack., Nat, fam. der Verben aceæ. Gr. Sumatra; hooge boom, met een hard en taai hout. = $b$. Stereos. permum Hasskarlii T. \& B., Nat. fam. der Bignoniaceæ. Gr. Java; boom. 4534. Ki-lantjang $\mathrm{S}$. = Polyalthia subcordata Bl. (Zie No. 915.) 4535. Ki-laroe Tr. = Cæsalpi- 
nia ferrug inea Desn., Nat. fam. der Papilionaceæ. GR. Jara en Timor; boom.

4536. Ki-laroek S. = Albizzia rostrata Bl., Nat. fam. der Mimos eæ. Java; boom.

4537. Ki-leat $\mathrm{S} .=a$. Premna corymbos a Rottl. (Zie No. 395.) = Claoxylon longifolium Endl., Nat. fam. der Euphor b a c e $æ$. GR. Jara; heester. GEBR. De jonge takjes eet men als groente bij de rijst, nadat zij eerst gervosterd zijn.

4538. Ki-leho S. = $a$. S a ur a y a c ren u la ta D. C. (Zie No.4481b.) = b. Sa u r y a Has $\mathrm{s}$ arlian a M iq. (Zie No. $4481 c$.) 二c. S a u r a a b r a cteo lat a D.C., Nat. fam. der T e rnst $r \propto m$ i a c e æ. Gr. Java; heester. $=d$. S a u r a a bracteo s a DC. Gr. Java; heester. $=e$. S a u r a y a a $\mathrm{liflor}$ a D. C. Gr. Java en de Mulukken: heester. = f. S a u r y a hirsu t a Bl. Gr. Java en Celebes; heester. $=y$. S a u r a y a pe ndula Bl. (Zie No. 3034.) Gerr. Volgens $\mathrm{H}$ a s s k a $\mathrm{l}$ diinkt men van som. mige $\mathrm{S}$ a u $\mathrm{r}$ a-soorten het sap tegen diarrhuea en dysenterie.

4539. Ki-leho-badak S. $=\mathrm{S}$ a u. raya nudiflora D. C. GR. Java; heester.

4540. Ki-leho-boeloe S. $=\mathrm{S}$ a ur a y a udiflora D. C. Gr. Java; heester.

4541. $\mathrm{Ki}$-leho-burrum $\mathrm{S} .=-\mathrm{S}$ a urava c a u lif l o r a D.C. (Zie No. 4538e.)

4542. Ki-leho-konneng $\mathrm{S}$. = $\mathrm{S}$ a u$r$ a y $R$ ein w a $r$ t i a $n$ a $B l$. GR. Java.

4543. Ki.leho-lalakkina $\mathrm{S} .=\mathrm{S}$ a ur a y a pe adula Bl. (Zie No. 3034.)

4544. Ki-leho-lumboet $\mathrm{S} .=a . \mathrm{S}$ a u$r$ a y a cauliflora D. C. $=6$. Sa uray a in i crant ha Bl. Gr. Java; heester. = c. S a u r a a s p a di c e a Bl. Gr. Java en Celebes; heester.

4545. Ki-leho-moendieng $\mathrm{S} .=\mathrm{S}$ a ur a y a gig a n t e a D.C. Gr. Java; heester. 4546. Kî-lihoet $\mathrm{S}$. $=\mathrm{A} \mathrm{n}$ i s o m eles ovata RBr. (Zie No. 818.)

4547. Ki.lilin-bunjier $\mathrm{S} .=\mathrm{L}$ i t h oc a r p s javensis B 1. (Zie No.1011.) 4548. Bi-limoet $\mathrm{S}$. $=\mathrm{Tetran}$. the ra citrat a N e es. (Zie No.401.) 4549. Kili-kili $\mathrm{Cr}_{\mathrm{r}}=a$. C a s s i a Sophora L. en b. Cassia Tora L. (Zie No. 73.)

45.50. Ki-loenghit $S .=S p$ at ho- de a gigantea B l., Nat. fam. der B i g n o n i a c e . GR. Java; zeer hooge boom. GEBR. Het grove, witte hout is geschikt voor huisbouw; het wordt niet door witte mieren aangetast.

4551. $\mathrm{Xi-loengloeng} \mathrm{S.}=a . \mathrm{Ar}$ o$\mathrm{madendron}$ elegans B l. (Zie No. 1890.) $=$ b. Guatteria pal1 i d a ß l., Nat. fam. der A n o n a c e Gr. Java; heester.

4552. Ki.loetoeng S. $=a . \mathrm{C}$ a l p icarpum Roxburghii G. Don., Nat. fam. der A p o c y n e . GR. Java in het wild en in tuinen; heester. $=b$. K o p si a a r b r e a B l., Nat. fam. dezelfde. Gr. West-Java; boom. GEbr. De fijn gewreven bladeren bezigt men uitwendig tegen hoofdpijn $=c$. M a r l e a t ome $\mathrm{t}$ os a $\mathrm{End}$ l., Nat. fam. der C o rn a c e æ. Gr. Java; groote heester.

4553. Ki-longlaijong $\mathrm{S}$. $=\mathrm{Z}$ e hneria hastata Miq., Nat. fam. der Cucurbitaceæ. Gr. Java. Gebr. De onrijpe vruchten van deze slingerplant worden afgekookt als groente bij de rijst gegeten. 4554. Ki-madoeän S. 二 D endro phthoë lepidota Bl. (Zie No. 36766.)

4555. Ki-malakkian S. 二 $a$. C r oton Tiglium L. (Zie No. 6 ) $=6$. Rottler a acuminat a Juss. (Zie No. 2813a.) $=c$. Plagianthera oppositifolia Rchb. \& Zoll. Nat. fam der Euphorbiaceæ. Gr. Java; heester.

4556. Ki-malakkian-goenong $\mathrm{S}$. = Croton tiglioides Bl., Nat. fam. als voren. Gr. Java; heester.

4557. Ki-mangal $\mathrm{S} .=\mathrm{G}$ or do. nia excelsa Bl. (No. 2531.)

4558. Ki-mangies-oetan $\mathrm{S}$. = $\mathrm{S}_{0}$ lenospermum javanicum Zoll. Nat. fam. der Hippocrateace æ. GR. Java ; heester.

4559. Ki-mangle $S . \in n$

4560. Ki-mangoe S. = Fragraa? Kimangu Bl., Nat. fam. Log a niace GR. Java; middelmatige boom.

4561. Ki-manilla $\mathrm{S} .=a$. Cassia ala ta L. (Zie No. 1740.) = Mastixia Kimanilla Bl., Nat. fam. der Cornaceæ. Gr Java; hooge boom.

4562. Ki.manjel S. $=a$. Go r donia excelsa Bl. (Zie No. 2531.) $=b$. Gordonia acuminata Chois, Nat. fam. der Ternstrœmiaceæ. Gr. Java; heester.

4563. Ki-manoek $\mathrm{S}$. $=\mathrm{T}$ a r rietia java nica Bl., Nat. fam. der S ter- 
cul iacece. Gr. Java; zeer hooge boom. Gebr. Het witte, grove, hards en sterke hout gebruikt men soms voor huisbouw, het wordt echter spoedig door witte mieren aangevieten.

4564. Kimbok J. $=$ L u f f a p e ntandra Roxb. (Zie No, 636b.)

4565. Ki-meong S. $=a$. Pla g ianthera oppositifolia Bchb. \& Zoll. (Zie No. $45 \check{5} \check{c}$. $)=b$. Rottlera acuminata Juss. (Zie No. 2313.) $=c$. Lasianthera macrophylla Miq., Nat. fam. der Icacinea. Gr. Java; hooge boom. $=d$. Lasianthera secundiflora Miq., Nat. fam. als voren. GR. Java; boum. GErR. Het grove en sterke hout van $c$. en $d$. bezigt men wel eens als bouwhout; het wordt echter spoedig door witte mieren aangetast. $=e . \mathrm{W}$ endlandia densiflora D. C., Nat. fam. der Pubiace a. Gr. Java; heester. Gebr. Men gebruikt het fraaie hout van dezen heester bij huisbouw en voor meubels; het wordt echter ook spoedig door insekten aangetast.

4566. Ki-merak S. $=a$. Leucoxylon buxifolium Bl. (Zie No. 4393b.) $=b$. Scepasma buxifolia Bl. Nat. fam. der Euphorbiaceæ. Gr. Java; heester. GEBR. Het hout van dezen heester is sterk, doch wordt spoedig door insekten aangetast; het wordt evenwel gebruikt voor huisbouw karren, gereedschappen enz. Het sap gebruikt men tegen tandpijn en tot het $\mathrm{z}$ wartverwen der tanden. $=c$. Podocarpus $\approx \mathrm{maraBl}$. (Zit No, $\left.3366 a_{0}\right)=d$. P odo c a $\mathrm{p}$ u s bracteata Bl. (Zie No. 39.) $=e$. Podocarpus cupressina R. Br. (Zie No. 2820.) $=f$. Podocarpus J ungh uh $и$ i a a M i q. Nat. fam. der Pod o c a rpe r. GR. Java; boom. = y. Podocarpus neglecta Bl. Na.. fam. als voren. Gr. Java; boom.

4567. Ki-merak-pahit $\mathrm{S} .=\mathrm{P}_{0}$ do carpus amara Bl. (Zie No.3366a.) 4568. Ki.merang $\mathrm{S}$. $=\mathrm{Ph} \propto \mathrm{be}$ $u$ m b elliflora Ne es. Nat. fam. der L a u rine a. Gr. Java, Borneo en elders; heester.

4569. Ki-merto I. $=\mathrm{C} æ s_{\text {a l }} \mathrm{p}$ ini a $\mathrm{Nug}$ a Ait. (Zie No. 627.)

4570. Ki-minjakh S. = a. Fagræa obovat a Wall. (Zie No. 1084.) $=$ b. Fagræa elliptica Roxb. Nat. fam. der Log an i a e æ. Gr. Java en de Molukken; heester.

4วั7l. Ki-moeka S. $=\mathrm{Glochi}$. di o n rubrum 13l. Nat. fam. der Euphorbiace a. Gr. Java; heester. 4572. Ki-m jekla of ki-mokla S. = a. Myristica corticosa Hk. \& T'h. (Zie No. 13\%.) $=6$. M y ristica la urina Bl. (Sie No. 29ə̌lb.) $=c$. Myristica intermedia Bl. Nat. fam. der L a u r i n e æ. Gr. Java, Sumatra, enz. boom.

4573. Ki-moelak-ketjil S. \& M. = Psychotria lioxburghi Dc. Nat. fam. der Rub iaceæ. Gr. Java, de Molukken; heester.

4574. Ki-moenoeng $\mathrm{S} .=\mathrm{P}$ ter oc y mbium javani cum R. Br. (Zie No. 1200c.)

4575. Ki-moentilan $\mathrm{S} .=\mathrm{Oph} \mathrm{i-}$ orrhiza Junghuhniana Miq. Nat. fam. der Rubiacex. Gr. Java; heester. 4576. Ki-mogmal $\mathrm{S}$. $=\mathrm{L}$ e p id adenia rubra Bl. (Zie No. 2931c.)

4577. Ki-mogmala $\mathrm{S}$. $=\mathrm{K} \mathrm{i} b$ a. $\mathrm{r}$ a coria cea Endl. (Zie No. $878 f$.)

4578. Ki-mokla $\mathrm{S}$. $=$ Viburnum sa m bucinum Rwdt. (Zie No. $307 c$.) 4579. Ki-monjenjen $\mathrm{S} .=\mathrm{Bud}$. leia asiatica Lour. (Zie No. 4449.) 4580. Kinar $\mathrm{Aur}$. $=\mathrm{Kl}$ e in ho$\nabla$ i a hospita L. (Zie No. 3927.$)$

$4.58 \mathrm{l}$. Kinareng $\mathrm{S}$ \& $\mathrm{I}$. $=\mathrm{S}$ a $\mathrm{u}$ raya rosea Jugh. Nat. fam. der Ternstramiacer. Gr. Java; heester.

4582. Kinauk S. = Gelon i u m glomerulatum B1. (Zie No. 1970.)

4583. Kindjarong $\mathrm{Br} .=\mathrm{Ocimum}$ sanctum L. (Zie No. 875.)

4584. Kindoch BK. $=\mathrm{Rhod} \mathrm{om} y \mathrm{r}-$ tus tomentosa DC. (Zie No. 2739c.)

458ว. Kindog of ki-êndog S. $=a$. Xanthophyllum excelsum Bl. = b. X. longifolium Bl. =c. X. vitellinum Bl. Nat. fam. der Polygalex. GR. Java; heesters of lage boomen. GEBl. Het hout van deze boomen is sterk, grofvezelig, duurzaam, en wordt niet door in. sekten aangetast. Men gebruikt het bij huisbouw.

4586. Kindog-aroij $\mathrm{S} .=\mathrm{S}$ e cu r id a c a inappendiculat a Hask. Nat. fam. der Polygaleæ. Gr. Jara; slingerplant.

4587. Kindra $\mathrm{I}$. $=\mathrm{B}$ a se $11 \mathrm{a} \mathrm{r} \mathrm{u}$ b r a L. (Zie No. 24l19a.)

4588. Kingkilaban $\mathrm{S} .=\mathrm{M}$ u s$s$ a ënd a L. Species divers a.

4589. Kingking $\mathrm{MAD}_{\mathrm{AD}}=\mathrm{H}$ a r r isonia Browrii A. Juss. Nat. fam. 
der Si maruba cea. Gr. Java en Madura; heester.

4590. Kingkit S. \& $\mathrm{I}$. $=\mathrm{T} \mathrm{r}^{\mathrm{i}}$ phasia trifoliata Dc. Nat. fam. der A urantiace re. Gr. Door geheel Indië in tuinen en omheiningen; heester GEBR. De bladeren bezigt men uitwendig dikwijls bij buikziekten; de kleine, fraaie en aangenaam riekende bessen worden gekonfijt gegeten.

4591. Ki-nitjing $\mathrm{S}$. $=\mathrm{Nelitris}$ polymorpha Bl. Nat. fam. der Myrtaceæ. Gr Java en Sumatra; heester.

4592. Kinjing Bк. 三 Evonymus bauc ana Miq. Nat. fam. der Celastrineæ. Gr. Bangka; kleine heester.

4593. Bintjoer $\mathrm{M}$. $=\mathrm{K} \mathrm{mpfe}$ ria Galanga L. (Zie No. 737.)

4594. Kintjoeran I. $=\mathrm{Ex}$ o c a $r$ p) us Iatifolia R. Br. Nat. fam. der S antala cer. Gr. Java en Nieuw-Guinea; kleine boom.

4595. Rioerai S. = Commersonia echinata Forst. (Zie No. 106.)

4596. Kioerat S. 二 P I a n t a 0 L. Species diverse. GEbr. (Zie No. 1765$.

4597. Xioeris $\mathrm{S}$. $=\mathrm{Hibiscus}$ grewirefolius $\mathrm{H}$ assk. Nat. fam. der Malvacea Gr. Java; heester

4598. Ki-oeter I. Z Quercus $\mathrm{l}$. neata Pl. (Zie No. 379a.)

4599. Ki-omboet S. 二 L n ffa a cutangula $R \backsim x b$. (Zie No. 2095.)

4600. Ki-ompong $\mathrm{S}$. $=\mathrm{A} \times \mathrm{th} \mathrm{h}$ phyllum ovalifolium Jngh. \& de Vr. Nat. fam. der Araliaceæ Gr. Java en Surnatra; boom

4601. Ki-oraij S. = $a$. Com m e sonia echinata Forst. (Zie No. 106.) 二 b. Grewia tomentosa Juss. (Zie No. 3904.)

\section{2 . Ki-padalie S. of}

4603. Ki-padella $\mathrm{S}$. $=\mathrm{Spathodea}$ gigantea Bl. (Zie No. 4550.)

4604. Ki-padella-lalakki 二 $а$. S pa. thodea gigautea Bl. = b. Spathodea glandulosa Bl. Nat. fam. der Bignoniacex. GR. West-Java; boom.

4605. Ki-pahit $\mathrm{s} .=a . \mathrm{Brucea}$ sumatrana Roxb. (Zie No. 296.) 二 b. Picrasma javan ica Bl. (Zie No. 1372.)

4606. Ki-paho (ki-paö) S. 二 $\mathrm{P}_{0}$ lyosma integrifolia Bl. (Zie No. 423.)

4607. Ki-painjar $\mathrm{s} .=\mathbf{J}$ a $\mathrm{m}$ bos a gl abrat a DC., Nat fam. der Myrtac e æ. Gr. Java; boom.

4608. Ki-pajong $\mathrm{S} .=a$. Scepas. ma buxifolia Bl. (Zie No. 4566b.) = b. Berberis nepaulensis Spreng., Nat. fam. der Berberide $x$; Gr. Java; heester. $=c$. Lithosanthes biflora

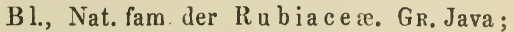
boom.

4609. Ki.pantjar $\mathrm{S} .=\mathrm{Mimusops}$ a c u minat a B 1. (Zie No. 2040.)

4610. Ki.pagpanka S. 二 Otophora a $m \propto n$ a B l. (Zie No. 4313.)

4611. Ki-parahoe $\mathrm{S} .=\mathrm{X}$ antho. phyllum Roxb.

$4612 \mathrm{Ki}$-paranga $\mathrm{S} .=$ Cycloste. mon longifolium Bl. Nat. fam. der E u phor b i c e re. Gr. Java; boom.

4613. Ki-pareh $\mathrm{S}_{.}=\alpha$. $\mathrm{B}$ ๓m meria nivea Gaud. (Zie No. 2387.) $=$ b. I, e$\mathrm{p}$ is a $\mathrm{nthes}$ montan a Bl. (Zie No. $4520 a.)=c$. M elanthes a virgata Bl. (Zie No. 4008.) $=d$. Glochidion gla uc um Bl. en $=e$. Gl. molle Bl., Nat. fam. der Euphorbiaceæ. Gr. Java; boomen. GEBR. Men bezigt het hout voor huisbouw, doch het is niet duurzaam.

4614. Ki-pareh-awehweh S. = Glo. chidion rubrum Bl. (Zie No. 4571.) 4615. Ki-pareh-ketjil M. of

4616. Ki-pareh-leutiek $\mathrm{S}$. $=\mathrm{Me}$ lanthesa rubra Bl., Nat. fam. der Euphorbi a ceæ. Gr. Java; heester.

4617. Xi-pasa $\mathrm{S}$. $=$ Hibiscus vitifolius L. (Zie No. $4064 d$.)

4518. Ki-passan S. \& J $=$ Quer. c ns induta Bl., Nat. fam. der Cupulifere. GR Java; hooge boom. GEBR. Deze boom levert een grof en sterk bouw. hout, dat echter licht door insecten wordt aangetast.

4619. Ki-passan-soesoe J. \& S. = Quercus spicata Smith. Nat. fam. als voren Gr. Java, Sumatra en Borneo. GEBR. Als voren.

4620. $\mathrm{Ki} \cdot$ pedes $\mathrm{S} .=\mathrm{C}$ in $\mathrm{na} \mathrm{mom} \mathrm{um}$ Pseudo-sas safras Bl., Nat. fam. der La urineæ. Gr. Java; boom.

462 L. Ki-pella S. $=a$. Enge lhardtia serrata Bl., (Zie No. $857 d$ ) $=b$. Canarium denticulatum Bl., Nat. fam. der Amyrider. Gr. Java ; Sumatra; hooge boom. $=c$. Canarium Kipella Miq, Nat. fam. als voren. Gr. Java; hooge boom. GrisR. Het harde, witte en grove hout wordt voor huisraad gebezigd, doch de witte mieren tasten het 
gaarne aau. De zaden worden, eren als die der Can. commune L., gegeten.

4622. Ki-petjil $\mathrm{S}$. $=$ Uraria argentea Bl. (Zie No. 573a.)

4623. Ki-peut $\mathrm{S} .=\mathrm{Ci}$ s ampelos

Pareira Lour. (Zie No. 447.)

4624. Ki-pieriet $\mathrm{S}$. $=\mathrm{Buddleia}$ asiatica Lour. (Zie No. 4449.)

4625. Ki-piiet $\mathrm{S} .=\mathrm{M}$ s a virgat a D.C., Nat. fam. der M y r s in eæ. Gr. Java; heester. GEBr. Van deze en andere $\mathbf{M}$ æ sasoorten worden de bladeren tegen graveel gegeten.

4626. $\mathrm{Ki}$-piiet-beurriet $\mathrm{S} .=a$. Mæsa Blumei Don. en $=b$. Mæsa mollissima D.C., Nat. fam. als voren. Gr. Java; heesters. Gebr. Als hiervoren. $=c . \mathrm{C}$ atha montana Hassk. (Zie No. 3410.)=d$. Celastrus alpestris $\mathrm{Bl}$; Nat. fam. der Celastriner. Gr. Java, heester.

4627. Ki-pilet-djongoet $\mathrm{S} .=\alpha$. M æs a virgat a D.C. (Zie No. 4625 .) b. M æ s a me mbra uace a D.C., Nat. fam. der M y r s i n e æ. Gr. Java; heester. Gebr. Als No. 4625.)

4628. Ki-piiet-lumboet $\mathrm{S} .=\mathrm{M}$ æs a la t if o li a D.C., Nat. fam., Gr. en Gebr. als de vorige plant.

4629. Ki-pinang $\mathrm{S}$. $=\mathrm{M}$ e m e c ylon laurifolium $\mathrm{N}$ aud. \& a liæ Spec. (Zie No. 4413c.)

4630. Bi-poèak S. = Eng el hard ti a serrata Bl. (Zie No. 857 d.)

4631. Ki-poetri S. $=a \mathrm{Podoc}$ al. pus Rumphii Bl. (Zie No. 39b.) $=6$. Podocarpus cupressina R. Br. (Zie No. 2820.) c. Podocarpus discolor Bl. en $=d$. $\mathrm{P}$ od. polystac h y a R. Br., Nat. fam, der $\mathrm{P}$ o d o c a $\mathrm{r}$ p e æ. Gr. Java; boomen. GeBr. Het hout dezer boomen is fijn, week, niet zeer sterk, doch wordt voor bouwhout en huisraad gebezigd.

4632. Ki-poetri-awehweh S. 二 $a$. Podocarpus bracteata Bl. (Zie No. $39 a.)=b$. Podocarpus amara Bl. (Zie No. $3366 a$ )

4633. Ki-poetri-lalakki $\mathrm{S}$. $=\mathrm{P}_{0}$ docarpus cupressina R. Br. (Zie No. 2820.)

4634. Ki-poik S. = a. Pitheco. lobium clypearia Benth. (Zie No. 3115 .) $=b$. Pithecolobium montanum Benth. (Zie No. 44436.)

4635. Ki-poik-ketjil M. of Ki-leutik S. = Pithecolobium an- gulatum Benth. (Zie No. 19916.) 4636. Ki-pöol S. = $\mathrm{G}_{0}$ mp $\mathrm{po}$ st emma phlomoides Benth., Nat. fam. der Labiatæ. Gr. Java; kleine heester.

463\%. Ki-pores $\mathrm{S}$. 三 Sola un ardisioides Bl., Nat, fam. der Solanex. Gr. Java; kleine heester.

4638. Ki-radjoen $\mathrm{S} .=\mathrm{P}$ a r a tr 0 pia scandens Miq. Nat. fam. der Ara. liaceæ. Gr. Java. Gebr. Het sap van dezen heester bezigt men uit- en inwendig tegen aandoeningen van het tandvleesch, en geeft het ook aan kinderen als wormdrijvend middel.

4639. Kira-kira $\mathrm{M} .=\mathrm{X}$ ylocar. pus Granatum Kœuig. (Zie No. 1319.)

4640. Kira-raweh S. = M u c una prurita Hook. (Zie No. 1699. )

4641. Kirahut-bandang S. 三 R hynchospermum verticillatumRnwd. Nat. fam. der Compositr. Gr. Jara; overblijvend.

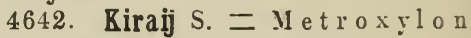
Sagus Rottb. (Zie No. 1322.)

4643. Kiraij-karbau-badoeri M. = Metroxylon Rumphi Mart. (Zie No. 279.)

4644. Kiraij-keboh S. = a. M e. troxylon Sagus Rottb. (Zie No. 1322.) $=$ b. M etroxylon hermaphroditum Hassk. Nat. fam. der Palmær. Gr. Java; hooge palm. Gebr. Als No. 1322, waarvan deze een rerscheidenheid schijnt te zijn.

4645. Kiraij-keboh-mienjak S. = Metroxylon lære llart. Nat. fam. dezelfde. Gr. Java. GeBr. (Zie voıig No.) 4646. Kiraij-keboh-tjaringnaho $b$. 二 een variëteit der vorige.

4647. Kiraij-keboh-tjoetjoek S. = Metroxylon Rumphi Mart. (Zie No. 279.)

4648. Kiramboetan S. cu

4649. Kiramboetan-oetan S. = Xerospermum Noronhianum Bl. (Zie No. 2286.)

4650. Ki-rantja $\mathrm{S} .=a \cdot \mathrm{C}_{\text {yano- }}$ daphne cuneata Bl. (Zie No. 1880.) $=6$. Viburnum sundaicum Miq. (Zie No. 4301.) $=c$. Phœbe macrophylla Bl. Nat fam. der Laurineæ. GR. Java; hooge boom. GEBR, Het sterke, fijne en roode lout ran dezen zwaren boom is zeer geschikt voor huisbouw en meabelen. $=d$. Alseodaphne excel- 
s a B1. Nat. fam. als roren. Gr. Java: boom. GEBR. l)eze boom levert een sterk, rood bouwhout.

46ว 1. Ki-rappat S. = $a$. Talauma mutabilis Bl Nat. fam. derMagn oli a c eæ. Gr. Java, Sumatra en elders; beester. GEBR. Het hout van dezen heester bezigt men voor spinnewielen; de bloemen zijn om haren geur zeer gezocht. 二 b. Talauma Candollei B l. Nat. fam. dezelfde. Gr. Java, veelal in tuinen; heester. GEвR. Men plant dezen heester veelal in omheiningen, omdat hij nimmer behoeft gesnoeid te worden, doch ook vooral om de bloemen, welke de vrouwen, wegens den aangenamen geur, gaarne in het haar dragen en tusschen de kleederen leggen.

4652. Ki-rarauntho $\mathrm{S}$. 三 $\mathrm{A} \mathrm{d} \mathrm{h} \mathrm{a-}$ toda vasica Nees (Zie No. 1304a)

46.53. Kiras Cer. = $\mathbf{G}$ a r c in i a celebic a Dc. Nat. fam. der Clusiac e r. Gr. Java; boum. Gebr. De vruchten worden gegeten, en de vruchtschillen gebruikt men even als die der $\mathbf{G}$ a r c inia $M$ \& $\|$ gostana I.

4654. Ki.rawaij S. $=a$. Uro. stigma ha matocarpu m Miq. (Zie No. $1875 c$.) $=$ b. Acaly pha Caturus Bl (Zie No. 22916)

46วั. Ki-rendang $\mathrm{S}$. $=a$. P a r atropia aromatica Miq. Nat. fam. der Ar a li a ceæ. Gr. Java; kleine boom. 二 b. Ostodes paniculata Bl. Nat. fam. der Euphorbiacer. Gr Java; boom. = $c$. Croton argyratum Bl. (Zie No. $3647 a.)=d$. Stillingia sebifera W1ld. (Zie No 3887.)

4656. Ki-rihadoe S. = Memecylon umbellatum Bl. (Zie No. 3043a.) 4657. Ki-ribigit S. of

4658. Ki.ringit $\mathrm{S}$. $=$ Weinmanuia Blumei Planch. Nat. fam. der Cunoniaceæ. Gr. Java: boom.

4659. Ki-rintjong $\mathrm{S} .=a . \mathrm{Nel}$ tris myrsinoides Bl. en $=b$. Nel. paryiflor a Bl. Nat. fam. der $\mathbf{M y r t a}$. ce $x$. Gr. Java ell Sumatra; heesters.

4660. Kirman I. 三 Duchesnea su ndaica Mi q Nat. fam. der Rosaсе æ. Gr. Java; heester GFBr. De bessen van dezen heester worden door sommigen gegeter.

4661. Ki.roehak S. = Stylocoryna laxiflora Bl. (Zie No. 4430 a.)

4662. Kisambie S. Z Schleicher a trijuga Wlld. (Zie No. 47.)

4f63. Ki-sampang $\mathrm{S} .=a$. Evo- dia glabra Bl. \& alix. Nat. fam. der Diosmeæ. Gr. Java; boom. GËr. Het fraaie, witte hout van dezen boom bezigt men voor huisbouw; de bladeren legt men op schurft en op wonden van paarden. 二 $b$. Zanthoxylu m aromaticum Mi q Nat. fam. der Di osmex. Gr. Java; boom. = c. Zanthoxylu m zeylanicum Bl. (Zie No. 3896.) = d. Berrya A m monilla Bl. Nat. fam. der Tiliace $æ$. Gr. Java; hooge boom. GEBR. Het lichte hout van dezen boom bezigt men op Java voor huisbouw en in Britsch-Indië voor prauwen, mass o olabo ats genaamd.

4664. Ki-sampang-goenong S. = Wendlandia densiflora Dc. (Zie No. $4565 e$ )

4665. Ki-sampie S. = Lei oc a $\mathrm{l}$. pus arboreus Bl. (Zie No. 1134.)

4666. Ki-samplak $\mathrm{S}$. $=\mathrm{Ardisia}$ speciosa Bl. (Zie No. 27396.)

4667. Ki-sangat $\mathrm{S}$. = Premna pubescens Bl. Nat. fam. der Verben a cer. Gr Java; heester.

4668. Ki-saöen S. 二 Tetracera rigid a B l. (Zie No. 146.)

4669. Ki.saör S. 二 Polyos m a integrifolia Bl. (Zie No. 423.)

4670. Ki-sapi S. 三 Gordonia excelsa Bl. (Zie No. 2531.)

4671. Ki-sapi-bener S. $=\mathrm{Hym} \mathrm{e-}$ $n$ ז a verucosa L. (Zie No. 3411.)

4672. Ki-sariawan S. 二 Sy m plocos odoratissima Chois., Nat. fam. der Sy mploceæ. Gr. Java; hooge boom. GEBr. Deze levert een sterk en deugdzaam timmerhout. 1)en bast geeft men in af kooksel tegen spruw en scheurbuik. De bladeren worden rauw en afgeknokt gegeten door kraamvrouwen, tot bevordering der kraamzuivering.

4673. Ki-sarira $\mathrm{S}$. = A crou $\mathrm{y}$ chi a arborea B l., Nat. fam. der 1) iosm e r. Gr. Java; hooge boom.

4674. Ki-sauchu $\mathrm{S} .=\alpha$. Gua tteria macrophylla Bl. (Zie No. 1548.) $=b$. Guat teria l a teriflora Bl. =c. Mitrophora obtusa $\mathrm{B} !$. $=d$. Orophea hexandra Bl. $=e$. Stelechocarpus? montana Bl. $=t$. Unona virgata Bl. en $=g$. Uvaria r ugosa Bl., alle boo. men of heesters, behoorende tot de Nat. fam. der A n o n a c e gr Gava.

4675. Ki-sauchun-hiedung $\mathrm{S} .=\mathrm{M}$. trephora obtusa $\mathrm{Bl}$ (Zie vorig $\mathrm{No}$.) 
46i6. Ki-sauchun-lalakki $\mathrm{S}=a$. Mitrephora obtusa Bl. = $b$. Orophea corymbosa Bl., Nat. fam. der An on a c ex. Gr. Java; heester. 4677. Ki-seggel $\mathrm{S} .=\mathrm{W}$ ormia excels a Bl. (Zie No. 2283.)

4678. Ki-sehreh $\mathrm{S} .=\mathrm{C}$ in n a m 0 mum Pseud o-s assafras $M$ eisn. (Zie No, 4620 .)

4679. Ki-sehür S. $=a_{\text {. }} \mathrm{A} \mathrm{n}$ ti des. m a mon t a n m Bl. (Zie No. 2888.) b. Antidesma velutinosum Bl., Nat. fam. der A n ti desmer. Gr. Java; boom.

4680. Ki-sehür-badak S. = A n ti. desma stipula re B l., Nat. fam als voren. Gr. Java; boom. Gebr. Het fraaie, gele hout is zeer sterk en deugdzaam, en zeer geschikt voor huisbouw en meubelen.

4681. Ki-sehür-bener $\mathrm{S} .=\mathrm{A} \mathrm{n} \mathrm{ti}$. de sma tetrandrum B l., Nat. fam. als roren. Gr. Java; boom.

4682. Ke-sehür-dioek $\mathrm{S} .=\mathrm{A}$ n t idesma littorale Bl (?). Nat. fam. als voren (?). $G_{R}$. Noesa.Kembangan; boom.

4683. Ki-sehür-monjet $\mathrm{S} .=\alpha$. Antidesma oblong if olium Bl., Nat. fam. dezelfde. GR. Java; boom. = b. Antidesma velutinosum $\mathrm{Bl}$. (Zie No. 4679b.) =c. Galearia sesslis Z. \& M. (Zie No. 919.)

4684. Ri-sekkel S. $=\operatorname{Pr}$ in os c $y$ mosa Hassk. (Zie No. 3810.)

4695. Ki-sekking S. = Grumilea a u r a ti a c a M iq. (Zie No. 4273.)

4686. Ki-semoet $\mathrm{S} .=a . \mathrm{J}$ a m b 0 $\mathrm{sa}$ a c u minatissima $\mathrm{H}$ ass $\mathrm{s}$. (Zie No. $3043 \alpha$.) $=$ b. J a m bos a densilora D.C. (Zie No. 1921.) $=c$. J a m b. line at a D.C. (Zie No. $3013 c$.) $=d$. Syzy gi m pyrifoliu m D.C., Nat. fam. der M y rtaceæ. Gr. Java; boom. $=e$. Streblus aspera Lour. (Zie No. 313.) $=f$. Erycibe glomer a t a B l., Nat. fam. der Ery c i b e GR. Java; slingerplant.

4687. Ki-sengat S. =a. A paristh. mi um javense Endl. (Zie No. 439lf.) $=b$. Guatteria littoralis Bl. (Zie No. 45 11.)

4688. Ki-serili $\mathrm{S} .=\mathrm{M}$ a r l e a to$m$ entos a Endl. (Zie No. 4552c.)

4689. Ki-seroet $\mathrm{S} .=\mathrm{Streblus}$ a s p e ra L o u r. (Zie No. 313.)

4690. Ki-serogol S. $=a$. A n tidesma oblongifoliam. (Zie No.
4683.) $=$ b. Tarrietia javanica B l. (Zie No. 4563.)

4691. Ki-seroh S. $=a$. L o n i c e r a Desf. Species divers $x .=b . C l a$. oxy 1 on min us Endl., Nat. fam. der Eu phor bi a c e r. Gr. Java; heester. $=c$. Prinos cymos a $\mathrm{Hassk}$. (Zie No. 3810.$)=d$. Prinos sicata Miq. Nat. fam. der Il i c i n eæ. Gr. Java; heester.

4692. Ki-sero $\mathrm{S} .=\mathrm{P}$ ol y o s m a velutina Bl. (Zie No. 4482.)

4693. Ki-seueur S. (Zie Ki-sehur S.) 4694. Ki-sieoeng $\mathrm{S} .=\mathrm{B}$ e r g s m i a $\mathrm{j}$ a va nic a Bl., Nat. fam. der Flac o u r ti a neæ. Gr. Java; hooge boom. 4695. Ki-sierum S (Zie Ki-semoet S.) 4696. $\mathrm{Ki}$-sierum-lumboet $\mathrm{S} .=\mathrm{E} \mathrm{u}$ ge n i a minima Bl., Nat. fam. der II y r a c e æ. GR. Jara ea Sumatra; heester.

4697. Ki-sigoeng $\mathrm{S} .=a . \mathrm{E} \mathrm{ch} \mathrm{i}$ noc arpus Sigun B l. (Zie No. 1101.) $=b$. Dysoxy lum alliace u Bl. (Zie No. 3212.)

4693. Ki-sikop $\mathrm{S}_{0}=\mathrm{M}$ o n o c e r a s ob t usu m Hassk. (Zie No. 289i $f$.) 4699. Ki-singhoep $\mathrm{S}$. $=\mathrm{Cl}$ e r 0 d endrum villosum Bl. (Zie No. 4144f.)

4700. Ki-sioe-gedeh $\mathrm{S}$. $=\mathrm{C}$ is su $\mathrm{s}$ thyrsiflora Bl. (Zie No. 542.)

4701. Ki-sirum S. = Stylocoryne hirsuta Bl., Nat. fam. der R u b i a c e æ. Gr. Java; heester.

4702. Ki-sojon $\mathrm{S}$. $=\mathrm{J}$ a m bos a melanosticta Bl., Nat. fam. der M y r t a c e æ. GR. Java; boom

4703. Ki-sokka $\mathrm{S} .=a$. P a rin a. rium glaberimum $\mathrm{H}$ assk. en $=$ b. Parin. scabrum Hassk., Nat. fam. der Chry s o b a l a u e æ. Gr. Java; boomen. Grir. Het witte, grove en sterke hout dient voor huisbouw en wordt niet door insekten aungetast. $=c . \mathrm{Cy}$ clos . temon longifolium B l. (Zie No. 4612.)=d$. S a r a c a ind i c L L. (Zie No. 1842.$)=e$. S a r a c a d e clin a t a $\mathrm{J}$ a ck en $=f$. S a r a c a minor Z $\mathrm{Z}$ lll., Nat. fam. der P a pili on a c e æ. Gr. Java en Sumatra; boomen.

4704. Ki-soka-gedeh $\mathrm{S}$. $=\mathrm{P}$ a $\vee$ e t't a a r b ore scens H a s sk., Nat. fam. der $\mathrm{R} \mathrm{u}$ bi a c e æ. Gr. Java; boom. 4705. Ki-sokka-kembang $\mathrm{S}$. = $\mathrm{P}$ avet t a L. speciesdivers 4706. Ki-sokka-lalakki S. = Cy. 
clostenion macrophyllum Bl. (Zie No. 126弓.)

4707. Ki-sokka-poetih $\mathrm{M}=\mathrm{Pa}$ vetta incarnata Bl. (Zie No. 1997a.) 4708. Ki-soör S., zie ki-sehür S.

4709. Ki-saor $\mathrm{S}=\mathrm{Poly}$ os ma integrifolia Bl. (Zie No, 423.)

4709a. Ki-surrielie $\mathrm{S}$. $=\mathrm{M}$ a rle a tomentos a Endl. (Zie No. 4552c.)

4710. Ki-taai $\mathrm{S} .=a . \quad \mathrm{Premna}$ corymbosa Rottl (Zie No. 395.) $=b$. Premna fotida Rwdt. (Zie No. $1 \tau 226.)=c$. Premna integrifolia L. (Zie No 2573.) $=d$. Saprosma arboreum Bl. (Zie No. 3154d.) $=e$. Celtis reticulosa Miq. Nat. fam. der Celtider Gr. Java; hooge boom.

471l. Ki-takki S. = Albizzia to. mentella Miq. Nat. fam. der Mimose æ. Gr. Java en Sumatra; boom.

4712. Ki-talang-boeloe $\mathrm{S} .=a . \mathrm{La}$ sianthus attenuatus Jack. en $=b$. Las. in æqualis Bl. Nat. fam. der Rub iaceæ. Gr. Java, Sumatra en Borneo; heesters.

47 3 . Ki-tallus $\mathrm{S} .=a$. Phabe declinat a Nees. (Zie No. 2913a.) = b. Phœbe macrophylla Bl. (Zie No. $4650 c$.) $=c$. Phœbe multiflora Bl. Nat. fam. der Lauriner. Gr. Java; hooge boom. $=d$ dlseodaphne excels a Bl. (Zie No $4650 d$.) $=e$. Acti. nodaphne glomerata Nees. (Zie No. $290 \%$.) $=$ (. Gla blaria vestita Miq. (Zie No.29l6e.) Gebr. De meeste La u r u ssuorten, die kitallus genoemd wordell, leveren een rood en sterk bouwhout, dat niet door witte mieren wordt aangetast.

4714. Ki-tallus-badak S $=\mathrm{Ph} \propto b \mathrm{e}$ cuneata Bl Nat. fam. der Laurinex. GR. Java; hooge boom.

4715. Ki-tallus.bedas $\mathrm{S} .=\mathrm{Gla}$ brariavestita Nliq. (Zie No. 2916e.)

4716 Ki-tallus-bener $\mathrm{S} .=\mathrm{Ph}$ he cuneata Bl. (Zi: No. 4714.j)

4717. Kï-tallus-boddas $\mathrm{S} .=a$.

Phobe cuneata Bl. = b. Polyadenia grandis Nees. Nat. fam. der Lauriner. Gr. Java; boom.

4718. Ki-tallus-gedeh $\mathrm{S}$. $=\mathrm{Poly}$ adenia gemmiflora Nees. (Zie No. $2899 d$.)

4719. Ki-tallus-merang $\mathrm{S} .=\mathrm{Ph}$ -

be $n \mathrm{mb}$ elliflora Nees. (Zie No. 4568 .)

4720. Ki-tallus-kirandjah S. en

4721. Ki-tallus-songong S. $=\mathrm{Ph} \propto$ b e macrophylla Nees. (Zie No, $4650 c$.)
4722. Ki-tambaga s. 二 $a$. Meme. cylon costatum Miq. (Zie No. 4413a.) 三 . Jambosa densiflora Dc. (Zie No. 1921$)=c$. Jambos a cerasiformis Hassk. Nat. fam. der $\mathbf{M}$ yrtaceæ. Gr. Java; boom. = d. Syzygium caryophyllifolium Dc. (Zie No. 1910.) $=e$. Sysygin pyrifolium. Dc. (Zie No. 4636d.) = f. S yzygium rostratum Dc. Nat. fam. der Myrtaces Gr. Java; hooge boom. = g.Cariophyllus fastigiatus Bl. (Zie No. 2544.) $=h$. Caryophilus flo. ribundus B l. Nat. fam. der Myrtaceæ. Gr. Java; hooge boom

4723. Ki-tamia S. = Disporum multiflorum G. Don. (Zie No. 1137.)

4724. Ki-tamiang $\mathrm{S}=\alpha$. S.ponia a mboinensis Desn. Nat. fam. der Celtideæ Gr. Java en de Molukken; boom. $=6$. Styrax javanicum Bl. groote heester. en $=c$. Styrax villosum Bl. Nat. fam. der Styraceæ. Gr. Java.

4725. Ki-tamiang-gedeh S. 二 Podocarpus latifolia Wall. (Zie No. 3366b.)

4726. Ki.tana $\mathrm{S}$. $=\mathrm{Z}$ anthoxy. lum Rhetza Dc. Nat fam. der $\mathrm{Z}$ a $n$. thoxyleæ. Gr. Java; hooge boom.

4\%2\%. Ki tandoh $\mathrm{S},=\mathrm{IT}$ e n d l a ndia densiflora DC. (Zie No 456 4728. Ki-tangkil $\mathrm{S}=\mathrm{G}$ netu $\mathrm{m}$ Gnemom L. (Zie No. 820.)

4729. Ki-tapang R. = Callicarpa lo $n$ gifolia Lam. (Zie No. 4020b.)

4730. Ki-tapog S. = Desmodium capitatum R. Br. (Zie No. 4284.)

4731. Ri-tarrietie $\mathrm{S}$. $=\mathrm{T}$ arietia jaran ica Bl (Zie No. 4563.)

4732. Ki-tegoe S. = Picrasma jaranica Bl. (Zie No. 43726)

4733. Ki-tehdja S. 三 $a . \mathrm{Kibessia}$ azurea DC. (Zie No. 1105.) =b. Ci inamomum iners $R$ wdt. (Zie No 2925.) $=c$. Cinnamomum nitidum Nees. Nat. fam. der L a u rin ex. Gr. Java; boom. GEBR. Men drinkt een aftreksel vau den bast en der bladeren bij hitte des lichaams, tegen koortsen. $=d$. Caryodaphue densiflora B l. (Zie No. 2913c.)

4734. Ki-tehrong $\mathrm{S}$. $a$ Alsodeia javanica Endl. Nat. fam. der Violacex. Gr. Java; heester. Gebr. $\mathrm{De}$ wortels worden met witte peper te zamen fijngestampt en daarmede wrijft men de kinderen in, om hunne huid fraai wit 
te maken. De fijngewreven bladeren neemt men in tegen buikloop. $=b . \mathrm{F}$ agræa littoralis Bl. (Zie No. 4255.) $=c$. Fagræa obovata Wall. (Zie No. 1084.) $=d$. Fagræa oxyphylla Miq. Nat. fam. der Loganiaceæ; Gr. Java en Sumatra; heester; soms parasitisch.

4735. Ei-tehrong-badak S. = Fagræa a uriculat a Jack. (Zie No 2327.)

4736. Ki-telong $\mathrm{S} .=a$. Gonio$s$ t o m a hæmatos permum Lind l. Nat. fam. der Loganiaceæ. Gr. Java, Sumatra; heester. $=b$. I a sianthus attenuatus Jack. (Zie No. 4712.) $=c$. Lasianthns hexandrus Bl. Nat. fam. der Rubiaceæ. Gr. Java; heester.

4737. Ki-telor S. \& M. = $a \mathrm{X}$ anthophyllum excelsum Bl. en $=b$. $\mathrm{X}$ anth. vitellinum Bl. (Zie No. 4585.) $=c$. Salacia prinoides D.C. (Zie No. 588 .)

4738. Ki-tenga $\mathrm{S} .=\mathrm{C}$ a $\mathrm{n}$ a ri u m Kitenga Iliq., Nat. fam. der Amyrider. Gr. Java; hooge boom.

4739. Ki-tespong $\mathrm{S}$. = Abrom a a u gusta I. (Zie No. 4480.)

4740. Ki-tetjangkier S. $=\mathrm{A}$ broma a ugusta I. (Zie No. 4480.)

4741. Ki-tikoekoer S. = Polyo$z$ us a cuminata Bl. (Zie No. 43786.)

4742. Ki-tipies-koelit $\mathrm{S}$. = Syz ygium costatum Miq., Nat fam. der Ilyrtaceæ. Gr. Java; boon.

4743. Ki-tiwoe $\mathrm{S}$. $=a$. Meliosma lanceolata Bl. (Zie No. 3171.)

$=$ b. Meliosma angulata Bl. = c. $M$ el. floribunda Bl. en $=d$. Mel. simplicifolia Endl., alle van de Nat. fam. der Meliosmea. Gr. Java, Sumatra, Borneo; boomen of groote heesters. GEBr. Het hout der Melios ma-soorten is grof, rood, doch zeer week; wordt spoedig door insekten verteerd en alleen voor huisraad gebruikt

4744. Ki-tiwoe-bener $\mathrm{S} .=a . \mathrm{M} \mathrm{e}$. liosma lance ol ata Bl. (Zie No.31\%l.) $=$ b. Mel. ferruginea Bl. Nat. fam. als vuren. Gk. Java, Borneo; boom.

4745. Ki-tiwoe-boeloe S.

4746. Ki-tiwoe-lalakki S. en

4747. Ki-tiwoe-pesawon S. $=\mathrm{Me}-$ liosma lanceolata Bl. (Zie No. 3171.)

4748. Ki-tiwoe-landoek S. $=\mathrm{Me}$ liosma nitida Bl. (Zie No. 3440.)

4749. Ki-tjaäng $\mathrm{S} .=a \cdot \mathrm{Pith}$ colobium fagifoliam Bl. en $=b$. Pith. fasciculatum Benth., Nat. fam. der Ml inusex. Gr. Java en Borneo; $a$. heester, $b$. boom. $=c$. Picrasmajavanica Bl. (Zie No. 4372b.) = d. Stereosperm um chelonoides DC. Nat. fam. der Bignoniacer. Gr. Java ; boom.

4750. Ki-tjaäng-aroij $\mathrm{S}$. $=\mathrm{C}$ onnarus L. diversa. $=b$. Erythrostigma diversifolia Hassk. (Zie No. 583.)

4751. Ki-tjabeh S. =a. Euchresta Horsfieldii Bnnt. (Zie No. 4396d.) $=b$. Eurya glabra Bl. (Zie No. 3155.) $=c$. Eurya serrata B l. Nat. fam. der Ternstromiaceæ. GR Java; boom. Gebr. (Zie No. 3155.)

4752. Ki-tjala $\mathrm{S}$. = Memecylon costatum Miq. (Zie No. 4413a)

4753. Ki-tjalietrie $\mathrm{S}$. $=$ Antidesma Brm.

4754. Ki-tjalikket $\mathrm{S}$. = Antidesma heterophyllum Bl. iZie No. $4367 a$ )

4755. Bi-tjaloeng $\mathrm{S} .=a$. Psendotrewia macrophylla 11 iq., Nat. fam. der Enphorbiacea. Gr. Java en. Bali; boom. = $b$ l) iospyros macrophylla Bl., Nat. fam. der Ebenaceæ. Gr. Java; hooge en zware boom. GelsR. Het sterke, fijne en roode hout wordt niet door insekten aangetast en is bijzonder geschikt voor bouw- en meubelhout.

4756 . Ki-tjaloeng-aroij $\mathrm{S} .=a \cdot \mathrm{Gy}-$ nopachys acumiuata Bl. (Zie No. $699 e)=b$. Combretum trifoliatun Vent. (Zie No. 198.) $=c$. Embryogouia lucida Bl., Nat. fam. der Combretaceæ. GR. Java; slingerplant.

4757. Ki-tjambang-badak S. $=\mathrm{Mle}$ mecylon excelsum Bl. (Zie No. 4412.).

4758. Ki-tjambeh S. $=$ Memecylon laurifoliu in Naud. (Zie No. $4413 c$.)

4759. Bi-tjandana $S .=$ Glycosmis pentaphylla Culebr. (Zis: No. 1148 .) $=$ b. Glycosmis simplicifoli a Sprg., Nat. fam der A u ranliaceæ. Gr. Java; heester. Gebr Men brandt de bladeren tot asch, mengt deze inet olie en. smeert dit in op schurft.

4760. Ki-tjangkeh S. en

4761. Ki-tjangkeh-goenong $\mathrm{S}$. $=$ Urophyllum glabrum Jack. en. W a ll.. Nat. fam. per Rubiac зæ. Gr. Java, Sumatra, Borneo; heester.

4762. Ki-tjangkoedan $\mathrm{S} .=\mathrm{Odi}$ na gummifera Bl. (Zie No. 1990.). 
4763. Ki-tjangkoedoe $\mathrm{S} .=\mathrm{F}$ agriea volubilis Wall (Zie No. 975.)

4764. Ki-tjangkoerang $\mathrm{S} .=a$. Arthrophyllum Bluneanum Z. en M. (Zie No. 1973.) = b. A rthrophyllum diversifolium Bl. (Zie No $4464 b.)=c$. Trevesia sundaic a Miq. (Zie No. 4404c.)

476 כ. Ki tjangtoeng-aroij S. $=a$. Habzelia? acuta Miq. (Zie No. 585.) $=b$. Melodorum Kentii Hook,, Nat. fam. der A nonacer. Gr. Java; slingerplant. $=c$. Oxymitra cuneiformis Bl. (Zie No.4418.) = $d$. Oxymitra latifolia $\mathrm{Hk}$ fs. \& L. Nat. fam. dezelfde. Gr. Java: slingerplaut.

$=e$. Polyalthia elliptica Bl. Nat. fam. \& Gr. als voren; heester. = $t$. Uva. ria macrophylla $R \times b$, Nat. fam. dezelfde. Gr. Java; slingerplant. Gebr. De bast en de bladeren der sub. 4767 en 476 כ vootkomende $\mathrm{An}$ on ace æ worden dikwijls door niet-zwangere vrouwen gegeten, wanneer zij een onaangenaam gevoel in den buik hebben. Den bast bezigt wen tot het zwartierven van garens en kleedingstukken

4.766. Ki-tjanting S. = $\mathrm{Picr}$ a sma javanica Bl., (Zie No. 4372b.)

4767. Ki-tjantoeng $\mathrm{S} .=d$. $\mathrm{P}$ olyalthia subcordata Bl. (Zie No. 915.) $=b$. Polyalthi a molli s Z. en M. Nat. fam. Uer A 11 o nac с æ. GR. Java; boom.

4768. Ki-tjapie S. = E 1 æ о c a rpus L. S pecies divers a (Zie No. 2612)

4769. Ki-tjarang-aroij S. = $\mathrm{C}_{\mathrm{on}}$ narus Hasseltii Bl. (Zie No. 586.)

4770. Ki-tjarirang $\mathrm{S}$. $=\mathrm{E}_{\mathrm{p} \mathrm{i} \mathrm{ch} \mathrm{a}}$. $r$ is? altis i m a Bl. (Zie No. 3823b.)

4771. Ki-tjaroeloek $\mathrm{S}$ = $\mathrm{Ca} \mathrm{n}^{-}$ thium glabrum Bl. (Zie No. 4502c.)

4772. Ki-tjatjangkier S. $=\mathrm{A} \mathrm{bro-}$ $m$ a a u g u st a J. (Zic No. 4480)

4773. Ki-tjauw $\mathrm{S}$. $=\mathrm{P}$ is onia excelsa Bl, Nat. fam. der Nyc tag in eæ. Gr. Java; hooge boom met grof en wit hout, doch bijzonder week, eren als dat van kajoe-gaboes.

4774. Ki-tjehai S. = Turpinia s p h æ r o c a r p a Hassk. (Zi. No. 994.)

4775. Ki-tjolang-aroij S. $=$ G ynopachys acuminata B L. (Zie No. $699 e$.

4776. Ki-tjengkeh $\mathrm{S}$. 二 $\mathrm{L}$ a si a nthus lævigat us B l. Nat. fam. der
R u b i a c e s. Gr. Java; heester. Gebr. Men eet het jonge loof als groente bij de rijst.

4777. Ki-tjepot S. = M elodor u m Kentii H ook. (Zie No. 4765 b.)

4778. Ki-tjerlang $\mathrm{S}$. $=\mathrm{P}$ terospermu $\mathrm{d}$ iversifoli umBl. Nat. fam. der $\boldsymbol{b}$ ü t $t$ n e ri a ce æ. Gr. Java, Celebes; hooge boom. Gebr. Deze levert een grof, doch geschikt bouwhout.

4779. Bi-tjiat $\mathrm{S}$. $=\mathrm{C}$ ovelli a l e ucople ura Mi g. Nat. fam. der A r t o c a r p e æ. Gr. Java; heester. Gebr. Men druppelt het melksap in de ooren tegen doof heid.

4780. Ki-tjileijouw $\mathrm{S}$, = Eriogloss um e dule Bl. (Zie No. 3580 ) 4781. Ki-tjilibadak $\mathrm{S}$. = Ficus pelt a t a B l., Nat. fam. der A r to carp e æ. Gr Java; boom.

4782. Ki-tjitap $\mathrm{S}$. $=\mathrm{Picrasma}$ javan i c a B l. (Zie No. 4372b.)

478:3. Ki-tjongtjorang S. 三 a $\mathrm{Do}_{0}$ donæa angustifolia Blanco. (Zie No. 2218.) = b. Pterolom a triquetrum Bent h. (Zie No. 4000.)

4784. Ki-toeä S. 二 K i b a r a co$r$ i a c e a $\mathrm{End}$ l.

4785. Ki-toeàk S. 二 $a$. C a n a r iopsis his pid a B l. (Zie No. 1249.) = b. C a n a ri u Kipell a Miq,, (Zie No. $4621 c$.) $=c$. $\mathrm{Parinarium} 0$ ry m bos um Miq., Nat. fam. del Ch rysobal a n e . Gr. Java; boom. $=d$. Parinarium multiflor um M i q., (Zie No. 132la.)

4786. Ki-toel S. = Covellia st i ct o c a r p a Ni q., (Zie No. 1573d) 4787. Ki-toelang $\mathrm{S}$. = $\mathrm{Campelia}$ gl a brata K anth. (Zie No. 4014.) 4788. Ki-toelang gedeh $\mathrm{S} .=a$. Polyalthia elliptica Bl. (Zie No. $4765 e$.) $=b . \mathrm{X}$ anthophy $11 \mathrm{um}$ excelsum B l. (Zie No. $4585 a$.)

4i89. Ki-toeloengkal S. = P ol yg a la ve u en os a Juss, (Zie No. 4029.) 4790. Ki-toembilah $\mathrm{S} .=\mathrm{P}_{\mathrm{y}}$ g x u m p a r vifl or um T. \& B. (Zie No. $4066 d$.)

4791. Ki-toengila $\mathrm{S}$. = M y r i sti c a gl a bra Bl. (Zie No. 3623)

4792. Ki-tokkeh S. en

4793. Ki-tokkeh-sabrang S. = A lbizzia latifolia Boivin, Nat fam. der M i mos e æ. Gr. Java; boom. Grbr. Men gebruikt den bast vall dezen boom bij het baden in plaats van zeep. 
4794. Ki-tollos s. en

4795. Ki-tollos gedeh $\mathrm{s} .=\mathrm{P}_{0}$ $1 \mathrm{y}$ adenia gem m if lura Nees. (Zie No. $2899 d$.)

4796. Bi-tolo eo S. en

4797. Ki-toloeo-bedas S. $=\mathrm{Gla}$ b raria vestit a $\mathrm{Miq}$. (Zie No. 2916c.) 4798. Ki-tongerret $\mathrm{S} .=a \cdot \mathrm{T} \mathrm{e}-$ tranthera resinos a Nees. (Zie No. 2909c.) $=$ b. An a colos a f r ute s cens Bl. Nat. fam. der Ola cac e æ. $\mathrm{Gl}_{k}$ Java ; boom.

4799. Ki-varaunto S. (zie Kirarauntho. S.)

4800. Klabang Bк. = G a r c in i a

$\mathrm{K} l \mathrm{a}$ b a ng $\mathbf{~} \mathrm{i}$ q. (Zie No. 2543.)

4801. Klabang $\mathrm{BK}_{0}=1 . \mathrm{G}$ a r c in i a b ancana II iq., Nat. fam, der Clus i a cer. Gr. Bangka; boom. 三 2. Garcinia c or nea L. (Zie No. 2026)

4802. Klabangan $\mathrm{I}$. = Pothos Horsfieldii lliq., Nat. fam. der O r o n t i a c e æ. Gr. Jara, Celebes; parasiet.

4803. Kladan $\mathrm{Ml}$. $=\mathrm{Kel}$ a $\mathrm{ng}$ so $\mathrm{uw} \mathrm{B}$ o.

4804 Kladie $11 . \&$ I. Colocas i a antiquorum Schott, (Zie No. 24ă.) 480 ว. Kladie-ajer $\mathbf{M} .=a$. Colocasia a ntiquor um S chott, var: nympheæfolia, (Zie No. $2 \pm j$ ) $=b$. Cyrtosperma lasioides Griff, Nat. fam. der Orontiaceæ. Gr. Bangka; overblijvend. $=\varsigma$. Pothos ma. lay a us M iq., Nat. fam. der Aroi. d eæ. Gr. Java en Sumatra; klimplant. $=d$. Aglaonema palustris T. \& B., Nat. fam. der $A$ r o ide $x$. Gr. Sumatra; overblijrend.

4806. Xladie-kandhati M. (Zie No. $4505 a$.)

4807. Kladong $\mathrm{S}$. $=$ Fle urya

in ter r u t a G a ud., (Zie No. 1701.) 4808. Klag0e J. = Petunga $\nabla$ a$\mathrm{riabilis} 11 \mathrm{assk}$. (Zie No. 4317.) 4809. Klajoe S. Eriogloss u m ed ule Bl. (Zie No. 3580.) 4810. Klajoe $e .=$ Allophyllus fulvinervis Bl. (Zie No. $439 \mathrm{l} c$.) 4811. Klakka-sijang $\mathrm{J}$. $=\mathrm{K} æ \mathrm{~m}$ pferia rotunda L. (Zie No. 3576.) 4812. Klampies J. $=a$. A c a c i a le ucophlæa Wlld., Nat. fam. der Mimoser. Gr. Java; hooge boom. Gebr. Deze boom lerert, volgens II a rtius, de Bassoora.gom en, volgens $L$ in d l e ij, de Koetera-gom ran den handel. In Noordelijk Indië zal uit het hout een vergift gedistilleerd worden. $=b . \mathrm{A} \mathrm{c} \mathrm{a} \mathrm{ci} \mathrm{a}$ t o m e n t o s a Wlld., Nat fam. dezelfde Gr. Java; boom.

4813. Klampok I. $=a$. J a in bos a densiflora D.C. (Zie No. 1921) $=b$. Jambosa Klampok Mi !., Nat. fam. der M y rtace æ. Gr. Java; boom.

4814. Blappa J. (Zie k a l a p a M. \& S.)

481ว. Elatjiem Вк. $=\mathrm{Costus}$ s pecio s u S m. (Zie No. 3247.)

4816. Kleedong J. D i os pyros. Melanoxylon R $\leq$ b., Nat. fam. der E b e n a c ex. Gr. Jara; honge boom, die een fraai, zwart hout oplevert.

4817. Kleedong-ketjil J. = D i o spyros frutescens Bl.. Nat. fam. als voren, GR. Java; boom.

4818. Kleho J. = A r dis i a tenuiramis Miq., Nat. fam. der $\mathbf{M} \mathrm{y}$ r sin e æ. Gr. Java; boom.

4819. Klethjo J. = a. M or ing a pterygosperma Gaertn., (Zie No. 4125.)=$ b. I) iospros macrophylla Bl. (Zie No. 475 5.)

4820. Blembong-pahit $\mathrm{BK}$. $=\mathrm{Cle}$ rodendrum villosum Bl. (Zie No. $4144 f$.

4821. Klepang BK. = Adinandra stylos a Miq, Nat. fam. der Ternstrœmiзce e. Gr. Sumatra en Bangka; boomachtig.

4822. Klepies $\mathrm{B}_{\mathrm{K}}=\mathrm{S}$ a ma de $\mathrm{ra}$ ind i c a G a rta., fructus. (Zie No. 2452)

4823. Klepo J. = Na aclea grandifolia D.C. (Zie No. 1870.)

4824. Klimosodo J. = Cordia subcordat a I, au. (Zie No. 10216.)

4825. Klimpar $\mathrm{BK}$. $=\mathrm{E} \mathrm{m} \mathrm{b} \mathrm{e} \mathrm{li} \mathrm{a}$ d a sythyrsa Mi q., Nat. fam. der II y r s i n e. Gr. Bangka; slingerplant. 4826. Klinting J. $=\mathrm{C} \mathrm{li}$ t or i a te $\mathrm{r}$ $n$ a te a L. (Zie No. 1359)

4827. Klinting-baroe of klintingbiroe J. = Schmiedelia racemosa L, Nat. fam. der S a p ind a c c a. Gr. Java; heester. GEBR. De bladeren gebruikt men tot het blauwverwen van kleedingstukken; de zaden worden son:s gegeten. 4828. Klipis $\mathrm{BK}$. $=\mathrm{S}$ a m a d e ra i n d i c a $G æ r$ tn. (Zie No. 2452.)

4829. Klitsji-klitji M, ook 4830. Klitsji-besaar II. ei 4831. Blitsji-laki-laki $11=\mathrm{G}$ u i- 
landiua Bonduc I. \& variett., (Zie No. 1475.)

4832. Klobang J. = G n a phalium involucratum Furst., Nat. fam. der Compositæ. Gr. Java; overblijvend.

4833. Kloei Sum. $=$ Bœhme ria nivea Gaud., (Zie No. 2387.)

4834. Kloekoep Bk. (Zie Damarserang $B$ K.)

4835. Kloembai BK. = Da lech a mpia bidentata Bl. (Zie No. 575.)

4836. Kloetoem LAMP. $=$ A r tocarpus altissima T. \& B. Nat. fam. der Artocarpece. Gr. Sumatra; hooge boom.

4837. Kloetoen M. = Morus? leucophylla Mi q., Nat. fam. als voren. GR. Sumatra; boom.

4838. Kloetoen Pac. $=\mathrm{Grewia}$ subcordata Mia., Nat. fam. der Lili aceæ. Gr. Sumatra Wk; heester.

4839. Kloetoen-bassa of (kl. bas. soh IAuP. = Adinandra stylosa II i q. (Zie No. 4821.)

4840. Kloetoen-bassa Laßr. $=\mathrm{L}$ a. placea aromatica Miq. Nat. fam.der Camelli ac e . Gr. Sumatra, boom.

4841. Kloetoen-nangka PAL. $=$ Grewia? subcordata Miq., (Zie No. 4838.)

4842. Kloetoeng-bassarang Lamp. =Adinandra lamponga Miq., Nat. fam. der Ternstrœmiaceæ. Gr. Sumatra; heester.

4843. Klomboe J. = Caryota furfuracea Bl. (Zie No. 2489.)

4844. Klompang M., zie kaloempang $M$.

4845. Klowak J. $=$ Pangium ednle $R w d t$. (Zie No. 387.)

4846. Klumba J. $=\mathrm{Rheum} \mathrm{pal-}$ matum L. radix; onder dezen naam is de Chineesche Rhabarberwortel op de Javaansche bazars te koop.

4847. Koait-bessie J. $=a$. Uncaria Schreb. Spec. div. $=b$. Griffithia fragrans W. \& Arn., (Zie No. 598 a.)

4848. Koäl Cel = Licuala Rum. phii Bl. Nat. fam. der Palma. Gr. Java, Celebes, Boeroe; lage Palm. GEBR. Het hout bezigt men slechts voor daklatten. De bladeren gebruikt men, even als die der wokka, tot het inpakken van tabak als anderszins.

4849. Koäng J. = Urostigma superbum Miq. (Zie No. 4337.)
4850. Kobanbara $\mathrm{S}$. $=$ Case aria velutina Bl., (Zie No. 3107).

48 ๖. Kodiho T. $=$ Codiaum moluccanum Dcsn. (Zie No. 126.)

4852. Kodiho-tjina $\mathrm{M}$. $=\mathrm{Ncrium}$ Oleander L. (Zie No. 1369.)

4853. Kodjanti J. = Eschynomene indica $L$.

4854. Kodong-seroeni J. = W ollastonia moluccana D. C. (Zie No. 3156$.

4855. Koёak Sum. WK. = Urostigma validu in Miq. (Zic No. 4348b.) 4856. Koeälot $\mathrm{J} .=\mathrm{Brucea}$ s umatrana Rxb. (Zie No. 296.)

4857. Koebaän Sus. WK. = Pierardia macrocarpa Miq., Nat. fam. der Euphorbiacere. GR. Sumatra; boom met eetbare viuchten.

4858. Koeban-abbal Aмв. = Phaanthus nutans HK. fs. \& TH. (Zie No. 1473.)

4859. Koeban-badja Aмв, = Cæsalpinia pulcherrima Sw. (Zie No. i386.) 4860. Koebang $M_{0}=$ Urostigma pruniforme Miq., (Zie No. 4327.)

4861. Koebang-bedoeloe Sum. Wr. $=$ Urostigma consociatum Miq. (Zie No. 4234.)

4862. Koeda-koeda J. \& M. $=a$. Odin a gummifera Bl. (Zie No. 1990.) =b. Spathodea Diepcnhorstii Miq. (Zie No. 3252b.)

4863. Koeda-koeda-sabrang M. = Odin a gummifera Bl. (Zie No. 1990.) 4864. Koeda-sondak S. $=\mathrm{Fl} \mathrm{a} \mathrm{cour}$ t i a R u k a m Z. \& M. (Zie No, 4.1 ..) 4865. Koedoe J. \& M. M or ind a cit rifolia I. (Zie No. $828 \alpha$.)

4866. Koedoe-kras M. = M orinda bracteata $R \times b$. (Zic No. 8286.) = b. Morinda Z ollingeriana Miq., vari et., Nat. fam. der Rubi a ce æ; Gr. Java; boom.

4867. Koedoepoel LaMp. $=\mathrm{F}$ i c u s s u brace mosa B l.; Nat. farn. der A r t o c a r p e a. Gr. Java en Sumatra; boom. GEBr. Volgens $J$ v $\mathrm{ngh}$ uh $\mathrm{n}$ levert het sap een soort van caoutchouk. In het Palembaugsche verzamelt men uit dezen boom een waschachtige stof, als g êt a la ö e in den handel bekend.

4868. Koedrang $\mathrm{J} \& \mathrm{M}$. = T a $\mathrm{x}$ otrophis Roxburghii B l., Nat. fam. der A rt o c a r p c æ. Gr. Java, Timor; heester. GFBR Het melksap druppelt men in dc oogen bij ontstekingen; 
de bladeren laat men in water aftrekken en drinkt dit tegen nierenlijden.

4869. Koejang-kotteng J. = G a s$\mathrm{s}$ i a $\mathrm{m}$ i mos o ides L. (Zie No. 3157.)

4870. Koejoeng PAL. $=\mathrm{V}$ a ti $\mathrm{c}$ a? eximi a $\mathrm{Niq}$. Nat. fam. der $\mathrm{Dipte}$ r o c a r p e r. Gr. Sumatra; hooge boom.

4871. Koejong $\mathrm{BK} .=\mathrm{S}$ h or e a e $\mathrm{x}$ mia Miq., Nat. fam. der Dipteroc a r p e $x_{0}$ Gr. Bangka; hooge boom.

4872. Koekel-ngowo J. $=a . \mathrm{O} \mathrm{p} \mathrm{h} \mathrm{e-}$ lia javanica Hassk. en $=b$. Ophelia oxyphylla Miq., Nat. fam. der G e n ti a n e a. Gr. Java; overblijvend.

4873. Kogkoe-badjang $\mathrm{BK} .=\mathrm{H}$ e pt a p leurum scandens Bnth. \& H k. (Zie No. 4638.)

4874. Koekoehoelang S. Zie aroijkoekoehoelang S)

4875. Koekoejaän $\mathrm{S} .=\mathrm{T}$ or e n i a edentula Griff. Nat. fam. der $\mathrm{S}$ c roph ula rine a. Gr. Java en elders; overblijvende plant. GeBr. Men legt het kruid op Herpes en wendt het als etterbevorderend middel aan bij wonden.

4876. Koekoek J. \& S. = L a genaria idolatrica Sering., Nat. fam. der C u curbit a c e . Gr. Bijna overal in Ned.-Indië; slingerplant. GEвR. De onrijpe vruchten eet men gekookt als groente bij de rijst; van de rijpe vruchten bezigt men de gedroogde vruchtschil als waterkruik of gendie.

4877. Koekoek-djantong J. = Trichos anthes anguina L. (Zie No. 1108.)

4878. Koekoek-soempoeng $\mathrm{S} .=\mathrm{Z}$ anonia macrocarpa Bl. (Zie No. 593.)

4879. Koekoelang $\mathrm{BK}$. $=\mathrm{G}$ a r d eni a c u rvata L. \& B. Nat. fam. der R u b i a c e æ. Gr. Java, Bangka, Bali; slingerplant.

4880. Koekoelang $\mathrm{PAL}_{\mathrm{L}}=\mathrm{Grif}$ fith i a palembanica Miq. Nat. fam. als voren; slingerplant.

4881. Koekoen R. $=\mathrm{H}$ eritiera lit t oralis D ryand. (Zie No. 752a.) 4882. Koekoeroe Min.

4883. Koeroe-koeroe Min. (Zie No. 4945.)

4884. Koe-kwa Cн. Во. = $\mathrm{I}_{0}$ mordia Charantia L. (Zie No. 639.)

4885. Koela Амв. $=$ M us a $\mathrm{pa}$. $\mathrm{radisi}$ a c a L. (Zie No. 1190.)

4886. Koela-abbal AxB. $=M$ u s a mindanensis $R m p h$. (Zie No.

$2325 a$.)

4887. Koela-beij Ахв. $=\mathrm{Musa}$ sim iar um R m ph. (Zie No. 1191.) 4588. Koela-hatoean Aus. = M u s a a $l p h u r i c a k m p h ., N a t$. fam. der M u s a c e æ. Gr. C e r a m; overblijvend. Gebr. De vrucht wordt door de $\mathrm{A}$ l f o e$r$ e n rauw en gekookt gegeten.

4889. Koelan Bк. = C e r a t o p h orus I, e r ii Hassk. (Zie No. 892.)

4890. Koelan $\mathrm{M}_{\mathrm{AK} .}=a$. G n e tu m e d u le Bl. (Zie No. 532.) = b. Gn etum funiculare Bl. (Zie No. 200.) $=c$. Gu et u m G n e mon L. (Zie No. 820.)

4891. Koelan-bantam MaK. $=\mathrm{Gne}$ t um G ne mon L. (Zie no. 820.)

4892. Koelan-besar $\mathrm{MAK}_{\mathrm{AK}}=\mathrm{G} \mathrm{n}$ et a m e dule Bl. (Zie No. 532.)

4893. Koelan-oetan Mak. $=\mathrm{G}$ n et um Gnemon L. (Zie No. 820.)

4894. Koelat-batoe M. $=a$. A garicus tuber regium Fr. en $=b$. Pa ch y m a tuber regium Fr. (Zie No. 1959.)

4895. Koelat-sendokh $\mathrm{M} .=\mathrm{P}$ o l yporus a mboinensis Fr., Nat. fam. der Hymenom ycetes. Gr. DeMolukken.

4896. Koele Solor. $=\mathrm{Schl}$ eichera trijuga WIld. (Zie No. 47.) 4897. Koelebet $\mathrm{BD} .=\mathrm{Psopho}$. carpus tetra gonolobus D. C. (Zie No. 1546.$)$

4898. Koelit.boegoelawan M. = Cinn a m om m Culila $w$ an Nees. (Zie No. 2287.)

4899. Xoelit-lawan M. = a. C innamomum Culilawan Nees. = b. Cin a m o mum c a m phoratum B 1., Nat. fam. der L a u rin eæ. GR. Java, Sumatra; boom. GEBR. De bladeren en schors zijn zeer aromatisch en bevat. ten een vluchtige olie, welke eenigszins kamferachtig naar nootmuskaat riekt. = c. Cinnamom um Keinwardtii $\mathrm{N}$ e e s Nat. fam. als voren. Gr. Java, Sumatra; boom.

4900. Xoelit-lawan-betoel M. = Cinnam om u Culilawan Nees. (Zie No. 2287.)

4901. Koeliet-manies SUM. = C i n$\mathrm{n}$ a mom u $\mathrm{m} \mathrm{K}$ i a mis Nees. (Zie No. 33676 .)

4902. Koelit-manies-riemboe Sum. $=$ Cinnamom um cyrtopodum 
$M$ i q., Nat. fam. der $L$ a u $r$ i n e $æ$. Gr, Sumatra; boom, die een goed bouwhout levert.

4903. Koelit-manies-toepai Sum. = Cinnamomum s u c uneatum Miq., Nat. fem. als rolen. Gr. Sumatra; boom. 4904. Koelit-niepies M. = M e m ec y lon coerulcum J a ck, Nat fam. der Melastom ac e h eester.

4905. Koeloer R. = A r t o c a p u s in $\mathrm{c}$ is a $\mathrm{I}_{\text {. }}$ (Zie No. 269.)

4906. Koeloes PaL. $=\mathrm{Orch} \mathrm{i} \mathrm{pe} \mathrm{da}$ sum atran a M i q., Nat. fam. der A p o с y n e ; Gr. Sumatra; heester.

4907. Koelong-sjuetsjoe T. $=P l u$ meria a cutifolia Poir. (Zie No. 1367.)

4908. Koemalandep $\mathrm{J}$. $=$ P r i o$n$ i t is H y trix Mi q. (Zie No. 1377.)

4909. Koemarogan S. = G y m n o. petalum leucostictum Miq. Nat. fam. der C u c ur bit a c e . GR. Java; slingerplant.

4910. Koembielie' M. $=a$. A rach is hypogæa. L. (Zie No. 3961.) $=b$. 1)ioscorea aculeata L. (Zie No. 1189)

4911. Koembielie-djawa M. = $\mathrm{C}_{0}$ leus tuberosus Benth. (Zie No. $1714 a_{0}$ )

4912. Koembielie-wolanda M. = Solanum tuberos um I. (Zie No. $2968 b$.)

4913. Koemies-badak S. 二 $a . \mathrm{G}$. ra $r$ din a $z$ e il a $n$ i c a Dcsn. Nat. Fam. der Urtic a c æ. Gr. Java \& Timor; éénjarig. $=b$. Elatos te m m macrophyllum Brongn. Nat. fam. als roren; Gr. Java, Amboina; éénjarig.

4914. Koemies-0etjing $\mathrm{S} .=a . \mathrm{O} \mathrm{r}$ tosiphon stamineus Benth. Nat. fam. der I abiateæ. Gr. Java, de Mo. lukken; éénjarig. $=b$. T a c c a l a n c æfoli a Z. \& M., Nat. fam. der T a cc a c e $x ; G R$. Java; overblijvend.

4915. Koempaai M. = L y c p od i $\mathrm{n} \mathrm{m}$. L.

4916. Koempai M. $=$ H ymenachne indica $\mathrm{B}$ üse (Zie No. 16576)

4917. Koempait $\mathrm{S}$. $=\mathrm{G}$ I in us 10 . to i d es $L$ o e f $\mathrm{l}$. Nat. fam. der $\mathrm{P}$ ort u l a c e r. Gr. Java tot Timor; zaadplant.

4918. Koeniet tamo riemboe Sur. $=\mathrm{Glob}$ b a u r a $\mathrm{n}$ i a c Miq., Nat. fam. der Zing i b e r a c eæ. Gr. Suma. tra; overblijvend.
4919. Koening M. en

4920. Koenir J. = Curcuma longa

L. (Zie No 2620.)

4921. Koenir poetih toma J. = C u r u m a Z e umbet R $\mathrm{xb}$. (Zie No. 3866 .)

4922. Koenjit M. $=\mathrm{Curcuma}$ long a l. (Zie No. 2620.)

4923. Koenjit-padi M. $=\mathrm{C} \mathrm{u} \mathrm{r} \mathrm{c} \mathrm{u} \mathrm{m} \mathrm{a}$ $\mathrm{Z}$ e r u m bet $\mathrm{R} \times \mathrm{b}$. (Zie No. 3867. )

4924. Koenjit-rimbo M. $=\mathrm{Cu} \mathrm{r}$. c u m a sumatran a Miq., Nat. fam. der Z ingiberace $æ$. Gr. Sumatra ; overblijvend.

4925. Koenjit-santan $\mathrm{M} .=\mathrm{Cu} \mathrm{r}-$ c u m a p u p u r a s e n s Bl., Nat. fam. als voren. Gr. Java; overblijvend.

4926. Koenroeloe $\mathrm{MAK}_{\mathrm{A}}=\mathrm{Cucur-}$ bita villos a Bl. (Zie No. 904b.)

4927. Koentang J. Zie later onder kondang S. \& J.

4928. Koenter-gauwa N.G.二Harpulia cupanioides $R \times b$. (Zie No. 3289.)

4929. Koentjie M. \& S. 二 $a$. K $æ$ m p. feria rotunda Is. (Zie No. 737.)

4930. Koepa $\mathrm{S}$. $=a$. J a m o s a c a $\mathrm{liflor}$ a D.C. (Zie No. 2629. = b. Ja m bos a macrocarpa Wight, Nat. fam. der M y $r$ a c e . Gr. Java, Sumatra; hooge boom. $=c . \mathrm{J}$ a m b o s a t e tra g o n a B l. (Zie No. 4433.)

4931. Koepa-dessa $\mathrm{S} .=a$. J a m. bos a cerasiform is $\mathrm{H}$ as s k. (Zie No. $4722 c$. $=$ b. S y z y g i u m l a x ifl o r u D.C. (Zic No. $4363 c$.) $=c$. Cipadessa fruticosa Bl.. Nat. fam. der M e li a c e æ. Gr. Java; heester.

4932. Koepa-gatel S. $=\mathrm{H} \mathrm{y} \mathrm{d} \mathrm{ro.}$ cotyle nepalcnsis Hk. (Zie No. 2589.)

4933. Koepa-landak S. 三 a. Flac o u r tia Ruk am Z. \& M. (Zic No. 415.) $=$ b. Flacourtiasapida $\mathrm{R} \times$ b., Nat. fam. der Fla c o u r ti a n e $æ$. GR. Java; heester.

4934. Koepa-manoek $\mathrm{S}$. = S y z ygium costatum Miq., (Zie No. 4742)

4935. Koepang Sum. $=\mathrm{M}$ a c rotropis sumatrana Mi q., Nat. fam. der Papilion a e r. Gr. Sumatra; heester.

4936. Koeping-minjangang $\mathrm{M}$. = a. Plantago Hasskarli $\mathrm{Dcsu}$; $=b$. P 1. incisa $\mathrm{H}$ ass k. en $=c$. P l. $\mathrm{maj}$ or I. GeBr. (Zie No. 1765.) 
4937. Koepoe-koepoe II. = В а u. hin ia tomentosa L. (Zie No. $4497 a$.)

4938. Koeraij S. $\cong \mathrm{S}$ pon i a C om. mers $=b$. Grewia tomentos a $J$ uss. (Zic No. 3904;)

4939. Koeraij-burrum $\mathrm{S} .=\mathrm{S}$ p onia $v$ e lutin a Pla n ch. (Zie No. 341.) 4940. Koerandjie J. \& M. 二 D i. a $l \mathrm{u} \mathrm{m}$ in d um L. Nat. fam. $\operatorname{der} \mathrm{Pa}$ pilio n a c ere. Gr Java, Sumatra, enz.; hooge boom. GEBr. Het sterke hout bezigt men voor molens, de bladeren gebruikt men om roestig ijzer schoon te maken, het vruchtmoes (tamarinde-plum) is alleraangenaamst zuur en wordt gaarne genuttigd. $=b$. De r r is Forste $\mathrm{F}$ a n a B 1. (Zie No. 3264.)

4941. Koerang.koerang M. $=\mathrm{Oxa}$. lis Reinwardtii Zucc. (Zie No. 25 l.) 4942. Koeranga Al. MIx. $=\mathrm{Hi}$ biscus rosa sinensis $L$. (Zie No. 1360.)

4943. Kôerdoe M. = P ty c hosperma ma la y a a Miq., Nat. farn. der P a lm r. Fr. Malakka, enz.; boom.

4944. Koeroe-kekoe Aus. $=a$. R ubus a cum inatissimus $H$ as $\mathrm{s}$. en $=b$. Rubus moluccanus J. (Zie No. 1396.)

4945. Koeroe-koeroe Aif. Mis. =a. O c im u m basilicum L, N'at. fam. $\mathrm{L}$ a $\mathrm{b}$ i a $t$ æ. GR. Door geheel Indië in het wild en in tuinen; éénjarig. GEBR. Dit aromatische kruid wordt als specerij bij vele spijzen gebruikt; als geneesmiddel bezit het opwekkende, zweetdrijvende eigenschappen, even als de $\mathrm{M}$ elisse en de Th ij $\mathrm{m}$, en wordt bij verkoudheid en lichte koortsen, veelal in aftreksel gedronken; ook geeft men het aan kraamvrouwen tot bevordering der lochiæ. De zaden zijn zeer slijmig; in water geweekt en met sniker, soms ook met agar-agar, gemengd gedronken, geren zij een aangenaam verkoelenden drank, die op bijna alle Javaansche bazars verkocht wordt. $=b .0 \mathrm{c}$. nl um s a n c u m L. (Zie No. 875.)

4946. Koeroelok S. $=\mathrm{C}$ a l o n y ction specios a $\mathrm{Chois.}$ (Zie No. 4s9d.)

4947. Koesa-koesa R. = Echin o ch lo a colon u B üse, Nat. fam. ner $\mathrm{G}$ r a $\mathrm{m}$ i $\mathrm{n}$ e $æ$. Gr. Op Java en elders in het wild en verbouwd. Gr. Dit gras levert een zeer geschikt voeder voor beesten.

4948. Koesambie M. \& S. $=$ Schle ichera trijuga Wlld. (Zie No. 47)
4949. Koesambie-betina M. = Serpicula hirsuta W. \& A. Nat. fam, der $\mathrm{H}$ a lor a g e æ. Gr. Sumatra's Wk.; waterplaut.

4950. Koessoe Mex \& T. $\mathrm{T}$ I m p erat a a r ndinacea C y r ill., (Zie 10. 263.)

4951. Koessoe-koessce MoL. = Chrysopogon aciculatus Fr. (Zie No. S09.)

4952. Koetet-gamong S. = Valeriana javanica Bl., Nat. fam. der Valerianeæ. Gr. Java en Sumatra; één. jarig.

4953. Koeti-katti M. = A n tidesma Bunias Spreng. (Zle No. 142 5.)

49 ว́t. Koetie-katti-goenoeng Mor. $=A n t i d e s m a k u m p h i i D u l a s n$, Nat. fam. der Antidesme æ. Gr. De Molukken; booin. GrBR. De jonge bladeren ziju door het rundvee zeer gezocht, en ook de inlanders eten ze afgekookt als groente.

4955. Koetil S. = Colocasia a n t i u or u $\mathrm{Schot}$. (Zie No. 24.5.) 4956. Koetjaij M. = Al1 i am nli$\mathrm{g}$ i n o s u m Do n. (Zie No. 1070.)

4957. Koetjoeboeng M. 三 a. D a. tura l. $=b$. S usum an the lm int h i c u m B l. (Zie No. 8706.)

495ร. Koetjoeboeng-boddas S. of 4859. Koetjoeboeng-poetih M. = $D$ a tura al ba N e es., Nat. fam. der S o la n a c e. Gr. Door geheel Nederl. Indië; éénjarig. Gebr. De bladeren en zaden worden om hunne bedwelmende en pijustillende eigenschappen, zoowel als geneesmiddel als tot een misdadig oogmerk aangewend; men mengt ze onder het opium. om na het schuiven het gevoel van welbehagen te verhoogen; men blaast den rook in beslotene vertrekken, om de daarin slapenden meer te bedwelmen en te gemakkelijker een diefstal te kuunen rolbrengen. Men druppelt het sap in de oogen tegen ijlboofdigheid. Men rookt het gedroogde kruid tegen aamborstigheid, en bezigt het uitwendig tegen hoofdpijn, op verwondin. gen en op pijnlijke zwerel en gezwellen.

4860. Koetjoeboeng-kajoe LBMP. = I a p pa ma crophy 11 a Kürz., Nat. fam. der E n p hor b i c e æ. Gr. Sumatra, Bangka, Celebes: boom.

4961 Koetjoeboeng-kassian $\mathrm{S}=a$. D a t u r a f a t u o s a L, Nat. fam. der S o l a n a c eæ. Gr. Door geheel Indië; 
éénjarig. GeBr. Als No 4959. Deze soort is in werking bijna gelijk aan D. Stramo n i u m I.; zij wordt op Java bovendien nog inwendig als a $\mathrm{n} t \mathrm{hel} \mathrm{m}$ int $\mathrm{i}$ c $\mathrm{u} \mathrm{m}, \mathrm{en}$ uitwendig tegen herpes rangemend. Zij zal eene nydriatische kracht bezitten even als dc B elladonna. = b. D a tura II e t el L., Nat. fam. en Gr, als voren. GEBR. Als No. 4567. Nog wordt deze op de Philippijnen vooral tegen scirrhus aangewend, en zou zij, volgens I, in d ley, te Delphi vroeger bij de orakels gebezigd zijn, om voorspellingen te kunnen bewerkstelligen.

4962. Koetjoeboeng-soesoen S. = Datura fastuosa (Zie vorig No.) 4963. Koewa of koowi SUy. IVK. $=$ Urostigma biverrucellum M i q., Nat. fam. der A r to c a r p e GR. Sumatra; boom.

4964. Koewala MaK. $=\mathrm{Corypha}$ Ge bang a L (Zie No. 1528.)

496ว. Koewo J. = M o n enteles c ory m o s u s $S$ ch ulz. Nat. fam. der Com positæ. Gr. Oost-Java; kruid.

4966. Kofassa Mex. \& T. = Vitex punctata. Schauer. Nat. fam. der Verb e n a c e $æ$. Gr. De Molukken; boom, die een vrij goed bouwhout oplevert.

4967. Rofassa-batoe MoL. $=\mathrm{Vi}$ tex $\mathrm{C}$ of assus $\mathrm{R} w \mathrm{~d}$ t. (Zie No. 4024.) 4968. நofassa-gabba-gabba Mrs. = Vitex L. et Cordia L. Spec. in d e f.

4969. Koffo Mrs. =a. M u s a a mbo inensis $R m p h$. en $=b$. M us a mindanansis $\mathrm{Rmph}$. (Zie No. 23256 .)

4970. Koheba-magolotsiffi T. $=a$.

Trevesia moluc cana Miq. (Zie

Na. 78.) = b. Uucaria lanosa W a 11. (Zie No. 27.)

4971. Kohleh S. $=$ M us a Trnf.

4972. Kohlehlet S. $=$ Urostigma elasticum NIiq. (Zie No. 24406 .)

4973. Kojo T. $=$ Mrsa paradisiaca L. (Zie No. 1190.)

4974. Kojoor J. $=$ Alchemilla villosa Jngh. (Zie No. 322.)

4975. Kojorono J. = Sonchus malajanus Miq. (Zie No. 1281.)

4976. Koka Амв. $=$ Cæsalpinia pulcherrima Sw. (Zie No. 1386.)

4977. Kokapoja Ces. = Sauraya eryolepis de Vr., Nat. fam. der Ternstr $\propto$ mi ace a. Gr. Cclebes; hecster.

4978. Kokin AмB. = Helicou iopsis amboine nsis Miq., Nat. fam. der
Musaceæ. Gr. De Molukken Java in tuinen; overblijvend. GEBr. Men bezigt de bladeren tot het inpakken van tabak, enz.

4979. Kokin-meirah Aмв. = Phrynium giganteum T. \& B. Nat. fam. der Cannacer. Gr. De Molukken; overblijvend.

4980. Kok0-assan S. = Canavallia gladiata D C. (Zie No. 3549.)

4981. Kokoejoehan S. (Zie koekoéjaän $S$.

4982. Kokontolan $\mathrm{S} .=a . \mathrm{Helic}$ teres Isora L. (Zie No. 1491.) $=6$. Oudemansia hirsuta Miq. (Zie No. 41076.)=c$. Oudemansia integerrima Miq., Nat. fam. der Sterculiacea Gr. Java, Sumatra; heester. $=d$. O ude mansia viscida Miq., Nat. farn. als voren. Gr. Java; heester.

4983. Kokossan MI. \& J. = L a nsium domesticum Jack。, var. (Zie No, 98.)

4984. Kokossan-monjet M. $=\mathrm{D}$ idymochiton nutans Bl., Nat. fam. der Meliaceæ. Gr. Java; heester. Gebr. Ien bezigt het hout voor huisbouw; het wordt niet door witte mieren aangetast. De zure vruchten worden gegeten.

4985. Kolaka CeL. $=$ Arta b otry s odoratissima R.Br., Nat. fam. der A nonaceæ. Gr. Java en elders in tuinen; slingerplant. GEBR.

4986. Kolang-koetjet J. $=\mathrm{R}$ ubu s $\mathrm{p}$ ulcherrimus Hk. Nat. fam. der Rosace æ, Gr. Java $3-8000^{\prime}$; heester.

4987. Koldie J. = Pyrus commun is L. Nat. fam. der Pomaceæ; Gr. Op Java in weinige tuinen gekweekt; de gewone Pereboom.

4988. Koli Mou. = Borassus flabelliforinis L. (Zie No. 3117.)

4989. Kollo-soesoe Men. = Pl llmeria acutifolia Poir. (Zie No. 1367.)

4990. Kollo-tala T. 二 Lee a sambucina Wlld. (Zie No. 133.)

4991. Kolobbe Boeton $=I_{1}$ agenaria vulgaris Ser. (Zie No. 3568.) 4992. Koloditi-manoora ' $\mathrm{T}$. of 4993. Koloditi-maseu $\mathrm{T}$. $=\mathrm{Hy}$ drosotyle a siatica L. (Zic No. 70) 4994. Koloeâng SuM. Wk. = M ezoneurum sumatranum W. \&Arn., Nat. fam. der Papilionacer. Gr.Sumatra; slingerplant.

4995. Koloeäng-parampoewan Suм. 
Wk. = Crsalpinia Nuga dit. (Zie No. 627.)

4996. Komak J.二a. Lablab cultratus Dc. (Zie No 3991.) $=b$. Lablab vulgaris Savi, (Zie No. $3544 a$.) 4997. Komangie J. \& M. $=a$. Ocimum Basilicum L. 'Zie No. $4945 a$.) $=b$. Ocimum sanctum L. (Zie No. 87ว.)

4998. Koemangie-0etan M. $=a$. O c i m u gratissimum L. (Zie No. 1458b.) $=b$. Ocimum sanctum L.

4990. Komarandjie J. = Guilan-

din a $L . S_{p}$. javan. indefin.

5000. Kombag-koening M. (?) =

Cassia gla uca Lam. (Zie No. 2568.) 5001. Komeh-oetan Men. = Morinda bracteata Rxb. (Zie No. 828b.) 5002. Komessoe J. = Monoceras robustum Miq., Nat. fam. der Tiliac eæ. Gr. Java; boom.

5003. Komi-komi T. 三 a. Morinda bracteata Rxb. (Zie No. S28b) $\equiv b$. Guettarda speciosa L. (Zie No. 1432 .

5004. Komlentoro J. = A langium hexapetalum $I_{a}$ m. Nat. fam. der A la ni ieæ. Gr. Java en Sumatra; slingerplant.

5005. Kondal $\mathrm{S}$. = Ficus rariegata $\mathrm{Bl}$. (Zie No. 1352.)

5006. Kondang S. 二 $a$. Ficus variegata Bl. $=b$. Ficus subracemosa B1. (Zie No 4867.) = c. Ficus s u b o p a c a Miq., Nat. fam. der A r t o c a rpeæ. Gr. Java; boom, die een veerkrachtige gomhars levert. $=d$. Fiucus u mbellata Vahl. (Zie No. 2506.) $=e$. Urostigma benghalonse Gasp. (Zie No. 790.) $=f$. Urostigma calophyllu m Miq., (Zie No. 4350.) = g. Urostigma cordifolium Miq Nat. fam. als voren. Gr. Java, boom.

5007. Kondang.bener S. = Ficus vari e g a t B B. (Zie No. 1352.)

5008. Kondang-koening M. 二 Ficus c h r y s o c a r p a $\mathrm{R} w \mathrm{~d}$ t. Nat. fam. der A r t o c a $\jmath^{p}$ e $æ$. Gr. Java, heester.

5009. Kondrang-sabrang S. 三 Covellia macrophylla Miq., Nat. fam. als voren. Gr. Java; boom.

5010. Kondang-waroe J. $=\mathrm{Hibus-}$ cus tilia ceus L. (Zie No. 2764.)

5011 . Kondoe S. = Ficus varieg a t a B l. (Zie No. 1352.)

5012. Kondondong M. 二 (Zie kadongdong M. \& S.
5013. Kondor $\mathrm{H} .=\mathrm{B}$ en incas a cerif er a Savi. (Zie No. 904a.)

5014. Kondorin AI. $=\mathrm{Adena} \mathrm{n-}$ thera $p$ avonina L. (Zie No. 52.)

5015. Kondorin-ketjil M. $=\mathrm{A}$ br us p) r c a t ori us L. (Zie No. ว3.)

5016. Konidei-aloes-daton Sur. Wk.

$=$ Briedelia tomentosa Bl. (Zie No. 3769.)

5017. Konjal S. $=\mathrm{Ficus}$ radic ans $R \times b$. (Zie No. 16ə2.)

5018. Konjal-beäs $\mathrm{S}$. 三 $a$. F i c u s microcarpa Mi q., (Zie No. 307.)

5019. Konjal-boenjoer S. 二 Ficus rupestris B l. Nat. fam. der $A$ rto. c a r p e æ. Gr. Java; heester.

5020. Konneng-boddas $\mathrm{S} .=\mathrm{Cur}$ c um a Z erumbet Rxb. (Zie No. 3866.)

5021. Konneng-gedeh $\mathrm{S} .=a . \mathrm{Cu}$ c u ma long a L. (Zie No. 2620.) $=b$. $\mathrm{Curcuma}$ r $\mathrm{r}$ ginos a $\mathrm{Rxb}$. Nat. fam. der Z ing i b e r a c e æ. Gr. Java; overblijvend.

5022. Konneng-hiedung $\mathrm{S} .=\mathrm{Cur}$. c u m a $æ r$ u i n o sa $R \times b$.

5023. Fonnen-parrie $\mathrm{S}$. $\mathrm{Curcuma}$ $\mathrm{Z}$ e r u m bet Rxb. (Zie No 3866.)

5024. Konneng-santen S. 二 Curc u ma purpurascens B l. (Zie No. 4925$.

5025. Konneng-tamman S. 二 $\mathrm{Cur}$ c u ma longa L. var: minor. (Zie No. 2620.)

5026. Konneng-tingang $\mathrm{Z}$. = $\mathrm{Cur}$ c u m a viridiflora $R \times b$. Nat. fam. der Z i n gibera c ex. Gr. Java, Sumatra; overblijvend. Gebr. Volgens $R$ о xb u r g h dient de wortel op Sumatra tot verfstof.

5027. Konrol MaK. = Benincasa c e rifera S a vi. (Zie No. 904a.)

5028. Kontjor $\mathrm{M}=\mathrm{K} æ \mathrm{~m} \mathrm{p}$ fer i a Ga 1 a ng a L. (Zie No. 737.)

5029. Kontol-kambing M. 二 $\mathrm{He}$ rit ie r a littora 1 is $D$ ry and, (Zie No. $752 a$.)

5030. Kontol-moending $\mathrm{S} .=\mathrm{S} \mathrm{y}$. n a c i a falcat a M i q., (Zie No. 609.) 5031. Kontel-monjet $\mathbf{M}$. = A n acardium occidentale L. Zie No. 1474.)

5032. Kool M. \& J. (Sic.) =Bra ssica olerace a L. Nat. fam. der Cruc i f e r e $æ G_{R}$. Op Java en elders wordt onze Europesche groene of witte kool als groente geteeld. 
5033. Kool-banda M. $=\mathrm{P}$ is o $\mathrm{n}$ i a a 1 b a S pa n., (Zie No. 120b.)

5034. Kool-kembang M. = Brassica oleracea L. varbotrytis c a uliflora; onze Europesche bloemkool.

5035. Kool-knol M. = B ras s ic a c a m pestris L., Nat fam. der C ruc if e ræ. Gr. Ook de veldkool teelt men hier en daar in tuinen.

5036. Kool-koening $\mathrm{M} .=\mathrm{B}$ a ssil a oceracea L., bullata vul$\mathrm{g}$ a r is, de geele kool.

5037. Kool-meirah M. $=\mathrm{Bras}-$ sica oleracea L., capitata varie t.

5038. Kool-poetih M. = B rassica ol eracea L., captata sphærica; beide laatste mede soorten van geele kool.

5039. Kool-rabi M. $=$ Brass ica oleracea L., caula rapa cumm u n is, de Koolraap.

5040. Koom-bonko-soesem N. G. $=0$ pilia Pentidis B l. Nat. fam. der O la c a c e $x$. Gr. Nieuw-Guinea; slingerplant.

5041. Kopa Br. $=X$ ylocarpus Grana \pm un Koe nig. (Zie No. 1319.)

5042. Kopa-poetih Амв. = Jas. min um S a m b a c A i t. (Zie No. 920.)

5043. Kopaäl $J .=$ D ille n ia serrata Th n b. (Zie No, 100.)

5044. Korpabbar of kopponabbal $\mathrm{AMB} .=\mathrm{C}$ a n a n g o dor a ta $\mathrm{Hook}$. (Zie No. 1373.)

5045. Koping J. = I it $\mathrm{s} æ a \mathrm{pu}$ berula $M$ iq., Nat. fam. der La u r.p e æ. Gr. Java; boom.

5046. Kopio-kopio Sum. WK. = Conyza riparia Bl. (Zie No. 236.)

5047. Koppan $S .=G y n u r a s a r-$ mentos a 1). C. (Zie No. 614.)

5048. Koppi J. \& M. = C offe a a r a bi c a I. (Zie No. 4050.)

5049. Koppi-koppi-riemboe Sur. WK. = Urophyllum corymbosu m Korth. (Zie No. 2915.)

5050 . Koppo $\mathrm{S}$. $=a$. $\mathrm{J}$ a m bos a a cutata Miq., Nat. fam. der M y rt a c e æ. Gr. Java 4-5000; boom. = b. J a m bos a c a uliflor a D. C. (Zie No. 2629.) $=c$. Jambos a dens i. flor a D.C. (Zie No 192l.) $=d$. Barringtonia speciosa l. (Zie No. 1.463 .

5051. Koppo-bearriet S. = Syzy- gium Zippelian um Miq. (Zie No. 2236.)

5052. Koppo-injar $\mathrm{S} .=\mathrm{J}$ a m bosa glabrata D.C. (Zie No. 4607.)

5053. Koppo-lalai S. = $a . \mathrm{J}$ a mbosa hypericifolia D. C., Nat. fam. der Myrtace æ. Gr. Java; boom. GeBr. Het hout levert zeer goede kolen; het jonge loof wordt als groente gegeten; ook nuttigt men de zuurzoete vruchten. $=b$. Ja mbos a formos a Wight. (Zie No. 1913.) $=c$. J a mbos a tetrago n a Bl. (Zie No. 4433.)

5054. Koppo-lalar $\mathrm{S} .=\mathrm{J}$ a m bo s a dens iflora D. C. (Zie No, 1921.)

5055. Koppo-lawut $\mathrm{S}$. $=\mathrm{J}$ a mbos a? littoralis B l, Nat. fan. der M y rta c ex. Gr. Java; boom, met een zeer hard hout.

5056. Koran S. $=$ Trevesia sun. d a i c a M i q. (Zie No. 4404c.)

5057. Korap of koerap $\mathrm{M}$. $=\mathrm{Cas}$. si a a 1 t a L. (Zie No. 1740.)

5058. Koreh BL. $=\mathrm{Cal}$ otropis g ig a $n$ te a R. Br. (Zie No. 817.)

5059. Korma M. = $\mathrm{Ph}$ h nix L. Enkele soorten van Dadelpalmen worden op Java en elders in tuinen gevonden.

5060. Korres S. $=\mathrm{Grumilea}$ a urantia ca Miq. (Zie No. 4273.)

5061. Korres-kéné $\mathrm{S}$. $=\mathrm{Grumi}$. le a di vergens M i q. (Zie No. 2301.) 5062. Korres-koeda $S_{\text {. }}=$ Bryonia perpusilla B l. (Zie No. 494.)

5063 . Korro-ronteng $\mathrm{S} .=\mathrm{E}_{\mathrm{ch}} \mathrm{h}$ m a ndra Blumean a M. J. Roemer (Zie No. 404a.)

5064. Korro-ronteng-kambing S.

= Bryonia marginata Bl. (Zie

No. 612.)

5065. Kosar S. = Myristica Teysmannii Miq., Nat. fam. der II y r i st i c a c e æ. Gr. Java; boom.

5066. Kossine $\mathrm{J}=\mathrm{Ehretia}$ buxifolia Rxb., Nat. fam. der Cordiaceæ. Gr. Vrij algemeen in Indië; heester. GEBR. In Indië wendt men den wortel als bloedzuiverend en antisyphilitisch geneesmiddel aan. Op Java bezigt men het gebrande hout tot zwartverwing der tanden en geeft een aftreksel der bladeren, zoo in- als uitwendig, bij koortsen, tot bevordering der huidafscheiding.

5067. Kossir Moc. = Bot r y morus paniculatus Miq. (Zie No. 3477.)

5068. Xotiffo-marau $\mathrm{T}$. = Poly- 
podium quercifolium Wlld. (Zie No. 181.)

5069. Koto-aros $\mathrm{Br}_{\mathrm{R}}=\mathrm{C}$ anarium L. S pec. in de fin.

5070. Koweh Sux. WK. Z a l a c c a W a ll i chi a n a II a rt., Nat. fam. der P a lmæ. Gr. Sum atra; lagc Palm. soort, GeBr. De rruchten worden gegeten.

ว071. Krah-krah BK. = Limnophila bancan a II iq., Nat. fam. der S c rop hul a rin ex. Gr. Bangka; waterplant.

5072. Krak M. en

ว073. Krak-lawok J. = B o n n a y a grandiflora Spreng. (Zie No. 1999g.)

5074. Krak-nassi M. \& J. $=\alpha$. Vallaris pergulaua Brm. (Zie No. 3865.) $=$ b. Pergular ia accedens B l. , Nat. fam. der A s c le piade x. GR. Jara, Sumatra, enz.; slingerplant. $=c$. Bidara pubiflora Miq., Nat. fam. dezelfde. Gr. Jara, Celebes; klimmende heester. $=d . \mathrm{V}$ a n d e $11 \mathrm{i}$ a crustace a Benth. (Zie No. 2155 5 a.) $=e$. Bonna $\mathrm{y}$ veronicæfolia S preng.(Zie No. 79b.) =f. Dentella re pens Forst. (Zie No. 79a.)

5075. Krak-nassi-foela-aros J. = Sty locoryua Webera A. Rich., Nat. fam. der $\mathrm{K}$ u bi a c e $x$. Gr. Java; heester.

50\%6. Kramanin BK. (Zie Grien BK.)

5077. Krandang J. \& M. $=\mathrm{C}$ it $\mathrm{rus}$ L im on um R is sa, Nat. fam. der A u$\mathrm{r}$ a ut $\mathrm{t}$ i a c e æ. Gr. Vrij algemeen in tuinen; boom. Gebr. De rersche vruchtschil bezigt men veel om het hoofd er mede te wasschen, soms wordt zij ook gekonfijt. Het zure vruchtensap bezigt men om te verwen.

5078. Krandjang $\mathrm{J}_{0}=\mathrm{C}$ a n a $\mathrm{v}$ a $\mathrm{l}$. li a obtusifolia D. C., Nat. fam. der Papilionace æ. Gr. Java en Timor; slingerplant. GEBR. De bladeren, bloemen en onrijpe peulen worden afgekookt en als groente bij de rijst gegeten.

5079. Krang-goenong J. = I) i anell a nemoros a I, am.; Nat. fam. der A spara g i u e æ. Gr. Java in tuiner; overblijrend. GEBR. Deze wordt vooral om de welriekende bloemen geteeld. Den gedroogden wortel brandt men als reukmid. del. Een afkooksel van den wortel geeft men bij moeilijke urincloozing, druiper en witten vloed.

5080. Krang-krang PaL. $=\mathrm{St}$ pell aria Zollingeri B aill., Nat. fam. der E u p h o r b i a c e æ, Gr. Sumatra; hesster.

5031. Kras R. = A le urites t rilo b a Forst. (Zie No. 312.)

5082. Kras-toelang M. a. C h loranthus officinalis Bl. $=b$. Chlo brachystachys Bl. = c. Chl. inconspicu us $\mathrm{S} w$. en $=d$. Chl. serratus R. \& S ch., Nat. fam. der $\mathrm{Cbl}$ or a n the æ. GR. Jara, reelal in tuinen; orerblijvend. GeBr. De wortels en het kruid dezer planten bezitten een aromatisch kamferachtigen geur, worden door B l u me ınet de $\mathrm{K}$ a dix $\mathrm{S}$ er pe $\mathrm{n}$ t a ri æ vergeleken, en door de Javanen als opwekkend en zweetdrijirend middel gebruikt. De Chineezen mengen het kruid door de thee.

5083. Kratau $\mathrm{M} .=$ I orus in. dic a $\mathrm{R} \mathrm{mph}$. (Zie No. 797a.)

5084. Kratong $\mathrm{BK}_{\mathrm{K}}=\mathrm{Helicia}$ o bor a t a Bennet. (Zie No. 3328.)

5085. Krakai Вк. $=$ Q uercus spic a t a $\mathrm{S}$ m. (Zie No. 4619.)

5086. Irawitan $J_{0}=\mathrm{C}$ a s sy t a L. S p e c. in d ef.

508\%. Krema-goenong $\mathrm{S} .=\mathrm{Ner}-$ te ra depressa Bznks. Nat. fam. der R u bia ce æ. Gr. Java, Sumatra, Borneo, 3-6000', kruipende plant.

5088. Krenjer J. $=\mathrm{Pol}$ yos $\mathrm{ma}$ ilic ifolia B l. (Zie No. $4490^{\circ} \mathrm{c}$.)

5089. Kribesa Tr. $=\mathrm{A} \mathrm{c}$ a $\mathrm{c}$ i a $q$ u adrilateralis D. C., Nat. fam. der M im o se r. Gr. Timor; heester.

5090. Krigitan $\mathrm{S} .=\mathrm{Pr}$ e $\mathrm{mn}$ a $\mathrm{co}$ r y mbos a Roetl. (Yie No. 395 .)

5091. Krikas $\mathrm{Bk}$. $=$ Quereus $\mathrm{s}$ pi c a t a $\mathrm{Sm}$.

5092. Krissan $J_{.}=\mathrm{S}$ c irpus m ac r othyrsus MI q., Nat. fam. der C y p er a c e æ. GR. Java; grassoort.

5093. Kröai $J_{.}=$Phase ol us $\mathrm{r}$ a d i a $t$ us L. (Zit No. 3l.)

5094. Krodee-kras $J_{.}=H$ u n t e ria s un da a a $\mathrm{M}$ i q. (Zio No. 2514.)

5995. Kroeboet $J .=R$ afflesia Arnoldi R. Br. (Zie No. 273.)

5096. Kroieng Lamr, en BK. = Dipterocarpus eurhychus Mi q., Nat. fam. der Dipt erocarpe æ. Gr. Sumatra, Bangka: hooge boom. GEBR. Men rerzamelt uit de zaden een vaste retstof, die in den inlandschen handel voorkomt.

๖097. Kroieng $\mathrm{R} .=\mathrm{M}$ e l a n o rrhœa glabra Wa l1., Nat. fam. der 
A n acardiare 5098. Krokot J. 二 $a$. Sesuvium re pens Wlld. (Zie No. 734.) $=b$. Pyxipoma polyandrnm Fenzl. (Zie No. 2482b.) $=c$. Trianthema sedifolia Vis. (Zie No. 2479c.)

5099. Kronket $J$. 三 A m o m im cili at um B l. Gr. Java; overblijvend.

5100. Krontoh J. 二 Uros tigm a pruniforme Miq. (Zie No. 4.327.)

5101. Kroondjieng BK. = Blai-angien $\mathrm{BK}$.

5102. Krossoh J. 二 Ficus le ucoptera Miq. (Zie No. 3829.)

5103. Krotjeh Mak. = Urostigma benghalense Gasp. (Zie. No. 790.)

5104. Krowang J. $=\mathrm{Chavica}$ frustrata Miq., Nat. fam. der Piperace æ. Gr. Java; slingerplant.

5105. Krowieng Вк. $=10$ Dipterocarpus Bandii Korth. en $=20$. Dipt. pterygocalyx Scheff., beide van de Nat. fam. der Dipterocarpeæ. GR. Sumatra en Bangka; hooge boomen.
5106. Kuge 'T. = $1 \mathrm{mpom}$ pa peltat a Chois. (Zie No. 303a.)

5107 . Kullehur of kullewur $\mathrm{BD} .=$ Casuariua nodiflora Forst. (Zie No. 122.)

5108. Kupessa Aмв. = Acalypha densiflora Bl. (Zie No 1440.)

5109. Kupessa-abal Амв. = A calypha Caturus Bl. (Zie No. 22916.)

5110. Kwas S. = Mucuna capitata D. C., Nat. fam. der Papilionaceæ. Gr. Door geheel Indië in tuinen; klimplant. Gebr. De rijpe ell onrijpe penlen worden, na eerst afgekookt te zijn, bij de rijst gegeten, daar zij anders giftig zijn.

5111. Kwas-bakol S. 二 Canavallia gladiata D.C. (Zie No. 3549.)

5112. Kwas-boddas S

5113. Kwas-boerik S.

5114. Kwas-heedjoh S. en

5115. Kwas-hiedung $\mathrm{S}$. 三 M ucuna c a pitata D.C., varietates.

5116. Kwi.pha Cn. Bo. 二 Helianthus ann нus I. (Zic No. 1385.)
5117. Laban M. = Vitex pubes. ce ns Vhl. (Zie No, 430c.)

5118. Laboe J. \& M. = a. Lagellaria idolatrica Ser. (Zie No. 4876.) $=b$. Lagenaria vulgaris Ser. (Zie No. 3568 .)

5119. Laboe-ajer M. = Lagenaria i dolatrica Ser.

ś120. Laboe-ambon M. = Cucnrbita Pepo L. Nat. fam. der Cucurbit a c ex. De pompoen wordt hier en daar in tuinen aangetroffen.

5?21. Laboe-baliek-lohdohr S.,

5122. Laboe-baliek-tjohmat S. en

5123. Laboe-dempeh-hawoet S. = Lagenaria hispida Ser. cum variett., Nat. fam. der Cucurbitacex. Gr. Uit Japan naar Java overgebracht en in tuinen gekweekt; slingerplant. Gkir. De vruchten worden, rijp en onrijp, rauw en gekookt, gegeten. De zaden zijn, even als die van alle kornkommers, diaretisch.

5124. Laboe-frangi 11. en

5125. Laboe-kastella M. 二 Cucurbita Pepo L. (Zie No. 5120.)

5126. Laboe-laboe Sum. WK. $=\mathrm{M} \mathrm{e-}$ lanolepis diadema Miq., Nat. fam. dcr Euph or bi a ceæ. GR. Sumatra; boom.

5127. Laboe-padie M. = Lagenaria hispida Ser. (Zie No. 5123.)

5128. Laboe-poetih M. = Cucurbita Pepo L. (Zie No. 5] 20.)

5129. Laboe-poetih-besar MI. 二 Iagenaria hispida Ser., variet.

5130. Labok Bu. = $a$. A marantus tristis I. (Zie No. 836a.) = b. Euxo. lus polygamus Moq. Tand. (Zic No 836b.)

5131. Lada M. = Piper nigrum L. (Zie No. 1091 a.)

5132. Lada-andjierg $\mathrm{M}$. $=\mathrm{Cu}$ beba canina Miq., Nat. fam. der Piperace x. Gr. Java, Sumatra. Borneo, de Molukken; slingerplant. GEıR. De vrucht bezigt men tot dezelfde doeleindeu als dc Semin a Cubebx.

5133. Lada-berejkor M. = Cubeba officinalis $\mathrm{Mliq}$ (Zic No. 3702.)

5134. Lada-djawa $\mathbf{M}$. = Chavica officinarum Miq., Nat. f:m. der Piperaces. Gr. Bijna overal in Indic in het wild en gekwcekt; klimplant. Girn. 
1) vruchteu worden door de inboorlingen als cen prikkelende specerij en als geneesmiddel gebruikt; zij komen in den handel als piper long $u \mathrm{~m}$ voor.

513 . Lada-hitam M. en

5136. Lada-ketjil N. = Piper nigr r m I. (Zic No. 109d.)

๖137. Lada-lada-riemboe II. = Strobilanthes crassifolia Miq., Nat. fam. der Acanthacex. Gr. Sumatra; heester.

5135. Lada-loemoet $\mathrm{S}$. $=\mathrm{Mul}$. dera cordat a $\mathbf{M}$ i q., Nat. fam. der Pi p e r a c e $æ$ Gr. Java; klimplant.

5139. Lada-pandjang $\mathrm{M}$. = $\mathrm{Ch}$ a. vica of ficinarum Miq. (Zie No.5̆134.)

5140. Lada-tjapo $M_{\mathrm{AK}}=$ Capsi. cum fastigiatum K l. (Zie No. 5591. )

515l. Lada-tjili M. = Capsicum Trnf., Spec div.

5142. Ladja M. \& S. = Alpinia cernua Bot. Mag., Nat. fam. der Zingiberacex. Gr. Java; overblijvend.

5143. Ladja-bener S. of

5144. Ladja-betoel M. en

5145. Ladja-burrum $\mathrm{S}_{.}=\mathrm{Al} p$ in ia Galanga Sw. (Zie No. 2370.)

5146. Ladja-gedeh $\mathrm{S}$. = Alpinia pyramidata Bl., Nat. fam. als roren. GR. Java; overblijvend. GFBR. De wortel wordt in plaats der $R$ ad. Galangæe gebruikt en in den handel gebracht; hij is echter veel slechter.

5147. Ladja-goä $=a$. Alpinia malaccensis Rosc. (Zie No. 392.) $b$. Alpinia javanica Bl., Nat. fam. als voren. GR. Java; overblijvend.

51.8. Ladja-limbo S. 二 Hellenia scrabra Bl.. Nat. fam. der Zing iberac e.$G_{R}$. Java; overblijvend. GEBR. Den knolwortel bezigt men, even als dien der ladja-soorten, tot bereiding van kerrysausen voor de rijsttafel.

5149. Lado-lado M. $=\mathrm{Ch}$ as alia Miq. (Zie No. 4506.̄.)

5150. Lado-lado-riembo M. 二 Stro. bilanthes pedunculosa Miq., Nat. fam. der Acanthaceæ. Gr. Java en Sumatra; heester.

51ว̆1. Láë Амв. of lahi Br. $=\alpha$. Dioscorea pentaphylla L., en $=b$. 1)ioscorea Kleiniana Kunth. (Zie No. 5.)

5̃ 152. Laéi-kong-kien Cн. Bо. = Hydrocotyle asiatica L. (Zie No. 70.)

5153. Lagam PAL. = Canarium eupteron Miq. (Zie No. 3300.)
5154. Lagansa M. $=a$. Gynandropsis pentaphylla D. C. en $=b$. Polanisia riscosa D.C. (Zie No. 12576.)

5155. Lage-lage $\mathrm{T}$. $=$ Lom aria scandens Wlld. (Zie No. 3587.)

5156. Lagoendi J. \& MI. 三 $\alpha$. Vitex trifolia L. (Zie No. 66.) $=b$. V it e $\mathrm{x}$ Negundo L. (Zie No. 13lb.) $=c$ V itex bicolor Wlld., Nat. fam. der Ver. ben aceæ. Gr. Java; heester. Gebr. (Zie No. 66.1

5157. Lagoendi-lawut $\mathrm{J} .=a . \mathrm{V}$. tex pubescens Vhl. (Zie No. $430 c$.) $=6$. Vitex timoriensis IV alp., Nat. farn. als voren. Gr. Timor; heester. Glißr. Vermoedelijk als No. 65. en 1316 .

5158. Lagoendie-lawut-lalakki M. $=$ Vitex Negundo L. (Zie No. 13/6.) 5159. Lagogo CeL. 二 Cicas circinalis $\mathrm{L}$.

5160. Lahang J. 二 Arenga saccharifera Lab. (Zie No. 243.)

5161. Lahi Boex. (Zie No. 515l.)

5162. Lahie Bo. 二 Lahia kutejensis Hssk. Nat. fam. der Sterculi. a c eæ: Gr. Borneo; hooge boom.

5163. Laikiet Alf. Mis. = $\mathrm{Heli}$. coniopsis amboinensis Miq. (Zie No. 4978.)

5164. Laikiet-nimbolo Alr. Mrs. = a. Canna coccinea Ait ell $=b$. Canna flavescens Lk. (Zie No 4150 a.) 5165. Laikou Амв. = Lomaria scandens Wlld. (Zie No. 3587.)

5166. Lais $\mathrm{BK} .=\mathrm{Pandanus} \mathrm{La}$ is Kürz, Nat. Fam. der Pandaneæ; Gr. Bangka; hooge boom.

516\%. Laisemboe M. = Ficus basidentula Miq., Nat. far. der A rtoc a rpe æ. Gr. Bali; boom.

5168. Lajang-lajang-simpai M. Sum. = Diploclinium racemosum. Miq.. Nat. fam. der Begoniacex; Gr. Sumatra, Celebes; overblijvend.

5169. Laijm of Laim Амв. 二 J a m. bosa domestica $\mathrm{Rmph}, \quad \nabla$ ar: $\mathrm{ni}$. gra. (Zie No. 1922.)

5170. Laijm-moehoe Амв. = $\mathrm{s} \mathrm{y.}$ zy gi m caryophyllifoli um D.C. (Zie No. 1910 .)

5171. Lakka M. \& S. 二 $a$. My ris tica iners Bl., Nat. fam. der Myristic a ceæ; Gr. Java; dikke boom. GEßr. Het fijne en roode hout dient wel roor bouwhout, doch wordt spoedig door den houtworm (boe boek) aangetast. Het hart of eigenlijke hout gebruikt men tot be- 
rooking. Het sap uit den stam drinkt men tegen pisopstopping. $=b$. M yristica $\mathrm{l}$ a $\mathrm{rr}$ in a Bl., (Zie No. 29513.)

5172. Lakka ambon 11 . = I m p atiens Balsam ina I. (Zie No. 259.)

๖ 173. Lakka-boetoe T. $=\mathrm{L}$ aws 0 nia alba L am. (Zie No. 1747.)

51i4. Lakka-ketjil M. = Impa. tiens Balsamina S. (Zie No. 259)

๖ 175. Lakkin (Lakin) CR. = Erythrina indica $\mathrm{I}_{\mathrm{a}} \mathrm{m}$, (Zie No. 1586b.)

5176. Lakodjong $\mathrm{I}_{\mathrm{A} M P}$. $=$ Gomph i a sumatrana Jack. (Zie No. 7848.)

šl77. Lakong M. 三 Cissus cinerea Iam. (Zie No. 65.)

5178. Lala Tr. = Uvaria ti riensis Bl. (fructus), (Zie No.4510.)

5179. Lalamoet AxB. of

5180. Lalanuit $\mathrm{Cr}$. $=\mathrm{Enhalus}$ Ko enigii Rich. (Zie No. 923b.)

5181. Lalang J. \& II. = a. Imperata arundinacea Cyrill. (Zie No. 263.) $=b$. Pennisetum setosum R. \& S. Nat. fam. der Gramineæ; Gr. Indië; overblijvend.

51 1 2. Lalangkapan boddas $\mathrm{s}$. $\mathrm{C}_{0}$. nyza lacera Brm., (Zie No. 10476.)

j183. Lalar S. = Dipterocarpus litteralis Bl., Nat. fam. der Dipterocarpex; Gr. Java; hooge boom.

5184. Lali J. = l3arrington i a specios a L. (Zie No. 1463.)

j185. Lalian J. $=$ M edinilla j a van ensis B l. (Zie No. 2749.)

5186. Laloektroe-Boeton = C oc os n uc if e r a L. (Zie No. 393.)

5187. Laloetie Sum. $=$ Stipella ria $\mathrm{Z}_{0} \mathrm{ll}$ ingeri B a ill., Nat. fam. der Enphorbiacex; Gr. Sumatra; heester.

5188. Lama Cr. $=\mathrm{M}$ a p pa Tan ar i a S p g. (Zie No. 2294b.)

5189. Lamarang $\mathrm{S}$. = Pithe c 0 lo bi u m umbellatum B nth. (Zie No. 2086.)

5l90. Lambatteh $M_{\text {AK. }}$ 二 I y c 0 . persicum cerasiforme l) csn. (Zie No. ร3816.)

5191. Lambeubeutang S. of

\section{Lambeutang S. en}

วั193. Lamboetang $\mathrm{S}$. 三 a. A 110 phyllus fulvinervis Bl. (Zie No. $4391 c$.) $=$ b. Allophyllus sundanus Miq. (Zie No. 1965.) = $c$. Premna fotida $k w d t$. (Zie No. $1722 b$ )

5194. Lambottang-aroij $\mathrm{S} .=\mathrm{Co}$ - lubrina asiatica Brgnt, Nat. fam. der $R$ h a $m \mathrm{n}$ e æ. Gr. Vrij algemeen in Indië; heester.

5195. Iamboeto Mak. = Cerbera la e tari a H a m. (Zie No. 1182.)

5196. Lameh of Lami MAK. = $\mathrm{O}$ e bi e $\mathrm{Ml}$.

5197. Lameh S. 二 $a$. Alsto nia K.Br. en $=b$. Cyrtosiphonia Miq.

5198. Lameh-aroij S. = Allamand a cathartica I, Nat. fam. der $A$ p o c y $\mathrm{n}$ e $x$. Gr. Java en elders in tuinen; heester. G EBR. De bladeren werken in kleine giften purgeerend, in groote braakwekkend. Op Java gebruikt men de bladeren in een dampbad bij koortsen.

๖) 99. Lameh-awehweh S." = Alstonia spectabili s R.Br., Nat. fam. der A p oс уn e æ. Gr. Jara, Timor, enz.; hooge boom. GEBR. Het hout van dezen fraaien boom is dunrzaam onder den grond, doch daarbuven wordt het spoedig door insekten verteerd; men bezigt het veel voor doodkisten; jong zijnde gebruikt men het in plaats van kurk, ook in insekten-kistjes. Ilet het melksap wrijft men het tandvleesch in bij bloedingen. De bast en het hout zijn zeer bitter, in werking aan de Gentiaan gelijk, en behooren tot de inlandsche koortsmidảelell. Een afkook. sel der bladeren geeft men aan de karbouwen bij buikziekte.

5200. Lameh-boddas $\mathrm{S} .=\mathrm{A} 1 \mathrm{st} 0$ ni a spathulata B l., Nat. fam. als voren. Gr. Java; hooge boom.

5201. Lameh-lalakki S. = C y rtosiphonia sumatrana $M$ i q. (Zie No. 436 )

5202. L ameh lawut $\mathrm{S}$. 二 B l a beropus sericeus A.D.C. (Zie No. 3260 .)

5203. Lamer J.二 $a . M$ e. a $\mathrm{n}$ thesa r u b ra B l. (Zic No. 4616.) =b. G lochidion cyrtostylum Miq., Nat. fam. der $E$ u pho r b i a c e. Gr. Oost. Java en Sumatra; lage boom.

5204. Lami MaK. = a lata L. $=$ b. I) ioscorcarulga ris M iq. (Zie No. 2808b.) =c. Tac. c a palm at a J. C. $\mathrm{S} c \mathrm{ch}$ a uer. (Zie No. 825.)

520 s. Lami-hoeta 1)J. = $\mathrm{T} \mathrm{a} \mathrm{c} \mathrm{c} \mathrm{a}$ palm at a J. C. S c h a u er. (Zie No. 825.)

52C6. Lammoet of lammoeta AMs. $=$ Cynometra cauliflora 1 , Nat. fam. der Papilion a cer. Gr. 
Vrij algemeen in tuinen; boom. GEBR. De aangenaam znurzoete vruchten van dezen fraaien boom worden rauw en ge. kookt veel gegeten en zijn gezond.

5207. Lammoet-abbal Аив. 二 $\mathrm{Cy-}$ no m e tra bij ug a s p a n., Nat. fam. als voren. Gr. Java, Borneo, de Molukken; boom, die een slecht timmerhout levert.

5208. Lamoe $\mathrm{M}$. $=\mathrm{E} u \mathrm{halus}$ $\mathrm{K}$ o e rigii $\mathrm{R}$ i ch. (Zie No. 923b.)

5209. Lamoekab Bk. = $\mathrm{Rh} \mathrm{izo-}$ p h o r a lat ifolia Miq. (Zie No. 247.) 5210. Lampajang $\mathrm{S}$. 三 $\mathrm{Schmie}$ de li a r a c emosa L. (Zie No. 4827.) 5211. Lampanie $\mathrm{S} .=a$. C l i m ac a ura obovata Miq. (Zie No.

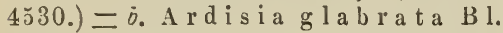
(Zie No. 45316.$)=c$. A rdis a villos a $\mathrm{R} \times \mathrm{b}$. (Zie No. 4485.)

5212. Lampanie-peutjang $\mathrm{S}$.二 $\mathrm{Ar}$ d i s i a h m i i s V h l. (Zie No. 4528.) 5213. Lampas $\mathrm{I}$. $=\alpha$. O c im u m B asilieum l. (Zic No. 4945.$)=b$. O c i m u m san ct u m L. (Zie No. 875.) 5214. Lampas-burrum S. en

5215. Lampas-hitam I. $=0 \mathrm{c} \mathrm{i-}$ m u m Basilicum J. variet.

5216. Lampiso Вк. 二 $\mathrm{Ard}$ is i a h u milis Vahl. (Zie No. 4528b.)

5217. Lampöein Mak. 二 Z i n g ib c a m a ricans Bl. (Zie No. 2401.) 5218. Lampoejang $\mathrm{M}$. 三 $a$. G lobba maculata Bl. (Zic No. 2224b.) = 6. Zingiber amaricans Bl. (Zie No. 24(01.) $=c . \mathrm{Zingiber} \mathrm{Zerumbet}$ Rosc. Nat. fam. der Z ingiberacex. Gr. Java en de Molukken; overblijvend. GEBR. als No. 2401 .

5219. Lampoejang-betoel M. 二 Zingiber amaricans Bl. (Zie No. 2401.)

5220. Lampoejang-goenoeng $\mathbf{M}$. = Zingiber inflexum 81 . Nat. fam. der $\mathrm{Z}$ ing i ber a eeæ. Gr. Java; overblijvend. 5221. Lampoejang-monjet $M$. = Zing iber elatum $R \mathrm{xb}$. Nat. fam. en Gr. als voren.

5222. Lampoejang-oetan M. =

Globba marantina 1. (Zie No. 2224a.) 5223. Lampoejang-0otan-ketjil M. $=\mathrm{Z}$ ingiber marginatum Rxb. (Zie No. 254.)

5224. Lampoejang-pahit M. $=a$. Zingiber a maricans Bl. (Zie No. 2401.) $=b$. Zingiber Cassumunar Rxb. (Zie No. 878.) = $c$. Z ingiber marginatum R $\mathrm{x}$ b. (Zie No. 254.) 5225. Lampoejang-wangie II = Zingiber gramineum Bl. (Zie No. 255.1

5226. Lampoejangan $\mathrm{S} .=a \cdot \mathrm{Pa}-$ nicum antidotale Ratz. en $=b$. Paspalum cartilagi u um Presl. Nat. fam. der Gramineæ. Gr. Java; grassoorten.

5227. Lampoejanjeng $\mathrm{S}$. $=\mathrm{Juncus}$ prismatoc arpus $R$. Br. Nat. fam. der J unce re. Gr. Java; rietsoort.

5228. Lampijoe Lasp. 二 Coffea lepidophloia Miq. Nat. fam. der Rubi a ceæ. Gr. Sumatra; heester.

5229. Lamtassij Bor. = Ėgicer as majns Gærtn. (Zie No. 1556.)

5230. Landap M. = Prionitis. Hystrix Miq. (Zie No. 1377.)

5231. Landja-badak S. 二 Solanum rhinocerotis Bl. Nat. fam. der Sola neæ. Gr. Java; heester.

5232. Landoek $\mathrm{S}$. 三 $a$. $\mathrm{C}$ is su $\mathrm{s}$ thyrsiflora Bl. (Zie No. 542,) = 6. M eliosma nitida Bl. (Zie No. 3440$.

5233. Landoek-gangjang $\mathrm{S} .=\mathrm{Jus}$ s i a re pens L. (Zie No. 476.)

5234. Landoel $\mathrm{I}$. $=\mathrm{Pri}$ o $\mathrm{n}$ i is H y s t $x$ ix M i q. (Zie No. 1377.)

5235. Langa M. \& MAK. = S e s a. in $u$ in i d i e $\mathrm{m}$ D.c. (Zie No. 246.)

5236. Langa-langa $M A k .=V$ e $x^{\text {- }}$ no $\mathrm{n}$ i a einere a I ess. (Zie No. 6ra.) 5237. Langadi $\mathrm{M} .=\mathbb{E}$ i c e ras majus Grtn. (Zie No. 1556.)

5238. Langgandjei Sux. Wk. = Syzygi um e une uron Miq. Nat. fam. der Myrta e e. Gr. Sumatra; boons.

5239. Langir I. \& M. $=\mathrm{Albizzia}$ S a pon aria B 1. (Zie No. 10416.)

5240 . Langkab M. \& S. $=a$. Arenga obtusifolia Mart. Nat. fam. der Palm a. Gr. Java en Sumatra; hooge boom. GEBr. Even als van de Sagueerpalm makt men ook van dezen een ruim gebruik; het $z$ ware en zwarte hout van dezen boom dient voor lansen cn weversgereedsehappen; den vezeligen bast tusschen den stam en de bladstelen bezigt men voor bezems, huisbedekking, enz., de jonge bladeren worden gegeten; het sap uit de bloemstelen is nog zoeter dan dat der Arcug. $=6$. Areng a Westerhouttii Griff. Zie No.321.) 5241. Langkabang SuM. WK. = 
C yrtandra i n c o mpta J ack., Nat. fam. der C y rtandraceæ. Gr. SuInatra; éénjarig.

5242. Langkadai $\mathrm{BK}$. $=\mathrm{Bru}$ guie ra parviflora W. \& A. (Zie No 34.736 .)

๖243. Langkeh-jangkang $\mathrm{S} .=\mathrm{V}$ i s. cum orientale Wlld. (Zie No. 3467.)

5244. Langkwas M. $=a$. A l p in i a $G$ a lang a $\mathrm{S} w$. (Zie No. 2370.) = b. Elettaria s c abra Bl. (Zie No. 2703.) $=c$. Hellenia scabra Bl. (Zie No. 5148.)

5245. Langkwas-lakkilakki M. = A l pin i a gigantea Bl. (Zie No.386.) 5246. Langkwas-malakka M. = A l pin i a malaccensis Rosc. (Zie No 392.)

ว247. Langnga Mak. = S e s a m u $\mathrm{m}$ in dic u m D.C. (Zie No. 246.)

5248 . Langong $\mathrm{M} .=\mathrm{M}$ a $\mathrm{ng}$ if e ra L a ng ong. II i q., Nat. fam. der A nac a r d i a c e æ. Gr. Sumatra; boom.

5249. Langsana-meirah M. = G ynandropsis pentaphylla D.C. (Zie No. 1287a.)

5250. Langsana-poetih M. $=\mathrm{Po}$. l a $\mathrm{n}$ i s i a viscosa D.C. (Zie No. 1287b.) 5251. Langsep $\mathrm{J} .=\mathrm{L}$ a n si $\mathrm{um}$ domestic um Jack. (Zie No. 98.)

5252. Lano-lano MAK. $=\mathrm{Heri-}$ tiera littoralis Dryand. (Zie No. 7ร2a.)

5253. Lanra $\mathrm{MAK}_{\mathrm{AK}}=\mathrm{V}$ itex trifolia L. (Zie No. 66)

5254. Lansa of Lanseh M. (Zie Lángsep $J$.

ว2らว. Lansa-goenong M. = Mil. ne a mo nt a n a $J$ a ck., Nat. fam. der $\mathrm{M}$ e li a c ex. Gr. Sumatra en de Molukken; boom. GEBR. Het hout is zeer geschikt voor huis- en scheepsbouw; de gomhars, uit dezen boom verkregen, gebruikt men tot het breeuwen van vaartuigen.

5256. Lansa-0etan M. = C o o k i a punctat a Retz. (Zie No. 99.)

5257. Lansiroh SuM $\mathrm{WVK}=\mathrm{R}$ ottlera tinctoria Rxb. (Zie No. 1201b.)

5258. Lanteboe M: $\mathrm{K}$. $=\mathrm{Ar}$ u nd o $I_{\text {. }}$.

э259. Lonting MAND $=\mathrm{S}$ o l a n u m verb a sc if ol ium L., Nat. fam. der S ol a n e a. Gr. Java, Sumatra en elders. GriBr. Het sap uit de stengels gebruiken de Javanen bij tandpijn en om de tanden zwart te verwen. $Z_{i j}$ geven de met zout fijngewreven bladeren tegen hoofdpijn en aan kraamvrouwen; nog üienen zij ze toe aan paarden tegen de droesziekte en geven ze aan honden, die afgericht worden op de jacht op grof wild. De vruchten worden gegeten, na eerst geroosterd te zijn.

5260. Laoija Mak. Z i n g i b e r offic in ale L. Zie No. 253.)

э261. Lapai Sum. W. K. = Covellia Ribes Mliq. (Zie No. 282h.)

5262. Lapai-koembang Sum. W. K. $=$ Urostigma validum Miq. (Zie No. 43386.)

5263. Lapi-apan J.二 I as ianthus densifolius Miq. (Zie No. 796.)

5264. Lapia Алв. $=$ Metroxylum Rumphii Mart. (Zie No. 279.)

5265. Lapia-abbal A мв. = Metro. xylum filare Mart., (Zie No. 1320.)

5266. Lipia-ihoel Амв $=$ Metro. xylum sylvestre Mart. Nat. fam.der Palmæ. Gr. Ceram, Amboina; hooge boom.

5267. Lapioe-loelioewe AMe $=$ Metroxylum micracanthum Hasskl, Nat. fam. als voren. Gr. Ceram; middelmatige boom.

5268. Lapia-makanaloe Aмв. of Lapia-makanora AмB. = Metroxyl n m longispinum Mart., Nat. fam. dezelfde. Gr. Amboina; middelmatige boom. Gebr. Deze is de minste der Sagoboomen; hij levert het slechtste meel en de smalste bladeren tot huisbedekking.

5269. Lapia-molat AмB. = Metroxylum Sagus Mart. (Zie No. 1322.) 5270. Lapoo-kajas Lamp. $=\mathrm{Lep}$. taspis urceolata RBr. (Zie No. 1035.) 5271. Larah PAL. = Miristica subglobosa Miq. (Zie No. 888.)

5272. Larak J. $=\mathrm{S}$ apindus $\mathrm{R}$ arak D.C. (Zie No. 1483.)

5273. Larep laup. = Uvaria $\mathrm{L}_{\mathrm{a}}$ rep Miq., Nat. fam. der A nonacea. GR. Sumatra; slingerplant.

5274. Larep-poetih Laup. = Uvaria purpurea Bl. (Zie No. 573b.)

5275. Lariang $\mathrm{M} .=$ Phrynium obscurum T. \& B., Nat. fam. der Cannaceæ. GR. Sumatra; overblijvend.

5276. Lariang-oelar M. = Phryninm sumatranum $M$ iq., Nat. fam. der C a n n a c e $x$. Gr. Sumatra; overblijvend.

5277. Lariang-siro M. = $\mathrm{Phry}$ 
nium obscurum T. \& B. (Zie No. 5278.)

5278. Laroh.batoe IAMP. = Uvaria a crantha 11 iq. Nat. fam. der An on aceæ. Gr. Sumatra; slingerplant.

5279. Laronan S. = Macropanax oreophil um II iq., Nat. fam. der Araliaceæ. Gr. Java en Sumatra: heester.

5280. Lassa T. en

5281. Lassata Auв. $=$ Lansium d omesticum Jack. (Zie No. 98.)

ว28\%. Lassa-soerôe $\mathrm{T}$. $=\mathrm{C}$ o okia punctata Retz (Zie No. 99.) 5283. Lassi-lassi $\mathrm{T}$. $=\mathrm{S}$ e $\mathrm{m}$ e c a r. pus Forsteni i Bl,, Nat. fam. der A n a c a r d i a ce æ. Gr. Ternate; hooge boom. GeBr. Als No. 1569.; deze boom bevat een uiterst scherp melksap.

5284. Lassoena MaL. $=\mathrm{B}$ aw ang M.

5285. Lass00 Sum. = Parthenoxylon Pseudo-sassafras Bl. (Zie No, 2927e.)

5256. Latang J. \& N. = Fleurya interrupta G a ud. (Zie No. 1701.)

5287. Latar PAL. $=$ Urophyllum umbellatum Miq. (Zie No. 3246.)

5288. Late $11 .=$ Scleria flabel. lum Sw., Nat. fam. der Cyperaceæ. Gr. Vrij algemeen overal; overblijvend.

5289. Lateri MaK. 三 I pom œa pescapræ Sw. (Zie No. 1039)

5290. Latiang $\mathrm{II}$. = Urena $10-$ bata L., Nat. fam. der M alvace . Gr. In geheel Ned. Indië; kleine struik.

5291. Latoeng Bo. = Calamus J. et I) monorops Bl.

5292. Lau AxB. en

5293. Lauesiij Aмв. = Dracontomelon mangiferum Bl. (Zie No. 1492.)

5294. Lauewul Cr. $=a$. Casuarima equisetifolia Forst. en $=b$. (jas. nodiflora Forst. (Zie No. 122.)

5295. Lau lassi $\mathrm{T} .=a$. Se mecarpus cassuvium Sprg. (Zie No. 1569.) = 8. Semecarpus Forsten i i Bl. (Zie No 5283.)

5296. Laula-tomma-wanga T. = Scleria lithosperma Wlld. (Zie No. 30056$.

5297. Laun-maun Avr. = Medinilla crispata Bl., Nat. fam. der Melastomacer. Gr. Celebes en de Molukken; slingerplant. Gebr. Men eet het jonge groen en kent het, zoo in- als uitwendig toegediend, een sterke wondhee. lende kracht toe.
5298. Laupa Aмв. = Cyperus rotundus L., Nat. fam. der Cyperaс е æ. Gr. Vrij algemeen in Indië. Gebr. Deze kleine grassoort is door het vee, vooral door de varkens, zeer gezocht, om hare kleine ronde knolletjes; deze knolletjes zijn aromatisch-bitter en worden als excitans aangeprezen. Sommigen bezigen een aftreksel van den wortel tegen dysenterie en kauwen ze tegen caries der tanden. 5299. Lau-urit of La-ulit Амв. = Cedrela Toona Rxb. (Zie No. 267). 5300. Laus I., en

5301. Lawas of Lawassa Aмв. = Alpinia Galanga Sw. (Zie No. 2370.) 5302. Lawassa-wakkan Aмв. =Alpinia malaccensis Rosc. (Zie No. 392.)

5303. Lawâttan S. 二 I pom a polyanth a Miq. (Zie No. 50\%.)

5304. Law0-lampareng MAK, en 5305. Law0-pai $\mathrm{I}_{\mathrm{AK}}$. = I,agenaria vulgaris Ser. (Zie No. 3568.)

5306. Laijoemboe BL. = Ficus basidentula Miq. (Zie No. 5167. ) 5307. Lea Cer. = Zingiber officinale L. (Zie No. 253.)

5308. Leangan-babi Sum. $=\mathrm{E} b \mathrm{cr}$ mayera trichocephala Miq. Nat. fam. der A cantha ceæ. Gr. Sumatra; kruipende plant.

5309. Lebang.boenga $\mathrm{M}$. = Vitex heterophylla $R_{x} b$. Nat. fam. der Verben aceæ. Gr. Sumatra; hooge boom.

5310. Legetang $I$. = Spilanthes rugosa Bl. Nat. fam. der Compositæ. Gr. Jara; klimplant.

5311. Leha Алв. = Symplocos spicata Rxb. Nat. fam. der Symploceæ. Gr. Java cu de Molukken; kleine boom.

5312. Lehles Sum. = Ficus subracemosa Bl. (Zie No. 4867.)

5313. Lehmoh S. = Tetranthera polyantha Wall. var. citrata. Nat. fam. der Laurineæ. Gr. Java; hooge boom.

5314. Leilem Alf. Min. $=\mathrm{Cle}$ rondendrum Minahassæ. T. \& B. Nat. fam. der Verben a ceæ. Gr. Celebes; boomachtig. GEBR. Het jonge loof van dezen boom is een gezochte groente der inlanders.

5315. Leka-leka T. $=\mathrm{Z}$ ing iber a maricans Bl. (Zie No. 2401.)

5316. Lekat S. = Stylocoryna polycarpa Miq. Nat. fam. der $R$ ubi a cex. Gr. Java; boom. 
5317. Léker of Liker $\mathrm{M}$. = $\mathrm{Con}$ ophallus? sativus Schott. Nat. fam. der A roides. Gr. In de Molukken, gekweekt. GEBR. De knol wordt gegeten en er ook zetmeel uit bereid. Zij is echter giftig.

5318. Leketan I. = Myriactis javanica De. Nat. fam. der Compositæ GR. Java; éénjarig.

5319. Leko MaK. = Chavica Betle Miq. (Zie No. 28 s)

5320. Leko-boeloe-boeloe MaK. = Commelina benghalensis L. (Zie No. 2549.)

5321. Lekoep $\mathrm{BK}$. $=\mathrm{M}$ a $\mathrm{ng}$ if era $f$ o $t$ id a $L$ o u r. (Zie No. 274.)

5322. Lelapoetang ALF. Min. = Arnndinaria glaucescens Beauv. (Zie No. 954.)

5323. Lele Амв. = Leptosperm $u m$ a $m$ boine $n s$ e $R w d t$. (Zie No. 2885.)

5324. Leleba $\mathrm{Aмв.}=\mathrm{B}$ a $\mathrm{m}$ b u s a verticillata Bl. (Zie No. 756.)

5325. Leléma ALf. MrN. = Callicarpa lanata Vhl. (Zie No. 4020a.)

5326. Leles $\mathrm{S} .=\mathrm{P}$ og o n o troph e a u r a ti a c a Miq. Nat. fam. der A rt o c a r p e x. Gr. Java; klimplant.

5327. Leles-aroij $\mathrm{S}$. $\mathrm{P}_{\mathrm{o}}$ g o no. trophe $\mathrm{l} æ \mathrm{vis} \mathbf{M i q}$. (ZieNo. 607a.)

5328. Leloeti M. = Stipellaria Zollingeri B a ill. (Zie No. 5080.)

5329. Lemam-lemam BL. = Olax sum a tra na Miq. Nat. fam. der $\mathrm{O} l$ a c a c e $x$. Gr. Sumatra; heester.

5330. Lemo of Lemon M. MoL. = Citrus L.

5331. Lemoekab Bк. = $\mathrm{Rhizo-}$ phora latifolia Miq. (Zie No. 247.)

5\%32. Lemon-boeleijn $\mathrm{M}_{\mathrm{AK}}=\mathrm{C} \mathrm{i}$ trua limonellus Hassk. (Zie No. 76l.)

5333. Lemon-gantong Suм. = C itrus crassa Has sk. var. (Zie No 2063.)

5334. Lemon-hitam M. = Citrus $v$ u garis $R$ isso. Nat. fam. der A urantiace x. Gr. De Mlolukken; boom. GEBR. Men gebruikt de vruchten tot het wasschen van het hoofdhaar; het sap er van tot het poetsen van koperen ijzerwerk en om mede te verwen.

5335. Lemon-jabba T. $=\mathrm{Citrus}$ $P$ a peda Miq. (Zie No. 2077.)
5336. Lemon-java T. $=$ Citrus limonellus Hassk. (Zie No. 761.) 5337. Lemon-kabi T. $=a$. C it $\mathrm{ru} \mathrm{s}^{\mathrm{s}}$ bergamia Risso (Zie No. 2213.) $=b$. Citrus Papeda M iq. (Zie No. 2077.)

5338. Lemon-kaloekoe Mak. = Citr us decu in a n a L. (Zie No. 2054.) 5339. Lemon-kambar Mak. zie jemon-kabi T.

5440. Lemon-kapas MaK. $=$ Citrus li monellus Hassk. (Zie No. 761.) 5341. Lemon-karbou M. zie Lemonkabi $\mathrm{T}$.

5342. Lemon-kasoemba $\mathrm{M}$. $=\mathrm{Ci}-$ trus decumana L. (Zie No. 2054.) 5343. Lemon-koeramas $\mathrm{H} .=\mathrm{Le}$. mon-kabi T.

5344. Lemon-maas $\mathrm{M} .=\mathrm{C}$ it $\mathrm{r}$ us limonellus Hassk. (Zie No. T61.) 5345. Lemon-madura $\mathrm{M} .=\mathrm{C} \mathrm{i-}$ trus madure lis is Lou r. Nat. fam. der A u ra n ti a c e æ. Gr. Madura, Java; boom. Gebr. De vruchten dezer Citrus worden geconfijt gegeten.

5346. Lemon-manies-besaar M. 二

Citrus A urantium L. (Zie No. 2049.)

534'. Lemon-manies-tjina M. = Citrus nobilis Lour. (Zie No. 2062)

5348. Lemon-oetan-bersagie $M=$ L imonia angulos a IV. \& A. Nat. fam. der A u ranti a c eæ. GR. Java; heester.

5349. Lemon-papeda M. = Citrus

$\mathbf{P}$ a ped a $\mathbf{M}$ i q. (Zie No. 2077.)

5350. Lemon-papoea M. en

5351. Lemon-poeroet $\mathrm{M}_{\mathrm{.}}=\mathrm{C}$ itrus

limett a $R$ isso. (Zie No. 762.)

5352. Lemon-sengalea $M_{A K}=\mathrm{C}$ i-

trus no bilis Lo ur. (Zie No. 2062.) 5353. Lemon soesoe M. $=\mathrm{C}$ it $\mathrm{r}$ il s

medica I. (Zie No. 2050.)

5354. Lemon-swangi M. en

5355. Lemontaal-hajam M. = C i-

trus limet to Risso. (Zie No. 762.) 5356. Lemon-tinigara $\mathrm{T} .=\mathrm{Citrus}$ limonellus Hassk. (Zie No. 761 . 5357. Lemon-titigela $\mathrm{T}$. $=\mathrm{Citrus}$ $\mathrm{limetta} \mathrm{R}$ isso. (Zie No. 762.) 5358. Lemon-tjina M. = Citrus A u ra ntium L. (Zie No. 2019.)

5359. Lempoei J. $=A \mathrm{~g}$ ! a $0 \mathrm{n} \mathrm{e}-$ simplex Bl., Nat. fam. der A ro id e $x$. Gr. Jara en Sumatra; overblijvend. Gerr. Men gebruikt de bladeren om er 
tabak in tc pakken en te bewaren; met de bladstelen te zamen gekookt, geeft men ze dikwijls aan kraamvrouwen, ter bevordering der zuivering.

5360. Lempoeng $\mathrm{S} .=\mathrm{Arg}$ e mon e mexic a n a $L_{\text {., Nat. fam. }}$ der $\mathrm{P}$ a pav e r a c e æ. Gr. Hier en daar in tuinen; zaadplant. GERR. De Javanen eten de bladeren op sommige plaatsen als groente; zij bezigen ze uitwendig tegen verouderde huidziekten. In West-Indië geeft men een aftreksel der bladercn als zweetdrijvend middel, en op de Philippijnen trekt men ze met Maderawijn af, als gencesmiddel tegen vlekken op het hoornvlies en wratten. Het plantensap kent men een wondheelende kracht toc, en geeft het ook tegen waterzucht en syphilis. De zaden werken sterk emetisch.

5361. Lenat Aмr. en

5362. Lenat-frangi $\mathrm{Aм \textrm {s }}=\mathrm{S}$ e mecarpus Cassuvium Spreng. (Zie No. 1569 )

5363. Lenga J. \& $\mathrm{BL}_{\circ}=\mathrm{S}$ e sa$\mathrm{mum}$ indi c u m D.C. (Zie No. 246.)

5364. Lengar $\mathrm{Bk} .=\mathrm{My} \mathrm{ristica}$ b a n c an a $\mathbf{~}$ iq., Nat. fam. der M y$r$ isti c a c e æ. Gr. Bangka boom.

5365. Leng-keng $\mathbf{M}_{0}=a$. $\mathrm{Nephe-}$ li um Li t.ch i C a in b. (Zie No. 4124.) $=b$. Nephelium Long.y an B l. Nat. fam der $\mathrm{S}$ a $\mathrm{p}$ in $\mathrm{d}$ a $\mathrm{c}$ e $æ \mathrm{G}_{\mathrm{R}}$. Op Java en elders in tuinen; boom GEBR. Als bij No. 4124 )

5366 Lengoegoe $\mathrm{M}$. $=\mathrm{Fag} \mathrm{ræa}$ volubilis Wall. (Zie No. 975)

5367. Lengsar $\mathrm{S}$. $=a$. I rin a g l a bra Bl. (Zie No. 1465.) = b. I rin a tom e ntos a B l. (Zie No. 1676b.)

ว368. Lenpidoh $\mathrm{P}_{\mathrm{A}}$. $=\mathrm{Ch}$ i o n a nthus $p$ ale mbanic a $M$ i q., Nat. fam. der Ole in eæ. Gr. Sumatra; boom.

5369. Lentjiouw PaL. $=\mathrm{Hed}$ chium sumatranum Jack. (Zie No. 2410.)

5370. Leow Alf. Min. $=\mathrm{D} \mathrm{rac}$ ontomelon mangifer $n$ m B . (Zie No. 1492.)

5371. Lepiauw $\mathrm{BK}$. = A reca? crythropoda M iq., Nat. fam. der $\mathrm{P}$ a $1 \mathrm{~m}$ æ. Gr. Bangka; boom.

5372. Lepoer J. $=\mathrm{Embeli} \mathrm{a} \mathrm{clu.}$ siæfolia 11 iq., Nat. fam. der M yrs i n e æ. Gr. Java; slingerplant.

5373. Letak-mêrih $\mathrm{S} .=\mathrm{W}$ h itia c a r u o s a B l., Nat fam. der Cyrtan d r a c e æ. Gr. Java en Sumatra; heester.
5374. Letta-haijam $\mathrm{S} .=a$. P ouzolz i a indica Ga ud. (Zie No. 2141.). $=6$. Hy rtanandra hirta Miq., Nat. fam. der U r t i c a c e æ. GR. Java; overblijvend.

537 . Leuntja $\mathrm{S} .=a$. L y c o persicum esculent u m Mill. (Zie No. 1111.) $=b$. Sol a n $\| \mathrm{m} u \mathrm{igrum} \mathrm{L}$. c u m vari e tt. (Zie No. 1660.)

5376. Leuntja-badak $\mathrm{S} .=\mathrm{Sola}$ n u $\mathrm{m}$ p ubescens Wlld., Nat. fam. der S o l a n e æ. Gr. Hier en daar in het wild en in tuinen; heester.

5377. Leuntja-bonglot $\mathrm{S} .=\mathrm{S}$ ol an u m denticulatum Bl. (Zie No.) 1345b.)

5378. Leuntja-burrum $\mathrm{S}$. $=\mathrm{S}$ olan u m atroviola ceum T. \& B. Nat. fam. der S o l a n $\mathrm{c}$ æ. Gr. Java; overblijvend.

5379. Leuntja-komier $\mathrm{S} .=a . \mathrm{S}_{0}$. la n u m nigrum L. (Zie No. 1660.) $=b$. L y copersicum esculentum Mill. (Zie No. 1111.) $=c$. L y co persicum ceras iforme Des n,. Nat. fam. der $\mathrm{S}$ o l a $\mathrm{n}$ ex. Gr. In vele tuinen; zaadplant. Gebr. Als bij No. 1111.

5380. Leuntja-monjet $\mathrm{S}$. = S o lan u m n i gr u nı L. (Zie No. 1660.)

5381. Lewer of Lewir $\mathrm{BD} .=\mathrm{Se}-$ mecarpus Cassuvium Spreng. (Zie No. 1569.)

5382. Liada $\mathrm{C}_{\mathrm{R}}=$ P t e r o carpus. fl a vus D.C. (Zie No. 735.)

5383. Lian Амв. $=$ Ventilago maderaspatana Gærtn. (Zie No. 999.)

5384. Libe-haloen $\mathrm{C}_{\mathrm{R}}=\mathrm{V}$ itis in d i c a L. (Zie No. 349.)

5385. Lidah-ajam M. $=a$. P olyg a l a javan a D.C., Nat. fam. der $\mathrm{P}_{0}$ ly g a l e . Gr. Java; overblijvend. = b. Pachycentria constricta Bl. (Zie No. 2748.) $=c$. S per macoce s c a b errima B l. (Zie No. 8263.)

5386. Lidah-andjing $\mathrm{M} .=$ Vernonia cinerea Less. (Zie No. 67a.)

5387. Lidah-badak M. $=\mathrm{O} p$ untia cochinillifera Mill., Nat. fam. der $\mathrm{C}$ a c te $x, G_{R}$. Op Java cn elders in tuinen; heester. GrBr. Deze wordt veelvuldig anngekweekt voor de cochenillekultuur.

5388. Lidah-bejbekh M. $=a$. Wh $\mathrm{i}$ tia carnosa Bl. (Zie No. 5373.) = $b$. Whitia oblongifolia Bl., Nat. fam. der C y r tandrace a. Gr. 
Java; leester. $=c . \mathrm{R}$ en a n the r a mat u $t$ in a Lind l., Nat. fam. der () rc h i d c a. Gr. Java; parasiet.

5390. Lidah-boeaija M. = A lö̈ b a r badensis Mill., Nat. fam. der Lili a c ex. Gr. Op Java en elders in tuinen; hecsteraehtig. GEBr. De gekneusde bladeren legt men tegen hoofdpijn op het voorhoofd; tegen het uitvallen van het hoofdhaar waseht men dit met het plantensap. Nadat de bladeren met kalkwater een tijd zijn uitgetrokken, makkt men er op Java cen soort gebak van, cn bereidt er ook een soort drank uit, Tjintjouw genaamd. Nog geeft men deze bladeren als ontlastingbevorderend middel tegen sommige buikaandoeningen.

5391. Iida-lidah $\mathrm{M} .=\mathrm{B}$ a $\mathrm{u} \mathrm{h}$ i $\mathrm{n}$ i a t o m e n t o s a I. (Zie No. 4497 a.)

5392. Liada-tiong Sum. WK. $=\mathrm{P}_{0}$ t a moget on natans L. (Zie No. 1195.)

5393. Liempaung Sur. = $\mathrm{H}$ e d yc a r pus cauliflora Has sk., Nat. farn. der Sapinda e e $a$. Gr. Java en Sumatr'a; boom.

5394. Lijitschoe $\mathrm{AuB}_{0}=\mathrm{A}$ l s t o $\mathrm{n}$ i a s e holaris R.Br. (Zie No. 2350.)

5395. Liketan J. $=\mathrm{Spilanthes}$ r ll gos a B l. (Zie No. 53:0.)

5396. Lili T. $=\mathrm{B}$ a sella rubra I. (Zie No. 2419a.)

5397. Lilisoengan of Lieliesoenan S. = Cyperus dilutus Vahl, Nat. fam. der C y p e r a c e x. Gr. Java.

5398. Lilitan-koetoe Sum. WK. = Pipturus velutinus Wedd., Nat. fam. der Urtic a ce ic. Gr. Java, Sumatra; de Molukkeu; heester.

5399. Liluwi 'T'. $=a$. C a s u a rina equ isctifolia $I_{\text {. }}$. en $=b$. Casuarina llodiflora Forst. (Zic No. 122.)

5400. Lima-0etan 13k. = I, n v $1 \mathrm{n} \mathrm{g}$ a calophylla Kz. Nat. fam. der Rutac č. Gr. Bangka.

54.01. Limang Bк. = Uvara f l a va T. en B., Nat. fam. der A n oи a с с х. Gr. Bangka; slingerplant.

54,02. Liman-poeroet-0etan Bк. = Pyramidanthe rufa Miq. (Zic voren.)

5303. Limassen-ketjil Sum. W.K. = Soncrila tenuifolia Bl. (Zic No. 2020e)

5404. Limatoeri $\mathrm{C}$. Fxo carpus phyllanthoides Endl. (Zie No. 1\%17.)
5405. Limau-saring $\mathrm{M}_{\text {. SuM }}=\mathrm{C} \mathrm{i}$. trus hystrix D. C.

5406. Limoe-limoe Sum. W.K. = Limonia spectabilis Miq., Nat. fann. der A uralliaeer. Gr. Sumatra; boom.

5407. Limoeng-sering SuM. W.K. $=\mathrm{X}$ a n t ophyllum ad c nopodum M i q. (Zic No. 3903c.)

5408. Limoes $\mathrm{M}_{0}=a$. $\mathrm{Mang} \mathrm{i-}$ fera fotida I, o r. (Zie No. 274.) $=6$. Mangifera ind ic a L., var. L i m o es. (Zie No. 275.)

5409. Limoh $\mathrm{S} .=\mathrm{T}$ et $\mathrm{ran}$ the $\mathrm{ra}$ citrat a $\mathrm{Nees}$. (Zie No. 401.)

5410. Limoh-limoh Sum. W.K, = Endiandra? euneata Miq. (Zie No. 3257.)

5411. Limoh-oetan Sum. WK. = Glycosmis pentaphylla Colebr. (Zie No. 1148.)

5412. Limpata Sum. WK. = Urostig m a De pen horstii M i q., Nat. fam. der A r to e a pe s. Gr. Sumatra; boom.

5413. Limpatoe $M_{0}=$ A r to e a rpus I,impato M i q., Nat. fam. der A r t o a r p e . Gr. Sumatra; boom.

5414. Linat of Linata Амв. = S em e car p u s Cassuvi u $\mathrm{m}$ s prg. (Zie No. 1569.)

5415. Lingöa $\mathrm{M}$. $=\mathrm{P}$ te ro e a $\mathrm{r}$ p us indic us W 11 d. (Zie No. 18.)

5416. Lingöa-batjang $M$. = Pteroc a r p u L. S pec. a mboin. indef. Dezc boom levert een goed bouw-en mellbelhout.

5417. Lingoa-batoe Амв. = $\mathrm{Pte}$ rocarpus saxatilis $R \mathrm{mpl}$ l.. Nat. fam. der Papilionace ac. Gr. De Mo. lukken; hooge boom. GEBR. Als bij No. 18 .

5418. Lingoa-boenga $M \mathrm{kN} .=\mathrm{P}^{\mathrm{te}} \mathrm{e}$ r o c a r p u s I. S p e c. C c l e b. i i d e f.; deze boom lerert een fraai neubelliout.

5419. Lingoa-gabba-gabba Амв. = Pterocarpus mollis $R \mathrm{mph}$. Nat. fam. der Papilio n a e a. Gr. De Molukken; boom.

5420. Lingoa-kastoerie $А$ мв. l'terocarpus saxatilis liumph. v a riet. ('/ic No. 5417.)

5421. Lingoa-meirah $\mathrm{M}$. = $\mathrm{Ptc}$ roc a r p us l., Spec. A mboin. indef.

5422. Linjal $\mathrm{J}=\mathrm{Col}$ o c a s i a a $u$ tiqu or $u$ m S c h o t t. (Zic No. 24.5.) 542\%. Linjoewang rimbo M. = Pollia japouica Thnb., Nat. fam. der 
C ommelynacex. Gr. Java en Sumatra; overblijvend.

5424. Linrapa MaK. $=$ Emilia son chifolia D. C. (Zie No. 2221.)

ว425. Lipa $\mathrm{S} .=\mathrm{N}$ i p a fr n t i cans W u r mb. (Zie No. 856.)

5426. Lipo M. = Ficus septica $\mathrm{R} \mathrm{m} \mathrm{ph}$. (Zie No. 764a.)

5427. Lipoeng $\mathrm{S}$. $=\mathrm{Phrynium}$ Wlld. Spec. diversere, Nat. fam. der Can n c ex. Gr. Java en elders; overblijvende planten. Gkbr. 1)e bladeren gebrnikt men tot het dekken van hnizen en het inpakken van goederen.

5428. Lire $\mathrm{T}$. $=\mathrm{Rucllia} \mathrm{re}-$ p a n d a L. (Zie No. 91.)

5429. Lire-lire $\mathrm{T}$. $=\mathrm{R}$ u e $\mathrm{ll}$ i a $\mathrm{d}$ i sc olor Necs. (Zie No. '72.)

5430. Lisoe-lalakki $\mathrm{S} .=\mathrm{Hed} \mathrm{y}-$ c arpus javanicus $\mathrm{M}$ iq., Nat. fam. der Euph or bi a c e c. Gr. Java; klcine boom.

5431. Lisoem Вк. $=\mathrm{Z}$ a l a c с a Wallichiaua Mart. (Zie No. 5070.)

5432. Litchi M. = Neple lin m L it-ch i C a m b. (Zie No. 4.124.)

5433. Lite $\triangle \mathrm{MB} .=A l s t o n$ ia schol aris R. Br. (Zie No. 2350.)

5434. Litjoh $M_{0}=$ Urostigma saxophilum Miq. (Zie No. 1321b.)

5435. Loä $S .=a$. Urostigma i n fectorium Miq., Nat. fam. der A r o c a r p ca. Gr. Java en Sumatra; boom. $=b$. Urostigma lucescens M i q., Nat. fam. dezelfde. Gr. Java; boom. Gebr. Het roode, lichte cn grove hout bezigt men tot het vervaardigen van eetgereedschappen, als doelangs, schotcls, enz. De vrnchten zijn zoet cn cetbaar, echter niet lekker.

54.36. Löa-sabrang $M$. = Corellia glomerata Ml q., Nat. fam. als voren. Gr. Java; hooge boom.

5437. Lobak M. \& $S$. $=R$ a phan us c a ud a $t$ us L., Nat. fam. der Cru c ifer ce. Gr. Door gehcel Indië in tuinen gekweekt; zaadplant. Gribr. Dc witte wortel wordt, even als de radijs, ranw met zont gegeten of wcl afgekookt bij de rijst, evenzoo gebruikt men de bladeren ranw en gekookt als groente.

5.338. Lobe-leyposso Aмв. $=\mathrm{Nc}$ penthes phyllamphora Wlld. (Zie No. 128.)

5439. Lobi-lobi-assam M. = Flaconrtia sapida Rxb. (Zie No. $4933 a$.)

5440. Lobi-lobi-manies $\mathrm{M}=\mathrm{Fla}$ - courtia R.ukain Z. \& M. '(Zie No. 4.15.)

5441. Lobi-lobi-sepat M. = Flaconrtia Yangomas Gmel. (Zie No. 3670 .)

5442. Loeffe-loeffe T. $=a$. Ocimum gratissimum I. (Zie No. 1458b.) $=b$. Ocimum sanctum L. (Zie No. 875.)

5443. Loehoe Amb. $=$ Arenga sacch arifera Lab. (Zie No. 243.)

5444. Loehoe-loehoe-akkar PAL. = D) issochrta palembanica Miq. Nat. fam. der Melastomacea. Gr. Sumatra; slingerplant.

5445. Loehoe-loehoe-gadjah PiL. = Melastoma sanguineum Don. (Zie No. 2260.)

5446. Loekoet-tjai S. $=a$. I, e m n a minor L. Nat. fam. der Lemnacex Gr. Vrij algemcen in Indië; waterplant. $=b$. Spirodela polyrhiza Schleid. Nat. fam. als voren. GR. De Sunda-Archipel; waterplant. $=c$. A zolla decomposita Zoll. Nat. fam. der Salvinia. cex. Gr. Java. $=d$. Salvinia elegans Hassk. Nat. fam. als voren. Gr. Java. $=e$. Marsilea quadrifolia I. Nat. fam. der Marsileaceir. Gr. Java; alle waterplanten.

54.47. Loelajo T. $=$ Graptophyllun hortense Nees. (Zic No. 90.)

5448. Loeleba $\mathrm{T}$. $=\mathrm{Bamb}$ a sa verticillata Bl. (Zie No. 756.)

5449. Loeli-loeli T. = Codiæn m molnccanum Desn. (Zie No. 126.)

5450. Loeloeän-sapi I. = S i s y rinch i um latifolium Sw. (Zie No. 1068.) 5451. Loeloeban $A м$ в. $=$ Loeffeloeff $\theta \mathrm{T}$.

5452. Loeloen Амв. = Heritiera littoralis Dryand. (Sie No. 752a.)

5453. Loeloena-tea BD. $=$ Clerodendrum infortunatum T. (Zie No. 758.)

5454. Loemboe I. = D i o scorea al a ta L. (Zie No. 2808a.)

5455. Loenboei Mot. = Flagellaria indica $\mathbf{T}$. (Zie No. 135.)

5456. Loemei Sum. Wh. = Argostemma micronidc Miq., Nat. fam. der R nbiace a. Gr. Sumatra; overblijvend.

5457. Leemis BG. = $\mathrm{Mangifera}$ minor Bl. Nat. fam. der Anacardiac е æ. Gr. Celebes en de Molıkken; boom. Dc vruchten dezer Mangasoort zijn minder gezocht. 
5458. Loemoe Maк. = Loelon Амв. 5459. Loemoet I. \& M. 三 Limnophila sessiliflora Bl. Nat. fam. der Serophularinex. Gr. Op Java en elders; waterplant.

5460. Loemoet-meragan I. 二 Di. cranum nanum Müll. Nat. fam. der Brya eeæ. Gr. Java; mossoort.

5461. Loemoet-warakas I. $=\mathrm{F}$ issidens filicinus Dz. \& Mlkb., Nat. fam. als voren. Gr. Java; mossoort.

5462. Loemoet-watoe I. = Sehlotheimia gonorrhyneha Dz., \& Mkb, Nat. fam. als voren. GR. Java; mossoort. 5463. Loendang Sum. $=a$. Myristiea valida Miq., Nat. fam. der Myristicere. Gr. Sumatra; boom. $=b$. Conoeephalus aznreus T. \& B., Nat. fam. der Artoearper. Gr. Sumatra; klimplant.

5464. Loending Sum. \& Bк. = $a$. Fieus gossipyra Wall. Nat. fam. der A rtosarpeæ. Gr. Sumatra; boom. = Fieus subraeemosa Bl. (Zie No. 4867.)

5465. Loenga-tambang I. $=\mathrm{A}$ e alypha densiflora Bl., (Zie No. 1440.)

5466. Loentas M. = Plachea in-. dica Bl.

5467. Loepa Вк. =a. Psyehotria l сuеосагpa Miq. Nat. fan. der Rubi acex. Gr. Sumatra, Bangka, Borneo; heester. $=b$. Psychotria sarmentosa B1., Nat. fam. als voren, Gr. Java, Bangka en Borneo; klimplant.

5468. Loessa-radja M. $=\mathrm{Brueea}$ sumatran a Rxb. (Zie No. 296.)

5469. Loetoe Bo. $=a$. Dioscorea a la ta L. (Zie No. 2808a.) $=b$. Dioseorea vulgaris Miq. (Zie No. 2808b.)

5470. Loetoe-kastela BD. $=\mathrm{B}$ a tatas edulis Chois. (Zic No. 635)

5471. Loetröa Амв. = Datura $\mathrm{I}_{\text {. }}$. Speeies plurimæ.

5472. Loettoen Амв. $=\mathrm{J}$ ambosa domestica Rmph. (Zie No. 1922.)

5473. Lofitti $\mathrm{T}$. $=$ Acalypha densif lor a Bl. (Zic No. 1440.)

5474. Lofitti-saloo-0ehi T. = A c alypha Caturus Bl. (Zie No. 2291b.)

5475. Logoeni S. = Ardisia a ttenuata Wall., Nat. fam. der $M$ yr. s in er. Gr. Java; heester.

5476. Lohoessoel Aмв. = G a r e i$n$ i a e ornea I. (Zie No. 2026a.)

5477. Lokan Sum. = Lasianthera seeandiflora Miq. (Zie No. 4565c.)
5478. Lokan-lokan SuM. $=\mathrm{V}$ a $\mathrm{n}$ gueria spirostylis Miq. Nat. fam. der Rubiaceæ. Gr. Sumatra; heester.

5479. Lokhsa S. = Conocephalus suaveolens Bl. (Zie No. 518.)

5480. Lolah Alf. MrN. = Fieus rhizoearpa T. \& de Vr., Nat. fam. der A rt o earpex. Gr. Minahassa; boom. GEBr. Het hout is gesehikt voor planken.

5481. Lolan Амв. $=$ Cæsalpin ia Sappan L. (Zie No. 1807.)

548\%. Lolan-ahoek Aмв.

54.83. Lolan-laijnoehi Амв, en

5484. Lolan-pantej Амв. $=$ S ophora tomentosa L. (Zie No. 1490.)

5485. Lolaroe M. MoL. $=\alpha . \mathrm{B} \mathrm{r} \mathrm{u}$ gniera Rumphii Bl. (Zie No. 866b.) $=$ b. Rhizophora conjugata $L$. (Zie No. 865.)

5486. Lolaroe-tomma-banga T. 二 Mangifera laxiflora Desr. (Zie No. 3021.)

5487. Lolin Амв. = Dyospyros Ebenum Retz. (Zie No. 32.)

5488. Loloh of Lolloh S. $=a$. Scin. dapsus Sehott. = $b$. Raplidophora $\mathrm{H}$ a ss k.; beide geslaehten van de Nat. fam . der A roidex.

5489. Loloh-bener $\mathrm{S} .=\mathrm{M}$ onstera eannæformis Sehtt, Nat. fam. der Ar oi deæ. Gr. Java; klimplant.

5490. Loloh-blang $\mathrm{S}$. $=$ Scindapsus pietus Hassk., Nat. fam. als voren. Gr. Java; slingerplant.

549i. Loloh-kawat $\mathrm{S}$. $=\mathrm{S}$ cinda $\mathrm{p}$ sus montanus Kth. (Zie No. 406.)

5492. Loloh-keboh S. = S c in d a psus pertusus Sehott., Nat. fam. als voren. Gr. Java, Sumatra, enz.; klimplant. GEвr. De luehtwortels bezigt men als touw ; de bladeren geeft men als wormdrijvend middel aan paarden.

5493. Loloh-moending S. (Zie vorig No.)

5494. Loloh-monjet $\mathrm{S}$. = S cindapsus offie inalis Sehott., Nat. fam. als boven. Gr. Java; klimplant GEBR. De bloernseheden verkoopt men in Bengalen als wormdrijvend middel onder den naam vall is u j-p i p u li.

5495. Lolo-monjet-leutiek $\mathrm{S} .=$ S e indaps us lingulatus Hassk, Nat. fam. als voren. Gr. Java; klimplant. 5496. Loloijang AlF. Min. 三 Ficus septiea Rm ph. (?). ('Zie No. 764a.) 5497. Loloro 'T. 三 I p o m a pesc a præ Sw. (Zie No. 1039.) 
5498. Lom J. = Pithecolobium u m bellatum B nth. (Zie No. 2086.)

5499. Lomba J. = Pothomorphe subpeltata Miq. (Zie No. 86.)

5500. Lombok J. = C a p sicum a n n u u m L. \& ali $\mathrm{S}_{\mathrm{p}}$ e c i es., Nat. fam. der $\mathrm{S}$ o l a a e $x$. GR. Door geheel Indië in tuinen $\mathrm{cn}$ in het wild; éénjarig. GEBR. De vruchten dienen tot specerij in dc meeste spijzen en zijn onmisbaar bij de rijsttafel; dc genceskrachtige aanwending, veelal uitwendig, verschilt niet veel van die in Europa.

5501. Lombok-rawèh of L-setan J. $=$ Capsicum fastigiatum Bl., Nat. fam., Gr. en GEBr. als voren.

5502. Lontar M. $=a$. B or a s u s flabelliformis L. (Zie No. 3117.) $=b$. I ivistona rotundifolia $\mathrm{M}$ a r t., Nat. fam. der $\mathrm{P}$ a $\mathrm{lm}$ æ. GR. Java, Celebes, Ceram; hooge Palm. Gebr. De bladeren van dezen 80 tot 100 voet hoogen Palm gebruikt men voor zonneschermen en tot het inpakken van goederen: van het hout maakt men daksparren en werpspiesen.

5503. Lontar-0etan M. = C o r y$\mathrm{pha}$ u mbraculifera L., $\mathrm{var}$ - $\mathrm{mi-}$ n o r. (Zie No. 1528.)

5504. Lontja-bonglot $\mathrm{S}$. $=\mathrm{Sol}$ anum denticulatum B l. (Zie No. $1345 b)$

5505. Lo-0etan J. = Hiptage II a d a b l o t a $\mathbf{G} æ r$ t n. (Zie No. 3564.) 5506. Lopang M. \& S. 二 $a . \mathrm{B}$ r y o$\mathrm{n}$ i a sc abrella I. L. (Zic No. 458.) $=b$. Trichosanthes costata B l. (Zie No. 62l.)

5507. Lo-pit Сн. Bo. $=\mathrm{R} \mathrm{a} \mathrm{pha.}$ n u s c a u d a tus J. (Zie No. 5437.)

5508. Loreh-mingarot $\mathrm{J}_{0}=\mathrm{P}^{0}$ 1 y g on um Posumbu H am. (Zie No. 1004.)

5509. Lorin $\mathrm{Am}$. $==\mathrm{D}$ i o spy $\mathrm{pos}$ E bc u m R etz. (Zic No. 32.)

5510. Loro-garoet $\mathrm{J}$. $=\mathrm{Achy}$. $r a n t h e s$ bidentata Bl. (Zic No. 740. .)

วั511. Loro-setoe J. = Andropo- gon muricatus Retz. (Zie No. 241.) 5512. Loro-wedoe J. $=\mathrm{Ad} \mathrm{hato.}$ da Betonica Nees. (Zie No. 2123.) 5513. Lorok J. $=\mathrm{S}$ a p indus $\mathrm{Ra}$ r a k D.C. (Zie No. 1483.)

5514. Lossa-Lossa Амв. $=a$. Bоnn a y a veronic felia $\mathrm{Spr}$. (Zie No. 79a.) $=b$. De n tell a repcns Forst. (Zie No. 79b.) =c. V a nd alli a crustace a Bnth.(Zie No. 2155a.) 5515. Lossal Mor. $=\mathrm{Cedr}$ ela To on a $\mathrm{R} x$ b. (Zie No. 267.)

5516. Loto-loto $\mathrm{M} .=a . \mathrm{C}$ a r d i o sperm um Halicacab um L. (Zic No. 433.) $=b$. Phsalis indica I a m. (Zie No. 1682b.)

5517. Lottoe-lottoe Амг, $=\mathrm{Sph}$ rococus lichenoides A g., var. t e $\mathrm{n} u$ is A g. (Zie No. 21.)

5518. Lou-lite Амв. = L a c t a r ia salubris $R \mathrm{mph}$., Nat. fam. der A p o с у n e $x$. GR. De Molukken; kleinc boom. GeBr. Men dient den wortel uitwendig toe tegen verschillende pijnen $\mathrm{cn}$ ziekten, en geeft hem inwendig als krampstillend middel tegen diarrhoea en cholera.

5519. Lou-lou-idjoe T. = A r u nd o $\mathbf{L}$.

5520 Lour $\mathrm{Am}$. $=a . \mathrm{C}$ a s u a $\mathrm{r}$ in a e quisetifolia Forst. en $=b$. Cas. nodiflora Forst. (Zie No. 122.)

5521. Louw T. $=\mathrm{Me} \mathrm{loc}$ a n n a h u milis R u pr., Nat. fam. der Gra. $\mathrm{m}$ in $\mathbf{c} æ$. Gr. Java en dc Molukken; Rietsoort. GrBR. De stokken van dit rict bezigt men voor hciningen en ook veclal voor groote vischfuiken of seroo's in zec.

5522. Lowara Cer. $=\mathrm{Gmclina}$ villos a $R \times$ b. (Zie No. 965.)

5523. Lungsir $\mathrm{S}$. $=\mathrm{Neph} \mathrm{cli} \mathrm{u} \mathrm{m}$ a ltissi m um T. \& B., Nat. fam. der S a p ind a c e æ. Gr. Java; hooge boom. 5524. Lunijar $\mathrm{J}_{\mathrm{N}}=\mathrm{M}$ o r o c a r pu s l o n g ifol i u s B l., Nat. fam. der U rt i c c æ. Gr. Java en Sumatra; hecster. 5525. Luha Mor. $=\mathrm{Mclanolc}$ pis? c a lcosa M iq. (Zie No. 37.) 
W.

5526. Maänuno $\Lambda$ мв, = C o r y $\mathrm{p} \mathrm{h} \mathrm{a}$ $u \mathrm{mb}$ a e ul ifera L. var. $\mathrm{m}$ in or. (Zic No. 1528.)

5527. Maboa-pantej Амв. = M ue un a gigantea D.c. Nat. fam. der Papilionacer. Gr. Door geheel Ned.-Indië; overblij vende slingerplant, GEBR. Vermoedelijk als bij No. 1699 is opgegeven.

5528. Mada-kakka 'T. $=\mathrm{P}^{\prime}$ h a $\mathrm{n}$ e $\mathrm{r}$ a? lingu a $\mathrm{M}$ i q. (Zie No 1750.)

5529. Madang (ook Medang) M. = Phoebe? holoseriee a Bl. Nat. fam. der L a urineæ. Gr. Sumatra; hooge boom.

5530. Madang-aloe $\mathrm{M} \cdot=\mathrm{A}$ e e $\mathrm{r}$ l a u rin u m Hassk. (Zic No. 789.)

5531. Madang-andjoeli Sum. WK. = Unon a dasymasehala Bl. (Zie No 574.)

5532. Madang-api-api M. = a. Crypt o e a rya impressa Mi q. Nat. fam. der $L_{\text {a }}$ u $r$ ine $x$. Gr. Sumatra; boom.= b. $\mathrm{H}$ a a s i a cl ong a t a B l. Nat. fam. als voren. Gr. Sumatra; hooge boom. GeBr. De stam van dezen boom levert een duur. zaam, doch niet zeer hard bouwhout; de schors is bitter-aromatisch.

5533. Madang-bedaka BK. = Tetranthera? oehrascens Miq. Nat. fam. der La urinex. Gr. Bangka; boom.

5534 . Madang-boenga-tandjoeng $M$. $=a$. Artabotrys parviflora Miq., Nat. fam. der A n o nacex. Gr. Sumatra; klimplant. $=b$ Monoceras odontopetalum Miq. Nat. fam. der Tiliae ex. Gr. Sumatra; hooge boom.

5535. Madang-boengka Suм. Wк. = Schima erenata Korth. eum. va rictas., Nat. fam. der Camelli a e $x$. Gr. Sumatra en Borneo; boom.

5536. Madang-boengkal $\mathrm{BK} .=a$. Cyanodaphne cuneata B1. (Zie No. 1880) $=b$. Tepidadenia cuntata Bl., Nat. fam. der I a uriner. Gr. Sumatra; boom.

5537. Madang-boewa-pala M. $=a$. Myristiea ealoearpa Miq. en $=b$. Myristiea sycoearpa Miq. Nat. fam. der Myristieeæ. Gr. Sumatra; boomen. 5538. Madang-dammar $\mathbf{M}=\mathbf{M}$ a $\mathrm{p}$ pa molueeana Spreng. (Zie No. 56.) รั53ง. Madang-djoendjoeng P'AI. =
A etinodaphue gracilis lliq. Nat. fam. der L a u r i n e x. Gr. Sumatra; boom.

5540. Madang-gandja Sum. $W_{\kappa}$. = Covellia grandifolia Miq. Nat. fam. der A rto e a r pex. Gr. Sumatra; boomachtig.

5541. Madang-gandja-nandjanten Sum. Wк. = L e p i da den i a $\mathrm{mag} n \mathrm{i}$ fi c a $M$ i q., Nat. fam. der $L_{4}$ a u r i n e Gr. Sumatra; boom.

5542. Madang-goegoer Sum. WK. $=$ Canthium polyanthum Bl., Nat. fam. der $\mathrm{R}$ u b i a c e $æ$. Gr. Sumatra; bnom.

5543. Madang-kajoe-kaleh Suм. $W_{\kappa}$. = Guatteria hypoleuea $\| l i q .$, Nat. fam. der A n o u a e ex. Gr. Sumatra; boom.

5544. Madang-karoes LAMP. $=\mathrm{Cy}$ lic od aphne obtusifolia Nees. (Zie No. 3376.)

5545. Madang-kladie M. $=\alpha$. T etranthera? subobovata Miq. Nat. fam. der $L$ a u $r$ in ex. Gr. Palembang; boom. $=b . \mathrm{Mang}$ lietia Oortii $\mathrm{K}$ or th. eu $=c$. M a nglietia sumatr a n a M iq., Nat. fam. der M a g 1 oli a c e æ. Gr. Sumatra; hooge boomen.

5546. Madang-koelit-manies $\mathrm{M}$. = a. Cinnamom $\mathrm{m}$ C ulilaw a u $\mathrm{N}$ e es. (Zie No. 2287.) $=b$. C inn amom u m eyrtopod um Miq. (Zie No. 4902.) $=c$. Cinna m o m m e u caly p to ides $\mathrm{N}$ e es. Nat. fam. der Laur i n e $x$. Gr. Java en Sumatra; hooge boom, $=d$. Cinn a mom um s u bave n i u m M i q. Nat. fam. dezelfde. Gr. Sumatra; boom.

5547. Madang-koeniet $M_{0}=P$ aratropia littoralis Mi g. Nat. fam. der A r a li a e e 2. Gr. Sumatra; heester.

5548. Madang-koening $\mathrm{M} .=a$. Cryptoearya palembaniea Miq. Nat. fam. der T، a u r i boom. $=$ b. Ph o e be? nitida Bl., Nat. fam. en Gr. Dezelfde; hooge boom.

5549. Madang-langhit $\mathrm{BK} .=\mathrm{L}$ i ts a a e h ry s o c o m a B I, Nat. fam. als voren. Gr. Java en Bangka; boom.

5550. Madang-lèso M. = Parth enoxylon porrectum Bl. (Zie No, $3262 b$.) 
5551. Madang-merawas Laup. = Tetrantera M crawas Miq. Nat. fam. der L a u rinex. Gr. Sumatra ; boom.

5552. Madang-padie $B k .=L i t s æ a$ latifoli a B l. (Zie No. 2939.)

5553. Madang-parrie M. = A c r ocarpus combretiflorus T. \& B. Nat. fam. der Papilion a c e Gr. Sumatra hooge boom.

ร̌554. Madang-patjang Suм. Wк. $=\mathrm{El}$ × ocar pus macrocarpus M i q., Nat. fam. der Tili a c e æ. Gr. Sumatra; boom.

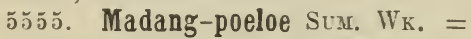
Guatteria hypoleuca Miq. (Zie No. 5543.$)$

5556. Madang-pondok Suм. WK. = Gu a t teria Pondok Miq. Nat. fam. der A n on a c a. Gr. Sumatra; heester.

5557. Madang-prawas $\mathrm{II}=\mathrm{P}_{0}$ $1 \mathrm{y}$ adenia lucida Nees. (Zie No. $2921 a)=b$. Syzggium brachybotryum Miq. (Zie No. 3190.)

5558. Madang-rewang LAMP. = $H$ a a $\mathrm{s}$ ia su b c æ s i M Miq. Nat. fam. der L a u r in e 2 . Gr. Sumatra boom.

55ว9. Madang-rimbo Stu. $\mathrm{WK}_{\mathrm{K}}$. = E $l æ o$ c a r p us ubdenticulatus M i q. Nat. fam. der Tili a cex. Gr. Sumatra; boom.

5ว60. Madang-sangi $\mathrm{M} .=\mathrm{C}$ r y $\mathrm{p}$ t oc a r y a crassinervia Mi q. Nat. fam. der L a u rine æ. Gr. Sumatra; boom.

5ว61. Madang-sangka Sux. WK. = Buch a nania macrophylla Bl., Nat. fam. der An a c a rd i a c e æ. Gr. Sumatra en Borneo; hooge boom.

5̌62. Madang-santen Sus. WK. = A rtroph fllum diversifolium B 1. (Zie No. 4464b.)

5563 . Madang-sarang-poetih Suxr. WK. = Elæocarpus hyadenus Mi q. (Zie No. 1606b.)

5564. Madang-sekan $\mathrm{Bk}$. en

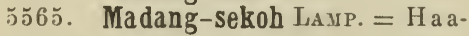
sia cæsia Bl., Nat. fam. als voren. Gr. Java en Sumatra; boom.

5566. Madang-selawang M. = A c rou ychia pedunculata Miq., Nat. fam. der l) ios m e x. Gr. Sumatra $\mathrm{Ok}$; boom.

5567. Madang-seloàng $\mathrm{P}_{\mathrm{AL}}$. = Is $\mathrm{e}$. pidadenia? Seloäng Miq., Nat. fam. der L a ur in exe. Gr. Sumatra; boom. ธ̌ร6. Madang-seloewang Вк. =
A lseodaph ue txe lsa Bl. (Zie No. $4650 d_{\text {.) }}$

556?. Madang-serai BK. = Tetranthe ra ban can a II i q., Nat. fam. der L a u r in e e. Gr. Bangka; boom.

5570. Madang-seroe $\mathrm{M} .=\mathrm{Ph} \propto$ be? holoserice a Bl. (Zie No. 5529. .)

5571. Madang-soehoen $\mathrm{M}$. = A ctinodaphne macroptera $\mathbf{M i q . .}$ Nat. fam. der L a u r in e æ. Gr. Sumatra; hooge boom.

ร̌ร72. Madang-soengi M. $=\mathrm{T} \mathrm{e}-$ tranthera ca pitulata Miq. (Zie No. 3362.)

5573. Madang-soesoe BK. = A c tinod a p h e procera $\mathrm{N} \in$ es. (Zie No. $2899 g$.)

5574. Madang-soesoen $M_{.}=\mathrm{D}$ a phniphyllum gla ucescens Bl. (Zie No. 2923h.)

5575. Madang-tahi-adjing $\mathrm{M}$. = a. Cryptocarya palembanica M i q. (Zie No. 5548a.) $=b$. C r y p t ocarya Te ysm an ni a a Miq., Nat. fam. der L a u ri neæ. Gr. Sumatra; boom. $=c$. Chion anthus insignis II i q., Nat. fam. der Ole in ex. Gr. Sumatra Ok.; boom.

5576. Madang-talang M. = C г у ptoc ary a crassinerria Miq. (Zie No. 5560 .)

5577. Madang-taloen $\mathrm{M}_{0}=\mathrm{T}$ a $\mathrm{l}$ a $\mathrm{u}-$ m a r u bra M i q., Nat, fam. der M a gn oli a c e r. Gr. Sumatra; boom.

5ร78. Madang-taloes LA MP. $=\mathrm{C}_{\mathrm{y}}$ anod aphne tome ntos a B l., Nat. fam. der la u rineæ. Gr. Sumatra, Celebes; boom.

ร5 79. Madang-tantem $\mathrm{M}_{.}=\mathrm{H}$ a a sia m i c r o c a r p a B l., Nat. fam. als voren. Gr. Java, Sumatra, Borneo; boom.

ว̌ร 80 . Madang-telor M. = T e t r a nthe ra a m a ra Nees. (Zie No. 2896.)

5581. Madang-telor-haijam M. = P h œ b e rigida M i q., Nat. fam. Jer L a u rin ex. Gr. Sumatra; hooge boom.

5582. Madang-tjampaka M. = M ic helia montan a Bl. (Zie No. 18906.) 5583. Madang-tjampega $\mathrm{M} .=\mathrm{T}$ al a u a rubra M i q. (Zie No. 5577.) 5584. Madang-tjoemen-djati Sum. WK. = Galearia? aristifera Miq., Nat. fam. der A u ti de s m e æ. Gr. Sumatra; heester.

5585. Madang-tjomara $\mathrm{M} .=\mathrm{D}$ acrydium elat um Wall. (Zie No. 3064 a.) 
5586. Madang-toendjang Sum. WK. $=$ Unona sumatrana Miq., Nat. fam. der A n o n a c e æ. Gr. Sumatra; boom.

5587. Madang-toero M. $=\mathrm{A} \mathrm{r} \mathrm{di-}$ sia linearifolia Mi (., Nat. fam. der M y r s i n e $æ$. Gr. Sumatra; heester.

NB. Vele dezer Madang- of Medangsoorten leveren op Sumatra een licht doch dunrzaam bouwhout, dat zelden door insekten wordt anngetast, omdat, vooral die, welke tot de $\mathrm{L}$ a u riner behooren, of een aromatisch, ò cen bitter beginsel bezitten.

э588. Madikapo T. $=\mathrm{C}$ o 1 y z a b a ls a $\mathrm{m}$ i f e r a L. (Zie No. 85b.)

5589. Madja M. \& J. $=a$. Fer 0 . nia elephantum Corr., (Zie No. 4059.) = b. Fgle Marmelos Corr. (Zie No. 1194.)

5590. Madja-batoe $M_{0}=\approx \mathrm{gl}$ e M a rmelos Corr., var. fruct. subglobosis.

5591. Madja-bun-wila Mak. 三 E g le M a r m e los C orr.

5592. Madjanang МaK. $=$ E ryth rina iudica lam. (Zic No. 15866.)

5593. Madjo T. 二 $\mathrm{Barringto-}$ $n$ i a speciosa $I_{\text {. }}$ (Zic No. 1463.)

5594. Madjong-oetan T. 三 C y c a s c i r c in a lis L. (Zie No. 2105.)

5595. Madong-alaban M. 三 V itex vestita $W$ a ll., Nat. fam. der V c r be n a e ex. Gr. Sumatra; boom.

5596. Madori J. \& $\mathrm{M}$. = $\mathrm{Callo-}^{-}$ tropis gigantea RBr. (Zic No. 817.)

5597. Magaij $\mathrm{s} .=\mathrm{Sol}$ a $\mathrm{n} \mathrm{m}$ Psendo-sapona ce um Bl., Nat. fann. der S ol a n c a. Gr. Java, Bornco, Celebes; heestertje. Grвк. De bitterc vruchten worden, nadat zij ecrst van hare zaden ontdaan zijn, ranw en gckookt bij dc rijst gegeten.

5598. Magori-tongking $\mathrm{M}$. = Pcrgularia odoratissiona T. (Zic 1395.)

5599. Mahalansot A $\mathrm{LF}$. MrN. $=$ M! ilnea dule is 'T. \& B. Nat. fam. der M eli a сех. Gr. Celcbes; kleime boom.

5600. Mahassan Pat. $=$ Canarium M a assan Miq. Nat. fam。 der $\Lambda$ m y ridec. Gr. Sumatra; hooge boom.

5601. Mahawenang Амв. = Rottlera hispida Kurz. (Zie No. 2671.)
5602. Mahee 'I'r. = A morphophallus campanulatus Bl. (Zie No. $750 a$.)

5603. Mahi-mahi M. = Tetrac e r a $l$ æ vigat a Miq. Nat. fam. der D ill e n i a c æ. Gr. Sumatra; klim. plant.

5604. Mahöa-pantej Амв. (Zie No. 5527$.

5505. Mahoe-lapia Амв. = Astronia protaria Bl. (Zie No. 412.)

5606. Mahoen $S .=P$ avet $t$ a ind i c a I. (Zie No. 383.)

5607. Mahuëwan $\Lambda$ мв. $=\mathrm{S}$ te $\mathrm{r}$ c n lia ureeolatas m. (Zic No. 1502.)

5608. Maibabo $\mathrm{Cr}$. = S e me e a rpus e assuvinm Sprg. (Zie No. 1569.)

5509. Majana M. - a. Cole $\mathrm{s}$ bi e olor Buth. (Zie No. 2019.) = b. Coleus scutellarioides Buth. (Zie No. 2016.)

5610. Majana-boessoek M. = $\mathrm{Po-}$ gostemou an ricularia Hassk. (Zic No. 14436.)

5511. Majana-maas M. $=$ Coleus scutellarioides B n th. (Zie No. 2016.)

5612. Majana-oetan M. (Zie No. 5610$.

5613. Majassa Cr. = Corypha $n \mathrm{mbra}$ u lifera L. var, $\mathrm{min}$ or. (Zie 1528.)

5614. Majoerat T. $\mathrm{T}$ Garcinia

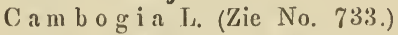

5615. Makila of Makilan Амв. = a. Machilus odoratissimus Nees. (Zie No. 119a.) $=b$. II a as a med i a B 1. (Zic No. 1196.)

5616. Makilan-dawon-ketjil Амв. =Actinodaphne an gustifolia N c es, Nat. fam. der I, a $)$ r i n c x. Gr. De Molakken, Java? boom.

5617. Makka Mos. $=\Lambda \mathrm{renga}$ s a e e h ar ifera $\mathrm{I}_{\text {a b }}$. (Zic No. 24:3.)

5618. Makka-foeta Br. eu

5619. Makka-hita ( $\mathrm{n}$. = Ex c $\alpha$ c ari A gallocha I. (Zie No. 22b.)

5620. Makkaë $\Lambda$ мB. Is dc harigc vezelstof van No. 243.

5621. Makka-lioem Bn. $=\Lambda$ verrhoa Bilimbi I. (Zie No. 85.3.)

5622. Makka-noenoet $\Lambda$ мв. = $\mathrm{M}$ : j as a c Cr.

5623. Makkeij Aмв. = Z ing i b e r C ass umanar $\mathbb{R} 0 \times$ b. (Zie No. 878.) 
5624. Makkou M. = E clipta a 1 b a 11 a 8 sk. (Zic No, 1809b.)

5625. Makoei Hor. $=$ Giobba u v if or m is L. (:?)

5626. Makoei-malakka MoL. 二 A l pinia malaceensis Rosc. (Zic No. 392.)

562\% Makoepa Min. $=J$ a m bos a vulgaris I). C. (Zie No. 1909.)

5628. Mak-se $\mathrm{CH}_{\text {. }} \mathrm{Bo} .=\mathrm{L}_{\mathrm{ac}} \mathrm{ctuca}$ s a tiv a L., Nat. fam. der Co m jos i t æ. Gr. De Salade wordt in Indië overal in tui. nen als groente anngekweekt en gegeten.

5629. Mala $\mathrm{Cr} .=\mathrm{Brouss}$ o n etia papyrifera Vent. (Zie No. 1S61.)

5630. Malaboëai Sux. = Alsto. $n$ i a? gr a ndifolia $M$ i q., Nat. fam. der A p o с y e æ. Gr. Sumatra; hooge boom.

5631. Malahoëol Aмв. of

5632. Malahoèor Амв. $=\mathrm{C}$ ovelli a $\mathrm{racem}$ ifera Miq. (Zie No. 1240.) 5633. Malaka J. = U r o p h y ll u m c o r y m bos um Korth. (Zie No. 2915.)

5634. Malakka M. \& S.二 $a . \mathrm{G}$ a rc i u i a c or ue a L. (Zie 2026a.) $=b$. Emblica officinalis $G \cong r t n$. (Zie No. 1485a.)

5635. Malakka-oedang Sum. WK. $=$ Ploiarium elegans Korth., Nat. fam. der C a melli a c e æ. Gr. Snmatra, Bangka. Bornco; boom.

5636. Malama-hoelo Gr. 二 Covel-

li a racim ifera Miq. (Zie No. 1240.) 5637. Malami-djanten Sum. Wh. $=$ Philagonia sambucina Bl. (Zie No. 4.3656 )

5638. Malang-beranjam $\mathrm{M}$. $\mathrm{Cle}$ rodendrum paniculat um L. (Zic No. $4144 d$.)

5639. Malangam-bajam PAL. = Jonesia palemb an ic a M iq.. Nat. fam. der Pa pilio n a c e e. Gr. Sumatra; boom.

5640. Malapari M. $=a$. M a l aparius flavus Miq., Nat. fam. der Papilion a c c ie. Gr. Sumatra; hooge boom. Geßr. Vermoedelijk als No. 735. 二 b. Pterocarpus [lavus Lour. (Zie No. 735.)

564l. Malatä0el Амв. $=\mathrm{Xyl}_{\mathrm{O}}$ c arpus Gran at $n \mathrm{~m} \mathrm{hocn.} \mathrm{(Zic} \mathrm{No.}$ 1319.)

5642. Malatti M. \& S. 二 J a s m in u m S a m b a c L, (Zie No. 920.)

5643. Malatti-aroij S. 二 $a$. J a s- minum er as sifolium Bl. (Zie No. 525ัa.) $=$ b. J a su in um scan de n s V a h l., Nat. fam. der J a sm in ex. Gr. Java; slingerplant; ook als sierplant dikwijls in tniucn.

5644. Malatti-gambir M. = J a sm in $n$ m grand i florum L. (Zie No. 1366.)

5645. Malatti-gambir-oetan M. = J a sminu m glabrius culum Bl. (Zie No. $525 \mathrm{c}$.)

5646. Malatti-goenong M. 二J a sm i u $\mathrm{m}$ u n d u l a t um WIld. (Zie No. 525e.)

5647. Malatti-kosta M. \& S. = Guettarda speciosa I. (Zie No. 1432.)

5648. Malatti-oetan M. 二 Cle r od e n d r u m fragans Vent., Nat. fam. der V e r b e n a c e a. Gr. Java, dikwerf in tuinen als sierplant

5649. Malatti-soesoen M. = Jasm in u m S a m ba c L., flore pleno. (Zie No. 920.)

5650. Malatti-toempoek M. (Zie No. 5648.)

5651. Malatti-toengkat M. $=a$. Pergularia odoratissima L. en $=b$. Pergularia minor And r. Nat. fam. der A s c lepiade æ. Gr. Op Java en elders in tuinen, even als No. 1177 om de geurige bloemen gekweekt.

5652. Malatti-tongking $\mathrm{M}$. 二 Pergularia odoratissima 1 .

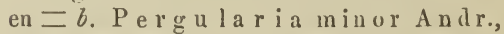
Nat. fam. der A s cle p i a der. Gr. Op Java en elders in tuinen, even als No. 1177 om de geurige bloemen gckweekt.

5653. Malatti-wolanda M. (Zic No. 5649$.

5654. Malepinan Aмв. $=a . \mathrm{Po-}_{0}$ thos gracilis $R \times b$., Nat. fam. der Oront i a c c s. Gr. A m b o i na; parasiet. GEBR. De klimmende stengels bezigt men als touw. $=b . \mathrm{S} \mathrm{ci}$ nd a p s n s? li n m phi Miq. (Zic No. 3499.)

5655. Malgi $\mathrm{S} .=\mathrm{H}$ i b is cus $\mathrm{s}$ riacus I. (Zic No. Al180.)

5656. Mali 11 . = Cy li co dapline $\mathrm{seb}$ if e r a $\mathrm{B}$ l.

5657. Mali-antoe PaL. $=\mathrm{I}, \mathrm{c}$ e a pa $1 \mathrm{cmba} n$ i ca 11 i q., Nat. fam. der A m p cli d c æ. Gr. Sumatra; heeste:

5658. Maling-maling $\mathrm{B}_{\mathrm{G}}$. = Ara. li a java u i a M i q. ('Lie No. 909a.)

565\%. Ma-li-pha (н. Во. = J a sminu m Sambac L. (Zie No. 920.) 
5560, Malisa-kamoel Auв. = Cha. vica officinarum MI 5134.)

5661. Maloe of Moeloe Аив, 二 Evi a a cida Com mers. var. B. (Zie No. 2890.)

5662. Maloemei Sux. Wк. $=\mathrm{P}$ h ilagonia sambucina B l. (Zie No. $4365 b$.)

5663. Maloer Str. $=$ B r u ce a sumatrana Roxb. (Zie No. 296.)

5664. Maloor II. $=\mathrm{D}$ a cr y di $\mathrm{um}$ e latum Wall. (Zie No. 3064a.)

566 s. Malorie Аив. 二 J a s m in um $\mathrm{S}$ a m b a c L. (Zie No. 920.)

5666. Malouw-dawon Вк. = II onoceras leucobotrya Miq. Nat. fam. der Tili a ce æ. Gr. Sumatra, Bangka; boom.

5667. Mamadi Mev. $=\mathrm{Le}$ e a $\mathrm{r} u$. b r a B l. (Zie No. 2520.)

5668. Mamaniran M. \& S. $=a$. Euphorbia thymifolia Lam. (Zie No. 1830.) = b. Phyllanthus Nuriri L. (Zie No. 7la.) =c. Phyllanthus urinaria Wlld. (Zie No. 71b.) $=d$. Es chynomene indica L. (Zie No. 2360f.) $=$ e. He d y otis c a pituliflora Miq. Nat. fam. der R u bi a c eæ. Gr. Java, Sumatra, enz.; half heester.

5669. Mamaniran-leutiek S. en

5670. Mamaniran-poetih M. = Por$t$ u la c a u a drifida L. (Zie No. 2482a.)

5671. Mamang-kokan M. en

5672. Mamanoekan. M. = Nothopan ax cochleatum Miq. (Zie No. $76 a$.)

5673. Mambo Bтл. = C a nariop$\mathrm{s}$ is d e cuman a Bl. (Zie No. 2651.)

5674. Mamelen Aмв. = Guettarda s peciosa L. a u t Cad a mba nocturna $\mathrm{H}$ a rn. (Zie No. 1432.)

5675. Mamiki-pantej MoL. = Dendrolobium umbellatum W. \& A. (Zie No. 1683a.)

5676. Ilamina Auв. = Caramb i u m a mboin i c u m Mi i. Nat. fam. der Euphorbiace e. GR. Amboina; hooge boom.

5677. Mamman-besar I. \& M. = Gy nandropsis specios a D c. Nat. fam. der C a p p ari d e æ. Gr. Op Java als sierplant in tuinen.

ว678. Mampelaän M. = M angifera indica L. (Zie No. 275 .)
5679. Manaër I. $=\mathrm{P}$ a vet t a ind i c a L. (Zie No. 383.)

5680. Manas Bu. $=\mathrm{An}$ an assa s ativa L. Nat. fam. der Bromel iac e æ. GR. Door geheel Indië in tuinen gekweekt, hier en daar verwilderd, overblijvend. GeBr. De A n a n a s-vrucht wordt, zoo rijp als onrijp, gestoofd en ingelegd gegeten, haar scherp zuur is echter licht schadelijk, veroorzaakt maagkramp, diarrhoea, enz.; van daar ze steeds door afwassching met zout van haar overtollig zuur dient ontdaan te worden. De onrijpe vrucht bezit wormdrijvende, pisdrijvende en stondenvloed bevorderende eigenschap. pen, en wordt raak als a bortivum misbruikt. Uit de bladvezelen verkrijgt men een fijn wit garen, bijna als zijde, zeer geschikt tot het weven van kleedjes, enz.

5681. Manau Sux. $=\mathrm{C}$ al amu s $\mathrm{M}$ a n a u M q. Nat. fam. der P a $1 \mathrm{~m}$ æ. $G_{R}$. Sumatra; slingerplant.

5682. Mandakaki M. $=\mathrm{T}$ a be rnæ montana coronaria R. Br. (Zie No. 264.)

5683. Mandalaksa S. $=a . \mathrm{Pla}_{a}$ te a excelsa $B$ l. en $=b$. Plate a latifolia Bl. (Zie No. 2233b.)

5684. Mandalika M. \& S. = Artoc a rpus rigid a B l. (Zie No. L454.) 5685. Mandarahan Sux. Wк. = C in a m om um calyculatum Miq. Nat. fam. der L a u r i n e æ. GR. Sumatra; boom. $=b$. M yristica M a ndarahan Miq. Nat. fam. der M y ris tic a c e æ. Gr. Sumatra; boom.

5686. Mandiki M. $=$ Citrullus edulis Spach. (Zie No. 10ə59.)

5687. Mandira M. =Urostigma R u mphi Miq. (Zie No. 103.)

5688. Mang $\mathrm{BK}=\mathrm{M}$ a p pa pruinos a Mi q. Nat. fam. der Eu phorb i a c e $x$. Gr. Sumatra, Bangka, hooge boom.

5689. Manga M. 三 M a n g if e r a L. 5690. Manga-ambatjang Mi. = Ma ngifera fotida L. var. sphæro id e a B l. (Zie No. 274.)

5691. Manga-ajer $M .=M$ a n gifera laurina B l. var. aquosa B l. (Zie No. 1115.)

5602. Manga-bappang M. $=a$. Mangifera indica I. var. M apang Bl. 三 $b$. MI angifera laurin a B l. var. M a rung a B l.

5693. Manga-bembem M. = Man- 
gifera laurina Bl. var. B emb em B l.

5694. Manga-bengala $\mathrm{M}$. 二 $\mathrm{M}$ angif era indica L. var. c ompressa Bl.

5695. Manga-benjala M. = Ma ngif era indica L. var. maxima $\mathrm{H}$ a s s k.

5696. Manga-besar $\mathrm{M}$. $=\mathrm{M}$ a $\mathrm{n}$ gifera fœtida Lour. var. Kawin i B l.

5697. Manga-betoel M. = $\mathrm{M}$ a $\mathrm{n}$ g if era la urin a Bl. var. Niela Bl. 5698. Manga-boedjoh M. = M an$\mathrm{g}$ if e ra $\mathrm{l}$ a urin a B l.

5699. Manga-bomba M. = M a n-

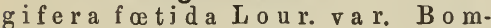
b o $\mathrm{m} \mathrm{Bl}$.

5700. Manga-brava I. = Cerbera lactaria Hamilt. (Zie No. 1182.)

5701. Manga-daging $\mathrm{M} .=\mathrm{M}$ a $\mathrm{n}-$ gifera fœtida Lour. var. mol1 is $B l$.

5702. Manga-derôpong $M .=M$ a n$\mathrm{g}$ if era laurina $B \mathrm{l}$. var. Derôpong Bl.

5703. Manga-dôdol M. = M a n g ifera indica L. yar. Dodol B l. 5704. Manga-gedeh I. Zie Manga besaar $\mathrm{M}$.

5705. Manga-hatie $\mathrm{M} .=\mathrm{Mangi-}$

fer a la u rina B l. var. Teloor Bl. 5706. Manga-kaaijer $\mathrm{M}_{\text {. }}=\mathrm{M}$ a n gifera indica L. var. Kaijer Grin. 5707. Manga-kalapa $\mathrm{M}$. = M ang $\mathrm{i}$ fera indica L. var. Kalapa Bl.

5708. Manga-kawehneh S. en

5709. Manga-kawini M. 三 a. Mangifera fotida Lour. var. Kawini B l. $=b$. Cerbera Odollam Gærtn. (Zie No. 118l.)

5710. Manga-kawini-maas $\mathrm{M}$. = Mang ifera fotida I o u r. var. Kaw in i Bl.

5711. Manga-kemang M.S. = Mangif era Kemanga Bl. (Zie No. 1180.) 5712. Manga-kidang $\mathrm{M}$. 三 $\mathrm{Man}$ gif era indica L. var. Kidang Bl. 5713. Manga-koekoeloe M. = Mangifera laurina Bl., var. Derôpong B l.

5714. Manga-malakka $\mathrm{M}$. $=\mathrm{M}$ a ngifera lauriua Bl., var. aquosa B ].

5715. Manga-maroenda $\mathrm{S} .=\mathrm{Man}-$ gifera la urina Bl., va $\mathrm{r}$ Mar unda Bl.
5716. Manga-maroenga $\mathrm{S} \cdot=\mathrm{M}$ angifera laurina Bl, var. Marung a B l.

571\%. Manga-menjala M. $=\mathrm{M}$ a n$\mathrm{g}$ if e r a in dic a L., var. compress a Bl.

5718. Manga-monjet M. $=a$. An acardi am occidental e $\bar{L}$. (Zie No. 1474.) $=b$. Mangifera la urina B l. (Zie No. 1115.)

5719. Manga-niela M. \& S. = Mangifera laurina Bl, var. $\mathrm{Ni}$ el a B l.

5720. Manga-oedang $M .=M a n-$ gifera la urina Bl., var. $\mathrm{micro-}$ c a r p a Bl.

5721. Manga-oetan $\mathrm{M} .=a \cdot \mathrm{M}$ a n. gifera macrocarpa Bl., (Zie No. 2607.) $=b$. M a ng if era Taipan $\mathrm{H}$ a milt, Nat. fam. der $\mathrm{A} n$ a c a r diac e æ. Gr. De Molukken; hooge boom. Gebr. De vruchten van dezen boom worden hier en daar door de inlanders gegeten; ze zijn echter minder lekker en zeer dradig. $=c$. Mangifera utana $\mathrm{Ha}-$ milt., Nat. fam. Gr. en Gubr. als bij $b$. 5722. Manga-padi M. = Mangaoetan M.

5723. Manga-pappan M. = $\mathrm{M}$ ang if era indica L., var. Bapang Bl.

5724. Manga-parrie M. \& S. 三 $a$. Mangifera Laurina B l. 三 $b$. Mang ifera Parih Miq, Nat. fam. der A n a c a r d i a c e æ Fr. Java; boom.

5725. Manga-pauw $\mathrm{M}$. $=\mathrm{Man}$ $\mathrm{g}$ if era altission Blanco (Zie No. 1033.)

5726. Manga-piit M. \& $S$. $=M$ ang if era la u rin a Bl., v ar Piit Bl.

5727. Manga-sangir M. $=\mathrm{Man-}$ gifera laurina Bl., var. Sangir Bl.

5728. Manga-sentok M. $=\mathrm{M}$ a ngifera la urina Bl., var. Sento k Bl.

5729. Manga-tahi-koeda M. $=\mathrm{M}$ a ngifera la urina Bl. var. globul a ria Bl.

5730. Manga-temoe-lawak M. 三 M a ngifera la urina Bl., var. Teloor Bl.

5731. Manga-telor $\mathrm{M}$. $=\mathrm{M}$ a ng fera la urina B l., var. Teloor Bl. 5732. Manga-wangie $\mathrm{M}$. 三 $\mathrm{M}$ a ngifer a indica L., var. gra $\mathrm{si}$ a B l.

5733. Mangana-meirah M. = D en- 
drophthö̈ repanda G. Don, Nat. fam. der $L$ oranthace $x$. GR. Java, Borneo; Celebes; parasiet.

5734. Mangandoe S. (Zie later Mengando S.)

5735. Mangarawang $\mathrm{S}=\mathrm{P}$ oly o s. ma velutina Bl. (Zie No. 4482.)

5736. Mangas Вк. $=$ I) ipter oc a r us e $\mathrm{rynch}$ ioides Scheff., Nat. fam. der Dipterocarpe æ. Gr. Bangka; hooge boom.

5737. Mangendar S. 三 $a . \mathrm{H} \mathrm{i} \mathrm{p} \mathrm{p} \mathrm{o-}$ cratea indica W $11 \mathrm{~d}$., (Zie No. 485 .) $=b$. S a la c i a b lo ng if oli a B l. (Zie No. 485 c.)

5738. Mangi-mangi M. = $\mathrm{Bru}$. g u i e a $\mathrm{Rumphi}$ i B l. (Zie No. 866b.) 5739. Mangi-mangi-akkar M. = $\mathrm{Rhizophora} \mathrm{mucronata} \mathrm{Lam}$. (Zie No. 868.)

5740. Mangi-mangi-boenga M. 二 无g i c e ras.floridum R. \& S. (Zie No. 130.)

5741. Mangi-mangi-goenong $\mathrm{M}$. = A c a c a Ma ngium W1ld., Nat. fam. der Mimoseæ. Gr. De Molukken, boom.

5742. Mangi-mangi-ketjil M. 二 $\mathrm{E}$ giceras majus Gærtı. (Zie No. 1556.)

5743. Mangi-mangi-laki-laki M. = $\mathrm{Rhizophora} \mathrm{mucronata} \mathrm{Lam.}$ (Zie No. 868.)

5744. Mangi-mangi-oetan M. $=\alpha$. A c a c i a M a $\mathrm{g}$ i u m W $1 \mathrm{ld}$. (Zie No. 5741.)=b$. M a ng if e a l axi flora Desrouss. (Zie No. 3021.)

5745. Mangi-mangi-padomara M. = a. Sonneratia a cida L. fs. en = b. Sonneratia alba Smith (Zic No. $866 d$.)

5746. Mangi-mangi-poetih M. $=a$. A vi cennia a 1 b a B l. (Zie No. 416b.) $=b$ Avicennia officinalis $I_{\text {. }}$ (Zie No. 14.)

5747. Mangi-mangi-tjengkeh $\mathrm{M}_{\text {. }}=$ B r u guier a caryophilloides Bl. (Zie No. 3742b.)

5748. Mangies $\mathrm{M} .=\mathrm{G}$ a r c in i M angost an a I., Nat. fam, der $\mathrm{Clu}$ $8 \mathrm{i}$ a cæ. GR. Door geheel Indië in tuinen; boom. Gквк. Deze boom wordt hoofdzakelijk om zijn aangename, geurige, zuurzoete vruchten angekweekt. Het hout is zwaar en sterk, geschikt voor bouwhout en rijststampers. J)en samentrekkenden bast geeft men tegen diarrhoea en als wormdrijvend middel. De mede zeer samentrekkende vruchtschillen zijn zeer dien. stig tot het looien van leder en tot het zwartverven van garens; als geneesmiddel geeft men ze bij chronische diarrhœa, dysenterie, spruw, zweren van mond en keelholte en bij salivatie. Het vruchtvleesch is stellig het gezondste en aangenaamste van alle Indische vruchien.

5749. Mangies-leuwung $\mathrm{S}$. $=\mathrm{G}$ a $\mathrm{r}-$ c in i javanic a B l., Nat. fam. als voren. Gr. Java. GEBr. Het hout van dezen boom is sterk en zeer geschikt voor rijststampers; de zoete vruchten worden gegeten.

5750. Mangies oetan $\mathrm{BK}_{.}=\mathrm{Garci-}$ nia parvifolia Miq. (Zie No. 37ó1.)

5751. Mangies-oetan $\mathrm{M}_{0}=a$. G a r. c i ni a cele bi c a DC. (Zie No.4653.) $=b$. Garcinia indica Chois., $\mathrm{N}$ a t. f a m., als voren. Gr. Java; boom $=c$. Garcinia javanica Bl. (zie vorige nommers) $=d$. G arcin ia? $0 \times \mathrm{i}-$ phylla M i q. Nat. fam. dezelfde. Gr. Sumatra; boom.

5752. Mangies-riembo $\mathrm{M}$. $=\mathrm{X}$ anthochymus nervosus $M$ i q., Nat. fam., als voren. Gr. Sumatra; boom.

5753. Mangkaras $\mathrm{BE}_{\mathrm{E}}=\mathrm{Aqu \textrm {i }}$ $\mathrm{lar}$ i a $\mathrm{malac}$ cen $\mathrm{s}$ is $\mathrm{L}$ a m. (Zie No. 2679.)

5754. Mangkata $\mathrm{BK} .=\mathrm{Ew} \mathrm{y} \mathrm{ckia}$ Korthalsian a Miq., Nat. fam. der M c l a s t o ma c e æ. Gr. Bangka; heester.

5755. Mangkepul Bк. = Quercus s picata $\mathrm{Sm}$. var. latifolia. (Zie No. 4619.)

5756. Mangkoeboeng BK. $=\mathrm{D}$ iplanthera bancan a Scheff., Nat. fam. der Bign o n i c e r. Gr. Bangka; boom.

5757. Mangkoedoe M. Zie Bangkoedoo M.

5758. Manglam $\mathrm{BK}$. 三 $\mathrm{J}$ a m bosa t e tr a ë d ra $M$ i q., Nat. fam. der Myrt a c e æ. Gr. Bangka; boom.

5759. Manglar S. $=$ Quercus J unghuh n i M i q., Nat. fam. der Cupu lif eræ. Gr. Java; hooge boom. 5760. Mangliet $\mathrm{M}$. \& $\mathrm{S}$. $=a$. Manglietia glauca Bl. (Zie No. 1026b.) $=6$. M i chelia champaca L. (Zie No. 4156.) $=$ c. M i cheli a velut in a Bl., Nat. fam. der M a g n oli a c eæ. Gr. Java; hooge boom. Gebr. Het hout is een goed bouw- en meubelhout, zeer geschikt voor fijn werk. 
5761. Mangliet-bener S. of

5762. Mangliet-betoel M. = $\mathrm{Mi}$ chelia ch a mpac a I. (Zie No. 4156.)

5763. Mangliet-boddas $\mathrm{S}$. $=\mathrm{MI}$ chelia montana Bl. (Zie No. 1890b.) 5764. Mangoe S. Zie Mangies M.

5765. Mangoe-leuwung $\mathrm{S}$. $=\mathrm{F}$ agræa volubilis Wall. (Zie No.975.)

5766. Mangoeba $\mathrm{BD}$. = $\mathrm{Mucuna}$ pru rit a Hook. (Zie No. 1699.)

5767. Mangong $\mathrm{S}$. = St a la g m ites dul cis C a m b. (Zie No. 2499.)

5768. Mangostan M. Zie Mangies M. 5769. Mangkrima of

5770. Mangtrima $\mathrm{BK}_{\text {. }}=\mathrm{G}$ on iothal a mus Slingerlandtianus $\mathrm{S}$ c h e ff., Nat. fam. der A n o n a c eæ. Gr. Bangka; kleine boom.

577i. Manienjo M. en

5772. Manienjo-oetan M. = Gnet u m G n e mon L. (Zie No. 820.)

5773. Manikin S. = L obelia

Horsfieldian a Miq. (Zie No. 1019.)

5774. Manila Амв. $=\mathrm{Hibiscus}$ ros a sine ns is L. (Zie No. 1360.)

5775. Manja S. en

5776. Manja-boddas S. = An d rosc epi a gi ga nte a Brong. Nat. fam. der Gram in e $æ$. Gr. Java en de Molukken; dit zeer hooge gras is de geliefde schuilplaats van tijgers en slangen.

5777. Manja-burrum S. = Anthisthiria ciliata L. (Zie No. 2126a.) 5778. Manjil $\mathrm{S} .=\mathrm{Eri}$ oca ulo o c t a n g u l a r e R n w d t. Nat. fam. der $\mathrm{Eri}$ о с a u l o n e æ. Gr. Java : éénjarig.

5779. Manoa Mor. $=\mathrm{A}$ n on a retic u lat a L. (Zie No. 1489.)

5780. Manoa-papoëa Mol. 三Anou a squa mos a l. (Zie No. 1477.)

5781. Manoetaijn Амв. $=\mathrm{L}$ or a nth a c e $æ$ d i vers $æ$.

5782. Manonang Men. = Artocarpus L. Spec. celeb. indef. GEBR. Deze levert een goed hout voor planken.

5783. Mantaj̈n Амв. $=\mathrm{Pandanus}$ ceramicus $\mathrm{R}$ in $\mathrm{ph}$. (Zie No. 1828.)

5784. Mantang $\mathrm{S}$. $=\mathrm{B}$ at at a s e d u lis Chois. (Zie No. 635.)

5785. Mantjarakan-gedeh $\mathrm{S}$. = Eragrostis verticillata R. \& S. Nat. fam. der G r a m in e æ. Gr. Java; hoog gras.

5786. Mantjerian I. = Ellettari a c o c cinea Bl, Nat. fam. der Z ing i ber a ce e. Gr. Jara; overblijvend.
GEBR. De jonge bladeren eet men gekookt bij de rijst; zij zijn een aangenaame, zure groente; de oude bladeren bezigt men tot het dekken van huizen. De zoete zaden worden gaarne gegeten.

5787. Mantjiro M. $=\mathrm{M} \mathrm{appa?}$ stricta Reich. \& Zoll. Nat. fam. der Euphorbia ceæ. Gr. Sumatra; heester.

5788. Maobobo Амв. $=M$ u u u a prurita $\mathrm{Hoob}$. (Zie No. 1699.)

5789. Maoen I. $=\mathrm{P}$ avetta indi c a L. (Zie No. 383.)

5790. Maöha Амв, en

5791. Maoha-abbar Aмв. Zie Maobobo Амв.

5792. Mapan $\mathrm{BK} .=\mathrm{Ficus} \mathrm{M} \mathrm{ap-}$ p a $\mathrm{M}$ i q. Nat. fam. der Artocarpeæ. Gr. Bangka; boom,

5793. Maraboet M. $=\mathrm{C}$ as u a $\mathrm{r}$ in a s u matrana J ngh. (Zie No. 332.)

5794. Maraboh M. = Intsi a am. boinensis Thouars. (Zie No. 830.) 5795. Marabou LAMP. = Intsia p a l embanic a Miq. Nat. fam. der Papilion a c æ. Gr. Sumatra; hooge boom.

5796. Marabou-pipit PaL. $=\mathrm{Clau}$ sena chrysogyne Miq. Nat. fam. der A u rantiaceæ. GR, Sumatra; heester.

5797. Maralim $\mathrm{PAL}_{\mathrm{L}}=\mathrm{P}$ a ra $\mathrm{rta}$ botrys sumatrana Miq. Nat. fam. der A n o n a c e $x$. Gr. Sumatra; heester.

5798. Marambang $\mathrm{M} .=\mathrm{V}$ ite $\mathrm{x}$ vestit a Wall. (Zie No. 5595.) $=b$. Vernonia javanica Dc. (Zie No. 1015b.)

5799. Marambong $\mathrm{M} .=\mathrm{Z}$ a $\mathrm{t}$ h $\mathrm{o-}$ $x$ y lon (Evodia) Marambong Miq. (Zie No. 4312.)

5800. Maramia Mak. $=$ U rostigma nitidum Miq. (Zie No. 855.)

5801. Marampoejan Sur. WK. = a. Rhodamnia cinerea Miq. en $=b$. Khod. concolor Miq. Nat. fam. der M y r tac e ce. Gr. Sumatra; beide hooge boomen.

5802. Maranginan $\mathrm{S} .=a . \mathrm{C}$ a $\mathrm{n}$ a. rium denticulatum Bl. (Zie No. 4621b.) $=$ b. Epicharis densiflora B l. Nat. fam. der Meli a ce $x$. Gr. Java, hooge boom. Gebr. Het sterk riekende, fijne en witte hout van dezeu boom wordt niet door insekten aangetast, is zeer geschikt roor bouw-en menbelhout, ook roor pedatties, enz. 
5803. Maranginan-boddas of

5804. Maranginan-postih M. = D y soxylum si.mile Bl. Nat. fam. der Me li a c e æ. Gr. Java; boom.

5805. Maranti BK. $=\mathrm{H}$ o $\mathrm{p}$ e a Meng a r a w a n I i q. (Zie No. 5928b.)

5806. Maranti-bras M. $=\mathrm{S}$ h o r e a nitens Miq. (Zie No. 7925.)

5807. Maranti-hitam $\mathrm{BK} .=\mathrm{Shorea}$ 1 ucida Miq. Nat. fam. der Dipteroc arpeæ. Gr. Sumatra, Bangka; hooge boom.

5808. Marantie Bk. \& Sum. $=a$. Hopea Marantie Miq. Nat. fam. der Dipterocarpea. Gr. Bangka; hooge boom. $=b . S$ hor e a le prosula Miq. (Zie No. 1012.) = c. Shorea? f u r f u race a M i q. Nat. fam. als voren. Gr. Sumatra; hooge boom.

5809. Marantie-djawi Bк. en Marantie-pinang $\mathrm{BK} .=\mathrm{V}$ atic a stipulos a M i q. Nat. fam. als voren. Gr. Su. matra, Bangka; hooge boom.

5810. Marapoegin M. $=\mathrm{D}$ a phnidi um c xs i u m B l. (Zie No. 2893b.) 5811. Marassie $\mathrm{S} .=\alpha$. Molin eri a latifolia K ürz. (Curculigo.) $($ Zie No. 24a. $)=b$. Molineria rec u r vata Kürz. Nat. fam. der $\mathrm{H}_{\mathrm{y}}$ poxid e a. Gr. Java; overblijvend. Gebr. als bij No. 24a.

5812. Marbo M. en

5813. Marbouw M. (Zie Maraboh en Marabouw.)

5814. Mardini T. $=\mathrm{Im} \mathrm{p}$ at i e $\mathrm{ns}$ B a ls a m in a L. (Zie No. 259.)

5815. Mare $\mathrm{Cr} .=\mathrm{Commerso-}$ nia echinat a Forst. (Zie No. 106.) 5816. Marehmeh $\mathrm{S} .=a . \mathrm{Gloch} \mathrm{i}$. di on dasyanthum Kürz. (Zie No. 2243.) $=6$. G loc hidion lucidum B l. (Zie No. 461 .) $=c$. G loc hid i on arborescens Bl. en $=d$. Glochi. dion opsis serice a Bl. Nat. fam. der Euphorbia ceæ. Gr. Java; boo. men.

5817. Marehmeh-awehweh S. = Glochidion macrocarpum Bl., Nat. fam. als voren. Gr. Java; heester.

5818. Marehmeh-lumboet $\mathrm{S} .=a$. A gy nia multiflora $\mathrm{Hassk}$, Nat. fam, als voren. GR: Java; lieester. $=b$. M elanthesa racemosa Bl, Nat. fam. dezelfde. Gr. Java; heester. = c. G lochidion rubrum B !., Nat. fam. dezclfde. Gr. Java; heester. Grir. Het hout wordt voor huisbouw gebezigd, de bladeren eet men als groente bij de rijst.

5819. Marehmeh-mienjak $\mathrm{S} .=a$. Glochidion arborescens Bl. (Zie No. $5816 c$ c) $=$ b. Glochidion rubrum Bl. (Zie No. 5818 c.)

5820. Marela Aлгв. $=\alpha$. Ha asia media Bl. (Zie No. 119b.) = b. Machilus odoratissima Nees. (Zie No. 119a.)

5821. Marelang Sum. WK. $=\mathrm{Pte}-$ rospermum? parrifolium Miq.4 Nat. fam. der Büttneriacex. Gr. Sumatra; boom.

5722. Maridjan J. $=$ Gentiaua quadrifaria Bl. (Zie No. 346b.)

5823. Marieboengan $\mathrm{PAL}_{\mathrm{A}}=\mathrm{Mil}$ letia atropurpurea Benth. (Zie No. 3391.)

5824. Marisa Амв. en

5825. Maritja M. $=a$. Piper nigrum J. (Zie No. 1090a.) = b. Chavica macrostachya Miq., (Zie No. 1091b.)

5826. Maritja-amme (Marisa-ammo) Aмв. = Chavica officinarum Miq. (Zie No. 5134.)

5827. Markisat-gedeh $\mathrm{S} .=\mathrm{P}$ assiflor a a la ta A t., Nat. fam. der Pas sif $l$ or e $æ$. Gr. Op Java en elders in tuinen, als sierlijke klimplant zeer gezocht.

5828. Markisat-leutiek S. $=\mathrm{P}$ a ssiflora la urifolia. L., Nat. fam. en $\mathrm{GR}$. als de vorige.

5829. Maroeng-lawi M. $=\mathrm{D}$ a 1 b e $\mathrm{H}$ gi a frondosa $R \times b$., Nat. fam. der Papilion a e æ. Gr. Java en Sumatra; boom.

5830. Maroengi-lawoe Sum. WK. $=$ Dalbergia monosperma Dallz. Nat. fam. als voren. Gr. Sumatra, Jara, de Molukken; heester.

5831. Maroerang Амв. $=\mathrm{Cler} 0$ dendrum infortunatum L. (Zie No. 758.)

5832. Maroewai MeN. = Intsia a m boinensis Thou ars. (Zie No. 830.)

5833. Marokka T. $=a$. S ter c ulia fotida L. (Zie No. 1641..) $=b$. Sterculia urceolata Smith. (Zie No. 1502 )

5834. Marokko-nonau T. $=$ M a pp a molucc an a S prg. (Zie No. 56.)

5835. Marong S. $=\alpha$. Cratoxylon Hernschuchi B l. (Zie No. 2819.) $=b$. Tridesmis formosa 
K o r t h., Nat. fam. der $\mathrm{H}$ y p e r i c i n e æ. GR. Door den geheelen Archipel; boom.

5836. Marra $\mathrm{S} .=a$. M a p a T an aria Spreng. (Zie No. 22946.) = b. M a p a tomentos a Bl., Nat. fam. der Euphor bi a c e $æ$. Gr. Java, heester.

5837. Marra-boddas $\mathrm{S} .=a . \mathrm{M}$ a $\mathrm{p}$. pa denticulat a B l. (Zie No. 1267.) $=b$. M appa tomentos a Bl. (Zie No. 5836b.) $=c$. A d enogyn $\mathrm{m}$ di s c ol or R. \& Z., Nat. fam. der E up h o r b i a c e æ. Gr. Java; heester. $=d$. Rottlera floribunda Hassk., Nat. fam. en Gr. als voren.

5838. Marra-burrum S. $=\mathrm{P}$ a c hystemon trilob um Bl., Nat. fam. dezelfde. Gr. Java; boom. Gebr. Men bezigt het oude hout voor huisbouw en gereedschappen; het melksap der jonge planten ksu voor boekbinderslijm dienen.

5839. Marra-mienjak $\mathrm{S} .=\mathrm{H}$ ern a ndia s o n or a L. (Zie No. 16.)

5840. Marsekan PaL. $=\mathrm{S}$ o l e $\mathrm{n}$ ost ig m a riges ce n s M i q., Nat.fam. der C elti d e æ. Gr. Sumatra; boom.

584. I. Martahoel $А м в .=X$ y l o c a rpus Granatum Koen. (Zie No. 1319.)

5842. Martjoh-goendâ J. = D r ymispermum Burmanni Dcsn., Nat. fam. der T h y m e læ a c e æ. Gr. Java; kleine heester.

5843. Maruasej Men. = I n t sia Thrs. Spec. celeb. indef., een hooge boom, die een zeer goed bouwhout, een soort van ijzerhout, levert.

5844. Masetja $\mathrm{BK} .=\mathrm{U}$ rostig ma infectori u m M i q. (Zie No. 5435a.)

5845. Nassala BK. $=\mathrm{E}$ u ry a $\mathrm{n} \mathrm{i-}$ tid a K th s. (Zie No. 8893.)

5846. Massen $\mathrm{CR}_{\mathrm{R}}=\mathrm{E} \mathrm{v}$ i a a $\mathrm{m}$ a $\mathrm{ra}$ C o m m. (Zie No. 3143b.)

5847. Massoelong $\mathrm{BK}$. $=\mathrm{S} \mathrm{yz} \mathrm{y}-$ gi u m nelitricarpum T. \& B., Nat. fam. der M y r t a c e æ. Gr. Bangka; boom.

5848. Massoessoe Амв. $=\mathrm{C}$ it r u s $\mathrm{n}$ o b il is $\mathrm{L}$ o u r. (Zie No. 2062.)

5849. Massooi M. $=a$. C in n a mo$\mathrm{m} n \mathrm{~m} \mathrm{~K}$ i a mis $\mathrm{N}$ e es. (Zie No. 3367b.) $=b$. Cinnamomum xanthone u. ram Bl. en $=c$. Sassafras? Goesi a n u m T. \& B., beide van de Nat. fam. der Lan rinex. Gr. Nieuw-Guinea, boomen. Grbr. De M a s $\mathrm{S}$ o o i-bast is op alle Javaansche bazars als geneesmiddel te koop; hij komt in aromatisch-adstringee- rende werking met den $\mathrm{S}$ in t o $\mathrm{k}$ orereen, nadert de Cassarilla en Simaruba. en wordt vooral toegediend bij diarrhœæ en krampen of pijnen in den-onderbuik.

5850. Mata-auwe $A м в$. $=\mathrm{Ph}$ æa nthus nutans H. Fs. \& Th. (Zie No. 14.73.)

5851. Mata-bagoes M. = Urostigma pilosum Miq. (Zie No. 1324b.)

5852. Mata-boeta $\mathrm{M} .=\mathrm{Ex} \times \propto$ caria a gallocha I. (Zie No. 22b.)

5853. Mata-hiang S. $=a$. Cæs alpinia Nuga Ait. (Zie No. 627.) = b. Guil andina B onduc L. (Zie No. 1475.)

5854. Mata-hoeli of Mata-hoeri Амв. = Excœcaria A galloch a J. (Zie No. 22b.)

5855. Mata-kantjil M. = Salacia prinoides Dc. (Zie No. 588.)

5856. Mata-koenai $M .=R h o d o-$ dendron citrin um Hassk. Nat. fam. der Ericaceæ. Gr. Java en Sumatra; heester.

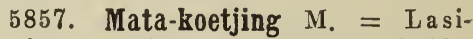
anthus oculusecati Rwdt. (Zie No. 330 s.) $=6$. Lasianthus cyanocarpus Jack. Nat. fam. der Rubiace 3 . GR. Java en Sumatra; heester.

5858. Mata-koetjing-nan-siri SuM. $\mathrm{WK}_{\mathrm{K}}=$ Chrysophllum sumatra n u M i q. (Zie No. 1625.)

5859. Mata-mata MAK. $=\mathrm{C}$ a $\mathrm{r}$. diopteris moluccana Bl. Nat, fam. der P h y t o c r e n e æ. Gr. Celebes en de Molukken; slingerplant. Gebr. De inlanders eten van deze plant de bladeren als groente bij de rijst; ook geven zij een afkooksel der stengels als geneesmiddel inwendig tegen geelzucht en uitwendig bij beri-beri.

5860. Mata-mata-poenei Sur. Wr. $=a$. Fluggea microcarpa Bl. Nat. fam. der E u phor b i a c ææ. GR. Java, Sumatra; heester. GeBr. De vruchten van dezen heester worden gegeten. = b. An isonema gla ucina Miq. Nat. fam. dezelfde. Gr. Sumatra; heester.

5861. Mata-oedang $\mathrm{M}$. $=a$. $\mathrm{C}$ is. sus cinerea $\mathrm{Lam}$. (Zie No. 65.) = b. Cissus repens Lam. (Zie No. 438.)

5862. Mata-pelandoe $\mathrm{BK} .=\mathrm{E} \mathrm{u}$. themis le ucocarpa Jack. Nat. fam. der $\mathrm{O}$ c h n a c e $x$. Gr, Bangka, de Molukken; heester.

5863. Mata-pergam $\mathrm{P}_{\mathrm{AL}}$. $=\mathrm{Di}$ - 
gaster sumatranus Miq. Nat. fam. der Ch aille ta c ex. Gr. Sumatra; heester.

5864. Mata-soetjie I. $=\mathrm{K} æ \mathrm{~m}$ pferia rotunda L. (Zie No. 3576.)

5865. Mata-tekel MeN. $=\mathrm{C}$ a s s i a a 1 a t a L. (Zie $\Lambda^{\top}$ o. 1740.)

5866. Matjaän $\mathrm{L}$. $=$ Qu ercus in fe ctoria L. (n u c es.) De galnoten groeien niet op $\mathrm{J}$ ava; zij worden van Perzië en elders aangevoerd, doch zijn onder dezen naam op de meeste Javaansche bazars te koop.

5867. Matjan-medang-ante $\mathrm{M}$. = M a $\mathrm{n}$ if era fœtida Lour. (Zie No. 274.)

5868. Matjan-riemboe M. $=\mathrm{Haa}$ sia cyrtopoda M i q. Nat. fam. der J، a u r i e æ. Gr. Sumatra; boom.

5869. Matoe-angang $\mathrm{M}$. = $\mathrm{M} \mathrm{y}$ ristica intermedia Bl. (Zie No. $4572 c$.)

5870. Matras of mentras $\mathrm{BK}$. = $\mathrm{J}$ a $\mathrm{mb}$ osia tetraptera M iq. Nat. fam. der Myrtacex. Gr. Bangka; boom.

5871. Mattahe AмB. of

5872. Mattahoe-malamaho Cк. = Urostigm a benghalense Gasp. (Zie No. 790.)

5873. Mattoea-massin $\mathrm{BK}_{\mathrm{K}}=\mathrm{S}_{\mathrm{o}}$ phora tomentos a L. (Zie No. 1490.)

5874. Maulanit $\mathrm{Aмв.}=a$. W o llastonia moluccana Dc. en 二 b. Woll. strigulos a Dc. (Zie No. $315 \alpha$.

5875. Mazzala $\mathrm{B \kappa}_{\mathrm{K}}=\mathrm{Eu} \mathrm{ry} \mathrm{a} \mathrm{e}$ prista K o rth., Nat. fam. der Ternst $r \propto m$ i a c e $æ$. Gr. Sumatra. Bangka; groote heester.

5876. Mebinso M. $=\mathrm{Gne} \tau \mathrm{um}$ G n e mon I. (Zie No. 820.)

5877. Medang Вк. zie Madang $M$. en volg.

5878. Medja M. $=$ He li c on i op. $\mathrm{s}$ is a moinensis $\mathrm{Miq}$. (Zie No. 4978.)

5879. Medjawa $\mathrm{S} .=\mathrm{Macropa-}$ nax oreophilum Miq. (Zie No. 5279.)

5880. Medini I. = Grewia o blong ifolia Bl. (Zie No. 3\%5.)

5881. Medinjo I. = Gnetum Gnem o n L. (Zie No. 820.)

5882. Medsoeardan I. $=$ Hedyotis venos a Korth (Zie No. 4398 c.)
5883. Meha-hatole $\mathrm{CR}_{\mathrm{R}}=\mathrm{B}$ idens W a llich ii D c. (Zie No. 68a.)

5884. Mehana $\mathrm{M}$. $=\mathrm{Coleus}$ atropurpureus Benth. (Zie No. 748.)

5885. Mehoe-hoä $\mathrm{Cr}_{\text {. }}=\mathrm{A}$ n a m irta Cocculus W. \& Arn. (Zie No. 339.)

5886. Mehoe-huäe $\mathrm{Cr}$. $=\mathrm{C}$ ord yline Ru in phi Bl. (Zie No. 337a) 5887. Mehoe-mamulin $\mathrm{Cr}$. $=\mathrm{Ruel}$ $\mathrm{li}$ a is color $\mathrm{N}$ e es. (Zie No. 72.) 5888. Mehoe-lapia Амв. = Astronia papetaria B l. (Zie No. 41\%.)

5889. Mehoe-latoe Амв. en

5890. Mehoe-tana-hane Амв. = Pl u m bago ros a L. (Zie No. 114.) 5891. Mehremi LAMP. $=$ A n tidesma paniculatum Bl. (Zie No. 1356.)

5892. Mehuaul Cr. $=$ Perist $\mathrm{ro-}$ $\mathrm{phe}$ tinctoria $\mathrm{Nees}$ (Zie No. 95.) 5893. Mekatak Bк. (Zie Mangkata Вк.)

5894. Melebokan PaL. = Shorea? pa le mban i a M i q. Nat. fam. der Di pt e roc a r p æ. Gr. Sumatra; hooge boom.

5895. Melekoh Bк. of

5896. Melikoh Вк. $=10$. Tern. str $\rightsquigarrow \mathrm{mi}$ a n e u a $\overline{\mathrm{Miq}}$. (Zie No. 6818.) $=20$. Ternstrœmia coria c e a S c heff., Nat. fam. der $T$ e r $n$ s t $r \propto m$ i a c e æ. Gr. Bangka; heester. 5897. Melen Амв. 三 Guet tarda s p e c i o a L. (Zie No. 1432.)

5898. Melinjoe I. 二 $\mathrm{F}$ ag $\mathrm{r} æ$ a coa r c t a a B l. Nat. fam. der I $0 \mathrm{~g} \mathrm{a-}$ n i a c e æ. Gr. Java, Borneo, de Molukken; heester.

5899. Meloekan $\mathrm{BK} .=\mathrm{Och} \mathrm{th}_{\mathrm{cm}}$ c h a r is javan i a B l. Nat. fam. der M e la s t o m a c cæ. Gr. Java, Bangka, Borneo; kleine heester.

5900. Memanoh PaL. 二 G lo c h idion cyrtophyllu m Mi q. Nat. fam. der Euphorbiaceæ. Gr. Sumatra; boom.

5901. Membaaran $\mathrm{BK}_{\mathrm{.}}=\mathrm{B}$ o b e a in $æ q u$ is e pala M iq. Nat. fam. der $\mathrm{R} \mathrm{u} \mathrm{b} \mathrm{i} \mathrm{a} \mathrm{c} \mathrm{e} x$. Gr. Bangka; heester.

5902. Memenigran $\mathrm{S} .=a$. Ps $\mathrm{y}-$ chotria rhinocerotis $R$ w d . (Zie No. 1690.) $=$ b. Chas a lia montana M i q. (Zie No. 4505 c.)

5903. Memetang. Вк. = E w y c$\mathrm{k}$ i a pan ic ulat a Miq. Nat. fam. der 
M e l a s t o m a c e æ. Gr. Bangka; heester. 5904. Memetang-hitam-boewa Вк. (Zie Mangkata Bk.) 5905. Memmaniram S. $=a$. 现. chynomene indica L. (Zie No. $\left.2360 f_{\text {. }}\right)=$ b. Euphorbia thy mifolia L a m. (Zie No. 1830.)

วั906. Memmaniran-leutiek $\mathrm{S}$. = Portula ca quadrifida L. (Zie No. 2482a.)

5907. Memêongan S. $=a . \mathrm{S} \mathrm{opho-}$ ra tomentosa D. (Zie No. 1490.) = b. Uraria crinita Desv. (Zie No 1442b.)

5908. Mempanjong Вк. $=\mathrm{Xylo}$. pia? Tooropian a Scheff., Nat. fam. der A nonaceæ. Gr. Bangka; boom.

5909. Mempiding $\mathrm{BK} .=\mathrm{H}$ a l o ragis disticha Jack. (Zie No. 3297.) 5910. Mempinang $\mathrm{BK}_{0}=1^{0} . \mathrm{Q}$ n e rcus sericea Scheff. (Zie Ampenieng.) $=2^{0}$. Quercus argentat a K ths., Nat. fam. der Cupilif e ræ. GR. Sumatra, Bangka, Borneo; boom.

5911. Menamang $\mathrm{BK} .=\mathrm{Wick}-$ strœmia tenuiramis Miq., Nat. fam. der D a ph noide æ. Gr. Rangka; heester.

5912. Menampa CeL. = Dilleni a $s p e c$ ios a Thnb. (Zie No. 61.) ร913. Mena-toeh-toeboe $A$ uв. $=\mathrm{P}$ itheculobium clyperia Bnth. (Zie No. 3115.)

5914. Menauwel $\mathrm{BK} .=\mathrm{D}$ e n d r otrophe umbellata Miq. (Zie No. 1207.)

5915. Mendara $\mathrm{BK}$. = Myristica b a n c a n a M iq. (Zie No. 5361.)

5916. Mendjangkit Вв. = Ur ostig. m a a c a m t o p hyllu m Miq., Nat. fam. der Arto c a r p æ. Gr. Bangka; hooge boom.

5917. Mendjaroem Вк. $=\mathrm{A} \mathrm{r} \mathrm{ta} \mathrm{b} \mathrm{o-}$ trys su a ve olen s Bl. (Zie No. 575.)

5918. Mendo J. $=\mathrm{W}$ a ll i chia Horsfieldii Bl., Nat. fam. der Palm æ. Gr. Java.

5919. Mendoeng $\mathrm{S} .=\mathrm{Fimbri}$. stylis efoliatus Steud. (Zie No. 2117.

5920. Mengando MI \& S. S. $=a$. Loranthaceæ et Viscacex. = b. Fragræa mi nor Rwdt., Nat. fam. der Log a n i a c e . Gr. De Molukken; heester.
5921. Mengondo-badak $\mathrm{S} .=\mathrm{F}$ agræa a uriculata Jack. (Zie No. 2327.)

ร922. Mengando-koetjoebong S. = a. Elytranthe albida B]., Nat. fam. der L o r a n th a cer. Gr. Java, Sumatra, Borneo; parasiet. $=b$. M a crosolen formosus Bl., Nat. fam. als voren. Gr. Java; parasiet.

5923. Mengando-manjal S. = Æ s c hynanth us purpurascens Hassk., Nat. fam. der C y rtandra c e ז. Gr. Java; overblijvend.

5924. Mengando-seringan S. $=V$ isc um orientale Wlld. (Zie No. 3467.)

5925. Mengando-tahi-boerong $\mathbf{M}$. a. Dendxophthoë pentandra L. (Zie No. 120弓́b.) = b. D e nd rophthoё attropurpurea G. Don, Nat. fam. der $L$ o r a n th a c e Java; parasiet.

5926. Mengantong $\mathrm{BK} .=\mathrm{A} \mathrm{moo-}$ ra aphanamixis R. \& Sch. (Zie 4466a.)

э927. Mengarawan $\mathrm{Bk}$. $=\mathrm{H}$ o $\mathrm{p}$ e a dryobalanoides Miq. (Zie No. 1624c.)

5928. Mengarawang $\mathrm{M}$. = $a . \mathrm{H}$. pea diversifolia Miq. en $=b$. Hopea lIengàrawan M iq., Nat. fam. der Dipter o c arpeæ. Gr. Lampongs; beide hooge boomen.

5929. Menger $\mathrm{S} .=\mathrm{Crat}$. $\mathrm{xy}-$ lon clandestinum Bl. (Zie No. $1123 a$.)

5930. Mengelam $\mathrm{BK}$, 二 $\mathrm{J}$ a m b os a t e tra ëdra Mi q. (Zie No. 5758.)

5931. Mengkirei $\mathrm{Bk} \cdot=\mathrm{Sp}$ on i a virgat a Pla n ch. (Zie No. 4498.)

5832. Mengkoedoe-oetan M. =- Lasianthus firmus Miq., Nat. fam. der R u b i a c e re Gr. Sumatra; heester. 5933. Mengkoedoe II. = Bangkoedoe $\mathrm{M}$.

5934. Mengkoedoe-gantong $\mathrm{M}$. = Mlorinda citrifolia L. (Zie No. 828a.) 5935. Mengkoedoe-keli Bk. = Limacia cuspidata Hk. fs. \& Th. Nat. fam. der $M$ en is perm a c e GR. B a n g k a; klimplant.

5936. Mengkoedoe-padang $\mathrm{M}$. = II orinda Teysmanniana Miq., Nat. fam. der R u bi a c c æ. Gr. Sumatra; boom.

5937. Mengkoewang $\mathrm{M} .=\mathrm{P}$ a $\mathrm{n}$ danus fursatus $R$ oxb., Nat. fam. 
der Pandaneie. Gr. Java, Riouw; boomachtig. GEBr. Men kookt de jonge toppen met water af, en geeft dit aftreksel te drinkeu tegen verschillende vergiftigingen; van de bladeren makt men vloermatten en geldzakken.

5938. Mengkrang $\mathrm{B \kappa}_{\text {. }}=\mathrm{M}$ ap pa $J$ av a ni c a Bl., Nat. fam der Eu phorbi с сег. Gr. Java, Bangka, hoogc boom.

5939. Mengkrang-woeroeng Вк. = Mappa pruinosa Miq. (Zie No. 5688.)

5940. Meninga $M .=G$ ne t u m G n e mon J. ('Lie No. 820.)

5941. Menjom-boeloe MaK. 二 Maclura javanica Miq. (Zie No. 2256$.

5942. Menkras-poetih $\mathrm{BK}=\mathrm{M} \mathrm{e}-$ mecylon Horsfieldi i M q., Nat. fam. der Melastom a c æ. Gr. Bangka; groote heester.

5943. Menona Bd. 二 A no n a ret i c u l a t a L. (Zie No. 1489.)

5944 Mensala BK. = Stylo coryn e lucida Miq. Nat. fam. der Rubiaceæ. Gr. Bangka; boom.

5945. Mensangie BK. 二 Sty loc o. r y a $\mathbf{l u c i d a} \mathbf{M}$ i q. Nat. fam. der R u bi a c e r. Gr. Bangka; boom.

5946. Mensidoen Рк. of Mensidoeng Bk. = Popowi a ba n can S cheff, Nat. Fam. der A n o n a e e. Gr. Bang. ka; kleine boom.

5947. Mensoeloeng-kajoe Bк. = B rackenridgea Hookerie A Gra ij Nat. fam. der O c h n a e r. Gr. Bangka, boom.

5948. Mensoeloeng-poetih Вк. = Gomphia angust ifolia Vahl., Nat. fam. der O c h n a c e $x$. Gr. Bangka; boom.

5949. Mentelsar Bк. 二 M y r i n e su matrana Mi q. Nat. fam. der M y r sin e a c ex. Gr. Bangka; heester. 5950. Menteng $\mathrm{S}$. $=$ Piërardia racemos a B l. (Zie No. 1580.)

5951. Mentiendok $B \kappa_{0}=1$ ) esmodium capitat $\mathrm{nm}$ DC. (Zie No. 4284.) 5952. Menjienjien $\mathrm{BK}$. en

5953. Mentjandiek Вк. 二 Garcinia brevirostris Scheff. Nat. fam. der Guttiferze. Gr. Bangka; klcine boom.

5954. Mentjena Bк. = Dapliniphyllnm bancan $\mathrm{nm}$ Kïrz, Nat. fain. der Fuphorbiacer. Gr. Bangka : boomachtig.
5955. Mentoenging $\mathrm{BK}_{\mathrm{K}}$ (Zie No. 5948.)

5956. Mentrong Вк. = Garcinia (Discostigma) brevirostris Scheff. Nat. fam. der Clusiácea. Gr. Bangka; boom.

5957. Meöng-dangdang S. = Freycinetia imbricata Bl., Nat. fain. der P and an eæ; klimplant. Gr. Java.

5958. Meöng-dangdang-litjie $\mathrm{s}$. 二 Freycinetia strobilacea Bl. Nat. fam. als voren. Gr. Java; de Molukken; klimplant. GFBR. De Chineezen gebruiken de roode bladeren tot het kleuren van arak.

5959. Mera-bintang Sum. WK. 二 Gardenia.resinifera Korth. (Zie No. 3418.)

5960. Merambong Sum. 二 Gloch idion cyrtostylum Miq. (Zie No. 5206b.)

5961. Merantie of Merateh Bк. = Hopea Marantie Miq. (Zie No. 5808a.)

5962. Merias Вк. $=\mathrm{Ardisia} \mathrm{hı.}$ $\mathrm{mil}$ is Vahl. ('Zie No. 45282.)

5963. Merkoe Вк. = Terustrœ. mia baucana Miq., Nat. fam. der Teru st $r œ m$ i a ceæ. Gr. Bangka heester. 5964. Meroengie M. = Moringa pterygosperma Gærtn. (Zie No. $4125 a$.)

5965. Mesang Вк. - Mensangie Вк. 5966. Mesegar $=\bar{D}$ ipterocarpus trinervis Bl. (Zie No. 6519.)

5967. Mesenong BK. 二 L e a s a mbucina Wild. var biserrata Miq. (Zie No. 133.)

5968. Mesenteh Вк. 二 Alstonia polyphylla Miq., Nat. fam. der A pocy neæ. Gr. Bangka; boom.

5969. Metebul Вк. - Ternstromia bancana Mi q. (Zie No. 5963.)

5970. Metepong Rк. - V ernon ia javan ica D c. (Zie No. 10156.)

5971. Metie of Mettie Br. 二 Griffithia latifolia T. \& B. Nat.fam. der $\mathrm{Rubi}$ a cc æ. Gr. Bangka; heester.

5972. Metsje Crs. = Licuala? Bissula M i q. (Zie No. 1259.)

59726is. Miana M. Zie Majana M. 5973. Mian-sjoe C'r. Bo. $=$ A sclepias curassavica I. (Zic No. 3812.)

5974. Miari-batoe Sum. WK. 二 Heritiera littoralis 1) ryand, (Zfe No. $752 \alpha$.) 
5975. Miendrie M. (Zie later Mindi S.)

s976. Mienjan M. 三 Sty rax Ben20 in Dryand. (Zie No. 33ila.)

5977. Mienjan-meirah $\mathrm{M}$. $=\mathrm{D}$ æmonorhops Draco Mart. (Zie No. 2046a.)

5978. Miereboe $\mathrm{BK}$. $=\mathrm{Glycos}$ mis pentaphylla Colebr. (Zie No. 1148.)

5979. Mi-jit Амв. $=$ Cy athea a r borca Wild (Zie No. 2659.)

5980. Miloe Mor. $=\mathrm{Z}$ e a M a y $\mathbf{L}$. (Zie No. 1878.)

5981. Miloe-miloe J. $=\mathrm{C}$ anna coccinea $\mathrm{A}$ it en $\mathrm{C}$ anna flavescen s Lk. (Zie No. 4l50a.)

5982, Mimbo of Miemboo M. $=a$. A z adirachta indica A. Juss. (Zie No. 3019.) $=b$. M eli a A zed ar a ch L. (Zie No. 3561 $b_{\imath}$ )

5983. Nimiran S. = Ore ocnide sylvatica Miq. (Zie No. 2205.)

5984. Mindl of Miendie S. $=\mathrm{M} \mathrm{e}$ li a L.. S pec. divers x.

5985. Mindie-boddas $\mathrm{S}$. 二 $\mathrm{Meli}$. o s m a B l. d i vers r.

5956. Minibatoe-ketjil $\mathrm{C}_{\mathrm{R}}$. = $\mathrm{D}$ iploclinium tuberosum Miq. (Zie No. 1054.)

5987. Minjalilen $\mathrm{J}$. $\mathrm{Cu} \mathrm{p}$ a $\mathrm{n}$ i a Minjalilen Bl., Nat, fam. der Sap i n d a c e æ. Gls. Java; kleine boom.

5988. Minjassal-oenting T. $=\mathrm{C} \mathrm{y}$ perus kyllingioides Vahl. Nat. fam. der C y perace $x$. Gr. De Molnkken; overblijvend. GEBR. De scherpe, aromatische wortel van dit riet gebruikt meu in de Molukken als specerij bij spijzen en als geneesmiddel.

5989. Moả of Moän T. $=M$ a ra n ta dichotoma Wall. (Zie No. 926.)

5990. Modjo J. (Zie Madja M.)

5991. Modoessan J. $=\mathrm{Gn}$ a ph a liu m javanicum $R w d t$., Nat. fam. der Compositæ. Gr. Java, Sumatra, Celebes; heester.

5992. Modori M. \& $J_{.}=\mathrm{C}_{\text {a l o tro- }}$ pis gigantea R. Br. (Zie No. 817.) 5993. Moedja J. = Plumbago rosea I. (Zie No. 114.)

5994. Moedoe T. $=\mathrm{Evia}$ a ma ra C o m m. (Zie No. 31436.)

5995. Moedoh-lingoh PaL. $=a$. M a p a costulata Miq (Zie No. 2096.) $=$ b. P a chystem on p op ulifolins Miq, Nat. fam. der Eup h o r b i a c e $x$. Gr. Suratra; boom.
5996. Moehoen $\mathrm{S} .=a . \mathrm{Gru} \mathrm{m} \mathrm{i-}$ 1 e a divergens Mi q. (Zie No. 2301.) $=b$. Pavetta indica 5 . (Zie No. 383.)

5997. Moehoen-boddas $\mathrm{S} .=\mathrm{Pa}$. vetta macrophylla B i., Nat fam. der R u b i a c e æ. GR. Java en Borneo; heester. Gebr. Met het sap van deze en andere $\mathrm{P}$ a vetta-soorten verwen de inlanders zich de tainden zwart.

5998. Moehoen-goenong $\mathrm{S}$. $=\mathrm{Pa-}$ vet t a montana $R w d t$., Nat. fam. als voren. Gr. Java; heester.

5999. Moehoen-kahoeroewang S. = $P$ avetta javanica Bl., Nat. fam. dezelfde. Gr. Java; heester.

6000. Moehoen-poetih M. = Tabernæ montana sphæroc arpa B l. (Zie INo. 2035)

6001. Moehoen-woengoe s. 二 $a$. Chasalia expansa Miq. (Zie No. $4505 b$.) $=b$. Chasalia montana M i q. (Zie No. $4505 c$.) $=c$. C h a s a li a ro busta Miq. (Zie No. 2697).

6002. Moe-kwa Сн. Bo. = $\mathrm{C}$ a ric a P a p a a L. (Zie No. 1092.)

6003. Moeka.parang BK. = A rdisia chrysophylloides Miq., Nat. fam. der M y rsin e æ. Gr. Bangka; heester.

6004. Moelebuäe Амв. $=$ Commersonia echinata Forst. (Zie No. 106.)

6005. Moeloe Amr. = Evi a a mar a C o m m. (Zie No, 3143b.)

6006. Moeloet-gaga M. $=$ M om ordica subangulata Bl. (Zie No. 262a.) 6007. Moemeniran $\mathrm{J} .=\mathrm{B} \propto \mathrm{hme}$ ria nivea Gaud. (Zie No. 2387.)

6008. Moendoe S. = Stalagmites duicis Camb. c. variett. (Zie No. 2499.)

6009. Moendoe-allas S. $=$ Stalagmites dulcis Camb. c. variett. (Zie No. 2499.)

6010. Moendoe amies S. $=S t a l a g-$ mites dulcis Camb. c. variett. (Zie No. 2499.)

6011. Moendoeng-indanoh Mrs. = Maranta dichotoma Wall. (Zie No. 926.)

6012. Moengsie J. $=$ Anethum graveolens L. (Zie No. 10b.)

6013. Moenteh MiN. = Djeroek M. en Lemon 1 .

60i4. Moentjang S. $=$ Aleurites triloba Forst. (Zie No. 312.) 
6015. Moentoh M. = Cyperus compressus L., Nat. fam, der Cyperaceie. Gr. Java en Sumatra; overblijvend.

6016. Moerang-moerang Вк. = M appa Zollingeriana Miq. Nat. fam. der Euphorbiaceæ. Gr. Bangka, heester.

6017. Moessoe Амв. $=a$. Covellia hispida Miq. (Zie No. 1255a.) $=b$. Covellia congesta Miq. Nat. fam. der Artocarpe æ. Gr. Amboina; heester. Gebr. Men eet de jonge bladeren van dezen heester als groentc bij de rijst; zoo ook de vruchten.

6018. Mohdang-koearen Sum. Wк. = Elæocarpus toincntosus Bl. (Zic No. $4474 a$.)

6019. Mohdang pier-aweh Suм. IVк. = Glochidion? cinerascens Miq. Nat. fam. der Euphorbiaceæ. Gr. Sumatra; heester.

6020. Mohoetoe T. $=$ Com mersonia echinata Forst. (Zie No. 106.)

6021. Mokal Амв. $=$ S cævola Koenigii Vahl. (Zie No. 1001.)

6022. Mokal-ahoea Амв. $=$ T о urnefortia argentea L. (Zie No. 3884.)

6023. Mombongan Mev. = Syzygium quadrialatum T. \& B. Nat. fam. der Myrtaccie. Gr. Celebes, de Molukken; hooge boom. Gевк. De zwarte vruchten van dezen boom zijn zuurzoet en samentrekkend, en worden door de in. landers gaarne gegreten.

6024. Mometie $\mathrm{BK}$. $=\mathrm{Jambosa}$ bracteata Miq. Nat. fam als voren.
GR. Sumatra, Bangka, Borneo; boom. 6025. Mondong-sapi I. $=$ Solan um ferox L. (Zie No. $388 \mathbf{l}$ b.)

6026. Mora-toppan S. $=\mathrm{Z}$ antho. xylon rhizinoides Bl. Nat. fam. der Di osmeæ. Gr. Java; boom.

6027. Moral Амв. $=$ Mokal Амв. 6028. Moral $\mathrm{Cr}$. $=\mathrm{Crinum}$ asiaticum L. (Zie No. 869a.)

6029. Moral-baboeloe M. Zie No. 6022.)

6030. Moran S. $=$ Commer oni a e chinata Forst. (Zic No. 106.)

6031. More-more Mak. $=$ Vitis indica L. (Zie No. 349.)

6032. Morfalla $\mathrm{T} .=\mathrm{E}$ ch in us $t \mathrm{ri}$ sulcus Lour. (Zie No. 3344.)

6033. Mormosôdô I. = Cordia subcordata I, am. (Zie No. 10216.)

6034. Mou AмB = Scindapsus? Rumphii Mliq. (Zie No. 3499.)

6035. Moumbi Men. = Artocarpus L. Spec. c cleb. indefinita. Een hooge boom, die een zcer goed timmerhout, vooral voor planken, levert.

6036. Mugmal S. (Zie Hoeroe-mug-

mal S.)

6037. Mugmal-aroij $\mathrm{S} .=$ Ery c i be paniculata Roxb. (Zic No. 632a.)

6038. Mugmal-burrum S. = Lepidadenia rubra Bl. (Zie No.2931c.) 6039. Mureila Амв. $=a$. Has sia media Bl. (Zie No. 119b.) $=6$. Machilus od oratissima Nees. (Zie No. 119 a.)

6040. Muri-muri $\mathrm{Cr} .=$ Costus speciosus S mith. (Zie No. 3247.) 6i41. Na Tr. $=$ pterocarpus ind i c us Wlld. (Zie No. 18.)

6042. Naboh IAMP. $=\mathrm{Als}$ o de i a d a s y c a ul a Miq. Nat. fam. der V io l a c e æ. Gr. Lampongs; boom.

6043. Nadoe Br. = $a$. A m a r a n-

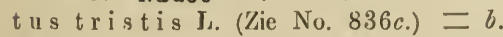
Euxolus polygamus Msq. Tand. (Zie No. 836b.)

$60+4$. Nagassarie I. M. \& S. $=a$. Acaci a Farnesian a Wlld. (Zie No. 2041.) $=b$. A c a c i a tortuos a Wlld. Nat. fam. der M i mose æ. Gr. Op Java als sierplant in tuinen; heester. $=c$. M e su a fer re a L. Nat. fam. der Clu si a c cæ. Gr. Java, Timor, de Molukken; boom GEBR. Het hout van dezen boom, dat ook tot het ijzerhout gerekend wordt, is een der hardste houtsoorten van den Archipel, zoodat het moeilijk te vellen is. Men lat gewoonliik den boom vallen, door vuur rondom den stam te doen brandelı. De wortel en de bast zijn aromatisch bitter; men rekent ze tot de zweetdrijpendc middelen. De bladeren ziju slijmerig. De bloemen zijn, on den aangenamen geur, zeer gezocht, en worden in vele zalven of smeersels (bobori) ge- 
mengd. De aromatische, scherpe vruchten hebben een purgeerende werking. $=d$. Achillea condensat a Miq. Nat. fam der Compositæ. Gr. Java; éénjarig.

604.5. Nagassi $\mathrm{I}$. = M e s u a ferre a $I_{\text {. }}$ Zie voren.

6046. Nakkil $\mathrm{Cr}$. $=$ Ery thrin a in di c a $\mathrm{L}$ a m. (Zie No. 15866.)

6047. Nala-kiri Амв. $=\mathrm{Pter} 0$ carpus indieus Wlld. (Zie No. 18.)

6048. Nalang Вк. $=1 \mathrm{mperata}$ arundinacea Cyrill. (Zie No. 263.)

6019. Naloer Br. en

6050. Naloer-naloel Aџв. $=\mathrm{Com}$. melina benghalensis L. (Zie No. 2549.)

605l. Nambong J. $=\mathrm{P}$ oth o morphe subpeltata Miq. (Zie No. 86.)

6052. Namnam M. \&. S. = a. Cy. no.metra cauliflora L. (Zie No. 5206.) $=6$ Cy nom e tra ramiflo$r$ a L. (Zie No. 4262.)

6053. Namnam-oetan M. = $\mathrm{Cy}-$ n o metra ramiflora L.

6054. Namoe-namoe Mol. Namnam M.

6055. Nampoe I. 二 $a$. H orn al on ema rubescens Kunth. (Zie No. 903.) $=b . \mathrm{seh}$ ismatoglottis latifoli a M iq. Nat. fam. der A roid e $\mathrm{GR}_{\mathrm{R}}$. Java; overblijvend. $=c$. Mi t s c h erlichia Junghuhniana Miq. Nat. fam. der B eg on i a c ex. Gr. Java; overblijvend.

6056. Nampong $\mathrm{S}$. $=\mathrm{X}$ a u thium in dic u $m$ R $x$ b. v a r., Nat. fam. der C o m p os it $æ$. Gr. Java; Sumatra, Bor• neo; éénjarig.

6057. Nam-tjau Сн. Во.二 $\mathrm{K} \mathrm{m} \mathrm{p}$ f eria Galanga L. (Zie No. 737.)

6058. Nanang Sum. WK. = $\mathrm{M} \mathrm{e-}$ lanolepis angulata Miq. Nat. fam. der E u ph or bi a c e æ. Gr. Sumatra; boom.

6059. Nanangkaän S. 二 $a$. Pby llanthus Nuriri 1. (Zie No.7la.) = b. Euphorbia pilulifera L. Nat. fam. der Euphor bi a ce æ. Gr. Java; éénjarig.

6060. Nanangkaän.gedeh $\mathrm{s} .=a$. Euphorbia reniformis Bl. (Zie No. $2155 h.)=b$. Euphorbia thymifolia Lam. (Zie No. 1830.)

6061. Nanangkaän-lumboet S. =
Phyllanthus quadrangolaris K le in Nat. fam. der Euphorbiac e . Gr. Java; kruid.

6062. Nanari Mol. 三 $a . \mathrm{C}$ a n ari u m c o m mu n e L. (Zie No. 3072a.) $=b$. Canarium sylvestre Gxrtn. (Zie No. 3070.)

6063. Nanari-mienjak Амв. = $\mathrm{C}$ a. narium microcarpum Wlld. (Zie No. 40.)

6064. Nanas of Nannas I. \& M. = An an as sa s ativa L indl. (Zie No. 5680.)

6065. Nánas-hiedjoe M. = An anassa sativa Lindl. va r. viri$\mathrm{d}$ is $\mathrm{H}$ a s s k.

6066. Nanas-kondoh N. = $\mathrm{An} \mathrm{a-}$ nas a sativa Lind l. var. poly. c e phal a $\mathrm{H}$ as sk.

6067. Nanas-kosta M. = A g a ve $\mathrm{C}$ a n t u la $\mathrm{R} \times \mathrm{b}$., Nat. fain. der $\mathrm{Am}$ eryll i deæ. Gr. Java, de Molukken, in tuinen. Gebr. De bladvezels van deze $A$ g a ve-soort leveren ook een soort van garen, grover dan dat der $\mathrm{A} n$ a $\mathrm{n}$ a s, echter geschikt tot het weven van kleed. jes. De fijngestampte bladeren legt men op kankergezwellen.

6068. Nanas-sabrang MI. Zie vorig No.

6069. Nanas-siesiek $\mathrm{M}$. $=\mathrm{A} \mathrm{u} \mathrm{a-}$ n a s s a bracteat a Lindl. Nat. fam. der Bromeli a c ex. Gr. Java in tuinen. Gebr. als No. 5680.

6070. Nanas-soerat $11 .=1 \mathrm{n} \mathrm{a-}$ nassa sativa Lindl. var. scrip$t$ a $\mathrm{H}$ a s s k.

6071. Nanas-tembaga M. = A na. na ss a sativa Lindl. var. rubens $\mathrm{H}$ a s s k.

6072. Nanas-toempang M. 二 $A \mathrm{n}$ an a s sa sativa Lindl. var. py ra$\mathrm{mid}$ a lis $\mathrm{H}$ a s s $\mathrm{k}$.

6073. Nanas-wolanda Ml. (Zie No. 6067.)

6074. Nane Мак. \& Вг, = Mim us ops Elengi L. (Zie No. 13996.)

6075. Nangi LaMP. $=\mathrm{Nau} \mathrm{cl} \in \mathrm{a}$ aralioi des Mliq. (Zie No. 3326.)

6076. Nangka II. \&. S. = A r t ocarpus integrifolia. L. (Zie No. 276.)

6077. Nangka-beurriet S. $=a . A \mathrm{r}$ tocarpus Kerta u Zoll. (Zie No. 4.271.) = b. Artocarpus poly$\mathrm{p}$ h e m a P e r. (Zie No. 144.)

6078. Nangka-hollanda M.=-A non a muricata D un. Nat. fam. der 
A n o n a ceæ. Gr. Door geheel Indië in tuinen; boom. Gввк. De viuchten, zuur. zak genoemd, bezitten een aangenaam zuur vleesch, dat gaarna wordt genuttigd, echter zacht laxeerend en oplossend werkt.

6079. Nangka-riemboe $\mathrm{BK}$. 二 A rtocarpus hirtussima K ürz. Nat. fam. der A r to c a r e æ. Gr, Bangka; hooge boom.

6080. Nangpong $\mathrm{S}$. $=$ s i e g e sbeckia orientalis l. (Zie No. 1974 )

6081. Nangsi S. 二 $a .0 \mathrm{reocnide}$ sylva tic a Mi q. (Zic No. 2205.) 二 b. Oreocnide major Miq. Nat. fam. der Urtic a e e. GR. Java; heester. $=c . \quad B \propto \mathrm{h} \mathrm{meria} n \mathrm{eglecta}$ B 1. Nat. fam. als voren. Gr. Java; heester. Geвr. H a s s k r l geeft aan, dat vall de $\mathrm{Nang}$ si-soorten het sap wordt gedronken tegen moeilijke urinelozing en ook bij natuurlijke en valsche pokken, o.ndat het een aangename verkocling zal aaubrengen. Uitwendig bezigt men het sap als oogwaschwater.

6082. Nangsi-aroij S. = P i p t ur u s r. pand us W e d d. (Zie No.622.)

6083. Nangsi-lumboet $\mathrm{S}$. 三 A c aJypha densiflora Bl, (Zic No. 14 40.)

6084. Nani Mak. = M im u s p s k a u ki L. (Zie No. 1497.)

6055. Nani Mol. en

6086. Nani-merak MoL. en

6087. Naniri MaK. $=1$ pomoe a reptans Poir (Zie No. 5\%6.)

6088. Nani-wajer MoL. $=\mathrm{N}$ a n i a ve ra M iq. (Zie No. 27796.)

6039. Nantahoele Амв. = La ctaria salubris $R \mathrm{~m} p \mathrm{~h}$. (Zie No. รว 18.$)$

6090. Nantoe Min. = Sapotac e æ. $S$ pec. Celebens in def. Een hooge boom, die een vrij goed timmerhout levert.

6091. Napo Амв. $\mathrm{M}$ i l uе a mont a ll a J a c k. (Zie No. 525̌.)

6092. Narawastoe $\mathrm{M}$. 三 $\mathrm{A}$ и d r opogon ul uricat us Retz. (Zie No. 241.)

6093. Narra Bt. =Pterocarpus in d i c u s IV 11 d. (Zic No. 18.)

6094. Narra-watoe Br. = J'teroc a r u s obtus a tus Miq. Nat. fam. der P a p i li o u a c e a. Gr. Bima; hooge boorn.

6095. Nassi-nassi A.rı. = d rolobium umbellatum W \&

A. (Zie No. 1863.)

6096. Nassi-nassi M. - D a r t u s perlarius Lour (?) (Zie No. 75.)

6097. Nassi-nassi Вк. 二 J a m b os a buxifoli a Miq. (Zie No. 3384.)

6098. Nau Амв. $=\alpha$. Mela st oma polyantum B 1. (Zie No. 110.) 二 b. Otanthera moluceana B l. (Zie No. 2238a.)

6099. Naun Br. en

6100. Nawa Auв. = A renga sa cc h a rif c ra L a b. (Zie No. 243.)

6101. Nela AuB. 二 Tournefortia a rgentea L. (Zie No. 3584.)

6102 . Nenga $\mathrm{s}$. 三 a A e c a $\mathrm{pu}$ mila Mart. (Zie No. 2713b.) $=6$. Ptychosperma costata Mi (Zie No. 1178c.)

6103. Nenoe Амв, en

6104. Nenoe-kiri Amr. $=\mathrm{M}$ o r i d a b r a cteat a I x b. (Zie No. 8286.)

6105. Nepoe T. 三 'T a c a p i n n atif ida Forst. Nat. fam. der T a cc a c e æ. Gr. Java en de Molukken; overblijvend. GєвR. De aan zetmeel rijke knolwortcl wordt door vele eilanders gegeten, hij is, nog rauw zijnde, bitter van smaak en cenigszins giftig.

6106. Newakan Cer. = S a u r a y a e ur yole pis de V r. (Zie No. 4977.) 610\%. New-djap Cri. Bo. 三 Chavica $\mathrm{B}$ e tle $\mathrm{Miq}$, (Zie No, 285.)

6108. Ngaro T. - Kleinhovia hospit a L. (Zie No, 3927.)

6109. Ngassie T. 二 C a l odra c on ter in in a is Pla n e h (Zie No.3336.)

6110. Ngassie-kolotidi 'T. 二 C o rdyline $\mathrm{Kumphii} \mathrm{Hook}$. (Zie No. $337 a$.)

6111. Ngauloe T. 二 $а$. Dra c o nt o melon m angif er um L. (Zie No. 1492.) $=6$. Evi a a c i a B 1. (Zic No. 2890.)

6112. Ngemblong $\mathrm{S}$. $=\mathrm{U}$ rost igma odoratu in Miq, Nat. fam. der A r to c a r pere. Gr. Java; boom, die een geurige hars uitzwect.

6113. Ngenneh $\mathrm{s}$. $=\mathrm{K}$ ibes s i a sessil is B1., Nat. fam. der Mel as. t o m a e e $x$. Gr. Java; heester.

6114. Ngepa-tanah BI $=$ Tr r ianthein a pentand a L, Nat. fam. der Portulacea. Gr. Bima, 'Timor; kruipende plant.

6115. Ngingeh $\mathrm{s}$. $=$ A rec a puin i l a M a r t. (źic No. 27136.) 
6116. Nia T. $=$ Canariopsis d e cumana B l. (Zie No. 265l.)

6117. Niam LaMp. 三 A n ti des ma puncticulat a Miq., Nat. fam. der Antidesmer. Gr. Sunatra; hooge boom.

6118. Niangka $\mathrm{S}$. = $\mathrm{S}$ cævola Kœnigii Vahl. (Zie No. 1001.)

6119. Nibong $\mathrm{M}$. 三 $a . \mathrm{A} \mathrm{reca}$ Nibung Mart. (Zie No. 2310.) = b. Cariota urens L. (Zie No. 384.) $=c$. Calyptrocalyx spicatus B 1. (Zie No, 2804,)

6120. Nibong-besar $\mathrm{Ml}$. = C a r y o t a Rumphiana Mart. (Zie No. 33l.)

612l. Nibong-ketjil M. = Ptyc hosperma $R$ um phi B l. (Zie No. $226 \pi b)$

6122. Nibong-meirah M. = Pty. chosperma punicea Miq. (Zie No. $4097 c$.)

6123. Nibong-meirah-ketjil M. = Ptychosperma saxatilis BI. (Zie No. 2984.)

6124. Niing Br. =Albizzia B enth a mi an a Bl., Nat. fam. der Mimosex. Gr. Java, Bali; hooge boom.

6125. Niha. T. of Nija T. 二 $\mathrm{C}$ a n ari u m co $\mathrm{mm}$ un e L. (Zie No. 3072a.)

6126. Nija-samaoh Амв. = 0 tanthera moluccana Bl. (Zie No. 2238a.)

6127. Nijeri J. $=\mathrm{x} \mathrm{y} \mathrm{lokarpus}$ Granatum Koe u. (Zie No. 1319.)

6128. Nila J, \& M. 三 $a$. Ind i g ofera tinctoria L. et aliæ. (Zie No. 2305.) $=$ b. Dipteracauthus dejectus $\mathrm{N}$ e es., Nat. fam. der A can. t h a c e $æ$ Gr. Java; kleine heester.

6129. Nila-koetjing M. = Diplophractum auriculatum Desf., Nat. fam. der Tili a c ex. Gr. Java, Sumatra; heester.

6130. Nini Aмв $=\mathrm{Maranta}$ dichot o m a Wall. (Zie No. 926.)

6131. Nini-pattoe Амв. 二 A verrhoa Carambola L. (Zie No. 851.)

6132. Nioe Br. en

6133. Nioera $\mathrm{C}_{R}$. of

6134. Nioh Br. en

6135. Nior R. 三 Cocos nucifera L. (Zie Nu. 393.)

6136. Nipa M. $=\mathrm{Nipa}$ frutic a n s Thn b. (Zie No. 856.)

6137. Niri $\mathrm{S}$. $\mathrm{Xylocarpus}$ obovatus A. Juss. (Zie No, 1480.)
6138. Nitoe Амв. $=$ Pavonia z e y l a n i c a Cav. (Zie No. 3792.)

6139. Nitoe-alaä Амв. $=\mathrm{Nepen-}$ thes phyllamphora Wlld. (Zie No. 128.)

6140. Nitoo-atoäij Амв. = $\mathrm{Ma}$. ranta dichotoma Wall (Zie No. 926.)

6 141. Niwel of Niwer Asв. $=\mathrm{C}_{0}$ cos nu cifer a L. (Zie No. 393.)

6142. Niwel-haboe Амв. $=\mathrm{Cocos}$ n u c if era L., var. pumila $\mathrm{H}$ assk. 6143. Niwel-latoe Амв. = Cocos n u c if e r a L., var. regi a B 1 .

6144. Niwel-loepoe Амв. $=\mathrm{Co}$ с os n u c iferaL., var. pumila Hassk.

6145. Niwel-lopoe Амв. = Cocos n u c if er a $L_{\bullet}$, var. ma chæroide Bl.

6146. Njam-djarah Laмp. 三 J a mbos a clavata K or th., Nat. fam. der M y rtace æ. Gr. Sumatra, Borneo; boom.

6147. Njamploeng $\mathrm{M}$. = $\mathrm{C}_{\mathrm{al}} \mathrm{O}$ phyllum inophyllu m L. (Zic No. 1139.)

6148. Njamploeng-sabrang $\mathrm{M}$. = I mbricaria coriacea I).C. (Zie No. 3066.)

6149. Njarang M. $\mathrm{M} . \mathrm{A} \mathrm{ch}$. ranthes bidentata B l. (Zie No. 740.) $=6$. Cyathula geniculata Lo u r. (Zie No. 741.)

6150. Njating Bo. Zo. = Vatica $\mathrm{R}$ a s s a $\mathrm{k}$ B l. (Zie No. 1632.)

6151 . Njating-mahambong Bo. Zo. = Hopea Balangeran Korth. (Zie No. 898.)

6152. Njating-mata-poesa Bo. Zo.en

6153. Njating-pleppek Bo. Zo. 二 $\mathrm{H}$ o pe a Sangal Korth.. Nat. fam. der Dipterocarper. Gr. Borneo; hooge boom, die een goed timmerhout en fraaie, witte hars oplevert.

6154. Njatoe of Njatoh M. = $a$. I s o n andra Gutta Hook. (Zie No. 890.) $=b$. Sideroxylon nitidum B l. (Zie No. 4053.) 二c. V a ti c a $R$ a ss a k B l. (Zie No. 1632.) $=d$. M y$r$ istica iteophylla Miq., Nat. fam. der M y rist i c a c e æ. Gr. Sumatra; hooge boom. $=e$. M y ristic a c orticosa Hook. (Zie No. 137.)

6155. Njatoo-laboer BK. = D a phniphyllum bancanum Kurz. (Zie No. 5954.)

6156. Njatoe-pisang Вк. 二 Is o- 
na ndra? rostrata Miq., Nat. fam. der S a p ot a c e a. GR. Bangka, hooge boom.

6157. Njatoek $\mathrm{s}$. $=\mathrm{Mimus}$ ops a cu min a t a B l. (Zie No. 2040.)

6158. Njelandieng $\mathrm{BK}$. = M e lanolepis diadema Miq. (Zie No. 5126$.

6159. Njenging $\mathrm{J}_{\text {. }}=\mathrm{Arec}$ a $\mathrm{pu}$ mil a M a rt. (Zie No. 2713b.)

6160. Njoe-ma Сн. Bo. $=\mathrm{Ses}$ a$\mathrm{m} \mathrm{um}$ indicum D.C. (Zie No. 246.)

6161. Nodjoh J. = Hy poës tes laxiflora Nees, $\nabla$ ar. albiflora Nat. fam. der A c a n th ac e æ. Gr. Java; overblijvend.

6162. Noedjar J. = Tradescanti a c a pitat a B l. (Zie No. 2130e.)

6163. Noenang $\mathrm{M} .=\mathrm{C}$ ordia s ubde ntat a M i q. (Zie No. 2824.)

6164. Noeno Aмв. = Ficus Altimeraloo $\mathrm{R} \times \mathrm{b}$. (Zie No. 1362.)

6165. Noeno-anahan Амв. = Ficus variegata Bl. (Zie No. 1352.)

6166. Noeno-assan Aмв. $=$ Urostigm a nitidum Miq. (Zie No. 855.) 6167. Noeno-hauëssi Амв. $=$ Ficus A l ti meral oo Rxb. (Zie No. 1362.)
6168. Noeno-hauëssi-poetih Амв. = Urostigma Tjiela Miq. (Zie 3048.)

6169. Noeno-laun-maun Амв. = Urostigma nitidum Miq. (Zie No. 855.$)$

6170. Noessoe T. $=a . \mathrm{Ter}$ in ali a Catappa L. (Zie No. 7.) $=b$. Terminalia moluccana Wlld. (Zie No. 3912.)

6171. Nogosarin $\mathrm{J}_{0}=\mathrm{J}$ a m b o s a lin e a $t$ a D.C. (Zie No. 304.3c.)

6172. Nono of Nonoe T. = M u ss a ënda frond o sa L., var. glabra. (Zie No. 74.)

6173. Nonno M. $=$ Tacea $\mathrm{Rum}$ ph i i J. C. S ch a u er. (Zie No. 2271b.) 61'74. Noöh-hoe Rtr. = Coc os nnc if e r a I. (Zie No. 393.)

6175. Nôpal J. $=\mathrm{Opuntia} \mathrm{coc-}$ c inellifera Mill. (Zie No. 5387.)

6176. Nopoe Амв. $=$ Crin $1 \mathrm{~m}$ a s i a t i c u m L. (Zie No, 869a.)

6177. Notja J. \& BL. = Mira bi$\mathrm{l}$ is $\mathrm{J}$ a 1 a p p a L. (Zie No. 1405.)

6178. Nua.hun Tr. $=$ Cocos nuc i f e r a I. (Zie No. 393.)
6179. Oär S. = Flagella ria i nd i c a L. (Zie No. 13ь̆.)

6180. Oär-leutiek S. $=\mathrm{Flag}$ l lla ria minor B l.. Nat. fam. der F'lag ell a ri e a. Gr. Java; slingerplant.

6181. Oär-naga S. 三 a. Flag e l$\mathrm{l}$ a $\mathrm{ri}$ a ind ic a $\mathrm{I}_{\text {. }}$ en $=b$. F lag. $\mathrm{mi}$ no r B l. (Zie No. 6180.) $=c$. Vanilla a $l$ b i d a B l. (Zie No. 378.)

6182. Oär-tambang $\mathrm{S}$. = $\mathrm{Fla-}$ gellaria indic a I. (Zie No.6180.)

618\%. Obak batah S. = Chavica s a r m e t o s a $11 \mathrm{iq}$. (Zie No. 292.)

6184. Obar PaL. = S yz y g i u m pa l e mban i c u m i q, Nat. fam. der M y r t a c e $x$. Gr. Sumatra; boom.

6185. Obat (oebat).dingin Амв. = Fu uhorbia nereifolia I. (Zie No. 44.)

6186. Obat-pamali Aмв. $=$ S о ul a me a a mara $I_{a} \mathrm{am}$. (Zie No. 1476.)

6187. Obat-papeda $M$. = A stron i a p a petaria Bl. (Zie No. 41 12.)
6188. Obat-radja $\mathrm{M}$. = $\mathrm{Smil} \mathrm{ax}$ z e y la n i c a L. (Zie No. 717.)

6189. Obat-ramboet $A м B$. = C o rdyline Rumplii Hook. (Zie No. $337 a$ )

6190. Obat-sageroe-hossaar Амв. en

6191. Obat sageroe-lemon Амв. = Garcin a I. 2 S ec. a m boin. in defin it r.

6192. Obat-sageroe-toedi Амв. = Garcinea pic rorhiza Mi q.; Nat. fam. der Clusia ce e. Gr. A m boina; hooge bocm.

6193. Obat-swangi M. = a.R u elli a dis color Nees. (Zie No. 72.) = b. R n elli a repanda I. (Zie No. 91.) 6194. Oeä J. = Korthalsia rob u sta B l. (Zic No. 2859b).

6195. Oeä (Ua)-ahoen-tanijn Amı. $=\mathrm{Ca}$ lamus graminosus Bl. Nat. fam. der P a l m x. Gr. Amboina; slingerplant. GивR. Dezc rottansoort bezigt men voor allerlei vlecht- en bindwerk; 
haar sap zal den haargroei bevorderen. 6196. Oeä.ela Aмr. (Zie rorig No.)

6197. Oeä-hahoeloe Aмв. = læ. monorops calapparius Bl., Nat. fam. der P a l m x. Gr. Amboina; slingerplant. GeBr. Men gebruikt deze rottan voor allerlei vlecht- eu bindwcrk on ook voor wandelstokken; hare palıniet of palmkuol is zcer lekker.

6198. Oeä-helite $\Lambda$ мв. $=\mathrm{D}$ х m on orops Rumphii Bl, Nat. fam. als voren. Gr. De Molukken; klimplant. GeBr. Deze rottan wordt veel gebruikt tot het vervaardigen van vischfuiken.

6199. Oeä-kawa $А м в .=C$ alanus equestris Wild. (Zie No. 2804.)

6200, Oeä-lahoen-sehi Aмв. $=\alpha$. Calamus graminosus Bl. (Zie No. 6195.) = b. Calamus? pisicarpus Bl., Nat. fam. als voren. GR. De Molukken; klimplant. GEBr. De stengels gebruikt men om te binden ell te rlechten, in de bladeren wikkelt en kookt men de sago.

6201. 0eä-lou-kana Азв. $=$ D «emonorops strictns Bl.. Nat. fam. dezelfde. Gr. Sumatra en de Molukken; klimplant. GeBr. Men gebruikt deze stengels voor bind-en vlechtwerk.

6202. Oeä-manima AмB. en

6203. 0еä-niwel Амв. $=\mathrm{D} æ \mathrm{mo-}$ norops calapparius Bl. (Zie No. 6197.)

6204. 0eä-metta Амв. = $а$. Dæmonorops melanochrtes Bl. (Zie No. 2861b.) $=b$. Damonorops niger Bl., Nat. fam. der Palmæ. Gr. De Molukken; klimplant. Gebr. Volgens $\mathrm{R} u \mathrm{mphius}$ koken de Alfoeren op Ceram de stengels in bamboezen kokers, splijten ze daarna, en vlechten cr eetkannen van; de palmiet wordt gegeten, doch is bitter.

6205. Oeä-orij Амв. = Calamus? pisicarpus Bz. (Zie No. 6200a.)

6206. 0eä-poetih Амв. = Calamus gr aminosus Bl. (Zie No. 6195.)

6207. Oeä-tehoe Амв. (Zie 0eä-mette Амв.)

6208. Oebar Sum. WK. = Syzygi a $\mathrm{m}$ ja m bola n u m. D.C. (Zie No. 1906.)

6209. Oebar-pago Sum. WK. = Glochidion sumatran nm Miq., Nat. fam. der Fuphorbiace r. Gr. Sumatra; boom.

6210. Oebar-paja $\mathrm{Bk} .=\mathrm{D}$ en dro. trophe umbellata Miq. (Zie No. 1207.)

6211. Oebie M. 二 $a$. Sol a nu m $\mathrm{t} u$ berosum L. (Zie No. 2968b.) b. $\mathrm{Di} o s c o r$ a alata L. en $c$. Di. oscorca vulgaris Miq. (Zie No. 28086.)

6212. Oebie-ajam M. en

62?3. Oebio-aléa M. $=\mathrm{D}$ i os co. $r$ e a $\mathrm{l}$ a $\mathrm{t}$. L. (Zie No. 2808a.)

6214. Oebie-baboewa M. = Dios. c ore a bulbifera I. (Zie No* 4.)

6215. Vebie-badak M. = Diosc ore a spiculata Bl. (Zie No.2871.)

62l6. Oebie-boetong M.,

6217. Oebie-dawon-soekoen M. en

6218. Oebie-djari M. alle $=\mathrm{D}$ i o s. c ore a a lat a L. (Zie No. 2808a)

6219. Oebie-dangdur $\mathrm{S} .=\mathrm{J}$ an $\mathrm{i}$ pha Manihot H. B. \& $\mathrm{Kth}$. (Zie No. 2872.)

6220. 0ebie-djawa M. = $a . \mathrm{B}$ a $t$ atas edulis Chois (Zie No. 635.) $=b$. Batatas? glaberrima Hassk. Nat. fam. der Convolvula c c x. Gr. Java, in den tuin te Buitenzorg, uit Frankrijk overgebracht; slingerplant.

6221. 0ebie-djindral $\mathrm{S}$, = $\mathrm{J}$ a nipha Manihot H. B. \& K. (Zie No. 2872.)

6222. Oebie-gadoeng M. \& S. $=$ Dioscorea hirsuta Bl. (Zie No. 475.)

6223. 0ebie-gorita M. $=\mathrm{Rox}$ burghia jaranica Kunth. (Zie No. 1534)

6224. Oebie-hollanda M. = S ol an n m t u beros um L. (Zie No. 2968b.) 6225. Oebie-kajoe M. = J a nipha $\mathrm{M}$ anih ot H. B. \& $\mathrm{Kth}$.

6226. Oebie-kastela $M$. 二 Bat tas edul is $\mathrm{Cho}$ is. (Zie No. 635.)

6227. Oebie-katella M. $=$ Oebie kastela $M$.

6228. Oebie-kentang $\mathrm{M} .=\mathrm{Colens}_{\mathrm{s}}$ tuberosus Bcnth. (Zie No. 1714a.)

6229. Oebie-kapas M.

6230. Oebie-laki-laki M. en

6231. Oebie-lilin $M$. alle $=$ Dioscorea al ata L. (Zie No. 2808a.)

6232. Oebie-oepas M. $=$ Dios corea bulbifera ]. (Zie No. 4.)

6233. Oebie-oetan M. = a. Dios. corea hirsuta Bl. (Zie No. 475.) = b. Dioscorca pentaphylla L. = c. Rox burghia javanica Kunth. (Zie No. 1534.) 
6234. Oebi-padjal I.\& M. 二 Tacea pinnatifida Forst. (Zie No. 6105.)

6235. 0ebi-pagger $M$. J Janipha Manihot H. B. \& Kth.

6236. 0ebie-pariaman of priaman I. \& T. 三 a. Dioscorea Kleiniana Kunth. (Zie No. 5.) = b. Dioscorea pentaphylla L. (Zie No. 5.)

6237. Oebie-prantjis Mand. $=\mathrm{J}$ anipha $M$ anihot H. B. \& K th.

6238. Oebie-radja M. 三 $\alpha . \mathrm{A}$ gariclls tuber regium Tr. en $=b$. Pachyma tuber regium Tr. (Zie No. 1959.)

6239. Oebie-saboet $\mathrm{S}$. = Dioscorea nummularia L. (Zie No. 1778.)

6240. Oebie-soeffoe M. = I po mœa mammosa (Chois. (Zie No. $972 \alpha$.)

6241. Oebie-tahon-tahon M. 三 $a$.

Dioscorea Kleiniana Knntl. (Zie No. 5.) $=b$. Dioscorea spiculata Bl. (Zie No. 2871.)

6242. Oebie-tangan M. = Dioscorea alata L. (Zie No. $2808 \alpha$ )

6243. Oebie-tjina M. = Dioscorea sativa I. Nat. fam. der Dioscorex. GR. Door gehecl Indië in tuinen en in het wild; slingerplant. GEBr. De kcollen, als gewone Yamswortels bekend, worden gaarne gegeten en zijn zeer aangenaam van smaak.

6244. Oebie-torana M. = Dioseorea spiculata Bl. (Zie No. 2871.)

6245. 0ebo-0ebo (Ubo-ubo) T. = Hibiscus rosa sinensis I. (Zie No. 1360$.

6246. Oedang-oedang $\mathrm{M} .=a$. Aglaja palembanica Miq. Nat. fam. der Nleliacex. Gr. Sumatra's Ok.; boom. 三 b. Chasalia robusta Miq. (Zie No. 2697.) $=c$. Ardisia fuliginosa Bl. (Zie No. 4309a.)

6247. Oedani 1. = Quisqualis indica I. (Zie No. 3234.)

6248. Oedar-oedar I. = Cassia pumila I. Nat. fam. der Papilionac еæ. Gr. Java; kruipende heester.

6249. Oede-dakan $\mathrm{C}_{\mathrm{R}}$. $=\mathrm{C}$ ost $11 \mathrm{~s}$ s p e c i os us Smith. (Zie No. 3247.)

6250. Oedjan-mas Pat. 二 Polyos. ma mutabilis Bl. (Zie No. 1423.) = b. Nothoprotinm sumatianum Miq. Nat. fam. der A m yrider. Gr. Sumatra; boom

62.5l. Oedjen-sapi I. 二 R ubus ro$s \approx f o l i u s$ Smith. (Zie No. 1122b.)

6252. Oetjong-atap $\mathrm{Ml}$. en

6253. Oedjong-rahah $\| 1 .=$ В се kea frutescens L (Zie No. 2395.) 6254. 0edoe-lada S. of

6255. Oedoel-adal S. = Baliospermum axillare Bl. Nat. fam. der E u ph o r b i a c e $æ$ Gr. Java; kleine heester.

6256. Oeët $\mathrm{B}$ o. $=\mathrm{V}$ iqua sinensis Savi. (Zie No. 3935.)

6257. 0ega $\mathrm{T}$. 三 Saccharum officinarum L. Nat. fam. der Gramineæ. Gr. Door geheel Indië als kultuur. plant. GrbR. Het gebruik der sniker en van het suikerriet is aan ieder bekend.

6258. Oega-0ega T. $=\operatorname{Cos} \pm n s$ speciosus Sm ith. (Zie No 324\%.) 6259. Oega-oegahan Ps. $=\mathrm{Co}_{0}$. vellia aurata Miq. (Zie No. 3335.)

6260. Oegai-moeli LAMP. = A reca nengah Bl. var. Sumatrana. Nat. Fam. der Palmre. Gr. Lampongs; boom. 6261. Oege-baja T. 三 a. A marantus tristis L. en $=b$. Euxolus polyganus $M$ oq. Tand. (Zie No. 836b.) 6262. Oege-bira T. $=$ Basella $\mathrm{rn}$ bra L. (Zie No. 2419a)

6263. Oege-ginotti $\mathrm{T} .=\Lambda$ garic ns Djamor Tr.

6264. Oege-jabba T. $=a$. Cardiopteris moluccana Bl. (Zie No. 5859.) $=b$. Coccinia grandis M.I. Roem. (Zic No. 640.)

6265. Oege-kello T. $=a$. Morin. ga pterygosperma $G$ aertu. en $=b$. Moringa polygona 1). C. (Zie No. 4.125b.)

6266. Oehe-talla Aмв. еи

6267. Oehe-walea $\mathrm{Cr}$. 三 Roxburghi a javanica Kunth. (Zie No 15 ร4.)

6268. Oehij Амв. zic Oebie M.

6269. Oehoelibita $\mathrm{C}_{\mathfrak{r}}$. of

6270. Oelibita $\mathrm{Cr} .=\mathrm{Dioscorea}$ hirsuta Bl. (Zie No. 475.)

627l. Oeja-oejaän J. $=a \cdot H_{i}$ ins asperiusenla Kunth \& Bollehé, Nat. fam. der Artocarpex. Gr. Java; slingerplant. Gér. De fijugewreven bladeren wendt men uitwendig an tegen kolijk en bnikloop. = $b$. F i c n s pol yc a r p a $R$ ox b., Nat. fam. dezelfúe. Gr. Java ell de Molukken; heester. GErR. Men rookt de bladeren van dezen hecster met opium.

6272. Oekka Aur. = Aralia javanica Niq. (Zie No. $909 a$.)

6273. 0ekke of 0ekken $\triangle \Perp в$. = Erythrina indica Tam. (Zie No.15S6b.) fi274. Oekke-ewan Imb. =Ochna 
squarrosa L., Nat. fam. der Ochinacex. Gr. De Molukken; boom.

6275. Oekke-moni Амв. еи

6276. Oekke-poetih Amb. = Erythrin a picta L. (Zie No. 2475.)

6277. Oekoe-manjoffoé T. $=\mathrm{Era}$ grostis plum osa Link. (Zie No. 21876.)

6278. 0ekoe-oekoe BL. = Ocimum gratissimum L. (Zie No. 14586.)

6279 . Oela-pala-pala Auв.=Ca lamus equestris Wlild. (Zie No. 2804.) 6280. Oelang -0elang $\mathrm{R}$. $=\mathrm{F}$ i c u s $v$ a $r$ i e a t a B 1 . (Zie No. 1352.)

6281. Oelasse AMB. $=\mathrm{Cedrela}$ Toona $\mathrm{Roxb}$. (Zie No. 267.)

6282. Oelat Амв. $=\Lambda \mathrm{g}$ a ricus $\mathrm{S}$ a j o r-k a j o e T r., Nat. fam. der H ymenom y c tes. Gr. De Molukken; eetbare champignon.

6283. Oelat-hatoe Амв. $=\alpha . \mathrm{Aga}$ ricus tuber regium Tr. en $=b$. Pachyma tuber regium Tr. (Zie No. 1959.)

6284. Oeleroem of Oeloeloen Amr. $=$ Iracontomelon sylvestre B 1. (Zie No. 1481.)

6285. Oelet $\mathrm{J} .=\mathrm{M}$ a o utia $\mathrm{ru}-$ gos a Bl. Nat. fam. der U r ti c a c e GR. Java; heester.

6286. Oelien Bo. = Eusideroxylon Zwageri T. \& B. (Zie No. 1103.) 6287. Oelit Ахr $=\mathrm{Ev}$ i a $\mathrm{c}$ id a B 1. (Zie No. 2890.)

6288. Oeloe-toepai Lasp. $=\mathrm{H}$ opea dryobalanoides Miq. (Zie No. 1624c.) 6289. Oemare Амв. = A r тос a $\mathrm{r}$ p us inc is a L. (Zie No. 269.)

6290. 0embel-oembelan $\mathrm{J} .=\mathrm{Sa}$ raya bracteosa D.C. (Zie No. $4538 c$.) 6291. 0embelan $\mathrm{S} .=\mathrm{S}$ a u raya microphyll a de V r, Nat. fam. der Ternstrœ m i a c e. Gr. Java; boomachtig.

6292. Cemboe-endoeroe J. = Cary ota ureas I. (Zie No. 384.)

6293. Oenas of Oenos Br. $=\mathrm{Ce}-$ drela Toona $\mathrm{R}$ oxb. (Zie No. 267.) 6294. Oendi of Oendis $\mathrm{BI}_{\circ}=\mathrm{C}$ ajanus indicus Sprg. (Zie No. 1210.) 6295. Oendor-0endor $\mathrm{J} \cdot=a$. A chy. ranthes bidentata Bl. (Zie No. 740.) $=b$. Cyathula geniculata Lour. (Zie No. 741.)

6296. Oene-bime MaK. $=$ M aranta dichotoma Wall. (Zie No. 926.) 6297. Oenglien Pat. (Zie Oelien Bo.)
6298. Oenglien $\mathrm{R} .=\mathrm{M} \mathrm{e} \mathrm{me} \mathrm{с} \mathrm{y-}$ lon oligoneurum Bl. (Zie No. $4390 d$.)

6299. Oenik Mand. en

6300. Oenin Ams. = Cu r c uma

lo ng a L. (Zie No. 2620.)

6301. Oenin-pakej Амв. = Z i $и$ g iber cassumunar Roxb. (Zie No. 878.)

6302. Oenti of 0enting Mak. =

Musa pradisi ac a L. (Zie No.

1190.)

6203. Oenti-dja wa MaK. en

6304. Oenti-0enti MaK. 三 Caric a $\mathrm{P}$ a $\mathrm{p}$ a y a L. (Zie No. 1092.)

6305. Oenting-oenting $\mathbf{M}$. = C lerodendrum Ja ckian u $W$ all., Nat. fam. der V e r b e n a c e æ. Gr. S umatra; heester.

6306. Oenting-oenting-besar M. = $\mathrm{St}$ erculia rubiginosa Vent. (Zie No. $2723 d$.)

6307. Oentj-0entj $M_{\mathrm{AK}}=$ $=$ Eiceras majus Gærtn. (Zie No. 1556.)

6308. Oe-0ejahan S. =a.P rocris C o m mers. Spec. divers $x$. $=b$. Elatostemma pedunculosum Miq., Nat. fam. der Ur tice $æ$ Gr. Sumatra ; éénjarig.

6309. Oepan-0epan S. = Cynuglossum micranthum Desf., Nat. fam. der B or r a g i n ex. Gr. De Sunda. eilanden; éénjarig.

6310. Oepang Mak. $=\mathrm{A}$ de $\mathrm{n}$ a $\mathrm{n}$ thera Gersenii $S$ cheffer, Nat. fam. der Papilionace $œ$. Gr. Celebes; boomachtig.

6311. Oeparim $\mathrm{Cr} .=\mathrm{Crot}$ o $\mathrm{m}$ T i g li u m L. (Zie No. 6.)

6312. Oepas-antjar S. = Antia$r$ is t ox i caria Le s c h. (Zie No. 408.) 6313. 0epas-bidji M. en

6314. Oepas-kamaroengi T. $=$ Sophora tomentos a L. (Zie No. 1490.) 6315. Oepas-laki-laki M. $=\mathrm{L} \mathrm{a} \mathrm{c-}$ taria salubris $R \mathrm{mph}$. (Zie No. 5518$.

6316. 0epas-massou T. cn

6317. Oepas-poetih Ахв. = S o ul a m e a m a r a L a m. (Zie No. 1476.) 6218. 0epas-radja $\mathrm{M} .=$ 0epasantjar $\mathrm{S}$.

6319. 0epas-tieuté M. = Strychnos Tieute L e s ch., Nat. fam. der I o g a n i a ceæ. Gr. Java en elders; klimplant. GkBR. In het sap van den schor's der wortels en stengels is het scherpste der pijlvergiften, het oepas-tieuté, dat door 
een overmat van stryclinine en andere alcaloiden spoediy den dood veroorzaakt.

6320. 0epassa (Upessa) Амв. = A caly pha densiflora Bl. (Zie No. 1440.)

6321. 0erang-oerangan $J .=a$. H y r t an andra pentandra Mi q., Nat. fam. der Urticeæ. Gr. Java; éénjarig. 二 b. Morocarpus dichotomus Bl. B 1. (Zie No. 4406b.)

6322. Oerat-sija M. = Dianella ensifolia $R$ ed., Nat. fam. der $A$ spara. y in ex. Gr. Sumatra; overblijvend.

6323. Oeréan $\mathrm{J}$. 二 Tacca pinna. tifida Forst. (Zie No, 6105.)

6324. Oereoel CR. = Casuarina equisetifolia Forst. (Zie No. 122.)

6325. 0eri BD. 二 Musa paradi. s iaca I. (Zie No. 1190.)

6326. Oeri-bengala Aмв. 二 Ananassa sativa I,indl. (Zie No. 5680.)

6327. Oeri-oma T. E $a . \mathrm{Cal}$ am us? pisicarpus Bl. (Zie No. 6200b.) $=b$. Flagellaria indica I. (Zie No. 135.) 6328. 0eris-oerissan S. 二 $a$. Gre. wi a lævigat a Vahl. (Zie No. 4518b.) 二 b. Grewia odorata Bl. (Zie No. 4วั19.)

6329. Oerit Aмв. en

6230. Oerit-ehoe Амв. = Evia acid a Bl. (Zie No. 2890.)

6331. Oero-oroet $S$. $=$ Prderia densiflora Miq. Nat. fam. der $\mathrm{Ru}$. bi a ceæ. GR. Java; slingerplart.

6332. 0eroe-pikal Mou. = 0elathatoe Aur.

6333. Deroe-weroe Амв. = Pittospor um Rumphii Pütterl. (Zie No. 319.)

6334. Oesi-oesi $\mathrm{I} .=\mathrm{Hibiscus}$ surattensis I. (Zie No. 731.)

633.5. Oesoeng-boegang $\mathrm{S} .=a$. ('h a s lia $l$ urida $M$ iq. (Zie No. 4506b.) = b. Chasalia robusta Miq. (Zie No. 269\%.) $=$ c. Pavetta fulgens Roxb. Nat. fam. der $R$ ubiac ex. Gr. Sumatra; kleine heester, even als $d$. dikwijls als sierplant in tuinen. $=d . \mathrm{Pa}$ vetta salicifolia Bl. Nat. fam. dezelfde. Gr. Java en Sumatra; heester.

6336. 0esse-ala MoL. $=$ C itrus m e d i c a I. r a r. I. (Zie No. 2050.)

6337. Oesse-ala-bol Axв. $=\mathrm{C}$ i. trus bergamia $R$ is soo. (Zie No. 2214b.)

6338. 0esse-krawo lis. = C it r u s li monellus Hassk. (Zie No. 761.)
6339. Oesse-metten $\triangle м$ в. $=\mathrm{Ci}$ trus vulgarus $R$ issoo. (Zie No. 5334 .)

6340. Cessi-ela-bal Aмв. $=\mathrm{Ci}-$ trus Paped a Miq. (Zie No. 2077.)

6341. Qessi-helawan Алв. $=\mathrm{C} \mathrm{i}$. t rus lim on ellus $\mathrm{H}$ as sk., var. I. (Zie No. 761.)

6342. Oessi-lapia Амв. = C itrus $\mathrm{P}$ a $\mathrm{p}$ e d a $\mathrm{M}$ i q.

6343. 0essi-maloemeit Амв. $=\mathrm{Ci}$. trus limetta Rissoo. (Zie No.762.

6344, 0essi-wale Амв. $=\mathrm{C}$ i t $\mathrm{r}$ и m e d i c a I., var. I. (Zie No. 2050.)

6345. Oete-pala of Oete-tala $M$. $=$ Plucknetia corniculata P ers. (Zie No. 674.)

6346. Oeteren Амв. = D recontomelon sylvestre Bl. (Zie No. 1481.)

6347. Oeteri NG. $=\mathrm{C}$ o c o s n ucif e r a L. (Zie No. 393.)

6348. Oeti MaK. = M us a parad is i a a I. (Zie No. 1190.)

6349. Oetta-aman Амв. = $a$. A chy$r$ anthes bidentata B l. (Zie No. 740.)=b$. Cy a thula genjculat a I. o u r. (Zie No. 741.)

6350. Oetta-aur Амв. = $\mathrm{Bam}$. busa verticillata Bl. (Zie No. 756.) 6351. Oetta-baja Axis. $=\alpha . \mathrm{Ama}$. rantus tristis I, our., en $=b$. Euxolus polygam us Moq. Tand. (Zie No. 836a.)

6352. Oetta-batoe Амв. $=10$ o d onæa ang ustifolia Blanco. (Zie No. 2218.)

6353. Oetta-bira ANB. = B a se l. 1 a r u b r a L. (Zie No. 2419a.)

6354. Oetta-hatoe Амв. = a. Aga. ricus tuber regi um Tr. (Zie No. 1959.) $=$ b. P a chy m $\mathrm{T} \mathrm{uber} \mathrm{re-}$ g i u in Tr. (Zie No. 1959.) $=c$. D $\mathrm{i}-$ ploclinium tuberosum Miq. (Zie No. 1054.)

635.̃. Oetta-lala Aмв. = Cardiopteris moluccan a Bl. (Zie No. ธ859.)

63ร6. Oetta-lapia-lari Aмв. = Trichos anthes trifoliata Bl. (Zie No. 262b.)

6357. Oetta-lau-kawa Avr. = Cala$\mathrm{mus}$ equestris IV lld. (Zie No. 2804.)

6358. Oetta-mahoe Aмв. = a. Cocc in i a grandis M. J. Roe n. (Zie No. 640.) $=$ b. Cardios per un $\mathrm{m}$ H a 1 i cacab $1 \mathrm{~m} \mathrm{I}$. (Zic No. 433.) 
63ј9. Oetta-manoek Aмв. $=a$. C assia fistula L. (Zie No. 1306a.) $=b$. Casia Sophora L en $c$. $\mathrm{C}$ assia Tor a L. (Zie No. 736.)

6360. Detta-mata $A M B .=N$ a rsdenia angatifolia Wight, Nat. fam. der A s clepi a dex. Gr. De Molukken, slingerplant. GEbir. Men eet het jonge loof als sroeute, eu geeft het als geneesmiddel tegen asthma. $=b$. Bid a ra tingeris D c s n, Nat. fam. en $G_{R}$, als a. GEBR, hetzelfde

6361. Oetta-niwel of Jetta-niwer Anв. $=a$. Helminthostachys d u l c is K a ulf., Nat. fam. der Op h i o. gl o s s e x. Gr. De Nlolukken; overblijvend. GEвk. Het loof houdt men, volgens

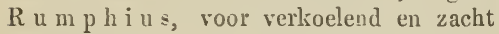
purgeerend. De jonge bladeren, de sajor$\mathrm{man}$ is of zoete groente der Maleijers, worden als groente gegeten. De jonge stengels worden toebereid bij wijze ran aspergies. $=b . \mathrm{Cycas} \mathrm{circillalis}$ L. (Zie No. 2105.)

6362. Oetta-poetih Амв. $=a$. A g ar i cus tuber regium Tr. en $=b$. Pachrma tuber regi nm Tr. (Zie No. 1959 .

6363. Oetta-renoet $\mathrm{A} \mathrm{MB} .=\mathrm{B}$ a. s ella rubra L. (Zie No. 2419a.)

6364. 0etta-soä Aмв. = Gnetum G n e mon L. (Zie No 820.)

636ว. Oetta-toboe Аув. $=$ Dendrolobium umbellatum W. \& A r.n. (Zie No. 1653a.)

ci366. Oetta-tuër Aмв. = C a r d iopteris moluccana Bl. (Zie No. 559 .)

6367. Detta-wani sмв. $=\mathrm{B}$ a $\mathrm{m}$ busa aspera Roem \& Sch (Zie No. 9346.)

6368 0etta-wau Aвв. = Diplaziu m malabaricum $\mathrm{s}$ ) r. (Zie No. 1028.)

6369. 03wer $\mathrm{BD}$. 二 $\mathrm{J}$ a m bosa a qu a $\mathrm{kmph}$. (Zie No. 1914.)

6370. Ohoepaë Cr. = C e r bera l a c taria il a m. (Zie No, 118\%.)

6371. Ohoepaë-tanah C'r. = Neuburgia mu $=c u l$ iformis II (Zie No. 4ら.)

6372. Ohrapoh Laup. = Dichroa cyanitis 11 iq. (Zie No. 2512.)

6373. 0jong $\mathrm{S} .=a$. L a ff a c o rdifolia Bl. (Zie No. šl4.) $=\mho$. Luff a $\mathrm{f} \propto \mathrm{tida}$ ('av. (Zie No. 465.) $=c$. L uffa pentandra Roxb. (Zie No. $636 b$.
6374. 0jot S. = Aroij S., e en slingerplant.

637ó. 0ijot-mienjak Bat. $=\mathrm{Ste}$ phania hernandiæfolia IV al p. (Zie No. 489c.)

6376. 0laär Аมв. $=\mathrm{C}$ is s u s repe us L a m. (Zie No. 438.)

637\%. Ola-ola Amb. Premna c o. ry m bos a $R$ ot t l. (Zie No. 395.)

6378. 0lassi MoL $=\mathrm{Echinus}$ t ris ulcus Lo ur. (Zie No. 3344.)

6379. Oli-oli T. $=$ Entada pur. $\mathrm{s} æ \mathrm{t}$ h a Dc. (Zie No. 482.)

6380. 0loeloe Амв. $=$ Premna c o r y m b os a Rott l. (Zie No. 395.)

6381. Ompoh-ompoh $M_{\mathrm{AxD}}=\mathrm{H}$-manthus puniceus L. (Zie No. 802.)

6382. Ondo Bozt. = 1) i o s c orea hirs ut a Bl. (Zie No. 47 j.)

6383. Onjam S. = Antid es ma paniculatum $\mathrm{Nl}$ iq. (Zie No. 1356.)

ن384. Ondeh-ondeh $\mathrm{S}$. $=$ An tid e s m a d i a $n d r$ u m S prg. Nat. farn. der A n tidesmex. Gr. Java; hooge boom.

6385. 0po-opo S. of Ohpoh-ohpoh S. $=a . \mathrm{Fleming}$ i a congesta Roxb. Nat. fam. der Papilion a e æ. Gr. Jara en Sumatra; heester. $=b$. C e $\mathrm{r}$ a st i n $\mathrm{m} \mathrm{glomerat} u$ in Thuill, Nat. fam. der C a ry o p h y ll e æ. Gr. Java; kruidachtig.

6356. 0possei Cru. = Pt y chosperma saxatilis Bl. (Zie No. 2984.)

6387. Oppa Воет. $=$ D i o s c o re a a culeata L. (Zie No 1189.)

6388. Orang-aring I. \& $\mathrm{M} .=a$. P o u z o z i a indica G a ud. (Zie No. 2141.) $=$ b. Wollastonia biflora D c. (Zie No. 181\%.)

6389. Orang-orang I \& $\mathrm{Ml} .=a$. Ageratum conyzoides I. (Zie No. 793b.) $=b . \mathrm{Pouzolz}_{\mathrm{i}}$ o valis II iq. (Zie N1o. 38266) =c. Pouzol$\mathrm{z}$ i a $\mathrm{glom}$ er a t a $\mathrm{H}$ a s s k. Nat. fam. der Urtic ex. Gr. Java, Sumatra en de Molukkeu; kleine lieester.

6390. Orok-orok S. = Co d o n op$\mathrm{sis} \mathrm{j}$ ava $\mathrm{nic}$ a $\mathrm{Ml}$ iq. (Zie No. 42506 .)

6391. Osjegoe $1 .=Q$ u is qualis in d i a L. (Zie No. 3234 .)

6392. Ossil AMr. $=\mathrm{Ent}$ a d a $\mathrm{pur}$ $\mathrm{s} æ \mathrm{th}$ a D c. (Zie No. 482.)

6393. Ota $M_{\mathrm{AK}} .=\mathrm{Ch}$ avic a betle M iq. (Zie No. 285.) 
6394. Oudjanjan Bo. 三 $\mathrm{Cal} \mathrm{a} \mathrm{mus}$ ¿ æsi us Bl. (Zic No. 2868.)

6395. OuW AMb. $=a$. M a ngifera Taipan 4 amilt. (Zie No. 5721b.) $=b$. I a n giferatimorensis B l.
Nat. fam. der A n a c a r d i a e e æ. Gr. De Molukken; hooge boom.

6396. Owa N. G. = Cocios nuc i f era I. (Zie No. 393.)
6397. Padang-biloelang BI. 二 $a$. Eleusine indica Gaertn. (Zie No. 1961.) ( b. Dactyloetenium ægyptiacum Wlld. (Zie No, 2344b.)

6398. Padang-jerak BL. = Orth opogon Burmanni R. Br. (Zic No. 2031.)

6399. Padie $\mathrm{M}$. = Oryza sativa L. Nat. fam. der Graminer. Gr. Door geheel Indië als kultuurplant. Gebr. Vau deze, zoomede van ảe andere rijstsoorten, bestaan een menigte verscheidenheden, te veel om op te sonumen; alleen in de kleine $\mathrm{M}$ in ahassa verbouwt men een 160 -tal variëteiten. Omtrent het bekendc huishou. delijk en geneeskrachtig gebruik dcr rijst zal ik niet uitwijden; alleen stip ik aan, dat het gebrande rijststroo een uitmuntende loog levert voor het wasschen van het hoofdhaar en van klcederen; dat de gekookte en daarna gebrande rijst in water in den dauw gezet, veel wordt gedronken tegen borstaandoeningen en bij diarrhœa.

6400. Padie-djawa M. 三 Pennisctum macrochrton $J$ acq. Nat, fam. der Graminex. Gr. Java. Gerb. Het zaad dient veelal tot voedsel van kleine vogels; het wordt eshter ook ontbolsterd, in stoom gekookt en daarna gegeten.

6401. Padie-ketan $M .=$ Oryza glutinosa Lonr. (Zie No. 4282.)

6402. Padie-pceloet M. als boven.

6403. Padie-rawa II. ook

6404. Padie-songo-negoro S, en

640อ̆. Padie-tjerreh S. $=$ Oryza montana Jour. Nat. fam. der Grain iner. Gr. Java als kultuurplant. Geirr. (Zie No. 63398.)

6406. Padie-tipar I. = Oryza præeох L, ur. Nat. fam. dezelfile. Gr. Op Java als kultuurplant; deze soort rijpt veel vrocger en kan zeer gocd tegen het zeewater. (ivinR. als No. 6398.

6406\%. Padosarie $11 .=0$ ph i o x y. lon quinatum Miq. Nat. fam. der A p o c in e æ. Gr. Sumatra; heester.

6407. Paga-paga Suм. $W_{K}=1, a-$ placea buxifolia Miq. Nat. fam. der C a melliace $x$. Gr. Sumatra; boom.

640s. Pagar-pagar-rimbo Sum. Wк. = Stylocoryna fragrans Bl. (Zie No. 4504.)

6409. Paidoh BI. $=\mathrm{Hydroco-}$ tyle as iatica L. (Zic No. 70.)

6410. Paija-mata Aмв. 三 Kyllingia monocephala Rottb., Nat. fam. der Cyperaecx. Gr. Bijna overal in Ned. Indië; grassoort, vooral door varkens om de knolwortels zeer gezocht.

6411. Pajong-lawut $M .=\mathbb{E g i -}$ ceras majus Grtn. (Zic No. 1556.)

64.12. Pakkies M., een kollektiefnaam voor alle Varensoorten. Onder dezen Laam komen voor Filices I., Cyeas L., Diplazium Sw. en Polydium L.

6413. Pakkies-galen J. 二 C y athea le ucophä̈s Hassk., Nat. fam. der Po. ly podiacer. Gr. Java; boomvaren.

6414. Pakkies-tahi J. $=\mathrm{Cy}$ c a s revoluta Thnb., Nat. fam. der Cyca. d e a cer. Gr. Java en de Molukken; boomachtig. GFir. Het merg van den stam bevat veel sago, wordt gegetcn en is zeer voedend; ook de vruchten worden door de Japaneezen genuttigd. Men noemt dezen boom ook ijzerboom.

641 ๖. Pakkies-tjeboek I. $=$ Gleichenia Hermanni R. Br. (Zie No. 1214.)

6416. Pakoe Sum. Wк. Z Syn $(x-$ eia diversifolia Miq. (Zic No. 418.)

6417. Pakoe I \& M., is, even als Pakkies M., cenc kollekticfnaam roor alle Varensoorten.

6418. Pakoe-aloes M. = Cheila llthes tenuifolia Wlld. Nat. fam. der Poly podiacer. Gr. Java; kruidachtig. 6419. Pakoo-andam s. $=$ Glei- 
chenia dichotoma Wall. Nat. fam. der Gleicheniaceæ. Gr. Java; kruidachlig.

$6+20$. Pakoe-andam boeloe S. $=\mathrm{Po}_{0}$ lypodium viscidum Sprg., Nat. fam. der Polypodiaceæ. Gr. Java; overblijrend.

6421. Pakoe-andong S. = Gleichenia vestita Bl., Nat. fam. der Gleicheniacex. Gr. Java; overblijvend.

6422. Pakoe-aroij S. = $a$. P hotinopteris Horsfieldii J. Sm. en = b. Nephrolepis obtusifolia Prsl., beide ran de Nat. fam. der Polypodiac ex. Gr. Java; klimplanten.

6423. Pakoe-badak S. = Cyc as circ in a lis L. (Zie No. 2105.)

6424. Pakoe-bangkong $\mathrm{S}$. $=\mathrm{Ml}$ a$r$ at tia $\mathrm{sambuc}$ in a $3 \mathrm{l}$., Nat. fam. der $N$ a r a t ti a c eæ. Gr. Java; overblijvend.

6425. Pakoe-besâr M. 二 P ol у р odi u m simile L., Nat. fam. der Po. l y p o d i a c e $x$. Gr. Java; overblijvend.

6426. Pakoe-biroe М. $\mathrm{M}$ A splen i u m crenat o-s e r rat u m Bl., Nat. fam. dezelfde. Gr. Java; overblijvend.

6427. Pakoe-boeä $M_{1}=a$. D i p ! azi um decussatum Bl. en $b$. Nephrolepis imbricata Prsl., beide van dezelfde familie als brven. Gr. Java; overblijvend.

6428. Pakoe-boenjoer $\mathrm{S} .=\mathrm{Psi}$ l o tu m Sw. d iv e r s

6429. Pakoe-daging $\mathrm{M}$. 二 L e canopteris carnosa Bl., Nat. fam. der P oly p od i a c e æ. Gr. Java; overblijvend.

6430. Pakoe-dioek S. $=\mathrm{H}$ e $\mathrm{lm}$ i nthostachys dulcis Kaulf. (Zie No, 636la.)

6431. Pakoe-doedoeitan $\mathrm{J} .=a$. D r. $\mathrm{gmog}$ o s sum num u larifoli um Mett. en $=b$. I) rym. piloselloides Prsl., beide van de Nat. fam. der Poly podi a ce æ. Gr. Door geheel Indië; parasieten. GEBr. Het sap der bladeren van de Duitenplant wordt tegen hoest, verstopping en gonorrhœa gedronken, vermengd met eenige andere kruiden; het schijnt een zacht oplossende en purgeerende kracht te bezitten.

6432. Pakoe-hadji M. = Cycas c irc in alis L. (Zie No. 2105.)

6433. Pakoe-hantam J. = Polypodium lin eare L., Nat. fam. der Poly podi a c ex. Gr. Java; overblijvend.
6434. Pakoe-haroepat $\mathrm{S} .=\mathrm{T} æ-$ nitis blechnoides Wlld., Nat. fam. als voren. Gr. Java; overblijvend.

6435. Pakoe-hatta $S .=$ Lygod i um circinnatum Sw. (Zie No. 2792.)

6436. Pakoe-hitam II. $=a . \mathrm{P} \propto$. cilopteris diversifolia Prsl. en $=b$. Polypodium nigripes H assk., beide van de Nat. fam. der Poly podi a ceæ. Gr. Java; orerblijvend.

6437. Pakoe-hoerang s. 三 $a$. Blechnum orientale $L$. $=\dot{b}$. Blechnum pyrophilu in Bl. en $=c$. Nephrodium exaltatum R. B r.. alle van de Nat. fam. als roren. GEBR. De stengels van $a$ als bindtouw.

6438. Pakoe-hoerang-leutiek S. = D a vallia elegans Sw.: Nat. fam. dezelfde. Gr. Java; overblijvend.

6439. Pakoe-kadakka S. Zeer vele soorten van $\mathrm{P}$ ol y podia ce $x$, die pseudo-parasitisch groeien, zoo als van de geslachten Acrostichum, Anthrophy um, Niphobolus, Platycerium, Lo maria, Vit t a ria, Polyp o d i u in.

6440. Pakoe-kadal S. $=a$. V e rschillende soorten van $\mathrm{D}$ a vallia $\mathrm{S} w$. $=b$. Poly podium quercifolium L. (Zi2 Nos. 181 en 182); behalve het daar vermelde nut kent men aan het afkooksel van den wortel een bloedstelpende kracht toe, en geeft dit tegen bloedspuwing, enz.

6441. Pakoe-kajakkas J. $=u$. Acrostichum inæquale Wlld., en $=b$. G y m nogramme javanic a B l., Nat. fam. der Poly podi a c e æ. Gr. Java; overblijvend.

6442. Pakoe-kapal M. = $\mathrm{N}$. Ne. phrodium lanuginosum $\mathrm{Hassk}$. en $=b$. Poly podium irreg 11 are B l., Nat. fam. als voren. Gr. Java; overblijvend. GeBr. De wol tan $a$, vooral die der bladsteleu, bezigt men als bloedstelpend middel; de korte stronk wordt tot poeder gestanpt en tegen schurft aangewend.

6443. Pakoe-kawat S. = Verschillende soorten van Linds ie a Dryand., Adiantum I., Diplazium Sw., $P$ te $\mathrm{r}$ is $\mathrm{L}$. en Poly podium L.

6444. Pakoe-kawat-besar M. = P teris dimidiata Wlld., Nat. fam. der Poly podia c ex. Gri. Jara; overblijvend. 
644.5. Pakoe-kembang M. = Doodia dives Kz., Nat. fam. als voren. Gr. Java; overblijvend.

6446. Pakoe-ketjil M. 三 Cheilanthes ten uifolia Wlld. (Zie No. 6418.)

6447. Pakoe-kidang $\mathrm{M} .=a$. A lsophila lurida Endl. en $=b$. B a lantium chrysotrichum H a s s k., Nat. fam. als voren. Gr. Java; boomvarens. GEBR. Aan de goudgele of rossige wol op den top des stronks kent men dezelfde bloedstelpende eigenschappen toe als aan die der Ciboti um gl a uce scens Knz. No. 175 .

6448. Pakoe-koempaai S. = Vitt a ria $S \mathrm{~m}$. S p e c. divers æ.

6449. Pakoe-koening M. = A s p idi um o b s cur um Bl, Nat. fam. als voren. GR. Java; overblijvend.

64วั0. Pakoe-lalaij S. = Aspleni u m s i mil e Bl., Nat. fam. dezelfde. Gr. Java; overblijvend.

645l. Pakoe-lalaij-leutiek S. = A splenium minus Bl., Nat. fam. en $G_{R}$. als voren.

6452. Pakoe-lehat S. = Poly podium I., species divers x.

6453. Pakoe-lehat-besar M. $=\mathrm{P}_{0}$ lidiu m pustulatum B l., Nat. fam. als voren. GR. Java; overblijvend.

64.54. Pakoe-loehoer S. $=a$. $\mathrm{D}$ iplazium malabaricum. Bl. (Zie No. 1028$)=b$. Diplazi um um. brosum Bl., Nat. fam. en Gr. als voren.

6455. Pakoe-loehoer-besar M. = Diplazium polypodioides Bl., Nat. fam. der Pol y podiacex. Gr. Java; overblijvend.

645̆6. Pakoe-malakoet M. = Diplazium spinulozum Bl., Nat. fam. en $G$ r. als voren.

6457. Pakoe-meirah $\mathrm{M}=a . \mathrm{Ac}-$ rostichum viscosum Sw., Nat. fam. en $\mathrm{Gr}$. als voren. $=b$. L o m a ri a s c a d d e n s R. Br. (Zie No 3587.)

64.58. Pakoe-merak M. = Pteris cren at a $\mathrm{S} w$., Nat. fam. en $\mathrm{Gr}_{\mathrm{r}}$ als voren.

6459. Pakoe-minjangan M. (Zie later Pakoe-oentjal S.)

6460. Pakoe-moending-gedeh $\mathrm{S}$. = Angiopteris erecta Kaulf., Nat. fam. der M a r a t ti a cer. Gr. Java; boomachtig.

6461. Pakoe-moending-leutiek S. = Maratia sylvatica Bl., Nat. fam. als voren. GR. Java; overblijvend.

646\%. Pakoe-mohdang S. $=a$. Pt e$r$ is a t te nu a t a $\mathrm{S} \pi$. = b. Pt. no rm al is Don., Nat. fam. der P ol y pod i a c e æ. Gr. Java; overblijvend.

6463. Pakoe-njehreh S. 二 $a$. D avallia polypudioides Don. en $=b$. Nephrolepis darallioides K n z., Nat. fam. als voren, Gr. Java. overblijvend.

6464. Pakoe-njehreh-gedeh $\mathrm{S} .=a$. Nephrolepis exaltata Scht en $=b$. Neph. splendens Prsl., Nat. fam. enz. als voren.

5465. Pakoe-njereh-leuwung $\mathrm{S}$. = D a valli a biser rata Bl., Nat. fam. als voren. Gr. Java; overblijvend.

6466. Pakoe-oedang M. = Lom aria scandens R. Br. (Zie No. 3587.)

6667. Pakoe-oedjan M. $=a$. A s p l e. $\mathrm{nium} \mathrm{abs}$ cissum Bl. en $=b$. A s. ple nium approximatum Bl., Nat. fam. enz. als voren.

6468. Pakoe-oentjal S. = a. Ol eandra hirtella $\mathrm{Miq.}=b$. O J. nereifolia $\mathrm{C}$ av. en $=c$. Platy cerium a l cicorne Ga ud, Nat. fam. enz. als voren.

6469. Pakoe-oetan M. $=a$. C y athe a a bore a Wlld. (Zie No. 2659.) $=b$. Polypodium glabrum Brm., Nat. fanl. enz. als voren.

6470. Pakoe-pajong $\mathrm{M}$. $=\mathrm{H}$ elminthostachys zeylanica Prsl., Nat. fam. der $O \mathrm{ph}$ iogloss ex. Gr. Java; overblijvend.

6471. Pakoe-pajong-leutiek S. = B otry chium ternatum Sw., Nat. fam. als voren. Gr. Java; overblijvend.

6472. Pakoe-pendekh M. = Blechn u m or i entale J. (Zie No. 6437 a) 6473. Pakoe-pohon M. = Cy athea a r b or e a W $11 \mathrm{~d}$. (Zie No. 2659.)

6474. Pakoe-ramboet $J_{0}=I_{1}$ y $g$ di u m icrophy 11 um R. Br. (Zie No. 2604.)

6475. Pakoe-raneh $\mathrm{S}_{0}=\mathrm{S}$ el ag $\mathrm{i}-$ nell a P. de B r.

6476. Pakoe-raneh-meirah $\mathrm{S} .=\mathrm{Sc}$ laginella intermedia S pring., Nat. fam. der L y copodi a c ese. Gr. Java ; overblijvend.

6477. Pakoe-rantjang $M .=D i d y ~ m o-$ chlæna sinuosa Ds s., Nat. fam. der Poly podiacer. Gr. Java; overblijvend.

6478. Pakoe-regeh S. $=\mathrm{D}$ ar $\mathrm{r}$ llia heterophylla S m., Nat. 
fam. als voren. Gu. Java; overblijvend.

6479. Pakoe-resam BK. = Gleichenia dichotoma Wlld. (Zie No. 6419.)

6480 . Pakoe rientjieng $\mathrm{M} .=\mathrm{Pte}-$ $r$ is a u rita B l., Nat. fam. der Polypod i a c e a. Gr. Java; overblijvend.

6481. Pakoe-sepat $\mathrm{M}=\mathrm{Nipho-}$ bolus abbreviatus Z. \& M., Nat. fam. als voren. Gr. Java; overblijvend.

6482. Pakoe-soerat M. $=a \cdot \mathrm{H} \mathrm{e}-$ mionit is cordata $\mathrm{R} \times \mathrm{b}$. $=6$. A 1 trophyum Boryanum Bl. = $c$. I i trophy u coriaccum Bl. en $=d$. A ut. l a n c e ol a tum B l., Nat. fam. van alle als voren, GR. Java; overblij vend.

6483. Pakoe-sorok-radja S. $=\mathrm{Ne}$ penthes melamphora $\mathrm{Rwdt}$. (Zie No. 1704b.)

6484. Pakoe-taratteh-gedeh S. = P o ly podium Dipteris B l., Nat. fam. als voren. Gr. Java; overblijvend.

6485. Pakoe-taratteh-leutiek S. = A crostichum trinerve Hassk. en $=b$. Ka ulfussia Bl, Nat. fam. voor $a$. der Poly podiace a, voor $b$ der M a rattia e c $x$. Gr. Jara; beide overblijvend

6486. Pakoe-tembaga $\mathrm{M}$. = $\mathrm{O}$ n y. c h i u m a u r a t u m Klf., Nat. fam. der Polypodiacex. Gr. Java; overblijvend.

6457. Pakoe-tijang M. = Alle Varens, waaronder de meeste scorten van A ls ophila R. Br., Cyathea Sw. J. S m; N N phrodium Rich. en Cyc a s $\mathrm{I}$.

6488. Pakoe-tijang-boddas S. -A ls ophophila gla u ca J. S m, Nat. lam. der Poly podiace $x$. Gr. Java; boomvaren.

6489. Pakoe-tijang-boeloe 11 . = A s pidi u $m$ ferox Bl., Nat. fam. als voreu. Gr. Java; overblijveud.

6490. Pakoe-tijang-burrum-gedeh S. $=A$ ls o p hila l u rida Endl. (Zie No. 6447 a.)

6491. Pakoe-tijang-burrum-leutiek S. = Polypodium ferox Hassk. Nat. farn. der Poly podi a c e æ. Gr. Java; overblijvend.

6492. Pakoe-tijang-hiedung $\mathrm{S}$. = Cyathca medullaris Sw., var. Nat. fam. der Poly podi a ceæ. Gr. Java, enz ; boomachtig. GEBR. Het jonge loof wordt in Nielıw-Zeeland voor een der heerlijkste gerechten gehouden.

6493. Pakoe tijang hitam $M=C$ y ath e a java u i c a B 1 ., Nat. fam. als voreu. Gr. Java; boomvaren.

6494. Pakoe-tijang-ketjil $M .=P$ hegopteris ferox 11 ett, Nat. fam. als voren. GR. Java; boomachtig.

6495. Pakoe-tijang-koening $\mathrm{M}$. = Os m u da javanica Bl., Nat. fam. der $\mathrm{Osmund}$ a cer. Gr. Java; boomachtig.

6496. Pakoe-tijang-pendekh M. = Blechnumorientale L. (Zie No. 6437 a.)

6497. Pakoe-tijang-tembaga M. = Cy at he a Walkerg Hook. Nat. fam. der Poly podiacer. Gr. Op Java, van Ceylon overgebracht; bo $m$ varen.

6498. Pakoe-tikoes M. = Campium re p a n d u m Prs l., Nat. fam. als voren. GR. Java; overblijvend.

6499. Pakoe-tjatjing $\mathrm{M}_{\mathrm{.}}=$ = Pol $\mathrm{y}$ p od i um Phy m a t od e s Bl. Nat. fam. der Poly pod i a c ex. Gr. Jara; over. blijvend.

6500. Pakoe-tjaroelang $\mathrm{M}_{0}=a_{0} \mathrm{Po}_{0}$. ly podium Pteropus Bl., en $=b$. Pœcilopteris heteroclita Prsl., Nat. fam. als voren. Gr. Java; beide overblijvend.

6501. Pakoe-tjaij S. $=a$. Acrostich um speciosum B l. en $=b$. Ceratopteris thalictroides Brgn. Nat. fam. als voren. Gr. Ja:a, waterplanten.

6502. Pakoe-tjoetjoek $\mathrm{S} .=$ D i cks o u i a scandens Bl. Nat. fam. als. voren. Gr. Java; klimplant.

6503. Pakoe-tjokkeh S. $=$ a. A s. pidium procurrens $\mathbf{M e t}$ en $=$ b. Aspidium subpectinatum Bl. Nat. fam. dezelfde. Gr. Java; overblij vend.

6504. Pakoe-walet S. = Polypodium Pteropus Bl. (Zie No. 6500a.)

6505. Pakoelong I. $=\mathrm{M}$ æ a $\mathrm{py}$. rifolia Miq., Nat. fam. der My r sin e æ. Gr. Java; boom.

6506. Pala M. = Myristica fragrans Houtt. (Zie No. 2631.)

6507. Pala-ala-manaij AMr. $=\mathrm{M} \mathrm{y} \cdot$ ristic a sylvestris Houtt., Nat. fam. der M y ristic a ce $x$. Gr. Bocroe, Ternate; boom. Gkir Nen bezigt het hout van dezen boom als licht timmerhout; de noten worden niet gebrnikt, allecn door dc vogels gegcten. 
6508. Pala-bilalang SuM. $\mathrm{W}_{\mathrm{K}}$. $=$ Dysoxylum lampongum Miq. (Zie No. 1085.)

6509. Pala-boerong M. (Zie No. 6507$.

6510. Pala-foeker BD. = M y ristic a fatua Houtt., Nat. fam. der II y r is tic a ce æ. Gr. Banda; hooge boom. GEBr. Men gebruikt de zaden als opwekkend geneesmiddel.

6511. Pala-kanari $\mathrm{M}$. $=\mathrm{M} \mathrm{y} \mathrm{r}$ stica globularia Bl. (Zie No. 3622 .)

6512. Pala-goenong M. = $\mathrm{M} \mathrm{y} \mathrm{r}$ stica corticosa. Hook. (Zie No. 137.)

6513. Pala-laki-laki M. = Palafoeker $\mathrm{BD}$.

6514. Pala-maba Halm en

6515. Pala.onem NG. = M y ristica succedanea $R w$. Nat. fam. der M yristic a c æ. Gr. Molukken; hooge boom. GeBr. De zaden worden als de gewone Notemuskaat gebruikt en zijn in den handel.

6516. Pala-oetan' M. (Zie No. 6507 en $6 \check{5} 10$.)

6517. Pala-radja Втз. = M у ristica $R$ adja II iq. Nat. fam. der Il y ristic a c e æ. Gr. Batjan; boom, met groote en zeer geurige noten.

6518. Pala-riemboe M. = M y ristica macrothyrsa Miq. Nat. fam. dezelfde. Gr. Sumatra; boom.

6519. Palaglar S. 三 a. Dipteroc a r p u triner ris B l. Nat. fam. der Dipt e roc a r pe æ. Gr. Java en Sumatra; hooge boom. GeBr. Het lichte ell weeke hout van dezen boom dient voor huisbouw, doch wordt spoedig door insekten aangetast. De harstachtige balsem gebruikt men als de $\mathrm{K}$ ar et ( $\mathrm{C}$ a o u tchouk). Hij staat echter verre achter bij deze; men gebruikt hem ook voor scheepsbouw, fakkels, uitwendig in zalf, als prikkelend middel bij atonische zweren en inwendig tegen gonorrhœ, bij wijze en ter vervanging der $\mathrm{Balsamum} \mathrm{co-}$ p a i bœ. 三 b. D i pterocar p u s gracilis B l. Gr. Jara; hooge boom.

6520. Palaglar-beurriet $\mathrm{S} .=a$. Gironniera costata Miq. (Zie No. 4398 ) $=$ b. Gironniera 8 ubæqualis $\mathrm{Planch}$. Nat. fam. der C el. ti d e æ. Gr. Java, Sumatra, Borneo; hooge boom. = c. Mlastixia rosr a t a B l. Nat. fam. der Corn a c eæ.
Gr. Java; hooge boom. $=d$. Mastixia trich ot o m a B J. (Zie No. 4400.)

6521. Palaglar-mienjak II. \& S. = a. Mastixiatrichotoma Bl. (Zie No. 4400.) $=b$. Dipterocarpus trinervis Bl. (Zie No. 6519.) = c. Dipterocarpus retusus B l. Nat. fam. der D i p t e r o c a r p e æ. Gr. Java; hooge boom. GEBR. Waarschijnlijk als bij D. triner vis Bl. is aangegeven.

6522. Palaglar-tengo $\mathrm{S} .=\mathrm{Di}-$ pterocarpus gracilis Bl. (Zie No. 65196 .)

6523. Palala Амв. $=\mathrm{M}$ y ris tic a fat u a Houtt. (Zie No. 65l0.)

6524. Palala-boerong Mor., zie Palaboerong $\mathrm{M}$.

6525. Palala-dawon-ketjil Mou. = M y ristica tinge n s B l., Nat. fam. der M y r istic a c e $æ$. GR. Amboina; boom. Gebr. Men gebruikt het hout van dezen boom voor daksparren en stijlen, de foelie om er de tanden en nagels mede rood te verven.

6526. Palala-kanari Mol. = $\mathrm{M} \mathrm{y-}$ ristica can a riformis Bl., Nat. fam. als voren GR. Amboina; boom.

6527. Palala-ketjil MoL. $=$ M yristica globularia B l. (Zie No. 3622.)

6528. Palala-laun-maun Aмr. (Zie No. 6525)

6529. Palangontan S. = L ei oc arpus arboreus Bl. (Zie No. 1134.)

6530. Palas Bo. $=\mathrm{Cal}$ a mu s cili a ris B l. (Zie No. 2853b.)

6531. Palawan BK. en

6532. Palawan-boeboer BK, of

6533. Palawan-toodak BK, en

6534. Palawan-toengouw $\mathrm{BK}$. Trist an i a obovata Bnnt. Nat. fam. der 11 s rta c e $x$. Gr. Bangka; groote hecster. GFBR. Het vaste hout van dezen heester levert zeer goede kolen, die tot het smelten van het tin gebruikt worden. 6535. Palawan $\mathrm{s}$. $=\mathrm{Combre}$ t u m trifoliat u m Vent. (Zie No. 198.)

6536. Pale Aure = Vitex $\mathrm{C}_{0-}$ fas us $\mathrm{Rwd}$ t. (Zie No. 4024.)

6537. Paléan Амв. $=\mathrm{N}$ i p a fruticans Warmb. (Zie No. 856.)

6538. Paleh $\mathrm{M}$. = L ic u a a a m$\mathrm{p} l$ ifrons Mi q. Nat. fam. der Pal. mæ. Gr. Sumatra; Palm. 
6539. Paling-manoek LAMP. $=\mathrm{S}$ alacia exsculpta Korth. Nat. fam. der $\mathrm{H}$ i p p o cra t e a c e r. Gr. Sumatra; slingerplant.

6540. Paloen Амв. 二 $a . P$ t y c h osperma Rumphii Bl. (Zie No. 2267b.) $=b$. B r u uiera $R$ umphii Bl. (Zie No. 866b.)

6541. Paloenen-paroen Амв. 二C aryota $\mathrm{Rnmphiana} \mathrm{Mart.} \mathrm{(Zie} \mathrm{No.}$ 331$.

6542. Paloow Bo. $=$ A rec a hor. rid a Griff. (Zie No. 834.)

6543. Pambong J. of Pampoeng J. $=a$. Dasyloma jaranicum Miq. (Zie No. 4281.) $=b$. Dasylo ma lac in i t um M iq. Nat. fam. der U mbell if e rie. Gr. Java; moerasplant.

6544. Pamij of Panij Boet. = Pang i u m e du le Rwdt. (Zie No. 387.)

6545. Panaitum Madura. $=\mathrm{M} \mathrm{y-}$ tilicoccus quercifolius Z. E M., Nat. fam. der E u p h o r b i c e æ. Gr. Madura; heester.

6546. Panawa-soffo T. = Sophora to me ut os a L. (Zie No. 1490.)

6547. Panawar M. $=a$. D is porum multiflorum Don. (Zie No. 1137.) = b. Luffa pentandra Rxb. (Zie No. 636b) =c. L u f f a acutang u la R×b. (Zie No. 2095.)

6548. Panawar-bëas $\mathrm{S}$. 三 $a$. $\mathrm{T}$ axotrophis javanica B l, Nat. fam. der Artocarpe a. Gr. Java; heester. $=$ b. $\Lambda$ lsodeiajaranica End . (Zie No. 4734.) $=c$. Lepionurus sylvestris Bl. (Zie No. 3165.) $=d$. Gelonium glomerulatum Endl. (Zie No. 1970.) $e$. Geloni u m spic a t u m End l., Nat. fam. der Euphorb i a c e r. Gr. Java; heester. $=f$. L asianthera javanica Miq., Nat. fam. der I c a c in eæ. Gr. Java en Sumatra; heester.

6549. Panawar-djambi M \& S. = a. Cilotium djambianum Hassk., Nat. fam. der Poly podiac e r. Gr. Java en Sumatra; boomraren. Gebr. Zie b. Cibotium gla ucescens Knz. (Zie No. 175.)

6550. Panawar-gongong Bu. =Erycibe paniculata $R \times b$. (Zie No. 632.)

6551. Panawar-pittis M. = $\mathrm{S}$ oula me a $\mathrm{m}$ a ra L a m. (Zie No. 1476.)

6ว52. Panawar-poetih Pal. = $\mathrm{S}_{0}$. nerila picta Korth. Nat. fam. der
M e l a s t o ma c e æ. Gr. Sumatra; overblijvend.

6553. Panawar-sariboe Bo. $=\mathrm{B}$ a uhin i a to mentos a L. (Zie No. 4497.) 6554. Pan-dan Сн. Bо. \& M. = Pandanus odoratissimns L., Nat. fam. der $\mathrm{P}$ and a $\mathrm{n}$ e $æ$. Gr. Door geheel Indië langs de kusten; boomachtig. Gebr. De bladeren en bloemen zijn zeer welriekend; men gebruikt ze daarom fijngesneden in het hoofdhaar, tusschen de kleederen en in oliën. De jonge bladeren kookt men ook in de rijst en bij visch, om deze geurig en aangenaam te maken. De oude bladeren dienen voor vloermatten en ook tot bedekking van verwondingen.

6555. Pandan-angriet $\mathrm{BK}$. = Pandanus latifolius $R \mathrm{mph}$. (Zie No. 1172 )

6556. Pandan-aren J. $=\mathrm{Pand}$ anu s bagê a Ml i q. (Zie No. 1673.)

6557. Pandan-bebaauw M. = $a$. $P$ andanus lat ifolius $R \mathrm{~m} \mathrm{ph}$. (Zie No. 1172$)=b$. Pandanus odoratiss i m u L. (Zie No. 6482.)

6558. Pandan-blang J. $=\mathrm{P}$ a n d an u s variegat u s Miq., Nat. fam.der P a nd a re e. Gr. Op Java en Madura in tuinen; boom.

6559. Pandan-goenong $\mathrm{M}$. = $\mathrm{Pan}$ danus cera micus $R$ m ph. (Zie No. 1828.)

6560. Pandan-kastoerie Aмв. = $\mathrm{Pan}$. d an us moschat us R mph. (Zie No. 2735.)

6561. Pandal-ketjil 11 . 二 $P$ a n dan us h u il is R m ph. (Zie No. 1129.)

6562. Pandan-lawoet $\mathrm{S}$. $=\mathrm{Pan}$ danus repens Rmph., Nat. fam. dezelfde. Gr. Molukken; boomachtig. Gebr. Van de bladeren maakt men mat. jes en hoeden (toedoeng).

6563. Pandan-lawut M. en

6564. Pandan-lawut-gedeh S. = $\mathrm{Pand}$ an us s purius $\mathrm{Rmph}$. (Zie. No. 4093.)

6565. Pandan-lawut-leutiek S. =Pandanus littoralis Jngh., Nat. fam. der P a n d a n e r. Gr. Java; boomachtig. GEBR. Van de bladeren maakt men leg- of vloermatjes. De jonge bladeren eet men bij vergiftiging door de zaden der Njamploeng (C a l o p h y 11 u m in o p h $5 \mathrm{llu} \mathrm{m} \mathrm{L}$.)

6566. Pandan-lengis $\mathrm{Bl}$. = $\mathrm{P}$ a $\mathrm{n}-$ danus moschatus Rmph. (Zie No. 2735.) 
656\%. Pandan-mati M. $=\mathrm{P}$ a n d anus spurius R m ph. (Zie No. 4093.)

6568. Pandan-meirah M. = Frejcinetia strobilacea Bl. (Zie No. 5958$.

6569. Pandan-oetan M. = a. $\mathrm{P}$ an$\mathrm{d}$ a $\mathrm{n} \mathrm{u} \mathrm{s} \mathrm{ce} \mathrm{r} \mathrm{a} \mathrm{m} \mathrm{i} \mathrm{c} \mathrm{us} \mathrm{R} \mathrm{m} \mathrm{ph.} \mathrm{(Zie} \mathrm{No.}$ 1828.) = b. Pandanus sylvestris $\mathrm{R} \mathrm{m} \mathrm{ph.} \mathrm{(Zie} \mathrm{No.} \mathrm{4102b.)}$

6570. Pandan-orang $\mathrm{J}$. $=\mathrm{P}$ a nd an us $\mathrm{Samak} \mathrm{H}$ assk. Nat. fam. der P a nd a n e . Gr. Java; boomachtig. GEBR. De bladeren dienen tot het vervaardigen van vloermatten of tika $r$.

6571. Pandan-passir M. $=\mathrm{P}$ a $n-$ danus littoralis Jngh. (Zie No. 6565 .)

6572. Pandan poedak $\mathrm{M}$. $=\mathrm{P}$ a ndanus mos chatus $R \mathrm{mph}$. (Zie No. 273ら.)

6573. Pandan-rampeh M. = P andan us latifoli us R m p. (Zie No. 1172.)

6574 . Pandan-rio J. en

6575. Pandan-samak $\mathrm{S}$. $=\mathrm{Pan-}$ danus Samak Hassk. (Zie No. 6570.)

6576. Pandan-sarengseng $\mathrm{S} .=\mathrm{Pan}$ danus humilis Rmph. (Zie No. $1129)$

6577. Pandan-tali II. = Freycinetia strobilacea Bl. (Zie No. 5958$.

6578. Pandan-tikar MI. = $\mathrm{P}$ a nda. n u s S a mak H a s sk. (Zie No. 6570.)

6579. Pandan-tjari M. = M orind a rigida $\mathrm{Ml}$ iq (Zie No. 217.)

6580. Pandan-wang J. $=\mathrm{P}$ a n daIn u b a gêa Miq. (Zie No. 1673.)

6581. Pandana.babi BL. = $11 \mathrm{y} \cdot$ ristic a geminata MI iq., Nat. fam. der M yristic a c e . Gr. Sumatra; boom.

6582. Pandji-pandji Sur. WK. -二 Polygonum erythrodes Mi q., Nat. fam. der Polyg o n e $x$. Gr. Sumatra; éénjarig.

6583. Pandjoe-kitar J. $=\mathrm{H} \mathrm{y} \mathrm{rta}-$ n a n dra hirta M i q. (Zie No. s374b.)

6584. Pandoga J. 三 P a n d a n u s S a m a k Hassk. (Zie No. 6570.)

6585. Pandotan I. = Polygon a m r u c inat um H a m. Nat. fam. der Polygon ex. Gr. Java; overblijvend.

6586. Pangais-monjet $\mathrm{I}$. = I, y g odinm circinnatum Sw. (Zie No. 2792.)
6587. Pangang $\mathrm{S} .=a . \mathrm{Tr}$ e vesia s unda ic a 11 i g. (Zie No. 4404c.) b. M a cropanax glomerulat um M i q., Nat. fam. der A rali a c e æ. Gr. Java; heester.

6588. Pangang-ketan $\mathrm{I}$. $=\mathrm{T}$ y $\mathrm{ph}$ a an gustifolia L. (Zie No. 738.)

65้89. Pangang-poejoe S. 三 a. M acropanax floribundum Miq. Nat. fam. der $A \mathrm{r}$ a $l$ i a ce e. Gr. Java; heester. $=b$. Paratropia a romatic a Miq. (Zie No. 4655.) = c. Paratropia serrat a II i q., Nat. fam. als voren. Gr. Java; kleine toom.

6590. Pangang-tapok S. = P a ratropia tomentosa $\mathrm{Ml}$ i q. Nat. fam. als roren. Gr. Java; herster. GeBr. Het sap uit den stam van deze en andere $\mathrm{P}$ ar at ropia-soorten wordt als wormdoodend middel gerocmd.

6591. Panggaga of Pengaga $I$. = Hydrocotyle a si atica L. (Zie No. 70 .)

6592. Pangi M. = Panginm e dule $R w d$ t. (Zie No. 387.)

6593. Pangi-pangi II. $=\mathrm{Clero-}$ d e ndr um condensatum Miq. Nat. fam. der V e r b e n a c e $x$. Gr. Sumatra's W K.; heester.

6594. Pangil-pangil-rimbo Sum. Wк. $=$ Rottlerasphærocarpa II iq. Nat. fam. der Euphorbi a c ex. Gr, Sumatra; boom.

6ə95. Panglaai of Pangleh S. Zie Banglaai 11 .

6596. Panglar S. = Agl aja a rge n t e a B l. Nat. fam. der Ml e'l i a ceæ. GR. Java; boom, veelal in omheiningell. 6597. Pangran Мak. $=\mathrm{A} n$ anas. s a s a tiva Lind l. (Zie No. 5680.

6ว98. Panigawong $\mathrm{I}$. $=\mathrm{H} \mathrm{y} \mathrm{d} \mathrm{ro-}$ cotyle asiatic a L. (Zie No. 70.)

6599: Paning II. = Cupania sumatra n a $\mathbf{M}$ i q., Nat fam. der S a pind a c e $x$. Gr. Sumatra; boom.

6600. Paning-fanini Sum. = Quercus Horsfieldi Miq. (Zie No. 4071b.)

6601. Paning-paning Sux. $=a$. Quercus cyrtopoda Miq. $=b$. Q. hypoleuca $M$ iq. en $=c$. $Q$. Teysmanni B l., Nat fam. der Cup ul iferæ. Gr. $a$. \& $b$. Sumatra. $c$. Java en Sumatra; hooge boomen.

6602. Pankolang I. = Alpinia gigantea Bl. (Zie No. 386.)

6603. Panrang Mak. = P anda- 
nus humilis Rmph. (Zie No 1129.) 6604. Pantjahar S. = a. Croton Tiglium L. (Zie No. 6.) $=6 . \mathrm{Ba}$. liospermum axillare Bl. (Zie No. 6255 .)

6605. Pantjar-mata-hari Suм. Wк. = Mussaënda frondosa 1. c. variet. (Zie No. 74.)

6606. Pantjar-sôno S. = Tinospora crispa Miers. (Zie No. 328.)

6607. Pantjerennian-balam S. = Rubus sumatranus Miq., Nat. fam. der Rosaceæ. Gr. Sumatra; heester.

6608. Pantsja I. en

6609. Pantsja-lôho I. = Cladostachys frutescens Don. (Zie No. 838.)

6610. Papadjaran S. = Monetia barlerioides Hérit., Nat. fam. der Ili c ineæ. Gr. Java en Timor; klimplant. 661l. Papaija M. = Carica Papау а L. (Zie No. 1092.)

6612. Papaija-oetan M. = Eupteron nodosum Miq. (Zie No. 4081.)

6613. Papaijta T. = Curanga a mara Juss. (Zie No. 89.)

6614. Papareh M. $=$ Momordica Charantia L. (Zie No. 639.)

6615. Papareh-oetan M. 三 Momordica Balsamina L., Nat. fam. der Cucurbitace ${ }^{2}$ Gr. Hier en daar in dezen Archipel; slingerplant. GEBR. Aan de bladeren kent men een purgeerende werking toe; ook zullen zij zeer geschikt als zeep kunnen dienen. De vruchten worden op olijfolie afgetrokken en deze olie, als oleum Momordicæ bekend, zeer geroemd om hare wondheelende kracht.

6616. Paparehan $\mathrm{s}$. = Blepharochloa ciliata Endl., Nat. fam. der Gramineæ. Gr. Java; grassoort. Gerr. De wilde rijst wordt gaarne door buffels en andere dieren gegeten.

6617. Paparihan Амв. = Momordica Charantia L. (Zie No. 639.)

6618. Paparihan-abbar Аль = $\mathrm{Mo-}$ mordica Balsamina L. (Zie No. 6615.)

6619. Papassang J. \& M. 二 Coccinia grandis Roem. (Zie No. 640.)

6620. Papassang-kali S. $=\mathrm{K}$ n oxi a mollis R.Br. (Zie No. 3825.)

6621. Papassang-lalakki J. = Coccinia Whightiana Roem. (Zie No. $521 d$.)

6622. Papatjeda Амв. 二 Scævola Koenigii Bl. (Zie No. 1001.)
6623. Papeda R. = Dialium ind u m L. (Zie No. 4940.)

6624. Papeda-papoea MoL. $=\mathrm{No}$. thopanax fruticosum Miq. (Zie No. 1153.)

6625. Papeä-âloes M. = Ly g odium microphyllum R.Br. (Zie No. 2604.)

6626. Pappe-pauna Амв. =Cassia fistula L. (Zie No. 1306.)

6627. Pappe-tale Амв. = $\mathrm{Hib}$ iscus tili aceus L. (Zie No. 2764.)

6628. Pappari $\mathrm{CR}_{\text {. }}=$ Egiceras miuus Grtn. (Zie No. 1558.)

6629. Parahoeloe-gedeh S. = A momum aculeatum $R \times b$., Nat. fam. der Zi ingiberaceæ. Gr. De Sunda-eilanden; overblijvend. Gr.Br. Het binnenste der stengels gebruikt men uitwendig tegen hoofdpijn en oogaandoeningen; de vleezige pitten worden gegeten.

6630. Parahoeloo-leutiek S. 二 $a$. Amomum gracile Bl. en $=b$. Am. heteranthum Bl., Nat. fam. Gr. en GeBr. als voren. = c. Amomum ciliatum B 1. (Zie No. 5099.)

6631. Paralli MaK. = Citrus Pa$p \in d a$ Miq. (Zie No. 2077.)

6632. Parang Анв. $=\mathrm{Entada}$ pursætha Dc. (Zie No. 482.)

6633. Parang Mak. = Pandanus humilis $\mathrm{Rmph}$. (Zie No. 1129.)

6634. Paranjeli I. 二 $\mathrm{C}$ a n th i u m g l a b r u m Bl. (Zie No. $4502 c$.)

6635. Parassi S. $=\mathrm{Curculigo}$ recurvata Dry a nd. (Zie No. 24.)

6636. Pare T. 二 Arcea Catechu (Zie No. 1286.)

6637. Pareh S. (Zie Padie M.)

6638. Pareh S. = Endiandra rubescens Miq. (Zie No. 2905.)

6639. Pareh-ajam S. = Papareh M. 6640. Parempeng of Parengpeng S. = Mappa javanica Bl. (Zie No. 5938.)

6641. Parena Амв. = Nipa fruticans Wurmb. (Zie No. 856.)

6642. Pareng M. 三 Entada pursæth a D.C. (Zie No. 432.)

6643. Pareng S. = Ficus cuspida ta $\mathrm{Rwdt}$. (Zie No. 4356.)

6644. Pari-boddas S. = A locasia? variegata C. Koch \& Bouché (Zie No. 1233 )

6645. Paria-hawara S. en

6646. Paria-leuheur S. = L uffa a cutangula Rxb. (Zie No. 2095.)

6647. Pariahan-kallak $\mathrm{s}$. $=a$. 
$\mathrm{Z}$ ehneria exasperata $\mathrm{Miq}$. en 二 b. Z. m n cronat a Miq. (Zie No. $520 c$ )

6648. Parianom J. $=\mathrm{C}$ a r d i pte $r$ is 10 ba ta W a 11 . (Zie No. 2385c.)

6649. Paritjôtô J. $=a$. Medinilla javanensis B l. (Zie No. 2749.) = b. Medinilla Horsfieldi i M q. $=c$. Med. intermedia Bl. en $=$ d. M e d. specios a B l., Nat. fam. der M e l a s t o m a c e æ. Gr. $b$ en $c$ op Java, d. op Java en de Molukken; kleine heesters. GEBr. End li e h e r vermeldt, dat men den slijmerigen bast van vele Moluksche soorten, nadat die van de opperhuid ontdaan is, als verzachtende pap aanwendt bij zwellingen der gewrichten. Ook bezigt men deze met worteltjes op versche wonden, vooral die door slangen- of vischbeten veroorzaakt ziju. Met de zure bladeren kookt men visch.

6650. Paro-paro M. 二 $\mathrm{R} \mathrm{h} \mathrm{y} \mathrm{n} \mathrm{c} \mathrm{hos.}$ pora a urea Va hl. (Zie No. 3003c.) b. Hypolytrum latifolium Rich. var.trinerve. (Zie No. 2768b.)

665l. Paroen Амв. 二 Brugu ier a R u m pii B l. (Zie No. 866b.)

6652. Paroen-maun Aмв. = Ptychosperma $R$ um phi B l. (Zie No. 2267b.)

6653. Parran-ketjil Амв. en

6654. Parran-mette $\mathrm{AmB}$. $=\mathrm{M} \mathrm{u}$ c un a gigante a D.C. (Zie 5527.)

6655. Parria-gingie $\mathrm{S} .=\mathrm{Z}$ e h ne$\mathrm{r}$ i a m u r o n a t a M q. (Zie No. 520.)

6656. Parrie of Parrih $\mathrm{S} .=\alpha$. Ma ngifera la urina Bl., var. Parih B l. (Zie No. 1115.) $=6$. M a n gifer a $\mathrm{Par}$ ih $\mathrm{M}$ iq. (Zie No. 5724)

6657. Pa-sjaga-oetan-ketjil J. = Le $\mathrm{p}$ is te mon ren iform is Hassk., Nat. fam. der Con $\mathrm{Col}$ v u la c eæ. GR. Java en Timor; slingerplant.

6658. $\mathrm{Pa}-\mathrm{sjoe}$. $\mathrm{CH}$. Bo. 二 $\mathrm{J}$ a m b o. sa domestica $R \mathrm{mph}$. (Zie No. 1922.)

6659. Pasoo-kroembing $\mathrm{BK}$. 二 $\mathrm{Sa}_{\mathrm{a}}$ 1 a c i a $B$ ud ing hi S cheffer. Nat. fam. der C e lastrin ex. Gr. Bangka; klimplant.

6660a. Passal Амв. = Vit e x C o-

fas us Rw dt. (Zie No. 4024.)

6660b. Passa
Quercus $\mathbf{l}$.

6661. Passan-batoe M. \& S. 二 L ithocarpus javensis Bl. (Zie No. 1011.)

6662. Passan-betoel M. = Quer- c us pse udo-molucca B1. (Zie No. 4385.)

6663. Passan-gedeh $\mathrm{S}$. $=\mathrm{Qu}$ e $\mathrm{r}$ cu s $P$ in ang a B l., Nat. fam. der $\mathrm{Cu}$ p u l if e ræ. GR Java; hooge boom.

6664. Passan-hieries $\mathrm{S} .=\mathrm{Qu}$ e $\mathrm{r}$ cus gemelliflora Bl., Nat. fam. dezelfde. Gr. Java en Sumatra; hooge boom.

6665. Passan-kajang S. 二 $a$. Quercus daphnoidea Bl. en $=b$. Q. pruinos a Bl., Nat. fam. als voren. Gr. Java; hooge boomen.

6666. Passan-kalimborrot S. $=a$. Quercus pseudo-m olucca Bl. (Zie No. 4385.) 二 b. Quercus thele c a r a M i q., Nat. fam. als voren. GR. Java; hooge boom.

6667. Passan-kapot S. $=$ Querc us spicat a S m ith. (Zie No. 4619.) 6668. Passan-kihioer S. $=\mathrm{Q}$ u e rc u s s und a i c a B 1. (Zie No. 4447.)

6669. Passan-koppia $\mathrm{S}$. $=\mathrm{Qu \text {ur- }}$ c us rotund at a B l.. Nat. fam. als voren. Gв. Java; hooge boom.

6670. Passan-lalakki S. $=a . \mathrm{Quer-}$ cus spic a t a $\mathrm{S}$ m ith. (Zie No. 4619.) 二 b. Quercus glutinosa Bl., Nat. fam. dezelfde. GR. Java; hooge boom.

6671. Passan-lawut M. \& S. 二 Quercus littoralis Bl., Nat fam. als voren. GR. Java; hooge boom.

667\%. Passan-mienjak M. \& S. = Quercus pruinosa B 1. (Zie No. 6665.)

6673. Passan-pinang M. \& S. 二 Quercus Pinang a Bl. (Zie No. 6663.)

6671. Passan-soesoe M. \& T. $=a$. Q nercus pseudo-molucca Bl. (Zie No. 4385.) $=$ b. Quercus $t \mathrm{he}$ le c a r p M i q. (Zie No. 6666.)

6675. Passan-tapok S. = Qu e rc u u s rotu n d a t a B 1. (Zie No. 6669.)

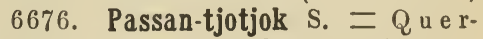
c us cos t a t a B 1., Nat. fam. als voren. Gr. Java en Sumatra; hooge boom.

6677. Passar S. 二 Artoc a p us r i g i a B l. (Zie No. 1454.)

6678. Passeh $\mathrm{Bg}$. $=\mathrm{Capsicum}$ $\mathrm{T}$ if $\mathrm{t}$.

6679. Passisir M. $=\mathrm{D} æ \mathrm{mon} 0$ rops Hystrix M art.

6680. Patada MAx. = $a$. Sonnera tia acida L. en $=$ b. S. a $1 \mathrm{ba}$ $\mathrm{S} \mathrm{m}$ i th. (Zie No. 866.) 
6681. Patakkar T. $\mathrm{T}$ K m p feria $\mathrm{G}$ a la $\mathrm{ng}$ a L. (Zie No. 737.)

6682. Patala-moedi J. $=\mathrm{sph} æ-$ ranthus microcephalus Wlld. (Zie No. 1094.)

6683. Patat S. = $a . \mathrm{Phr}$ y i u m c apitatu in Wlld. (Zie No. 350b.) = b. Phrynium latifolium Bl., Nat. fam. der C a n n a c e æ. Gr. Java; overblijvend. GEBR. De bladeren gebruikt men tot het dekken van huizen en het inpakken van groenten. = $c$. C y a $\mathrm{n}$ odaphne cun eat a B l. (Zie No. 1880.)

6684. Patat-lipoeng S. = Phrynium latifolium B l. (Zie No. 6683b.)

6685. Patat-sagoe S. = M a ranta in di c a L. (Zie No. 431.)

6686. Patat-soerat $\mathrm{S}$. = Phrynium $\mathrm{H}$ ou t te a u $\mathrm{m} \mathrm{Koch}$, Nat. fam. der C a n n a c e æ. Gr. Java; overblijvend.

6687. Pate-abbal Амв, = Albizzia s a ponaria Bl. (Zie No. 1041.)

6688. Pateg-keboh S. $=\mathrm{Z}$ i p pelia be goniæfolia Bl. Nat. fam. der Pi p e l’a c e æ. Gr. Java; heester.

6689. Patei (Pati) Sum. Wк. = Pithecolobium clypearia Bnt h. (Zie No, 3115.)

6690. Patei-pappan Sux. Wк. 二 Pa rkia singularis Miq. Nat. fam. der M imos ex. Gr. Sumatra; hooge boom.

6691. Patei-rimbo Sum. Wr. = Pithecolobium rostratum Miq. Nat. fam. als voren. Gr. Sumatra; hooge boom. $=b$. Ints i a p berula Miq. Nat. fam. der Papilion a ceæ. Gr. Sumatra; hooge boom. $=c$. Evonymus recurvans Mi q., Nat. fam. der C el a stri in e æ. Gr. Sumatra; heester.

6692. Patei-tjatjang Suм. Wк. = a. Intsi a p u be ru la M i q., zie vorig No. $=b$. Pahudia javanic a Miq. (Zie No. 4422.)

6693. Pati-ati I. 二 Trides m is formos a Korth. (Zie No. 4215.) 6694. Patikan I. =- E u phor bi a thym if olia L a m. (Zie No. 1830.) 6695. Patina $\mathrm{I}$. $=\mathrm{Hib}$ is cus mutabilis L. (Zie No. i358.)

6696. Patjar I. \& S. 三 a. Laws o$\mathrm{n}$ i a alb a L a m. (Zie No. 1747.) $=b$. M u rra уа ex otica I. (Zie No. 3708.) 6697. Patjar-ajer M. $=a$. Im patiens Balsamina I. (Zie No. 259.) $=b$. Jusiæa repens L. (Zie No. 476.) $=c$. Artanema sesamoides Buth., Nat. fam. der Scrophularineæ. Gr. Java ; éénjarig.

6698. Patjar-banjoe I. Zie vorig No. 6699. Patjar-djawa M. = Lawsonia alba Lam. (Zie No. 1747.)

6700. Patjar-goenoeng M. 三 Stereoderma javanicum Bl. Nat. fam. der Oleineæ. Gr. Java; bocm.

6701. Patjar-koekoe M. = a. Lawsonia alba Lam. (Zie No 1747.) = b. I m patien $\mathrm{s}$ B l sa mina L. (Zie No. 259.)

6702. Patjar-leuwung S. = $a . \mathrm{Im}$ patiens javensis Steud. $=b$. I m p. lat ifolia L. en $=c$. I m p. mi cranth a B l. Nat. fam. der Bal. s a $\mathrm{m}$ in e æ. Gr. Java; alle énjarig.

6703. Patjar-petok I. = L a w s o. n i a a lb a La m. (Zie No. 174.7.)

6704. Patjar-tjalong I. als voren.

6705. Patjar-tjina M. = $a$. L a wso n i a l b a Lam. (Zie No. 1747.) $=b$. Impatiens Balsamina L. (Zie No. 259.) $=\mathrm{Aglaja}$ odorata Lour. (Zie No. 3710.)

6706. Patjeh I. $=$ Morinda ci$t r$ if o li a $L$. (Zie No. 828.)

6707. Patjing I. $=a$. Costus speciosus Smith. (Zie No. 3247.). $=b$. Costus sericeus Bl. Nat. fam. der Z i n g i be raceæ. Gr. Jara; overblijvend.

6708. Patjing-dawar S. 二 Costus g lo bos us Bl. Nat. fam. als voren. Gr. Java; overblijvend.

6709. Patjo Mak. en

6710. Patjo-mangkasar $\mathrm{M}_{\mathrm{AK}}$. = Colocasia antiquor um S chot t. (Zie No. 245.)

6711. Patma I. $=\mathrm{R}$ afflesia $P$ a tma Bl., Nat. fam. der $R$ affles i a c e æ. Gr. Java; parasiet.

6712. Patma $\mathrm{M} .=\mathrm{N}$ elu m bi u m speciosum Wlld., Nat. fam. der N e l u m b i a c e $x, G$. Door geheel Ned. Indië in vijvers en meeren gekweekt. Gebr. Van deze schoone waterplant, de Lotus der Ouden, wordt een veelvuldig gebruik gemaakt. Een af kooksel der oude wortels geeft men als pisdrijvend middel; de jongere wortels eet men gekookt en gebraden als groente na langdurige diar rhœe. De jonge bladeren en stengels kunnen mede als groente worden gegeten; de oude. bladeren gebruikt men tot bet inpakken. 
van goederen. Het lijmige melkachtige sap der bloemstelen en bloembladeren zegt men heilzaam te zijn tegen maagkramp, braking en diarrhœa. De zaden eet men, zoo rauw als gekookt, als lekkernij. Men raadt een brei, gekookt van de on rijpe zaden met suiker, aan voor kinderen, die ån diarrhoa en atrophie lijden. De Chineesche geneeskundigen prijzen als heilzaam bij dysenterie eeu moes aan, gekookt van de oude zaden.

6713. Patoe-sengoeling LAMP. = Connarus polyphyllus Miq. Nat. fam. der Con n a r c e $æ$. Gr. Sumatra; slingerplant.

6714. Patoek-gagah $\mathrm{S} .=\alpha$. Commely n a paludos a Bl. (Zie No.2089.) = $b$. Thu nbergia javanica Gaertn. (Zie No. 642c)

6615. Patoekoe CeL. 二 Cy cas circ i n 1 is L. (Zie No. 2105.)

6616. Patok-bebekh $\mathrm{I}=\mathrm{K}$ a la nc ho ë p i n na ta P e r s. (Zie No. 1436.)

6717. Patola-gadja Mак. 二 I، uf a c ordifolia B l. (Zie No. 5 14.)

6718. Patola-oelara $\mathrm{MAK}_{\mathrm{AK}}$ 二 Trychosanthes anguina I. (Zie No. 1108 )

6719. Patrakoembala S. 二C as a lpinia pulcherrima Sw. (Zie No. 1386.)

6720. Pa-tse CH. Bo $=a$. Psidiu m Guaja $\mathbf{a}$ Rad di. (Zie No. 1911.) = b. Psidium pumil um Vahl. (Zie No. 19396.)

6721. Patta-kamoedie M. = Emi.

lia sonchifolia D c. (ZieNo.2221.) 6722. Patta-toelang $\mathrm{M}_{\text {. }}=\mathrm{Euphor}$. b i a Ti uca 11 i L. (Zie No. 3397.)

6723. Pattene Mak. = Pteroc arp ns indicus Dc. (Zie No. 18.)

6724. Patti-lalar I. $=$ Picrasma Javanica B l. (Zie No. 4372b.)

6725. Patti-oelar I. $=0 \mathrm{ph}$ iorhiz a M ungos L. Nat. fam. der R ub i a c e æ. GR. Java en Sumatra; overblijvend. GEBR. De zeer bittere wortel wordt als een goed middel tegen slangenbeten geroemd, en was vroeger officineel. 6726. Pattikan $I=$ Soneri la he terophylla Jack. Nat. fam. der Melastomace $x$. Gr. Java en Sumatra; overblijvend.

6727. Pattong S. $=$ Fleming i a stricta Roxb., Nat. Fanl. der Pa$\mathrm{p}$ il i o n a c e $x, \mathrm{Gr}_{\mathrm{r}}$. Java; heester.

6728. Pau BD. = II angifera a 1 tis $\mathrm{s}$ a B la n co. (Zie No. 1033.) 6729. Pau-rimbo Sun. WK. = Sterc ulia geniculata Miq., Nat. fam. der Sterculiace æ. Gr. Sumatra; boom. 6730. Pawan M. = Cle rodendru m i n e r m e G a e r t n. (Zie No. 1243.)

6731. Pedalen S. = M a c rop a n a flor ibund u m M iq. (Zie No. 6589.) 6732. Pedarahan Sum. WK. $=\mathbf{M} \mathrm{y}$. ris t i a c a lo c arpa M i q., Nat. fam. der M y ris t i c e æ. Gr. Sumatra; boom.

6733. Pedas of Pedes J. 二 P i per n i g r u m T.. (Zie No. 1.090.)

6734. Pedas-lenwung $\mathrm{S}$. $=\mathrm{P}$ i p e $\mathrm{r}^{\circ}$ arborescens $\mathrm{Rxb}$. (Zie No. 288.)

6735. Pedej BL. = Ptychosperm a $\mathrm{Rumph}$ i i Br. (Zie No. 2267e.)

6736. Pegoh-pegoh-bonter Sus. WK. 二 a. Ficus microtus Miq., Nat. fam. der A r t o c a r pe æ. Gr. Sumatra; heester.

673\%. Peher of Peër S. 二 $a . \mathrm{Fi}-$ cus grew iæfol i a Bl; Nat. fam. als volen. Gr. Java en Timor; heester. = b. Ficus radicans $R \times \mathbf{b}$. (Zie No. 1652.) $=c$. Covellia ribes Miq. (Zie No 282b.)

6738. Pehtekan J. $=\mathrm{Nertera}$ de pressa Ba nks. (Zie No. 5087.)

6739. Peijlale Cr. $=\mathrm{Urostigma}^{\mathrm{m}}$ $\mathrm{Tj}$ iela Miq. (Zie No. 3048)

6740. Pekan $M$. = J a s m in u m g r a n d iflor u m L. (Zie No. 1366.)

6741. Pelaglar $\mathrm{S} .=$ Tetranthera o p positifoli a Miq. (Zie No. 1532.) 6742 . Pelaö M. \& S. $=\mathrm{M}$ a n g i. f e r a f $\propto t$ i a L o u r. (Zie No. 274.)

6743. Pelas BK. $=$ Urostigma infectori u m M iq. (Zie No. 5435.)

6744. Pelas Sur. $=\mathrm{F}$ i c u s g e m in if ol i a M q. (Zie No. 1573e)

6745. Pelempang-hitam $\mathrm{B \kappa} .=\mathrm{Ad}$ n a ud r a sty los a M i q., Nat. fam. der Ternstrœmi a c æ. GR. Sumatra, Bangka; heester.

6746. Pele-tjedangan $\mathrm{Br}$. $=\mathrm{V}$ a llaris pergulana Brm. (Zie No. 3865.)

6747. Peloetan M. $=$ Urena 10 . b a t a L. (Zie No. 5290.)

6748. Pempan of Pempang $\mathrm{BK}=$ a. F i c us a 1 b a $R$ wdt. (Zie No. 2684b.) = Ficus fulva Rwdt. (Zie No.2682.) $=c$. Covellia a u rata M q. (Zie No. 3335.)

6749. Penaga $\mathrm{BK}_{\circ}=\mathrm{Calophyl.}$ lu m inophyllum L. (Zie No. 1139.) 
6750. Penaga Mavn. = Urostigm a elasticum Mi q. (Zie No. 2440b.)

$675 \mathrm{l}$. Pendjalin J., een benaming vour verschillende Rottan soorten.

6752. Pendjalin-tjatjing $\mathrm{J}_{0}=\mathrm{Ca}$ la mus ciliar is Bl. (Zie No. 2853b.)

6753. Pendjalinan J. $=$ Pru n $\mathrm{s}$ J u n g h uhnian a M i q, Nat. fam. der A m y gdale æ. Gr. Java; boom.

6754. Pengan $\mathrm{M}=\mathrm{S}$ cindaps us? R u m phi M iq. (Zie No. 3499.)

6755. Pengantan-sewoe Man. = Senecio javanicus Wlld., Nat. fam. der C om positæ. GR. Java en Madura; overblijvend.

6756. Pengling J. = Pogo notrophe $\mathrm{ph} æ 0 \mathrm{p}$ od a $\mathrm{Ml}$ i . (Zie No. 446.)

6757. Pening-pening Sux. = Lith o. c arpus? angustifolia Miq., Nat. fam. der C u p ulif e ræ. Gr. Sumatra; boom.

6758. Pening-pening-ramboetan Sus. WK. = Nephelium mutabile Bl., Nat. fam: der S a p inda ce æ. Gr. Op Java, Sumatra en Borneo gekweekt; boom. GEBR. Het grove, zware en roode hout dient soms voor hnisbouw, doch wordt spoedig door insecten aangetast. Het aangenaam sinakende en zuurzoete vruchtvleesch wordt gaarre gegeten en is gezond. Uit de zaden kan lampolie gemaakt worden.

6759. Penjalinan $\mathrm{S} .=a$. C y p e r u s melanocephalus Miq. en $=b$. Cyp. Junghuhnii Miq., Nat. fam. der $\mathrm{C}_{\text {y }}$ e r a c e $æ$. GR. Java.

6760. Pentis $\mathrm{J}_{0}=\mathrm{M}$ orinda citrifolia L.; de onrijpe vrucht, zie No. 828.

6761. Pentjeringeh Suм. Wк. $=$ Rubus alceæfolius Poir. (Zie No. 2446.)

6762. Pepe-0etan S. $=0 \times y$ stel ma esculentum R. Br., Nat. fam. der Aselepiadeæ. GR. Java; slingerplant. GEBR. Het jonge loof wordt als groente genuttigd.

6763. Pepe-pepe Mak. = Avicennia officinalis L. (Zie No. 14.)

6764. Pepe-repepetan $\mathrm{S}$. 三 Rungia parviflora Nees, Nat. fam. der A c an th a cere. Gr. Java; kruipende plant.

6765. Pepet-gangan-lawut $\mathrm{S}$. = Peliosantles javanica Hassk. (Zie No. 2222.)

6766. Pepidjan La๗r. = An is onema hypoleuca Miq., Nat. fam. der Eu ph orbiaceæ. GR. Sumatra; heester.
6767. Pepinjo-tikoes $\mathrm{M}$. = Æch. mandra indica $R$. Wight (Zie No. 4046.)

6768. Pepinoh LauP. = Ardisia densa Miq., Nat. fam. der Myrcineæ. Gr. Sumatra; heester.

6769. Pepinoh badak Lamp. $=a$. Ardisia lamponga Miq., en $=b$. Ardisia pubicalyx Miq., Nat. fam. als voren. $G_{k}$. Sumatra; heesters.

6770. Pepisiung BK. 二 Hedychium coronarium Koen. (Zie No. 2409a.)

6771. Perapat-darat $\mathrm{Bk}$. $=\mathrm{Ma-}$ crosolen? rotundatus Miq, Nat. fam. der Loranthaceæ. Gr. Bangka; parasiet.

6772. Pereng S. $=a$. Ficus cuspidata $R$ wdt. (Zie No. 4356.) $=b$. Ficus paradoxa Bl., Nat. fam. der Artocarper. Gr. Java; heester. $=c$. Covellia Ribes Miq. (Zie No. 282b.) $=d$. Urostigma rigidum Miq. (Zie No. 4348a.)

6773. Pereng-gantong $\mathrm{S} .=a . \mathrm{Fi}$ cus disticha Bl., Nat. fam. der Artocarpeæ. GR. Java; heester $=b$. Synœcia diversifolia Miq. (Zie No. 418.)

6774. Pereng-lumboet $\mathrm{S}$. $=\mathrm{Ficus}$ cuspidata Miq. (Zie No. 4356.)

6775. Perkottat S. = Viburnum Junghuhnii Miq, Nat. fam. der Caprifoliace æ. Gr. Java; boomachtig

6776. Peron J. = Anamirta Cocculus W. \& A rn. (Zie No. 339.)

6777. Pertjah M. = Isonandra gutta Hassk. (Zie No. 890.)

6778. Petasi J. = Polygala venenosa Juss. (Zie No. 4029.)

6779. Pete Амв. $=a$. Dioscorea pentaphylla L. (Zie No. 4.) $=b$. Dioscorea Kleiniana Kunth. (Zie No. 6.)

6780. Peteh M. \& S. 二 a. Parkia africana R. Br. (Zie No. 2565.) $=b$. Parkia speciosa Hassk.; Nat. fam. der Mimoseæ. Gr. Java; hooge boom. Gebr. Als bij No. 2565.

6781. Peteh-ceijlon T. 二 I е uсæ и a gl a uca Bnth. (Zie No. 3679.)

6782. Peteka M. = Citrullus ednlus Spach. (Zie No. 1059.)

6783. Petier of Poetir S. = Parkia intermedia Hassk. (Zie No. 4073.)

6784. Petola M. $=$ Momordica Charantia L. (Zie No. 639.)

6785. Petola-bengala M. = Luffa a cut a g.ula Rxb. (Zie No. 209 o.) 
6786. Petolar-oelar M. = Trichos antes anguina I. (Zie No. 1108.)

6787. Fetola-oetan $\mathrm{M} .=a . \mathrm{L} \mathrm{uffa}$ sylvestris II iq.. Nat. fam. der Cuc u r b it a c e æ. GR. Amboina; slingerplant. Gввк. J)e bittere bladeren worden door sommigen als gioente gegeten; aan de vruchten kent men een sterke braakwekkende en purgeerende werking toe. $=b$. L, uffa pentandra $R \times b$. (Zie No. 636b.)

6788. Petola Pandjang M. en

6789. Petola-tjina M. = I u f f a petola Sering. (Zie No. 685.)

6790. Pettet-sohreh $\mathrm{S} .=a$. De smodium gyroides D C., Nat. fam. der P a p ilion a c e æ. Gr. Java en Sumatra; éénjarig. GEBr. Men legt het fljngestampte kruid op wonden, tegen lendenpijn, enz. $=b$. l) es modium polyc a r p u m D C. (Zie No. 1664.)

6791. Peupeutjangan-lawut $\mathrm{S}$. = Peliosanthes javanic a $\mathrm{H}$ as sk. (Zie No. 2222.)

6792. Peurries $\mathrm{S} .=\mathrm{L}$ e i o c a r pu s fruticos us Bl. (Zie No. 2029.)

6793. Peusong S. = D i chros tach y s c in ere a W. \& A rn., Nat. fam. der II $\mathrm{i}$ mosex. Gr. Vrij algeneen in geheel Indië; kleine boom. Gris. Het sterke hout gebruikt men voor roeiriemen, roeren enz.

6794. Piangoe PaL. $=a$. M y rist i c a ge minat a Miq. (Zie No. 6581.) $=b$. Urophyllum peltistigma M i q., Nat. fam. der $\mathrm{R} n \mathrm{~b}$ i a c e æ. Gr. Sumatra; boom.

f795. Piarang $\mathrm{BK}_{0}=\mathrm{Gl}$ y cos $\mathrm{m}$ is pentaphylla Colebr. (Zie No. 1148 )

6796. Pias BK. = Don a codes a perta T. \& B, Nat. fum. der Z i ng i be r a c e $x$. Gr. Bangka; overblijvend. 6797. Pidada $\mathrm{S} .=\mathrm{S}$ onn er a ti a a c id a L. f s. (Zie No. 866c.)

6798. Pidaroh M. $\mathrm{M}$ X imenia a $m \in$ ric a n I., Nat. fam. der Olac a с е ж. Gr. Java, Sumatra, Celebes, Timor; heester. GEBR. De vruchten en de amandelachtige pitten worden als lekkernij gegeten. Men houdt over het algemeen deze plant voor laxeerend.

6799. Pidêmo J. $=\mathrm{R}$ afflesia Patma B l. (Zie No. 6711.)

6800. Pie-ma Cн. Bо. = Ricinus ruber Rmph. (Zie No. 1977b.) 6801. Piengkoe S. E E pich aris c a u liflora B l., Nat, fan, der Me lia c e æ. Gr. Jara; hooge boom. Gebr. Het sterke en grove, ronde hout is zeer geschikt voor huisbonw, het wordt niet door witte mieren aangetast.

6802. Pietiespieties $\mathrm{BK}$. 二 $ઋ \mathrm{sch}$ nanthus parvifolia R BR., Nat. fam. der C y r t a n d r a c ex. Gr. Bang$\mathrm{ka}$; overblijvend.

6803. Pietjoeng S. = $\mathrm{Pangium}$ e d u le Rwdt. (Zie No. 387.)

6804. Pigagan J. 二 C o m mel y a I.

6,805. Pigi-pigi Sux. = Ficus Re mblas M i q., Nat. familie der A rt o c a r p eæ. Gr. Java en Sumatra Volgens $\mathrm{Miquel}$ een boom ran circa 40 voet; volgens $T$ e y s m a $n$ en $B i n n$ en$\mathrm{d}$ ij $\mathrm{k}$ een slingerplant.

6806. Pikkat BL. = Ent a d a pur. $\mathrm{s} x \mathrm{th}$ a DC. (Zie No. 482.)

6807. Piladong-rimbo Sty. WK = Sonerila insignis Bl., Nat. fam. der $\mathrm{M}$ e last o m a cer. Gr; Sumatra; overblijvend.

6808. Pilakoes of Pilakoet Sum. WK. $=a . \mathrm{Ficus} \mathrm{lasiocarpa} M \mathrm{iq}$. en $=b$. Ficus phlebophylla M iq., Nat. fam. der A rtocarpex. GR. Sumatra; heesters.

6809. Pilandoek Sum. WK. $=\mathrm{S}_{\mathrm{a}-}$ la ci a prinoides DC. (Zie No. 588.)

6810. Pilang J. \& S. $=a . A \mathrm{c}$. cia leucophlæa Wlld. (Zie No. 4812.) $=b$. Pithecolobium $\mathrm{mm}$. bellathum Benth. (Zie No. 2086.) 6811. Pilang-gedeh $\mathrm{S} .=\mathrm{P}$ ith ecolobium nmbellatum Benth.

6812. Pilang-leutiek S. $=\mathrm{Di}$ chrostachys cinerea W. \& Arn. (Zie No. 6793.)

6813. Pina-pina LaMP. $=\mathrm{Ardj}$. $\mathrm{s}$ i a a t ten u a ta Wall. (Zie No. 5475.) 6814. Pinang $\mathrm{M}$. = A reca Cat e c h u L. (Zie No. 1286.)

6815. Pinang-baih Sus. $W_{\kappa}$. A quilaria? macrophylla 11 iq., Nat. fam. der Th y mele a cea. Gr. Sumatra; hooge boom.

6816. Pinang.bajas BK. = Areca? erythropoda M i q. (Zie No. 5371.)

6817. Pinang-bantjong $\mathrm{P}_{A \mathrm{~L}}$ en

6818. Pinang-bariet $\mathrm{BK}$ 。 $=a . \mathrm{Pt} y-$ chos perma. I, a bill. S pec. bang$\mathrm{kan}$. indef. $=b$. Ternst $\mathrm{r} \propto \mathrm{mia}$ a ne ura $\mathrm{Ml}$ i q., Nat. fam. der Terns tr $\propto$ miace e. Gr. Bangka; kleine boom. 6819. Pinang-besar $\mathrm{M}$. = C a l y p- 
trocalyx spicatus Bl. (Zie No. 2811.)

6520. Pinang-betool M. = $\mathrm{Arec}$ a

$\mathrm{C}$ a te $\mathrm{ch}$ u I. (Zie No. 1286.)

6821. Pinang-boeboe M. = Areca a I b a $R \mathrm{~m} \mathrm{ph}$. (Zie No. 1902.)

6822. Pinang-boerong $\mathrm{M}$. = P t ychosperma malayana Miq. (Zie No. $49+3$.)

6823. Pinang-gila PAL. $=$ Ptychosperma Labill. Spec. Sumatr a n. in def.

6324. Pinang-gomoetoe Амв. = A reca glandiformis Hout t. (Zie No. 2267.)

6825. Pinang-jang of P.-jjang $\mathrm{BK}$. $=$ Ptychosperma polystachya M i q. Nat. fam. der P a $1 \mathrm{~m}$ æ. Gr. Bang. ka; boom.

6926. Pinang-kalappa M. $=a$. Ptychosperma? callapparia Mi q. (Zie No. 2834b.) $=b$. P t y c hosperma coron a t a M q., Nat. fam. der P a lm æ. Gr. Java; boom. Gebr. De vruchten of zaden zijn eetbaar, doch zullen licht graveel veroorzaken.

6827. Pinang-kra $\mathrm{BK} .=\mathrm{P}$ in a ng a patula B l.

6828. Pinang-lansa А.м. = A re ca gl a diformis Huutt. (Zie No. 2267.)

6829. Pinang-loeloeng $S$. of

6830. Pinang-loendoeng S. = A reca a l b a $\mathrm{R} \mathrm{mph}$. (Zie No. 1902.)

683l. Pinang-oetan M. = a. P t yshos perma Kuhlii Miq. (Zie No. 1178b.) $=b$. Ptychosperma p unicea Miq. (Zie No. 4097c.) $=c$. Ptychosperma saxatilis Bl. (Zie No. 2984.)

6832. Pinang-oetan Амв. = Goen a g a $\mathrm{T}$.

6833. Pinang-oetan-besar M. = Calyptrocalyx spicatus Bl. (Zie No. 2811.)

6934. Pinang-oetan-ketjil M. = Ptychosperma saxatilis Bl., (Zie No. 2984.)

683. Pinang-pandan MoL. = Arec a glandiform is $\mathrm{H}$ ou t t. (Zie No. 2267.)

5836. Pinang-pandjawar S. = Ptychosperma sylvestris Miq., Nat. fam. der P a l m æ. GR. Java; boom. GEBR. De noot wordt soms bij het sirihkauwen gebruikt in plaats van die der echte Pinang ( $\mathrm{Arec}$ a $\mathrm{C}$ a t e chu L.)
6837. Pinang-pinang Sun. $=\mathrm{Pt}$ chosperma noxa Miq. (Zie No. $1178 d$.)

6838. Pinang-pinang-goendi SuM. $=A d i n a n d r a$ stylosa Miq. (Zie No. 4821.)

6839. Pinang-poetih M. = A reca a 1 b a $\mathrm{R} \mathrm{m}$ ph. (Zie No. 1902.)

6340. Pinang-poetih Sus. WK. = A dina ndra glabra Mi q. (Zie No. 3435.)

6841. Pinang-rambeh $\mathrm{M} .=\mathrm{I} g-$ nan ura geo nem formis Mar t, Nat. fam. der P a l m x. Gr. Malakka; boom.

6842. Pinang-rendah M. 二 $a$. Bentinck i a $\mathrm{R}$ enda $h \mathrm{M}$ ar t., Nat. fam. als vorell. GR. Sumatra; boom. $=b$. Areca triandra Rxb. (Zie No. 1904.)

6843. Pinang-rendeh of rendi M. (Zie vorig No.)

6344. Pinang.rimbo M. $=\mathrm{Pt} \mathrm{y}$ chos perina coccinea H. L. B., Nat. fam. der P a lm $x$. GR. Sumatra en Bangka; boom.

6845. Pinang-saleh M. \& S. = Ptychosperma saxatilis Bl. (Zie No. 2984)

6846. Pinang-sinagaar M. en

6847. Pinang-tjinaga $\mathrm{M}$. ook

6948. Pinang-wangie $M .=A \mathrm{re}$ c a a l b a $\mathrm{Rm} \mathrm{ph}$. (Zie No. 1902.)

6849. Pinang-toewa $\mathrm{BK}$. of

6850. Pinang-toewoh $\mathrm{BK} .=10$. Myrsine aren is A. Dc. (Zie No. $4235)=2^{\prime \prime}$. Myrsine a f inis A. De. (Zie No. 7573.) $=3^{0}$. My r s ine s u m a tra n a Miq. GR. Bangka; heester.

68ว̌l. Pinango S. $=\mathrm{D}$ i d y m o ch iton nutans Bl. (Zie No. 4984.)

6852. Pindis $\mathrm{M}_{0}=\mathrm{N}$ a n i a $\mathrm{v}$ e $\mathrm{ra}^{\circ}$ M i q. (Zie No. 27796.)

6553. Pingar-0etan $\mathrm{J} .=\mathrm{Ca} 10-$ tropis gigantea R. Br. (Zie No. 817.)

6854. Pinning $\mathrm{S} .=\mathrm{Elettaria}$ m in 0 r B l., Nat. fam. der $Z$ ing i ber a c e æ. Gr. Java; overblijvend. (jebr. Van vele Elett a $\mathbf{r}$ i a-soorten zijn de zaden asngenaam zoet en worden gegeten; van andere worden de zure bladeren bij de rijst gebruikt.

6855. Pining-bawang $\mathrm{S}$. = $\mathrm{D}$ on acodes alli a c e um T. \& B., Nat. fam. der Z i n g i b e r a c e ז. Gr. Java; overblijvend. 
6856. Pining-kentjeh $\mathrm{S}$. $=\mathrm{D}$ o n ac o d e s $m$ in o $r$ T. \& B., Nat. fam. en GR. als voren.

6857. Pining-kisie S. Een variëteit van de vorige.

6858. Pining-kiessie S. en

6859. Pining-landak $\mathrm{S} .=\mathrm{D}$ о и acodes paludosa Miq., Nat. fam. en $G R$. als voren.

6860. Pining.lumboet $\mathrm{S}$. 三 Elett a ria $\mathrm{minor} B \mathrm{l}$. (Zie No. 6854.)

6861 . Pining-randja of randjang S. = Don a codes Pininga Bl.. Nat, fam. der Z i n g i b e r a c e æ. Gr. Java; o verblijvend.

6862. Pining-rangong S. $=a$. Do$n$ a codes $\mathrm{P}$ in inga Bl. = 6 . Elet. t a ria mollis B l., Nat. fam. en GR. als voren.

6863. Pining-tottot S. = E l et t aria vill o s a Miq., Nat. fam. en Gr. als voren.

6864. Pinka T. $=\mathrm{Crotallaria}$ retu s a L. (Zie No. 2495.)

6865. Pinten J. $=$ D i cliptera ch in e $\mathrm{n} s$ is $\mathrm{N}$ e es., Nat. fanı. der A c a $n t$ h a $s$ e $x$. GR. Java; kruidachtig. 6866. Pioeta $\mathrm{BK}=$ Cryptoc ary a infectoria Miq., Nat. fam. der L a u r in e æ. GR. Bangka; boom.

6867. Pioeta Sum. $=\mathrm{J}$ a m bos a symphytocarpa Miq., Nat. fam. der If y rt a c e . GR. Sumatra; boom. 8868. Pipi-ait $\mathrm{S} .=$ II æ s a m e mbran a cea A. DC. (Zie No. 4627b.)

6869. Piroe Cr. $=\mathrm{Cyn}$ y metra $\mathrm{r}$ a $\mathrm{m}$ i f lo ra L. (Zie No. 4262.)

6870. Piroe MoL. = Premna ce$r$ amens is Miq., Nat. fam. der Ver. b e n a c e $x$. Gr. C e r a m; heester.

6871. Pisang M. $=\mathrm{M}$ n s a Trnf.

6872. Pisang-ajer $\mathrm{M} .=\mathrm{R}$ a $\mathrm{ve}$ nal a madagas cariensis Adans., Nat. fam. der M u s a c e re. Gr. Java en plders in tuinen; de Waterboom of "l'A rbre des roy a ge u r s" vindt men als sierplant bij vele huizen.

6373. Pisang-alfoeroe $M .=M u s a$ a] $\mathrm{phuric}$ a $\mathrm{Rm} \mathrm{ph}$. (Zie No. 4888.)

6874, Pisang-badak $\mathrm{S}$. $=\mathrm{M} \mathrm{u} \mathrm{s}$ a c hinensis Sw., Nat. fam. der M us a c e $x$. GR. Java in tuinen; boomachtig.

6875. Pisang-baroek Sim. WK. = Phytocrene macrophylla Bl. (Zie No. 644h.)

6876. Pisang-batoe M. en

6877. Pisangbidji M. $=M \mathrm{us} \mathrm{a}$ s a p ie n t um I. v a r., Nat. fam, der $M$ u s a c e $æ G_{R}$. Door geheel Indië in tuinen; boomachtig. Gebr. Als bij No. 1190 aangegeven.

6878. Pisang-biokaïkok BL. $=\mathrm{He}$ liconiopsis amboinensis Miq. (Zie No. 4978.)

6879. Pisang-ceram $\mathrm{M}$. $=\mathrm{M} \mathrm{u}$ s a alphurica Rmph. (Zie No. 4888.)

6880. Pisang-jakki Mot. $=\mathrm{M}$ u s a simiarum Rumph. (Zie No. 1191.)

6881. Pisang-kembang-woengoe $I$. $=$ Musa ornata Rxb. Nat. fam. der Musac eæ. Gr. Java; boomachtig.

6882. Pisang-kipas M., zie P.-ajer M.

6883. Pisang-madja $M$. $=M$ u s a sapientum L. (Zie No. 6877.)

6884. Pisang-patjing $\mathrm{I}$. = Heliconiorisis amboinensis Miq. (Zie No. 4978.)

6885. Pisang-pidak $\mathrm{I} .=\mathrm{M} \mathrm{usa}$ gl auca Rxb. Nat. fam. der M usace Fr. Java; boomachtig.

6886. Pisang-pisang PAI. = $\mathrm{P}_{\text {se }} \mathrm{u}-$ duvaria reticulata Miq. (Zic No. $4509 e_{\text {e) }}$

6887. Pisang-pisang $\mathrm{M}=\mathrm{Prem} \mathrm{n}$ a flavida Miq. (Zie No. 3321.)

6888. Pisang-sirandoh $\mathrm{S}_{0}=\mathrm{Musa}$ $\mathrm{ch}$ in en s is $\mathrm{Sw}$. (Zie No. 6874.)

6889. Pisang-toenkjoek-langhit M. en

6890. Pisang-tongkat-langhit $\mathrm{M}$. = II usa uranoscopos Rmph. Nat. fam. der $M$ u s a c e $x$. Gr. De Molukken; boomachtig. GEBr. De vruchten worden zeldzaam gegeter; na geroosterd te zijn, zij zullen een pisdrijvende werking bezitten.

6891. Pisangan J. $=a$. Mitre. phora macrantha Hassk. (Zie No. $573 g.)=b$. Alphonsea lutea $\mathrm{Hk}$. fs. \& T., Nat. fam. der A nonacer. Gr. Java; boom.

6892. Pisere-kekel S. $=1$ ichroa c yanitis Miq. (Zie No. 2512.)

6893. Pisi-kembang line. $=a$. Curculigo recurvata Dryand. (Zie No. 5812b.) $=$ b. Hypoxis major Kurz. (Curculigo or chioides G xtno), Nat. fam. der Hypoxidex. Gr. Madura, Sumatra; overblijvend. Gribr. De wortel wordt door sommigen gekonfijt gegeten, en ook op pijnlijke gezwellen, fuu unculi, gelegd.

6894. Pitada Mrk. = a. Sonneratia alba l. fs. en $=b$. Sonn. alba $S \mathrm{~m}$. (Zie No. 866.) 
6895. Pitiesan J. = Acrost ichum n ummularifolium Bl. (Zie No. 2231.)

6896. Pitjoeng-tjelleng S. = Trichosauthes coriacea Bl. (Zie No. 644 )

6897. Pitoe-lintjar S. $=\mathrm{Conyz} \mathrm{a}$ lacera Brm. (Zie No. 1047b.)

6898. Pitoengang-pipi Sum. = Casuarina sumatraua Jngh. (Zie No. 332.

6899. Pitojo T. $=$ Cy c a s c i c inalis r. (Zie No. 2105.)

6900. Pitpisan S. $=\mathrm{V}$ angueria latifolia Miq. (Zie No. 1907b.)

6901. Pitties-pittiesan $\mathrm{Bl} .=a$. Hoy a in acrophylla BI. (Zie No. 563.) $=b$. Hoya Rumphii Bl. (Zie No. 1776b.)

6902. Pitties-pittiesan-ketjil Bl. = a. Dischidia nummularia R. Br. (Zie No. 223ld.) $=b$. Dischidia $R$ afflesiana Wall. (Zie No. 17776.)

6903. Plaai Вк. = Alston ia eximia Miq. (Zie No. 2034.)

6904. Plam-djawa Pas. $=M$ angifera indica L. (Zie No. 275.)

6905. Plawan BK. = $\mathrm{Tr}$ ista $\mathrm{n}$ i a obovata Bnnt. (Zie No. 6534.)

6906. Plawan-broek Bк. = Euthemis le ucocarpa Jack. (Zie No. 5862.) 6907. Plesiek-boerong $\mathrm{BK} .=\mathrm{Ar}-$ disia Teysmanniana Scheff. (Zie Grien.)

6908. Plillak $S_{0}=\mathrm{G} \mathrm{lochid}$ i ou molle Bl. (Zie No. 4613a.)

6909. Plisse-dangan $\mathrm{Br}_{\mathrm{c}}=\mathrm{V}$ allaris pergulana Brm. (Zie No. 3866.) 6910. Plossoh J. $=$ Butea frondos a $\mathrm{R} \times \mathrm{b}$., Nat. fam der PapillioIl a c e æ. Gr, Door gebeel Indië; sierlijke boom. Gebr. De stam levert de OostIndische Kina voor de apotheken; uit de bloemen verkrijgt men een gele kleurstof. 6911. Piumpang-abang PAL. = A din a d r a glabra Miq. (Zie No. 3435 .)

6912. Plumpang-hitam $\mathrm{BK} .=\mathrm{Ad} \mathrm{i}$ n a ndra trichocoryna Kths., Nat. fam. der Ternstræmi ace e. Gr. Bangka; booln.

6913. Plumpang-poetih Вк. 二 $\mathrm{L}$ aplacea marginata Chois., Nat. fam. der Ternstr m i a c æ. GR. Bangka; boom.

6914. Plumpang-poetih PAL. = Laplacea subintegerrimra Miq.,
Nat. fam. der C a in elli a ce a. Gr. Sumatra; boom.

6915. Poboän $\mathrm{S}$. Z P il e a le u c op h æ a B l., Nat. fam. der U r t i c e æ. Gr. Sava; kleine heester.

6916. Poch-pochan S. = $\alpha$. Pilea miconiæfolia Miq., = b. Pilea oreophila Miq. en $=c$. Pilea s tipul o s a Mi q., Nat. fam. en Gr. als voren. Gebr. De jonge takjes en bladeren van deze half heesters worden rauw bij de rijst gegetell.

69i7. Poe Cec $=$ Quercus mo$\mathrm{l} \mathrm{u} \mathrm{c} \mathrm{c} \mathrm{a} \mathrm{Km} \mathrm{ph}$. (Zie No. 109.)

6918. Poeä Bd. 二 $\mathrm{Arec}$ a Catec h u L. (Zie No. 1286.)

6919. Poeän M. = Cleroden$\mathrm{d} \mathbf{r u m}$ in e $r$ m e $\mathbf{G}$ æ $\mathrm{t}$ n.(Zie No.1243.)

6920. Poeän-boenga $\mathrm{M}$. = Cle rodendrum ealamitosum L. (Zie No. 4.144)

6921. Poeär Bk. \& R. 二 a. A in om u m Cardamomu m L. (Zie No. 3830.) = b. Alpinia $\mathrm{mal} \mathrm{a} \mathrm{c} \mathrm{censis}$ R os c. (Zie No. 392.)

6921. Poeär Sun. WK, = Ele t taria Diepenhorstii T. \& B., Nat. fam. der Z i n g i b e r a c e æ. Gr. Simatra; overblijpend.

6922. Poeär-amoet Sum. Wk. = G l o b b a ciliat a J a ck., Nat. fam. enz. als voren.

6923. Poeàr-laki $R_{\text {. }}=$ Am or u u gracile 81 . (Zie No. 6630.)

6924. Poeär-lilipan $\mathrm{P}_{\mathrm{AL}}$. $\mathrm{T}$ acea c ris t a t a $J$ a c k., Nat. fam. der 'T a cc a c e æ. Gr. Sumatra; overblijvend.

6925. Poeär-poelaga M. = A m om u m Cardamom um I. (Zie No. 3830.)

6926. Poedak M. \& S. $=P$ a n d a. n us moschat us Rin ph. (Zie No. 2735.)

6927. Poeding M. = Graptophyllum hortense Nees. (Zie No. 90.)

6928. Poeding-oetang $\mathrm{M} .=a$. Chasalia lurida Miq. (Zit No. 4506b.) $=b$. Wend landi a Teysma n n i a a M i q.; Nat. fam. der R ub i a c e æ. Gr. Sumatra; heester.

6929. Poeding-poetih M. = Gra ptophyllum hortense Nees. (Zie No. 90.)

6930. Poeding-rlmbo M. $=a . \mathrm{P}_{0}$ lyphragmon hvdrange folium M i q., Nat. fam. der $\mathrm{R} \mathrm{u} \mathrm{b}$ i a c e 
Sumatra; heester. $=\dot{o}$. St y loc or y n a polycarpa Miq. (Zie No. 5319.) = c. $\mathrm{Ch}$ as alia $\mathrm{lurida} \mathrm{Miq}$. (Zie No. $4506 b$.) $=d$. C l e rod e ndrum serr a t u m S p rg., Nat. fam. der V e r b en a c e ж. Gr. Java, Sumatra, enz.; heester. Gebr. De wortel wordt fijngewreven en gegeten orn een heldere stem te krijhen. De bladeren geeft men tot bevordering der kraarnzuivering; een aftreksel er van geeft men tegen koorts, en aan kinderen tegen buikpijn en wormeu. De vruchten worden geroost bij de rijst gegeten.

6931. Poedja of Poetsja MaK. $=a$. B a r ingt o n i a a l b a Has s k., Nat. fam. der M y r t a c e æ. Gr. Java, Celebes, de Molukken; boom. Gkibr. Als van de B. $\mathrm{r} n \mathrm{~b} \mathrm{r}$ a B l. (No. 2962c.) $=b$. B a rriugtonia racemosa Bl. (Zie No. 983.)

6932. Poein $\mathrm{M}_{.}=\mathrm{Curcnligola-}$ tifolia Dryand. (Zie No. 24.)

6933. Poeki-andjing M. = C y n ome tra c a u lif l o r a L. (Zic No. 5206.)

6934. Poelaga Sur. = Polyadenia pe peri c a rpa $\mathrm{M}$ i q. (Zie No. 402.)

6935. Poelaga-antarsa Sum. WK. = a. Polyadenia pepericarpa Miq. (Zie No. 402.) = b. Tetranthera Die penhors ti i M i q., Nat. fam. als voren. Gr. Sumatra; boom.

6936. Poelangeh M. = Poly a denia salicifolia Miq., Nat. fam. der Laur i n e æ. Gr. Java, Sumatra; boom.

6937. Poolassan M. \& S. 三 Nepheli u m la p pa ce uin L. cum variett., Nat. fam. der $\mathrm{S}$ u p i i d a c ex. Gr. Door geheel Indië gekweekt; boom. Geвir. Het roode, grove en zware hout dient soms voor bouwhout, doch wordt spoedig door witte mieren aangetast. Het aangenaam smakendt en zuurzoete vruchtvleesch (Ramboetau) wordt veel gegeten en is zeer gezond; nit de zaden kan een lampolie gerronuen worden. $=b . \mathrm{Ne} \mathrm{pheli} \mathrm{n} \mathrm{m}$ mutabile Bl. (Zie No. 6758.)

6938. Poelassan-allas $\mathrm{S} .=\mathrm{N}$ e $\mathrm{p}$ helium altissimn 'T. \& B. (Zie No. 5523.)

6939. Poelassan-boddas S. en

6940. Poelassan-hiedung S. $=\mathrm{Ne}$. phelinm la p pacen m $\mathrm{I}_{\text {. }}$ (Zie No. 6937.)

3941. Poelassarie S. \& M. = A ly xi a stellata R. \& S. (Zie No. 646.)

6942. Poelassarie-gedeh $\mathrm{S}_{0}=\mathrm{Al}$ y $\mathrm{x}$ i a stellata R. \& S. var. latifolia Bl.
6943. Poelassarie-lalaki $\mathrm{S} .=\mathrm{C}$ h i. locarpus snaveole ns Bl. (Zie No. 478.)

6944. Poelassarie-poetih $\mathrm{M} .=\mathrm{Ch}$ locarpus de u udatus Bl. (Zie No. $603 b$.

6945. Poelawa-hidjoe S. $=a . \mathrm{H} y$ poëstes polythyrsi Miq. ell= b. H y p. Z ollingeria n a i q. Nat. fam. der A c a $\mathrm{t}$ h a ce ex. Gr. Java; éénjarig.

6946. Poeleh J. \& M. = a. F'agræa imperialis Mi q., Nat. fam. der Log a $\mathrm{n}$ i a $\mathrm{c}$ e æ. Gr. Sumatra; kleine boom. b. Alstonia s cholaris R.Br. (Zie No. 2350.) $=c$. B l a beropus sericе и s A.DC. (Zie No. 3260.) $=d$. Blaberopus villos us Miq., Nat. fam. der A p o c yn e æ. Gr. Java; heester.

6947. Poeleh.batoe M. $=\mathrm{B}$ o be a W a lli c h i a u a $\mathrm{K}$ or th, Nat. fam. der $\mathrm{R} \mathrm{u} \mathrm{bi} \mathrm{a} \mathrm{c} \mathrm{e} x$. Gr. Borneo; boom.

6948. Poeleh-pandak J. \& M. $=a$. Ophioxylou serpentinu in L., Nat. fam. der A p o c y n e æ. Gr. Java en de Molukken; kleine heester. Gebr. Aalı den bitteren wortel van dit saprijke heestertje kent men versterkende en koortsdrijvende eigenschappen toe; men prijst diel zeer als een goed middel tegen slangenbeten aan; geeft hem als maagsterkend middel tegen kolijk en cholera, en dient hem inwendig tegen lintworm en nitwendig tegen schurft toe. Het melksap wendt men tegen vlekken op het hoornvlies aan. De stengel wordt gekanwd bij koorts, buikpijn en cholera. In de veeartsenijkunde geeft men het kruid aan paarden als laxeerend middel in, en legt het, fijngewreven, met kalk en water op wonden, door het drukken der zadels ontstaan. $=6.0 \mathrm{ph}$ i o x ylon trifoliatnm Gratn. (Zie No. 237.) $=c$. Ophiox ylon obvers um M i q, Nat. fam. als voren. Gr. Java; heester. Gebr. Vermoedelijk als bij $a$ en $b$ is opgegeven.

6949. Poeleh-pipi Sun. WK. = Alstonia calophylla Mi q., Nat. fan. dezelfde. Gr. Sumatra; heester.

6950. Poelei BK. $=\alpha$. A lstoul i polyphylla Miq. (Zie No. 5968.) $=b$. Eurycles amboinenis Herb. (Zie No. 1062.)

6951. Poelei-lalaki MAD. $=$ Cyrtosiphonia madurensis T'. \& B. Nat. fam. der A pocyue dura; heester. 
6952. Poeli J. =Alstonia spec. tabilis R Br. (Zie No. 5199.)

6953. Poeloe-lata J. = Thalictrum gly phocarpum W. \& Arn. (Zie No. 41276$.

6954. Poeloe-poeloenan-betina SuM. WK. = Sida cordifolia L. Nat. fam. der $\mathrm{MI}$ a l vace $æ$. Gr. Java, Sumatra; Rotti; heester.

6955. Poeloengan J. = $a$. C a rdiospermum Hali cacabum L. (Zie No. 433.) $=$ b. Cardiosperma m microcarp um H., B. \& K. Nat. fam. der S a p i n d a c e $x$. Gr. Java; klimplanten. GEBr. Als No. 433.)

6956. Poeloes S. =- Urtica Trnf. en La p orte a G a u d.

6957. Poeloes-aroij $\mathrm{S} .=\alpha . \mathrm{C}$ esmone javanica Bl., Nat. fam. der E uph or bi a ceæ. Gr. Java; klimplant. = b. Tragia hirsuta Bl. (Zie No. 1326.)

6958. Poeloes-djalatong $=a$. I, aportea costata Iiq. $=b$. L a p. crenulata Gaud. = c. Lap. oblong a ta Miq., Nat. fam. der Urticac е æ. Gr. Java; heesters. $=d$. L a p. st im ulans Mi q. (Zie No. 1698c.)

6959. Poeloes-gatel S. en

6960. Poeloes-gatel-besar S. = Laportea de cumana W edd. (Zie No. 121.)

6961. Poeloes-heedjoh S. = a. I, aportea cost a t a Miq. (Zie No. 6958.) $=b$. Laporteastimulans Miq. Zie No. $1698 c$.)

6962. Poeloes-malaba S. en

6963. Poeloes-malehla S. $=\mathrm{La-}$ portea microstigma Gaud. (Zie No. 1698b.)

6964. Poeloet-beurriet $\mathrm{S}$. $=\mathrm{K}$ o p$\mathrm{si}$ a a r b ore a B l. (Zie No. 4552b.)

6965. Poeloet-laki-laki BK. = U ren a $\mathrm{L}$ a p pago $\mathrm{Sm}$. (Zie No. 314.)

6966. Poeloet-poeloet-kambing Sum. = Triumfetta cana Bl. (Zie No. 2593.)

6967. Poeloetan J. (Zie later Pompoerroetan S.)

6968. Poeloetan-lawut M. $=\mathrm{A}$ b util on Striatum Hook., Nat. fain. der MI a lva c e æ. Gr. Op Java en elders in tuinen als sierplant; kleine heester.

6969. Poenaga Sux. WK. $=a$. Urostigma cyclone arum Niq., Nat. fam. der A rto c a r p e. Gr. Sumatra boom. $=b$. Trostigma luc e s cens Miq. (Zie No. $5435 b$.)
6970. Poenanga-boeg MaK. $=\mathrm{Ca}$ lophyllum inophyllum L. (Zie No. 1139.)

6971. Poenei-poenei M. = A n tidesma salaccense Zoll. (Zie No. 1132.)

6972. Poengang $\mathrm{S}$. $=\mathrm{B}$ arring. to $n$ ia racemos a B l. (Zie No. 983.) 6973. Poengoel PaL. $=\mathrm{Z}_{\mathrm{anth}} \mathrm{n-}$ xylon eu n e ron Miq., Nat. fam. der D i o s m e æ. Gr. Sumatra; heester.

6974. Poenteh ALF. Mis. = Pisang II.

6975. Poerasane Aмв. = Alyxi a stellat a R. \& S. (Zie No. 646.)

6976. Poerdoppo-wali J. = Tinospora crispa Miers. (Zie No. 328.) 6977. Poeroet S. = a. Artocarpus calophylla Z. \& M., Nat fam der Artoc arpeæ. Gr. Java; hooge boom $=b$. Artocarpus rigida Bl. (Zie No. 1454.)

6978. Poeron $\mathrm{BK}$. = L e piron ia mucronata Rich., Nat. fam. der C y p er a c e æ. Gr. Bangka; grassoort.

6979. Poerwo-djamboe J. 三 Gaultheria punctata B l. (Zie No. 2403.) 6980. Poerwo-genni J. = V a ccinium varing i folium Miq. (Zie No. 2836.)

6981. Poerwo-koening $\mathrm{J}$. $=\mathrm{N}$ orysca Java nica Bl. (Zie No. 4411.) 6982. Poerwo-koetjet $\mathrm{J}$. $=\mathrm{Ru}$ b us 1 in eat 11 s $R$ wt. (Zie No. 3577) 6883. Poerwo-sottoh J. = Ga ultheria le ucocarpa Bl., Nat. fam. der E r i c a c e æ. Gr. Java 4000'-7000'; kleine heester.

6984. Poerwo-tjeng J. = Pim pinella Pruatjan IIolkenb., Nat. fam. der U m bell if e $r$. Gr. Java $3000^{\prime}-11000^{\prime}$; éénjarig. GEBR. Men geeft den aromatischen wortel van dit kruid inwendig als zweetdrijvend middel.

6985. Poespa M. \& S. $=a . \mathrm{S} \mathrm{ch} \mathrm{i-}$ ma Noro n $æ \mathbb{R}$ wdt., Nat. fam. der C a m el li a c e $æ$. Gr. Java, Sumatra, Bali; hooge boom. GEBR. Het fijne, roode en zware hout is zeer duurzaam en geschikt voor bouw- cn meubelhout. $=b$. Schima Wallichii Chois. (Zie No.2894.) $=c$. Gordon ia excels a B l. (Zie No. 2531.) $=d$. Gordonia in t e g e rim a T. \& B., Nat. fam. der C a m ell i a c e. Gr. Java; hooge boom. $=e . \mathbf{G}$ labraria tersa L., $v$ ar. (Zie No. 2669b.)

6986. Poespa-lumboet S. 二 A cro- 
nodia punctata Bl. (Zie No. 2490.)

6987. Poespa-nidra $\mathrm{S} .=\mathrm{C}$ a $\mathrm{l}$ p andria lance olata B l.. Nat. fam. der Ca melli a c eæ. Gr. Java, Borneo; heester. $=b . \mathrm{C}$ a n n a co c c in e a $\mathrm{A}$ it. (Zie No. 4150.) 三c. Ca n n a orien$t$ a lis $\mathrm{R}$ os c., Nat. faın. der $\mathrm{C}$ a $n$ n ac e æ. Gr. Java; overblijvend.

6988. Poespa-tjarang $\mathrm{S}$. $=\mathrm{H} \mathrm{a} \mathrm{a-}$ si a microcarpa Bl. (Zie No. 5579.)

6989. Poetag S. 二 $\alpha$. A c r o nodia punctata Bl. (Zie No. 2490.) $=b$. Syzygium ra cemosum DC., Nat. fam. der M y r t a c e $x$. Gr. Jara; hooge boom.

6990. Poetar S. = Helicteres Is or a L. (Zie No. 1491.)

6990bis. Poetat J. = a. B a ri n gto nia al b a Hassk. (Zie No. 6931.) $=b$. Barringtonia racemosa Bl. (Zie No. 983.) =c. B a r r ington i a rubra B l. (Zie No. 2960c.) $=d$. Barrington i s picat a Bl., Nat. fam. der II y $\boldsymbol{r}^{\mathrm{t}}$ a c e ce. Gr. Java; boom. $=e$. Planchonia sundaica Nat. fam. dezelfde. Gr. Java, Sumatra; hooge boom. Gebr. De bast en bladeren worden als adstringens tegen diarrheœ toegediend.

6991. Poetat-ajer BK. $=\mathrm{E}$ u th e$m$ is $m$ in or J a ck., Nat. fam. der $\mathrm{O}$ c h n a c e æ. Gr. Bangka; heester.

6992. Poetat-darat $\mathrm{BK} .=\mathrm{Eu}$ th eun is le ucocarpa Jack. (Zie No. 5862 .)

6993. Poetat-goenong S. $=\mathrm{Pl}$ a nchonia sundaica Miq. (Zie No. 6990 e.)

6994. Poetat-laki s. $=\mathrm{B}$ a r ring. to nia spicata Bl. (Zie No. 6990d.)

6995. Poetat-waleh $\mathrm{S} .=\mathrm{T}$ in o spora crispa Miers. (Zie No. 328.)

6996. Pooteran M. \& S. $=\mathrm{Helic-}$ te res Is ora L. (Zie No. 1491.)

6997. Poeterandjio Sum. $=\mathrm{Ph}$ y $\mathrm{l}$ lagathis rotund ifolia Bl., Nat., fam. der Melastom a ce ic. Gr. Sumatra; lage heester.

6998. Poetjoek S. $=$ Coryph a u mbraculifera J. (Zie No. 1528.)

6999. Poetjoek-soelang $\mathrm{S} .=a$. Aloc a sia Veit chii S chot t., Nat. fan. der A lo ide x. Gr. Java, Borneo; orerblijvend. $=b$. ' c o lo r H a s sk., Nat. fam. dezelfde. Gr. Java; overblijvend. $=c$. A de n o s a cme c a uliflora $M$ i q., Nat. fam. der R u- b i a c e a, Gr, Java, Sumatra; kleine heester.

7000. Poetjoeng $J .=P$ a ng i u m edule Rwdt. (Zie No. 357.)

7001. Poetjoeng-0etan M. $=\mathrm{Cle-}$ rodendrum paniculatum L. (Zie No. 4144.t.)

7002. Poetjuengan $\mathrm{J} .=\mathrm{C}$ a $\mathrm{mpe}$ li a glabrata K unth. (Zie No.4014.)

7003. Poetrawalli $J .=\mathrm{T}$ in os $\mathrm{p} 0-$ $\mathrm{r}$ a crispa Miers. (Zie No. 328.)

7004. Poetria M. $=$ M u s s a ëu da frondosa I. (Zie No. 74.)

7005. Poh Br. = M a ng if e r a indi c a L. (Zie No. 275.)

7006. Poh-anges Br. = M a n g ife. $\mathrm{ra} \mathrm{m}$ in or B l. (Zie No. 5457.)

7007. Pohodoelang S. = S c re vol a K n ig ii Vahl. (Zie No. 1001.)

7008. Pohon-dawon-saga BL. = Albizzia julibrissin Bois., Nat. fam. der Mimoseæ. Gr. Hier en daar in tuinen; boom.

7009. Pohon-hidop J. 二 Euporbia Tirucalli L. (Zie No. 3397.)

7010. Pohon-ipo S. = Covellia mollis Miq., Nat. fam. der Artocarpeæ. Gr. Java, boom, wiens vruchten eetbaar zijn.

7011. Pohon-kerambang M. en

7012, Pohon-kerambil M. = $\mathrm{C}_{0-}$ cos nucifera L. (Zie No. 393.)

7013. Pohon-knitni J. = Elæ0. carpus angustifolius Bl. (Zie No. 104.)

7014. Pohon-krangeän J. = 'I'etranthera citrata Nees. (Zie No. 401.)

7015. Pohon-kot J. 二 Acacia te. nerrima Jngh., Nat, fam. der $\mathbf{M}$ i moseæ. Gr. Java; boom.

6016. Pohon-lengkak M. $=a$. Trapa cochinchinensis Lour. en $=b$. Trapa quadrispinosa $R \times b$., Nat. fam. der 'Trapeæ. Gr. Op Java en elders gekweekt; waterplanten. GEBr. De vruchten, waternoten genoemd, worden gegeten, doch zijn moeilijk verteerbaar.

7017. Pohon-mangir J. $=$ Pitecolobium Junghuhni an um Benth., Nat. fam. der Mimose a. Gr. MildenJava 3-5000'; een prachtige boom, met karmozijnroode, groote bloemhoofdjes.

7018. Pohon-0epas M. = Antiaris toxicaria Luesch. (Zie No. 408.) 7019. Pohon-pahit 11. = Actino 
daphne angustifolia Ne es. (Zie No. 5616.$)$

7020. Pohon-palam MrN. = Bar$r$ ingtonia rubra Bl. (Zie No.2962c.)

$70 \approx 1$. Pohon-plebber J. = Viburn um coria cenm Bl. (Zie No. 4318.)

7021bis. Pohon-sikat BD. 二 Albizzia? moluccauna Miq., Nat. fam. der Mimoscæ. Gr. Banda; boorn.

7022. Pohon-tjat $\mathrm{M}$. $=\mathrm{Rhus}$ suc. c edanea l., Nat. fam. A n a cardiex. Gr. Op Java, van Japan overgebracht; boom. Gesr. Deze boom levert het schoone vernis, waarmede de Japarneezen hunne fraaie lakwerken maken.

7023. Pohon-weroe J. $=a$. A lbizzia procera B enth. (Zie No.4448c.) = b. I.itsaa densifolia Miq. (Zie No. 3529).

7024. Pohpohan S. (Zie Pochpochan S.)

7025. Pohsor S. $=$ Peristrophe pallida Nees, Nat. fam. der Acanthac eæ. Gr. Java; éénjarig.

7026. Pohung $\mathrm{S}$. 二 Dichrosta. chys cinerea W. \& A. (Zie No.6793.)

7027. Poko J. = Peperomia javanica Miq., Nat. fam. der Piperac e æ. Gr. Java; overblijvend.

7028. Pokor-koepan AмB. en

7029. Pokor-koepan-wassi Амв. = Talauma Rumphii Bl., Nat.fam. der Magnoli a ceæ. Gr. Amboina; boom, die om de geurige bloemen zeer gezocht is.

7030 Pokroe S. = Strychnos Tieuté Jiesch. (Zie No. 6319)

7031. Pola ADF. Min. 二 Saccharum officinarum L. (Zie No. 62ь\%.)

7032. Polat- of Polot AмB. $=\mathrm{La}$ por tea decumana Wedd. (Zie No. 121.)

7033. Polat-poetih Амв. 二Laportea a mplissima Miq. (Zie No. 121.) 7034. Polei-lalaki Mad. (Zie Poelei-lalaki MaD.)

7035. Polendo-darat $\mathrm{BL} .=\mathrm{Tre}$ vesia moluccana Miq. (Zie No. 78.)

7036. Polendo-lawut BL. = Sc vola Kœnigii Vahl. (Zie No. 1001.)

2037. Polloe $\mathrm{S}=\mathrm{Z}$ ehneria exasperata Miq. (Zie No. 5206.)

7038. Pollong J., M. \& $\mathrm{S}$. $=\mathrm{P}$ isum sativum L. cum variett., Nat. fam. der Papilionaceaæ. Gr. Bijna overal in Indië gekweekt; klimplanten. GEBR. Ook in Indië levert de gewone tuin- of doperwt, een zeer gezochte groente.
7039. Pollong-assoe $\mathrm{S}$. $=\mathrm{L}$ epistemon flavcscens Bl. (Zie No 4636.)

7040. Polomit-sjoe $\mathrm{CH}_{\text {. }}$ Во. $=a$. Artocarpus integrifolia I. (Zie 276.) $=b$. Anona muricata Don. (Zie No. 6078.)

7041. Polong M. = Caryophyl. lus a rom aticus $\mathbf{L}$., (de rijpe viuchten). (Zie No. 1292.)

7042. Polto-polto MaND. $=$ Callicarpa can a L. (Zie No. 2.)

7043. Pompoeloetan S. of

7044. Pompoeroetan J, \& $\mathrm{S} .=a$. Triumfetta Flum. en $=b$. Ureua I. Spec. div., Nat. fam. der Malva. ceæ. GF.BR. Het harde en taaie hout dezer heestertjes gebruikt men om er pennen van te maken, die men door het neusmiddenschot der karbouwen steekt, om deze gemakkelijk in bedwang te kunnen houden. $=c . \mathrm{Melochia} \mathbf{B u r m a n n i}$ Z. \& M., Nat. fam. der Buttneriaceæ. Gr. Java; éénjarig. $=d$. X anthin indic am Rxb. (Zie No. 6056.)

7045. Pompoeroetan-boddas S. = Triumfetta cana Bl. (Zic No. 2593.)

7046. Pompoeroetan-bunjer S. = Sida viscidula B1., Nat. fam. der Malvaceæ. Gr. Java; kleine heester.

7047. Pompoeroetan-burrum s. $=$ Urena heterophylla Sm., Nat. fam. als voren. Gr. Java; éénjarig.

7048. Pompoeroetan-konneng S. $=$ Tri umfet a villosi us ula Bl., Nat. fam. als voren. Gr. Java; eenjarig.

7049. Pompohrang $\mathrm{S}$. $=\mathrm{Cal}$ osanthes indica Bl. (Zie No. 1418.)

7050. Pong J. en

7051. Pong-pahang $\mathrm{J}$ 二 Dichro. stachys cinerea W. \& A. (Zie No. 6793.)

7052. Pongokan $\mathrm{J} .=\mathrm{Henslo-}$ via paniculat a Miq. (Zie No. 803.)

7053. Pontjô-soedô J. = $a$. J a sminum quinquenervium Bl. (Zie No. 1533 ) = Z. Jasminum pubesc ens Wlld., Nat. farn. der Jas m ine GR. Java; klimplant.

7054. Pontjullok J. = Piliostigma acidum Bnth. (Zie No. 3\%4l.)

7055. Popina LAMP. $=$ Ardisia attenuata Scheff. (Zie No. 5475.)

7056. Popoejoet Alf. Min. 二 Ule. na lobata 1.. (Zie No. 5290.)

7057. Pöpoh ALF. Mis. $=\mathrm{Cocos}$ nucifera I. (Zie No. 393.)

7058. Popotjangan $\mathrm{S} .=\mathrm{Psycho-}$ 
tria bantamensis Miq., Nat. fam. der R ub i a c eæ. GR. Java; hcester.

7059. Popotjangan-lawut $\mathrm{S}$. $=\mathrm{Pe}-$ liosanthes javanica Hassk. (Zie No. 2222.)

7060. Poppija-oetan M. $=a$. Momordica subangulata Bl. en $=b$. Trichosanthes trifoliata Bl. (Zie No. 262.)

7061. Porang J. \& S. $=a$. Scævola K ænigii Vahl. (Zie No. 1001.) $=b$. Seævola piliplena Miq. Nat. fam. der Goodenovieæ. Gr. Java; h eester.

7062. Porin BK. = Artocarpus dimorphophylla Miq., Nat. fam. der Artoc a r p ex. Gr. Bangka; boom.

7063. Possi-possi T. $=a$. S o n n eratia acida I. fs. en $=b$. Sonn. a l b a S m. (Zie No. 866 d)

7064. Pottong-koedjang MI. \& S. = a. Desmodium D.C. S pec. perm ult $æ$. $b$. Caten aria 1 a b u r n ifolia Benth., Nat. fam. der P a pilio n a c е. Gr. Java; kleinc hecster.

7064. Pra R. E Elateriosperin u $\mathrm{m}$ 'T a pos B l., Nat. fam. der E u$\mathrm{ph}$ o r b i a c e æ. GR. Java en elders; boom. GeBr. Het hout is fraai on wit, doch word t spoedig door witte mieren aangetast; de vruchten leveren een lampolie, die soms ook bij het eten gcbruikt wordt.

7065. Pradak-poeding R. 二 Gra ptophyllum hortense Nees. (Zie No. 90.)

7066. Pradjitan J. = Crotallaria retus a L (Zie No. 2495.)

7067. Pran J. 二 Dichrocephala panicula.ta Miq. (Zie No. 1093.)

7068. Prapat J. 三 Sonneratia I. f s.

7069. Prapat-darat $\mathrm{B \kappa}$. = Ternstromia coriacea Scheff, (Zie Meiikoh.)

7070. Prapat-ketjil M. = $\mathrm{E} g \mathrm{i}-$ ceras majus G a tn. (Zie No. 1556.)

7071. Prego J. =Elettaria macroce $\mathrm{phal}$ a M iq., Nat. Pam. der $\mathrm{Z}$ ing i b e ra c c æ. Gr. Oost-Java; overblijvend.

7072. Preh $\mathrm{S}$. 三 $a$. Urostigma canaliculat um II iq. en $=b$. Ur. m a crocarp u m II iq., Nat. fam. der
Artocarpex. Gr. Java; hooge boomen. 7073. Prellak S. = 1 iospy pos c a u liflora B l., Nat. fam. der E b en a c e $x$. Gr. Java; boom.

7074. Prending S. $=\mathrm{Hyd} \mathrm{r} \mathrm{oc} 0$. tyle hirta D.C., Nat. fam. der U nlb ell if e ræ. GR. Java; éénjarig.

7075. Pringgat $R_{0}=\mathrm{V}$ itis indica I. (Zie No. 349.)

7076. Pringgi R. $=\mathrm{Cucurbita}$ P e p o I. (Zie No. 5120.)

707\%. Priokra R. $=\mathrm{Nepenthes}$ ph ylla m phor a Wlld. (Zie No. 128.) 7078. Proeatjan $\mathrm{S} .=$ Pi mpinella Pruatjan Molken b. (Zie No. 6984.)

7079. Proet $\mathrm{S}$. $=\alpha$. V a c c in i u m L. Spec. div. $=b$. B a la nophora Forst., Spe c. omnia. Nat. fam. der B a l a n o phor e . Gr. Java. Gebr. Deze met vele wortelknollen bedeelde plantjes zijn rijk aan was, waarom daaruit veelal kaarsen worden vervaardigd.

7080. Proet-bunjieng $\mathrm{S} .=\mathrm{B}$ a la. nophora elongata Bl., Nat. fam. als boven. Gr. Java 6-9000'. GeBr. Als voren.

7081. Proet-kibarerah S. = $\mathrm{Raf}$ flesia Rochussenii T. \& B., Nat. fam. der R afflesia ce æ. Gr. Java; parasiet.

7082. Proet-soesoeän S. = $\mathrm{Brug}$ mans i a Z i p eli i B l., Nat. fi.m. als voren. Gr. Java; parasiet.

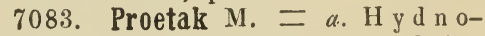
phytum montanum Bl. \& al. Sp. (Zie No. 3018.) = b. M y rmecodia e chin at a G a d. (Zie No. 3018c.)

7084. Prômôsôdô J. = C o r dia s u b c ordata L a m. (Zie No. 1021b.) 7085. Pronodjiwa J. = Euchresta Horsfieldi i Bennct. (Zie No. 4.396d.) 7086. Protak S. = $\mathrm{Pachyccn-}$ tria constricta B I. (Zie No. 2748.) 7087. Pühüng S. 三 Dichrostachys cine rea W. \& $A$. (Zic No. 6793.) 7088. Puntoi S. = Parki a a $\mathrm{fr}$ ic a n a R. B r. (Zie No. 2565)

7089. Pussaar $\mathrm{S}=\mathrm{Art}$ o e a r p us r i gi d a B l. (Zic No. 1454.)

7090. Putir S. = Parkia in ter. medi a ll as sk. (Zie No. 4073.)

7091. Putoi S. = Parkia s pecios a II assk. (Zie No. 67506) 
7092. Raba J. = B rassica Rapa L., Nat. fam. der C ru c i f eræ. Gr. Op Java en elders wordt de raap in sommige tuinen gekweekt en levert zeer smakelijke knollcn.

7093. Rabassa J. $=\mathrm{H} \mathrm{y} \mathrm{d} \mathrm{roco.}$ tyle as iatica L. (Zie No. 70.)

7094. Rabeij $\mathrm{Cr}_{0}=\mathrm{L}_{\mathrm{y}} \mathrm{y}$ o o d i u m c ircin at um Sw. (Zie No. 2792.)

7095. Raboeset $J_{\text {. of }} \mathrm{MAD}_{\mathrm{AD}}=\mathrm{D}$ isemma Horsfieldi Miq., Nat. fam. der Passiflore ce. Gr. Java en Madura; slingerplant.

7096. Raboet-leuta-langam S. = Jasin in um funale DCne., Nat. fam. der $J$ a s in in e æ. Gr. Java en Tirnor; slingerplant. GeBr. Men bezigt de ranken in plaats van touw.

7097. Rabong.rabong Sum. Wк. = E u r y om a longifoli a J a ck. (Zie No. 804.)

7098. Rabna-bakadja I. $=\mathbf{G}$ o m. phren a globosa L. (Zie No. 9.)

7099. Radies $\mathrm{I} .=\mathrm{R}$ a phan u s sativus L., Nat. fam. der Crucifer Gr. Op Java en elders wordt de gewone radijs veelvuldig in tuinen gekweekt; zij komt zeer goed op, doch verbastert spoedig.

7100. Radja $R .=H$ erna ndia sonora L. (Zic No. 16.)

7101. Radja-kajoe M. $=\mathrm{D}$ a m m a ra a l b a $\mathrm{Rm} \mathrm{m}$. (Zie No. 1618.)

7102. Radja (kajoe) R. = Cassia $\mathrm{j}$ a $\mathbf{v}$ a $\mathrm{n}$ i c a L. (Zie No. 1025.)

7103. Radjoen S. $=\mathrm{P}$ a r a i ropia s c a $n$ dens $M$ i q. (Zic No. 4638.)

7104. Radjoen-lalaki S. = L asianthus lucidus 13 l. (Zie No. 3320.)

7105. Radna-poetih $\mathrm{I} .=\mathrm{G} 0 \mathrm{~m}$. phrena globosa L. (Zie No. 9.)

7106: Ràgeh Sum. Wк. $=$ Para. bephelium xestophyllu an Miq. (Zie No. 2445)

7107. Rággi $\mathrm{I} .=\mathrm{I}$ le noc a r p u s frutescens R. Br. (Zie No. 3089b.)

7108. Ragoeloh $\mathrm{I}=\mathrm{Abelmo-}$ schus moschatus Mönch. (Zie No. 2402.)

7109. Ragoeloh-goenong $\mathrm{I} .=\mathrm{N}_{0}$. rysca cill erca B l. Nat. fam. der H y p e r i c in cæ. Gr. Java; heester.
7110. Raij-raij $\mathrm{T}$. $=a$. Achyranthes bidentata B l. (Zie No. 740.) $=b$. Cyathula geniculata Lour. (Zie No. 741.)

7ill. Rakat R. $=\Lambda$ brus prec a t orius L. (Zie No. 53.)

7112. Rak-nassi I. \& M. = Kraknassi $\mathrm{M}$.

71!3. Raman-oetan Sum. $=$ B o u e a diversifolia Miq., Nat. fan. der A n a c a r d i a c e æ. Gr. Lampongs; boom.

7114. Ramanin Вк. (Zie Grien ВK)

7115. Rambak $\mathrm{S}$. = Urostigma glaberrimum Miq. (Zie No. 4351b.)

7116. Rambang I. = Brugui e r a g y $m$ or h i a L a in. (Zie No. 242.)

7117. Rambega Men. $=\mathrm{Ca}$ lot ropis giga nte'a R. Br. (Zic No. 817.)

7118. Rambeh-rambeh $\mathrm{M}$. = D iplacrum caricinum R. Br. Nat. fam. der C y per a c eæ. Gr. Java, Sumatra, Amboina; overblijvend.

7119. Rambei-rimbo Sus. Wk. = Gnetum cuspidatum Bl, Nat. fam. der G n e t a c e æ. Gr. Sumatra; slingerplant.

7120. Rambia $\mathrm{M}$. = M e troxylo n Sa g u R ottb. (Zie No. 1322.)

7121. Ramboeset Mad, zie Raboeset $\mathrm{I}$.

7122. Ramboet-dawon $\mathrm{M} .=O \mathrm{ph}$ i 0 derma pendulum Endl. (Zie No. 3786$.

7123. Ramboet-kaloga M. = Jussi æa repens L. (Zie No. 476.)

7124. Ramboet-poetri M. = C a ssy ta filiformis I. (Zie No 203.)

7125. Ramboeta T. = Bixa Orel. la n a L. (Zie 1697.)

7126. Ramboetan M. \& S. $=\alpha . \mathrm{Ne}$ phelium lappaccum L., met hare menigvuldige verscheidenheden. (Zie No. 6937.)=b$. Nephelinm mutabile B 1 (Zie No. 6758.)

7127. Ramboi-tjong sum. WK. $=$ Microsepala ac nminata Miq. (Zic No. 1083.)

7128. Rameh s. of Rami M. $=a$. B hmcria nivea Gaud. (Zie No. 2387.) $=$ b. L e u k s y k b imensis Z. \& M. Nat. fam. der Urtic a c e Gr. Bima; kleilie heester. $=c$. Maoutia $R$ ugosa Wedd. (Zie No. 6285) $=d$. 
Pouzolzia ovalis Miq. (Zie No. 3826.) = e. corchorus olitorins L. (Zie No. 2042.)

712.9 Rameh-boeloes S. $=\mathrm{B} \propto \mathrm{h}$ meria r ugosissima Miq. Nat. fam. der Ur. ticaceæ. Gr. Java. Sumatra; heester.

7130. Rameh-goenong $\mathrm{S}$. = $\mathrm{B} \propto \mathrm{h}-$ meria nivea Gaud., var. tenac issi ma. (Zie No. 2387.)

7131. Rameh-tjina $\mathrm{M}=$ Corchorus c a psularis 1., (Zie No. 2412.)

7132. Ramis MAK. = Caryota Rumphia na Mart. (Zie No. 331.)

7133. Ramnia R. = Bouea oppositifolia Meisn., Nat. fam. der Anac a r d i a e e. Gk. Riouw, Malakka; boom.

7134. Ramok-daging S. 二 a. Leiocarpus arboreus Bl. (Zie No. 1134.) $=$ b. Kibara coriacea Endl. (Zie No. 884.)

7135. Ramok-daging-lalaki s. = Clerodendrum phyllomega Steud. Nat. fam. der Verbenace r. Gr. Java; heester.

7136. Ramok-gellang S. $=\mathrm{Por}-$ tu la ca oleracea 1. (Zie No. 2479)

7137 Ramok-gilling S. 二 $a$. Para. tropia scandens Miq. (Zie No. 4638.) = b. Paratropia divaricata Miq. Nat. fam. der A raliaceæ. Gr. Java heester. Volgens $\mathrm{H}$ as skarl geeft men het sap nit den stam van vele $\mathrm{Paratropia-}$ soorten aan kinderen te drinken als worm. doodend geneesmiddel. $=c$. P a ratropia long ifolia De. (Zie No. 1972.)

7138. Ramok-giling-huntje $\mathrm{s}$. = Paratropia parasitica Miq. Nat. fam. als voren Gr. Java; hecster.

7139. Ramok.goendi S. 二 a. Paratropia brachybotrya Miq. Nat. fam. en GR. als voren; heester. $=b . \mathrm{Pa}$ ratropia corona-sylva Miq. Nat. fam. enz. als voren. 三 c. Paratropia parasitica Miq. (Zie No. 7138) = d. Paratropia polybutrya Miq., Nat. fam. en Gr. als voren. Z e.Paratropia tomentosa Miq. (Zie No. 6.) 90 .)

7140. Ramôkêkesh I. 三 $\mathrm{F}$ i c u s japenica Bl. Nat. fam. der Artocarpeæ. Gr. Op Java in tuineu, uit Japan overgebracht. GEBR. Men wendt de bladeren uitwendig tegen $\mathrm{Sakitblah}$ (Frambosiæ. der voetzolen) aan.

714l. Rampai R. = Pandanns latifolius Rmph. (Zie No. 1172.)
7142. Rampanei M. = Ardisia humilis Vahl. (Zie No. 4.j286.)

7143. Ramplas MeN. = Ficus semicordata Miq., Nat. fam, der A r t o c a r p e æ. Gr. Noord-Celebes; heester.

7 144. Rampoekassang S. en

7145. Rampoekassang-burrum S. = A nth isthiria ciliata 1. (Zie No. 2126.)

7146. Rampoekassang-leutiek s. = A pluda mutica $J_{1}$, Nat. fam. der Gramines. Gr. Java en de Molukken; grassoort.

7147. Randa-katissan $\mathrm{s}=\mathrm{J} u \mathrm{~s}$ siæa repens L. (Zie No 476.)

7148. Randi S. 二 Solanum nig r u m I.. var. uliginosum. (Zie No. 1660.

7149. Randjeh-Bakoeng $\mathrm{S}$. = Susum anthelminticum Bl. (Zie No. $870 b$.

7150. Randoe J. = Eriodendrum a nfraçtuosum DC. (Zie No. 28.)

7151. Randoe-agong J. = Salmalia nuabarica Sch. \& Fndl. (Zie No. 1639.)

7152. Randoe-allas J. 三 $a$. Salmalia malabarica Sch. \& Endl. (Zie No. 1639.), = b. Cratava magna D C. (Zic No. 1024.)

7153. Randoe-badak J. = Psychotria rhinocerotis $R \mathbf{w d}$. (Zie No. 1690.)

7154. Randoe kapok J. = Erio. dendrum anfractuosum DC. (Zic No. 28.)

7155. Randoe-leuwung S. 二 Salmalia malabarica Sch. \& Findl. (Zie No. ]6:39.)

7156. Raneh J. \& M. 二 I y c o pod i u m L. Sp. d i v e r a. Grbr. Neze plantjes wendt men, fijngewreven. op verwondingen aan.

7157. Raneh-gampang $\mathrm{s}=\mathrm{I}$ y $\mathrm{co-}$ podi um eern u n m L., Nat. fam. der I, y c op od i a c c a. Gr. Java; overblijvend. GEBR. Als voren.

7158. Rangeh $\mathrm{M}=\mathrm{Sen}$ e c a $\mathrm{l}-$ pus heterophylla Bl., Nat. fam. der A nacardiacese. Gr. Java en Sumatra; boom. GErr. Het gebruik der vruchten veroorzaakt zwelling en uitslag.

715 !. Rangetan J. Z $\mathrm{A}$ v a s a $\mathrm{n}$. gu inolent a Bl. (Zie No. 2609.)

7160. Ranggandji Sum. = C in n amom um subcuncatum Miq. (Zie No. 4903.) 
7161. Rang0-rango M. = Orc bi. peda f atida B l. (Zie No. 26966.)

7162. Rangoek $\mathrm{s}$. $=$ Diplocli. ni um repandum Miq. (Zie .No. 27556$.

7163. Kangong $\mathrm{Bk}$. $=$ Nephelium eriopetalum Miq. (Zie No. 1089.)

i164. Rangsadan J. = Lansi um a qu æu m Jack. Zie No. 142.)

7165. Ranjie S. $=$ Dialium in. d a m L. Zie No. 4910.)

i166. Ranteh J. 三 Solanum nigrum L, var. uniflorum. (Zie No. 1660$.

i16\%. Ranteh-peutjang $\mathrm{S} .=\mathrm{R}$ i$v$ in a $p$ urpurascens $\mathrm{S}$ chrd., $\mathrm{Nat}$. fam. der Phytolaccaceæ. Gr. Op Jara in tainen als sierplant; kleine heester.

7165. Rapodjawa Msk. = s.z g. gi um jambolanum DC. (Zie No. 1906.)

i169. Rapo Jak. = Areca Cat e chu L. (Zie No. 1256.)

7170. Rapo-leko Msk: = C havica siriboa Miq. (Zie No. 11\%0.)

i171. Rappoes $\mathrm{Bk}$. $=\mathrm{Samadera}$ indica Gærtn. (Zie No, 2452.)

1172. Rappotsjidoe Mak. 三 Ar. t ocarpus integrifolia L. (Zie No. 276.)

7173. Rara Mak. = Ergthrina ind i c a La m. Zie No. 15866 .)

ilit. Rara-ajam M. = Celosia crist a $\mathrm{t}$ a L. (Zie No. $4 \overline{19}$.)

ilis. Rarak S. = a. Sapindus R a rak DC. (Zie No. 1483.$)=6.0$ to. phora spectabili= Bl. Zie No. $4313 c$.)

ili6. Rarak sus. Wh. = Litho. carpus?angustifnlia Miq. (Zie No. $675 \%$.

i17\%. Raraweha $\mathrm{s} .=a . \mathrm{Mu}$ cu. na prurita Hook. (Zie No. 1699.) $=b$. I! uc una hirsufa W. A Arn., Nat. fam. der Papilio n a c ex. Gr. Java, éénjarig. GLvR. Als No. 1698.

717s. Rareh T. $=$ Adenant bera falcat a L. (Zie No. 3451 .)

7179. Rasak Sir. WK. = Quercus ne urophylla Ml iq.. Nat. fam. der C'upilifer $x$. Gr. Sumatra; hooge boom.

ils0. Rassauw BK. $=\mathrm{Pand}$ an u s he licopus Kurz., Nat. fam. der Pan. d a n e r. Gr. Bangka; boom.

7181. Rassa Sim. Wh. = Quereus
Ras sa If iq., Nat. fam. der Cupulif eræ Gr. Sumatra; hooge boom.

i152. Rassamala S. \& M. = Li. quidambar Altingiana Bl., Nat. fam. der $\mathrm{H}$ a m a melid e $x$. Gr. lieur. Guinea en Jara; zeer hooge boom. Gribr. Het hout ran dezen 140 tot 150 roet hoogen boom is fijn, rast, bruinrood ran kleur, zeer balsamiek van gear en geschikt roor huisbour. Uit de schors rloeit een in de lucht hard wordende hars, Storax, die de Javanen in plaats ran Benzoë gebruiken voor reukwerk, enz.

i183. Rassa-malam Mak. = PoIs anthes tuberosus L. (Zie No. 4190.)

7184. Ratjam-ratjam BL. = $\mathrm{Di}$. ploclininm tuberosum Miq. (Zie No. 1054 .)

7185. Ratjoen-laki AMB. of

7156. Ratjoen-lani AMB. $=\mathrm{S}$ am a. dera ind ica G r r tn. (Zie No. 2452.)

718i. Rad J. $=$ Prosorus indic us Dalz., Nat. fam. der Eaphorb i a c e a. Gr. Karimon, Java; hooge boom.

ils8. Rau M. en

7189. Rauhitoe $M_{A \mathrm{~K}}$. $=\mathrm{Dracon}$. tomelon mangiferum Bl. (Zie No. 1492 ?

i190. Rauparoro T. $=$ Nothopa. nascochleatum Miq. (Zie No. i6.)

719l. Raweh J. $=$ u. Il u c una prurita Hook. (Zie No, 1699) = b. Il edinilla Sp. dirersæ. (Zie No. 6649.)

719!a. Raijana S. $=a$. L a ctuca indi c a L., Nat. fam. der Compo. s i tæ. GR. Java; éénjarig. GeBr. De jonge bladeren worden door sommigen als groente gegeten: het fjjngewrerene kruid legt men op zweren, gezwellen, enz. als weekmakend middel.

6192. Raj̈ana-boddas s. = Son. chus as per Vill. (Zie No. 2030.)

i193. Raj̈ana.burram $\mathrm{s}$. = Sonchus oleraceus L., Nat. fam. der Compositæ. Gr. Java en Sumatra; éénjarig. Gebr. Als No. i191.)

7194. Reboet $\mathrm{Br}_{0}=$ Crinum asiaticum L. (Zie No. 869.)

7195. Reluksa-aroij $S=P i p t u r u s$ re pand u s Wedd. (Zie No. 622.)

7196. Reman Bк. = Symplocos it e ophrlla Miq. (Zie No. 3490.)

7197. Remang S. = Cratox rlum Hornschuchii B 1. (Zie No. 2319.) i198. Remang-poetoen S. = Tri- 
desmis formosa Korth. (Zie No. 4215$.

7199. Remblas S. = Ficus Rem. blas 1 i iq (Zie No. 6805.)

7200. Rempadang Вк. $=10$ ! V a c. cinium baucanum Miq. (Zie No. 4227.) $=20$. V accinium malacc ense Wght. (Zie No. 138.)

7201. Rempoedieng BK. = Pinanga patula Bl.

7202. Rempoedoeng Sum. $=$ Mo. noceras leucobotrya Miq. (Zie No. 5666.$)$

2203. Rendandam Alf. Mis. = Grapt ophyllum hortense Nees., v ar. r ub u m. (Zie No. 90)

6204. Rendang $\mathrm{N}$. $=$ Cariss a C a rand as L. (Zie No. 3860.)

7205. Rendeh Sus. = Bentincki a $R$ endah Mart. (Zie No. 6842.)

i206. Rendeng J. $=\mathrm{Hydroco}_{0}$ tyle hirsut a D.C. (Zie No. 7074 .)

7207. Rendoy J. \& S. = a. Pty. chosperma Kuhlii Miq. (Zie No. 11786.)=6$. Cyrtandra Forst. en $=c$. Ruellia L., plurim\& Speries. Gebr. De jonge bladeren dezer heestertjes worden rauw bij de rijst gegeten.

7208. Rendoe badak S. = C y rt a n. dra glabra Jack., Nat. fam. der Cyrtandrace $x$. Gr. Java en Suma. tra; overblijvend. GEBR. De bladeren en jonge toppen gebruikt men in. en uitwendig tegen rhcumatische stijfheid en opzwellingen der gewrichten.

7209. Rendoe-burrum S. = Ruellia colorata Bl., .Nat, fam. der $\Lambda$ c anthace $x$. Gr Java en de Molukken; overblijvend. Gввr. Even als van andere R uelli a-soorten eet men de jonge bladeren rauw bij de rijst en bezigt ze op gezwellen en tegen betoovering.

7210. Rendoe-lalaki S. = Cyrtandra pendula Bl., Nat, fam. der Cyrt andraceæ. GR. Java; overblijvend.

7211. Rendoe-peutjang S. = Eberull aycra incana Hassk., Nat. fam. der A canthacer. Gr. Java; overblijvend.

7212. Rendoel-ribatan S. \& Sux. = Chasalia I urida Miq. (Zie No. $4506 b$.)

7213. Renghas of Runghas S. $=a$. Glut a lienghas L. (Zie No. 1099.) $=b$. Scmecarpus heterophylla 131. (Zic No. 7159. )

7214. Renghas-balang Iasm. = $13 \mathrm{ll}$ chanamia sessilifolia Bl.,
Nat. fam. der A n a c a rd i a c e Sumatra; hooge boom.

7215. Renghas-boerong M. of

7216. Rengbas-manoek s. 二 $a$. G luta velutina B 1., Nat. fam. der A n a c a r d i a c e æ. Gr. Borneo; boom. 二 b. Buchan a n a a r orescens B 1. (Zie No. 3029.) $=c . \mathrm{Bachana-}$ ni a bancana M i q., Nat. fam. als $a$. Gr. Bangka; boom. $=d . \mathrm{B} n \mathrm{c} \mathrm{h}$ a $\mathrm{n} \mathrm{a} \mathrm{n} \mathrm{i} \mathrm{a}$ l u c i d a B l., Nat. fam. dezelfde. Gr. De Sunda-eilandeu; boom. Gebr. Al deze boomen leveren een fijn, rood en zwaar bouw - en menbelhout, dat echter, wegens de hardheid en het scherpe melksap, moeilijk te verwerken is.

7217. Rengis J. en

7218. Renjoe $\mathrm{S}$. $=\mathrm{Rhodamn} \mathrm{i} \mathrm{a}$ spectabilis B l. (Zie No. 1128.)

7219. Repambong BK. 二 G loc h idion bancanum Miq., Nat. fam. der Euphorbia cex. Gr. Bangka; kleine boom.

7220. Repambong-lawut Be. = G 10 . chidion das y phy llum Miq., Nat. fam. en GR, Als voren.

7221. Repoeloet Bк. 二 Canthium læve T.\& B., Nat. fam. der Rubiaceæ. GR. Bangka; boom.

7222. Resak Bк. = 10. Vatica b a ll cana Scheff. en $=20$. Vatica Schoutcnia Scheff., beide tot de Nat. fam. der Dipteroc a r p e behoorende. GR. Bangka; boomen.

7223. Resôpôh LaMr. = C a $11 \mathrm{i}$ c arpa c a n a I. (Zie No. 2.)

7224. Riang Sum. $=$ Platycen. trum Teysma nian um Miq., Nat. fam. der $B$ ego $\mathrm{n}$ i a c e $x$. Gr. Sumatra; ovcrblijvend.

7225. Riang-riang $\mathrm{BK}$. = P lo i arium elegans Korth. (Zie No.563j.)

7226. Riang-riang MAxD. $=\mathrm{Vitis}$ i n d i c a J.. (Zie No. 349.)

7227. Riang-riang-mani Sum. = 1) i ploclinium atrichum Miq., Nat. fam. der B e g o n i a e a. Gr. Sumatra; overblijvend.

7228. Ribadien $\mathrm{S}$. $=\mathrm{R}$ u b u s a 1 pes $t r$ is 13 l., Nat. fam. der $R$ o s a c e r. Gr. West-Java; heester.

2729. Ribeij (ir $=\mathrm{L}$ y g o d i u m c irci ul a t um T. (Zic No. 2792.)

2730. Ribes J. = Ficus gibbosa B 1. (Zic No. 2979.)

2731. Riboe-riboe $\mathrm{M}=\mathrm{Helm}$ in th os tachys dulcis Kanlf. (Zie No. 6361 . 
7232. Riboe-riboe sum. W.K. = Leucoxylou binxifolium Bl. (Zie No. 43936

7233 Kiboea $\mathrm{Cr}_{\mathrm{r}}$ = Crinum asi. a ticu:n 1.. (Zie No. 869.)

7234; Rig0-rigo-djanten Su.. WK. = Ophiorrhiza quadrifida Miq., Nat. fam. der Rubiaceæ. Gr. Java en Sumatra; orerblijvend.

7235. Rigo-rigo-rimbo Sum. WK. = Strobilanthes Teysmanni Miq., Nat. fam. der A canthacer. Gr. Sunitra; kleine heester.

7236. Ri.in Aмв. = Heleconiopsis amboinensis Miq., (Zie No. 4978.)

7237. Ri-larat J. $=$ Hibiscus surattensis L. (Zie No. 731.)

7238. Rimbam Br. = Bassia long i foli a Lam. (Zie No. 38.)

7239. Rinat Амв. $=$ semecarpus Cassuvium Spr. (Zie No. 1569.)

7240. Rindengan J. = Cardiopteris lobata Wall. (Zie No. 238ác.)

7241. Rindo $\mathrm{S}$. $=\mathrm{Ebermayera}$ e $l$ o ngat a $\mathrm{Miq}$, Nat. fam. der Acantha ceæ. Fr. Java; éénjarig.

7742. Ringan-ringan J. \& M. = a. Flemingia strobilifera R.Br. (Zie No. 265fic.) - b. Dodonæa Waitziana Bl. (Zie No 3223f.)

7243. Ringging SrM. WK. $=\mathrm{C}$ a s. sia timorensis DC. (Zie No. 2762b.)

7244. Rinoe $\mathrm{S}$. $=\mathrm{Cubeba}$ officinalis M iq. (Zie No, 3702.)

7245. Rinoe-leuwung $\mathrm{S}$. $=\mathrm{M}$ แdera recurva Miq., Nat. fam. der P i peracex. Gr. Jara; klimplant.

7246. Rinoe-Manoek S. = $a . \mathrm{M}_{11} \mathrm{l}$. dera baccata Miq. (Zie No. 548. = b. Piper arborescens Rxb. (Zie No 288.) =c. Piper acre Bl., Nat. fam. der Pi peraceæ. GR. Java; klimplant.

7247. Rintjik-rintjik $\mathrm{R}$. $=\mathrm{H}$ о у a lacunosa Bl. (Zie No. 1790.)

7248. Rioed of Rioen AMB. $=\mathrm{He}$ liconiopsis amboinensis $\mathrm{Miq}$ (Zie No. 4978 .)

7249. Risisir $\mathrm{I}=\mathrm{Berberis}$ a siatica Rxb., Nat. fam. der Berberidere GR Java; heester.

7250. Rita MAK. en

7251. Rite Амв. = Alstonia scho. laris R. Br. (Zie No. 2350.)

7252. Roaaij $\mathrm{S}$. $=$ Phaseolus lunatus I. (Zie No. 3955.)

7253. Roe R. = Casuarina equi- setifolia Forst. (Zie No. 122.)

7254. Roekem II. \& S, 二 a. Fla. courtia Comm. Species diversa. $=$ b. Scolopia rhinanthera Benn. (Zie No. 966.)

7255. Roekem-assem M. \& S. Flacourtia sapida Roxb. (Zie No.4933b.)

7256. Roekem-kembang $\mathrm{MI}$ = Sco. lopia rhinanthera Benn. (Zie No. 966.)

7257 Roekem-lawut Sum. Wk. = Phoberos maritima Miq. Nat. fam. der Bix a ce æ. Gr. Sumatra, boom.

7258. Roekem-manis $\mathrm{M}=a . \mathrm{Fla}$. courtia cataphacta Rxb. (Fl. Rukam Z. \& M. Zie No. 41 . $)=b$. Flacourtia inermis Rxb. Nat. fam der Bixaceæ. Gr. Sumatra en de Molukken; boom.

7259. Roekempoetih $\mathrm{PAI}_{\mathrm{A}}=\mathrm{Pho-}$ beros Roxburghii B enn. Nat fam. als voren. GR. Sumatra; heester.

7260. Roekem-sepat M. = Flacourtia Jangomas Gmel. (Zie No. 3670$.

7261. Roekoe Mak. 二 $a$. Cyperus rotundus I. (Zie No. 5298.) $=b$ Orthopogon Burmanni R. Br. (Zie No. 2031.)

7262. Roekoe-roekoe M. 三 a. Ocinu u gratis simum I. (Zie No. 1458b.) $=b$. Ocimum sanctum L. (Zie No. 875.)

7263. Roekoe-teker M. = Ele o. $c$ haris $t u b e r o s a ~ S c h u l t$. Nat fam. der C y per a c eæ. GR. Duor bijna geheel Indie; grassoort. GrBR. De knollen worden door rele inlanders gekookt gegeten; een aftreksel er ran geeft men bij koorts te drinken.

7264. Roekoem S. = sphæro c a rya moschifera Bl. Nat. fam. der S a ntal a c e r. Gr. Java en Su. matra; boom.

7365. Roemah semoet M. = $a$. Hydnophytnm formicarum Jack. (Zie No. 3018c) $=b$. M y rmecodia $\mathrm{t} u$ berosa J a c k. Nat. fam. der R u-

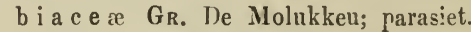

7266. Roemboeta S. = All o phyl. lus sundanus Miq. (Zie No 1965 )

7267. Roemoet Ачв. $=0$ phioglossum pendulum Endl. (Zie No. 17896.)

7268. Roemoet Br. $=U$ rostigma balicum Miq. (Zie No. 1430). 
7269. Roempoet of Rompot M., zie Djoekoet S. onkruid.

7270. Roempoet-assap. M. = E ragrostis plumosa I,k. (Zie No. $2187 b$.)

7271. Roempoet-bedara Sum. Wк. = Brachys japonica Wght. (Zie No. 4307.)

7272. Roempoet-bengala $M$. 三 Paspalum mollicomum Kunth. Nat. fam. der Gramine 2 . Gr. Op Java gekweekt. Geßr. Dit van Manilla ingevcerde gras is eell zeer goed voeder voor paarden.

7273 Roemboet-boeloe-babi .11. = Fimbristylis polytrichoides $\mathrm{N}$ e es. (Zie No 2989)

7274. Roemboet-boeloe-mata M. 二 $\mathrm{S}$ pinife $\mathrm{x}$ s quarrosus L. (Zie No. 2140.)

7275. Roempoet-boewang $\mathrm{M}$. = Com in elyna benghalensis $L$. (Zie No. 2549.)

7276. Roempoet-djinten $\mathrm{H}$. (Zie No. 7273.)

7277. Roempoet-emboen M. $=\mathrm{An}$ dropogon pertusus Wlld. (Zie No. $2133 d$.)

7278. Roempoet-grientiengan 11 . = Cynodon dactijlon Pers (Zie No. 2133.)

7279. Roempoet-kakarendengan M. Anthisthiria ciliat a L. (Zie No. 2126.)

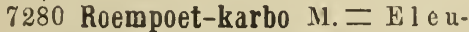
s in e ind i c a G ær tr. (Zie No. 1961.) 7281. Roempoet-kassan M. (Zie No. 7279.)

7282. Roempoet-koeda M. = $\mathrm{Or}$ thopogon Burmanni R. Br. (Zie No. 2031.j

17283. Roempoet-koekoeboelo S. of 7284. Roempoet-koekoehoelang M. = Limnophila villosa Bl. (Zie No. 1088.)

7285. Roempoet-krah BK. = $a$. Eriocaulon longifolinm Nees., Nat. fam. der G r a mi n e æ. Gr. Bangka en Sumatra, grassoort. $=6 . \mathrm{V}$ a n d ellia st emodioides Miq., Nat. fam. der S croph u l a rin ex. Gr. Bangka; éćnjarig.

7286 Roempoet-kras N. (Zie No. 7380 .)

7287. Roempoet-lawit M. = S t i pa littorea Burro. Nat. fam. der framin e $r$. Gr. Java; grassoort.
7288. Roempoet-lidah-koetjing Вк. 二Conyza riparia Bl. (Zie No. 236.)

7289. Roempoet-malela $\mathrm{M}$. $=\mathrm{P}$ a. " i c u m lim u u $\mathrm{m} \mathrm{S}$ t e u d. Nat.fam. der Gram i nex. Gr. Java; grassoort.

7290. Roempoet-mani-mani M. = Coix agrestis Itour. (Zie No. 42.)

6291. Roempoet-oedang-oedang $M$

$=$ D i ploclin i u m o m by cin $n \mathrm{~m}$ Bl. Nat. fam. der B e g o u i a c e æ. GR Java en Sumatra; overblijvend. GEBR. De inlanders op Sumatra bezigen dit kruid om hunne krissen van roest te zuiveren.

7292. Roempoet-oetan $\mathrm{M}$. $=\mathrm{F} \mathrm{im}$ bristylis miliacea Vahl. (Zie No. 2173.)

7293. Roempoet-pakkêt I. = A rgy reia molli s Chois. (Zie No. 597.)

7294. Roempoet-palias $\mathrm{I}$. $=\mathrm{Pen}$ n isetum holeoides R. \& Seh., Nat. fam. der Gramine r. GR Door geheel Indië; grassoort.

7295. Roempoet-ploomboen J. $=$ I s ch m u m barbatum Retz., Nat. fam. als voren. Gr. Java: grassoort.

7296. Roempoet-poetri $\mathrm{H}$. 三 C a ssy ta filifor in is L. (Zie No. 203.)

7297. Roempoet-salingsin M. $=a$ Lepironia enodis Miq. en = b. L e p. su nu atran a M i q., Nat. fam. der Cy per a c e $æ$. Gr. Sumatra; overblijvend.

7298. Roempoet-sariboe-ajer M. = Ulva javanica DC., Nat. fam.der U l v a c e æ. Gr. Java; wiersoort.

7299. Roempoet-sereh $\mathrm{H}$. $=\alpha$ Eleusine coracona Grtn. (Zie No. 1892.) $=$ b. Androp og on Schœn anthus L. (Zie No 2523.)

7300. Roempoet-seret J. $=\mathrm{Ga}_{\mathrm{a}}$ livm innocu u M Miq. (Zie No. 4383.)

7301. Roempoet-takki S. $=$ Kyl. lingia fuscata Miq, Nat. fam. der Cyper a ceæ. Gr. Java.

7302. Roempoet-tali-sait $\mathrm{R} .=\mathrm{C} y$ anotis axillaris R. \& S. Nat. fam. der Commclyneæ. Gr. Jara, Sumatra; enz. kruipende plant

7303. Roempoet-tuwan-Schill M. = Turllera ulinifolia I., Nat. fam. der Turneraceac. Gr. Op Java en elders als sierplant in tuinen, thans geheel verwilderd; kleine heester.

7304. Roempoet-walang-genni $\mathrm{J}$. = Polygonum tomentosum Wlld., 
Nat. fam. der Poly gonea. Gr. Java; kleine heester.

7305. Roena Br. $=\mathrm{A} \mathrm{b} \mathrm{roma}$ fast u o s a R. Br. (Zie No. 4096)

7306. Roendoe S. (Zic Rendoe S. en $\mathbf{E}$ bermayer $\mathrm{div}$ c r s

7307. Roepong BD. Sponia a mbo inens is D e csn. (Zie No. 4724.)

7308. Roeremoe $T$. en

7309. Roeroen Axв. = H e ritiera

littoralis Dryand. (Zic No. 752.)

7310. Roeroe-teker M. \& MaK. = El e och aris tuberosa Sehult. (Zic No. 7263.)

7311. Roeroekoe S. 三 $a .0 \mathrm{c} \mathrm{i} \mathrm{m} \mathrm{u} \mathrm{m}$ sanctum I. (Zie No. 875.) $=b$. Te ucrium viseidum Bl., Nat. fam. der $\mathrm{L}$ a b i a $t$ æ. Gr. Java en Timor; éénjarig.

7312. Roeroh N. G. $=\mathrm{Cocos}$ n $n$ e if era I. (Zie No. 393.)

7313. Roessimal N. G. = Rassamala $M$.

7314. Roessoe-laijn Cr. = Soph or a tomentosa I. (Zie No. 1490.)

7315. Roetjaga T. en

7316. Roetjaga-goffo T. $=\alpha . \mathrm{Bi}$ dens peduncularis Gaud. en $=b$. B. Wallichii D C. (Zie No. 68.)

7317. Roetoe-maun Амв. $=\mathrm{J}$ ambosa aquæa Rmph. (Zie No. 1914.)

7318. Roetoe-roetoe Men. $=\mathrm{No}_{0}$ thopanax fruticosum Miq. (Zie No. 1153.)

7319 Roetoe-roetoe-kajoe M. = Ly copodium phlegmaria I. (Zie No. 4493 .)

6320. Roetoen Азв.,

7321. Roetoen-laijn Aмв.,

7322. Roetoen-moela AмB. en

7323. Roetoen-oar Амв. alle 二

Jambosa domestica Rmph cum v ariett. (Zie No 1922.)

7324. Roetoen-tjapë0 Амв. $=\mathrm{J}$ ambosa aquiea Rmph. (Zie No. 1914.)

7325. Rogare $\mathrm{MAK}_{\mathrm{A}}$ 三 Guilandina Bonduc L. (Zic No. 1475.)

7326. Rogodjampi S. = Solan um a troanthum l) un., Nat. fam. der $\mathrm{S}$ o. l a neæ. Gr. Java; heester.

7327. Rohpot Вк. = Pterostigma capitatum Benth., Nat. fam. der Scrophularinex. Gr. Bangka; éénjarig.

7328. Roekonang LAMP. $=R$ ott. lera rhynchophylla Miq. (Zie No. 3390.)
7329. Rombia $\|_{\mathrm{AK}}$. en

7330. Romiho Bn. = Metroxylon $\mathrm{Sagns} R \mathrm{ttb}$. (Zic No. 1322.)

7331. Romo J. = Lactuca indic a

L var. macrothyrsa (Zie No. 7191.)

7332. Rondong $J .=$ Suffrenia dichotoma Miq., Nat. fam. der Ly. thrarieæ. Gr. Java en Timor; kleine heester.

7333. Rong R. = Garcinia Cam. bogia Desrouss. (Zie No. 733.)

7334. Rongget $\mathrm{S}$. $=$ Elettaria alba Bl. et al. Spec. Nat. fam. der Zingiberace æ. Gr. Java, Celebes; overblijvend.

7335. Ropal-deda J. $=$ Dischidia punctata Decsul, Nat. fam. der As. c le p i a d e æ. Gr. Java; klimplant.

7336. Ropanang Isur. = Cocco. ceras sumatranum Miq., Nat. fam. der Euphorbiac cæ. Gr. Sumatra; boom.

7337. Rordko T. $=a$. Parkinsonia acnleata L. (Zie No. 3254.) = b. Diphaca cochinchinehinensis Lour., Nat. fam. der Papilionace Gr. De Molnkken; boom. Gebr. Men geeft een aftrcksel der bladeren tegen beri-beri en framboesire (Anıbonsche pokken) te drinken.

7338. Roro Tid. = Cæsalpinia Sappan I. (Zic No. 1807.)

7339. Rosmarijn-ambon M. $=\mathrm{He}$. dyotis crateogonum Spreng., Nat. fam. der R ubiacex. Gr. Java en de Molakken; éénjarig.

7340. Rosso-djagoh $\mathrm{PAL}_{\mathrm{A}}=\mathrm{Nephe}$ lium eriopetalum Miq. (Zie No No. 1089.)

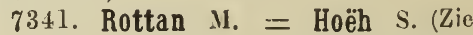
No. 2534 en volgg, de algemeene benaming voor elke rottan-soort.)

7342. Rottan-ajer M. = Calamus littoralis Bl. Nat. farn. der Pal un GB. Java ; klimplant.

7343. Fottan-alëa $\mathrm{M}_{0}=a$. Cal a mus g ram inosu s Bl., Nat. fam. als voren Gr. Amboina; klimplant. Gebr. Deze rottan bezigt men voor allerlei vlechten bindwerk; haar sap zal den haargroei bevorderen. $=b$. Ceratolobus rudentum Isour. (Zie No. 2857.)

7344. Rottan-assam M. = Dæmo. norops barbatus Mart. Nat. fam. als voren. Gr. Celebes en de Molnkken; klimplant. Gér. De vruchten worden op Nieuw-Gninen tot sieraden anneengeregen; 
op Celebes eet men de. zure vruchten bij wijze van tamarinde.

7345. Rottan-batoe M. = C a lam us l)iepenhorstii II iq., Nat. fam. als voren. Gr. Sumatra; klimplant.

7346. Rottan-boeboet M. = J) æmonorops Rumphi Mart. (Zie No. 6198.$)$

7347. Rottan-boeloe M. $=a$. $\mathrm{D} x \mathrm{mon}$ orops strictus Bl. (Zie No. 6201.) 二 b. C a l a mus? pisic a r u s B l. (Zie No, 6200b.)

7348. Rottan-boengkoes $\mathbf{M}$. $=1$ æmonorops trichorus Miq., Nat. fam. als voren. Gr. Sumatra; klimplant.

7349. Rottan-dahan M. 二 $a . \mathrm{K}$ ort. halsia debilis B l. en $=6 . \mathrm{Kor}$ thalsia flagellaris Miq., Nat. fam. der P a l m æ. Gk. Sumatra; klimplanten.

7350. Rottan-dini Bк. = Bromheadia Finlarsonian $\mathrm{Lind}$. (Zie No. 2852.)

7351. Rottan-djerenang $\mathbf{M}=\mathrm{D}$ æmonorops Draco M art. (Zie No. 2046.)

7352. Rottan-djerenang-kejil M. = Calamus subangulatus Miq. Nat. fam. der P a l m æ. Gr. Snmatra; klimplant.

7353. Rottan-gelag M. $=\mathrm{Cala-}$ $\mathrm{mus}$ h or e n s B l. Nat. fam. als boven. Gr. Java, bij Batavia; klimplant.

7354. Rottan-glatiek Sum. 二 $\mathrm{Ca-}$ la $\mathrm{m}$ us fasciculatus $\mathrm{R}$ oxb. Nat. fam. dezelfde; GR. Sumatra; klimplant.

7355. Rottan-goenong $\mathrm{M}$. = $\mathrm{Cal}$ a$\mathrm{m}$ us exilis G riff. Nat. fam. Gr. als voren.

7356. Rottan-hitam M. 二 a. I) æmonorops melanochætes Bl. (Zie No. $286 \mathrm{l} c$.) $=$ b. $\mathrm{D}$ æm o n o rops n i g e B l. (Zie No. 6204b.)

7357. Rottan-jamoerangan Sum. = Ca la m us stoloniferus T.\& B. Nat. fam. als voren. GR. Sumatra; klimplant.

7358. Rottan-jawa M. = $\mathrm{C}$ a lamus viminalis Rwdt. (Zie No. $2848 c$.)

7359. Rottan-kalang-sintang PAL. 二 D monorops hirsutus Bl. Nat. fam. als voren. Gr. Sumatra; klimplant.

7360. Rottan-kalapa M. = D æmouorops cala p parius Bl. (Zie Na. 6197.)
7361. Rottan-karokrok M. = $\mathrm{C}$ alam us micranthus B l. Nat. fam. der P a lmæ. GR. Java en Sumatra; klimplant.

7362. Rottan-kawa M. 二 $\alpha$. C a la$\mathrm{m}$ us $\mathrm{C}$ aw a B l. Nat. fam. als voren. Gr. De Molukken; klimplant. GEBR. Deze soort is zeer geschikt voor vlechtwerk. $=b$. Calamus e questris W 11 d. (Zie No. 2804.)

7363. Rottan-kikier $\mathrm{BK},=\mathrm{Cal}$ a. m us Oxley a n s T. \& B. Nat. fan . dezelfde. Gr. Bangka; klimplant.

7364 Rottan-kikier Sum. = C a lam us trichrous Miq. Nat. fam. dezelfde. Gr. Sumatra, klimplant.

7365. Rottan-korro S. $-\mathrm{C}$ a l a mus het e roideus Bl. (Zie No. 2845.)

7366. Rottan-korwaër I. 三 $\mathrm{Fla-}$ gellaria indica L. (Zie No. 135.) 7367. Rottan-kroh BK. = Flagellaria minor B l. (Zie No. 6180.)

7368. Rottan-landak PAL. $=\mathrm{D}$ æ. monorops periacanthus $\mathrm{Miq}$. Nat. fam. als voren. GR. Sumatra; klimplant.

7369. Rottan-latong M. = $\mathrm{C} \mathrm{a} \mathrm{la-}$ m u s c r s i u s B l. (Zie No. 2868.)

7370. Rottang-lellang PAL. $=\mathrm{D}$ monorops palembanicas Bl. Nat. fam. als voren. Gr. Sumatra; klim. plant. GEBR. Deze rottan is zeer gezocht voor wandelstokken en ook geschikt voor bind. en vlechtwerk.

7371. Rottan-leumeus S. $=a . \mathrm{Ca}$. lamus asperimus Bl. (Zie No. 2851.) $=$ b. Calamus melanolo m a M a r. (Zie No. 2850b.)

7372. Rottan-lilien M. = $\mathrm{Cala}$ m us calole pis $M$ i q. Nat. fam. der $\mathrm{P}$ a $1 \mathrm{~m}$ æ. Gr. Java; klimplant.

7373. Rottan-loeloes S. (Zie No. 7371$.

7374. Rottan-mantje Bk. en

7375. Rottan-marouw Bк. 二 Fla. g e l l a ri a m in o $\mathrm{r}$ B l. (Zie No.6180.)

7376. Rottan-njappa M. 二 Ceratolobus glaucescens Bl. (Zie No. 2855.)

7377. Rottan-oedang $\mathrm{PAL}_{\mathrm{A}}$ - $=\mathrm{D} x-$ monorous periacanthus Miq. (Zie No. 7368.)

7378. Rottan-oelet Sum. $=\mathrm{C}_{\text {a }}$ la $\mathrm{m}$ us $\mathrm{rhom}$ boide us B l. (Zie No. 2859.)

7379. Rottan-oerei-djanang Sus. 二 C a l a m u c æsius Bl. (Zie No.2868.) 
7380. Rottan-0etan M. $=\mathrm{Flag}$ e lla ria indic a L. (Zie No. 135.)

7381. Rottan-ohat Bo. Zo. = Cala mus marginatus Mart. Nat. fam. der P a l mæ. Gr. Borneo; klimplant.

7382. Rottan-pella S. = $\mathrm{D} \approx \mathrm{m} 0-$ norops oblongus M art. (Zie No. 2839.)

7383. Rottan-poetih M. = Cal amus rudentum Iour. (Zie No. 2857.)

7384. Rottan-sabote M. $=\mathrm{D}$ æ $\mathrm{mo-}$ norops Hystrix Mart. (Zie No. 6679.)

738 . Rottan-salak M. $=\mathrm{Z}$ a l a cc a e dulis $\mathrm{R} w \mathrm{~d}$ t., Nat. fam. der P a l$\mathrm{m}$ æ. Gr. Java, Bali, de Molukken; lage palmsoort. GeBr. Deze Palm wordt om zijne sterkriekende, aangenaam zuur en samentrekkend smakende vruchten veelvuldig aangeplant; deze worden rauw, gepekeld en gestoofd gegeten, zijn moeilijk verteerbaar, en zullen, volgens $\mathrm{H}$ a s s k a r l, de teeldriften anzetten. Ook de top van den stam of hoemoet wordt rauw en gekookt gegeten en tegen kiespijn aangewend. Uit de oude stammen vervaardigt men weverskammen. De oude bladeren gebruikt men tot het dekken van huizen en tot het inpakiken van zwarte- of arensuiker.

7386. Rottan-sampej J. = K orthalsia Junghuhni Miq., Nat. fam. dezelfde. Gr. Java; klimplant.

7387. Rottan-segah M. = Calamus heteroideus Bl. var. (Zie No. 2845.)

7388. Rottan-segah-banioe Sum. = Ca l a m us m i ranthus B l. (Zie No. 7361.)

7389. Kottan-selang S. = D $\approx \mathrm{m}$ onorops palembanicus Bl. (Zie No. 7370.)

7390. Rottan-sikeij Sur. = $a . \mathrm{C}$ al a mus depressiusculus T. \& B. en $=\dot{b}$. Dæmonorops longipes MI q., beide van de Nat. fam. der P a l$\mathrm{m}$ æ. Gr. Sumatra; klimplanten.

7391. Rottan-simote M. = Kort- h a lsi a scapigera M a r., Nat. fam. dezelfde. Gr. Oost-Indië; klimplant.

7392. Rottan-tapah Sur. = C a l amus m a n ic atus T. \& B., Nat. fam. als voren. Gr. Java en Sumatra; klimplant.

7393. Rottan-teboe M. = $a$. $\mathrm{D}$ æmonorops niger Bl. (Zie No. $6204 b.)=b$. Dæmonorops melan o c hæt e s B l. (Zie No. 2\$61 6 .)

7394. Rottan-tjatjieng $\mathrm{M}$. $=\mathrm{C}$ a$\mathrm{l}$ a m u s javen s is B l. (Zie No. 2854b.) 7395. Rottan-tjetjeret $\mathrm{J} .=\mathrm{C}$ a 1 amus Reinwardii M a r t. (Zie No. 2841.)

7396. Rottan-toem-dawor-besar M. $=a$. Calamus? pisicarpus B l. (Zie No. 6200b.) $=\mathrm{D} x \mathrm{monorops}$ st $x$ ictus Bl. (Zie No. 620l.)

7397. Rottan-toeni M. = D æ m onor o p s R u m p h i i B l. (Zie No. 6198.)

7398. Rottan-tsjavoni M. = C a l am u s e q u estris Wlld.(Zie No. 2804.) 7399. Rottan-waij-orij Амв. (Zie No. 7394.)

7400. Rottan-wanitette Mor. $=a$. $\mathrm{C}$ a $]$ a m u s buroëns is M a t., Nat. fam. der P a lmæ. Gr. De Molukken; klimplant. Gribr. Deze rottan is zeer geschikt voor alle bind- en vlechtwerk. = b. Calamus viminalis $R$ wd t. (Zie No. 2848c.)

7401. Rourita TrD. $=$ Alphiton i a moluccana T. \& B., Nat. fam. der Rh a mnex. Gr. De Molukken; heester.

7402. Roweh Mak. $=$ Moring a pterygosperma Grtn. (Zie No. 4125.)

7403. Ruha $\mathrm{Cr}_{\mathrm{r}}=\mathrm{M}$ e l a nol epis calcos a Miq. (Zie No. 37.)

7304. Rungang $\mathrm{S} .=\mathrm{M}$ e $\mathrm{m}$ e c $\mathrm{y}-$ lon tinctori u $\mathrm{K}$ o e n, Nat. fam. der M e l a s t o m a c ex. Gr. Java; heester. 7305. Rungkeng J. = \& a siol epis Bennettii Planch. (Zie No. 4239.)

7306. Ruün Аґв, en

7307. Ruün-moela Aмrв. $=\mathrm{J}$ a mbos a domestica Rmph. (Zie No. 1922.) 
7408. Saaij S. $=$ Brous s o n e t. i a papyrifera Vent. (Zie No. 1861.)

7409. SaärS. $=\mathrm{S}$ o r g h u m fulv u m P. B e a u v., Nat. fam. der Gram i n e æ. Gr. Java, Timor, de Molukken; éénjarig.

7410. Saauw of Sauw M. 二 $a \mathrm{Mi}$ musops Ka uki I. (Zie No. 1497.) =6. Mimusops Ma nilkara Don., Nat. fam. der S a pot a c e . Gr. Op Java in tuinen; boom. Gebr. als $a$.

7411. Saauw-manila M. $=\mathrm{S}$ a $\mathrm{p}$ ot a A chras L. (Zie No. 1496.)

7412. Saba-saba T. $=$ Trevesia moluccana M i q. (Zie No. 78.)

7413. Sabbeh $\mathrm{S} .=\mathrm{C}$ a n a $\mathrm{L}$., Spec.plurim $x$.

7414. Sabe Br. = Pis o n i a a l b a S p a n. (Zie No. 1206.)

74.15. Saboer-nekkoer Ахв. 二 C о-

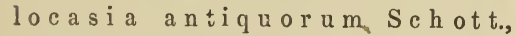
va r. (Zie No. 245.)

7416. Sadab R. $=R$ u t a g r a $\nabla$ e o1 en s L. (Zie No. 3030.)

7417. Sadang S. \& J. = a. Pholi do c a r pus Jhar Bl. (Zie No. 2995.) 二 b. I.icuala peltata Roxb., Nat. fam. der P a l m æ. GR. Oost-Indië;

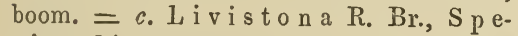
e i es divers e.

7418. Sadangan S.二Livis tonæ d i v e r s .

7419. Sadingin $\mathrm{R} .=\mathrm{K}$ a l a $\mathrm{nchoe}$ la c in i a t a DC. (Zie No. 46.)

7420. Sadjeng J. \& S. 三 Livistona rotundifolia Mart. (Zie No. 5็ 026.$)$

7421. Saga Sum. WK. 二 Lithoc arpus? angustifolia Miq. (Zie No. 6757.)

7422. Saga M. \& S. $=\mathrm{Ablus}$ p r x a torius I. (Zie No. 53.)

7423. Saga-aroij S. als voren.

7424. Saga-kajoe M. = A de n a nther a pavonina L. (Zie No. 52.)

7425. Saga-0etan BK. Als voren.

7426. Saga-pohon Ml. $a$ a. Als voren. $=$ b. Pongamia? corollaria M i q. (Zie No. 60.)

74.27. Saga-toentong J. $=\mathrm{A} \mathrm{brus}$ precatoris L. (Zie No. 53.)
7428. Sagar J. (Zagar J.) = Beil. sch miedia lancifolia Miq., Nat. fam. der L a u rin e æ. Gr. Java; boom.

7429. Sage-mane J. = Fre y cinetia $G$ a id icha udii R. Br. \& B enn., Nat. fam. der $\mathrm{P}$ a nd an e . Gr. Oost-Java; klimplant.

7430. Sagoe M. $=M$ etroxyl on $R$ o t tb., S pecies diversæ.

7431. Sigoe-dengkol $\mathrm{BK}$. $=\mathrm{Ma-}$ crotropis? bancana Miq., Nat. fam. der P a pil i o n a c eæ. Gr. Bangka.

7432. Sagoe-doeri-rottan M.二M etroxylon micracanth um Mart. (Zie No. 5267.)

7433, Sagoe-ihoer M. $=$ Metroxylon sylvestre Mart. (Zie No. 5266$.

7434. Sagoe-makanaroe Амв. = $\mathrm{M}$ еtroxylon long is pinum Mart. (Zie No. 5268.)

7435. Sagoe-molat Амв. $=\mathrm{Me-}$ troxylon Sagus Rottb. (Zie No. 1322.)

7436. Sagoe-oetan M. $=M$ e troxylon filare Mart. (Zie No. 1320.)

7437. Sagoe-papeda M. en

7438. Sagoe-parampoean M. $=\mathrm{M}$ etroxylon Sagus Rottb. (Zie No. 1322.)

7439. Sagoe-rottan M.二 M e t roxylon filare Mart. (Zje No. 1320.)

7440. Sagoe-toeni $M .=M$ etroxylon Rumphi Mart. (Zie No. 279.)

7341. Saha-saha T. (Zie Saba-saba T.)

7442. Sahit-metten $A$ мв. = Uva$r$ i a a rge nte a B 1. (Zie No. 573.)

7443. Sehoe J. $=$ Guil and in a B ond uc L. (Zie No. 1475.)

7444. Sahoe Amb. $=\mathrm{D}$ i os corea ac ule a ta $L$. (Zie No. 1189.)

4745. Sahoe-nakkoer Aur. (Zie Saboer-nekkoer Амв.)

7446. Saihe-maroeani $\mathrm{Cr}$. $=\mathrm{Sm}$ ilax zeylanica L. (Zie No. 71\%.)

7447. Sai-se-sjoe Cн. Bo. $=M$ a ng i fer a ind ic a L. (Zie No. 275.)

7448. Saja-baki T. $=$ Gra m mato phyllum scriptum B l. (Zie No. 365.) 
7449. Saja-kananga T. = C a n a n a od or at a $\mathrm{H}$ ook. fs. \& Th. (Zie No. 1373.)

7450. Saja-kotele $\mathrm{T} .=\mathrm{C}$ lit or i a t er na te a L. (Zie No. 1359.)

7451. Saja-mamj. T. $=\mathrm{P}$ avet $\mathrm{ta}$ a $\mathrm{mboinic}$ a Bl. (Zie No. 101.)

745\%. Saja-manoeri T. $=\mathrm{J}$ a s m i. n $u \mathrm{~m} \mathrm{~S}$ a $\mathrm{mb}$ a c L. (Zie No. 920.)

7453. Saja-marra $\mathrm{T}$. $=\mathrm{C}$ as sia a $l$ a t a L. (Zie No. 1740.)

7454. Saja.ngalli-ngalli $\mathrm{T}$. $=\mathrm{Hi}$ b i s cus m utabil is L. (Zie No. 1358.) 475̌. Saja-ngawan T. (Zie Sajabaki T.)

47j6. Saja-tjina $\mathrm{T} .=\mathrm{C} æ \mathrm{~s}$ a l p inia pulcherrim a Sw. (Zie No. 1386.)

7457. Sajor II. (GROENTE of TOESPIJS.) $=a$. Amarantus tristis $L$. en $=b . \mathrm{Euxolus}$ polygam us Moq. $\mathrm{T}$ and. (Zit No. 836.)

7458. Sajor-ajam $\mathrm{M} .=a \cdot \mathrm{C}$ a ssia Sophora $L$. en $=b$. Cassia Tor a L. (Zie No. 736.)

7459. Sajor-bábi II. = a. Colocasia? humilis Hassk. (Zie No. 427.) $=$ b. Pouzolziaglomerata $\mathrm{H}$ a s sk. (Zie No. 6388c.) $=c$. Ve rnonia cinerea Less. (Zie No. 67.) $=d$. Bigelovia ocymoides Miq., Nat. fam. der R u bi a c e æ. Gr. Java en Bangka; éénjaris.

7460. Sajor-bandan II. $=$ Coloc asia? humilis Hassk. (Zie No. 4.26.)

7461. Sajor-bengala-ketjil M. = Alternanthera sessilis R.Br. (Zie No. 1791.)

7462. Sajor-bintor M. = E 110 b ocarpus oleraceus Kaulf., Nat. fam. der Poly pod i a c e æ. Gr. O-Ind.

7463. Sajor.boeloe-ketjil M. 二 C o m$\mathrm{m}$ e lin a be $\mathrm{ngh}$ a $\mathrm{l}$ en $\mathrm{s}$ is $\mathrm{L}$. (Zie No. 2549.)

7464. Sajor-gebe MoL. = Gos s ypium vitifolium Lam. (Zie No. 3784$.

7465. Sajor-kajoe $\mathrm{II}=\mathrm{Agaricus}$ $\mathrm{S}$ a jor kajoe Tr., Nat. fam. der $\mathrm{H} y$ menomycetes. Gr. De Molukken; Champignon.

7466. Sajor-kalapa M. $=\mathrm{C} \mathrm{y} \mathrm{c} \mathrm{a} \mathrm{s}$ c ir cin a 1 is L. (Zie No. 2105.)

7467. Sajor-kambing M. = Premna c or y mbos a R ot tl. (Zie No. 395.)

7468. Sajor-kangkoeng M. 三 I po. m $\propto$ a reptans Poir. (Zie No. 526.)

7469. Sajor-karang $\mathrm{M}$. $=\mathrm{Sph}$. rococcus lichenoides A g.. var. te nu is A g. (Zic No. 20.)

7470. Sajor-koddak J. = A triplex lit oralis $\bar{I}$. (Zie No. 265.)

7471. Sajor-kodokh J. = $a$. U lv a j a ra nica Dll. (Zie No. 7298.) $=b$. Ellobocarpus oleraceus Kaulf. (Zie No. 7462.) $=c$. Ceratopteris thalictroides Brongn. (Zie No. 6501 b.)

7472. Sajor-lilin Mev. 二 S a c ch ar u in ed ul e Hassk. (Zie No. 2998.)

7473. Sajor-lomba M. $=\mathrm{P}$ ot ho. morphe subpeltat a Miq. (Zie No. 86.)

7474. Sajor-mamma M. 三 $a$. G y na ndropsis penta phylla DC. en $=b$. Polanisia $\mathrm{viscosa}$ DC. (Zie No. 1287.)

7475. Sajor-manis M. $=\mathrm{Hel} \mathrm{m}$ in. thostachys dulcis Ka $u^{\prime} \mathrm{f}$. (Zie No. 6361.)

7476. Sajor-moeka-manis $\mathrm{M}$. = Emilia sonchifolia DC. (Zie No. 2221.)

2477. Sajor-morsego M. = Trichosanthes trifoliata Bl. (Zie No. $262 b$.)

7478. Sajor-noeno Амв. = Fic u s Altime ral o o Roxb. (Zie No. 1362.)

7479. Sajor-0edang II. = Alternanth era sessilis R.Br. (Zie No. 1791.)

7480. Sajor-pakoe M. $=\mathrm{Di} p \mathrm{la}-$ zi u m malabaricum $\mathrm{S}$ pr. (Zie No. 1028. GeBr. Het jonge loof is, gekookt als groente en bij wijze van salade toebereid, zeer gezucht, ook door Europeanen.

7481. Sajor-pangajoe $\mathrm{II}_{\mathrm{O}}=\mathrm{O} \mathrm{ph}$ iogloss um ovatum Bl. (Zie No. 1797.)

7482. Sajor-panoe M. = Jus uiæa a n g ustifolia La m. (Zie No. 1767.)

7483. Sajor-pépé-dawon-besar M. $=\quad M a r s d e n i a n g u s t i f o l i a$ Wight. (Zie No. 6360.)

7484. Sajor-pêpé-dawon-ketjil M. = B i d ara tingens Desn. (Zie No. $6360 z$.

7485. Sajor-poetih MI. $=a$. A g a. ricus Sajor kajoe Tr. (Zie No. 7465.) $=$ b. P isonia alba S pan. (Zie No 120b.)

7486. Sajur-poppia M. $=a$. M o. mordica subangulata Bl. en = 
b. Trichosanthes trifoliata B l. (Zie No. 262.)

7487. Sajor-radja $\mathrm{M} .=\mathrm{C}$ y c s c i r c in a lis I. (Zie No. 2105.)

7488. Sajor-selar J. $=$ Bryo $\mathrm{n} \mathrm{i} \mathrm{a}$ la c in i o a L. (Zie No. 6416.)

7489. Sajor-songa M. = Wollasto $\mathrm{n}$ i a moluccana DC. (Zie No. 315b.)

7490. Sajor-telor-ikan M, en

7491. Sajor-troeboe M. 三 S a ccharum edule $\mathrm{H}$ as s. (Zie No. 2998.)

7492. Sajor-wassa $\mathrm{Aмв.}=\mathrm{Fi}$. cus Wa ss a Roxb. (Zie No. 2597.)

7493. Saka-rambajan Sum. WK. $\mathrm{Viscum}$ articulatum B urm. (Zie No. 3õ0e.)

7494. Sakandal M. $=$ Cordia M y a I. (Zie No. 117.)

7495. Sakelan $\mathrm{CR}_{\text {. }}=\mathrm{M}$ ela le u c a I, e u c a de $n d r o n$ L. (Zie No. 120.)

7496. Saketa ALF. MIN. $=$ J a tropha Curcas L. (Zie No. 913.)

7497. Saketa $T$. $==$ A le u rites triloba Forst. (Zie No. 312.)

7498. Sakka Амв. = Covelli a his pi a Mi q. (Zie No. 1255.)

7499. Sak-njong-pha Сн, Bo. = Pardanthus chinensis Ker. (Zie No. 238.)

7500. Sakoepoe-rimbo S.rm. WK. $=\mathrm{Chirita}$ glabra Miq. Nat. fam. der Cyrtandrace æ. Gr. Sumatra; éénjarig.

7501. Sak-sak BI。 $=\alpha$. Wo l lastonia moluccana DC. en $=6$. Wollastonia strigulos a DC. (Zie No. 31 ๖.)

7502. Sakti R. $=\mathrm{Nasturtium}$ i n d i cum DC. (Zie No. 2175.)

7ь03. Sala Aмв. $=\mathrm{B} \propto \mathrm{h}$ meria interruta W 11 d. (Zie No. 1701.) 7504. Sala PaL. = Eurya $r$ irens Bl. (Zie No. 3283.)

750 5. Sala-balitsjaga $\mathrm{T} .=\mathrm{H}$ i b i s. c us mutabilis L. (Zie No. 1358.)

7506. Sala-lakoe $\mathrm{M}$. $=\mathrm{C}$ is us q u a drang u laris L. (Zie No. 275lb.)

7507. Sala-moelia Aмв. = Cor. dia subcordata Lam. Zie No. 1021b.)

7508. Sale-Sala Mak. $=$ B r u u iera Rumphi i B l. (Zic No. 866b.)

7509. Salada J. $=$ L a c tuca s a$\mathrm{t}$ i v a L. (Zie No 5628.)

7510. Salai Aмв. = Astronia papetaria B l. (Zie No. 412.)
7511, Salak il. $=\mathrm{Z}$ a $\mathrm{I}$ a c c a e d uli s Bl. (Zie No. 7385.)

75 12. Salak-rimbo M. 二 $\mathrm{Z} \mathrm{a} \mathrm{l} \mathrm{a} \mathrm{c} \mathrm{c} \mathrm{a.}$ W a l l i c hia n a M a t. (Zie Mo 5070.)

7513. Salakkal of Salakkar Aмв. 二 $\mathrm{Cinnamom} \mathrm{um} \mathrm{Gulilaban}$ $\mathrm{N}$ e e s. (Zie No. 2287.)

7514. Salam J. \& $\mathrm{M}$, 二 $\mathrm{Euge}$ ni a luc id u la Miq., Nat. fam. der M. y r tace æ. Gr. Java; boom. Gebr. De bladeren worden als specerij gebruikt in plaats der laurierbladeren.

7515. Salam-andjing $\mathrm{M}$. $=\mathrm{J}$ a $\mathrm{m}$ bo s a saligna M i q., Nat. fam, als voren. Gr. Java; boom. Gebr. Het roode, grove en zware hout gebruikt men voor huisbouw en rijststampers.

7516. Salam-badak S. 二 Sy z ygi um nodosum Miq., Nat. fam. als boven. Gr. Java en Sumatra; boom.

7517. Salam-garo $\mathrm{T}$. $=\mathrm{Hi} \mathrm{b}$ iscus surattensis L. (Zie No. 731.)

75 18. Salamang J. 二 Syzygi u m s u b d e currens M i q., Nat. fam. der M y rtace æ. Gr. Java; boom.

75 19. Salassie M. \& S. (Zie later bij Selassie S.)

7520. Salattan BD. = L a portea d e c u m a $n$ a W e d d. (Zie No. 121.)

7521. Salawat $\mathrm{J} .=\mathrm{O}$ i m um s a n c um L. (Zie No. 87 ь.)

7522. Salea $C_{R}$. $=P$ a n $\mathrm{g}$ n m e di l e $R$ w d t., (Zie No. 387.)

75 23. Saleh MoL. $=$ Co ix L a c ym a L. (Zie No. 1894.)

7524. Saleh-oetan MoI $=\mathrm{C}_{0}$ ix a grest is Lo ur. (Zie No. 42.)

7525. Saleit Br. $=\mathrm{Ptych}$ os perma vestiaria Miq.. Nat. fam. der P a l m æ. Gr. Boeroe; boom. Gebr. Van de bastvezels weven de inlanders een grove soort van kleedjes.

7526. Salekong M. $=$ A crostichum a u r i u $\mathrm{m}$ pr. Nat. fam. der P o ly p o d i a c e $x$. Gr. Oost-Indië; overblijvend.

7527. Salempat S. 二 $a$. Colocasia humilis $\mathrm{Hassk}$. var. (Zie No. 426.) $=b$. S ch is m a toglot t is rupestris Zoll., Nat. fam. der A roide æ. Gr, Java; overblijvend.

7528. Salempat toolis $\mathrm{S}$. $=\alpha$. S chis m a toglot is picta T.\&B., Nat. fam. en Gr. als voren. 二 $b_{0} . \mathrm{Cl}_{0}$ locasia humilis $H_{\text {ass }}$, var. p icta. (Zie No. 426.) 
75229. Salier S. = A cronychia la urifolia Bl. (Zie No. 1798.)

7530. Saligi J. $=\mathrm{Li}$ iston a ro tund ifolia Mlart. (Zie No. 5502b.)

7531. Salim s. $=a \cdot \mathrm{Aglaja}$ I o u r.. Species diversæ. $=$. A moora aphanamixis R, \& Sch. (Zie No. 4466.)

7532. Salim-lalaki S. = A g l a y a spe c i os a Bl., Nat. fam. der M eli ac e .. Gr. Java; heester.

9533. Salimoeri T. $=\mathrm{C}_{\text {o }} \mathrm{rdi}$ a s u b c o rdat a L a m. (Zie No. 102lb.)

7534. Salioe Сн. Bо. $=\mathrm{Punic} \mathrm{a}$ Granatum L. (Zie No. 1608.)

7535. Salisoe Aмr. $=\mathrm{Ph}$ anera? $\mathrm{l}$ ing ua $\mathrm{M}$ iq. (Zie No. 1750.)

7536. Salo 'T. en

7537. Salo-baboda $\mathrm{T} .=\mathrm{D}$ a $\mathrm{m} \mathrm{m}$ a $\mathrm{ra}$ a l b a $\mathrm{R} \mathrm{mph}$. (Zie No. 1618.)

7538. Salo-garo $\mathrm{T}$. $=\mathrm{Hope}$ se lan ic a $R$ oxb. (Zie No. 824.)

7539. Salo-kokloé S. $=\mathrm{C}$ an arium rostratum Zipp. (Zie No. 1619.)

7540. Saloe Amb. $=$ Dioscorea a c ül e a t a L. (Zie No. 1189.)

7541. Salöea Амв. $=\mathrm{D}$ en drolo. bi um umbellatum W. \& A. (Zie No. 1683.)

7542. Saloempang $\mathrm{S}$. $=$ Scin. dapsus pothoides Miq., Nat. fam. der Orontiac ex. Gr. Java; klim. plant.

7543. Saloeng-saloeng BK. = Psychotria gendarussefolia Bl. (Zie No. $4506 c$ c)

7544. Saloengeri $\mathrm{T}$. $=\mathrm{C}$ ord i a subcordata $\mathrm{L}$ am. (Zie No. 1021b)

7545. Saloengi-poetih LAMP. = Gr r t nera Junghuhni ana Miq., Nat. fam. der L o g a ni a c e . Gr. Sumatra; heester.

7546. Salonjowo J. $=\mathrm{H}$ y r ta $\mathrm{n}$ a ndra pentandra Miq. (Zie No. 6321.)

7547. Salor $\mathrm{S} .=\mathrm{Flacourtia}$ Ruk a m Z. \& M. (Zie No. 415.)

7548. Samak of Samak Bu. $=S \mathrm{y}$ zygium variifolium Miq., Nat. fam. der M y t a ce æ. Gr. Bangka; hooge boom.

7549. Samal of Samar Amb. en

7550. Samal-batoe AмB. $=B l$ a c kwelli a f ctida Wall. (Zie No. 2779.)

7 šl. Samang $B k_{0}=U$ varia purp u re a Bl. (Zie No. 573.)
7552. Samangi J. $=\mathrm{Hydroco-}$ tyle latis e cta $\mathrm{Z}$ oll.. Nat. fam.der $\mathrm{U} \mathrm{m}$ b ell if e ræ. Gr. Java; éénjarig.

7553. Samangi-goenong $J_{0}=a$. $\mathrm{Hydrocotyle} \mathrm{Zollingeri} \mathrm{Mlkbr}$. (Zie No. 3644.) $=b$. Desmodium m i crophyllum D C., Nat. fam. der $\mathrm{P}$ a pil o n a c e $x$. Gr. Java; heester.

7554. Samangka of Semangka J. \& M. = Citrullus edulis Spach. (Zie No. 1059.)

7555. Samar Pax. = S yzy gi u m pale mba n i cum Miq. (Zie No.6184.)

7556. Sambal of SambeI J.二A g a ti $\mathrm{grand}$ if lor a D e s v. (Zie No. 3135.)

7557. Sambang-tjollok J. = $\mathrm{Hyr}$ tanandra pentandra Miq. (Zie No. 6321.)

7558. Sambaroeka BD. $=a$. Wollastonia moluccana DC. en 二 b. Wollostrigulos a D C. (Zie No. 315.)

7ร59. Sambeng J. 三 Colocasia humilis Hassk. (Zie No. 426.)

7560. Sambi Br. $=\mathrm{Schleich}$ era trijuga Wlld. (Zie No. 47.)

7561. Sambinoer Bтт. $=\mathrm{D}$ a cryd i u m J unghuhn i M iq. (Zie No. 3064b.)

7562. Sambodja J. $=$ P l u meria a cu tifolia Poir. (Zie No. 1367.)

7563. Samboeta J. $=$ Dille nia s peciosa Th n b. (Zie No. 61.)

7564. Samboeta $\mathrm{MAK}_{\mathrm{A}}$. 二 $\mathrm{Exc} \propto-$ c a ria A galloch a L. (Zie No. 22.)

7565. Sambong BL. $=\mathrm{Sc}$ in d a $\mathrm{p}$. sus pertusus Schott. (Zie No. 54.92.)

7566. Sambông-toelang BL. $=\mathrm{C}$ issus repens Lam. (Zie No. 438.)

7567. Sameh M. $=\mathrm{M}$ a p a $\mathrm{T}$ anaria Spreng. (Zie No. 2294b.)

7568. Sami Br. = Livistona rotund ifolia Mart. (Zie No. $5502 b$.)

7569. Saminta $\mathrm{S} .=\mathrm{T}$ e tran th er a a mara $\mathrm{N}$ e es. (Zie No. 2896.)

7570. Samirin $\mathrm{Cr}$. = $a . \mathrm{N}$ o thopanax? Anisum Miq. (Zie No. 389.) $=6$. Z anthoxylum armat u m lioxb. (Zic No. 3692c.)

7571. Sam-kok-kwa CH. Bo. = P so. phocarpus tetragonolobus DC. (Zie No. 1546.)

7572. Samoän BL. $=a$. Di o s c orea Kleiniana Knntb. en $=b$. Dioscorea pentaphylla I. (Zie No. 5.) 
7573. Samparantoe J. $=\alpha$. M y rsine avenis A. D. C. (Zie No.4235.) $=b$. Mylsine affinis A. D. C., Nat. fam. der M y rsine æ. Gr. Java; heester.

7574. Samparantoe Sux. = $\mathrm{S}$ indora sumatrana Mi q., Nat. fam. der Papilion a ceæ. Gr. Sumatra; hooge boom.

7575. Sampio S. 二 $a$. Ty phonium Re inwardtian um de Vr. en Mi q., Nat. fam. der A roi de æ. Gr. Java; waterplant; overblijvend. $=6$. Lasia heterophylla sehott, Nat. fam. der Aroideæ. Gr. Java; overblijvend. Gebr. Van de vele $\mathrm{L}$ as i asoorten eet men de bladeren, nadat ze afgekookt zijn, bij de rijst; fijngewreven bezigt men ze uitwendig tegen buikpijn.

7576. Sampie-gedeh $\mathrm{S}$. $=\mathrm{L}$ a si a M e rkusii H a s sk., Nat. fam. en Gr. als voren.

7577. Sampie-leutiek S. 二 L a sia a cule at a L o ur., Nat. fam. en Gr. als voren.

7578. Sampie-hitam S. = Cryptocoryna spiralis Fisch., Nat. fam. als voren. Gk. Java en Sumatra; waterplant.

7579. Sampohra S. $=\mathrm{Coln} \mathrm{m} \mathrm{bia}$ ja va n i a B l. (Zie No. $2284 c$.)

7580. Sana Tr. $=\mathrm{P}$ tero c a p u s ind i c u s Wlld. (Zie No. 18.)

7581. Sandoedoe Sum. Wr. $=$ Me. las toma 'Teysmanni Miq., Nat. fam. der M ela s tom a ce æ. Gr. Sumatra; heester.

7582. Sandori M. $=\mathrm{Sand}$ or icum indicu $\mathrm{m} \mathrm{C}$ a v. (Zie No. 113.)

7583. Sangahap Cr. Bo. $=\mathrm{M}$ e l a stoma polyanthum Bl. (Zie No. 110.)

7584. Sanga-boeana $S_{.}=\alpha . P$ a r atropia divaricata Miq. (Zie No. 71376.) $=$ b. Paratropia long i. foli a D. C. (Zie No. 1972.) =c. $\mathrm{Pa}$ ratropia rigida D. C. (Zie No. 3493.) $=d$. Paratropia toment os a Mi q. (Zie No. 6590.)

7585. Sanga-langhit $\mathrm{S} .=\mathrm{C}$ a s s y ta filif or m is L. (Zie No. 203.)

7586. Sangal Bo. Zo. $=\mathrm{Hopea}$ S angal Korth. (Zie No. 6153.)

7587. Sanggar $J_{0}=\mathrm{M} \mathrm{y} \mathrm{r} \mathrm{istic} \mathrm{a}$ gl a bra Bl. (Zie No. 3623.)

7588. Sanghar J. $=$ Eranthemum acuminatissim um Miq.,
Nat. fam. Cer A c a n th a c e æ. GR. Java; kleine heester.

7589. Sangi Cel. $=$ Dillenia s e r r a t a D C. (Zie No, 102.)

7590. Sangiet Sum. WK. = C la use na sumatrana W. \& A., Nat. fam. der A urantia ce æ. Gr. Sumatra; heester.

7591. Sangke Sux. WK. $=\mathrm{Ad} \mathrm{e-}$ lia nereifolia $W \mathrm{ght}$ t. \& var. (Zie No. 22076.)

7592. Sangkei-allas PaL. $=\mathrm{V}$ angueria palembanica Miq. (Zie No. 3215 .)

7593. Sangket $\mathrm{S}$. $=\mathrm{T}$ е и $\mathrm{crium}$ viscidu m Bl. (Zie No. 73116.)

7594. Sangket-rambat $\mathrm{S}$. = A c r oe e phalus capitat as Bnth. (Zie No. 1.)

7595. Sangketan S. $=$ Plectra nthus javanicus Benth., Nat. fam. der L a b i a t $æ$. GR. Java; overblijvend.

7596. Sangkir Sun. WK. (Zie No. 7591.)

7597. Sangklappa $R$. $=\mathrm{G}$ a r d en i a florid a L. (Zie No. $4158 b$.

7598. Sangowaij ALF. Mrs. $=\mathrm{Me}$ dinill a celebira Bl., Nat. fam. der $\mathrm{Il}$ el a st o m a c æ. Gr. Celebes; heester.

7599. Sanienten $=\mathrm{C}$ a st a n e a a $\mathrm{r}$ ge n t e a Bl., Nat. fam. der C up uli. f'e $r$ æ. Gr. Java; hooge boom. Gr.br. Het witte, grove en harde hout bezigt men voor huisbouw, het is zeer sterk. De zaden worden rauw, gekookt en geroosterd gegeten even als onze kastanjes.

7600. Sanka S. $=$ T e tran the r a a mara Nees, var. (Zie No. 2896.)

760l. Sanko-hidong M. $=a . \mathrm{A} \mathrm{c} \mathrm{h} \mathrm{y-}$ ranthes bident at a B l. var. (Zie No. 740.) $=b$. C y a th ula geniculat a L o ur. (Zie No. 741.)

7602. Sanoekoe-woeboe S. $=$ Pilea o re ophila M i q. (Zie No. 6916b.)

7603. Santen M. \& S. $=P$ a vetta L. Spec. plurimæ. (Zie later bij Sokka S.)

7604. San-tiau-sjoe Cr. Bo. = C a psic um a n nu u L. (Zie No. 5500.) 7605. Santoe MI. $=\mathrm{Rhodole} \mathrm{ia}$ T eysmanni Miq. (Zie No. 3206.)

7606. Santoel M. of

7607. Santoor Mak, \& T. $=\mathrm{S}$ a $n$ doricum indicum Cav. (Zie No. 11\%.)

7608. Saöen Амв. = $\mathrm{P}$ a n danus 
Ceram i cus $\mathrm{Rm} p$ h. (Zic No. 1828.) 7609. Saoentjoen S. = P a n i c u m paln æ f o li um Koen. (Zie No. 1754.)

7610. Satan-mienjakh M. $=\mathrm{Ta}$. b e rn x mon $t$ ana te n i flor a M i q., Nat. fam. der A p o с y n e $æ$. Gr. Sumatra; heester.

7611. Saöwa N.G. = Metroxy. lon fil a re II a r. (Zie No. 1320.)

7612. Sapa Mak. $=\mathrm{C}$ æs a lp in i a S a p p a n l. (Zie No. 1807.)

76 13. Sapanon S. $=0 \mathrm{ph}$ ior hiza filistipula Miq., Nat. fam. der $R$ u bi a c e $æ$. Gr. Java; kleine heester.

7614. Sapat $\mathrm{BK}$. 三 J a m b os a tenu i cusp is Mi q., Nat. fam. der My rt a c e æ. Gr. Java en Bangka; boom.

7615. Sapeh-gadang Sus. WK. 三 MI ppa Diepenhorstii Miq., Nat. fam. der Euphorbia ce . Gr. Sumatra; hooge boom.

7616. Sapeh-lajang-lajang Sum. WK. = $a$. Mappa? h yoleuca Z. \& 11., Nat. fam. als voren. Gr. Sumatra; hooge boom. $=6$. M a p a p ruinos a MI iq. (Zie No. 5688.)

7617. Sapeh-0ebar Sur. WK. en

7618. Sapeh-oedang Sus. WK. = M a p pa Tanaria Sprg. (Zie No. 22946.)

7619. Sapi M. $=\mathrm{Podocarpus}$ e uryncha Mi q., Nat. fam. der $\mathrm{P}$ od o c a r p e æ. Gr. Sumatra; boom.

7620. Sapi S. $=a$. Gordonia excels a Bl. (Zie No. 2531.) $=b$. Myristica la u rina Bl. (Zie No. 29. 16.$)$

7621. Sapi-toengoel M. $=\mathrm{Ch}$ irita humilis Miq., Nat. fam. der Cy rtandra ce $æ$. Gr. Sumatra; kleine heester.

7622. Sapiri MaK. $=$ A le urites trilo b a Fors't. (Zie No. 312.)

7623. Sapoenega S. $=$ Go mphos. temm a javanicum Bnth. (Zie No. 36436.)

7624. Sappar Aмв. $=$ C o m mersonia echinata Forst. (Zie No. 106.)

7625. Sarabang J. $=\mathrm{P}$ ou zolzi ovalis Mi q. (Zie No. 3826b.)

7626. Sarabboeng J. $=\mathrm{R}$ a $\mathrm{n} \mathrm{u} \mathrm{n}-$ c ul u s diffusus DC. (Zie No. 344c.)

7627. Sarabrassa MAK. $=\mathrm{A} n$ on a reticulat a L. (Zie No. 1489.)

7628. Saradraö BL. $=$ M a n g ifera utana Ham. (Zie No. 5721c.)
7629. Sarakaden $J .=S$ an icula mo n tan a $\mathrm{Rwdt}$., var. (Zie No. 2245.)

7630. Sarangan J. en

7631. Sarang-boerong $\mathrm{J}_{0}=\mathrm{C}$ a st a ne a a ge n tea B l. (Zie No 7599.)

7632. Sarapsap-sirih ALF. Mr. = Fic us Rie deli i T. \& B., Nat. fam. der A r t o c a r p ex. Gr. Celebes; boom.

7633. Sarawang M. $=0 \mathrm{c} \mathrm{i} \mathrm{m} \mathrm{u} \mathrm{m}$ s an ctum L. (Zie No. 875.)

7634. Sarengseng $\mathrm{J} .=\mathrm{P}$ a n d anus caricosus $\mathrm{Rmph}$. (Zie No. 2767.)

7635. Sarengseng-besar $J_{0}=P_{\text {a n}}$ dan us microcarpus Ku r., Nat. fam. der Pa n d a n e æ. GR. Java; boomachtig.

7636. Sargar J. $=\mathrm{W}$ i s s a d u la ze yla n ic a Me di k. (Zie No. 909c.)

7637. Sari-bollong $\mathrm{J}_{0}=\mathrm{Mel}$ ale uca Le ucade ndron L., fruct u s. (Zie No. 120.)

7638. Sari-gading $J_{0}=N_{y}$ c t a $n$ thes arbor tristis L., Nat. fam. der J a s m i n e æ. Gr. Op Java en elders in tuinen, waar deze sierlijke heester wordt aangekweekt, en om zijne geurige bloemen zeer gezocht is.

7639. Sariboe M. $=\mathrm{Li}$ iston a rotundifolia Mart. (Zie No. 5502b.)

7640. Sarila-halat Aurв. $=\mathrm{N}_{0}-$ thopanax fruticos um Miq. (Zie No. 1153.)

7641. Sario-sit J. $=\mathrm{A} \mathrm{c}$ a c i a F a rnesian a Wlld. (Zie No. 2041.)

7642. Sarisoe Алв. = Salisoe $А м$.

7643. Sarodja $\mathrm{R} .=\mathrm{N}$ e l u m bi u m specios um IT ild. (Zie No. 6712.)

7644. Saroenie M. (ook Seroenie M.) $=a$. Pyrethrum DC. en $=$ b. Wollastonia DC. Species dive rs æ. Gebr. Van deze planten, die men gewoonlijk als sierplanter bij de woningen vindt, wordt een aftreksel der bloemen door velen in plaats : van Kamillethee gedronken. $=c . A \mathrm{~A} \mathrm{al} \mathrm{y} \mathrm{p} \mathrm{a}$ ind i c a L. (Zie No. 7652.) = d. A c aly pha hispida B rm. (Zie No. 2174.) $=e$. Fleurya cymosa Hassk., Nat. fam. der U r t i c a c e æ. GR, Java; éénjarig.

7645. Saroenie-ajer M. $=a . \mathrm{W}_{0} \mathrm{l}$. lastonia moluceana DC. (Zie No. 315.) $=b$. We delia c a lendula ce a Less., Nat. fam. der Comp os it æ. Gr. Java; éénjarig. = c. P y- 
x i pom a polyandrum Fenzl. (Zie No. 24826.)

7646. Saroeni-ajer-ketjil $\mathrm{M} .=$ $\mathrm{L}$ u d wigi a p e re $\mathrm{n}$ is L., Nat. fam. der O u agrarie re. Gr. Java; éénjarig.

7647. Saroenie-goenong $\mathrm{M} .=\mathrm{W}$ ollastonia DC. S pec. div.

7645. Saroenie-hollanda M. 二 Pyrethrum ind i c u $\mathrm{Cass}$. (Zie No. 4183.)

7649. Saroenie-lawut $M .=\alpha$. Wollastonia as perrima Decsn., Nat. fam. der Co m p o s i ær. Gr. Java; éénjarig. $=6 . \mathrm{Cl}$ e rode $\mathrm{ndr} \mathrm{rm}$ iner$\mathrm{me} \mathrm{G} \propto \mathrm{rtn}$. (Zie No. 1243.)

7650. Saroenie-tjina M. 二 W o llastonia moluc can a DC. (Zie No. 315$.

7651. Saroet M. $=\mathrm{B} \propto \mathrm{hmeria}$ clide $\mathrm{m}$ i o ide s $M 1 \mathrm{i}$. (Zie No. 2587.)

7652. Saroi M. 三 Acaly pha ind i c a L., Nat. fam. der Euphor bi aс е æ. Gr. Jara, Timor; heester.

7653. Saroi S. of Sarraij S. - $a$. A reca pumila Mart., varr. (Zie No. 27136.) $=6$. Wa 11 i chia porphyrocarpa M a rt. (Zie No. 4456.) =c. Caryota furfuracea B l. (Zie No. 2489.) $=d$. C aryota propinqua Bl. (Zie No. 3760.) $=e$. Caryota sobolifera IV all., Nat. fam. der P a $1 \mathrm{~m}$ æ. Gr. Van de Molukken naar Java overgebracht; boom.

7654. Sasak BK. $=\mathrm{Hopea} \mathrm{fagi-}$ foli a M iq. (Zie No. 4075.)

7655. Sasakke-sehij Cr. = Flindersia a mboine $\mathrm{ms}$ is DC. (Zie No. 3209.)

7656. Sasawi II. = $\mathrm{S}$ in a $\mathrm{p}$ is a 1 b a L., Nat. fam. der Cruc if er r. Gr. Op Jara en elders wordt de witte mustaard veelvuldig als groente in tuinen gekweekt.

7657. Sasawi-leuwung s. = Gynandropsis pentaphylla DC. (Zie No. 1287.)

7658. Sasawi-0etan M. = C a r da. mine $t r$ ifoliata L., Nat. fam. der C r u c if e r. Gr. Java; éénjarig.

7659. Sasawi-oetan-sabrang T. $=$ Gynandropsis speciosa DC. (Zie No. 5̌677.)

7660. Sasawi-poetih II. (Zie No. 7656$.

7661. Sasoeroe BL. = G l ut a B e n g h a s L. (Zie No. 1099.)
7662. Sassa S. $=$ Tetractinost ig m a microcaly $\mathrm{x}$ Has s., Nat. fam. der E u p h o b i a c æ. Gr. Java; boom.

7663. Sassa-bener S. $=\alpha$. L e i ocarpus arboreus Bl. (Zie No. 1134.) $=$ b. Leiocarpus frutic os us B l. (Zie No. 2029)

7664. Sassa-lumboet S. $=\alpha$. L e iocarpus fruticosus Bl. (Zie No. (2029.) $=$ b. A g y n i a b c c if or. $\mathrm{m}$ i s A. J u s s., Nat. fam. der F u p h o rb i a c e æ. Gr. Java; kleine heester.

7665. Sassea Mol. $=\mathrm{Evodia}$ la $\mathrm{t}$ if oli a DC. (Zie No. 36.)

7666. Sassoerroe Алв. $=\mathrm{H}$ e dera $\mathrm{u} \mathrm{m} \mathrm{bellifera} \mathrm{DC.,} \mathrm{Nat.} \mathrm{fam.} \mathrm{A} \mathrm{ra-}$ li a c e æ. Gr. Amboina; heester; die volgens $\mathrm{Rumphius}$ een geurige harssoort oplevert.

7667. Sassôerroe-oetan BL. $=\mathrm{Cer}$ be ra O do l l a m H a m. (Zie No.1181.)

7668. Sasulen Ame. $=\mathrm{Cyatha}$ a r b o rea W 11 d. (Zie No. 2659.)

7669. Satore $\mathrm{Cr}$. $=\mathrm{Ent}$ a d a $\mathrm{P}$ u rs $x$ th a DC. (Zie No. 482.)

7670. Sattoel M. $=\mathrm{Sand}$ oric u m in d i $\mathrm{c} \mathrm{m}$ Cav. (Zie No. 113.)

7671. Sattoeloo $\mathrm{MAK}_{\mathrm{A}}$. 二 S a n d oric. in d i u m C a v. (Zie No. 113.)

7672. Sauchun S. $=\mathrm{Pan}$ ic um p a l m æ f o li u m Koen. (Zie No. 1754.) 三 6. Pani c um nepalense Sprg., Nat. fam. der Gramineæ. Gr. Java; grassoort.

$7672 a$. Sauchun-beurriet S. = Centotheca lappacea Desv., Nat. fam. als voren; grassoort, een goed voeder voor beesten.

7673. Sauchun-goenong $\mathrm{S}$. 三 $\mathrm{Pa}$ nicum nepalense S prg. (Zie N'o. 7672b.)

7674. Saüng $\mathrm{S}$. 三 Fre y c in e t i a gr a $m$ in e B l., Nat. fam. der P a nd a n e æ. Gr. Java; klimplant.

7675. Saüng-riengang $\mathrm{s}$. $=\mathrm{F}$ r e $\mathrm{s}$ cinetia stenophylla K ur z., Nat. fam. en $G_{R}$. Als voren.

76\%6. Saüng-riengang-leutiek S. = Chloöpsis caulescens Bl., Nat. fam. der M e la n tha c e æ. Gr. Java; éénjarig.

7677. Sawakkal Amв. 二 A ga ric us Djamor'Tt.. Nit. fam. der $\mathrm{H} \mathrm{y}$. menom y cetes. Gr. De Molukkell; Zwamsoort.

7678. Sawala S. = Li cuala spec- 
ta bil is $\mathbf{M}$ i q., Nat. fam. der $\mathrm{P}$ a $1 \mathrm{~m}$ æ GR. Java; boom.

7679. Sawan $\mathrm{T}$. $=\mathrm{Pang} \mathrm{i} \mathrm{m}$ e du l e $R$ w d t. (Zie No. 387.)

7680. Sawaroi S. $=$ C a ryot a

f urfuracea B l. (Zie No. 2489.)

7681. Sawo M. (Zie Saauw M.)

7682. Seakan $\mathrm{AM}$. $=\mathrm{A}$ de $n$ a $\mathrm{n}$ thera $\mathrm{Pavo}$ in a L. (Zie No. 52.)

7683. Seappa Мак. $=\mathrm{Di}$ o s corea h i r s u t a B l. (Zie No. 475.)

7684. Sebassoh PAL. $=\mathrm{E} l \propto 0$ ca $r$ pus subpuberus II iq., Nat. fam. der Tili a c e æ. GR. Sumatra; boom.

7684bis. Sedah J. $=$ Ch avic a Betle Miq. (Zie No. 285.)

7685. Sedangan $J_{.}=\mathrm{V}$ all a $\mathrm{r}$ is pergulan a Brm. (Zie No. 3S6ว.)

7686. Sedep-malam J. \& $\mathbf{M}=\mathbf{P}_{0-}$ lyanthes tuberosa I،. (Zie No. 4190.)

7687. Sedoedoe-ajer $\mathrm{PAL}_{\mathrm{AL}}=\mathrm{M}$ a $\mathrm{r}$ mia muscos a B l. (Zie No. 495)

7688. Suganen $J_{0}=$ Astron ia macrophylla B l. (Zie No. 3690b.)

7689. Segatel PAL. $=$ Pogonotrophe su in atrana $M$ i q. (Zie No. 4368 .)

7690. Segaweh $J_{.}=$A d en a $n-$ thera micros perma T. \& B., Nat. fam. der M i mos e æ. Gr. Java; hooge boom.

7691. Segel S. $=\mathrm{X}$ erospermum Noronhianum B l. (Zie No. 2286.) 7692. Seghan $\mathrm{S}$. $=\mathrm{Ficus}$ a l b a R w d t. (Zie No. 26846.)

7693. Segoelang $J_{.}=M$ s a i ndi c a A. DC., Nat. fam. der M y r s in e æ. Gr. Java; heester.

7694. Sehit AмB en

7695. Sehit-ela Амв. = Guila n. d i n a B o n d u c I. (Zie No. 1475.)

7696. Sehit-ketjil Aмв. en

7697. Sehit-rara Амв. $=\mathrm{C}$ æs a l. pin i $N$ ug a A i t. (Zie No. 627.)

7698. Sehij Амв. $=\mathrm{Zing} \mathrm{i} \mathrm{ber}$ officinale L. (Zie No. 253.)

7699. Sehij-Iale Auв. of

7700. Sehij-rara $\mathrm{AmB}$. $=\mathrm{Z}$ i n g $\mathrm{i}$. b e $r$ g a m ineum Bl. (Zie No. 255.)

7701. Seho Men. \& T. $=$ A reng a s a c charifera L a b. (Zie No. 243.)

7702. Sehreh M. \& S. $=\mathrm{Andr} 0$. pogon $\mathrm{S}$ c hæn anthus L. (Zie No. 2523.)

7703. Sehreh-lampoeng S. = A plu- d a aristat a L., Nat. fam. der G r a m i n e æ. Gr. Java.

7704. Sehreh-goenneng $\mathrm{S} .=\mathrm{G}$ a hn i a javan i c Z Z. \& M. (Zie No. 30036.)

7705. Seidang-lowang $\mathrm{M}_{\mathrm{.}}=\mathrm{Pt}_{\mathrm{y}}$. chosperma simplicifrons Miq., Nat. fam. der P a l m æ. Gr. Sumatra; kleine palm.

7706: Sekar-boeboe $\mathrm{BK}_{\mathrm{K}}=\mathrm{Uv}_{\mathrm{a}-}$ ria ovalifolia 131 ., Nat. fam. der A no n a c e. Gr. Sunatra, Bangka; klimplant.

7707. Sekar poetih $\mathrm{J}_{.}=\mathrm{M}$ ill ington a hortensis L. fs. (Zie No. 2661.)

7708. Sekoel Aив. $=$ Sandoric $\mathrm{um}$ in dic um Cav. (Zie No. 113.)

7709. Sekoer Aмв. $=$ Wiospyr us Ebe num Retz. (Zie No. 32.)

7710. Selabang $\mathrm{M} .=\mathrm{Cyrtan-}$ d r a m a rophyll a Jack., Nat. fam. der Cyrtandra cer. Gr. Sumatra; éénjarig.

7711. Selako LAMP. $=a \cdot \mathrm{V}$ a t i c a p a u ciflora B l., Nat. fam. der I) i p. t e r o c a p e æ. Gr. Sumatra; een hooge, harsgevende boom. $=b$. E l æ og e n e sum atran a Miq., Nat. fam. der Euph or b i c eæ. Gr Sumatra; boom. GEBR. De inlanders persen uit de zaaddoozen eer vette olie.

7712. Selalassor S. $=\mathrm{J}$ us si a re p e us L. (Zie No 476.)

7713. Selampiet Bк. = S y z y gi u m nelitricarpum T. \& B. (Lie No. 5847.)

7714. Selangkar S. 二 L e e samb u c i n a W l l d. (Zie No. 133.)

7715. Selantom MaND. = G rapto ph yll u m hortense $\mathrm{Ne}$ es. (Zie No. 90.)

7716. Selapan LAMP. \& $\mathrm{BK}_{\mathrm{K}}$ - $a$. G a $r$ c in i l a m pong a M i q., Nat. fam. der Clus i a e æ. Gr. Sumatra; boom. $=b$. Rhinostigma macrophy 11 u m Mi q., Nat. fam. en Gr. als voren.

7717. Selassie M. $=0$ с i $\mathrm{m} \mathrm{u}$ B a sili c u m L; (Zie No. 4945.)

7718. Selassie-ajer M. 二 $\mathrm{A} \mathrm{n}$ is 0 me les ma labarica R. Br. (Zie No. 793.)

7719. Selassie-ajer-ketjil M. = Limno phila puncta ta Bl. (Zie No. 1730.)

7720. Selassie-ketjil M. = G e $n$ iosporum prostratum Bnth, Nat. fam. der $L$ a b i a $t$ c. Gr. Jara; 
éénjarig. Gєвк. Als de $\mathrm{O}$ c i nı u msoorten.

7721. Selassie-nibik BL. $=0 \mathrm{c} \mathrm{i-}$ $\mathrm{mum}$ s a n e t u m L (Zie No. 875.)

7722. Selassie oetan $M .=a .0 \mathrm{c} \mathrm{i-}$ $\mathrm{mum}$ s a n c $\mathrm{t} \| \mathrm{m} \mathrm{L}$. $=b$. E b e r mayera nelsonioides Miq., Nat. fam. der A c a n t h a c e $x$. Gr. Bangka; éénjarig.

7723. Selassie-rimbo $\mathrm{M} .=\mathrm{Scu}-$ te llaria s u matran Miq., Nat. fam. der I a b i a ta. Gr. Sumatra; éénjarig.

7724. Selassie-banjoe $B K .=P$ terostigm a villos um Benth., Nat. fam. der $\mathrm{S}$ c ro p hula rin e æ. Gr. Java en Bangka; éénjarig.

7725. Selendap $R .=\mathrm{Crinum}$ a si a ti c n m L. (Zie No. 869 )

7726. Selepok S. 二 Col e us mae ropus $M$ i q., Nat. fam. der L a b i a$t æ$. Gr. Java; éénjarig.

7727. Selewakoe Mou. $=\mathrm{A}$ Ib iz zi a mol uc cana Miq. (Zie No. 702ibis.)

7728. Selingsing Sum. $=$ Thoracostach y um sumat $x$ a n m KRz. Nat. fam. der C y pera c ex. Gr. Su. matra; rictsoort.

77:9. Seloän-badak LAMP. 二 $a . \mathrm{Ch}$ asa 1 i a ex pansa Miq. (Zie No.4505b.) $=b$. Chassalia mont an a Miq. (Zie No. 450õc.) $=c$. Chas a li a ro. b us t a M iq. (Zie No. 2697.)

7730. Seloemar Вк. 二 $\mathrm{Jackia}$ o rn a t a W ll., Nat. fam, der $\mathrm{k}$ u b i a. c e æ. Gr. Bangka, Borneo; hooge boom.

7731. Seloloh PaL. = A n tidesin a lunat um Miq., Nat. fam. der A ntidesm eæ. Gr. Sumatra; boom.

7732. Semamboe Bo. $=1 \mathrm{x} \mathrm{mo-}$ norops grandis Griff., Nat. fam. der P a $1 \mathrm{~m}$ æ. Gr. Borneo en Sumatra; klimplant.

7733. Semangka M. = CitrulI us edulis $\mathrm{Spach}$. (Zie No. 1059.)

7734. Semangen J. $=\mathrm{Paroche}$ tu s c o m in u $u$ is $\mathrm{H}$ a m., Nat. fam. der Pa pilio n a c e æ. Gr. Java 5̌-9000; éénjarig.

773ว. Semangkit Bк. 二 Croton d i a d e m u m M i q., Nat. fam. der Eup h or b i a c e. GR. Bangka; heester.

7736. Semaran-poeloe M. = Rhombospora Com inersonni Korth., Nat. fam, der R u bi a ceæ. Gr. Sumatra; klimplant.

7737. Semboeng M. \& S. 二 a. C o- nyza ba lsainifera I. (Zie No. 85b.) = b. A tho is ma viscidu m Z. \& M., Nat. fam. der Compositæ. Gr. Java en Borneo in de rijstvelden; éénjarig. $=c . \mathrm{Gn} \mathrm{a} \mathrm{ph} \mathrm{li} \mathrm{um} \mathrm{java \cdot}$ n i c u $\mathrm{R}$ wdt. (Zie 5991.) $三 d$. Gn a $p$ hali um lo $\mathrm{ng}$ ifolium Bl., Nat. fam. der Com pos it æ. Gr, Java $3-6000^{\prime}$; heesterachtig. $=e . \mathrm{Gn}$ a p hali $u$ m $v$ is c id u m B l., Nat. fam. en $\mathrm{GR}_{\mathrm{R}}$ als voren. $=f$. V e rnon i a e patorioides B l., Nat. fam. en Gr. als voren.

7738. Semboeng-awehweh S. 二 Conyza ba ls a m if era L. (Zie No. 85b.)

7739. Semboeng-besar J. 二 C o n yz a hirsuta I., Nat. fam. als voren. Gr. Jara; heester.

7740. Semboeng-dedak S. en

7741. Semboeng-koeälot J. =- V e rn o n ia java n c a DC. (Zie No. 1015b.)

7742. Semboeng-lalaki $\mathrm{S}$. $=\mathrm{Co}_{0}$ n yz a ma croph ylla B l., Nat. fam. der Com pos it r. Gr. Java tot $6000^{\prime}$; heester. GEBR. Men geeft den wortel in af kooksel tegen buikpijn en aan kraamvrouwen; de bladeren bezigt men in aftreksel als zweetdrijvend middel, en legt ze uitwendig op rersche wonden, zooals op die na de besnijdenis.

7743. Semboeng-lanang $\mathrm{S} .=\mathrm{Budd}$ le i a $\mathrm{N}$ e e m d a $\mathrm{H}$ a m., Nat. fam der L o g a n i c e æ. Gr. Java tot 7000'; boomachtig.

7744. Semboeng-langoh $\mathrm{s} .=a$. Innla salviod or a S c hultz., Nat. fam. der Composits. Gr. Java tot 7000'; éénjarig. $=b$. G n a p h a 1 i a m jav an i u m DC. (Zie No. 5991.)

7745. Semboeng-leutiek S. 二 $\mathrm{C}_{0}$ n yz a Is., S p e c. di v.

7746. Semboeng-oetan M. = $\mathrm{C}_{0}$ n y z a b l s a m if e r a L. (Zie No. 85b.)

7947. Semer-kassoena $\mathrm{M}$. $=\mathrm{C}$ i n. $\mathrm{n}$ a $\mathrm{momum}$ s ubcuneat $\mathrm{nm}$ M i . (Zie No. 4903.)

7748. Sempoer M. \&. S. jook Soempoer M.) $=$ Dillen i a u rea $\mathrm{Sm}$. Nat. fam. der D i ll e $n$ i a c e æ. Gr. Java; hooge boom. GF.BR. Het hout wordt zeer hard en wordt gebruikt tot het slijpen van messen; de asch daarvan zal den haargroei bevorderen; de vruchten bezigt men tot het wasschen van kleederen en der hoofdharen, zij zullen het ongedierte dooden. 
7749. Sempoer-ajer M. of

77ะ0. Sempoer-tjai S. = Dillenia speciosa Thnb. (Zie No. 61.)

7751. Sempoer-tjai s. =- Dilleni a pent agyna $R x b$., Nat. fam. als voren. Gr. Java. Gebr. Als No. 7748.)

7752. Sempohl BL. = He d y c h i u m c or o n a ri um Ko en. (Zie No. 2409.)

7753. Se-meöng Сн. Во. 二 I mperata arundinacea Cyrill. (Zie No. 263.)

7754. Senar Вк. = Commerso. nia echinat a Forst. (Zie No. 106.)

7755. Sendang 3. = $\mathrm{Hrdroco}$. tyle a siatica L. (Zie No. r0.)

7756. Sendoero J. (ook Sindoeroe J.) $=\alpha$. G n a phalium Re inwardtianum Miq., Nat. fam. der! Compositæ. Gr. Java 3-4800'; éénjarig. $=6$. Gnaphalium javanic u m R w d. (Zie No. 5991.)

7757. Sendoero-besar J. $=\mathrm{Gn}$ a$\mathrm{phalium}$ longifolium Bl. (Zie No. 7737 d.)

7758. Sengang S. en

7759. Sengang-bener S. = $a . \mathrm{A} \mathrm{m} \mathrm{a-}$ rantus oleraceus L. (Zie No. $\left.836 d_{\text {. }}\right)=b$. A marantus retroflexus L. (Zie No. 839.)

7760. Sengang-burrum S. = A m arantus melancholicus L. (Zie No. 844.)

7761. Sengang-monjet $\mathrm{S} .=a$. Euxolus polystachyus Miq. (Zie No. 845b.) = $b$. E $\mathrm{x} \times \mathrm{l}$ u s viridis $\mathrm{M}$ o q. T a nd. (Zie No. $845 \mathrm{c}$.)

7762. Sengang-tjoetjoek S. 二 A m arantus spinos us L. (Zie No. 846.) 7763. Sengani of Singani J. = a. M e. lastoma polyanth um Bl. (Zie No. 110.) $=$ b. Melastoma asper u m B l. (Zie No. 1252.)

7764. Sengkêl of Siengkiel S. = a. Premna lucidula Miq. en $=$ o. Premna le ucostoma Miq. Nat. fam. der Ver b e n a c e r. Gr. Java; beide heester's.

7765. Sengo J. $=$ Kerria ja ponic a DC. (Zie No. 2827.)

7765 bis. Sengon J. $=\Lambda 1$ bizzia stipulat a Boix. (Zie No. 2223.)

7766. Senka MAK. = I) ioscor e a a cule at a L. (Zie No. 1?89.)

7767. Sentarong Sux. WK. $=\mathrm{Sp}$ onia velutina Planch. (Zie No. 341.)

7768. Senteh S. $=a . \mathrm{Homalo-}$ nema alba Hassk. (Zie No. 317.) $=$ b. Alocasia macrorhiza S c h o t t. (Zie No. 1239.)

7769. Senteh-boddas S. = Alocasia macrorrhiza Schott, var. p alli da. (Zie boven.)

7770. Senteh-heedjoh S. = Alucasia macrorrhiza Schott var. atro viridis. (Zie boven.)

7771. Senteh-hitam S. = Alocasia macrorrhiza Schott.var. rubra. (Zie boven.)

7772. Senteh-woelong $\mathrm{S} .=\mathrm{Ho}-$ malonema rubescens Kunth. (Zie No. 903.)

7773. Senteng S. $=$ Homalonema cordata Schott., Nat. fam. der A roider. Gr. Java en de Molukken; overblijvend. GeBr. Men bezigt den wortel tot het bedwelmen en vangen van visschen en legt ze op vergiftigde wonden.

7774. Sentigi Mak. = Egiceras floridum R. E S. (Zie No. 130.)

7775. Sentoel M. = Sandoricum indicum Cav. (Zie No. 113.)

7776. Sentohloh J. $=\mathrm{Abroma}$ fastuosa R.Br. (Zie No. 4096.)

7777. Sentollong CAR. JAva. 二 Pisonia sylvestris T. \& B. (Zie No. 1603.)

7778. Sepang M. = Cæsalpinia S a p a n I. (Zie No. 1807.)

7779. Sepano of Sipanoe Sur. ITK. $=a$. Quercus Diepenhorstii Miq. en $=b$. Quercus encleisocarpa Korth., Nat. fam. der Cupuliferæ. Gr. Sumatra; hooge boomen.

7780. Seperoh-mano LaMp. = Ecdysanthera pedunculosa Miq. Nat. fam. der A pocy n e :e. Gr. Sumatra; slingerplant.

7781. Sepit Bк. = Tabernæmontana rhynchophylla Miq., Nat. fam. als voren. Gr. Bangka; heester.

7782. Sepoegang $M .=V$ it e $x$ pteropoda Miq., Nat. fam. der Verbe nace æ. Gr. Sumatra O.K.; boom.

7783. Sepra-besar J. $=$ Dichrocephala I atifolia 1)C. (Zie No. 1524c.)

7784. Sepra-ketjil J. = 1) uc hesnea sundaica Miq. (Zie No. 4660.)

7785. Sera-api Sum. WK. = Fi. cus biglandulosa Miq. (Zie No. 282f.)

7786. Seradan-kajoe S. = Fla. courtia sepiaria Rxb., var., Nat. fam. der Flacourtianer. Gr. Java; 
heester; de vruchten worden gegeten. 7787. Serantoe PAL. $=\mathrm{Helicia}$ s umatrana $\mathbf{M i q . , ~ N a t . ~ f a m . ~ d e r ~ P r o - ~}$ t e a c æ. Gr. Sumatra; heester.

7788. Serengseng S. = Scirpo. dendron pardan iforme Z ipp., Nat. fam. der Cyperacere. Gr. Java. (Zie No. 246;6.)

7789. Sereti-besar S. = C alophyllum spectabile Wlld. (Zie No. 1224.)

7790. Serewoeng $\mathrm{Al \textrm {kN }}$ 二 Celosia cristata Moq. T and. (Zie No. 419.)

7791. Sergadieng M., ook Sirih. gadieng S. en Srigadieng S, (Zie Sari. gadieng J. \& M.)

7792. Seriawan $\mathrm{S}$. $=$ S gmplocos od oratissima Chois. (Zie No.4672.)

7793. Serie-banjoe $B \kappa .=B l y x a$ Roxburghi i Rich. (Zie No. 24216.)

7794. Serientiel J. 二 Piddingt on i montan a Miq., Nat. fam. der L obe li a ceæ. Gr. Java; éénjarig.

7795. Serientiel-ientiel $\mathrm{J}$ = $\mathrm{Co}$. donopsis javanica Miq. (Zie No. 4256.)

7796. Seriwan M. = Plumbago zeylanica I., Nat. fam. der Plum. bagi nere. Gr. Java, Timor, de Mo. lukken; heester. GrBR. Men gebruikt den wortel soms als bijtmiddel, voornamelijk om wratten weg te maken.

7797. Seroe Bk. 二 S chima ban. cana $\mathbf{M i q . ~ N a t . ~ f a m . ~ d e r ~ T e r n s t r œ - ~}$ miaceæ. Gr. Bangka; hooge boom.

7798. Seroe Вк. 二 Schima Wal. lichii Chois. (Zie No. 2864.)

7799. Seroe J. $=$ Cordyline Rum phii Hook. (Zie No. 337.)

7800. Seroe-leuwung $\mathrm{S} .=\mathrm{Cu}$. beba canina Miq. (Zie No. 5132.)

7801. Seroenen J. = Spilanthes Pseudo-a cmel la L. (Zie No. 1753.)

7802. Seroenen-walang J. $=\mathrm{B} \mathrm{i-}$ gelovia mitracarpoides Miq., Nat. fam. der Rubiaces. Gr. Java; éénjarig.

7803. Seroeng-dioek S. = Zippelia begonixfolia Bl. (Zie No. 6688.)

7804. Seroeroe BAT. = Cocculus (Pericampylus) incanus Colebr. (Zie No. 489.)

750ว. Seroo (Sieroet) J.二Claoxylon minus Endl. (Zie No, 469l6.)

7806. Seroet-tjina $\mathrm{N}$. $=\mathrm{Ehre-}$ tia buxifolia $R x b$. (Zie No. 5066.)
7507. Seroh S. Z Ficus tricolor Miq. (Zie No. 3105.)

7808. Seroja Вк. = Isonandra Gutta Hook. (Zie No. 890.)

7809. Serok-radja-mantrie $\mathrm{S}_{\text {. }}=$ $\mathrm{N}$ e penthes phyla m phora Wlid. et. a l. Spec. (Zie No. 128.)

7810. Sesaloeng-boddas $\mathrm{S} .=\mathrm{G}$ × $\mathrm{r}$ tnera Z o lli ngeri a n M i q., Nat. fam. der Log a ni a c æ. Gr. Sumatra; lieester.

7811. Sesang-aroes LaMr. $=\mathrm{Ade}$ lia nereifolia Wght. (Zie No. 22076.)

7812. Sesapang $\mathbf{M}=$ I n t si a $\mathrm{pa}$ le $\mathrm{mb}$ a ic a M iq. (Zie No. 5795.)

7813. Sesepang LAMP. $=\mathrm{S}$ a $\mathrm{m}$ aropyxys ellip tica Miq., Nat. fam. der E uphorbiace x. GR. Sumatra; boom.

7814. Sescbeh Sum. WK. $=a$. Cann a c occinea $\mathrm{A}$ it. en $=6$. Canna flave scens $\mathrm{L}$ in k. (Zie No. 4150.)

781ว. Sesoerie-tjina $\mathrm{J} .=\mathrm{N}$ a sturtium indicum DC. (Zie No. 2175.)

7816. Setabah-rimbo Sum. Wh. = Hoy a $\mathrm{T}$ ey smannian a $\mathrm{M}$ i q., Nat. fam. der A s cle piade ce. Gr. Sumatra; klimplant.

7817. Setadja-hiiam PaL. = Turræa trichostyla Miq., Nat. fam. der M eli a c eæ. Gr. Sumatra; heester.

7818. Setarok Sum. WK. 二 M appa g u m m iflua Miq., Nat. fam. der E u ph or bi a c æ. Gr. Sumatra; boom.

7819. Se.teo Сн. Bo. 二 $\mathrm{L} \mathrm{a} \mathrm{bl} \mathrm{a} \mathrm{b}$ v u l garis S v. (Zie No. 3544.)

7820. Setjang $\mathrm{S} .=a, \mathrm{~A} \mathrm{c}$ a $\mathrm{c}$ i pennata Wlld. (Zie No. 4806.) = b. Casalpi nia S a p pan L. (Zie No. 1807.) $=c$. C $x$ s l pinia nitida H a s sk., Nat. fain. der $\mathrm{P}$ a p il i o n ac e $x$. GR. Java; heester.

7821. Setjang-lumboet S. 二 Cæ. sa 1 pin ia se piaria $R \times$ b., Nat. fam. als voren. Gr. Java, Sumatra, enz.; klimplant.

7822. Setjereh Sum. WK. = Cla usena sum atrana W. \& A. (Zie No. 7590.)

7823. Setoel Auв. 二 Sandorium in d i u m C a v. (Zie No. 113.)

7824. Seuëurbadak $\mathrm{s} .=\Lambda \mathrm{nt}$ desma stipulare Bl. (Zie No. 4680 .)

7925. Seuëur-dioek $s$ 二 A n ti- 
desma littorale Bl. (Zie No.4682.) 7826. Seureu S. = Sirih $\mathrm{M}$.

7827. Seurisati S. $=\mathrm{Cal}$ o p y l$1 \mathrm{um}$ spectabile IVlld. (Zie No. 1224$.

7828. Siafoe BD. \& T. en

7829. Siaho Амв. $=D$ i os c ore a a c u le a t a L. (Zie No. 1189.)

7830. Siambeh Sum. WK. 二 De smodi um dasy lob u m Mi q., Nat. fam. der Papilion a e æ. Gr. Sumatra; heester.

7831. Siang-sraai Laмp. 二 Caryophyllus fastigiatus Bl. (Zie No. 2544.)

7832. Sianga M. = Eriocaulon l uz u læ folium II art., Nat. fam. der Erioc a u lo n e æ. Gr. Sumatra; éénjarig.

7833. Siangit-padang Sum. WK. = Cyperus piptolepis sta. (Zie No. 2143.)

7834. Siani-mantji M. = Burmann i a su matran a M i q., Nat. fam. der B u rman ia ce æ. Gr. Sumatra; één. jarig.

783. Siawaho Амв. of

7836. Siawaro АмB. $=\mathrm{Z}$ i n g i b e r a maricans B l. (Zie No. 240l.)

7837. Sibak-langa B 1. = Momord i c a s u b ang n lat a Bl. (Zie No. 262.)

7838. Sibarik-barik Sux IVK. = A r disia la m pong a Miq. (Zie No. 6769.)

7839. Sibaroengoet SuM. WK. = Stephania capitata Spr. (C issampelos Pareira L.) (Zie No. 447.)

7840. Sibaroewas Sum. WK, en

7841. Sibaroeweh Sum. WK. 二 D is c ostigma f a b rile Mi q., Nat.fam. der Clus i a s e. Gr. Sumatra; boom.

7842. Sibasa PAL. 二 $\mathrm{T}$ a l a u ma S e bass a Miq., Nat. fam. der M a gno li a c e æ. Gr. Sumatra; boom.

7843. Sibasar M. = Milnea mont a n a J a ck. (Zie No. ว25. )

7844. Sibassa PAL. 二 $\mathrm{Tu}$. trichostyla Miq. (Zie No. 7817.)

784. Sibassoh Sux. 二 $a$. Cephalotrophis ja $\nabla$ an ica B l. (Zie No. 7976.) $=$ b. Leiocarpus frutico. sus B l. (Zie No 2029.)

7846. Sibilantih Sum. WK. $=\mathrm{Me}$. dinilla $\mathrm{H}$ as seltii Bl., Nat. fam. der Melastomaceæ. Gr. Sumatra; heester.
7847. Siboe of siboet Br. = Aleurites triloba Frst. (Zie No. 312.)

7848. Siboeroe 11 . $=$ Gomphia sumatran a J ack., Nat. fam. der Ochn aceæ. GR. Sumatra; boom.

7849. Sidagori J. $=a$. A butilon DC. en $=b$. Sida L. Spec. plurimæ. Gezr. Men bezigt de bladeren van deze Malvaceæ om er garens mede te bestrijken in plaats vau met was. $=c$. Riedleia concatenat a IDC.. Nat. fam. der Büttneriacex. Gr. Java, Sumatra, Borneo; éénjarig. $=d$. Calotropis gig antea R.Br. (Zie No. 817.)

4850. Sidagori-aroij S. 二 Sida javensis Cavan. Nat. fam. der Malva. ceæ. Gr. Java. Timor; kruipende plant.

7851. Sidagori-awehweh S. $=\mathrm{Si}$ d a rhombifolia L., Nat. fam en Gr. als voren; kleine heester.

7852. Sidagori-lalaki S. = $\mathrm{Sida}$ acuta Brm. (Zie No. 1802.)

7853. Sidagori-lanang S. $=\mathrm{Urena}$ Blumei Hassk., Nat. fam. als voren. $G_{R}$. Java; kleine heester.

7854. Sidagori-parampoean M. = Sida retusa I., Nat. fam. als voren. GR. Door geheel Ned. Indië; kleine struik.

7855. Sidawaija of Sidowaija J. = a. Nerium Oleander L. (Zie No. 1369.) = b. Grislea tomertosa. Rxb. (Zie No. 1421.)

7856. Sidingin-oetan $M .=\mathrm{Gru}$ milea polycarpa Miq., Nat. fam.der R u bi a c eæ. Gr. Sumatra; Bangka; klimmende heester.

7857. Sidodo-akkar PAL. $=\mathrm{D}$ issochæpa palembanica Miq (Zie No. 5444.)

7858. Sië Aмв. = Oxalis Reinward ti Z Z cc

7859. Sienie (Sini) M. = C'apparis fotida Bl., Nat. fam. der Cruciferæ. Gr. Java; heester.

7860. Sienjie BK. = Barathranthus axanthus Kths.. Nat. fam. der Loranth a ceæ. Gr. Bangka, Sumatra; parasiet.

7861. Siga-dimpa Sum. WK. = Ardisia fertilis Miq. Nat. fam. der Myrsi neæ. Gr. Sumatra; heester.

7862. Siga-doergdoeng Sux. WK. $=a$. Liquidambar Altingiana Bl. (Zie No. 7182.) $=$ b. liquidambar tricuspis $\mathbf{M i q}$, Nat. fam.der $\mathrm{Hama-}$ melideæ. Gr. Sumatra; boom. GeBr. Als No. 7182.) 
7866. Sigam PaL، = Gironniera Planch. (Zie No. 3394.)

7867. Sigam Sum. Wh. = Phæan. thus sum atrau a Miq., Nat. fam. der A non aceæ. Gr. Sumatra ; boomachtig.

7868. Sigam-badak Sum. WK. = a. Mitrephora Diepenhorstii Miq., Nat. fam. als voren. GR. Sumatra; boom. $=$ b. Guatteria Teysmanni Miq. (Zie No. 986.)

7869. Sigarangara M. = Dispo. rum multiflorum Don. (Zie No. 1137.)

7870. Sigar-gadja M. = Urophyllum corymbosum Korth. (Zie No. 2915 )

7871. Siger $\mathrm{Br}_{\mathrm{r}}=$ Cory pha umbraculifera L.. var. (Zie No. 1528.)

7872. Siggaweh J. $=$ Melastoma polyantbum Bl. (Zie No. 110.)

7873. Sigoen S. $=$ Echinocarpus Sigun B l. (Zie No. 1101.)

7874. Sija of Sijë Aмв. 二 Adenanthera falcata L. (Zie No. 3451.)

i875. Sijapoe M. = Monophy]. lica hirtella Miq., Nat. fam. der Cyrtandracer. Gr. Sumatra; éénjarig.

7876. Sikakauw Sum. WK. 二 Heptapleurum ellipticum Bnth. \& Hk. (Zie No. 3745.)

7877. Sikakauw sum. WK. $=\mathrm{Pa}$. ratropia micrantha Niq., Nat. fam. der A raliaceæ. Gr. Sumatra; heester.

7878. Sikandjar Sum. WK. 二 $\mathrm{Pa}$ ratropia longifolia DC, var. in curva. (Zie No. 1972.)

7879. Sikandoedoek Sum. WK. = Marumia Korthalsiana Miq., Nat. fann. der M elastnma c ex. Gr. Sumatra; heester.

7880. Sikandoeh-rimbo Sum. WK. = Hylocharis macrophylla Miq., Nat. fam. als vorell. Gr. Sumatra; heester.

788]. Sikandong SuM. WK. = Sterculia spectabilis Miq. Nat. fam. der Sterculiacex. Gr. Sumatra; boom.

7882. Sikap-burrum S. = Ehretia javanica Bl, Nat. fam. der Cordi acex. Gr. Java; hooge boom.

7883. Sikappa BL. = l)ioscorca hirsuta Bl. (Zie No. 475.)

7884. Sikat BD. 二 a. Adenan. thera falcata L. (Zie No. 345l.) = b. Albizzia? moluceana Miq. (Zie No. 7021 bis.)

7885. Sikattang S. = a. Gyno. pachys corymbosa Bl. Nat. fam. der Rubiaceæ. Gr. Java 5000'; heester. = b. Ardisia Blumei A. DC. (Zie No. 4539.) = c. Actophila javanica Miq., Nat. fam. der Euphorbiaceæ. Gr. Java; heester.

7886. Sikeh-sikeh-rimbo SUM. WK. = Grrtnera Junghuhu i ana Miq. Miq. (Zie No. 7545.)

7887. Sikiliëh Sum. WK. 二 Eschynanthus brevicalys Miq., Nat. fam. der Cyrtandraceæ. GR. Sumatra; overblijvend.

7888. Sikkeij $\mathrm{CR}_{\mathrm{R}}$ 二 Lygodium microphyllum R.Br. (Zie No. 2604.)

7889. Sikkie-meirah Амв. 二 $\mathrm{Te}$ tranthera Rumphii Bl. (Zie No. 2323b.)

7890. Sikkih-poetih Амв. = Tе tranthera $S$ pec. amboin. indef. 7891. Sikoejoe-lawut Sum. WK. = Podocarpus Teysmanni Miq., Nat. fam. der Podocarper. Gr. Sumatra; boom.

7892. Siko-hajate Амв. 二 Evodia latifolia DC. (Zie No. 36.)

7893. Silaijoe-badak Sum. WK. = Sauraya Teysmanniana Miq., Nat. fam. der Ternstræmiaceæ. Gr. Sumatra; heester.

7894. Silaijoe-mienjak Sum. WK. = Mussaënda Wallichiana G. Don. Nat. fam. der Rubiaceæ. Gr. Sumatra; heester.

7895. Silaka M. = Arytera Silaka Miq.; Nat. fam. der Sapind ace e. Gr. Sumatra; boom.

7896. Silaka-rimbo Sum. WK. = Muldera cordata Miq. (Zie No. 5138.)

7897. Silar Cex. = Corypha 1 mbraculifera L. (Zie No. 1528.)

7898. Silatoet Sum. WK. = Connarus semidecandrus Jack. (Zie No. 3852.)

7899. Silong-doewa $\mathrm{M}_{\mathrm{AND}}$. 二 $\mathrm{H}_{\mathrm{o}}$ malonema rubescens Kunth. (Zie No. 903 .)

7900. Simangin Sux. WK. 二 I, etcosyke javanica Z. \& M. (Zie No. $4401 b$.)

7901. Simalan Sur. WK. 二 A rdisia fertilis Miq. (Zie No. 7861.) 7902. Simani Srm. WK. = Sau- 
ropus sumatranus Miq., Nat. fam. der E u ph or b i a c e ce. Gr. Sumatra; heester.

7903. Simanis-mata Sux. WK. = Ps chotria rhodocarpa T. st $B$.

7903bis. Simar-bantaijan Sus. WK. = Dryobalanops Camphora C o l e br., Nat. fam. der Dip ter 0 . c a $r$ pere. Gr. Sumatra, Borneo; groote boom. Glbr. Deze boom levert de Sumatrasche kamfer (Kapoer-baros M.) en de kamfer-olie. De kamfer komt uit de oude stammen door scheuren en spleten te voorschijn.

7904. Simasam Sux. WK. $=\alpha$. Ardis ia fertilis Miq.. (Zie No. 7871. = b. Polygala Simassan M i q., Nat. fam. der Polyg a le æ. Gr. Sumatra; overblijvend.

7905. Simasam WK. Sum. = A r. disia sumatrana Mi q. Nat. Fam. der M yrsineaceæ. Gr. Sumatra; heester.

7906. Simbar J. $=a . \mathrm{O}_{\mathrm{ph}} \mathrm{i}_{\mathrm{O}}$ glossum pendulum L. (Zie No. 17896.) $=$ b. Poly podium querc if o li u m Wlld. (Zie No. 181.)

7907. Simbar-boerong M. = Es. chynanthus radicans Jack., Nat. fam. der Cyrtandrace $\boldsymbol{C}_{\text {. }}$. Sumatra; woekerplant.

7908. Simbar-koebang PaL. = II a p a macrophy lla Kürz. (Zie No. 4960 .)

7909. Simbar-lajangan $\mathbf{M}_{\text {. }}=\mathrm{P}_{\mathrm{o}}$ ly podium quercifolium IV $11 \mathrm{~d}$. (Zie No. 181.)

7910. Simboëam-lemna J. = 01 . denlandia hirsuta L. fs., Nat. fam. der R u bi a c e $æ$. GR. Java en Sımatra 4000'; éénjarig

7911. Simboe-badak S. = $\mathrm{C} \mathrm{y} \mathrm{r-}^{\circ}$ tosiphonia sumatrana Miq. (Zie No. 436.$)$

7912. Simengala-gala Sur. WK. 二 Urostigma nitidum Miq. (Zie No. 855.)

7913. Simpeurum S. $=\mathrm{Fluggea}$ ja va n i a Bl., Nat. fam. der Eupholb i a c e æ. Gr. Java; heester.

7914. Simpeurum-leutiek S. $=$ Fluggea microcarpa Bl. (Zie No. 5860 .)

7915. Simpoor Вк. 二 . $\mathrm{W}$ о г. $\mathrm{m}$ i a excels a $J$ a c k. (Zie No. 2283.) = 6 . Wormia subsessilis $\mathbf{M i q}$.
Nat. fam. der Dillen i c ea. $G_{k}$. Bangka; heester.

7916. Sinagaar M. \& S. = $a . \mathrm{Pty}$. chosperma coronata Miq. (Zie No.6826b.) 二 b. A reca pumila M a r.t., v ar. (Zie 27136.)

7917. Sindo-kapoer MAD. = C a lli c a r p c a n a L. (Zie No. 2).

7918. Sindoor Sum. = Sind or a sumatrau a Miq. (Zie No. 7574.)

7919. Sindoekan $\mathrm{S}$. $\mathrm{R}$ ot t ler a s c abrifolia A. Jus s., Nat. fam. der Euphorbia c e. GR. Java en Timor; klimmende heester.

7920. Singa-dapoer J.,

7921. Singa-depah S. en

7922. Singah-padoe $\mathrm{S}$. $=\mathrm{Bra}$ gantia tomentos a R. Br., Nat. fam. der A ristoluch i e æ. Gr. Java; overblijiend. GEBR. De bladeren en den stengel van dit struikje bezigt men als zeep; uit. en inwendig wendt men ze aan tegen keel- cn borstaandoeningen; men dient dit kruid ook als e $\mathrm{mm}$ e $\mathrm{nog}$ a$\mathrm{g} \mathrm{u} \mathrm{m} \mathrm{toe.}$

7923. Singa-depah-lawut M. \& S. = Munronia javanica Benn. (Zie No. 2556.)

7924. Singa-rono J. $=\mathrm{Gnapha.}$ li um longifoli um Bl. (Zie No. $7737 d$.)

7925. Singkawang Sum. WK. = Shorea? nitens Mi q., Nat. fam. der Dipteroc arpeæ. Gr. Sumatra hooge boom. $=6$. Ho pea? Sing k a. w a ng M i q., Nat. fam. dezelfde. Gr. Als voren.

7926. Singkoäng-kajoe M. 二 Dracontomelon puberulum Miq. Nat. fam. der A n a c a rdia c e a. GR. Sumatra; hooge boom.

7927. Singoegoe S. = Clero. de ndrum serrat u $\mathrm{s}$ pr. (Zie No. $6930 d$.)

7928. Sinkoer-batoe Sur. WK. = Coix L a c h r m a L. (Zie No. 1894.) 7929. Sinkti T. = Crotalaria re tus a L. (Zie No. 2495.)

7930. Sinsim J. = Pothos Z ol. ling e rian a S chot t., Nat. fam. der O ronti a c e. Gr. Java; parasiet.

7931. Sintaka R. = Plu m b g o ros e a L. (Zie No. 114.)

7932. Sintoe-sintoe Sum. IVK. 二 El o ocarpus hypadenus Miq.; (Zie No. 1606)

7933. Sintok (Sientok) M. $=a$. 
Cinn a mon $\mathrm{m} \mathrm{m}$ S intok B l., Nat. fam. der L a u r i n $x$. Gr. Java, Suma. tra, Borneo, enz,; hooge boom. GeBr. Men geeft den bast tegen wormen en op verwaarloosde zweren. (Zie overigens als No. 2287.) $=6$. C i un a m o m u m Culi la wan $\mathrm{N}$ ees. (Zie No, 2287.) $=c$. Cin a mo m u m P s u do-S in to k M i q., Nat. fam. als voren. Gr. Java; hooge boom. $=d$. I a p l a c a a roma. t i c a Mi q. (Zie No. 4840.)

7934. Sintok-baroek M. = Clerodendrum serratum Spr. (Zie No. $6930 d$.)

7935. Sintok-bener $J_{.}=\mathrm{C}$ in n amo m u $\mathrm{m} \mathrm{S}$ in to k B l. (Zie No. 7933.)

7936. Sintok-besar $\mathrm{M} .=\mathrm{C}$ i n $\mathrm{n}$ amom um camphoratum B l. (Zie No. 4899.)

7937. Sintok-lantjang M. \&. S. = a. Cinnamom $\mathrm{nm}$ c a m phorat um B l. = b. Cinnamomum sulphur a t a m N e es. (Zie No. 3353.)

7938. Sintok-monjet $\mathrm{S}$. $=\mathrm{L}$ i t $\mathrm{s}$ a poli t a B l., Nat. fam. der I, a urin eæ. Gr. Java; boom.

7939. Sioe-hunaë of S-humate Амв. = Evodia latifolia I).C. (Zie No. 36.)

7940. Sioer-sioer Pis. $=$ Scaphi n m I a n c e a tum Miq., Nat. fam. der T h y m e læ a c e æ. Gr. Sumatra; heester.

7941. Sipadi Sum. WK. $=a$. Ficus o btusidens Miq., Nat. fam. der Artoc a r p $x$. Gr. Java, Sumatra; heester. $=b . \mathrm{Ficus} \mathrm{s} u \mathrm{bulata} \mathrm{Bl}$. (Zie No. 1649.) = c. Phrynin m Houtteanum C. Koeh. (Zie No. 6686.)

7942. Sipadi-njang-gedang-betina Sum. WK. $=$ Ficus gibbos a Bl. et $\mathrm{v}$ a r. e t; (Zic No. 2979.)

7943. Sipadi-rimbo SuM. WK. = I. a s i n thus cy anocar pus Jack. (Zie No. 5857b.)

7944. Sipannas $M_{0}=A \mathrm{glaj}$ a $\mathrm{S} \mathrm{i-}$ p a n a s Miq., Nat. fam. der M e liac e æ. Gr. Sumatra; boom.

7945. Sipodi Sum. IVK. =- I n odaphnis lanceolata Miq., Nat. fam. der Th y mel $x$ c c $x$. GR. Sumatra.

7946. Sipoengoèl (Sipoeroengoel) $\mathrm{PAI}_{\text {. }}=\mathrm{Z}$ anthoxylon e n n u ron II i q. (Zie No. 6973.)

7947. Sipoengoel-djanten PAL. $\mathrm{Z}$ a nthoxylon luc ic n m Miq., Nat. fam. der J) iosmex. Gr. Sumatra; heester.
7948. Siramja-djanten Sum. WK. = Monoceras odontopetalum Miq. (Zie No. 5534.)

7949. Sir ampoh Sum. WK. = Evo. dia Marambong Miq. (Zie No. 4312 ,)

7950. Siranda Scm. WK. = B a $\mathrm{r}$ ringtonia a cuminata Korth., Nat. fam. der M y r t a ce æ. Gr. Sumatra, Borneo; boom.

7951. Sirandah Sum. WK. $=\mathrm{H}$ pea? S i r a n a M i q., Nat. fam. der Di p te ro a r pex. Gr. Sumatra; hooge boom.

7952. Sirandoh Sun. WK. $=\mathrm{Ge}$ lonium? oxy phylum Miq., Nat. fam. der $\mathrm{E} u \mathrm{p}$ b o r b i c e æ. Gr. Sumatra; heester.

7953. Siree-oetan T: $=\mathrm{P}$ o a a $\mathrm{m}$ b o ine $n$ s is L.. Nat. fam. der G r a$\mathrm{m}$ i n e $x$. Gr. De Molukken; overblijvend.

7954. Sirih M. $=\mathrm{Ch}$ avica Betle Ml i. (Zie No. 28ว.)

7955. Sirih-ajer M. $=\mathrm{Chavica}$ de n s a $M$ i q. (Zie No. 686.)

7956. Sirih-aloes-tabal $\mathrm{S}_{0}=\mathrm{Ch}$ a$\nabla$ i c a B l n m e i M i q. (Zie No. 544.)

7957. Sirih-andjing $\mathrm{M} .=\alpha . \mathrm{C}$ h a. vica sphrostachys Miq. (Zie No. 290.) $=$ b. C u b b a c an in a If i q. (Zie No. 5132.)

7958. Sirih-antoe M. $=\mathrm{C} \mathrm{h}$ a v ic a $\mathrm{m}$ in i a t a $\mathrm{M}$ i q. (Zic No, 408\% b.)

7959. Sirih-Atjeh M. = Chavica m ultinervi a $M$ i q., Nat. fam. der P i p e r a e r. Gr. Sumatra; klimplant.

7960. Sirih-badjak M. = T $011 \%$ nefortia a rgentea I. fs. (Zie No. 3884.)

7961. Sirih.bopar S. $=\mathrm{F}$ i cus se pti c a S p r. (Zie No. 765.)

7962. Sirih-boddas $\mathrm{S} .=\mathrm{Ch}$ a $\mathrm{v}$ i a B et le Mi q. (Zie No. 285.)

7963. Sirih-boewa M. en

7964. Sirih-burrum S. $=\mathrm{Cha-}$ vic a $\mathrm{Siriboa} \mathrm{Miq.} \mathrm{(Zie} \mathrm{No,} \mathrm{1170.)}$

7965. Sirih-dingin M. $=\mathrm{Ch}$ avic a s a $r \mathrm{mentos}$ a $\mathrm{Miq}$. (Zic No. 292.)

7966. Sirih-djawa $\mathrm{H}$. Chavica Bl u me i $\mathrm{ll}$ i q. (Zic No. эั44.)

7967. Sirih-goenong $\mathrm{S} .=\mathrm{Piper}$ s u l c a t u m B I., Nat. fam. der Pi per a c e $æ$. Gr. Java; lieester.

7968. Sirih-hitam M. = Ch a $\mathrm{Fic}$ i B e t le M i q. (Zie No. 285.)

7969. Sirih-kadoh $\mathrm{M}=\mathrm{Ch}$ a $\mathrm{v}$ is a de ns a M i q. (Zie No. 686.) 
7970. Sirih-kandbata M. = G havica mela miris Miq. (Zie No. 286.) 7971. Sirih-karoewang S. = C havica majuscula Miq. (Zie No. 289.)

7972. Sirih-koening $\mathrm{M}$. = Charica Betle Ii q., var. (Zie No. 285.)

7973. Sirih-konneng $\mathrm{S} .=\mathrm{Ch} \mathrm{a}$. vica? maculata Miq., Nat. fam. der Pi pera c ex. Gr. Java; heester.

7974. Sirih-leuwung S. $=\mathrm{P}$ i per sul c a t u m B l. (Zie No. 7967.)

7975. Sirih-lowong $\mathrm{S}=\mathrm{Cu}$ b e b a L o w o n g $11 \mathrm{iq.}$. Nat. fam. als roren.

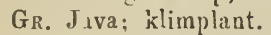

7976. Sirih-lowang-podol s. = Piper muricatum Bl. (Zie No. 3885.)

7977. Sirih-meirah M. 三 Chavica $\mathrm{Sir}$ iboa $\mathrm{M}$ i q. (Zie No. 1170.)

7978. Sirih-monjet $\mathrm{M} .=\mathrm{C} \mathrm{ub} \mathrm{eb}$ a $\mathrm{c}$ a $\mathrm{i}$ in a Miq. (Zie No. 5l32.)

7979. Sirih-oetan M. 二 a. Cubeba c a $\mathrm{n}$ in a $\mathrm{II}$ i q. (Zie No. 5132 ) $=b$. liper arboreseens Rxb. (Zie No. 285.) $=c$. Chavica densa Mi q. (Zie No. 6S6.) $=d$. Chavica melamiris Miq. (Zie No. 286.) $=e$. Chavica miniata Miq. (Zie No. 4087b.)

7980. Sirih-oetan-bebaauw M. = Pi per arborescens Rxb. (Zie No. 285.)

7991. Sirih-oetan-dingin $\mathrm{M}$. $=\mathrm{Ch}$ avica sarmentosa Miq. (Zie No. 29.)

7982. Sirih-rimbo M. = A g a l. myla angustifolia Miq., Nat. fam. der C y r tandrace a. Gr. Sumatra; parasiet.

7983. Sirih-seitam M.

79\$4. Sirih-swangi $M$, en

7985. Sirih-talang M. = Chavica majuscula M i q. (Zie No. 289.)

7986. Sirih-tanah .1. 三 Chavica s ph ar ostachy a Miq. (Zie No. 290.)

7987. Sirih-tjoek S. $=\mathrm{Piper}_{\mathrm{mu}}$ $r$ i c a t u m B l. (Zie No. 3885 .)

7988. Sirikaija M. $=a$. A n о и a squamosa L. (Zie No. 1477) $=6$. A nona reticulata L. (Zie No. 1489.) 7989. Sirikaijnona T. $\mathrm{T}$ A n on a reticulata L. (Zie No. 1489.)

7990. Siriogin M. = Urostig m a n i tidum M i q. (Zie No. 855.)

7991. Sirit-0entjal S. 二 Sphæria a 11 ut a ce a Prs, Nat. fam. der Pyre n o m y c e te s. Gr. Java; zwamsoort. 7992. Siroëeh Sum. WK. = Para. panay sessile Miq., Nat. fam. der A r a li a c e æ. Gr. Sumatra; heester.

7993. Sisangkil Mavo. 二 Ge n da. russa vulgaris Nees. (Zie No. 1665.)

7994. Sitaboe M. = Plecto comia sumatran a Miq., Nat. fam. der P almie Gr. Sumatia; hooge Pulm.

7995. Sitadjo-hitam M. = B in. nendykia trichostylis K ii rz., Nat. fam. der Tili a c cæ. Gı. Sımatra (Palembang); heester.

7996. Sitakan-nan-djanten Sum. WK. = Rhus nodosa Bl. (Zie No. 3144.)

7997. Sitang-gadang Sum. WK. = Sty I ocoryna dasyph y 11 a Miq., Nat. f $₫$. der $R$ a b i a c e æ. GR. S umatra; heester.

7998. Sitapoeng Sum. W.K. 二 Callic a r p a Wallichiana Walp., Nat. fam. der Verben a c e $x$. Gr. Sumatra; heester.

7999, Siti-boppal of Siti-boppo Амв. 二 Ficus septica Sprg. (Zie No. 765.) 8000. Sitjantang $\mathrm{M}$. 三 $\mathrm{S} \mathrm{chmie-}$ delia mutabilis Bl., Nat. fam. der S a p ind a c e $\propto$. Gr. Java, Sunnatra; heester.

8001. Siwalen J. 二 B orassus flabelliform is L. (Zie No. 3117.) 8002. Siwarah J. $=$ Go u a nia retinaria D.C. (Zie No. 664c.)

8003. Siwe $\mathrm{Amb.}$. $\mathrm{Zingiber}$ of $\mathrm{fic}$ in a le L. (Zie No. 253.)

8004. Siwe-lale $\mathrm{Am}$. 二 $\mathrm{Z}$ ing iber g r a mi n e u m Bl. (Zie No. 25..)

8005 . Sjak-son Cн. Bo. = $\mathrm{Cr}$ inum a siaticum L. (Zie No. 869.)

8006. Sjamdaa-ingat Sum. WK. 二 otanthera moluccana Bl. (Zie No. 2238.)

8007. Ssjoe-0e CH. Во. = D io sc ore a al a ta L. (Zie No. 2803)

8008. Sjoe sjie.kw $\mathbf{1}$ Сн. Bо. $=\mathrm{Ci}$ trullus edalis Spach. (Zie No. 1059.)

8009. Sjoe-tjie-kap-pha Сн. Bo. = I m p tiens B a ls amina $\bar{L}$. (Zie No. 258.)

8010. Sjok-ma-foe CH. Bo, en 8011. Sjong-ma-foe CH. Bo. = Lagenaria idolatrica Ser. (Zie No. 4876.)

8012. Sjong-meong Сн. Bо. Andropogon Schœna nthus $\mathrm{L}$. (Zie No. 2523.)

8013. Sjuggi-fida T. $=\mathrm{E} u$ p h or- 
b i a nereifolia L. (Zie No. 44).

8014. Slada-ajer M. of

8015. Slada-tjai $\mathrm{S}$. $=\mathrm{N}$ a sturt i u $\mathrm{m}$ officinale R.Br., Nat. fam. der $\mathbf{C}$ r u c i f e $\mathbf{r}$ œ. Gr. Op Java gekweekt; overblijvend. Grir. De Waterkers is als toespijs en voor salade zeer gezocht, en wordt als geneesmiddel aangewend.

8016. Slocmar Вк. = J a c ki a orn a $t$ a W a ll. (Zie No. 7730.)

8017. Sloera-batoe Sum. WK. = A n tidesma pubescens Rxb., v a r. a. Nat. fam. der A n tid e s m e æ. Gr. Java, Sumatra; boom.

8018. Soä-abbal Amis en

8019. Soä-wali of Soa-wari Амв. $=a$. G netum edule B l. (Zie No. 532.) $=$ b. Gnetum funiculare B 1. (Zie No. 200.)

8020. Sobe-leijposso Aмв. = $\mathrm{Ne}$ penthes phyllamphora Wlld. (Zie No. 123.)

8021. Soë-weijer $C_{R}$. = Can ariopsis hirsuta B l. (Zie No. 2662.) 8022. Soeba-goratsji $\mathrm{T}$. $=\mathrm{Spi}-$ lanthes Pseudo-A cmella I. (Zie N o. 1753.)

8023. Scedjie M. $=$ Cordy lin e R u $\mathrm{mphii} \mathrm{Hк.} \mathrm{(Zie} \mathrm{No.} \mathrm{337.)}$

8024. Soedoe J. $=\mathrm{Euphorbia}$ a n tiquorum I. (Zie No. 1814.)

8025. Soedoe-soedoe J. 二Eu p h orb i a $n$ ere if olia L. (Zie No. 44.)

8026. Soegi-soegi Sum. WK. = P o. lygala Simassan Miq, var. l a n ce ol ata. (Zie No. 7904.)

S027. Soeka-doeka M. = $\mathrm{C}$ a s s i a m i mosoides I. (Zie No. 3157.)

8028. Soeka.rameh $J_{0}=\mathrm{S}_{\mathrm{a} \mathrm{m} \mathrm{b}} \mathrm{u}-$ c us javanica Rw dt. (Zie No. 4475 .)

8029. Soekan M. 二 Cole us a mb o in i cus. I. o u r. (Zie No. 69.)

8030. Soekat-kremi J. $=\mathrm{C}_{\text {a s- }}$ $8 \mathrm{yta}$ filiform is L. (Zie No. 203.) 8031. Soekat-srêp $=\mathrm{R}$ u b i a cordifolia L. (Zie No. 2380.)

8032. Soeket-kolonjono J. 二 A ta. $x$ i a $\mathrm{H}$ or sfieldii R. Br., Nat. fam. der $G \times$ a $m$ in e 2 . Gr. Java $5-8000^{\prime}$. Gr.BR. Dit gras is cen bijzonder gced roeder voor het vee en wordt veeal gezocht voor de paarden der Javaansche grooten.

8033. Soekkoen-bidji M.,

8034. Soekkoen-kapas M.,

8035. Soekkoen-oetan BD. cu

8035. Soekkoen-radja Bn. alle =
Artocarpus incisa L. (Zie No. 269.)

8037. Soekmo-deloewi J. = G u nner a macrophylla Bl., Nat. fam. der G u n nera c c.. Gr. Java 6000', Sumatra ; éénjarig. Gezr. De inlanders gebruiken de vrucht als prikkelend (stimuleerend) geneesmiddel.

8038. Soelabeh $\mathrm{Cr}_{\mathrm{r}}=\mathrm{De}$ end rolobium umbellatum W. \&. A. (Zie No. 1683.)

8039. Soelamoe M. $=a$. s o u la. me a a ma r a $\mathrm{L}$ a m. (Zie No. 1476.) 二 b. Heritieralittoralis Dryand. (Zie No. 752.)

8040. Soelamoe-ambon Алв. 二 A namirta flavescens Miq. (Zie No. 645b.)

8041. Soelamoe-kajoe M. = S o ul a m e a ma ra Lam. (Zie No. 1476.)

8042. Soelangari $\mathrm{S}$. $=\mathrm{L} \mathrm{ig} \mathrm{h} \mathrm{t-}$ footia gracilis Miq. (Zie No. 346.) 8043. Soclangkar S. = $a$. L e e a s u nd a i c a M i q., Nat. farn. der Le ea. c e æ. Gr. Java; hecster. Gebr. De inlanders drinkeu het sap van den wortel, vermengd met adas en poelassari, tegen dysenterie. (Zie overigens bij No. 133.) = 6 . Lee a s a mbucina Wlld. (Zie No. 133.)

8044. Soelangking $\mathrm{J}_{\mathrm{O}}=a$. A n i. someles ovata R. Br. (Zie No. 818.) $=b$. Pogostemon a u $\mathrm{x}$ cularia Hassk. (Zie No. 1443b)

8045. Soelangono J. $=\mathrm{G}$ a lium java n i cum Bl., Nat. fam. der $R$ ub i a c e æ. Gr. Java 6000'; éénjarig.

8046. Scelassie 11. (Zie Sielassie M.)

8047. Soelatri M. $=a . \mathrm{C}$ a l o phyl$\mathrm{lum}$ das y pod u m Miq, Nat. fam. der Clusiacer. Gr. Java; hoom. = $\dot{b}$. Calophyllum javanicum Miq., Nat. farn. als voren; booge boom. $=c$. Calophyllum spectabile Wlld. (Zie No. 1224.) $=d$. C a l o ph y ll $1 \mathrm{~m}$ Te y smanni Z oll., Nat. fam. als voren; boom. $=e . \mathrm{Cal}_{\mathrm{O}} \mathrm{phyll} \mathrm{um}$ venulos um Zull., Nat. fam. en Gr. dezelfde; hooge boom. $=f$. M e s u a f errea L. (Zie No. 6044)

8048. Soeli MAK. 二 Coloc a sia a n tiqu orn m S c hott. (Zie No. 245.) 8049. Soelowakko M. en

8050. Soelowakko-poetih M. = A denanthera falcata $\mathrm{L}$.

8051. Soembel-woeboe J. = Sani. 
c ula inontana Rwdt, var. (Zie No. 2245.)

8052. Soemboe $\mathrm{S} .=\alpha$. H y m e nachne interrupta Büse. (Zie No. 1657.)=$ b. Ju ucus communis. E. M eye r, Nat. fam. del J un e e æ Gr. Java 6000'; overblijvend. Grir. De wortels dienen voor pitten in de lampen.

8053. Soeminta $\mathrm{S}_{0}=$ Tetranthera a $\mathrm{m}$ a $\mathrm{r}^{\circ} \mathrm{N}$ e es. (Zie No. 2896.)

80j4. Soemoeroek Bo. = Teysmannia altifrons Z. \& M. (Zie No. 1110.)

805 5. Soengkej M. = a. Pero n ema c anescens Jack. (Zie No. 4533.) $=b$. Spathodea macroloba Miq., Nat. fam. der Bign o ni a e ex. Gr, Suinatra; hooge boom.

8056. Soengkej-allas $\mathrm{M} .=\mathrm{V}$ a $\mathrm{n}-$ gueria (Canthium) palenbaII i a M i q. (Zie No. 3215.)

80ь\%. Soenia $\mathrm{T} .=\mathrm{C} \approx \mathrm{s}$ al pin ia S a p pan L. (Zic No. 1807.)

8058. Soentie J. $=a . \mathrm{Z} \mathrm{ing} \mathrm{i} \mathrm{b} \mathrm{e} \mathrm{r}$ gramineum B l. (Zie No. 255.) = b. Kæmpferia pandurat a $R \times b$., Nat. fam. der Z i ngi b e r a e e æ. GR. Jara, Sumatra, de Molukken gekweekt en in liet wild; overblijvend. GEBR. Zie dat der K. rot unda I., No. 3576.; nog bezigt men dezen wortel als geneesmiddel tegen hoest en spruw.

8059. Soonting-poetih Sum. WK. $=$ Anthisthiria ciliata L. (Zie No. 2126.)

8060. Soepa-djeroek S. = L y e ope r d on gi gan te u m B atseh., Nat. fam. der $G$ a steromyetes. Gr. Java; Zwam.

8061. Soepan Bı. $=\mathrm{C}$ x s a l p in a S appan I. (Zie No. 1807.)

8062. Soera-diëng J. $=\mathrm{E} u$ p h o rbia plumerioides Teysm., Nat. fam. der E u phorb i a ce a. Gr. Midden-Java, op de graven geplant; heester.

80 i3. Soerantih Ml., Sum. $=$ Sh or ea lue ida $M$ iq (Zie No 5807.)

8064. Soerawoeng $\mathrm{S} .=a .0 \mathrm{O}$ imum sanctum L. (Zie No. 875.) = b. O e i m u m c a n u Sims., Nat.fam. der $\mathbf{L}$ a b i a $t$ $x$. Gr. Jara en Sumatra; éénjarig. $=c$. Cole us callos us $\mathrm{H}$ assk. (Zie No. 2100b)

8065. Soerawoeng-langhit $\mathrm{S}$. = a. Plectranthus javanicus Benth. (Zie No. 7595.) = b. Mosehosma polystachyum Benth. (Zie No. 832.)

8086 . Soerawoeng-leuwung $\mathrm{s}$. = Moschosma polystachyum Benth. (Zie boven.)

8067. Soeren J. $=\mathrm{Cedrel}$ a Too. n a $\mathrm{R} \times$ b. (Zie No. 267.)

8068. Soeren-lawat $\mathrm{J} .=\mathrm{Ce}$ d rela Teysmanni H assk.; Nat farn. der C edrelea. Gr. Oost-Java; hooge boom.

8069. Soeren-meirah J. = Cedrela in o d o r a Nat. fam. als voren. Gr. WestJava: hooge boom.

8070. Soeren-poetih J. = C e d r el a Toon a $\mathrm{Rxb}$. (Zie No. 267.)

S071. Soerian $\mathrm{S} .=\mathrm{C}$ a nariopsis hispida B l. (Zie No. 1249.)

8072. Soerian WK. $=\mathrm{Cedrela}$ ser r ul a t a Ml i ., Nat. fam. der C ed rele $æ$. Gr. Sumatra; hooge boom.

8073. Soerô J. $=\mathrm{C}$ h avie a Betle $M \mathrm{i} \mathrm{q.} \mathrm{(Zie} \mathrm{No.} \mathrm{28j.)}$

8074. Soero panda $J .=P l$ a $\mathrm{ta}$. go inc is a Hassk., Nat. fam. der P l a nt a g in e a. Gr. Java; overblijvend. Gebr. Als No. 1765.)

8075. Soeroe J. $=\mathrm{Euphorbia}$ nere if ol i a L. (Zic No. 44.)

8076. Soesoeän $M$ kM. $=\mathrm{Drym}$ i s. permu m u rens $k$ wd t., Nat. fam. der Thymelxacex. Gr. Celebes; fraaie boom.

8077. Soesoe karbo J. \& $M .=T$ abern mont a na floribunda Bl., Nat. fanı. der A p o c yn e $x$. Gr. Java; heester.

8078. Soesoe-moending $\mathrm{S} .=a . \mathrm{T}$ a. ber n x mont an a floribunda Bl. $=b$. Tabernamontana multiflor a S m., Nat. fam. als voren. Gk. De Molukkeu; heester. $=c . \mathrm{B}$ e a umontia multiflora T. \& B., Nat. fam. dezelfde. Gr. Jara; heester.

8079. Soesoe-poeloen LaMP. = Strob id i a sumatran a Miq., Nat. fam. der Zi nyiberacex. Gr. Sumatra; overblijvend.

8080. Soesoeroe (Sosoeroe) S. = a. Euphorbia an tiquorum $\mathbf{L}$. (Zie No.1814.) $=b$. Euphor bi a nereifolia L. (Zie No. 44.) $=c$. Euphorbia ligularia. Rxb., Nat. fam. der Euphor b i a e e . Gr. Java, Bali, de Molukken, veelal in hegren; boomachtig. GEBR. Zic de beide voolgaande. 
8081. Soesoeroe-boboeto T. $=\mathrm{F}$ le urya interrupta Gaud. (Zie No. 1701.)

8082. Soewala J. $=\mathrm{Licuala}$ spectabilis Miq. (Zie No. 7678.)

8083. Soewalan J. $=$ Borassus

flabell iformis L. (Zie No. 3117.)

8084. Soewalio S. $=\mathrm{E} n \mathrm{gel}$ h a rdtia spic ata B l. (Zie No. 4452d.)

8085. Soewangkong $\mathrm{J} .=a . \mathrm{Pty}$ chosperma appendiculat a Bl., Nat. fam. der Palm æ. Gr. De Molukken; boom. GEBR. Het hout gebruikt men voor lansen en gerecdschappen; de top van den stam (ho e moet) wordt, gekookt, gegeten; de bladscheden bezigt men voor vlechtwerk. $=b$. C a r y ot a f u rfuracea Bl. (Zie No. 2489) $=c$. Caryota maxima Bl., Nat. fam. der Palmx. Gr. Java 3-4000'; boom. $=d$. Caryota propinqua Bl. (Zie No. 3760.)

8086. Soewangkong-besar M. = Caryota maxima B l.

8087. Soffo-mani-mani T. $=a$. Dartus perlarius Lour. (Zie No.75.) $=b$. Botrymorus paniculata $\mathrm{M}$ i q. (Zie No. 3477.)

8088. Soffo-moetiara T. $=\mathrm{V}$ e rnonia leptophylla DC. (Zie No. $67 b$.

8089. Soga J. $=a . \mathrm{C} x \mathrm{~s}$ a $l p$ in ia ferruginea Dcsn. (Zie No. 4535.) $=b$. Serianthus grandiflora B e $n$ th., Nat. fam. der Mimose $x$. Gr. Java, hooge boom.

8090. Sohleh S. $=a$. M u s a o r$\mathrm{n}$ at a $\mathrm{R} \times \mathrm{b}$. (Zie No. 6881.) $=$ b. M u s a c o c e in e a A nd r., Nat. fam. der M us a c e æ. Gr. Java en Sumatra; overblijvend.

8091. Sohwoh J. = Engelh a r d$t$ i a spicata Bl. (Zie No. 4452d.)

8092. Sokir-sokor Sum. WK. = A dinandra cyrtopoda Miq. (Zie No. 421.)

8093. Sokka S. (Zie Santen S. \& M.) 8094. Sokka-boddas S. en

8095. Sokka-blaauw S. = Pavet$\mathrm{t}$ a in carnat a B l. (Zie No. 1997.) 8096. Sokka-burrum $\mathrm{S} .=a \cdot \mathrm{Pa}$ vet ta coeeinca L. (Zie No. 4177.) $=b$. Pavetta stricta Rxb. (Zie No. $4177 c$.)

8097. Sokka-djaroeng $\mathrm{S} .=\mathrm{Pa}$ vetta in e arn a ta B1. (Zie No. 1997.) 8098. Sokka-doeka M. = C a s i a mimosoides L. (Zie No. 3157.) 8099. Sokka-goenong S. = Pavet$t a s$ alie ifolia Bl. (Zie No. $6335 \mathrm{~d}$.) 8100. Sokka-koening M. = Pave tt a stricta Rxb. (Zie No. 4177c.)

8101. Sokka-konneng $\mathrm{S} .=a . \mathrm{P}$ avetta salicifolia Bl. = $b$. $\mathrm{Pa}$ vet t a a m boin i a B l. (Zie No. 101.) $=c$. Parctta fulgens Rxb. (Zie No. 633 šc. $=d$. P a vett a javan ic a B 1. (Zic No. 5999.)

8102. Sokka-oetan M. $=$ P a ve t$t$ a rosea $W$ all., Nat. fam. der $R$ ub i a c ex. Gr. Java; heester.

8103. Sokka-pootih M. = P a v t. t a nigrica ns R. Br., Nat. fam. als voren. Gr. Java; heester.

8104. Sokko T. en

8105. Sokoer $\mathrm{BD} .=\mathrm{K} æ \mathrm{mp}$ feria G a l a ng a L. (Zie No. 737.)

8106. Sôkô J. $=a . \mathrm{S}$ ar a k a min or M iq. (Zie No. 4703/.) $=\mathrm{S}$ a r a c a Zollingeriana Miq. (Zie No. 3474.)

8107. Soloelo.pohon M. $=\alpha$. P a r. $k$ insonia aculeata L. (Zie No. 3254.)=b$. Diph a c a co hinch i. $n$ en s is I, o ur. (Zie No. 7337.)

8108. Soloeng-badak LaMP. = Grumilea a urantiaca Miq. (Zie No. 4273.)

8109. Somangen J. = P a r o c h e$\mathrm{t} u \mathrm{~s}$ communis Ham. (Zie No. 7734.)

8110. Somangi $\mathrm{l}$. $=0 \mathrm{x}$ a $\mathrm{l}$ is cornie ulat a L. (Zie No. 1671.)

8111. Somangi-goenong $\mathrm{J}$. $=\mathrm{Pa-}$ roe het us communis $\mathrm{Ham}$.

8112. Sombang $\mathrm{BD} .=\mathrm{F}$ ir $\mathrm{u} \mathrm{s} \mathrm{v}$ arieg at a Bl. (Zie No. 1352.)

8113. Sombok $\mathrm{BD}_{0}=\mathrm{Cal}$ odra. conterminalis $\mathrm{Planch}$. (Zie No. 333b.)

8114. Sondak $\mathrm{BL}_{\mathrm{L}}=\mathrm{C}$ a n a n g a od or a t a H k. fs \& Th. (Zic No. 1373.)

8115. Songo-langhit $\mathrm{S}$. $=\mathrm{C}$ u $\mathrm{p}$ ani a regularis Bl., Nat. fam. der $\mathrm{S}$ a $\mathrm{p}$ i n d a c e $x$. Gr. Java, Sumatra, Borneo; booin.

8116. Songgom S. $=u . \mathrm{B}$ a r r ingto n a a lb a H a s s. (Zie No. 6931.) $=b$. Barringtonia a e $\operatorname{congula}$ Grtn. (Zie No. 9836.) $=c$. B a rringto ni a macrocarpa Hassk., Nat. fam. der M y r t a c e æ. Gr. Java; boom. $=d$. Barringtonia insignis Miq., Nat. fam. en Gr. dezelfde. $=e . \mathrm{B}$ a r. ringtonia? macrophylla $M$ i q., Nat. fam. en Gr. dezelfde. $=f$. B a r.- 
ring touia ra cemosa B l. (Zie No. 983.)=9$. Barrilgtoni a Vriesei T. \& B., Nat, fam. en GR. als roren. GeBr. De wortels der B a r r ingt on i æ schijnen verdoovende eigenschappen te bezitten, en worden daarom bij de vischrangst gebezigd. De schors dient tot het zwartverwen van garens. Het hout is wit en vast en geschikt voor timmerhout en kleine prauwen. Uit de zaden ran sommige soorten kan eene roode lampolie geperst worden.

8117. Songgom-andjing $\mathrm{S} .=a$. B a r ringtonia? macrophylla II i q. en $=b$. B arr. V riese i T. \& B. (Zie roren.)

8118. Songgom-lalaki S. $=\mathrm{B}$ a rringtonia speciosa L. (Zie No. 1463.)

8119. Songgom-lawut $\mathrm{S} .=\mathrm{B}$ a rringtonia macrocar j a Hassk. (Zie No. 8116.)

8120. Songi Cel. of

8121. Songin $\mathrm{B}_{\mathrm{G}}$. en

8122. Songo $11 .=$ Dillenia specios a Thn b. (Zie No. 61.)

8123. Songkam CH. Bo. $=\mathrm{Ci}$ trus limonellus Hassk. (Zie No. 761.)

8124. Songko J. = L a s i an thus purpureus Bl. (Zie No. 3154.)

8125. Sono J. en

8126. Sono-kling J. $=\mathrm{P}$ t e r o c a rpus indicus WIId. (Zie No. 18.)

8127. Sonoeboe-woeboe J. = Pilea or e ophila Miq. (Zie No. 69l6b.)

8128. Sontol M. $=\mathrm{S}$ andoricum in d i c u m Cav. (Zie No. 113.)

8129. Soö J. = Gnetum frnemon I. (Zie No. 820.)

8130. So-0elo Амв. of

8131. So-oer Amв. $=\mathrm{K} x \mathrm{mp}$ feria Ga la ng a L. (Zie No. 737.)
8132. Soör S. = a. A ut idesma diandrum Sprg. (Zie No. 6383.) = b. Antidesma pubescens Rxb. (Zie No. 8017.) $=c$. Antidesma tetra n drum B l. (Zie No. 4681.)

8133. Soör-poetih M. $=$ A n t ideswa monta u u B Bl. (Zie No. 2888.)

8134. Sosa $A$ ur. = Gendarussa vulgaris Nees. (Zie No. 1665.)

8135. Sosal Амв. $=\mathrm{Codiæum}$ moluccan um Desn. (Zie No. 126.)

8136. Sosillo Hox. = B ot r y morus paniculata $\mathrm{Iliq.} \mathrm{(Zie} \mathrm{No.} \mathrm{3477.)}$ 8137. Sou T. $=$ II a p pa molucc a $\mathrm{n}$ a $\mathrm{Spr}$. (Zie No. 56.)

8138. Soun Aзв. = A rt o c a rpus in cis a L. f s. (Zie No. 269.)

8139. Souniba-lawut-biberan T. of

8140. Souniba-lawat.boubou $\mathrm{T}$. = Sophora tomentosa L. (Zie No. 1490$.

814l. Sowagi S. en

8142. Sowagi-aroij $\mathrm{S} .=a$. Goua. n i a ja $r$ an ic a II i q., Nat. fam. der $\mathrm{R} \mathrm{h}$ a $\mathrm{m}$ n e æ. Gr. Java; klimplant. $=b$. Gonania leptostach y a D.C. (Zie No. $664 b.)=c$. Gou a nia micro. c a r pa D.C. Nat, fam. en Gr, als $a$.

8143. Stangi $\mathrm{S} .=$ M urra 5 a $\mathrm{f}$ œtidissima T. \& B. (Zie No. 4381.)

8144. Stiela $\mathrm{BK}_{\mathrm{K}}=\mathrm{B}$ at a $\mathrm{t}$ a s edulis Chois. (Zie No. 635.)

S145. Suelen $\mathrm{BD}_{\mathrm{D}}=\mathrm{I}$ e 1 o c a n n 2 humilis Rupr. (Zie No. 5521 .)

8146. Sughang $\mathrm{S}$. $=\mathrm{Ficus} \mathrm{hirta}$ $V$ a h l. (Zie No. 2682.)

8147. Sunda- Soenda) assam J. = T a mariudus indica Is. (Zie No. 723.)

8148. Sane Анв. $=\mathrm{Artoc}$ arp us in c is a l. f s. (Zie No. 269.)

8149. Sussuela $\mathrm{M} .=\mathrm{H}$ о у а с 0 ron a ria Bl. (Zie No. 5j6c.)
8150. Taä Аuв. = Conophallus? sativus Schott. (Zie No. 5317.)

81šl. Taai (tahi) angin $\mathrm{H}=\mathrm{C}$ assytafiliform is L. (Zie No. 203.)

8152. Taai-boerong $\mathrm{ML}=a$. Vis. cum articulatum Brm. \& al. Spec. (Zie No. $350 e$.) $=6$. Dendroph- tho ë pentandra L. et aliæ Loranthaceæ. (Zie No. 1205.) $=c$. Hydnophytum montannm Bl. (Zie No. 3018.)

81533. Taai-boerong-meirah M. = D e ndrophtlı ë. II a t. Spec.

8154. Taai-gigi $H_{0}=\mathrm{El}$ rocar 
p us o blongus $\mathrm{s}$ m. (Zie No. 4011.) 8155. Taai-hajam M. $=\alpha$. Tagetes erecta L. et $b$. Tagetes pa. t $u$ l a L., Nat. fam. der Com pos itæ. Gr. De Afrikaan vindt men door geheel Indië in tuinen als sierplant; éénjarig.

8156. Taai (kajoe) M. $=$ S te r. c u lia fot id a L. (Zie Nu. 1641.)

8157. Taai-manoek S. (Zie No. 8152.) 81 5. Taai-0etan M. = Lasianth us stercorarius Bl., Nat. fam. der $\mathrm{R} u$ bi ace $x$. Gr. Java en Sumatra; heester.

8159. Tabakoeli $\mathrm{T}$. $=$ Cy at he a a r b o r a L. (Zie No. 26 6 9.)

8160. Tabalissa M. $=\mathrm{Ky} 11 \mathrm{in}$. lingia monocephal a Rottb. )Zie No. 6410.)

8161. Taban LINGga $=1$ s o n a nd ra G u t a H o ok. (Zie No. 890.)

8162. Tabaratie $\mathrm{BK}_{\mathrm{K}}=\mathrm{Coleus}$ atropurpure us Benth. (Zie No. 748.)

8163. Tabat Cr. $=\mathrm{Bambusa}$ verticillat a Bl. (Zie No. 756.)

8164. Tabatiko.nani $\mathrm{T}$. $=\mathrm{B}$ a $\mathrm{m}$. b us a fera Miq. (Zie No. 774.)

8165. Tabatiko-toei T. $=\mathrm{B} \mathrm{a} \mathrm{m}$. busa longinodis Miq. (Zie No. 1340.)

8166. Taboapoei PAL. $=a$. Elæo. c a r p s ovalis Miq., Nat. fam. der Tili a c e r. Gr. Sumatra; boom. $=b$. Daphniphyllum glaucescens B 1. (Zie No. 2923h.)

8157. Taboeng-broe M. $=\mathrm{Ne}-$ penthes phyllamphora Wlld. (Zie No. 128).

8168. Tadjam J. 二 $\mathrm{H}$ i $\in$ us 'T a dja $\mathrm{m}$ M i q. (Zie No. 1446)

8169. Tadjam M. 二 G a le a ria elliptica Miq., Nat. fam. $\operatorname{der} \mathbf{A}$. ti d e s m e æ. Gr. Sumatra; heester.

8170. Tadjoe S. 二C in n a m o m u n itid u m Nees. (Zie No. 4733c.)

Taëing Mak = Artocarpus pubescens $\mathrm{Bl}$. (Zie No. 1119.)

8171. Taêroe Акв. = W e in man. n i a $\mathrm{Blum}$ e i Planch. (Zie No.4658.)

8172. Taëwan Aмв. - A n t i a $r$ is

Fretessi $i$ ' $T$. \& Bk., Nat. fam. der A r t o c a r p e a. Gr. De Molukken; hooge boom

8173. Tagalgnama $\mathrm{T}$. $=\mathrm{A} \mathrm{n} \mathrm{th}$ is. tiria ciliata Is. (Zie No. 2126.)

8174. Tagal-0etan T. 二 a. $\mathrm{Poa}$ a mboinensis I. (Zie No. 7953). =
6. Scleria lithosperma Wlld. (Zie No. 3005̃b.)

8175. Tagallo T. en

8176. Tagalola MEx. 二 $\mathrm{Ficus}$ se ptica S p reng (Zie No. 764.)

8177. Tagarei J. = C a s s i a Tora

I. (Zie No. 73.)

8178. Tagoelela Aмв. of

8179. Tagoerela Амв. en

8180. Tagorera $\mathrm{BD}_{1}=\mathrm{A}$ ver r h o a

B i li m b i L. (Zie No. 853.)

8181. Tagogak S. = Flem ing i a stricta $\mathrm{Rxb}$. (Zie No. 6727.)

8182. Tagogan $\mathrm{S} . \overline{\mathrm{F}} \mathrm{lem}$ ing ia latifolia Bnth. (Zie no. 427) 二 b. Flemingia congesta $R \times b$. (Zie No. 6338.) 二c. Desmodium poly c a r p in DC. (Zie No. 1664.)

8183. Tagorela Aмв. 三 El во. c arpus edulis T. \& B., Nat. fam. der Tiliace $æ$. Gr. Amboina; boom.

8184. Tahalale $\mathrm{Aмв.}=\alpha$. A g a ricus tuber regi u $\mathrm{Tr}$. en $=b$. $\mathrm{Pachyma}$ t uber regium Tr. (Zie No. 1959.)

818ว. Tahi Амв. 二 Bruguiera R u m phi i B l. (Zie No. 8666.)

8186. Taiba of Taipa Амв. \& Мак. 二 $\quad \mathrm{Ma}$ I g ifera indica L. (Zie No. 275.) $=b$. M a n if er a T' a p u $\mathrm{H}$ a m. (Zie No. 57216.) 三c. Mang ifera timorensis Bl. (Zie No.639כ̌b.)

8187. Taiba-bonka Mak. 二 M a ngifer a indica L. va r, d. (Zie No. 275.)

8188. Taibi-pali-pali MAK. $=M$ an. gif e r a m in o r B l. (Zie No. 5457.)

8189. Taindeh ArF. MIN. $=\mathrm{Z}$ e a II a is L. (Zie No. I878.)

8190. Tai-soi Cн. Bo. 二 A rtan ema sesamoides Bnth. (Zie No. 6697 c.)

8191. Takka M. 二 Conophal. lus? sativus Schott. (Zie No. 5317$.

8192. Takka-besar M. 二 A mor. phophallus campan $\mathrm{platus} \mathrm{Bl.}$ (Zie No. 750.)

8193. Takka-goenong M. 二 $a$.

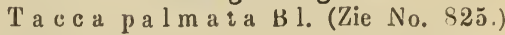
二 b. Tacca $\mathrm{R} n \mathrm{mphi}$ Schauer. (Zie No. 2271b.)

8194. Takka-koelat M. - Zie No. 8132.)

8195. Takka-lawat $\mathrm{M}$. 二 T a c c a pinnatifida Forst. (Zie No.6105.) 8196. Takka-oetan M. - $а . '$ 'Т а с с a 
pa $1 \mathrm{mata}$ B l. (Zie No. 825.) $=b$. A morphophallus campanulat u s B l. (Zie No. 750 .)

8197. Takka-oetan-ketjil M. =T a c c a $\mathrm{R} \mathrm{m} \mathrm{phi} \mathrm{Schauer}$. (Zie No. 22716.)

8195. Takkari T. = Di a n ell a nemoros a I a m. (Zie No. 5079.)

8199. Takkari-lawut T. = C y perus kylling io ides V a hl. (Zie No. 5988.)

8200. Takki T. = Cy perus rot u n d u s I. (Zie No. 5302.)

8201. Takoässa Амв. = C r i u m a s i a ti c $11 \mathrm{~m} \mathrm{L.} \mathrm{(Zie} \mathrm{No.} \mathrm{869.)}$

8202. Takoet-manoesija M. 二 $\mathrm{Oxa-}$ lis Reinwadti $\mathrm{Z}$ ucc. (Zie No. 251.)

8203. Takokkak S. $=$ Solan u m i l d i c u m N e es.. Nat. fam. der So. I a n e æ. Gr. Java; heester.

8204. Takokkak-boddas S. 二 $a$. S o. l a num indicum Ne es. (Zie voren.) = b. Solanum Pseudo-saponac e u m B l. (Zie No. 5597.)

8205. Takokkak-lumboet $\mathrm{S}$. $=\mathrm{S}_{0}$ -

la n u m indic um Nees.

8ฆ06. Takokkak-0etan $\mathrm{S}$. $=\mathrm{Cle}-$ rodendrum fragrans Vent (Zie No. ว 648 .)

8207. Takokkak.pahit S. 二 S o la. n $\mathrm{um} \mathrm{indicum} \mathrm{N}$ e es.

8208. Tal J. of

8209. Tala Mak. 二 Borassus f 1 a bell iform is I. (Zie No. 3117.)

8210. Taladjauw PAL. $=N$ o thoprotium sumatran u $\mathrm{m}$ iq. (Zie No. 6250 .

8211. Talak S. = Rott lera dis$p$ a $r$ B l., Nat. fam. Uer $E n p h o r b$ i ac e æ. Gr. Java en Bali; heester.

8212. Tal-ü̈ Aмв. 二 Trichosanthes trifoliata B l. (Zie No. 262b.)

8213. Tali-ajer I. = Un c a ria lanos a Wa 11 . (Zie No. 27.)

3214. Tali andjing M. 三 a. A c:a$1 \mathrm{ypha}$ densiflora Bl. (Zie No. 1440.) $=b$. Cladostachys frutescens Don. (Zie No. 838)

82 $1^{\circ}$. Tali-api M. $=\mathrm{T} \mathrm{ragi} \mathrm{a} \mathrm{h}$ ir. s u ta Bl. (Zie No. 1326.)

8216. Tali-baboeni M. $=a$. C issus repens Lam. (Zie No. 438.) = b. Cis us latifolia Vahl., Nat. fam. der Ampeli dex. Gr. De Molukken; klimplant. FreBr. Men bezigt de bladeren als rijpmakend en etterbevorderend middel op abcessen, zweren, enz.

8217. Tali.bakompol M. 二 D e $\mathrm{r}$. $r$ is montana Benth., Nat. fam. der Papilionacea. Gr. De Molukken; klimplant. Grir. Men eet de jonge bladeren als groente; in aftreksel toegediend zullen zij licht zweetdrijveud werken.

8218. Tali-boeboet $\mathrm{M}$. = Ventilago maderaspatana Gictn. (Zie No. 999.)

8219. Tali-gnemon M. 二 $\mathrm{tum}$ e dule B l (Zie No. 532.) $=6$. Gnetum funic: ulare B l. (Zie No. 200.)

8220. Tali-kaffa J. = Poly podi u m la cin iatu m L, (Zie No. 3537.) 8221. Tali-kandjoe $\mathrm{S}$. $=\mathrm{B}$ a u h $\mathrm{i}$. $\mathrm{n}$ i a tom entos a L. (Zie No. 4497.)

8222. Tali-kandjoe-burrum S. = $\mathrm{Ph}$ ane $\mathrm{r}^{\circ} \mathrm{v}$ a $\mathrm{r}$ egat a B e $\mathrm{nth}$., Nat. fam. der Papilion a c ex. Gr. Java ; slingerplant.

8223. Tali-karbou M. $=\mathrm{Artabo}$. trys suaveoleus B l. (Zie No. 5̌

8224. Tali-koening $\mathrm{M}$. 三 A n a$\mathrm{mirtaflavescens} \mathrm{Miq}$. (Zie No. 6456.)

8225. Tali-koepang $\mathrm{M}$. $=\mathrm{D}$ ios. c orea num ularia $\mathrm{n}$ a m. (Zie No. 1778.)

8226. Tali-koessoe M. 二 $\mathrm{Agla}$. nema? c us cu a i a Mi q., Nat. fam. der A roid e æ. Gr. Amboina; overblijvend. GEBr. De bloemen en vruchten dezer plant ziji door de buidelratten zeer gezocht.

8227. Tali-morea $\mathrm{N} .=a . \mathrm{Med}$. nilla macrocarpa Bl. (Zie No. 64.) = b. Medinilla crispata Bl. (Zie No. 52 297.)

8228. Tali-pisang M. 二 U varia argentea Bl. (Zie No. 573.)

8229. Tali-sait $\mathrm{M}=a . \mathrm{C} \circ \mathrm{m} \mathrm{me}$ ly na benghalensis L. (Zie No. 2549.) $=$ b. Commelyna com mu$\mathrm{nis} 1$. $=c$. Com mely a salic ifolia $R \times b$. en $=d$. Aneilema lineolatum $K u n t h .$, alle van de Nat. fam. der $\mathrm{C}$ o m m e l y n e æ. Gr. Op Java en elders; overblijvend. GEBR. De stengels en bladeren dezer plantjes worden in stoom gekookt en bij de rijst als groente gegeten.

8230. Tali-tali R. 三 Qua moclit v u l g a r is Chois. (Zie No. 533.)

8231. Tali-toeakka M. 三 $\mathrm{Fa}$. 
græa littoralis Bl. (Zie No. 4255.) 8232. Taliabo-soela-bassa Xula. $=\mathrm{Quercus} \mathrm{molucea} \mathrm{R} \mathrm{m} \mathrm{ph.} \mathrm{(Zie}$ No. 109.)

8233. Taliengkcep S. $=\mathrm{Cl}$ a o $\mathrm{x}$ -

lon indi cum Fndl. (Zie No. 1268.) 8234. Talimpoek of Talipoek BK. Rottlera macrostachya Miq. (Zie No. 4123.)

8235. Talioe-batoe Вк. = Term inali a $\mathrm{C}$ at a p a C. (Zie No. 7.)

8236. Talipoe Mak. $=$ Limnan$\mathrm{them} \mathrm{um} \mathrm{indicum} \mathrm{Griseb.} \mathrm{(Zie}$ No. 4200.)

8237. Talipoh Sum. WK. - $\mathrm{Nym}$ phra stellata Wlld. (Zie No. 3765.) 8238. Talisseij $\mathrm{M}_{\mathrm{AK}}$. $=\mathrm{B}$ a r $\mathrm{r}$ in gton i a specios a L. (Zie No. 1463.) 8239. Talla of Tallan $\mathrm{Bn} .=\mathrm{Pi}$ soni a lb a Span. (Zie No. 120b.) 8240. Talla-hoho MAK. $=\mathrm{Sida}$ a cuta L. (Zie No. 1802 )

8241. Tallak $S .=$ Di os pyros frutesceus R. Br. (Zie No. 4817.)

8242. Tallam MaK. 三 M elocanna h u milis Rupr. (Zie No. 5521.)

8243. Talla-talla J. = $\mathrm{Smilax}$ z e y l a nic a L. (Zie No. 717.)

8244. Tallas of Tallus $\mathrm{S}$. $=\mathrm{C}$. loc asia antiquor u m Schott. (Zie No. 245.)

8245. Tallens-benteng S. $=\mathrm{Col}$ oc a sia antiquorum Schott., var. a trosang u in ea $\mathrm{Hskl}$. (Zie voren.) 8246. Talleus-boeng-boelan S. $=$ Colocas ia a ntiquorum Schott. v ar. $\mathrm{min}$ or $\mathrm{H}$ a s sk. (Zie voren.)

8247. Talleus-heedjoh S. $=$ Coloc a si a a tiquorum Schott., var. a troviridis $\mathrm{H}$ assk. (Zie voren.)

8248. Talleus-kangkaring S. $=\mathrm{C}_{0}$ locasia antiquorum Schott., var. variegat a Hassk. (Zie voren.)

8249. Talleus-ketan S. 三 Colocasia a n ti quor um Schott., var. s cripta Hassk. (Zie voren.)

8250. Talleus-koekoek S. 二 Coloc a sia antiquorum Schott., var. l urida $\mathrm{H}$ as sk. (Zie voren.)

8251. Talleus-roemah S. $=\mathrm{Col}$. casia antiquorum Sehott., var.

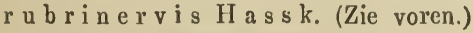

8252. Talleus-soerat $\mathrm{S} .=\mathrm{Col}$ casia antiquorum Schott., var. s c ripta Hassk. (Zie voren.)

8253. Talli-wal NG. = Pittos. porum chelidospermum Bl., Nat. fam. der Pittos poreæ. Gr. NieuwGuinea; boom.

8254. Taloe-radjin Sum. WK. 三 Vitis Teysmanni Miq.. Nat. fam. der A mpelideæ. Gr. Sumatra; slingerplant.

8355. Taloeka Aмв. = Bixa Orellana L. (Zie No. 1697.)

8256. Taloetoe MAK. 二 Aralia javanic a Miq. (Zie No. 132.)

8257. Talok J. \& S. $=a . R$ ot t. lera dispar Bl. (Zie No. 8211.) = b. Grewia tomentosa Juss. (Zie No. 3904.) $=c$. Grew a celtidif o li a J u s s., Nat. fam. der Tili a ceæ. Gr. Java; boom. $=d$. G r e w i a in qua lis Bl., Nat. fam. dezelfde. Gr. Java, Timor; boom.

8258. Talom BL. = Indigo f e ra tintoria L. (Zie No. 2305.)

8259. Tama-aöer Амв. = Pуgeu m a c u m in a t u m Colebr., Nat. fam. $\operatorname{der} \Lambda \mathrm{m} y \mathrm{gdal}$ e æ. Gr. Amboina, enz; boom.

8260. Tamalaki BD. = Tamarind u s ind ic a L. (Zie No. 723.)

8261. Tamalla BL. = Melo canna h u milis $\mathrm{R} \mathrm{u} \mathrm{pr.} \mathrm{(Zie} \mathrm{No.} \mathrm{5521.)}$

8262. Tamalasse (of Tamaloessel) Амв. = Dysoxylon alliaceum B l. (Zie No. 3212.)

8263. Tamandilang $S$. en

8264. Tamanti S. = A n tid esm a heteroph s ll u m Bl. (Zie No. 4367.)

8265. Tamasoe Sum. WK. 三 Schi$\mathrm{m}$ a crenat a $\mathrm{K}$ or $\mathrm{th}$. (Zie No. 5535 .)

8266. Tamatta MaK. $=\mathrm{C}$ a rd i op. ter is moluccana Bl. (Zie No. 5859)

8267. Tamatta $M$. en

8268. Tamatta-bontal M. en

8269. Tamatta-taijris M. = L y c opersicum esculent um Mill. (Zie No. 1111.)

8270. Tambaga $\mathrm{s}$. 二 $\mathrm{J}$ a mbos a te $\mathrm{n}$ u i cuspis Miq. (Zie No. 7614.)

8271. Tambakan S. = Polyg on u m c h in ense I. (Zie No. 1822.)

8272. Tambakkoän $\mathrm{S}$. = T o u $\mathrm{r}$ nefortia argentea L. (Zie No. 3884.)

8273. Tambako of Tambakoo M. $=\mathrm{Nicotiana} \mathrm{Tabacum} \mathrm{L.} \mathrm{(Zie}$ No. 867.)

8274. Tambako-arab J. $=\mathrm{Nico-}$ ti a n a rustica L.. Nat. fam. der Sol a ne æ. Gr. Op Java en elders in tuinen; zaadplant. 
8275. Tambako-djapon J. $=\mathrm{Ni}$ cotiau a Langs ouf i i Weinm. Nat. fam. als voren. Gr. Op Java in tuinen, nit Brazilië; zaadplant.

8276. Tambako-kaap J. en

8277. Tambako-kadoe J. 三 Ni c otiana fruticosa L. cum var. a ngu stif o li a D u n., Nat. fam. dezelfde. Gr. Op Java gekweekt, van de Kaap overgebracht; heesterachtig.

8278. Tambako-lalai J. = Ni c o. tian a plumbaginifolia Viv., Nat. fam. als voren. Gr. Op Java in tuinen, uit Mexico en Cuba; zaadplant.

A! deze tabaksoorten komen als rookof pruimtabak in den inlandschen handel voor.

8879. Tambako-lawat $\mathrm{M}$. = Tournefortea argentea I. (Zie No. 3884.)

8280. Tambako-lessari J. $=\mathrm{Ni}$. cotiana La lug dorfii Weinm. (Zie No. 8265.)

8281. Tambak0-0etan M. 三 Laws o $n$ i a a l b a L a m. (Zie No. 1747.)

8282. Tambak0-tjina J. $=\mathrm{Ni}$ c 0 tian a chine n s is $\mathrm{k}^{\mathrm{i}}$ is ch. Nat. fam. der S ol a n c æ. Gr. Op Java in tuinen uit China; zaadplant.

8283. Tambakoän S. = E hretia d i c hot o m a B l., Nat. fam. der C o rd i a c e æ. Gr. Java; kleine boom.

8284. Tambang $\mathrm{J} .=\mathrm{A} \mathrm{c} \mathrm{a} \mathrm{l} \mathrm{y} \mathrm{p} \mathrm{h} \mathrm{a}$ h ispida $R$ wdt. (Zie No, 2174.)

8285. Tambang-tambang Sum. WK. $=$ Polyphragmon compressic a u le Miq., Nat. fam. der Rubiac e æ. Gr. Sumatra; heester.

8286. Tambar MaK. = I u ff a p entandra Roxb. (Zie No. 636.)

828\%. Tambara-maritja Mak. 二 B r uce a sumatrana Roxb. (Zie No. 296.)

8288. Tambara-rappoe-rappoe MaK. = Clerodendrum inerme Gærtn. (Zie No. 1243.)

8289. Tambatiko-ake T. $=\mathrm{B}$ a mb us a a spera R. \& S. (Zie No. 934b.) 8290. Tambesoe (Tambessoe) M. = Fagræa fragrans Roxb. (Zie No. $4363 b$ )

8291. Tambesoo-rawang $\mathrm{M}$. = Fagræa elliptica Roxb. (Zie No. 45706 )

8292. Tambesoe-renah M. $=a$. F a græa fragrans Roxb. (Zie No. 43636 .) $=$ b. Fagræa percgrina B l. Nat. fam. der Loganiacea. Gr.
Java, Sumatra, de Molukkẹn; hooge boom . 8293. Tambesoe-talang M. = F agræa fragrans Roxb. (Zie No. 4363b.)

8294. Tamboe Mak. 三 X y loc arpus Granatum Koen. (Zie No. 1319.)

8295. Tamboe-noeno BG. 二 $\mathrm{G}$ u il a ndin a $B$ ond u c L (Zie No. 1475.)

8296. Tamboeli-lato CeL. 二 $\mathrm{Eu}$ c a lyptus deglupta Bl. (Zie No. 35$.

8297. Tamboen Men. $=\mathrm{Streblus}$ macrophyllus Bl., Nat. fam. der A r toc a r p e . Gr. Noord-Celebes bij Likoepang; kleine boom. Grir. Het hout dient voor rijststampers.

3298. Tamboen-tahi M. \& PAL. 二 a. M yristica iners B l. (Zie No. $7171 . j=b .1$ a l berg i a $\mathrm{Z}$ ollingeri a n a i q. (Zie No. 1316b.)

8299. Tambontoe Sum. $=\mathrm{M}$ æ s a polyanth a $S \mathrm{ch}$ eff., Nat. fam. der M y r si ll e a c c x. Gr. Sumatra; heester. 8300. Tambos S. = Cyperns H a span L., Nat. fam. der C y p e ra. c e æ, Gr. Java, Sumatra, euz.; overblijvend.

8301. Tamia S. = Dispor $\mathrm{nm}$ multiflorum Don. (Zie No. 1137.) 8302. Tamma-lassin Aмr. 二 G arc i n i a C a mbogia Des rouss. (Zie No. 733.)

8303. Tamoegas-djamboe PaL. = M emccylon caloneuron Miq., Nat. fam. der M e las to maceæ. Gr. Sumatra; heester.

8304. Tamok BK. = P i erar dia r a c c mos a B l. (Zic No. 1580.)

8305. Tampa-badak-lawut M. = L a ctaria salubris Rmph. (Zie No. 5518.)

8306. Tampa-bessi Sux. = C a l. li carpa sum atran a M i q. Nat. fam. der V e r b e n a c ex. Gr. Sumatra; heester.

8307. Tampa-lari Sum. WK. = C a ll i c a r a long if olia Lam (Zie No. 4020b.)

8308. Tampak-belah of Tampokbelah BL. = Mussa ënda Te ys$m a n n$ i a a M i q., Nat. fam. 'der $R u$ b i a c e $æ$, Gr. Bali; heester.

8309. Tampal-badak $\mathrm{S}$. $=$ C y $\mathrm{r}$. tosiphonia sumatrana Miq. (Zie No. 436.)

8310. Tampan-bessie Sum. WK. = Meliosma confusa B1., Nat. fam. der 
I e li osme æ. Gr. Sumatra; heester.

8311. Tampang LAMP. = Artocarpus L. S pec. diversæ.

8312. Tampang Sum. WK. $=a$. Ficus Tampang Miq., Nat. fam. der A rto c a r pe a. Gr. Sumatra; boom. $=$ b. Artocarpus rigida 81 . (Zie No. 1454.)

8313. Tampang-telor $\mathrm{M}$. = $\mathrm{Fi}-$ c us inconstantissim a Miq. Nat. fam. als boven. Gr. Sumatra; heester.

8314. Tampar-kidang $\mathrm{S}$. = A ntid e sma to m e n t o s u m Bl., Nat. fam. der A n tid e sm e a. Gr. Java; heester.

8315. Tampinies $\mathrm{BK}$. $=\mathrm{Slo}$ e tia Si d e r ox y lon T. \& B. (Zie No. 38246.)

83i6. Tampoang-lawut $\mathrm{M}$.二 $\mathrm{Ch}$ o nanth u s littorea Mi q., Nat.fam. der Ole in e æ. Gr. Sumatra; boom.

8317. Tampoe-song $\mathrm{T}$. $=\mathrm{N}$ o thopanax fruticosum Miq. (Zie No. 1153.)

8318. Tampoh-tampoh-badak Sum. WK. = Gardenia resinifera K orth. (Zie No. 3418.)

8319. Tampoea M. = P i ër ar r ia d u l c is J a ck. (Zie No. 1503.)

8320. Tampoei M. 二 $a$. Pi ërardia macrocarpa Miq. (Zie No. 4857.) $=$ b. Hed y car pus ma la yan u s J a c k. (Zie No. 1500.)

8321. Támpoei-bernei Bк. 二 $\mathrm{Pi}$. ërardia pubera Miq., Nat. fam. der Euphorbia c ex. Gr. Bangka; boom.

8322. Tampoei-boerong $\mathrm{BK}_{\mathrm{K}}$ 二 $\mathrm{Pi}$ ërardia dulc is Jack. (Zie No. 1503.)

8323. Tampceni Sum. WK. 二 A rt o c a r us rigida Bl. (Zie No. 1454.)

8324. Tampoerau M., Bo. Zo. = Dipterocarpus Tampurau Korth., Nat. fam. der. Di ptero c a pea. Gr. Borneo; hooge boom.

8325. Tampoeti $\mathrm{T}$. $=\mathrm{K} æ \mathrm{~m} \mathrm{p} \mathrm{fe}$ ria pandurata Roxb. (Zie No. 80586$.

8326. Tampong-batti-rimbo Sum. IVK. 二 Sty loc ory ne das y p y lla II i q. (Zie No. 7997.)

8327. Tanasa Ar. 二 Clima c a nd r a s licifolia $M$ i q., Nat. fam. der M yrsine a c e $æ$ Gr. Aroe-Archipel; boom.

8328. Tandai BK. = Quercus brevipetiolatus Scheff. (Zic Blai-angien.)
8329. Tandang-tandang M. = $\mathrm{Pr}$ e m n a $\mathrm{l}$ viga ta $\mathrm{M}$ i q., Nat. fam. der Verbenacer. Gr. Sumatra; heester.

8330. Tandika-batoe Sum. WK. = Meliosma polyptera Miq. (Zie No. 808.)

8331. Tandjang $\mathrm{J}$. 三 $\mathrm{Br}$ u $\mathrm{g} \mathrm{u}$ i e ra c y li n d ri c a B l. (Zie No. 1662.)

8332. Tandjong $\mathrm{M}$. $=\mathrm{M}$ i m u s o p s E leng i L. (Zie No. 13996.)

8333. Tandjondong-ampaleh Sum. WK. = Salix Horsfieldiana M i q. (Zie No. 2583.)

8334. Tandoe-tandoe $\mathrm{M}$. = $\mathrm{W}$ il$\mathrm{lugh} \mathrm{beia} \mathrm{firma} \mathrm{Bl.} \mathrm{(Zie} \mathrm{No.} 250 \mathrm{l}$.

$83: 6$. Tandoek-minjangan $\mathrm{M}$. = Dic e rolepis paludosa Bl., Nat. fam. der Ascle pi a deæ. Gr. Javi ; slingerplant.

8337. Tandong-rimoe M. = Premna populifolia M iq., Nat. fam. der V e r b e n a c e. Gr. Snmatra; heester.

8338. Tangan-tangan-djara MaK. = Ricin u s com $\mathrm{m} \mathrm{un}$ is L. (Zie No. 1975.)

8339. Tangan-tangan-kalli Maк. = Curcans purgan s Mddk. (Zie No. 1987.)

8340. Tangan-tangan-nikaureh MaK. = Carica papaya (Zie No. 1092.)

8341. Tangi-tangi-sanorongeh Sum. WK. 二 H e y e a s u m tran a Miq., Nat. fam. der M c li a c e æ. Gr. Sumatra; boom.

8342. Tangies Вк. = Con ocephalus ellipticus Tréc. Nat fam. der A r t o c r per, Gr. Bangka en Riouw; klimmeude heester.

8343. Tangiesan-baroek. Sum. WK. 二 H eynea s u matrana Miq. (Zie No. 8341.)

8344. Tangiling M. \& S. 二 T a c ca palmata Bl. (Zie No. 825.)

8345. Tanginoer Bat. $=\mathrm{Ny} \mathrm{m-}$ phæa stellata Bl. (Zie No. 3765.)

8346. Tangkal-mienjān S. Z Styrax Benzoin Dryand. (Zie No.3311.)

8347. Tangkallak $\mathrm{S}$. $=\mathrm{Le} \mathrm{pida-}$ denia Wightiana $\mathrm{N}$ ees. (Zie No. 2893.)

8348. Tangkawang-pinang Bo. WK. = 1o. Shorea Pinanga S cheff. en $=20$. Shorea Martiniana; beide van de Nat. fam. der Dipter oc a $\mathrm{r}$ p e $\boldsymbol{x}$. Gr. Borneo; plantenvet-gevende boomen. 
8349. Tangkiel (Tangkil) $\mathrm{S} .=\mathrm{Gn}$ et u m G n e mon. I. (Zie No 820.)

8350. Tangkiel-assoe S. en

83ŏl. Tangkiel-bourriet s. = Gnet u m edule Bl. (Zie No. 532 .

83 šl $\alpha$. Tangkiel-karang S. = G n et u m ne glectum Bl. (Zie No. 168.)

8352. Tangkiel-0etan $\mathrm{S}$. $=\mathrm{Gne}$. $\mathrm{t} u \mathrm{~m}$ G n e mon L; (Zie No. 820.)

8353. Tangkoeloe S. 二 $\mathrm{Eg} \mathrm{le} \mathrm{mar-}$ melos Corr. (Zie No. 1194)

83s 4. Tangkoelong (Tangoelong) S. 二 $a$. M i m us ops K a k i L. (Zie No. 1497.) $=b$. Protiu $\mathrm{j}$ a vani e $\mathrm{m}$ B u r in. (Zie No. 4031b)

835̌. Tangkoelong-ketjil M. = Sehinus terebiuthifolius Radd i. Nat. fam. der A n a eardieæ. Gr.op Java in eenige tninen, uit Amerika gebraeht; deze altijd als met kristallen bedekte boom zweet eehte terpentijn uit.

8356. Tangkoerat J. = Fieus radieans Roxb. (Zie No. 1652.)

8357. Tangkoeroengo M. 三 K orthalsia Teysmanni Miq.; Nat. fam der $\mathrm{Palm}$ a . Gr. Sumatra; klimplant.

8358. Tangkolloh $\mathrm{S} .=\mathrm{Kle}$ inhovia hospita L. (Zie No. 3927.)

8359. Tanglar S. 三 $a$. Canarium littorale Bl., Nat. fain. der A myri deæ. Gr. Java; hooge boom. $=b$. Ag la y a a r g e n tea Bl. (Zie No. 6596.) $=c$. A glaya i næqualis T. \& B. Nat. fam. der Meli a e æ. Gr. Java; boom.

8360. Tanglar-monjet S. = $a$. Milu e a Sul in gi T. \& B. (Zie No. 4516b.) 二 6 . Dy soxylon ae uminatissimum Bl., Nat. fam. der Meliacex. $\mathrm{G}_{\mathrm{R}}$. Java; boom.

8361. Tangoeli J. = $a$. Cassia fistul a L. (Zie No. 1306.) = 万. Cassi a javianie a L. (Zie No. 1025.)

8362. Tangogo of Tangohgon $\mathrm{S} .=$ a. Castanea javaniea Bl. (Zie No. 2468.) $=$ b. Castanopsis Tungur r li Miq., Nat. fam. der Cu puli f e $r$ æ. Gr. Java; boom. Gebr. Zie bij No. 2468.

8363. Tangtang-angin S. $=a$. Deeringia eelosioides R. Br. (Zie No. $995 b)=b$. Deeringia indiea Zoll. (Zie No. 995.) $=e$. Thyssanolæn a a e a r if era A. \& N., Nat. fam. der $\mathrm{Gr}$ a in in ex. Gr. Java; overblijvend.

8364. Tangtang-goelo S. $=\mathrm{T} \mathrm{e}-$ lanthera strigosa Moq. Tand. (Zie No 1636.)

836ว. Tanidri $\mathrm{M}_{\mathrm{AK}}$. = I pomæ reptans Poir. ("ie No. 526.)

8366. Tanjoerah s. = Myrmeeodia eehinata Gaud. (Zie No. $3018 c$.)

8367. Tankal-raijana $\mathrm{S}=\mathrm{La}$ et u c a in d ic a L. (Zie No. 7191a.a.)

8368. Tankal-sauki $\mathrm{S}=\mathrm{Pid}$. dingtonia nummularia A. DC, Nat. fam. der L o beli a e e æ. Gr. Java; kruipende plant.

8369. Tankari Амв. = Dianella ne moros a La m. (Zie No. 5079.)

8369a. Tankei-lajoe M. = Trie holobus fulvus Bl. (Zie No. 811 .)

8370. Tankelle $\mathrm{S}$. $=\mathrm{Kleinho-}$ vi a hospita L. (Zie No. 3927.)

8371. Tankoerak S. 二 $a . \mathrm{H} \mathrm{y} \mathrm{d.}$ nophytum montanu $\mathrm{m}$ B l. (Zie No. 3018.) = 3. M y r meeodia eehi. nata G a ud. (Zie No. $3018 c$.) $=c$. Paehyeentria eo nstrieta B I. (Zie No. 2748.)

8372. Tankoerak-monjet S. \& M. 二 a. Triehosanthes la einiosa K le i n (Zie No. $521 c$.) $b$. C u e u r b i. ta littoralis Hsskl., Nat. fam. der C u e u r b i t a e e re. Gr. Java; overblijvend $=c .11$ od g son i a hetero. elita Hk. fs. \& Th, Nat. fam. dezelfde. GR. Java; klimplant

8373. Tankokkak S. (Zie Takokkak S )

8374. Tan-kwee J. $=\mathrm{Cu}$ e urbi ta villos a 13l. (Zie No. 904b.)

8375. Tanna J. $=\mathrm{C}$ ol e u s atro. purpureus Buth. ('Zie No. 748.)

8376. Tapanawa Амв. = Poth os graeilis Rxb. (Zie No. 5654.)

8377. Tapanawa-bediri Амв. 二 A gla on em a marant.æfolium Bl., Nat. fam. der. A ro idere. Gr. De Molukken; overblijvend.

8378. Tapanawa-ketjil Амв. 二 Pothos seanden s L. (Zie No. 571.)

8379. Tapanawa-Taijris Амв. = Seindapsus pertusus Sehott. (Zie No. 5492.)

8380. Tapa-pokang Solor. = C oe os nu e if e ra L. (Zie No. 393.)

8381. Tapah-liman J. = Ele. phan topus seaber L.. Nat. fam. der $\mathrm{C}$ om p o sit æ. Gr. Zeer algemeen door geheel Indië; overblijvend. GEBR. 1)e wortel, en ook de geheele plant, geeft men 
in afkooksel als versterkend en minnedriften opwekkend geneesmiddel. Een koud aftreksel dient men toe tegen slepende buikziekten en spruw. De bladeren eet men als groente; ook worden ze als wondheelend middel zeer geroemd. Men geeft ze ook aan paarden tegen hoest door koudevatting en rermoeidheid veroorzaakt.

8382. Tapak-djalak (Hapok dja. lak) $J .=a$. Dactylocten u m æ g y p i a c u in Wlld. (Zie No. 234tb.) 二 b. Phalænopsis am abilis B 1. (Zie No. 374.)

8383. Tapak-lehman Sum. WK. Panax tricochleatum Miq., Nat. fam. der Araliace a. Gr. Sumatra; heester.

8384. Tapen J. \& S. 二 Rottlera acuminat a Juss. (Zie No. 2813.)

8.385. Tapen-saijoeng S. 二 $a$. Rotliera acutifolia $\mathrm{Hassk.}$ Nat. fam. der Eupborbia ceæ Gr. Java; heester. 二 b. Rottlera scabrifolia Juss. (Zie No. 7919.)

8386. Tapeussa Амв. 二 $\mathrm{Cr}$ i n u m a siaticum L. (Zie No. 869)

8387. Taping J. 二 Lus i a thus inod orus BI, Nat. fam. der Rubia c ег GR. Java; heester.

8388. Tapis Sum. WK. 二 $\alpha$. Guatteriagla u ca M i q. (Zie No. 3503.) = b. Guateria s umatrana Mi q. (Zie No. 1113.)

8389. Tapi-bareh Sum. WK. en

8390. Tapis boelan Sum. WK. G u a t t eria $\mathrm{s}$ u in a $\mathrm{r}$ a $\mathrm{n}$ a $\mathrm{Mi}$.

8391. Tapis-mienjak M. = G oniothal am us Ta p is Miq. (Zie No. 3497.)

8392. Tapis-sagar Su.r. WK. = G u a t e ria 'Teys man i M i q, Nat. fam. der $\mathbf{A}$ n o nacese. Gr. Sumatra; boom.

8393. Tapoes S. $=a$. Elet taria a 1 b a B 1. (Zie No. 7334) = b. Elettaria coccinea B 1. (Zie No. 5786.)

8394. Tapoes-bener S. = Elettaria c o c c in e a B 1. (Zie No. 5786.)

8395. Tapoes-sigoeng $\mathrm{S}$. $=\mathrm{El}$ e t. taria fotens B l. Nat. fam, der Z i n g i e r a c ex. Gr. Java; éénjarig. 8396. Tapos S. E Elaterios perma T a pos B l. (Zie No. 7064.)

8397. Tappa-gadja M. = I p om a peltata Chois. (Zie No. 303.)

8395. Tappa-rawa-rawa Мак. 三 II angiferaminor Bl. (Zie No. 5457.)
8399. Tappal-inam M. = I pо ґа peltat a Chois. (Zie No. 303.)

8400. Tarangti $\mathrm{BK}$. $=\mathrm{Melod} \mathrm{i}$ nus lavigatus Bl, Nat. fam. der A p o c y n e æ. Gr. Java; slingerplant.

8401. Tarangtan Sum. WK. 二 $a$. B uchanani a u r culata. B l, Nat. fam. der A n a c r d i a c e. GR. Sumatra, Borneo; hooge boom. $=b . \mathrm{B}$ chanania macrophyll a Bl. (Zie No. 5561 .)

8402. Tarantang-ajam PAL. 二 $\mathrm{B} u$ chan a i a sessilifolia Bl. (Zie No. 7214.)

8403. Tarantang-boerong M. = B uchan ania splendens Miq., Nat. fam. als voren. Gr. Sumatra; hooge booin.

8404. Tarapandi Lamp. = $\mathrm{P} t \mathrm{t}$. rocarpus? hypostictus Miq., Nat. fam. der Papilionace a. Gr. Sumatra; boom.

8405. Tarattas $\mathrm{S} .=\mathrm{D} \times \mathrm{mon}$. rops oblongus $\mathrm{M}$ art. (Zie No. 2839.)

8106. Taratteh $\mathrm{M}$. $=\mathrm{Nelu} \mathrm{m}$. bium speciosum Wlld. (Zie No. 6712)

8407. Taratteh-biroe M. $=\mathrm{N} \mathrm{y} \mathrm{m}$ phæa stellata W lld. (Zie No. 3765.)

8408. Taratteh.gedeh S. $=\mathrm{Ne}$ $\mathrm{lumbi}$ un specios u m Wld. (Zie No. 6712.)

8409. Tarratteh-goenong M. = G un era ma crophylla Bl. (Zie No 8037.)

8410. Taratteh-ketjil N. of

84.11. Taratteh-leutiek s. $=a$. if y m p a a s tellat a W $11 \mathrm{~d}$. (Zie No. 3756.$)=b$. N y m p ra L o t u s L. (Zie No. 4198.) $=c$. L im n a them u m in di c u m Gris. (Zie No. 4200.)

8412. Taratteh-sajor M. 二 L i m. na n the m u m indic $n \mathrm{~m} \mathrm{Griseb.}$

3413. Tarigoe M. 二 $a$. S e c a le cereal e L. Nat. fain der Gra minece. Gr. De Rogge wordt op Java en elders verbouwd. 二 $b$. Tri t i c u in v ulg a r e L. (Zie No. 24l4.)

8414. Tarissie $\mathrm{S}$. $=\mathrm{A} \mathrm{l} \mathrm{b} \mathrm{izz} \mathrm{i} \mathrm{a}$ micrantha Boiv. (Zie No. 4449b.)

1515. Tarissie-aroij $\mathrm{S}$. $=\mathrm{A} 1 \mathrm{biz}-$ z i a $r$ fa B nth., Nat. fam. der M im o s e s. Gr. Java; klimplant.

8416. Taroe Sum. IVK. 二 Artoc a r us incisa I. (Zie No 269) 
8417. Taroem $11 . \&$ S. $=$ Indi. go fera L. S pec. diversæ.

8418. Taroemaloes $\mathrm{M}$. $=\mathrm{I}$ nd igofera leptostachya DC., Nat. fam. der Papili o n ace ex. Gr. Java; zaadplant.

8419. Taroem-akkar M. = M ars. denia tinctoria R.Br. (Zie No. $676 b$.)

8420. Taroem-aroij $S=a$. Marsdenia tinctoria R.Br. (Zie No. $676 b$.) $=$ Marsdenia parviflora 1) c sn. (Zie No. 676.)

8421. Taroem-bengala M. = I ndigofera tinctoria L. (Zie No. 2305 .)

8422. Taroem-goenong $\mathrm{M}=\mathrm{Par}-$ s o n si a javanic a B l., Nat. fam. der A p o c y n eæ. Gr. Java; heester?

8423. Taroem-kajoe M. = In digofera tinctoria $L$. var. (Zie No. 2305.)

8424. Taroem-kembang $M$. 二 Indigoferia Anil I., Nat. fam. der Papilion a ceæ. Gr. Java; éénjarig.

8425. Taroem-oetan M. 三 Indigofera ga legoides DC., Nat. fam. als voren. Gr. Java, Sumatra; kleine heester.

8426. Taroemtembanga $M$. = In. digofera Anil L., var. (Zie No. 8424.)

8427. Taroentoem BK. = I، u mnitzera coccinea W. \& A., Nat. fam. der C a m b reta ceæ. Gr. De Sunda-eilanden; heester.

8428. Taroentoeng $\mathrm{BK}$. $=\mathrm{S}$ id e $\mathrm{r}$ oxylon attenuatum DC. (Zie No. 1203.)

8429. Taroes-poetih Sum. WK. 三 A morphophallus campanula. t u s B l. (Zie No. 750.)

8430. Tarrietie $\mathrm{S}$. $=\mathrm{T}$ arrietia ja va nic a B l. (Zie No. 4563.)

8431. Tasbeh-burrum $\mathrm{S} .=\mathrm{C}$ anna co c cine a A it. (Zie No. 4150.)

8432. Tasbeh-konneng S. 三 Canna f I a vescens L k. (Zie No. 4150.)

8433. Tatambagan $=a$. Eragrostis ciliata Nees., Nat. fam. der Gram in eæ. Gr. Java; overblijvend = b. Eragrostis verticillata $\bar{R}$. \& S. (Zie No. 8785.)

8434. Tatambagan-aloes S. = Spart in a glabri us cula H assk., Nat. fam. der Gra mi n e æ. Gr. Java; overblijvend.

8435. Tatambagan-boddas S. =
A taxia Horsfieldii R. Br. (Zie No, 8032.)

3836. Tatambagan-gedeh $\mathrm{S} .=\mathrm{Sp}$ orobol us pulchellus R. Br., Nat. fam. der Gramine x. Gr. Java; overblijvend.

8437. Tatapaijan S. = A rgy re i a mollis Chois. (Zie No. 597.)

8438. Tataroe-maä J. $=\mathrm{D}$ er ris montana $B$ nth. (Zie No. 8217.)

8439. Tataroeman S. = a. Polyo$\mathrm{zus}$ a c u min a t a Bl. (Zie No.4378b.) $=b$. M elodinus laxiflorus Bl., Nat. fam. der A p o c y n e æ. GR. Java; slingerplant. $=c$. $\mathrm{D}$ e ndrocharis in fl a t a $\mathrm{II}$ i q, Nat. fam. dezelfde. Gr. Java en Sumatra; slingerplant.

8440. Tatempéan J. $=a . A \mathrm{~d} \mathrm{~h} \mathrm{a-}$ tod a vasica Nees. (Zie No. 1304.) $=b$. Barleria lupulina Lindl. Nat. fam. der A c a $\mathrm{t}$ h a c e $x$. GR. als sierplant op Java in tuinen; heester.

8441. Tatengoran S. $=\mathrm{Grewia}$ tomentos a Juss. (Zie No. 3904.)

8442. Tatepal of tatupele Амв. Seleria lithosperma Wlld. (Zie No. $3007 a$.)

8443. Tatoeme-auer Амв. еn

8444. Tatoeme-kaboele Амв. $=$ Me. lanolepis? calcosa Miq. (Zie No. 37.)

8445. Tatter $\mathrm{S}$.二 Sol a n u $\mathrm{m}$ verb a s c ifolium L. (Zie No. 5249.)

8446. Tat-wel Bl. = Artoc a r pu s in te grifolia I. (Zie No. 276.)

8447. Taunoewie Амв. $=\mathrm{Ruel-}$ lia d is color Nees. (Zie No. 72.)

8448. Tawan M. 三A r t o c arpus e ch in a t a $R x b$, Nat. fam. der A rt o c a r p e æ. Gr. Sumatra (Lampong); boom.

8449. Tawar-tawar Sum. WK. 二 Costus speciosus Sm. (Zie No. 3247.)

4450. Tawas BL. $=W h r i g h$. ti a pubescens R.Br. (Zie No. 1184.) 8451. Tawas M. = Poly podium quercifolium Wlld. (Zie No. 181.)

8452. Tawassen Alf. Min. = M etrosylon Rumphii Mart. (Zie No. 279.)

8453. Tawawe T. $=\mathbb{E}$ giceras fl oridum R. \& S. (Zie No. 130.)

8454. Taijas Sur. $=\mathrm{Par}$ in ari u m costatum Bl., Nat. fam. der C hry s o b a la n e . Gr. Sumatra; boom. 
845. Teba-teba Mor. = B a m bu s a T e ba Miq. (Zie No. 1325.)

8456. Tebabak Bk. (Zie Mensidoen Bk.)

84.57. Tebe-poessa $\mathrm{CR}_{\mathrm{r}}=\mathrm{C}$ o stus speciosus Sm. (Zie No. 3247.)

84ว8. Teboe M. \& S. $=\mathrm{Sacch}$ a$\mathrm{r} u \mathrm{~m}$ of $\mathrm{ficin}$ a $\mathrm{rum}$ L. (Zie No.6257.)

8459. Teboe-asrap of Teboe-assap S. $=\mathrm{Saccharum}$ officinarum $\mathrm{I}_{\text {., }}$ v a r. fu mosu m H a ssk.

8460. Teboe-burrum-gedeh S. = $\mathrm{Sacch}$ a rum of ficinar u $\mathrm{mL}$. var. n ig r u m H a s k.

8461. Teboe-burrum-leutiek S. S a ccharum officinar um L., $\nabla$ ar. rubrum hamile Hassk.

8462. Teboe-burrum-tingi S. S a ccharum officinarum L., var. $\mathrm{rubrum}$ altum Has sk.

8463. Teboe-hiedung $\mathrm{S} .=\mathrm{S}$ a ccharum officinarum L., var. n igru m Hass.

8464. Teboe-japara $\mathrm{S}$. = S a c ch a. ru m of ficinar u m L., var. lit te$\mathrm{ratum} \mathrm{H}$ as sk.

8465. Teboe-konneng-amoh $\mathrm{S} .=$ $\mathrm{S}$ a c charum officinarm $\mathrm{L}$, var. $\mathrm{luteum} \mathrm{molle} \mathrm{Hassk}$.

8466. Teboe-konneng-kras S. S acch a r m of ficinarum L., var. late um d urum H a s s k.

84.67. Teboe-lilin $\mathrm{S} .=\mathrm{S}$ a $\mathrm{ch}$ a r u $\mathrm{m}$ off i c in a r u m L., var. cand elare $\mathrm{H}$ a s s k.

8468. Teboe-meirah-pendekh S. = $\mathrm{S}$ a ch ar u m officinarum I., var. $\mathrm{rubrum}$ humile Hassk.

8469. Teboepekes $\mathrm{S} .=\mathrm{Saccha-}$ rum officnarum L., var. lit te$\mathrm{r}$ a t u m H assk.

8470. Teboe-rapoe $\mathrm{S} .=\mathrm{S}$ a charum officinarum L. var. luri. $\mathrm{du} \mathrm{m} \mathrm{H}$ a s s k

8471. Teboerottan S. $=\mathrm{S}$ ac ch a. rum officicarum L., var. cala$\mathrm{mi} \mathrm{H}$ as sk.

8472. Teboe-soerat S. S a c h a r um officinarum L., var. litter a. tu m Hassk.

8473. Teboe-soerat.pendek S. 二 S a c. charum officinaru $L$, var. litteratum breve $\mathrm{H}$ ass $\mathrm{k}$.

8474. Teboe-tawar Вк. = Costus speciosus Sm. (Zie No. 3247.)

8475. Teboe-telor M. en

8476. Teboe-troeboe $\mathrm{M}$. $=\mathrm{sac}$. charum edule Hassk. (Zie No. 2998.)
8477. Teboe-toetoenoe BD. $=\mathrm{Ar}$ is. tolochia indica L. (Zie No. 207.)

8478. Teboeboek Вк. 三 $\mathrm{Hopea}$ fagifolia Miq. (Zie No. 4075.)

8479. Teboel-tiboel S. $=$ Hоу a coronaria Bl. (Zie No. 576c.)

8480. Tedjo Cr. 三 Cin n a mom um Culilawan Nees. (Zie No. 2287.)

8481. Teedja M. = Cinnamomum eucalyptoides Nees. (Zie No. $5546 c$.)

8482. Tegerang $\mathrm{M}$. $=\mathrm{Cudranus}$ a mboineasis $\mathrm{Rmph}$. (Zie No. 760.)

8483. Tehe Амв. 三 Schleichera trijuga Wlld. (Zie No. 47.)

8484. Te-hit-sjoe Cн. Bo. 三 $\mathrm{C}$ a lodracon Jacquini Planch. (Zie No. 333.)

8485. Tehij Asв. = Bruguiera Rumphii Bl. (Zie No. 866b.)

8486. Tehoe-lepoe Амв. 三 Costus speciosus Sm. (Zie No. 3247.)

8487. Tekabbal Cr. 三 Crin u m a siaticum L. (Zie No. 869.)

8488. Tekari J. = Dianella ne. morosa Lam. (Zie No, 5079.)

8489. Teker M. \& CeL. 三 Eleocharis tuberosa Schult. (Zie No. 7263.)

8490. Tekie M. \& S. 二 $a$. Fimbristylis communis Kunth., Nat. fam. der Cyperaceæ. Gr. Java en elders; overblijvend. $=b . \mathrm{Fimbristyl-}$ lis latifolia Kunth., Nat. fam. en Gr. als voren. $=c$. Ele ocharis ery. throchlamys Miq., Nat. fam. en Gr. als voren. $=d$. Cy'perus rotundus L. (Zie No. ә298.) 三e. Cyperus tu. berosus Rottb., Nat. fam. en Gr. als voren.

8491. Tekie-keboh S. 三 Cyperus rotundus L. (Zie No. 5298.)

8492. Tekie-laki-laki M. = C vperus hexastichus R. \& S., Nat. fam. der Cy peraceæ. Gr. Java; overblijvend.

8493. Tekie-lawut M. 二 a. C yperus kyllingioides Vahl. (Zie No. 5998.) = 6. Cyperus longus L., Nat. fam. der Cyperaceæ. Gr. Java en Su. matra; overblijvend.

8494. Tekieh-poetih M. = K $\mathrm{l}$ lingia monocephala Rottb. (Zie No. 6410.)

8495. Tekie-wangi M. = Cу perus tuberosus Rottb. (Zie No. $8490 e$.) 8496. Tekini J. = $\mathrm{Hydrocotyle}$ asiatica I. (Zie No. 70.) 
8497. Telang Mi. = Cjitoria ternatea L. (Zie No. 13ว9.)

8498. Telieng $\mathrm{BK}_{\mathrm{K}}=\mathrm{Commer-}$ sonia echinata Forst. (Zie No. 106.)

8499. Telin-hahoeloe Амв. 二 Ва mbusa aspera R. \& S. (Zie No. 934b.)

8500. Telioe BD. = Terminalia moluccana Wlld. (Zie No. 3912.)

8501. Telioe Sum. = Cardiospermum Halicacabum L. (Zie No. 433.)

8502. Telipok S. 二 Limnanthe$m u m$ calycinum Miq., Nat. fam. der G e n ti a neæ. Gr. Java; éénjarig.

8503. Teloek S. = Hibiscus vulpi nus $R w d t$., Nat. fam. der Mlalrac e æ. Gr. Java, in tuinen als sierplant; heester.

8504. Telontaga of Telongtaga J. = Alternanthera denticulata R. Br., Nat. fam. der $\Lambda$ marantaceæ. GR. Java; éénjarig.

8505. Tema Cr. = Musa paradisi ac a L. (Zie No. 1190.)

8506. Tema-tenalla-langit $\mathrm{Cr}$. = II usa uranoscopus Rmph. (Zie No. 6890$.

8507. Tembassouw M. $=a$. Rourea florida $\mathrm{Miq}$, Nat. fam. der Conn arac eæ. Gr. Sumatra; Borneo; slingerplant. = $b$. R ourea a cutipetal a Miq. Nat. fam. dezelfde. Gr. Sumatra; slingerplant.

$\mathrm{BK})$

8508. Tembesoe Bк. (Zie Tambasoe

8509. Temboeloe J. = Metroxylo n Sagus R ottb. (Zie No. 1322.)

8510. Temedah Lamp. = Artocarpus varians Miq., Nat. fam. der Art o carpeæ. Gr. Sumatra; hooge boom.

85 11. Temeras-akkar M. =Strychnos lanceolaris Miq, Nat. fam. der L oga niaceæ Gr. Sumatra; klimplant.

85̃12. Temeras-rawang $\mathrm{P}_{\mathrm{AI}}=\mathrm{Van}$. gueria lucidula Miq, Nat. fam. der R ubiaceæ. Gr. Sumatra; heester.

8513. Temeroe $\mathrm{Bk}$. = Fagræa peregrina Bl. (Zie No. 8292b.)

8514. Temiki M. = Citrullus edulis Spach. (Zie No. 1059.)

8515. Temman J. = Graptophyllum hortense Nees. (Zie No. 90.)

8516. Temoe (temo) M. = Curcuma Zerumbet $\mathrm{Rxb}$. (Zie No. 3866.)

8517. Temoe-giring $\mathrm{M}$. $=\mathrm{Cur}$ cuma viridiflora $\mathrm{kx}$ b. (Zie No. 5026.)

8518. Temoe-koentji M. = $a$. Kæmpferia pandurata $R \times b$. (Zie
No. $8058 b.)=b$. $\mathrm{K} æ \mathrm{mpferia}$ rotundata L. (Zie No. 3576.)

3519. Temoe-lawak M. en

8520. Temoe-tis J. $=\mathrm{Curcuma}$

Zerumbet Rxb. (Zie No. 3866.)

8521. Temoetoen BK. = Trides$\mathrm{m}$ is formosa Korth. (Zie No. $583 \mathrm{~s} b$.) 8522. Tempo-triong J. = Gynura a urantiaca DC. (Zie No 22196.)

8523. Tempo.wijong J. =Emilia sonchifolia D.C. (Zie No. 2221.)

8524. Tempoeja bali BL. = $\mathrm{H}$ y $\mathrm{pt}$ is suaveolens Poit (Zie No. 791.)

8525. Tenam Вк. = Psychotria le uc ocoma T. \& B., Nat. fam. der Rubia ceæ. Gr. Bangka; heester.

8526. Tenam sangi BK. = $a$. Psy. chotria Sangiana Miq., Nat. farm. als voren. GR. Bangka; heester. $=b$. Grumilea Teysmanniana Miq., Nat. fam. en GR. als boven.

8527. Tenarrom $\mathrm{Bk}$. = Indigofera tinctoria I. (Zie No. 2305)

8528. Tengkawang Bo. $=\mathrm{Hopea}$ $R x b$. Spec. diversæ. Alle hooge en harsrijke boomen, die reel plantenvet ('T e n g k a w a n g-olie) opleveren en ook voor timmerhout zeer geschikt zijn.

8529. Tengkawang-batoe Bo. = Hopea Seminis de Vr.; Nat. fam. der Dipterocarpeæ. Gr. Borneo; hooge boom.

8530. Tengkawang-blongseng $\mathrm{B} \circ$ = Hopea Balangeran Korth. (Zie No. 898.)

8531. Tengkawang-lajar Bo. = Hopea macrophylla de Vr.. Nat. fam. als boven. Gr. Borneo; hooge boom.

8532. Tengkawang-seloengsoeng $B o$ = Hopea Balangeran Korth. (Zie No. 898.)

8533. Tengkawang-tarinda Bo. = Ho pea lanceolata de Vr., Nat. fam. en $\mathrm{Gr}$, als boven.

8534. Tengkel S. = Tylophora tenuis Bl. (Zie No. 642b.)

8535. Tengoeloeng $\mathrm{S}$. = Tangkoelong $\mathrm{S}$.

8ร36. Tjengtjektja $\mathrm{S}$. $=\mathrm{Nanclea}$ parvifolia Rxb (Zie No 969.)

8537. Tenjo $\mathrm{S}$. = a. Mastixia pentandra Bl. (Zie No. 2914.) $=b$. Mastixia trichotomo Bl. (Zie No 4400.)

85̌38. Tèo-koh Ch. Bo. = Vigna sinensis Sa vi (Zie No. 3935.)

3539. Tepoen-ottop S. = Stellaria 
saxatilis $\mathrm{H}$ amilt., Nat. fam. der Caryopylle a. Gr. Java 6000'; éénjarig.

8540. Tepoes $\mathrm{S} .=a$. El e t ta. ri a a l b a B l. (Zie No. 7334.) = 6 . Elet taria coceinea Bl. (Zie No. 5786$.

8541. Tepoes-bener S. = Elet$t$ a $r$ a c oc cine a $\mathrm{B}$.

85 42 . Tepoes-leuwung $\mathrm{S}$. 三Ele tt a ria coc cine a B l., var.aperta. 8543. Tepoes-malehleh S. E Ele tt a $\mathrm{r}$ i a a 1 b a B l.

8544. Tepoes-sigoeng $\mathrm{S}$. $=\mathrm{Elet}$ t a ria $f$ te n s Bl. (Zie No. 8395.)

8545. Tepoes-tjangkrie S. en

8546. Tepoes-tjatjaboetan S. = Elett a ria cocin e a Bl., varie$\mathrm{t}$ a t es. ( $\mathrm{Zie}$ boven.)

8547. Tepohot Bo. $=\mathrm{Me} \mathrm{mecy-}$ lon appendic a latum Bl. (Zie No. 4496.)

E548. Tepon J. $=\mathrm{Campelia}$ g la brata K unth. (Zie No. 4014).

S549. Teponang $\mathrm{J}$. $=\mathrm{Com} \mathrm{m} \mathrm{e-}$ l у и р а I udosa B l. (Zie No. 2089.)

85วั0. Tepong-Tepong PAL. $=\mathrm{C}$ a llicarpa Wallichiana Walp. (Zie No. 7998.)

8551. Terap R. $=A r t o c a r p u s$ e last i ca Rwdt. (Zie No. 1307.)

Sรัว2. Teratap Вк. 三 L е и о р оgon malayan us J a ck., Nat. fam. der E p a c $\mathrm{r}$ id e æ. Gr. Suniatra; kleine boom.

85๊ร3. Teregoh LaMP. $=$ C a sta. u е a $\mathrm{T}$ ung u r r u B l. (Zie No. $8362 b$.)

8554. Terin-rahoeroe Амв.二 В а mbusa aspera R. \& S. (Zie No. 9346.)

85ร5. Teroes J. $=\mathrm{Gendarussa}$ vulgaris $\mathrm{N}$ e es. (Zie No. 1665.)

8556. Terong J, M. \& S. 二 a. S ola num I., Species plurimæ. 二 b. Solanum Melongena L. (Zie No. 2340.) $=$ c. Solanum ferox L.; var. involucratum B l. (Zie No. 38786.)

5557. Terong-andjing $\mathrm{M}$. $=\mathrm{S}_{0-}$ l a n m pressum Dun., Nat. fam. der Sola n e æ. GR. De Molukken; heester. GEBr. De vruchten worden rauw gegeten, nadat zij eerst van de zaden ontdaan zijn. Men kent aan den wortel een sterk uitdrijvend vermogen toe.

8558. Terong-bali M. en

8559. Terong-blanda M. $=\mathrm{L} \mathrm{y-}$ copersic $1 \mathrm{~m}$ esculentum Mill. (Zie No. 1111.)

8๊60. Terong-boddas S. 二 $a$. S olanum Melongena L. (Zie No. 2340.) $=6$. Solan um Pseudo. undatum B l.. var. le ucocarpum B l. Nat. fam. der Sol a n e æ. Gr, Java in tuinen; heester. GEBR. De vruchten worden rauw en gekookt gegeten.

No.)

8562. Terong-gedeh $\mathrm{S}$. $=\mathrm{Sola}$ n u m M longen a L. (Zie No. 2340.)

8563. Terong-getah S. 二 Solan u m pressum l) un. (Zie No. 85̌57.)

8564. Terong-hoemboet M. 二 So. la $\mathrm{num}$ M e longena L., $\nabla$ a r.

8565. Terong-kapipit J. $=\mathrm{P} \circ \mathrm{ly}$ ga la venenos a J uss. (Zie No. 4029.)

8566. Terong-kenda S., ook

8567. Terong-kendie S. = Solanum Melongen a L., var. minus a r c o la tum.

8568. Terong-koepa S. 二 Sola$\mathrm{numPseudo-undatum} \mathrm{Bl.var.}$ a t ropurpuras cens. (Zie No. 85606.)

8569. Terong-korri-boddas S. = $\mathrm{C}$ a lon y c tion s pecios u m Bl. (Zie No. $489 d$.)

8570. Terong-korri-burrum S. = Calonyction speciosum Bl. v a l. $1 \mathfrak{\text { ve }} \mathrm{Cho}$ is.

8571. Terong-korri-heedjoh S. 二 Calonyction speciosum Bl. var. $\mathrm{pubescens} \mathrm{Cho}$ is.

8572. Terong-lehles S. 二 Solan u m Pse udo=undatum Bl., $v$ a r., al. b i florum B l. (Zie No. 8560b.)

8573 Terong-oetan $\mathrm{M}$. = Solan $\mathrm{nm}$ trongum Poir. (Zie No. 3878c.)

8574. Terong-pahit M. 二Sola num undatum L am.. Nat, fam. als boven. GR. Java en Borneo in tuinen; heester. GEBR. Als No. 8557.

8575. Terong-pandjang M. (Zie Te. rong-boddas S.)

8576. Terong-piiet S. = Solanum a l b u m L o u r., Nat. fam, als voren. Gr. Java; heester. Geвr. Als No. 8557.

8577. Terong-pipit S. = Solanum atroanthum Dun. (Zie No. 7326.)

8578. Terong-poegoer of -poehoer S. Z Solanum undatum I am., 
var. sph cerocarpum Hassk. (Zie No. 8574.$)$

8579. Terong-poetih M. $=$ Solan um Pseudo-u ud at um Bl. var. le uc o c arpam B l. (Zie No. 85606.)

8580. Terong-prah $\mathrm{H}$. = a. Sola$\mathrm{n} \mathrm{u} \mathrm{m} \mathrm{a} \mathrm{l} \mathrm{bu} \mathrm{m} \mathrm{Lo} \mathrm{u} \mathrm{r.} \mathrm{(Zie} \mathrm{No.} \mathrm{8576.)}$ $=$ b. Solanum pressum l) un. (Zie No. $855 \%$.)

8581. Terong-rangoe $\mathrm{S}$. $=\mathrm{S}$ ol an u m Pseudo-undat um Bl,, var. a l b iflorum B l. (Zie No. 85606.)

8582. Terong-sapi M. $=\mathrm{S}$ o l a nu m ferox L. (Zie No. 38786 .)

8583. Terong-sirit-koeda J. = $\mathrm{S}_{0}$. lan um Melongena l., var. (Zie No. 2340.)

8ว 84. Terong-tjinnang $\mathrm{S}$. $=\mathrm{S}_{0-}$ l a um Trongum Poir. (Zie No. 3878c.)

8ว 8. . Terongan $\mathrm{S}$. $=\mathrm{Sola} \mathrm{num}$ parasitic u m Bl. Nat. fam der Sol a n e . Gr. Java; Sumatra; heester ; parasiet.

8586. Terrie S. = Salix Horsfie $1 \mathrm{~d}$ ian a M i q. (Zie No. 2583.)

8587. Tespong M. \& S. $=a . \mathrm{Da}$. syloma javanicum Miq. (Zie No. 4281.) $=b$ (Enanthe javan ica DC., Nat fam. der U m b ellife $r$. GR. Java; eenjarig. $=c$. G y in no pet a $1 \mathrm{u} \mathrm{m}$ piperifoli u m M i g., Nat. fam. der C u c u r b i t a c eæ. Fr. Java, slingerplant.

8588. Tespong.poetih M. $=\mathrm{D}$ i chrocephala paniculata Miq. (Zie No. 1093.)

8589. Tetangies $\mathrm{Br} .=\mathrm{F}$ i c u s $\mathrm{T}$ etangi es $\mathbf{M}$ i q., Nat. fam. der A r toc a r p e æ. Gr. Bangka; heester.

8590. Tetengoran $\mathrm{S} .=\mathrm{Gr}$ ew ia tomentos a Juss. (Zie No. 3904.) 8591. Tetera $\mathrm{S}_{0}=\mathrm{Pidding \textrm {t } _ { 0 - }}$ nia patens Miq., Nat. fam. der Lob eli a c e æ. Gr. Java; éénjarig.

8592. Teterongan $\mathrm{S} .=\mathrm{G} \mathrm{ly} \mathrm{cos} \mathrm{m}$ is chlorosperma Sprg. (Zie No. 3348.)

8593. Tetjang $\mathrm{BK} .=$ Chrys ophyllum firm um Aliq., Nut fam. der Sa pot a c e $æ$. GR 'Bangka; hooge boom.

8594. Tetoelang $\mathrm{BK.}=\mathrm{Coffea}$ le pidophloia. Miq. (Zie No. 5228.)

8595. Tetoemboen PAL. $=\mathrm{J}$ o n e. sia palembanica Mic. (Zie No. 5639.)

8596. Tewer BD. = Alstonia scholaris R. Br. (Zie No. 23ว0.)

8597. Tewoe S. (Zie Teboe M.)

8598. Thèh (Téh) M. = $a$. The a sinensis $S$ ims c. variet, et $=b$. Thea cochinchinensis I o ur.. Nat. fam. der C a m e ll i a c e æ. Gr. Deze heesters worden op Java als kultuurplanten in geregelde tuinen aangeplant.

8599. Thèh-ambon $M$. = $\mathrm{S}$ i d a retusa L. (Zie No. 7854 .)

8600. Thèh-besar M. en

8601. Théh-gedeh S. = T lı a c oc h in chinens is l, o u r. (Zie voren.)

8602. Thè-oetan M. $=a$. Sida $r$ etusa I. (Zie No. 7854) $=b$. Lagerstromia indic a L., Nat. fam. der L y thrariez. Gr. Op Java en elders als sierplant in tuinen; heester.

8603. Thong-se-soe Cн. Bo. = A. leurites triloba Forst. (Zie No. 312.)

8604. Tiau-tsoi CH. Bo. = Solan um Melongena $\mathbf{L}$ (Zie No. 2340.)

8605. Tiba BL. = Morind a bracte a a $\mathrm{Rx}$ b. (Zie No. 8286.)

8606. Tiboeaija $\mathrm{S} .=\mathrm{L}$ e a $\mathrm{s}$ a $\mathrm{m}$ b u c in a B l. (Zie No. 133.)

8607. Tiboalok Sux. IV.K. = Glochidion varians Miq. (Zie No. 3313.)

8608. Tibowang.lompo MaK $=\mathrm{Vig}$ n a sinensis $\mathrm{S}$ a vi (Zie No. 3935.)

8609. Tibowang-tjadi MAK. $=\mathrm{Pha}_{\mathrm{a}}$ seolus radiatus L. (Zie No. 31 .)

3610. Tiemboel J. \& M. = A $\times \mathrm{to-}^{-}$ c arpus incis a L. (Zie No. 269.)

8611. Tigel-kio J. $=a$. $\mathrm{Emilia}$ sonch ifolia DC. (Zie No. 2221.) = b. G y u ra $\mathrm{Pse} u \mathrm{~d} o-\mathrm{china}$ DC., Nat. fam. der C o m pos i æ. Gr. Java; éénjarig.

8612. Tigo T. $=$ Sida a cut a B rm. (Zie No. 1802).

8613. Tihing-ampel $\mathrm{Br} .=13 \mathrm{am}$ busa fera Miq. (Zie No. 774.)

8914. Tij (Ti) BL. = Conophallus? sativus Schott. (Zie No. 5260.)

8615. Tikal-baloeng $\mathrm{S} .=a . \mathbf{E} n-$ phorbia Tirucalli L. (Zie No. 3396.) $=$ b. Cissus quadrang $\mathrm{n}-$ $1 \mathrm{ar}$ is L. (Zie No. 27516.)

8618. Tikal-toelang $\mathrm{J} .=\mathrm{C}$ is su s qua drangu la ris $L$. (Zie voren.)

8617. Tikeh $J=$ Eleocharis tuberos a Schult. (Zie No. 7263.) 8618. Tikoek Lamp. $=\mathrm{T}_{\text {e }}$ p ironia 
m u c ronata $\mathrm{R}$ ich. (Zie No. 6978.)

8619. Tikoessan J. = I n u la s a lviodora S e hultz. (Zie No 7744.)

8620. Tilam-balang $\mathrm{PAL}_{\mathrm{AL}}=\mathrm{Z}$ a nthoxylon e une uron Miq. (Zie No. 6i93.)

8621. Tilging $\mathrm{S} .=a . \mathrm{Plat}$ y c e trum rupicolum Miq. en $=b$. Platycentrum ten ifolium M i q., Nat. fam. der B e g o n i a c e. Gr. Java; éénjarig.

8622. Timbang-mas $\mathrm{M}_{0}=\mathrm{Glo} \mathrm{b}-$ b a oliganth a M i q., Nat. fam. der $\mathrm{Z}$ in g i b e ra c e . Gr. Sumatra (Lampongs); overblijvend.

8623. Timo-timo Sum. WK. = Mu ssaënda frondosa I. (Zie No. 74.)

8624. Timoe $\mathrm{M}_{0}=\mathrm{D}$ i d y m o c arpus c rinita J a c k., Nat. fam. der Cy r t a u dra c eæ. Gr. Java, Sumatra, enz; kruidachtig.

8625. Timoe-ketjil M. $=\mathrm{D}$ i d $\mathrm{y}^{-}$ mocarpus reptans Jack., Nat. fam. als voren. Gr. Sumatra; kruipende plant.

8626. Timoen $\mathrm{M} .=\mathrm{Cucumis}$ s a t i u s I. (Zie No. 403.)

8627. Timoen-baloe M. = Tric bosanthes tricuspis $\mathrm{Mi}$ q., Nat. fam. der C и с u r b i t a c e æ. Gr. Java; éénjarig.

8628. Timoho J. $=$ Kle inho$\nabla$ ia hospit a L. (Zie No. 3927.)

8629. Timon AMB. = B o be a W a 11 i c hi a n a K or t h. (Zie No. 6947.) 8630. Timpoele $\mathrm{Cr}_{\text {. }}=\mathrm{Cl}$ a usena excavata $\mathrm{B} \mathrm{rm}$. (Zie No. 1697.)

8631. Tinat AмB. = Marauta d i c hotom a Wa ll. (Zie No. 926.)

8632. Tindjang-beloekar PaL. = Tetrant hera lucida $\mathrm{H}$ as sk. (Zie No. 2900b.)

8633. Tindjou Lasp. $=\mathrm{Ca} 11 \mathrm{i}$ c a r a W a llichian a Walp. (Zie No. 7998.)

S634. Tinggiling-mentik S. = T a c c a lance foli a Z. \& M. (Zie No. 49146.)

8635. Tingie Вк. = C eriops lu c id a M i q. (Zie No. 2884.)

8636. Tingi-lakka $\mathrm{BD} .=\mathrm{L}$ a $\mathrm{w}$ s o n i a a l b a I a m. (Zie No. 1747.)

8637. Tingkassan $\mathrm{J} .=a . \mathrm{Z} \mathrm{e} \mathrm{h-}$ neria hastat a Miq. (Zie No.4553.) $=$ b. Zehneria connivens Miq., Nat. fam. der C u c u r b t a c e a. Gr. Java; slingerplant. GEBR. Als No. 45う3.)
8638. Tingoelong 11. \& S. $=$ Prot i u m javic um Brm. (Zie No. 39316.)

8639. Tinta MrN. = Sterculia u r ceolat a Sm. (Zie No. 1502.)

$86 \leq 0$. Tintinga $\mathrm{BL}_{\circ}=\mathrm{Cl}$ orode $\mathrm{n}$ d r u m infortunat am B l. (Zie No. 758.)

8641. Tioep-tioep $\mathrm{B}_{\mathrm{K}}=\mathrm{A}$ din andra glabra Mi q. (Zie No. 3435.)

8642. Tipies-koelit $\mathrm{M}=a$. S $\mathrm{y}-$ z y g i m costat u m Mi q. (Zie No. 4742.)=b$. J a m b o line a $\mathrm{ta}$ DC. (Zie No. 3043c.) =c. Nelitris parviflora B l. (Zie No. 46596.) $=d$. $\mathrm{Nelitris}$ polymorpha (Zie No. 4591.) $=e$. $\mathrm{Chiloc} \mathrm{arpus} \mathrm{com} \mathrm{po-}$ s i u s B l., Nat. fam. der A p o c y n e Gr. Java; heester.

8643. Tirantorg Sum. WK. $=\mathrm{Fi}$ c us gibbos a B l. (Zie No. 2979.)

8644. Tiroe-boddas $\mathrm{S}$. $=$ A locasia indira Schott. (Zie No. 1145.)

8645. Tiroe-makir Амв. $=-$ Col. ly is major Vahl. (Zie No. 1682.) 8646. Tiroe-poetih M. = Tiroeboddas $\mathrm{S}$.

8647. Tisoek $\mathrm{S}$. $=\mathrm{H} \mathrm{i} \mathrm{b}$ is c u s v u I p in us R w d. (Zie No. 8503,)

8648. Titaweij Cr. $=$ Urostigm a $R$ um phi i M i q. (Zie No. 103.)

8649. Titikoesan J. \& M. $=a$. Typhonium divaricat um B l. (Zie No. 1236.) $=$ б. Typhonium c u s pidat u m B 1. (Zie No. 441.)

8650. Titiwoëan $\mathrm{S} .=a$. P olyg o n u m c hinense I. (Zie No. 1822.) $=$ b. Ioxotis obliqua R. Br., Nat. fam. der Cy r t a d r a c ex. Gr. Java, Sumatra, Timor; éénjarig. $=c$. Rhy nchoth ec um parviflor u m B 1., Nat. fam. dczelfde. Gr. Java; heester. 8651. Tiwera BD. $=\mathrm{C} r \mathrm{inum}$ a siatic u m L. (Zie No. 869.)

8652. Tiwoe S. (Zie Tewoe M. \& S.) 8653. Tiwoe-landoek $\mathrm{S} .=a . \mathrm{M} \mathrm{e}$ liosma nitida Bl. (Zie No. 3440) = 6. Artocarpus glaca Bl. Nat. fam. der A r to c a r p e a. Gr. Java; hooge boom. GEBr. Het grove en roode hout wordt voor huisbouw gebezigd, doch spoedig door witte mieren aangetast. = c. Artocarpus pomiform is 'T. \& B., Nat. fam. en Gr. als boven.

8654. Tiwoek S. $=a$. L u f f a c ordifolia Bl. (Zic No. 5l4.) $=6$. 
Trichosanthes origera Bl. (Zie No. 65 šb.)

8655. Tja Сн. Во. $=\mathrm{Sacch}$. r u m officin a r um L. (Zie No.6257.)

8656. Tjabeh S. \& M. =a. C a psicum I. Spec. diversæ. $=b$. Piper L. Spec. dirersæ. $=c$. Charica officinarum 11 iq. (Zie No. 5134.$)=d$. Stylocorgna po. Iy c a r p a $11 \mathrm{iq.}$ (Zie No. 5316.)

S6ว7. Tjabeh-aroij $\mathrm{S} .=a \cdot \mathrm{Cha}$ vica densa $M$ iq. (Zie No. 6 86.) = b. Charica officinarum Miq. (Zie No. วัl3t.)

8658. Tjabeh-atjoeng M.,

8659. Tjabeh-bedat S. tn

8660. Tjabeh-besar $\mathrm{M}$. $=\mathrm{C}$ a $\mathrm{p}-$ sicum frutescens L., Nat. fam. der $\mathrm{S}$ ol a n e æ. Gr. Door geheel Indië in tuinen en langs heggen; heester. GEBR. Even als van Capsicu $\mathrm{m}$ a n $\mathrm{nu} \mathrm{u} m$ L. en andere.

8661. Tjabeh-betoel M. = C a psicum sinense J c q.. Nat. fam. als voren. GR. Op Jara in tuinen als sierplant. GEBR. (Zie rorig No.)

8662. Tjabeh-beurriet $\mathrm{S} .=\mathrm{Ch}$ avic a C hab a Miq., Nat fam. der P i. p er a c e æ. Gr. Java; klimplant. Gebr. De rruchten gaau in den handel reelal roor die van Piper longum door.

8663. Tjabeh-djawa M. (Zie No. $865 \%$.)

5664. Tjabeh-gedeh $\mathrm{S} .=a . \mathrm{C}^{\mathrm{ap}}$ sicum a nnum L. (Zie No. 5500.) $=b$. Capsicum fratesceus L. (Zie No. 8660.) $=c$. C a psicum l o n g um DC., Nat. fam. der Sola neæ $G_{R} . O_{p}$ Jara reelal in tuinen; heester. GFBr. Van deze soort bezigt men bij roorkeur de onrijpe rruchten.

8665. Tjabeh-hiedjoe M. = C a ps i cum 10 n $\mathrm{gum}$ DC.

8666. Tjabeh.kling J. \& BL. = Capsicum pendulum Wlld., ra.r. torulosum Finght., Nat. fam. der Solaneæ. Gr. Java en Bali; heesterGebr. Als van C. a nn n n $\mathrm{m}$ L. en an. dere.

S667. Tjabeh-oetan .I. = a. P iper arborescens R I b. (Zie No. 288.) $=b$. Charica macrostach s a Miq. (Zie No. 109lb.)

8668. Tjabeh-prahoe M. $=a$. C h a. vica densa MI iq. (Zie No. 686.) $=b$. Charica officinarum Miq. (Zie No. 5134.)
S669. Tjabeh-rawiet $\mathrm{l}:=\mathrm{C}_{\mathrm{a}}$. sicun fastigiatum Bl. (Zie No. 5501.)

$86 \div 0$. Tjabeh-sabrang S. 三 a. Capsicum frutescensL. (Zie No. 8660.) $=b$. Capsicum longam DC. (Zie 8664c.)

S6i1. Tjabeh-salassie $\mathrm{M}$. = $\mathrm{C}$ a psicum bi ${ }^{\circ}$ olor Jac q., Nat. fam. der Sol a n e a. Gr. Op Jara in tuinen; heester. GEBr. Als van $C$. a n $n \mathrm{nu} m \mathrm{~L}$.

86i2. Tjabeh-tjangek $\mathrm{M}$. $=\mathrm{C}$ a $\mathrm{p}-$ si cum long a m l)C. (Zit roren.)

8673. Tjabeh-woengoe S. $=a$. Capsicum longu m DC. (Zie roren.) $=\dot{0}$. Ca p sicum bicolor Jacq. (Zie No. 8671.)

8674. Tjai S. $=\mathrm{A}$ de n a $11 \mathrm{th}$ er a paronina L. (Zie No. 52.)

86ij. Tjajoer S. = Pterosperin u m B lumeanum Frths. (Zie No. S5i.)

8675. Tiaka S. = Coffe a salicifolia Mi q., Nat. fam. der Rubia c e æ. Gr. Jara 4000'; kleine boom.

867i. Tjaki J. = Pupa li a a tro. purpurea II q. T a nd. Nat. fam. der A $m$ ar a n t a c e æ. Cr. Jara, Timor, éénjarig.

86i8. Tjakra-ajam J. = B r Jo- $^{\circ}$ uia laciniosa I. (Zie No. 641b.)

8679. Tjakra-Tjikri Bat. 三 Acacia F arnesiana WIId. (Zie No. 2041.)

s6so. Tjakka-mabido T. $=\mathrm{Cha}$ vica majuscula II iq. (Zie No. 289.)

8681. Tjaliek-angin S. (Zie Baliekangin S.) $=b$. P l ag i a $\mathrm{th}$ er a oppositifolia R. B. en $Z_{0} 11$., Nat. fam. der Euphorbi a c e . Gr. Jara: kleine boom.

868\%. Tjaliengtjieng $\mathrm{S}$. = A rerr ho a Garambola L. (Zie No. Sól.) 8683. Tjaloebangbang S. 二 Scindapsus pertusus Schott. (Zie No. 5492.)

8684. Tjaloeng $\mathrm{S} .=\mathrm{G}$ a r cinia c ornea L. (Zie No. 2026.)

8655. Tjaloentjoeng S. = a. $11 \mathrm{a}$. rumia muscosa Bl. (Zie No. 495.) $=b$. Creochiton pudibundaBl. (Zie No 688.)

8686. Tjaloentjoeng.aroij S: = Dissochæta cyanocarpa Bl., Nat. fam. der II elast om a cer. Gr. Java ; slingerplant. 
8687. Tjaloentjoeng-burrum S. = Marumia muscosa Bl. (Zie No. 495.)

8688. Tjamantring S. of Tjamintring $\mathrm{S}$. 三 $\mathrm{Chavic} \mathrm{a} \mathrm{Ch}$ a b a $\mathrm{Mi}$. (Zie No. 8662.)

8689. Tjamara M. $=a$. Podoc a r us cupressin a R. Br. (Zie No. 2820.) $=$ b. C a s u arina e quisetifolia Forst. (Zie No. 122.) = c. Casuarina Junghuhniana M i q., Nat. fam. der $\mathbf{C}$ a s u a rine æ. Gr. Java; hooge hoom. GEbr. (Zie No. 122.)

8699. Tjamaro-goenoeng $\mathrm{MI}$. $\mathrm{Ca}$ su a rin a mion t a n a $\mathrm{Jgh}$, Nat. fam. als voren. GR. Java 4-9000'; boom. Gebr. (Zie No. 122.)

8691. Tjamara-lawut M. 二 $\mathrm{Ca-}$ suarina equise tifolia Forst. 8692. Tjamarra $\mathrm{C}_{\mathrm{r}}$ 二 $\mathrm{Clero}$ dendrum infortunatum L. (Zie No, 758.)

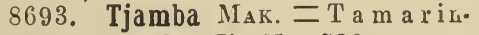
d u s in d ic a L. (Zie No. 723.)

8694. Tjambahan J. 二 Millet i a $t$ h y r if lor a B e n th., Nat. fam. der Pa pilio n a c e $æ$. Gr. Java; heester.

8695. Tjambai J. $=\mathrm{Cl}$ a $\nabla$ i c a $\mathrm{S}$ ir i o a $11 \mathrm{i}$ q. (Zie No. 1170.)

8696. Tjambang BL. = Erythrin a fu s c a L o u r. (Zie No. 1595.)

8697. Tjaming-tjaming $R$. 二A verr ho a Carambola L. (Zie No. 85l.) 8698. Tjamoen $\mathrm{S}$. 三 Pipturus velu tinus TV ed d. (Zie No. 5398.)

8699. Tjampahoe $\mathrm{S} .=\mathrm{T}$ amari . d u s indi c a L. (Zie No. 723. )

3700. Tjampaka M. en $\mathrm{S}$. 三 $\mathbf{M ~ i - ~}$ c heli a Ch a m p a c a L. (Zie No.4156.)

8701. Tjampaka-boddas $\mathrm{S}$. = $\mathbf{M} \mathrm{i}$ chelia longifolia Bl, Nat. fam. der M a g noli a c e $x$. Gr. Java; hooge boom, wiens bloemen een zachteren meer citroenachtigen gell verspreiden dan die van M. Ch a m p a a, GEвr. Als deze.

8702. Tjampaka-boeloe $\mathrm{S} .=a$. $\mathrm{M}$ i chelia Cham paca L. $=b . \mathrm{M}$ i chelia velutin a Bl. (Zie No. 5760c.)

8703. Tjampaka-goenong II. 二 $\alpha$. Michelia montana Bl. (Zie No. 18906.) $=$ b. Tala um a $\mathrm{Rumphi}$ B 1. (Zie No. 7029.)

8704. Tjampaka-gondok 11 . en S. = a. Talauma mutabilis Bl. (Zie No. 4199.) = b. 'T'a l a um a ju$\mathrm{m}$ i la A n d r., Nat. fam. der M a g $\mathrm{n}$.
I i a c e r. Gr. Jara; kleine heester, veelal in heiningen. GEBR. De witte, appelgeurige bloemen worden zeer veel in het hoofdhaar en tusschen kleederen gedragen.

8705. Tjampaka-gondok-0etan M. = C a p p ris c a 11 o s a B. Nat. fam. der $\mathrm{C}$ a p p a rid e $æ$. Gr. Java; slingerplant.

8706. Tj ampaka-leuwung $\mathrm{s}$. 二 Tal a u a mutabilis Bl. (Zie No. 4.199.)

s70\%. Tjampaka-loentoeng-aroij S. = Capparis flexuosa Bl. (Zie No. 3640.)

8708. Tjampaka-meirah M. = Michelia Cham paca L., var. r a fin e ria. (Zie No. 4156.)

8709. Tjampaka-moelia M. $=a$. Parkinsonia a c le at a L. (Zie No. 3254.) $=$ b. Pl um ieri a a $\mathrm{cu}$ tifolia Poir. (Zie No. 1367, ) $=c$. Dianella nemoros a L m. (Zie No. 5079.)

8710. Tjampaka-oetan M. = $a$. $\mathrm{Talam}$ a $\mathrm{R}$ m phi B l. (Zie No. 7029.) 二 b. T a 1 a u m a $\mathrm{illo}$ s a $M$ iq., Nat. fam. der M a $\mathrm{g} 0 \mathrm{li}$ a c e $æ$. GR. Sumatra; boom. $=c . \mathrm{Mi}$ ch e $\mathrm{li}$ a $\mathrm{Cham}$ $p$ a c a L., Nat. fam. als voren Gr. De Molukken; hooge boom. GËrR. Het hout is zeer geschikt voor huisbouw en meubels. $=d$. M i c h eli a I., S p e c. M e$\mathrm{n}$ a d o; mede een goed bouwhout. $=e$. G a rdenia resinifera Korth.

8711. Tjampaka-poetih M. = Mi. chelia longifolia Bl. (Zie No. 8701.)

8712. Tjampaka-ceijlon M. = Myris tica H orsfiel di i B l., Nat.fam. der My risticer. Gr. Op Java in tuinen; boom. GEBR. De bloemell van dezen boom hebben een sterken, aangenamen geur, welke door insekten zeer gemeden wordt. De vruchten worden gegeten. Van de uit de zaden geperste olie maakt men kaarsen.

8713. Tjampara-toepai $\mathrm{Bk}$. 二 Vis. c u rn articulat u $\mathrm{m} \mathrm{Brm}$. (Zie No. $350 e$.)

8714. Tjampedah M. en S. 二 A rtoc a r p s poly phem a P e rs. (Zie No. 144.)

8715. Tjampedah-ajer M. = $\mathrm{Ar}$. tocarpus varians Mi q. (Zie No. 8วั10.)

8716. Tjampedah-oetan M. $=0 \mathrm{ch}$ n a s q a rosa I. (Zie No. 6274.) 
8717. Tjamplong J. $=\mathrm{Cal}$ o phy $\mathrm{h}$ l u m in o ph y l l u m L. (Zie No. 1139.) 8718. Tjamporang $\mathrm{S} .=\mathrm{J}$ an iph a M anihot H. B. \& K. (Zie No. 2 872.)

8719. Tjanar $\mathrm{S} .=a$. S milax Tnft.Spec.diver s b. Smilax odoratis sima Bl., Nat. fam. der $\mathrm{S} m \mathrm{il}$ a $\mathrm{c}$ i $\mathrm{n}$ e æ. Gr. Java; slingerplant. $=c$. $1 \mathrm{ios}$ ore a s alicifoli a B l., Nat. fam. der Dioscoreæ. Gr. Java; slingerplant.

8720. Tjanar-babi M. \& S. $=a$. Z a no nia ind i c a L., Nat. fam. der Nhandirobeæ. Gr. Java; slingerplant. GEBR. In Indië gebruikt men de gekneusde bladeren in baden en tot het bereiden van een krampwerend smeersel. De bessen worden gegeten; zij bezitten den smaak en den reuk van komkommers. $=b$. S milax od o ratis sima B l. (Zie No. S719b.) $=c$. Smilax zeylanica L. (Zie No. 717.)

8721. Tjanar-betoel $\mathrm{M}$. = S m ilax zeylanica L. (Zie No. 717.)

8722. Tjanar-bokkor S. $=a$. Smilax zeylanica $L$. (Zie voren) $=b$. Smilax glycyphylla Sm. $=c$. $\mathrm{Sm}$. la urina Kth. $=d$. Sm. le u. cophyla $\mathrm{Bl} .=e$. Sm. macrocarpa B l. en $=f$. Sm. perfoliat a Lour., Nat. fam. der S m il a c i n e æ. Gr. Java en de Molukken; orerblijvende planten.

8723. Tjanar-bokkor-Ialaki S. = $\mathrm{Smilax}$ glycyphylla Sm. (Zie No. 872\%b.)

8724. Tjanar-bokkor-mienjak S. = Smilax leucophylla Bl., var. heteror hylla. (Zie No. $8722 d$.)

8725. Tjanar-wangi M. = Smilax odoratissima Bl. (Zie No. S719b.)

8726. Tjang BL. $=\mathrm{C}$ æsalpinia S a p p a n L. (Zie No. 1807.)

8727. Tjanging $\mathrm{BL}$. = Erythri. n a fus c a L our. (Zie No. 1595.)

8728. Tjangkir S. = Abroma a ug u sta L. (Zie No. 4480.)

8729. Tjangko J.\& S. = Quercus s p i c a t a S mith. (Zie No. 4619.)

8730. Tjangkoeang $\mathrm{S} .=\mathrm{P}$ a ndan us furcatus R $\mathbf{x}$ b. (Zie No. 5937.)

8731. Tjangkoedoe S. (Zie Bangkoedoe S. \& M.)

8732. Tjangkoedoe-kantjil J. = 110 rinda bracteata Rxb. (Zie No. 828b.) 8733. Tjangkoedoe-lalaki $\mathrm{S} .=\mathrm{N}$ a clea grandifolia D) C. (Zie No. 1870)
8734. Tjangkoerang S. = Trevesia sundaica Mi i. (Zie No. 4404c.)

8735. Tjangkorreh S. $=1$ ) in ochloä Tjangkorreh Büse. (Zie No. 783.)

8636. Tjangkorreh-dioek S. = I e ptaspis ureolata R. Br. (Zie No. 1035.)

8537. Tjangkring $\mathrm{J}, \& \mathrm{M} .=a$. Erythrina fusca l,our. (Zie No. 1595.) $=b$. Erythrina indica. L a m. (Zie No. 1586b.)

8738. Tjangkoeloe.kras J. $=\mathrm{C}_{0}$ vellia lepicarpa lliq. (Zie No. 1312.)

8739. Tjangtjang $\mathrm{S} .=\mathrm{El}$ e p h a ntopus scaber L. (Zie No. 8381.)

8740. Tjanigara J. $=\mathrm{Cochlos-}$ permum Gossypium D.C., Nat. fam. der Bix a ceæ. Gr. Java, Bali; hooge boom.

8741. Tjantekkeh (Tjantokkeh) $\mathrm{S}$. $=\mathrm{B}$ o ue a G andaria B l. ('Zie No. 2404.)

8742. Tjantigi $\mathrm{S} .=a . \mathrm{Rhodo}$. dendrum I. S pec. diversæ. = b. V a c cinium I., Spec. diversæ. $=c$. Pernettia repens Zoll. (Zie No. 2637.) $=d$. Acronodia punct a ta B l. (Zie No. 2490.) $=e$. Dod o$\mathrm{n} \rightsquigarrow$ a $\mathrm{n}$ gustifolia Blanco. (Zie No. 2218.) $=f$. S c e pasma buxifolia Bl. (Zie No. 4566b.) = g. Leucoxylon buxifolium Bl. (Zie No. 4393b.) $=h$. Pemphis acidula F orst. (Zie No. 1555) $=i$. Lasianthus subsessilis Miq., Nat. fam. der R ubi a c ex. Gr. Sumatra (Lamp on g s); heester.

8743. Tjantigi-betoel $\mathrm{S} .=\mathrm{V}$ a ccinium varingiefolium Miq. (Zie No. 2836)

8744. Tjantigi-boddas $\mathrm{S} .=\mathrm{G}$ a utie ra l e u c oc a r p a Endl., Nat. fam. der Eri c a c e æ. Gk. Java; heester.

8745. Tjantigi-boeloe $\mathrm{S} .=\mathrm{Rho}$. do den drum tubiflorum D.C., Nat. fam. als voren. GR. Java; heester.

8746. Tjantigi-gedeh $\mathrm{S}$. $=\mathrm{V}$ accini um floribund um Miq., Nat. fam. der Eri c a c e æ. Gr. Java 9000'; heester.

8747. Tjantigi-goenoeng $\mathrm{S} .=\mathrm{Lep}$ tospermum floribund um Jngh. Nat. fam. der M y rtaceæ. Gr. Java S-10000'; boom.

8748. Tjantigi-leutiek $\mathrm{S} .=\mathrm{V}$ a cc inium lucid um M i q., Nat. fam. 
der Er i c a ce æ. Gr. Java; kruipende plant.

8749. Tjantigi-wangi M. \& S. = Gaultheria punctat a Bl. (Zie No. 2403.)

8750. Tjantjau S. = Elephantop ll s s c aber L., (Zic No 8381.)

8751. Tjanterrettan $\mathrm{S}=a$. A nthocephalus ind je us Rich. (Zie No. 989.) $=b$. Anthocephalus morindæfolius Korth. (Zie No. 4508 .) $=c . \mathrm{Nauclca}$ c x cels a Bl., Nat. fam. der R u b j a c e æ. Gr. Java; boom.

8752. Tjantjerretan badak $\mathrm{S}$. = a Anthocephalus morind efoli us Korth, (Zic 4508.) $=6$. Na t1c le a g labra $R \times b$., Nat. fam. der R u bi a c e $x$. Gr. Java; heester. Geir. (Zie No. 277.)

8753. Tjantjerrettan-beurriet $\mathrm{S}$. = $\mathrm{N}$ a u cl c a moll is Bl., Nat. fam. als voren. Gr. Java; kleine boom. GeBr. (Zie No. 277.)

8754. Tjantjerrettan mienjak $\mathrm{S} .=$ $\mathrm{N}$ a u cl e a o b tus a B l., Nat. fam. enz. als voren.

8755. Tjapa R. $=\mathrm{C}$ on y z a b a l. $\mathrm{s}$ a $\mathrm{m}$ if era I. (Zic No. 85b.)

8756. Tjapoea-le 1 wung $\mathrm{S}$. $=\mathrm{T}$ a . lauma mutabilis Bl. (Zie No. 4199.)

8757. Tjapoe-toehoer $\mathrm{S} .=a \cdot \mathrm{Cy}_{\mathrm{y}}$ noctonu in muricatum Desn., Nat. fam. der $\Lambda$ s c le $\mathrm{p}$ i a d e re. Gr. Java; slingerplant. $=b . \quad \mathrm{Conyza} \mathrm{L}$. S pe cies divcrsæ. Gebr. Níen legt de bladeren op versche wonden en wel vooral op die door de besnijdenis veroorzaakt. De wortels wordey in water ge. weekt, en hiervan tegen hnidziekte gedronken. (H a s s k a r l.).

8758. Tjaptjek-meirah $\mathrm{M} .=\mathrm{Nc}$. rium odorum Soland. (Zic No. 2208.)

8759. Tjaptjek-poetih $\mathrm{M} .=\mathrm{Ne}$. rium Oleander L. (Zic No. 1369.)

8760. Tjarehan $\mathrm{S} .=\mathrm{R}$ u b i a c o r. difolia I. (Zie No. 2380.)

8761. Tjariaroe of Tjariang $\mathrm{S}=$ A gla one ma simplex Bl. (Zie No. 5359 )

8762. Tjariang-boddas $\mathrm{S} .=11 \mathrm{o-}$ mal one in a alba ll assk. (Zic No. 317.)

8763. Tjariang-burrum S. $=\mathrm{Ho}$ malonema rubescens $k$ u th. (Zie No. 903.)
8764. Tjariang-hiedjoe $\mathrm{N} .=\mathrm{Ho-}$ malonema aromatic a Schott., Nat. fam. der A ro ide æ. Gr. Java; overblijvend.

8765. Tjariang -meirah M. (Zie No. 9268).

8766. Tjariang-peutjang $\mathrm{S} .=\mathrm{Ch}$ amæcladon lanceolatum Miq., Nat. fam. der A roi de æ. Gr. Java er Sumatra, aan beckjes; overblijvend.

8767. Tjariang-poetih M. (Zie No. $8762)$

8768. Tjariengien $\mathrm{s} .=a$. Urosti g m a be nja min um M i q. (Zie No. 1565.) = b. Urostigma h $\mathrm{mat} 0$. carpum Miq. (Zie No 1875 c.) $=c$. Urostigma lucescens Miq. (Zie No. 54356.) $=d$. Urostigma microc arpum Miq. (Zie No 4332). = $e$. U rostigma nitidum Miq. (Zie No. 855$)=f$. Urostigma pisic a rpum Mi q., Nat fam. der A r to. c a rpe x. Gr. Java; hooge booin Al dcze boomen worden vcel op pleinen (aloenaloen) en andere plaatsen geplant, die in zckeren eerbied staan; zij dicnen tot sieraad on geven een aangename en koele schaduw.

8769. Tjarioe S. = En ta d a Pur$s æ t h$ a DC. (Zie No. 482.)

8770. Tjariwoe $\mathrm{s} .=\alpha \mathrm{sch}$ ismatoglottis lougipes Miq., Nat. fam. der A i o ide $x_{\text {. Gr. Java; }}$ overblijvend. GEBR De geheele plant - wortels, bladstelen en bladeren - wordt gekookt door menschen en varkens gegeten. $=b$. Colocasiahumilis $\mathrm{H}$ assk. (Zie No. 426.) $=c . A l o c$ as a ind ic a $\mathrm{Sch}$ ot t. (Zie No. 1145.)

8771. Tjariwoe-boddas $\mathrm{S}$ =Aloc a s i a ind ic a S chott. (Zie boven.)

8772. Tjariwoe-gedeh $\mathrm{S}$. = $\mathrm{C}_{0-}$ locasia humilis II assk., var. m a jor. (Zie No. 426.)

8773. Tjariwoe-leutiek $\mathrm{S}=\mathrm{Co}$ locasia humilis Hassk., var. minor. (Zic No. 426 )

8774. Tjariwoe-peutjang $\mathrm{S}$ = $\mathrm{Cha}$. m x clad on la nce ol a tu m M i q.(Zie No. 8766.$)$

8775. Tjaroek-djikin M. = Ficus urophylla Wall. (Zie No. 1655.)

8776. Tjaroelang $\mathrm{S}$. = $\mathrm{sp}$ a tholobus ferrugincus linth., Nat. fam. der P apiliona c e slingerplant.

8777. Tjarooi Вк. = Garciu ia 
brevi rostris Scheff. (Zie Menjienjien )

8778. Tjatjabehan $\mathrm{S} .=\mathrm{Euchres}$ ta Horsfieldii Bnnt. (Zie No. $4396 d$.)

8779. Tjatjandie $\mathrm{S} .=\mathrm{S}$ es b ania c o chinchinensis DC. (Zie No. 2360g.)

8780. Tjatjang of Tjatjeng $\mathrm{S}_{0}=$ Eleph antopus scaber L. (Zie No. 8381.)

8781. Tja-tjorokok S. $=\mathrm{S} \mathrm{ol} \mathrm{a} \mathrm{n} \mathrm{u} \mathrm{m}$ indicum N ces. (Zie No. 8203.)

8782. Tjau S. $=\mathrm{P}$ i s a n $\mathrm{g}$ M.

8783. Tjau-kaleh $\mathrm{S}$. = M us a si$\mathrm{mi}$ a r u $\mathrm{mmph}$. (Zie No. 1191.)

8784. Tjau-soleh $\mathrm{S} .=\mathrm{M}$ u s a o $\mathrm{r}$ $n$ at a $\mathrm{R} \times \mathrm{b}$. (Zie No. 6881.)

8785. Tjawehneh-soreh $\mathrm{S}=a$. Turpinia sphrocarpa Hassk. (Zie No. 994.) $=b$. Rhododendrum javani c u m B enn. (Zie No. 2361.)

8786. Tjeboengan J. $=$ Fle mingia capitata Zoll., Nat. fam. der Papili on a ceæ. Gr. Java, Celebes; éénjarig.

8787. Tjeiska $\mathrm{S} .=\mathrm{Urost} \mathrm{igma}$ strictum Miq., Nat. fam. der A r. t o c a r p e æ. Gr. Java; hooge boom.

8788. Tjekkoeroe $\mathrm{M}_{\mathrm{AK}} .=\mathrm{K} æ \mathrm{~m} \mathrm{p}$ feria gal anga L. (Zie No. 737.)

8789. Tjekok J. $=\mathrm{Q}$ u is qu a lis ind i c a L (Zie No. 3234)

8790. Tjelanka $\mathrm{S} .=\mathrm{Ki}$ b a $\mathrm{r}$ a $\mathrm{co-}$ riace a Endl.

8791. Tjelegor $\mathrm{J}_{\mathrm{.}}=\mathrm{C}$ o $\mathrm{mmelin}$ a p a l u d os a Bl. (Zie No. 2089)

879\%. Tjeli S. $=\mathrm{Pl}$ antago $\mathrm{H}$ as skarlii i) cs n. (Zie No. 1765.)

8793. Tjemaroh Sum. WK. = Cephalotaxis sumatrana Miq, Nat. fam. der $\mathrm{T}$ a $\mathbf{x}$ in e æ. GR. Sumatra; boom.

8794. Tjembaul J. $=\mathrm{S}$ o l a n u $\mathrm{m}$ $m a c r a n t h u m ~ D u n$, Nat. fam. der Solaneæ. GR, Op Jara als sierplant in tuinen; boom.

8795. Tjemôrô J. Zie Tjamara M.

8796. Tjengal I AnP. $_{\text {. }}=\mathrm{Hopea}$ diversifolia Miq. (Zie No. 5928)

8797. Tjengkeh M. \& S. = Caryophyllus aromaticus L. (Zie No. 1292.)

8798. Tjengkeh-oetan $\mathrm{M} .=a \cdot \mathrm{C}$ a. ryophyllus sylvestris T. \& B., Nat. fam. der I y r t a c e æ. Gr. De Molukken; boom. $=b$. J a m b os a ob tus if o li a MI iq., Nat. fam. en Gr. als $a$. $=c$. Nelitris pyrifolia Miq., Nat. fam. dezelfde. Gr. Java; boom.

S799. Tjengkeh-oetan-dawon-ketjil II. $=a . \mathrm{Fabrici}$ ? bracteata $\mathrm{R} \times \mathrm{b} . \quad($ Zie No. $3846 c$.) $=b$. Nelitris a 1 b a Bl. en $=c$. Nelitris rubra B l. (Zie No. 5l.)

8800. Tjengkeh-oetan-ketjil $M,=$ $\mathrm{Nelitris} \mathrm{rubra} \mathrm{Bl}$. (Zie No. 5l.)

8801. Tjengkeh papoea T. en

8802. Tjengkeh-radja $\mathrm{M}_{\text {. }}=\mathrm{Caryo}$. phyllus aromaticus I. (Zie No. 1292.)

8803. Tjenettan S. of

8804. Tjentjenettan $\mathrm{S} .=\mathrm{Ph}$ y s a$\mathrm{l}$ i s a $\mathrm{ng}$ u l a t a I., Nat. fam. der S ol a n e æ. Gr. Java en de Molukken; éénjarig GeBr. De wortel wordt op Java fijngewreven en tegen ingewandswormen toegediend. De rijpe vruchtjes worden gegeten, en zullen, volgens $\mathrm{Bl}$ a n c 0 , als pisdrijvend middel toegediend worden tegen icterus, ischuria, hydrops en andere.

8805. Tjepena $\mathrm{BK} .=a . \mathrm{Daphn} \mathrm{i-}$ phyllum bancanum Kurz. (Zie No. 5954.) $=b$. I) aphniphyllum gla uccscens B l. (Zie No. 2923h.)

8806. Tjeraken $J_{.}=$Croton Tigli u m L. (Zie No. 6.)

8807. Tjereboet J. $=\mathrm{C}$ on oph a llus giganteus Schott. (Zie No. $750 c$.)

8808. Tjereh S. = O ryza mont a n a Lo u r. (Zie Nn. 6405.)

8809. Tjerehan-aijam $\mathrm{S}$. $=\mathrm{Rubia}$ c ordif olia 1. (Zie No. 2380.)

8810. Tjering J. $=\mathrm{Pithecol}$ obium lobatum Bnth. (Zie No. 1991.)

8811. Tjerlang $S .=P$ terosper$\mathrm{m} u \mathrm{~m}$ diversifolium $\mathrm{Bl}$. (Zie No. 4778.)

8812. Tjermeh S. $=$ Cic c a nodif 10 r a L a m. (Zie No. 3093.)

8813. Tjermeh-leuwung $\mathrm{S}$. = S cepasma buxifolia BI (Zie No. 4566b.)

8814. Tjerogol-monjet $\mathrm{S} .=$ Xerospermum Noronhianum Bl. (Zie No. 2286.)

8815. Tjetjan-kahan S. $=a$. Lasianthus tomentosus Bl. (Zie No. 2696c.) $=b$. Ophior rhiza M ungos l. (Zie No. 6725.)

8816. Tjetjang-koedoean S. $=\mathrm{K}$ ib a r a c or i a c e a Endl. (Zie No. 884.)

8817. Tjetjer-ketjepet $\mathrm{S}:=\mathrm{R}$ oureopsis javanica Planch. (Zie No. 64.8.) 
8818. Tjetjerennean S. $=a . \mathrm{Sce}-$ pasma longifolia Hassk., Nat. fam. der Euphorbiaceæ. Gr. Java; heester. $=b$. Nelanthesa rhamnoides Bl. (Zie No. 1453b.) =c. Glochidion glaucum Bl. (Zie No. $4613 d$.)

8819. Tjetjerennean-aroij $\mathrm{S} .=a$. Dalbergia $t$ a marind jolia $R \times b$. (Zie No. 697.) = b. Dalbergia litto$r a l i s$ Hassk., Nat. fam. der Papilion a ce $x$. Gr. Java; slingerplant. GFir. De stengels van deze beide kunnen zonder eenige toebereiding als touwwerk gebruikt worden.

8820. Tjetjerobet S. = Busea decurrens Miq., Nat. fam. der Cyrtandraceæ. Gr Java; heester.

8821. Tjettek $S .=S t r y c h n o s$ Tieuté Lesch. (Zie No. 6319.)

8822. Tjeulie-badak $\mathrm{S}$. = Opuntia d e cumaua H aw.. Nat. fam. der Cac. teæ. Gr. Op Java en elders in tuinen; heester.

8823. Tjeulie-badak-bener S. = Opuntia tomentosa S. D., Nat. fam. en Gr. Als voren.

8824. Tjeulie-badak gedeh S. (Zie No. 8822.)

8825. Tjeulie-badak-tjeribon S. = Opuntia coccinillifera Mll., (Zie No. ว387.)

8826. Tjeulie-badak-tjoektjoek S. $=a$. Opuntia elatior Mill., Nat. fam. en Gr. Als No. 8822.) = b. Opuntia monacantha Haw., Nat. fam. en Gr. Als voren. $=c$. Opuntia polyantha Haw. (Zie No. 2255.) Gebr. De meeste Opuntia-soorten worden uitsluitend voor de Cochenille-kultuur aangeplant. No. 8822 tot 8825 dienen voor de kweeking der in. -sekten, die onder No. 8826 meer uitsluitend om hare stekels voor spelden, om de hoedjes met de moederinsekten op de eerste vast te steken. De vruchter van alle zijn flauw-zoet, doch eetbaar.

8827. Tjeulie-meöng $\mathrm{S} .=\mathrm{Cubeba}$ mollissima 11 iq. (Zie No. 705.)

8828. Tjeurie $\mathrm{S} .=a$. Garcinia dioica Bl. $=$ b. G. lateriflora Rl, et aliæ. (Zie No. 2026c.)

8829. Tjieboeang S. = Grewia tomentosa Juss. (Zie No. 3904.)

8830. Tjiboelan $J .=A$ grimonia javanica Jngh. (Zie No. 2562.)

8831. Tjigau J. = Quisqualis indic a L. (Zie No. 3234.)

8832. Tjigige $\mathrm{J}_{0}=$ Viola serpens
Wall., v ar., Nat. fam. der Violarie Gr. Java 3-z̃000'; éénjarig.

8833. Tjikoer $\mathrm{S} .=a . \mathrm{K} æ \mathrm{mpferia}$ Galanga L. (Zie No. 737.) = b. Tacca pinnatifida Forst. (Zie No. 6105)

8834. Tjiloepiet $\mathrm{BK} .=\mathrm{Elæocar-}$ pus adenopus 11 iq., Nat. fam. der Tiliaceæ. Gr. Java, Bangka; boom.

8835. Tjing-rerem $\mathrm{S}$. = Duchesnea sundaica Miq.

8836. Tjinga-tjinga $\mathrm{T} .=\mathrm{W}$ oll astonia strigulosa 1.C. (Zie No. 315.)

8837. Tjinteh $\mathrm{S} .=\mathrm{Lantana} \mathrm{L}$. Spec. div.

8838. Tjintekka J. $=$ Plu mbago rosea L. (Zie No. 114.)

8839. Tjinti BтJ. $=\mathrm{Z}$ ingiber Cassumunar Rxb. (Zie No. 878.)

8840. Tjipait S. = Agalmyla staminea Bl., Nat. fam. der Cyrtandrac e $æ, G_{R}$ Java 4000'; eenjarig.

8841. Tjiploekan J. $=\mathrm{Ph}$ isal is angulata L. (Zie No. 8804.)

8842. Tji-too Cr. Bo. = Arachis hypogæa L. (Zie No. 3961.)

8843. Tjitjabean-0etan S. = Gomphostemma petiolare Miq. (Zie No. 23726.)

8844. Tjitjap S. = Ficus alluta. ce a Bl. (Zie No. 765.)

8845. Tjitjikoeran $\mathrm{S} .=\mathrm{T}$ acca pinnat if a Forst. (Zie No. 6105.)

8846. Tjijhe-badak $\mathrm{S} .=\mathrm{S}$ о у a Wightii Grah., Nat. fam. der Papilionaceæ GR. Java; sliugerplant.

8847. Tjijhe-kandoeri-ketjil MI. = A brus præcatorius L. (Zie No. 53.) 8848. Tjoebang-deri-oetan $\mathrm{M} .=\mathrm{J} 0$ des tomentella Mliq., Nat. fam. der Phytocrenex. Gr. Java, Halmaheira; slingerplant.

8849. Tjoejer S. = Adelia uereifolia Wight. (Zie No. 2207b.)

8850. Tjoekilan J. $=$ Schmiedelia racemusa L. (Zie No. 4827.)

88žl. Tjoektjoek-lamaran S. = Gardenia Blumeana 1).C., Nat. fam. der Rubiaceæ. Gr. Java; heester.

88ว2. Tjoektjoek-lamaran-badak S. = Gardeuia tomentosa Bl., Nat. fam. en GR. Als voren.

88ว5. Tjoelang M. = A glaja odorata Lour. (Zie No. 3710.)

88ว4. Tjoemata of Tjoemateh Sum. WK. = Fluggea microcarpa Bl. (Zie No. 5860 .)

8855. Tjoengoelan J. = Ethulia 
mega cephala Schultz., Nat. fam. der Compositæ. Gr. Java 6-10000'; éénjarig.

8856. Tjoeng-neo CH. Bo. = $\mathrm{Cha}$ vica Roxburghii Miq. (Zie No. 295.)

8857. Tjoeni S. = Gynotroches axillaris Bl. (Zie No. 1017.)

8858. Tjoenjoen-bebaauw M. en

8859. Tjoenjoen-wangi $\mathrm{M}$. = $\mathrm{Ta}$ lauma Candollei Bl. (Zie No. $4051 b$.)

8860. Tjoenkangkang $\mathrm{S} .=a . \mathrm{C} \propto-$ lospermum scandens Bl. (Zie No. 699d.) $=b$. Ecdysanthera ba rb at a Miq., Nat. fam. der A pocynex. Gr. Java; heester. $=c$. Ecdysanthera densiflora Miq., Nat. fam. en Gr. Als $b$. = d. Chilocarpas denudatus Bl. (Zie No. 603b.) =e. Cyrtoceras mul. tiflorum Benn. (Zie No. 699f.) $=f$. Cyrtoceras laurifolium Miq., Nat. fam. der A sclepiader. Gr. Java; heester. 三g. Cystidianthus campanulatus Hassk. (Zie No. 699g.) $=h$. Salacia melittocarpa Bl. (Zie No. 589.)

8861 . Tjoenkankang-goenong S. 三 Dendrocharis inflata Miq. (Zie No. $8439 c$.)

8862. Tjoenkankang-lalaki s. = $a$. Chilocarpus suaveolens Bl. (Zie No. 478.) $=$ b. Chilocarpus densiflora Bl., Nat. fam. der A p ocyneæ. Gr. Java en Sumatra; slingerplant.

8863. Tjoen-seu CH. Bo. $=\Lambda \mathrm{pium}$ graveolens L., Nat. fam. der Umbelliferæ; onze gewone Selderij.

8864. Tjoen-tjiou Сн. Bo. = $\mathrm{M}$ u a paradisia ca L. (Zie No. 1190.)

8865. Tjoeran-rambat $\mathrm{S}$. 三 Leukosyke alba Z. \& M. (Zie No. 343.)

8866. Tjoerei $\mathrm{S} .=a$. Gynotroches axillaris Bl. (Zie No. 1017.) = b. Henslovia paniculata Miq. (Zie No. 803.)

8867. Tjoektjoek-kaliageh $\mathrm{S} .=a$, Taxotrophis Roxburghii Bl. Zie No. 4868.) $=b$ Pisonia anisophylla Hassk., Nat. fam. der Nyctag in ex. $\mathrm{GR}_{\mathrm{R}}$. Java; groote heester. $=c$. C a n th in $\mathrm{m}$ Rheedii D.C., Nat. fam. der Rubiace Gr. Java; heester. GuBR. De aangenaam zure vruchten worden afgekookt bij de rijst gegeten.

8868. Tjoewawoet J. = Pennise. t um macrochæton J c q. (Zie No.6399) 8869. Tjok Сн. Bo. = $\mathrm{B} \mathrm{a} \mathrm{m} \mathrm{b} \mathrm{u} \mathrm{s} \mathrm{a}$ $\mathrm{S} \mathrm{ch} \mathrm{reb.}$

8870. Tjokai S. $=$ Pol yos ma integrifolia Bl. (Zie No. 423.) 8871. Tjoklat MI. $=\mathrm{T}$ h e obroma $\mathrm{C}$ a c a o L. (Zie No. 3556.)

8872. Tjomoe-toeffa $\mathrm{T}$. $=$ Ophioglossum ovatum Sw. (Zie No. 1797.) 8873. Tjongkok $\mathrm{S}$. 三 $a . \mathrm{Curcu}$. ligo latifolia Dryand. (Zie No. 24.) $=$ b. Curculigo recurvata D r y a n d. (Zie No. 581]b.)

8874. Tjongkodo-kir J. $=\mathrm{M} \mathrm{e}$ las toma poly a $\mathrm{thum} \mathrm{Bl}$. (Zie No. 110.

8875. Tjontjong-beloet $\mathrm{J}$. $=\mathrm{Me}$ lanthesa rhamnoides Bl. (Zie No. $1453 b$ )

8876. Tjopo M. = Conyz a bals a mif er a L. (Zie No. 85b.)

8877. Tjoppi-toehoer S. $=\mathrm{Craw}$ furdi a Blamei G. Don., Nat. fam. der Ge n t i a n e æ. Gr. Java. 9000'; slingerplant.

8878. Tjotjok-boewoe $\mathrm{s} .=a . \mathrm{Chi}$ rit a $H$ or sfieldii R. B r., Nat. fam. der C y r tandrace $æ$. Gr. Java, Sumatra; heestertje. $=b$. Pellionia e la t o s temoides Ga ud, Nat. fam. der Urtice $x$. Gr. Java; éénjarig. 三 c. Elatostem ma Forst. Spec. di. versa. $=d$. Sonerila heteroph yll a Jack. (Zie No. 6726.)

8879. Tjotjok-boewoe-leutiek S. 二 Ophiorrhiza trichocarpa Bl.. Nat. fam. der $R$ u b i a c ex. Gr. Java; éénjarig.

8880. Tjotjor-behbekh J. = $\mathrm{Ka-}$ lanchoë pinnata Pers. (Zie No. 1437.)

4881. Tjotjorokkot S. = $a$. S o lanum ind icum Nees. (Zie No. 8203.) = b. Solaum Pseudo-saponac e um B l. (Zie No. 5597.)

8882. Tjotogo T. = Diploclinium t u beros n M i q. (Zie No. 1054.)

8883. Tjou-njok $\mathrm{CH}_{\mathrm{H}}$. Bo. $=\mathrm{Plum}-$ b a g o rose a L. (Zie No. 114.)

8884. Tjouw S. 三 M us a Tnft. 8885. Tjou-tjai $S .=R$ avenala madagascariensis Adans. (Zie No. 6872.)

8886. Toä ALf. Min. 三 Na u clea p a rvifolia $R \times b$. (Zie No. 969.)

8887. Toän T. 三 Metroxylon S a g u Rottb. (Zie No. 1322.)

8888. Toänsing MEN. = C ostus specios us S m. (Zie No. 3247.)

8889. Tobba-toko T. $=\mathrm{A}$ butilon hirtum F. Don. (Zie No. 347. 
8890. Tobo-tobo Mak. $=\mathrm{Ficus}$ septica Rmph. (Zie No. $76 \overline{4 .}$ )

8891. Toeä-hoe RTt. en

8892. Toeä-hoeä T. = Borassus flabelliformis Linn. (Zie No. 3117.) 8893. Toeängau Bo. Zk. = Eurya nitida Korth, Nat. fam. der Ternstromiacex. Gr. Borneo; boom.

8894. Toeba-awehweh S. 二 Derris uliginosa Bnth. (Zie No. 595.)

8895. Toeba-berebai Lamp. = A $\mathrm{r}$. tanema sesamoides Bnth. (Zie No. 6697c.)

8896. Toeba-bidji M. = a. Ana. mirta Cocculus W. \& B. (Zie No.260.) $=b$. Tinospora crispa Miers. (Zie No. 328.)

8897. Toeba-djenoe of T-djenoh S. = Pongamia volubilis Z.\&M., Nat. fam. der Papilionaceæ Gr. Java; slingerplant. GEBR De stengels van deze plant zijn zeer gezocht voor de visscherij, daar zij de visschen spoediger bedwelmen dan de andere $\mathrm{T}$ oe ba-soorten.

8898. Toeba-gatel S. = $\alpha$. Mille. tia sericea W. \& A. (Zie No. 187.) = b. Milletia? rostrata Miq., Nat. fam. der Papilionaceæ. Gr. Java; slingerplant. GeBr. Ook de stengels van deze plant zijn on hunne bedwelmende eigenschappen voor de vischvanost zeer gezocht.

8899. Toeba-kajoe M. = Derris uliginos a Bnth. (Zie No. 595.)

8900. Toeba-lalur S. = Milletia sericea W. \& A. (Zic No. 187.)

8901. Toeba-parampoean M. 二 Derris Forsteniana Bl. (Zie No. 3264.) 8902. Toeba-siapar Sum. WK. = Hartighsea acuminata Miq., Nat. fam. der Meliacer. Gr. Sumatra; hooge boom.

8903. Toeba-toeni M. = A n amir. ta Cocculus W. \& A. (Zie No. 339.) 8904. Toebe BD. (Als vorig No.) 8905. Toobe-abbal Aмв. 三 Derris Forsteniana Bl. (Zie No. 3264.)

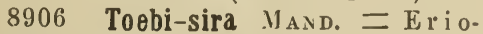
glossum edule Bl. (Zie No. 3580.) 8907. Toeboe-toeboe Амв. 二 Cоs. tus speciosus $\mathrm{Sm}$. (Zie No. 3247.) 8908. Tooboe-toeboe-waät-ketjil Aмв. = Egiceras floridnm R. \& S. (Zie No. 130.)

8909. Toedjoe J. = Argem one mexicana L. (Zie No. 5360.)

8810. Toedong-lawut M. 三 $A \mathrm{gi}$. ceras minus Gretn. (Zie No. 1558)
8911. Toe-gankoet $\mathrm{s}$. $=$ Mentha, javanica Bl (Zie No. $130 \overline{9}$.)

8912. Toehe Bu. (Zie Toebe Bi).)

8913. Toehe-abbal Aмв. $=$ Derris Forstenia ua Bl. (Zie No. 3264.)

8914. Toehe-toettoenoe BD. A ristolochia indica L. (Zie No. 207.) 9815. Toejong-pongor Mann. 二 Datura alba Nees. (Zie No. 4959.)

8916. Toeká-doeffa 'T. $=\mathrm{Musa}$ uranoscopos $R \mathrm{mph}$. (Zie No. 6890.)

8917. Toekas Вк. = Caryota furfuracea Bl. (Zie No. 2489.)

8918. Toekoel-takal M. \& J. = Berrya Ammonilla Rxb., Nat. fam. der Tiliaceæ. Gr. Op Java, van Ceylon overgebracht; hooge boom. GEBR. Deze boom levert het Trincomale e hout, dat vooral voor scheepsbouw, hoofdzakelijk voor zoogenaamde Massoolaboats, gebruikt wordt.

8919. Toelak-tangal $\mathrm{S} .=\mathrm{Para}$. tropea longifolia D. C.

8920. Toelalot $J .=W$ endlandia tinctoria (1). C., Nat fam. der Rubiaceæ Gr. Java; boom. Gebr. De schors bezigt men tot het verwen van katoenen, gareus, enz.

8921. Toelang-toelang Sum. WK.二 Memecylon costatum Miq. (Zie No. 4.13.)

8922. Toelian Bo. $=\mathrm{Ecuside}$ roxylon Zw a geri T.\&B. (Zie No. 1103.) 8923. Toelin $\mathrm{BK}$. = Cyathocalyx ram iflorus M aing. Nat. Fam. der A nonaceæ. Gr. Bangka, boom.

8924. Tooloek BD. 二 Bambusa longinodis Miq. (Zie No. 1340.)

8925. Toelowodji BiJ. $=\mathrm{Ophi-}$ oxylon serpentinum L. (Zie No. 6948.3

8926. Toematangtáng AlF. Mrs. = Covellia subopposita Miq. (Zie No. 1416$.

8927. Toembal Bк.二Tacca $\mathrm{R} u \mathrm{~m}$ phii Schauer. (Zie No. 2271.)

8928. Toemboeloen J. $=$ Metroxylon Sagus Rottb. (Zie No. 1322)

8929. Toemboeng-kanjpet M. \& S. E Canthium Rheedii D.C. (Zie No. $8867 c$;

8930. Toemboeng-kanjoet-litjin S. = Canthium horridum Bl., Nat. fam. der Rubiaceic. Gr. Java en Snmatra; heester.

8931. Toemboeng-boeloe S. 二 $\mathrm{Can}$ thin $\mathrm{m}$ ornelia Ch. \& $\mathrm{Sch}$.. Nat. 
fam. als voren GR. Java; heester. GkBR. Volgens $\mathrm{H}$ as skarlworden de zure, eenigs. zins wrange vruchten: der Canthiumsoorten afgekookt en bij de rijst gegeten.

8932. Toemboeng-litjin M. \& S. (Zie No. 8930.$)$

8933. Toemoen-telong J. = Geniostoma montanum Z. \& M. (Zie No. 3054 )

8934. Toendjang J. = Bruguiera cylindrica Bl. (Zie No. 1662.)

8935. Toendjing-Iontjet SuM. WK. = Stylocoryna albituba Miq., Nat. fam. der R u b i a c e x. Gr. Sumatra: boom

8936. Toendjoek-langit M. $=\mathrm{O} \mathrm{phi}$ glossum ovatum Bl (Zie No. 1797.)

8937. Toendjoeng M. \& S. $=a$. Tala uma mutabilis. Bl. (Zie No. 4199 .) $=$ b. Tala u ma Candolle i B 1. (Zie No. $465 ! b$.)

8938 Toendjoeng-barak BL. $=\mathrm{N} \mathrm{y} \mathrm{m}$. ph æa. Lotus L., var, purpurea. (Zie No 4198.)

8939. Toendjoang-biroe BL. = N y mphra stellata Wlld., var. cyanea. (Zie No. 3765.)

8940. Toendjoeng-dado $\mathrm{BL} .=\mathrm{N} \mathrm{y} \mathrm{m-}$ phæa Lotus I., var. rosea.

8941. Toendioeng-malatti BL. of

8942. Toendjoeng-nila-watti $\mathrm{BL}_{\mathrm{L}}=$ Limnanthemum indicum Gris. (Zie No. 4200 )

8943. Toendjoeng-poetih BI. = Ny mphra lootus L., var. alba.

8944. Toendoen of Toentoen M. \& S. = Nephelium Lappaceum L. (Zie No. 6937.)

8945. Toengerreh S. of

8946. Toengoerroet $\mathrm{S}$. $=$ Castanea Tungurrut Bl. (Zie No. 2468.)

8947. Toenging.mantji Sum. WK. = Elæocarpus integri ptalus Miq., Nat. fam. der Tili a c e æ. Gr. Sumatra;boom. 8948. Toengkar Sum. WK = A ralidium dentatum Miq.. (Zie No 3337.) 8949. Toengkeh-alie SuM. WK. = Eurycoma longifolia Jack. (Zie No. 804.)

8950. Toenjang-toenjang.lontjeh Sum. WK. = Stenochasma ancolanum Miq., Nat. fam der Urticacer. Gr. Sumatra; heester

895 L. Toenjoeng S. $=\mathrm{C}$ ar u mbium giganteum Miq., Nat. fam. der Euphorbiacex. Fr. Java 3-6000'; zware boom.
8952. Toentoeng $\cdot$ monjet $\mathrm{S}$. = Uiscostigma rostratum Hask. (Zie No. 343\%.)

8953 Toepa $\mathrm{M}=\mathrm{Pi}$ erardia dulcis Jack. (Zie No. 1503.)

8954. Toepak T. $=a$. Barringtonia acutangula frertn. (Zie No. $983 b)=b$. Barringtonia racemosa Bl. (Zie No. 983.) = c. Barringtonia rubra Bl (Zie No. 2962c.)

8955. Toeri $.1 .=$ Agati grandiflora Dsv. (Zie No. 3135 .

8956. Toeri-rawa J. = Eschynomene aspera L., Nat. fam. der Papili on aceæ. Gr. Java; cenjarig.

8957. Toeroejan $\mathrm{S}$. = Cassia indec ora H. B. \& K. (Zie No. 39l6.)

8958. Toeroe-muksa $\mathrm{S}$. = Ruelli a Blumeana Nees., Nat. fam. der Aca $n$th a ceæ. Gr. Java en de Molukken; éénjarig. GEßk Even als de anderc Ruellia-soorten, bezigt men dit kruid uitwendig als rijpmakend middel op abcessen en tegen herpesachtigc uitslagziekten.

8959. Toeroe peutjang S. = Loxotis obliqua R. Br. (Zie No 8650b.)

8960. Toeroep S. = a. Urostigma annulatum Miq., Nat. fam. der Artocarpeæ. Gr. Java; hooge brom. $=b$. Artocarpus Blumei Tréc. (Zie No. 1119.)

8961. Toeroep-aroij S. = Urostigma depressum Miq., Nat. fam. als voren. Gr. Java; kiimplant. $=b$. Urostig in 3 globosin Miq. (Zie No. 3245.) 8962. Toernep-boeöek S. = Artocarpus elastica Rwdt. (Zie No. 1307.) 89๕3. Toesam Sum. WK. $=\mathrm{P}$ in u s Merknsii Jngh \& de Vr. (Zie No. 3521 .)

8964. Toetoe-kekoe BD.= Scrvola Konigii Vahl. (Zie No. 1001.)

8965 . Toetoe-massoniha $\mathrm{T} .=X \mathrm{y}$ locarpus Granatum Kon. (Zie No. 1319)

8960. Toetoep RL. = Pavoniazeylanica Cav. (Zie No. 3792.)

8967. Toetoep-antjoer BL. $=\mathrm{Mappa}$ moluccana Sprg. (Zie No. 56.)

8968. Toetoer-atap $\mathrm{BK}=$ Brckea frutescens L. (Zie No. 2395.)

8969. Toeton M. \& J. = Poly toca bracteata R. Br., Nat. fam. der Gra$\mathrm{m}$ ineæ. Gr. Java; hoog gras.

8970. Toetop M. = Abutilon indicum G. Don. (Zie No. 3124.)

8971. Toewa M.\&S. ,Zie Toeba M.\&S.) 
8972. Toewa $\mathrm{J} .=\mathrm{L}$ eea sambucina Wlid. (Zie No. 133.)

8973. Toewi (Toewei) Sum. WK. = Spat hodea Lobbii T. \& B. (Zie No. 31 ว.)

8974. Toewi-gadang Sum. WK. = Stereospcrm um gla d a losum M i q., Nat. fam. der Big n on i a ce æ. Gr. Java en Sumatra; boom.

8975. Toewi-negri Sum. WK. = Limonia curvispina Miq., Nat. fam. der A u rantiac cæ. Gr. Sumatra; heester.

8976. Toggare $\mathrm{J}_{0}=\mathrm{Di}$ a nclla en sifolia Redout. (Zie No. 6322.)

897\%. Tohon BL. \& A n u m M elongen a L. (Zie No. 2340.)

8978. Tohon-kanji $\mathrm{BL}=\mathrm{S}$ olanum tro n g u m Poir. (Zie No. 3878c.)

8979. Tois Alf. Min. $=$ A nanassa sativa Lind l. (Zie No. 5680.)

8980. Toja BD. $=\mathrm{C}$ on ophallus? sativus Schott. (Zie No. 5317.)

8981. Toja-oetan BD. = Typh onium divaricatum Bl. (Zie No. 12:36.)

8982. Tokbraai S. $=$ Elateriospermum Tokbray B l. (Zie No. 1513.)

8983. Tokej J. = A l b i z z i a lat ifolia Bois. (Zie No. 4793.)

8984. Tokokkah $\mathrm{S}$. $=\mathrm{S}$ ol a n u $\mathrm{m}$ g i ga n t e u $\mathrm{m} J$ a c q., Nat. fam. der Sola n e $x$. Gr. Java; heester.

8985. Takokkah-boddas $\mathrm{S} .=\mathrm{S}$ ol a n u m Pse udo-s a p on a c e m B l. (Zie No. 5597.

8986. Tola-topolo $\mathrm{T} .=\mathrm{Kyll} \mathrm{i \textrm {n }}$. gia monocephala Rottb. (Zie No. 64.10 .

M.

8987. Tolasi Mak. $=$ S oelas si

8988. Tolasion BangaAJ. = Querc n s molu c ca Rmph. (Zie No. 109.)

8989. Toloen Амв. $=a \cdot \mathrm{P}$ a nd a. nus montanus Miq. (Zie No. 437 ) $=b$. Pandau u ceramicus $R \mathrm{mph}$. (Zie Nu. 1828.)

8990. Tolong S. $=\mathrm{Ar} \mathrm{a} \mathrm{c} \mathrm{i} \mathrm{m} \mathrm{l}$ vigat u m M iq., Nat. fam. der C o mposit x. Gr. Java, Sumatra, de Molukken; éénjarig.

8991. Tom J. = Indigofera t in ct ori a L. (Zie No. 2305.)

8992. Tomandellan $\mathrm{J}$. $=\mathrm{P}$ a $\mathrm{v}$ e $\mathrm{t} \mathrm{t}$ a macrophylla Bl., var. long if 0 I i a. (Zie No. 5997.)
8993. Tomatti $\mathrm{H}=\mathrm{L}$ y copersicum esculentum Mill. (Zie No 1111.)

8994 Tommo of Tommon J. \& M. $=\mathrm{Curcuma} \mathrm{Z}$ er u m bet Rxb. (Zie No. 3866 .)

8995. Tommo hitam M. of

8996. Tommo-iran $\mathrm{B}_{\mathrm{L}}$. $=\mathrm{C} u$ r $\mathrm{u}$. ma cæsia $\mathrm{R} \times \mathrm{b}$.; Nat. fam. der Z ing i berace r. Gr. De Molukken; overblijvend. Gebr. Zie de overige $\mathrm{Cu}$ u c u. m a-soorten.

8997. Tommon J. $=\mathrm{Gr}$ a p tophyll u m horterse Nees. (Zie No 90.) 8998. Tommon-gering $\mathrm{J}_{\text {. }}=a$. $\mathrm{Cu} \mathrm{r-}$ c u m a lo 1 g a L. (Zie No. 2620) $=b$. Curcuma viridiflora $R x h$. (Zie No. 5026 )

8999. Tomoemoe T. $=\mathbb{E}$ giceras florid um R. \& Sch. (Zie No. 130.) 9000. Temok BK. $=$ Bruguiera oxy phylla Miq. (Zie No. 249b.)

9001. Tomok-meirah Bk. $=\mathrm{B} \mathrm{ru-}$ gu ie ra cylindrica Bl.(ZieNo 1662.) 9002. Tomok-poetih $\mathrm{BK} .=\mathrm{Bru}$ guiera oxyphylla Miq. (Zie No. 24.9.)

9003. Tompowit S. = Cassyta p ubescens R. Br. (Zie No. 652b.)

9004. Tondjo-poetih M. en

9005. Tondjong-tedjalor M. $=\mathrm{Lim}$. nan them um ind icum Griseb.

(Zie No. 4200.)

9006. Tonggoeli J. $=$ Protiu m javanic u m Brm. (Zie No. 4031b)

9007. Tongkeng $\mathrm{M} .=a$. $\mathrm{P}$ erg ularia odoratissima I. (Zie No. 1395.) $=b$. Pergularia minor Andr. (Zie No. 5652b.)

9008. Tongkir BK. $=\mathrm{B} \mathrm{rug} \mathrm{u} \mathrm{i} \mathrm{e} \mathrm{r}$ oxy phyll a $\mathrm{Miq}$. (Zie No. 249.)

9609. Tongoh ALF. Min = P a vett a incarnata Bl. (Zie No. 1997.)

9010. Tongtak $\mathrm{S} .=\alpha . \mathrm{Z}$ i n g i b e r a maricans Bl. (Zie No. 2401) $=b$. $\mathrm{Z}$ ing iber inflex u $\mathrm{m}$ l. (Zie No. 5220.) =c. Z ing i bcr od orifer u m Bl., Nat. fam der Z ing i beraceæ.

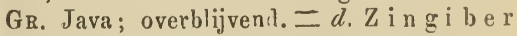
ovoideum B l., Nat. fam en Gr Als voren.

9011. Tongtak-gedeh $\mathrm{S}$. $=\mathrm{Z}$ ing $\mathrm{i}$ b c r od or if crum B l. (Zie No. 9010c.)

9012. Tongtak-leutiek $\mathrm{S} .=\mathrm{Z}$ i n g iber ovoideum Bl. (Zie No. 9010d.)

9013. Tongkat-monjet $\mathrm{S}$. 二 Zingiber od oriferum B1. (Zie No. $9010 c$.) 
9014. Tonja PaL. $=\mathrm{Can}$ a rium v) a te ntinervium Miq., Nat. fam. der Amyrid e $æ$. Gr. Sumatra; hooge boom.

9015. Tonjo Mak. $=\mathrm{Nel} \mathrm{u} \mathrm{m} \mathrm{bium}$ speciosum Wlld. (Zie No. 6712)

9016. Tonkat-langit M. 二 $a$. Ophioglossum ovatum Sw. (Zie No. 1797.) = b. Quamoclit vulga$\mathrm{r}$ is $\mathrm{C}$ hois. (Zie No. 533.) $=c$. M u sa u ranosco pos Rmph. (Zie No.6890.) 9017. Tonkat-seetan $\mathrm{M}$. $=\mathrm{M}$ a $\mathrm{r}$ a $\mathrm{n}$ t a dichotom a Wall. (Zie No. 926.)

9018. Tonkeh M. = $\mathrm{Brugui}$ r ra Rumphi Bl. (Zie No. 8666.)

9019. Tonkeh-parampoean M. = B ruguiera cylindrica B l. (Zie No. 1662.)

y020. Tonkia $\mathrm{S} .=$ Dischidia $\mathrm{n} \mathrm{u}$ in $\mathrm{m} \mathrm{u} \mathrm{laria} \mathrm{R.} \mathrm{B} \mathrm{r.} \mathrm{(Zie} \mathrm{No.} \mathrm{2231d.)}$

9021. Tonkin $\mathrm{S} .=\mathrm{V}$ all a ris ovalis Mi q., Nat. fam. der A p oc yn e Gr. Jara en de Molukken; slingerplant; wordt aangeplant om hare geurige bloemen.

9022. Tonkolloh S. = K leinhoria hospita L (Zic No. 3927.)

9023. Tonkon Bo. $=\mathrm{L}$ or a n th ac e $\rightsquigarrow$ M r s. divers $æ$.

9024. Tonokoekoe Амв. $=\mathrm{H}$ e d e ra umbellifer a D C. (Zie No. 7666 .)

9025. Toombo (Toemboe)-darat Вк. $=\mathrm{Laplacea}$ maginata Chois. (Zie Plumpang-poetin $\mathrm{BK}$.)

9026. Toppa-lima $\mathrm{S} .=\mathrm{El} \mathrm{eph} \mathrm{a} \mathrm{u-}$ to pus sc \& b e r L. (Zie No. 8381.)

9027. Toralak $S .=G$ u t teria Torala k B l., Nat. fam. $\operatorname{der} A$ n o na. c e $æ$ GR. Java; heester.

9028. Toropatti BD. $=\mathrm{Dracon}$. tomelon sylvestre Bl. (Zie No. 1481 .

9029. Totara-hitam MoL. = Commersonia e chinata Forst. (Zie No. 106.)

9030. Totara-palekong Моь. $=a$. II a p a moluc c a a S prg. (Zie No. 56.) $三$. Nap p Tan aria Sprg. (Zie No. 2294b)

9031. Totebo of Toteho T. $=$ Cord i a M y $x$ a I. (Zie No. 117.)

9032. Totokbrai S. (Zie Tokbraai S.) 9033. TotongoänS. $=S$ a l vi a c occ i n e a L., Nat. fam. der L a b i a tæ. Gr. Java in tuinen als sierplant; overblijvend. 9034. Totoüöan S. $=$ M o r o c a rpus dich ot o m us B l. (Zie No. 4406b.)
9035. Towada T. $=A \mathrm{rtoc}$ a r pu s polyphema Pers. (Zie No. 144.)

9036. Tran of Toän J. = II e troxylon Sagus Rottb. (Zie No. 1322) 9037. Trangdoenia $\mathrm{M} .=a \cdot \mathrm{C} æ-$ salpinia pulrherrima Sw. (Zie No. 1386.) $=b$. Es chy nom e ne indic a L. (Zie No. 2360f.)

9038. Trasen $\mathrm{S} .=\mathrm{C}$ e ropegia Horsfieldian a Miq., Nat. fam. der A s c le p i a d e $æ$. Gr, Java en Bali; slingerplant.

9039. Traseng J. $=$ Sanicula mont a n a $R$ wd t., var. ge nuina (Zie Ns. 2245.)

9040. Trassen J. = a. Gy nura a urantiaca DC. (Zie No. 22i9b.) = b. Elatost e m m a paludosum Miq., Nat. fam. der U r t i c e æ. GR. Java; éénjarig.

9041. Tratap $\mathrm{BK} .=\mathrm{Leucopo-}$ gon malayanus Jack. (Zie No. 8552.)

9042. Treba-djapan M. \& S. $=a$. $\mathrm{Rhinacanthus}$ communis $\mathrm{N}$ s. (Zie No. 240.) $=b$. C rossandra infundibuliformis Wlld. (Zie No. 2006.) =c. Andrographis paniculat a Ne es., Nat. fam. der A c anth a c e æ. Gr. Java; overblijvend. Gebr. Het kruid is zeer bitter, en wordt daarom op Ceylon reel als geneesmiddel aangewend.

9043. Treham-ajam $\mathrm{S} .=\mathrm{R}$ u b i a c ord if olia L. (Zie No. 2380.)

9044. Trembaloe J. $=$ C assia g la u c a L a m. (Zie No. 2568.)

8045. Trembiloengan S. = Plat $\mathrm{y}^{-}$ centrum robustum Miq. (Zie No. 730.)

9046. Trimboekoe $\mathrm{S}=\mathrm{R}$ aphidospora dichotoma Nees., Nat. fam. der A c a nthace æ. Gr. Java; heestertje.

9047. Troeëp S. $=$ Artocarpus el astic a $R$ wd. (Zie No. 1307.)

9048. Troena-malan M. = Pol $\mathrm{y}-$ a $n t h$ es tuberos a L. (Zie No. 4190.) 9049. Troentong M. $=\mathbb{E}$ giceras majus Gærtu. (Zie No. 1556.)

9050. Troes-goenong M. $=\mathrm{H} \mathrm{ar}-$ tighsea excelsá Juss. (Zie No. 4382.)

90วl. Tropongan $J_{0}=\mathrm{V}$ a le riana jaranica Bl. (Zie No. 4952 )

9052. Tsampej J. = Cananga odorata Hook fs. (Zie No. 1373.)

9053. Tsjakka-mangoli T. = Scle- 
ria sumatranens is Retz., Nat. fam. der Cyperaceæ. Gr. Sumatra, Java; de Molukken; hoog gras.

90ə4. Tsjakkar-bebekh J. $=\mathrm{Kalan}$ choë laciniata DC. (Zie No. 46.)

90弓ว. Tsjali-moeri T. $=$ Cordia subcordata Lam. (Zie No, 1021.)

9056. Tsjamarkijen T. $=\mathrm{Cro}$.Ton

Tigli u m L. !Zie No. 6.)

90ว7. Tsjamba $M_{\mathrm{AK}}$. $=$ Tamarindus indica $\mathrm{L}$. (Ze No 723.)

90ว8. Tsjampeh J. = Michelia

Champaca L. (Zie No. 4156.)

90ว9. Tjsampoelan $\mathrm{J}_{0}=\mathrm{C}$ alophyllum inophyllum L. (Zie No. 1139$.

9060. Tsjangkok J. (Zie vorig No.) 9061. Tsjappo-tsjappo $\mathrm{M}$. = $\mathrm{M}$ onochoria vaginalis Presl. (Zie No. 912.)

9062. Tsjavoni $\mathrm{M} .=\mathrm{Calamus}$ equestris Wlld. (Zie No. 2804.)

9063. Tsjendana BG. \& $\mathrm{M} .=a$.

Santalum albumL. (Zie No. 3519.) =

b. Pterocarpus indicus Wlld. (Zie

No. 18.)

9064. Tjserekan BG. $=\mathrm{C}$ issus repens Lam. (Zic No, 43S.)
9065. Tsjili MoL。 $=$ Capsicum Tnft. Spec. diversæ.

9066. Tsjili-abbal A $\mathrm{ar} .=\mathrm{Ad} \mathrm{ha-}$ toda Moretiana Miq., (Zie No. 1762.) 9067. Tsjinga-tsjinga $\mathrm{T}$. $=\mathrm{Wol}_{\mathrm{l}}$ lastonia moluccana DC. (Zie No. 315 .)

9068. Tsjira (Tschira) BL. = $\mathrm{T}$ axo. trophis Roxburgii Bl. (Zie No. 4868.)

9069. Tsjonkor M. = $\mathrm{K} æ \mathrm{mpfe}-$ ria Galanga L. (Zie No. 737.)

9070. Tsjopelon T. $=$ Calophyllum inophyllum L. (Zie No, 1139.) 9071. Tsjorro T. $=$ Covellia racemifera Miq. (Zie No. 1240.)

9072. Tsjorro-boboa T. en

9073. Tsjorro-mamma T. $=a$

Gynandropsis pentaphylla DC. (Zie No. 1287.) = b. Polanisia viscosa DC. (Zie No. 12876.)

9074. Tsoi-teo Сн. Bo. $=\mathrm{Rapha-}$ nus c a d atus L. (Zie No. 5437.)

9075. Tubi-pokkol Амв. $=\mathrm{Sida}$ a c u t a $13 \mathrm{rm}$. (Zie No. 1802.)

9076. Tueijl Mak. ën

9077. Tueỉlo Аıв. $=S$ p a th od e a $\mathrm{R} h$ e edii Wall. (Zie No. 3252c.)
9078. Waäan-semane $\mathrm{CR}_{\mathrm{r}}=\mathrm{Bam}$ b u s a fera 11 iq. (Zie No. 774.)

9079. Waät Aмr. $=\mathrm{Brugu}$ i e r a Rumphii B l. (Zie No. 866b.) $=b$. Sonnexatia a cida L.fs en $=c$. Sonneratia alba Sm. (Zie No. $866 c$. en $d$.)

9080. Waät-mahina $A x r$. $=\mathrm{Eg}$ ic eras majus Gærtn. (Zie No. 1556.) 9082. Waàt-tehij Амв. $=\mathrm{Rh}$ iz 0 phora mucronata Lam. (Zie No. 868.)

9083. Wabba of Wabbo Aмв. = Cerbera lactaria Ham. (Zie No. 1) 82.$)$

9054. Wabbo-goenong $\mathrm{Cr}_{\mathrm{r}}=\mathrm{N}$ e $\mathrm{u}$. burgia musuliformis Miq. (Zie No. 45.)

9085. Wabbo-meijt Aмв. = L a c. taria salubris Rmph. (Zie No. 5́518.) 9086. Wadori J. $=$ Calotropis gigantea R. B r. (Zie No 817.)

9087. Wadran J. $=$ a.Pile a ore 0 - phila Miq. (Zie No. 6916b.) $=b$. Elatostem m a yrtandræfolium M i q., Nat. fam. der U r ti c a c e Java ; éénjarig.

y088. Waëkor $\mathrm{Cr} .=\mathrm{T}$ a c c a $\mathrm{R} u \mathrm{~m}$. phi i J. C. S c h a u er. (Zie No. 22716.) 9089. Wait-kodi Lamp. = Premna $r$ ufidula Mi q., Nat. fam. der V e rb e n a c e æ. Gr. Sumatra; heester.

9090. Wait-larap LAMP. $=\mathrm{V}$ e $\mathrm{n}$. til ago luce ns Mi l., Nat. fam. der $\mathrm{R} h$ a $\mathrm{m} n$ e æ. GR. Snmatra; slingerplant.

9091. Wait-linwoeang LaMr. = Spatholobus macropterum Miq. Nat. fam. der Papilionacea. Gr. Sumatra; slingerplant.

9092. Wait-salowewoh Lasp. = S patholobus ferrugineus B nth. (Zie No. 8776.)

9093. Wait-sekedie LAMP. $=\mathrm{R}$ a ffles i a A r nold i L. B r. (Zie No. 273.) 9094. Wait-serakak LAMP. $=A$ lang i um sundanum M iq., Nat. fam. 
der Corna ceæ. Gr. Java, Sumatra; heester.

9095. Wait-sesatak Sur. WK. = A langium hexapetalum I a m. (Zie No. 5004.)

9096. Wait-sinongan LAMP. $=\mathrm{V}$ entila go lucens Ml iq. (Zie No.9090.)

9097. Wait-tengalan LaMP. $=\mathrm{Ficus}$ recurva Bl. (Zie No. 306.)

9098. Waij-waij Амв. = M a n g ifera indica L., $v$ ar. dome stica. (Zie No. $5721 b$. ) $=$ b. Mang ifera $\mathrm{T}$ a i pan $\mathrm{Ham}$. (Zie No. 5721b.) $=c$. Il angifera utana Ham. (Zie No. $5721 c$.)

9099. Waijle Arr. $=\mathrm{Cl}$ e roden$\mathrm{drum}$ in erme L. (Zie No. 1243.)

9100. Waijlo-hittota Амв. $=\mathrm{P} æ-$ deria f œtida L. (Zie No. 17396.)

9101. Wajawang $\mathrm{S}$. $=$ Pogono. troplue a urantiaca Miq. (Zie No. 5326.)

9102. Wakkat Амв. $=a$. B r ugu i er a $\mathrm{Rumphi} \mathrm{i} \mathrm{Bl.} \mathrm{(Zie} \mathrm{No.} \mathrm{866c.)}$ $=b . \mathrm{Bruguiera} \mathrm{caryophylloi}$. d e s B l. (Zie No. 3742b.) =c. S o nneratia a cida L.fs. (Zie No. 866c.) $=d$. Sonneratia alba Smith. (Zie No. $866 d$.)

9103. Wakkat-bessie Aмв. = $\mathrm{Ag}$ iceras floridum R. \& Sch. (Zie No. 130.)

9104. Wakoen-ranoe $\mathrm{BD} .=\mathrm{P}$ a ndanus Bagêa Miq. (Zie No. 1673.)

9105. Wala of Walo Амв. = Flagellaria ind i c a L. (Zie No 135.)

9106 Walambang MEN. = Urostig m a Hasseltii Miq. var. (Zie No. 2464.)

9107. Walan M. = Pterosperm um diversifolium B l. (Zie No. 4778.)

9108. Walang $S .=$ Elettaria (Donacodes) Walang Miq., Nat. fam. der Z i n giber a c eæ. Gr. Java; overblijvend.

9109. Walantakka MeN, = Erythrina lithosperma Bl. (Zie No. 1587b.)

9110. Walarian J. $=\mathrm{C}$ is s u s s ca. ri o s a Bl. (Zie No. 553.)

9111. Walat $\dot{B}_{R}=$ Caryota $\mathrm{Rum}$ phia n a M art. (Zie No. 33].)

9112. Wale-bessi Амв. $=\alpha$. Ноу а A ria dne Dcsn., Nat. fam. der A sclepiadeæ. Gr. Celebes en de Mo. lakker ; klimplant. $=b$. H о y a c or o- naria R.Br. (Zie No. 576c.) $=c$. Hoya macrophylla Bl. (Zie No. 563 ) $=d$. Hoy a R u m p i i Bl. (Zie No. 1776b.)

9113. W'alo-bessi-ketjil Aмв. $=a$. Dischidia Gaudich a u di Desn. (Zie No. 1777.) = D) is chidia $n u m-$ mularia R. Br. (Zie No. 2231d.) = c. Dischidia orbicularis Dcsn, Nat. fam. der A s cle pia dex. Gr. De Molukken, Timor; klimplant. $=d$. $\mathrm{D} \mathrm{i}$ s chidia $R$ um phii $M$ iq., Nat. farn. dezelfde. Gr. Amboina; klimplant.

9114. Wale-makel tм onema? cuscuaria Miq. (Zie No. 8226 )

9115. Wafe-pinan Амв. $=$ Scindapsus? Ru in phi Miq. (Zie No. 3499.)

9116. Wale-topo J. = Dendrolobium Cephalotes Bnth. (Zie No 168:)

9117. Walen S. $=\mathrm{C}$ ovellia $\mathrm{R}$ ib e s M i q. (Zie No. 2826.)

9118. Walen.badak S. $=\mathrm{Ficus}$ sc ab errima Bl. (Zie No. 1256.)

9119. Walet $\mathrm{S}$. $=\mathrm{L}$ oure a vespertilion is Desv. (Zie No. 2195.) 9120. Wali J. $=$ M a o utia ru. go s a W ed d. (Zie No. 6285.)

9121. Wali-ahoêoen $\triangle \mathrm{M}$ в. $=$ Derris montana buth. (Zie No. 8217.)

9122. Wali-angin $\mathrm{J}_{\mathrm{O}}=a . \mathrm{M}$ a o.utia odontophylla Miq., Nat. fam. der Urti c e $x$. GR. Java; heester. $=b$. M a o tia rugosa Wedd. (Zie No. 6285$.

9123. Waii-hoelan Амв, = $\mathrm{An}$. mirta flavescens Miq. (Zie No. $645 b$.)

9124. Wali-hoelan-hakoeloe Амв. = Cocculus glaucus Dc. (Zie No. 1687.)

9125. Wali-kambing $\mathrm{J} .=\mathrm{S}$ a r c 0 lo b u s Spanoghei Miq., Nat fam. der A s c le pi a de $æ$. Gr. Java; slingerplant. GeBr. Deze plant, benevens andere van ditzelfde geslacht, gebruikt men om varkens, tijgers en andere dieren bij gevechten dronken te maken; wordt het dier niet gewond, dan sterft het aan deze vergiftiging; krijgt het echter eene bloedende wond, dan herstelt het.

9126. Wali-katoepoh J. $=a$. D e smodium lat if oli u m D.C. Nat. fam. der Pa pili o n a c e æ. Gr. Java, Timor en elders; klimplant. $=b$. D e s m o d i u m strangulatum W. \& A., Nat. fam. 
als voren. Gr. Jara, Sumatra, de Moluk ken; eenjarig.

9127. Wali-koekoen J. $=\mathrm{S} \mathrm{ch} \mathrm{ou-}$ tenia ovata Korth. (Zie No. 2761b.)

9125. Wali-maloekoe Амв. $=a$. M ediuilla erassinervia Bl., Nat. fam. der M elast om a e ex. Gr. De Molukken; slingerplant, welke in harc stengels cen zecr gocd drinkwater bevat. $=b$. Medinilla crispata Bl. (Zie No. $5297)=c$. Medinilla macrocarpa Bl. (Zie No. 64.)

9129. Wali-mawa Амв, of

9130. Wali-mette Амв. = Uvaria a r g e n te a Bl. (Zic No. 573.)

9131. Wali-poetih-lolaha Aмв. = Cle rodendrum incrme Gretn. (Zie No. 1243.)

9132. Wali-saä Aмв. of Wali-soä $\mathrm{Aмв}_{\text {, }}=\mathrm{Gne} \mathrm{tam}$ ed ule B I. (Zie No. 532.)

9133. Waliklar J. $=a$. Acer la lr in um H as sk. (Zie No. 789.) $=b$. Cupania Lessertiana Camb., Nat. fam. der S a p i n d a c e æ. Gr. Java, Sumatra; boom.

9134. Walingi $\mathrm{J} .=\mathrm{T} y \mathrm{ph}$ a a $11-$ g u st if oli a L. (Zie No. 738.)

9135. Waliran S. $=\alpha$. Tylophora tenu is BI. (Zie No. 642b.) = b. Raphidophora dichotoma Nees. (Zie No. 9046.)

9136. Walla Br. (Zie Walat Br.)

9!37. Wallas J. \& S. $=a$. A ris. tolo ebia acuminata Lám. (Zie No. 454.) $=$ b. Aristoloch i a in. d i c a (Zie No. 207.)

9138. Waloe J. $=a$. L a g e n a ri a vulgaris Ser. (Zie No. 3568.) $=b$. Lagenaria hispida Ser. (Zie No. 5123$.

9139. Waloer $\mathrm{S} .=\mathrm{S}$ a u ro m a $\mathrm{t} u \mathrm{~m}$ ? Hor sfieldii Miq., Nat. fam. der A r o i d e x. Gr. Java; overblijvend.

9140. Wana J. = S milax z e y. l a n i c a I. (Zie No. 717.)

9141. Wanga Cel. $=\alpha$. Metroxylon el at um Mart. (Zie No. 1131.) $=b \mathrm{Metroxyloufilare} \mathrm{Mart}$. (Zic No. 1320)

9142. Wangi malako $\mathrm{T}$. = Emilia so $\mathrm{nch}$ ifolia 1).C. (Zic No. 2221.)

9143. Wangi-malako-maibo T. = Eclipta alba Hask. (Zic No. 18096.)

9144. Wangi-malako-tali ' $\mathrm{T}$. = $\mathrm{G}$ ynu $r$ a sarmentosa D.C. (Zie No. 614)
9145. Wangkoedoe J. (Zie Bangkoedoe $\mathrm{M}$.)

9146. Wangoerer Alf. Min. $=P$ hæa u t h us u u tans H k. fs. \& Th. (Zie No. 1473.)

9147. Wangong-langhit $M$. en

914.8. Wangong-lawut $\mathrm{M} .=\mathrm{Mo}$ schosma polystaehy um Bnth. (Zic No. 832.)

9149. Wanè of Wani BL. = M a ngif e r a f ct id a L o u r. (Zie No. 274.)

9150. Wanijer Bo. = Pteroc a rpus flavas I, o r. (Zic No. 735.)

9151. Wanitan J. $=$ Orophaearet ie ulat a Miq., Nat fam. der A non a c e $æ$. Gr. Oost-Java; heester.

9152. Wanlekoe Cr. = Phalænop$\mathrm{s}$ is a m a bilis Bl. (Zie 374.)

9153. Wannat $\mathrm{Aмв.}=$ Melocanna h u milis R ü pr. (Zie 5521.)

9154. Wanong $S .=O l a x$ obtusa B l. , Nat. fam. der $\mathrm{Ol}$ a c a c ex. Gr. Java; sliugerende hecster.

9155. Wara of Waro AMB. = Flagell aria ind i c a L. (Zie No. 135.)

9156. Wareng S. = Gmelina asiati e a L. (Zie No. 2258.)

9157. Wargot $\mathrm{S} .=a$. L i e u a la $\mathrm{Rmph}$. Species diversa. $=b$. Rhapis javanica Bl., Nat. fam. der P a $1 \mathrm{~m} x$. Gr. Java; boom. Gebr. Uit den stam dezer en der volgende palmen vervaardigt men wandelstokken.

9158. Wargoe-gedeh $S_{.}=$Iicuala el e ga n s B l,, Nat. fam. als voren. Gr. Sumatra; boom. (Zie rorig No.)

9159. Wargoe-leutiek S. = Li e uala pumila $R$ wdt. (Zie No 970.)

9160. Warhokar Aмв. = Tetra th era $R$ um phii 13l. (Zie No. 23:23b.)

9161. Wari J. $=\mathrm{Hibiscus} \mathrm{rosa}$ s in ens is L. (Zie No. 1360.)

9162. Waai-hismoe Амв. = Cis. s u s repens I a m. (Zie No. 438.)

9163. Wari-hoelan Aмв. (Zie Walihoelan.)

9]64. Wari-lottoe-lottoe Амв. = Cis us repens Ia m. (Zie No. 4.38).

9165. Wari-metten $\mathrm{AмB}$. $=$ A rt abotrys suaveoleus Bl. (Zie No, 575.)

9166. Wari sahoe $\Delta \mathrm{mв}$. $=\mathrm{I}_{\mathrm{p}} \mathrm{m}$ ma c y mo s a Bl. (Zie No. 303b)

9167. Wari-unear Амв. = Gyu uгa s a rm cntos a D.C. (Zie No. 614.)

9168. Wari-wari-poetih BL. en

9169. Waribang $\mathrm{J} .=\mathrm{Hib}$ iscus rosa sinensis L. c. var. ("Zie No. 1360.) 
9170. Waringin $\mathrm{M}$. \& $\mathrm{J}_{.}=\alpha$. U rostigma benjaminum Miq. (Zie No. 1565.) $=b$. Urostig a c un e t u m Miq, Nat. fam. der A r toc arpex. GR. Java; hooge boom. $=c$. Uro stig. $\mathrm{ma} \mathrm{h} m$ at oc a r p u M iq. (Zie No. $1875 c$ c) $=d$. Urostigma microcarpum Miq. (Zie No. 4332.) $=e$. Urostigma pisocarpum Miq. (Zie No. $8768 f$.) $=f$. F i c us v a riegat a Bl. (Zie No. 1352 )

9171. Waringin-dawon-besar M. = Fic u s varieg a ta B l. (Zie No. 1352.)

9172. Waringin-dawon-ketjil M.= Urostigma nitidum Miq. (Zie No. 855 .)

9173. Waringin-tsjampadaha M. = Ficus variegat a Bl. (Zie No. 1352.)

9174. Warisa Alf. Min. $=\mathrm{Cap}$. si c u m T n t. S pec. o m nes.

9175. Waroe M. $=$ Hibiscus elatus S w., Nat. fam. der Malvaceæ. Gr. Java; boom. GEBR. Den bast bezigt men veelal als touw, hij bevat een sterke vezelstof. (Zie No. 2764.)

9176. Waroe-dôgong $\mathrm{J}_{\text {. }}=\mathrm{Cl}$ e ro. dendrum pan ic ulat um L. (Zie No. $4144 d$ )

9177. Waroe-goenong M. = Hibis. cus tiliaceus I. (Zie No. 2764.)

9178. Waroe-landak M. \& S. $=a$. Hibiscus venustus B l. (Zie No. 3543.)=b$. Hibiscus mutabilis I. (Zie No. I 358.)

9179. Waroe-lawut M. $=a . H \mathrm{H}$. biscus $t$ iliace us L. (Zie No. 2764.) $=b$. Thespesia macrophylla B 1. (Zie No. 854.) $=c$. Thespesia populnea Corr., Nat. fam. der M al. v a c e æ. Gr. Java, Timor; boom. Gebr. Als No. 854.) $=d$. Cordia s u b c o rd a t a L a m. (Zie No. 1021b)

9180. Waroe-lot J. $=\mathrm{Hi}$ b i s cus venustus Bl. (Zie No. 354.3.)

9181. Waroe-ranoe BD. en

9182. Waroe soesoen $\mathrm{J} .=\mathrm{H}$ i b i scus tiliace us L. (Zie No. 2764.)

9183. Waroema-koessoe $\mathrm{T} .=a$. Bidens Wallichii DC. en $=b$. Bidens peduncularis Gaud. (Zie No. 68.)

9184. Waron $\mathrm{J}_{0}=\mathrm{Trigonella}$ $\mathrm{F} \propto \mathrm{num}$ græc u $\mathrm{m}$ L a m, Nat. fam. der Papilion a ceæ; Gr. Java in tuinen; zaadplant, wier zaad de bekende Semin a f x i græci zijn.

9185. Warren J. = Gmelina villos a $R \times$ b., (Zie No. 965.)

9186. Wassa $\mathrm{AmB} .=\mathrm{F}$ ic u s Wass a $\mathrm{R} \times$ b. (Zie No. 2537.)

9187. Wateran J. $=$ Sonerila he te r op h y lla J a c k. (Zie No. 6726.)

9188. Watoetan S. $=$ Pasp alum scrobiculatum L., Nat. fam. der G r a m i n e æ. Gr. Java, Sumatra; Geвr. Dit gras is een zeer goed voeder voor paarden en koeien.

9189. Watoetan-gedeh S. = E rio chlö̈ tomentos a Juss., Nat. fam. als varen. Gr. Java; éénjarig. Gebr. Het zaad wordt als gierst gegeten.

9190. Watta Амв. =a. So $\mathrm{n} n \mathrm{e}-$ ratia a cida $L_{\text {. }}$ fs. en $=b$. S o nneratia a lba S m. (Zie No. $866 d$.)

9191. Watta.boehoe-lawan Амв. = B ruguiera caryophylloides B l. (Zie No. 37426.)

9392. Watta-koembang Амв. = Eg i c e r a f 1 oridum R. en S. (Zie No. 130.) $=$ b. Avicennia of ficin a lis L. (Zie No. 14.)

9193. Watta-lepoe Aмв. = B r и-

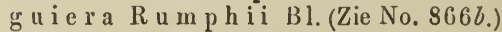

9194. Watta-mahina $\mathrm{Aм \textrm {B }}$. $=\alpha$. Bruguiera caryophylloides B l. (Zie No. 3742b.) = b. Br "gu i era cylindrica Bl. (Zie No. 1662) $=c . \mathrm{Bruguiera} \mathrm{Rh}$ e edi Bl, Nat. fam. der Rhizophorex Gr. Sumatrá; boom.

9195. Watta-toebe-toebe $\mathrm{Cr}_{\mathrm{r}}=$ E g i e ras minus $\mathrm{G}$ r $\mathrm{t}$. (Zie No. 1558.)

9196. Wawahoeliengin Alf. MIN. $=\mathrm{Climac} a \mathrm{dra}$ obovata Miq. (Zie No. 4530.)

9197. Wawalingian $\mathrm{S} .=a \cdot \mathrm{T} y$ pha angustifolia I. (Zie No. 738.) = 6 . Fuirena pentagonaWight (Zie No. 3821.)

9198. Wawalingian-betoel $\mathrm{S}$. = S cirpus mucronat us L., Nat. fam. der C y peraces. Gr. Java, Timor; overblijvend.

9199. Wawalingian-leutiek S. = Fi mbristylis globulos a Wall, Nat. fam. der L y p er a c e æ. Gr. Java; overblijrend.

9200. Wawalingian-tali $\mathrm{S} .=a$. Fimbristylis efoliata $S$ te ud. (Zie No. 2117.) $=$ b. Fuirena pentag on a Wight. (Zie No. 3821.)

920l. Wawaloehan $\mathrm{S} .=\mathrm{Bryo-}$ nia geminat a Bl., Nat, fam. der 
C u c u r b i t a ce $x$. GR. Java; slingerplant.

9202. Wawaloetan $\mathrm{S} .=\Delta \mathrm{n}$ i sone in a d u bi u m B l, Nat. fam. der E u phor b i ace a. Gr. Java, Timor; heester.

9203. Wawarau $\mathrm{J}=\mathrm{A}$ b el mo sehus moschatus Mönch. (Zie No. 2402.)

9204. Wawoie N.G. $=\mathrm{Met}$ r ox ylon filare Mart. (Zie No. 1320.)

9205. Weddor Амв. en

9206. Wedoele Aмв. $=a$. C onvolvulus bilobatus Rxb. (I pomo e a pes c a præ $\mathrm{S}_{\text {w.) }}$ (Zie No. 1039.)

9207. Wedoesan $J .=A$ g e r a tu m conyzoides L. (Zie No. 7936.)

9208. Wenang A I.F. Mrn. = M a p. pa macrophylla K ïrz. (Zie No. 4960.)

9209. Weenong of Winong $\mathbf{J}$. = Te trameles n ud if lora R. Br. (Zie No. 12006)

9210. Wehtes Alf. Min. = W ar i n g i n M.

9211. Weligi $\mathrm{S}$. $=\mathrm{Cy}$ perus el at $\mathrm{u}$ s L., Nat. fam. der C y p e r a c e Gr. Java, Sumatra; eelı zeer hoog gras.

9212. Welihissa Aмв. = Scleria

lit hos p erma Wlld. (Zie No. 3005b.) 9213. Wellat Aмr. $=F$ ic us polit o ria I, a m. (Zie No. 299.)

9214. Welloeaijt-abbal Амв. = $\mathrm{C}$ ord y line $\mathrm{Rumphi} \mathrm{Hook}$ (Zie No. 337.)

9215. Welloeang $А м B_{*}=\mathrm{C}_{0} \mathrm{rdy}$ line timorensis Ten ars. (Zie No. 1763.)

9216. Welloega Aмв. = Calo. dracon terminalis Planch. (Zie No. 333b.)

9217. Wereng-koesaj MEN. $=\mathrm{Fi}-$ cu $s \mathrm{~m}$ in a has $\mathrm{s} x$., Nat. fam. der $\mathrm{A} r$ t o c a r p e . Gr. C el e b es; boom.

9218. Weri Амв. $=$ I mperata a r u n din a ce a C y rill. (Zie No. 263) 9219. Wering-ampel $\mathrm{BL}=\mathrm{B}$ a mbus a fera Miq. (Zie No. 774.)

9220. Weroe J. $=a . A 1 b$ izzia micrantha Boiv. en $=6$. Albiz. z i a procera Bnth. (Zie No. 4448c.)

9221. Weroe-kebo J. $=\mathrm{T}$ e tranthera alnoides Miq. (Zie No. 2578.)

9222. Weroo-siffi AyB. $=\mathrm{C}_{\text {allo- }}$ dracon terminalis Planch. (Zie No. 3336.)
9223. Werot ALf. MIN. $=\mathrm{C}_{\mathrm{od}} \mathrm{i}-$ æu m u oluccan um D csn. (Zie No. 126 )

9224. Wersingan Амв. = $\mathrm{Cal}_{\text {a- }}$ dracon terminalis Planch. (Zie No. 333b.) $=b$. Cordyline tim orens is Thou ars. (Zie No. 1763.)

9225. Weul $\mathrm{CR}_{\mathrm{r}}=\mathrm{M}$ etrox y lon fil are Mart. (Zie No. 1320.)

9226. Wewejan J. = Monoehoria vagi nalis Presl. (Zie No, 912.) 9227. Wewinkelen ALF. Мıк. Cla oxylum indicu in Endl. (Zie No. 1268.)

9228. Widadari $\mathrm{J} .=\mathrm{M}$ e l a s to. ma polyanthum Bl. (Zie No. 110.)

9229. Widara M. (Zie Bidara M.)

9230. Widasari of Widosari $\mathrm{J}$. $=$ Canthium scandens Bl. (Zie No. 710 .)

9231. Wiojojo-kesoema J. en BL. $=$ Pisonia sylvestris T. en B. (Zie No. 1603.)

9232. Widosari $J_{0}=\mathrm{P}$ o $\mathrm{r}$ a 11 a $\mathrm{v} 0$ l u bilis B rm. Nat. fam. der Convolvulaceæ. Gr. Java Timor, de Molukken; slingerplant.

9233. Wiedjen of Wiedjien J.en M. 二 S esam um in di c u m l) C. (Zie No. 246.)

9234. Wiedjien-allas J. $=a . \mathrm{S}$ es a$\mathrm{m} \mathrm{um}$ ind i c u Do. (Zie No. 246.) = A rtanema sesamoides Bnth. (Zie No. 6697c) $=$ c. Hedyotis prostrata Krths. (Zie No. 4023.) $=d$. Hedyotis latifolia Rwdt; Nat. fam. der R u b i a c e æ. Gr. Java; kleine heester.

9235. Wiedjien-leuwung $\mathrm{S}$. = A r$\mathrm{t} a \mathrm{n}$ e ma ses a mo ides $\mathrm{B}$ n $\mathrm{th}$. (Zie No. 6697 c.)

9236. Wiewiedjenan S. Als roren.

9237. Wijauw A LF. Miv. $=A$ l e u. rites tril o b a Forst. (Zie No. 312.) 9238. Wik-wik ALF. MIN, $=\mathrm{S}$ a uropus rhamnoides Bl. (Zie No. 805$.

9239. Wilingi $J_{.}=S$ c i r p u s sun. danu s Miq., Nat. fam. der Cy p er a ceæ. Gr. Java, Sumatra; overblijvend.

9240. Wiloeroe J. $=\mathrm{Entada}$ P u rs tha DC. (Zie No. 482.)

924. W. Wilodo J. $=\mathrm{C}$ ovel li a didy $\mathrm{m} \mathrm{a} \mathrm{Miq}$. (Zie Mo. I578c.)

9242 . Wining of Winong J. 二 Pte- 
rocyubium javanicum Bnut. (Zie No. 1200c.)

9243 . Wirangin-badak $\mathrm{S} .=\mathrm{Psy}$ chotria rhinocerotis $\mathrm{Rwd}$. (Zie No. 1690.)

924t. Wirangon S. $=$ Vandel. li a Ellobum Bnth. Nat. fam. der Scrophularineæ. Gk. Java; éénjarig.

9245. Wiroe S. $=a$. Licuala pumila $\mathrm{R} w \mathrm{dt}$. (Zie No. 970) $=6$. L i. cuala $\mathrm{Rumphii} B \mathrm{l}$. (Zie No. 4948.) $=c$. Licuala spectabillis $M \mathrm{iq}$. (Zie No. 7678 .) $=d$ I i cuala spiuos a W u rmb., Nat. fam. ler Palmæ. Gr. Java; boom. GFBr. Men rolt fijne tabak in de gedroogde bladeren en rookt ze dan als sigaretten.

9246. Wiroe-gedeh $\mathrm{S}$. $=\mathrm{R}$ h a $\mathrm{p}$ is javani c a Bl. (Zie No. 91576.)

9247. Wiroe-ketjil M. of

9248. Whroe-leutiek S. = Licuala pumila Rwdt. (Zie No. 970.)

9249. Wiroe-lalaki S. $=a$. Licuala spinos a W u rmb. (Zie No. 9245b.) =?. Rhapis javanica Bl. (Zie No. $915 \%$.)

9250. Wit.krambil J. = Cocos n u c if e r a L. (Zie No. 393.)

9251 . Witjenang $\mathrm{S} .=\mathrm{Hed}$ y o t is rugosa Korth. Nat. fanı, der R ubi a cea; Gr. Jara, Sumatra う̌ $5000^{\prime}$, kleine heester.

9252. Wodi Br. $=$ Urostigma $\mathrm{R} \mathrm{um} \mathrm{phii} \mathrm{M} \mathrm{iq.} \mathrm{(Zie} \mathrm{No.} \mathrm{103.)}$

9253. Wodoesan J. $=\mathrm{Hibiscus}$ suratteusis L. (Zie No. 731.)

9254 . Woea ne-waleh Mrs. $=$ Goen a g a $\mathrm{T}$.

9255. Woedani J. $=\mathrm{Qu}$ is qu a lis in d i c a (Zie No. 32:34.)

9256. Woedelang J. $=a$. Scævola Koenigi i Vahl. (Zie No. 1001.) = b. Kyllingia bifolia Miq, Nat. fam. der C y p e r a c e æ. Gr. Java 6000'; grassoort.

9257. Woedoe Alf. Mis. $=$ B a mbusa longinodis Miq. (Zie No. 1540.)

9258. Woengoe J. = Lagerst r $\propto$. $\mathrm{m}$ i a reginæ $\mathrm{R} \mathbf{z}$ b. (Zie No. 1123b.)

9259. Woeng-soi Cн. Bo. = I pomoa reptans Poir. (Zie No. 526.)

9260. Woeni S. (Sie Hoenie M. \& S. 9261. Woenji Sum. Wh. = Filet. t a ria a tropur purea T. \& B, Nat. fam. der Zing i bera ceæ. Gr. Sumatra; overblijvend.

9262. Woerieng Men. $=\mathrm{Crat}$ $x y l o n$ clandestinn m Bl. (Zie No. 1123.)

9263. Woetoelang S. $=X y$ ris mela no ce phala Mi q. (Zie No. 19.)

9264. Woe-tse CH. Bo. = Alocasia indica Schott. (Zie No. 1145.)

9265. Woh-hah ALF. MIs. en

9266. Woh-han J. = A reca Cat e ch u L. (Zie No. 1286.)

9267. Wokka Cet. S T. $=\mathrm{Li}$ i istonia rotundifolia Mart. (Zie No. 55026 .)

9265. Wokka-oetan M. $=\mathrm{Pholi}$ docarpus I hur Bl. (Zie No. 2995.) 9269. Wokka-wokka MoL. $=\mathrm{C}_{0-}$ rypha umbraculifera L., $r a r$. (Zie No. 1528.)

9270. Womoet (ook Wonuth) J. = a. Cy nom etra bijuga Span. (Zie No. $520 \%$. $=b$. Cynometra ramiflora I. (Zie 1 o. 4262.)

9271. Wonelau $A$ sв. $=\mathrm{Z}$ i u gi ber margin a $t u m R x$ b. (Zie No. 254.)

9272. Wong-kioek-pha Сн. Во. = Pyrethrum ind icum Cass., var. flore luteo-ple no. (Zie No. 4l 83.) 92 i3. Wongli $\mathrm{CH}$. Bo. = A n auassa s at i va Lind. (Zie No. 5680.)

9274 . Wongski Сн. Bo. = G a rdeni a grandiflora Lour. (Zie No. 4158.)

9275. Wonoséné S. = Cryptoc arya? lucidula Mi q., Nat. fam. der La urineæ Gr. Java; boom.

9276. W00 Cel. = Broussouctia papyrifera Vent. (Zie No. 1861.)

9277. Wooëng $S .=$ Premua cycloph ylla $M$ iq., Nat. fam. der Verbenacer. Gr. Jara; heester.

9278. Wora-wari-toempoek J. = Clerodendrum fragrans Vent. (Zie No. 5648.)

9279. Woraka (Zie Goraka T)

9280. Wori Mrs. = Ormocarpum g l a brum T. \& B. (Zie No. I539.) 9281 . Worsa (of Wrassa) J. = A momum maximum Rxb. (Zie No. 270s.) 9282. Wotel of Wotele Noessa-Laut. = Urena heterophylla Smith. (Zie No. 7047.)

9283. Wowo $\mathrm{S}_{0}=$ Flagellaria indica L. (Zie No. 135.) 


\title{
ALPHABETISCH REGISTER
}

DER

\author{
L A T IJ N S C E P L A N T E N A M E N.
}

\begin{tabular}{|c|c|c|c|c|c|c|c|c|c|}
\hline \multirow{2}{*}{\multicolumn{4}{|c|}{ ABELMOSCHUS esculentus }} & \multicolumn{2}{|c|}{$\begin{array}{c}\text { No. } \\
. \quad 4064\end{array}$} & \multicolumn{2}{|l|}{ ACRONICHIA pedunculata } & \multicolumn{2}{|r|}{$\begin{array}{l}\text { No. } \\
5666\end{array}$} \\
\hline & & & & $\cdot$ & $\begin{array}{l}4064 \\
. \quad 2610\end{array}$ & $\begin{array}{l}\text { ACRUNICHA peduncula } \\
\text { ACROSTICHUM auritum }\end{array}$ & & . & \\
\hline Manihot . & . & . & . & . & 1844 & inæquale . . & . & . & 6441 \\
\hline moschatus. & . & te & . & . & 24.02 & lanceolatum. & : & . & 3538 \\
\hline Scsculentus & . & . & & . & 4064 & nummularifolium. & . & : & 2231 \\
\hline Vrieseanus. & . & . & . & . & 4066 & speciosum . . . & . & . & 6501 \\
\hline ABROMA augusta & - & . & . & . & 4480 & trinerve. & . & . & 6485 \\
\hline denticulata. & . & . & . & . & 1015 & viscosuin $\cdot$. & & & 6457 \\
\hline fastuosa & . & . & . & . & 4096 & ACTINODAPHNE angust & tifol & & 5616 \\
\hline A BRUS acutifolius & & . & . & . & 493 & areolata . . & . & . & 2901 \\
\hline melanospermu & & . & . & . & 572 & glabra . & . & . & 2931 \\
\hline præcatorius & & . & & . & 53 & glomerata. & . & & 2907 \\
\hline BUTILON atropur & rpure & eum & & . & 2700 & gracilis. . & . & . & 5539 \\
\hline hirtum. & . & . & . & . & 347 & heterophylla & . & . & 3752 \\
\hline indicum & . & . & & . & 3124 & javanica . & & . & 2894 \\
\hline striatum. & . & . & . & . & 6968 & macrophylla & & . & 2903 \\
\hline sundaicum. & - & . & & . & 2700 & macroptera & . & . & 5571 \\
\hline ACACIA concinna & . & . & & . & 480 & moluccana. & . & . & 3668 \\
\hline Farnesiana. & . & . & . & . & 2041 & procera. . & . & . & 2899 \\
\hline Hooperiana & . & . & . & . & 2612 & pubescens . & . & . & 2202 \\
\hline Instia . . & & . & . & . & 480 & quercina. & • & . & 2936 \\
\hline leucophlæa & . & . & . & . & 4811 & Rumphii . & . & . & 55 \\
\hline Mangium . & . & . & . & . & 5741 & spærocarpa . . & . & . & 2938 \\
\hline pennata. & & . & . & . & 480 & ACTOPHILA javanica. & . & . & 7885 \\
\hline quadrilateralis & & . & . & . & 5089 & ADAMIA cyanea. . & . & : & 4407 \\
\hline tenerrima & & & & . & 7015 & ADELIA javanica. & . & . & 4391 \\
\hline tomentosa. & 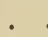 & & & & 4812 & nereifolia . & . & . & 2207 \\
\hline tortuosa & . & 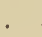 & & . & 6044 & ADENANTHERA falcata & . & . & 3451 \\
\hline ACALYPHA bractea & & - & . & - & 428 & microsperma & . & . & 7690 \\
\hline Catarus & . & . & & . & 2291 & paronina . . & . & . & 52 \\
\hline densiflora . & & & - & • & 1440 & ADENOCREPIS javanica & . & . & 2987 \\
\hline hispida. . & . & & . & . & 2174 & ADENOGINUM discolor & . & . & $5: 37$ \\
\hline indica . & & & & & 7652 & A DENOSACME cauliflor & & . & 6999 \\
\hline ACANTHOPHIPPIL & & jav & & ica & 357 & ADENOSTEMMA fastigia & atum & & 2150 \\
\hline ACER laurinum . & & & . & . & 789 & ovatum. & $\cdot$ & . & 2151 \\
\hline ACHILLEA condens: & sata & & 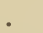 & . & 6044 & ADHATODA betonica & . & . & 2123 \\
\hline ACHRAS Sapota. & . & & • & . & 1496 & moretian๘. & . & . & 1762 \\
\hline ACHYRANTHES as & spere & & • & . & 1716 & vasica . . . & • & . & 1204 \\
\hline bidentata & . & • & . & - & 1758 & A DINANDRA cyrtopoda & . & - & 421 \\
\hline canescens & ${ }^{\circ}$ & & & . & 1866 & dumosa . . & • & . & 1800 \\
\hline ACORUS terrestris & . & & & . & 135 & glabra . & . & . & 3435 \\
\hline ACROCARPUS com & abret & tiflo & orus & & 5553 & lamponga. & . & . & 4842 \\
\hline ACROCEPHALUS C & capi & itatu & & . & & stylosa. & . & . & 4821 \\
\hline ACRONODIA punct & tata & & . & . & 2490 & trichocoryna. & - & . & 6912 \\
\hline ACRONICHIA apicu & ulate & & . & . & 3505 & IECHMANDRA Blumean & & . & 404 \\
\hline arborea. & & & & & 4673 & indica . . . . & & & 404 \\
\hline laurifolia . & . & & & & 1798 & EGICERAS floridum & & . & 130 \\
\hline
\end{tabular}




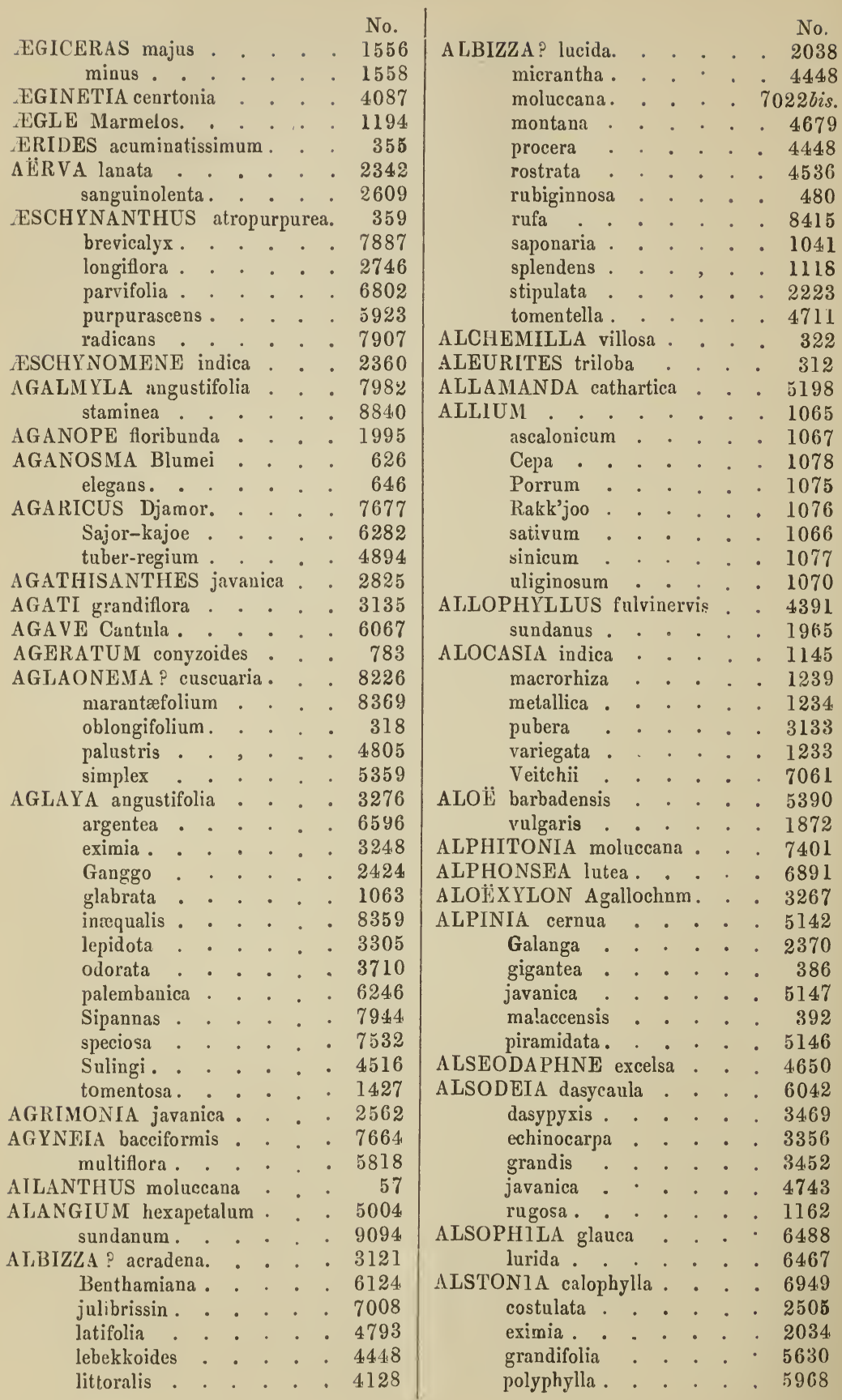


ALSTONIA scholaris. No. spathulata . . . . 5200 spectabilis. . . . . . 5190

ALTERNANTHERA denticulata . 8504 sessilis . . . . . 1791

ALYSICARPUS bupleurifolins. . 1014

ALYXIA stellata. . . . . . 646

AMARACARPUS pubescens . . 1568

$\triangle$ MARANTHUS melancholicus . 844.

oleraceus . . . . . 835

paniculatus . . . . 849

retroflexus . . . . 839

spinosus . . . . . 837

tritis . . . . . . . 836

$\triangle M O M U M$ aculeatum . . . 6629

Cardamomum . . . 3830

ciliatum . . . . . 2297

dealbatum . . . . . 2707

gracile . . . . . . . 2297

heteranthuin . . . . 6630

maximum . . . . . 2705

villosum . . . . . 385

AMOORA aphanamixis . . . 4466

Teysmanniana . . . 390

AMORPHOPHALLUS campanulatus 750 gigas . . . . . . 4]0 planus . . . . . . 4270

AMPHIDONAX bifaria. . . 2630

AMYGDALUS communis . . . 3738

ANACARDIUM occidentale . . 1474

ANACOLOSA frutescens . . . 4798

ANAMIRTA cocculus . . . . 339

flavescens . . . . 695

ANANASSA bracteata . . . 6069 sativa . . . . . 5680

ANAUA sumatrana . . • . . 3176

ANAXAGOREA sumatrana . . 3386

ANDROGRAPHIS paniculata . . 9042

ANDROPOGON Iwarancusa . . 2177 muricatus . . . . . 241 pertusus . . . . . . 2133

schœnanthus . . . . 2523

ANDROSCEPIA gigantea . . 5776

ANEILEMA diversifolium . . . 1667

lincolatum . . . . 8229

monadelphum. . . . 2130

nudiflorum . . . . 2130

secundiflorum . . . . 538

ANETHUM graveolens . . . 10

ANGIOPTERIS evecta. . . . $\mathbf{6 4 6 0}$

ANISEIA medium . . . . 3774

ANISOMELES albiflora. . . 792 malabarica. . . . . 792 orata . . . . . 818

ANISONEMA dubia . . . 9202 hypolenca . . . . $\mathbf{6 7 6 6}$
ANISOP'TERA palembanica

No.

1029

706

ANODENDRUM coriaceum reticulata. squamosa

ANTHISTHIRIA ciliata

6078 - zurvect

1489-6. nonma

1477- Sirillaja

2126

991

989

4508

8172

3044

3487

3044

408

1355

6384

4367

1133

4682

7731

3309

2888

1356

8017

6117

4683

4954

1132

1016

4680

4681

8314

4.679

ANTHROPHYUM Boryanum, coriaceum en lanceolatum . 6482

APARISTHMIUM javense . . 4391

APIUM graveolens . . . . . 8863

APLUDA aristata. . . . . . 7703

mutica. . . . . . 7146

APODYTES javanica. . . . . 4138

APOROSA frutescens . . . 3649

APOSTASIA Wallichii . . 2108

AQUILARIA Agallocha. . . . 22

24.41

6815

2679

2438

ARACHIS hypogæa . . . . $\quad 3961$
ARACIUM lævigatum . . . 8990

ARALIA dasyphylla . . . 2275

javanica . . . . . 132

montalla . . . . . 909

ARALIDIUM dentatum. . . 3337

ARAOCARRPUS velutinus. . . 1254

ARDISIA attenuata. . . . 5475

Blumei. . . . . . 4531 
ARDISIA chrysophylloides .

No.

complanata . . . . 4528

crispa . . . . . . 836

decus-montis . . . . 3832

densa . . . . 6768

fertilis . . . . . 7861

fuliginosa . . . . 4309

glabrata . . . . 4530

humilis . . . . 4528

lævigata . . . . . 2459

lamponga . . . . . 6769

linearifolia. . . . . 5587

lurida . . . . . . 4529

macrophylla . . . . 4527

marginata . . . . 4528

miqueliana. . . . . 1584

rutans . . . . . 4526

palembanica . . . . 1212

polyneura . . . . 4402

pubicalyx . . . . . 6769

pumila. . . . . . 2137

purpurea . . . . . 1582

rubiginosa. . . . . . 3

sumatrana. . . . . 7904

semidentata . . . . 4309

speciosa . . . . . . 2739

tenuiramis. . . . . 4818

villosa . . . . . . 4485

ARECA alba . . . . . 1902

Catechu . . . . . 1286

? erythropoda . . . . 5371

glandiformis . . . . 2267

horrica. . . . . 834

Nibung . . . . . 2310

nengah. . . . . . 6260

paniculata. . . . 2579

pumila. , . . . . 2713

triandra . . . . 1904

ARENGA obtusifolia. . . . 5240 saccharifera . . . . 245

ARENGA Westerhoutii . . . 321

ARGEMONE mexicana . . . 5360

ARGOSTEMMA macrosepalum . 2417

microcnide. . . . . . 5456

Teysmannianum . . . 1247

ARGYREIA capitata. . . . 463

mollis . . . . . 597

nitida . . . . . 597

speciosa . . . . . . 467

tiliæfolia . . . . . 597

ARIS EMA filiforme. . . . 3012

ARISTOLOCHIA acuminata . . 454 indica . . . . . 207

AROMADENDRUM elegans . . 1890

ARTABOTRYS hamatus . . . 573

intermedius . . . . 3649 $\begin{array}{ll} & \text { No. } \\ \text { ARTABOTRIS odoratissimus . } \quad 4985\end{array}$

parviflorus. . . . . 5534

sumatranus . . . . 1002

suaveolens. . . . . 575

ARTANE.IA sesamoides . . 6697

ARTEMISIA indica. . . . 619

lavendulsefolia. . . . . 619

vulgaris . . . . . . 1023

ARTHROPHYLLUM Blumean. . 1973

diversifolium . . . . 4464

ovalifolium. . . . 4600

ARTOCARPUS altissima . . . 4836

anisophylla . . . . 1030

Blumei. . . . . . 1119

calophylla . . . . . 6977

Dadah . . . . . . 1586

dimorphophylla . . . 1062

elastica. . . . . . 1307

elongata . . . . . 3824

echinata . . . . . 8448

glauca . . . . . 8653

hirsutissima . . . . 6078

incusa . . . . . . 269

integrifolia. . . . . . 276

Kemando . . . . . 3370

Kertau . . . . . 4271

Limpato . . . . . $\mathbf{5 4 1 3}$

polyphema. . . . . . 344

pomiformis . . . , 8653

rigida . . . . . . 1454

tephrophylla . . . . 1585

tylophylla. . . . . . 4247

varians. . . . . 8510

venenosa . . . . 1334

ARUNDINARIA glaucescens . . 954

ARYTERA Karang . . . . . 3862

? littoralis. . . . . 4454

macrocarpa . . . . 736

montana . . . . 3863

Silaka . . . , . . 7895

ASCLEPIAS curassavica . . 3812

ASPIDIUM ferox. . . . . . 6489

obscurum . . . . . . 6449

procurrens. . . . 6503

subpectinatum . . . 6503

ASPLENIUM abscissum . . . 6667

approximatum . . . . 6667

crenato-serratum . . . 6426

minus . . . . . . 6451

simile . . . . . . 6450

ASTAXYA Horsfieldii . . . . 8032

ASTRONIA macrophylla . . . 4442

papetaria... . . 412

spectabilis . . . . . 3690

ATALAYA salicifolia. . . . 745

ATHROISMA viscidum. . . 7737 
ATRIPLEX littoralis.

No.

ATYLOSIA albicans scarabroides

A VERRHOA Bilimbi carambola .

1270

A VICENNIA alba officinalis

AZADIRACHTA indica. . . 3019

AZOLLA decomposita . . . . 5446

BECKEA frutescens. . . . 2395

BALANOPHORA . . . . . 1573 elongata . . . . . 7080

BALANTIUM chrysostrichum. - 6447

BALIOSPERMUM axillare. . . 6255

BAMBUSA Apus. . . . . . 767 asdera . . . . . 434

elegantissinna. . . . . 770

excelsa . . . . . . 1336

fera. . . . . . 744

longinodis . . . . . 1340

nigra . . . . . 777

nigro-ciliata . . . . 769

Teba . . . . . 1325

vertieillata. . . . . . 930

vulgaris . . . . . . 938

BARATHRANTHUS axanthus 7860

BARLERIA cristatil. . . . 2001

dichotoma. . . . . . . 2007

lupulina . . . . . . . 8440

BARATHIANTHUS axanthus. . 7860

BARRINGTONIA acuminata . . 7950

acutangula. . . . . 983

alba. . . . . . . 6931

excelsa . . ; . . . . 918

insignis . . . $\$ 116$

macrocarpa . . . . 8116

macrophylla . . . . . 8116

racemosa . . . . . 983

Reinwardtii . . . . 3312

rubra . . . . . . 2992

speciosa . . . . . 1463

BARRINGTONIA spicata . . 6990bis Vrieseï. . . . . 8116

BASELLA alba . . . . . 2418

cordifolia . . . . . 2419

rubra . . . . . . 2419

BASSIA Balem . . . . . 879

elongata. . . . . . 3508

hypoleuca . . . . . 881

longifolia . . . . . 38

sericea . . . . . . 2039

BATATAS edulis. . . . . 635

glaberrina. . . . . 6220

BAUHINIA hirsuta . . . . 4478

tomentosa. . . . . 4497

BEAUMONTIA multiflora. No.

BEGONIA lepida. . . . 1245

BEILSCHMIEDIA lancifolia . . 7478

Madang . . . . . 2916

BELOAN'TFERA oppositifolia. . 2360

BELOPERONE? fulgida . . . 1834

BENIN('ASA cerifera . . . . 904

BENTINCKIA Renda . . . . 6842

BERBERIS asiatica . . . 7240 nepaulensis. . . . . . 4608

BERGSMIA? acuminata . . 3274 javanica . . . . . 4694 sumatrana. . . . . . 1429

BERRYA ammonilla. . . . 4663

BETA vulgaris . . . . . 1186

BIDARA pubiflora . . . . 5074 tingens . . . . . 6360

BIDENS leucantha . . . . 2775 peduncularis . . . . . 68 pilosa . . . . . . 13

Wallichii . . . . . . 68

BIGELOVIA mitracarpoides . 7802 ocymoides . . . . . . 7459

BINNENDYKIA trichostylis . . 7995

BISCHOFIA javanica . . . . 1229

BIXA Orellana . . . . . . 1697

BI,ABEROPUS sericens. . . . 3260 villosus. . . . . . . 6946

BLACKWELLIA foetida. . . . 2779 tomentosa . . . . . 2228

BLECHNUM orientale . . . . 6437 pyrophilum . . . . . 6437

BLEPHAROCHLOA ciliata . . 6616

BLYXA lioxburghii . . . . 2421

BOBEA inæquisepala. . . . $590 \mathrm{l}$ sericantha. . . . . 3199

Wallichiana . . . . 6947

BCEHMERIA clidemioides . . 2587

javanica . . . . . 2736

neglecta . . . . . 6081

nivea . . . . . . 2387

palmata . . . . 2737

rugosissima . . . . 7129

scrabella • . . . . 819

BONNAYA brachiata . . . 2155

grandiflora. . . . . . 1999

reptans. . . . . . 2155

veronicæfolia . . . . . 79

BORASSUS flabelliformis . . . 3117

BO'TRYCHIUM ternatum . . . 6471

BOTRYMORUS paniculatus . . 3477

BOUEA diversifolia . . . . . 7113

gandaria . . . . 2404

oppositifolia . . . . 7133

BRACHYPTERUM microphyll. . 3441

scandens . . . . 2448 


\begin{tabular}{|c|c|c|c|c|c|c|c|c|c|c|c|}
\hline BRACHYSPA'IHA & Mluc & elleri & & & $\begin{array}{l}\text { No. } \\
\text {. } 3012\end{array}$ & CALAMUS adspersu & & & & & $\begin{array}{l}\text { No. } \\
2842\end{array}$ \\
\hline variabilis & & & & & - 3012 & asperrimus & & . & . & . & 2851 \\
\hline BRAGANTIA tomer & atosa & & & & . 7922 & buroënsis . & . & . & & & 7400 \\
\hline BRASSICA campestr & & • & . & & 5035 & crsius. . & . & . & & & 2868 \\
\hline oleracea & - & . & & & 5032 & calolcpis & . & . & & & 7372 \\
\hline Rapa . . & . & • & & & 7092 & Cawa. & . & . & . & & 7362 \\
\hline BRATHYS japonica & . & • & . & & 4307 & ciliaris . . & . & - & . & & 2853 \\
\hline BRIEDELIA glauca & & & 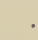 & & 4066 & depressiuscult & & . & . & & 7390 \\
\hline lanceolata & . & • & . & & 2644 & Diepenhorstii & . & - & . & & 7375 \\
\hline stipularis . & & . & . & & 154 & equestris . & . & . & & & 2804 \\
\hline tomentosa & . . & . . & & & 3769 & exilis . . & . & . & . & & 7355 \\
\hline BROMHEADIA Fin & lays & sonia & ana & & 2852 & fasciculatus & . & . & & & 7354 \\
\hline BROUSSONETIA $p$ & apyr & rifer & $a$. & & - 1861 & glaucescens & . & - & & & 2858 \\
\hline BRUCEA sumatrana & & & & & 296 & graminosus & . & . & & & 6195 \\
\hline BRUGMANSIA Zip & pelii & & & & 7082 & heteroideus & . & - & & & 2845 \\
\hline BRUGUIERA caryo] & phyl & lloid & & & 3747 & horrens . & - & - & . & & 7353 \\
\hline cylindrica . & - & . & & & 1410 & javensis & . & . & & & 2854 \\
\hline gymnorrhiza & . & . & & & 242 & littoralis & . & . & . & & 7342 \\
\hline oxyphylla . & . & . & . & & 249 & Manau . & . & . & . & . & 5681 \\
\hline parviflora. & . & . & . & & 3473 & manicatus. & . & . & . & . & 7392 \\
\hline Rheedii . & . & . & . & & 9194 & marginatus. & . & - & . & . & 7381 \\
\hline Rumphii . & - & . & 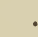 & & 249 & melanoloma & . & . & . & - & 2850 \\
\hline BBYONIA geminata & . & . & . & & 9201 & micranthus & . & - & . & . & 7361 \\
\hline laciniosa & . & - & . & & 641 & ornatus. . & . & . & . & . & 2847 \\
\hline marginata . & . & . & . & & 612 & Oxleyanus. & . & . & . & . & 7363 \\
\hline perpusilla . & . & • & . & & 494 & pallens. . & . & . & . & . & 2845 \\
\hline scabrata. & . & . & . & & 619 & pisicarpus & . & . & . & . & 6200 \\
\hline scabrella & . & . & & & 458 & Reinwardtii & . & . & . & . & 2841 \\
\hline BRYONOPSIS leuco & carp & & . & & . 2695 & rhomboidens & & . & - & . & 2855 \\
\hline BUCHANANIA ar' & ores & scens & s & & . 3029 & spectabilis . & . & . & - & . & 2854 \\
\hline auriculata & . . & • & . & & 8401 & stoloniferus & & - & - & • & 7356 \\
\hline bancana . & . & • & . & & 7216 & subangulatus & . & . & . & . & 7352 \\
\hline lucida . & . & . & . & & 7216 & trichous . & & . & . & . & 7363 \\
\hline macrophylla & . & • & & & $556 \mathrm{l}$ & viminalis & & . & . & . & 2848 \\
\hline oxyrhachis & . & $\bullet$ & . & & 409 & CALANTHE veratri & ifoli & & . & & 26 \\
\hline racemiflora & . & & $\bullet$ & & 1130 & CALLÆOCARPUS & & amnif & ffolia & & 1237 \\
\hline sessilifolia, & . & & . & & 7214 & sumatrana & . & . & & & 4210 \\
\hline splendens & . & & & & 8402 & CALIJCARPA cana & & - & . & . & \\
\hline BUCHNERA acuta & . & • & . & & 4134 & lanata & & . & . & . & 4020 \\
\hline BUCIDA nitlda . & . & . & 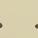 & & 1200 & longifolia . & . & . & . & $\bullet$ & 4020 \\
\hline BUDDLEIA asiatica & & • & . & & 4449 & pentandra. & . & & . & . & 1152 \\
\hline Neemda & & . & & & 7743 & sumatrana. & & & . & . & 8306 \\
\hline BURMANNIA suma & atran & & & & 7834 & CALLICARPA Wal & llich & aiana & & . & 7998 \\
\hline BUSEA decurrens & - & . & . & & 8820 & CALODRACON Jac & cqui & inii & - & • & 333 \\
\hline BUTEA frondosa. & & . & & & 6930 & tirminalis & & . & - & · & 333 \\
\hline BUTTNERIA angula & lata & . & & & 4467 & CALONYCTION sp & ecio & osum & & • & 409 \\
\hline flaecida . & . & & & & 4468 & trichospermu & & . & & • & 634 \\
\hline & & & & & & CALOPHYLLUM ar & & & & - & 1217 \\
\hline CESALPINIA acant & thob & botr. & & & 160 & bancanum & . & . & & & 1219 \\
\hline ferruginea & . & . . & . & & 4535 & cymosum. & . & . & . & • & 1221 \\
\hline nitida . . & & & & & 7820 & dasypodum & . & . & - & . & 8047 \\
\hline Nuga . . & . & . & & & 627 & Diepenhorstii & i . & . & - & . & 1218 \\
\hline pulcherrima & . & $\cdot$ & 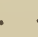 & & 1386 & inophyllum & . & . & - & . & 1139 \\
\hline Sappan. . & . & . & • & & 1807 & javanicum. & . & . & - & - & 8047 \\
\hline sepiaria. & . & . & & & 7821 & lanigerum . & - & . & - & - & 1218 \\
\hline CAJANTS indicus & . & & . & & 1210 & plicipes . & - & . & . & - & 1225 \\
\hline
\end{tabular}


REGISTER.

CALOPHYLLUM spectabile Teysmanni venulosum

CALOSANTHES indica.

CALOTROPIS gigantea.

CALAPANDRIA lanceolata quincosaura

CALPICARPUM Roxburghii CALYPTROCALYX spicatus CALYPTROON sumatranum CAPMELIA glabrata molissima

CAMPHORA officinarum sumatrana

CAMPIUM repandum

CANANGA odorata .

CANARIOPSIS altissima

decumana

glabra .

hirsuta

hispida.

CANARIUM commune.

denticulatum .

dichotomum

eupteron

fissistipulum

Kipella .

Kiteng

litorale.

longiflorum

Mahassan .

mehenbethene.

microcarpuin .

odontophyllum

patentinerviuin

rostratum .

rostriferum

rugosum

serricuspe .

subrepandum

sylvestre

CANARIUM zephyrinum

CANAVALIIA gladiata. obtusifolia . virosa .

CANNA coccinea . flavesccns orientalis

CANNABIS sativa

CA NTIIIUM glabrum

glomcrulatum.

horridum

lave

palembanicum

polyanthum
No.

1224

1222

8047

14.18

817

6987

2280

4552

2811

3295

2130

4014

1248

3825

3825

6498

1373

4445

2651

1628

2662

1249

3072

$462 \mathrm{I}$

1624

3300

719

4621

4738

8359

1620

5600

3072

40

1633

9014

1619

719

2508

1621

3400

3070

3074

3549

5078

2585

4150

4150

6987

2411

4502

866

4206

7221

3261

5542
8867

710

3433

524

8705

3640

7859

CAPSICUM annuum. . . . 5500

bicolor . . . . . . 8671

fastigiatum . . . . 5501

frutescens . . . . . . 8660

longum. . . . . . 8664

pendulum . . . . . . 8666

sinense. . . . . $866 \mathrm{l}$

CAPURA Zollingeriana . . . 1230

CARALLIA confinis. . . . 895

symmetria . . . . . . 4490

CARDAMINE trifoliata. . . . 1658

CARDIOPTERIS lobata . . . 2385 moluccana. . . . . . 5859

CARDIOSPERMUM Halicacabum 433 luridum . . . . . . 6954 microcarpum . . . . . 6955

CAREX curvirostris . . . . . 4267

CARGILIA maritima . . . . 4477

CARICA Papaya.. . . . 1092

CARISS A Carandas . . . . 3860

CARPOPHYLLIUM macrocarp. . 1499

CARTHAMUS tinctorius . . . 3860

CARUM Carvi . . . . . . 2099

CARUMBIUM amboinicum . . 5676 giganteum. . . . . 8951 populifolium . . . . . 1295

CARYODAPHE densiflora . . . 2913

CARYOPHYLLÜS aromaticus. . 1292

fastigiatus . . . . . 2544

floribundus . . . . 4722

CARYOTA farfuracea. . . . 2489

maxima . . . . . 8085

No. . . . . . . 3387

propinqua . . . . . 3760

Rumphiana . . . . . 331

CARYOTA sobolifera . . . . 7653

urens . . . . . 384

CASEARIA gonocarpa . . . 886 subcuneata. . . . . 3238

velutina . . . . . 3107

CASSIA alata. . . . . . 1740

floribunda . . . . . 2272

florida . . . . . 2211

fistula . . . . . . 1396

glauca . . . . . 2568

indecora . . . . . 3916

javanica . . . . . 1025

marginata . . . . . 1283

megalantha . . . 1306 
CASSIA mimosoides.

No. montana occidentalis . . . . 3890 obtusifolia . 3918 pumila. sophora

6248 suffruticosa timoriensis tomentosa . Tora

CASSYTHA filiformis pubescens .

CASTANEA argentea brevicuspis javanica sessilifolia . spectabilis. costata.

CASTANOPSIS Tungurrut.

CASUARINA equisetifolia . Junghuhniana. montana nodiflora sumatrana.

CATENARIA Jaburnifolia

CATHA montana.

CEDRELA serrulata.

Teysmanni.

Toona

CELASTRUS alpestris

CELOSIA argentea cristata:

CELTIS cinnamomea reticulosa.

CENTOTHECA lappacea

CEPHA ËLIS stipulacea .

CEPHALOTAXIS sumatrana CEPHALOTROPHIS javanica. CERAMANTHUS gracilis .

CERASTIUM glomeratum .

CERATOLOBUS glaucescens . rudentum : $\cdot$.

CERATOPHORUS Leerii . longepetiolatus

CERATOPTERIS thalictroides CERBERA lactaria Odollam candoleana

CERIOPS lucida.

CEROPEGIA Horsfieldiana.

CHETOCYPERUS setaceus

CHÆNOLOBIUM decemjugum septemjugum .

CHAILLETIA sumatrana . .

CHAM ECLADON angustifolinm . lanceolatum

8689

8690

122

322

7064

3410

8072

8078

267

4626

1136

419

3491

4710

$7672 a$.

2698

8793

797

1453

6025

2855

2857

893

1125

6501

1182

1181

864

2884

9038

1333

3299

4360

150

870

8766

\begin{tabular}{|c|c|c|c|c|}
\hline CHAKIESSA suaveole & lens. & & & $\begin{array}{l}\text { No. } \\
2085\end{array}$ \\
\hline CHASALIA expansa. & & . & . & 4505 \\
\hline lurida. & - & . & . & 4506 \\
\hline montana & . . & . & . & 4505 \\
\hline robusta. & . & . & & 2697 \\
\hline CHAVICA Betle. & - & . & - & 285 \\
\hline Blumei . & . & . & . & 544 \\
\hline Chaba . . & . & . & . & 8662 \\
\hline densa . . & . . & . & . & 686 \\
\hline frustatra . & . . & . & . & 5̆104 \\
\hline macrostachya. & . & . & . & 1091 \\
\hline ? maculata & . & . & & 8662 \\
\hline majuscula. . & · & · & . & 289 \\
\hline melamitis . & - & & & 286 \\
\hline miniata. . & . & . & . & 4087 \\
\hline mnltinervia & .. & . & . & 7959 \\
\hline officinarum & . . & . & & 5134 \\
\hline Roxburghii & . & . & . & 295 \\
\hline sarmentosa & .. & . & . & 292 \\
\hline siriboa . . & - & . & . & 1170 \\
\hline sphærostachya & & & . & 290 \\
\hline CHEILANTHES tenn & nifolia & & . & 6418 \\
\hline CHEILOSA montana. & & . & . & 2897 \\
\hline CHENOPODIUM fili & icifoli & & & 850 \\
\hline CHILIODARPUS con & mposi & itus & & 8642 \\
\hline ? costatus. & $\cdot$ & . & . & 2507 \\
\hline densifiora. & . & . & . & 8862 \\
\hline denudatus. & . & . & . & 603 \\
\hline Diepenhorstii . & . & & . & 206 \\
\hline montana. & . & . & . & 4388 \\
\hline suaveolens. . & • . & . & . & 478 \\
\hline CHIONANTHUS div & versifo & olia & . & 1204 \\
\hline insignis. . . & & . & . & 5575 \\
\hline laxiflorus. . & . . & . & . & 1818 \\
\hline littorens. . & . & . & . & 8316 \\
\hline anicus. & . & . & . & 5368 \\
\hline CHIRITA glabra. & . & & . & 7500 \\
\hline Horsfieldii . & . . & & . & 8878 \\
\hline humilis . . & & . & . & 7621 \\
\hline mollis . & . & . & . & 1311 \\
\hline CAISOCHETON dive & ergen & & . & 917 \\
\hline diversifolium . & . & & - & 2394 \\
\hline & & & . & 916 \\
\hline CHLOOPSIS caulesce & ens. & & & 7676 \\
\hline HUS bra & achys & & & 5082 \\
\hline inconspicuus . & & & & $\check{5082}$ \\
\hline officinalis. . & . & & . & 5082 \\
\hline & & & . & 5082 \\
\hline CHRYSOPHYLLUM & bane & & & 34.21 \\
\hline firmum. . & $\cdot$ & . & & 8593 \\
\hline lanceolatum. & & & & 4517 \\
\hline neurum. & & & & 3869 \\
\hline & & & & 1625 \\
\hline CHRYSOPOGON acic & culatu & & & 809 \\
\hline CHYLOCALYX perfol & liatus & & & 2398 \\
\hline CIBOTIUM djambina & & & & . 6549 \\
\hline
\end{tabular}

2085

450

4505

697

285

544

686

5104

1091

289

286

959

5134

295

292

290
2897

2507

8862

206

4388

5575

1518

368

500

621

311

3394

916

082

082

082

421

8593

517

1625

809

6549 
REGISTER.

\begin{tabular}{|c|c|c|c|c|c|c|c|c|c|c|}
\hline glaucescens & & & & & $\begin{array}{l}\text { No. } \\
175\end{array}$ & crassa . & & & & $\begin{array}{l}\text { No. } \\
2063\end{array}$ \\
\hline CICCA nodiflora. & & & . & . & 3093 & decumana. & $\dot{0}$ & $\dot{0}$ & & 2054 \\
\hline CINNAMOMUM caly & lycu & latu & $\mathrm{um}$ & . & 5685 & grandis. & & . & & 2051 \\
\hline camphoratum. & & . & & . & 4899 & limetta. & 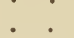 & . & & 762 \\
\hline Culilawan. & . & . & & . & 2287 & limonellus. & . & . & & 761 \\
\hline eyrtopodum. & . & . & & . & 4962 & limonum. & . & . & . & 5077 \\
\hline eucalyptoides. & & . & & . & 5546 & madurensis & . & . & & 5345 \\
\hline iners . & . & . & . & . & 2925 & medica. . & . & . & . & 2050 \\
\hline Kiamis. . & . & . & . & . & 3367 & nobilis & . & . & . & 2062 \\
\hline lampongum & . & - & . & . & 34,49 & obversa & . & . & & 2055 \\
\hline nitidum . & & . & . & - & 4733 & ovata.. & . & . & & 2080 \\
\hline Psendo-sassafr & fras & . & . & - & 4620 & macracantha. & . & . & & 2053 \\
\hline Pseudo-sintok & & - & & . & 7933 & Papaya. . & . & - & & 2076 \\
\hline ium & & . & & . & 5546 & Papeda. . & . & . & & 2077 \\
\hline atum & & - & & . & 4903 & pyriformis . & . & . & & 2061 \\
\hline . $\cdot$ & & . & . & . & 7933 & sarcodactylis. & . & . & & $208 \mathrm{l}$ \\
\hline atum & & . & . & . & 3353 & vulgaris & . & . & . & 5334 \\
\hline eurum & & . & . & - & 5849 & CI,ADIUM Mariscus & as . & - & & 3005 \\
\hline zeyla & & . & & . & 3367 & DOSTACHYS fr & & cens & & 838 \\
\hline CIPADESS & & & - & . & 4931 & CLAOXYLON indicu & um & . & & 1268 \\
\hline MPELOS Par & reira & & . & . & 4,47 & longifolium & . & . & & 4537 \\
\hline JS a & . & . & . & - & 580 & minus & . . & . & & 4691 \\
\hline idea & . & . & . & - & 1415 & CLAUSENA chrysog & gyne. & . & & 5796 \\
\hline a. & . & . & . & . & 580 & sumatrana . & & . & & 7590 \\
\hline cineria & . & . & . & . & 65 & CLEGHORNIA cym & nosa. & . & . & 3436 \\
\hline ssa . & . & . & . & . & 549 & CLEISOSTOMA spat & athulat & tum & & 323 \\
\hline pa. & . & , & . & . & 616 & CIEMATIS I Leschen & naultia & ana & . & 568 \\
\hline trix . & . & . & . & . & 858 & smilacifolia & & & & 3130 \\
\hline Dari & . & . & . & . & 157 & CLERODENDRUM & calam & nitos & sum & 4.144 \\
\hline toma. & . & . & . & . & 554 & condensatum & . . & . & . & 6593 \\
\hline . & . & . & . & . & 468 & disparifolium & . & . & . & 4367 \\
\hline ata. & . & . & . & . & 617 & eriosiphon. & - & . & - & 4367 \\
\hline . . & . & . & . & - & 587 & fallax . & . & . & & 4144 \\
\hline incarnata. & - & . & . & • & 788 & fragans. . & . & . & - & 5648 \\
\hline & . & . & . & . & 549 & inerme. . & . & . & . & 1243 \\
\hline Landuk & . & . & . & . & 615 & infortunatum & . & . & . & 758 \\
\hline latifolia . & . & . & . & . & 93 & Horsfieldii . & . & . & . & 4.152 \\
\hline atabilis . & . & . & . & . & 550 & Jackianum . & . & . & . & 6305 \\
\hline dosa. . & . & . & . & . & 460 & lævifolium . & . & . & - & 3109 \\
\hline ovata & . & . & . & . & 452 & minahassæ. & . & . & . & 5314 \\
\hline pillosa. & . & . & . & . & 557 & paniculatum & . & . & - & 4144 \\
\hline acea & . & . & . & . & 555 & Phṛllomega & . & . & . & 7135 \\
\hline & . & . & . & . & 199 & CLERODENDRUM & & tum & . & 6930 \\
\hline rhodasys & & . & . & . & 232 & siphonanthus . &. & . & . & ] 389 \\
\hline rangulari & & . & . & . & 2751 & villo & & . & . & 4144 \\
\hline repanda . & . & . & . & . & 580 & CLIMACANDRA obo & ovata & . & . & 4530 \\
\hline repens. . & . & . & . & . & 438 & Salicifolia . & & . & . & 8327 \\
\hline rhodocarpa. & . & - & . & . & 553 & CLITOREA ternatea. & . & . & . & 1359 \\
\hline ariosa . & . & . & . & - & 553 & CNESMONE javanica & ca & . & - & 6957 \\
\hline rrulata . & . & . & . & . & 556 & COCCINIA grandis. & . & - & - & 640 \\
\hline yrsiflora. & . & . & . & . & 542 & Wightiana. • & . $\cdot$ & . & . & 521 \\
\hline & . & · & . & . & 215 & COCCOCERAS sumat & atrana & . & . & . 7336 \\
\hline UILLUS edulis & . & . & . & - & 1059 & COCCULUS bantame & ensis & . & . & 644 \\
\hline ara . & - & & . & . & 2061 & glaucus. - & . & - & . & 2702 \\
\hline & & & - & . & 2049 & & & & . & 4500 \\
\hline bergamia . & & & & & 2214 & COCHLOSPERMUM & 1 Goss & sypi & & 8740 \\
\hline
\end{tabular}


CODIÆU.M molucum. • . . . 126

CODONOPSIS javanica. • . . 4256

CCELACHNE iufirme • . . . 3129

(CELOSPERMUM scandens • . 699

COFFEA arabica. . . . 4050

densiflora ... . 4502

lepidophloia . . . . . 5228

madurensis. . . . . 3522

salicifolia . . . . 8676

sundana . . . . 4502

COIX agrestis. . . . . 47

Kœnigii • . . . . . 1896

Lacryma . . . . . 1894

COLEUS amboinicus. . . . 69

atropurpureus. . . . 748

bicolor. . . . . . 2019

carnosus ...... 2100

galeatus . . . . . 2018

macrophyllus . . . . 2017

macropus . . . . . 7726

scutellarioides. . . . 2016

tuberosus . . . . . 1714

COLLYRIS major . . . . . 1682

COLOCASIA antiquorım . . 245

humilis. $\quad 426$

COLUBP.INA asiatica . . . 5194

COIUMBIA celebica. . . . . 3538

javanica . . . . . 2284

serratifolia. . . . . . 3560

COMBRETUM latifolium . . . 45I

neurophyllum . . . . 451

punctatum. . . . . 502

sundaicum. . . . . 827

trifoliatum. . . . . 198

Wallichii . . . . . 708

COMMELYNA . • • . . . 2130

benghalensis . . . . 2549

communis . . . . . 8229

paludosa . . . . . . 2089

salicifolia . . . . . . 8229

suffruticosa . . . . . 4483

COMMERSONIA echinata . . 106

CONNARUS Diepenhorstii. . . 233

grandis.

4509

586

233

3852

5463

8342

543

750

750

5317

508

85
CONYZA hirsuta: ..... 7739

indica . . . . . 413

lacera . . . . . 1047

lactucæfolia . . . . 4137

macrophylla . . . . 7742

nitida . . . . . . 720

riparia . . . . . . 236

COOKIA punctata . . . . 99

CORCHORUS capsularis . . . 2412

olitorins . . . . . 2042

CORDIA bantamensis . . . 3743

calocoma . . . . 4232

latifolia. . . . . 4224

mуха . . . . . 117

subcordata. . . . . 1021

subdentata. . . . . 2824

suaveolens. . . . . 1736

CORDYLINE flexuosa . . . . 2718

oxyphylla . . . . . 3221

Rumphii . . . . . 337

Siboldii . . . . . . 2718

timoriensis . . . . . 1763

CORIANDRUM sativum . . . 4019

CORYPHA umbraculifera . . 1528

COSCINIUM Blameanum . . . 177

COSTUS globosus... . . 6708

sericeus . . . . . 6707

speciosus . . . . . 3247

COVELLIA albipila. . . . . 429

aurata . . . . . . 3335

canescens . . . . . 1255

congesta . . . . . . 6017

didyma. . . . . . 1578

dasycaula . . . . 1578

grandifolia. . . . . 5540

glomerata . . . . 5436

hispida . . . . . . 1255

lepicarpa . . . . . 1312

leucopleura . . . . 4779

macrophylla . . . . 5009

mollis . . . . . 7010

racemifera . . . . 1240

Ribes . . . . . 282

rufescens . . . . . 1577

srabra . . . . . 4321

stictocarpa. . . . . 1573

subopposita . . . . 1416

Zollingeriana . . . . 282

CRATEVA magna . . . . 1024

religiosa . . . . . 1640

Tapia . . . . . 3921

CRATOXYLON celebicum . . 3189

clandestinum . . . . 1123

Hornschuchii . . . . . 2819

lanceolatım . . . . 3355

microphyllum . . . . . 2996 
No.

CRAW FURDIA Blumei.

CREOCHITON bibracteata.

8877

2740 pudibunda. . . . . . 688

CRINUM asiaticum . . . . . 869 bancanum . . . 869

CROSSANDRA infundibuliformis . 2006

CROTALLARIA retusa. . . . 2495 sericea. . . . . 2656 striata . . . . . . 3554 verrucosa . . . . 2270

CROTON argyratum. . . . 3647 aromaticum . . . . 1675 denticulatum . . . . 707 diademum . . . . 7735

-Tiglium . . . . . . 6

Tiglioides . . . . . 4556

CRUDYA orientalis . . . . 591

CRYPTOCARYA acutiflora. . . 2909 costata . . . . . . 2932

crassinervia . . . . 5560

diversifolia. . . . . 4066

ferrea . . . . . 2895

infectoria . . . . . 6867

impressa . . . . . 5532

? lucidula . . . . . . 9275

palembanica . . . . 5548

Preticulata . . . . . 2901

Teysmanniana . . . . 5575

tomentosa . . . . 2916

CRYPTOCORYNE spiralis. . . 7578

CUBEBA canina. . . . . . 5132

Lowong . . . . 7975

mollissima . . . . . 705

officinalis . . . . . . 3702

phyllosticta . . . . . 183

CUBILIA Rumphii . . . . . 271

CUCUMIS flexuosus. . . . . 1529

Melo . . . . . 4295

sativus. . . . . . 403

CUCURBITA littoralis . . . 8392

Рepo . . . . . 5120

villosa . . . . . 904

CUDRANUS amboinensis . . . 760

CUDRANUS obovatus . . . . 3530

CUMINUM Cyminum . . . 2102

CUPANIA diplopetala . . . 4454

erythrorachis . . . . . 3398

fuseescens . . . . . . 4454

Lessertiana . . . . . 9133

? Minjalilen . . . . . ๖987

pleuropteris . . . . 3354

regularis . . . . . 8115

sumatrana. . . . . . 6599

CURANGA amara . . . . 89

CURCULIGO latifolia . . . 24

CURCUMA æruginosa . . . . 5021
CURCUMA cæsia. . . . . 8996

longa . . . . . 2620

purpurascens . . . . 4925

sumatrana. . . . . 4924

viridiflora . . . . . $\mathbf{5 0 2 6}$

Zerumbet . . . . . 3866

CYANODAPHNE cuneata . . . 1880

tomentosa . . . . . 5578

CYANOTIS axillaris. . . . 7302

CYATHEA arborea . . . . 2659

javanica . . . . . 6493

leucophaës. . . . . 6413

medullaris. . . . . 6492

Walkeræ . . . . . . 6497

CYATHOCALYX maginalis . 988

ramiflorus . . . . 8923

CYATHULA geniculata. . . 741

CYCAS circinalis. . . . 2105

revoluta. . . . . . 6414

CYCLOSTEMON cuspidatum . . 2381

longifolium . . . . 4612

macrophyllum. . . . 1265

mucronatum . . . . 2761

CYLICODAPNE Noronhiana . . 2899 obtusifolia . . . . . 3376

CYMBIDIUM aloifolium . . 371

bicolor. . . . . 352

cuspidatum . . . . : $\mathbf{3 5 3}$

ovatum. . . . . . 360

CYNOCTONUM Blumei . . 1327

muricatum. . . . . 8757

CYNODON Dactylon. . . . 2133

setigerus . . . . . 3557

CYNOGLOSSUM javanicum . . 1096

micranthum . . . . 6309

robustum . . . . . 3939

CYNOMETRA bijuga . . . 5207

cauliflora . . . . 5206

ramiflora . . . . 4262

CYPERUS . . . . . . . 2118

compressus . . . . 6015

dilitus . . . . . . 5397

elatus . . . . . . 9211

eragrostis . . . . . 2158

Haspan. . . . . . . 8300

hexastichus . . . . 8492

Iria. . . . . . . . 2157

Junghuhnii . . . . . 6759

kyllingioides . . . . . 5988

longus . . . . . . 8493

melanocephalus . . . 6159

pennatus . . . . . 2121

piptolepis . . . . . 2143

rotund us . . . . . . 5298

tuberosus . . . . . 8490

CYPRIPEDIUM jaranicum . . 323 


\begin{tabular}{|c|c|c|c|c|c|c|}
\hline CYRTANDRA glabra & & & $\begin{array}{l}\text { No. } \\
7208\end{array}$ & DAVALLIA heterophylla & & $\begin{array}{l}\text { No. } \\
6478\end{array}$ \\
\hline incompta & . . & . & 5241 & polypodioides & . & 6463 \\
\hline macrophy!la . & . . & . & 7711 & DEERINGIA celosioides. & & 995 \\
\hline pendula . . & . . & - & 7210 & indica . . . . & - & 995 \\
\hline rostrata . & & . & 2371 & DELIMA sarmentosa . & . & 547 \\
\hline CYRTOCERAS laurifoli & lium . & . & 8860 & DENDROBIUM angulatum & . & 323 \\
\hline multiflorum . & & & 699 & bifarium . . . . & • & 356 \\
\hline CYRTOSIPHONIA ma & adure & ensis & 6951 & concinnum & . & 1881 \\
\hline sumatrana . & & & 436 & purpureum . . . & •. & 356 \\
\hline ERMA lasioi & ides . & & 4805 & DENDROCALAMUS strictu & & 931 \\
\hline NTHUS cam & npant & ulatus & 699 & RIS inflata. & . & 8439 \\
\hline JM elatum & . & . & 3064 & $\begin{array}{c}\text { ENDROLOBIUM cephalot } \\
\text { umbellatum } .\end{array}$ & & $\begin{array}{l}1683 \\
1683\end{array}$ \\
\hline hnii . & . & . & 3064 & DENDROPHTHOE atropur & urpur & 5925 \\
\hline TENIUM & ægyp & ptiacur & 2344 & ta. . . . &. & 1205 \\
\hline DPS acced & lens. & . . & 2857 & lepidota . & . & 3676 \\
\hline & . . & . & 7344 & pentandra. & . & 1198 \\
\hline cius . & . & & 61 & rep & & 5733 \\
\hline & . & & 2843 & DENDROTROPHE pluriner & via & 1205 \\
\hline Draco . & . & . & 2046 & umbellata . . . & . & 195 \\
\hline grandis. & . & • & 7732 & DENTELLA repens . & . & 79 \\
\hline hirsntus. & . & . & 7359 & DERRIS bantamensis & . & 4057 \\
\hline Hystrix . . & . & . & 6679 & iana . & . & 3264 \\
\hline longipes . . & . & - & 7390 & a. & . & 7403 \\
\hline nochætes. & . & . & 2861 & multiflora . & . & 2509 \\
\hline & & - & 6204 & pubipetala. & . & 2253 \\
\hline oblongus. . & 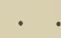 & & 2839 & osa . . . & . & 595 \\
\hline banicus. & . & . & 7370 & DESMODIUM barbatum & . & 2362 \\
\hline athus . & - & - & 7368 & um . . . & . & 4284 \\
\hline anthus . & . & . & 2866 & dasylobum & . & 7830 \\
\hline hii . . & . & . & 6198 & ticum & . & 3960 \\
\hline strictus. . & • & - & . & giroi & - & 6790 \\
\hline trichorus . . & . & . & 7348 & latifolium . & . & 9126 \\
\hline ALBERGIA congesta & . & . & 680 & microphyllnm. & . & 7553 \\
\hline osa . . & & - & 5829 & pum . & . & 1664 \\
\hline littoralis . & & . & 8818 & reniforme. & - & 3951 \\
\hline monosperma. & . & . & 5830 & retoflexum. & . & 2264 \\
\hline Pseudosissoo . & . & - & 654 & triflorum & . & 1988 \\
\hline$\cdot \cdot$ & - & . & 654 & DIALIUM indum . & . & 4940 \\
\hline ifolia. & - & - & . & DIANEJ,LA bancana & . & 234 \\
\hline riana . & & . & 130 & ensifolia . & . & 6322 \\
\hline IA biden & ntata & a & 515 & javanica & 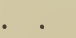 & 1899 \\
\hline ba. . & . . & - & 1618 & montana. & . & 238 \\
\hline NIA racemosa. & & . & 1278 & nemerosa . . . & - & 5079 \\
\hline IE pendula. . & & . & 3541 & DICEROLEPIS paludosa & . & 8336 \\
\hline HNIDIUM cæsium & & . . & 2893 & DICHROA cyanitis, . . & . & 2512 \\
\hline APHNIPHYLLUM b & bancal & & 5954 & DICHROCEPHALA capitat & ita . & 1093 \\
\hline & & & 2923 & lia . . . & .. & 1524 \\
\hline arins . & . & . & 75 & CHYS cinerea & . & 6793 \\
\hline vanicum & & . & 4281 & DICKSONIA scandens. . & . & 6502 \\
\hline & & - & & DICLIPTERA Burmanni & & 1999 \\
\hline DATURA alba. . & & . & 4.281 & chinensis . . & . & 6865 \\
\hline fastuosa & . & . & 4961 & 1)ICRANUM nanum. . & . & 5460 \\
\hline Metel . . & • & . & $496 !$ & DIDACTYLON ramosum & . & 2187 \\
\hline UCUS Carota. . & • & . & 178 & DIDYMOCARPUS crinita. & . & 8624 \\
\hline AVALLIA bișerrata & & & 6465 & reptans. . . . & . & 8625 \\
\hline
\end{tabular}


DIDYMOCHITON nutans. . 4984

DIDYMOCHLÆNA sinuosa . . 6477

DIGASTER sumatranus. . . . 5863

DIGITARIA ciliaris . • . . 2186

digitata. . . . . . 2184

pruriens . . . . . . 2185

ropalotricha . . . . 2185

sanguivalis . . . . 2183

DILIVARIA ebracteata . . . 2047

ilicifolia . . . . . 472

robusta . . . . . 2277

scandens . . . . . 2047

DILLENIA aurea . . . . 7748

elongata . . . . 302

ochreata . . . . 4118

pentagyna. . . . . 7751

serrata. . . . . 100

speciosa . . . . . 61

DINACHLOA Tjangkorreh. . . 783

DIOSCOREA aculeata . . . 1189

alata . . . . . 2808

hulbifera . . . . . . 4

Diepenhorstiana . . . 162

filiformis . . . . . 409

hirsuta. . . . . . . 499

Kleiniana . . . . . 5

mollissima. . . . . 2878

nummularia . . . . . 1778

pentaphylla . . . . . 5

pubera. . . . . 2882

salicifolia . . . . 8719

sativa . . . . . . 6243

spiculata . . . . . 2871

triphylla . . . . . . 2879

vulgaris . . . , . 2808

Zollingeriana . . . . 961

DIOSPYROS cauliflora . . . 7073

cystopus . . . . . 1656

Diepenhorstii . . . . 1929

Ebenum . . . . . 32

frutescens . . . . . 4817

heterophylia . . . . 1158

Kaki . . . . . 4507

macrophylla . . . . 4755

DIOSPYROS melanoxylon . . 4816

pyrrhocarpa . . . . 2693

Teysmanni. . . . . . 3385

DIPHACA cochinchinensis . . 7337

DIPLACRUM caricinum . . . 7118

DIPLAZIUM decussatum . . . 6427

malabaricum . . . . 1028

polypodioides . . . . 6455

spinulosum . . . . . 6456

umbrosum. . . . . . 6454

DIPLANTHEA bancana. . . . 5756

DIPLOCI,INIUM areolatum
DIPLOCLINIUM atrichum . . 7227

bombycinum . . . . 6291

Hasskarlianum . . . . 729

longifolium . . . . 2755

racemosum . . 5168

repandum . . . . . 2755

tuberosum . . . . . 1054

DIPLOPHRACTUM auriculatum . 6129

DIPLYCOSIA pilosa. . . . . 4514

DIPTERACANTHUS dejectus. . 6128

appendiculatus . . . 713

bandii . . . . . 713

UIPTEROCARPUS eurhynchus . 5096

eurynehioides. . . . 5736

gracilis. . . . . 6519

littoralis . . . . 5183

retusus. . . . . 6521

Tampurau. . . . . . 8324

trinervis . . . . . 1349

DISCHIDIA cochleata . . . 1351

Gaudichaudii . . . . 1777

nummularia . . . . 2231

orbicularis. . . . . 9113

punctata . . . . . 7335

Rafflesiana. . . . . 1777

rhombifolia . . . . . 562

Rumphii . . . . . . 9113

sagittata . . . . . . 4499

DISCOSTIGMA fabrile . . . 7841

rostratum . . . . . 3432

DISEMMA Horsfieldii . . . . 7095

DISPORUM multiflorum . . . 1137

DISSOCH $\mathrm{E}^{\prime} \mathrm{T} A$ astrostica . . . 223

cyanocarpa . . . . 8686

Diepenhorstii . . . . 158

gracilis . . . . . 2741

palembanica . . . . 5444

DODOCASTEMON Teysmanni . 3746

DODON王A augustifolia . . 2218

Burmanniana. . . . 4274

? lamponga • . . . . 4106

Waitziana . . . . , 3223

DOLICHOS Junghuhnianus . . 3953

lignosus . . . . . 3544

scabriusculus . . . . 3981

unguiculatus . . . . 3545

uniflorus . . . . . 2632

DONACODES alliaceum . . 6855

aperta . . . . . 6796

incarnnata. . . . . 2534

minor . . . . . 6856

paludosa . . . . . 6859

Pininga . . . . . 6861

I)OODIA dives . . . . . 6445

1)RACONTOMELON mangiferum. 1492 pubcrulum. . . . . 7926 


\begin{tabular}{|c|c|c|c|c|c|c|c|}
\hline \multirow{4}{*}{\multicolumn{4}{|c|}{$\begin{array}{l}\text { DRACONTOM LLON sylvestre } \\
\text { DRYMARIA diandra. } \\
\text { DRYMOGLOSSUM nummularifo- }\end{array}$}} & $\begin{array}{l}\text { No. } \\
\text {. } 1481\end{array}$ & ELAOCARPUS resinosus. & & $\begin{array}{l}\text { No. } \\
4011\end{array}$ \\
\hline & & & & 2136 & serratus . . . . & & 104 \\
\hline & & & & & stipularis . . . & & . 2932 \\
\hline & & & & 6431 & subdenticulatus . & . & 5559 \\
\hline piloselloides . & & & & 6431 & submonoceras. & . & 746 \\
\hline DRYMISPERMUM I & Blume & ei & & 422 & subpuberus . & & 7684 \\
\hline Burmanni . & & & & 5842 & tomentosus . & & 4474 \\
\hline laurifolium & & . & & 3541 & EI.EOGENE sumatrana & . & 7712 \\
\hline revolutum . & & . & • & 3079 & ELATERIOSPERMUM Tap & & 7064 \\
\hline & & . . & • & . 8076 & Tokbray . . . & & 1513 \\
\hline DRYOBA & Camph & cra. & & 7903 bis & ELATOSTEMMA cyrtandræfo & & 9099 \\
\hline DUABANGA moluce & cana & . . & & . 4077 & phyllum . . & - & 4913 \\
\hline I)UCHESNEA chrysa & an tha & . & & 1080 & osum. . & . & 9040 \\
\hline su & & & & 4660 & pedunculosum. . & - & $627 i$ \\
\hline DURIO z & & . . & • & 2252 & ELEOCHARIS erythrochlamy & & 8490 \\
\hline M acumi & inatiss & simum & & 8360 & subprolifera . . . & . & 1332 \\
\hline ulum . & $\cdot$. & $\cdot$ & & 272 & $\mathrm{sa} \cdot . \quad$. & . & 7263 \\
\hline . & . & - & & 3212 & ELEPHANTOPUS scaber . & . & 8381 \\
\hline ngum & .. & - & & 1085 & ELETTARIA alba . . . & . & 7334 \\
\hline laxiflorum . & . & . & & 3823 & odioides . & . & 2972 \\
\hline longifolium . & . & . & & 916 & atropurpurea . & - & 9261 \\
\hline irpum . & . & . & & 2240 & comum. & . & 2708 \\
\hline simile . . & & $\cdot$ & & $5 S 04$ & a. . & . & 5786 \\
\hline & & & & & penhorstii . & . & 6921 \\
\hline EBERMAYERA elong & agata & . & & 7241 & s. . . & . & 8395 \\
\hline & $\cdot \quad \cdot$ & - & & 7211 & hæmisphærica. & . & 2975 \\
\hline Nelsonioides . & & . & & 7722 & ocephala. & - & 7071 \\
\hline subpaniculata . & . & - & & 4076 & r. . & - & 6854 \\
\hline phala . & . $\cdot$ & . & & 5308 & minuta. & . & 2297 \\
\hline ECDYSANTHERA b & barbata & a. & & 8860 & mollis . & . & 6862 \\
\hline & 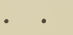 & . & & 8860 & pallida . & - & 2973 \\
\hline ulosa . & & . & & 7780 & rubra . . : & . & 2976 \\
\hline ECHINOCARPUS Si & igum & . & & . 1101 & salaris . . . & . & 2977 \\
\hline $\mathrm{OA}$ colc & lonum & . & & . 4947 & speciosa . & . & 2971 \\
\hline alli . & $\cdot$. & . & & 1881 & tomentosa . & . & 3848 \\
\hline & - & - & & 2149 & villosa. . & - & 6863 \\
\hline ECHINUS $\mathrm{t}$ & . & . & & 3344 & Walang . & . & 9108 \\
\hline TA a & . & , & & 1809 & ELEUSINE coracana. & . & 1892 \\
\hline ifolia . & - & . & & 5066 & indica . . . . & . & 1961 \\
\hline & - & . & & 8283 & ELIOBOCARPUS oleraceus & . & 7462 \\
\hline & . . & . & & 7882 & ELSHOLTZIA elata. . & . & 2107 \\
\hline ELEAGNUS ferrugin & inea. & . & & 525 & ELYTHRANTE albida & . & 1198 \\
\hline latifolia . & .. & . & & 473 & EMBELIA clusiæfolia . & . & 5372 \\
\hline & . . & - & & 473 & dasythyrsa. . . & . & 147 \\
\hline ELAOCARPUS aden & nopus & & & 8834 & garciniæfolia . & . & 534 \\
\hline olins . &. & . & & 104 & javan & . & 535 \\
\hline & . & . & & 1277 & EMBLICA officinalis. . . & - & 1485 \\
\hline ndus & . & . & & 2654 & EMBRYOGONIA arborea. & - & 2381 \\
\hline & - & & & 2654 & lucida . . . . & . & 4756 \\
\hline us. & - & . & & 1606 & EMILIA sagittata & - & 2220 \\
\hline integripetalus. & & $\cdot$ & & 8947 & sonchifolia. . . . & . & 2221 \\
\hline longifulius. . & • & - & • & 2654 & ENCHIDIUM verticillatum. & . & 3668 \\
\hline macrocarpus. & . & & & 5544 & ENDIANDRA cuneata . . & . & 3257 \\
\hline macrophyllus. & . & & & 4012 & rubescens . . & . & 2905 \\
\hline onc & . & . & & 4011 & sumatrana & & 3528 \\
\hline ovalis . . & & & & . 8166 & ENGELHARDTIA aceriflora & & 1642 \\
\hline
\end{tabular}




\begin{tabular}{|c|c|c|c|c|c|c|c|c|c|}
\hline \multicolumn{3}{|c|}{ ENGELHARDTIA palembanica } & \multirow{2}{*}{\multicolumn{2}{|c|}{$\begin{array}{l}\text { No. } \\
\text {. } \quad 1564 \\
\text {. } 4452\end{array}$}} & \multirow{2}{*}{\multicolumn{3}{|c|}{$\begin{array}{l}\text { EUPATORIUM Ayapanna. } \\
\text { EUPHORBIA antiquorum }\end{array}$}} & \multirow{2}{*}{\multicolumn{2}{|c|}{$\begin{array}{l}\text { No. } \\
. \quad 140\end{array}$}} \\
\hline rigida & & . . & & & & & & & \\
\hline serrata. & & . & & 857 & hirta . . . & & & & 2988 \\
\hline spicata . & & - & & 4452 & ligularia & & • & & 8080 \\
\hline NHALUS Kœnigii & & . & & 923 & neriifolia . & - & - & & 44 \\
\hline NHYDRA palcdosa & & - & - & 24.23 & plumerioides. & - & - & - & 8062 \\
\hline NTADA pursætha & - & - & - & 482 & pilulifera. . & & - & & 6059 \\
\hline SPICHARIS altissim & na & . & & 3823 & reniformis . & . & . & & 2155 \\
\hline cauliflora . & . & . & & 6801 & thymifolia . & . & . & & 1830 \\
\hline densiflora. & & . & - & 5802 & tirucalli . . & & & & 3397 \\
\hline macrocarpa & & . & . & 887 & EUPTERON nodosum & & . & & 4,081 \\
\hline sericea. & & . & & 2763 & EURYA clandestina. & . & . & & 4467 \\
\hline PIDFNDRUM cani & inum & . & & 351 & Blumeana. . & . & . & . & 4458 \\
\hline tuberosum & & - & - & 24 & euprista . & . & . & & 5875 \\
\hline RAGROS'TIS ciliate & ta & - & - & 8433 & glabra . . & . & . & & 3155 \\
\hline roä. . & . & . & • & 2162 & hirsutula. & . & - & & 808 \\
\hline plumosa & . & . & . & 2187 & nitida . . & . & . & & 8893 \\
\hline ata. & . $\cdot$ & $\therefore$. & . & 5785 & phyllantoides. & . & . & & 2103 \\
\hline RANTHEMUM acu & iminat & tissimu & & 7588 & serrata. . & . & & & 4751 \\
\hline & & . . & & 2003 & virens . . . & & & & $328: 3$ \\
\hline $\mathrm{ON}$ longi & cifoliun & $\mathrm{m}$. & • & 7285 & EURYCLES amboinens & & . & & 1062 \\
\hline $\operatorname{linm}$ & . . & . & - & 7832 & javanica . & & . & & 798 \\
\hline & & - & . & 5778 & A longifolia & & & & 804 \\
\hline gular & & - & • & 801 & XYION Zn & wager & & & 1103 \\
\hline lare & - & - & - & 800 & EUTHEMIS leucocarpa & a. & - & & 5862 \\
\hline m. & . & . & . & 801 & minor . . & . & . & & 6991 \\
\hline tomen & atosa & $\cdot \quad \cdot$ & • & 9189 & EUXOLUS caudatus. & - & - & & 836 \\
\hline $\mathrm{UM}$ an & nfractit & nosinm & & 18 & polygamus. & . & . & & 836 \\
\hline M edu & ale . & . $\cdot$ & & 3580 & achyus. & . & & & 84.5 \\
\hline APHE punice & & - & • & 2360 & viridis . . & . & & & 845 \\
\hline nptobot & trya. & . & • & 235 & EVIA acida . & . & . & & 2890 \\
\hline & 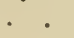 & - & • & 4686 & amara & . & & & 3143 \\
\hline & 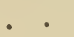 & . & • & 632 & borbonica & . & . & & 3150 \\
\hline ulata . & . & - & - & 632 & EVODIA glabra . & - & & & 4.663 \\
\hline RYTHRINA . . & - & - & - & 1586 & latifolia. & - & - & & 36 \\
\hline fusca . & . & • & - & 1595 & hassæ . & . & . & & 414 \\
\hline indica . . & . & . & . & 1586 & Roxburghiana & . & . & & 4365 \\
\hline lithosperma & . & . & • & 1587 & EVONYMUS bancanus & . & . & & 4592 \\
\hline lobnlata. & & - & • & 1587 & icus . . & . & . & . & 1874 \\
\hline picta. . & 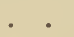 & . & • & 2475 & recurvans. & . & . & . & 6691 \\
\hline spathacea . & $\cdot$ & - & . & 1589 & EWYCKIA paniculata & . & . & & 5903 \\
\hline vespertilio . & . & . & - & 1850 & tuberculata & & . & & 964 \\
\hline RYTHROPALUM & scand & dens. & . & 570 & EXCECARIA Agalloch & & & & 22 \\
\hline RYTHROSTIGMA & diver & rsifolia & . & 583 & EXOCARPUS latifolia & . & . & & 4594 \\
\hline ETHULIA megaceph & hala . & $\cdot \cdot$ & • & 8855 & phyllantoides. & . & . & . & 1717 \\
\hline EUCALYPTUS alba. & & . & & 3423 & & & & & \\
\hline UCAI,YPTUS deglt & Iupta & . & • & 35 & FABRICIA ? bracteata & . & . & & 3846 \\
\hline & & - & & & FAGRÆA auriculata & . & & & 2327 \\
\hline A Horsfi & fieldii & . & & & coarctata. . & - & & & 5898 \\
\hline rasoides & 8 & • & & & ica . & . & & & 4570 \\
\hline & $\cdot$ & . & • & & ans . & . & & & 4363 \\
\hline botrya . & • & • & • & 42 & rialis . & & & & 6946 \\
\hline $\mathrm{m}$ & $\cdot$ & . & • & 4696 & latifolia . & . & & & 3388 \\
\hline aatensis & • & • & • & 4249 & littoralis & . & & & 4255 \\
\hline & • & . & & 1920 & Kimangn . & . & & & 4.255 \\
\hline FUIA LIA japonica. & & . & & 2529 & minor , . & & & & 5920 \\
\hline
\end{tabular}




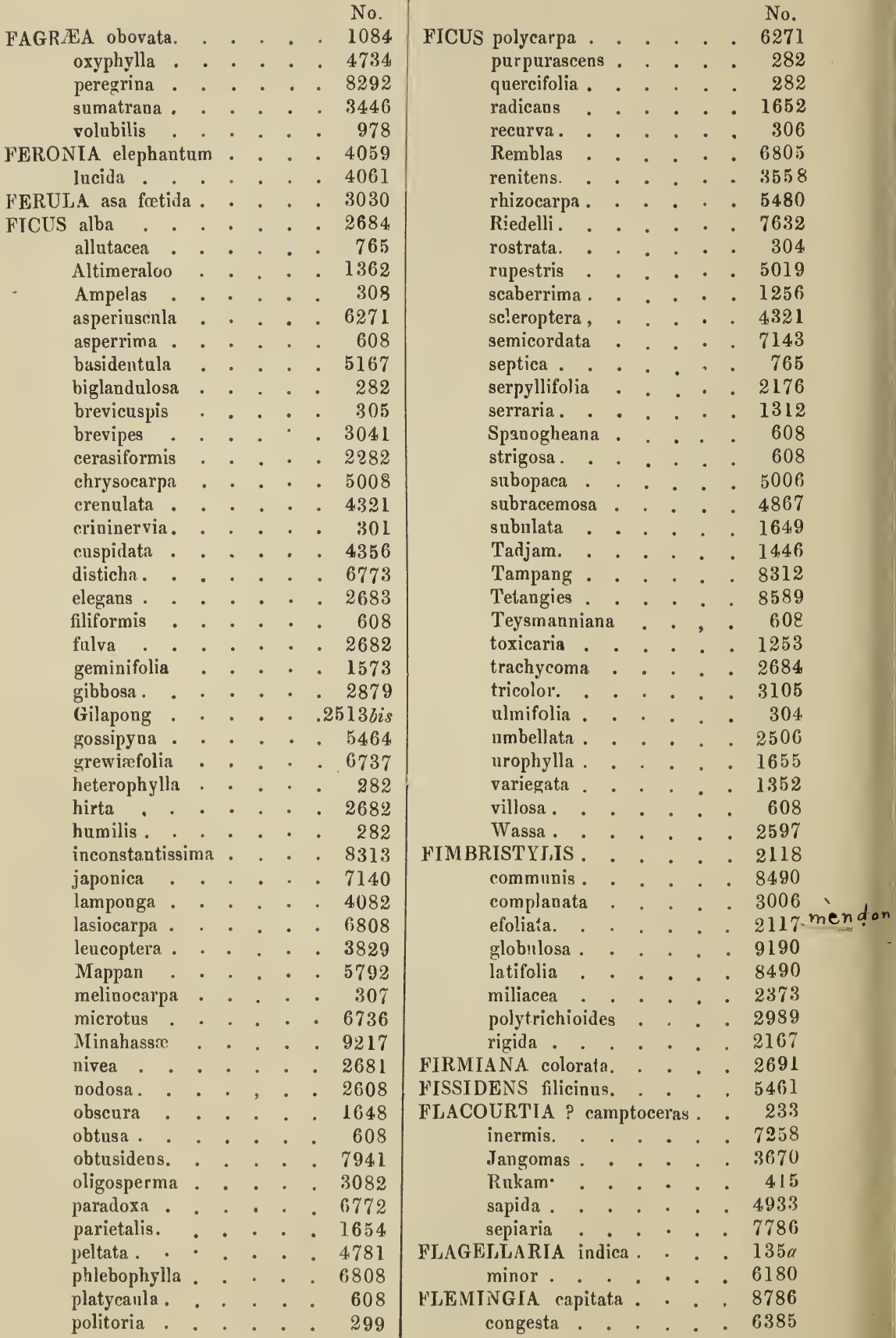




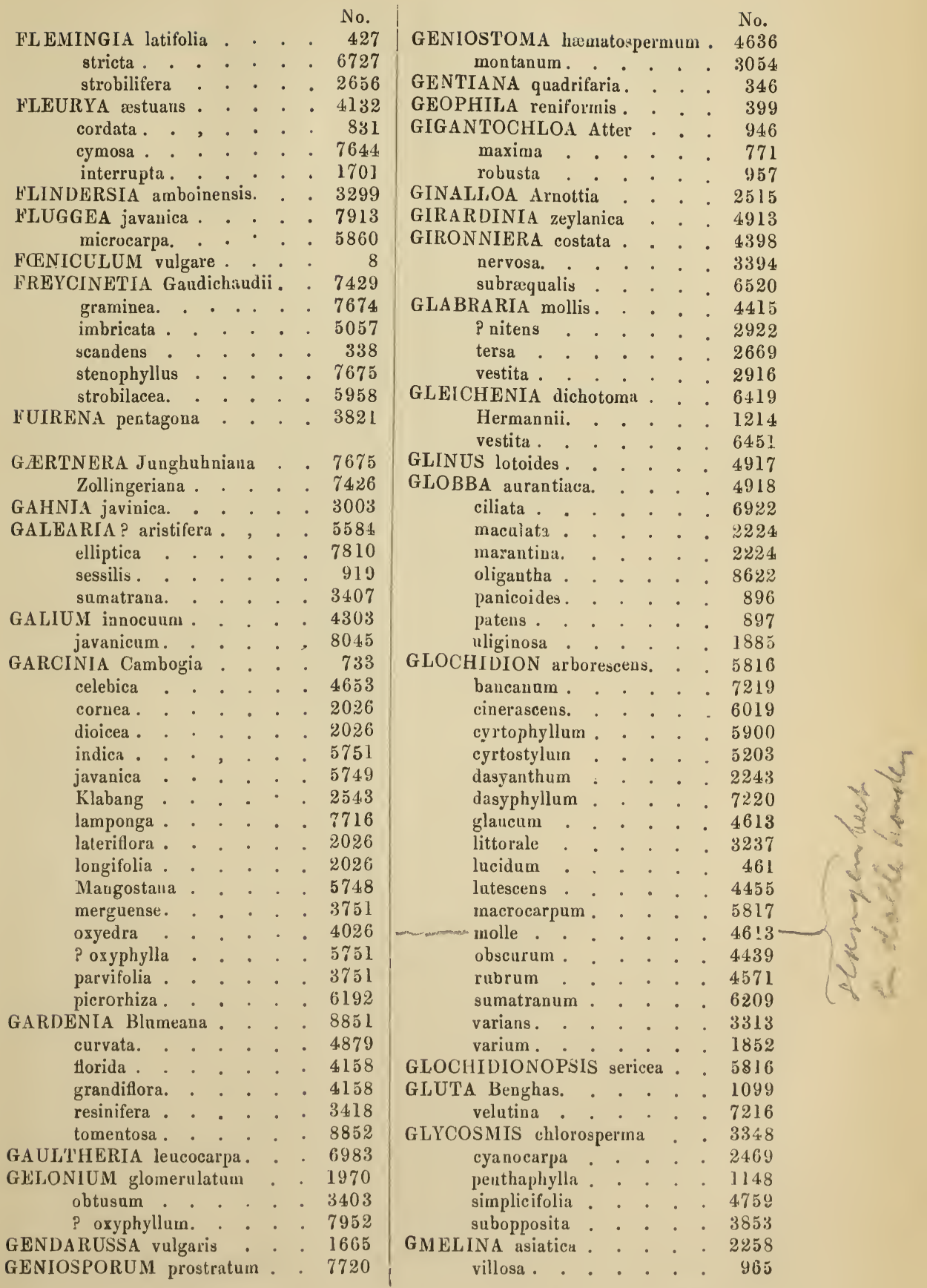




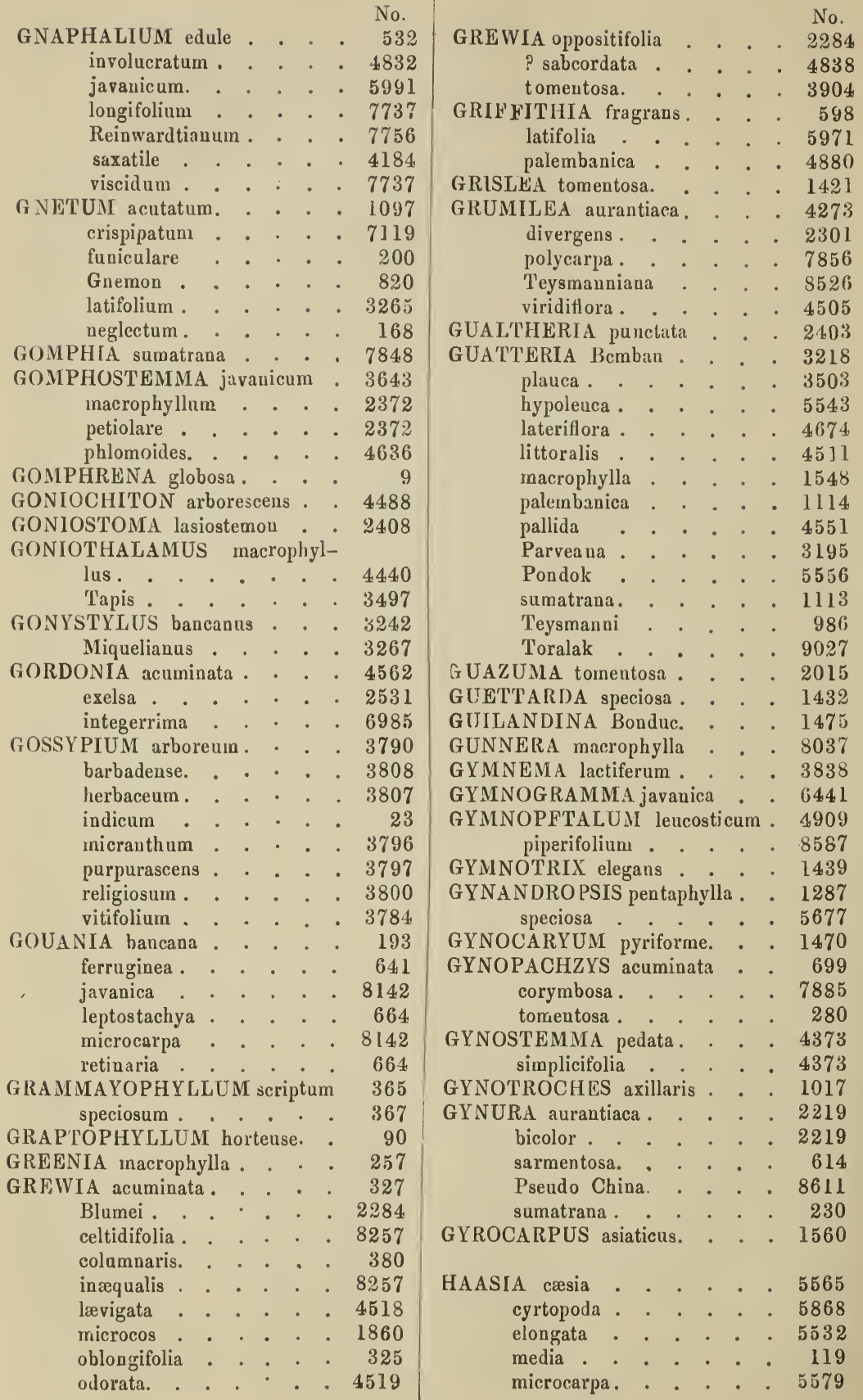


HAASIA subcesia . . . 5558

HABZELIA acuta. . . . . 585

HÆMANTHUS puniceus . . . 802

HALORAGIS disticha . . . 3297

HARPULIA cupanoides. . . . 3289

repestris . . . . . 4522

HARRISONIA Brownii. . . 4589

HARTIGHSEA acuminata. . 8902

angustifolia . . . . 3219

costulata . . . . . 3250

excelsa . . . . . 4382

Forsteri . . . . . 4382

mollissima . . . . . 4081

HEDYCARPUS cauliflorus . . 5393

javanicus . . . . . 5430

malayanus . . . . . 1500

HEDYCHIUM augustifolium . . 1873

coronarium . . . . 2409

lingulatium . . . . 2409

Roxburghii . . . . 350

sumatranum . . . . 2410

HEDYOTIS capituliflora. . . . 5668

crateogonum . . . . . 7339

latifolia. . . . . . 9234

prostrata . . . . . 4023

jugosa . . . . . . 9251

venosa. . . . . . 4398

HELIANTHUS annuus. . . . 138 ว

HELICIA javanica • . . . 3756

obovata . . . . . . 3328

robusta. . . . . . 3758

serrata. . . . . 3381

sumatrana. . . . . 7787

HELICONIOPSIS amboinensis . 4978

HELICTERIS Isora. . . . . 1491

HELIGME javanica . . . . . 647 minahassæ. . . . . 3874

HELIOPHYTUM indicum . . 1445

HELENIA bracteata. . . . 2225 scabra . . . . . . 5148

HELMINTHOSTACHYS dulcis . 6361 zeylanica . . . . . 6470

HEMICYCLIA rhadodiscus. . . 3501

HEMIONITIS cordata . . . 6482

HENSLOWIA paniculata . . . 803

HERITIERA littoralis . . . . 752

HERNANDIA ovigera . . . . 43

sonora . . . . . 16

HERPESTIS Monnieria. • . 2582

HETEROPOGON polystachyus. . 2152

HETEKOSTEMMA acuminatum - 2566

HEYNEA quinquejuga . . . 4466 sumutrana. . . . . 8341

HIBISCUS elatus. . . . . 9175 ficulnoides. . . . . 4181

grewiæfolius . . . . 4597
H1] BISCUS lampas No.

3542

1358

2394

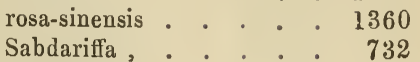

surattensis. . . . . 731

syriacus . . . . . . 4180

tiliaceus . . . . . 2764

venustus . . . . . 3543

vitifolius . . . . . 4064

vulpinus . . . . . 8503

HIPPOCRATEA Glaga . . . 485

indica . . . . . . 485

HIPTAGE javanica . . . . . 469

Madablota. . . . . 3564

HODGSONIA heteroclita . . . 644

HOMALIUM grandiflorum . . 3210

obovale. . . . . 3430

sumatranum . . . . 3430

HOMALONEMA alba . . . 317

aromatica . . . . . 8764

cordata. . . . . . 7773

rubesccns . . . . . . 903

HOPEA Balangeran . . . . 898

diversifolia. . . . . 5928

dryobalanoides . . . 1624

? fagifolia . . . . 4075

lanceolata . . . . . 85233

macrophylla . . . . 8531

maranti . . . . 5808

Mengarawan . . . . 5928

Sangal . . . . . 6153

selanica. . . . . 824

Seminis . . . . 8529

? Singkawang. . . . 7925

? Siranda . . . . . 7951

HORSFIELDIA aculeata . . 2334

HOYA Ariadne . . . . . 9112

carnosa. . . . . . 596

clandestina . . . . 576

coriacea. - . . . . 565

coronaria . . . . . 576

difersifolia. . . . . 562

lacunosa . . . . . 1790

lanrifolia . . . . 565

macrophylla . . . . 563

polystachya . . . . 3843

Rumphii . . . . . 1776

Teysmanniana . . . 7816

HUNTERIA sundana . . . . 2514

HYDNOCARPUS lævis. . . . 3273

HYDNOPHYTUM formicarum. . 3038

montanum . . . . 3018

HYDRILLA najadifoliá . . . 2313

HYDROCHARIS asiatica . . 2317

HYDROCO'TYLE asatica . . . 70 
HYDROCOTYLE hirsuta . . . 7074

latisecta . . . . . . 7552

nepalensis . . . . . . 2589

nitidula. . . . . . . 398

splendens . . . . 400

sundaica . . . . . 1808

Zollingeri . . . . . 3644

HYGROPHILA assurgens . . 2004

obovata. . . . . . 2003

IJYLOCHARIS macrophylla . . 7880

HYMENACHME interrupta . . 1657

HYMENEA verrucosa . . . . 3411

HYMENODICTYON Horsfieldii . 829

timoranum . . . . . 15

BYMENOPHALLUS dæmonum . 1053

HYPAPHORUS subumbrans . . 1594

HYPOBATHRUM frutescens . . 4502

HYPOËSTES laxiflora... . 6161

polythyrsa . . . . . 6945

purpurea . . . . . . 96

rosea . . . . . . 1962

Zollingeriand . . . . 6945

HYPOLYTHRUM myrianthum . 2768

HYPOXIS major. . . . . . 6893

HYPTIS suaveolens . . . . 791

HYRTANANDRA hirta. . . 5347

pentandra . . . . . 6321

HUNTERIA veratrifolia. . . 358

ICHNOCARPUS bantamensis . . 558 frutescens . . . . . 3089

IGUANURA geonemæformis . . 6841

ILLICIUM anisatum:. . . . . 12

ILLIGERA dasyphylla . . . . 300

IMBRICARIA coriacea . . . . 3066

IMPATIENS albo-flava. . . 3025

Balsamina . . . . . 254

Diepenhorstii . . . 3026

javensis . . . . . 6702

latifola. . . . . 6702

micrantha. . . . . 6702

pyrrhotricha . . . . 3026

Teysmanni. . . . 3027

INPERATA arundinacea . . . 263

INDIGOFERA Anil. . . . . 8424

galegoides . . . . . 8425

hirsuta . . . . . . 2092

leptostachya . . . . 8418

tinctoria . . . . . 2305

340

794.5

830

5795

6691

7744

1877
No.

tomentella $\cdot . \cdot 8848$

IPOMEA cymosa . . . . . 303

dasysperma . . . . 541

filicaulis . . . . . 577

involucrata . . . . 677

linifolia . . . . . 540

littoralis . . . . 540

mammosa . . . . . 972

obscura. . . . . . 545

peltata . . . . . . 216

pes-capræ . . . . . $103 y$

polyantha . . . . 507

reptans . . . . . 526

sidæfolia . . . . . 973

tuberosa . . . . . 540

turpethum. . . . . 505

vitifolia . . . . . 463

IRINA glabra. . . . . . . 1465

tomentosa . . . . . 1676

ISCA EMUM barbatum . . . 7295

ciliare . . . . . . 2133

muticum . . . . 2166

ISOLEPIS uninodis . . . . 2166

ISONANDRA Gutta • . . . 890

lamponga . . . . 3631

Prostrata . . . . . 6156

ISCHUROCHLOA floribunda . . 955

IXIONANTHUS cuneata . . . 4003

JACKIA ornata . . . . . 7730

JAGERA speciosa. . . . . . 753

JAMBOSA alba . . . . . 50

acuminatissima . . . . 3043

acutata . . . . . . 5050

Panastomosens . . . . 3291

aquæa . . . . . . . 1908

aromatica . . . . . 3500

bifaria. . . . . 48

bracteata . . . . . 6024

buxifolia . . . . . 3384

cauliflora . . . . . 2629

celebica . . . . . 1151

JAMBOSA cerosiformis . . . 4722

clavata. . . . . 6146

cornifolia . . . . 3150

corymbosa. . . . . 4473

densiflora . . . . . 1921

domestica . . . . . . 1922

formosa . . . . . 1908

glabrata . . . . . 4607

hypericifolia . . . . 5053

Klampok . . . . . 4813

linearis. . . . . 1916

lineata . . . . . 3643

? littoralis . . . . . 5055

macrocarpa . . . 4930 
$\begin{array}{ll} & \text { No. } \\ \text { JAMBOSA melanosticta. . . } & 4702\end{array}$

moluccana. . . . . 3375

obtusifolia . . . . . 8798

peregrina . . . . . 1721

perforata . . . . . 3630

puncticulata . . . . 3251

rhynchophylla. . . . 3180

rhytidocarpa . . . . 1943

rubricaulis. . . . . 2560

saligna. . . . . . 7515

subsessilis . . . . . 1936

symphytocarpa . . . 6867

tenuicuspis . . . . 1857

tetraedra . . . . . 5758

tetragona . . . . . $\mathbf{4 4 3 3}$

tetraptera . . . . . 5870

virens . . . . . . 2649

vulgaris . . . . . 1909

2 VE JANIPHA Manihot . . • 2872

JASMINUM crassifolium . . , 525

distichum . . . . . 1732

funale . . . . . . 7096

glabriusculum . . . 525

glabrum . . . . . 525

yrandiflorum . . . . . 1366

insigne . . . . . . 3244

pubescens . . . . 7053

quinquenervium . . . 1533

Sambac . . . . . . 920

scandens . . . . . . 5643

subelongatum. . . • . 525

undulatum . . . . 525

JATROPHA Curcas . . . . 913

multifida . . . . . . 1987

JONESIA palembanica . . . 5639

JUNCUS communis . . . . 8052

prismatocarpus . . . . 5227

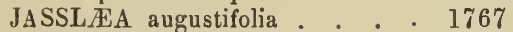

Blumeana . . . . . 476

repens . . . . . . 476

suffruticosa . . . . . 476

KADSURA cauliflora. . . . 501

scandens . . . . . 501

KÆMPFERIA Galanga. . . . 737

pandurata. . . . 3658

rotunda . . . . . 3576

KAKOSMANTHUS macrophyllus. 8870

KALANCHOË laciniata. . . . 46 pinuata.

KARIVIA Rheedii . . . . 500

KAULNUSSIA xsculifolia. . . 6484

KERRIA japonica. . . . . . 2827

KIBARA coriacea. . . . . . 884

KIBESSIA azurea. . . . . 1105

sessilis . . . . . 6113

KIESERA minor. . . . . 2303
KIESERA sericea. 3817

KIXIA arborea. . . . . . 4317

KLEINHOVIA hospita. . . . 3927

KNOXIA mollis . . . . . 3825

KOPSIA arborea . . . . . 4552

KORTHALSIA debilis . . . . 7349

flagellaris . . . . . . 7349

Junghuhnii . . . . . 7386

robusta. . . . . . 2859

scapigera . . . . . 7391

Teysmanni. . . . . 8357

KYLIINGIA bifolia. . . . 9256

brevifolia . . . . . 2122

fuscata . . . . . . 7301

monocephala . . . . 6410

pumilis. . . . . . 2122

vaginata . . . . 2153

LABLAB cultratus . . . . . 3991

microcarpus . . . . . 3547

perannans . . . . 35540

vulgaris . . . . . . 3544

LAC'TARIA coccine . . . . . 41

salubris. . . . . 5518

LACTUCA indica. . . . . $7191 a$ sativa . . . . . 5628

LAGENARIA hispida . . . 1511

idolatrica . . . . . . 1509

vittata . . . . . 1531

vulgaris. . . . . . 3568

LAGERSTREEMIA indica . . . 8602

ovalifolia . . . . . 1123

reginæ . . . . . . 1123

LAHIA cutejensis. . . . . 5162

LANSIUM aquæum . . . . . 142

domesticum . . . . . 98

LANTANA mixta. . . . . 1840

stricta . . . . . . 2164

LAPLACEA aromatica . . . 4840

buxifolia . . . . . 6407

marginata . . . . . 6913

subintegerrima . . . . 6914

LAPORTEA amplissima. . . 121

costata. . . . . . 6958

crenulata . . . . 6958

decumaua . . . . . 121

macrostigma . . . . . 1698

oblongata . . . . . 6958

stimulans . . . . . 1698

LASIA aculeata . . . . . 7577

hetcrophylla . . . . 7575

Merkusii . . . . 7576

Zollingeri . . . . . 2373

IASIANTHERA javanica . . 6548

macrophylla . . . . 4565

secundiflora . . . . 4565 


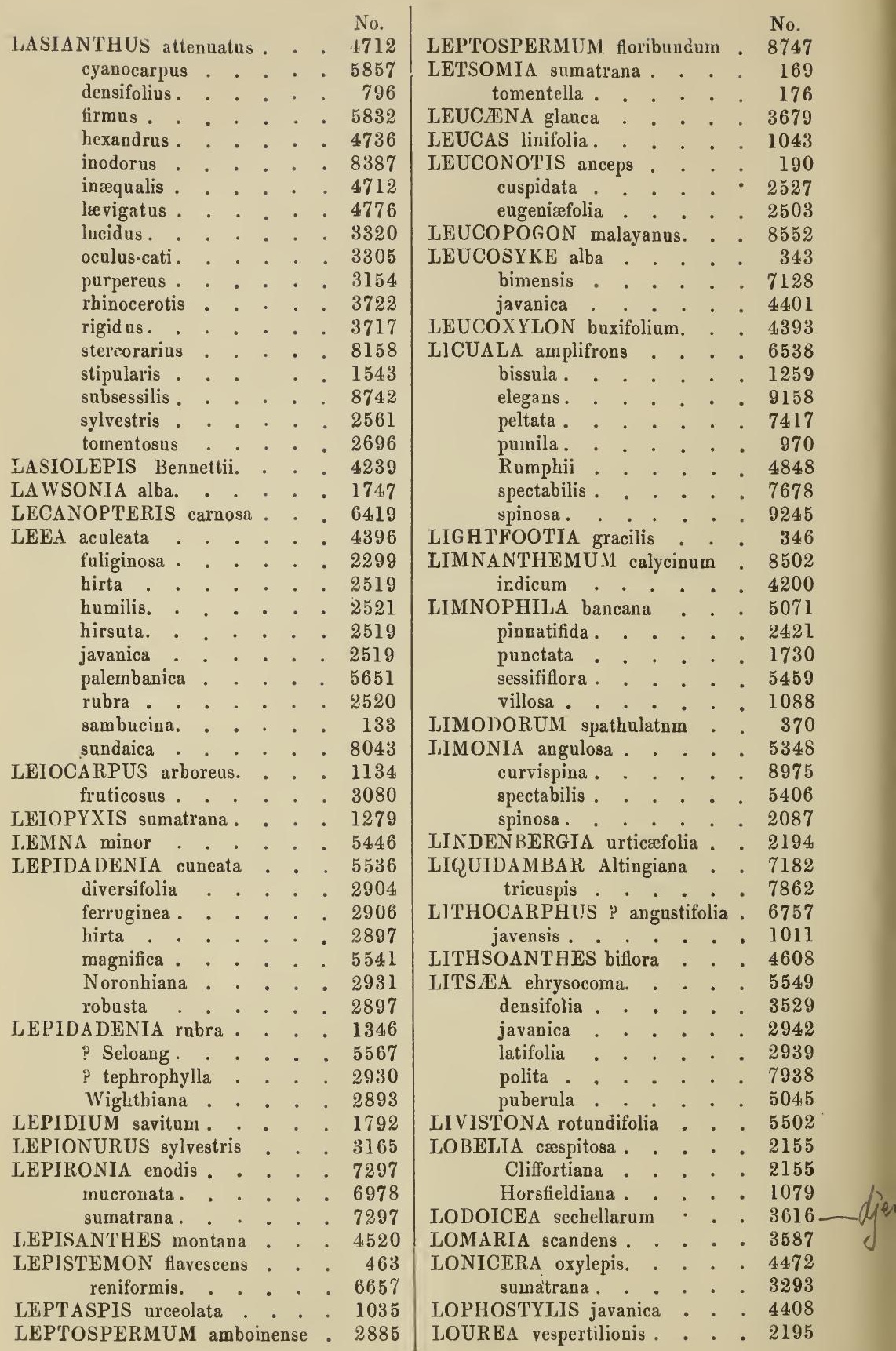




\begin{tabular}{|c|c|c|c|}
\hline LOXOTIS obliqua . & & & $\begin{array}{l}\text { No. } \\
8650\end{array}$ \\
\hline LUDWIGIA perennis. & . . & . & 7646 \\
\hline LUFFA acutangula. & . & . & 2095 \\
\hline cordifolia . & . & . & ว 14 \\
\hline fœtida. . & . & . & 465 \\
\hline pentandra. & . & . & 636 \\
\hline pentola. . & . & . & 685 \\
\hline sylvestris . . & . & . & 6787 \\
\hline UMNITZERA coccinea & a & . & 420 \\
\hline racemosa . . & . & . & 2232 \\
\hline LUERINGA calophylla & . & . & 54.00 \\
\hline IMCOPERDON . & . & . & 1960 \\
\hline giganteum . . & & . & 8060 \\
\hline COPERSICUM cer: & siform & & 5379 \\
\hline esculentum & & . & 1111 \\
\hline YYCOPODIUM . & . & . & 7156 \\
\hline cernuum . & - & , & 7157 \\
\hline phlegmaria. . & . & . & 4493 \\
\hline LYGODIUM circinnatun & in & & . 2792 \\
\hline microphyllum. & & & . 2604 \\
\hline
\end{tabular}

MABA Ebeuus . . . . 107

MACHILUS odoratissima . . . 119

MACLURA javanica . . . . . 2206

MACODES petola. . . . . 1775

MACRODERRIS polyantha. • 821

MACROPANAX floribundum . . 6589 glomerulatum. . . . 6587

oreophilum . . . . . 5279

MACROSOLEN formosus . . 5922 retusus. . . . . . 1198

? rotundatus . . . . 6771

tetragonus. . . . . . 2559

MACROTROPIS ? bancana . . 7431

sumatrana . . . . . 4935

MESA Blumei. . . . . . 4626

indica . . . . . . 5692

latifolia . . . . . 4628

membranacea . . . . 4627

mollissima . . . . 4626

polyantha . . . . 8299

pyrifolia . . . . . 6505

virgata. . . . . . 4625

MALAPARIUS Havus . . . 5640

MANGIFERA altissima. . . . 1033

fotida . . . . . . 274

Gedebeh . . . . . 2463

indica . . . . . . 275

Kemanga . . . . . 1180

Langong . . . . . 5248

laurina. . . . . . 1115

laxiflora . . . . . 3021

macrocarpa . . . . 2607

minor . . . . . . 5457

Parih . . . . . 5724

similis. . . . . 724
MANGIFERA Taipan $\quad$ No.

timorensis . . . . . 6395

utana . . . . . 5721

MANGLIETIA glauca * . . 1026

Oortii . . . . . . 5545

sumatrana . . . . 5545

MAOUTIA odontophylla . . . 9122

rugosa . . . . . . 6285

MAPPA costulata. . . . . . 2096

denticulata. . . . . . 1267

Diepenhorstii . . . . 7615

gummiflua. . . . . 7818

? hypoleuca . . . . 7616

javanica . . . . . 5938

macrophylla . . . . . 4960

moluccana . . . . . 56

montana . . . . . 4436

pruinosa . . . . . 5688

? stricta . . . . . 5787

tanaris. . . . . . 2294

tomentosa . . . . . . 5836

trichocarpa . . . . 3562

Zollingeriana . . . . 6016

MARANTA dichotoma . . . 926

grandis. . . . . . 927

indica . . . . . . 431

MARATTIA sambucina . . . 6424 sylvatica . . . . . 6461

MARISCUS umbellatus . . . 2144

MARLEA tomentosa. . . . 4552

MARSDENIA augustifolia . . . 676

parviflora . . . . . 676

tinctoria . . . . . . 676

MARSILEA quadrifolia . . . . 5446

MARUMIA Korthalsiana . . . 7879

muscosa . . . . 495

MASTIXIA cuneata . . . . 4495

Junghuhniana. . . . 2899

Kimanilla . . . . . . 4561

pentandra . . . . . 2914

rostrata. . . . . . 6520

trichotoma. . . . . 4400

MAZUS lævifolius. . . . . 2155

MECOSTYLIS acalyphoides. . . 2672

MEDINILLA celebica . . . 7598

crassifolia . . . . . 2744

crassinervia . . . . . 9128

crispata. . . . . . 5297

Hasseltii . . . . . 7846

Horsfieldii. . . , . 6649

hypericifolia . . . . 2746

intermedia . . . . . . 6649

javanensis . . . . . . 2749

Korthalsii . . . . . . 1209

macrocarpa . . . . 64

radicans . . . . . 624 


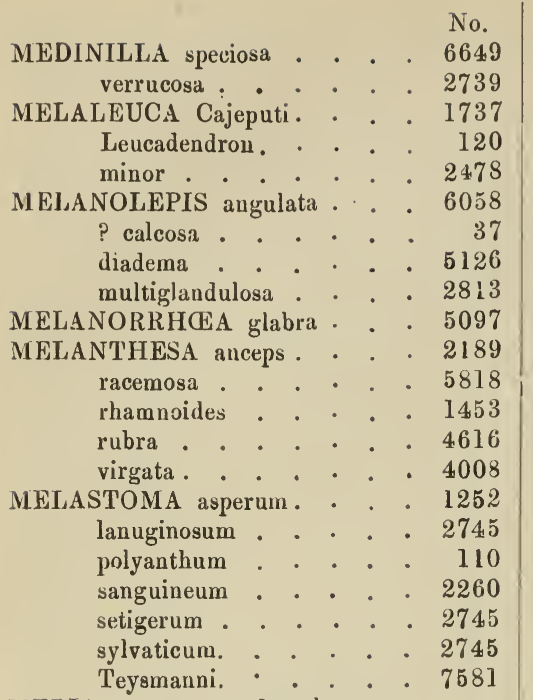

MELIA arguta, Azedarach, sambucina et tomentosa. . . 3561

MELIOSMA angulata . . . . 4743 confusa. . . . . 8310

ferruginea . . . . . 4744 floribunda . . . . . 4743 lanceolata . . . . 3171 nitida . . . . . . 3440 polyptera . . . . . . 808 simplicifolia . . . . • 4743

MEI,OCANNA Blumei . . . . 953 brachyclada . . . . 937 gracilis. . . . . . 935 humilis. . . . . 5521 serpentina :. . . . . 950 tenuispiculata . . . . . 945 Zollingeri . . . . . . 951

MELOCHIA Burmanni . . . 7044

MELODINUS lævigatus. . . . 8400 laxiflorus . . . . . 560 orientalis . . . . . 560

MELODORUM bancanum . . 186 Kentii . . . . . 4765 latifolium . . . . . 573 sphærocarpum . . . . 584

MEMECYLON appendiculatuIn - 4496 caloneurum . . . . 8203 cœruleum . . . . . . 4904 costatum . . . . . 4413 edule . . . . . . . 4390 exelsum . . . . . . 4412 Horsfieldii . . . . . 5942 lampongum . . . . 3342 laurifolium . . . . 4413

MEMECYLON luteolum No. ninutiflorum . . . . 3629 nigrescens . . . . 1411 oligoneurum . . . . 43390 subtrinervium . . . . 1606 tinctorium. . . . . 7304 umbellatum . . . . , 3043

MEN'THA javanica . . . . . 1309 MEPHITIDIA sanguinea . . . 4398 MESONA palustris . . . . . 1966 MESUA ferrea . . . . . . 6044 METHONICA superba . . . 3065 METROSIDEROS saligua . . . 1783 METROXYLON elatum. . . 1131 filare . . . . 1320 hermaphrodituin . . . 4644 læve . . . . . . 4645 logispinnm . . . . 5268 micracanthum. . . . 5267 Rumphii . . . . 279 Sagus . . . . . . 1322 sylvestre . . . . . 5266

MEZONEURUM sumatranuin. . 4994 MEZZEBTIA umbellata . . . 3720 MICHELIA Champaca . . . . 1365 longifolia . . . . . 8701 montana . . . . . . 1890 Tsjampaca . . . . 8710 velutina . . . . 5760

MICROCARPÆA muscosa . . 2161 MICROGLOSSA volubis . . . 1285 MICROSEPALA acuminata . . 1033 MIKANIA volubilis . . . . . 459 MILLETIA atropurpurea . . . 3391 ? rostrata. . . . . . 8898 sericea . . . . . 198 thysiflora . . . . . . 8694

MILLINGTONIA hortensis . . 2661 MII,NEA Blumei. . . . . . 4391 dulcis . . 5599 montana . . . . . 5255

MIMOSA asperata . . . . 481 hamata. . . . . . 435 pudica. . . . . . . 649

MIMUSOPS acuminata . . . 2040 Elengi . . . . . . . 1399 Kauki . . . . . . 1497 Manilkara . . . . 7410

MIRABILIS dichotoma. . . 4191 Jalappa . . . . . . 1405

MITREPHORA Diepenhorstii . . 7868 humilis. . . . . 573 micrantha. . . . . 573 multiflora . . . . 573 obtusa . . . . . . 4674 polypyrena. . . . . . 4509 
MITRELLA Kentii

MITSCHERLICHIA coriacea . . 2754 Junghuhniana . . . . 6055

MODECCA acuminata . . . 642 cardiocarpa . . . . 642

cordifolia . . . . . . 2148

heterophylla . . . . 643

lobata . . . . . 642

macrophylla . . . . 642

oblonga . . . . . 642

obtusa . . . . . . 642

palmata . . . . . 642

populifolia. . . . . 642

MOLINERIA longiflora • . . 3642

recurvata . . . . 5811

MOLLUGO stricta 2115

MOMORDICA Balsamina . . 6615

Charantia . . . . 639

denticulata . . . 167

subangulata . . . . 262

MONENTELES corymbosus . . 4965

MONETIA barlerioides . . . . 6610

MONOCERAS lanceolatum . . 277

leucobotrya . . . . 5666

obtnsum . . . . . . 2897

odontopetalum . . . . 5534

palembanicum . . . . 986

robustum . . . . . . 5002

MONOCHORIA hastæfolia. . 2315

linearis. . . . . 2318

pauciflora . . . . . 2313

vaginalis 912

MONOPHYLLÆA hirtella. . . 7875

MONSTERA cannæformis . . $\quad \mathbf{5 4 8 9}$

MORINDA bracteata . . . . 828

citrifolia . . . . . $8 \% 3$

polyneura . . . . . 2485

rigida . . . . . 217

sarmontosa . . . . 3540

Teysmanniana . . . 5936

umbellata . . . . . 516

Zollingeriana . . . . . 4866

MORINGA polygona. . . . 4 4125

pterygosperma . . . 4125

MOROCARPUS dichotomus . . 4406

longifolius. . . . . 5524.

MORUS indica . . . . . 797

MORUS ? leucophylla . . . . 4837

macroura . . . . . 323

MOSCHOSMA polystachyum . . 832

MUCUNA spec. . . . . . . 486

capitata . . . . 5110

gigantea . . . . 2586

hirsuta . . . . . 7177

monosperma . . . 2585

prurita .
No

cordata 0.5138

recurva . . . . 7245

MUNRONIA javanica . . . . 2556

MURRAYA exotica . . . . 3708

fœtidissima . . . . 4381

sumatrana . . . . . 1723

MUSA alfurica . . . . . 4888

amboinensis . . . . 2325

chinensis . . . . . 6874

glauca . . . . . . 6885

-mindanensis . . . 2325-k of $f_{0}$

ornata . . . . . . 6881

-paradisiaca. . . . 1190 -pisang.

sapientum . . . . . 6877

simiarum . . . . . 1191

MUSSAËNDA sp. div. . . . 577

frondosa . . . . . 74

rufinervis . . . . . 900

Teysmanniana . . . 8308

Wallichiana . . . . 7894

MICROSTYLIS Rheedii •. . 363

MYRIACTIS javanica . . . 5318

MYRISTICA aruana. . . . . 1466

bancana . . . . 5364

colocarpa . . . . . 5537

canariformis . . . . 6526

corticosa . . . . . 137

fatua . . . . . 6510

fragrans . . . . 2631

geminata . . . . . 6581

glabra . . . . . 3623

globularia . . . . . . 3622

Horsfieldli . . . . . 8713

hyposficta. . . . . 4397

intermedia. . . . . 4572

Irya . . . . . . . . 3622

iteopliylla . . . . . 6154

lævigaca . . . . . 885

laurina. . . . . . 2951

leucoxyla . . . . . 3484

iners . . . . . 5171

macrothyrsa . . . 6518

Mandarahan . . . . 5685

palembanica . . . . 3225

Radja . . . . . . 6527

MYRISTICA subglobosa . • 888

sublanceolata . . . . 3357

sycocarpa . . . . 5537

sylvestris . . . . . . 248

succedanca. . . . . . 6525

Teysmanni . . . . 5065

tingens. . . . . . 6515

valida . . . . . 5463

MYRMECODIA echinata . . 3018

tuberosa . . . . 7365 
MYRCINE affinis $\quad$ No. avenis . . . . 4235 sumatrana . . . . 3371

MYRTUS communis . . . . . 1938

MYRTILICOCCUS quercifolius . 6545 MYXOPYRUM nerrosum . . 569

NANIA vera

NANOPETALUM myrianthum

NASTURTIUM indicum . . . officinalc . . . . . .

NAUCLEA sp. . . . . . . aralioides $0^{\circ} \cdot{ }^{\circ} \cdot{ }^{\circ}$

exelsa . . . . . 8751

fagifolia . . . . . 3343

glabra . . . . . 8752

grandifia . . . . . 1417

lanceolata . . . . $\quad 379$

mollis . . . . . . 8753

obtusa . . . . . 8754

oxyphylla . . . . . 2444

parvifolia . . . . . . 969

purpurascens . . . . $346 \mathrm{l}$

NEESIA altissima • . . 1120

NEILLIA thyrsiflora. . . . 2773

NELITRIS alba . . . . . 51

myrsinoides . . . . . 4659

pallescens . . . . . . 3249

parviflora . . . . . 4659

polymorpha . . . . $459 \mathrm{l}$

pyrifolia . . . . . 8798

rubra . . . . . . 51

NELUMBIUM speciosum . . 6712

NEPENTHES ampullacea . . . 4276

Boschiana . . . . 1815

eustachya . . . . 4 4025

gracilis. . . . . . 3664

Korthalsiana . . . . 4277

macrostachya . . . . 1704

melamphora . . . . 1704

phyllamphora . . . . 128

Rafflesiana . . . . 4278

Reinwardtiana. . . . 228

Teysmanniana . . . . 4280

NEPHELAPHYLLUM tenuiflorum . . . . . . 357

NEPHELIUM altissimum . . . 5523

eriopetalum . . . . . 1089

NEPHELIUM lappaceum . . , 6937

Li-tschi . . . . . 4124

Loug-yan . . . . . 5365

mutabile . . . . . 6738

NEPHRODIUM exaltatum . . . 6437

lanuginosum . . . 6442

NEPHROLEPIS davallioides . . 6463 exaltata

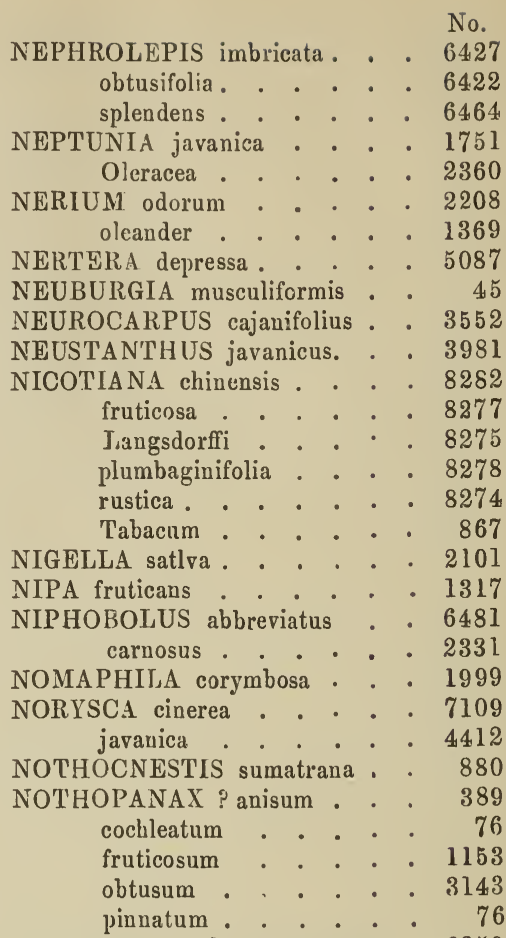

NO'THOPROTIUM sumatranum . 6250

NOTNCHL $2 N A$ piloselloidcs . . 2231

NYCTANTHES arbortristis. . . 7638

NYMPH无A hirta . . . 747

Lotus . . . . . . . 4198

stellata. . . . . . 3765

OCHNA squarrosa . . . . . 6274

OCHTHOCHARIS javanica . . 5899

OCIMUM Basilicum . . . . 4945

canum . . . . . . 8064

gratissimum . . . 1458

sanctum . . . . . . 4998

OCTOMELES sumatrana . . . 1126

ODINA gummifera . . . . . 1990

ENONTHE javanıca . . . . 8587

$\mathrm{OI}_{4} \mathrm{AX}$ obtusa. . . . . . 9154

sumatrana 5329

OLDENLANDIA brachypoda . . 2168

Heynii . . . . . . 2168

hirsuta. . . . . 7910

nudiflora . . . . . 2480

paniculata . . . . . 2173

Teysmanniana. . . . 720

OLEA lancea .. . . . . 4460

OLEANDRA hirtella. . . . 6468 


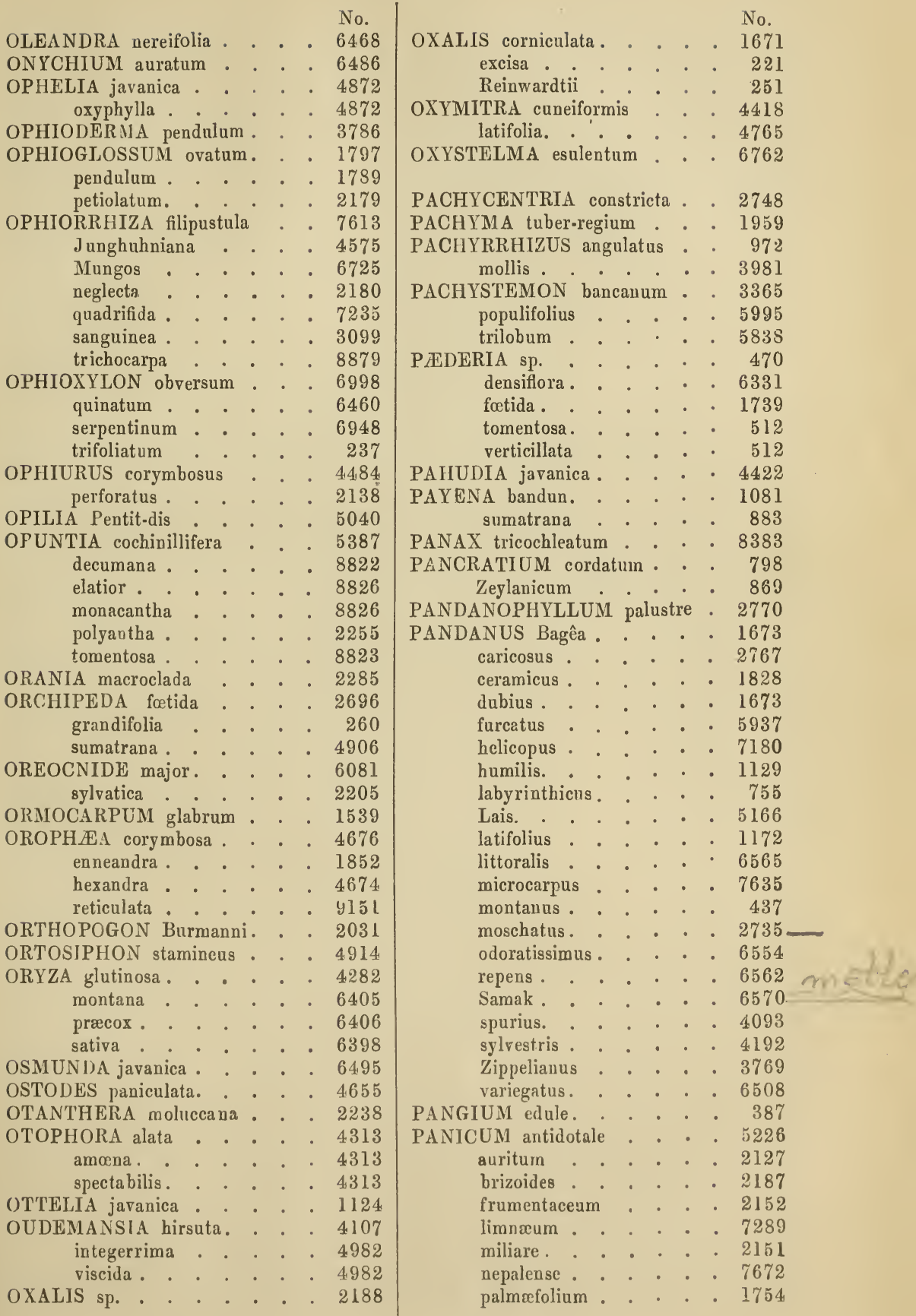




\begin{tabular}{|c|c|c|c|c|c|c|c|c|}
\hline PANICUM prostratum & & & & $\begin{array}{l}\text { No. } \\
998\end{array}$ & PAVETTA incarnata. & & & $\begin{array}{l}\text { No. } \\
1997\end{array}$ \\
\hline rigens. . & . & . & & 2133 & indica. & 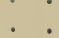 & & 383 \\
\hline tenue. & . & . & & 2139 & javanica & . & & 5999 \\
\hline trigonum & & & & 2193 & lcucoxylon. & . & & 337 \\
\hline PARANEPHELIUM & xesto & phyl & llum & 2445 & macrophylla & . & & 5997 \\
\hline APANAX sessile & & . & & 7992 & montana. & . & & 5998 \\
\hline PARATABOTRYS su & umatr & rana. & & 5797 & nigricans & . & & 8103 \\
\hline PARASPONIA parvifl & lora & . . & & 3179 & odorata . . & . & & 2532 \\
\hline PARATROPIA aroma & atica & . & & 4655 & pulcherrima . & . & & 4004 \\
\hline brachybotrya . & . & . & & 4070 & rosea . . & . & 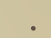 & 8102 \\
\hline a-sylvæ . & . & - & - & 7139 & salicifolia . . & . & & 6335 \\
\hline divaricata. . & . & - & - & 7137 & stricta . . & . & & 4177 \\
\hline elliptica . . & . & . & & $374 \bar{j}$ & subvelutia . & . & & 958 \\
\hline Junghuhniana & . & . & & 3514 & sylvatica . . & & & 4367 \\
\hline littoralis . . & . & . & . & 5547 & PAVONIA zeylanica. . & . . & & 3792 \\
\hline longifolia . & & . & & 1972 & PELIOSANTHES javani & nica . & & 2222 \\
\hline micrantha. & & . & & 7877 & PELLIONIA elatostemoi & oides & & 8878 \\
\hline tica . & . & . & & 7138 & PEMPHIS acidula. . & . . & & 1555 \\
\hline otrya. & • & - & & 7139 & PENNISETUM holcodes & & & 7294 \\
\hline rigida . . & . & - & & 3493 & macrachæton . & . & & 6400 \\
\hline scandens . & . & . & . & 4638 & m. . . & . & & 5181 \\
\hline serrata & & . & & 6589 & PENTAPETES phœnicea & & & 1368 \\
\hline tomen & & . & & 6590 & PEPEROMEA javanica . & & & 7027 \\
\hline PARDANTHUS chiner & ensis & & & 238 & PERGULARIA accedens & & & 5074 \\
\hline PARDINARIUM asper & ervulur & & & 4115 & minor $\cdot$. & - & . & 5651 \\
\hline bosum . & & - & & 4785 & odoratissima . . & - & . & 1390 \\
\hline $\cos$ & • & . & & 84.54 & PLUS incanv & nus . & . & 489 \\
\hline mum . & - & - & . & 4703 & nosus . & - & - & 489 \\
\hline ophyllum & - & - & . & 4409 & PERISTROPHE albiflora & a & - & 1304 \\
\hline multiflorum . & - & - & . & 1321 & pallida . • . & . & . & 7025 \\
\hline polyneurum & - & . & & 2253 & ? salicifolia. & - & . & 2147 \\
\hline scab & . & - & . & 4703 & tinctoria . . & . & . & 95 \\
\hline sumatranum & & . & & 794 & PERNETTIA repens. & . & . & 2637 \\
\hline PARKIA africana. & & . & - & 2565 & PERONEMA canescens. & & . & 4533 \\
\hline intermedia. & & . & & 4073 & PERSEA gratissima . & . & . & 424 \\
\hline carpa & & - & - & 4351 & trana. . & . & . & 889 \\
\hline singularis . & & . & . & 6690 & PETALANDRA micranth & tha . & - & 4666 \\
\hline specios & . & . & . & $67 \varepsilon 0$ & PETUNGA variabilis . & . . & . & 4317 \\
\hline suma & . & . & . & 256 & PHÆANTHUS nutans & . & . & 1350 \\
\hline PARKINSONIA acule & leata & . & . & 3254 & sumatrana. & . & • & 7867 \\
\hline PAROCHETUS comm & nunis & . & . & 7734 & PHAJUS Blumei. & - & & 352 \\
\hline PARSONSIA javanica & & . & & 604 & callosus . . & . & - & 377 \\
\hline PASPALUM sp. & ${ }^{\circ}$ & . & . & - 2116 & PHAL ANOPSIS amabilis & lis . & . & 374 \\
\hline cartilagineum . & & . & . & . 5226 & PHANERA acumiuatissim & ima. & - & 227 \\
\hline mollicomum . & . & . & . & 7272 & lpæfolia . . & . . & - & 226 \\
\hline scrobiculatum. & - & . & . & 9188 & cordifolia . & - & • & 3470 \\
\hline & . & & & 2125 & corymbosa. & - & - & 665 \\
\hline XYLON & porr & & & 3467 & debilis . . & - & . & 684 \\
\hline Pseu & as . & . & . & 2927 & $\mathrm{a} \cdot$. & - & . & 161 \\
\hline PASSIFLORA alata. & & . & - & 5827 & Junghuhniana. & . & . & 605 \\
\hline laurifololia. . & & . & . & 5828 & lingua. . & - & . & 1750 \\
\hline PAVETTA amboinica & & - & $\cdot$ & 101 & purpurea . & . & • & 605 \\
\hline arborescens . & & . & . & 4704 & pyrrhaneura. & & & 208 \\
\hline Bandhuca . & e & . & . & 1991 & scandens . & - & - & 605 \\
\hline coccinea . & . & - & ${ }^{\circ}$ & 4177 & variegata : & . & . & 8222 \\
\hline fulgens . . & & & & 6335 & PHARBITIS hispida. & . & & 506 \\
\hline
\end{tabular}




\begin{tabular}{|c|c|c|c|c|c|c|c|c|}
\hline \multicolumn{3}{|c|}{ PHASEOLUS atropurpurens } & & $\begin{array}{l}\text { No. } \\
3982\end{array}$ & & & & No. \\
\hline caracolla & & & & $\begin{array}{l}3982 \\
3981\end{array}$ & 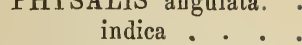 & & & $\begin{array}{l}8804 \\
1682\end{array}$ \\
\hline chrysanthus & & . & - & 3989 & PHYTOCRENE gigantea & ea & & 644 \\
\hline spidulus . & . & . & . & 3989 & macrophylla . & . & & 644 \\
\hline Hernandezii & . & . & . & 3989 & PICRASMA javanica. & . . & . & 4372 \\
\hline lunatus . & . & . & . & 3955 & PIDDINGTONIA monta & $\operatorname{tana.}$ & . & 7794 \\
\hline nanus . & . & . & . & 3908 & nummularia . . & . . & & 8368 \\
\hline radiatus & - & & - & 31 & patens. . . & . & & 8591 \\
\hline trilobus . & . & . & . & 3981 & PIERARDIA dulcis. & - & & 1503 \\
\hline trinervius . & . . & . & . & 3973 & macrocarpa & . & & 4857 \\
\hline vulgaris . & . & . & - & 3946 & pubera. . & - & & 8321 \\
\hline Xuarezii . & . & . & . & 3963 & racemosa. & . & & 1580 \\
\hline HEGOPTERIS fer & & . & : & 6494 & PILEA leucophæa & . & & 6915 \\
\hline HILAGONIA samb & bucius & $1 \mathrm{a}$. & . & 4365 & miconiæfolia & . & & 691 \\
\hline cata. & .. & & . & 4714 & oreophila . . & . & - & 6916 \\
\hline ? euspidata & . & & . & 2894 & pyrrhotricha . & - & & 333 \\
\hline declinata . & - & & . & 2913 & osa . . & - & & 6916 \\
\hline ? holosericea & . & & . & 5529 & MA acidum. & . & & 3471 \\
\hline ? incerta . & . & & . & 2923 & PIMPINELLA Anisum. & . & & 19 \\
\hline lamponga . & - & & - & 2928 & a. . . & • & & 2216 \\
\hline macrophylla & - & & . & 4650 & Pruatjan . & • & & 698 \\
\hline multiflora . & . & & . & 4713 & PINANGA prtula & . & & • \\
\hline ? nitida. . & & & . & 5548 & PINUS Merkusii. & . & - & 3521 \\
\hline parviflora . & . & & . & 2913 & PIPER acre . & . & . & 724 \\
\hline pubescens. & & & - & 2923 & arborescens & , & & 288 \\
\hline rigida . . & & & . & 5581 & muricatum. & . & & 3885 \\
\hline spathulata. & . & & - & 2899 & nigrum!. . & . & & 109 \\
\hline umbelliflora & - & . & - & 4568 & sulcatum . . & . & & 7967 \\
\hline PHENIX Spec. . & - & & - & 5059 & PIPTURUS propinquus. & - & & 4406 \\
\hline Benneltianum & & & . . & 1198 & andus . . & - & & 622 \\
\hline PHENICANTHEML & UM & long & & & velutinus . & - & & 539 \\
\hline & . . & . & . & 1208 & PISONIA alba . & . & & \\
\hline petalum & & & . & 3185 & anisophylla & . & & 886 \\
\hline HOLIDOCARPUS & Ihur & r. : & - & 2995 & excelsa. & . & . & 4773 \\
\hline PHOBEROS $\mathrm{m}$ & & . & . & 7257 & sylvestris . & . & . & 1603 \\
\hline urghii & & & & 7259 & villosa . & • & & 573 \\
\hline PHOTINOPTERIS & Hors & sfieldi & & 6422 & PISTIA Stratiotes & . & & 1669 \\
\hline PHRAGM & ormis & . & . & 3901 & PISUM sativum . & . & . & 7038 \\
\hline ghii. & . . & & . & 2528 & PITHECOLOBIUM acu & atangul & & 1992 \\
\hline PRYNIUI & . & . & - & 5427 & tnm. . & . $\quad \cdot$ & & 199] \\
\hline capitatum. & - & . & - & 350 & ium . & - & & 2 \\
\hline densiflorum & . & & . & 391 & clyp & . & & \\
\hline um. & . & - & . & 4979 & fagifolium . & - & & \\
\hline Houtteannm & - & & . & 668 & fasciculatum . & . & & \\
\hline latifolium . & . & & . & 6683 & Junghuhnianunı . & . & & \\
\hline obscurum . & - & & . & 5275 & lobatum . . & . & & 19 \\
\hline sumatranum & & & . & 5276 & montanum. & - & & 4443 \\
\hline villosulum . & & & & 3053 & oppositum . & & . & 1993 \\
\hline PHYLLAGATHIS $\mathrm{rC}$ & otund & difolia & & 6997 & rostratum . & . & . & 6691 \\
\hline PHYLLANTHEPA & bifida & & . & 517 & umbellatum . & . & . & 2086 \\
\hline PHYLLANTHUS N & Turiri & & . & 71 & PITTOSPORUM chelido & & & 8253 \\
\hline oxyphyllus. & & & . & 224.1 & densiflorum . & & & 4460 \\
\hline gulari & & & . & 6061 & hii . . . & & & $3]$ \\
\hline & & . & - & 70 & HERA oppos & sitifolia & & 455 \\
\hline M eleg & rans. & & • & 2656 & UM sumat & tranum & & \\
\hline pulchellum & & & & . $\quad 425$ & PLANCHONIA sundaica & & & 6990 bis \\
\hline
\end{tabular}




\begin{tabular}{|c|c|c|c|c|c|c|c|}
\hline PLANTAGO incisa & & & $\begin{array}{l}\text { No. } \\
4936\end{array}$ & POLYADENIA gemmiflor & & & $\begin{array}{l}\text { No. } \\
2899\end{array}$ \\
\hline major . . . & & . & 1765 & grandifolia. . & . & . & 2654 \\
\hline PLATANTHERA Susan & & . & 377 & grandis. . & . & . & 4717 \\
\hline PLATEA excelsa. . & & . & 2233 & lucida & - & . & 2921 \\
\hline latifolia $\cdot$ • & & . & 2233 & macrophylla & - & . & 2899 \\
\hline PLATYCENTRUM robu & & & 730 & pepericarpa & . & . & 402 \\
\hline rupicolum . . & & . & 8621 & polyantha. & - & . & 2894 \\
\hline tenuifolium . & - & . & 8621 & salicifolia . . & . & & 6936 \\
\hline Teysmannianum . & . & . & 7224 & subumbelliflora & . & & 2912 \\
\hline PLATYCERIUM alcicorr & ne. & . & 6532 & POLYGALA densiflora & . & - & 2148 \\
\hline LECTOCOMIA elongat & & - & 1298 & glomerata . & - & - & 2148 \\
\hline sumatrana. . & & . & 7994 & javana. . & . & & 5385 \\
\hline LECTRANTHUS javan & aicus & . & 7595 & Simassan . & . & - & 7904 \\
\hline tus & . & . & 3098 & sumatrana. & • & . & 3292 \\
\hline PLOCOGLOTTIS javanic & & . & 372 & venenosa . . & . & & 4029 \\
\hline PLOIARIUM elegans . & • & - & 5635 & POLYGONUM barbatum & . & . & 2126 \\
\hline ? oblongifolium . & . & . & 967 & chinense . . & . & & 1822 \\
\hline PLUKENETIA cornicula & ata. & - & 674 & erythrodes. & & . & 6582 \\
\hline PLUMBAGO rosea . & & . & 114 & orientale. & & . & 1969 \\
\hline PLUMERIA acutifolia . & & . & 1364 & perforatum & . & . & 2434 \\
\hline POA amboinensis. . & & - & 2957 & Posumbu. & . & . & 1004 \\
\hline PODOCARPUS amara. & & . & 3366 & runcinatum & . & . & 6585 \\
\hline bracteata . & & . & 39 & tomentosum . & . & . & 7304 \\
\hline cupressina. & & . & 2820 & POLYOSMA fragrans & & . & 3498 \\
\hline discolor . . & . & . & 4631 & ilicifolia & . & . & 4490 \\
\hline eurhyncha. . & & . & 7619 & integrifolia & & . & 423 \\
\hline Junghuhniana & & . & 4566 & mutabilis . & . & . & 1423 \\
\hline latifolia . . & . & . & 3366 & velutina . . & . & . & 4482 \\
\hline neglecta . & & . & 4566 & POLYOZUS acuminata. & . & . & 4378 \\
\hline polystacha. & & & 4631 & latifolia. . . & & . . & 558 \\
\hline Rumphii . & & & 39 & GMON comp & press & sicaule & 8285 \\
\hline Teysmanni. . . & & e & 7891 & hydrangeæfolium . & $\cdot$ & .. & 6930 \\
\hline PCECILOPTERIS diversi & ifolia & & 6468 & sericeum . . & . & . & 129 \\
\hline lita . . & & . & 6500 & POLYPODIUM dipteris. & . & - & 6485 \\
\hline HERA pulv & gerule & enta & 2740 & . . . . & - & . & 6491 \\
\hline NATHERUM crin & itum & & 2165 & glabrum . & . & . & 6469 \\
\hline POGONOTROPHE aura & antiac & & 4368 & irregulare . & - & - & 6442 \\
\hline flavidula . . & . & . & 2686 & laciniatum. & . & . & 3537 \\
\hline javana. & . & . & 306 & lineare. . & . & . & 6433 \\
\hline lævis . . & • & - & 607 & nigripes . & . & . & 6436 \\
\hline phæopoda . & . & . & 446 & phymatodes & . & • & 6499 \\
\hline piperifolia. & . & - & 607 & pteropus. & - & - & 6500 \\
\hline & - & - & 607 & pustulatum . & - & . & 6453 \\
\hline atrana. . & . & . & 4348 & quercifolium . & - & . & 181 \\
\hline POGOSTEMON auricula & aria & . & 1443 & simile . . . & . & . & 6425 \\
\hline sus . . . & . & . & 1858 & vioscidum . . . & . & . & 6420 \\
\hline cristatus . & . & . & 1858 & POLYPORUS amboinensi & sis . & . & 4895 \\
\hline fraternus. & . & . & 1858 & PONGAMIA ? corollaria & a & . & 60 \\
\hline gracilis. . & & - & 1858 & grandifolia. . . & . & . & 1257 \\
\hline menthoides & & . & 1858 & volubilis . . & . & . & 8897 \\
\hline tomentosus . & • & . & 1858 & PORANA volubilis . & . & - & 9232 \\
\hline POLANISIA viscosa & . & & 1287 & PORTULACA oleracea. & & . & 2479 \\
\hline POLYALTHIA elliptica & & - & 4765 & PORTULACA quadrifida & & & 2482 \\
\hline & . & - & 4767 & POTAMOGETON natan & & . & 1195 \\
\hline data. & . & & 915 & POTHOMORPHE subpe & & & 86 \\
\hline POLYANTHES tuberosa & - & & $419_{0}$ & POTOS gracilis . . & •. & • & 5654 \\
\hline
\end{tabular}




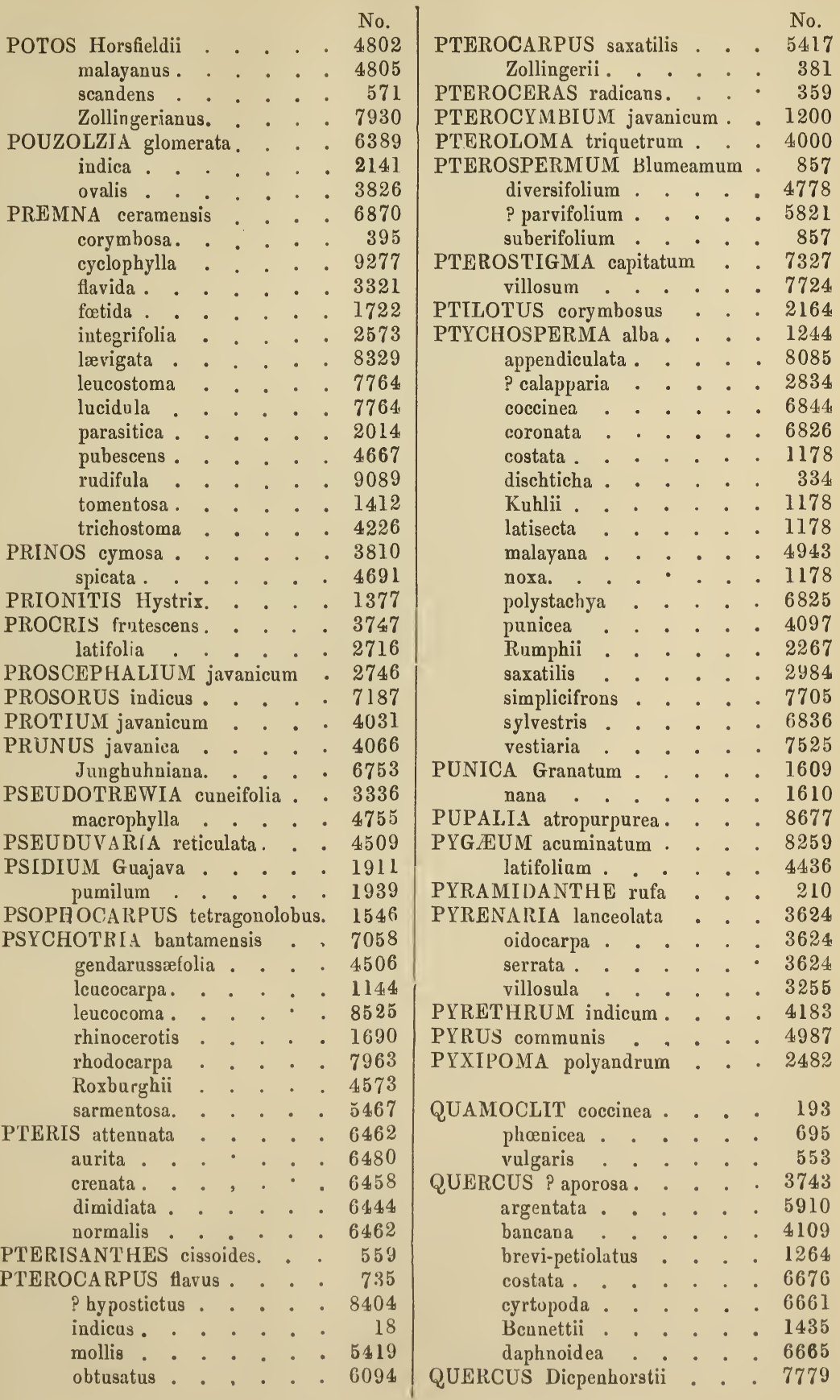




\begin{tabular}{|c|c|c|c|c|c|c|c|c|}
\hline & & & & No. & & & & No. \\
\hline $\begin{array}{l}\text { fagiformis. } \\
\text { f. }\end{array}$ & & & & $\begin{array}{l}7779 \\
4322\end{array}$ & $\begin{array}{l}\text { RHODAMNIA spectabilis } \\
\text { RHODODENDRUM citrin }\end{array}$ & aum & & $\begin{array}{l}1128 \\
5856\end{array}$ \\
\hline gemelliflora & . & : & . & $\begin{array}{l}\text {. } \\
. \quad 6322 \\
. \quad 6664\end{array}$ & $\begin{array}{l}\text { RHODODENDRUM citrin } \\
\text { javanicum. }\end{array}$ & . & & $\begin{array}{l}5806 \\
2361\end{array}$ \\
\hline glutinosa. & . & . & . & . 6670 & multicolor. . & . & . & 3859 \\
\hline Horsfieldii . & . & . & . & 4071 & tubliflorum. . . & . & & 8745 \\
\hline hypoleuca . & . & . & . & 6601 & RHODOI.EIA Teysmanni & . & . & 3206 \\
\hline induta. . & - & . & . & 4618 & RHODOMYRTUS tomento & & & 2739 \\
\hline infectoria .: & - & . & . & 5866 & RHOMBOSPORA Comme & erson & & 7635 \\
\hline Junghuhnii & - & - & . & 5759 & RHUS nodosa. . . . & . & - & 3144 \\
\hline lineata. . & - & . & . & 379 & pubiger. & . & & 3143 \\
\hline littoralis . & . & . & . & 6671 & retusa. & . & . & 3146 \\
\hline mappacea . & . & . & - & 3162 & rufa . . & . & . & 3294 \\
\hline miqueliana. & . & . & . & 310 & succedanea. . & . & & 7022 \\
\hline molucca & . & . & . & 109 & RHYNCHOSIA viscosa . & . & & 3940 \\
\hline nenrophylla & . & . & . & 7179 & RHYNCHOSPERMUM & rertic & cil & \\
\hline oxyrhyncha & - & - & - & 3402 & tum. $\cdot$. & . & & 4641 \\
\hline pinanga. . & . & . & . & 6663 & RHYNCHOSPORA aurea & & & 3003 \\
\hline pruinosa . . & . & . & - & 6665 & Wallichiana & & & 1282 \\
\hline Pseudo-molucca & a . & . & - & 4385 & RHYNCHOTHECUM par & iviflo & orum & 8663 \\
\hline Rassa . . & . . & . & . & 7181 & RICINUS communis. & . & & 1975 \\
\hline rotundata & - & - & . & 6660 & inermis. . & . & & 1979 \\
\hline serisea . . & - & - & - & 310 & ruber . . . & • & & 1977 \\
\hline spicata. . & . & . & . & 4619 & rugosus . . & . & & 1977 \\
\hline sundaica . & . & . & . & 4477 & spectabilis. . . & . & & 1978 \\
\hline thelecarpa . & - & . & - & 6666 & RIEDLEIA eoncatenata. & . & & 7849 \\
\hline turbinata. & . & . & . & 310 & RIVINA purpurascens. & . & . & 7161 \\
\hline Teysmannii . & • & - & . & 6601 & ROSA centifolia... & . & . & 4140 \\
\hline QUISQUÄLIS indica & & . & . & 3224 & $\begin{array}{l}\text { damascena. } \\
\text { ROSTELLULARIA diffisa }\end{array}$ & . & & $\begin{array}{l}\text {. } 4141 \\
\text {. } 1117\end{array}$ \\
\hline RAFFIESIA Arnoldi & & . & - & 273 & ROTTBOELLIA exaltata & . & & - 2138 \\
\hline Patma . . & & . & - & 6711 & muricata . . & . & . & 2152 \\
\hline Rochussenii & & . & - & 7081 & ROLTLERA acuminata. & . & & 2813 \\
\hline RANDIA scandens. & & . & . & 630 & acutifolia . . & . & & 8385 \\
\hline RANUNCULUS diffus & sus & - & • & 344 & affinis . . & . & . & 1201 \\
\hline APHANUS candatus & & & . & 5437 & alba . & . & . & 901 \\
\hline sativus . . & & & . & 7099 & dispar . . . & . & . & 8211 \\
\hline RAPHIDOPHORA di & lichot & toma & & 9046 & ferruginea. . & . & . & 906 \\
\hline RAPHISTEMMA Hoo & operi & ianun & & 693 & flavigutta. & . & . & 3207 \\
\hline RAVENALA madagaso & scarie & ensis & & 6872 & floribunda. & . & . & 5837 \\
\hline REMUSATIA vivipara & ca . & & - & 3132 & hispida.. . . & . & - & 2671 \\
\hline RENANTHERA arach & hnite & & - & 362 & macrostachya . & - & . & 4123 \\
\hline matutina . & & - & . & 5388 & paniculata. . & . & & 908 \\
\hline moluccana . & & & & 370 & rhynchophylla. & - & . & 3390 \\
\hline RHAPHIDOSTIGMA & $\mathrm{Zol}$ & llinge & erii . & 4501 & scabrifolia. . & . & . & 7919 \\
\hline RHAPIS javanica. & . & & & 9157 & sphærocarpa . & - & . & 6594 \\
\hline RHEITRÖPHYLLUM & I sul & bvert & tici- & & Zippelii. . . & . & . & 907 \\
\hline latum . & & & 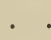 & 350 & ROUREA acutipetala & . & . & 8507 \\
\hline RHEUM palmatum . & & & . & 4846 & florida . . . & . & - & 8507 \\
\hline RHINACANTHUS CO & ommu & unis & & 240 & ROUREOPSIS javanica. & • & . & 648 \\
\hline RHINOSTIGMA macr & croph & ayllun & & 7716 & ROXBURGHIA javanica & - & . & 1534 \\
\hline parvifolium . & & 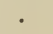 & & 3750 & RUBIA cordifolia. . & • & & 2380 \\
\hline RHIZOPHORA conjug & gata & & • & 865 & RUBUS acuminatissimus. & . & - & 139 \\
\hline . . . & . & - & • & 247 & alceæfolius. & . & & 24,46 \\
\hline & & • & & 868 & alpestris . & - & & 7228 \\
\hline RHODAMNIA cinera & . & & . & 5801 & elongatus . & - & . & 2774 \\
\hline concolor . . & & - & & 5801 & fraxinifolius . . & - & & 1122 \\
\hline
\end{tabular}




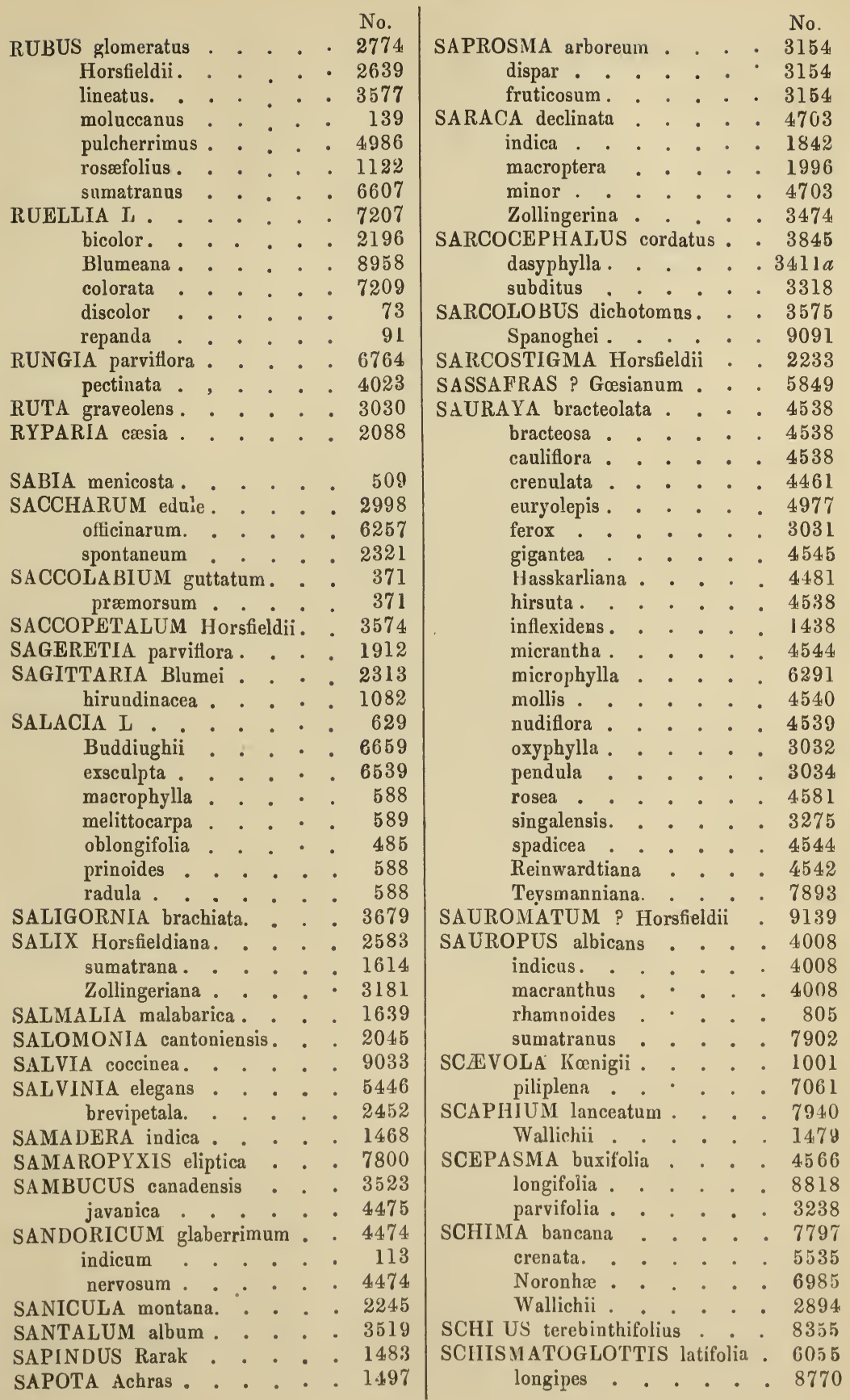




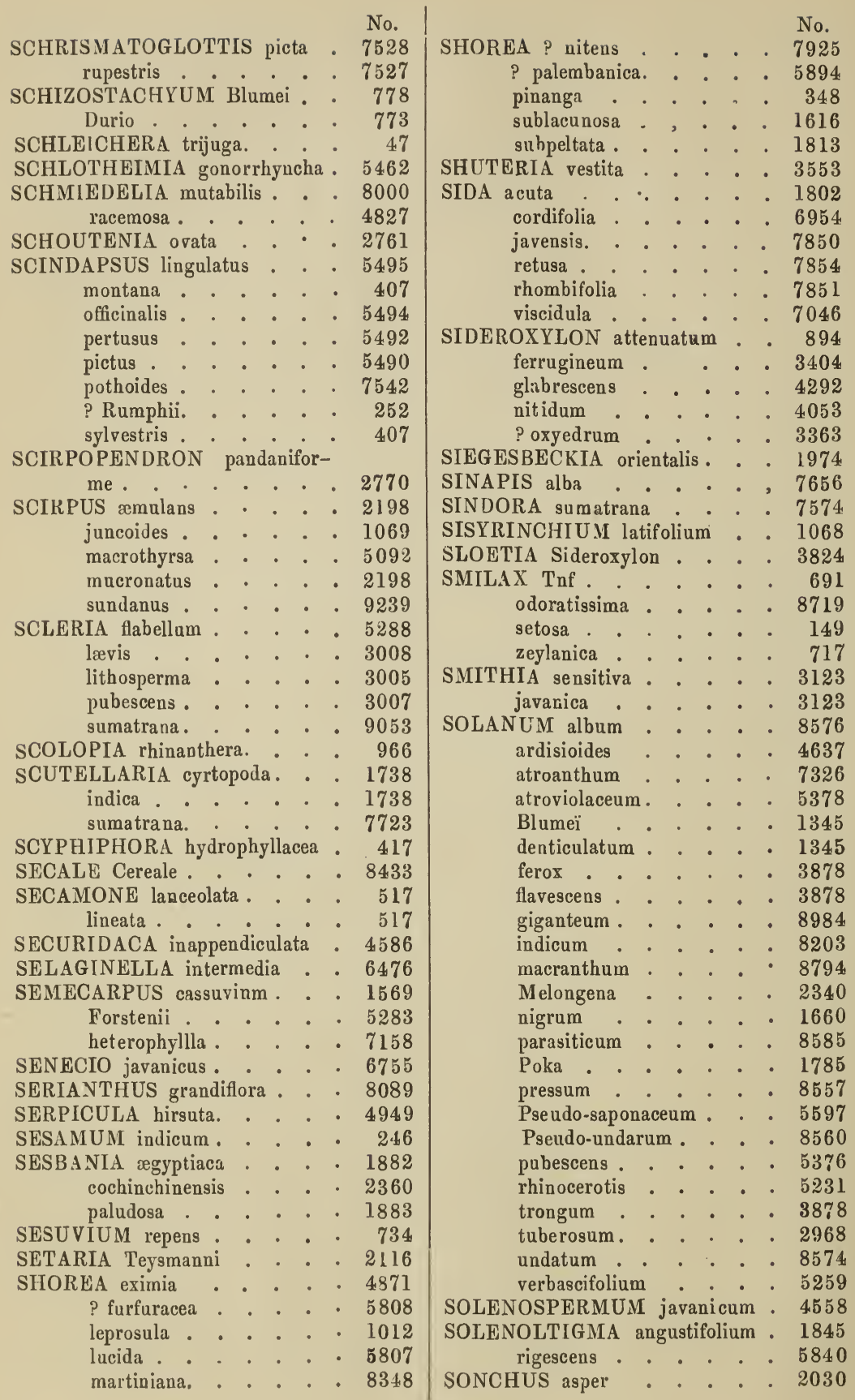




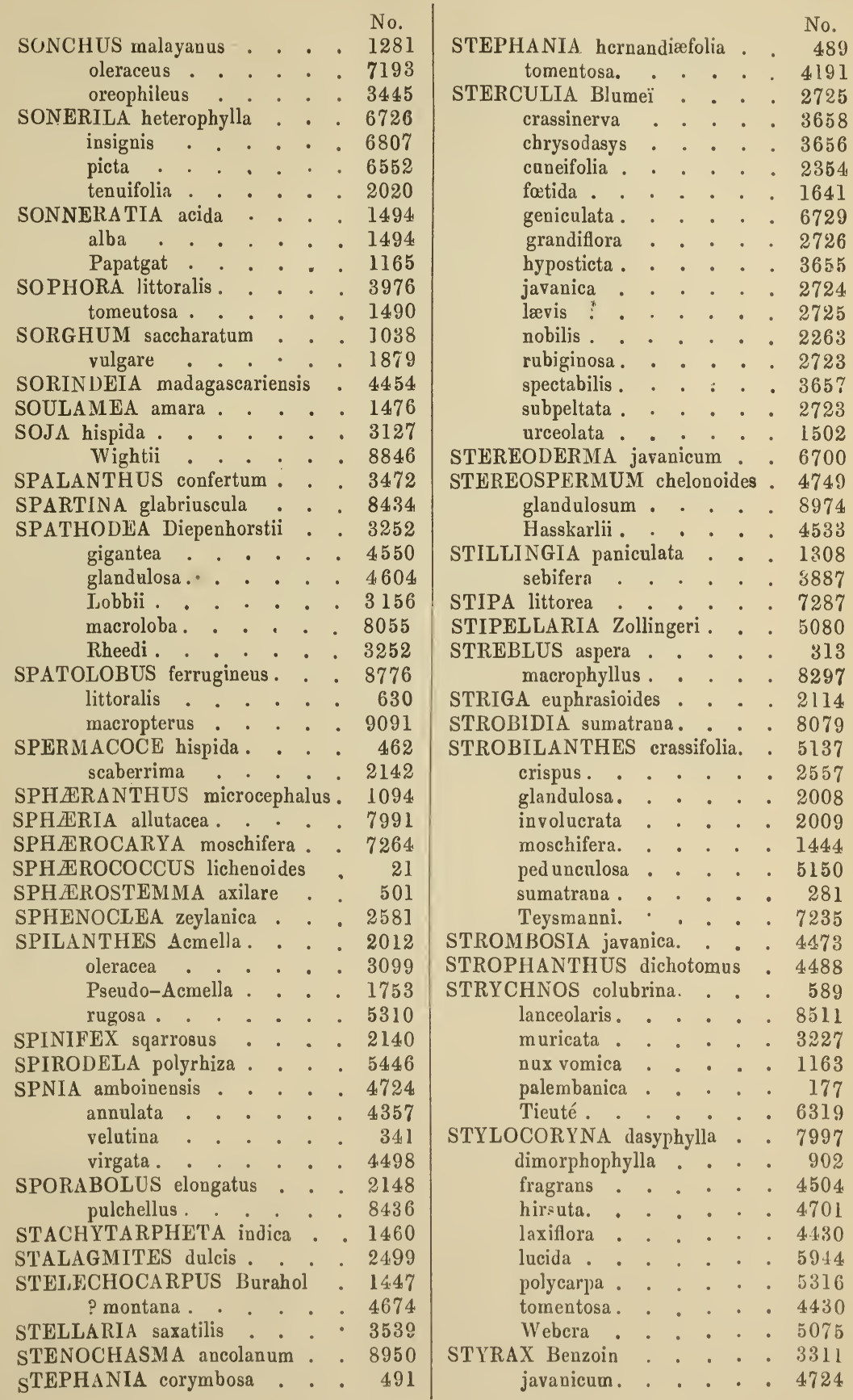




\begin{tabular}{|c|c|c|c|c|c|c|c|c|}
\hline \multirow{2}{*}{\multicolumn{2}{|c|}{$\begin{array}{l}\text { STYRAX subdenticulata. } \\
\text { villosum . }\end{array}$}} & & & $\begin{array}{l}\text { No. } \\
\text {. } 3311\end{array}$ & TAGETES patula . & & & $\begin{array}{l}\text { No. } \\
8155\end{array}$ \\
\hline & & - & . & . 4724 & TALAUMA Candollii & . & & 4651 \\
\hline SUEDA indica. & & . & . & 266 & gigantifolia. . & - & & 960 \\
\hline SUFFRENIA dichotor & & - & . & 7332 & mutabilis . & - & . & 4199 \\
\hline SUREGAI)A lanceolat & & . & . & 3403 & pumila. . & . & • & 8704 \\
\hline SUSUM anthelminthic & cum & . & . . & 870 & rubra . . & - & • & 5577 \\
\hline SYMPHYSICARPUS & chry & & & 3843 & TALAUMA Rumphii, & - & • & 7029 \\
\hline SYMPLOCOS fascicul & lata & . & . . & 2091 & Sebassa & . & . & 7844 \\
\hline ferruginea . & & . & - & 4234 & villosa . . & - & . & 8710 \\
\hline iteophylla . & & . & . & 3490 & TAMARINDUS indica & - & . & 732 \\
\hline lachnobotrya. & & - & . & 3269 & TARAKTOGENOS Blum & & . & 1045 \\
\hline odoratissima. & & - & . & 4612 & TARRIETIA javanica . & .. & . & 4563 \\
\hline repandula. & & . & . & 3755 & TAXOTROPHIS javanica & & . & 6548 \\
\hline spicata. . & & . & . & 5311 & Roxburghii . & . & - & 4868 \\
\hline SYNECIA diversifolia & . & - & - & 418 & TECTONA grandis . . & - & . & 2013 \\
\hline falcata . . . & & . & . & 609 & TELANTHERA strigosa & a . & . & ] 636 \\
\hline SYZYGIUM brachybot & tryur & & . & 3190 & TERMINALIA adenopod & & . & 3306 \\
\hline caryophyllifoliu & & - & - & $19] 0$ & Catappa . . & •. & - & 7 \\
\hline n. & & . & . & 4742 & chebula . & & . & 3905 \\
\hline euneuron & & - & . & 5238 & laurinoides. . & & . & 2212 \\
\hline jambolanum . & & . & . & 1906 & nollis . . . & • & . & 3907 \\
\hline icum . . & - & - & . & 3486 & moluccana. & - & - & 3912 \\
\hline laxiflorum. & & & - & 4363 & sumatrana. & & . & 3913 \\
\hline minutiflorum . & . & & . & 3290 & sylvestris . . & & . & 3911 \\
\hline arpum. & . & & . & 3290 & TERNSTREMIA aneura & & - & 6818 \\
\hline & - & - & . & 5847 & bancana . & . & . & 5863 \\
\hline nicum. & . & - & . & 7516 & coriacea & . & . & 5896 \\
\hline Pseudo-jambol & anur & & . & 6184 & patens . . . & • & - & 1607 \\
\hline im. . & . & 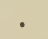 & - & 4686 & TETRACERA L. . & • & - & 546 \\
\hline rialatum . & - & . & - & 6023 & lævigata . & - & . & 5603 \\
\hline tum . & - & . & . & - 4722 & rigida $\cdot$ & & & 146 \\
\hline sum . & 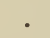 & - & - & $6990 \mathrm{bis}$ & scaberrima & & . & - $\quad 145$ \\
\hline arrens . & . & & . & . 7518 & TETRACTINOSTIGMA & micr & & yx 7662 \\
\hline dosum. & . & - & . & . $\quad 3287$ & 'TETRAMELES nudiflor & a. & . & 1301 \\
\hline subtile. . & - & - & . & . 3063 & rufinervis . . & . & . & 2723 \\
\hline variifolium . & - & & . & . 7548 & TETRAMERISTA glabre & a . & . & 1485 \\
\hline Zippelianum . & & & . . & 2236 & TETRANDRA Zollingeri & iana & - & . $\quad 665$ \\
\hline & & & & & THERA alnoid & & - & - 2578 \\
\hline TABERN & & coro & naria & 264 & . . . & • & . & - 2896 \\
\hline ana. & & . & . & 4160 & angulata & . & - & 2921 \\
\hline fagr & • & & . & 3090 & bancana & • & - & 5569 \\
\hline nda. & & & . & 8077 & Brassas. . & • & . & 1559 \\
\hline & • & & . & 261 & capitulata . . & • & . & 3362 \\
\hline ora . & 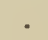 & & - & 8078 & chrysopleura . & . & - & 2894 \\
\hline alis . & . & & . & 882 & citrata. . & . & - & 401 \\
\hline pauciflora. . & . & & . & 4164 & Dengek. •. & . & - & 2898 \\
\hline iophylla & . & . & . & 7781 & Diepenhorstii . & - & . & 6935 \\
\hline pa. & . & $\cdot$ & $\cdot$ & 2035 & elliptica . . & • & . & 2916 \\
\hline tenu & 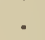 & & 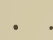 & 7610 & Forstenii . & . & . & 2670 \\
\hline TACCA cristat & . & & . & 6924 & intermedia. & • & . & 4394 \\
\hline lanceæfolia & • & & . & 4914 & lucida . . & & . & 2900 \\
\hline palmata . & & . & . & 825 & macrocarpa & . & - & 2922 \\
\hline pinnatifida. & • & $\cdot$ & $\cdot$ & $6] 05$ & mappacea . & • & - & 3822 \\
\hline Rumphii . & & & . & 2271 & Merawas . & • & . & 5551 \\
\hline lechnoides & 3 & . & $\cdot$ & 6434 & Mogol. . & • & . & 2930 \\
\hline GETES erecta. . & & . & . & 8155 & monopetala & & & 2323 \\
\hline
\end{tabular}




\begin{tabular}{|c|c|c|c|c|c|c|c|c|}
\hline & & & & $\begin{array}{l}\text { No. } \\
\mathbf{5 5 3 3}\end{array}$ & TRICHOSANTHES $\mathrm{t}$ & trifoliat & & $\begin{array}{c}\text { No. } \\
262\end{array}$ \\
\hline oppositifolia & & & . & 1532 & villosa. . & Hillot & & 444 \\
\hline Pantjara. & ( & . & . & 2942 & TRICHOSPERMUM & jarani & cum & 2265 \\
\hline polyantha. & . & & - & 5313 & TRIDESMIS formosa & . & & 4215 \\
\hline resinosa. & . & - & - & 2909 & TRIGONELLA Fœnu & am-græ & enum & 9183 \\
\hline Rumphii . & . $\cdot$ & - & . & 2323 & TRIGONIASTRUM h & nypoleu & cum & 3243 \\
\hline ? subovata. & & & . & 5545 & TRIPHASIA sarmento & osa. & & 3639 \\
\hline varians. . & . & . & . & 3208 & trifoliata & . & - & 4590 \\
\hline TEUCRIUM viscidu & & • & - & 7311 & TRISTANIA obovata & . & . & 6534 \\
\hline TEYSMANNIA alti & frons & . & - & 1110 & TRITICUM valgare. & . & & 2414 \\
\hline THALICTRUM gly & phocar & pum & & 4127 & TRIUMFETTA cana & - & . & 2593 \\
\hline HEA chinensis . & & & & 8598 & villosinscula . & . . & . & 7047 \\
\hline cochinchinens & & & - & 8598 & TROOSTWYKIA sing & gularis & & 3427 \\
\hline THEOBROMA Cac & & . & . & 3556 & TURNERA ulmifolia. & . . & . & 7303 \\
\hline THESPESIA macro & phylla & . & . & 854 & TURPINIA sphæroca & irpa & . & 994 \\
\hline populnea . & & & & 9179 & TURR无A trichostyla & . & & 7817 \\
\hline HEVETIA nercifo & & & . & 2522 & TYLOPHORA cissoid & les . & & 647 \\
\hline THORACO & $\mathrm{ON}$ su & mat & & um 7728 & cuspidata . & . & . & 647 \\
\hline THUNBERGIA java & anica & & . & . $\quad 642$ & tenuis. . & . & . & 642 \\
\hline THYSSANOL正NA & acarif & & & 8363 & villosa & . & . & 537 \\
\hline TILIACORA acumir & nata. & . & - & 570 & TYPHA augustifolia . & . & . & 738 \\
\hline TIMONIUS Rumphi & & - & . & 3217 & TYPHONIUM cuspid & latum. & . & 441 \\
\hline TINOSPORA crispa & & & . & 191 & color. & - & . & 6999 \\
\hline TODDALIA aculeat & & & - & 182 & divaricatum . & • & • & 1236 \\
\hline micracantha & . & . & . & 487 & Reinwardtianur & & & 7575 \\
\hline TORENIA asiatica & & & . & 4105 & & & & \\
\hline edentula & & & & 4875 & ULVA javanica & . & • & 7298 \\
\hline TORILIS Antriscus & & & . & 278 & UNCARIA acida. & . & . & 1702 \\
\hline TOURNEFORTIA & argent & & & 3884 & eurhyncha. & - & . & 1135 \\
\hline Horsfieldii . & & & & 382 & ferruginea . & - & . & 165 \\
\hline TOXOCARPUS Bli & mei . & & & 450 & Gambir . & . & . & 2388 \\
\hline macrophyllus & & & & 450 & glabrata . & . & - & 165 \\
\hline TRADESCANTIA & capitata & & . & 2130 & lanosa. . & . & . & 27 \\
\hline TRAGIA hirsuta. & $\cdot$. & . & . & 1326 & pedicellata. & . & . & 3160 \\
\hline TRAPA cochinchina & nsis . & . & - & 6016 & UNONA dasymaschala & a. & . & 514 \\
\hline quadrispinosa & & & . & 6016 & discolo & - & • & 187 \\
\hline TREVESIA molucce & ana . & $\bullet$ & . & 78 & sumatrana & . & - & 5586 \\
\hline & & 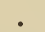 & . & 4404 & virgata. & . & & 3416 \\
\hline TREWIA nodiflora & & & & 1202 & URARIA crinita . & . & & 1442 \\
\hline TRIANTHEMA per & atandre & & & 6114 & lagopoides . & . & . & 2290 \\
\hline & & & . & 2479 & obcordata. & . & & 833 \\
\hline TRICHOLOBUS fu & lvus. & . & . & 811 & picta . & . & . & 1442 \\
\hline ANTHES & augui & & & 1108 & URENA Blumeï . & . & • & 7853 \\
\hline cea . & . . & . & . & 204 & lappago & . & . & 314 \\
\hline ata. & . & . & . & 62 & heterophylla & . & . & 7047 \\
\hline $\mathrm{g}$ & . & . & . & 47. & & . & . & 5290 \\
\hline erma & . & . & . & 644 & UROPHYLLUM cori & aceum & & 3281 \\
\hline & . & 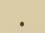 & . & 1107 & mbosum. & . & • & 2915 \\
\hline niosa . & & & . & 521 & glabrum . & . & & 4761 \\
\hline carpa & - & - & . & 519 & peltistigma. & - & • & 6794 \\
\hline ovigera. . & . & • & . & 685 & umbellatum & & . & 3246 \\
\hline pilosa . & . & $\bullet$ & . & 523 & UROSTIGMA acampt & tophyll & lum & 5916 \\
\hline pubera. . & - & • & • & 482 & altissimum. & - . & - . & 3237 \\
\hline grandiflora. & - & & & 204 & annulatum & . & . & 1353 \\
\hline pidata & . & & $\cdot$ & 521 & balicum .. & . & . & $14: 30$ \\
\hline tricuspis . & & & & 8627 & benghalense & & & 790 \\
\hline
\end{tabular}




\begin{tabular}{|c|c|c|c|c|c|c|c|c|c|}
\hline STIGMA benjar & $\operatorname{minu}$ & & . & $\begin{array}{l}\text { No. } \\
\text {. } 1565\end{array}$ & UROSTIGMA virgatum & & & & $\begin{array}{l}\text { No. } \\
4324\end{array}$ \\
\hline bicorne. & . . & . & . & . 1324 & Wightianum & . & . & . & 4345 \\
\hline Binnendyki & . & . & - & - 4325 & xylophyllum . & . & . & . & 4321 \\
\hline biverrucellum & n. & - & - & - 4963 & URTICA ? ovalifolia & - & . & . & 1663 \\
\hline calophyllum & . & - & - & - 4350 & UVARIA acrantha . & . & - & . & 5278 \\
\hline canaliculatum & n. & . & . & . 7072 & argentea . & - & . & - & 573 \\
\hline chrysothrix & - & - & - & 4323 & astrosticta . & - & - & - & 1002 \\
\hline clusioides & . & - & - & 4345 & concava. . & . & - & - & 573 \\
\hline consociatum & - & - & . & - 4334 & dulcis . . & - & . & - & 170 \\
\hline cordifolium & · & - & . & . 5006 & flava. & . & - & - & 5401 \\
\hline crassirameum. & a. & . & . & - 3748 & hirsuta . & - & . & . & 212 \\
\hline cuneatum . & - & - & . & . 9170 & Laha . . & - & - & - & 184 \\
\hline cycloneurum . & - & - & . & - 6969 & Larep . . & . & - & - & 213 \\
\hline depressum . .. & . & . & - & . 8961 & macrophylla & . & . & . & 222 \\
\hline Diepenhorstii & i. & . & - & 5412 & ovalifolia . & . & - & - & 197 \\
\hline elasticum . & - & - & - & 2440 & purpurea . & . & - & - & 573 \\
\hline euneuron . & . & - & - & - 4323 & rufa. & . & . & - & 3574 \\
\hline excelsum . & . & . & . & - 4352 & rugosa . & . & . & . & 4674 \\
\hline flavescens . & - & - & - & . 1314 & timoriensis & . & - & . & 4510 \\
\hline giganteum. & - & . & . & . 4345 & & & & & \\
\hline glabellum. & . & . & . & - 2504 & VACCINIUM bancanur & & - & . & 4227 \\
\hline g!aberrimum . & - & - & - & . 4351 & coriaceum . & & . & . & 4513 \\
\hline globosum . & - & - & . & . $\quad 3245$ & floribundum . & . & . & . & 8746 \\
\hline hæmatocarpum & m & - & - & . 1875 & lucidum . & $\cdot$ & . & - & 8748 \\
\hline Hasseltii . & - & . & . & 2464 & malaccense. . & . & . & . & 138 \\
\hline infoctorium . & - & . & - & . 5435 & varingiæfolium & . & • & . & 2836 \\
\hline involucratum. & . & - & - & . 4351 & VAHEA gummifera . & - & . & - & 484 \\
\hline Karet . . & - & - & - & . 2504 & VALERIANA javanica & . & - & . & 4952 \\
\hline lucescens . & . & . & . & . 5435 & VALLARIS laxiflora. & - & . & . & 700 \\
\hline macrocarpum . & . & - & . & . 7072 & ovalis . . & - & . & . & 9021 \\
\hline microcarpum . & . & - & . & - 4332 & pergulana. & - & . & - & 3865 \\
\hline mysorense. . & . & . & . & . 4323 & VANDA furra . & . & . & . & 364 \\
\hline nervosum . & . & . & . & 1080 & lissochiloides & . & . & . & 367 \\
\hline nitidum & . & - & - & 855 & VANDELLIA crustacea & & - & . & 2155 \\
\hline obtusifolium & . & - & . & 2393 & ellobum . . & . & . & . & 9244 \\
\hline obversum . & . & . & . & - 4345 & nervosa & . & . & • & 2119 \\
\hline odoratum . & . & - & - & - 6112 & obtusa. . & . & . & . & 2155 \\
\hline pilosum . & - & - & - & 1324 & sphærocarpa . & . & . & . & 2582 \\
\hline pisicarpum & . & . & . & 8768 & stemodioides . & . & - & - & 7285 \\
\hline procerum . & - & - & . & 2442 & VANGUERIA dicocca & . & . & . & 4417 \\
\hline pruniforme . & . $\cdot$ & . & . & 4327 & latifolia . . & . & . & . & 1907 \\
\hline Pseudo-rubrur & um . & . & . & 4344 & lucidula . & . & . & . & 8512 \\
\hline pyrifolium. • & - $\cdot$ & - & - & 4349 & palembanica & . & . & . & 3215 \\
\hline religosum . & . & - & - & 1430 & spirostylis . & • & . & . & 5478 \\
\hline retusum . & . & - & - & 1324 & VANILIA albida. & • & . & . & 378 \\
\hline rigidum . & . & . & - & 4348 & bancana . & - & . & - & 7222 \\
\hline rubescens. & . & . & . & 4349 & VATICA ? eximia & . & . & . & 4870 \\
\hline Rumphii . & - & . & . & 103 & paucitlora & . & . & . & 7711 \\
\hline saxophilum & . & . & . & 1321 & Rassak. . & . & . & - & 1632 \\
\hline strictum . & . & . & . & . 8787 & Schoutenia & • & . & . & 7222 \\
\hline sumatranum . & . & . & . & . 4055 & stipulosa & . & . & . & 5809 \\
\hline sundaicum. & . & . & . & 4324 & sublacunosa & . & . & . & 1622 \\
\hline superbum . & . & . & . & 4337 & ? venulosa . & . & . & - & 3438 \\
\hline Tjiela . . & - & $\bullet$ & • & 3048 & VENTILAGO lucens & - & . & - & 9090 \\
\hline trichocarpum . & & $\cdot$ & $\cdot$ & 386 & maderaspatana. & • & . & - & 995 \\
\hline validum . & & & & - 4338 & VERNONIA Blumeana & & . & . & 2690 \\
\hline
\end{tabular}


REGISTER.

VERNONIA cinerea. . . . 67

eupatorioides . . . . 7737

javanica . . . . . 1015

leptophylla . . . . . 67

VIBURNUM coriaceum . . . 4318

Junghuhnii . . . . . 6775

sambucinum • . . . 307

sundaicum. . . . . 4318

VIGNA Catjang . . . . . 30

sinensis . . . . . 3935

VILLARESIA scandens. . . . 2281

VINCA rosea. . . . . . 2343

VIOLA alata . . . . . . 2363 serpens. . . . . 8832

VISCUM articulatum . . . 350 orientale . . . . 3467

VISENIA indica . . . . . . 3706

VISIANIA phyllothyrsa. . . . 3706 robusta. . . . . . 3709

VITEX bicolor . . . . . 5156 Cofassus . . . . 4024

heterophylla . . . . 5309

leucoxylon. . . . . 3187

Loureirii . . . . • 2796

moluccana. . . . . 3513

Negundo . . . . . 131

pteropoda . . . . . 7782

pubescens . . . . . 430

punctata . . . . . 4966

timoriensis. . . . . 5157

trifolia. . . . . . 66

vestita . . . . . . 5595

VITIS cymosa. . . . . . 664

Diepenhorstii . . . . 229

hastata . . . . . 728

imperialis . . . . 152

indica . . . . . . 340

pubiflora . . . . 668

Teysmanni. . . . . 8254

trifolia . . . . . 615

vinifera . . . . . 348

VOANDZEIA subterranea. . . 3941

WALLICHIA Horsfieldii . . 5918 porphyrocarpa . . . . 4456

WEDDELIA calendulacea . . . 7645

WEINMANNIA Blumeï . . . 4658

WENDLAND1A densiflora . . . 456

glabrata . . . . . 2366

lævigata . . . . . 1544

Teysmanniana . . . 6928

tinctoria . . . . . 8920

WHITIA carnosa. . . . . 5373

oblongifolia . . . . 5388

WICKSTREEMIA tenuiramis . . 5911

WILLUGHBEIA ? apiculata . . 2526
WIILUGHBEIA firma javanica . . . . 558

WISSA DULA zeylanica. • • $\quad 909$

WOLLASTONIA asperrima • . 7649

biflora. . . . . 1817

moluccana. . . . . 315

montana . . . . 3100

strigulosa . . . . . 315

WORMIA excelsa . . . . 2283

subsessilis . . . . . 7915

WRIGHTIA pubescens . . . 1184

XANTHIUM indicum . . . 6056

XANTHOCHYMUS nervosus . . 5752

XANTHOPHYLLUM adenopodum 3903

excelsum . . . . . 4585

longifolium . . . . 4585

vitellinum . . . . . 4585

XEROCHLOA latifolia . . . 2172

XEROSPERMUM Noronhianum . 2286

XEROTES arenaria . . . . 3003

longifolia . . . . 3005

XIMENIA americana . . . 6798

XYLOCARPUS Granatum . . 1319

obovatus . . . . . . 1480

XYLOPIA ? Tooropiana . . 5908

XYRIS calocephala . . . . . 799

melanocephala . . . 19

ZALACCA edulis. . . . . 7385

Wallichiana ... . 5070

ZANONIA indica . . . . 155

macrocarpa . . . . 593

ZANTHOXYLUM armatum . . 3692

aromatieum , . . . 4663

euneuron . . . . . 6973

lucidum . . . . 7947

Ma rambong . . . . 4312

montanum. . . . . 4369

Rhetza. . . . . . 4726

rhizinoides. . . . . 6026

scandens . . . . . 456

zeylanicum . . . . . $\quad \mathbf{3 8 9}$

ZEA Mays . . • . . . . 1241

ZEHNERIA connivens . . . 8637

deltoidea . . . . . 2492

exasperata . . . . 520

hastata. . . . . 4553

mucronata. . . . . 520

ZINGIBER amaricans . . . 2401

aquosum . . . . 878

Casumanar . . . . 878

elatum . . . . . 5221

gramineum . . . . 255

inflexum . . . . . 5220

marginatum . . . : 254 
REGISTER.

\begin{tabular}{|c|c|c|c|c|c|c|c|c|}
\hline & & & & No. & ZIVYPHUS Juiuh & & & No. \\
\hline & & & & $\begin{array}{r}901 \\
25\end{array}$ & 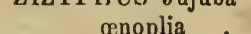 & & & . \\
\hline & & & & 90 & rufula. & . & & \\
\hline & & & & 521 & subquinquene & ervia. & . & \\
\hline goniæfolia & & & & 668 & & & . & . \\
\hline difolius & & & & 59 & ZOSTEROS & arachnite & & \\
\hline i. . & & & & 48 & ZOYSIA pi & & & - \\
\hline javanensis . . & & & & 598 & ZUCCARINIA maer & rophylla. & & \\
\hline
\end{tabular}




LR 
